\title{
Das Auftreten acidophiler/calcifuger Pflanzenarten in Kalk-Halbtrockenrasen
}

\author{
Die Calcicolen/Calcifugen-Problematik unter edaphischen, \\ autökologischen und synökologischen \\ Gesichtspunkten
}

\begin{abstract}
Dissertation
zur Erlangung des Doktorgrades

der Mathematisch-Naturwissenschaftlichen Fakultäten der Georg-August-Universität zu Göttingen
\end{abstract}

vorgelegt von

Christoph Fühner

aus Rheine

Göttingen 19.09.2005 
D7

Referent:

Prof. Dr. M. Runge

Korreferent:

Prof. Dr. C. Leuschner

Tag der mündlichen Prüfung: $\quad 02.11 .2005$ 
Ay me!

what perils do environ

The man

that meddles with cold iron

Hudibras pt I. canto III.1, I SAMUel ButLer (1612-1680) 


\section{Danksagung *}

Viele Freunde, Bekannte und Kollegen haben mich direkt oder indirekt bei der Anfertigung dieser Arbeit unterstützt. Besonders bedanken möchte ich mich bei:

MagdoIna Weller, die über eineinhalb Jahre außerordentlich zuverlässig und engagiert die Freilandarbeiten und experimentellen Untersuchungen begleitet hat - Simone Klatt für die Durchführung eines Großteils der Kulturversuche - Cornelia Becker für die Einführung in die vegetationskundliche Geländearbeit, die Unterstützung bei den Vegationsaufnahmen und die Bestimmung der Moose - den Mitarbeitern der Technischen Werkstatt, ganz besonders Herrn K. Unger, der alle wichtigen Hilfsmittel hergestellt hat, perfekt, und dies immer viel schneller als zunächst in Aussicht gestellt - Kathrin Baumann für die Hilfe bei der Freilandarbeit und die Korrektur von Teilen der Dissertation, ganz besonders aber auch für die vielen Aufmunterungen und Bestärkungen - Stefan Thyen unter anderem für die gemeinsamen Suche von Saatgut im Nordwesten, Hilfestellungen in der Statistik und das gemeinsame Fortschreiten in Studium und Promotion - nach vielen Jahren werden nun zwei alte Männer fast gleichzeitig fertig - Alexander Paul, der nicht nur maßgeblich an den blattanatomischen Untersuchungen beteiligt war, sondern mir auch durch gemeinsame Exkursionen, die Bereitstellung von Literatur und viele Anregungen einen Zugang zur Vegetationskunde eröffnete - Thomas Becker unter anderem für die Bearbeitung der Übersichtskarten, manch anregende Kaffeepause und zusammen mit Ute Becker für die Ernte und Bereitstellung von Saatgut verschiedener Pflanzenarten - den Technischen Angestellten der Abteilung Ökologie und Ökosystemforschung, insbesondere Uta Nüsse-Hahne und Herrn $\mathrm{H}$. Wildberger, für die Durchführung verschiedener Analysen - Bernd Raufeisen für die Anfertigung der Übersichtskarten und Zeichnungen - Christian Kluth nicht nur für die Grundlagen und Utz Bandow nicht nur für die Programmierung eines EXCEL-Addlns, das die Automatisierung des Schaich-Hamerle-Tests erlaubte - Stefanie Kluth für die Korrektur eines frühen Teils der Dissertation • Ute Jandt und Helge Bruelheide für die gemeinsame Auswahl der Untersuchungsflächen - Till Savelkoul, der einen Ferientag für den Ausflug in die Botanik und die Mithilfe bei der Anfertigung von Vegetationsaufnahmen opferte - Frank Thomas für die Einführung in die neue Wirkungsstätte zu Beginn der Promotion und viele spannende und entspannende Kaffeepausen insbesondere zu Zeiten, in denen es im Institut ruhig wurde - Christoph Leuschner für das Korreferat, die Überlassung des Arbeitsplatzes und für verschiedene organisatorische Hilfestellungen - Birte Junge für die Bereitstellung von Bodenkarten, die Mithilfe bei einer Probennahme und die Organisation der Bodenartenbestimmung - Herrn A. Capelle vom Niedersächsischen Landesamt für Bodenforschung für die Durchführung der Bodenartenbestimmung • dem Zentrallabor des Forschungszentrums Waldökosysteme, namentlich Herrn N. Lamersdorf, für die TOC/DOC-Analysen • Herrn L. Nitsche aus der Abteilung Naturschutz des Regierungspräsidiums Kassel für die schnelle Sondergenehmigung der Untersuchungen in den Naturschutzgebieten des Unteren Diemeltals - der Abteilung Vegetationskunde und Populationsbiologie für die Bereitstellung des Metallsuchgeräts - der Abteilung Pflanzensystematik für die Ermöglichung der mikroskopischen Untersuchungen - Wolfgang Schmidt und Dirk Gries für manch tief greifende Diskussion über die pflanzliche Mineralstoffernährung - Michael und Ingrid Fischer, die mit ihren Kindern für mich eine zweite Familie sind - Norbert Heidelmann für Reflexionen, Motivationen und Vieles mehr - Gisela Mohr-Fiegenheim, Bernd und Jan Martin Fiegenheim, Bernard und Beate Savelkoul nicht nur für die Möglichkeit, von Zeit zu Zeit die Arbeit an der Dissertation mit ein wenig Urlaub in der zweiten Heimat zu verbinden • der Mensarunde, die sehr viel mehr als eine Essensgemeinschaft ist - der gesamten Abteilung Ökologie und Ökosystemforschung für das wirklich außerordentlich kollegiale und freundschaftliche Miteinander in all den Jahren.

Zu jeder Zeit konnte ich auf meine Familie bauen: Mutter Gertrud und die Brüder Martin, Hannes und Daniel mit ihren Partnerinnen und Kindern.

Der größte Dank gilt aber ohne jeden Zweifel Herrn M. Runge. Er war als Betreuer immer ansprechbar und hat die Arbeit auch im Ruhestand bis zu ihrem Ende begleitet. Ich habe Vieles von inm lernen dürfen.

\footnotetext{
Die vorliegende Arbeit wurde in der Abteilung Ökologie und Ökosystemforschung des Albrecht-von-Haller-Instituts für Pflanzenwissenschaften unter Förderung durch die Deutsche Forschungsgemeinschaft (RU 136/10-2) angefertigt.
} 


\section{Inhaltsverzeichnis}

Abbildungsverzeichnis VIII

Tabellenverzeichnis $\quad$ XI

Abkürzungsverzeichnis XIII

$\begin{array}{llr}1 & \text { Einleitung } & 1\end{array}$

2 Material und Methoden $\quad 9$

$\begin{array}{lll}2.1 & \text { Standorte und Vegetationskunde } & 10\end{array}$

2.1.1 Untersuchungsstandorte 10

2.1.2 Vegetationskundliche Untersuchungen 15

$\begin{array}{lll}2.2 & \text { Bodenkundliche Untersuchungen } & 17\end{array}$

$\begin{array}{lll}2.2 .1 & \text { Bodenprobennahme } & 17\end{array}$

2.2.2 Probenaufbereitung, Bestimmung von Wasser- und Skelettgehalten 19

2.2.3 Analysen luftrockener Feinerdehomogenate 19

2.2.4 Herstellung wässriger Bodenextrakte 20

2.2.5 Analytik wässriger Bodenextrakte 23

2.2.6 Nicht-sequentielle Fraktionierung essentieller Schwermetalle 29

2.2.7 Untersuchungen zur Redoxdynamik von Eisen und Mangan 31

2.2.8 Mobilisierung und Immobilisierung von Eisen durch Chelatlösungen 33

2.2.9 Sequentielle Phosphatfraktionierung 34

$\begin{array}{lll}2.3 & \text { Autökologische Untersuchungen } & 36\end{array}$

2.3.1 Saatguternte, Bodenprobennahme und Bodenanalysen 36

2.3.2 Identifizierung der Unterarten von Danthonia decumbens 36

2.3.3 Keimungs- und Kulturexperimente $\quad 37$

$\begin{array}{lll}2.4 & \text { Statistische Auswertungen } & 38\end{array}$

3 Ergebnisse $\quad 41$

3.1 Vegetationskundliche Untersuchungen $\quad 42$

$\begin{array}{lll}3.2 & \text { Standortökologische Untersuchungen } & 47\end{array}$

3.2.1 Physikoedaphische und klimatische Faktoren $\quad 47$

3.2.2 Chemismus wässriger Bodenextrakte $\quad 51$

3.2.3 Kohlenstoff/Stickstoff-Verhältnisse $\left(C_{0} / N\right) \quad 78$

3.2.4 Effektive Kationenaustauschkapazitäten (CEC $\left.C_{\text {eff }}\right) \quad 80$

3.2.5 Verfügbarkeit essentieller Schwermetalle $\quad 82$

$\begin{array}{ll}\text { 3.2.6 Phosphorverfügbarkeiten } & 96\end{array}$

3.2.7 Zusammenfassung der bodenkundlichen Untersuchungen 99

$\begin{array}{lll}3.3 & \text { Keimungs- und Kulturexperimente } & 103\end{array}$ 
4 Der Calcicolen/Calcifugen-Komplex 105

$\begin{array}{lll}4.1 & \text { Allgemeines } & 106\end{array}$

4.2 Bodenkundliche Aspekte des Calcicolen/Calcifugen-Komplexes 110

4.2.1 Bedeutung von $\mathrm{pH}$ und $\mathrm{E}_{h}$ für den Bodenchemismus 111

4.2.2 Reaktionen der Bodenpufferung und Bodenversauerung 112

4.2.3 Reaktionen des Calciumcarbonat-Systems 114

4.2.4 Parameter der pflanzlichen Eisenverfügbarkeit $\quad 115$

4.3 Autökologische Aspekte des Calcicolen/Calcifugen-Komplexes 120

4.3.1 Grundlagen der pflanzlichen Mineralstofftoleranzen und -effizienzen 120

4.3.2 Aspekte pflanzlicher Aluminiumintoxikationen und Aluminiumtoleranzen 121

4.3.3 Aspekte variierender Eisenkonzentrationen 122

4.3.4 Aspekte variierender Mangankonzentrationen 128

4.3.5 Aspekte variierender Calcium- und Hydrogencarbonatkonzentrationen 129

4.3.6 Aspekte variierender Phosphorkonzentrationen 136

4.3.7 Interaktion und Regulation autökologischer Adaptationen 138

5 Die Etablierung acidophiler/calcifuger Pflanzenarten im Gentiano-Koelerietum

5.1 Vegetationskundliche Aspekte des Auftretens acidophiler/calcifuger $\begin{array}{ll}\text { Arten in Kalk-Halbtrockenrasen } & 142\end{array}$

5.1.1 Synsystematik der Festuco-Brometea 142

5.1.2 Synsystematik des Gentiano-Koelerietum 144

5.1.3 Synökologie der Subassoziationen des Gentiano-Koelerietum
im Unteren Diemeltal und am Südharzrand

5.1.4 Autökologie ausgewählter Arten des Gentiano-Koelerietum danthonietosum 149

5.2 Allgemeine standortökologische Aspekte des Auftretens acidophiler/calcifuger Arten in Kalk-Halbtrockenrasen $\quad 154$

5.2.1 Geologisch-geographische, edaphische und zeitliche Muster der Etablierung acidophiler/calcifuger Arten in Kalk-Halbtrockenrasen 154

5.2.2 Topographische und physikoedaphische Faktoren der Etablierung acidophiler/calcifuger Arten in Kalk-Halbtrockenrasen

5.3 Chemoedaphische und autökologische Aspekte des Auftretens $\begin{array}{ll}\text { acidophiler/calcifuger Arten in Kalk-Halbtrockenrasen } & 159\end{array}$

5.3.1 Operationale und konzeptionelle Definition von Bodenlösungen 159

5.3.2 Gleichgewichts-, Perkolations- und Druckbodenlösungen 163

5.3.3 Bodenfaktoren in Abhängigkeit von den jahreszeitlichen Witterungsbedingungen 172

$\begin{array}{lll}\text { 5.3.4 Bodenaciditäten } & 174\end{array}$

$\begin{array}{lll}\text { 5.3.5 Ionenaktivitäten } & 178\end{array}$

5.3.6 Hydrogencarbonat 179

5.3.7 Calcium 182

5.3.8 Magnesium 186 
$\begin{array}{llr}5.3 .9 & \text { Kalium } & 187\end{array}$

$\begin{array}{lr}\text { 5.3.10 Eisen } & 188\end{array}$

$\begin{array}{lr}\text { 5.3.11 Phosphor } & 202\end{array}$

$\begin{array}{ll}5.3 .12 \text { Stickstoff } & 215\end{array}$

5.4 Integrative Betrachtung biotischer und abiotischer Faktoren 224

5.4.1 Nährstoff- und Wasserverfügbarkeiten 225

\begin{tabular}{ll}
5.4 .2 & Interaktionen abiotischer Faktoren \\
\hline
\end{tabular}

$\begin{array}{ll}5.4 .3 & 228\end{array}$

5.4.4 Anthropo-zoogene Einflüsse $\quad 231$

$\begin{array}{lll}5.4 .5 & \text { Mikrobielle Symbiosen } & 233\end{array}$

5.4.6 Palaeogeographie acidophiler/calcifuger und basiphiler/calcicoler Arten 238

$\begin{array}{llr}5.5 & \text { Synthese und Ausblick } & 240\end{array}$

6 Zusammenfassung 249

$\begin{array}{llr}7 & \text { Literatur } & 255\end{array}$

8 Anhang $r$ 


\section{Abbildungsverzeichnis}

Abbildung 1: Standorte der vegetationskundlichen und bodenkundlichen Untersuchungen sowie der Saatguternten

Abbildung 2: Standorte der vegetationskundlichen und bodenkundlichen Untersuchungen im Unteren Diemeltal

Abbildung 3: Idealisierte stratigraphische Gliederung des Zechsteins im Bereich der Oberharz-Schwelle

Abbildung 4: Klimadiagramme der Untersuchungsstandorte im Unteren Diemeltal und am Südharzrand

Abbildung 5: Zylindersystem zur Probennahme und Herstellung von Perkolationsbodenlösungen und Druckbodenlösungen

Abbildung 6: Probennahmeschema der Untersuchungsflächen der Referenzstandorte Auf der Burg und Hölleberg

Abbildung 7: Perkolationssystem und Lösungsflussschema für die Herstellung von Perkolationsbodenlösungen

Abbildung 8: Überdruckapparatur zur Gewinnung von Druckbodenlösungen

Abbildung 9: Leitfähigkeits-Detektion und UV-Detektion der HPIC-Anionenanalytik mit Gynkochrom-AX-5i-Säulen und Phthalat-Eluenten

Abbildung 10: UV-Detektion der $\mathrm{NO}_{2}^{-}-$und $\mathrm{NO}_{3}^{-}$-Analytik mit Gynkochrom-AX-5c-Säulen und Phosphatpuffer-Eluenten

Abbildung 11: HPIC-Kationenanalytik mit Gynkochrom CAT-125-Säulen, Ascorbinsäure/Oxalsäure-Eluenten und negativer Leitfähigkeitsdetektion

Abbildung 12: Schematischer Aufbau von Mikrolysimetern (rhizon soil moisture sampler)

Abbildung 13: Dendrogramm quadrierter Euklidischer Distanzen der Vegetationsaufnahmen

Abbildung 14: Dendrogramm der Gemeinschaftskoeffizienten nach Sørensen (1948) und Zeigerwerte nach Ellenberg et al. (1992) für Arten der pflanzensoziologischen Tabelle

Abbildung 15: Korngrößenverteilung des Feinbodens der CC- und CF-Bestände aller Untersuchungsstandorte

Abbildung 16: Bodentiefen von CC- und CF-Beständen der Standorte Auf der Burg und Hölleberg

Abbildung 17: Niederschläge und Temperaturen im Unteren Diemeltal im Jahr 1998

Abbildung 18: Wassergehalte, Feinerde-Lagerungsdichten und Skelettgehalte der Referenzstandorte Auf der Burg und Hölleberg im Jahresverlauf 1998

Abbildung 19: Abhängigkeit der relativen elektrischen Leitfähigkeiten und relativen Mineralstoffkonzentrationen von der Perkolationsdauer

Abbildung 20: Prozentuale Verteilungen der Abpressdauer für die DBL-Herstellung aus Bodenmonolithen der CC- und CF-Bestände der Standorte Auf der Burg und Hölleberg.

Abbildung 21: $\mathrm{pH}-$ Werte von GBL, PBL und DBL der Referenzstandorte Auf der Burg und Hölleberg im Jahresverlauf 1998 
Abbildung 22: $\mathrm{pH}-$ Werte von Feinerde/ $\mathrm{H}_{2} \mathrm{O}-$ Suspensionen und Feinerde/ $\mathrm{KCl}$-Suspensionen der CC- und CF-Bestände der Standorte Hölleberg-Süd, Flohrberg, Pagenberg und Steinkirche

Abbildung 23: Fe-Löslichkeiten der Feinerde der CC- und CF-Bestände der Referenzstandorte Auf der Burg und Hölleberg im Jahresverlauf 1998

Abbildung 24: Mn-Löslichkeiten der Feinerde der CC- und CF-Bestände der Referenzstandorte Auf der Burg und Hölleberg im Jahresverlauf 1998

Abbildung 25: Ca-Löslichkeiten der Feinerde der CC- und CF-Bestände der Referenzstandorte Auf der Burg und Hölleberg im Jahresverlauf 1998

Abbildung 26: Ca-Löslichkeiten von CC- und CF-Feinerdehomogenaten der Vergleichsstandorte

Abbildung 27: Mg-Löslichkeiten der Feinerde der CC- und CF-Bestände der Referenzstandorte Auf der Burg und Hölleberg im Jahresverlauf 1998

Abbildung 28: Mg-Löslichkeiten von CC- und CF-Feinerdehomogenaten der Vergleichsstandorte

Abbildung 29: K-Löslichkeiten der Feinerde der CC- und CF-Bestände der Referenzstandorte Auf der Burg und Hölleberg im Jahresverlauf 1998

Abbildung 30: K-Löslichkeiten von CC- und CF-Feinerdehomogenaten der Vergleichsstandorte

Abbildung 31: Na-Löslichkeiten der Feinerde der CC- und CF-Bestände der Referenzstandorte Auf der Burg und Hölleberg im Jahresverlauf 1998

Abbildung 32: Na-Löslichkeiten von CC- und CF-Feinerdehomogenaten der Vergleichsstandorte

Abbildung 33: $\mathrm{NH}_{4}{ }^{+}$-Löslichkeiten der Feinerde der CC- und CF-Bestände der Referenzstandorte Auf der Burg und Hölleberg im Jahresverlauf 1998

Abbildung 34: $\mathrm{NH}_{4}{ }^{+}$-Löslichkeiten von CC- und CF-Feinerdehomogenaten der Vergleichsstandorte

Abbildung 35: $\mathrm{NO}_{3}^{-}$-Löslichkeiten der Feinerde der CC- und CF-Bestände der Referenzstandorte Auf der Burg und Hölleberg im Jahresverlauf 1998

Abbildung 36: $\mathrm{NO}_{3}{ }^{-}$-Löslichkeiten von CC- und CF-Feinerdehomogenaten der Vergleichsstandorte

Abbildung 37: $\mathrm{NO}_{2}^{-}$-Löslichkeiten der Feinerde der CC- und CF-Bestände der Referenzstandorte Auf der Burg und Hölleberg im Jahresverlauf 1998

Abbildung 38: $\mathrm{NO}_{2}^{-}$-Löslichkeiten von CC- und CF-Feinerdehomogenaten der Vergleichsstandorte

Abbildung 39: $\mathrm{SO}_{4}{ }^{2-}-$-Löslichkeiten der Feinerde der CC- und CF-Bestände der Referenzstandorte Auf der Burg und Hölleberg im Jahresverlauf 1998

Abbildung 40: $\mathrm{SO}_{4}{ }^{2-}$-Löslichkeiten von CC- und CF-Feinerdehomogenaten der Vergleichsstandorte

Abbildung 41: $\mathrm{Cl}^{-}$-Löslichkeiten der Feinerde der CC- und CF-Bestände der Referenzstandorte Auf der Burg und Hölleberg im Jahresverlauf 1998

Abbildung 42: $\mathrm{Cl}^{-}$-Löslichkeiten von CC- und CF-Feinerdehomogenaten der Vergleichsstandorte

Abbildung 43: Feinerdebezogene elektrische Leitfähigkeiten der CC- und CF-Bestände der Referenzstandorte Auf der Burg und Hölleberg im Jahresverlauf 1998

Abbildung 44: Mediane Extraktionsverhältnisse kationischer und anionischer Komponenten in Abhängigkeit vom Extraktionsverfahren

Abbildung 45: Massenanteile der Feinerde an $\mathrm{C}_{0}$ und $\mathrm{N}$ sowie $\mathrm{C}_{\mathrm{o}} / \mathrm{N}$-Verhältnisse in CC- und CFBeständen der Referenzstandorte Auf der Burg und Hölleberg im Jahresverlauf 1998 
Abbildung 46: Abhängigkeit der $\mathrm{Fe}^{2+}-$ Komplexierung von der Extraktionsdauer und der Ferrozine ${ }^{\circledR}-$ Konzentration in Böden von CC- und CF-Beständen des Standorts Auf der Burg

Abbildung 47: Fe-Löslichkeiten der Feinerde von CC- und CF-Beständen der Referenzstandorte Auf der Burg und Hölleberg nach Extraktion von Bodenmaterial unterschiedlicher Struktur und Lagerung mit $\mathrm{H}_{2} \mathrm{O}, \mathrm{NH}_{4}$-Acetat, DTPA, NTA, Oxalat und Dithionit.

Abbildung 48: Löslichkeiten verschiedener Fe-Fraktionen feldfrischer Feinerdehomogenate

Abbildung 49: Löslichkeiten verschiedener Mn-Fraktionen feldfrischer Feinerdehomogenate

Abbildung 50: Löslichkeiten verschiedener Zn-Fraktionen feldfrischer Feinerdehomogenate

Abbildung 51: Löslichkeiten verschiedener Cu-Fraktionen feldfrischer Feinerdehomogenate

Abbildung 52: Dynamik der Fe-Lösung in Bodenmonolithen von CC-Beständen und CF-Beständen des Standorts Hölleberg unter reduktiven, re-oxidativen und re-reduktiven Inkubationsbedingungen

Abbildung 53: Dynamik der Mn-Lösung in Bodenmonolithen des Standorts Hölleberg während einer 40tägigen reduktiven Inkubation

Abbildung 54: Fe-Mobilisierung/Immobilisierung durch Schüttelung von CC/CF-Trockenhomogenaten des Standorts Auf der Burg mit FeEDTA- und FeEDDHA-Lösungen

Abbildung 55: Löslichkeiten verschiedener P-Fraktionen im Rahmen der sequentiellen P-Fraktionierung gemahlener, lufttrockener Feinerdehomogenate von CC- und CF-Beständen der Standorte Auf der Burg und Hölleberg

Abbildung 56: P-Löslichkeit von CC- und CF-Feinerdehomogenaten im Rahmen verschiedener wässriger Extraktionsverfahren

Abbildung 57: Einfluss des $\mathrm{CO}_{2}$-Partialdrucks auf den $\mathrm{pH}$ und die $\mathrm{HCO}_{3}{ }^{-}$-Konzentration im Lösungsgleichgewicht mit Calcit

Abbildung 58: Einfluss des pH auf die Aktivitäten anorganischer Fe(III)-Spezies im Gleichgewicht mit 'soil iron'

Abbildung 59: Stabilitätsfelder von Fe-Hydroxiden überfluteter Böden in Abhängigkeit von $\mathrm{E}_{\mathrm{h}}$ und $\mathrm{pH}$; Abhängigkeit der $\mathrm{Fe}^{2+}$-Oxidationskinetiken von Hydroxidkonzentration, Sauerstoffpartialdruck und Lösungstyp

Abbildung 60: $\mathrm{pH}-\mathrm{Abhängigkeit} \mathrm{der} \mathrm{Stabilität} \mathrm{von} \mathrm{Fe}(\mathrm{III})-\mathrm{Komplexen}$ verschiedener organischer Säuren und des Siderophors Desferrioxamin B (DFOB)

Abbildung 61: Synsystematische Stellung des Gentiano-Koelerietum innerhalb der Klasse Festuco-Brometea

Abbildung 62: Vegetationszonierung entlang eines hangparallelen Transektes in Abhängigkeit von der Bodenbildung über karbonischem Kalkstein

Abbildung 63: Nichtlineare Regression der Beziehung log c $(\mathrm{Fe})[\mathrm{M}]$ vs. $\mathrm{pH}\left(\mathrm{H}_{2} \mathrm{O}\right)$ aller Untersuchungsbestände und Lösungstypen 


\section{Tabellenverzeichnis}

Tabelle 1: Klimaelemente in den Bezirken der Untersuchungsstandorte

Tabelle 2: Pufferkonzentrat des Phthalat-Eluenten für die Anionenanalytik mit Gynkochrom AX-5-Säulen

Tabelle 3: Testansatz zur sequentiellen kolorimetrischen Bestimmung von $\mathrm{Fe}^{2+}$ und $\mathrm{Fe}(\mathrm{II}+\mathrm{III})$ mit BPDS

Tabelle 4: Vegetationskundliche Differenzierung des Gentiano-Koelerietum der CC- und CFBestände der Standorte Auf der Burg, Hölleberg, Hölleberg-Süd und Flohrberg im Unteren Diemeltal sowie Pagenberg und Steinkirche am Südharzrand

Tabelle 5: Mediane geographischer, edaphischer und vegetationskundlicher Parameter sowie ökologische Zeigerwerte von CC- und CF-Beständen der Untersuchungsstandorte

Tabelle 6: Parameter der Makrogefügeeigenschaften der Feinerde von CC- und CF-Beständen der Standorte Auf der Burg und Hölleberg

Tabelle 7: Proportionalitätsfaktoren für die Umrechnung von medianen massenbezogenen Stoffgehalten in Konzentrationen der Gleichgewichtslösungen (GBL, PBL) und 'aktuellen' Bodenlösungen (DBL)

Tabelle 8: Mediane Bodenaciditäten der Referenzstandorte in Abhängigkeit von der Lösungspräparation und Bodentiefe

Tabelle 9: Gesamt-Äquivalenzkonzentrationen, Anionendefizite, Ca-Äquivalenzkonzentrationen, Differenzen der prozentualen Anionendefizite und Ca-Äquivalenzkonzentrationen sowie Ionenstärken in GBL, PBL und DBL von CC- und CF-Beständen der Standorte Auf der Burg und Hölleberg

Tabelle 10: Mediane GBL : PBL : DBL-Verhältnisse verschiedener Standortfaktoren von CC- und CF-Vegetationsbeständen der Standorte Auf der Burg und Hölleberg

Tabelle 11: Mediane prozentuale Differenzen verschiedener Bodenfaktoren von CF- und CC-Beständen der Standorte Auf der Burg und Hölleberg in Abhängigkeit vom Lösungstyp

Tabelle 12: Kennwerte anorganischer und organischer Kohlenstofffraktionen in der Feinerde von CC- und CF-Beständen der Standorte Auf der Burg und Hölleberg

Tabelle 13: Effektive Kationenaustauschkapazitäten, Basensättigungen sowie absolute und prozentuale Kationenbelegungen der Feinerde von CC- und CF-Beständen der Standorte Auf der Burg und Hölleberg

Tabelle 14: Prozentuale Beziehung zwischen den $\mathrm{H}_{2} \mathrm{O}$-extrahierbaren und sorptiv gebundenen Fraktionen ausgewählter Nährelemente

Tabelle 15: Fe-Konzentrationen in PBL und DBL der CC- und CF-Bestände der Standorte Auf der Burg und Hölleberg, die nicht durch Ultrazentrifugation und Membranfiltration aufgereinigt wurden

Tabelle 16: Versuchsfaktoren und -variablen zur Untersuchung der Bedeutung verschiedener Schwermetallfraktionen für die Vegetationsdifferenzierung von Kalk-Halbtrockenrasen

Tabelle 17: CC/CF-Verhältnisse verschiedener Fe-Fraktionen feldfrischer Feinerdehomogenate 
Tabelle 18: CC/CF-Verhältnisse verschiedener Mn-Fraktionen feldfrischer Feinerdehomogenate

Tabelle 19: CC/CF-Verhältnisse verschiedener Zn-Fraktionen feldfrischer Feinerdehomogenate

Tabelle 20: CC/CF-Verhältnisse verschiedener Cu-Fraktionen feldfrischer Feinerdehomogenate

Tabelle 21: P-Gesamtlöslichkeiten und P-Fraktionsanteile im Rahmen der sequentiellen Extraktion gemahlener, lufttrockener Feinerdehomogenate

Tabelle 22: Prozentuale Verteilung von $\mathrm{P}_{\mathrm{i}}$ und $\mathrm{P}_{\mathrm{o}}$ in $\mathrm{NaHCO}_{3}$ - und $\mathrm{NaOH}$-Extrakten der sequentiellen P-Fraktionierung gemahlener, lufttrockener Feinerdehomogenate

Tabelle 23: Signaturen und Definitionen der Klassenkennwerte für die Berechnung sog. Ordinationsindizes

Tabelle 24: Mediane bodenkundlicher Standortfaktoren von CC- und CF-Beständen der Untersuchungsstandorte im Unteren Diemeltal und am Südharzrand.

Tabelle 25: Mediane Keimraten, Sprossmassen, S(pross)/W(urzel)-Verhältnisse und Chlorophyllkonzentrationen von Pflanzenpopulationen basischer/kalkreicher und saurer, basenarmer Standorte in CC- bzw. CF-Bodenmonolithen des Standorts Auf der Burg

Tabelle 26: Charakteristika saurer Mineralböden und alkalischer Kalkböden

Tabelle 27: pH-Pufferbereiche und Pufferreaktionen von Böden

Tabelle 28: Übersicht pflanzensoziologischer Arbeiten zum Auftreten von acidophilen/calcifugen Pflanzenarten in Kalk-Halbtrockenrasen

Tabelle 29: Artenzahlen und mittlere Zeigerwerte nach Ellenberg et al. (1992) in Abhängigkeit vom Bestandstyp und Untersuchungsraum

Tabelle 30: Standörtliche, morphologische und cytologische Charakteristika der Subspezies von Danthonia decumbens (L.) LAMK. et DC

Tabelle 31: Charakteristika und Funktionen der Bodenporenklassen

Tabelle 32: Ergebnisse der GEOCHEM-PC-Berechnungen der $\mathrm{HCO}_{3}{ }^{-}-$Konzentrationen auf Grundlage von Kationen/Anionen-Analysen sowie Messungen des $\mathrm{pH}$ und $\mathrm{C}_{\mathrm{T}}$ von $\mathrm{GBL}, \mathrm{PBL}$ und $\mathrm{DBL}$

Tabelle 33: Mittlere Ca/Mg-Verhältnisse der GBL feldfrischer Feinerdehomogenate der CC- und CF-Beständen des Gentiano-Koelerietum

Tabelle 34: Mittlere Ca/K-Verhältnisse der GBL feldfrischer Feinerdehomogenate der CC- und CF-Bestände des Gentiano-Koelerietum

Tabelle 35: Extraktionsmittel und bindungschemische Eigenschaften sowie mediane Verhältnisse und absolute Konzentrationswerte verschiedener Fe-Fraktionen in feldfrischen Feinerdehomogenaten des Gentiano-Koelerietum typicum und Gentiano-Koelerietum danthonietosum

Tabelle 36: Fraktionen und Bindungsformen der sequentiellen P-Extraktion lufttrockener Feinerdehomogenate

Tabelle 37: Exsudation organischer Säuren durch acidophile/calcifuge und basiphile/calcicole Arten in Abhängigkeit von der Kultivierung der Versuchspflanzen und der Gewinnung der Analysenlösung

Tabelle 38: Anteil von Oxalat und Citrat an der Exsudation organischer Säuren acidophiler/calcifuger und basiphiler/calcicoler Arten in Abhängigkeit vom Kultursubstrat 


\section{Abkürzungsverzeichnis}

\section{Abkürzungen}

ABA abscisic acid, Abscisinsäure

AEC adenylate energy charge, Energieladung des Adenylatsystems;

$\mathrm{AEC}=\left(\mathrm{C}_{\mathrm{ATP}}+0,5 \mathrm{C}_{\mathrm{ADP}}\right) /\left(\mathrm{C}_{\mathrm{ATP}}+\mathrm{C}_{\mathrm{ADP}}+\mathrm{C}_{\mathrm{AMP}}\right)$

BPDS Bathophenanthrolin-disulfonsäure = 4,7-Diphenyl-1,10-phenanthrolinDisulfonat; $\mathrm{C}_{24} \mathrm{H}_{16} \mathrm{~N}_{2} \mathrm{O}_{6} \mathrm{~S}_{2}$

BS Basensättigung; $[B S]=\left[\mathrm{c}_{\mathrm{c}(\Sigma \mathrm{Ca}-\mathrm{Mg}-\mathrm{K}-\mathrm{Na})} / \mathrm{CEC}\right]=\%\left(\mathrm{n}_{\mathrm{c}} / \mathrm{n}_{\mathrm{c}}\right)$

CDC critical deficiency content - kritische Stoffmengenkonzentration im Pflanzengewebe, unterhalb derer der Trockenmasseertrag < $90 \%$ des Maximalertrags beträgt; $[C D C]=\mathrm{mol} / \mathrm{g}_{\mathrm{TG}}$

CEC cation exchange capacity, Kationenaustauschkapazität; $[\mathrm{CEC}]=\left[\mathrm{n}_{\mathrm{c}} / \mathrm{m}_{\mathrm{FE}-\mathrm{TG}}\right]=\mathrm{mmol}_{\mathrm{c}} / 100 \mathrm{~g}$

$\mathbf{C}_{\mathbf{i}} \quad$ inorganic carbon, Fraktion des anorganischer Kohlenstoffs

Co organic carbon, Gesamtfraktion des organischen Kohlenstoffs

$\mathbf{C}_{\mathrm{t}}$ total carbon, Gesamtfraktion des organischen und anorganischen Kohlenstoffs

CV coefficient of variance, Varianzkoeffizient; $[\mathrm{CV}]=[\mathrm{SD} / \mathrm{MW}]=\%$

DIC $^{1} \quad C_{t}$; dissolved inorganic carbon (=total carbonate), Gesamtfraktion des gelösten anorganischen Kohlenstoffs (=Gesamtcarbonat $\mathrm{H}_{2} \mathrm{CO}_{3}{ }^{*}+\mathrm{HCO}_{3}{ }^{-}+\mathrm{CO}_{3}{ }^{2-}$ )

DOC TOC; dissolved/total organic carbon, Gesamtfraktion des gelösten organischen Kohlenstoffs

DON dissolved organic nitrogen, Gesamtfraktion des gelösten organischen Stickstoffs

DTC dissolved total carbon, Gesamtfraktion des gelösten Kohlenstoffs
DTPA Diethylentriamin-pentaessigsäure = Bis-(2aminoethyl)-amin-N,N,N',N",N"-pentaessigsäure; $\mathrm{C}_{14} \mathrm{H}_{23} \mathrm{~N}_{3} \mathrm{O}_{10}$

EC electrical conductivity, elektrische Leitfähigkeit; $[E C]=S / c m$

ECM ectotrophic mycorrhiza, ektotrophe Mykorrhiza

EDDHA N,N'-Ethylen bis[2-(2-hydroxyphenyl)]Glycin; $\mathrm{C}_{18} \mathrm{H}_{20} \mathrm{~N}_{2} \mathrm{O}_{6}$

EDTA Ethylendiamintetraessigsäure = Ethylendiamin-N,N,N',N'Tetraessigsäure; $\mathrm{C}_{10} \mathrm{H}_{16} \mathrm{~N}_{2} \mathrm{O}_{6}$

FE Feinerde; Bodenfraktion $\varnothing<2 \mathrm{~mm}$

$\mathbf{F e}$ (II) Fraktion aller ionaren und komplexen $\mathrm{Fe}^{2+}$ Formen

$\mathrm{Fe}(\mathrm{III})$ Fraktion aller ionaren und komplexen $\mathrm{Fe}^{3+}$ Formen

Ferrozine $^{\circledR 2}$ PDTS = 3-(2-Pyridyl)-5,6-diphenyl1,2,4-4',4"-disulfonsäure = 5,6-Diphenyl-3(2-pyridyl)-1,2,4-triazin-4,4'-disulfonsäure; $\mathrm{C}_{20} \mathrm{H}_{14} \mathrm{~N}_{4} \mathrm{O}_{6} \mathrm{~S}_{2}$

GV Glühverlust; [GV] $=\% \mathrm{~m} / \mathrm{m}_{\mathrm{FE}-\mathrm{TG}}$

i. d. R. in der Regel

i. e. S. im engeren Sinne

i. w. S. im weiteren Sinne

MAD median absolute deviation, Medianabweichung

MHB mycorrhiza helper bacteria, Mykorrhizierung begünstigende Bakterien

MW Mittelwert

NM nicht mykorrhiziert

$\mathrm{N}_{\text {min }} \quad$ Mineralstickstoff; $\mathrm{N}_{\min }=\mathrm{NH}_{4}^{+}+\mathrm{NO}_{2}^{-}+\mathrm{NO}_{3}^{-}$

NR Nitratreduktase

NTA Nitrilotriessigsäure = Tris-(carboxymethyl)amin; $\mathrm{C}_{6} \mathrm{H}_{9} \mathrm{NO}_{6}$

\footnotetext{
1 Je nach Thematik werden in der Literatur unterschiedliche Abkürzungen für die Fraktion des gelösten anorganischen Kohlenstoffs verwendet. $\mathrm{C}_{T}$ umfasst neben $\mathrm{H}_{2} \mathrm{CO}_{3}$ und den Dissoziationsspezies der Kohlensäure auch gelöstes $\mathrm{CO}_{2}$. Damit entspricht diese Fraktion im Wesentlichen derjenigen des gelösten anorganischen Kohlenstoffs DIC.
}

\footnotetext{
2 Das für den Nachweis von $\mathrm{Fe}^{2+}$ verwendete Agens wird hier unter dem geschützten Warenzeichen Ferrozine ${ }^{\circledast}$ geführt. Es ist nicht mit Ferrozin (=Kaliumhexacyanoferrat(III) $=K$ Ferricyanid) zu verwechseln. Bei Ferrozine ${ }^{\circledR}$ handelt es sich um das Mononatriumsalz des PDTS $\mathrm{C}_{20} \mathrm{H}_{13} \mathrm{~N}_{4} \mathrm{O}_{6} \mathrm{~S}_{2}$ (Na).
} 
NUE nutrient use efficiency, Biomasseproduktion pro Einheit Mineralstoff im Pflanzengewebe; $[N U E]=\left[m_{\text {Biomasse }} / m_{\text {Nährstoff }}\right]$ oder $\left[\mathrm{m}_{\text {Biomasse }} / \mathrm{n}_{\text {Nährstoff }}\right]=\mathrm{g} / \mathrm{g}$ oder $\mathrm{g} / \mathrm{mol}$

PEP Phosphoenolpyruvat

PWP Permanenter Welkepunkt; $[\mathrm{PWP}]=\mathrm{Pa}$

RGR relative growth rate, relative Wachstumsrate;

$[R G R]=\left[\left(m_{2}-m_{1}\right) /\left(m_{1} \cdot d t\right)\right]=d^{-1}$ oder $\left.[R G R]=\left[\ln \left(m_{2} / m_{1}\right) / d t\right)\right]=d^{-1}$

RWR root weight ratio, Anteil der Wurzelmasse an der Gesamtbiomasse;

$[R W R]=\left[m_{\text {Wurzel }} / m_{t}\right]=\% \mathrm{~m} / \mathrm{m}$
SD standard deviation, Standardweichung

SM Schwermetall

SLA specific leaf area, Blattoberfläche pro Gewichtseinheit Blatt; $[S L A]=[A / m]=\mathrm{m}^{2} / \mathrm{g}$

TEA Triethanolamin $=2,2^{\prime}, 2^{\prime \prime}$-Nitrilotriethanol

TG Trockengewicht; [TG] = g

T-RFLP terminal restriction fragment length polymorphism

(V)AM (vesikulär-) arbuskuläre Mykorrhiza

XRD $\quad x$-ray diffraction, Röntgenbeugung

\section{Größen, Größengleichungen und Einheiten}

\footnotetext{
A Fläche; $[\mathrm{A}]=\mathrm{m}^{2}$

$\mathbf{E}_{\mathrm{h}} \quad$ Normal(redox)potenzial; $\left[\mathrm{E}_{\mathrm{h}}\right]=\mathrm{V}$

F Kraft; $[\mathrm{F}]=\mathrm{N}$

V Volumen; $[\mathrm{V}]=10^{-3} \mathrm{~m}^{3}=\mathrm{I}$

$\boldsymbol{b}_{\boldsymbol{i}}{ }^{1} \quad$ massebezogene Stoffmenge des Stoffs $i$;

$\left[b_{i}\right]=\left[\mathrm{n}_{\mathrm{i}} / \mathrm{m}_{\mathrm{t}}\right]=\mathrm{mol} / \mathrm{g}$
$\boldsymbol{c}_{\boldsymbol{i}} \quad$ Stoffmengenkonzentration, "Molarität"; $\left[\mathrm{c}_{\mathrm{i}}\right]=\left[\mathrm{n}_{\mathrm{i}} / \mathrm{V}_{\mathrm{t}}\right]=\mathrm{mol} / \mathrm{l}$

$\boldsymbol{w}_{\boldsymbol{i}} \quad$ Massenanteil des Stoffs $i$; $\left[w_{i}\right]=\left[m_{\mathrm{i}} / \mathrm{m}_{\mathrm{t}}\right]=\mathrm{g} / \mathrm{g}$ oder $\% \mathrm{~m} / \mathrm{m}$

m Masse; $[\mathrm{m}]=\mathrm{g}$

$\boldsymbol{n} \quad$ Teilchenmenge; $[\mathrm{n}]=\mathrm{mol}$

p Druck; $[\mathrm{p}]=[\mathrm{F} / \mathrm{A}]=\mathrm{Pa}$ oder bar

pe negativer dekadischer Logarithmus der relativen Elektronenaktivität; [pe] = -log $\mathrm{M}$
}
pH negativer dekadischer Logarithmus der $\mathrm{H}^{+}$- Aktivität; $[\mathrm{pH}]=-\log \mathrm{M}$
$\mathbf{p K}_{\mathbf{S}} \quad$ negativer dekadischer Logarithmus der Säurekonstante $\mathrm{K}_{\mathrm{s}} ;\left[\mathrm{pK_{ \textrm {S } }}\right]=-\log \mathrm{M}$ Zeit; [t] = s (Sekunde), min (Minute), d (Tag), a (Jahr)
$\boldsymbol{x}_{\boldsymbol{i}} \quad$ Molenbruch des Stoffs $i$; $\left[X_{i}\right]=\left[\mathrm{n}_{\mathrm{i}} / \mathrm{n}_{\mathrm{t}}\right]=\mathrm{mol} / \mathrm{mol}$ oder $\% \mathrm{n} / \mathrm{n}$
$\rho_{i}^{*} \quad$ Massenkonzentration des Stoffs $i$; $\left[\rho^{*}\right]=\left[m_{i} / V_{t}\right]=g / l$
$\delta \quad$ spezifische Dichte von Flüssigkeiten; $[\delta]=[\mathrm{m} / \mathrm{V}]=\mathrm{g} / \mathrm{l}$
$\rho \quad$ Dichte von Feststoffen; $[\rho]=[\mathrm{m} / \mathrm{V}]=\mathrm{g} / \mathrm{l}$
$\Theta \quad$ Wassergehalt; $\left[\Theta_{\mathrm{m}}\right]=\left[\mathrm{m}_{\mathrm{H} 2 \mathrm{O}} / \mathrm{m}_{\mathrm{TG}}\right]=\% \mathrm{~m} / \mathrm{m}$ oder $\left[\Theta_{\mathrm{V}}\right]=\left[\mathrm{V}_{\mathrm{H} 2 \mathrm{O}} / \mathrm{V}_{\mathrm{t}}\right]=\% \mathrm{~V} / \mathrm{V}$

\footnotetext{
1 Die massenbezogenen Stoffmengen beziehen sich hier auf den Boden und damit auf eine Feststoffmischung. Sie können daher nicht als Molalitäten i. e. S. $\left(\left[b_{i}\right]=n_{i} / m_{\text {Lösungsmittel }}\right)$ bezeichnet werden.
} 
Einleitung 


\section{Gegenstand der Arbeit}

Why do certain plants grow on certain habitats and not on others? What are the causes for floristic differences between plant communities? If these questions are asked for 'normal', i.e. relatively species rich constant natural or seminatural plant communities (more than 10-20 phanerogams) and if no single extreme, e.g. climatic or toxic factor or human interference occurs, the answers are whole constellations of factors (...). Then a further question arises. Which is the most important factor?

Mit diesen Sätzen formuliert Gigon (1987) zugleich die zentralen Fragen und das fundamentale Problem kausaler Ökosystemanalysen. Selbst für die hier angeführten Sonderstandorte, deren extra- oder azonale Vegetation sensu Ellenberg (1996) durch außergewöhnliche klimatische oder edaphische Einflüsse geprägt ist, kann das komplexe Beziehungsgefüge aus abiotischen und biotischen Faktoren, Antagonismen und Synergismen, Grenzwerten und nicht-linearen Bezügen sowie zeitlichen Fluktuationen und räumlichen Variationen, das der Entwicklung jeder Biozönose zugrunde liegt, nie in all seinen Details untersucht und verstanden werden. Bereits der Versuch, die standörtliche Vegetationsdifferenzierung auf die Wirkung eines einzelnen Faktor zu reduzieren, widerspricht den grundlegenden Prinzipien der Ökologie (Nentwig et al. 2004).

Ausgehend von der Beschreibung des bevorzugten Auftretens mancher Arten auf Kalkböden in einer Abhandlung zur Flora Göttingens von Link (1789) und ersten Untersuchungen von Unger (1836) zum "Einfluss des Bodens auf die Vertheilung der Gewaechse" sind die Ursachen des Wachstums basiphiler bzw. calcicoler Pflanzen in alkalischen, kalkreichen und acidophiler bzw. calcifuger Pflanzen in sauren, kalkarmen Böden Gegenstand einer der ältesten kausalökologischen Fragestellungen (Larcher 1994). Wenngleich dieses Phänomen seit mittlerweile mehr als 200 Jahren untersucht wird, ist die relative Bedeutung auffälliger, gleichzeitig aber miteinander korrelierender Faktoren für die Vegetationsdifferenzierung der betreffenden Standorte bis heute umstritten. Verantwortlich hierfür dürfte nicht zuletzt sein, dass die Vernetzung abiotischer und biotischer Faktoren in den meisten Untersuchungen nur unzureichend berücksichtigt wurde. Vor diesem Hintergrund widmet sich die vorliegende Arbeit der Frage nach den Ursachen der floristischen Differenzierung basenarmer und basenreicher Standorte und behandelt sie am Beispiel von zwei Kalk-Halbtrockenrasengesellschaften integrativ unter phytosoziologischen, bodenkundlichen und autökologischen Gesichtspunkten. Gleichzeitig werden palaeogeographische Aspekte sowie die potenzielle Bedeutung symbiontischer Interaktionen in die Diskussion des Calcicolen/Calcifugen-Komplexes einbezogen.

\section{Theoretische Grundlagen der Arbeit}

Die biologische Ausgestaltung terrestrischer Standorte ist im Kern auf die erdgeschichtliche Entwicklung ihrer geologisch-geographischen Faktoren, darunter solche der Petro-, Topo- und Klimatographie, zurückzuführen. Den Rahmen der biologischen Evolution markierend, stellen sie die eigentlichen ökosystemaren Determinanten dar. Allerdings sind es an vielen Standorten in erster Linie von ihnen abgeleitete Größen, etwa solche des Bodenchemismus, die über die Entwicklung der Biozönose entscheiden (Gigon 1987).

Die Identifizierung der für die Vegetationsdifferenzierung verantwortlichen Standortfaktoren wird dadurch erschwert, dass von diesen die meisten in einer mehr oder weniger engen Beziehung zueinander stehen. Daraus folgt, dass in der Regel das Auftreten und Fehlen bestimmter Pflanzen und deren Vergesellschaftung gleichzeitig mit sehr vielen Faktoren korreliert. Selber Funktionen des Ausgangsmaterials, 
der Textur und der Feuchte des Bodens sind die Protonenaktivitäten $(\mathrm{pH})$, das Redoxpotenzial $\left(\mathrm{E}_{\mathrm{h}}\right)$ und die Ionenstärke (I) übergeordnete Schlüsselfaktoren des Bodenchemismus, die ihrerseits eine Vielzahl anderer Bodeneigenschaften gleich- oder gegensinnig beeinflussen (Wolt 1994). So nehmen in der Regel die Gesamtkonzentrationen der Hydrolysespezies des Carbonatsystems und der $\mathrm{pH}$ mit dem Kalkgehalt des Bodens zu, während die Löslichkeiten des Fe, Mn, Zn, Cu und Al mit der Acidität ansteigen. Optimale P- und N-Verfügbarkeiten liegen für gewöhnlich bei intermediären Bodenreaktionen (pH 5,0-6,0) vor, wobei sich die Bindungsspezies dieser Nährelemente in sauren und basischen Böden voneinander unterscheiden (Kinzel 1982; Marschner 1995).

Der Summe abiotischer und biotischer Einflüsse steht die Autökologie der Pflanzen gegenüber. Als Produkt evolutiver Anpassungen an die Umwelt entscheidet sie über die Etablierung des jeweiligen Genotypus unter den gegebenen Standortbedingungen. Die Verhältnisse des Bodenchemismus lassen ein mehrfaktorielles und verbreitungsspezifisches Muster der Mineralstoffeffizienzen und Mineralstofftoleranzen acidophiler/calcifuger und basiphiler/calcicoler Pflanzen erwarten. Von verschiedenen Autoren wird vermutet, dass in erster Linie die pflanzlichen Fe- und P-Effizienzen die abweichende Vegetationszusammensetzung von Standorten alkalischer, basenreicher sowie saurer, basenarmer Böden bestimmen (z. B. Grime 1963a; Tyler 1994; Gries \& Runge 1995). Viele acidophile/calcifuge Taxa stellen vergleichsweise hohe Ansprüche an die Fe- und P-Versorgung. Ähnlich dem Fe zeigt die Löslichkeit des Mn eine unmittelbare Abhängigkeit nicht nur vom $\mathrm{pH}$, sondern auch vom Redoxpotenzial des Bodens und muss desgleichen als limitierender Faktor für die Besiedlung von Kalkstandorten in Betracht gezogen werden (s. Kinzel 1982; s. Marschner 1995). Auf die Bedeutung erhöhter $\mathrm{HCO}_{3}{ }^{-}$-Konzentrationen für die Ausbildung von Fe-Defizienzen nicht adaptierter Pflanzen verweisen u. a. Loeppert (1986) und Mengel (1994). Das Fehlen Acidophiler/Calcifuger an Standorten alkalischer, kalkreicher Böden und Basiphiler/Calcicoler an Standorten saurer, kalkarmer Böden wurde außerdem mit dem Auftreten von Ca-Toxizitäten und Ca-Defizienzen in Zusammenhang gebracht (z. B. Jefferies \& Willis 1964a, 1964b; Snaydon \& Bradshaw 1961, 1969).

Dort, wo keine extremen Umwelteinflüsse herrschen, wird die Vergesellschaftung der Pflanzen v.a. durch die Ressourcenverteilung (Ricklefs 1977) sowie die daraus resultierenden direkten und indirekten Interaktionen zwischen den verschiedenen Taxa (Aarsen 1983, Grace \& Tilman 1990) und funktionellen Gruppen (Brown \& Gange 1989; Dobson 1994; de Ruiter et al. 1995; Westover \& Bever 2001) bestimmt. Neben essentiellen können toxische oder sonstige schädigende Faktoren Teil des hier wirksamen Konkurrenzausschlusses sein (Gause 1934). Diesbezüglich sind in vielen Pflanzengesellschaften anthropo-zoogene Einflüsse von ausschlaggebender Bedeutung. In neuerer Zeit wird zudem die Bedeutung mikrobieller Symbiosen für die Vegetationsdifferenzierung diskutiert. Die Ausbildung dieser Lebensgemeinschaften hängt u. a. von der Wirtskompatibilität und Standortspezifität des Mikrobionten ab (Bever et al. 1997; Vandenkoornhuyse et al. 2003; van Aarle et al. 2003).

\section{Konzeption der Untersuchungen}

Angesichts der für alle ökologischen Bereiche typischen interrelativen Multikausalitäten bieten Lebensräume, die sich bei einer Vielzahl von Gemeinsamkeiten in nur wenigen Punkten unterscheiden, große Vorteile für die Analyse ihrer biologischen Differenzierung. Vegetationsbestände, in denen graduell oder abrupt Verschiebungen des Artengefüges auftreten, vereinfachen den Abgleich standörtlicher und autökologischer Faktoren. Entsprechendes gilt für Wuchsorte bestimmter Taxa innerhalb und außerhalb ihres Verbreitungsschwerpunkts. Im einen Fall wird dem Standort, im anderen den Pflanzen eine indikative 
Bedeutung beigemessen. Wiederkehrende Bindungsmuster geben Hinweise auf Faktoren, die für die Vegetationsdifferenzierung wichtig sind. Pflanzengesellschaften mit vergleichbaren abiotischen und biotischen Einflüssen in der Vergangenheit und der Gegenwart stellen also besonders geeignete Studienobjekte für kausalökologische Untersuchungen dar (Glavac 1996). Dieser Ansatz wurde der vorliegenden Arbeit zugrunde gelegt.

Die in Mitteleuropa verbreitete pflanzensoziologische Assoziation der Enzian-Schillergrasrasen, das Gentiano-Koelerietum pyramidatae (KNAPP 1942) ex BORNKAMM 1960, ist in ihrer typischen Ausbildung durch flachgründige, vergleichsweise trockene und basenreiche Böden sowie die Vergesellschaftung fast ausschließlich oligotropher, basiphiler/calcicoler Pflanzen gekennzeichnet (Bornkamm 1960). Indes wachsen in manchen dieser anthropo-zoogenen Kalk-Halbtrockenrasen auch bestimmte Acidophile/Calcifuge, darunter Calluna vulgaris, Potentilla erecta und Agrostis tenuis. Dem Auftreten solcher Arten wurde durch die Ausweisung edaphisch geprägter Subassoziationen Rechnung getragen (Bornkamm 1960; Oberdorfer \& Korneck 1976; Bultmann 1993). Deren häufigste ist das Gentiano-Koelerietum danthonietosum decumbentis mit Danthonia decumbens als namengebender Differentialart.

Unter der Annahme, dass sich die autökologischen Eigenschaften und hier v. a. die pflanzlichen Mineralstoffeffizienzen und Mineralstofftoleranzen von Vertretern der beiden Verbreitungsgruppen unterscheiden, stehen vergleichende bodenkundliche Untersuchungen des Gentiano-Koelerietum typicum und Gentiano-Koelerietum danthonietosum im Mittelpunkt der vorliegenden Arbeit. Dem oben beschriebenen Prinzip der Komplementarität standörtlicher und autökologischer Faktoren folgend, werden die Ergebnisse dieser Untersuchungen mit bekannten Anpassungen der betreffenden Taxa abgeglichen. Auf diese Weise soll versucht werden, die relative Bedeutung von Faktoren weiter einzugrenzen, die für die floristische Differenzierung des Gentiano-Koelerietum einerseits und für die autökologischen Unterschiede acidophiler/calcifuger und basiphiler/calcicoler Taxa andererseits verantwortlich zeichnen.

\section{Auswahl und allgemeine Charakterisierung der Untersuchungsstandorte}

Pflanzensoziologische Untersuchungen nach Braun-Blanquet (1964) und Verfahren der numerischen Vegetationsanalyse nach Sørensen (1948) und Digby \& Kempton (1987) dienten zunächst der floristischen Beschreibung der Versuchsbestände des Gentiano-Koelerietum typicum und Gentiano-Koelerietum danthonietosum. Für die Auswahl der insgesamt sechs im nordhessischen Diemeltal und niedersächsischen Südharz gelegenen Kalk-Halbtrockenrasen, in denen jeweils beide Subassoziationen vertreten sind, wurde eine möglichst weit reichende Einheitlichkeit der für das Pflanzenwachstum maßgeblichen Rahmenbedingungen vorausgesetzt. Dazu gehören mit dem Ausgangsgestein, der Inklination, der Exposition und dem Klima Faktoren, die für die Bodengenese ausschlaggebend sind. Nicht zuletzt aufgrund ihrer Einflusses auf die Gründigkeit und die Textur bestimmen sie die physikochemischen Eigenschaften der Böden, darunter deren Wasserhaushalt und Redoxreaktionen. In dieser Hinsicht spielt auch das organische Material eine wichtige Rolle. Neben dem Kalkgehalt wurden daher die Glühverluste und die im Rahmen gaschromatographischer Messungen der C/N-Verhältnisse ermittelten C-Konzentrationen der Feinerde für die grundlegende Beschreibung der Untersuchungsstandorte herangezogen. Gelöste organische Kohlenstoffverbindung (DOC, dissolved organic carbon) sind insbesondere für die Lösung essentieller Schwermetalle von Interesse. Wie einige andere Faktoren auch wurden die DOC-Konzentrationen nur für zwei Referenzstandorte untersucht. 
Da die Lösung und Umsetzung gleich mehrerer Elemente der pflanzlichen Mineralstoffernährung und Mineralstoffintoxikation vom $\mathrm{pH}$ abhängig sind, wurde bei der Auswahl der Untersuchungsstandorte darauf geachtet, dass die jeweiligen Vergleichsbestände möglichst einheitliche Bodenreaktionen im alkalischen Bereich aufweisen. Auf diese Weise sollte eine Maskierung der vegetationsdifferenzierenden Faktoren durch unspezifische pH-Effekte verhindert werden. Im Vorfeld der Untersuchungen wurde davon ausgegangen, dass auch bei gleichen Bodenaciditäten die Pflanzenverfügbarkeiten des $\mathrm{Fe}, \mathrm{Mn}, \mathrm{Cu}$ und/oder Zn im Gentiano-Koelerietum danthonietosum diejenigen des Gentiano-Koelerietum typicum übersteigen. Desweiteren bilden höhere $\mathrm{P}$ - und $\mathrm{NH}_{4}{ }^{+}$- sowie niedrigere $\mathrm{NO}_{3}^{-}{ }^{-}, \mathrm{Ca}^{2+}$ - und $\mathrm{HCO}_{3}{ }^{-}$-Konzentrationen in Vegetationsbeständen, die durch das Auftreten acidophiler/ calcifuger Taxa gekennzeichnet sind, die hypothetische Grundlage der vorliegenden Arbeit.

\section{Methodische Aspekte der mineralstoffökologischen Untersuchungen}

Die Behandlung mineralstoffökologischer Fragestellungen wird dadurch kompliziert, dass eine eindeutige Benennung der für das Pflanzenwachstum ausschlaggebenden Nährstofffraktionen nicht möglich ist. Neben den Lösungs- bzw. Bindungsformen können die räumlichen und zeitlichen Verteilungsmuster die Vegetationsdifferenzierung entscheidend beeinflussen. Die Verwertung oder die intoxikative Wirkung der so gekennzeichneten Fraktionen ist außerdem eine Funktion des pflanzlichen Physiotypus. Andererseits werden die physiko- und chemoedaphischen Milieubedingungen durch die Pflanzen selber beeinflusst, so dass die für das Wachstum relevanten Verhältnisse in der Rhizosphäre von den durchschnittlichen Bodenbedingungen abweichen. Systemimmanent sind bodenchemischen Untersuchungen gerade auch in Bezug auf ihre räumliche Selektivität versuchstechnische Grenzen gesetzt. Diesen Aspekten wurde hier durch die Auswahl und Entwicklung von Versuchsverfahren Rechnung getragen, die für die Behandlung der jeweiligen Fragestellung besonders geeignet erscheinen. Methodische Neu- oder Weiterentwicklungen beziehen sich u. a. auf die Gewinnung von Bodenlösungen und bilden einen weiteren Schwerpunkt der vorliegenden Arbeit.

Kulturexperimente in Festsubstraten von van Helmont (1652) und hydroponische Untersuchungen von Woodward (1699) stehen am Anfang einer Reihe von Arbeiten, die zusammen mit denen von de Saussure zu Beginn und von Sachs und Knop in der Mitte des 19. Jahrhunderts die besondere Bedeutung der Bodenlösung für das Pflanzenwachstum aufgezeigt haben (Epstein 1972). Definitionsgemäß umfasst die Bodenlösung das Interstitialwasser mit dessen Soluten und den gelösten Gasen (Litaor 1988a). Sie ist das Medium, das die verschiedenen Bodenkompartimente miteinander vernetzt und aus dem die Pflanzen ihre Nährstoffe aufnehmen. Joffe (1933) prägte angesichts dieser Verhältnisse das Bild einer "blood circulation of the soil body". Über die Zusammensetzung der Bodenlösung können Rückschlüsse auf die Bodenfestphase, die Sorption und Metabolisierung von Pflanzennährstoffen und somit auf das Pflanzenwachstum gezogen werden. Unter chemischen und ökologischen Gesichtspunkten ist sie daher die interessanteste Bodenkomponente, deren Analyse in vielen Fällen die Aufdeckung der Ursachen für die Etablierung oder Eliminierung bestimmter Pflanzenarten an einem Standort erlaubt (Ulrich 1987). Ein zentrales Problem besteht darin, dass weder praktisch noch theoretisch eine Lösung gewonnen werden kann, die ohne Einschränkungen die realen Verhältnisse im Boden widerspiegelt. So ist es aus thermodynamischen Gründen beispielsweise nicht möglich, das Bodenwasser zusammen mit den darin gelösten Stoffen in vollem Umfang zu extrahieren. Energetisch wird die Bodenlösung durch ihr Wasserpotenzial $\Psi_{\mathrm{w}}$ definiert. Dieses setzt sich aus vier Teilpotenzialen zusammen (Scheffer \& Schachtschabel 1992): 
$\Psi_{w}[P a]=\Psi_{m}+\Psi_{o}+\Psi_{z}+\Psi_{g}$

$\Psi_{\mathrm{m}} \quad$ Matrixpotenzial

$\Psi_{z} \quad$ Gravitationspotenzial

$\Psi_{o} \quad$ osmotisches Potenzial

$\Psi_{g} \quad$ Gaspotenzial

Gravitationspotenzial $\Psi_{\mathrm{z}}$ und Gaspotenzial $\Psi_{\mathrm{g}}$ spielen im Zusammenhang mit der Gewinnung von Bodenlösungen eine untergeordnete Rolle. ${ }^{1}$ Das Matrixpotenzial $\Psi_{\mathrm{m}}$ und das osmotische Potenzial $\Psi_{\mathrm{o}}$ sind Funktionen des Bodenwassergehalts $\Theta$ und unterliegen damit den klimatischen und physikoedaphischen Faktoren. Neben der Bodenfeuchte beeinflusst die Bodentextur das Matrixpotenzial. Der Verlauf von pFKurven, d. h. die semilogarithmische Darstellung der Saugspannung, die bei gegebener Bodenfeuchte für die Gewinnung des Bodenwassers angelegt werden muss (log $\Psi$ vs. $\Theta$ ), gibt Hinweise auf den Wasserhaushalt, aber auch die potenziellen Redoxeigenschaften des Bodens. Im Rahmen der vorliegenden Arbeit wurden neben den aktuellen Wassergehalten auch die Bodenarten, die Skelettanteile und die Feinerdelagerungsdichten bestimmt.

Die Zusammensetzung aller Bodenlösungen hängt von der Art ihrer Herstellung ab. Aus diesem Grund müssen sie grundsätzlich operational und konzeptionell definiert werden (Dahlgren 1993; Wolt 1994). Bodenlösungen i.w. S. umfassen sowohl die aktuelle Bodenlösung, d. h. diejenige bei aktuellem Wassergehalt des Bodens in situ als auch Bodenextrakte, die eine vorherige Aufsättigung des Bodenmaterials erfordern. Für trockene und fein strukturierte, tonreiche Böden, deren sehr niedrige Wasserpotenziale selbst bei Einsatz von Hochgeschwindigkeitszentrifugationen die Gewinnung der aktuellen Bodenlösung verhindern, können nur Bodenextrakte Antworten auf kausalökologische Fragestellungen geben. Zudem geht die Gewinnung der aktuellen Bodenlösung in den meisten Fällen mit einer Zerstörung der natürlichen Bodenstruktur einher. Da die räumlich voneinander abweichenden physikochemischen Eigenschaften innerhalb des Bodenporensystems für die Mineralstoffernährung sowie die potenzielle Intoxikation der Pflanzen von großer Bedeutung sind, ist dies ein entscheidender Nachteil entsprechender Verfahren. Die Pflanzenwurzeln dringen in der Regel nur in Poren mit einem Lumen von mehr als $10 \mu \mathrm{M}$ vor. Sie können demnach ausschließlich mit der Lösung und der Matrix der Grobporen in direkten Kontakt treten. Hingegen stehen sie mit den Mittelporen (Äquivalenzdurchmesser 0,2-10 $\mu \mathrm{M}$ ) lediglich über Massenflüsse entlang matrikaler oder evapotranspirationsbedingter Wasserpotenzialgradienten, mit den Mikroporen im Innern der Bodenaggregate (Äquivalenzdurchmesser $<0,2 \mu \mathrm{M}$ ) nur über Diffusionsprozesse in Verbindung (Wolt 1994).

Zwangsläufig weichen die Eigenschaften der Gas-, Lösungs- und Festphase der verschiedenen Bodenbereiche voneinander ab. Da diese in unterschiedlichem Maß auf die Pflanzen direkt oder indirekt einwirken, widmet die vorliegende Arbeit dem Einfluss des Bodengefüges auf die Zusammensetzung wässriger Bodenextrakte besondere Aufmerksamkeit. Dazu wurden zwei Verfahren für die Extraktion von Bodensäulen intakter Aggregatstruktur entwickelt und die so gewonnenen Bodenextrakte mit Gleichgewichtsbodenlösungen feldfrischer Feinerdehomogenate (GBL) verglichen. Für die Herstellung sog. (Gleichgewichts-) Perkolationsbodenlösungen (PBL) wurden feldfrische Bodenmonolithe unter Einstellung vorgegebener Boden/Lösungs-Verhältnisse zyklisch perkoliert. Der Gewinnung von Druckbodenlösungen

\footnotetext{
$\Psi_{w}$ basiert auf dem Konzept chemischer Potenziale $\mu: \Psi_{w}=\left(\mu_{w}-\mu_{w}{ }^{\circ}\right) / V_{w}$. Das Wasserpotenzial $\Psi_{w}$ ist demnach die auf das molale Volumen des Wassers bezogene Abweichung des aktuell vorliegenden chemischen Potenzials $\mu_{w}$ des Wassers von seinem chemischen Potenzial $\mu_{w}{ }^{\circ}$ unter Standardbedingungen. Chemische Potenziale $\mu_{i}$ eines Stoffes $i$ berechnen sich u.a. auf Grundlage seines Aktivitätsterms $R \cdot T \cdot \ln a_{i}$. Faktoren, wie Erhöhung der Konzentration gelöster Stoffe oder Matrixeffekte, erniedrigen $\mu_{w}$ und damit $\Psi_{w}$. Matrixpotenzial $\Psi_{m}$ und osmotisches Potenzial $\Psi_{o}$ besitzen somit negative Werte.
} 
(DBL) diente eine Apparatur, die nach $\mathrm{H}_{2} \mathrm{O}$-Supplementierung eine umgehende Abpressung der Bodenlösung erlaubt. Konzeptionell wird davon ausgegangen, dass hierdurch in situ-Bodenlösungen in verdünnter Form gewonnen und so Rückschlüsse auf deren Zusammensetzung gezogen werden können. Anhand der Gleichung für den Wassertransport idealer Kapillaren können in erster Näherung die Über- oder Unterdrücke berechnet werden, die für die Gewinnung der Lösung von Poren oberhalb definierter Äquivalenzdurchmesser erforderlich sind. Die Unterschiede der GBL, PBL und DBL beziehen sich methodisch also auf die Extraktionszeit und das Gefüge des eingesetzten Bodenmaterials, inhaltlich auf die Erfassung der aktuellen Bodenlösung sowie Lösungen, die im chemischen Gleichgewicht mit dem Bodenmaterial eines desintegrierten bzw. intakten Aggregatsystems stehen.

\section{Experimentelle Untersuchungen}

Mit Hilfe der wässrigen Extraktionsverfahren wurden für die Referenzbestände des Gentiano-Koelerietum typicum und Gentiano-Koelerietum danthonietosum die saisonalen Fluktuationen der pH-Werte, der Ionenaktivitäten sowie der Konzentrationen ausgewählter Mineralstoffe bestimmt. Das zugrunde liegende Beprobungsschema erlaubte außerdem die Erfassung der lateraler Variabilitäten in den Kalk-Halbtrockenrasen. Ziel dieser Untersuchungen war es, unter Berücksichtigung ihrer stoffspezifischen Extraktions- sowie räumlichen und zeitlichen Auflösungseffizienzen Hinweise auf die Eignung der verschiedenen Bodenlösungstypen für die Benennung der vegetationsdifferenzierenden Standortfaktoren zu gewinnen.

Die bodenchemischen Untersuchungen der vorliegenden Arbeit beziehen sich nicht nur auf die in den GBL, PBL und DBL gelösten, sondern auch auf verschiedene gebundene Mineralstofffraktionen. Ionen des Sorptionkomplexes lassen sich mit Hilfe konzentrierter Austauscherlösungen erfassen. Konzentrationen des $\mathrm{Ca}, \mathrm{Mg}, \mathrm{K}, \mathrm{Na}, \mathrm{Fe}, \mathrm{Mn}, \mathrm{Zn}$ und $\mathrm{Al}$ in $\mathrm{BaCl}_{2}$-Extrakten dienten zugleich der Bestimmung der effektiven Kationenaustauscherkapazitäten. Besonders eingehend wurden die pflanzlichen Fe-Verfügbarkeiten untersucht. Für die selektive Extraktion von Fe(II) und die Differenzierung der zwei- und dreiwertigen Fe-Fraktionen in feldfrischen Feinerdehomogenaten kam ein neu entwickeltes Verfahren mit Ferrozine $^{\circledR}$ als Komplexbildner zum Einsatz. Ammoniumacetat-, DTPA-, NTA-, Oxalat- und DithionitLösungen dienten hier der weiter gehenden Fraktionierung des Fe, aber auch Mn, Cu und Zn. Durch zyklische Perkolationen von Bodenmonolithen der Referenzstandorte wurde die Verteilung der essentiellen Schwermetalle im Porensystem, durch die Extraktion luftgetrockneter Feinerdehomogenate der Einfluss einer diesbezüglichen Vorbehandlung des Bodenmaterials untersucht.

Inkubationen wassergesättigter Bodenmonolithe und regelmäßige Analysen ihrer mit Hilfe von Mikrolysimetern gewonnenen Bodenlösungen sollten Hinweise auf die Redoxdynamik des Fe und Mn in den Böden des Gentiano-Koelerietum typicum und Gentiano-Koelerietum danthonietosum geben. Schließlich wurde durch die sequentielle Extraktion getrockneter Feinerdehomogenate mit Hilfe eines Anionenaustauscherharzes sowie $\mathrm{NaHCO}_{3}$-, $\mathrm{NaOH}$ - und $\mathrm{HCl}$-Lösungen das Angebot verschiedener organischer und anorganischer P-Fraktionen in den Böden der beiden Subassoziationen quantifiziert.

Die standörtlichen Untersuchungen wurden durch Keimungs- und Kulturexperimente acidophiler/calcifuger und basiphiler/calcicoler Taxa in Bodenmaterial der beiden Subassoziationen des Gentiano-Koelerietum ergänzt. Experimente zur Fe- und N-Ernährung von Koeleria pyramidata, Potentilla neumanniana sowie Danthonia decumbens in Nährlösungen begleiteten diese Arbeiten. Aufgrund ihres geringen Umfangs und ihrer daher nur begrenzten Aussagekraft werden die betreffenden Untersuchungsergebnisse lediglich im Anhang und an entsprechenden Stellen der Diskussion behandelt. 


\section{Interdisziplinarität der Arbeit}

Die interdisziplinäre Ausrichtung der vorliegenden Arbeit ließ es sinnvoll erscheinen, die hier skizzierten phytosoziologischen, bodenkundlichen und ökophysiologischen Aspekte des Calcicolen/CalcifugenKomplexes noch einmal detailliert in einem eigenen Kapitel zu behandeln. Dies gilt um so mehr, als die letzte umfassende und integrative Behandlung der Thematik von Kinzel (1982) mittlerweile mehr als 20 Jahre alt ist und bisher nur wenige der in der Zwischenzeit gewonnenen Erkenntnisse benachbarter Disziplinen gezielt in diesen Zusammenhang gestellt wurden. In der abschließenden Diskussion finden neben den eigenen Versuchsergebnissen insbesondere solche aus Examens-, Diplom- und Doktorarbeiten Berücksichtigung, die im ehemaligen Systematisch-Geobotanischen Institut der Universität Göttingen ${ }^{1}$ zum Thema angefertigt, aber noch nicht an allgemein zugänglicher Stelle veröffentlicht wurden.

Einige der potentiell an der Vegetationsdifferenzierung saurer, basenarmer und alkalischer, basenreicher Standorte beteiligten Faktoren konnten im Rahmen der eigenen Arbeiten nur theoretisch behandelt werden. Neben denen, die bereits seit vielen Jahrzehnten Gegenstand der Calcicolen/Calcifugen-Forschung sind, handelt es sich um solche, die erst durch methodische Neuentwicklungen in den vergangenen Jahren einer eingehenderen Untersuchung zugänglich gemacht wurden. Dazu gehören die verschiedenen Formen pflanzlich-mikrobieller Symbiosen. Betrachtungen allein der Autökologie der Pflanzen und der physikound chemoedaphischen Eigenschaften des Standorts lassen nach Jahrzehnten ihrer intensiven Untersuchung keine neuen Impulse für den Calcicolen/Calcifugen-Komplex erwarten. Vielmehr zeichnet sich ab, dass erst die integrative Behandlung der verschiedenen ökosystemaren Einheiten inklusive ihrer evolutiven und biogeographischen Vernetzungen ein besseres Verständnis der Vegetationsdifferenzierung saurer, basenarmer und alkalischer, basenreicher Standorte erlauben wird. Dieser Feststellung wurde in der vorliegenden Arbeit Rechnung getragen

1 Die Abteilung für Ökologie und Ökosystemforschung des Albrecht-von-Haller Institut für Pflanzenwissenschaften, in der die vorliegende Arbeit angefertigt wurde, ist 1998 aus dem Systematisch-Geobotanischen Institut der Universität Göttingen hervorgegangen. 
Material und Methoden 2 


\subsection{Standorte und Vegetationskunde}

Die Ursachen für das Auftreten von calcifugen/acidophilen Arten und die darauf basierende syntaxonomische Differenzierung des Gentiano-Koelerietum danthonietosum wurden anhand kleinräumig benachbarter Vegetationsbestände von insgesamt sechs Kalk-Halbtrockenrasen bei Trendelburg im Landkreis Kassel sowie im niedersächsischen Südharzvorland bei Osterode und Herzberg untersucht (Abbildung 1).
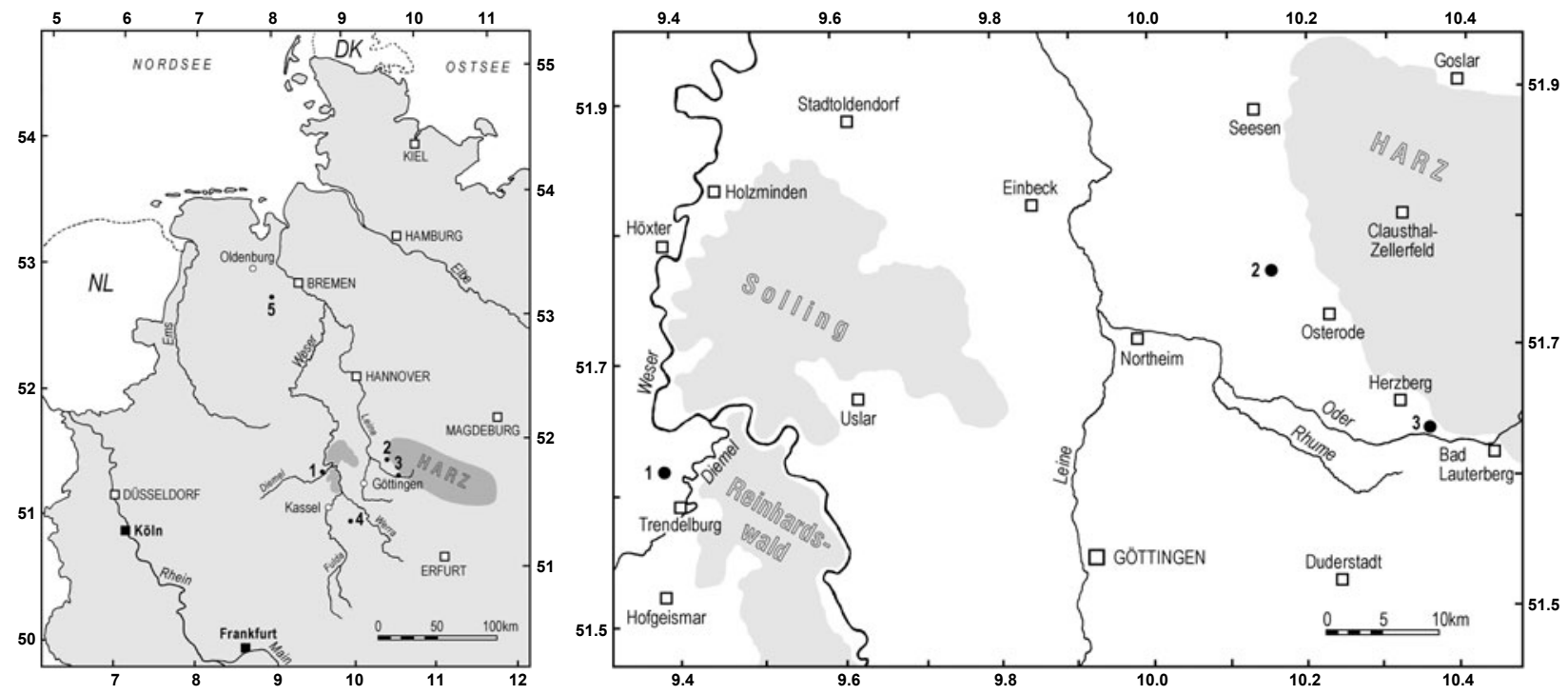

Abbildung 1: Standorte der vegetationskundlichen und bodenkundlichen Untersuchungen sowie der Saatguternten in den Landkreisen Kassel (1=Auf der Burg und Flohrberg bei Deisel, Hölleberg und Hölleberg-Süd bei Langenthal), Osterode am Harz (2=Pagenberg bei Eisdorf, 3=Steinkirche bei Scharzfeld), Werra-Meißner (4=Viehhaus bei Hausen) und Oldenburg (5=Glaner Braut bei Dötlingen). Angabe geographischer Koordinaten (ED 50) in dezimaler Skalierung.

Floristisches Kriterium für die Auswahl der Untersuchungsstandorte waren die Absenz bzw. Präsenz calcifuger/acidophiler Arten, wie Calluna vulgaris, in Rasengesellschaften, deren charakteristische Artenkombination das Gentiano-Koelerietum typicum (CC-Bestände) bzw. Gentiano-Koelerietum danthonietosum (CF-Bestände) kennzeichnen. Weiterhin dienten topographische, geologische und edaphische Angaben in vegetationskundlichen Veröffentlichungen der Vorauswahl möglicher Vergleichsstandorte. Um unterschiedliche klimatische Einflüsse auszuschließen, betrug die räumliche Distanz der Untersuchungsflächen eines Standorts maximal $300 \mathrm{~m}$, ihr Höhenunterschied höchstens $25 \mathrm{~m}$. Das geologische Ausgangsmaterial der Bodenbildung sollte kalkreich sein und in den Vergleichsbeständen eines Standorts einander entsprechen. Im Hinblick auf die multiple Wirksamkeit der Bodenreaktion auf den Lösungschemismus und die zentrale Frage nach der Bedeutung der Zusammensetzung der Bodenlösung für die Ausbildung von Vegetationsunterschieden wurden Vergleichsbestände gesucht, deren pH-Werte eine Pufferung durch $\mathrm{CaCO}_{3}$ anzeigen und diesbezüglich möglichst geringe Abweichungen aufweisen.

\subsubsection{Untersuchungsstandorte}

Etwa $40 \mathrm{~km}$ westlich von Göttingen und $30 \mathrm{~km}$ nördlich von Kassel befinden sich im Unteren Diemeltal bei Trendelburg (Landkreis Kassel) die mit einer Gesamtfläche von mehr als 200 ha größten und zugleich bedeutendsten Kalk-Halbtrockenrasen Hessens (Nitsche \& Bultmann 1995). Innerhalb der biogeographischen 
Region Weserbergland (36) gehört die betreffende Muschelkalk-Hochfläche zum Naturraum Beverplatten der naturräumlichen Haupteinheit 361 Oberwälder Land (Klausing 1988). Im Hinblick auf die Erfassung räumlicher und zeitlicher Fluktuationen erfolgten hier über einen Zeitraum von einem Jahr regelmäßige bodenchemische Untersuchungen von CC- und CF-Beständen zweier Standorte. Der Standort Auf der Burg ist Teil des Naturschutzgebiets Flohrberg und Ohmsberg bei Deisel, der Hölleberg liegt im Naturschutzgebiet Stahlberg und Hölleberg bei Langenthal (Abbildung 2). Neben diesen Referenzflächen wurden einmalig CC- und CFBestände des Flohrberg und des südwestexponierten Hangs des Hölleberg (Hölleberg-Süd) untersucht. Alle Untersuchungsflächen des Unteren Diemeltal liegen entlang eines nord-nordöstlich orientierten Transekts von 3,1 km Länge und in einer Höhe von 210-245 mü. NN.

Vegetations- und bodenkundliche Untersuchungen wurden außerdem in der naturräumlichen Haupteinheit Südwestliches Harzvorland (376) auf dem Pagenberg bei Eisdorf (Naturraum 376 ${ }_{21}$ Osteroder Kalkberge) und an der Steinkirche bei Scharzfeld (Naturraum $376_{27}$ Scharzfelder Zechsteinhügel) im Landkreis Osterode am Harz durchgeführt.

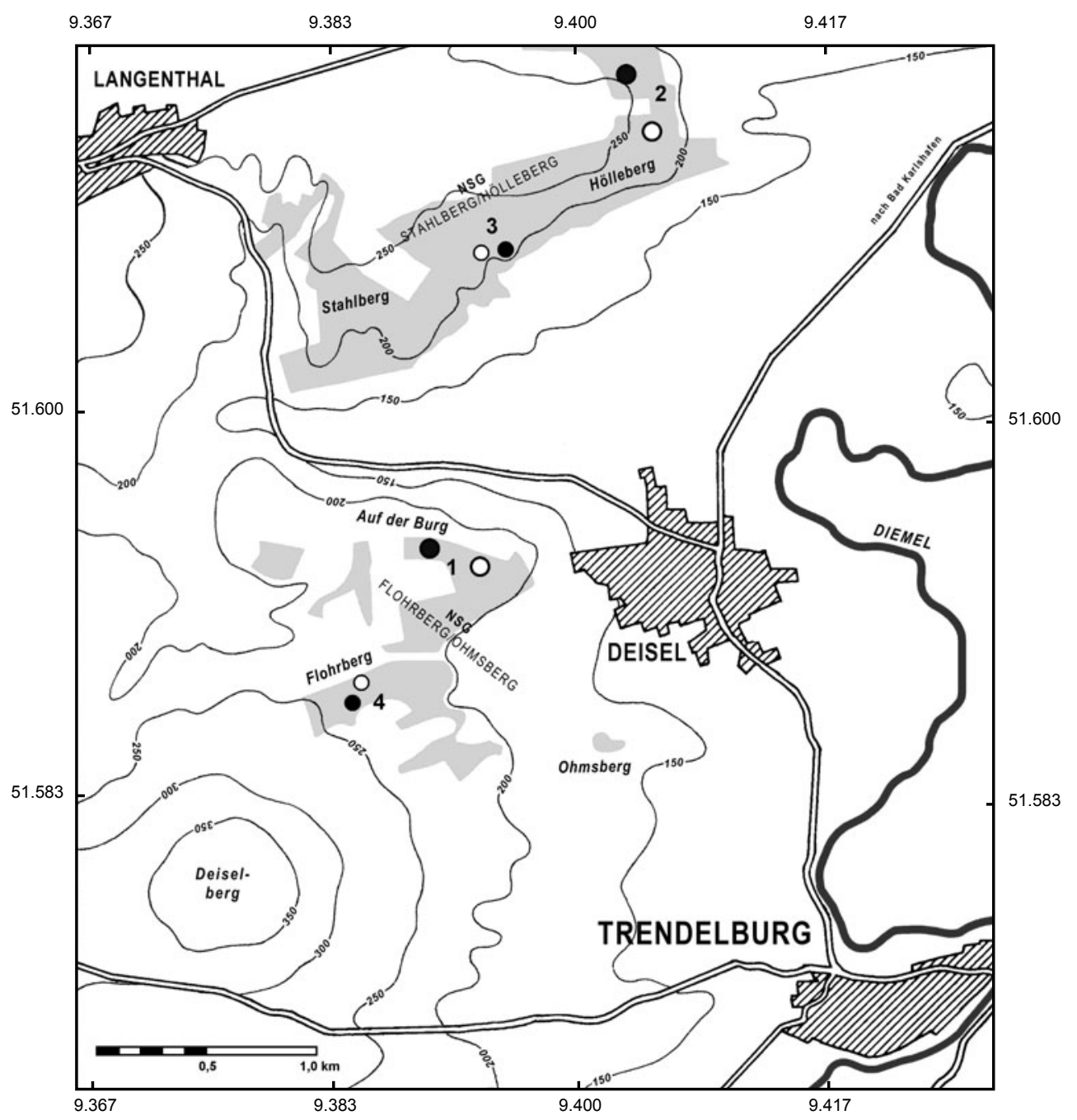

Abbildung 2: Standorte der vegetationskundlichen und bodenkundlichen Untersuchungen im Unteren Diemeltal. 1 Auf der Burg, 2 Hölleberg, 3 Hölleberg-Süd, 4 Flohrberg; O CC-Bestände, $\bullet$ CF-Bestände; große Symbole verweisen auf die Referenzstandorte mehrmaliger, kleine Symbole auf Standorte einmaliger Beprobungen. Schattierungen kennzeichnen Kalk-Halbtrockenrasen. Geographische Koordinaten (ED 50) in dezimaler Skalierung. 


\section{Geologie der Untersuchungsgebiete}

Unterer Muschelkalk (mu) bildet das geologische Ausgangsmaterial der Böden aller Untersuchungsflächen im Unteren Diemeltal (von Linstow 1928, 1929; Lepper 1976a, 1976b). In vertikaler und entstehungsgeschichtlicher Abfolge findet er sich hier zwischen dem älteren Oberen Buntsandstein (so) und den aufgelagerten Schichten des Mittleren Muschelkalks (mm) in erster Linie als Wellenkalk. Im Quartär noch komplett mit Löss bedeckt, wurde dieses Material im Laufe der Zeit von Hanglagen wieder abgetragen (von Linstow 1928). Während im Bereich der meisten Untersuchungsflächen Unterer Wellenkalk (mu1) ansteht, findet sich in der Plateaulage des CF-Bestands Auf der Burg eine Terebratelbank (muT), die zum Oberen Wellenkalk (mu2) überleitet.

Kleinräumig tritt am Flohrberg eine Oolith-Zone (muO) an die Oberfläche. Oolithbänke kennzeichnen den Beginn von Sedimentationszyklen des Unteren Wellenkalks. Die Ausbildung der entsprechenden Schichten bezog bereits verfestigte Sedimente des Meeresbodens mit ein. Durch selektive Auflösung zwischen diesen Geröllanteilen haben die oolithischen Bruchschillkalke eine poröse Struktur erhalten und werden daher auch als Schaumkalke bezeichnet.

Ein mehrfacher Wechsel zwischen niedrigwüchsigen Rasen und gut entwickelten Gebüschstreifen am süd-südöstlich exponierten Hang des Höllebergs verweist auf Verwerfungen von Unterem Wellenkalk und Oolithbänken (Lepper 1976a, 1976b). Zusammen mit den verstärkten Erosionserscheinungen in diesem Bereich sind sie als Ursache lokal erhöhter Bodengründigkeiten anzusehen. Während die Mehrzahl der untersuchten Standorte auf den Beverplatten recht flachgründige Mull-Rendzinen aufweisen, sind die Böden der CF-Bestände hier und auf dem Flohrberg weiter entwickelt und als Braunerde-Rendzinen anzusprechen.

Petrographisch lässt sich die Bodenbildung der Untersuchungsstandorte am Südharzrand auf carbonatreiche Sedimente des Zechsteins zurückführen, die im Osterode-Herzberger Vorland ausstreichen (Hövermann 1963). Zyklen mariner Transgression und Eindampfung während der Zechsteinzeit (vor etwa 240 bis 225 Millionen Jahren), jeweils einhergend mit initialer und geringmächtiger Sedimentation von Tonen und der Ausfällung von Dolomiten, Anhydriten, Stein- und Kalisalzen, entsprechen den geologische Folgen der Werra (z1)-, Staßfurt (z2)-, Leine (z3) und Aller (z4)-Serie, wie sie heute zur Gliederung der Abteilung herangezogen werden. Im Zechsteingürtel des südlichen Harzrandes treten Bereiche aller Serien zu Tage, wobei an den Hängen des Harzes die salinaren Folgen durch Oberflächenwasser abgelaugt und somit nur die schwerer löslichen Horizonte erhalten blieben (Abbildung 3).

Auf dem nördlich von Osterode zwischen Eisdorf und Badenhausen gelegenen Pagenberg findet sich carbonatreicher Stinkdolomit aus der Staßfurt-Serie (Jordan 1976a, 1976b). Diese älteste Schichtfolge im Sedimentationszyklus wird nach der alten Gliederung noch der Abteilung des Mittleren Zechsteins zugeordnet. Die nachfolgenden Horizonte der Serie gehören bereits zum Oberen Zechstein (Möbus 1966). Subrosion des unterliegenden Werra-Anhydrits führte in weiten Bereichen des Gebiets zu Verkarstungserscheinungen. Während hier der Schichtverband des Dolomits aufgebrochen und kavernös ist, bilden auf dem Pagenberg Flachwassersedimente in Form geschlossener bituminöser Dolomitbänke das geologische Ausgangsmaterial der Bodenbildung. Die beiden Vergleichsbestände des hier untersuchten Halbtrockenrasens weisen mehr oder weniger flachgründige Rendzinen auf. 


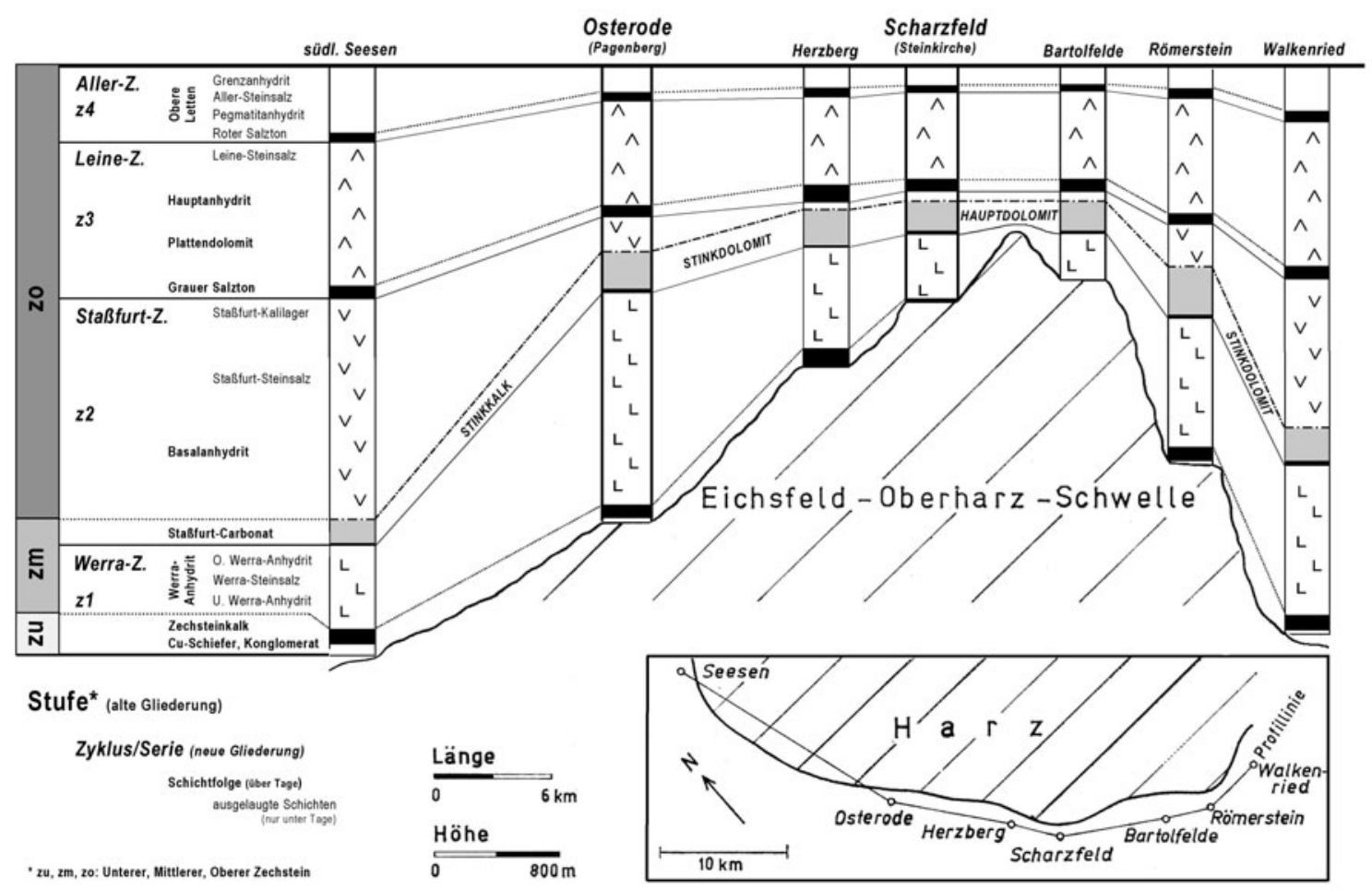

Abbildung 3: Idealisierte stratigraphische Gliederung des Zechsteins im Bereich der Oberharz-Schwelle (verändert nach Richter 1941, 1942; Herrmann 1956).

Eine tiefgründigere Verwitterung des Ausgangsgesteins kennzeichnet den Standort Steinkirche bei Scharzfeld. Wie auf dem Pagenberg handelt es sich auch hier um Staßfurt-Carbonat, in der Fazies des Hauptdolomits allerdings als dickbankiges, zelliges Sediment, das weitgehend frei von Bitumen ist und vergleichsweise schnell feinsandig verwittert (Möbus 1966). Insgesamt ist die Zechsteinformation im Bereich um Scharzfeld durch Denudation und Erosion stark zerstückelt (Schriel 1939). Als inselförmige Schollen liegen sie dem paläozoischen Gebirge auf. Wie an der Steinkirche bildet der Dolomit nicht selten an Bergabhängen und Bergkuppen infolge seiner spezifischen Verwitterungseigenschaften hohe, pfeiler- oder klotzförmige Felsen. Der Name des Standorts bezieht sich auf eine den Untersuchungsflächen unmittelbar benachbarte Klufthöhle, die Teil einer solchen Felspartie ist und in frühchristlicher Zeit als Höhlenkirche genutzt wurde. Wie die Bodentextur vermuten lässt, ist im Bereich des CF-Bestands das stark carbonathaltige Verwitterungsmaterial des Dolomits mit Löss vermischt. Zur Vereinheitlichung der Nomenklatur wird abweichend von den Kennzeichnungen der neueren Bearbeitung des Blattes Osterode (z2,d; Lepper 1976a) auch für den Standort Pagenberg die Signatur zm1 der älteren Klassifizierung des Staßfurt-Carbonats im Mittleren Zechsteins verwendet.

\section{Klima der Untersuchungsgebiete}

Das Untere Diemeltal wird dem Klimabezirk Oberes Weserbergland zugeordnet, die beiden Untersuchungsgebiete am Südharzrand liegen an der Grenze des Klimabezirks Oberes Leinegebiet zum Harz (Deutscher Wetterdienst 1964). Klimatisch sind alle Versuchsstandorte subatlantisch geprägt. Von den drei sich unterhalb des 52. Breitengrads von Westen nach Osten ablösenden Klimabezirken zeigen das Obere Weserbergland und das Obere Leinebergland vergleichbare topographische und klimatische Verhältnisse (Tabelle 1). Höhen- und reliefbedingt ergeben sich für den Harz größere Niederschlags- und Temperaturamplituden. 
Tabelle 1: Klimaelemente in den Bezirken der Untersuchungsstandorte (Deutscher Wetterdienst 1964).

\begin{tabular}{|c|c|c|c|c|c|c|c|c|}
\hline \multirow[t]{2}{*}{ Klimabezirk } & \multirow[t]{2}{*}{ Höhe [m] } & \multicolumn{2}{|c|}{$\begin{array}{c}\text { Mittlere Temperatur } \\
{\left[{ }^{\circ} \mathrm{C}\right]}\end{array}$} & \multirow{2}{*}{$\begin{array}{c}\text { Jahres- } \\
\text { Amplitude } \\
{\left[{ }^{\circ} \mathrm{C}\right]}\end{array}$} & \multicolumn{2}{|c|}{$\begin{array}{l}\text { Anzahl der } \\
\text { Tage }\end{array}$} & \multirow{2}{*}{$\begin{array}{l}\text { Nieder- } \\
\text { schlag } \\
\text { [mm/a] }\end{array}$} & \multirow{2}{*}{$\begin{array}{c}\text { Schnee } \\
\geq 0 \mathrm{~cm} \\
\text { [d] }\end{array}$} \\
\hline & & Januar & Juli & & $\geq 5^{\circ} \mathrm{C}$ & $\geq 10^{\circ} \mathrm{C}$ & & \\
\hline $\begin{array}{l}\text { Oberes Weser- } \\
\text { Bergland }\end{array}$ & $80-500$ & $-2,0-0,0$ & $14,5-16,5$ & $16,5-17,0$ & $195-225$ & $130-160$ & $600-1000$ & $35-75$ \\
\hline $\begin{array}{l}\text { Oberes Leine- } \\
\text { Bergland }\end{array}$ & $100-500$ & $-2,0-0,0$ & $15,0-17,0$ & $17,0-17,5$ & $195-225$ & $135-160$ & $600-900$ & $35-60$ \\
\hline Harz & $250-1100$ & $-4,5--0,5$ & $10,0-17,0$ & $14,5-18,0$ & $140-220$ & $50-55$ & $600-1600$ & $50-150$ \\
\hline
\end{tabular}

Die Abbildung 4 zeigt Klimadiagramme für die Untersuchungsgebiete im Unteren Diemeltal und am Südharzrand. Für die Darstellung der langjährigen Monats- und Jahresmittel der Niederschlagssummen und Temperaturen wurden, soweit möglich, Daten der Periode von 1961 bis 1990 der jeweils nächstgelegenen Niederschlags- und Klimastationen des Deutschen Wetterdienstes verwendet. Für die Temperaturangaben der Standorte Pagenberg und Steinkirche musste auf Daten der Station in Herzberg zurückgegriffen werden. Erst 1991 von einer reinen Niederschlags- zu einer Klimastation ausgebaut, umfassen die Angaben dieser Station Temperaturen aus dem Zeitraum bis ins Jahr 2000. Angesichts der regelmäßigen Untersuchungen der Standorte Auf der Burg und Hölleberg im Jahresverlauf werden hier neben den langjährigen Mitteln auch die Werte für 1998 dargestellt (vgl. Abbildung 17, S. 49).

Im langjährigen Jahresmittel ist das Untere Diemeltal bei vergleichbaren Höhenlagen der den Klimadiagrammen zugrunde liegenden Wetterstationen trockener und kälter als der Südharzbereich. Dies gilt auch für die meteorologische Vegetationsperiode zwischen Mai und Juli und hier in gleicher Weise für 30 (7)jährige Betrachtungszeiträume und das Jahr 1998. Letzteres war im Unteren Diemeltal mit Jahresmitteln von $994 \mathrm{~mm}$ und $8,4^{\circ} \mathrm{C}$ überdurchschnittlich feucht und warm. Verantwortlich für die hohen Jahresdurchschnittswerte im Untersuchungsgebiet zeichneten ergiebige Regenfälle im Herbst sowie im März und April. In den Monaten der ersten Jahreshälfte wurden deutlich höhere Temperaturen als im langjährigen Mittel gemessen. Die meteorologische Vegetationsperiode war 1998 mit einer Niederschlagshöhe von
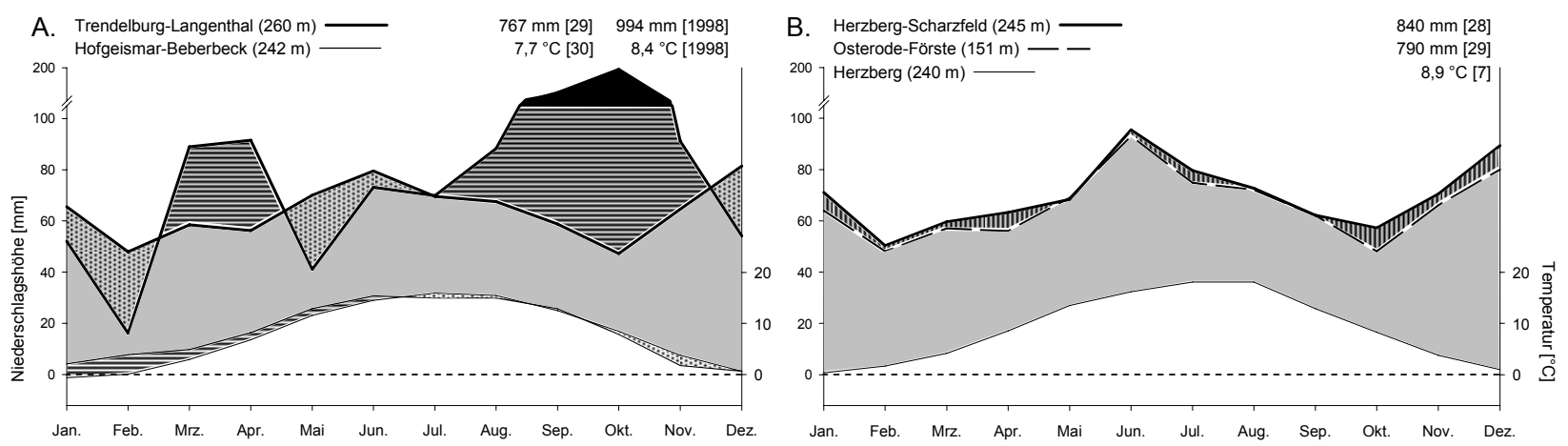

Abbildung 4: Klimadiagramme der Untersuchungsstandorte im Unteren Diemeltal (A.) und am Südharzrand (B.) mit mittleren monatlichen und jährlichen Niederschlagssummen und Tagestemperaturen.

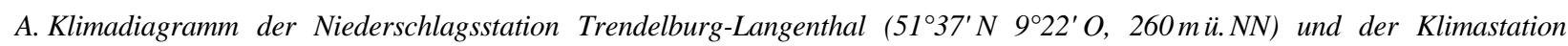
Hofgeismar-Beberbeck (51 ${ }^{\circ} 32^{\prime} N$ 9 ${ }^{\circ} 29^{\prime}$ O, 242 mü. NN). Punktierungen und Schraffuren kennzeichnen Jahresabschnitte, in denen die langjährige Monatsmittel ([Anzahl] Bezugsjahre) über bzw. unter den Monatsmittel des Untersuchungsjahr [1998] liegen.

B. Klimadiagramm langjähriger Monatsmittel ([Anzahl] Bezugsjahre) der Niederschlagsstationen Herzberg-Scharzfeld (51 ${ }^{\circ} 38^{\prime} N$

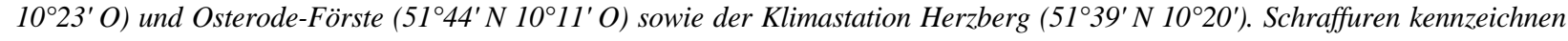
die Niederschlagsdifferenz der Stationen in Herzberg-Scharzfeld und Osterode-Förste. 
$184 \mathrm{~mm}$ gegenüber $219 \mathrm{~mm}$ trockener und mit $14,4^{\circ} \mathrm{C}$ gegenüber $14,0^{\circ} \mathrm{C}$ wärmer als im langjährigen Mittel. Insgesamt entsprechen diese Abweichungen des Jahrs 1998 dem Bild in weiten Bereichen Norddeutschlands. Auch im Südharzgebiet lagen die Jahres-Niederschlagssummen zwischen $25 \%$ und $50 \%$ und die Tagesdurchschnittstemperaturen zwischen $0,5^{\circ} \mathrm{C}$ und $1,0^{\circ} \mathrm{C}$ oberhalb des langjährigen Mittels (Deutscher Wetterdienst 1999).

Legt man der Bewertung des Kontinentalitätsgrads die Temperaturdifferenz zwischen dem wärmsten und kältesten Monat zugrunde, so spiegeln Werte von $17,7^{\circ} \mathrm{C}$ in Herzberg und $16,5^{\circ} \mathrm{C}$ in Hofgeismar-Beberbeck die relative geographische Lage des Südharzes und des Unteren Diemeltals wider. Während die höhere thermische Kontinentalität des östlich gelegenen Untersuchungsgebiets dem makroklimatischen Gradienten folgt, geben Niederschlagshöhe und -verteilung als hygrisches Kontinentalitätsmaß keinen Hinweis auf eine kontinentalere Klimaprägung der Untersuchungsflächen am Südharzrand. Für die insgesamt recht ausgeglichene Niederschlagsneigung mit einem Hauptmaximum im Juni und einem Nebenmaximum im Winter sind am Südharzrand gleichmäßig auftretende Steigungsregen an der Harzschwelle verantwortlich (Glässer 1994). Legt man schließlich der Bewertung der Kontinentalität als kombiniertes thermisch-hygrisches Maß den Quotienten aus dem tausendfachen Monatsmittel der Julitemperatur und der mittleren Jahressumme der Niederschläge zugrunde (Ellenberg 1996), so zeigen sich bei gleicher Höhenlage von etwa 240 mü. NN mit Werten von 19,6 (Hofgeismar-Beberbeck) und 20,9 (Herzberg am Harz) nur geringfügige Abweichungen zwischen den beiden Untersuchungsgebieten, die aber der relativen geographischen Lage entsprechen.

\subsubsection{Vegetationskundliche Untersuchungen}

Die vegetationskundlichen Beschreibungen der Untersuchungsflächen folgen dem pflanzensoziologischen Konzept von Braun-Blanquet (1964). Ergänzend wurden für den Vergleich der Vegetationsbestände und der Vergesellschaftung einzelner Pflanzenarten numerische Klassifizierungsverfahren herangezogen.

Die Vegetationsuntersuchungen der Referenzflächen Auf der Burg und Hölleberg wurden im Juli bzw. August 1998, diejenige der restlichen Standorte im Juli 1999 auf Grundlage einer kombinierten Abundanz- und Deckungsskala durchgeführt (Dierschke 1994):

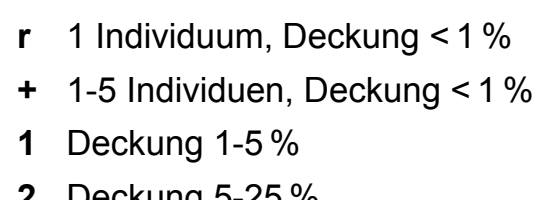

3 Deckung $25-50 \%$

4 Deckung $50-75 \%$

5 Deckung $75-100 \%$

2 Deckung $5-25 \%$

Das Areal der Vegetationsaufnahmen betrug 2,5 m·2,5 m. Für die Standorte Hölleberg-Süd, Flohrberg, Pagenberg und Steinkirche wurden in diesen Flächen zur gleichen Zeit auch alle Bodenprobennahmen durchgeführt. Abweichend hiervon wurden für die mehrmaligen, bodenkundlichen Untersuchungen der Referenzstandorte Auf der Burg und Hölleberg Versuchsflächen mit einer Größe von $10 \mathrm{~m} \cdot 10 \mathrm{~m}$ ausgewiesen und in 16 Quadranten unterteilt. Vegetationsaufnahmen wurden hier nur für die acht alternierenden Parzellen der Reihe A angefertigt (vgl. Abbildung 6, S. 19).

\section{Pflanzensoziologische Auswertung der Vegetationsaufnahmen}

Die Angaben der Kopfzeilen kennzeichnen die Vegetationsaufnahmen der pflanzensoziologischen Tabelle 4 (S. 43). Ein dreistelliger Index verweist auf den Standort (B Auf der Burg, H Hölleberg, F Flohrberg, P Pagenberg, S Steinkirche) und Bestände mit oder ohne calcifugen/acidophilen Arten (CC 
bzw. CF). Eine weitere Kopfzeile benennt die Quadranten der Daueruntersuchungsflächen. Die Angabe "EA" (Einzelaufnahme) bezieht sich hier auf Flächen, die nur einmal untersucht wurden. Weitere Zeilen geben topographische, edaphische und vegetationskundliche Parameter der betreffenden Vegetationsbestände an.

In der synthetischen Tabelle werden neben der Abundanz bzw. Deckung in den einzelnen Vegetationsaufnahmen die prozentualen Stetigkeiten der Arten in den jeweiligen Vegetationseinheiten angegeben (Dierschke 1994):
r $0-5 \%$
III $40-60 \%$
$+5-10 \%$
IV $60-80 \%$
I $10-20 \%$
V $80-100 \%$
II $20-40 \%$

Die Nomenklatur der Phanerogamen folgt der Standardliste der Farn- und Blütenpflanzen Deutschlands von Wisskirchen \& Häupler (1998), diejenige der Moose der Referenzliste von Koperski et al. (2000). Flechten sind dem Katalog von Scholz (2000) entsprechend benannt. Die Ausweisung von Differentialund Charakterarten verschiedener Syntaxa erfolgt in Anlehnung an Oberdorfer \& Korneck (1976). Wie die Sortierung der Vegetationsaufnahmen in der pflanzensoziologischen Tabelle, so wurden auch die im weiteren dargestellten Clusteranalysen für Vegetationsaufnahmen und Pflanzenarten sowie Bearbeitungen von ökologischen Zeigerwerten (Ellenberg et al. 1992) mit Hilfe des vegetationskundlichen Tabellenprogramms SORT (Durka \& Ackermann 1993; Durka \& Ackermann 1994) durchgeführt.

\section{Numerische Auswertung der Vegetationsaufnahmen}

Im Gegensatz zum klassischen pflanzensoziologischen Ansatz wird bei der numerischen Bearbeitung von Vegetationsaufnahmen nicht zwischen diagnostisch relevanten Charakter- sowie Differentialarten und indifferenten Arten unterschieden.

Als Distanzmaß der floristischen Zusammensetzung der verschiedenen Vegetationsbestände dienen quadrierte Euklidische Distanzen. In SORT werden sie als Quotient der Aufnahmenanzahl angegeben:

$$
E D=\frac{\sum\left(x_{k i}-x_{k j}\right)^{2}}{p} \quad \text { Digby \& Kempton (1987) }
$$

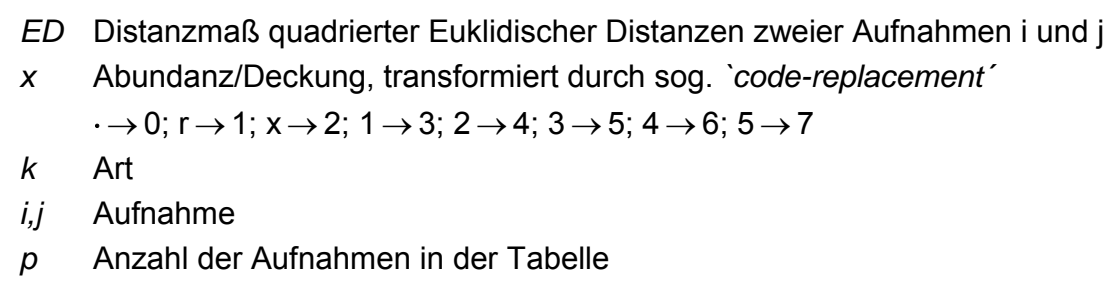

Im Fall einer absoluten Übereinstimmung zweier Vegetationsaufnahmen ist $\mathrm{ED}=0$. Mit zunehmender Heterogenität nimmt der Zahlenwert des Distanzmaßes zu. Im Gegensatz zum Distanzmaß der Vegetationsaufnahmen wurde mit dem Gemeinschaftskoeffizienten $G_{S}$ nach Sørensen (1948) ein Ähnlichkeitsmaß für die Vergesellschaftung von Pflanzenarten gewählt, das nur die Präsenz bzw. Absenz, nicht aber den Deckungsgrad und die Abundanz der betreffenden Arten in den Vegetationsbeständen berücksichtigt. Mit dem Ziel, standörtlich differierende Artengruppen numerisch zu klassifizieren, wurden in diese Analyse lediglich Arten mit Gesamtstetigkeiten zwischen $20 \%$ und $80 \%$ einbezogen: 


$$
G_{S}=\frac{2 a}{(2 a+b+c)} \quad \text { Sørensen (1948) }
$$

$G_{S}$ Ähnlichkeitskoeffizient zweier Arten $\mathrm{i}$ und $\mathrm{j}$ nach Sørensen

a Anzahl Aufnahmen, in denen zugleich Art i und Art j vorkommen

$b$ Anzahl Aufnahmen, in denen nur Art i vorkommt

c Anzahl Aufnahmen, in denen nur Art j vorkommt.

Treten zwei Arten ausschließlich gemeinsam auf, so ist $\mathrm{G}_{\mathrm{s}}=1$. Der Ähnlichkeitskoeffizient nähert sich mit zunehmender Diversität des Auftretens der Arten und mit der Anzahl betrachteter Vegetationsaufnahmen dem Wert 0.

Sowohl die Clusteranalyse auf Grundlage der quadrierten Euklidischen Distanzen als auch diejenige der Sørensen-Indizes basieren auf der Methode einer schrittweisen hierarchischen Agglomeration. Hierbei wird zunächst jede Aufnahme bzw. Art als einzelner Cluster betrachtet und die Distanzmaße/Ähnlichkeitskoeffizienten für alle paarweisen Kombinationen berechnet. Aus der resultierenden Distanz- bzw. Ähnlichkeitsmatrix werden als erstes die beiden ähnlichsten Cluster, d. h. die mit dem geringsten Distanzmaß bzw. höchsten Ähnlichkeitskoeffizienten zu einem Cluster zusammengefasst und im Folgenden als Einheit betrachtet. Für die Berechnung der Euklidischen Distanz bzw. des Sørensen-Index zweier mehrgliedriger Clustereinheiten wurde die Methode des sog. average linkage gewählt. Hierbei wird aus den Werten der Distanz- bzw. Ähnlichkeits-Matrix aller Teilglieder zweier Cluster ein gemeinsamer Mittelwert berechnet. Dieses Verfahren gewährleistet hohe Resistenz gegenüber Ausreißern. In den folgenden Schritten werden solange Gruppen gebildet bis schließlich alle Aufnahmen/Arten in einem Cluster zusammengefasst sind. Die Darstellung der numerischen Klassifizierungen erfolgt in Form von Dendrogrammen. Die Festlegung von Ähnlichkeitsschwellenwerten, die darüber entscheiden, wie viele und welche Vegetationseinheiten oder (ökologische) Artengruppen tatsächlich unterschieden werden, bleibt auch bei Anwendung numerischer Verfahren in der Vegetationskunde subjektiv (Glavac 1996).

\subsection{Bodenkundliche Untersuchungen}

\subsubsection{Bodenprobennahme}

Bodenproben wurden mit Hilfe des in Abbildung 5 dargestellten Zylindersystems aus den oberen $10 \mathrm{~cm}$ des $\mathrm{A}_{\mathrm{h}}$-Horizontes entnommen. Gewinde erlauben den variablen Einsatz der Zylinder für die Probenentnahme im Gelände und die Gewinnung von Extrakten aus Bodenmonolithen im Labor (vgl. Abbildung 7, S. 21). Auf der einen Seite mit einem Schlagaufsatz, auf der anderen Seite mit einem Schneidring aus VA-Stahl versehen, wird der Messingzylinder vertikal in den Boden getrieben und seitwärts herausgehebelt, so dass das natürlichen Bodengefüge weitgehend ungestört bleibt.

Ausgehend von $250 \mathrm{ml}$ Zylindervolumen wurden mit einem scharfen Messer oberirdisches Pflanzenmaterial und organische Auflage entfernt und anschließend der Bodenmonolith mit Hilfe eines $50 \mathrm{ml}$ Kolbens von oben nach unten verdrängt und so das Bodenkernvolumen im Zylinder auf $200 \mathrm{ml}$ reduziert. Ebene Grenzflächen, die durch vorsichtige Entfernung des verbleibenden Materials geschaffen werden, sind für die Stabilität des Monolithen während der nachfolgenden Behandlungen von großer Bedeutung. 


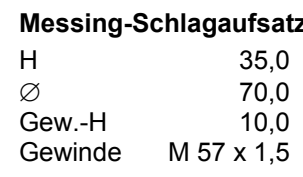

VA-Stahl-Schneidaufsatz

$\mathrm{H} \quad 35,0$

A. $\varnothing \quad 70,0$

I. $\varnothing \quad 52,0$

Gew.-H 10,0

Gewinde M $57 \times 1,5$
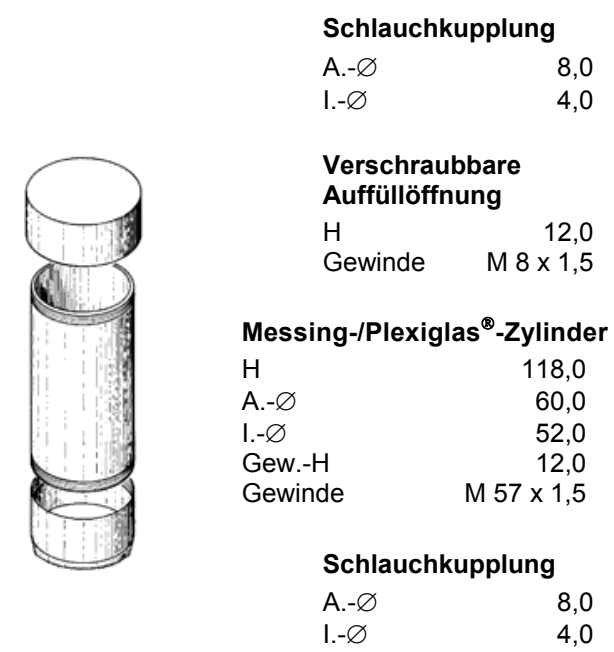

Plexiglas ${ }^{\circledR}$-Verschraubung

(Volumenstauaufsatz)

A.-H 74,0

A. $-\varnothing \quad 80,0$

I.-H 62,0

I.- $\varnothing \quad 52,0$

Gew.-H 10,0

Gewinde M $57 \times 1,5$

Runddichtungen

H 16,0

60,0

Plexiglas ${ }^{\circledR}$-Verschraubung

$\mathrm{H} \quad 16,0$

$\begin{array}{ll}\mathrm{B} & 80,0 \\ \mathrm{~T} & 80,0\end{array}$

Gew.-H $\quad 10,0$

Gewinde M $57 \times 1,5$

Abbildung 5: Zylindersystem zur Probennahme und Herstellung von Perkolationsbodenlösungen (PBL) und Druckbodenlösungen (DBL; vgl. Abschnitt 2.2.4, S. 20 ff.). Links: Zylindersystem für die Entnahme von Bodenmonolithen; Rechts: Zylindersystem mit Volumenstauaufsatz und Unterverschraubung für den Einsatz in Perkolations- und Überdrucksystemen (vgl. Abbildung 7, S. 21, und Abbildung 8, S. 23).

Um bei Extraktionen von Bodenmonolithen Kontaminationen v. a. durch Kupfer und Zink auszuschließen, kann der Messingzylinder durch einen entsprechenden Zylinder aus inertem Plexiglas ersetzt werden. Insbesondere bei skelettreichen Böden besteht die Gefahr, dass bei der Überführung des Bodenkerns in den neuen Zylinder das natürliche Bodengefüge gestört wird. Um dies zu verhindern, wird der Plexiglaszylinder auf der einen Seite mit der in Abbildung 5 dargestellten Unterverschraubung versehen und auf der anderen Seite mit einem Adapterring an den Messingzylinder gekoppelt. Mit Hilfe eines Kunststoffkolben kann nun der Bodenkern vorsichtig von unten in den Plexiglaszylinder geschoben werden.

Für die Untersuchung saisonaler und räumlicher Variabilitäten der Mineralstoffkonzentrationen in Bodenextrakten von CC- und CF-Vegetationsbeständen der Standorte Auf der Burg und Hölleberg wurden in den $10 \mathrm{~m} \cdot 10 \mathrm{~m}$ großen Untersuchungsflächen 16 Quadranten ausgewiesen. Nach Untersuchungen im Januar, Februar und März erfolgte die Beprobung dieser Flächen bis Ende November in etwa zweimonatigen Abständen. In der Regel lagen zwischen den Untersuchungen der Standorte Auf der Burg und Hölleberg zwei Wochen. Der Auswahl der Probennahmepunkte diente das in Abbildung 6 dargestellte Probennahmeschema.

Alternierende Quadranten bildeten zwei Reihen, die abwechselnd beprobt die acht Parallelen eines jeden Versuchsdurchgangs lieferten. Für die Herstellung verschiedener wässriger Bodenextrakte und weitere bodenanalytische Untersuchungen wurden an den ausgewiesenen Stellen in Abständen von $20 \mathrm{~cm}$ drei Bodenmonolithen entnommen. Von diesen Tripletts wurde jeweils eine Bodensäule in einen PE-Beutel überführt, in gleicher Weise wie die verbleibenden, mit Schraubkappen verschlossenen Zylinder gekühlt ins Labor transportiert und bis zu ihrer Aufarbeitung innerhalb der drei folgenden Tage bei $4{ }^{\circ} \mathrm{C}$ gelagert.

Proben der Vergleichsstandorte Hölleberg-Süd, Flohrberg, Pagenberg und Steinkirche wurden in gleicher Weise gewonnen und behandelt. Allerdings musste hier auf eine mehrmalige Beprobung und auf die Herstellung und Untersuchung von Extrakten aus Bodenmonolithen verzichtet werden (s. u.). Analysiert wurden hier vier Zufallsproben aus 2,5 m·2,5 m großen Vegetationsbeständen. 


\begin{tabular}{l|l|ll|ll|ll|ll|l|}
10,00 & & & & & & & & & \\
\hline
\end{tabular}

Abbildung 6: Probennahmeschema der Untersuchungsflächen der Referenzstandorte Auf der Burg und Hölleberg. Ziffern vor den Signaturen der Probennahmepunkte kennzeichnen laufende Nummern der Probennahmetermine, Ziffern hinter den Signaturen die betreffenden Parallelen der Quadranten-Gruppen A und B.

\subsubsection{Probenaufbereitung, Bestimmung von Wasser- und Skelettgehalten}

Für die Bestimmung der Lagerungsdichten sowie die nachfolgende Berechnung der Skelett- bzw. Feinerdefraktionen wurden zunächst die Nettogewichte der bereits im Gelände aus den Zylindern entfernten Bodenkerne sowie die Bruttogewichte der ungestörten Bodenmonolithe ermittelt. Aus den erstgenannten Proben wurde das Skelett- und Wurzelmaterial ausgesiebt, die Steine gespült, getrocknet, gewogen und die feldfrische Feinerde $(<2 \mathrm{~mm})$ gründlich homogenisiert. Teilproben dieser Fraktion dienten der gravimetrischen Bestimmung der aktuellen Wassergehalte. Dazu wurden etwa $10 \mathrm{~g}$ des feldfrischen Feinerdehomogenats in Rollrandgläser eingewogen, bei $106^{\circ} \mathrm{C}$ bis zur Gewichtskonstanz getrocknet und vor der Auswaage in einem evakuierten Exsikkator abgekühlt. Das verbleibende Feinerdematerial wurde teils feldfrisch weiterverwendet, teils in Papiertüten luftgetrocknet und für spätere Untersuchungen gelagert.

Die Ergebnisse von Analysen lufttrockener Proben beziehen sich ebenso wie die von feldfrischem Boden auf die ofentrockene Feinerdefraktion. Für deren Kalkulation wurden die Wassergehalte von Aliquots der lufttrockenen Homogenate zum Zeitpunkt der jeweiligen Untersuchungen bestimmt.

\subsubsection{Analysen lufttrockener Feinerdehomogenate}

\section{Carbonatbestimmung}

Carbonatgehalte der Feinerdefraktion wurden nach Scheibler mittels Volumetrie des durch die Reaktion von $\mathrm{CaCO}_{3}$ mit $\mathrm{HCl}$ freigesetzten $\mathrm{CO}_{2}$ bestimmt (Schlichting et al. 1995).

\section{Bestimmung des Kohlenstoff/Stickstoff-Verhältnisses}

Mit Hilfe eines automatischen C-N-Analysators (Carlo Erba NA 1500) wurden die Kohlenstoff- und Stickstoffgehalte in Proben von etwa $10 \mathrm{mg}$ ofentrockener und gemahlener Feinerdehomogenate quantifiziert. Angesichts der stark abweichenden $\mathrm{CaCO}_{3}-\mathrm{Gehalte}$ der verschiedenen Böden und dem daraus resultierenden Einfluss auf die C/N-Verhältnisse wurden auf Grundlage der Werte des gaschroma- 
tographisch ermittelten Gesamt-C und den C-Werten der Carbonatbestimmung nach Scheibler die Massengehalte an organischem Kohlenstoffs $\left(\mathrm{C}_{0}\right)$ berechnet und der Diskussion von $\mathrm{C}_{\mathrm{o}} / \mathrm{N}$ zugrunde gelegt.

Zur Überprüfung der so erhobenen $\mathrm{C}_{0}$-Anteile wurde für den dritten Probennahmetermin der Glühverlust von etwa 500 mg ofentrockener Probe bestimmt (Steubing 1965; Steubing \& Fangmeier 1992). Um den Einschluss von Humusstoffen in Kieselsäure zu verhindern, wurden diese zunächst eine Stunde bei $250^{\circ} \mathrm{C}$ verschwelt. Nach Temperaturerhöhung auf $600^{\circ} \mathrm{C}$ erfolgte in weiteren vier Stunden die Veraschung des organischen Materials und darüber die Kalkulation des diesbezüglichen Gewichtsverlusts.

\section{Bestimmung der effektiven Kationenaustauschkapazität}

Die effektiven Kationenaustauschkapazitäten $\left(\mathrm{CEC}_{\mathrm{eff}}\right)$ der Böden aller Quadranten in den Vergleichsbeständen der Standorte Auf der Burg und Hölleberg wurden in Anlehnung an Falkengren-Grerup et al. (1995) ermittelt. Einer zweistündigen Schüttelung von $5 \mathrm{~g}$ lufttrockenem Feinerdehomogenat in $50 \mathrm{ml}$ $0,1 \mathrm{M} \mathrm{BaCl}_{2}$ folgten Zentrifugationen (10 min, $\left.1500 \cdot \mathrm{g}\right)$ und Filtrationen (Schleicher \& Schuell $589^{3}$ ) sowie abschließend pH- und AAS-Analysen der Lösungen.

\subsubsection{Herstellung wässriger Bodenextrakte}

Für die Untersuchung der Mineralstoffverfügbarkeiten in den verschiedenen Vegetationsbeständen und im Jahresverlauf kamen drei wässrige Extraktionsverfahren feldfrischer Bodenproben zur Anwendung. In allen Fällen wurde ein Feinerdetrockengewicht/Gesamtlösungs-Verhältnis von 1:2 angestrebt. Die Unterschiede der Verfahren beziehen sich methodisch auf die Extraktionszeit und das Gefüge des eingesetzten Bodenmaterials, inhaltlich auf die Erfassung der aktuellen Bodenlösung sowie Lösungen, die nach eintägiger Equilibrierung im Gleichgewicht mit Bodenmaterial zerstörten bzw. intakten Aggregatsystems stehen.

\section{Gleichgewichtsbodenlösung feldfrischer Feinerdehomogenate (GBL)}

Die Herstellung der GBL erfolgte in Anlehnung an Ludwig et al. (1999). Dazu wurden $25 \mathrm{~g}$ Feinerde in $100 \mathrm{ml}$ Erlenmeyer-Kolben eingewogen und das anhand des aktuellen Bodenwassergehalts für die Einstellung eines Feinerdetrockengewicht/Gesamtlösungs-Verhältnisses von $1: 2$ berechnete Aufsättigungsvolumen $\mathrm{H}_{2} \mathrm{O}$ demin. zugesetzt, die Kolben mit Parafilm ${ }^{\circledR}$ verschlossen und das Boden/Lösungs-System unter Horizontalschüttelung $24 \mathrm{~h}$ bei Raumtemperaturen von $20 \pm 2{ }^{\circ} \mathrm{C}$ equilibriert.

\section{Perkolationsbodenlösung feldfrischer Bodenmonolithe (PBL)}

Die PBL entspricht in den wesentlichen Punkten der Gleichgewichtsporenlösung nach Hildebrand (1994, 1991). In einem geschlossenen System wird $\mathrm{H}_{2} \mathrm{O}$ demin. mittels einer Mehrkanalperistaltikpumpe $24 \mathrm{~h}$ bei $20 \pm 2{ }^{\circ} \mathrm{C}$ durch die Bodenmonolithen perkoliert. Komponenten der Perkolationsapparatur sind neben den Zylindern mit den Bodenkernen und der Schlauchpumpe Ober- und Unterverschraubungen aus Plexiglas mit Schlauchanschlüssen und Dichtungsringen, Gaswaschflaschen sowie flexibles, inertes Schlauchmaterial (Abbildung 7). 


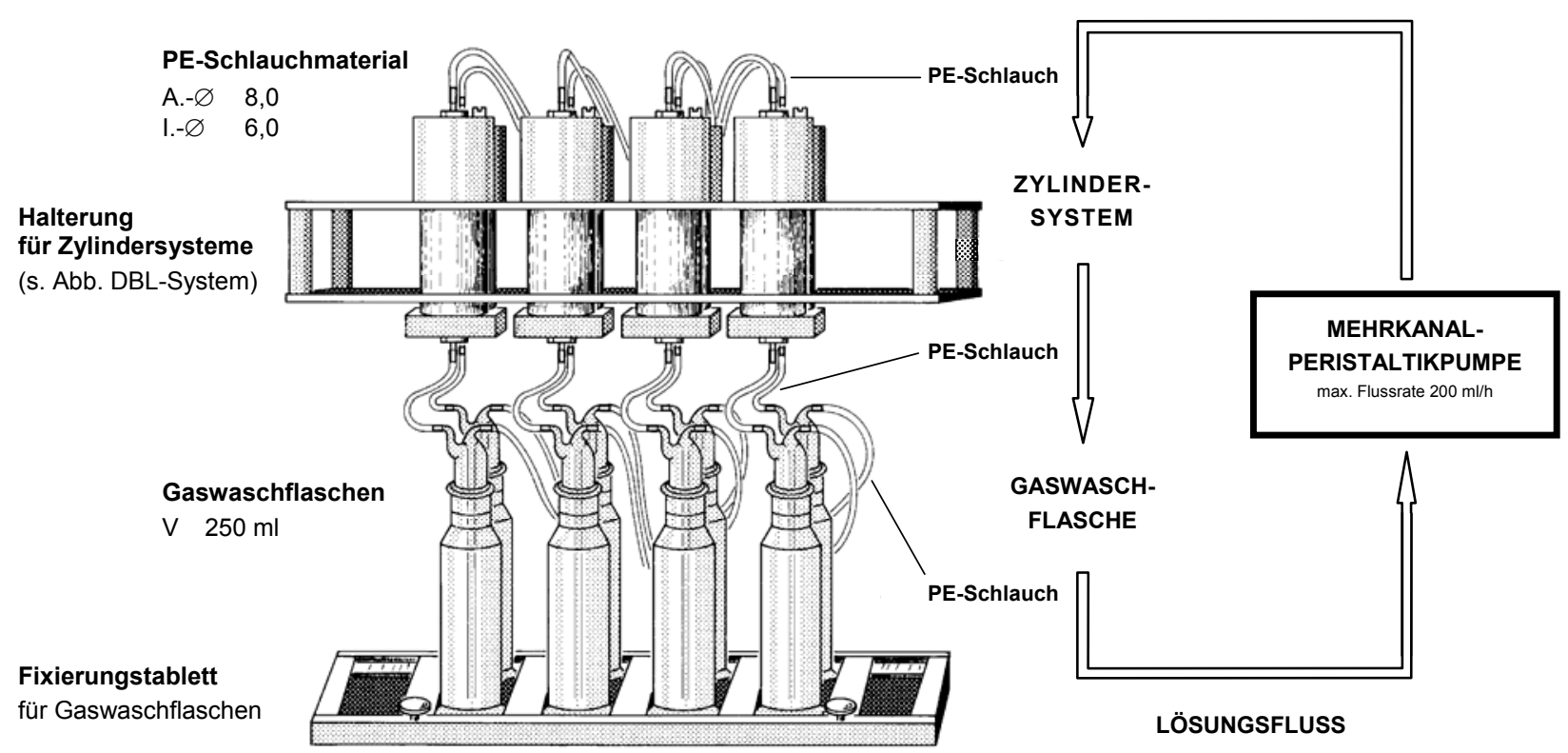

Abbildung 7: Perkolationssystem und Lösungsflussschema für die Herstellung von Perkolationsbodenlösungen (PBL).

Die Pumpe fördert aus der Gaswaschflasche Lösung in den Volumenstauaufsatz der Oberverschraubung und baut zugleich einen Unterdruck auf, der den Fluss von Bodenwasser aus dem Monolithen in die Waschflasche nach sich zieht. Beide Seiten des Bodenkerns werden vor der Perkolation mit aschefreien Schwarzbandfiltern (Schleicher \& Schuell 589 ${ }^{1}$ ) versehen. Diese verhindern ein Auswaschen von partikulärem Material aus dem Zylinder bzw. eine tropfenweise Störung der oberen Grenzfläche des Bodenmonolithen.

Wie bei der GBL sollten für die Extraktion von Bodenkernen Feinerde/Lösungs-Verhältnisse von 1:2 eingestellt werden. Für die Berechnung der Aufsättigungsvolumina der Bodenmonolithen muss u. a. die Masse des Skelettmaterials in den Zylindern bekannt sein. Theoretisch lässt sich der gewichtsbezogene Skelettanteils $\chi$ in den ungestörten Bodensäulen auf Grundlage der Dichten $\rho$ des Monolithen insgesamt (als Quotient aus Nettogewicht des Bodenzylinders und Zylindervolumen) sowie seines Skelettmaterials ( $\rho=2,69 \mathrm{~kg} / \mathrm{l}$ ) und seiner Feinerde (ermittelt anhand das Materials der GBL-Probe) wie folgt kalkulieren:

$\chi=\frac{\rho_{\text {gesamt }}-\rho_{\text {Skelett }}}{\rho_{\text {Feinerde }}-\rho_{\text {Skelett }}}$

Überprüfungen der Ergebnisse entsprechender Berechnungen haben nur unbefriedigende Korrelationen zur tatsächlichen Verteilung der Fraktionen in den Bodenzylindern ergeben. Das für die Einstellung des gewünschten Feinerde/Lösungs-Verhältnisses erforderliche und in der Gaswaschflasche individuell vorzulegende Aufsättigungsvolumen konnte daher nicht allein anhand der Nettogewichte der intakten Bodenmonolithe sowie der Wassergehalte und Dichten der benachbarten GBL-Bodenproben ermittelt werden. Stattdessen wurden den Berechnungen der Aufsättigungsvolumina neben den aktuellen gewichtsbezogenen Wassergehalten der feldfrischen Feinerdehomogenate durchschnittliche Skelettgehalte in den oberen $10 \mathrm{~cm}$ des Bodens der betreffenden Standorte zugrunde gelegt: 


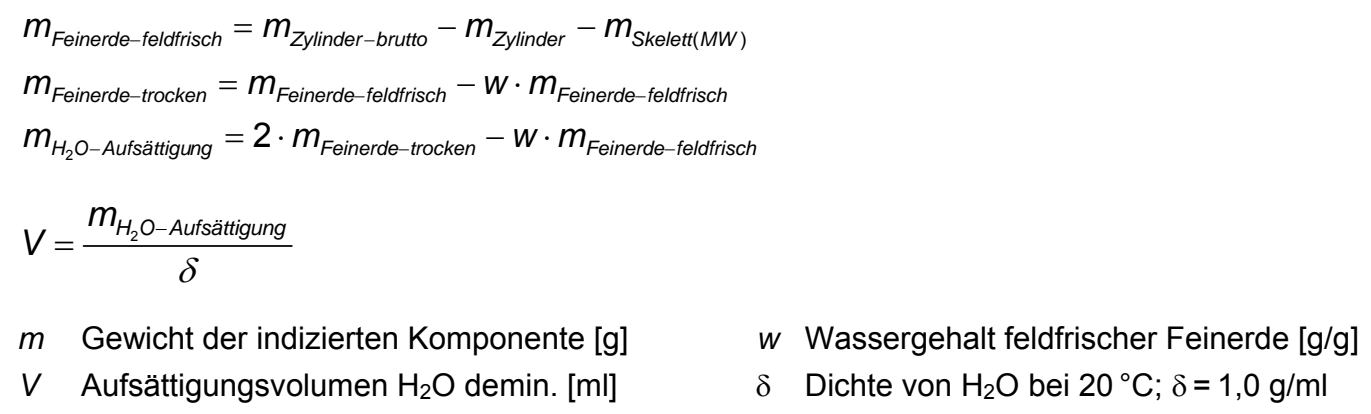

Das Perkolationssystem erlaubte - bei gegebenen Einstellungen der Geschwindigkeit und des Andrucks der Peristaltikpumpenwalze sowie bei Verwendung von Tygon ${ }^{\circledR}$-Schläuchen mit einem Innendurchmesser von 2,06 mm - maximale Durchflussraten von etwa $200 \mathrm{ml} \cdot \mathrm{h}^{-1}$ und eine maximale Ansaugspannung von $80 \mathrm{kPa}$. Je nach hydraulischer Leitfähigkeit des Bodens können allerdings Flussrate und Unterdruck variieren. Die für die Einstellung der Lösungsgleichgewichte erforderliche Equilibrierungszeit wurde in Vorversuchen an jeweils acht Bodenmonolithen der vier Untersuchungsflächen der Referenzstandorte bestimmt. Dazu wurden den Perkolationsansätzen nach 1, 3, 6, 12 und 24 h Aliquots entnommen und neben den pH- und EC-Werten die Konzentrationen verschiedener Anionen und Kationen ionenchromatographisch analysiert.

Mit Hilfe des in Abbildung 7 abgebildeten Perkolationssystem können gleichzeitig acht Bodenmonolithen behandelt werden. Für die Extraktion von je acht Proben beider Vergleichsbestände waren daher zwei Versuchsdurchgänge erforderlich. Um mögliche Verfälschungen der Versuchsergebnisse durch Lagerungseffekte zu minimieren, wurden in die beiden Perkolationsläufe jeweils vier Monolithen eines Vegetationstyps einbezogen. Für die exakte Kalkulation der Mineralstoffverfügbarkeiten auf Basis des Bodentrockengewichts musste nach der Extraktion das Skelettmaterial aller Bodensäulen ausgesiebt und gewogen werden. Angesichts des vernachlässigbaren Anteils von Wurzeln an der Gesamttrockenmasse wurden diese in nachfolgenden Kalkulationen der Feinerdefraktion zugeordnet.

\section{Druckbodenlösung feldfrischer Bodenmonolithe (DBL)}

Wie die PBL, so wird auch die DBL unter Verwendung ungestörter Bodenproben gewonnen. Im Gegensatz zu den beiden Gleichgewichtslösungstypen GBL und PBL soll bei dem DBL-Verfahren die Equilibrierung von Boden, Bodenlösung und Aufsättigungslösung vermieden werden. In Annahme eines reinen Verdrängungs- und Verdünnungseffekts können daher die Ionenkonzentrationen des Bodenwassers berechnet werden. Abbildung 8 zeigt den Aufbau der Überdruckapparatur. Die Berechnung der $\mathrm{H}_{2} \mathrm{O}-$ Volumina zur Einstellung des gewünschten Boden/Lösungs-Verhältnisses und die Erhebung der Bezugsgrößen für die Kalkulation der Mineralstoffgehalte auf Feinerde-Trockengewichts-Basis erfolgten in gleicher Weise wie für die Herstellung der PBL.

Der Schwarzbandfilter der Unterverschraubung der Druckapparatur muss mit gewaschener Filterflockenmasse und weiterem Filterpapier im Porus des Schlauchanschlusses stabilisiert werden. Einer kurzfristigen Aufsättigung und Infiltration des Bodenmonolithen über die verschließbare Einfüllöffnung in der Oberverschraubung des Zylindersystems folgte die Abpressung der DBL. Der hierfür erforderliche Druck wurde durch Anschluss einer Gasflasche aufgebaut, über eine in der Zylinderhalterung integrierte Verteilereinheit parallelisiert und mittels eines Kugelventils in der Oberverschraubung des Zylindersystems für jeden Bodenmonolithen separat reguliert. 
A.

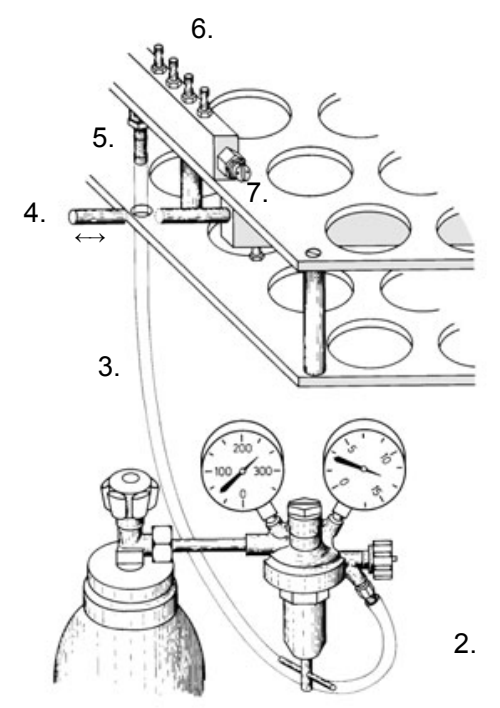

B.

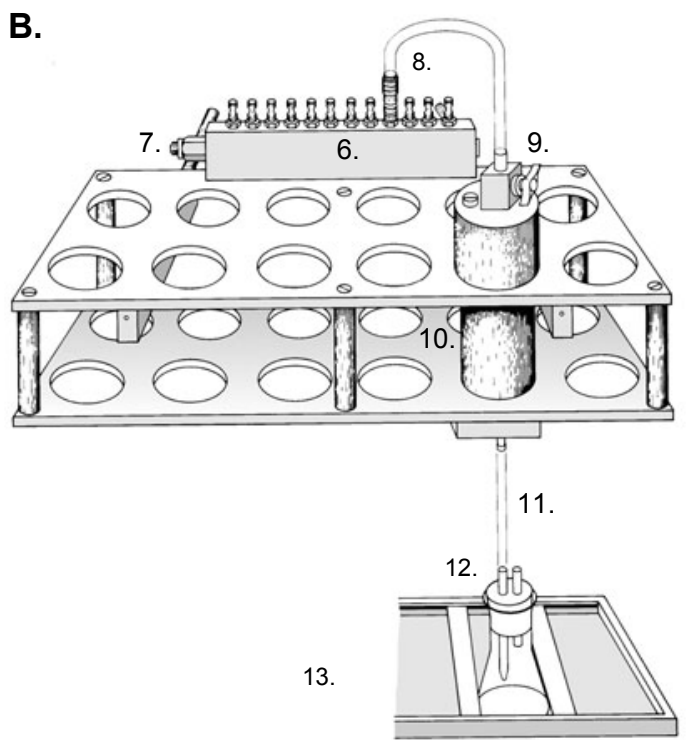

Abbildung 8: Überdruckapparatur zur Gewinnung von Druckbodenlösungen (DBL):

A. Seitenansicht, B. Frontalansicht.

1. Halterung für Zylinder mit Druck-Verteilereinheit

2. $\mathrm{N}_{2}$-Gasflasche mit Druckminderer und Manometer

3. PE-/Gewebe-Schlauch (A.- $\varnothing 16 \mathrm{~mm}, \mathrm{I} .-\varnothing 10 \mathrm{~mm}$

4. Stativrohr für Fixierung der Zylinder-Halterung an Laborzeilen ( $\varnothing 12 \mathrm{~mm}, \mathrm{~L} 100-200 \mathrm{~mm}$ )

5. Sicherheitskupplung Gewebeschlauch - Verteilereinheit Einstecktülle - Kupplung - Einstecknippel (R 1/2")

6. Druck-Verteilereinheit mit Einstecknippeln ( $R$ 1/8")

1.

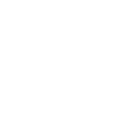


Für die Untersuchung der aktuellen Acidität $\mathrm{pH}\left(\mathrm{H}_{2} \mathrm{O}\right)$ und der potenziellen Acidität $\mathrm{pH}(1,0 \mathrm{M} \mathrm{KCl})$ in Bodentiefen von 0-5 cm und 5-10 cm wurde mit Suspendaten feldfrischer Bodenhomogenate entsprechend Schlichting et al. (1995) verfahren.

\section{Elektrische Leitfähigkeit (EC)}

Messungen der elektrischen Leitfähigkeiten (EC, electrical conductivity) wurden in Anlehnung an Steubing \& Fangmeier (1992) durchgeführt und dienten der halbquantitativen Bestimmungen der Ionenaktivitäten I in den wässrigen Bodenextrakten. Temperaturkompensierte EC $\left(25^{\circ} \mathrm{C}\right)$ wurden in den Probenaliquots der pH-Messungen mit Hilfe einer Leitfähigkeitsmesszelle und einem separaten Temperaturfühler ermittelt.

\section{Gelöster organischer Kohlenstoff (DOC)}

Insbesondere im Hinblick auf ihre Funktion als potenzielle Fe-Komplexoren wurden für die wässrigen Bodenextrakte des dritten Probennahmetermins die Konzentrationen gelöster organischer Verbindungen mit Hilfe eines TOC-Analysators (Shimadzu TOC-5000/5050) bestimmt. Auf Grundlage der Infrarotabsorption von $\mathrm{CO}_{2}$ werden bei diesem Verfahren der anorganische Kohlenstoff (DIC, dissolved inorganic carbon) und der Gesamtkohlenstoff (DTC, dissolved total carbon) in der Probenlösung ermittelt. Die Konzentration des gelösten organischen Kohlenstoffs (TOC=DOC, total/dissolved organic carbon) beträgt demnach:

$D O C(T O C)=D T C-D I C$

\section{lonenaustausch-Chromatographie (HPIC)}

Die HPIC (high performance ion chromatography) stellt innerhalb der Ionenchromatographie (IC) ein Verfahren dar, bei dem die Trennung der Analyte auf Ionenaustausch-Prozessen zwischen mobilen Phasen und anwendungsspezifischen, an Trägermaterialien gebundenen Austauschergruppen basiert. Sie wird überwiegend in Säulen durchgeführt und hat sich zu einem speziellen Teil der modernen Flüssigkeitschromatographie (HPLC) entwickelt (Weiß 1991).

Sowohl für die Anionen- als auch für die Kationenanalytik wurden isokratische Einsäulenverfahren angewendet. Die Quantifizierung der Analyte erfolgte alternativ oder kombiniert mittels UV- oder/und Leitfähigkeitsdetektion. Das kombinierte Gynkotek/Waters-HPLC-System umfasste folgende Komponenten:

- Degaser Shodex/Gynkotek KT 35

- Doppelkolben-Pumpe Gynkotek M480 G

- Autosampler Gynkotek Gina 80

- Säulenofen Gynkotek STH585

- UV-Detektor Gynkotek SP-6

- Leitfähigkeitsdetektor Waters Model 430

Die Anlagensteuerung sowie die Auswertung der Chromatogramme erfolgte unter Verwendung des Gynkotek/Dionex-Chromatographie-Datensystems Chromeleon (Versionen 3.14-4.20).

Für die HPIC-Analytik wurden alle wässrigen Lösungen, darunter die Eluenten, mit $\mathrm{H}_{2} \mathrm{O}$ bidest. angesetzt und Reagenzien höchsten Reinheitsgrads verwendet. Natrium- bzw. Chloridsalze der betreffenden Anionen und Kationen dienten der Herstellung von Standardlösungen. Die Kalibrierung vor jeder der maximal 
50 Proben umfassenden Sequenzen erfolgte durch Variation der Injektionsvolumina in einem Bereich von 5 - $250 \mu$ l. Zusätzliche Validierungsstandards zwischen den Proben dienten der Diagnose von Störungen während der Analysen. Bei Über- oder Unterschreiten des Konzentrationsbereichs der Kalibrierung wurden die Analysen unter Anpassung der Probenvolumina wiederholt.

\section{Anionenaustausch-Chromatographie}

Die ionenchromatographische Anionenanalytik erforderte aufgrund hoher Konzentrationen interferierender $\mathrm{Ca}^{2+}$-Ionen einen präparativen Kationenaustausch der Bodenextrakte. Überdies sollten die Proben im Hinblick auf die pH-Empfindlichkeit des Silica-Basismaterials der hier verwendeten Trennsäule pH 7,5 nicht überschreiten. Der Kationenaustausch und die Einstellung des pH der Analysenlösungen erfolgte mit Hilfe selbst hergestellter Austauschersäulen.

Für etwa 50 präparative Austauschersäulen wurden 5 g Amberlite CG-120 II (200 - 400 mesh) in einen $250 \mathrm{ml}$ Erlenmeyerkolben eingewogen und potenzielle Kontaminationen des Austauschermaterials durch aufeinanderfolgende Schüttelungen mit $100 \mathrm{ml}$ 0,5 N NaOH, $100 \mathrm{ml}$ 0,1 N NaOH + 0,02 M EDTA $\cdot \mathrm{Na}_{2}$ und $300 \mathrm{ml} \mathrm{H}_{2} \mathrm{O}$ bidest. beseitigt. Die verschiedenen Lösungen lassen sich nach Sedimentation des Harzes mit Hilfe einer Wasserstrahlpumpe problemlos entfernen. Im Anschluss an die Funktionalisierung mit $50 \mathrm{ml} 1 \mathrm{M} \mathrm{HCl}$ wurde das Austauscherharz so oft mit $\mathrm{H}_{2} \mathrm{O}$ bidest. gewaschen, bis der wässrige Überstand klar und säurefrei war. Abschließend erfolgt eine Konditionierung des Kationenaustauschermaterials mit $50 \mathrm{ml}$ Methanol (100\%) und dessen Resuspension in $45 \mathrm{ml}$ Methanol (40\% V/V).

Von dem Suspendat wurden $1000 \mu \mathrm{l}$ in Pipettenspitzen entsprechender Größe überführt. Diese Menge ist so kalkuliert, dass nach Zentrifugation in Corex ${ }^{\circledR}$-Röhrchen $(\varnothing 10 \mathrm{~mm}$ x H $75 \mathrm{~mm} ; 2 \mathrm{~min}, 1000 \mathrm{rpm})$ die Füllhöhe des Harzes etwa 8-10 mm betrug. Etwas Mineralfaserwatte in der Pipettenspitze verhinderte ein Austreten von Austauschermaterial. Um möglichst einheitliche Säulen zu erhalten, musste das HarzMethanol-Gemisch während des Pipettierens mit Hilfe eines Magnetrührers kontinuierlich homogenisiert werden. Die Anzahl der Säulen eines Zentrifugationsgangs wurde so bemessen, dass sie vor ihrer Verwendung nicht austrocknen konnten.

Für die Aufreinigung wurden $1 \mathrm{ml}$ Probenlösung in die präparativen Kationenaustauschersäulen pipettiert, die ersten Tropfen verworfen und der verbleibende Rest direkt in Ampullen des HPLC-Autosampler überführt. Für die Anionenanalyse wurde Säulenmaterial auf Kieselgelbasis mit quartären Ammoniumbasen als funktionellen Gruppen und Phthalatpuffer als Eluent verwendet. Letzterer wurde für jede Analysenreihe durch Verdünnung $(1: 125)$ des in Tabelle 2 beschriebenen Pufferkonzentrats frisch hergestellt. Der Quantifizierung von Phosphat, Chlorid und Sulfat diente die folgende Applikation:

- Säulenmaterial:

- Eluent:

- Injektionsvolumina:

- Flussrate:

- Laufzeit:

- Temperatur:

- Detektion:
Gynkochrom AX-5i (120 • 4,6 mm) mit Vorsäule

Phthalat 1,5 mM - pH 5,8

$100-200 \mu \mathrm{l}$

$1,5 \mathrm{ml} \cdot \mathrm{min}^{-1}$

$20 \mathrm{~min}$

$20^{\circ} \mathrm{C}$

UV-Absorption ( $\lambda=280 \mathrm{~nm}$, negativ) + Leitfähigkeit 
Tabelle 2: Pufferkonzentrat des Phthalateluenten für die Anionenanalytik mit Gynkochrom AX-5-Säulen.

\begin{tabular}{|c|c|c|c|c|}
\hline Komponente & $\mathrm{C}_{\text {Konzentrat }}[\mathrm{mM}]$ & $\mathrm{C}_{\text {Eluent }}[\mathrm{mM}]$ & $\mathbf{M}_{\mathbf{r}}$ & $\rho^{*}$ Konzentrat $[g / l]$ \\
\hline Kaliumhydrogenphthalat $\mathrm{C}_{8} \mathrm{H}_{5} \mathrm{KO}_{4}$ & 188 & 1,50 & 204,2 & 38,3 \\
\hline Borsäure $\mathrm{BOH}_{3}$ & 500 & 4,00 & 61,8 & 30,9 \\
\hline Natriumhydroxid $\mathrm{NaOH}$ & 170 & 14,1 & 40,0 & 6,80 \\
\hline $\mathrm{Na}_{2}$-EDTA $\mathrm{C}_{10} \mathrm{H}_{14} \mathrm{~N}_{2} \mathrm{Na}_{2} \mathrm{O}_{8} \cdot 2 \mathrm{H}_{2} \mathrm{O}$ & 6,25 & 0,05 & 372,2 & 2,34 \\
\hline Formaldehyd $\mathrm{CH}_{2} \mathrm{O} ; 37,5 \%$ & 1250 & 10,0 & 30,0 & 101 \\
\hline
\end{tabular}

Unter den hier eingestellten Bedingungen zeigt die Leitfähigkeitsdetektion für die Mehrzahl der Analyte ein höheres $\mathrm{p}(\mathrm{eak}) / \mathrm{n}$ (oise)-Verhältnis und damit eine höhere Sensitivität als die UV-Detektion (Abbildung 9). Die Erfassung sowohl des Leitfähigkeitschromatogramms als auch der UV-Absorption des Eluates erlaubt eine Absicherung der Analysenergebnisse und eine eindeutige Zuordnung des Phosphat-Peaks. $\mathrm{H}_{2} \mathrm{PO}_{4}{ }^{-}$zeigt ein inverses Verhalten hinsichtlich der Leitfähigkeit und der UV-Absorption und ist daher von dem nächsteluierenden $\mathrm{Cl}^{-}$eindeutig abzugrenzen. Dennoch war in vielen Fällen eine Quantifizierung des $\mathrm{H}_{2} \mathrm{PO}_{4}^{-}$nicht möglich. Die AX-5i-Säulen besitzen bei gegebener Applikation nicht nur einen niedrigen Selektivitätsterm $\alpha$ für $\mathrm{H}_{2} \mathrm{PO}_{4}{ }^{-}$und $\mathrm{Cl}^{-}$, sondern auch für $\mathrm{HCO}_{3}{ }^{-}$und $\mathrm{H}_{2} \mathrm{PO}_{4}{ }^{-}$. Hydrogencarbonat eluiert in unmittelbarer Nähe der Totzeit $\mathrm{t}_{\mathrm{m}}$ und zeigt ein vergleichbares Leitfähigkeits- und UV-Absorptionsverhalten wie $\mathrm{H}_{2} \mathrm{PO}_{4}{ }^{-}$. Im Hinblick auf die unzureichende Auftrennung von $\mathrm{HCO}_{3}{ }^{-}$und die Problematik der Einstellung von Gleichgewichten zwischen den Probenlösungen und atmosphärischem $\mathrm{CO}_{2}$ wurde daher auf eine Auswertung der $\mathrm{HCO}_{3}^{-}$-Peaks verzichtet.
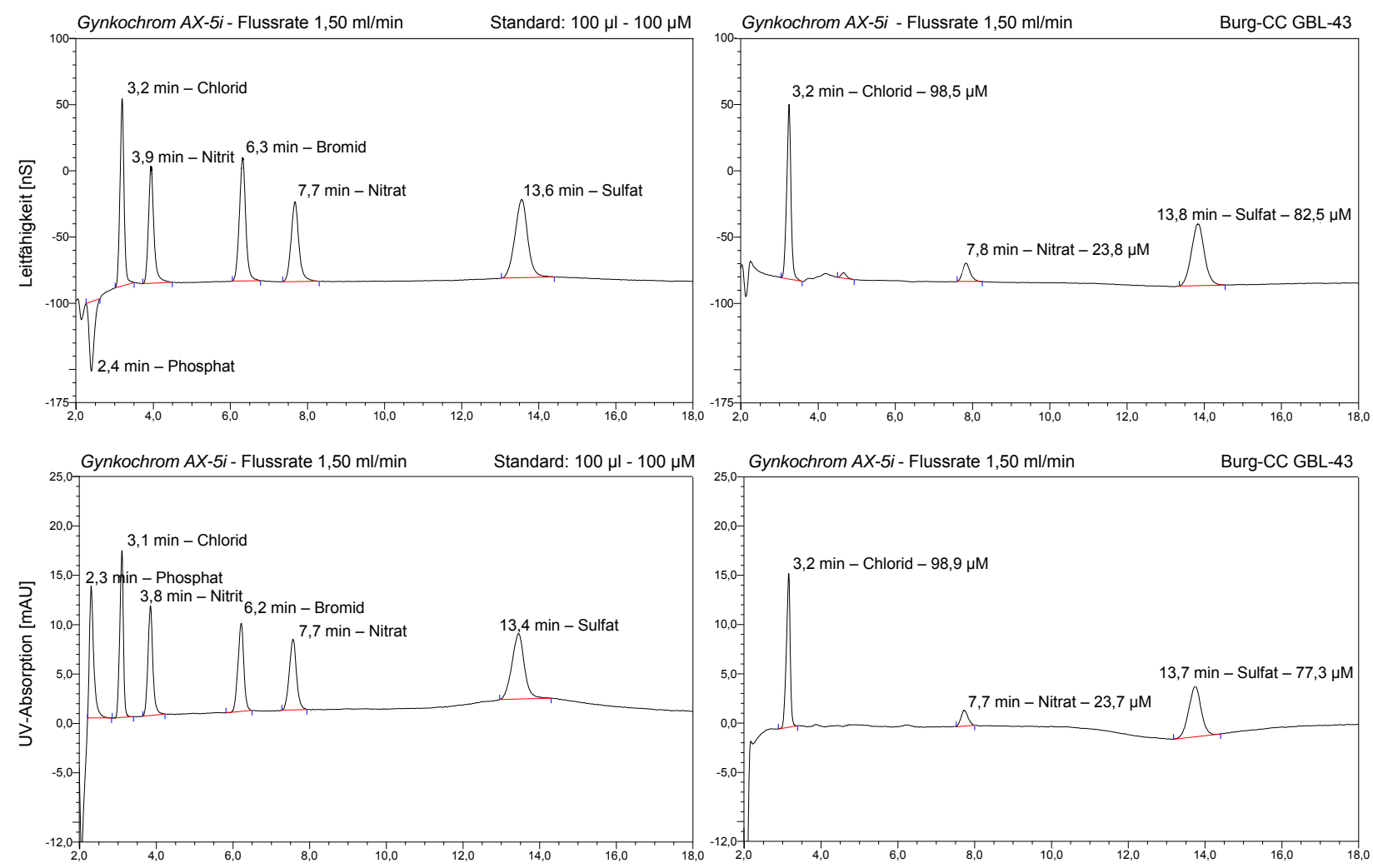

Abbildung 9: Leitfähigkeits-Detektion (oben) und UV-Detektion (negativ, $\lambda=280 \mathrm{~nm}$, unten) der HPIC-Anionenanalytik von $100 \mu \mathrm{l}$ Standardlösung $(100 \mu \mathrm{M}$, links) und $100 \mu \mathrm{l}$ wässrigem Bodenextrakt (rechts) mit GynkochromAX-5i-Säulen und Phthalat-Eluenten (weitere Spezifikationen s. Text). 
Besonders hohe Absorptionsmaxima im unteren UV-C-Bereich zwischen $200 \mathrm{~nm}$ und $250 \mathrm{~nm}$ erlauben bei Verwendung eines UV-inaktiven Eluenten eine etwa zehnfache Reduktion der Nachweisgrenzen von Nitrit und Nitrat auf $1 \mathrm{ppb}\left(21 \mathrm{nM} \mathrm{NO}_{2}^{-}, 16 \mathrm{nM} \mathrm{NO}_{3}^{-}\right)$. Angesichts der z.T. sehr niedrigen Konzentrationen der beiden Stickstofffraktionen in den wässrigen Bodenextrakten wurde für alle Proben eine entsprechende HPIC mit Phosphatpuffer als Laufmittel durchgeführt (Abbildung 10). Durch Verwendung einer kleineren Trennsäule gleichen Austauschermaterials konnten die Laufzeiten deutlich verkürzt werden:

- Säulenmaterial:

- Eluent:

- Injektionsvolumina:

- Flussrate:

- Laufzeit:

- Temperatur:

- UV-Detektion:
Gynkochrom AX-5 c (60 • 4,6 mm) mit Vorsäule $6,0 \mathrm{mM} \mathrm{KH}_{2} \mathrm{PO}_{4}+4,0 \mathrm{mM} \mathrm{K} \mathrm{HPO}_{4}$ (+300 ppm Formaldehyd) $50-200 \mu \mathrm{l}$

$1,0 \mathrm{ml} \cdot \mathrm{min}^{-1}$

$15 \mathrm{~min}$

$20^{\circ} \mathrm{C}$

$\lambda=208 \mathrm{~nm}$, negativ
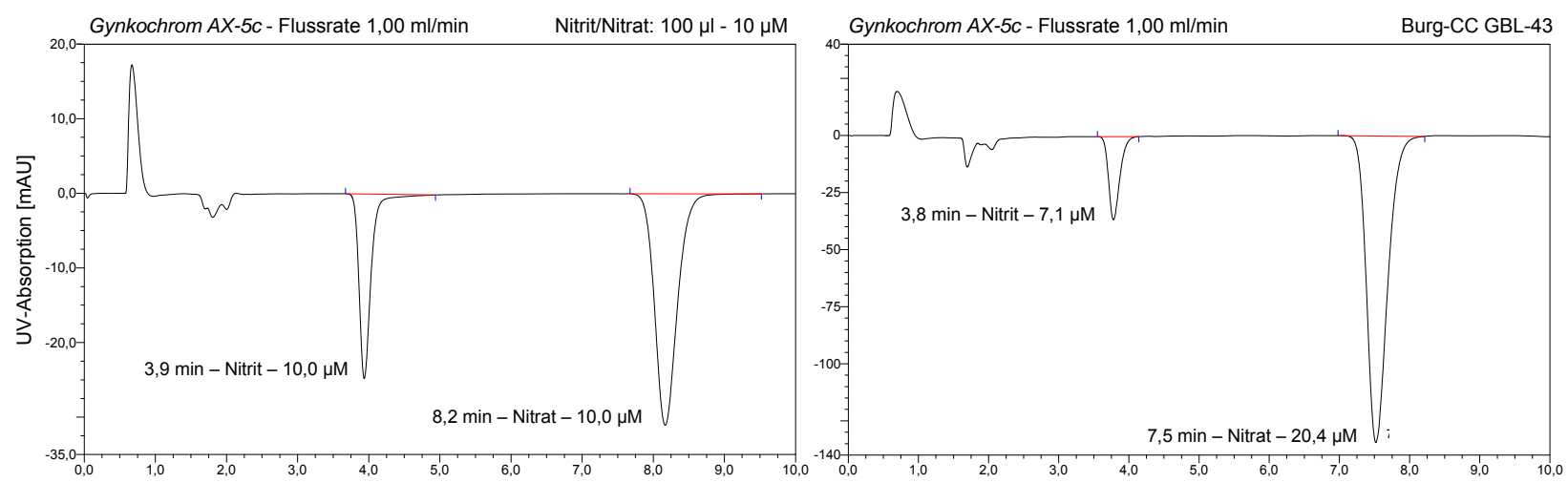

Abbildung 10: UV-Detektion (negativ, $\lambda=208 \mathrm{~nm})$ der $\mathrm{NO}_{2}^{-}$und $\mathrm{NO}_{3}{ }^{-}$-Analytik in $100 \mu$ l Standardlösung $(10 \mu \mathrm{M}$, links) und $100 \mu \mathrm{l}$ wässrigem Bodenextrakt (rechts) mit Gynkochrom-AX-5c-Säulen und Phosphatpuffer-Eluenten (weitere Spezifikationen s. Text).

\section{Kationenaustausch-Chromatographie}

Die HPIC-Analytik von $\mathrm{Na}^{+}, \mathrm{K}^{+}, \mathrm{Ca}^{2+}, \mathrm{Mg}^{2+}$ sowie $\mathrm{NH}_{4}{ }^{+}$wurde für die wässrigen Bodenextrakte der ersten Beprobungen der Referenzstandorte mit Säulenmaterial durchgeführt, dessen Kationenaustausch auf Polybutadien-Maleinsäure-Funktionen basiert. Das Überschreiten der Säulenkapazität durch überproportional hohe $\mathrm{Ca}^{2+}$-Konzentrationen, die daraus resultierende Überlagerung des benachbarten $\mathrm{Mg}^{2+}$ Peaks sowie das extreme tailing des $\mathrm{Ca}^{2+}$-Peaks bei Injektionsvolumina zwischen $100 \mu \mathrm{l}$ und $200 \mu \mathrm{l}$ machten eine zweite IC-Analyse mit $10 \mu$ Probe erforderlich. Sehr viel stärker noch als in Abbildung 11 für die Probe eines CF-Bestands dargestellt, zeigten sich $\mathrm{Ca}^{2+}$-Überfrachtungen bei Messungen von Bodenextrakten der CC-Vegetationsbestände. Die Kationenanalysen wurden entsprechend den folgenden Spezifikationen durchgeführt.

- Säulenmaterial:

- Eluent:

- Injektionsvolumina:

- Flussrate:

- Laufzeit:
Gynkochrom CAT-125 (125 • 4,6 mm) mit Vorsäule

4,3 mM Ascorbinsäure + 2,3 mM Oxalsäure

$100-200 \mu \mathrm{l} / 10 \mu \mathrm{l}$

$0,75 \mathrm{ml} \cdot \mathrm{min}^{-1} / 1,5 \mathrm{ml} \cdot \mathrm{min}^{-1}$

20-25 min / 10-15 min 
- Temperatur:

- Detektion: $20^{\circ} \mathrm{C}$

Leitfähigkeit (negativ)

Die beiden organischen Säuren des Eluenten sind leicht oxidierbar. Aus diesem Grund wurde das für den Eluenten verwendete $\mathrm{H}_{2} \mathrm{O}$ bidest. unmittelbar vor dem Ansatz mit Hilfe eines Vakuumaggregats entgast. Überdies erfolgte eine Stabilisierung des Eluenten, indem die Vorratsflasche des Laufmittels in einem eisgefüllten Styropor ${ }^{\circledR}$-Behälter vor photooxidativer Strahlung geschützt wurde.
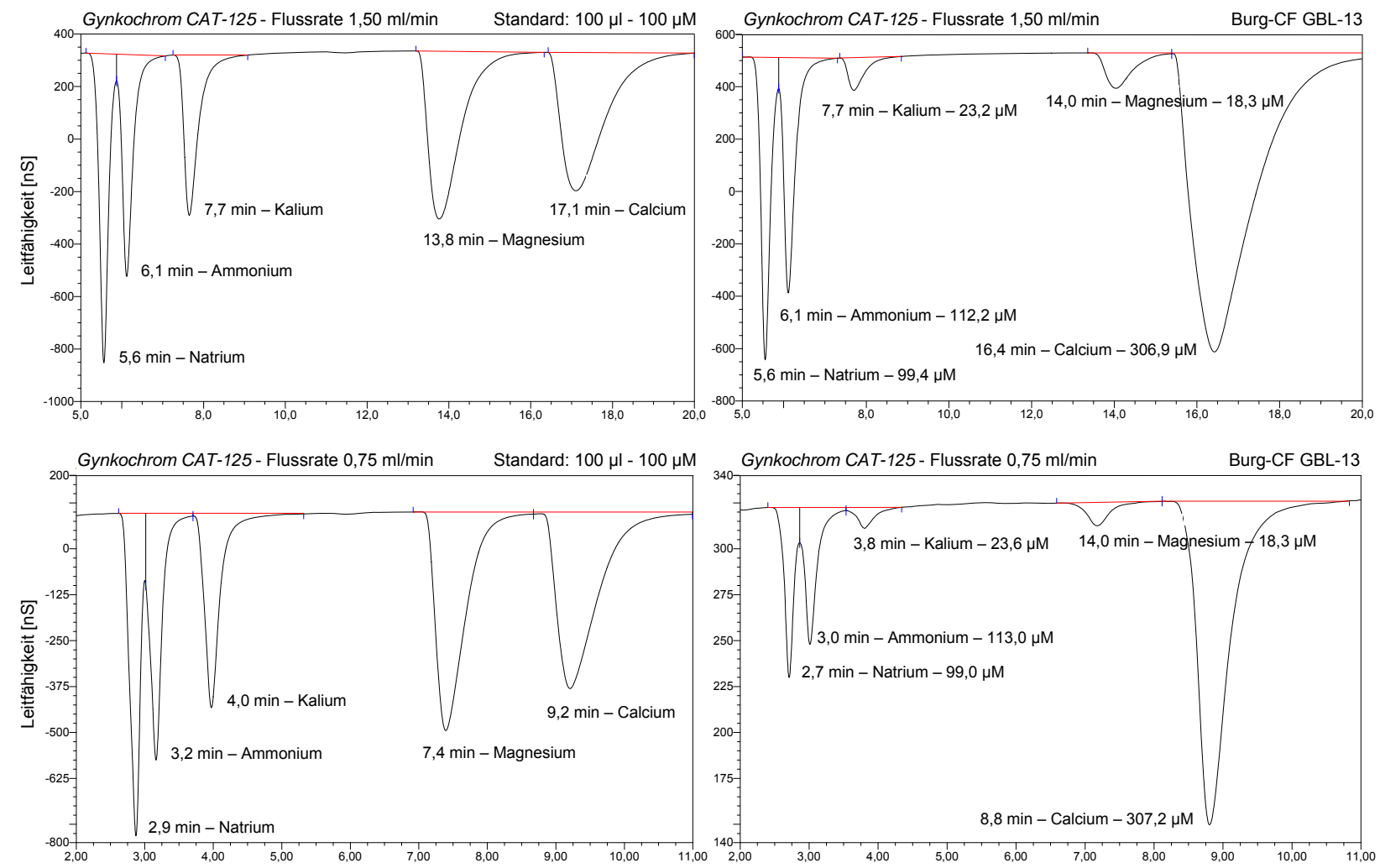

Abbildung 11: HPIC-Kationenanalytik von Standardlösung (links) und wässrigem Bodenextrakt (rechts) mit Gynkochrom CAT-125-Säulen, Ascorbinsäure/Oxalsäure-Eluenten und negativer Leitfähigkeitsdetektion. Oben: Flussrate $0,75 \mathrm{ml} \cdot \mathrm{h}^{-1} ; 100 \mu \mathrm{l}$ Standard $(100 \mu \mathrm{M}), 100 \mu \mathrm{l}$ Bodenextrakt. Unten: Flussrate $1,5 \mathrm{ml} \cdot \mathrm{h}^{-1} ; 100 \mu \mathrm{l}$ Standard (100 $\mu \mathrm{M}), 10 \mu \mathrm{l}$ Bodenextrakt (weitere Spezifikationen s. Text).

\section{AAS-Analytik}

In den meisten Fällen erfolgten die Analysen der Na-, K-, Mg-, Ca-, Mn-, Fe-, Cu- und Zn-Konzentrationen in den verschiedenen Bodenextrakten mittels Atomabsorptionsspektrometrie (AAS). Die apparativen Einstellungen und Messkonditionen folgten dem analytischen Handbuch des Flammen-Atomabsorptionsspektroskopen (Varian SpectrAA 30, Varian-Techtron 1989).

Durch Zusatz von 2,0 mg $\cdot \mathrm{ml}^{-1} \mathrm{~K}$ als $\mathrm{KNO}_{3}$-Lösung (Ca, Na), 1,0 mg $\cdot \mathrm{ml}^{-1} \mathrm{Cs}$ als CsCl-Lösung (K) bzw. $1,0 \mathrm{mg} \cdot \mathrm{ml}^{-1} \mathrm{La}$ als $\mathrm{La}\left(\mathrm{NO}_{3}\right)_{3}$-Lösung $(\mathrm{Mg})$ wurden Interferenzen, die auf die Ionisierung der Analyte in $\mathrm{N}_{2} \mathrm{O} / \mathrm{C}_{2} \mathrm{H}_{2}$ - bzw. Luft/ $\mathrm{C}_{2} \mathrm{H}_{2}$-Flammen zurückgehen, verringert. Für die Kalibrierung der AAS wurden Lösungen verwendet, deren Matrizes den Extraktionsmittel der jeweiligen Probenlösungen entsprachen. 


\subsubsection{Nicht-sequentielle Fraktionierung essentieller Schwermetalle}

Im Hinblick auf die pflanzlichen Fe-, Mn-, Cu- und Zn-Verfügbarkeiten in den verschiedenen Vegetationsbeständen wurden nicht-sequentielle Extraktionen von Feinerdehomogenaten und Bodenmonolithen mit Ferrozine ${ }^{\circledR}$, Ammoniumacetat, Diethylentriaminpentaessigsäure (DTPA), Nitrilotriacetat (NTA), Oxalat und Dithionit durchgeführt. Für die Referenzstandorte Auf der Burg und Hölleberg erfolgte - mit Ausnahme des Ferrozine ${ }^{\circledR}$-Ansatzes - nicht nur eine Schwermetallfraktionierung feldfrischer Feinerde, sondern auch lufttrockener Feinerdehomogenate und feldfrischer Bodenmonolithe. Für die Perkolation der Bodenmonolithe wurde ein einheitliches Extraktionslösungsvolumen von $200 \mathrm{ml}$ gewählt. Feinerdeproben wurden unter Horizontalschüttelung in Erlenmeyerkolben extrahiert. Die Angaben zum Boden/ Lösungs-Verhältnis beziehen sich in den Literaturvorlagen auf lufttrockenes Bodenmaterial und wurden auf die Extraktion der feldfrischen Feinerdehomogenate übertragen. Verdünnungen der Extraktionsmittel durch Bodenwasser sowie darauf zurückzuführende Unterschiede im Feinerde/Lösungs-Verhältnis der Parallelen können vernachlässigt werden. Insbesondere bei der Ammoniumacetat-, NTA-, Oxalat- und Dithionit-Extraktion sind die Boden/Lösungs-Verhältnisse so weit, dass bei Verwendung feldfrischer Feinerdehomogenate aus den aktuellen Wassergehalten der Proben keine relevanten Verdünnungseffekte resultieren. Wie in allen anderen Fällen wurde aber auch bei den Auswertungen dieser Untersuchungen die jeweilige Bodenfeuchte berücksichtigt.

Die Aufreinigung der Bodenextrakte für die atomabsorptionsspektroskopische Mineralstoffanalytik erfolgte mittels Filtration durch Blaubandfilter (Schleicher \& Schuell $589^{3}$ ). Ferrozine ${ }^{\circledR}$-Suspendate wurden 30 min zentrifugiert ( $g_{\max }=100000 \cdot \mathrm{g}, \mathrm{T}=4^{\circ} \mathrm{C}$ ) und das Fe im Überstand kolorimetrisch bestimmt.

\section{Ferrozine $^{\circledR}$-Extraktion}

Ferrozine $^{\circledR}$ (PDTS, 3-(2-Pyridyl)-5,6-diphenyl-1,2,4-triazin-4',4"disulfonsäure Mononatriumsalz) bildet mit $\mathrm{Fe}^{2+}$ hochaffin einen violetten 3:1-Komplex und erlaubt darüber den Nachweis von $\mathrm{Fe}(\mathrm{II})$. Zugleich stabilisiert die Chelatisierung die Fraktion des redoxlabilen $\mathrm{Fe}^{2+}$. Um das Ausmaß der oxidativen Immobilisierung von $\mathrm{Fe}^{2+}$ zu minimieren, wurden $20 \mathrm{~g}$ feldfrische Feinerde unmittelbar nach ihrem Aussieben im Verhältnis 1:2 mit $500 \mu \mathrm{M}$ Ferrozine ${ }^{\circledR}$-Lösung versetzt und $24 \mathrm{~h}$ extrahiert.

Zur näheren Charakterisierung der so erfassten Fraktion wurde für jeweils drei Bodenproben der CC- und CF-Bestände des Standorts Auf der Burg die Abhängigkeit der Fe-Komplexierung von der Extraktionszeit und von der Konzentration des Chelatbildners untersucht. In beiden Untersuchungen wurde der aktuelle Wassergehalt der feldfrischen Feinerdehomogenate bei der Einstellung der Bodentrockengewicht/Lösungs-Verhältnisse und der Ferrozine ${ }^{\circledR}$-Konzentrationen berücksichtigt.

Für die Erstellung der zeitbezogenen Komplexierungskinetiken wurden $70 \mathrm{~g}$ Feinerdehomogenat im Gewichtsverhältnis 1:5 mit der Art definierten Ferrozine ${ }^{\circledR}$-Lösungen versetzt, dass die Konzentration des Komplexbildners in allen Versuchsansätzen $500 \mu \mathrm{M}$ betrug. Nach Horizontalschüttelung über 0,25-0,501,0-2,0-4,0-8,0-24 und 29h wurden den Suspendaten Aliquots von jeweils $10 \mathrm{ml}$ entnommen und diese umgehend analysiert.

Der Ermittlung der Substratkinetiken der Fe(II)-Komplexierung dienten Versuchsansätze, in denen $10 \mathrm{~g}$ feldfrisches Feinerdehomogenat mit Extraktionslösungen auf ein exaktes Boden/Lösungs-Verhältnis von 1:5 und Konzentrationen von 0-125-250-500-1000-2000 $\mu$ M Ferrozine ${ }^{\circledR}$ eingestellt wurden. Die Extraktion von $\mathrm{Fe}^{2+}$ erfolgte hier unter Horizontalschüttelung über einen Zeitraum von $24 \mathrm{~h}$. 
Nach der Ultrazentrifugation der Bodensuspendate wurde durch Kolorimetrie bei $\lambda=562 \mathrm{~nm}$ die Konzentration des $\left[\mathrm{Fe}\left(\text { Ferrozine }^{\circledR}\right)_{3}\right]^{4-}$-Komplexes in den Extraktionslösungen ermittelt. Den Berechnungen der Fe(II)-Gehalte liegt ein Extinktionskoeffizient von $\varepsilon=24,6 \mathrm{mM}^{-1} \cdot \mathrm{cm}^{-1}$ zugrunde.

Im Zusammenhang mit der Entwicklung der Ferrozine ${ }^{\circledR}$-Extraktion wurden Untersuchungen zur Immobilisierung und Eliminierung labiler Fe(II)-Spezies während der Gewinnung von PBL und DBL sowie durch nachfolgende Ultrazentrifugation und Membranfiltration der Lösungen durchgeführt. In diesem Rahmen wurde außerdem ein Verfahren getestet, mit Hilfe dessen Versuchslösungen für die nachfolgende kolorimetrische Fe-Analytik aufkonzentriert werden können. Unmittelbar im Anschluss an die Perkolation bzw. an das Abpressen der Bodenlösungen wurden 7,0 ml klare PBL und DBL in Reaktionsröhrchen überführt und im Trockenschrank bei $70^{\circ} \mathrm{C}$ über mehrere Tage vollständig eingeengt. Der kolorimetrische Fe-Nachweis erfolgte in Anlehnung an Voelker \& Sulzberger (1996). Nach der Resuspension und Reduktion des Fe durch zweistündige Vertikalschüttelung in 1,5 ml Hydroxylaminhydrochlorid-HClLösung und Zusatz von 1,0 ml Ferrozine ${ }^{\circledR}$-Ammoniumacetatpuffer-Lösung wurden die Lösungen umgehend bei $562 \mathrm{~nm}$ photometriert. Der Überprüfung der Zuverlässigkeit dieses Verfahrens dienten vergleichende Untersuchungen nicht eingeengter FeEDTA-Standardlösungen. Die Nettoextinktion des Fe(Ferrozine $\left.^{\circledR}\right)_{3}$-Komplexes wurde entsprechend den Ausführungen in Abschnitt 2.2.7 ermittelt.

\section{Ammoniumacetat-Extraktion}

Die Bodenextraktion mit 1,0 M Ammoniumacetatlösung (pH6,0) nach Zeien \& Brümmer (1989) dient der Erfassung spezifisch adsorbierter und oberflächennah okkludierter Fe-Formen sowie metallorganischer Komplexe geringer Bindungsstärke.

Im Hinblick auf die Vergleichbarkeit der Extraktion von feldfrischen Bodenmonolithen und Feinerdehomogenaten erfolgte keine präparative Auflösung von $\mathrm{CaCO}_{3}$ mittels $\mathrm{HCl}$ und damit keine Eliminierung des carbonatgebundenen Fe. Wie bei allen nachfolgend dargestellten Extraktionen auch, wurden die Monolithe mit $200 \mathrm{ml}$ Extraktionslösung perkoliert. Für die Untersuchung der feldfrischen bzw. lufttrockenen Feinerdehomogenate wurden $5 \mathrm{~g}$ Bodenmaterial mit $50 \mathrm{ml}$ Ammoniumacetatlösung versetzt. Die Extraktionsdauer betrug sowohl für die Behandlung der Feinerdehomogenate als auch Bodenmonolithe $24 \mathrm{~h}$.

\section{DTPA-Extraktion}

Bei der Diethylentriamin-N,N,N',N',N'-pentaacetat (DTPA)-Extraktion handelt es sich um die Standardmethode zur Bestimmung des "pflanzenverfügbaren" Fe, aber auch Mn, Zn und $\mathrm{Cu}$ in kalkreichen Böden. Mit 0,1 M Triethanolamin (TEA) auf pH 7,3 gepuffert, extrahieren 5 mM DTPA-Lösungen v.a. austauschbare Schwermetallfraktionen (Lindsay \& Norvell 1978).

Der Zusatz von $\mathrm{CaCl}_{2}(0,01 \mathrm{M})$ soll die Auflösung von $\mathrm{CaCO}_{3}$ des Bodens während der Extraktion verhindern. Da für die zuverlässige Perkolation von Bodenmonolithen eine zweistündige Extraktion nicht ausreicht, wurde die Extraktionszeit aller Versuchsansätze verdoppelt. Für die Schüttelungen wurden jeweils 25 g Feinerdehomogenat und $50 \mathrm{ml}$ Extraktionslösung eingesetzt.

\section{NTA-Extraktion}

Nitrilotriacetat (NTA) löst und komplexiert v. a. organisch gebundenes Fe. Die Extraktion der Böden mit 0,1 M NTA-Lösung ( $\mathrm{pH} 8,3$ ) erfolgte in Anlehnung an Yuan et al. (1993). Vorversuche zeigten, dass durch die in der Originalanleitung angegebene Vorbehandlung lufttrockener Bodenproben mit 0,01 M $\mathrm{HCl}$ die Fe-Konzentrationen in den Extraktionslösungen nur um 2,6 \% reduziert werden. Die NTA-extra- 
hierbaren Mn-, Cu- und Zn-Gehalte säuregewaschener Bodenhomogenate waren leicht erhöht. Im Hinblick auf den geringfügigen Effekt und die Durchführung vergleichender Untersuchungen an feldfrischen Bodenproben wurde daher auf diesen präparativen Schritt verzichtet. Für die Untersuchung von Feinerdehomogenaten wurde ein Verhältnis von $1 \mathrm{~g}$ Bodenmaterial auf $50 \mathrm{ml}$ Extraktionslösung gewählt.

\section{Oxalat-Extraktion}

Die Oxalat-Extraktion dient der Erfassung amorpher, nicht-kristalliner und wenig geordneter Fe(Hydr)Oxide, wie v. a. Ferrihydrit, aber auch besser kristallisierter Fe-Oxide, wie Lepidokrokit und Magnetit. Als starker Ligand komplexiert Oxalat darüber hinaus Fe organischer Verbindungen (Schwertmann 1964; Campbell \& Schwertmann 1984; Borggaard 1988). Angesichts der hohen Photosensitivität des Fe-Oxalat-Komplexes erfolgte die vierstündige Extraktion mit 0,2 M Ammoniumoxalat/Oxalsäure $(\mathrm{pH} 3,25)$ sowie die nachfolgende Lagerung der Lösungen bis zu ihrer Analyse unter Lichtausschluss. Für die Extraktion der Feinerdehomogenate wurden $5 \mathrm{~g}$ Bodenmaterial mit $50 \mathrm{ml}$ Extraktionslösung versetzt.

\section{Dithionit-Extraktion}

Die Dithionit-Extraktion nach Kostka \& Luther (1994) zielt auf die Erfassung amorpher und kristalliner Fe(III)-Oxide sowie säurelöslicher Fe(II)-Sulfide ab. 0,35 M Essigsäure und 0,2 M Na-Citrat puffern eine 0,29 M Natriumdithionit-Lösung auf pH 4,8. Der Zusatz von Citrat als Fe-Komplexbildner erfolgt auch im Hinblick auf die abnehmende Konzentration und Wirksamkeit des Reduktionsmittels während der Extraktion (Borggaard 1988). Die Verlängerung der Extraktionszeit von $4 \mathrm{~h}$ auf $24 \mathrm{~h}$ erlaubte eine Versuchsdurchführung bei Raumtemperatur (Holmgren 1967 in Loveland 1988). Bei Einsatz von 50 ml Extraktionslösung betrug für die Schüttelung der Feinerdehomogenate das Boden/Lösungs-Verhältnis 1:5.

\subsubsection{Untersuchungen zur Redoxdynamik von Eisen und Mangan}

Untersuchungen zur Fe- und Mn-Dynamik zielten darauf ab, den Umfang und die Geschwindigkeit oxidoreduktiver Umsetzungen in Böden von CC- und CF-Vegetationsbeständen und deren potenzielle Bedeutung für die pflanzliche Mineralstoffernährung aufzuzeigen. Die edaphische Redoxdynamik wurde exemplarisch für den Standort Hölleberg untersucht.

Je 16 Bodenmonolithe der beiden Vegetationseinheiten wurden im November 1998 den Ausführungen in Abschnitt 2.2.1 entsprechend gewonnen. Mit abdichtenden Unterverschraubungen versehen, erfolgte für die Bodenlösungsgewinnung die Installation sog. Mikrolysimeter mit $5 \mathrm{~cm}$ langen, inerten Polymerfäden in den Bodensäulen. Über Luer-Lock-Konnektoren wurden die Mikrolysimeter mit 50 ml Einwegspritzen verbunden und durch Arretierung der Spritzenkolben ein Unterdruck von -80 kPa aufgebaut.

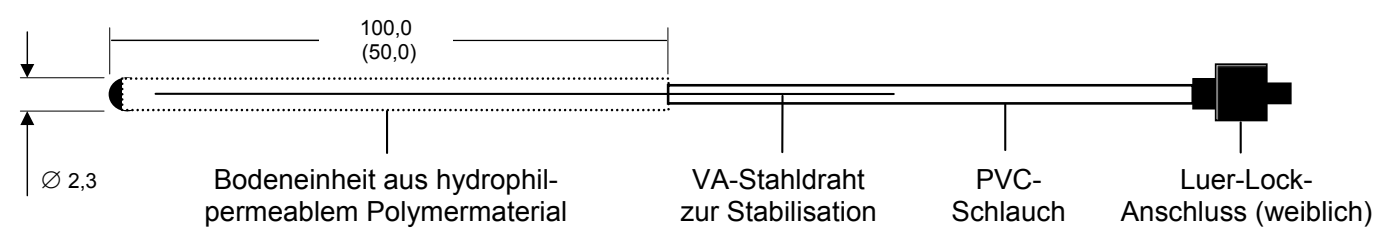

Abbildung 12: Schematischer Aufbau von Mikrolysimetern ('rhizon soil moisture sampler', Eijkelkamp Agrisearch Equipment, Giesbeek, Niederlande. Maßangaben in [mm]). Der Anschluss der Unterdruckeinheit erfolgt mit Hilfe eines Luer-Lock-Konnektors. Die Wandstärke und der Porendurchmesser des inerten Polymermaterials betragen 0,35 mm bzw. 0,1 $\mu$ M, das Totvolumen der Lysimetereinheit > 1 ml (Grossmann 1988). 
Nach einer initialer Aufsättigung der Bodenzylinder mit $\mathrm{H}_{2} \mathrm{O}$ demin. wurde bei Raumtemperatur in einem Versuchszeitraum von 50 Tagen der Effekt einer reduktiven Inkubation (d0-d40) auf die Fe- und MnKonzentrationen sowie derjenige re-oxidativer und re-reduktiver Inkubationen (d40-d49) auf die FeFraktionen der Bodenlösung untersucht. Die reduktive Lagerung der Bodenmonolithen wurde an d40 durch die Entwässerung der Bodenmonolithen mit Hilfe der Mikrolysimeter und durch saugfähiges Papier, auf das die Plexiglaszylinder nach Entfernung der Unterverschraubungen gestellt wurden, beendet. Die Wiederaufsättigung von je vier Bodenmonolithen und die Untersuchung der Fe-Immobilisierung durch die oxidativen Bedingungen erfolgte nach einem Tag (d41) sowie nach zwei, vier und neun Tagen (d43/44/49). Die Aufsättigungszeit und der Zeitraum für die Gewinnung der entsprechenden Mikrolysimeterlösungen betrugen jeweils zwei Stunden. Im weiteren wurden die Auswirkungen der re-reduktiven Konditionen der ersten drei Probenquartetts auf die reduktive Fe-Mobilisierung bis zum Versuchsende untersucht.

Für den Nachweis der reduktiven Mn-Mobilisierung wurden die Gesamtkonzentrationen der gelösten Manganfraktionen der Mikrolysimeterlösungen atomabsorptionsspektroskopisch gemessen. Demgegenüber erfolgte für die Untersuchungen der oxidoreduktiven Fe-Dynamik eine valenzspezifische Fraktionierung auf Grundlage eines kolorimetrischen Testansatzes. Die Konzentration freier $\mathrm{Fe}^{2+}$-Ionen und der Fe(III)-Fraktion der Bodenlösungen wurden mit Bathophenanthrolindisulfonsäure (BPDS) als Indikator bestimmt. Grundlage des $\mathrm{Fe}^{2+}$ - und Fe(II+III)-Nachweis in einem gemeinsamen Testansatz ist die Kolorimetrie der Fe-Komplexierung vor und nach Zusatz von Hydroxylaminhydrochlorid-HCl als Reduktionsmittel. Dabei kann die durch den weiteren Volumenzusatz bedingte Erniedrigung der BPDS-Konzentration vernachlässigt werden. Eine unmittelbare Überführung der Mikrolysimeterproben in die BPDSLösung gewährleistet eine sofortige Komplexbindung und damit die Minimierung möglicher Fehler durch oxidative $\mathrm{Fe}^{2+}$-Ausfällungen. Die Fe-Analysen wurden mit Hilfe des in Tabelle 3 dargestellten Testansatzes durchgeführt.

Tabelle 3: Testansatz zur sequentiellen kolorimetrischen Bestimmung von $\mathrm{Fe}^{2+}$ und $\mathrm{Fe}(\mathrm{II}+\mathrm{III})$ mit BPDS.

\begin{tabular}{|c|c|c|c|c|c|c|}
\hline & & Bodenlösung & BPDS & Acetatpuffer pH 4,7 & $\mathrm{NH}_{2} \mathrm{OH} \cdot \mathrm{HCl}$ & $\mathrm{HCl}$ \\
\hline \multicolumn{7}{|c|}{$\mathrm{Fe}^{2+}$-Assay } \\
\hline V & {$[\mathrm{ml}]$} & 3,0 & 0,5 & 0,5 & & \\
\hline CStammlsg. & [mM] & & 6,0 & 400 & & \\
\hline \multirow[t]{2}{*}{ CAssay } & {$[\mathrm{mM}]$} & & 0,75 & 50 & & \\
\hline & & $\mathrm{Fe}^{2+}-$ Nachweis: & gation $(1$ & 10 min) - Photometrie $\epsilon$ & S $2,0 \mathrm{ml}$ Aliquot & $5 \mathrm{~nm})$ \\
\hline \multicolumn{7}{|c|}{ Fe(II+III)-Assay } \\
\hline V & {$[\mathrm{ml}]$} & & & & 0,25 & 0,25 \\
\hline CStammlsg. & {$[\mathrm{mM}]$} & & & & 750 & 750 \\
\hline $\mathrm{C}_{\text {Assay }}$ & {$[\mathrm{mM}]$} & & 0,6 & 40 & 75 & 75 \\
\hline \multicolumn{7}{|c|}{ Fe(III)-Reduktion: Inkubation $30 \mathrm{~min}, 60^{\circ} \mathrm{C}$} \\
\hline V & {$[\mathrm{ml}]$} & & & 0,5 & & \\
\hline CStammlsg. & {$[\mathrm{mM}]$} & & & 1600 & & \\
\hline CAssay $_{\text {Asta }}$ & {$[\mathrm{mM}]$} & & 0,5 & 300 & 62,5 & 62,5 \\
\hline
\end{tabular}


Der Bestimmung des rotfarbigen $\mathrm{Fe}^{2+}(\mathrm{BPDS})_{3}$-Komplexes wurde ein Extinktionskoeffizient von $22,14 \mathrm{mM}^{-1} \cdot \mathrm{cm}^{-1}$ bei $\lambda=535 \mathrm{~nm}$ zugrunde gelegt (Schmidt $\&$ Fühner 1998). Die Mikrolysimeterlösungen zeigten z. T. deutliche Eigenfärbungen. Um eine exakte Quantifizierung auch bei sehr niedrigen Fe-Konzentrationen zu gewährleisten, wurde $\Delta \mathrm{E}$ unter individueller Berücksichtigung des allein aus der unspezifischen Färbung und Trübung der Probe resultierenden Extinktionswerts berechnet. Für jede Konzentrationsberechnung sind daher vier Extinktionswerte erforderlich:

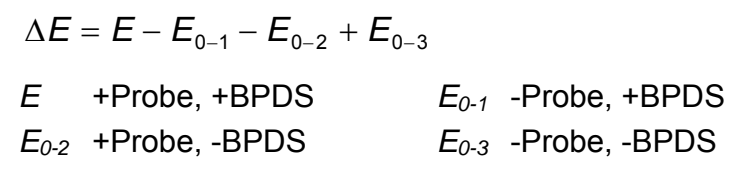

Die Extinktionen der Quarzküvette mit den Testlösungen Hydroxylaminhydrochlorid-HCl und Natriumacetat-Puffer werden bereits mit dem gängigen Blindwert $\mathrm{E}_{0-1}$ (Substitution von Probe durch $\mathrm{H}_{2} \mathrm{O}$ bidest.) berücksichtigt, so dass nach Subtraktion des Trübungswertes $\mathrm{E}_{0-2}$ deren Extinktion mit $\mathrm{E}_{0-3}$ zusätzlich erfasst werden muss. Für die Messungen der verschiedenen Blindwerte werden die fehlenden Lösungen durch entsprechende Volumina $\mathrm{H}_{2} \mathrm{O}$ bidest. ersetzt.

\subsubsection{Mobilisierung und Immobilisierung von Eisen durch Chelatlösungen}

Durch die Schüttelung von Feinerdehomogenaten mit Fe-Chelatlösungen definierter Konzentrationen und die Messung der daraus resultierenden Konzentrationsverschiebungen kann das Ausmaß der Mobilisierung und Immobilisierung von $\mathrm{Fe}(\mathrm{III})$ in verschiedenen Böden und damit deren Chlorosepotenzial bestimmt werden. Diesbezügliche Reaktionen wurden exemplarisch für Feinerdetrockenhomogenate der CC- und CF-Bestände des Standorts Auf der Burg untersucht. Hierfür wurden $20 \mu \mathrm{M}$ FeEDTA (Fe-Ethylendiamin-N,N,N',N'-Tetraacetat)- und FeEDDHA (Fe-N,N'-Ethylen bis[2-(2-hydroxyphenyl)-Glycin])Lösungen eingesetzt.

Für die Fe(III)/EDTA-Komplexierung und die Herstellung einer $10 \mathrm{mM}$ Chelatlösung wurden äquimolare Mengen $\mathrm{FeCl}_{3}$ in 0,5 N HCl und EDTA in 1,0 N NaOH gelöst und durch langsamen Zusatz der basischen zur sauren Lösung vereinigt. Um hierbei eine Ausfällung von $\mathrm{Fe}(\mathrm{OH})_{3}$ zu verhindern, wurde durch Zusatz weiterer $\mathrm{HCl}$ der Anstieg der Protonenaktivität auf Werte oberhalb pH 1,0 unterbunden, dann die Lösung mit verdünnter $\mathrm{NaOH}$ zunächst auf diesen Wert, schließlich durch Zusatz von TRIS ( $\alpha, \alpha, \alpha$-Tris-(hydroxymethyl)-methylamin) auf pH 5,5 eingestellt und mit $\mathrm{H}_{2} \mathrm{O}$ bidest. auf das Endvolumen aufgefüllt. Die Verdünnung der Stammlösung im Verhältnis 1:500 für die Herstellung der Inkubationslösung bewirkt eine nur leichte $\mathrm{pH}$-Erniedrigung auf $\mathrm{pH} 5,4$.

Der Herstellung einer 10 mM FeEDDHA-Stammlösung diente Sequestren ${ }^{\circledR} 138$ (Novartis, Frankfurt), ein wasserlösliches Präparat, das für die Behandlung von Böden mit hohem Chlorosepotenzial $6 \%(\mathrm{~m} / \mathrm{m})$ vollchelatisiertes Fe enthält. Die Protonenaktivität der für die Bodenschüttelung verwendeten $20 \mu \mathrm{M} \mathrm{Fe}-$ Komplexlösung betrug pH 6,0.

In $50 \mathrm{ml}$ Erlenmeyerkolben wurden 2,5 g lufttrockenes Feinerdehomogenat mit 12,5 ml FeEDTA- bzw. FeEDDHA-Lösung versetzt und die Bodensuspension nach 24stündiger Horizontalschüttelung $30 \mathrm{~min}$ zentrifugiert. Einer zweiten dreißigminütigen Zentrifugation bei $100000 \cdot g$ folgte die AAS-Messung des klaren Überstandes. Die bodenspezifischen Mobilisierungs- und Immobilisierungsraten wurden unter Vergleich mit entsprechend behandelten bodenfreien Ansätzen ermittelt. 


\subsubsection{Sequentielle Phosphatfraktionierung}

Für die Untersuchung der pflanzlichen P-Verfügbarkeiten und ihrer Bedeutung für die Vegetationsdifferenzierung von Kalkmagerrasen wurden lufttrockene, gemahlene Feinerdehomogenate sequentiell mit verschiedenen Lösungen extrahiert, die definierte P-Fraktionen des Bodens erfassen. Unter Vernachlässigung möglicher jahreszeitlicher P-Fluktuationen wurden für die Ermittlung eines repräsentativen Jahresdurchschnittwerts Sammelproben aller Probennahmen eines Quadranten und damit insgesamt 16 Homogenate pro Vegetationsbestand analysiert (vgl. Abbildung 6).

Die sequentielle P-Fraktionierung erfolgte in Anlehnung an Tiessen \& Moir (1993). Die Extraktionsmittel wirken über Austausch- oder Lösungsreaktionen und erfassen in der Reihenfolge ihrer Verwendung abnehmend pflanzenverfügbares P. Extrakte, die in erheblichem Umfang organisches P enthalten können, erfuhren eine Subfraktionierung von $\mathrm{P}_{\mathrm{i}}$ und $\mathrm{P}_{0}$. Da diese von geringer Bedeutung für die pflanzliche PErnährung sind, wurde abweichend von der Literaturvorlage auf die Extraktion mit konzentrierter $\mathrm{HCl}$ und auf Gesamtaufschlüsse der residualen Bodenfraktion verzichtet.

Die Extraktion von 500 mg eingewogenem Bodenhomogenat erfolgte durch Überkopfschüttelung in Polycarbonat-UZ-Röhrchen ( $\mathrm{V}=94 \mathrm{ml})$ mit jeweils $30 \mathrm{ml}$ der betreffenden Lösungen. Die Extraktionszeit betrug in allen Fällen $16 \mathrm{~h}$. Die Analysenlösungen und weitgehend lösungsfreies Bodenmaterial für die nachfolgende Bodenextraktion wurden durch Zentrifugation (30 min, $g_{\max }=25000 \cdot \mathrm{g}, \mathrm{T}=4^{\circ} \mathrm{C}$ ) gewonnen. Vor der kolorimetrischen P-Analytik wurden restliche partikuläre Verunreinigungen des dekantierten Überstands mit Hilfe von Cellulose-Acetat-Membranfiltern (Porenweite 0,45 $\mu \mathrm{m}$ ) entfernt.

\section{Phosphatextraktion mit Hilfe von Anionenaustauscherharz}

(Resin-extractable $P$, Amer et al. 1955, Sibbesen 1977)

Für die Bestimmung der labilen, leicht austauschbaren und damit leicht pflanzenverfügbaren P-Fraktionen wurde das Bodenmaterial zusammen mit einem stark basischen Anionenaustauschermaterial geschüttelt und darüber $\mathrm{H}_{2} \mathrm{PO}_{4}{ }^{-} / \mathrm{HPO}_{4}{ }^{2-}$ an dessen funktionellen Gruppen gebunden. Auf diese Weise kann eine umgehende Gleichgewichtseinstellung des $\mathrm{P}$ zwischen dem Bodenmaterial und der Bodenlösung verhindert werden. Um die Trennung von Boden- und Austauschermaterial im Anschluss an die Schüttelung zu erleichtern, wurden $4 \mathrm{~cm}^{3}$ des Anionenaustauschers (Dowex ${ }^{\circledR} 1 \times 8,20-50$ mesh) in $2 \cdot 3 \mathrm{~cm}$ PE-Netzgewebesäckchen eingenäht. Die Funktionalisierung des Anionenaustauschergels erfolgte mit $0,5 \mathrm{M} \mathrm{HCl}$, seine Neutralisierung durch mehrmaliges Spülen mit $\mathrm{H}_{2} \mathrm{O}$ bidest. Zum Abschluss der Extraktion wurde anhaftendes Bodenmaterial zweimal mit $10 \mathrm{ml} \mathrm{H}_{2} \mathrm{O}$ bidest. abgespült und die betreffende P-Fraktion durch dreißigminütige Vertikalschüttelung der Austauschersäckchen in $25 \mathrm{ml} 0,5 \mathrm{M} \mathrm{HCl}$ desorbiert. Spül- und Extraktionslösungen wurden vereinigt, das Bodenmaterial für die nachfolgende Extraktion abzentrifugiert und der Überstand verworfen.

Die im Vergleich zu rein wässrigen Ausschüttelungen deutlich höheren Konzentrationen der durch Rücktausch gewonnenen P-Lösungen sind nicht nur Grundlage der besonderen Zuverlässigkeit dieser Methodik, sondern sie kennzeichnen gleichzeitig auch das P-Nachlieferungspotenzial des Bodens.

\section{Phosphatextraktion mit 0,5 $\mathrm{M} \mathrm{NaHCO}_{3}$}

(Olsen et al. 1954; Colwell 1963; Bowman \& Cole 1978)

Die Extraktion von Bodenmaterial mit $\mathrm{HCO}_{3}{ }^{-}$erfasst austauschbares, labil an Oberflächen von Bodenaggregaten gebundenes anorganisches sowie organisches Phosphat. Gerade auch im Hinblick auf die wur- 
zelbürtige $\mathrm{CO}_{2} / \mathrm{HCO}_{3}{ }^{-}$-Abgabe im Rahmen von Atmungs- und Transportprozessen gibt diese Methode Hinweise auf eine gut pflanzenverfügbare P-Fraktion. Die gleichzeitige Extraktion von organischem Material macht eine getrennte Analyse von $\mathrm{P}_{\mathrm{i}}$ und Gesamt-P erforderlich. Um angesichts der pH-abhängigen Verteilung der Dissoziationsspezies im Carbonatsystem eine quantitative Vorlage von 0,5 $\mathrm{M} \mathrm{HCO}_{3}{ }^{-}$ zu gewährleisten, wurde die entsprechend konzentrierte $\mathrm{NaHCO}_{3}$-Lösung mit $\mathrm{NaOH}$ auf pH 8,5 eingestellt.

\section{Phosphatextraktion mit $0,1 \mathrm{M} \mathrm{NaOH}$}

(Barrow 1983)

$\mathrm{OH}^{-}$löst an Fe- und Al-(Hydr)oxide fixiertes $\mathrm{P}$ sowie P des basenlöslichen organischen Materials. Wie bei der $\mathrm{HCO}_{3}{ }^{-}$-Extraktion auch wurde angesichts der Lösung von organischen Verbindungen eine Subfraktionierung von $\mathrm{P}_{\mathrm{i}}$ und $\mathrm{P}_{\mathrm{o}}$ vorgenommen.

\section{Phosphatextraktion mit 1,0 M HCI}

(Williams et al. 1971)

Zum Abschluss der sequentiellen P-Fraktionierung des Bodenmaterials erfolgte die Lösung von Apatit mit 1,0 M HCl.

\section{Subfraktionierung von anorganischem und organischem Phosphat}

Der $\mathrm{P}_{\mathrm{i}}$-Nachweis erfolgte im Anschluss an die Säureausfällung des organischen Materials. Dazu wurden $6,0 \mathrm{ml}$ des $\mathrm{HCO}_{3}{ }^{-}$-Extraktes mit 2,0 $\mathrm{ml} 1,35 \mathrm{M} \mathrm{H}_{2} \mathrm{SO}_{4}$ versetzt, bei jeweils $4^{\circ} \mathrm{C}$ die organischen Verbindungen $30 \mathrm{~min}$ ausgefällt und $30 \mathrm{~min}$ bei 300000 .g abzentrifugiert. $\mathrm{NaOH}$-Extrakte wurden in entsprechender Weise mit $0,5 \mathrm{M} \mathrm{H}_{2} \mathrm{SO}_{4}$ behandelt.

Für die Erfassung des Gesamt-P in den $\mathrm{NaHCO}_{3}$-Bodenextrakten wurde organisches Material von 2,0 ml Zentrifugat mit 4,0 ml Ammoniumpersulfat-Lösung (0,22 $\mathrm{M}\left(\mathrm{NH}_{4}\right)_{2} \mathrm{~S}_{2} \mathrm{O}_{8}$ in $\left.0,9 \mathrm{M} \mathrm{H}_{2} \mathrm{SO}_{4}\right) 1 \mathrm{~h}$ bei $110^{\circ} \mathrm{C}$ aufgeschlossen. Dem gleichen Verfahren folgten Aufschlüsse von 3,0 ml NaOH-Extrakt mit 6,0 ml $0,26 \mathrm{M}\left(\mathrm{NH}_{4}\right)_{2} \mathrm{~S}_{2} \mathrm{O}_{8} / 0,9 \mathrm{M} \mathrm{H}_{2} \mathrm{SO}_{4}$. Volumenverluste aus den mit Glaskugeln verschlossenen Reagenzgläsern wurden bestimmt und in den nachfolgenden Berechnungen berücksichtigt.

Die $\mathrm{P}_{\mathrm{o}}$-Konzentrationen berechnen sich aus der Differenz der Gesamt-P- und $\mathrm{P}_{\mathrm{i}}$-Konzentrationen.

\section{Phosphatanalytik}

Die P-Analysen der Bodenextrakte erfolgten in Anlehnung an Murphy \& Riley (1962) durch Bildung eines blaugefärbten Molybdatkomplexes und dessen Photometrie bei $712 \mathrm{~nm}$. In Vorversuchen wurden die für die verschiedenen Lösungstypen erforderlichen $\mathrm{NaOH}$ - bzw. $\mathrm{H}_{2} \mathrm{SO}_{4}$-Konzentrationen ermittelt, die zu einer Einstellung von pH5,4 in den Bodenextrakten und damit zu einer optimalen Farbkomplexbildung führen. Auf diese Weise konnte eine separate $\mathrm{pH}$-Einstellung jeder einzelnen Probe umgangen und durch Einbeziehung standardisierter Volumina entsprechend konzentrierter Base bzw. Säure der Probendurchsatz deutlich erhöht werden. Für jedes Extraktionsverfahren wurden separate Kalibrierungen des kolorimetrischen Testansatzes im Konzentrationsbereich von 0-20 $\mu \mathrm{M}$ P durchgeführt. Diese ergaben für die Extinktionskoeffizienten zwischen $15,8 \mathrm{mM}^{-1} \cdot \mathrm{cm}^{-1}$ (resin extractable $P$ ) und $17,3 \mathrm{mM}^{-1} \cdot \mathrm{cm}^{-1}\left(\mathrm{P}_{\mathrm{o}}\right.$ der $\mathrm{HCO}_{3}{ }^{-}$-Extraktion). 


\subsection{Autökologische Untersuchungen}

Um den potenziellen Einfluss der Bodeneigenschaften auf die Ausbildung verschiedener Subassoziationen innerhalb des Gentiano-Koelerietum zu untersuchen, wurden Keimungs- und Kulturexperimente an Koeleria pyramidata, Danthonia decumbens, Potentilla neumanniana und Potentilla erecta in Bodenmonolithen der beiden Kalk-Halbtrockenrasen des Standorts Auf der Burg durchgeführt.

\subsubsection{Saatguternte, Bodenprobennahme und Bodenanalysen}

Die Saatguternte von P. neumanniana erfolgte im Mai, die der anderen Arten im Juli 1999 am Standort Hölleberg. Neben den Populationen des hiesigen Kalk-Halbtrockenrasens, kamen für D. decumbens die eines Borstgrasrasens, für P. erecta die eines basenarmen Sandbodens zum Einsatz. Sowohl das Bodenmaterial der betreffenden Standorte als auch solches für die nachfolgenden Keimungs- und Kulturexperimente wurde entsprechend den oben dargestellten Analysenverfahren auf die $\mathrm{CaCO}_{3}-\mathrm{Gehalte}, \mathrm{C} / \mathrm{N}$ Verhältnisse, aktuellen und potenziellen Aciditäten sowie die Mineralstoffkonzentrationen der GBL und die Schwermetallkonzentrationen der Lösungen nicht-sequentieller Extraktionen feldfrischer Feinerdehomogenate untersucht. Für die Entnahme von jeweils 75 Bodenmonolithen aus den CC- und CF-Einheiten am Standort Auf der Burg im August 1999 wurden die in Abbildung 5 dargestellten Zylindersysteme verwendet.

\subsubsection{Identifizierung der Unterarten von Danthonia decumbens}

Das Taxon Danthonia decumbens umfasst zwei vikariierende Unterarten. In sauren, basenarmen Böden tritt in der Regel $D$. decumbens ssp. decumbens, in basischen, kalkreichen Böden $D$. decumbens ssp. decipiens auf. Eine Differenzierung der beiden Subspezies ist nur anhand ihrer Chromosomensätze und Blattanatomie möglich. Diesbezügliche Untersuchungen dienten einer eindeutigen Zuordnung der den Keimungs- und Kulturversuche zugrunde liegenden Populationen des Kalk-Halbtrockenrasens und des Borstgrasrasens.

\section{Bestimmung der Ploidie des Chromosomensatzes}

D. decumbens ssp. decumbens ist hexaploid $(2 \mathrm{n}=36)$, D. decumbens ssp. decipiens tetraploid $(2 \mathrm{n}=24)$. Da bei vielen Pflanzenarten vor Beginn der Beleuchtungsperiode besonders hohe Wurzelwachstumsraten und somit hohe Mitoseaktivitäten vorliegen, wurden für die Ploidieuntersuchungen von fünf in Nährlösung kultivierten Pflanzen früh morgens jeweils fünf 2-3 mm lange Wurzelspitzen geerntet. Für die nachfolgenden mikroskopischen Untersuchungen wurden diese $4 \mathrm{~h}$ in Eppendorf-Reaktionsgefäßen mit 2,0 mM Hydroxychinolin-Lösung inkubiert und anschließend in $3: 1$ (V/V) Ethanol-Eisessig-Lösung fixiert. Nach zehnminütiger Hydrolyse der Wurzelspitzen in $1 \mathrm{~N} \mathrm{HCl}$-Lösung bei $60^{\circ} \mathrm{C}$ erfolgte die Anfärbung der Chromosomen unter vorsichtiger Erwärmung über einer Glühbirne mit einem Tropfen Orcein-Essigsäure. Abschließend wurden die Wurzelsegmente mit einem Deckglas vorsichtig auf dem Objektträger zerdrückt und die Chromosomen von jeweils zehn anaphasischen Zellen der Quetschpräparate ausgezählt und fotografiert. 


\section{Auszählung der Blattgelenkzellen}

Die Blätter von $D$. decumbens ssp. decumbens weisen beiderseits der Mittelrippe jeweils 5-7, Blätter von D. decumbens ssp. decipiens mehr als 7 Gelenkzellreihen auf. Für die Auszählung der Gelenkzellen unter dem Binokular wurden Handquerschnitte in $\mathrm{H}_{2} \mathrm{O}$ hergestellt und diese auf dem Objektträger mit Safranin und Astrablau simultan angefärbt. Die beiden Farblösungen können nacheinander mit Hilfe eines Filterpapiers unter dem Deckglas hinweggezogen werden. Überschüssige Farblösung wird in gleicher Weise mit Wasser entfernt (Braune et al. 1999).

\subsubsection{Keimungs- und Kulturexperimente}

Vor der Aussaat von 25 (K. pyramidata, D. decumbens) bzw. 50 (P. neumanniana, P. erecta) Samen wurde der Bewuchs der feldfrischen Monolithen mit einem scharfen Messer entfernt und die Bodenmonolithen in Plexiglaszylinder mit lichtdichten Manschetten aus schwarzer Kunststofffolie überführt. Um während der Kultivierung Bodenlösungen für die ionenchromatographische Anionen- und Kationenanalytik sowie kolorimetrische Untersuchungen der Fe-Konzentrationen gewinnen zu können, erfolgte in fünf der zehn Versuchswiederholungen und in fünf Kontrollansätzen ohne Einsaat eine Installation von Mikrolysimeter.

Die Keimungs- und Kulturversuche wurden im Gewächshaus über einen Zeitraum von zehn Monaten bei einer Tag/Nacht-Periodik von $16 / 8$ h bei $23 / 17 \pm 5^{\circ} \mathrm{C}$ durchgeführt. Natrium-Hochdrucklampen ergänzten während der Tagphase die Sonneneinstrahlung und gewährleisteten minimale Strahlungsintensitäten von $200 \mu \mathrm{E} \cdot \mathrm{m}^{-2} \cdot \mathrm{s}^{-2}$. Der Bewässerung von jeweils zwei Bodenmonolithen dienten rechteckige Trägereinheiten, die an den Zylinderpositionen mit Gazé-überspannten Bohrungen versehen waren und über Filterpapier in kapillarem Kontakt zu einem basalen Wasserreservoir standen. Auf diese Weise konnten annähernd bodenspezifische Feldkapazitäten in den Kultureinheiten eingestellt werden. Während der Keimungsphase erfolgte eine zusätzliche oberflächige Bewässerung. Durch Randomisierung der Versuchsansätze im Abstand von 14 d wurden mögliche Positionseffekte weitgehend ausgeschlossen.

Für Koeleria pyramidata und die Danthonia decumbens-Population des Standorts Hölleberg wurden die Keimraten nach einem Monat, aufgrund ihrer deutlich langsameren Keimung die der anderen Aussaaten nach drei Monaten ermittelt. Im Anschluss wurde mit Ausnahme von jeweils fünf Individuen das Sprossmaterial der restlichen Pflanzen jeder Kultureinheit geerntet, dieses nach zweitägiger Trocknung bei $70{ }^{\circ} \mathrm{C}$ im Exsikkator abgekühlt und anschließend ausgewogen. Für die versuchsbegleitende Dokumentation des Pflanzenwachstums in den Versuchszylindern wurde im Abstand von $14 \mathrm{~d}$ mit jeweils einer weiteren Pflanze in gleicher Weise verfahren. Die letzte Pflanze jedes Versuchsansatzes verblieb bis zehn Monate nach der Aussaat in den Kultureinheiten. Für diese wurden abschließend die Chlorophyll a- und Chlorophyll b-Gehalte einzelner Blätter nach Extraktion mit N, N-Dimethylformamid kolorimetrisch bestimmt (Moran \& Porath 1980; Moran 1982), das Spross- und Wurzelmaterial separiert, letzteres sorgfältig ausgewaschen und die Trockenmassen ermittelt. In der vorliegenden Arbeit werden nur die Keimraten und die Ergebnisse dieser Abschlussuntersuchungen dargestellt. 


\subsection{Statistische Auswertungen}

Die statistischen Auswertungen des Datenmaterials wurden unter Verwendung des Programmpakets SPSS ${ }^{\circledR}$ für Windows 8.0 durchgeführt und folgten hinsichtlich der parametrischen und multivariaten Verfahren den Lehrbüchern von Sachs (1992), Backhaus et al. (1994) und Bortz (1999), hinsichtlich der verteilungsfreien Methoden den Ausführungen von Bortz et al. (1990). Nicht-linearen Kurvenanpassungen und der Analyse der betreffenden Regressionsfunktionen dienten zusätzlich die Statistikfunktionen des Graphikprogramms SigmaPlot für Windows 6.0.

Je nach Umfang der Datensätze wurde für die statistische Analyse der Untersuchsergebnisse zunächst mit Hilfe eines Shapiro-Wilk-Tests $(n \leq 50)$ bzw. einen Kolmogorov-Smirnov-Anpassungstests mit Signifikanzkorrektur nach Lilliefors ( $\mathrm{n}>50$ ) die Normalverteilung geprüft. Konnte mit Hilfe des Testverfahrens nach Levene gleichzeitig Varianzhomogenität der abhängigen Variablen und somit die Voraussetzungen für eine parametrische Datenanalyse nachgewiesen werden, wurden einfaktorielle Varianzanalysen mit zwei Faktorenstufen mittels Student-t-Tests, bei mehrfaktoriellen Untersuchungen und/oder Betrachtung von mehr als zwei Faktorenstufen Varianzanalysen mit anschließenden multiplen Mittelwertsvergleichen nach Scheffé durchgeführt. Im Falle fehlender Normalverteilung oder Varianzhomogenitäten wurde das Datenmaterial mit Hilfe verteilungsfreier Verfahren analysiert. Im Hinblick auf eine einheitliche Behandlung von Beobachtungen und Experimenten gleichen Designs und gemeinsamer Fragestellungen wurden in einigen Fällen auch für Datensätze, die die Voraussetzungen für parametrische Analysemethoden erfüllten, abschließend nicht-parametrische Statistiken gewählt. Vergleiche zweier unabhängiger Stichproben erfolgten hier durch den U-Test nach Mann-Whitney. Vergleiche von mehr als zwei unabhängigen Stichproben wurden anhand von Rangvarianzanalysen nach Kruskal-Wallis durchgeführt und bei signifikanten Unterschieden zwischen den Stichproben durch multiple paarweise Vergleiche nach SchaichHamerle abgeschlossen. Verteilungen zweier verbundener Stichproben wurden nicht-parametrisch mit dem Wilcoxon-Test untersucht.

Die Behandlung multifaktorieller Fragestellungen erfolgte auf Grundlage eines varianzanalytischen linearen Modells (GLM, general linear model). Dieses ist unempfindlich gegenüber Abweichungen von der Normalverteilung. Die Daten müssen jedoch symmetrisch verteilt sein. Bei nicht gegebener Varianzhomogeneität wurde daher der Empfehlung gefolgt, die Signifikanzgrenze nicht bei $\alpha=0,05$, sondern bei $\alpha=0,01$ anzusetzen. (Bühl \& Zöfel 2000). Die Kennzeichnung der Irrtumswahrscheinlichkeiten wurde entsprechend angepasst.

Die tabellarische und graphische Darstellung der abschließenden Untersuchungs- und Auswertungsergebnisse erfolgte im Falle parametrischer Analysen durch Mittelwerte (MW) und Standardabweichungen (SD), bei nicht-parametrischer Analyse durch Mediane und entsprechende Parameter verteilungsfreier Methoden. Bei Stichprobenumfängen $\mathrm{n} \geq 8$ wurden Mediane in Box-Whisker-Plots, d.h. zusammen mit dem ersten (Q25) und dritten (Q75) Quartil sowie 5\%- und 95\%-Perzentilen angegeben. Soweit angesichts komplexer oder vergleichender Untersuchungen, wie im Falle der regelmäßigen Bodenlösungsuntersuchungen für die Standorte Auf der Burg und Hölleberg, Box-Whisker-Plots zu unübersichtlichen Abbildungen geführt hätten, wurden die Ergebnisse in Balkendiagrammen dargestellt. Die Teststatistiken sind den hier eigens angeführten Kopfzeilen zu entnehmen (vgl. Abbildung A 7, S. 316). Bei geringen Stichprobenumfängen $(n<8)$ wurden grundsätzlich Balkendiagramme der Mediane den Box-Whisker-Plots vorgezogen und in diese die Medianabweichungen (MAD, median absolute devia- 
tion) einbezogen. Als analoges Dispersionsmaß nicht-normalverteilter Datensätze zur Standardabweichung (SD) kennzeichnet die MAD den Median der betragsmäßigen Abweichungen der einzelnen Beobachtungswerte vom gemeinsamen Median $\tilde{\chi}$ der Beobachtungswerte (Sachs 1992):

$\tilde{D}=$ Median $\left\{\left|\chi_{i}-\tilde{\chi}\right|\right\}$

$\tilde{D}$ Mediandeviation (MAD)

$\chi_{i} \quad$ Zahlenwert der Beobachtung $\mathrm{i}$

$\tilde{\chi} \quad$ Median aller Beobachtungswerte.

An verschiedenen Stellen wurden für die Untersuchung bivariater Beziehungen Rangkorrelationskoeffizienten $\rho$ nach Spearman, im Fall parametrischer Auswertungsansätze solche nach Pearson berechnet.

In Abbildungen wie auch in Tabellen werden die Ergebnisse vergleichender Analysen von mehr als zwei Stichproben durch kleine Buchstaben dargestellt, wobei abweichende Indizes signifikante Unterschiede der Faktorenstufen auf einem Signifikanzniveau von $\alpha \leq 0,05$ anzeigen. Irrtumswahrscheinlichkeiten von Analysen mit zwei Faktorenstufen werden demgegenüber wie folgt gekennzeichnet:

- n.s. $\alpha>0,050$

- $\quad \alpha \leq 0,050$

- $* * \quad \alpha \leq 0,010$

- $\quad * * * \quad \alpha \leq 0,001$ 

Ergebnisse 3 


\subsection{Vegetationskundliche Untersuchungen}

Anhand der in Tabelle 4 aufgeführten Vegetationsaufnahmen und hier angegebenen Charakterarten lassen sich alle untersuchten Vegetationsbestände dem Gentiano-Koelerietum (Enzian-Schillergrasrasen) innerhalb des Verbands Mesobromion erecti (Subozeanische Trocken- und Halbtrockenrasen) zuordnen. BetaDiversitäten (sensu Whittaker 1977), die auf Grundlage der Präsenzen und Abundanzen der Pflanzensippen mittels Quadrierter Euklidischer Distanzen bestimmt wurden (Abbildung 13), bestätigen die in der pflanzensoziologischen Tabelle vorgenommene Differenzierung der untersuchten Vegetationsbestände in zwei Subassoziationen. Abweichungen des numerischen vom klassischen tabellarischen Auswertungsansatz ergeben sich lediglich für die Halbtrockenrasen des Standorts Steinkirche sowie den CF-Bestand des Standorts Pagenberg.

Einen Ähnlichkeitsschwellenwert von > 0,5 zugrundelegend, bestätigt das Dendrogramm der Clusteranalysen der Gemeinschaftskoeffizienten nach Sørensen (1948) weitgehend die Differentialartengruppen der Tabelle 4 (Abbildung 14). D2 umfasst insbesondere calcifuge/acidophile und mesophile Arten und wird in Anlehnung an die grundlegende Bearbeitung des Gentiano-Koelerietum von Bornkamm (1960) als Subassoziation von Danthonia decumbens gefasst. Nach den Untersuchungen der vorliegenden Arbeit wird das Gentiano-Koelerietum typicum durch eine eigene Gruppe calcicoler und heliophiler Arten gekennzeichnet. Da bei dem ausschließlich präsenzbezogenen, numerischen Auswertungsansatz nur Arten mit Stetigkeiten zwischen $20 \%$ und $80 \%$ berücksichtigt wurden, fallen die hier differenzierenden Artencluster deutlich kleiner aus. Neben den in der Vegetationstabelle aufgeführten Arten prägen weitere Basiphile/Calcicole und Heliophile das Bild der typischen Subassoziation. In der pflanzensoziologischen Tabelle wurde der Zuordnung in Charakterartengruppen höherrangiger Taxa Priorität gegenüber der Ausweisung als Differentialarten auf Subassoziationsebene eingeräumt. Hiervon betroffen sind beispielsweise Sanguisorba minor (KC), Anthyllis vulneraria (OC) und Carlina vulgaris (VC), die eine um zwei Stetigkeitsklassen höhere Präsenz im Gentiano-Koelerietum typicum aufweisen und mit einem Gemeinschaftskoeffizient von >0,5 mit den anderen Arten der Heliophilen- und Calcicolen-Gruppe vergesellschaftet sind. Neben Arten, wie Potentilla erecta, Luzula campestris, Polygala vulgaris und Hylocomium splendens, die wegen ihres insgesamt begrenzten Auftretens nicht in die numerische Auswertung einbezogen wurden, identifiziert die Gemeinschaftsanalyse verschiedene Mesophile der Differentialartengruppe D2, wie Holcus lanatus und Trisetum flavescens, nicht als vegetationsdifferenzierende Elemente. Demgegenüber finden sich mit Euphrasia stricta und Ranunculus bulbosus zwei Arten in dem betreffenden Cluster, die weder als calcifug/acidophil noch als mesophil gelten, aber eindeutig heliophil sind (Tabelle 4, Abbildung 14).

Das Gentiano-Koelerietum danthonietosum weist nicht nur acidophile/calcifuge, sondern auch mesophile Arten auf, die in umfangreicheren vegetationskundlichen Bearbeitungen hfg. zu Subassoziationen von Arrhenaterum elatius (Bruelheide 1991) oder Trisetum flavescens (Bultmann 1993) und damit zu Gesellschaften der Arrhenateretalia überleiten. Gleichzeitig nehmen Stetigkeit und Deckungsgrad der kriechenden und rosettenbildenden Charakterarten der Brometalia, wie Potentilla neumanniana und Anthyllis vulneraria, in den Beständen ab. 
Tabelle 4: Vegetationskundliche Differenzierung des Gentiano-Koelerietum der CC- und CF-Bestände der Standorte Auf der Burg(B), Hölleberg(H), Hölleberg-Süd (H-EA) und Flohrberg (F) im Unteren Diemeltal sowie Pagenberg $(P)$ und Steinkirche $(S)$ am Südharzrand .

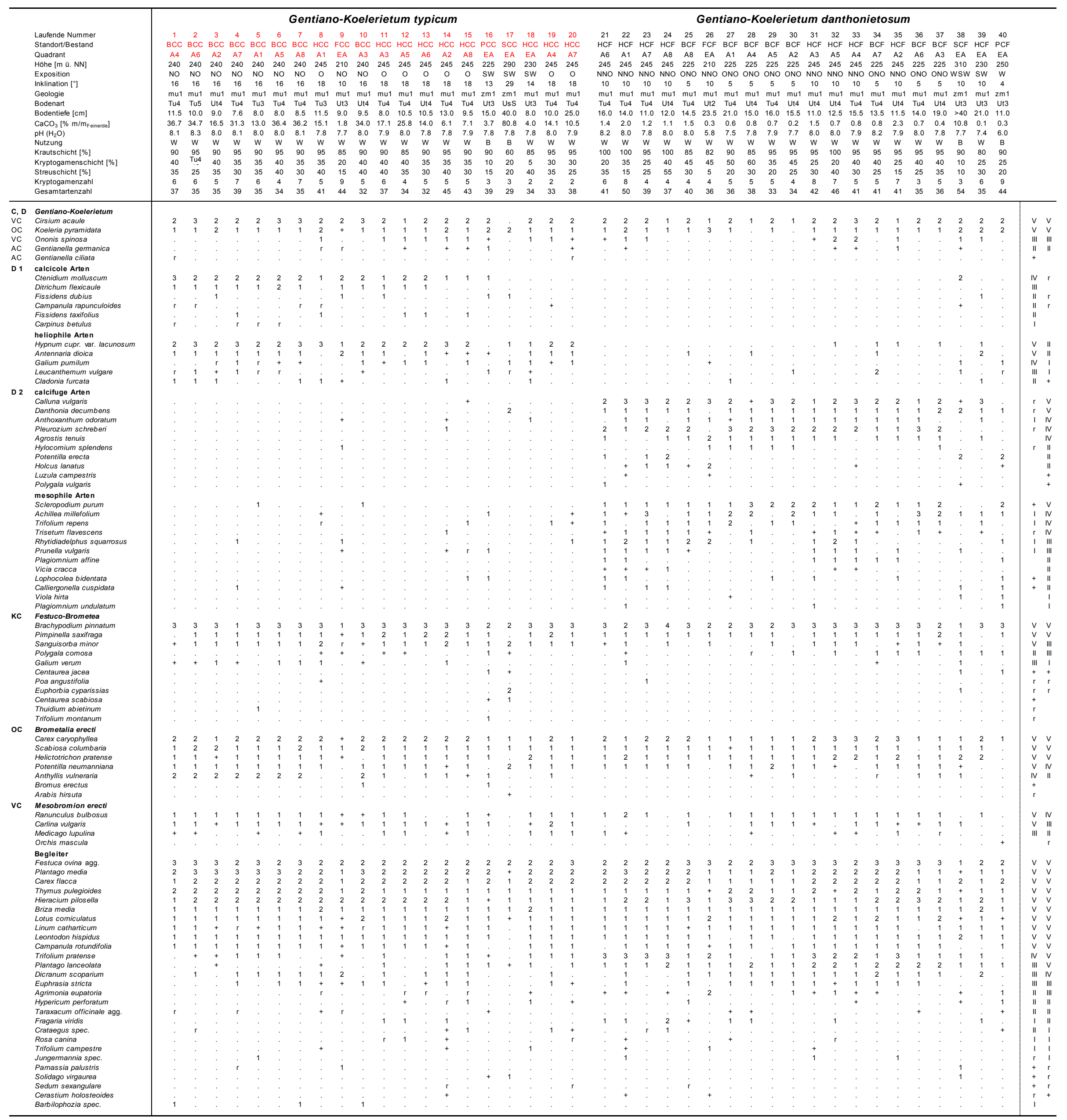

Außserdem mit maximal zwei Nennungen Franerogamen: Acer pseudoplatanus 17:1; Acinos arvensis 17:1; Betula pendula 38:1; Carex montana 38:1; Carex panicea 38:2; Cerastium pumilum 32:;; Convolvulus arvensis 8:r, 14:5; Cornus sanguinea 6:5; Epipactis atrorubens 38:r; Euphrasia rostkoviana 9::; Festuca rubra agg. 40:2,

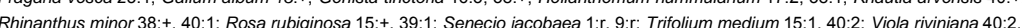

Kryptogamen: Brachythecium rutabulum agg. 40:1; Bryum spec. 3:1; Campylium calcareum $9: 1$;
Peltigera spec. 1:: 2:1: Thuidium delicatulum 40:2; Weissia condensa 17:1, Weissia spec. 1:1, 7:1,

Standort

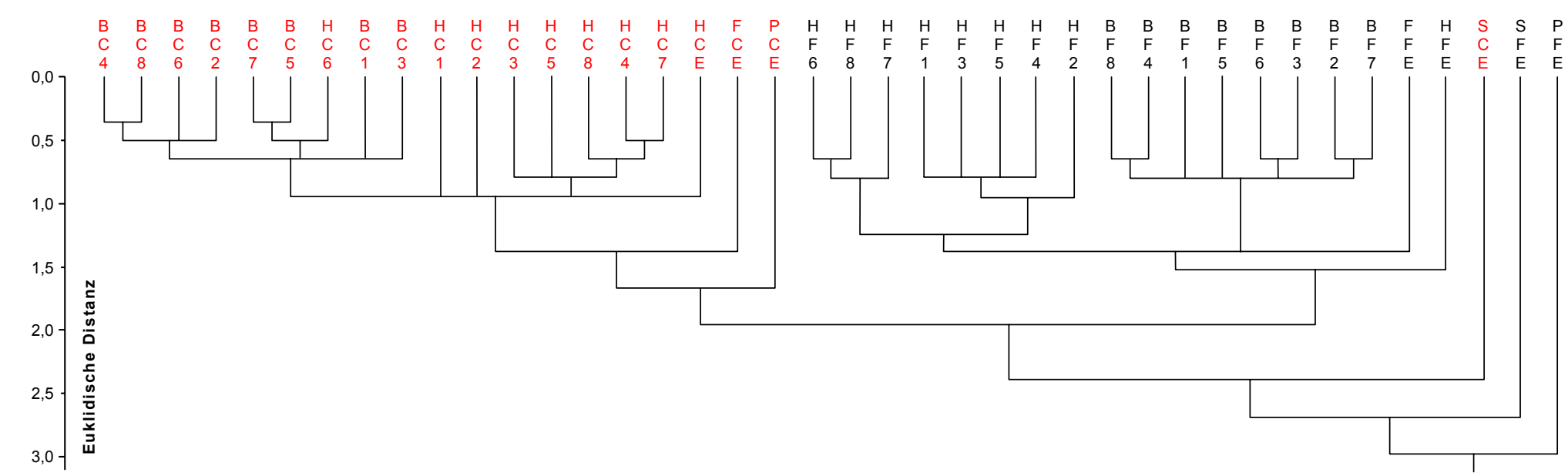

Abbildung 13: Dendrogramm quadrierter Euklidischer Distanzen der Vegetationsaufnahmen der Tabelle 4. 


\begin{tabular}{l} 
Arten \\
\hline mit Stetigkeiten II - IV \\
Taraxacum officinale agg. \\
Rosa canina \\
Crataegus spec. \\
Gentianella germanica \\
Polygala comosa \\
Leucanthemum vulgare \\
Ononis spinosa \\
Medicago lupulina \\
Hypericum perforatum \\
Galium pumilum \\
Agrimonia eupatoria \\
Holcus lanatus \\
Prunella vulgaris \\
Rhytidiadelphus squarrosus \\
Calliergonella cuspidata \\
Trisetum flavescens \\
Fragaria viridis \\
\hline$\frac{0}{0}$
\end{tabular}

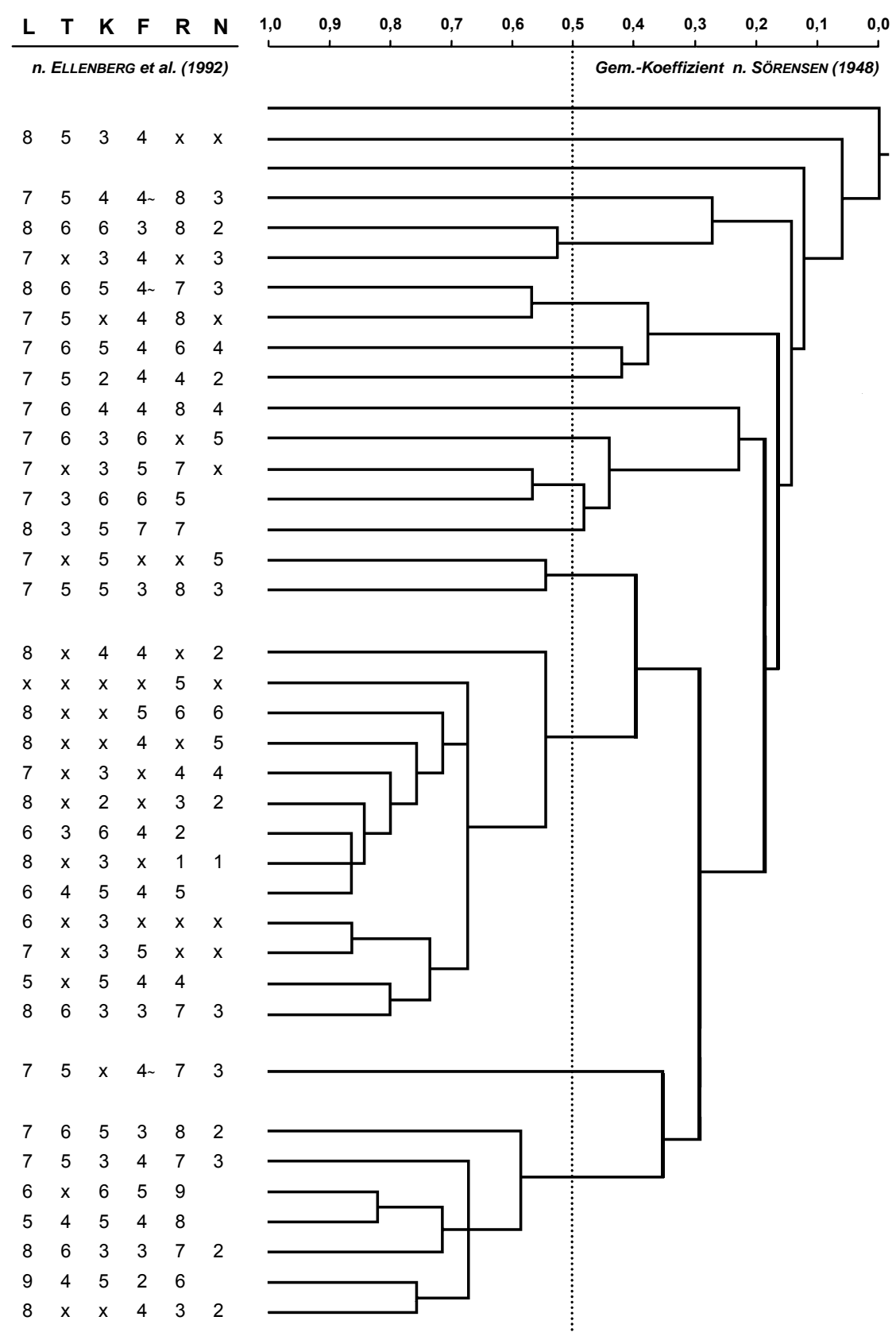

Abbildung 14: Dendrogramm der Gemeinschaftskoeffizienten nach Sørensen (1948) und Zeigerwerte nach Ellenberg et al. (1992) für Arten mit Stetigkeiten zwischen $20 \%$ und $80 \%$ in der pflanzensoziologischen Tabelle 4.

In Tabelle 5 sind allgemeine geographische, edaphische und vegetationskundliche Parameter der Standorte und die diesbezüglichen Verhältnisse zwischen den CC- und CF-Beständen der Untersuchungsstandorte aufgeführt. Bei indifferenter Exposition findet sich das Gentiano-Koelerietum danthonietosum in nahezu ebener Lage oder doch an deutlich weniger geneigten Hängen als die typische Subassoziation. Höhere $\mathrm{CaCO}_{3}$-Gehalte in der Feinerde der CC-Bestände sind bezogen auf alle Untersuchungsstandorte negativ mit der Bodengründigkeit korreliert. $\mathrm{C}_{0} / \mathrm{N}$-Verhältnisse mit Werten zwischen 11,4 und 13,3 kennzeichnen potenziell hohe Mineralisierungsraten im $\mathrm{A}_{\mathrm{h}}$-Horizont. $\mathrm{C}_{\mathrm{t}} / \mathrm{N}-\mathrm{Verhältnisse,} \mathrm{wie} \mathrm{sie} \mathrm{aufgrund}$ von Störungen des $\mathrm{CO}_{3}{ }^{2-}$-Nachweises nach Scheibler bei der Analyse von Böden des Dolomitstandorts Steinkirche angegeben werden müssen, liegen in der Tendenz etwas höher, folgen aber dem Bild eines engeren $\mathrm{C} / \mathrm{N}-$ Verhältnisses in den Böden des Gentiano-Koelerietum typicum. 
Tabelle 5: Mediane geographischer, edaphischer und vegetationskundlicher Parameter sowie ökologische Zeigerwerte von CC- und CF-Beständen der Untersuchungsstandorte. L(icht)-, T(emperatur)-, K(ontinentalitäts)-, F(euchte)-, R(eaktions)- und N(ährstoff/Stickstoff)-Zahlen entsprechen den Medianen der betreffenden Zeigerwerte nach Ellenberg et al. 1992).

\begin{tabular}{|c|c|c|c|c|c|c|c|c|c|c|c|c|}
\hline & \multicolumn{2}{|c|}{ Auf der Burg } & \multicolumn{2}{|c|}{ Hölleberg } & \multicolumn{2}{|c|}{ Hölleberg-Süd } & \multicolumn{2}{|c|}{ Flohrberg } & \multicolumn{2}{|c|}{ Pagenberg } & \multicolumn{2}{|c|}{ Steinkirche } \\
\hline & CC & $\mathrm{CF}$ & CC & CF & CC & $\mathrm{CF}$ & CC & CF & CC & CF & CC & CF \\
\hline \multirow[t]{2}{*}{ Koordinaten } & \multicolumn{2}{|c|}{9,3930} & \multicolumn{2}{|c|}{$9,405 \bigcirc$} & \multicolumn{2}{|c|}{9,3890} & \multicolumn{2}{|c|}{9,3830} & \multicolumn{2}{|c|}{10,1970} & \multicolumn{2}{|c|}{10,3800} \\
\hline & \multicolumn{2}{|c|}{$51,594 \mathrm{~N}$} & \multicolumn{2}{|c|}{$51,613 \mathrm{~N}$} & \multicolumn{2}{|c|}{$51,607 \mathrm{~N}$} & \multicolumn{2}{|c|}{$51,587 \mathrm{~N}$} & \multicolumn{2}{|c|}{$51,758 \mathrm{~N}$} & \multicolumn{2}{|c|}{$51,634 \mathrm{~N}$} \\
\hline Höhe [m ü. NN] & 240 & 225 & 245 & 245 & 230 & 230 & 210 & 210 & 225 & 250 & 290 & 310 \\
\hline Exposition & NO & ONO & $\mathrm{O}$ & NNO & SW & sW & NO & NNO & SW & w & SW & WSW \\
\hline Inklination & \multicolumn{2}{|c|}{$16^{\circ}>5^{\circ}$} & \multicolumn{2}{|c|}{$18^{\circ}>10^{\circ}$} & \multicolumn{2}{|c|}{$14^{\circ}>10^{\circ}$} & \multicolumn{2}{|c|}{$10^{\circ}=10^{\circ}$} & \multicolumn{2}{|c|}{$13^{\circ}>4^{\circ}$} & \multicolumn{2}{|c|}{$29^{\circ}>10^{\circ}$} \\
\hline Bodentiefe [cm] & \multicolumn{2}{|c|}{$9,0<15,5$} & \multicolumn{2}{|c|}{$10,0<12,5$} & \multicolumn{2}{|c|}{$8,0<21,0$} & \multicolumn{2}{|c|}{$9,0<23,5$} & \multicolumn{2}{|c|}{$15,0>11,0$} & \multicolumn{2}{|c|}{$40,0<>40$} \\
\hline $\mathrm{CaCO}_{3}[\% \mathrm{~m} / \mathrm{m}]$ & \multicolumn{2}{|c|}{$31,2>0,5$} & \multicolumn{2}{|c|}{$14,6>1,4$} & \multicolumn{2}{|c|}{$4,0>0,1$} & $1,8>$ & 0,3 & $3,7>$ & $>0,3$ & 80,8 & $>10,8$ \\
\hline $\mathrm{C}_{\mathrm{o}} / \mathrm{N}[\mathrm{m} / \mathrm{m}]$ & 11,4 & 12,1 & 11,0 & 11,9 & 11,7 & 13,0 & 11,6 & 13,3 & $12,8>$ & 12,7 & 12,3 & $<13,4$ \\
\hline $\mathrm{pH}\left(\mathrm{H}_{2} \mathrm{O}\right)$ & $8,0>$ & 7,4 & $7,9=$ & $=7,9$ & $7,8>$ & 7,4 & $7,7>$ & 5,8 & $7,8>$ & $>6,0$ & 7,8 & $>7,7$ \\
\hline Arten & 35 & 36 & 38 & 41 & 34 & 36 & $46>$ & 36 & $39<$ & $<44$ & 30 & $<55$ \\
\hline L-Zahl & $7,3>$ & 7,2 & $7,3>$ & 7,2 & $7,3=$ & : 7,3 & $7,3>$ & 7,1 & $7,3>$ & $>7,2$ & 7,2 & $<7,3$ \\
\hline T-Zahl & $5,4>$ & 5,1 & $5,5>$ & 5,1 & 5,5 & 5,6 & $5,0=$ & $=5,0$ & $5,5>$ & $>4,9$ & 5,5 & $>5,3$ \\
\hline K-Zahl & 3,6 & 3,8 & 3,7 & 3,9 & 3,6 & 3,7 & $3,9=$ & 3,7 & $3,7<$ & $<4,0$ & $3,7=$ & $=3,7$ \\
\hline F-Zahl & $3,8=$ & 3,8 & 3,8 & 4,1 & 3,8 & 4,0 & $4,1=$ & $=4,1$ & $3,8<$ & $<4,3$ & 3,8 & $<4,0$ \\
\hline R-Zahl & $6,5>$ & 5,9 & $6,5>$ & 6,2 & $6,5>$ & 6,0 & $6,5>$ & 5,8 & $6,8>$ & $>6,4$ & 6,7 & $>6,6$ \\
\hline N-Zahl & 2,5 & 2,7 & 2,6 & 2,8 & 2,5 & 2,9 & 2,5 & 2,9 & $2,6<$ & $<2,8$ & 2,3 & $<2,6$ \\
\hline
\end{tabular}

Kursive Zahlen des Standorts Steinkirche verweisen auf $\mathrm{CaCO}_{3}$-Gehalte, die weit oberhalb derjenigen liegen, wie sie im Rahmen der chromatographischen $C / N$-Analytik für den Gesamt-C-Gehalt $\left(C_{t}\right)$ der Feinerdehomogenate bestimmt wurden. Aus diesem Grund werden hier $C_{t} / N$ - und nicht $C_{o} / N$-Verhältnisse angegeben.

Mit Ausnahme derer der Standorte Hölleberg und Steinkirche liegen die $\mathrm{pH}\left(\mathrm{H}_{2} \mathrm{O}\right)$-Werte der CCBestände signifikant über denen der CF-Bestände. Damit konform übertreffen in allen Fällen die medianen Reaktionszahlen (Ellenberg et al. 1992) der typischen Subassoziation diejenigen des Gentiano-Koelerietum danthonietosum. Der Rangkorrelationstest nach Spearman belegt für die in Tabelle 5 aufgeführten Halbtrockenrasen eine positive Korrelation zwischen den Zeigerwerten der Vegetation und den $\mathrm{pH}\left(\mathrm{H}_{2} \mathrm{O}\right)$ des Bodens. Die Zeigerwertspektren in Abbildung A 1 (S. 312) geben die Verteilung der Reaktionszahlen und der anderen ökologischen Kennzahlen für die CC- und CF-Bestände aller Untersuchungsstandorte an. Mediane Krautschichtdeckungen von 90\% und 95\% im Gentiano-Koelerietum typicum und Gentiano-Koelerietum danthonietosum finden sich in Übereinstimmung mit den die Wasserhaushaltsverhältnisse abbildenden Licht-, Temperatur- und Feuchtezahlen. Ein Bezug zwischen den oben beschriebenen C/N-Verhältnissen der lufttrockenen Feinerdehomogenaten und den mittleren Stickstoffzahlen der Vegetationsbestände liegt hingegen nicht vor. Letztere sind übereinstimmend mit der Ausweisung mesophiler Differentialarten für die Subassoziation von Danthonia decumbens signifikant höher.

Die verschiedenen Auswertungen der vegetationskundlichen Untersuchungen - pflanzensoziologischtabellarische und numerische Assoziierung auf Ebene der Vegetationsbestände, Berechnung von Gemeinschaftskoeffizienten als quantitatives Maß für die Vergesellschaftung auf Ebene der Pflanzensippen sowie die Charakterisierung der Vegetationsbestände auf Grundlage ihrer medianen Zeigerwerte - lassen die Klassifizierung aller Untersuchungsflächen in CC-Bestände des Gentiano-Koelerietum typicum mit einer Gruppe v. a. heliophiler Differentialarten und in CF-Bestände des Gentiano-Koelerietum danthonietosum mit einer Reihe calcifuger/acidophiler und einem hohen Anteil mesophiler Arten für die zusammenfassende Bewertung der nachfolgenden Untersuchungen gerechtfertigt erscheinen. 


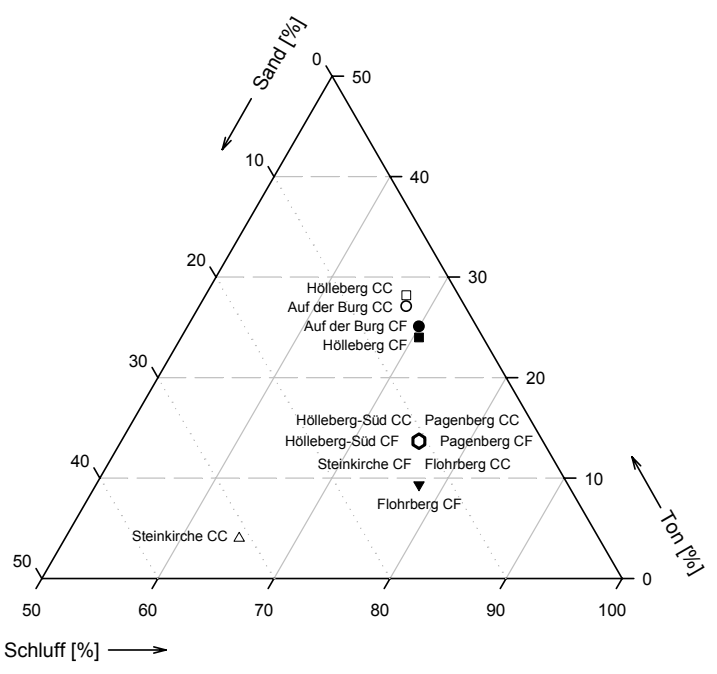

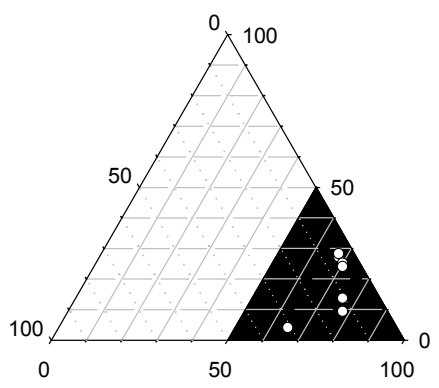

Abbildung 15: Korngrößenverteilung [\%] des Feinbodens der CC- und CF-Bestände aller Untersuchungsstandorte. Die Darstellung oben zeigt den Ausschnittsbereich der linken Abbildung.

Die Korngrößenverteilung des Feinbodens weist für die verschiedenen Standorte und Bestände nur geringe Unterschiede auf (Abbildung 15). Die Bodenunterarten reichen von mittel bzw. stark schluffigem Ton (Tu3, Tu4) der CC- bzw. CF-Bestände der beiden Referenzstandorte Auf der Burg und Hölleberg über mittel tonigen Schluff (Ut3) bis hin zu einem schwach tonigen Schluff (Ut2) des Bestands Flohrberg-CF. Nur die Feinerde des Gentiano-Koelerietum typicum am Standort Steinkirche weicht von diesem Bild ab und besitzt bei geringeren Tongehalten deutlich höhere Sandanteile.

\subsection{Standortökologische Untersuchungen}

\subsubsection{Physikoedaphische und klimatische Faktoren}

Im Gegensatz zu den Erhebungen für die jeweils nur einmal untersuchten 2,5 $\mathrm{m} \cdot 2,5 \mathrm{~m}$ großen Beständen der Standorte Hölleberg-Süd, Flohrberg, Pagenberg und Steinkirche erlauben die Ergebnisse der regelmäßigen bodenkundliche Untersuchungen der Referenzstandorte Auf der Burg und Hölleberg mit ihren jeweils 16 Teilflächen pro Vegetationsbestand eine Bewertung auch der räumlichen und zeitlichen Variabilitäten in den beiden Subassoziationen des Gentiano-Koelerietum.

\section{Bodengründigkeit und Skelettgehalte}

Abbildung 16 zeigt die Bodentiefen in den vier Untersuchungsflächen. Diese wurden mit Hilfe eines skalierten Metallstabs durch Einstiche an den Kreuzpunkten von zwei um 62,5cm versetzten Rastern ermittelt, deren quadratischen Felder Seitenlängen von 1,25 m aufwiesen. Die in Tabelle 5 aufgeführten medianen Bodengründigkeiten der CC- und CF-Bestände weichen signifikant voneinander ab. Dabei sind höhere Werte der Subassoziation von $D$. decumbens mit den Skelettgehalten der oberen $10 \mathrm{~cm}$ des Bodens, wie sie in Abbildung 18 als Mediane aller Probennahmen dargestellt sind, negativ korreliert. Während der $A_{h}$-Horizont des CF-Bestands am Standort Auf der Burg bei einer Tiefe von 15,5 cm über dem bankigen Ausgangsgestein nahezu skelettfrei ist, enthalten die flachgründigeren Oberböden der anderen Versuchsflächen Skelettanteile von 8\% (Hölleberg-CF), $20 \%$ (Hölleberg-CC) und 28\% (Auf der Burg CC). Geröll bzw. Kies als Skelettfraktionen der CF-Bestände und Steine bzw. Grus als diejenige der CC-Bestände verweisen auf eine fortgeschrittene Verwitterung des Kalkgesteins im GentianoKoelerietum danthonietosum. 

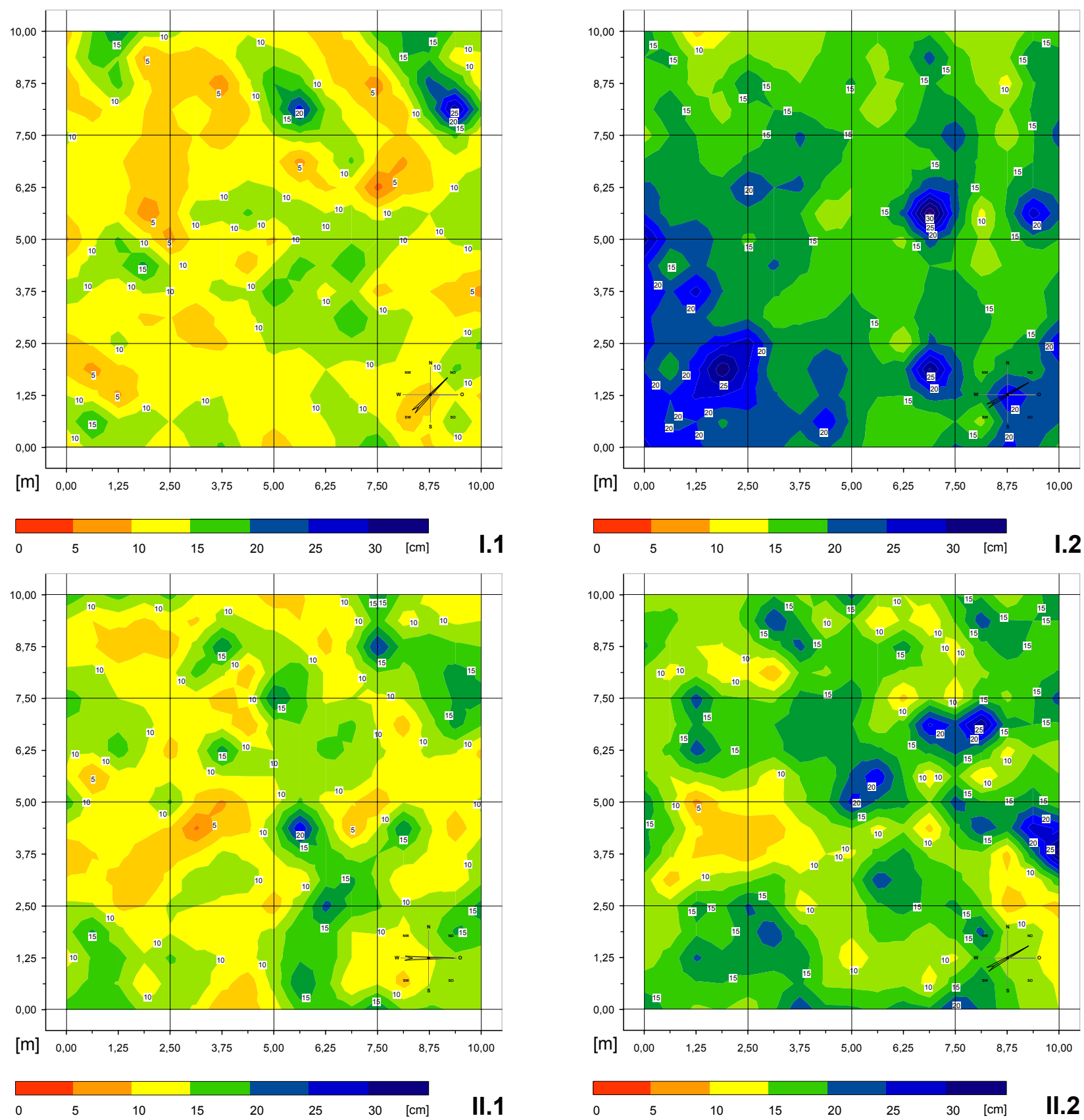

Abbildung 16: Bodentiefen [cm] von CC-Beständen (-.1) und CF-Beständen (-.2) der Standorte Auf der Burg (I.-) und Hölleberg (II.-)(Exposition, Inklination und Mediane der Bodengründigkeiten vgl. Tabelle 5).

Die Untersuchungsflächen sind nicht nur floristisch-vegetationskundlich sehr homogen (Tabelle 4, Abbildung 13). So lassen sich für die Quadranten keines Vegetationsbestands signifikante Unterschiede im Bodenskelettgehalt nachweisen. Eine nennenswerte Abweichung der Bodentiefe weist nur der besonders tiefgründige Quadrant A1 der Untersuchungsfläche Auf der Burg-CF auf. Abbildung 16 I.2 belegt für diesen Bestand eine allmähliche Abnahme der Gründigkeit von A1 nach B7. Zwischen den Quadrantenreihen A und B innerhalb der vier Bestände existieren keine signifikanten Unterschiede (zur Bezeichnung der Quadranten s. Abbildung 6, S. 19). 


\section{Witterungsverlauf und Parameter von Bodengefüge und Bodenfeuchte}

Für die Bewertung der zeitlichen Fluktuationen verschiedener Standortfaktoren zeigt Abbildung 4 in Monatsauflösung, Abbildung 17 in Tagesauflösung die Niederschlags- und Temperaturverteilungen im Jahresverlauf. Betrachtet man die Witterung und die Bodenwassergehalte $\Theta_{\mathrm{t}-\mathrm{V}}$ (Abbildung 18) im Jahr 1998, so finden sich Minima der Bodenfeuchte für den Standort Hölleberg Mitte Mai nach einer zweiwöchigen überdurchschnittlich warmen Trockenperiode und für den Standort Auf der Burg Ende Juni in einer warm-heißen Phase z. T. recht ergiebiger Niederschläge, aber auch regenfreier Tage (Abbildung 18 I/II.1). Am Standort Auf der Burg resultieren besonders hohe Wassergehalte des Bodens im November aus einer niederschlagsreichen Periode, die bereits Ende September begann. Am Standort Hölleberg sind Maxima der Bodenfeuchte Ende November offensichtlich die Folge einer verminderten Drainage und Evaporation während der ersten Frostperiode des Jahrs. Die nach Abbildung 18 recht ausgeglichenen Bodenfeuchten verweisen auf ansonsten gute Entwässerungseigenschaften aller Versuchsstandorte. Grundsätzlich liegen die auf das Gesamtvolumen des Bodens bezogenen Wassergehalte $\Theta_{\mathrm{t}-\mathrm{V}}$ der CFBestände signifikant über denen des Gentiano-Koelerietum typicum, im Jahr 1998 am Standort Auf der Burg im Durchschnitt um mehr als 70 \%, am Standort Hölleberg um $23 \%$.

Für den Umfang und die Geschwindigkeit oxidoreduktiver Umsetzungen ist neben dem $\mathrm{pH}$ und dem Gehalt an organischem Material v. a. die Bodendurchlüftung und damit die Lagerungsdichte (LD) des Bodens von Bedeutung. Da der Skelettanteil stark schwankt, werden hier die Rohdichten nicht auf die Gesamtfraktion des Bodens $\left(\rho_{\mathrm{B}}\right)$, sondern auf die Feinerdefraktion ( $\left.\rho_{\mathrm{FE}}\right)$ bezogen. Rückschlüsse auf das Gefüge derjenigen Bodenbereiche, in denen die relevanten mikrobiellen Reaktionen stattfinden, würden durch das hohe spezifische Gewicht des Carbonatgesteins $\left(\rho_{\text {Calcit }}=2,69 \mathrm{~kg} \cdot \mathrm{l}^{-1}\right.$; Scheffer \& Schachtschabel 1992) verfälscht. Die für die Gasdiffusion im Boden ausschlaggebenden Porenvolumina PV - und hier v. a. der luftgefüllte Porenraum LV - können anhand des verfügbaren Datenmaterials nicht exakt kalkuliert werden. Hierfür hätte die Dichte des Festmaterials der Feinerdefraktionen $\mathrm{s}_{\mathrm{FE}}$ separat bestimmt und der Porenanteil nach PV $[\% \mathrm{~V} / \mathrm{V}]=1-\left(\rho_{\mathrm{FE}} / \mathrm{s}_{\mathrm{FE}}\right) \cdot 100$ berechnet werden müssen.

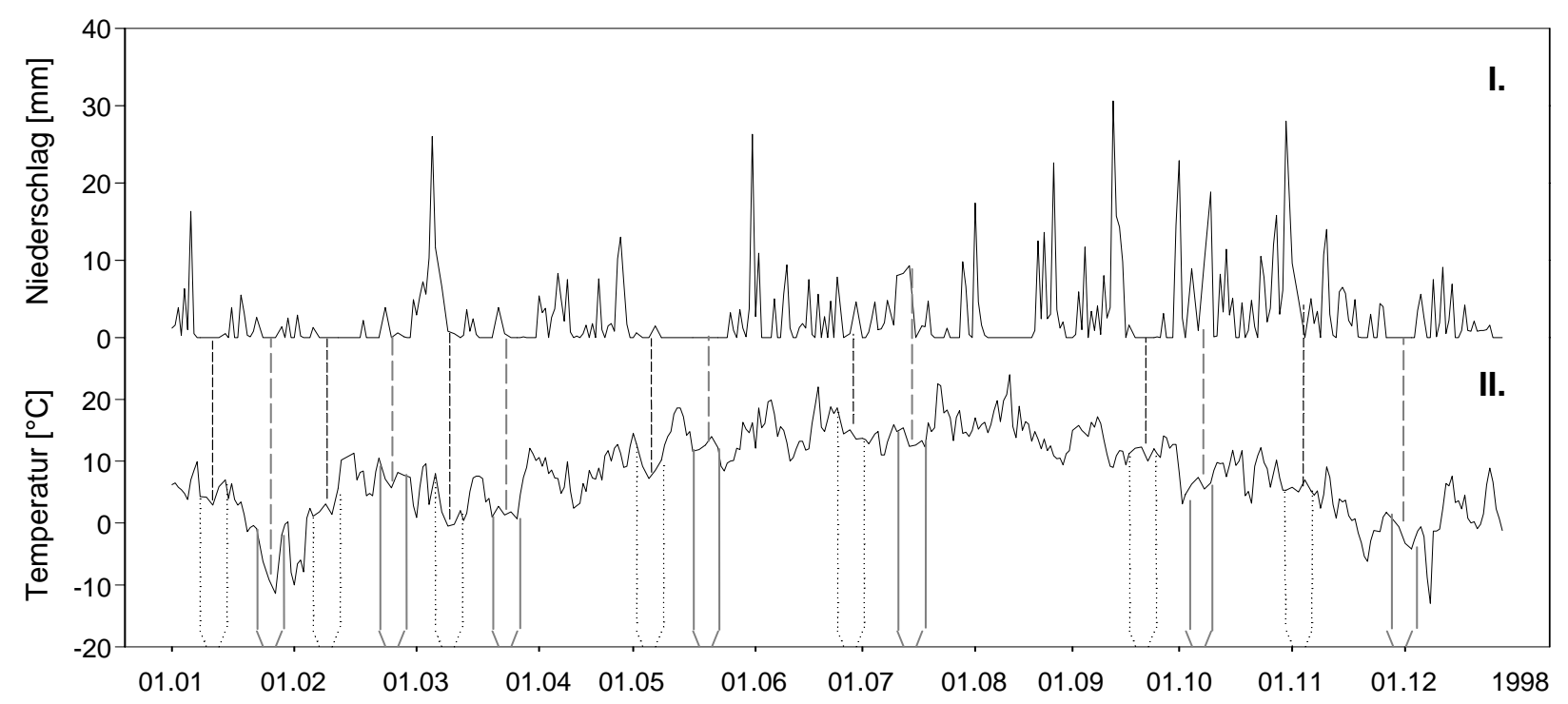

Abbildung 17: Niederschläge und Temperaturen im Unteren Diemeltal im Jahr 1998. I. Niederschlagswerte [mm] der DWD-Station Trendelburg-Langenthal; II. Temperaturwerte $\left[{ }^{\circ} \mathrm{C}\right]$ der DWD-Station Hofgeismar-Beberbeck. Abträge von der Abszisse auf die Temperaturkurve kennzeichnen eine Streckung der Skalierung um $100 \%$ im Zeitraum \pm 2 d der Probennahmen (Auf der Burg: schwarz punktiert, Hölleberg: grau liniert). Gestrichelte Linien zwischen den Jahresgängen verweisen auf die Probennahmen. 

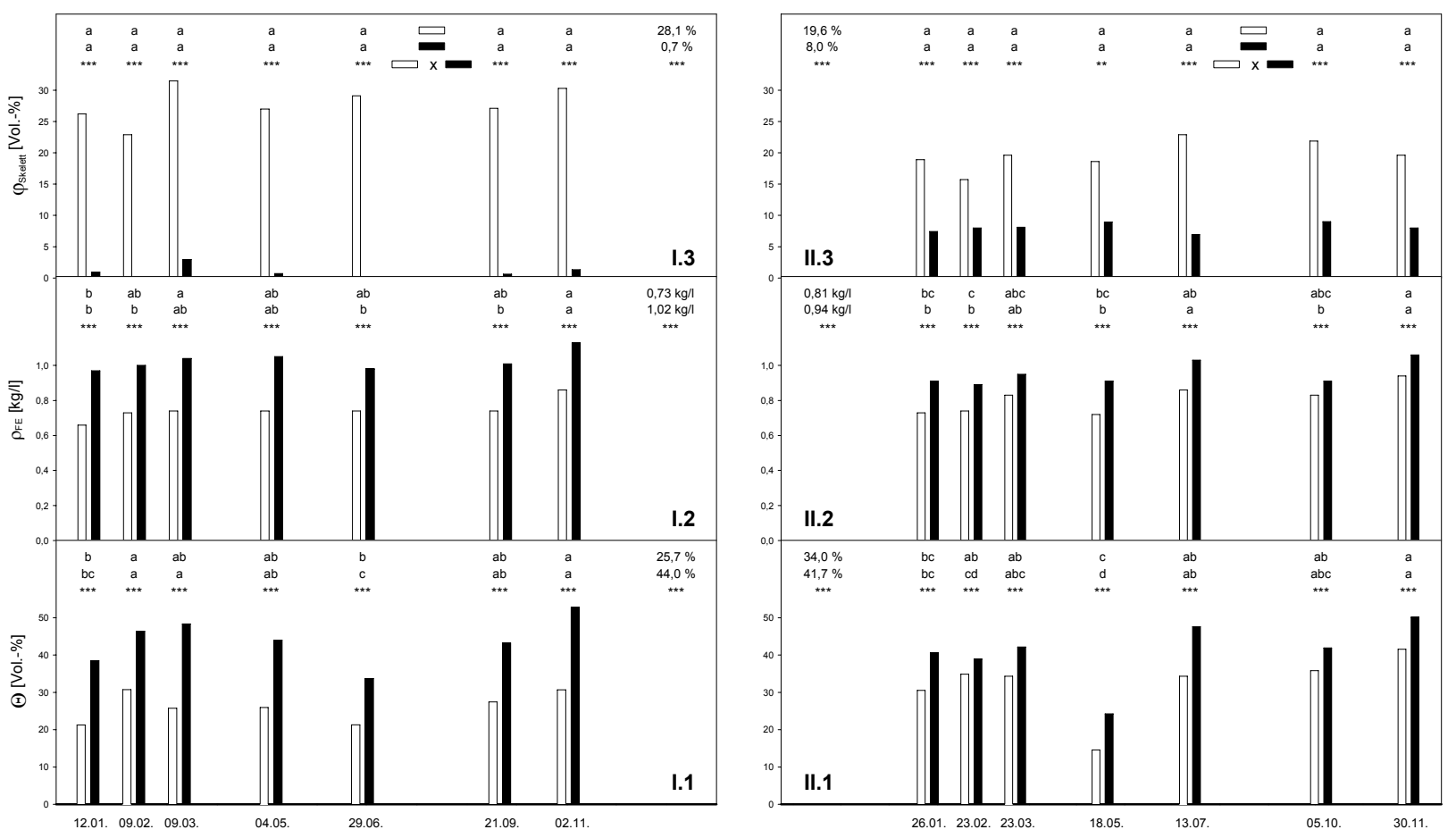

Abbildung 18: Wassergehalte $\Theta_{t-V}\left[\%\right.$ V/V] (I/II.1), Feinerde-Lagerungsdichten $\rho_{F E}\left[\mathrm{~kg}_{T G} \cdot \mathrm{l}^{-1}\right]$ (I/II.2) und Skelettgehalte $\varphi[\% \mathrm{~V} / \mathrm{V}]$ (I/II.3) der Referenzstandorte Auf der Burg (I.) und Hölleberg (II.) im Jahresverlauf 1998 (CC offene Balken, CF geschlossene Balken). Die Abbildung A 7 ( S. 316) erläutert weitere Elemente der graphischen Darstellung dieser und anderer physiko- und chemoedaphischer Untersuchungen der Referenzstandorte im Unteren Diemeltal.

Kalkulationen mit einer einheitlichen Festdichte $\mathrm{s}_{\mathrm{FE}}$, die auf dem $\mathrm{CaCO}_{3}$-Gehalt der Feinerde und der Calcit-Dichte von 2,69 $\mathrm{kg} \cdot \mathrm{l}^{-1}$ sowie der Annahme reinen Quarzes mit einer Dichte von 2,65 $\mathrm{kgl}^{-1}$ für den verbleibenden Feinerdeanteil basieren, ergeben indes Porenanteile der Feinerde von 72,6\% bzw. 61,5\% für die CC- bzw. CF-Bestände des Standorts Auf der Burg und 69,5\% bzw. 64,5\% für die betreffenden Vegetationsbestände des Standorts Hölleberg. Legt man der Bewertung des Makrogefüges neben der Dichte $\rho_{\mathrm{FE}}$ den Tonanteil $w_{\mathrm{Ton}}$ der Feinerde zugrunde, so verweisen Werte von $\mathrm{Ld}<1,40 \mathrm{~kg} \cdot \mathrm{l}^{-1}$ für alle hier untersuchten Böden auf sehr geringe effektive Lagerungsdichten, die ein feines Aggregatgefüge mit sperriger Lagerungsart und losem bis sehr losem Zusammenhalt kennzeichnen (Tabelle 6; Scheffer \& Schachtschabel 1992; Kuntze et al. 1994).

In der Tendenz folgen die trockengewichtsbezogenen Lagerungsdichten der Feinerde $\left(\rho_{\mathrm{FE}}\right)$ den Wassergehalten des Bodens. Wie diese liegen sie in den CF-Bestände über denen der Vergleichsbestände, für den Standort Auf der Burg um 40\%, am Hölleberg um 16\%. Als Ursachen sind Verschlämmungen des Bodenmaterials und eine mögliche Abhängigkeit potenzieller Bodenverdichtungen bei der Entnahme der Monolithen vom Bodenwassergehalt in Betracht zu ziehen. Ein weiterer Faktor, der berücksichtigt werden muss, ist der im Jahresverlauf variierende Wurzelanteil. Die am jeweiligen Minimalwert orientierte Variationsbreite der Feinerde-Lagerungsdichten liegen im Betrachtungszeitraum für die CC-Bestände bei etwa $30 \%$, für die CF-Bestände bei $<20 \%$.

Das Fehlen von signifikanten Unterschieden der Skelettgehalte aufeinanderfolgender Probennahmen entspricht den obigen Ausführungen zur Homogenität der Versuchsflächen. Abbildung 18 erlaubt aufgrund der gemeinsamen Darstellung von Skelettgehalten, Feinerde-Lagerungsdichten und gesamtvolumenbezogenen Wassergehalten Rückschlüsse auf die feinerdevolumen- und massebezogenen Bodenwassergehalte. 
Tabelle 6: Parameter der Makrogefügeeigenschaften der Feinerde von CC- und CF-Beständen der Standorte Auf der Burg und Hölleberg. $L d=\rho_{F E}+0,009 \cdot w_{T o n}(A G$ Boden 1994).

\begin{tabular}{lccccc}
\hline & \multicolumn{2}{c}{ Auf der Burg } & \multicolumn{2}{c}{ Hölleberg } \\
& CC & CF & CC & CF \\
\hline mittlerer Tonanteil $\mathbf{w}_{\text {Ton }}[\% \mathrm{~m} / \mathrm{m}]$ & 27 & 25 & 28 & 24 \\
Feinerde-Rohdichte $\rho_{\mathrm{Fe}}\left[\mathrm{kg} \cdot \mathrm{I}^{-1}\right]$ & 0,73 & 1,02 & 0,81 & 0,94 \\
eff. Lagerungsdichte $\mathrm{Ld}\left[\mathrm{kg} \cdot \mathrm{I}^{-1}\right]$ & 0,97 & 1,25 & 1,06 & 1,16 \\
\hline
\end{tabular}

Unterschiedliche Bodenskelettgehalte von CC- und CF-Beständen tragen erheblich zu den Differenzen der dargestellten Bodenfeuchten bei. Dies gilt insbesondere für den Standort Auf der Burg. Dennoch ergeben sich in allen Fällen auch bei Bezug auf das Feinerdevolumen höhere Bodenfeuchten im Gentiano-Koelerietum danthonietosum, im Schnitt um etwa $20 \%$ und $10 \%$ für die beiden Standorte. Der Quotient aus feinerdevolumenbezogenem Wassergehalt $\Theta_{\mathrm{FE}-\mathrm{V}}[\% \mathrm{~V} / \mathrm{V}]$ und trockengewichtsbezogener Feinerdedichte $\rho_{\mathrm{FE}}\left[\mathrm{kg}_{\mathrm{TG}} \cdot \mathrm{l}^{-1}\right]$ führt in Annahme einer spezifischen Dichte des Bodenwassers von $1,0 \mathrm{~kg} \cdot \mathrm{l}^{-1}$ zurück auf die gravimetrisch ermittelten Wassergehalte $\Theta_{\mathrm{FE}-\mathrm{m}}\left[\% \mathrm{~m} / \mathrm{m}_{\mathrm{TG}}\right]$. Im Gegensatz zu den volumenbezogenen Werten liegen diese für das Gentiano-Koelerietum typicum höher als diejenigen der Subassoziation von $D$. decumbens.

Korngrößenverteilungen (Abbildung 15) und Lagerungsdichten (Tabelle 6) sowie die volumenbezogenen Bodenwassergehalte (Abbildung 18) der Vergleichsbestände geben auch ohne die Darstellung von pFKurven oder die (in skelettreichen Böden und bei $\mathrm{pF}>3$ nicht zulässige) Bestimmung von Saugspannungen unter Verwendung von Tensiometern eindeutige Hinweise auf eine bessere pflanzliche Wasserverfügbarkeit im Gentiano-Koelerietum danthonietosum.

\subsubsection{Chemismus wässriger Bodenextrakte}

Soweit nicht anders gekennzeichnet, werden im Hinblick auf eine einheitliche Darstellung und unmittelbare Vergleichbarkeit die Analysen aller Bodenextrake auf die Feinerdefraktion bezogen und in den nachfolgenden Graphiken als massebezogene Stoffmenge $b$ [mol/g] oder Massenanteil w [g/g bzw. \% m/m] angegeben. Für die Herstellung der GBL, PBL und DBL wurde unter Berücksichtigung des aktuellen Wassergehalts ein Verhältnis von 1:2 zwischen Feinerde und Bodenlösung angestrebt. Exakt konnte dieses aber nur für die GBL eingestellt werden. Der Faktor für die Berechnung der Gleichgewichtskonzentrationen der GBL beträgt daher für alle Proben $0,5 \mathrm{~kg} \cdot \mathrm{l}^{-1}$. Für die Berechnung der PBL- und DBL-Aufsättigungsvolumina mussten Wassergehalte von Teilproben der GBL-Feinerdehomogenate und durchschnittliche Skelettgehalte der betreffenden Vegetationsbestände herangezogen werden. Hieraus resultieren leichte Abweichungen von dem gewünschten Boden/Lösungs-Verhältnis. Tabelle 7 gibt die mittleren Proportionalitätsfaktoren für die Umrechnung der massebezogenen Stoffmenge $b$ bzw. Massengehalte $w$ der PBL in die Konzentrationen der equilibrierten Analysenlösung an. Überdies enthält sie Faktoren für die Berechnung der theoretischen Konzentrationen der aktuellen Bodenlösung aus den in den Graphiken numerisch angeführten Stoffgehalten der DBL. Es handelt sich hierbei um die reziproken Jahresmittel der auf das Feinerdetrockengewicht bezogenen Wassergehalte $\Theta_{\mathrm{FE}}\left[\% \mathrm{~m} / \mathrm{m}_{\mathrm{TG}}\right]$.

Unter ökologischen Gesichtspunkten ist in verschiedenen Fällen auch ein Bezug von Komponenten der pflanzlichen Mineralstoffernährung auf das Gesamtbodenvolumen zweckmäßig. Anhand der medianen Bodenskelettgehalte und Feinerdedichten berechnen sich die in Tabelle 7 angegebenen Proportionalitäts- 
faktoren für die Umrechnung aller in den nachfolgenden Graphiken dargestellten Massen- und Stoffmengengehalten in bodenvolumenbezogene Massen- oder Stoffmengenkonzentrationen wie folgt:

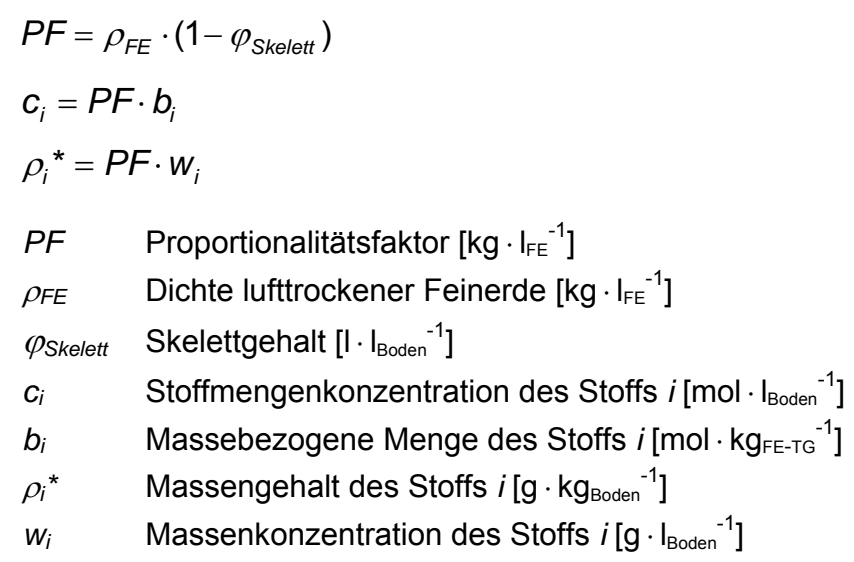

Tabelle 7: Proportionalitätsfaktoren (PF) für die Umrechnung von medianen massenbezogenen Stoffgehalten $w\left[\mathrm{~g} \cdot \mathrm{kg}_{\mathrm{FE}-\mathrm{TG}}{ }^{-1}\right]$ bzw. $b$ [mol $\left.\cdot \mathrm{kg}_{\mathrm{FE}-\mathrm{TG}}{ }^{-1}\right]$ in Konzentrationen der Gleichgewichtslösungen (GBL, $P B L$ ) und 'aktuellen' Bodenlösungen (DBL) $\rho^{*}\left[\mathrm{~g} \cdot \mathrm{l}_{\text {Lösung }}{ }^{-1}\right]$ bzw. $\mathrm{c}\left[\mathrm{mol} \cdot \mathrm{l}_{\text {Lösung }}{ }^{-1}\right]$ sowie bodenvolumenbezogene Konzentrationen (GBL, PBL, DBL) $\rho^{*}\left[\mathrm{~g} \cdot \mathrm{l}_{\text {Boden }}{ }^{-1}\right]$ bzw. $c\left[\mathrm{~mol} \cdot l_{\text {Boden }}{ }^{-1}\right] .^{1}$

\begin{tabular}{|c|c|c|c|c|c|c|}
\hline \multicolumn{3}{|c|}{ Proportionalitätsfaktor } & \multicolumn{2}{|c|}{ Auf der Burg } & \multicolumn{2}{|c|}{ Hölleberg } \\
\hline$w, b$ & $\rightarrow$ & $\rho^{*}$ bzw. c & CC & CF & CC & CF \\
\hline GBL: & $\rightarrow$ & Analysenlösung & 0,50 & 0,50 & 0,50 & 0,50 \\
\hline PBL: & $\rightarrow$ & Analysenlösung & 0,50 & 0,51 & 0,54 & 0,53 \\
\hline \multirow[t]{7}{*}{ DBL: } & $\rightarrow$ & Bodenlösung (MW) & 2,04 & 2,29 & 2,04 & 2,28 \\
\hline & & Probennahme 1 & 2,21 & 2,45 & 2,01 & 2,05 \\
\hline & & Probennahme 2 & 1,84 & 2,13 & 1,81 & 2,10 \\
\hline & & Probennahme 3 & 2,02 & 2,08 & 1,94 & 2,08 \\
\hline & & Probennahme 4 & 1,99 & 2,30 & 3,83 & 3,37 \\
\hline & & Probennahme 5 & 2,42 & 2,90 & 1,91 & 2,03 \\
\hline & & Probennahme 7 & 1,88 & 2,08 & 1,79 & 1,95 \\
\hline \multicolumn{2}{|c|}{ G/P/DBL $\rightarrow$} & Bodenvolumen & 0,52 & 1,00 & 0,65 & 0,86 \\
\hline
\end{tabular}

Das CC/CF-Verhältnis dieser Proportionalitätsfaktoren zeigt, dass das Gentiano-Koelerietum danthonietosum bei gleichem Stoffmengen- oder Massengehalt der Feinerde um etwa 1,9fach (Auf der Burg) bzw. 1,3fach (Hölleberg) höhere Stoffgehalte pro Volumeneinheit Boden aufweist als die typische Subassoziation.

1 In den nachfolgenden Darstellungen werden die Massenanteile $w$ und massebezogenen Stoffmengen $b$ immer auf die Basiseinheit Gramm (und nicht Kilogramm) bezogen. Eine Umrechnung dieser Werte in die betreffenden Massenkonzentrationen $\rho^{*}$ und Teilchenmengenkonzentrationen ("Molarität") c erfordert demnach eine Multiplikation mit dem Faktor $10^{3}$. 


\section{Einfluss der Perkolationsdauer auf die Zusammensetzung wässriger Bodenextrakte}

Während im Fall der DBL durch eine möglichst schnelle Extraktion der Monolithen die Einstellung chemischer Gleichgewichte zwischen der Bodenfestphase und der Aufsättigungslösung verhindert werden soll, zielt die Herstellung der PBL auf eine Equilibrierung des Lösungssystems ab. Im Rahmen der Entwicklung des zyklischen Perkolationsverfahrens wurde die diesbezüglich erforderliche Perkolationsdauer für verschiedene Anionen und Kationen ermittelt. Für die Auswertung dieser Vorversuche wurden, wie in Abbildung 19 dargestellt, die Analysenergebnisse jedes Perkolationsansatzes auf den Maximalwert der jeweiligen Zeitreihe bezogen und die daraus resultierenden relativen Konzentrationswerte für jede Extraktionszeit gemittelt.
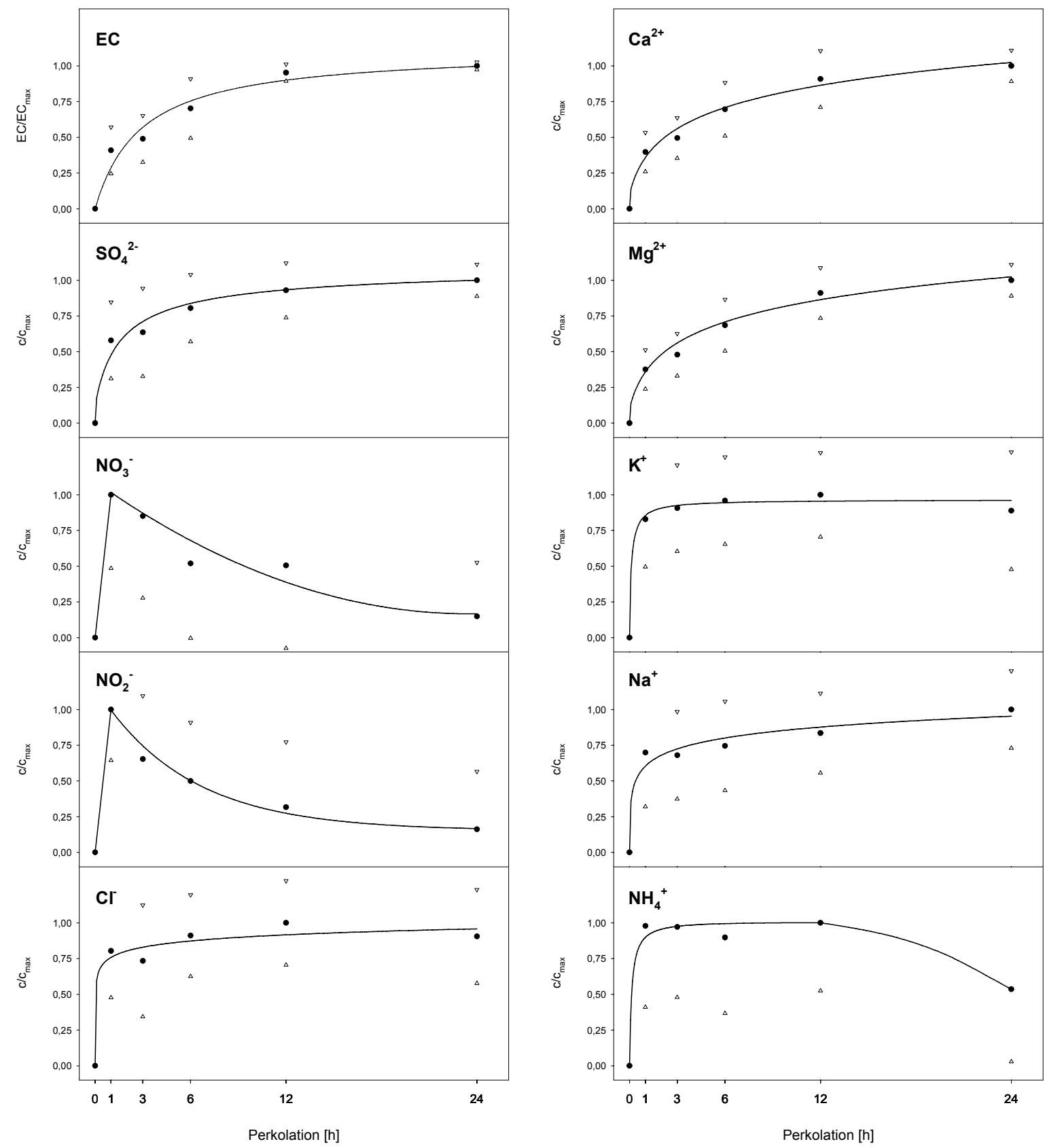

Abbildung 19: Abhängigkeit der relativen elektrischen Leitfähigkeiten EC/EC $C_{\max }$ und relativen Mineralstoffkonzentrationen $c / c_{\max }$ von der Perkolationsdauer. Bei den N-Fraktionen wurde im Hinblick auf eine angemessene Ordinatenskalierung auf die beidseitige Darstellung der Standardabweichungen $(\triangle \nabla)$ verzichtet. $(n=32)$. 
Das Lösungsgleichgewicht der hier untersuchten monovalenten Ionen $\left(\mathrm{Cl}^{-}, \mathrm{K}^{+}\right.$, und $\left.\mathrm{NH}_{4}^{+}\right)$wird bereits nach einer einstündigen Extraktion der Bodenmonolithen annähernd erreicht. Auch für die hier dargestellten $\mathrm{pH}$-Werte ließen sich im weiteren Versuchsverlauf keine wesentlichen Veränderungen nachweisen. Demgegenüber erfordert die Equilibrierung der bivalenten Anionen $\left(\mathrm{SO}_{4}^{-}\right)$und Kationen $\left(\mathrm{Ca}^{2+}, \mathrm{Mg}^{2+}\right)$ deutlich längere Perkolationen.

Bei sehr hohen Varianzen der relativen Konzentrationswerte sind für $\mathrm{NO}_{2}^{-}$und $\mathrm{NO}_{3}^{-}$Kurvenverläufe kennzeichnend, die auf eine starke Denitrifikation und/oder Assimilation bereits während der ersten Stunde der Perkolation hinweisen. Innerhalb von $24 \mathrm{~h}$ werden die anionischen N-Fraktionen fast vollständig aus den Lösungen eliminiert. Demgegenüber ist $\mathrm{NH}_{4}{ }^{+}$bei Raumtemperatur über einen Zeitraum von $12 \mathrm{~h}$ stabil und zeigt erst in der zweiten Versuchshälfte eine signifikante Konzentrationsabnahme.

Als integratives Maß für die Lage des Lösungsgleichgewichts kann die elektrische Leitfähigkeit betrachtet werden. Deren Höhe wird primär durch die $\mathrm{Ca}^{2+}$-Aktivitäten bestimmt (Abbildung 25, S. 61). Wie der im Vergleich mit der $\mathrm{Ca}^{2+}$-Lösungskinetik etwas steilere Kurvenverlauf belegt, spiegelt die EC aber auch das Lösungsverhalten der monovalenten Ionen wider. Dem Verlauf der elektrischen Leitfähigkeit zufolge ist die Gleichgewichtseinstellung zwischen Bodenmaterial und Perkolat nach etwa $12 \mathrm{~h}$ bis $24 \mathrm{~h}$ abgeschlossen. Die Variationsbreite der meisten Analytkonzentrationen nimmt mit zunehmender Perkolationsdauer ab (Abbildung 19). Trotz deutlicher Konzentrationsverluste aller gelösten Stickstofffraktionen und angesichts der gleichzeitigen Herstellung von DBL, die eine Beurteilung der N-Verfügbarkeiten in den verschiedenen Vegetationsbeständen erlauben, erscheint daher eine Extraktionsdauer von $24 \mathrm{~h}$ für die Herstellung von Gleichgewichtslösungen feldfrischer Feinerdehomogenate (GBL) und Monolithe mit weitgehend ungestörtem Bodengefüge (PBL) angemessen.

\section{Abpressdauer von Bodenmonolithen}

Wie die Perkolationsgeschwindigkeit, so ist auch die Dauer, die im Rahmen der Herstellung der DBL für das vollständige Abpressen der Aufsättigungsvolumina erforderlich ist, von der Bodenart und dem Bodengefüge der Monolithen abhängig. Abbildung 20 zeigt die prozentuale Verteilung der Abpressdauer in sechs Zeitklassen. Dargestellt sind die Ergebnisse für Bodenzylindern von je drei Probennahmen in den CC- und CF-Beständen der Standorte Auf der Burg und Hölleberg.

Die Abpressdauer der aufgesättigten skelettreichen CC-Monolithen unterschreitet in der Regel die der CF-Proben. Die Extraktion von $70 \%$ aller CC-Monolithen konnte innerhalb einer halben Stunde abgeschlossen werden. Hingegen erfordert die DBL-Herstellung von über der Hälfte der Bodenmonolithe des Gentiano-Koelerietum danthonietosum eine mehr als 30minütige Überdruckbehandlung. Insbesondere bei Extraktionszeiten von weniger als 10 min gewinnen offenbar Randeffekte, d.h. ein verstärkter Lösungsfluss zwischen Wandung des Stechzylinders und Bodenkern, an Bedeutung. Auf der anderen Seite benötigen ein Drittel der CF-Monolithen des Standorts Auf der Burg und über $40 \%$ derjenigen des Standorts Hölleberg Abpresszeiten von mehr als 60 min. Von letzteren konnte bei etwa einem Fünftel der Proben auch nach $4 \mathrm{~h}$ bei einem Überdruck von bis zu 1 MPa die Extraktionslösung nicht vollständig abgepresst werden. Zusammenfassend muss daher darauf hingewiesen werden, dass DBL-Analysen insbesondere von CC-Monolithen unter dem Gesichtspunkt der Wirksamkeit möglicher Randeffekte, diejenigen der CF-Monolithen unter Berücksichtigung z. T. sehr langer Extraktionszeiten zu bewerten sind. Die wässrigen Überdruckextrakte entsprechen daher nur bedingt ihrer konzeptionellen Definition, nach der die aktuelle Bodenlösung durch hydraulischen Überdruck aus den Bodenporen verdrängt und durch kurze Einwirkungszeiten ohne Gleichgewichtseinstellung gewonnen werden. 

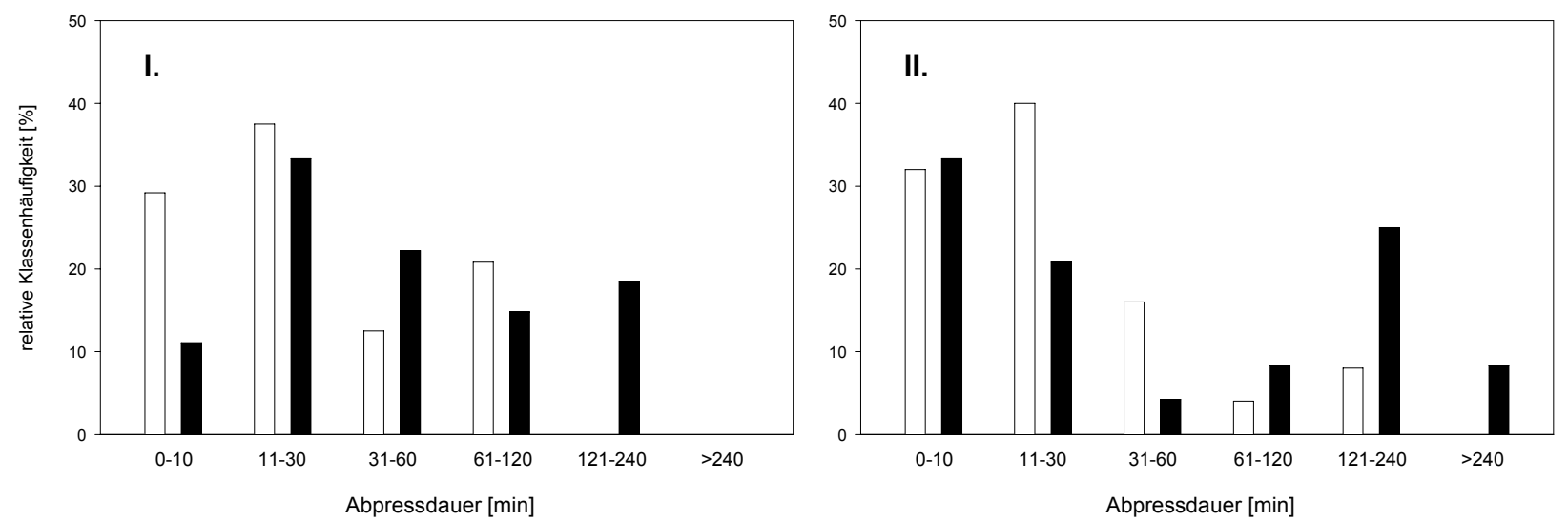

Abbildung 20: Prozentuale Verteilungen der Abpressdauer für die DBL-Herstellung aus Bodenmonolithen der CCund CF-Bestände der Standorte Auf der Burg und Hölleberg. I. Auf der Burg, II. Hölleberg; CC offene Balken, CF geschlossene Balken $(n=24)$.

\section{Bodenaciditäten}

Der pH ist ein Schlüsselfaktor des Bodenchemismus. Neben den in Abbildung 21 im Jahresverlauf dargestellten pH-Werten der drei verschiedenen Lösungstypen wurden für die Daueruntersuchungsflächen auch vertikale Verteilungsmuster der aktuellen und potenziellen Aciditäten feldfrischer Feinerdehomogenate untersucht (Tabelle 8). Mit Medianwerten aller Lösungstypen zwischen pH 6,5 (PBL-Mai, Auf der Burg$\mathrm{CF}$ ) und pH 8,4 (PBL-März, Auf der Burg-CC) lässt Abbildung 21 eine Carbonatpufferung aller hier untersuchten Böden vermuten (Ulrich 1987).
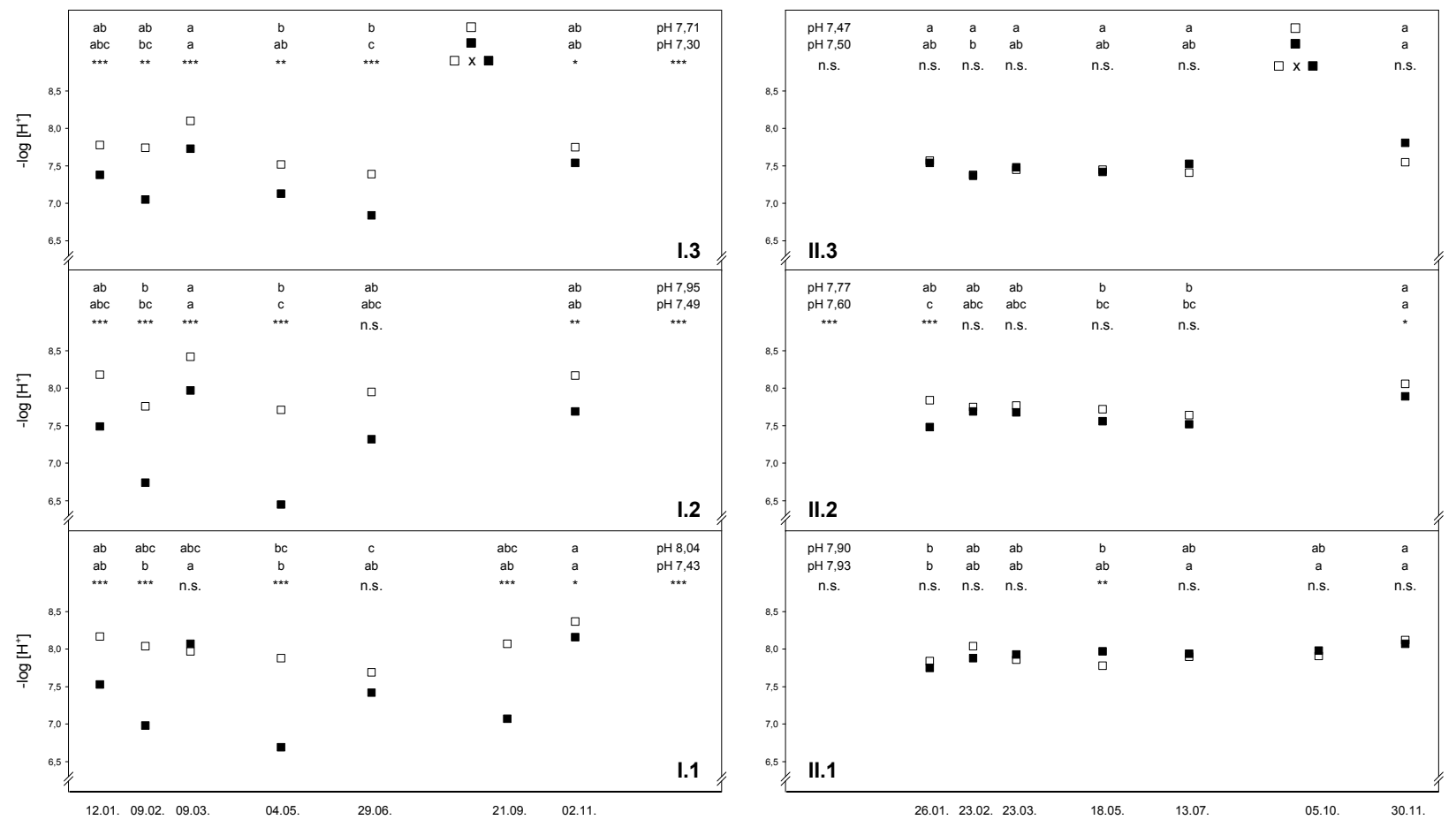

Abbildung 21: pH-Werte von GBL (I/II.1), PBL (I/II.2) und DBL (I/II.3) der CC- und CF-Bestände der Referenzstandorte Aufder Burg(I.) und Hölleberg(II.) im Jahresverlauf 1998 (CC offene Symbole, CF geschlossene Symbole). 
Bezogen auf die oberen $10 \mathrm{~cm}$ des Bodens sind am Standort Auf der Burg die pH-Werte im GentianoKoelerietum danthonietosum zu fast allen Zeitpunkten niedriger als diejenigen der typischen Subassoziation. Legt man die Jahresmediane der GBL von pH8,04 für den CC-Bestand und pH 7,43 für den CFBestand zugrunde, so überschreiten die Protonenaktivitäten des CF-Bestands diejenigen der typischen Subassoziation signifikant um mehr als $300 \% .{ }^{1}$ Noch deutlichere Abweichungen zwischen den Beständen indizieren die PBL und DBL. Ein entsprechendes Verhältnis zwischen den Vergleichsbeständen lässt sich am Standort Hölleberg für die hier betrachtete Bodentiefe nur anhand des Jahresmedians der PBL belegen.

Die Untersuchungen geben keine Hinweise auf bestimmte jahreszeitliche Trends der pH-Werte. Am Standort Auf der Burg ist eine leichte Sommerdepression des Boden-pH zu erkennen. In nur wenigen Fällen validieren die statistischen Auswertungen aber Unterschiede zwischen den Probennahmen. Nach besonders ergiebigen Niederschlägen im März liegen die pH-Werte für die Böden des Standorts Auf der Burg überdurchschnittlich hoch. Dies gilt insbesondere für die Subassoziation von D. decumbens.

Während die jahreszeitlichen Variabilitäten der pH-Werte in den wässrigen Bodenextrakten der anderen Vegetationsbestände weniger als 0,5 pH-Einheiten betragen, differieren die Protonenaktivitäten der GBL und PBL des Bestands Auf der Burg-CF mit $\Delta \mathrm{pH} \approx 1,5$ um Faktoren von etwa 30. Geringere Abweichungen sind hier allein für die DBL zu verzeichnen. Die zeitlichen Variabilitäten der Bodenreaktion übersteigen nicht nur grundsätzlich die räumliche Variationsbreite innerhalb der betrachteten Vegetationsbestände von $100 \mathrm{~m}^{2}$, sondern auch die Unterschiede zwischen den jeweiligen Vegetationseinheiten. ${ }^{2}$ Werden der Bewertung der verschiedenen Bodenextrakte die Ergebnisse aller Versuchsbestände und Probennahmen zugrunde gelegt, so ergeben sich signifikante Unterschiede für die $\mathrm{pH}$-Werte in der Reihenfolge $\mathrm{DBL}<\mathrm{PBL}<\mathrm{GBL}^{3}$

Ein differenzierteres Bild der pH-Verhältnisse in den Böden zeichnet Tabelle 8. Während die Jahresmediane der GBL das oben dargestellte Bild bestätigen, nach dem nur am Standort Auf der Burg das Auftreten acidophiler/calcifuger Arten mit einer erhöhten Bodenacidität einhergeht, belegen die Messungen von $\mathrm{H}_{2} \mathrm{O}$ - und KCl-Suspendaten horizontierter Feinerdeproben eine oberflächige Entbasung auch des CFBestands am Standort Hölleberg.

An beiden Standorten weichen die $\mathrm{pH}\left(\mathrm{H}_{2} \mathrm{O}\right)$-Werte der Bodenhorizonte 0-5 cm und 5-10 cm in den CCBeständen nur geringfügig voneinander ab. Demgegenüber liegen die $\mathrm{pH}\left(\mathrm{H}_{2} \mathrm{O}\right)$ des unteren Horizonts der CF-Bestände gundsätzlich um etwa eine pH-Einheit über denen des Oberbodens. Die Differenzen zwischen $\mathrm{pH}\left(\mathrm{H}_{2} \mathrm{O}\right)$ und $\mathrm{pH}(\mathrm{KCl})$ betragen im Vegetationsbestand Auf der Burg-CC jeweils <0,7, für die Subassoziation von $D$. decumbens hingegen $1,4(0-5 \mathrm{~cm})$ und $1,2(5-10 \mathrm{~cm})$.

\footnotetext{
${ }^{1}$ Ergebnisse statistischer Vergleiche zwischen CC- und CF-Beständen sind in Tabelle 11 (S. 77) aufgeführt. Soweit nicht durch andere Verweise gekennzeichnet, beziehen sich entsprechende Angaben auch im nachfolgenden Text auf diese Tabelle.

${ }^{2}$ Wie für alle nachfolgenden Untersuchungen von GBL, PBL und DBL sind neben den in den Graphiken dargestellten Ergebnissen nicht-parametrischer Statistiken im Anhang die Variationskoeffizienten CV der räumlichen Variabilität (Tabelle A 2, S. 302) und der zeit-räumlichen Variabilität (Tabelle A 3, S. 302) sowie die prozentualen Abweichungen (Tabelle A 4, S. 303) der betreffenden CV-Werte angegeben. Entsprechende Angaben im nachfolgenden Text beziehen sich auf diese Tabelle.

${ }^{3}$ Ergebnisse statistischer Vergleiche zwischen verschiedenen Extraktionsverfahren sind in Tabelle 10 (S. 76) aufgeführt. Entsprechende Angaben im nachfolgenden Text beziehen sich auf diese Tabelle
} 
Tabelle 8: Mediane Bodenaciditäten der Daueruntersuchungsflächen in Abhängigkeit von der Lösungspräparation und Bodentiefe. Sternsignaturen kennzeichnen Ergebnisse der nicht-parametrischen paarweisen Vergleiche entlogarithmierter Werte nach Mann-Whitney (n.s. $\alpha>0,05, * \alpha \leq 0,050, * * * \alpha \leq 0,001 ; n=56$ für GBL bzw. $n=16$ für $\mathrm{H}_{2} \mathrm{O}$ - und $\mathrm{KCl}$-Suspendate).

\begin{tabular}{|c|c|c|c|c|c|c|c|}
\hline \multirow[t]{2}{*}{ Lösungstyp } & \multirow{2}{*}{$\begin{array}{c}\text { Bodentiefe } \\
{[\mathrm{cm}]}\end{array}$} & \multicolumn{2}{|c|}{ Auf der Burg } & \multicolumn{4}{|c|}{ Hölleberg } \\
\hline & & CC & CF & & CC & CF & \\
\hline GBL & $0-10$ & 8,04 & 7,43 & $* * *$ & 7,90 & 7,93 & n.s. \\
\hline \multirow[t]{3}{*}{$\mathrm{H}_{2} \mathrm{O}$-Suspendat } & $0-5$ & 7,78 & 5,86 & $* * *$ & 7,63 & 6,71 & $* * *$ \\
\hline & $5-10$ & 7,77 & 6,86 & $* * *$ & 7,99 & 7,75 & $* * *$ \\
\hline & & n.s. & $* * *$ & & $* * *$ & $* * *$ & \\
\hline \multirow[t]{3}{*}{ KCl-Suspendat } & $0-5$ & 7,10 & 4,50 & $* * *$ & 6,96 & 5,92 & $* * *$ \\
\hline & $5-10$ & 7,11 & 5,62 & $* * *$ & 7,03 & 6,86 & $* * *$ \\
\hline & & n.s. & $* * *$ & & * & $* * *$ & \\
\hline
\end{tabular}

Die Untersuchungen aktueller und potenzieller Bodenaciditäten der Standorte Hölleberg-Süd, Flohrberg, Pagenberg und Steinkirche bestätigen die oben ausgeführten Unterschiede zwischen den beiden Subassoziationen des Gentiano-Koelerietum. Abbildung 22 zeigt die medianen $\mathrm{pH}\left(\mathrm{H}_{2} \mathrm{O}\right)$ und $\mathrm{pH}(\mathrm{KCl})$ in Feinerdehomogenaten der oberen $10 \mathrm{~cm}$ des Bodens sowie ihre Abweichungen zwischen den jeweiligen Vegetationsbeständen. Überdies werden in der Graphik pH-Bereiche angegeben, die Rückschlüsse auf die stoffliche Zusammensetzung der Böden und die Grundlagen ihrer pH-Pufferung erlauben (Ulrich 1987).

Die aktuellen Aciditäten von $\mathrm{pH}\left(\mathrm{H}_{2} \mathrm{O}\right)$ 7,7-7,8 verweisen auf eine Carbonatpufferung der Böden aller CCBestände. Am Standort Steinkirche liegt kein Unterschied des $\mathrm{pH}\left(\mathrm{H}_{2} \mathrm{O}\right)$ zwischen der typischen Subassoziation und derjenigen von $D$. decumbens vor. Auf nur geringfügig, dennoch aber signifikant niedrigere aktuelle Aciditäten des $\mathrm{A}_{\mathrm{h}}$-Horizonts im Gentiano-Koelerietum danthonietosum lassen die vergleichenden Messungen für den Standort Hölleberg-Süd schließen. Demgegenüber sind die Böden dieser Subassozia-

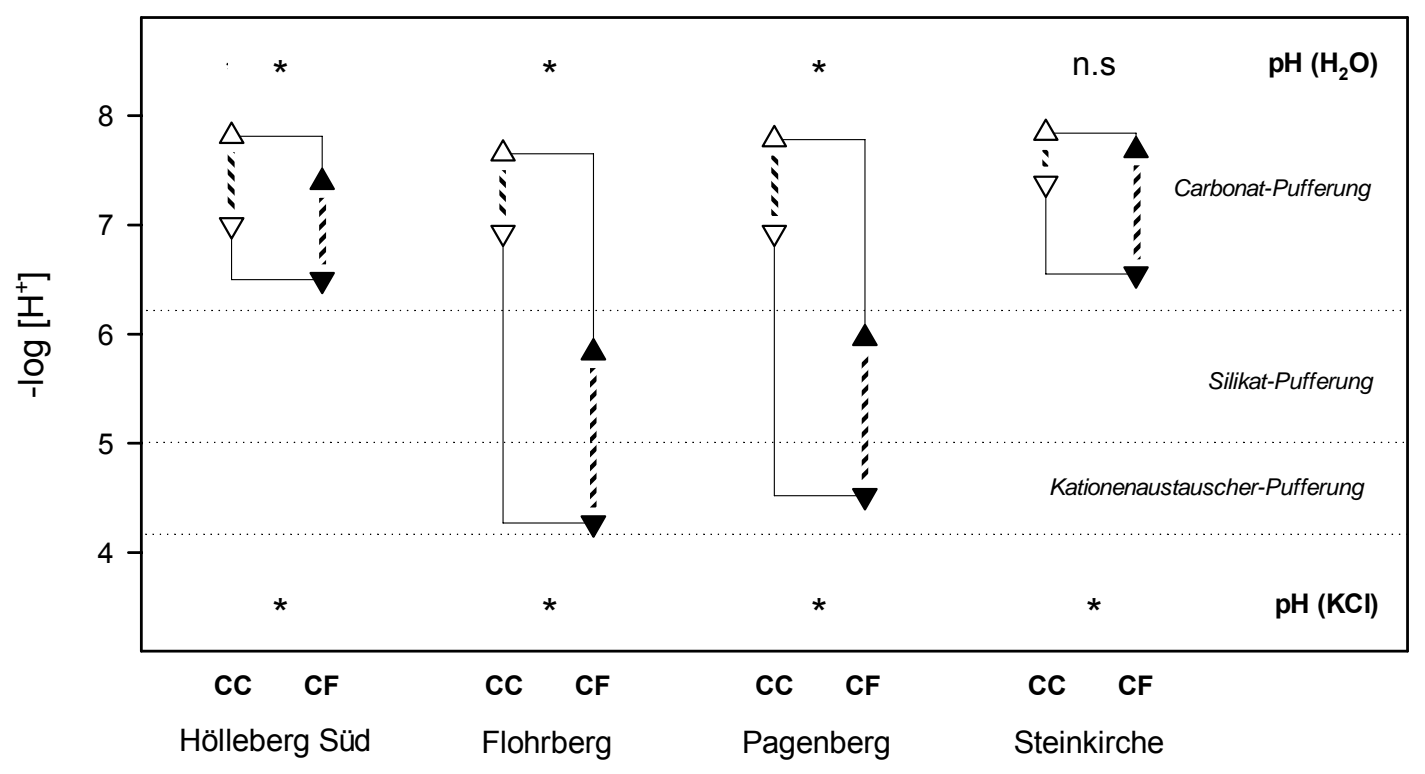

Abbildung 22: $\mathrm{pH}$-Werte von $1: 2,5$ Feinerde/ $\mathrm{H}_{2} \mathrm{O}$-Suspensionen ( ) und Feinerde/KCl-Suspensionen ( ) der CCBestände (offene Symbole) und CF-Bestände (geschlossene Symbole) der Standorte Hölleberg-Süd, Flohrberg, Pagenberg und Steinkirche. Schraffuren geben die Differenz zwischen den Medianen der aktuellen und potenzieller Aciditäten an, Signifikanzindizes beziehen sich auf die Ergebnisse des U-Tests nach Mann-Whitney $(n=4)$. 
tion an den verbleibenden Standorten offensichtlich nicht mehr durch Carbonate, sondern v. a. durch primäre Silikate in einem Bereich unterhalb pH 6,2 gepuffert. Mit Ausnahme des Standorts Hölleberg-Süd sind die Differenzen zwischen $\mathrm{pH}\left(\mathrm{H}_{2} \mathrm{O}\right)$ und $\mathrm{pH}(\mathrm{KCl})$ für die CF-Bestände deutlich höher als für die CCBestände. Dieser stärkere $\mathrm{H}^{+}$-Austausch ist verantwortlich dafür, dass auch an der Steinkirche die potenziellen Aciditäten in Böden des Gentiano-Koelerietum typicum und Gentiano-Koelerietum danthonietosum signifikant voneinander abweichen.

\section{Eisen wässriger Bodenextrakte}

Die Fe-Löslichkeit ist im Wesentlichen eine Funktion des pH und Redoxpotenzials. Im Hinblick auf die primär aus dem Verwitterungsverhalten des geologischen Ausgangsmaterial resultierenden chemo- und physikoedaphischen Faktoren ist die pflanzliche Fe-Verfügbarkeit als ein potenziell limitierender Faktor für das Auftreten von acidophilen und/oder calcifugen Arten auf kalkreichen Standorten anzusehen.

In Abbildung 23 sind die Fe-Löslichkeiten in den CC- und CF-Beständen der Untersuchungsstandorte Auf der Burg und Hölleberg im Jahresverlauf dargestellt, wie sie auf Grundlage der drei verschiedenen wässrigen Bodenextraktionsverfahren für die Feinerde ermittelt wurden. Noch weniger als bei den Bodenaciditäten lässt sich hier ein jahreszeitlicher Trend erkennen. Für die Hälfte der Varianten (mit den Faktoren Bestand und Lösungstyp) sind trotz z. T. erheblicher Abweichungen der Jahresmediane keine signifikanten Unterschiede zwischen den einzelnen Probennahmetermine nachzuweisen - ein Hinweis darauf, dass die Fraktion des $\mathrm{H}_{2} \mathrm{O}$-löslichen Fe nicht nur durch hohe temporäre sondern auch räumliche Variabilitäten gekennzeichnet ist.

Weder für die Bestandsvarianten eines Standorts, noch für die Extraktionsvarianten derselben Vegetationsbestände lassen sich im Jahresgang gleich gerichtete Entwicklungen der Fe-Konzentrationen erkennen. In vielen Fällen unterschritten die Fe-Konzentrationen in Bodenlösungen des Gentiano-Koelerietum typicum die Nachweisgrenze der AAS. Auf den gesamten Untersuchungszeitraum bezogen übersteigen die feinerdebezogenen Fe(GBL)-Konzentrationen der CF-Bestände am Standort Auf der Burg diejenigen der CC-Einheiten um 700\%. Bei der DBL und PBL liegen die betreffenden Werte sogar um das 16fache bzw. 17fache höher. Deutlich geringere Unterschiede zwischen den beiden Subassoziationen des Gentiano-Koelerietum weisen die Daueruntersuchungsflächen des Standorts Hölleberg auf. Anhand der PBL lässt sich hier zu keinem Zeitpunkt ein signifikanter Unterschied zwischen den beiden Vegetationseinheiten nachweisen. Für den Untersuchungsbestand Hölleberg-CF wurden Fe-Analysen der DBL nur an drei Terminen durchgeführt. Wie bei der GBL sind nicht nur für die Mehrzahl dieser Einzeluntersuchungen signifikant höhere Fe-Löslichkeiten im Gentiano-Koelerietum danthonietosum nachweisbar, sondern auch für den betreffenden Jahresmedian. Zusammenfassend lassen die Untersuchungen der Böden aller Vegetationsbestände auf Extraktionseffizienzen in der Reihenfolge GBL > DBL > PBL schließen. Allerdings sind nur die Differenzfaktoren von 2,3 für die GBL/PBL-Beziehung und 1,7 für die DBL/PBLBeziehung statistisch abzusichern. Unterschiede zwischen der GBL und DBL sind in der Regel nicht zu belegen.

Außer denen der GBL, PBL und DBL wurden im Rahmen der vorliegenden Arbeit die Gehalte weiterer Fe-Fraktionen ermittelt. Wie auch die der wässrigen Bodenextrakte wurden diese nicht nur für die beiden Referenzstandorte Auf der Burg und Hölleberg, sondern auch für die Vergleichsstandorte im Unteren Diemeltal und am Südharzrand untersucht. Die Ergebnisse dieser Analysen werden in Abschnitt 3.2.5 (S. 87 ff.) vorgestellt. 

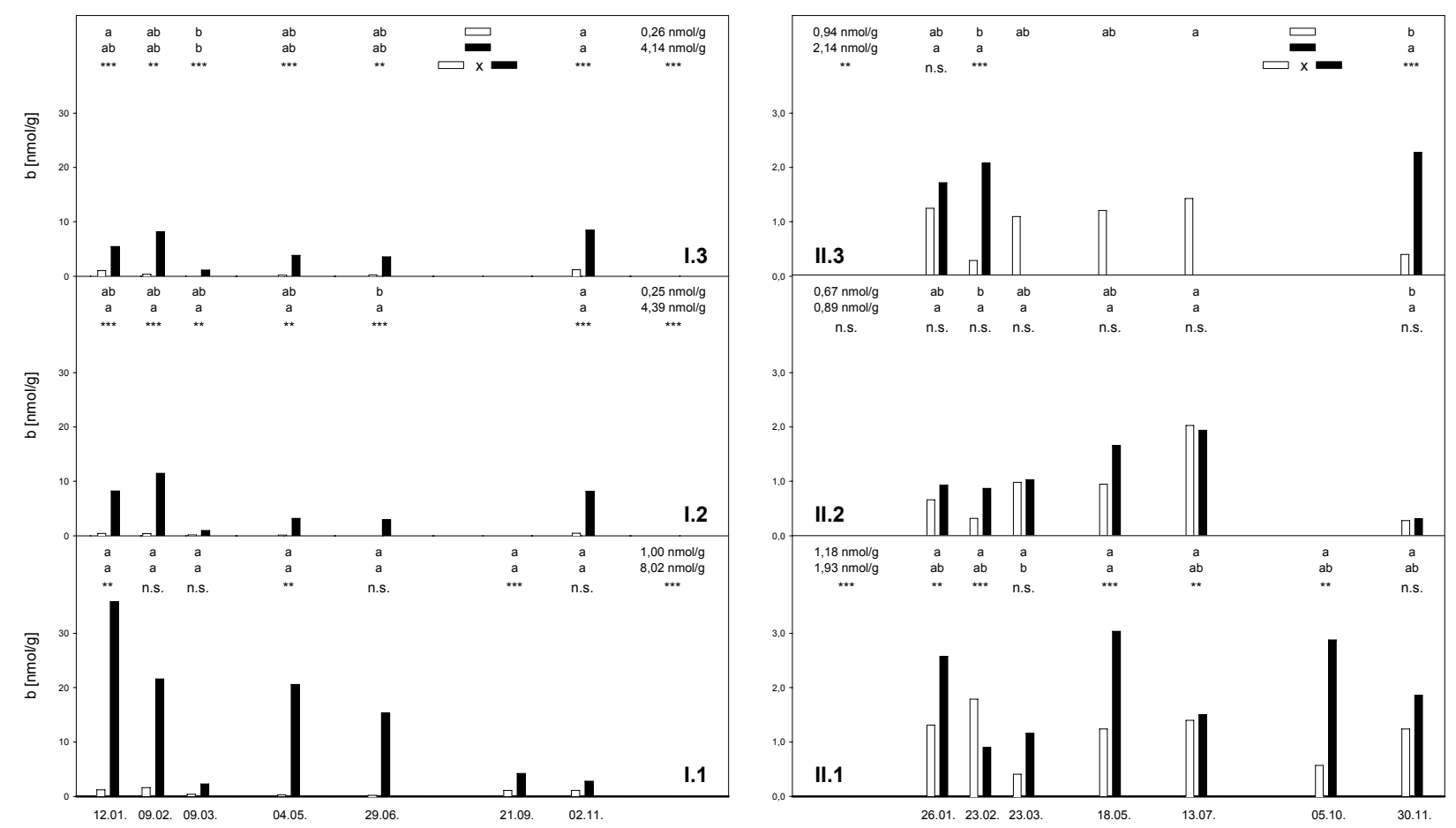

Abbildung 23: Fe-Löslichkeiten der Feinerde [nmol $\left.\cdot \mathrm{g}_{T G}{ }^{-1}\right]$ der CC- und CF-Bestände der Referenzstandorte Auf der Burg (I.) und Hölleberg (II.) im Jahresverlauf 1998 entsprechend den Stoffmengenkonzentrationen der GBL (1), PBL (2) und DBL (3). Für die CF-Bestände des Standorts Hölleberg wurden keine DBL der Probennahmen im Mai, Juli und Oktober analysiert. Die CC- und CF-Jahresmediane wurden allein auf Grundlage von Ergebnissen der verbleibenden Untersuchungstermine berechnet.

\section{Mangan wässriger Bodenextrakte}

Abbildung 24 zeigt die durch Analysen der GBL, PBL und DBL ermittelten Mn-Gehalte der Feinerde. Die Ergebnisse dieser Untersuchungen lassen keine einheitliche zeitliche Entwicklung der Mn-Löslichkeiten erkennen. Minima der ersten und letzten Probennahmetermine, wie sie für alle Lösungsvarianten des Standorts Hölleberg und die DBL-Extraktionen des Standorts Auf der Burg erkennbar sind, finden sich für die verbleibenden Varianten nicht. Die Ergebnisse sind unter dem Vorbehalt sehr niedriger Lösungskonzentrationen zu bewerten. Von allen hier untersuchten Faktoren übertreffen die zeitlichen die räumlichen Variabilitäten beim $\mathrm{Mn}$ am stärksten.

Die Ergebnisse der einzelnen Untersuchungstermine lassen nur für die GBL-bezogenen Mn-Gehalte am Standort Auf der Burg systematische Unterschiede zwischen den CC- und CF-Beständen erkennen. Aus diesen resultieren bei der Betrachtung des gesamten Untersuchungszeitraum um 375\% höhere Mn-Werte in den Aufnahmen des Gentiano-Koelerietum danthonietosum, ein Ergebnis, dass wohl durch die Tendenzen der Jahresmediane für die PBL und DBL, nicht aber durch Vergleiche einzelner Versuchsdurchgänge dieser Extraktionsvarianten bestätigt wird. Sofern hier signifikante Unterschiede vorliegen, verweisen diese auf höhere Mn-Konzentrationen in den CC-Beständen. Die hinsichtlich der Relationen zwischen den Vergleichsbeständen indifferenten Abweichungen der medianen Mn-Gehalte am Standort Hölleberg liegen für alle Extraktionsverfahren bei nicht mehr als $11 \%$ und erreichen in keinem Fall statistische Signifikanz. Bezogen auf alle Vegetationsbestände wird durch die Überdruckextraktion im Vergleich zu den beiden Gleichgewichtsverfahren etwas mehr Mn erfasst. Unterschiede zwischen den GBL und PBL lassen sich hier nicht nachweisen. 

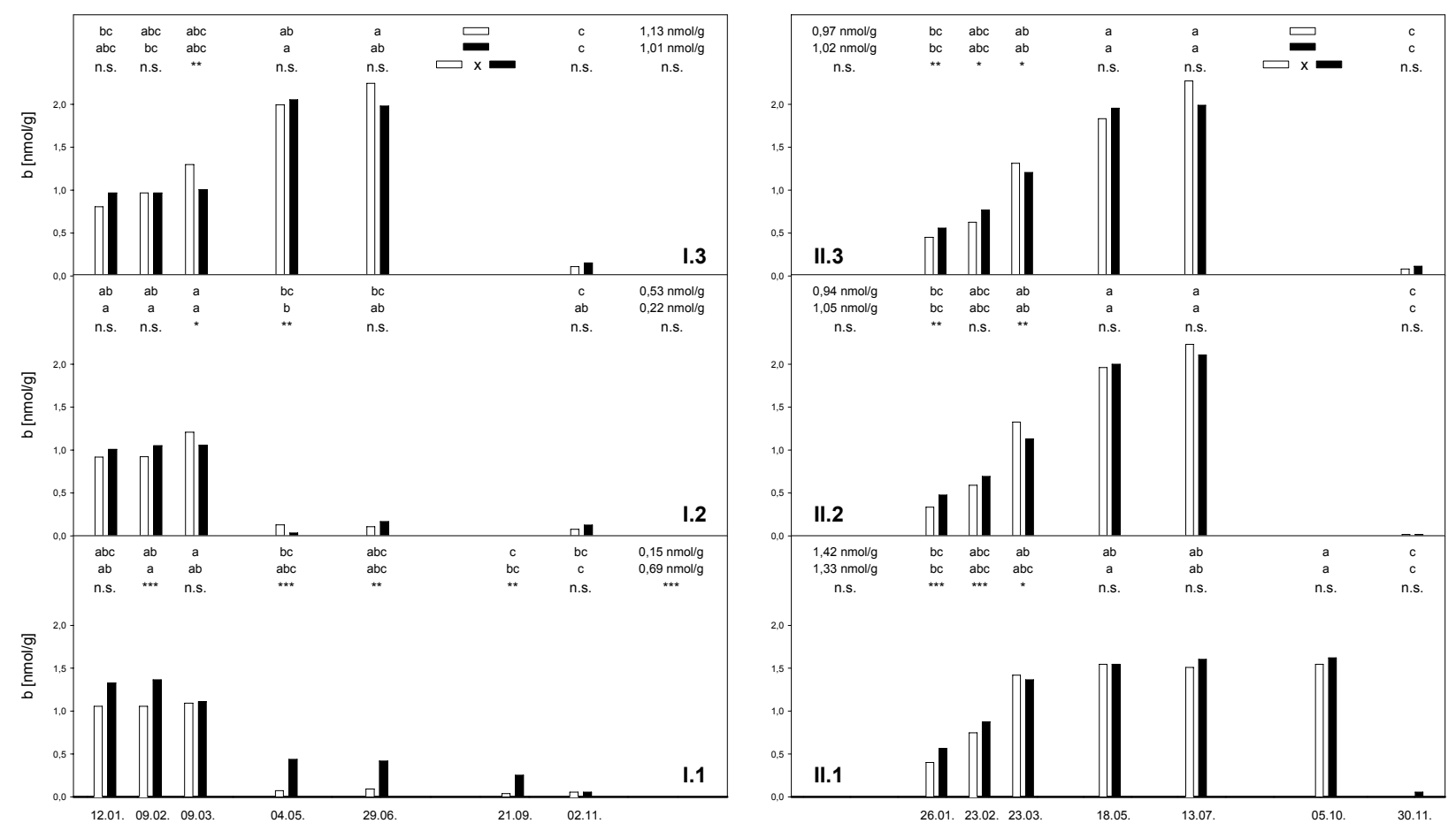

Abbildung 24: Mn-Löslichkeiten der Feinerde $\left[\mathrm{nmol} \cdot \mathrm{g}_{\mathrm{TG}}{ }^{-1}\right]$ der CC- und CF-Bestände der Referenzstandorte Auf der Burg (I.) und Hölleberg (II.) im Jahresverlauf 1998 entsprechend den Stoffmengenkonzentrationen der GBL (1), PBL (2) und DBL (3).

Wie die Löslichkeit des Fe wird auch die des Mn im Boden nicht nur durch den $\mathrm{pH}$ und das Redoxpotenzial, sondern auch durch die Art und den Umfang der mineralischen und organischen Komplexierung bestimmt. Ergebnisse diesbezüglicher Fraktionierungen feldfrischer Feinerdehomogenate sowohl der Referenz- als auch Vergleichsstandorte werden zusammen mit Untersuchungen zur Redoxdynamik in den Böden des Standorts Auf der Burg in Abschnitt 3.2.5 (S. 89 f.) behandelt.

\section{Calcium wässriger Bodenextrakte}

Die feinerdebezogenen Ca-Konzentrationen der GBL, PBL und DBL lassen insbesondere am Standort Auf der Burg nur geringfügige jahreszeitliche Schwankungen erkennen. Lediglich für die GBL und DBL der CC-Bestände können signifikante Unterschiede zwischen Einzelergebnissen der Jahresreihen belegt werden. Demnach treten die niedrigsten Ca-Löslichkeiten im Januar bzw. November auf. Zugleich sind mit Ausnahme des Bestands Auf der Burg-CF die räumlichen Variabilitäten vergleichsweise gering.

Die statistischen Auswertungen der Bodenuntersuchungen des Standorts Auf der Burg belegen für alle Lösungstypen und für fast alle Untersuchungstermine deutlich höhere Ca-Konzentrationen in der typischen Subassoziation. Entsprechendes gilt für die Relationen der PBL- und DBL-Varianten der beiden Vegetationsbestände am Hölleberg. Obwohl hier die $\mathrm{CaCO}_{3}$-Gehalte in der Feinderde des CC-Bestands diejenigen des CF-Bestands um eine Größenordnung übersteigen (vgl. Tabelle 5), lassen sich anhand der GBL keine signifikanten Unterschiede zwischen den Jahresmedianen der beiden Subassoziationen des Gentiano-Koelerietum nachweisen. Bezogen auf alle drei Bodenextrakte liegen die Ca-Löslichkeiten der Feinerde am Standort Auf der Burg für die CC-Bestände mehr als dreifach, am Standort Hölleberg um einen Faktor 1,3 über denen der CF-Variante. Die Untersuchungen belegen gleiche Extraktionseffizienzen des GBL- und PBL-Verfahrens. DBL erreichen lediglich etwa $40 \%$ der Ca-Konzentrationen in den Gleichgewichtsbodenlösungen. 

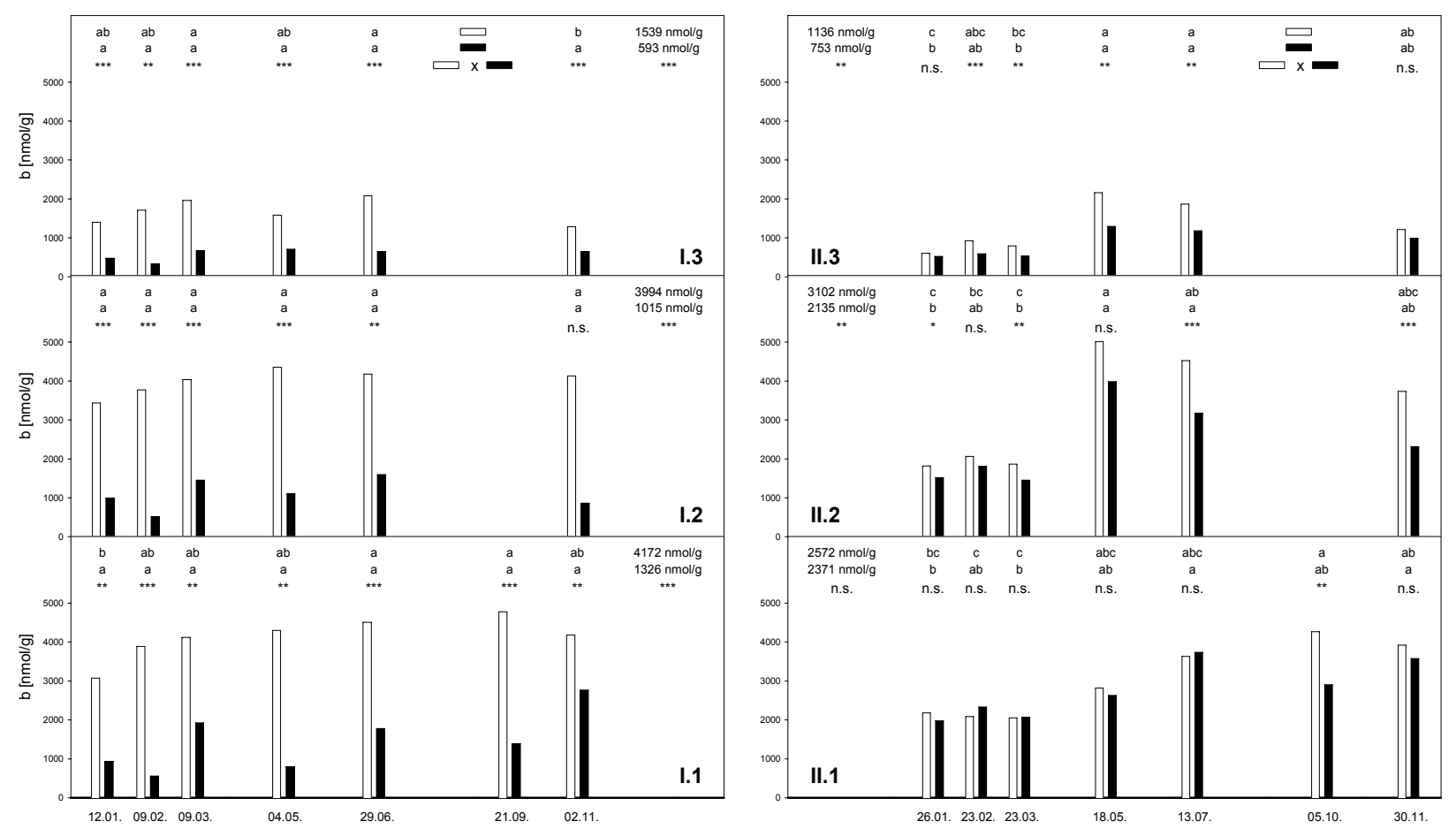

Abbildung 25: Ca-Löslichkeiten der Feinerde $\left[\mathrm{nmol} \cdot \mathrm{g}_{\mathrm{TG}}^{-1}\right.$ ] der CC- und CF-Bestände der Referenzstandorte Auf der Burg (I.) und Hölleberg(II.) im Jahresverlauf 1998 entsprechend den Stoffmengenkonzentrationen der GBL (1), PBL (2) und DBL (3).

Die GBL von drei der vier Vergleichsstandorte bestätigen höhere Ca-Löslichkeiten der Feinerde in den CC-Beständen (Abbildung 26). Nahezu identische Ca-Löslichkeiten im Gentiano-Koelerietum typicum und Gentiano-Koelerietum danthonietosum treten wie am Standort Hölleberg auch am Standort Hölleberg-Süd auf. Selbst wenn die wegen der möglichen Miterfassung von Mg-Carbonaten zweifelhaft hohen $\mathrm{CaCO}_{3}$-Werte der beiden Untersuchungsbestände des Standorts Steinkirche unberücksichtigt bleiben, lässt sich für die Feinerde der verbleibenden Untersuchungsflächen kein signifikanter Bezug zwischen dem $\mathrm{CaCO}_{3}$-Gehalt und der $\mathrm{Ca}^{2+}$-Konzentration in wässrigen Gleichgewichtsextrakten nachweisen. Die

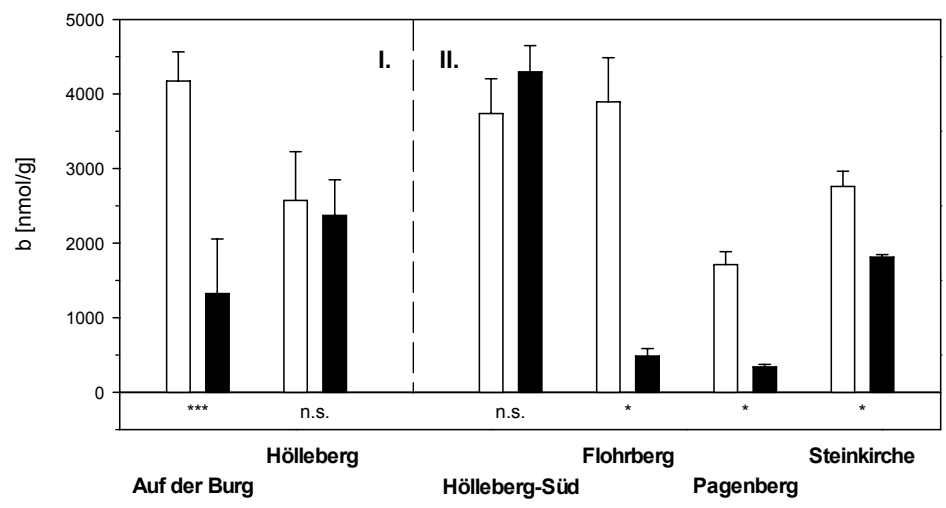

Funktion der betreffenden Korrelationsanalyse $\left(b\left(\mathrm{Ca}^{2+}\right)=63,7 \cdot w\left(\mathrm{CaCO}_{3}\right)+2122\right.$, $\left.\mathrm{r}^{2}=0,18\right)$ weist einen Korrelationskoeffizienten von lediglich 0,422 auf.

Abbildung 26: Ca-Löslichkeiten von CC- und CF-Feinerdehomogenaten (offene, geschlossene Balken); Median \pm MAD [nmol $\left.\cdot g_{T G}{ }^{-1}\right]$.

I. Referenzstandorte $(n=7 \cdot 8)$;

II. Vergleichsstandorte $(n=4)$.

\section{Magnesium wässriger Bodenextrakte}

Die Alkali- und Erdalkaliionen wurden für die ersten drei Probennahmen ionenchromatographisch und im weiteren durch AAS analysiert. Während Testuntersuchungen für Calcium, Kalium und Natrium methodisch bedingte Abweichungen der Messergebnisse von weniger als $10 \%$ belegen, liegen die Messergebnisse der Ionenchromatographie für Mg mehr als $30 \%$ über denen Atomabsorptionsspektrometrie. Diese Irregularitäten können insbesondere bei den DBL als ursächlich für die im Vergleich zu den rein räumlichen 

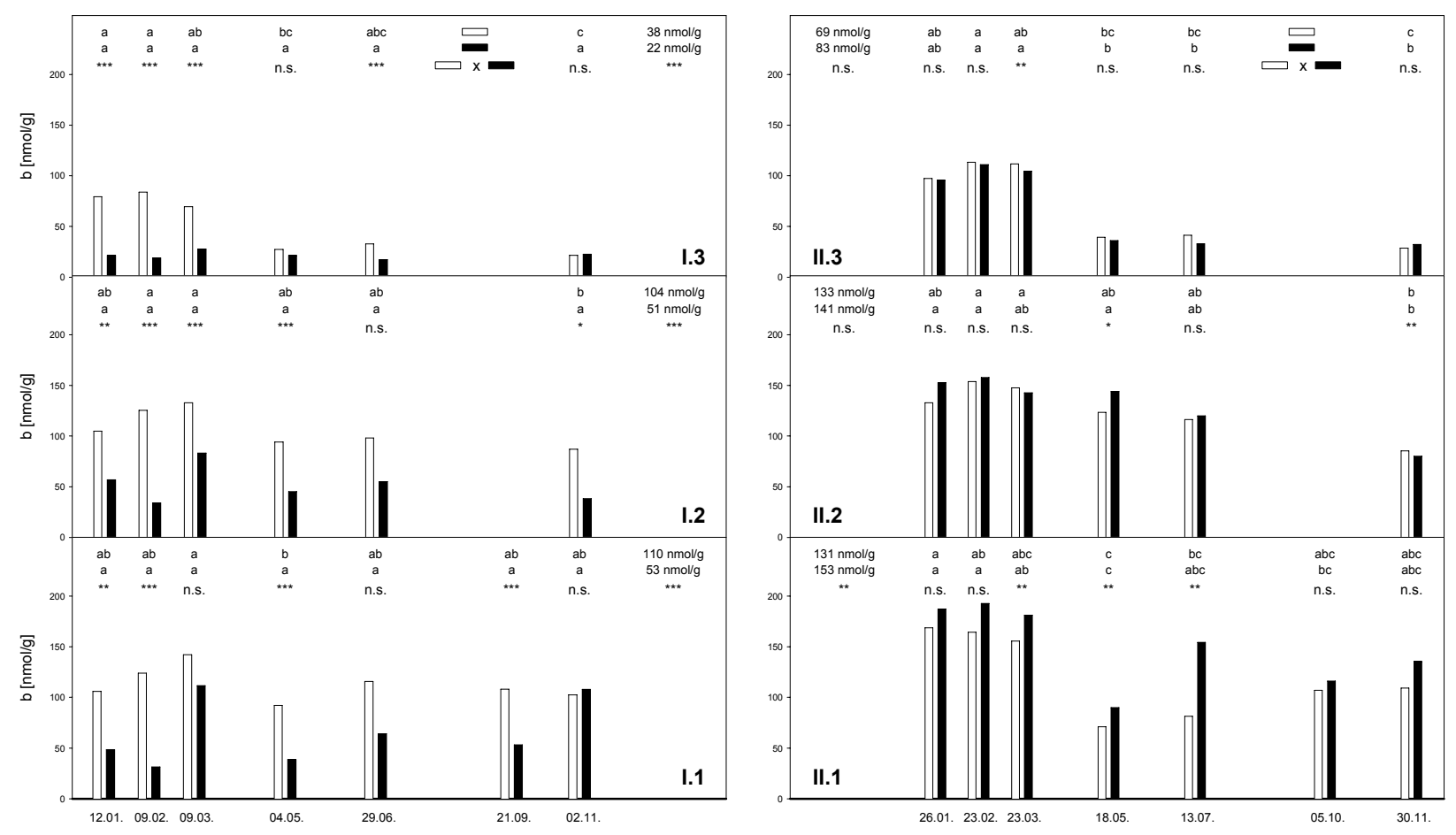

Abbildung 27: Mg-Löslichkeiten der Feinerde $\left[\mathrm{nmol} \cdot \mathrm{g}_{\mathrm{TG}}{ }^{-1}\right.$ ] der CC- und CF-Bestände der Referenzstandorte Auf der Burg (I.) und Hölleberg (II.) im Jahresverlauf 1998 entsprechend den Stoffmengenkonzentrationen der GBL (1), PBL (2) und DBL (3).

Variabilitäten recht hohen zeit-räumlichen Variationskoeffizienten angesehen werden. Eine Bewertung der Entwicklungen der Mg-Konzentrationen, wie sie in Abbildung 27 für den Jahresverlauf dargestellt werden, ist daher nicht möglich. Diese methodischen Unzulänglichkeiten müssen auch beim Vergleich der medianen Jahreswerte der Referenzflächen mit den ionenchromatographischen GBL-Analysen der verbleibenden Untersuchungsbestände berücksichtigt werden.

Die im Vergleich zum Standort Hölleberg signifikant höheren Mg-Werte der Kalk-Halbtrockenrasen des Standorts Hölleberg sind vermutlich auf Unterschiede des geologischen Ausgangsmaterials zurückzuführen. So konnten in einigen Bohrkernen gelbfarbige Kalk- oder Mergelsteine gefunden werden. Lepper (1976b) verweist auf geringere Mächtigkeiten des Unteren Muschelkalks der Beverplatten nordöstlich von Langenthal (vgl. Abbildung 2, S. 11). Hier kommen im Übergangsbereich zwischen dem Röt 4, also der jüngsten Schicht des Buntsandsteins, und den grauen Kalksteinen des Unteren Muschelkalks eigelbe dolomitische Basisgelbkalke vor, die die erhöhten Mg-Gehalte in den Böden des Hölleberg erklären.

Während am Standort Auf der Burg alle Lösungstypen niedrigere Mg-Verfügbarkeiten im GentianoKoelerietum danthonietosum belegen, verweisen die PBL und DBL der Untersuchungsflächen am Standort Hölleberg auf tendenziell und für die GBL auf signifikant höhere feinerdebezogene Mg-Konzentrationen in den CF-Beständen. Die CF/CC-Verhältnisse werden grundsätzlich nur geringfügig durch die Extraktionsvarianten beeinflusst. Im Vergleich zur Überdruckbehandlung für die Herstellung der DBL und ähnlich den Verhältnissen beim Ca erfassen die GBL- und PBL-Verfahren mehr als doppelt so viel Mg aus der Feinerde.

Die GBL von Böden der Untersuchungsstandorte Flohrberg, Pagenberg und Steinkirche bestätigen die Relationen der Mg-Verfügbarkeiten, wie sie am Standort Auf der Burg für die CC- und CF-Bestände des Gentiano-Koelerietum vorgefunden wurden (Abbildung 28). Die im Vergleich zum CF-Bestand um eine Größenordnung höhere Mg-Lösung aus Feinerdehomogenaten der typischen Subassoziation am Standort 
Pagenberg lassen Dolomit als Ausgangsmaterial der Bodenbildung erkennen. Dies gilt auch für die MgKonzentrationen der beiden Kalk-Halbtrockenrasen an der Steinkirche, die mit mehr als $1 \mathrm{mmol} \cdot \mathrm{g}^{-1} \mathrm{um}$ ein Vielfaches über den Durchschnittwerten liegen. Obwohl - wahrscheinlich aufgrund des deutlich geringeren Stichprobenumfangs - die diesbezügliche Signifikanz des Referenzstandorts Hölleberg nicht

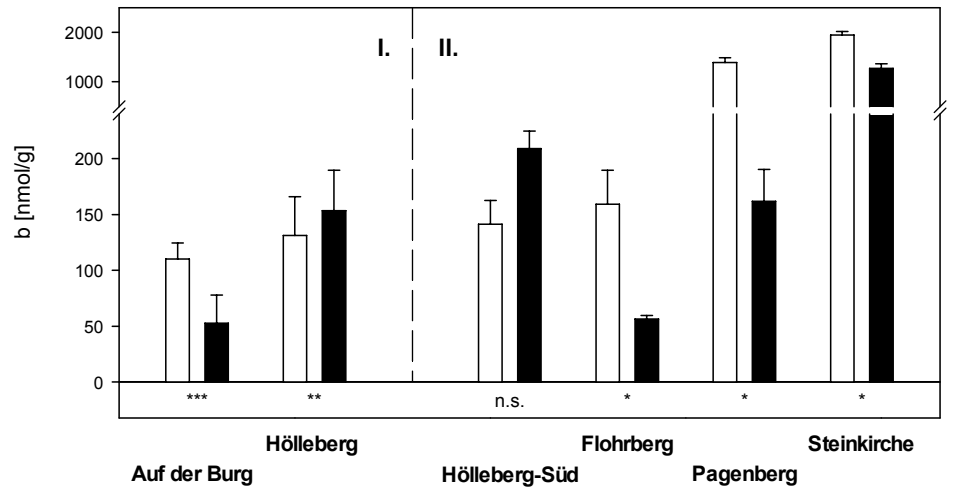
erreicht wird, stützen die Untersuchungen des benachbarten Vegetationsbestands (Hölleberg-Süd) das Ergebnis niedrigerer Mg-Löslichkeiten der Feinerde des Gentiano-Koelerietum typicum.

Abbildung 28: Mg-Löslichkeiten von CC- und CF-Feinerdehomogenaten (offene, geschlossene Balken); Median \pm MAD [nmol $\left.\cdot g_{\mathrm{TG}}{ }^{-1}\right]$.

I. Referenzstandorte $(n=7 \cdot 8)$;

II. Vergleichsstandorte $(n=4)$.

\section{Kalium wässriger Bodenextrakte}

Vergleichsweise hohe laterale Variabilitäten innerhalb der Versuchsflächen bei nur intermediären zeitlichen Abweichungen sind verantwortlich dafür, dass für nur sehr wenige Probennahmetermine signifikante Unterschiede der K-Löslichkeiten belegt werden können (Abbildung 29). Noch weniger als bei anderen Elementen zeigen die Balkendiagramme eine gleich gerichtete Entwicklung feinderdebezogener K-Gehalte der verschiedenen Lösungstypen. Dies ist ein möglicher Hinweis darauf, dass bei $20 \mathrm{~cm}$ Abstand der Bodenbeprobung für die parallele Herstellung von GBL, PBL und DBL ein erheblicher Anteil der Variabilität kleinräumig auftritt.
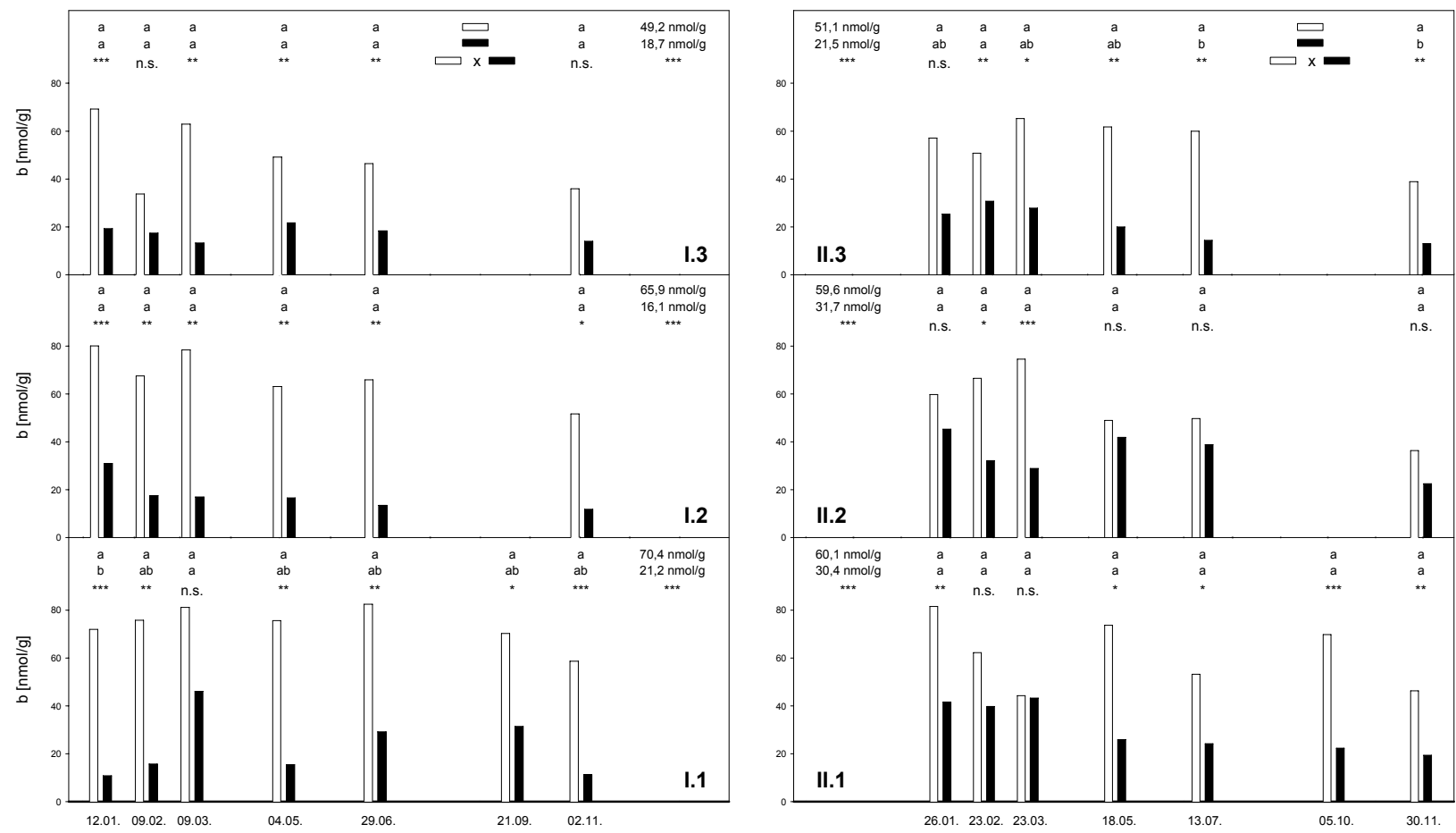

Abbildung 29: K-Löslichkeiten der Feinerde $\left[\mathrm{nmol} \cdot \mathrm{g}_{T G}^{-1}\right.$ ] der CC- und CF-Bestände der Referenzstandorte Auf der Burg (I.) und Hölleberg (II.) im Jahresverlauf 1998 entsprechend den Stoffmengenkonzentrationen der GBL (1), PBL (2) und DBL (3). 
Alle Extraktionsverfahren belegen für die Referenzstandorte bessere pflanzliche K-Verfügbarkeiten in den Beständen des Gentiano-Koelerietum typicum. Bei mittleren Faktoren von 1,3 bzw. 1,2 für die GBL und PBL gegenüber denen der DBL unterschreiten die feinerdebezogenen K-Löslichkeiten in den CFBeständen diejenigen in den CC-Beständen um durchschnittlich etwa 70\% am Standort Auf der Burg bzw. $50 \%$ am Standort Hölleberg.

Die Analysen der K-Löslichkeiten in den verbleibenden Untersuchungsflächen stimmen nicht mit den betreffenden Ergebnissen für die Standorte Auf der Burg und Hölleberg überein (Abbildung 30). Höhere K-Konzentrationen in den GBL der CC-Homogenate sind hier nur für Untersuchungsflächen an der Steinkirche bei Scharzfeld nachzuweisen. Zusammen mit der nahezu identischen Extraktion von $\mathrm{K}$ aus den Feinerdehomogenaten der CC- und CF-Bestände des Standorts Flohrberg sowie den diesbezüglich nur tendenziellen Abweichungen zwischen den Vegetationsbeständen der Standorte Hölleberg-Süd $(\mathrm{CC}<\mathrm{CF})$ und Flohrberg $(\mathrm{CC}>\mathrm{CF})$ ergibt sich insgesamt ein vollkommen indifferentes Bild hinsichtlich der

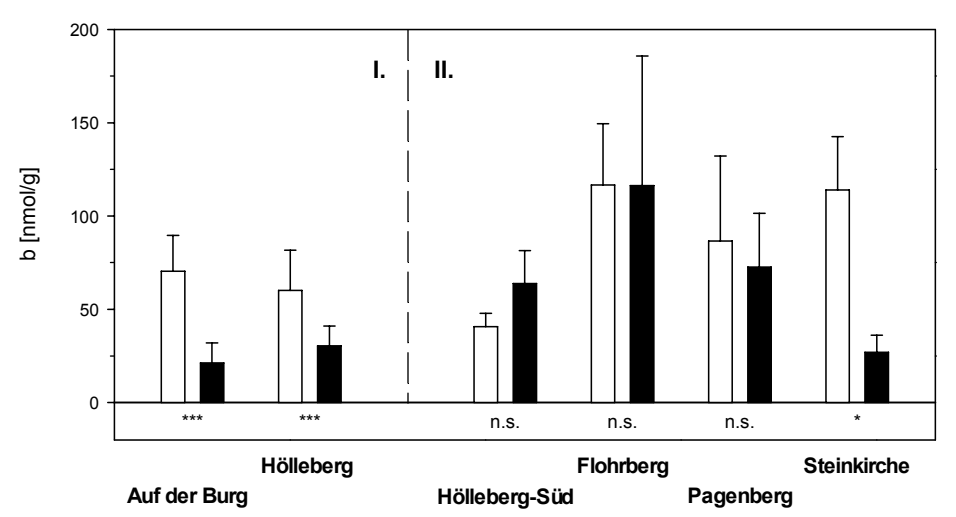
pflanzlichen K-Verfügbarkeiten in den beiden Subassoziationen des GentianoKoelerietum.

Abbildung 30: K-Löslichkeiten von CC- und CF-Feinerdehomogenaten (offene, geschlossene Balken);Median \pm MAD [nmol $\left.\cdot g_{T G}^{-1}\right]$.

I. Referenzstandorte $(n=7 \cdot 8)$;

II. Vergleichsstandorte $(n=4)$.

\section{Natrium wässriger Bodenextrakte}

Als nicht-essentielles Element der Mineralstoffernährung hat Natrium an den meisten Standorten eine nur geringe ökologische und physiologische Bedeutung für die Pflanzen. In salzreichen Lebensräumen indes belasten hohe Na-Aktivitäten, zumeist in Kombination mit Chlorid, durch den Aufbau niedriger osmotischer Potenziale $\left(\Psi_{\pi}\right)$ den pflanzlichen Wasserhaushalt und können überdies eine antagonistische Wirkung bei der Aufnahme essentieller Nährelemente entfalten.

Wie bei den meisten anderen der hier untersuchten Analyte können auch für Na keine Konzenzentrationsentwicklungen nachgewiesen werden, die auf einen bestimmten Jahresgang hinweisen würden (Abbildung 31). Ebenso fehlen eindeutige Bezüge zu übergeordneten Faktoren, wie der Bodenfeuchte. Hinsichtlich der mittleren räumlichen und zeit-räumlichen Variationskoeffizienten nimmt $\mathrm{Na}^{+}$eine intermediäre Stellung ein. Insbesondere die CC-Varianten lassen keine Unterschiede zwischen den Probennahmeterminen erkennen. Bei den verbleibenden Erhebungen sind nur in begrenztem Umfang parallele Entwicklungen für die verschiedenen Lösungstypen eines Untersuchungsbestands zu erkennen. Legt man der statistischen Auswertung die Verhältnisse der Analysenergebnisse für die drei Extraktionsverfahren eines jeden Probennahmepunkts zugrunde, so lassen sich Effizienzen für die Extraktionsverfahren in der Reihenfolge GBL > PBL > DBL mit medianen Verhältnissen von 1,7:1,4:1,0 belegen.

Der Vergleich der medianen Na-Löslichkeiten in den CC- und CF-Beständen der beiden Referenzstandorte ergibt ein uneinheitliches Bild. Während für den Standort Auf der Burg tendenziell oder signifikant höhere Werte in der typischen Subassoziation nachgewiesen wurden, liegen am Standort Hölleberg höhere Na-Konzentrationen in Feinerdelösungen des Gentiano-Koelerietum danthonietosum vor. 

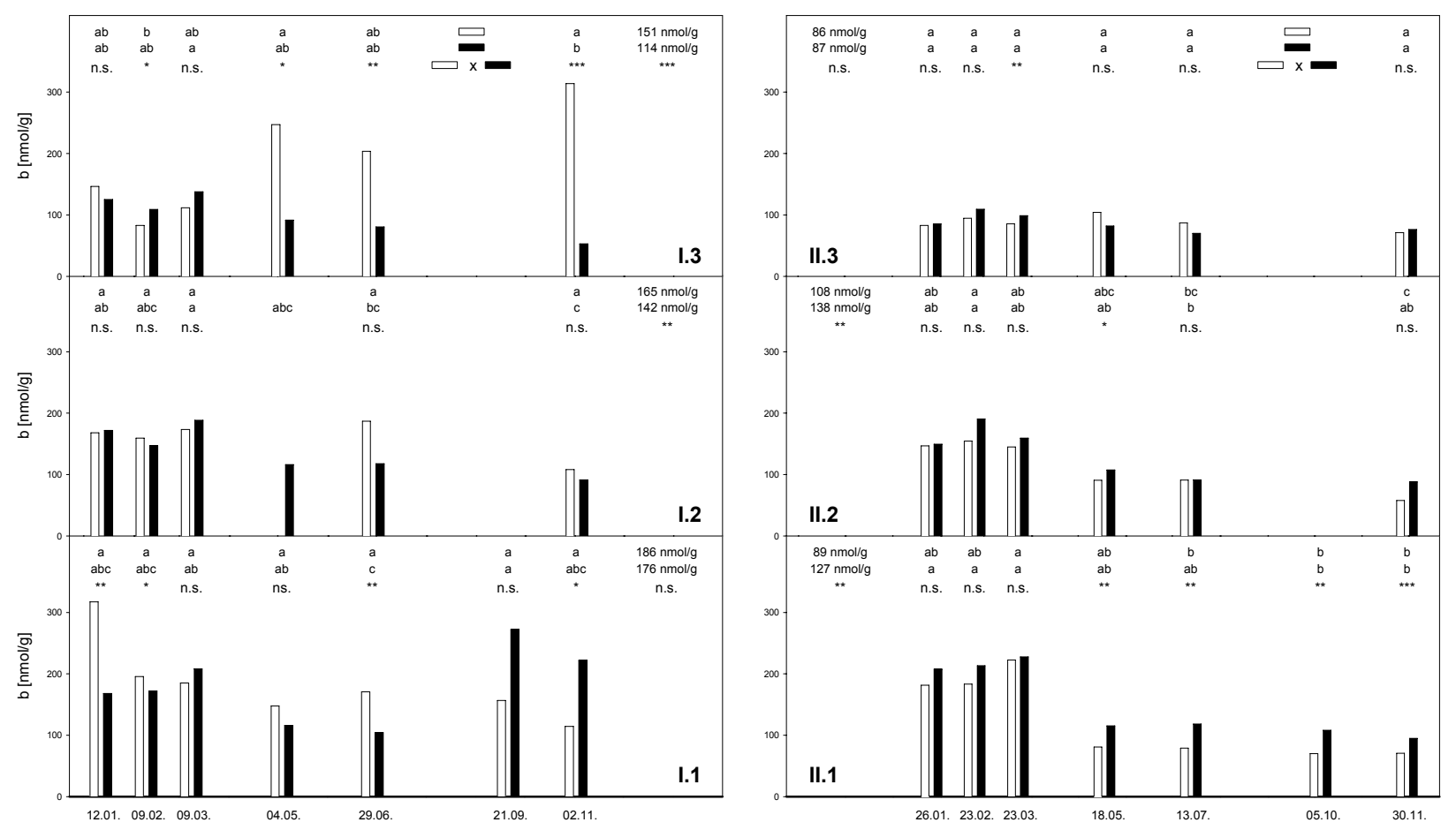

Abbildung 31: Na-Löslichkeiten der Feinerde [nmol $\cdot \mathrm{g}_{\mathrm{TG}}^{-1}$ ] der CC- und CF-Bestände der Referenzstandorte Auf der Burg (I.) und Hölleberg (II.) im Jahresverlauf 1998 entsprechend den Stoffmengenkonzentrationen der GBL (1), PBL (2) und DBL (3).

Das indifferente Bild der Na-Konzentrationen in den CC- und CF-Bestände der Referenzstandorte wird durch die Untersuchungsergebnissen der Vergleichsstandorte bestätigt (Abbildung 32). Bei nur vier parallelen Erhebungen konnten hier zwar in keinem Fall signifikante Unterschiede nachgewiesen werden, doch stimmen tendenziell höhere feinerdebezogene Na-Löslichkeiten im Gentiano-Koelerietum typicum der Standorte Flohrberg, Pagenberg und Steinkirche mit den Ergebnissen für den Standort Auf der Burg

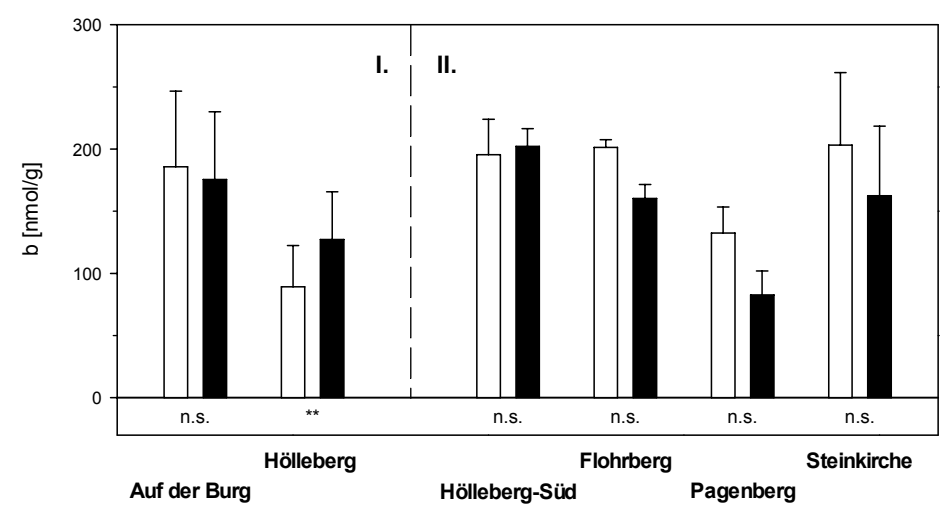
überein, während beide Standorte auf dem Hölleberg höhere Na-Konzentrationen im Wurzelraum der CF-Bestände erwarten lassen.

Abbildung 32: Na-Löslichkeiten von CC- und CF-Feinerdehomogenaten (offene, geschlossene Balken); Median $\pm \mathrm{MAD}\left[\mathrm{nmol} \cdot \mathrm{g}_{\mathrm{TG}}{ }^{-1}\right]$.

I. Referenzstandorte $(n=7 \cdot 8)$;

II. Vergleichsstandorte $(n=4)$.

\section{Ammonium wässriger Bodenextrakte}

Analysen der $\mathrm{NH}_{4}{ }^{+}$-Konzentrationen in wässrigen Bodenextrakten der Standorte Auf der Burg und Hölleberg wurden nur für die ersten drei Probennahmetermine durchgeführt. Wie auch die Box-Whisker-Plots der Abbildung 33 belegen sind die $\mathrm{NH}_{4}{ }^{+}$-Konzentrationen durch erhebliche räumliche und v. a. zeitliche Variabilitäten gekennzeichnet. Die in Abbildung 33 dargestellten höheren $\mathrm{NH}_{4}{ }^{+}$-Gehalte im Januar sind nicht in allen Fällen signifikant. Auch geben die Untersuchungen der wässrigen Extrakte keine Hinweise auf systematische Unterschiede zwischen den CC- und CF-Beständen. 

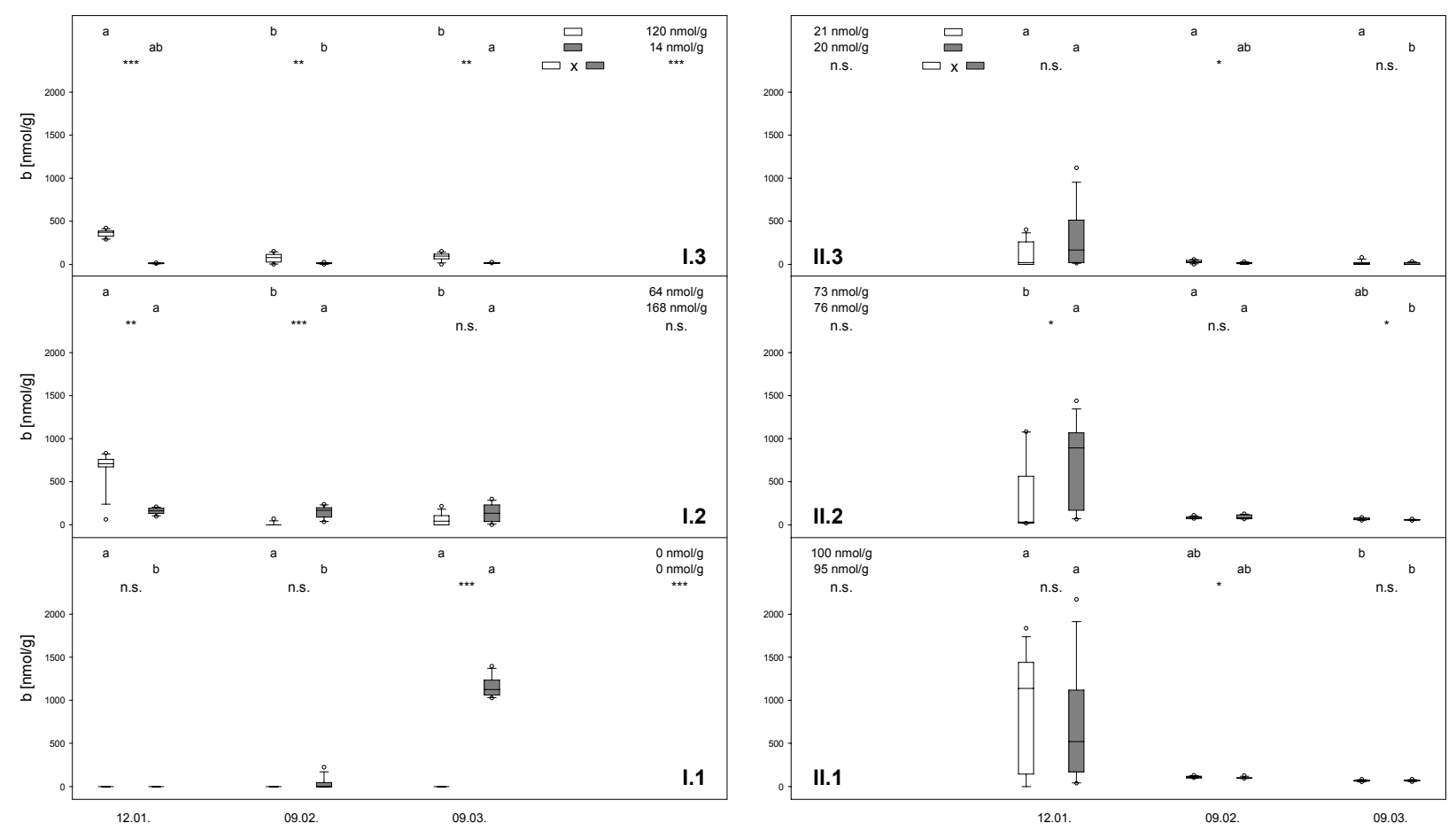

Abbildung 33: Box-Whisker-Plots der $\mathrm{NH}_{4}{ }^{+}$-Löslichkeiten der Feinerde $\left[\mathrm{nmol} \cdot \mathrm{g}_{\mathrm{TG}}{ }^{-1}\right.$ ] der CC- und CF-Bestände der Referenzstandorte Auf der Burg-CC/CF (I.) und Hölleberg-CC/CF (II.) im Januar, Februar und März 1998 entsprechend den Stoffmengenkonzentrationen der GBL (1), PBL (2) und DBL (3).

Trotz identischer Medianwerte von $0 \mathrm{nmol} \cdot \mathrm{g}^{-1} \mathrm{NH}_{4}{ }^{+}$beider Vergleichseinheiten am Standort Auf der Burg belegt die nicht-parametrische Auswertung für die GBL höhere $\mathrm{NH}_{4}{ }^{+}$-Verfügbarkeiten im GentianoKoelerietum danthonietosum. Gestützt wird dieses Ergebnis durch die Untersuchungen der PBL. Hingegen lassen die Analysen der DBL auf bessere $\mathrm{NH}_{4}{ }^{+}$-Verfügbarkeiten in der typischen Subassoziation schließen. Bei nur geringfügig voneinander abweichenden Medianwerten sind am Standort Hölleberg in keinem Fall Unterschiede zwischen den Vegetationseinheiten nachzuweisen. Für die Extraktionseffizienzen gilt $\mathrm{PBL}>\mathrm{GBL}>\mathrm{DBL}$.

Ergebnisse für die Referenzstandorte, nach denen sich die feinerdebezogenen $\mathrm{NH}_{4}{ }^{+}$-Gehalte zwischen den Vegetationsbeständen nicht unterscheiden, werden durch Analysen von Bodenproben der verbleibenden Untersuchungsflächen bestätigt (Abbildung 34). In den GBL der CC- und CF-Bestände des Standorts Pagenberg konnte grundsätzlich kein $\mathrm{NH}_{4}{ }^{+}$nachgewiesen werden. Entsprechendes gilt für solche des Gentiano-Koelerietum danthonietosum an der Steinkirche. Wie für die beiden Vergleichsstandorte im

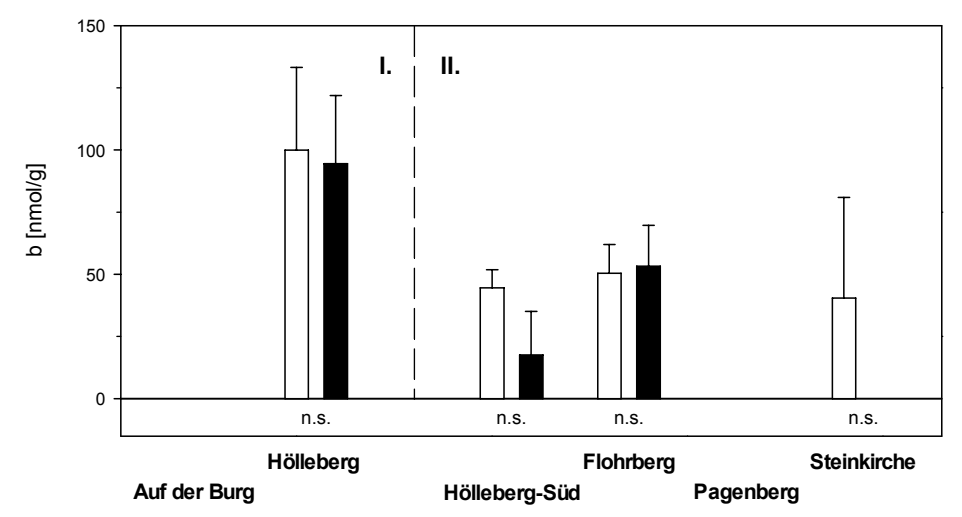

Unteren Diemeltal lagen auch hier keine signifikanten Unterschiede der feinerdebezogenen $\mathrm{NH}_{4}{ }^{+}$-Gehalte in den $\mathrm{CC}$ - und CF-Beständen vor.

Abbildung 34: $\mathrm{NH}_{4}{ }^{+-}$Löslichkeiten von CC- und CF-Feinerdehomogenaten (offene, geschlossene Balken); Median \pm MAD [nmol $\left.\cdot g_{\mathrm{TG}}{ }^{-1}\right]$.

I. Referenzstandorte $(n=7 \cdot 8)$;

II. Vergleichsstandorte $(n=4)$. 


\section{Nitrat wässriger Bodenextrakte}

Die Ergebnisse der $\mathrm{NO}_{3}{ }^{-}$-Untersuchungen sind wie die der $\mathrm{NH}_{4}{ }^{+}$-Analysen durch hohe räumliche und zeitliche Variabilitäten gekennzeichnet. Bezogen auf die $10 \mathrm{~m} \cdot 10 \mathrm{~m}$ großen Untersuchungsflächen der Referenzbestände und die acht Parallelen einer jeden Beprobung liegt für $\mathrm{NO}_{3}{ }^{-}$der mittlere räumliche Variationskoeffizient der Untersuchungsvarianten mit CV > $100 \%$ über dem aller anderen hier untersuchten Mineralstoffe. In einer gleichen Größenordnung bewegen sich die zeitbezogenen Variabilitäten für die sieben (GBL) bzw. sechs (PBL, DBL) Probennahmen in den 2,5 m • 5,0 m großen Untersuchungsflächen.
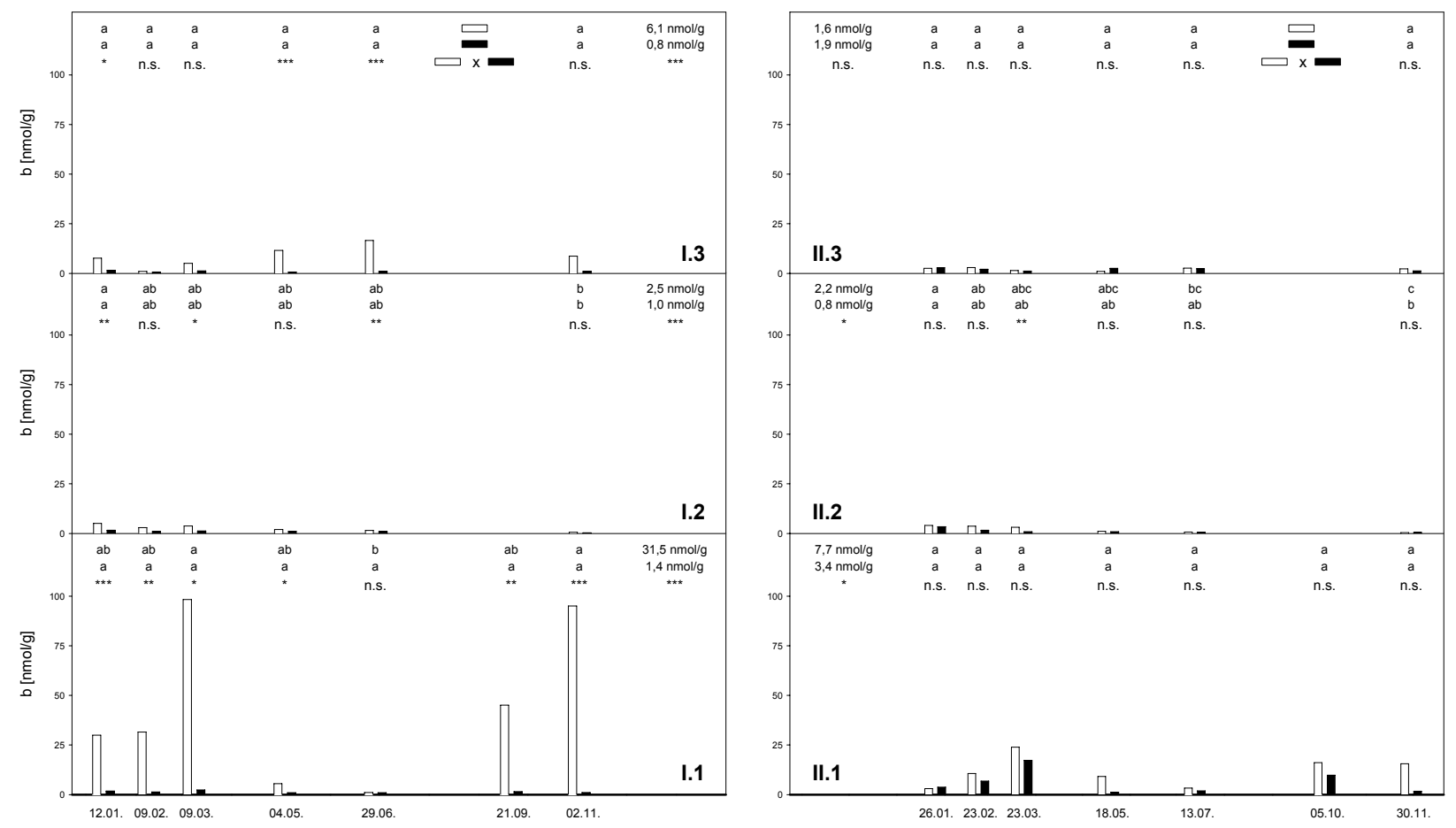

Abbildung 35: $\mathrm{NO}_{3}^{-}$-Löslichkeiten der Feinerde $\left[\mathrm{nmol} \cdot \mathrm{g}_{\mathrm{TG}}^{-1}\right.$ ] der CC- und CF-Bestände der Referenzstandorte Aufder Burg (I.) und Hölleberg (II.) im Jahresverlauf 1998 entsprechend den Stoffmengenkonzentrationen der GBL (1), PBL (2) und DBL (3).

Aufgrund der außergewöhnlich hohen räumlichen Abweichungen erreichen die in der Abbildung 35 für verschiedene Lösungstypen und Bestände angedeuteten Sommerdepressionen der $\mathrm{NO}_{3}{ }^{-}$-Konzentrationen in vielen Fällen die vorgegebene Signifikanzgrenze nicht. Allerdings können für die GBL des Bestands Auf der Burg-CC Unterschiede zwischen den Maxima im März und November sowie den besonders niedrigen Werten Ende Juni auch statistisch abgesichert werden. Die PBL aller Referenzbestände wiesen ein Maximum im Januar und ein Minimum im November aus. Für die verbleibenden Varianten sind keine Unterschiede zwischen den Probennahmeterminen nachzuweisen.

Mit Ausnahme der DBL des Standorts Hölleberg belegen alle anderen Extraktionsvarianten signifikant höhere $\mathrm{NO}_{3}{ }^{-}$-Verfügbarkeiten im Gentiano-Koelerietum typicum. Die CF-Bestände am Standort Auf der Burg erreichen lediglich $4 \%$ (GBL) bzw. $40 \%$ (PBL) der $\mathrm{NO}_{3}{ }^{-}$-Konzentrationen der CC-Einheiten. Weniger als die Hälfte $\mathrm{H}_{2} \mathrm{O}$-extrahierbares $\mathrm{NO}_{3}{ }^{-}$wurden durch Analysen der GBL und $\mathrm{PBL}$ auch für die Feinerde der CF-Bestände des Standorts Hölleberg nachgewiesen.

Die Horizontalschüttelung feldfrischer Feinerdehomogenate bei der Herstellung von GBL führte im Vergleich zu den PBL- und GBL-Verfahren für Bodenmonolithe zu einer etwa doppelt so hohen Extraktion von $\mathrm{NO}_{3}{ }^{-}$pro Gewichtseinheit lufttrockener Feinerde. 
Auf eine verbesserte pflanzliche $\mathrm{NO}_{3}{ }^{-}$-Verfügbarkeit im Gentiano-Koelerietum typicum verweisen auch die GBL der Vergleichsstandorte (Abbildung 36). Insbesondere die CC-Bestände der Standorte Steinkirche und Flohrberg zeigen mit Werten von $425 \mathrm{nmol} \cdot \mathrm{g}^{-1}$ und $265 \mathrm{nmol} \cdot \mathrm{g}^{-1}$ sehr hohe $\mathrm{NO}_{3}{ }^{-}$-Gehalte. Bei einer recht hohen $\mathrm{NO}_{3}^{-}$-Extraktion aus der Feinerde des CF-Bestands, liegt für den Standort Steinkirche mit einem Faktor von etwa 10 eine geringeres CC/CF-Konzentrationsverhältnis vor als für die Standorte Flohrberg (Faktor $\approx 60$ ) und Pagenberg (Faktor $\approx 100$ ). Mit Ausnahme derer des Vergleichsstandorts Hölleberg-Süd kann für alle anderen Untersuchungsflächen ein signifikanter Unterschied der $\mathrm{NO}_{3}^{-}$-Konzentrationen in den beiden Subassoziationen des Gentiano-Koelerietum belegt werden. Auch hier deuten aber

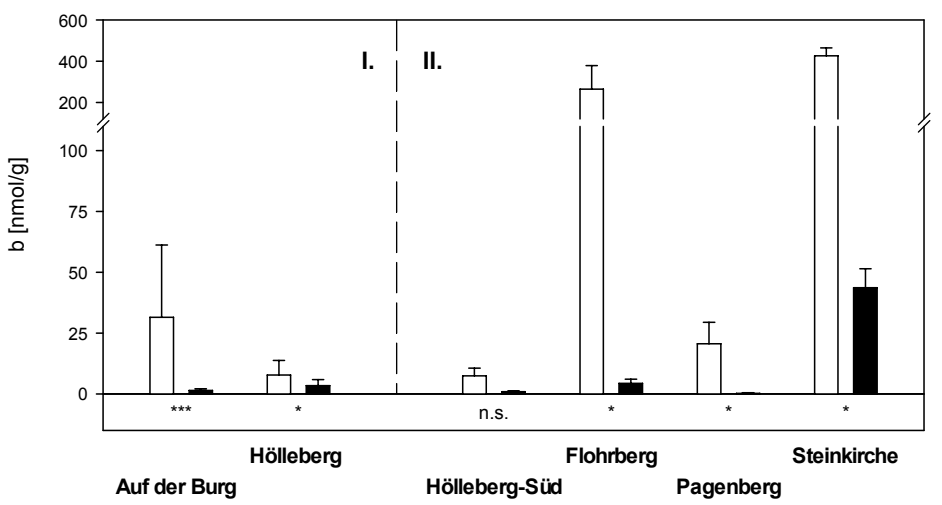
die Medianwerte eine mehr als doppelt so hohe $\mathrm{NO}_{3}{ }^{-}$-Konzentration in der Feinerde des CC-Bestands an.

Abbildung 36: $\mathrm{NO}_{3}^{-}$-Löslichkeiten von $\mathrm{CC}$ - und CF-Feinerdehomogenaten (offene, geschlossene Balken); Median \pm MAD [nmol $\left.\cdot g_{T G}^{-1}\right]$.

I. Referenzstandorte $(n=7 \cdot 8)$;

II. Vergleichsstandorte $(n=4)$.

\section{Nitrit wässriger Bodenextrakte}

Abweichend von der verbreiteten Annahme, dass in den gut durchlüfteten und trockenen Böden von Halbtrockenrasen $\mathrm{NO}_{2}{ }^{-}$als Intermediat der Nitrifikaktion nicht nachweisbar ist, tritt es in allen Lösungstypen und Vegetationsbeständen in nennenswerten Mengen auf.
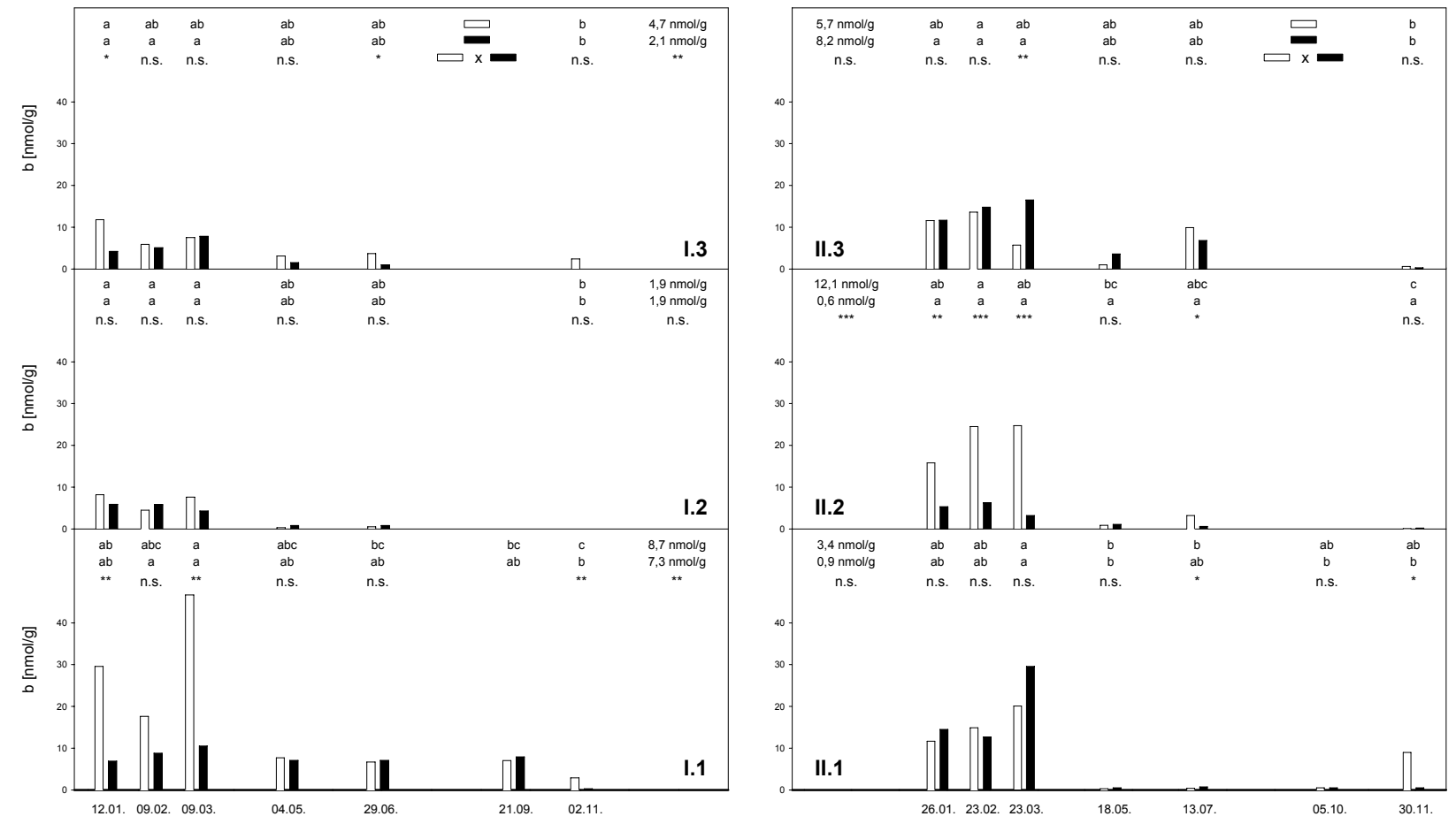

Abbildung 37: $\mathrm{NO}_{2}^{-}$-Löslichkeiten der Feinerde [nmol $\cdot \mathrm{g}_{T G}^{-1}$ ] der CC- und CF-Bestände der Referenzstandorte Aufder Burg (I.) und Hölleberg (II.) im Jahresverlauf 1998 entsprechend den Stoffmengenkonzentrationen der GBL (1), PBL (2) und DBL (3). 
Die $\mathrm{NO}_{2}{ }^{-}$-Lösung aus dem Bodenmaterial ist vom Extraktionsverfahren abhängig (Tabelle 10). Besonders hohe $\mathrm{NO}_{2}^{-}$-Konzentrationen wurden in den ersten drei Monate des Untersuchungsjahrs und hier v. a. im März vorgefunden (Abbildung 37). $\mathrm{NO}_{2}^{-}$weist von allen untersuchten Analyten die höchsten zeitlichen Variabilitäten auf. Werden die Verhältnisse zwischen den Lösungstypen direkt benachbarter Probennahmen zusammengefasst, so ergeben sich Extraktionseffizienzen in der Reihenfolge GBL > DBL > PBL und mediane Differenzfaktoren von 2,3 : 1,7:1. Besonders hohe Abweichungen zwischen den GBL und den beiden anderen Lösungstypen weisen die Untersuchungsbestände des Standorts Auf der Burg auf.

Mit durchschnittlichen feinerdebezogenen $\mathrm{NO}_{2}^{-}$-Konzentrationen von weniger als $0,2 \mathrm{nmol} \cdot \mathrm{g}^{-1} \mathrm{im}$ Sommer 1999 wiesen die GBL der Vergleichsstandorte nicht einmal 5 \% der Jahresmediane (Januar-Dezember 1998) der Referenzflächen auf. Die Gehalte der meisten GBL, darunter aller des Standorts Pagenberg, erreichten die Nachweisgrenze der ionenchromatographischen $\mathrm{NO}_{2}{ }^{-}$-Analytik nicht. Zudem entsprechen die signifikant (Auf der Burg) oder tendenziell (Hölleberg) höheren $\mathrm{H}_{2} \mathrm{O}$-extrahierbaren $\mathrm{NO}_{2}{ }^{-}$-Gehalte, wie sie für die CC-Bestände der Referenzstandorte nachgewiesen wurden, nicht den Verhältnissen der verbleibenden Versuchsstandorte (Abbildung 38). In keinem Fall treten für letztere signifikante Unterschiede zwischen den beiden Vegetationseinheiten des Gentiano-Koelerietum auf. Tendenziell übersteig-

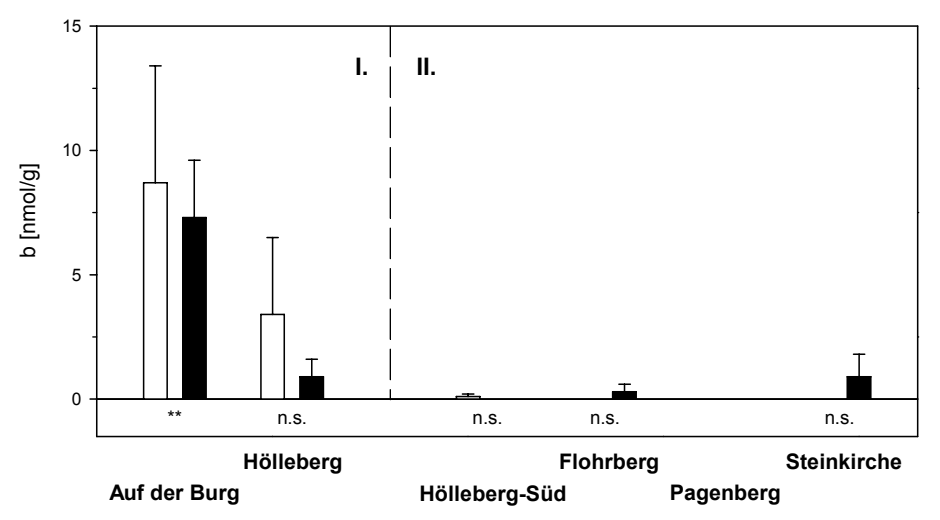
en die $\mathrm{NO}_{2}^{-}$-Gehalte in den CF-Beständen auf dem Flohrberg und an der Steinkirche diejenigen der typischen Subassoziation.

Abbildung 38: $\mathrm{NO}_{2}^{-}$-Löslichkeiten von $\mathrm{CC}$ - und CF-Feinerdehomogenaten (offene, geschlossene Balken); Median \pm MAD $\left[\mathrm{nmol} \cdot \mathrm{g}_{\mathrm{TG}}{ }^{-1}\right]$.

I. Referenzstandorte $(n=7 \cdot 8)$;

II. Vergleichsstandorte $(n=4)$.

\section{Sulfat wässriger Bodenextrakte}

Die Ergebnisse der $\mathrm{SO}_{4}{ }^{2-}$-Analysen weisen mit mittleren Variationskoeffizienten von $24 \%$ und $28 \%$ die geringsten räumlichen und raum-zeitlichen Abweichungen auf. Insbesondere die $\mathrm{SO}_{4}{ }^{2-}$-Verfügbarkeiten in den CF-Bestände der beiden Daueruntersuchungsstandorte waren sehr ausgeglichen. Unterschiede der feinerdebezogenen $\mathrm{SO}_{4}{ }^{2-}$-Gehalte verschiedener Probennahmentermine im Jahresverlauf sind nur für die beiden CC-Bestände nachzuweisen, im Fall des Standorts Auf der Burg für die DBL, am Standort Hölleberg für alle Lösungstypen. Kennzeichnend ist, dass trotz Bezug auf die Feinerdefraktion und standardisierten Verhältnissen von Boden zu Extraktionsvolumen bei niedrigen Bodenwassergehalten Ende Juni (Auf der Burg) bzw. Mitte Mai (Hölleberg) insbesondere für die DBL hohe $\mathrm{SO}_{4}{ }^{2-}$-Gehalte vorlagen. Berücksichtigt man die in Tabelle 7 (S. 52) aufgeführten Proportionalitätsfaktoren, so wird der Bezug zwischen Bodenfeuchte und $\mathrm{SO}_{4}{ }^{2-}$-Konzentration in der aktuellen Bodenlösung noch verdeutlicht.

Unterschiede zwischen der Extraktionseffizienz der PBL- und DBL-Verfahren existieren nur für die beiden CC-Flächen. Werden die Analysenergebnisse aller Bestände und Probennahmen zusammengefasst, so entsprechen die Ergebnisse denen der CF-Bestände mit der Reihenfolge GBL > PBL > DBL und Relationen von $2,3: 1,3: 1,0$. 

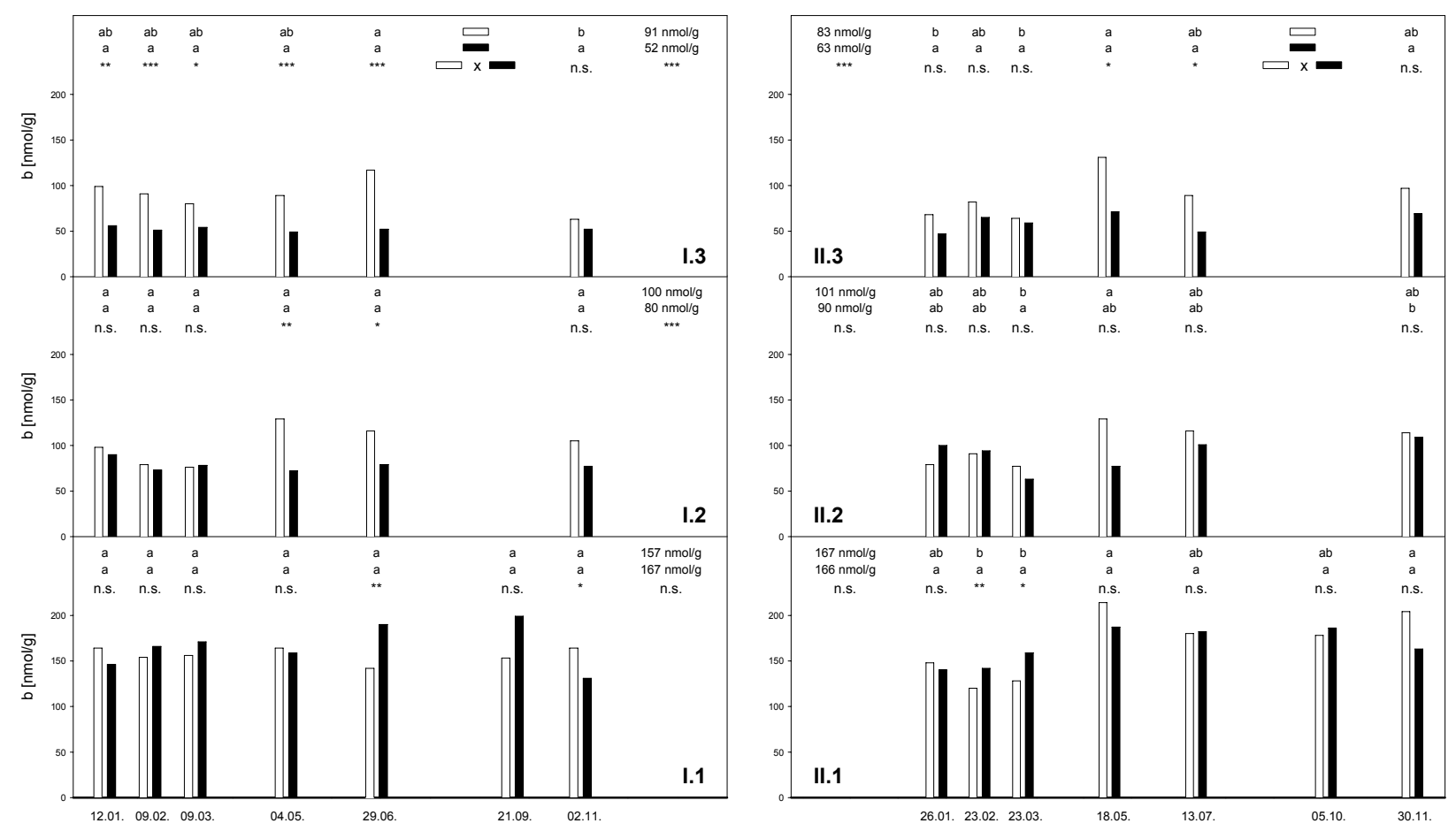

Abbildung 39: $\mathrm{SO}_{4}{ }^{2-}$-Löslichkeiten der Feinerde $\left[\mathrm{nmol} \cdot \mathrm{g}_{\mathrm{TG}}{ }^{-1}\right.$ ] der CC- und CF-Bestände der Referenzstandorte Auf der Burg (I.) und Hölleberg (II.) im Jahresverlauf 1998 entsprechend den Stoffmengenkonzentrationen der $G B L$ (1), $P B L$ (2) und $D B L$ (3).

Die Jahresmediane lassen Unterschiede zwischen den beiden Subassoziationen des Gentiano-Koelerietum v. a. für die DBL-bezogenen $\mathrm{SO}_{4}{ }^{2-}$-Gehalte erkennen. Wie die PBL-Extraktionen von Bodenmonolithen der beiden Bestände des Standorts Auf der Burg verweisen diese auf eine bessere $\mathrm{SO}_{4}{ }^{2-}$-Verfügbarkeit in den CC-Beständen. Konsistent ist diese Aussage nur für Feinerde- und Lösungsbezüge. Durch Bezug auf die Bodenvolumina werden diese Unterschiede ausgeglichen. Wie die GBL-Analysen für die Standorte Auf der Burg und Hölleberg geben auch die für die verbleibenden Untersuchungsflächen keine Hinweise

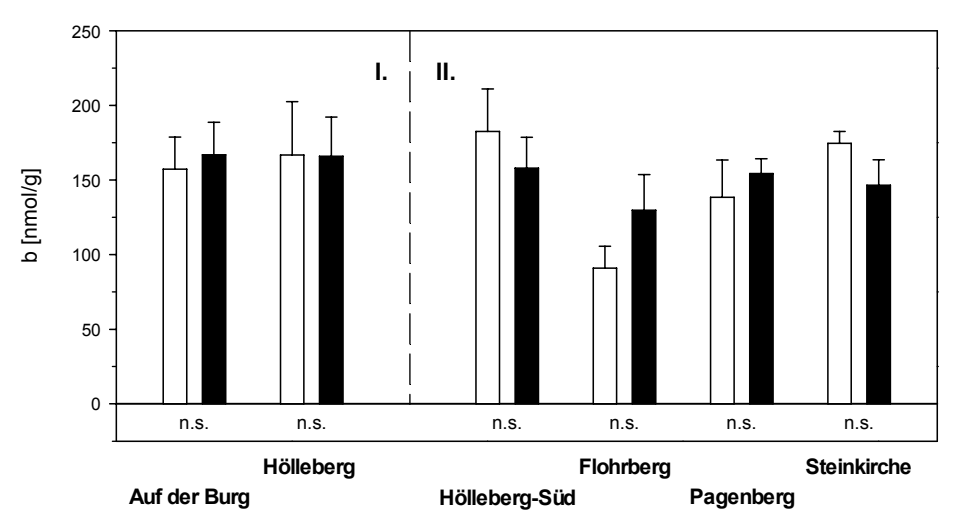
auf unterschiedliche $\mathrm{SO}_{4}{ }^{2-}$-Verfügbarkeiten in den beiden Vegetationseinheiten (Abbildung 40).

Abbildung 40: $\mathrm{SO}_{4}{ }^{2-}$-Löslichkeiten von CC- und CF-Feinerdehomogenaten (offene, geschlossene Balken); Median \pm MAD $\left[\mathrm{nmol} \cdot g_{\mathrm{TG}}{ }^{-1}\right]$.

I. Referenzstandorte $(n=7 \cdot 8)$;

II. Vergleichsstandorte $(n=4)$.

\section{Chlorid wässriger Bodenextrakte}

Wie Natrium spielt Chlorid in der Regel nur an meso- und euhalinen Standorten eine vegetationsdifferenzierende Rolle. Manche Halopyten nutzen $\mathrm{Cl}^{-}$als vakuoläres Osmotikum für die Regulation des zellulären Wasserhaushalts. Im Hinblick auf die umfassende Darstellung des Bodenchemismus der untersuchten Vegetationsbestände und die Wirksamkeit der verschiedenen Extraktionsverfahren sollen hier dennoch kurz die Ergebnisse der $\mathrm{Cl}^{-}$-Analysen für die hier behandelten Kalk-Halbtrockenrasen dargestellt werden. 

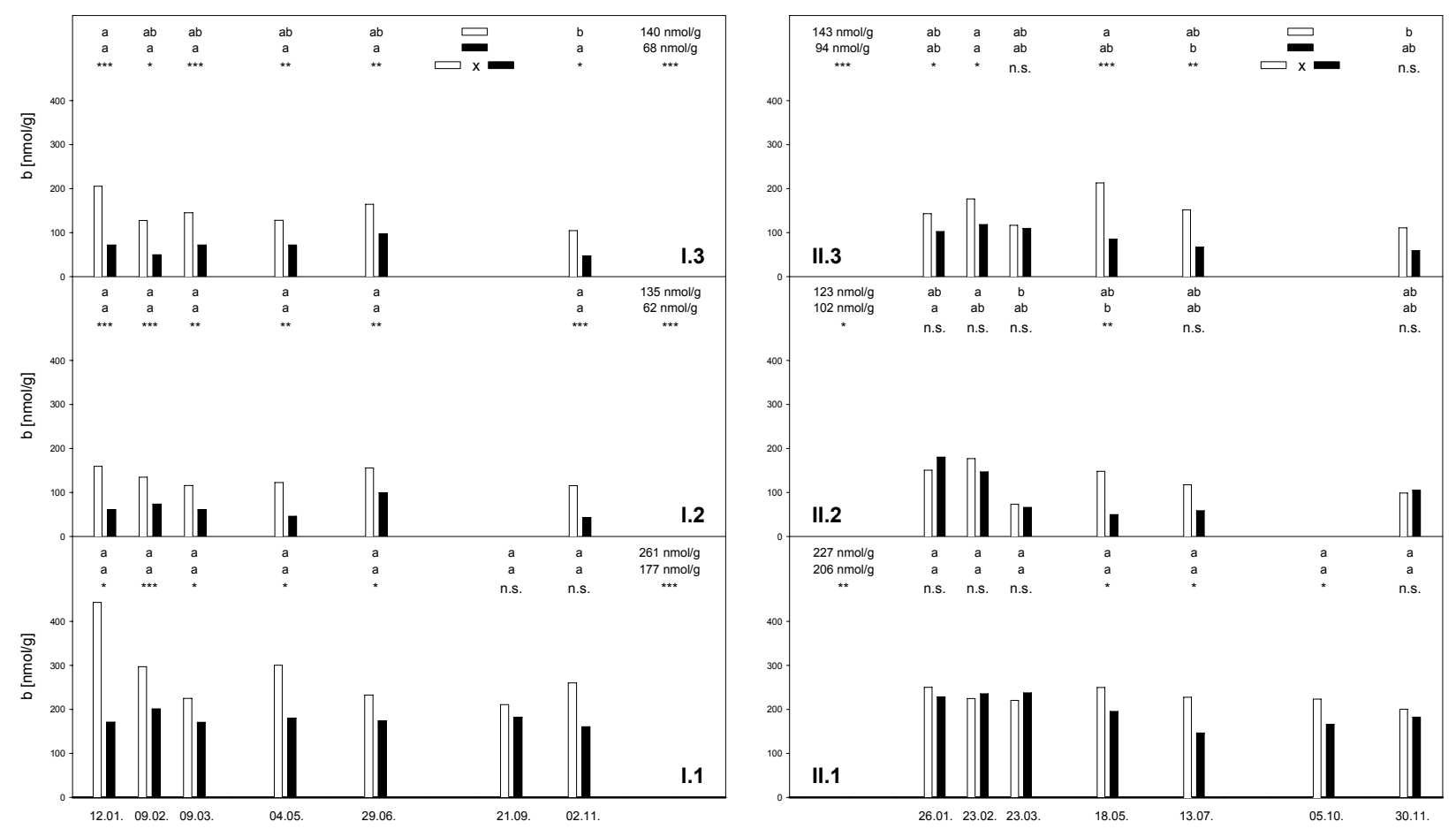

Abbildung 41: $\mathrm{Cl}^{-}$-Löslichkeiten der Feinerde $\left[\mathrm{nmol} \cdot \mathrm{g}_{\mathrm{TG}}{ }^{-1}\right.$ ] der CC- und CF-Bestände der Referenzstandorte Auf der Burg (I.) und Hölleberg (II.) im Jahresverlauf 1998 entsprechend den Stoffmengenkonzentrationen der $G B L$ (1), $P B L$ (2) und $D B L$ (3).

Die Variationskoeffizienten der feinerdebezogenen $\mathrm{Cl}^{-}$-Konzentrationen lassen für alle Lösungstypen intermediäre räumlich und nur vergleichsweise geringe zeitlich bedingte Variabilitäten erkennen. Für die jahreszeitlichen Entwicklungen der $\mathrm{Cl}^{-}$-Löslichkeiten in den verschiedenen Vegetationsbeständen und die verschiedenen Extraktionsverfahren kann kein einheitliches Bild gezeichnet werden (Abbildung 41). Signifikante Fluktuationen der feinerdebezogenen $\mathrm{Cl}^{-}$-Konzentrationen sind nur für die PBL- und DBLExtraktionen des Standorts Hölleberg und die DBL des Bestands Auf der Burg-CC nachzuweisen. Die auf Grundlage des GBL-Verfahrens ermittelten $\mathrm{Cl}^{-}$-Gehalte der Feinerde übersteigen die der PBL- und DBLExtraktionen im Durchschnitt um etwa 100 \%. Die Jahresmediane der Cl-Löslichkeiten aller CF-Varianten liegen in den Daueruntersuchungsflächen signifikant unter denen der CC-Bestände, am Standort Auf der Burg im Schnitt um etwa 50\%, am Standort Hölleberg um $20 \%$. Betrachtet man unter Verwendung der in Tabelle 7 (S. 52) aufgeführten Umrechnungsfaktoren die auf das Bodenvolumen bezogenen Teilchenmengen, so werden diese Relationen ausgeglichen.

Die höheren $\mathrm{Cl}^{-}$-Löslichkeiten der Feinerde in den Beständen des Gentiano-Koelerietum typicum der Referenzstandorten können zwar für die Vergleichsstandorte nicht statistisch abgesichert werden, doch

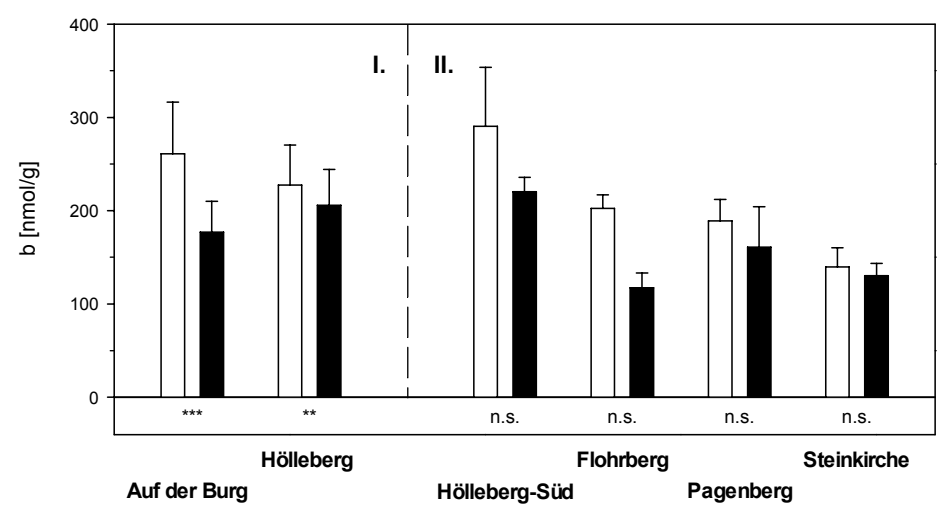

führten diese Untersuchungen in der Tendenz zu entsprechenden Resultaten.

Abbildung 42: $\mathrm{Cl}^{-}$-Löslichkeiten von CC- und CF-Feinerdehomogenaten (offene, geschlossene Balken); Median $\pm \mathrm{MAD}\left[\mathrm{nmol} \cdot \mathrm{g}_{\mathrm{TG}}^{-1}\right]$.

I. Referenzstandorte $(n=7 \cdot 8)$;

II. Vergleichsstandorte $(n=4)$. 


\section{Elektrische Leitfähigkeit wässriger Bodenextrakte}

Die elektrische Leitfähigkeit (EC) von Lösungen ist ein integratives Maß für deren Elektrolytaktivitäten. Abbildung 43 zeigt die feinderdebezogenen EC in Abhängigkeit vom Beprobungstermin, Lösungstyp und Untersuchungsbestand.

Mit Ausnahme der drei Lösungsvarianten des Bestands Auf der Burg-CF weisen die elektrischen Leitfähigkeiten vergleichsweise geringe räumliche und zeitliche Variabilitäten auf. Korrelationsanalysen der feinderdebezogenen EC und Wassergehalte $\left(\Theta_{\mathrm{m}}\right)$ geben nur für die DBL-Variante Hölleberg-CC und die PBL-Variante Hölleberg-CF Hinweise auf eine Aufkonzentrierung der Bodenlösung in Trockenphasen (vgl. Abbildung A 2, S. 312). Zusammenfassende Auswertungen aller Analysen eines Lösungstyps lassen indes auf eine positive Korrelation der EC der GBL und der $\Theta_{\mathrm{m}}$ der Feinerde schließen. Die beiden anderen Extraktionverfahren geben keine Hinweise auf eine signifikante Beziehung dieser beiden Faktoren zueinander.

Mit Ausnahme der GBL des Standorts Hölleberg lassen die EC aller anderen Bodenextrakte auf höhere feinerdebezogene Ionenaktivitäten in den CC-Bestände schließen. Je nach Extraktionsverfahren liegen die Werte für das Gentiano-Koelerietum typicum des Standorts Auf der Burg zwischen 60 \% (DBL) und $70 \%$ (GBL) über denen der Böden der Subassoziation von D. decumbens. Demgegenüber betragen die Unterschiede der Vergleichsbestände des Standorts Hölleberg im Schnitt nur ca. 15\%. Die Verfahren der GBL- und PBL-Herstellung zeigen eine vergleichbare Extraktionseffizienz. Die feinerdebezogenen EC dieser beiden Lösungstypen lagen um 150 \% über denen der DBL.
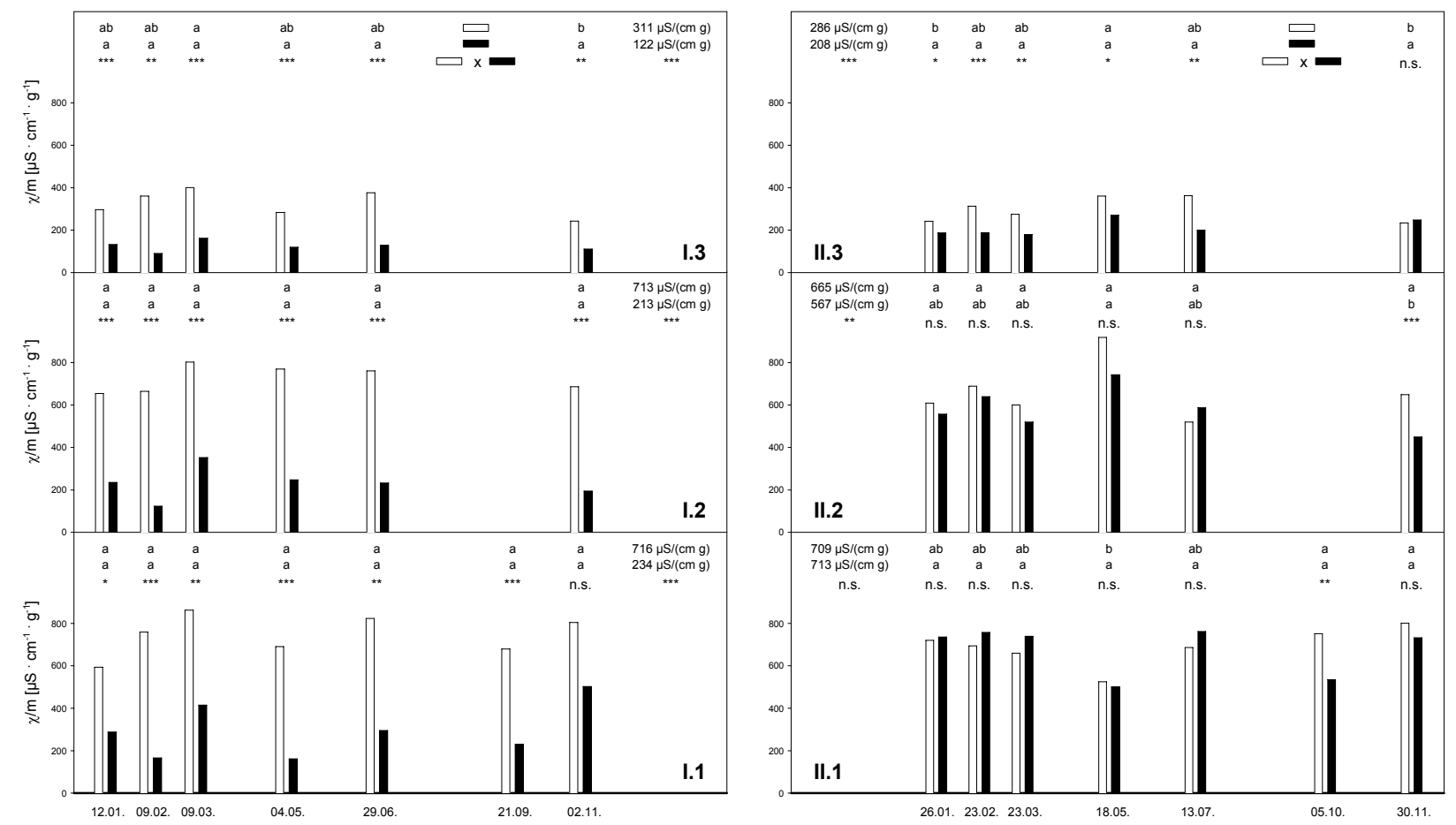

Abbildung 43: Feinerdebezogene elektrische Leitfähigkeiten $\left[\mu \mathrm{S} \cdot \mathrm{cm}^{-1} \cdot \mathrm{g}_{\mathrm{FE} \text {-TG }}^{-1}\right.$ der CC- und CF-Bestände der Referenzstandorte Auf der Burg-CC/CF (I.) und Hölleberg-CC/CF (II.) im Jahresverlauf 1998 entsprechend den Messungen von $G B L$ (1), $P B L$ (2) und $D B L$ (3). 


\section{Zusammenfassung der vergleichenden Mineralstoffanalysen wässriger Bodenextrakte}

Tabelle 9 fasst noch einmal die Ergebnisse aller vergleichenden GBL-, PBL- und DBL-Untersuchungen zusammen. Den hier dargestellten Auswertungen liegen die Konzentrationen der Extraktionslösungen selber und nicht die auf die Feinerdemasse bezogenen Konzentrationen zugrunde.

In Spalte I. sind die Äquivalenzkonzentrationen $\sum \mathrm{c}_{\mathrm{c}}$ aller analysierten Anionen und Kationen aufgeführt. Die GBL und PBL weisen vergleichbare $\sum \mathrm{c}_{\mathrm{c}}$ auf. Demgegenüber erreichen die $\sum \mathrm{c}_{\mathrm{c}}$ der DBL nur etwa die Hälfte der betreffenden GBL- und PBL-Elektrolytkonzentrationen. Unterschiede zwischen den Vergleichsbeständen eines Standorts folgen den Konzentrationsverhältnissen für Calcium (vgl. Tabelle 11). Wie die $\mathrm{Ca}^{2+}$-Konzentrationen liegen in den meisten Fällen auch die $\Sigma \mathrm{c}_{\mathrm{c}}$ in den Bodenlösungen der typischen Subassoziation über denen des Gentiano-Koelerietum danthonietosum.

Die Spalte II. lässt in allen Fällen erhebliche analytische Anionendefizite der wässrigen Bodenextrakte erkennen. Diese betragen bezogen auf die Kationen-Äquivalenzkonzentrationen etwa $80 \%$ bis $95 \%$. In aller Regel sind sie in den CC-Beständen höher als in den CF-Beständen. Die PBL weisen ein höheres Anionendefizit als die GBL und DBL auf.

Betrachtet man in Spalte III. die Äquivalenzkonzentrationen und Ladungsanteile von Calcium, wiederum bezogen auf die kationische Fraktion, so zeigen sich für die einzelnen Lösungstypen positive Korrelationen zwischen dem prozentualem Anionendefizit und $c_{c}\left(\mathrm{Ca}^{2+}\right)$. Dieses Ergebnis lässt darauf schließen, dass die hohen Anionendefizite im Wesentlichen auf den fehlenden Nachweis der Carbonat-Anionen aus der Kalklösung zurückzuführen sind.

Tabelle 9: Gesamt-Äquivalenzkonzentrationen (I.), Anionendefizite (II.), Ca-Äquivalenzkonzentrationen (III.), Differenzen der prozentualen Anionendefizite und Ca-Äquivalenzkonzentrationen (IV.) sowie Ionenstärken (V.) in GBL, $P B L$ und DBL von CC- und CF-Beständen der Standorte Auf der Burg und Hölleberg. $M W \pm S D$ (GBL: $n=56$; PBL, $D B L: n=48)$.

\begin{tabular}{|c|c|c|c|c|c|c|c|}
\hline \multicolumn{2}{|c|}{ Standort / Lösung } & \multirow{2}{*}{$\begin{array}{c}\text { I. } \Sigma \mathbf{c}_{\mathbf{c}} \\
{\left[\mathrm{mmol}_{\mathrm{c}} / \mathrm{l}\right]}\end{array}$} & \multirow{2}{*}{$\begin{array}{c}\text { II. }\left(\Sigma \mathrm{c}_{\mathrm{c}}{ }^{+}-\Sigma \mathrm{c}_{\mathrm{c}}{ }^{-}\right) / \Sigma \mathrm{c}_{\mathrm{c}}{ }^{+} \\
{[\%]}\end{array}$} & \multicolumn{2}{|c|}{ III. $\mathrm{Ca}^{2+}$} & \multirow{2}{*}{$\begin{array}{c}\text { IV. II - III } \\
{[\%]} \\
\end{array}$} & \multirow{2}{*}{$\begin{array}{c}\text { V. I } \\
{[\mathrm{mmol} / \mathrm{l}]}\end{array}$} \\
\hline & & & & {$\left[\mathrm{mmol}_{\mathrm{C}} / \mathrm{l}\right]$} & {$\left[\begin{array}{lll}\% & \mathrm{c}_{\mathrm{c}} / \Sigma \mathrm{c}_{\mathrm{c}}^{+}\end{array}\right]$} & & \\
\hline \multirow[t]{4}{*}{ Auf der Burg CC } & GBL & $4,8 \pm 0,8$ & $91,3 \pm 3,3$ & $4,0 \pm 0,7$ & $92,3 \pm 5,0$ & $-1,1 \pm 5,9$ & $6,3 \pm 1,7$ \\
\hline & PBL & $4,5 \pm 0,7$ & $95,6 \pm 1,4$ & $4,0 \pm 0,6$ & $92,1 \pm 5,3$ & $3,5 \pm 5,4$ & $6,4 \pm 1,0$ \\
\hline & DBL & $2,1 \pm 0,4$ & $90,5 \pm 2,6$ & $1,7 \pm 0,4$ & $87,5 \pm 6,0$ & $3,0 \pm 5,9$ & $2,8 \pm 0,6$ \\
\hline & & & 92,4 & & 90,7 & 1,8 & \\
\hline \multirow[t]{4}{*}{ Auf der Burg CF } & GBL & $2,3 \pm 1,3$ & $79,3 \pm 13,3$ & $1,7 \pm 1,2$ & $79,2 \pm 15,0$ & $0,2 \pm 14,6$ & $3,0 \pm 1,9$ \\
\hline & PBL & $1,7 \pm 0,7$ & $90,5 \pm 4,4$ & $1,3 \pm 0,7$ & $84,3 \pm 9,3$ & $6,2 \pm 7,8$ & $2,3 \pm 1,0$ \\
\hline & DBL & $0,9 \pm 0,5$ & $85,2 \pm 5,9$ & $0,7 \pm 0,5$ & $83,1 \pm 9,0$ & $2,1 \pm 5,4$ & $1,2 \pm 0,7$ \\
\hline & & & 85,0 & & 82,2 & 2,8 & \\
\hline \multirow[t]{4}{*}{ Hölleberg CC } & GBL & $3,3 \pm 0,8$ & $89,6 \pm 2,9$ & $2,7 \pm 0,9$ & $87,9 \pm 9,0$ & $1,8 \pm 8,7$ & $4,4 \pm 1,3$ \\
\hline & PBL & $3,7 \pm 0,9$ & $94,5 \pm 2,3$ & $3,3 \pm 1,0$ & $91,4 \pm 6,0$ & $3,1 \pm 5,2$ & $5,3 \pm 1,4$ \\
\hline & DBL & $1,7 \pm 0,6$ & $87,2 \pm 4,0$ & $1,3 \pm 0,6$ & $85,1 \pm 11,6$ & $2,1 \pm 11,0$ & $2,3 \pm 0,9$ \\
\hline & & & 90,4 & & 88,1 & 2,3 & \\
\hline \multirow[t]{4}{*}{ Hölleberg CF } & GBL & $3,3 \pm 1,0$ & $89,7 \pm 3,5$ & $2,7 \pm 1,1$ & $87,4 \pm 8,7$ & $2,3 \pm 8,0$ & $4,5 \pm 1,5$ \\
\hline & PBL & $3,0 \pm 0,7$ & $93,5 \pm 2,7$ & $2,4 \pm 0,8$ & $86,8 \pm 8,8$ & $6,7 \pm 7,8$ & $4,1 \pm 1,1$ \\
\hline & DBL & $1,3 \pm 0,4$ & $87,6 \pm 4,9$ & $1,0 \pm 0,4$ & $81,7 \pm 13,0$ & $5,8 \pm 11,8$ & $1,7 \pm 0,6$ \\
\hline & & & 90,3 & & 85,3 & 5,0 & \\
\hline \multirow[t]{3}{*}{ Pool } & GBL & 3,4 & 87,5 & 2,8 & 86,7 & 0,8 & 4,6 \\
\hline & PBL & 3,2 & 93,5 & 2,8 & 88,6 & 4,9 & 4,5 \\
\hline & DBL & 1,5 & 87,6 & 1,1 & 84,3 & 3,3 & 2,0 \\
\hline
\end{tabular}

* Die Kalkulationen von I basieren auf den Ergebnissen der Anionen- und Kationenanalysen. Als primäre Komponente der Anionedefizite wurde $\mathrm{HCO}_{3}^{-}$angenommen und in die Kalkulationen mit einbezogen. 
Spalte IV. listet den Anteil des Anionendefizits auf, der nicht durch Carbonat - bei gegebenen $\mathrm{pH}$-Werten v. a. $\mathrm{HCO}_{3}{ }^{-}-$aus der initialen Lösung von $\mathrm{CaCO}_{3}$ abgedeckt wird. Die besonders hohen Werte der PBL belegen, dass durch die zyklische Perkolation von Bodenmonolithen proportional weniger Anionen erfasst werden als durch die beiden anderen Extraktionsmethoden. Die mit weitem Abstand geringsten Differenzen zwischen den Äquivalenzkonzentrationen der Kationen einerseits und der Summe aus tatsächlich analysierten Anionen und dem auf Grundlage der $\mathrm{Ca}^{2+}$-Konzentrationen berechneten Carbonationen weisen die GBL auf. Offenbar bestreiten Anionen, die im Rahmen der vorliegenden Arbeit nicht analysiert wurden, in Schüttelungslösungen feldfrischer Feinerdehomogenate einen deutlich geringeren Anteil als in den Extraktionslösungen der Bodenmonolithe.

Am Ausgleich des (rechnerischen) Anionendefizits sind auch gelöste Kohlenstoffverbindungen (DOC), darunter beispielsweise niedermolekulare organische Säuren, beteiligt (Wolt 1994). DOC-Analysen lassen jedoch vermuten, dass der diesbezügliche Beitrag gelöster organischer Verbindungen weit hinter den von $\mathrm{HCO}_{3}{ }^{-}$zurücktritt. Tabelle 12 (S. 79) belegt für die GBL der CC-Bestände im Mittel mehr als $20 \%$ niedrigere DOC. Dennoch liegen die Anionendefizite der CC-Einheiten über denen der CF-Bestände (Auf der Burg) oder doch zumindest in gleicher Höhe (Hölleberg).

Neben dem $\mathrm{pH}$ und dem $\mathrm{E}_{\mathrm{h}}$ ist die Ionenstärke $I$ eine weitere Schlüsselvariable des Lösungschemismus. Diese ist u. a. für Kalkulation der Aktivitätskoeffizienten $y$ erforderlich, die ihrerseits für Umrechnungen von Ionenkonzentrationen in Ionenaktivitäten und damit etwa für die Berechnung chemischer Gleichgewichte im Rahmen der chemischen Spezifizierung von Bodenlösungen herangezogen werden müssen (Lindsay 1979). Die Ionenstärken $I$ in Spalte V der Tabelle 9 ist wie folgt definiert (Lewis \& Randall 1961):

$I=0,5 \cdot \Sigma\left(c_{i} \cdot z_{i}^{2}\right)$

I lonenstärke, [M]

$c_{i} \quad$ Konzentration des lons i, [M]

$z_{i} \quad$ Ladungszahl des lons $\mathrm{i}$

Im Vorliegenden wird davon ausgegangen, dass die gelösten Elemente ausschließlich in einer einzigen ionaren Form vorliegen. Für den Ausgleich des Anionendefizits wurde in der Kalkulation von $\mathrm{I} \mathrm{HCO}_{3}{ }^{-}$ berücksichtigt. Die Ionenstärken folgen den Verhältnissen der gemessenen Äquivalenzkonzentrationen und aufgrund der Dominanz von Calcium dessen Konzentrationen in den Lösungen. Gleich gerichtete Unterschiede der Ionenstärken in Böden der beiden Subassoziationen des Gentiano-Koelerietum sind nur für den Standort Auf der Burg nachzuweisen. Die GBL des CF-Bestands am Standort Hölleberg weisen tendenziell etwas höhere Ionenstärken auf als die des benachbarten Vergleichsbestands. Unter Bezug auf alle Messungen sind keine signifikanten Unterschiede zwischen den GBL und PBL zu belegen. Insgesamt übersteigen deren Ionenstärken die der DBL um etwa $100 \%$.

\section{Spezifität und Effizienz der Extraktionsverfahren}

Die Extraktionsverfahren der GBL, PBL und DBL, wie sie für die vergleichenden Untersuchungen der Kalk-Halbtrockenrasen der Referenzstandorte im Unteren Diemeltal durchgeführt wurden, müssen unter dem Gesichtspunkt ihrer Effizienz und Spezifität bewertet werden. Die nachfolgenden Auswertungen der bereits im Detail dargestellten Analysenergebnisse behandeln noch einmal zusammenfassend: 
- die Verhältnisse der auf die Feinerdemasse bezogenen Lösungsmengen in Abhängigkeit vom Extraktionsverfahren, spezifiziert für die verschiedenen Analyte (Tabelle 10)

- die Verhältnisse der Extraktion verschiedener Analyte, spezifiziert für die verschiedenen Extraktionsverfahren (Abbildung 44)

- die prozentualen Abweichungen der auf die Feinerdemasse bezogenen Lösungsmengen verschiedener Analyte in den CC- und CF- Beständen eines Standorts nach $\left(b_{i}(C F) / b_{i}(C C)-1\right) \cdot 100$, spezifiziert für die verschiedenen Extraktionsverfahren (Tabelle 11)

Auf die Angaben der Tabelle 10 wurde bereits bei der Besprechung der jeweiligen Standortfaktoren eingegangen. Aufgeführt sind hier die Verhältnisse der Lösungskomponenten in Abhängigkeit vom Extraktionsverfahren und Untersuchungsbestand. Reduziert man die Betrachtung auf die Zusammenfassungen der Ergebnisse aller Untersuchungsstandorte ("Pool"), so lassen sich die Analyte hinsichtlich ihrer Konzentrationen in den verschiedenen Bodenextrakten gruppieren.

$\mathrm{Ca}^{2+}, \mathrm{Mg}^{2+}$ und $\mathrm{K}^{+}$werden in gleichem Umfang durch die GBL und PBL, aber in deutlich geringerem Umfang durch die DBL erfasst $(\mathrm{GBL}=\mathrm{PBL}>\mathrm{DBL})$. Durch die Dominanz von $\mathrm{Ca}^{2+}$ in den Bodenextrakten bezieht sich dieses Verhältnis auch auf die elektrische Leitfähigkeit. Eine zweite große Gruppe bilden Analyte, die durch das Sieben und Homogenisieren des Bodenmaterials verstärkt gelöst werden (GBL > PBL). Im Fall von $\mathrm{Na}^{+}$und $\mathrm{SO}_{4}{ }^{2-}$ übersteigen die feinerdebezogenen Stoffmengen, wie sie mittels dieser beiden Extraktionsverfahren ermittelt wurden, zugleich diejenigen der DBL (GBL > PBL > DBL). Bei den beiden anionischen Stickstoffspezies werden vermutlich während der 24stündigen Equilibrierung Denitrifikationsreaktionen wirksam, die zu einem Absinken der betreffenden PBL-Werte unter diejenigen der DBL führen (GBL > DBL > PBL). Während für Mn keine Abhängigkeit der ermittelten Stoffmengen vom Equilibrierungsverfahren nachgewiesen werden kann, liegen in den PBL höhere $\mathrm{NH}_{4}{ }^{+}$-Konzentrationen als in den GBL vor. Die Mn-Konzentrationen der DBL überschreiten, die $\mathrm{NH}_{4}{ }^{+}$-Konzentrationen unterschreiten diejenigen der Gleichgewichstbodenlösungen. Die zyklische Perkolation der Bodenmonolithen geht offenbar mit einer Immobilisierung von Fe einher. Aus diesem Grund liegen die Fe-Konzentrationen der PBL unter denen der DBL. Durch die eintägige Schüttelung von Feinerdehomogenaten wird tendenziell, aber nicht signifikant mehr Fe extrahiert als durch die Überdruckbehandlung aufgesättigter Bodenmonolithe (GBL $=$ DBL $>$ PBL).

Auffallend ist die gute Übereinstimmung der in Tabelle 10 dargestellten Ergebnisse mit den Untersuchungen zur Abhängigkeit der Lösungskonzentrationen von der Perkolationsdauer natürlich gelagerter Bodenproben (Abbildung 19). Die feinerdebezogenen $\mathrm{Ca}^{2+}-\mathrm{Mg}^{2+}$ - und $\mathrm{SO}_{4}{ }^{2-}-$ Konzentrationen der PBL liegen signifikant über denen des DBL-Verfahrens und bestätigen, dass die Equilibrierung bivalenter Ionen deutlich langsamer erfolgt als die monovalenter Anionen und Kationen. Entsprechend liegen für $\mathrm{Cl}^{-}$keine Unterschiede zwischen den beiden Extraktionsverfahren vor. Die nur geringfügig, dennoch aber signifikant höheren K- und Na-Gehalte in den PBL verweisen darauf, dass trotz der sehr hohen Austauschkinetiken monovalenter Kationen und der in manchen Fällen recht langen Abpressdauer der aufgesättigten Bodenmonolithe eine Gleichgewichtseinstellung zwischen der Bodenmatrix und der Extraktionslösung verhindert werden konnte. 
Tabelle 10: Mediane GBL : PBL : DBL-Verhältnisse verschiedener Standortfaktoren von CC- und CF-Vegetationsbeständen der Standorte Auf der Burg und Hölleberg. Berechnungsgrundlage sind Verhältnisse zwischen den feinerdebezogenen Stoffmengen bzw. Aktivitäten (für $\mathrm{H}^{+}$) der Analysenlösungen paralleler Probennahmen aller drei Lösungstypen. Abweichende Buchstuben kennzeichnen signifikante Unterschiede auf Grundlage multipler Einzelwertvergleiche nach Schaich-Hamerle ( $n=48, \alpha=0,05)$.

\begin{tabular}{|c|c|c|c|c|c|c|c|c|c|}
\hline \multirow[t]{2}{*}{ Faktor } & \multicolumn{2}{|c|}{ Auf der Burg-CC } & Auf der Burg-CF & Hölleberg-CC & \multicolumn{2}{|c|}{ Hölleberg-CF } & \multicolumn{3}{|c|}{ Pool } \\
\hline & GBL : & : PBL : DBL & GBL : PBL : DBL & GBL : PBL : DBL & GBL : PBL & DBL & GBL : & : PBL & : DBL \\
\hline $\mathrm{H}^{+}$ & $0,5^{\mathrm{b}}$ & $: 0,5^{\mathrm{b}}: 1^{\mathrm{a}}$ & $0,5^{\mathrm{b}}: 0,7^{\mathrm{ab}}: 1^{\mathrm{a}}$ & $0,3^{\mathrm{b}}: 0,5^{\mathrm{b}}: 1^{\mathrm{a}}$ & $0,4^{c}: 0,8^{b}$ & $1^{\text {a }}$ & $0,4^{c}$ & $: 0,6^{\mathrm{b}}$ & $: 1^{\mathrm{a}}$ \\
\hline $\mathrm{Fe}^{\mathrm{x+}}$ & $1,4^{\text {a }}$ & $: 0,3^{\mathrm{b}}: 1^{\mathrm{a}}$ & $2,9^{a}: 1,3^{a b}: 1^{b}$ & $1,3^{a}: 0,8^{b}: 1^{a b}$ & $0,8^{a}: 0,4^{b}$ & $1^{\text {a }}$ & $1,4^{\text {a }}$ & $: 0,6^{\mathrm{b}}$ & $: 1^{\mathrm{a}}$ \\
\hline $\mathrm{Mn}^{\mathrm{x+}}$ & $0,8^{b}$ & $: 0,8^{\mathrm{b}}: 1^{\mathrm{a}}$ & $1,0^{\mathrm{a}}: 0,8^{\mathrm{a}}: 1^{\mathrm{a}}$ & $0,9^{a}: 1,0^{a}: 1^{a}$ & $0,9^{a}: 0,9^{a}$ & $1^{\text {a }}$ & $0,9^{b}$ & $: 0,9^{\mathrm{b}}$ & $1^{\text {a }}$ \\
\hline $\mathrm{Ca}^{2+}$ & $2,5^{\mathrm{a}}$ & $: 2,4^{\mathrm{a}}: 1^{\mathrm{b}}$ & $2,3^{\mathrm{a}}: 2,1^{\mathrm{a}}: 1^{\mathrm{b}}$ & $2,3^{\mathrm{a}}: 2,5^{\mathrm{a}}: 1^{\mathrm{b}}$ & $3,3^{a}: 2,9^{a}$ & $1^{b}$ & $2,6^{\mathrm{a}}$ & $: 2,5^{a}$ & $: 1^{\mathrm{b}}$ \\
\hline $\mathrm{Mg}^{2+}$ & $2,9^{\text {a }}$ & $: 2,5^{a}: 1^{b}$ & $2,9^{a}: 2,4^{a}: 1^{b}$ & $1,8^{a}: 1,7^{a}: 1^{b}$ & $2,2^{a}: 2,1^{a}$ & $1^{\mathrm{b}}$ & $2,2^{\mathrm{a}}$ & $: 2,3^{a}$ & $: 1^{\mathrm{b}}$ \\
\hline $\mathrm{K}^{+}$ & $1,4^{\mathrm{a}}$ & $: 1,3^{\mathrm{a}}: 1^{\mathrm{b}}$ & $1,0^{a}: 0,8^{a}: 1^{a}$ & $1,2^{\mathrm{a}}: 1,1^{\mathrm{a}}: 1^{\mathrm{a}}$ & $1,5^{\mathrm{a}}: 1,5^{\mathrm{a}}$ & $1^{b}$ & $1,3^{\mathrm{a}}$ & $: 1,2^{\mathrm{a}}$ & $: 1^{\mathrm{b}}$ \\
\hline $\mathrm{Na}^{+}$ & $1,5^{a}$ & $: 1,5^{\mathrm{a}}: 1^{\mathrm{b}}$ & $1,5^{\mathrm{a}}: 1,4^{\mathrm{a}}: 1^{\mathrm{b}}$ & $1,7^{\mathrm{a}}: 1,4^{\mathrm{a}}: 1^{\mathrm{b}}$ & $2,0^{a}: 1,5^{a}$ & $1^{b}$ & $1,7^{\text {a }}$ & $: 1,5^{a}$ & $: 1^{\mathrm{b}}$ \\
\hline $\mathrm{NH}_{4}^{+}$ & $0,0^{\mathrm{b}}$ & $: 0,8^{a}: 1^{a}$ & $0,0^{b}: 12^{a}: 1^{b}$ & $3,7^{a}: 3,6^{a}: 1^{b}$ & $5,2^{a}: 4,2^{a}$ & $1^{b}$ & $2,8^{\mathrm{b}}$ & $: 3,4^{a}$ & $: 1^{\mathrm{c}}$ \\
\hline $\mathrm{SO}_{4}{ }^{2-}$ & $1,7^{\text {a }}$ & $: 1,0^{\mathrm{b}}: 1^{\mathrm{b}}$ & $3,2^{a}: 1,5^{b}: 1^{c}$ & $1,7^{\mathrm{a}}: 1,1^{\mathrm{b}}: 1^{\mathrm{c}}$ & $2,7^{\mathrm{a}}: 1,3^{\mathrm{b}}$ & $1^{c}$ & $2,4^{\text {a }}$ & $: 1,2^{b}$ & $1^{c}$ \\
\hline $\mathrm{NO}_{3}^{-}$ & $5,2^{a}$ & $: 0,4^{\mathrm{b}}: 1^{\mathrm{b}}$ & $1,2^{\mathrm{a}}: 1,1^{\mathrm{a}}: 1^{\mathrm{a}}$ & $3,7^{\mathrm{a}}: 1,0^{\mathrm{b}}: 1^{\mathrm{b}}$ & $1,6^{\mathrm{a}}: 0,4^{\mathrm{b}}$ & $1^{\text {a }}$ & $1,8^{\mathrm{a}}$ & $: 0,8^{\mathrm{b}}$ & $1^{\mathrm{b}}$ \\
\hline $\mathrm{NO}_{2}^{-}$ & $1,9^{\text {a }}$ & $: 0,4^{\mathrm{c}}: 1^{\mathrm{b}}$ & $3,0^{\mathrm{a}}: 0,7^{\mathrm{b}}: 1^{\mathrm{b}}$ & $0,7^{a}: 1,3^{a}: 1^{a}$ & $0,9^{a}: 0,3^{b}$ & $1^{\mathrm{a}}$ & $1,4^{\text {a }}$ & $: 0,6^{c}$ & $1^{b}$ \\
\hline $\mathrm{Cl}^{-}$ & $2,0^{a}$ & $: 1,0^{b}: 1^{b}$ & $2,6^{a}: 0,9^{b}: 1^{b}$ & $1,6^{a}: 0,8^{b}: 1^{b}$ & $2,4^{a}: 1,2^{b}$ & $1^{b}$ & $2,1^{a}$ & $: 1,0^{\mathrm{b}}$ & $1^{b}$ \\
\hline EC & $2,4^{a}$ & $: 2,4^{\mathrm{a}}: 1^{\mathrm{b}}$ & $2,4^{a}: 2,0^{a}: 1^{b}$ & $2,3^{a}: 2,3^{a}: 1^{b}$ & $3,1^{\text {a }}: 2,8^{a}$ & $1 \mathrm{~b}$ & $2,5^{a}$ & $: 2,4^{a}$ & $1^{b}$ \\
\hline
\end{tabular}

In Abbildung 44 sind für die drei wässrigen Extraktionsverfahren die relativen feinerdebezogenen Konzentrationen der verschiedenen Analyte dargestellt. Für die Abbildung wurden die Verhältnisse der jeweiligen Anionen bzw. Kationen zu dem grundsätzlich in den geringsten Konzentrationen auftretenden Mn gebildet und diese logarithmisch aufgetragen. Diese Darstellung erlaubt beispielsweise einen Vergleich der Extraktionsverfahren für die Abschätzung möglicher Kompetitionen der pflanzlichen Mineralstoffernährung.

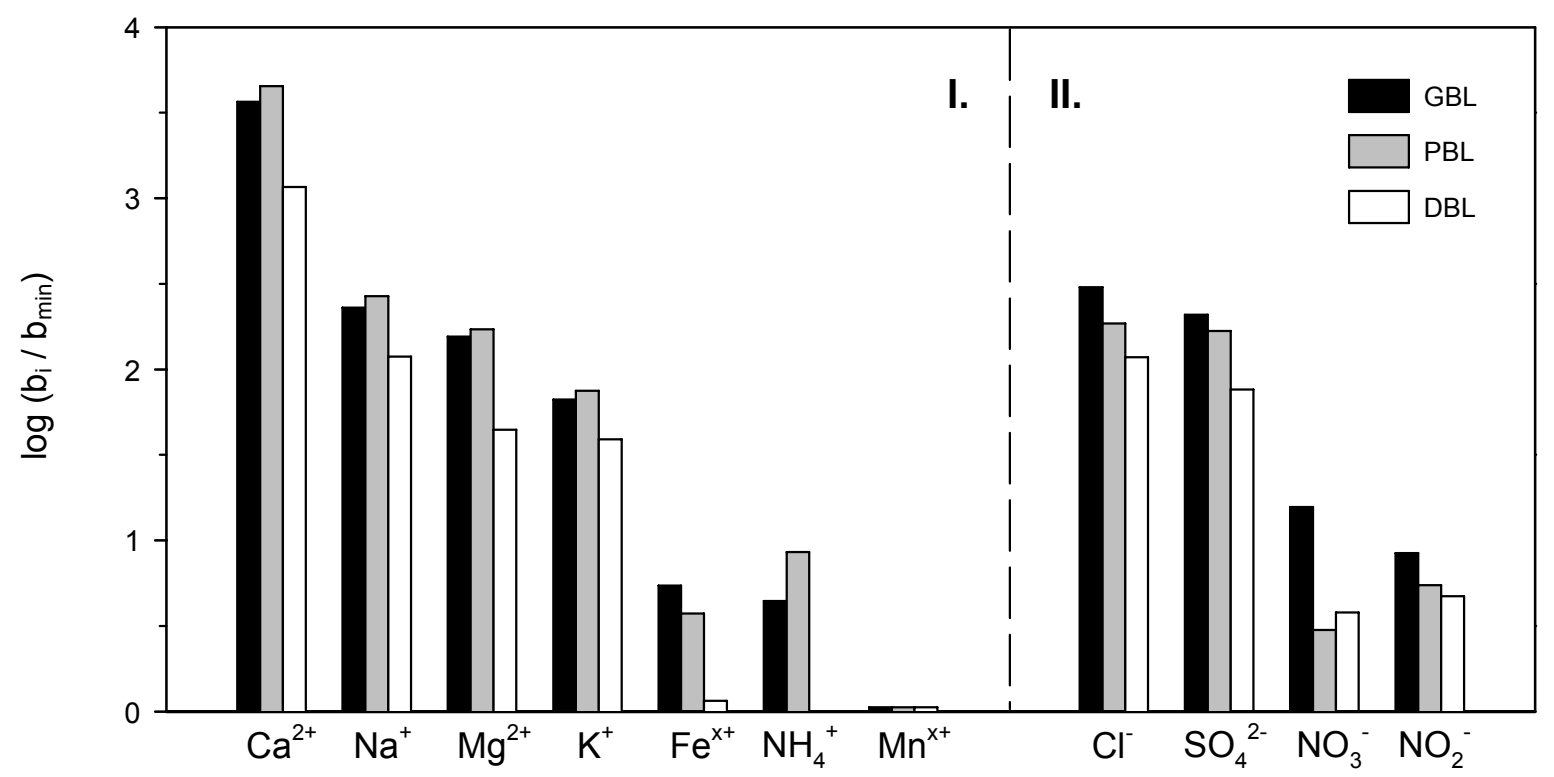

Abbildung 44: Mediane Extraktionsverhältnisse $\log \left(b_{i} / b_{\min }\right)$ verschiedener kationischer (I.) und anionischer (II.) Komponenten in Abhängigkeit vom Extraktionsverfahren. Bezugsgröße für die relativen Extraktionswerte sind die Analysenergebnisse für $\mathrm{Mn}^{x^{+}}$, das grundsätzlich in minimalen Konzentrationen erfasst wurde. 
Im Median übersteigen die $\mathrm{Ca}^{2+}$-Konzentrationen die des Mn um Faktoren von $4500\left(10^{3,65}\right)$ für die PBL-, $3660\left(10^{3,56}\right)$ für die GBL- und $1160\left(10^{3,06}\right)$ für die DBL-Variante. Mit wenigen Ausnahmen ist die Abfolge der Konzentrationsverhältnisse der verschiedenen kationischen und anionischen Komponenten für alle Extraktionsverfahren gleich. Unterschiede treten nur bei der Verteilung der Stickstofffraktionen auf. Das PBL-Verfahren extrahiert im Gegensatz zu denen der GBL und DBL mehr $\mathrm{NH}_{4}{ }^{+}$als Fe. Während in den GBL überwiegend $\mathrm{NO}_{3}{ }^{-}$vorliegt, ist in den PBL und DBL etwas mehr $\mathrm{NO}_{2}{ }^{-}$gelöst.

Die prozentualen Verhältnisse der wasserlöslichen Mineralstoffkonzentrationen in Feinerdematerial des Gentiano-Koelerietum typicum und Gentiano-Koelerietum danthonietosum spiegeln die für die meisten ökologischen Fragestellungen ausreichende Übereinstimmung der drei Extraktionsverfahren noch einmal wider (Tabelle 11). Mit Ausnahme der GBL- und DBL-bezogenen $\mathrm{NH}_{4}{ }^{+}$-Konzentrationen des Bodenmaterials der beiden Vegetationseinheiten des Standorts Auf der Burg liegen keine widersprüchlichen Ergebnisse für die jeweiligen Vergleichsbestände vor. In einigen Fällen werden aber signifikante Unterschiede zwischen den CC- und CF-Bestände nicht durch alle Lösungstypen bestätigt. Dies ist beispielsweise für Mn und $\mathrm{NO}_{2}^{-}$der Fall. Berechnet man als stark vereinfachtes Maß für die Unterschiede des Bodenchemismus der beiden Subassoziationen die Mittelwerte der prozentualen Abweichungen aller Lösungstypen, so verweisen diese für den Standort Auf der Burg auf größere Divergenzen (163\%). Im Durchschnitt weichen die hier untersuchten Faktoren in den CC- und CF-Beständen des Standorts Hölleberg deutlich weniger voneinander ab (30\%). Tendenziell differenzieren dabei Gleichgewichtslösungen und Drucklösungen aufgesättigter Bodenmonolithe (PBL, DBL) die Unterschiede zwischen den beiden Subassoziationen der Kalk-Halbtrockenrasen um $20 \%$ bis $30 \%$ stärker als die Gleichgewichtslösungen homogenisierter Feinerdeproben (GBL).

Obwohl die Variabilitäten der Fe-Analysen beträchtlich sind, belegen mit Ausnahme derer der PBL des Standorts Hölleberg alle anderen Untersuchungen signifikant höhere Fe-Verfügbarkeiten für das Gentiano-Koelerietum danthonietosum. Kein anderes Analyt der Untersuchungen zeigt so große Abweichun-

Tabelle 11: Mediane prozentuale Differenzen verschiedener Bodenfaktoren von CF- und CC-Beständen der Standorte Auf der Burg und Hölleberg in Abhängigkeit vom Lösungstyp. Berechnungsgrundlage sind die feinerdebezogenen Stoffmengen bzw. Leitfähigkeiten und Lösungsaktivitäten (für $\mathrm{H}^{+}$) nach CF/CC $\cdot 100-100$. Sternsignaturen kennzeichnen Ergebnisse des nicht-parametrischen paarweisen Vergleichs CC vs. CF nach Mann-Whitney (n.s. $\alpha>0,05, * \alpha \leq 0,050, * * \alpha \leq 0,010, * * * \alpha \leq 0,001 ; n=48$ ).

\begin{tabular}{|c|c|c|c|c|c|c|}
\hline \multirow[t]{2}{*}{ Faktor } & \multicolumn{3}{|c|}{ Auf der Burg CF : CC [\%] } & \multicolumn{3}{|c|}{ Hölleberg CF : CC [\%] } \\
\hline & GBL & PBL & DBL & GBL & PBL & DBL \\
\hline $\mathrm{H}^{+}$ & $+307^{* * *}$ & $+188^{* * *}$ & $+160^{* * *}$ & $-7^{\text {n.s. }}$ & $+48^{\cdots *}$ & $-7^{\text {n.s. }}$ \\
\hline $\mathrm{Fe}^{\mathrm{xt}}$ & $+700^{\cdots *}$ & $+1636^{\cdots *}$ & $+1511^{m *}$ & $+64^{\cdots *}$ & $+40^{\text {n.s. }}$ & $+140^{*}$ \\
\hline $\mathrm{Mn}^{\mathrm{x+}}$ & $+375^{\cdots}$ & -60 n.s. & $-11^{\text {n.s. }}$ & $-6^{\text {n.s. }}$ & $+11^{\text {n.s. }}$ & $+5^{\text {n.s }}$ \\
\hline $\mathrm{Ca}^{2+}$ & $-68^{\cdots}$ & $-75^{\cdots}$ & $-61^{\cdots \cdots}$ & $-8^{\text {n.s. }}$ & $-31 *$ & $-34^{\cdots+}$ \\
\hline $\mathbf{M g}^{2+}$ & $-52^{\cdots *}$ & $-52^{\cdots}$ & $-40^{\cdots *}$ & $+17^{*}$ & $+6^{\text {n.s. }}$ & $+19^{\text {n.s }}$ \\
\hline $\mathrm{K}^{+}$ & $-70^{\cdots *}$ & $-76^{\cdots *}$ & $-62^{\cdots *}$ & $-49^{\cdots *}$ & $-47^{\cdots \cdot}$ & $-58^{\cdots+}$ \\
\hline $\mathrm{Na}^{+}$ & -6 n.s. & $-14 *$ & $-25^{\cdots *}$ & $+43^{*}$ & $+27^{* *}$ & $+2^{\text {n.s. }}$ \\
\hline $\mathrm{NH}_{4}{ }^{+}$ & $+\infty{ }^{\cdots *}$ & $+163^{\text {n.s. }}$ & $-89^{\cdots *}$ & $-5^{\text {n.s. }}$ & $+4^{\text {n.s. }}$ & $-5^{\text {n.s }}$ \\
\hline $\mathrm{SO}_{4}{ }^{2-}$ & +6 n.s. & $-20 \cdots$ & $-43^{\cdots *}$ & $-1^{\text {n.s. }}$ & $-11^{\text {n.s. }}$ & $-25^{\text {n.s }}$ \\
\hline $\mathrm{NO}_{3}^{-}$ & $-96^{\cdots \cdots}$ & $-60^{\cdots}$ & $-86^{\cdots *}$ & $-56^{*}$ & $-62^{*}$ & $+17^{\text {n.s }}$ \\
\hline $\mathrm{NO}_{2}^{-}$ & $-16 *$ & $+1^{\text {n.s. }}$ & $-55^{* *}$ & $-73^{\text {n.s. }}$ & $-95^{\cdots *}$ & $+45^{\text {n.s }}$ \\
\hline $\mathrm{Cl}^{-}$ & $-32^{\cdots}$ & $-54^{\cdots *}$ & $-51^{\cdots *}$ & $-10^{*}$ & $-17^{*}$ & $-34^{\cdots \cdots}$ \\
\hline EC & $-67^{\circ *}$ & $-70^{\prime \prime \prime}$ & $-61^{\prime *}$ & $+1^{\text {n.s. }}$ & -15 & $-27^{\cdots}$ \\
\hline
\end{tabular}


gen der gelösten Fraktion zwischen den Vergleichsbeständen. Legt man den Analysenergebnissen das Gesamtvolumen des Bodens zugrunde, so werden diese Unterschiede als Folge unterschiedlicher Skelettgehalte der beiden Subassoziationen sogar noch um Faktoren von 1,9 (Auf der Burg) bzw. 1,3 (Hölleberg) erhöht (vgl. Tabelle 7, S. 52). In anderen Fällen erfolgt durch diese Umrechnungen eine Umkehrung der Analytverhältnisse zugunsten der CF-Bestände. Dies ist überall dort der Fall, wo die feinerdebezogenen GBL-Konzentrationen des Gentiano-Koelerietum danthonietosum weniger als 48,5\% (Auf der Burg) bzw. 32,3\% (Hölleberg) unter denen der typischen Subassoziation liegen. Tabelle 11 zeigt, dass der Volumenbezug v. a. bei den GBL-Analysen für den Standort Hölleberg die Relationen zwischen den CCund CF-Beständen invertieren kann. Die volumetrischen GBL-bezogenen Ca-Löslichkeiten beispielsweise verschieben sich hier (trotz höherer $\mathrm{CaCO}_{3}$-Gehalte in der Feinerde) deutlich zugunsten des $\mathrm{CF}$ Bestands. Bei den Stickstofffraktionen bestätigen die Volumenbezüge bessere $\mathrm{NO}_{3}^{-}$-Verfügbarkeiten im Gentiano-Koelerietum typicum. Entsprechendes gilt für die $\mathrm{NO}_{2}^{-}$-Konzentrationen der DBL des Standorts Auf der Burg und denen der PBL des Standorts Hölleberg.

\subsubsection{Kohlenstoff/Stickstoff-Verhältnisse $\left(C_{0} / N\right)$}

Abbildung 45 zeigt die jahreszeitliche Entwicklung der organischen Kohlenstofffraktionen und der Stickstofffraktionen sowie deren Quotienten $\mathrm{C}_{\mathrm{o}} / \mathrm{N}$ in der Feinerde der Daueruntersuchungsflächen. In allen Fällen liegen die Abweichungen der $\mathrm{C}_{0^{-}}$und $\mathrm{N}$-Gehalte zwischen den Probennahmeterminen unterhalb des vorgegebenen Signifikanzniveaus. Auch sind für die beiden Vegetationsbestände des Standorts Auf der Burg keine jahreszeitlichen Abhängigkeiten der $\mathrm{C}_{0} / \mathrm{N}$-Verhältnisse nachzuweisen. Diesbezügliche Abweichungen der medianen $\mathrm{C}_{0} / \mathrm{N}$-Verhältnisse des Standorts Hölleberg, wie sie zwischen den hohen Werten beider Subassoziationen im Oktober und den Minima des CF-Bestands im Januar und Februar bzw. des CC-Bestands im Februar und März belegt werden können, betragen weniger als $20 \%$.
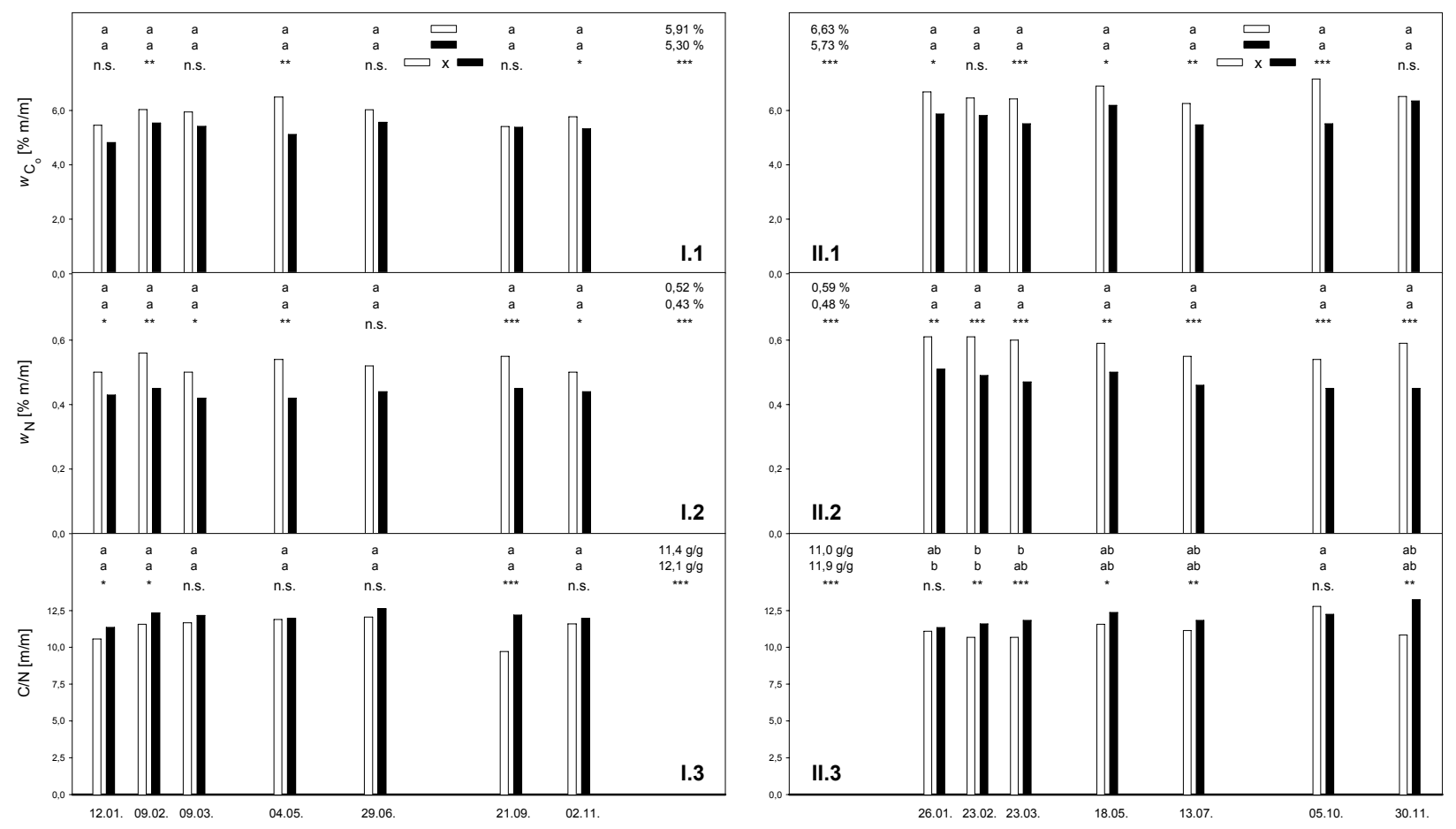

Abbildung 45: Massenanteile [\% $\mathrm{m} / \mathrm{m}_{\text {FE-TG }}$ ] der Feinerde an $C_{o}$ (I/II.1) und $N$ (I/II.2) sowie $C_{o} / N$-Verhältnisse [m/m] (I/II.3) in CC- und CF-Beständen der Referenzstandorte Auf der Burg und Hölleberg im Jahresverlauf 1998. 
Zum Zeitpunkt der meisten Probennahmen übersteigen sowohl die $\mathrm{C}_{\mathrm{o}^{-}}$als auch die N-Gehalte in der Feinerde des Gentiano-Koelerietum typicum diejenigen der Subassoziation von D. decumbens. Bei Jahresmedianen zwischen 5,3\% und 6,6\% wurden für die $\mathrm{C}_{0}$-Gehalte der Feinerde Relationen entsprechend Auf der Burg-CF $<$ Hölleberg-CF $\approx$ Auf der Burg-CC $<$ Hölleberg-CC ermittelt. Unterschiede der N-Fraktionen mit medianen Werten zwischen 0,43\% und 0,59\% sind in der Abfolge Auf der Burg$\mathrm{CF}<$ Hölleberg-CF $<$ Auf der Burg-CC $<$ Hölleberg-CC zu verzeichnen. Aus diesen Werten resultieren schließlich $\mathrm{C}_{0} / \mathrm{N}$-Verhältnisse, die für beide Standorte gleichermaßen günstigere Mineralisationsvoraussetzungen in der typischen Subassoziation des Gentiano-Koelerietum erwarten lassen und in dieser Hinsicht mit den Ergebnissen der feinerdebezogenen $\mathrm{NO}_{3}^{-}$- und $\mathrm{NO}_{2}^{-}$-Löslichkeiten übereinstimmen.

Für die Feinerdehomogenate der Probennahme im März 1998 wurden neben den gasvolumetrisch ermittelten $\mathrm{CaCO}_{3}$-Gehalten und gaschromatographisch ermittelten $\mathrm{C}_{\mathrm{i}}$-Gehalten der Glühverlust (GV) und die Massenkonzentrationen $\mathrm{H}_{2} \mathrm{O}$-löslicher, organischer Kohlenstoffverbindungen (DOC) bestimmt (Tabelle 12). Hintergrund dieser ergänzenden Untersuchungen waren einerseits die Überprüfung der $\mathrm{C}_{0}$-Massenanteile, wie sie als Differenz aus $w\left(\mathrm{C}_{\mathrm{i}}\right)$ und $w\left(\mathrm{CaCO}_{3}\right)$ berechnet wurden, andererseits die Bestimmung des Gehalts potenziell komplexierender organischer Verbindungen, die zu einer Erhöhung der Fe-Konzentrationen in der Bodenlösung beitragen können.

Die Ergebnisse der GV-Messungen einerseits und der $\mathrm{C}_{0}$-Messungen andererseits stimmen für die Böden aller vier Untersuchungsflächen gut überein. Demnach betragen die Verhältnisse der Mediane dieser Größen zwischen etwa 2,25 (Auf der Burg CF) und 2,45 (Hölleberg CF). Es ist daher davon auszugehen, dass die höheren Gehalte an organischem Kohlenstoff im Gentiano-Koelerietum typicum, wie sie in der Tendenz für den Standort Auf der Burg und statistisch abgesichert für den Standort Hölleberg nachgewiesen wurden, nicht die Folge einer unzureichenden analytischen Trennung des organischen und anorganischen Kohlenstoffs waren. Korrelationsanalysen zwischen $w\left(\mathrm{CaCO}_{3}\right)$ und $w(\mathrm{GV})$, die die direkte Überprüfung einer potentiellen Mitverbrennung von Kalk im Muffelofen erlauben würden, können anhand des vorhandenen Datenmaterials nicht erfolgen. Obwohl die Massenanteile der organischen Gesamtfraktion 10-20 \% über denen der CF-Bestände lagen, wiesen übrigens die GBL der CC-Feinerde durchschnittlich $20 \%$ weniger gelösten Kohlenstoff (DOC) auf.

Tabelle 12: Kennwerte anorganischer und organischer Kohlenstofffraktionen in der Feinerde von CC- und CFBeständen der Standorte Auf der Burg und Hölleberg. Werte beziehen sich auf Untersuchungen der Probennahmen im März 1998. Mediane \pm MAD $(n=8)$; Sternsignaturen kennzeichnen die Ergebnisse des nicht-parametrischen paarweisen Vergleichs CC vs. CF nach Mann-Whitney (n.s. $\alpha>0,05, * \alpha \leq 0,050, * * \alpha \leq 0,010$, *** $\alpha \leq 0,001$ ).

\begin{tabular}{|c|c|c|c|c|c|c|c|}
\hline \multirow[t]{2}{*}{ Faktor } & & \multicolumn{2}{|c|}{ Auf der Burg } & & \multicolumn{2}{|c|}{ Hölleberg } & \\
\hline & & CC & $\mathrm{CF}$ & & CC & $\mathrm{CF}$ & \\
\hline $\mathrm{CaCO}_{3}$ & {$\left[\% \mathrm{w} / \mathrm{w}_{\mathrm{FE}}\right]$} & $34,4 \pm 2,2$ & $0,7 \pm 0,1$ & $* * *$ & $14,0 \pm 3,3$ & $1,3 \pm 0,4$ & $* * *$ \\
\hline $\mathrm{C}_{\mathrm{o}}$ & {$\left[\% \mathrm{w} / \mathrm{w}_{\mathrm{FE}}\right]$} & $5,9 \pm 0,4$ & $5,4 \pm 0,4$ & n.s. & $6,4 \pm 0,2$ & $5,5 \pm 0,2$ & $* * *$ \\
\hline GV & {$\left[\% \mathrm{w} / \mathrm{w}_{\mathrm{FE}}\right]$} & $14,3 \pm 1,0$ & $12,1 \pm 0,7$ & n.s. & $14,6 \pm 0,6$ & $13,5 \pm 0,4$ & $* *$ \\
\hline $\mathrm{DOC}_{\mathrm{GBL}}$ & {$\left[\mu \mathrm{g} / \mathrm{g}_{\mathrm{FE}}\right]$} & $24,3 \pm 2,1$ & $30,8 \pm 2,1$ & * & $23,8 \pm 0,9$ & $30,3 \pm 3,9$ & $* *$ \\
\hline
\end{tabular}

$D O C_{G B L}$ 'dissolved organic carbon' in $G B L$

GV Glühverlust 


\subsubsection{Effektive Kationenaustauschkapazitäten (CEC eff $_{\text {) }}$}

Neben den Inhaltsstoffen der Bodenlösung, die anhand der GBL, PBL und DBL eingehend charakterisiert wurden, dienen viele weitere Fraktionen des Bodens der pflanzlichen Mineralstoffernährung. Diese stehen über Gleichgewichtsreaktionen in direkter oder indirekter Beziehung zueinander. Mineralisch und organisch gebundene Nährelemente bilden über Verwitterungs- und Mineralisierungsreaktionen die sog. nachlieferbare Reserve. Von dieser Fraktion können die in den äußeren Bereichen der Minerale und in der leicht abbaubaren organischen Substanz gebundenen Nährstoffe durch wurzelbürtige Exsudate, etwa chelatisierende organische Säuren, und durch Exoenzyme mobilisiert werden. (Kuntze et al. 1994).

Im Folgenden werden für die Untersuchungsflächen der Standorte Auf der Burg und Hölleberg die kationischen Komponenten des an den geladenen Oberflächen sorbierten Nährstoffpools beschrieben. Insbesondere auch durch die Wirkung rhizodermaler $\mathrm{H}^{+}$-ATPasen können diese Nährionen ausgetauscht und so von der Pflanze verfügbar gemacht werden. Der Umfang der bei bodeneigenen pH-Werten wirksamen, negativ geladenen Gruppen der Oberfläche wird als effektive Kationenaustauschkapazität CEC $_{\text {eff }}$ bezeichnet, der Anteil basisch reagierender Kationen $\left(\mathrm{Ca}^{2+}, \mathrm{Mg}^{2+}, \mathrm{K}^{+}, \mathrm{Na}^{+}\right)$an der CEC als Basensättigung BS. Neben diesen beiden Parametern werden in Tabelle 13 die absoluten und prozentualen Austauscherbelegungen der Feinerde angegeben. In die Betrachtung der CEC gehen neben den Kationen, die bereits im Rahmen der Untersuchungen wässriger Bodenextrakte analysiert wurden, auch $\mathrm{Al}^{3+}$ und $\mathrm{Zn}^{2+}$ mit ein. $\mathrm{NH}_{4}{ }^{+}$konnte nicht berücksichtigt werden.

Tabelle 13: Effektive Kationenaustauschkapazitäten (CEC $\left.C_{\text {eff }}\right)$, Basensättigungen (BS) sowie absolute und prozentuale Kationenbelegungen der Feinerde von CC- und CF-Beständen der Standorte Auf der Burg und Hölleberg. Median \pm MAD ( $n=16)$; Sternsignaturen kennzeichnen Ergebnisse des nicht-parametrischen paarweisen Vergleichs CC vs. CF nach Mann-Whitney (n.s. $\alpha>0,05, * \alpha \leq 0,050, * * \alpha \leq 0,010$, *** $\alpha \leq 0,001$ ).

\begin{tabular}{|c|c|c|c|c|c|c|c|c|c|c|c|c|}
\hline \multirow[t]{2}{*}{ Faktor } & & \multicolumn{4}{|c|}{ Auf der Burg } & & \multicolumn{6}{|c|}{ Hölleberg } \\
\hline & & & Cc & & CF & & & CC & & & CF & \\
\hline CEC $_{\text {eff. }}$ & {$\left[\mathrm{mmol}_{\mathrm{c}} / 100 \mathrm{~g}_{\mathrm{Dw}}\right]$} & 16,7 & $\pm 0,7$ & 14,3 & $\pm 0,7$ & $* * * *$ & 18,3 & \pm & 0,6 & 16,6 & $\pm 0,5$ & $* * *$ \\
\hline BS & {$\left[\% \mathrm{CEC}_{\text {eff. }}\right]$} & 100 & $\pm 0,0$ & 99,0 & $\pm 0,4$ & $* * *$ & 100 & \pm & 0,0 & 99,5 & $\pm 0,2$ & $* * *$ \\
\hline $\mathrm{Ca}^{2+}$ & $\begin{array}{l}{\left[\mu \mathrm{mol} / \mathrm{g}_{\mathrm{oww}}\right]} \\
{\left[\% \mathrm{CEC}_{\text {eff }}\right]}\end{array}$ & $\begin{array}{l}79,3 \\
94,8\end{array}$ & $\begin{array}{l} \pm \quad 3,4 \\
\pm 0,4\end{array}$ & $\begin{array}{l}64,7 \\
90,7\end{array}$ & $\begin{array}{l} \pm \quad 3,3 \\
\pm 0,9\end{array}$ & $\begin{array}{l}* * * \\
* * *\end{array}$ & $\begin{array}{l}86,1 \\
94,3\end{array}$ & $\begin{array}{l} \pm \\
\pm\end{array}$ & $\begin{array}{l}2,5 \\
0,4\end{array}$ & $\begin{array}{l}76,7 \\
93,0\end{array}$ & $\begin{array}{l} \pm 2,7 \\
\pm 0,7\end{array}$ & $\begin{array}{l}* * * \\
* * *\end{array}$ \\
\hline $\mathrm{Mg}^{2+}$ & $\begin{array}{l}{\left[\mu \mathrm{mol} / \mathrm{g}_{\mathrm{oww}}\right]} \\
{\left[\% \mathrm{CEC}_{\text {eff. }}\right]}\end{array}$ & $\begin{array}{l}2,5 \\
3,1\end{array}$ & $\begin{array}{l} \pm \quad 0,2 \\
\pm 0,2\end{array}$ & $\begin{array}{l}4,5 \\
6,2\end{array}$ & $\begin{array}{l} \pm \mathbf{0 , 1} \\
\pm 0,6\end{array}$ & $\begin{array}{l}* * * \\
* * *\end{array}$ & $\begin{array}{l}3,4 \\
3,8\end{array}$ & $\begin{array}{l} \pm \\
\pm\end{array}$ & $\begin{array}{l}\mathbf{0 , 4} \\
0,3\end{array}$ & $\begin{array}{l}4,0 \\
4,7\end{array}$ & $\begin{array}{l} \pm 0,3 \\
\pm 0,5\end{array}$ & $\underset{* * \star}{\text { n.s. }}$ \\
\hline $\mathrm{K}^{+}$ & $\begin{array}{l}{\left[\mu \mathrm{mol} / \mathrm{g}_{\mathrm{ow}}\right]} \\
{\left[\% \mathrm{CEC}_{\text {eff. }}\right]}\end{array}$ & $\begin{array}{l}2,9 \\
1,8\end{array}$ & $\begin{array}{l}\mathbf{\pm} \quad \mathbf{0 , 2} \\
\pm \quad 0,2\end{array}$ & $\begin{array}{l}\mathbf{2 , 1} \\
1,5\end{array}$ & $\begin{array}{l} \pm \mathbf{0 , 2} \\
\pm 0,2\end{array}$ & $\begin{array}{l}* * * \\
*\end{array}$ & $\begin{array}{l}3,2 \\
1,7\end{array}$ & $\begin{array}{l} \pm \\
\pm\end{array}$ & $\begin{array}{l}\mathbf{0 , 2} \\
0,2\end{array}$ & $\begin{array}{l}2,4 \\
1,5\end{array}$ & $\begin{array}{l} \pm \quad 0,2 \\
\pm 0,2\end{array}$ & ${ }_{* * *}^{* *}$ \\
\hline $\mathrm{Na}^{+}$ & $\begin{array}{l}{\left[\mu \mathrm{mol} / \mathrm{g}_{\mathrm{oww}}\right]} \\
{\left[\% \mathrm{CEC}_{\text {eff }}\right]}\end{array}$ & $\begin{array}{l}\mathbf{0 , 4} \\
0,2\end{array}$ & $\begin{array}{l} \pm \quad 0,2 \\
\pm 0,1\end{array}$ & $\begin{array}{l}\mathbf{0 , 7} \\
0,5\end{array}$ & $\begin{array}{l} \pm \mathbf{0 , 1} \\
\pm 0,1\end{array}$ & $\begin{array}{l}* * * \\
* * *\end{array}$ & $\begin{array}{l}\mathbf{0 , 4} \\
0,2\end{array}$ & $\begin{array}{l} \pm \\
\pm\end{array}$ & $\begin{array}{l}\mathbf{0 , 1} \\
0,0\end{array}$ & $\begin{array}{l}\mathbf{0 , 5} \\
0,3\end{array}$ & $\begin{array}{l} \pm \mathbf{0 , 0} \\
\pm 0,0\end{array}$ & ${ }_{* *}^{* *}$ \\
\hline $\mathrm{Fe}^{3+}$ & $\begin{array}{l}{\left[\mathrm{nmol} / \mathrm{g}_{\mathrm{ow}}\right]} \\
{\left[\% \mathrm{CEC}_{\text {eff. }}\right]}\end{array}$ & $\begin{array}{l}\mathbf{0 , 0} \\
0,0\end{array}$ & $\begin{array}{l} \pm 0,0 \\
\pm 0,0\end{array}$ & $\begin{array}{l}\mathbf{5 , 5} \\
0,0\end{array}$ & $\begin{array}{l} \pm \mathbf{5 , 5} \\
\pm 0,0\end{array}$ & $\begin{array}{l}* * \\
*\end{array}$ & $\begin{array}{l}\mathbf{0 , 0} \\
0,0\end{array}$ & $\begin{array}{l} \pm \\
\pm\end{array}$ & $\begin{array}{l}\mathbf{0 , 0} \\
0,0\end{array}$ & $\begin{array}{l}\mathbf{0 , 0} \\
0,0\end{array}$ & $\begin{array}{l} \pm 0,0 \\
\pm 0,0\end{array}$ & $\begin{array}{l}\text { n.s. } \\
\text { n.s. }\end{array}$ \\
\hline $\mathrm{Mn}^{2+}$ & $\begin{array}{l}{\left[\mathrm{nmol} / \mathrm{g}_{\mathrm{ow}}\right]} \\
{\left[\% \mathrm{CEC}_{\text {eff. }}\right]}\end{array}$ & $\begin{array}{r}\mathbf{2 2 , 9} \\
0,0\end{array}$ & $\begin{array}{l} \pm 6,2 \\
\pm 0,0\end{array}$ & $\begin{array}{r}647 \\
0,9\end{array}$ & $\begin{array}{l} \pm \mathbf{2 9 1} \\
\pm 0,4\end{array}$ & $\begin{array}{l}* * * \\
* * *\end{array}$ & $\begin{array}{r}29,9 \\
0,0\end{array}$ & $\begin{array}{l} \pm \\
\pm\end{array}$ & $\begin{array}{l}12,4 \\
0,0\end{array}$ & $\begin{array}{r}407 \\
0,5\end{array}$ & $\begin{array}{l} \pm 144 \\
\pm 0,2\end{array}$ & $\begin{array}{l}* * * \\
* * *\end{array}$ \\
\hline $\mathrm{Al}^{3+}$ & $\begin{array}{l}{\left[\mathrm{nmol} / \mathrm{g}_{\mathrm{ow}}\right]} \\
{\left[\% \mathrm{CEC}_{\text {eff }}\right]}\end{array}$ & $\begin{array}{l}\mathbf{0 , 0} \\
0,0\end{array}$ & $\begin{array}{l} \pm 0,0 \\
\pm 0,0\end{array}$ & $\begin{array}{l}\mathbf{0 , 0} \\
0,0\end{array}$ & $\begin{array}{l} \pm \mathbf{0 , 0} \\
\pm 0,0\end{array}$ & $\begin{array}{l}\text { n.s. } \\
\text { n.s. }\end{array}$ & $\begin{array}{l}\mathbf{0 , 0} \\
0,0\end{array}$ & $\begin{array}{l} \pm \\
\pm\end{array}$ & $\begin{array}{l}\mathbf{0 , 0} \\
0,0\end{array}$ & $\begin{array}{l}\mathbf{0 , 0} \\
0,0\end{array}$ & $\begin{array}{l} \pm \quad 0,0 \\
\pm 0,0\end{array}$ & $\begin{array}{l}\text { n.s. } \\
\text { n.s. }\end{array}$ \\
\hline $\mathrm{Zn}^{2+}$ & $\begin{array}{l}{\left[\mathbf{n m o l} / \mathbf{g}_{\mathrm{Dw}}\right]} \\
{\left[\% \mathrm{CEC}_{\text {eff. }}\right]}\end{array}$ & $\begin{array}{l}\mathbf{0 , 6} \\
0,0\end{array}$ & $\begin{array}{l} \pm 0,6 \\
\pm 0,0\end{array}$ & $\begin{array}{r}21,5 \\
0,0\end{array}$ & $\begin{array}{l} \pm 10,1 \\
\pm 0,0\end{array}$ & ${ }_{* * *}^{* *}$ & $\begin{array}{l}1,7 \\
0,0\end{array}$ & $\begin{array}{l} \pm \\
\pm\end{array}$ & $\begin{array}{l}\mathbf{0 , 5} \\
0,0\end{array}$ & $\begin{array}{l}2,0 \\
0,0\end{array}$ & $\begin{array}{l} \pm 0,9 \\
\pm 0,0\end{array}$ & $\begin{array}{l}\text { n.s. } \\
\text { n.s. }\end{array}$ \\
\hline $\mathrm{H}^{+}$ & $\begin{array}{l}{\left[\mathrm{nmol} / \mathrm{g}_{\mathrm{Dw}}\right]} \\
{\left[\% \mathrm{CEC}_{\text {eff. }}\right]}\end{array}$ & $\begin{array}{l}\mathbf{0 , 1} \\
0,0\end{array}$ & $\begin{array}{l} \pm 0,1 \\
\pm 0,0\end{array}$ & $\begin{array}{r}90,0 \\
0,1\end{array}$ & $\begin{array}{l} \pm \quad 36,8 \\
\pm 0,0\end{array}$ & $\begin{array}{l}* * * \\
* * *\end{array}$ & $\begin{array}{l}\mathbf{0 , 1} \\
0,0\end{array}$ & $\begin{array}{l} \pm \\
\pm\end{array}$ & $\begin{array}{l}\mathbf{0 , 1} \\
0,0\end{array}$ & $\begin{array}{l}\mathbf{0 , 2} \\
0,0\end{array}$ & $\begin{array}{l} \pm \quad 0,1 \\
\pm 0,0\end{array}$ & $\begin{array}{l}\text { n.s. } \\
\text { n.s. }\end{array}$ \\
\hline
\end{tabular}


Mit Werten von $16,7 \mathrm{mmol}_{\mathrm{C}} \cdot 100 \mathrm{~g}_{\mathrm{TG}}{ }^{-1}$ bzw. $18,3 \mathrm{mmol}_{\mathrm{C}} \cdot 100 \mathrm{~g}_{\mathrm{TG}}{ }^{-1}$ liegen die effektiven Kationenaustauschkapazitäten der typischen Subassoziation des Gentiano-Koelerietum um 16\% bzw. 10\% über denen der Subassoziation von Danthonia decumbens. Desgleichen übersteigen die Basensättigungen der CC-Bestände signifikant diejenigen der CF-Bestände. Die Mediane erreichen hier nach Rundung der zweiten Dezimalstelle $100 \%$. Geringfügig niedrigere Basensättigungen der CF-Einheiten sind offenbar auf eine etwas weiter fortgeschrittene Bodenverwitterung zurückzuführen, die mit einer absoluten und prozentualen Abnahme der Ca-Belegung der Kationenaustauscher einhergeht. Allerdings liegt diese auch im Gentiano-Koelerietum danthonietosum noch bei mehr als $90 \%$.

Nur in wenigen Fällen zeigen die Analysen der Austauscherextrakte eine gute Übereinstimmung mit denen der rein wässrigen Bodenextrakte. Beispielsweise verweisen sowohl die $\mathrm{H}_{2} \mathrm{O}$ - als auch $\mathrm{BaCl}_{2-}$ Extraktionen auf eine bessere feinerdebezogene K-Verfügbarkeit im Gentiano-Koelerietum typicum. Andererseits werden die CC/CF-Verhältnisse der GBL für die Standorte Auf der Burg und Hölleberg für manche Elemente nicht bestätigt. Austauscherextrakte lassen für beide Standorte eine etwas bessere MgVerfügbarkeit im Gentiano-Koelerietum danthonietosum vermuten. Bemerkenswert sind auch die MnAnalysen: Während sich die beiden Vegetationsbestände des Standorts Hölleberg hinsichtlich der MnKonzentrationen in den GBL, PBL und DBL nicht unterscheiden, kennzeichnen die CEC-Lösungen eine Mn-Austauscherbelegung des CF-Bodens, die diejenige des Vergleichsbestands um einen Faktor 14 übersteigt. Betrug die GBL-bezogene Mn-Löslichkeit der Feinerde des Bestands Auf der Burg-CF nur etwa das Fünffache der Vergleichsfläche, so findet sich hier für die $\mathrm{BaCl}_{2}$-Extrakte ein dreißigfach höherer Wert.

Diese Unterschiede gehen insbesondere darauf zurück, dass durch die wässrigen Extraktionsverfahren der CF-Varianten im Schnitt nur 0,25\% des Mn der sorbierten Fraktion erfasst wird (Tabelle 14). Demgegenüber beträgt die Ausbeute für die CC-Bestände etwa 4\%. Die CEC-bezogenen GBL-Extraktionseffizienzen der meisten Elemente liegen in einem Bereich von $1 \%$ bis $5 \%$. Abweichungen von diesem Bild zeigen $\mathrm{Na}(31,7 \%)$ und $\mathrm{Fe}(100 \%)$. In der Regel konnte in den $\mathrm{BaCl}_{2}$-Austauscherlösungen kein $\mathrm{Fe}$ nachgewiesen werden. Außer für den CF-Bestand des Standorts Auf der Burg geben die Ergebnisse der $\mathrm{Ba}^{2+}$-Extraktionen keine Hinweise auf sorptiv gebundenes Eisen in den hier untersuchten Böden. In allen Fällen lagen die Konzentrationen an austauschbarem $\mathrm{Al}$ bei bodeneigenen $\mathrm{pH}$-Werten unterhalb der Nachweisgrenze.

Tabelle 14: Prozentuale Beziehung zwischen den $\mathrm{H}_{2} \mathrm{O}$-extrahierbaren und sorptiv gebundenen Fraktionen ausgewählter Nährelemente nach $b(G B L) / b\left(B a C l_{2}\right) \cdot 100$. Median $\pm M A D(n=16)$.

\begin{tabular}{lrrrrr}
\hline Element & \multicolumn{2}{c}{ Auf der Burg } & \multicolumn{2}{c}{ Hölleberg } & Pool \\
& \multicolumn{1}{c}{ CC } & \multicolumn{1}{c}{ CF } & \multicolumn{1}{c}{ CC } & \multicolumn{1}{c}{ CF } & \\
\hline $\mathbf{F e}$ & $100,0 \pm 0,0$ & $28,2 \pm 24,1$ & $100,0 \pm 0,0$ & $100,0 \pm 0,0$ & 100,0 \\
$\mathbf{M n}$ & $4,5 \pm 1,5$ & $0,2 \pm 0,1$ & $3,6 \pm 1,7$ & $0,3 \pm 0,1$ & 1,9 \\
$\mathbf{C a}$ & $4,1 \pm 0,5$ & $2,5 \pm 1,0$ & $2,5 \pm 0,2$ & $2,7 \pm 0,4$ & 2,6 \\
$\mathbf{M g}$ & $4,6 \pm 0,5$ & $2,4 \pm 1,5$ & $4,9 \pm 0,5$ & $4,5 \pm 0,4$ & 4,5 \\
$\mathbf{K}$ & $2,2 \pm 0,6$ & $1,0 \pm 0,7$ & $1,8 \pm 0,6$ & $1,7 \pm 0,3$ & 1,8 \\
$\mathbf{N a}$ & $38,2 \pm 9,1$ & $20,3 \pm 3,9$ & $33,3 \pm 5,4$ & $30,0 \pm 3,1$ & 31,7 \\
\hline
\end{tabular}




\subsubsection{Verfügbarkeit essentieller Schwermetalle}

Ein zentraler Aspekt der vorliegenden Arbeit zum Auftreten acidophiler/calcifuger Arten in Kalk-Halbtrockenrasen ist die pflanzliche Fe-Verfügbarkeit. Neben der wasserlöslichen Fraktion, die bereits in Abschnitt 3.2.2 für die beiden Standorte Auf der Burg und Hölleberg behandelt wurde, sollen im Folgenden für alle Untersuchungsbestände die Ergebnisse einer weiter führenden Fraktionierung des bodenbürtigen Fe vorgestellt werden. Geeignete Extraktionsmittel dienten hier aber nicht nur der Spezifizierung verschiedener Eisenfraktionen sondern auch derjenigen anderer essentieller Schwermetalle der pflanzlichen Mineralstoffernährung, namentlich Mangan, Kupfer und Zink. Für die CC- und CF-Bestände des Standorts Hölleberg wurden in Bodenmonolithen der Umfang und die Geschwindigkeit oxidoreduktiver Reaktionen des Fe und Mn untersucht. Abschließend sollen in diesem Kapitel die Ergebnisse eines Experiments vorgestellt werden, im Rahmen dessen nach Zusatz definierter Fe-Chelatlösungen das Ausmaß der Fe-Immobilisierung bzw. Fe-Mobilisierung in den Böden der beiden Subassoziationen des Standorts Auf der Burg untersucht wurde.

\section{Eisenimmobilisierung im Rahmen wässriger Bodenextraktionen}

Gelöste Fe-Spezies und hier v. a. freie $\mathrm{Fe}^{2+}$-Ionen können während der Herstellung, Lagerung und Präparation von wässrigen Bodenextrakten immobilisiert und damit ihrem quantitativen Nachweis entzogen werden. Darauf verweisen die Fe-Konzentrationen in den PBL und DBL, die unmittelbar nach Abschluss der Extraktion ohne Aufreinigung durch Ultrazentrifugation und Membranfiltration aufkonzentriert und kolorimetrisch bestimmt wurden. Für die Aufkonzentrierung wurden 7,0 ml der betreffenden Lösungen eingeengt und in 2,5 ml Assay-Volumen resuspendiert. Die sehr geringe Abweichung der molaren Extinktionskoeffizienten von $25404 \mathrm{M}^{-1} \cdot \mathrm{cm}^{-1}$ und $25606 \mathrm{M}^{-1} \cdot \mathrm{cm}^{-1}$ für Konzentrationsreihen nicht eingeengter bzw. eingeengter Fe-EDTA-Standardlösungen belegten die Zuverlässigkeit dieses Verfahrens.

Tabelle 15: Fe-Konzentrationen [nmol $\cdot g_{F E-T G}^{-1}$ in PBL und DBL der CC- und CF-Bestände der Standorte Auf der Burg und Hölleberg, die nicht durch Ultrazentrifugation und Membranfiltration aufgereinigt wurden. Median \pm MAD ( $n=8)$; Sternsignaturen kennzeichnen Ergebnisse der nicht-parametrischen paarweisen Vergleiche CC vs. CF und PBL vs. DBL nach Mann-Whitney (n.s. $\alpha>0,05, * \alpha \leq 0,050, * * \alpha \leq 0,010, * * * \alpha \leq 0,001$ ).

\begin{tabular}{|c|c|c|c|c|}
\hline \multirow[t]{2}{*}{ Standort } & \multirow[t]{2}{*}{ Lösung } & \multicolumn{2}{|c|}{$\mathrm{c}(\mathrm{Fe})\left[\mathrm{nmol} \cdot \mathrm{g}^{-1} \mathrm{FE}-\mathrm{TG}\right]$} & \multirow[b]{2}{*}{ CC vs. $\mathrm{CF}$} \\
\hline & & CC & $\mathrm{CF}$ & \\
\hline \multirow{3}{*}{ Auf der Burg } & PBL & $1,40 \pm 0,12$ & $3,07 \pm 1,28$ & ** \\
\hline & DBL & $3,25 \pm 0,69$ & $8,93 \pm 1,12$ & $* * *$ \\
\hline & PBL vs. DBL & $* * *$ & $* * *$ & \\
\hline \multirow[t]{3}{*}{ Hölleberg } & PBL & $0,25 \pm 0,16$ & $1,12 \pm 0,04$ & ** \\
\hline & DBL & $1,44 \pm 0,23$ & $8,48 \pm 2,20$ & $\star * *$ \\
\hline & PBL vs. DBL & *** & *** & \\
\hline
\end{tabular}

\section{Aspekte der Eisenextraktion mit Ferrozine ${ }^{\circledR}$}

Die Entwicklung des Ferrozine ${ }^{\circledR}$-Extraktionsverfahrens folgte den oben dargestellten Hinweisen auf eine Ausfällung von Fe während der rein wässrigen Bodenextraktionen sowie den methodischen Problemen, die sich im Rahmen der Quantifizierung labiler Fe-Fraktionen ergaben. Durch Schüttelung von feldfrischem Bodenmaterial mit dem Chelatbildner wird $\mathrm{Fe}^{2+}$ komplexiert und stabilisiert, bevor eine oxidative Immobilisierung zweiwertiger Eisenverbindungen erfolgen kann. Damit ist die in vielerlei Hinsicht zu- 
verlässigere und praktikablere Verwendung von Feinerdehomogenaten für den Nachweis von $\mathrm{Fe}^{2+}$ v.a. auch aus microsites mit niedrigen Redoxpotenzialen möglich.

Die Ferrozine ${ }^{\circledR}$-Extraktion feldfrischer Feinerdehomogenate erfolgte analog der GBL-Herstellung. Diese hinsichtlich des Verhältnisses Bodenmaterial :Extraktionsmittel sowie der Extraktionszeit standardisierten Untersuchungen geben noch keine Aussagen über den Ursprung des komplexierten Fe(II). Neben der Erfassung freier $\mathrm{Fe}^{2+}$-Ionen kann eine Lösung von gebundenem $\mathrm{Fe}(\mathrm{II})$ u.a. aus Fe-haltigen Mineralien nicht ausgeschlossen werden. Nach Lindsay (1988) liegt zweiwertiges Eisen in Bodenmineralien v. a. in Form von Mg-Silikaten vor. Komplexierungskinetiken erlauben Rückschlüsse auf die Herkunft des $\mathrm{Fe}^{2+}$. Falls ausschließlich freie $\mathrm{Fe}^{2+}$-Ionen extrahiert werden, sollte allenfalls eine geringe Abhängigkeit der Fe(II)-Ferrozine ${ }^{\circledR}$-Komplexierung von der Extraktionszeit existieren. Gleichzeitig ist in diesem Fall davon auszugehen, dass die Ferrozine ${ }^{\circledR}$-Konzentration von untergeordneter Bedeutung für das Ausmaß der $\mathrm{Fe}^{2+}$ Komplexierung ist. Abbildung 46 zeigt die Ergebnisse von Untersuchungen an Bodenmaterial der beiden CC- und CF-Vergleichsbestände des Standorts Auf der Burg.

Die Untersuchungen belegen eine Sättigungskinetik der Ferrozine ${ }^{\circledR}-\mathrm{Fe}^{2+}$-Komplexierung aus feldfrischem Bodenhomogenat (Abbildung 46 A). Hohe Raten innerhalb der ersten Stunde lassen eine schnelle Bindung von freien und labil gebundenen $\mathrm{Fe}^{2+}$-Ionen vermuten. Im Zeitraum von $15 \mathrm{~min}$ bis $30 \mathrm{~min}$ sind die Fe-Komplexierungsraten für die Böden beider Vegetationstypen des Gentiano-Koelerietum nahezu identisch. Die in der Folge deutlich stärkere und anhaltende Lösung von Fe(II) aus Böden des CF-Bestands kennzeichnet Unterschiede im Gehalt stabilerer, Ferrozine ${ }^{\circledR}$-extrahierbarer Fe-Fraktionen.

Wie die Extraktionskinetiken, so lassen auch die Untersuchungen zum Einfluss der Ferrozine ${ }^{\circledR}$-Konzentration auf die Erfassung von adsorbierten oder in anderer Art gebundener Fe(II)-Fraktionen schließen (Abbildung 46 B). Eine besonders starke Abhängigkeit von der Extraktionsmittelkonzentration zeigt die Fe(II)-Komplexierung aus dem Boden des Gentiano-Koelerietum danthonietosum. Die Erhöhung der Ferrozine $^{\circledR}$-Konzentration von $125 \mu \mathrm{M}$ auf $2000 \mu \mathrm{M}$ zieht für Bodenmaterial des CC-Bestand eine etwa 30fach, für solches des CF-Bestands eine 40fach höhere Fe-Komplexierung nach sich.
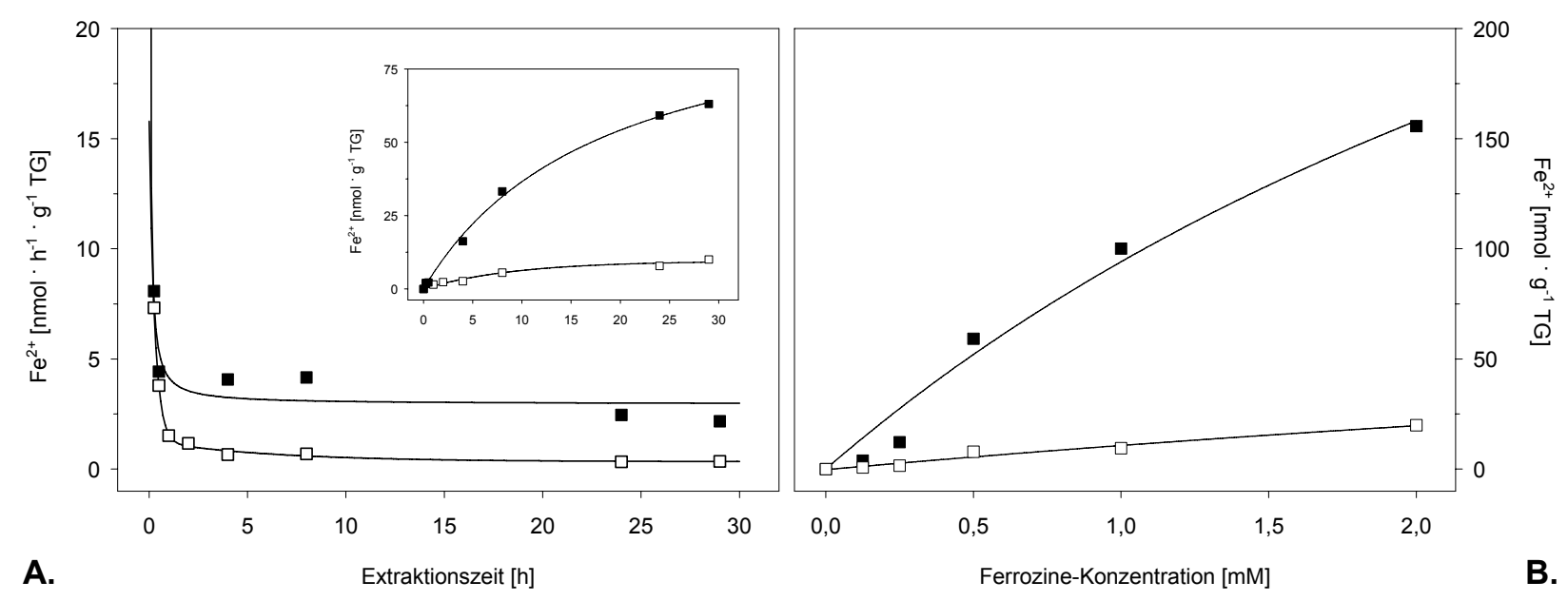

Abbildung 46: Abhängigkeit der $\mathrm{Fe}^{2+}$-Komplexierung von (A.) der Extraktionsdauer $\left[\mathrm{nmol} \cdot h^{-1} \cdot \mathrm{g}^{-1} \mathrm{FE}-\mathrm{TG}\right.$ ] und (B.) der Ferrozine ${ }^{\circledR}$-Konzentration [nmol $\cdot g^{-1}{ }_{F E-T G}$ ] in Böden von CC-Beständen ( $\square$ ) und CF-Beständen $(\boldsymbol{\square})$ des Standorts Auf der Burg. Die eingefügte Graphik in Abbildung A zeigt die kumulierten Konzentrationen des komplexierten $\mathrm{Fe}^{2+}\left[\mathrm{nmol} \cdot \mathrm{g}_{\mathrm{FE}-\mathrm{TG}}^{-1}\right]$ im Verlauf der Bodenextraktion. $\mathrm{MW}(n=3)$. 


\section{Fraktionierung essentieller Schwermetalle}

Die nachfolgend beschriebenen nicht sequentiellen Bodenextraktionen dienen der Untersuchung verschiedener Fe-, Mn-, Zn- und Cu-Fraktionen und ihrer potenziellen Bedeutung für die Vegetationsdifferenzierung von Kalk-Halbtrockenrasen. Ergänzend zu den vergleichenden Analysen von Extrakten feldfrischer Feinerdehomogenate der CC- und CF-Beständen aller Standorte wurde für Material der Referenzstandorte Auf der Burg und Hölleberg auch der Einfluss unterschiedlicher Vorbehandlungen des Probenmaterials untersucht.

\section{Einfluss der Präparation des Bodenmaterials auf die Extraktion verschiedener Schwermetalle}

Neben der Quantifizierung (mehr oder weniger) definierter Schwermetallfraktionen durch die Verwendung verschiedener Extraktionsmittel verfolgen diese Untersuchungen mit der Variation der Extraktionsverfahren hinsichtlich Bodenstruktur und Bodenlagerung (feldfrisch/lufttrocken) zugleich die grundlegende Frage nach der sinnvollsten Präparation des Bodenmaterials für standardisierte Schwermetallanalysen. Alle diesbezüglichen Faktoren und Variablen sind in Tabelle 16 aufgeführt.

Tabelle 16: Versuchsfaktoren und -variablen zur Untersuchung der Bedeutung verschiedener Schwermetallfraktionen für die Vegetationsdifferenzierung von Kalk-Halbtrockenrasen.

\begin{tabular}{lllll}
\hline Standort & Bestand & Struktur/Lagerung & Element & Extraktionsmittel \\
\hline Auf der Burg & G.-K. typicum (CC) & Bodenmonolith, feldfrisch & Eisen & Acetat \\
Hölleberg & G.-K. danthon. (CF) & FE-Homogenat, feldfrisch & Mangan & DTPA \\
& & FE-Homogenat, lufttrocken & Zink & NTA \\
& & Kupfer & Oxalat \\
& & & Dithionit \\
\hline
\end{tabular}

Stellvertretend für alle anderen Schwermetalle werden im Folgenden die Ergebnisse der Fe-Extraktionen besprochen. Neben den in Tabelle 16 genannten Faktorenkombinationen werden in Abbildung 47 auch die Analysenergebnisse zeitgleich hergestellter PBL und GBL, also rein wässriger Extrakte feldfrischer Bodenmonolithen und Feinerdehomogenate, gezeigt. ${ }^{1}$ Die Ergebnisse für die Ammoniumacetat-Untersuchungen sind in einigen Fällen nicht normalverteilt, wurden im Hinblick auf eine einheitliche Darstellung aber dennoch parametrisch behandelt und durch geeignete nicht-parametrische Verfahren überprüft. Bei den multifaktoriellen Varianzanalysen, die in Tabelle A 8 im Anhang (S. 306) dargestellt sind, trugen Anpassungen der Signifikanzgrenzen der fehlenden Normalverteilung und/oder Varianzhomogenität Rechnung.

Abbildung 47 verweist in allen Fällen auf eine im Vergleich zur Horizontalschüttelung von Feinerde geringere Fe-Extraktionseffizienz der Perkolation von Bodenmonolithen. Signifikant geringere perkolative Extraktionen können auch für die Mehrzahl der anderen Schwermetalle belegt werden. Hohe Zn- und Cu-Konzentrationen insbesondere in den DTPA-Extrakten zeigen aber, dass bei der Verwendung von Messingzylindern für die Entnahme der Bodenmonolithen Kontaminationen durch eine unverzügliche Überführung der Bodenkerne in Plexiglaszylinder verhindert werden müssen.

\footnotetext{
1 Die Ergebnisse aller anderen Schwermetallextraktionen sind in Tabelle A 4 für den Vergleich von CC- und CF-Beständen, in Tabelle A 5 für den Vergleich der Extraktionsverfahren aufgeführt. Tabelle A 8 schließlich zeigt die Ergebnisse der multifaktoriellen, univariaten Varianzanalyse mit den Faktoren Standort, Bestand und Lagerung sowie den betreffenden Feinerdekonzentrationen der Schwermetallfraktionen als abhängige Variable.
} 

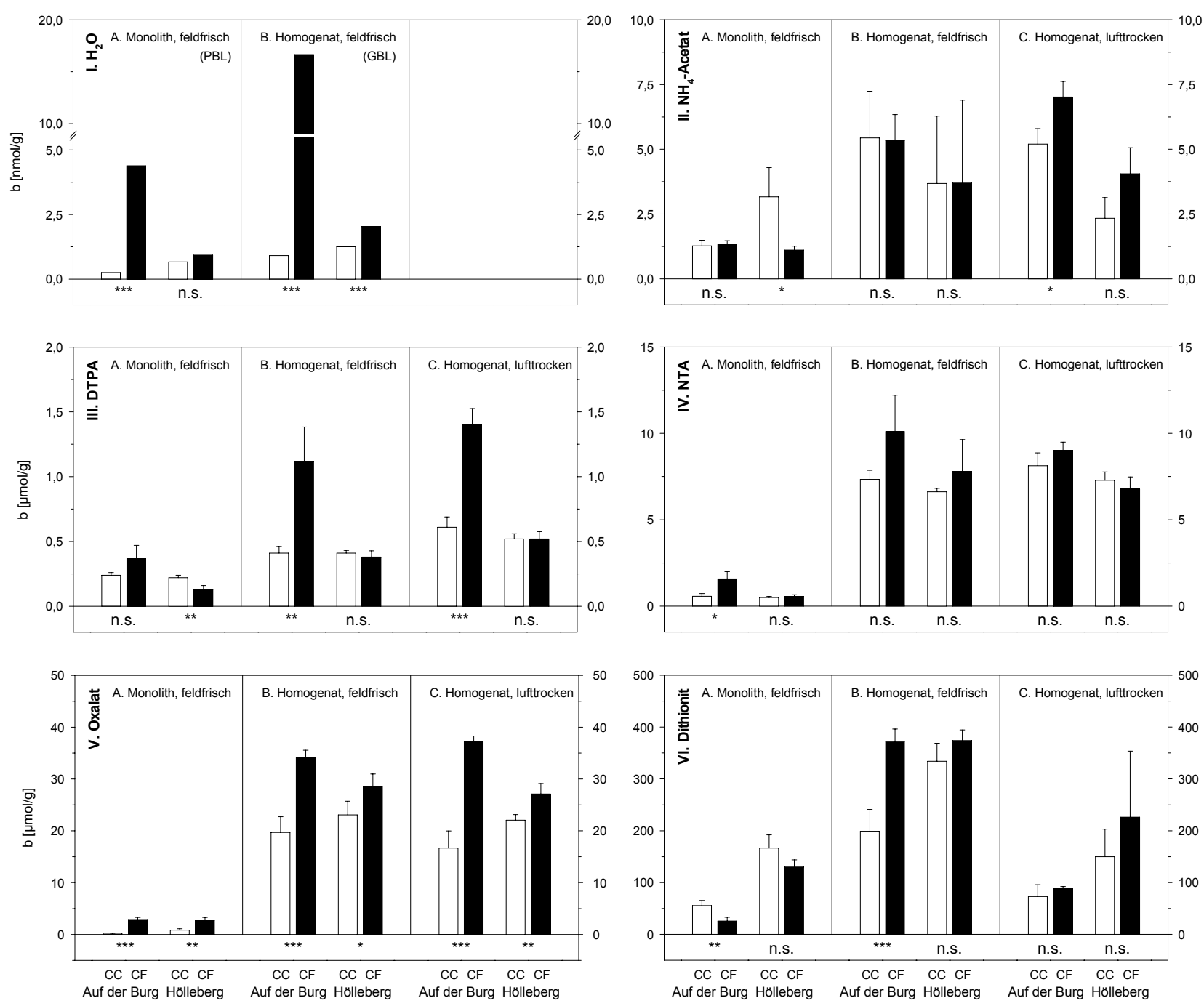

Abbildung 47: Fe-Löslichkeiten der Feinerde $\left[\mathrm{mol} \cdot \mathrm{g}_{\mathrm{TG}}{ }^{-1}\right]$ von CC- und CF-Beständen der Referenzstandorte Auf der Burg und Hölleberg nach Extraktion von Bodenmaterial unterschiedlicher Struktur und Lagerung (A. Bodenmonolithe, feldfrisch, B. Feinerdehomogenat, feldfrisch, C. Feinerdehomogenat, lufttrocken) mit I. $\mathrm{H}_{2} \mathrm{O}$, II. $\mathrm{NH}_{4}$-Acetat, III. DTPA, IV. NTA, V. Oxalat und VI. Dithionit. MW $\pm S D(n=4)$ bzw. (für I.) Mediane ( $\left.n=48\right)$; Sternsignaturen kennzeichnen Ergebnisse der paarweisen Vergleiche CC vs. CF mittels Student-t-Tests bzw. UTests nach Mann-Whitney (I.) (n.s. $\alpha>0,05, * \alpha \leq 0,050$, ** $\alpha \leq 0,010$, *** $\alpha \leq 0,001$ ).

Die Ammoniumoxalat- und Dithionitextraktionen von Bodenmonolithen sind unter methodischen Gesichtspunkten unbefriedigend. Offensichtlich wird durch die saure Oxalatlösung das $\mathrm{CaCO}_{3}$ des Bodenmaterials gelöst. Besonders bei der CC-Variante des Standorts Auf der Burg verursachte dies einen Überdruckaufbau und darüber Leckagen in der Extraktionsapparatur. Dithionit-Lösungen vermindern die hydraulische Leitfähigkeit und führten in einigen Fällen zu einem Perkolationsstau. Während trotz der genannten Komplikationen die Ergebnisse der perkolativen Fe-Extraktion mit Oxalat hinsichtlich der CC/CF-Verhältnisse mit denen der Extraktion feldfrischer und lufttrockener Feinerdehomogenate übereinstimmen, stehen im Fall der Dithionitextraktion signifikant (Auf der Burg) oder tendenziell (Hölleberg) niedrigere Fe-Konzentrationen bei der Behandlung von Bodenmonolithen des Gentiano-Koelerietum danthonietosum den Ergebnissen der beiden anderen Extraktionsverfahren entgegen. Diese Abweichungen sind wahrscheinlich auf die höheren Feinerdegehalte und die durch Dithionit weiter verminderten Flussraten in den CF-Monolithen zurückzuführen. 
Auch die Lufttrocknung von Feinerdehomogenaten beeinträchtigt die Fe-Extraktion durch Dithionit. Entsprechendes gilt für Zn. Ein positiver Trocknungseffekt kann für die Fe- und Mn-Extraktion durch DTPA sowie für die Mn-Extraktion mit NTA nachgewiesen werden. Im Vergleich zu den Ergebnissen von Leggett \& Argyle (1983) und Geiger \& Loeppert (1994) ist der Einfluss der Bodentrocknung auf die DTPA-Extraktion in den eigenen Untersuchungen aber gering. Einer Stimulation der Fe-Extraktion durch Lufttrocknung zwischen $25 \%$ und $50 \%$ in den eigenen Untersuchungen stehen hier zwei- bis vierfach erhöhte Extraktionsraten gegenüber.

Im Allgemeinen stimmen die Ergebnisse der drei Extraktionsverfahren für die relativen Schwermetallverfügbarkeiten in den CC- und CF-Bestände recht gut überein. Dies gilt insbesondere für die beiden Feinerdeextraktionsverfahren. Wie beschrieben unterscheiden sich in Einzelfällen die Ergebnisse, die mittels Perkolation von Bodenmonolithen und Horizontalschüttelung von Feinerdehomogenaten für die beiden Vegetationseinheiten gewonnen wurden. Voneinander abweichende Ergebnisse lassen sich auf die oben ausgeführten Probleme bei der Perkolation von Bodenmonolithen zurückführen. In anderen Fällen können aber vergleichsweise geringe Unterschiede zwischen CC- und CF-Beständen, wie sie für Feinerdehomogenate ermittelt wurden, durch Extrakte von Bodenmaterial natürlicher Lagerung deutlicher abgebildet und erst darüber statistisch abgesichert werden. Dies deutet auf Unterschiede in der räumlichen Verteilung der durch die verschiedenen Extraktionsmittel erfassten Fe-Fraktionen im Porensystem hin. So bestätigen beispielsweise die NTA-Perkolationen der Böden des Standorts Auf der Burg höhere Gehalte des organisch gebundenen Eisens in den CF-Beständen, die im Rahmen der Extraktion feldfrischer und lufttrockener Feinerdehomogenate nur in der Tendenz zu Tage traten.

Perkolationen von Bodenmonolithen sind methodisch aufwändig und störanfällig, haben auch dadurch hohe Variabilitäten zur Folge und führen bei der Verwendung verschiedener Extraktionsmitteln zu unbefriedigenden Resultaten. Angesichts des vergleichsweise geringen Einflusses der verschiedenen Verfahren auf die relative Schwermetallextraktion wurde in den Untersuchungen aller Vergleichsstandorte im Unteren Diemeltal und am Südharzrand auf die Herstellung von Extrakten feldfrischer Bodenmonolithe und lufttrockener Feinerdehomogenate verzichtet. Die Schüttelung feldfrischer Feinerde mit den verschiedenen Extraktionsmitteln ist besonders praktikabel und berücksichtigt bei einer unmittelbaren Vergleichbarkeit mit den Analysenergebnissen für die GBL der rein wässrigen Bodenextraktionen in ausreichendem Maß die in situ-Bedingungen der Standorte.

\section{Schwermetallfraktionen feldfrischer Feinerdehomogenate}

Die nachfolgenden Abschnitte fassen die Ergebnisse der Fe-, Mn-, Zn- und Cu-Fraktionierungen der feldfrischen Feinerdehomogenate aller hier untersuchten Kalk-Halbtrockenrasen zusammen. Während sich die Analysen der Zn- und Cu-Verfügbarkeiten auf Extraktionen mit DTPA, NTA, Ammoniumoxalat und Dithionit beschränkten, wurden für Fe Untersuchungen auch anhand von GBL sowie Ferrozine ${ }^{\circledR}$-Extrakten, für Mn auch solche anhand von GBL und Acetat-Extrakten durchgeführt. ${ }^{1}$

\footnotetext{
1 Ergänzend zu den Ergebnissen der Student-t-Tests (bzw. Mann-Whitney-Tests für GBL- und Pool-Ergebnisse) in den nachfolgenden Abbildungen und Tabellen für die CC/CF-Vergleiche eines Standorts werden in Tabelle A 9 für alle Versuchsstandorte die Ergebnisse univariater Varianzanalysen mit den Faktoren Standort und Bestand dargestellt.
} 


\section{Eisen-Fraktionen}

Die Graphiken der Abbildung 48 stellen die feinerdebezogenen Löslichkeiten der verschiedenen Fe-Fraktionen in den CC- und CF-Beständen aller Untersuchungsstandorte dar. Die Angaben der Konzentrationsverhältnisse zwischen den Vergleichsbeständen eines Standorts sowie aller Untersuchungsstandorte ("Pool") in Tabelle 17 erlauben einen schnellen Überblick über die Unterschiede zwischen den beiden Subassoziationen des Gentiano-Koelerietum.

GBL-Analysen der Vergleichsbestände im Unteren Diemeltal und am Südharzrand bestätigen die Untersuchungen für die Referenzstandorte Auf der Burg und Hölleberg aus Abschnitt 3.2.2. Danach liegen in der Bodenlösung des Gentiano-Koelerietum danthonietosum deutlich höhere wasserlösliche Fe-Gehalte vor als in der des Gentiano-Koelerietum typicum. Die feinerdebezogenen Fe-Konzentrationen der wasserlöslichen Fraktion in den CF-Beständen übersteigen die der CC-Bestände median um das Fünffache. Mit Ausnahme derer für den Standort Hölleberg-Süd sind diese Unterschiede statistisch signifikant.
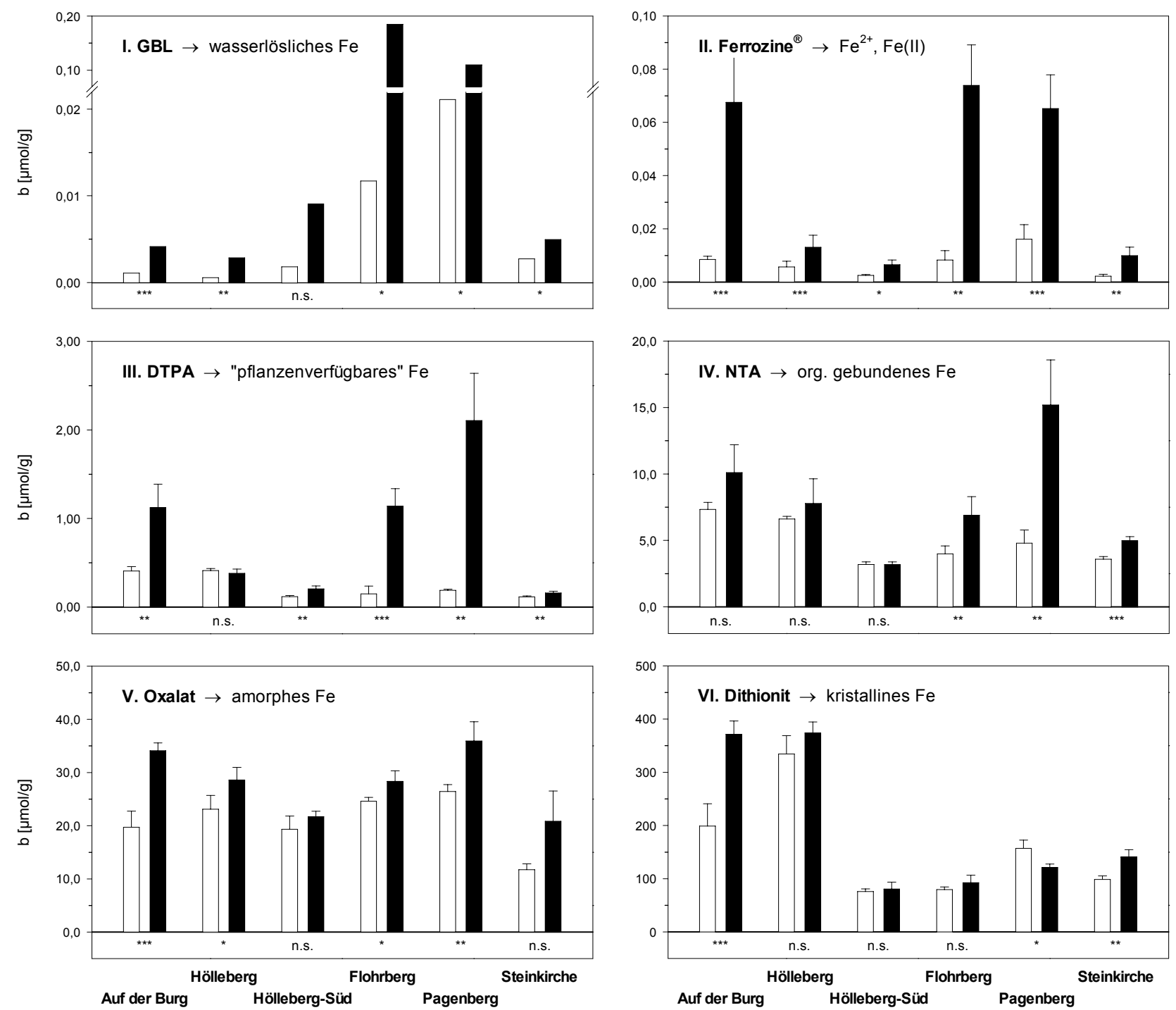

Abbildung 48: Löslichkeiten verschiedener Fe-Fraktionen feldfrischer Feinerdehomogenate $\left[\mathrm{mol} \cdot \mathrm{g}_{T G}{ }^{-1}\right] . M W \pm S D$ bzw. Mediane (I.) ( $n=4, n=8$ für I./II. Auf der Burg und Hölleberg); Sternsignaturen kennzeichnen die Ergebnisse der paarweisen Vergleiche CC vs. CF mittels Student-t-Tests bzw. U-Tests nach Mann-Whitney (I.) (n.s. $\alpha>0,05$, $* \alpha \leq 0,050, * * \alpha \leq 0,010$, *** $\alpha \leq 0,001)$. 
Tabelle 17: CC/CF-Verhältnisse verschiedener Fe-Fraktionen feldfrischer Feinerdehomogenate. $M W \pm S D$ bzw. Mediane (GBL, Pool) ( $n=4, n=8$ für GBL und Ferrozine ${ }^{\circledR}$-Extraktionen der Standorte Auf der Burg und Hölleberg); Sternsignaturen kennzeichnen die Ergebnisse der paarweisen Vergleiche CC vs. CF mittels Student-t-Tests bzw. U-Tests nach Mann-Whitney (n.s. $\alpha>0,05, * \alpha \leq 0,050$, ** $\alpha \leq 0,010$, *** $\alpha \leq 0,001$ ).

\begin{tabular}{|c|c|c|c|c|c|c|c|c|c|c|c|c|c|}
\hline \multirow{2}{*}{$\begin{array}{l}\text { Extraktions- } \\
\text { mittel }\end{array}$} & \multirow{2}{*}{\multicolumn{2}{|c|}{$\begin{array}{l}\text { Auf der Burg } \\
\qquad \text { CC : CF }\end{array}$}} & \multirow{2}{*}{\multicolumn{2}{|c|}{$\begin{array}{l}\text { Hölleberg } \\
\text { CC : CF }\end{array}$}} & \multirow{2}{*}{\multicolumn{2}{|c|}{$\begin{array}{l}\text { Hölleberg-Süd } \\
\qquad \text { CC : CF }\end{array}$}} & \multirow{2}{*}{$\begin{array}{l}\text { Flohrberg } \\
\text { CC : CF }\end{array}$} & \multirow{2}{*}{\multicolumn{2}{|c|}{$\begin{array}{l}\text { Pagenberg } \\
\text { CC : CF }\end{array}$}} & \multirow{2}{*}{$\begin{array}{l}\text { Steinkirche } \\
\text { CC : CF }\end{array}$} & \multicolumn{3}{|c|}{ Pool } \\
\hline & & & & & & & & & & & $\mathrm{CC}$ & : CF & \\
\hline $\mathrm{H}_{2} \mathrm{O}$ (GBL) & $1:$ & $3,8^{\star \star *}$ & 1 & $: 5,0^{* *}$ & 1 & : 4,9 n.s. & $1: 16^{*}$ & 1 & $: 5,2$ * & $1: 1,8^{*}$ & & : 5,0 & \\
\hline Ferrozine & $1:$ & : $7,9^{\star \star \star}$ & 1 & $: 2,3^{* \star *}$ & 1 & $: 2,6$ * & $1: 9,0^{* *}$ & 1 & $: 4,1^{\star \star \star}$ & $1: 4,5^{* \star}$ & 1 & $: 4,3$ & ** \\
\hline DTPA & $1:$ & $2,8^{\star \star}$ & 1 & $: 0,9^{\text {n.s. }}$ & 1 & $: 1,7^{* *}$ & $1: 7,6^{* \star *}$ & 1 & $: 11^{\star *}$ & $1: 1,4^{\star \star}$ & 1 & $: 2,2$ & * \\
\hline NTA & $1:$ & $1,4^{\text {n.s. }}$ & 1 & $: 1,2^{\text {n.s. }}$ & 1 & $: 1,0^{\text {n.s. }}$ & $1: 1,7^{* *}$ & 1 & $: 3,2^{* *}$ & $1: 1,4^{\star \star *}$ & 1 & $: 1,4$ & ** \\
\hline Oxalat & $1:$ & $1,7^{\star \star \star}$ & 1 & $: 1,2^{*}$ & 1 & $: 1,1^{\text {n.s. }}$ & $1: 1,2^{*}$ & 1 & $: 1,4^{* \star}$ & $1: 1,8^{\text {n.s. }}$ & 1 & $: 1,3$ & ** \\
\hline Dithionit & $1:$ & $: 1,9^{\star \star \star}$ & 1 & $: 1,1^{\text {n.s. }}$ & 1 & $: 1,1^{\text {n.s. }}$ & $1: 1,2^{\text {n.s. }}$ & 1 & $: 0,8^{*}$ & $1: 1,4^{\star \star}$ & 1 & $: 1,1$ & * \\
\hline
\end{tabular}

Die Fe-Extraktion und der kolorimetrische Fe-Nachweis feldfrischer Feinerdehomogenate mit Ferrozine ${ }^{\circledR}$ verweisen ebenfalls auf signifikant höhere Eisenverfügbarkeiten im Gentiano-Koelerietum danthonietosum. In allen Fällen signifikant, liegen hier die feinerdebezogenen Fe(II)-Konzentrationen durchschnittlich etwa $300 \%$ über denen der typischen Subassoziation.

Nicht zuletzt aufgrund ihrer besonderen Eignung für die simultane Erfassung auch anderer Schwermetallionen, gilt die DTPA-Extraktion als Standardmethode für die Fe-Analytik kalkreicher Böden. Lindsay \& Norvell (1978) geben eine Übersicht über Untersuchungen, die enge Korrelationen zwischen den Fe-, Zn-, Mn- und Cu-Konzentrationen in DTPA-Bodenextrakten und Parametern der pflanzlichen Mineralstoffernährung auf Gewebeebene belegen. Aus diesem Grund wird die durch DTPA austauschbare Fraktion von vielen Autoren als "pflanzenverfügbar" bezeichnet. Mit Ausnahme derer vom Standort Hölleberg lassen die Analysen aller anderen Kalk-Halbtrockenrasen höhere Fe(DTPA)-Gehalte in der Feinerde der CF-Bestände erkennen. Median liegen sie hier um mehr als das Doppelte über denen der Vergleichseinheiten. Besonders große Unterschiede weisen die Vergleichsbestände des Standorts Pagenberg auf.

Wie die $\mathrm{H}_{2} \mathrm{O}$ - und Ferrozine ${ }^{\circledR}$-Extraktionen lassen auch die DTPA-Extraktionen sehr hohe Abweichungen der Fe-Konzentrationen zwischen den verschiedenen Standorten erkennen. Neben konstitutiven Unterschieden können hohe zeitliche Variabilitäten, wie sie in Abbildung 23 für die GBL, PBL und DBL der Referenzstandorte dargestellt wurden, dazu beitragen, dass in einigen Fällen die Fe-Konzentrationen im Gentiano-Koelerietum typicum des einen Standorts diejenigen des Gentiano-Koelerietum danthonietosum an einem anderen Standort übertreffen. Die Untersuchungen der bodenbürtigen Schwermetallfraktionen erfolgten zwar für die Vergleichsbestände eines Standorts zeitgleich, doch mussten die Probennahmen für die einzelnen Versuchsstandorte z. T. an voneinander abweichenden Terminen durchgeführt werden.

Aufgrund der vergleichsweise großen Varianzen können die höheren Gehalte des organisch gebundenen Eisens für die Bestände des Gentiano-Koelerietum danthonietosum der Standorte Auf der Burg und Hölleberg statistisch nicht abgesichert werden. Während die NTA-Extraktionen für die Feinderde der beiden Vegetationsbestände des Standorts Hölleberg-Süd nahezu ausgeglichene Konzentrationsverhältnisse vermuten lassen, liegen diese für die CC-Bestände der verbleibenden Untersuchungsstandorte um 40-55 \% unter denen der CF-Bestände. Ebenfalls keine signifikanten Unterschiede zwischen den beiden Subassoziationen der Kalk-Halbtrockenrasen des Standorts Hölleberg lassen sich für die Fe-Extraktion mit Ammoniumoxalat nachweisen. Hingegen liegen für die restlichen fünf Standorte durchschnittlich $50 \%$ höhere Konzentrationen der amorphen Fe-Fraktion in der Feinderde der CF-Einheiten vor. 
Im Unterschied zu allen anderen Fe-Fraktionen gibt die der Dithionit-Extraktionen keine Hinweise auf grundsätzliche Unterschiede der bodenbürtigen Fe-Konzentrationen in den jeweiligen Vergleichsbeständen. Lediglich die Standorte Auf der Burg und Steinkirche lassen eindeutig höhere Gehalte an kristallinem Fe in der Feinerde des Gentiano-Koelerietum danthonietosum erkennen. In den beiden Versuchsbeständen des Standorts Pagenberg liegen inverse Relationen dieser Fraktion vor.

Betrachtet man die Verhältnisse der verschiedenen Fe-Fraktionen aller Untersuchungsstandorte, so zeigt sich, dass die Konzentrationsunterschiede zwischen den Subassoziationen in der Reihenfolge wasserlösliches $\mathrm{Fe}, \mathrm{Fe}(\mathrm{II})$, austauschbares ("pflanzenverfügbares") Fe, organisch gebundenes Fe, amorphes $\mathrm{Fe}$ und kristallines Fe abnehmen, während zugleich die absoluten Extraktionsmengen kontinuierlich und insgesamt in einer Größenordnung von etwa $2 \cdot 10^{3}$ ansteigen (Tabelle 17, Abbildung 48). Je "leichter" die betreffenden Fraktionen extrahiert werden können und je höher demnach vermutlich ihre Pflanzenverfügbarkeit ist, desto größer sind die diesbezüglichen Unterschiede zwischen dem Gentiano-Koelerietum typicum und dem Gentiano-Koelerietum danthonietosum.

\section{Mangan-Fraktionen}

Die vergleichsweise locker gebundenen Fraktionen lassen vermuten, dass an den meisten der hier untersuchten Standorte auch die Mn-Verfügbarkeiten in den CF-Beständen besser sind als in der typischen Subassoziation (Abbildung 49). Allerdings zeigt Tabelle 18, dass für keines der Extraktionsmittel gleich gerichtete Ergebnisse aller Versuchsstandorte vorliegen, von denen auf eine grundsätzlich bessere MnVerfügbarkeit im Gentiano-Koelerietum danthonietosum geschlossen werden kann. Die Feinerdefraktionierungen verweisen darauf, dass in den CF-Beständen der Standorte Auf der Burg und Hölleberg eine besonders gute und ausgeglichene Mn-Versorgung der Pflanzen vorliegt. Tendenziell gilt dies auch für den Standort Pagenberg. Indifferent sind die Ergebnisse für den Standort Flohrberg. Höheren feinerdebezogenen Mn-Konzentrationen der GBL und der DTPA-Extrakte von CF-Böden steht hier eine vermehrte Mn-Extraktion aus den Böden der CC-Bestände durch NTA, Ammoniumoxalat und Dithionit gegenüber. Bessere Mn-Verfügbarkeiten im Gentiano-Koelerietum typicum belegen die Untersuchungen der Standorte Hölleberg-Süd und Steinkirche.

Tabelle 18: CC/CF-Verhältnisse verschiedener Mn-Fraktionen feldfrischer Feinerdehomogenate. MW $\pm S D$ bzw. Mediane (GBL, Pool) ( $n=4, n=8$ für GBL der Standorte Auf der Burg und Hölleberg). Sternsignaturen kennzeichnen die Ergebnisse der paarweisen Vergleiche CC vs. CF mittels Student-t-Tests bzw. U-Tests nach Mann-Whitney (n.s. $\alpha>0,05, * \alpha \leq 0,050$, ** $\alpha \leq 0,010$, *** $\alpha \leq 0,001$ ).

\begin{tabular}{|c|c|c|c|c|c|c|c|c|c|c|}
\hline $\begin{array}{l}\text { Extraktions- } \\
\text { mittel }\end{array}$ & $\begin{array}{c}\text { Auf der Burg } \\
\text { CC : CF }\end{array}$ & $\begin{array}{l}\text { Hölleberg } \\
\text { CC : CF }\end{array}$ & $\begin{array}{l}\text { Höllebe } \\
\text { CC : }\end{array}$ & $\begin{array}{l}\text { erg-Süd } \\
\text { : CF }\end{array}$ & $\begin{array}{l}\text { Flohr } \\
\text { CC : }\end{array}$ & $\begin{array}{l}\text { rberg } \\
\text { CF }\end{array}$ & $\begin{array}{l}\text { Page } \\
\text { CC : }\end{array}$ & $\begin{array}{l}\text { nberg } \\
\text { CF }\end{array}$ & $\begin{array}{l}\text { Steinkirche } \\
\text { CC : CF }\end{array}$ & $\begin{array}{c}\text { Pool } \\
\text { CC : CF }\end{array}$ \\
\hline $\mathrm{H}_{2} \mathrm{O}$ (GBL) & $1: 7,0^{* *}$ & $1: 1,0^{\text {n.s. }}$ & $1:$ & $0,0^{\text {n.s. }}$ & 1 & $52^{\text {n.s. }}$ & $1:$ & $15^{*}$ & $1: 0,4^{*}$ & $1: 4,0^{\text {n.s. }}$ \\
\hline Acetat & $1: 4,5^{* * *}$ & $1: 7,3^{* * \star}$ & & & & & & & & \\
\hline DTPA & $1: 2,3^{* * *}$ & $1: 1,4^{*}$ & 1 & $0,7^{\text {n.s. }}$ & 1 & $2,0^{\text {n.s. }}$ & 1 & $5,1^{* *}$ & $1: 0,66^{* * *}$ & $1: 1,7$ n.s. \\
\hline NTA & $1: 1,7^{* *}$ & $1: 1,4^{\text {n.s. }}$ & $1:$ & $0,8^{*}$ & 1 & $0,4^{*}$ & $1:$ & $0,7^{* *}$ & $1: 2,4^{\text {n.s. }}$ & $1: 1,1$ n.s. \\
\hline Oxalat & $1: 1,2^{\text {n.s. }}$ & $1: 1,3^{\star \star *}$ & 1 & $1,0^{\text {n.s. }}$ & 1 & $0,5^{\text {n.s. }}$ & 1 & $1,3^{* * *}$ & $1: 0,1^{* * *}$ & $1: 1,1$ n.s. \\
\hline Dithionit & $1: 1,2^{\text {n.s. }}$ & $1: 1,9^{* * *}$ & 1 & $0,9^{*}$ & 1 & $0,8^{*}$ & $1:$ & $1,0^{\text {n.s. }}$ & $1: 0,6^{\text {n.s. }}$ & $1: 0,9$ n.s. \\
\hline
\end{tabular}



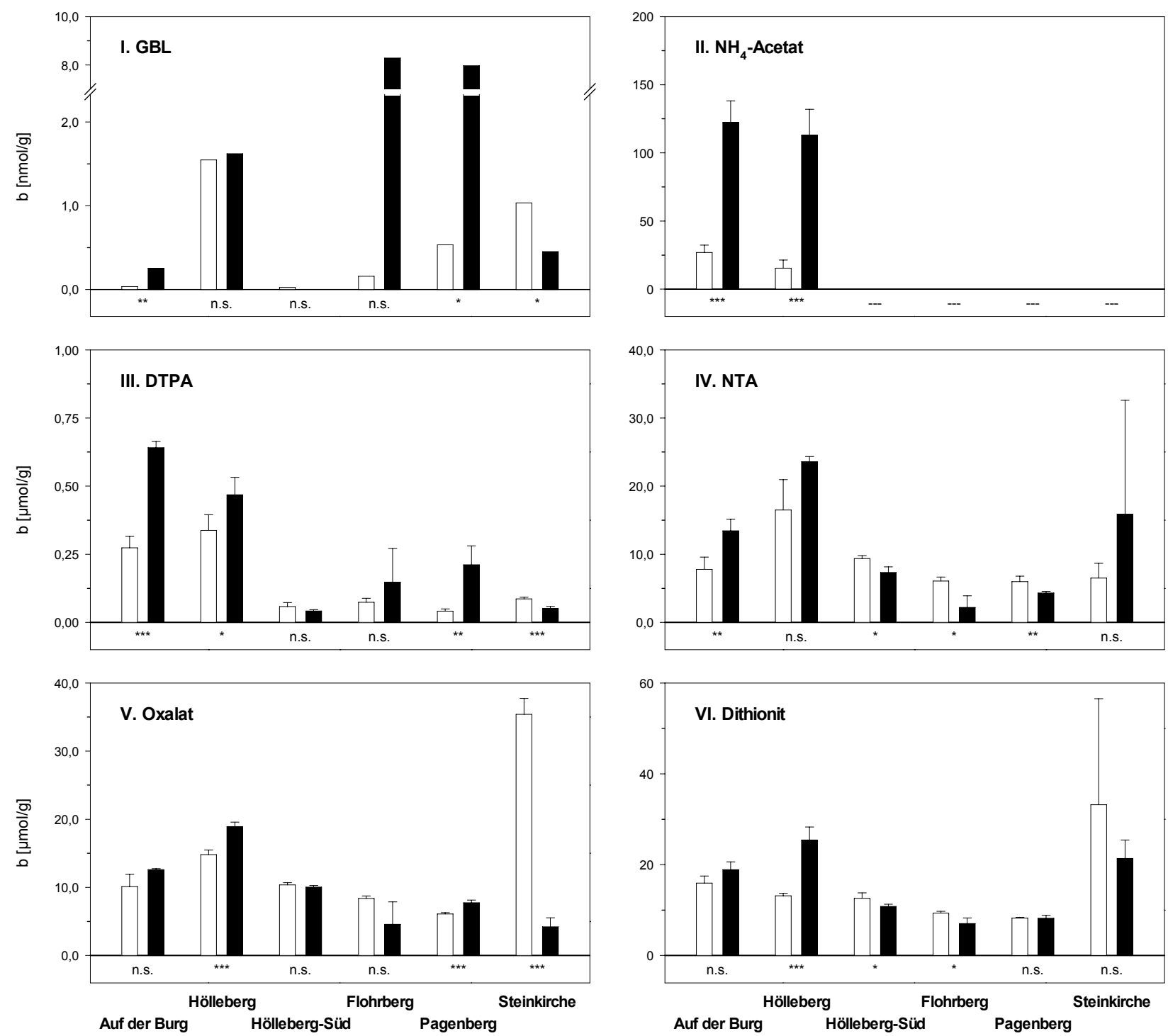

Abbildung 49: Löslichkeiten verschiedener Mn-Fraktionen feldfrischer Feinerdehomogenate $\left[\mathrm{mol} \cdot \mathrm{g}_{\mathrm{TG}}{ }^{-1}\right]$. Für die Vergleichsstandorte Hölleberg-Süd, Flohrberg, Pagenberg und Steinkirche wurden keine Acetat-Extraktionen durchgeführt. $M W \pm S D$ bzw. Mediane (I.) ( $n=4, n=8$ für I. Auf der Burg und I. Hölleberg); Sternsignaturen kennzeichnen die Ergebnisse der paarweisen Vergleiche CC vs. CF mittels Student-t-Tests bzw. U-Tests nach MannWhitney (I.) (n.s. $\alpha>0,05, * \alpha \leq 0,050$, ** $\alpha \leq 0,010$, *** $\alpha \leq 0,001$ ).

\section{Zink-Fraktionen}

Im Vergleich zu Fe und Mn zeigt Zn geringe Konzentrationsunterschiede nicht nur zwischen den gleichen Fraktionen verschiedener Standorte und Bestände, sondern auch zwischen den Lösungen der verschiedenen Extraktionsmittel (Abbildung 50).

In fast allen Fällen liegen die Zn-Konzentrationen, wie sie auf Grundlage der Feinerdeextraktionen mit NTA, Oxalat und Dithionit für die CF-Bestände bestimmt wurden, unter denen der CC-Bestände. Nur der Standort Auf der Burg aber weist signifikante Relationen dieser Art bei allen Zn-Fraktionen auf (Tabelle 19). Allerdings sind hier die Unterschiede der Dithionit-Extrakte sehr gering. 

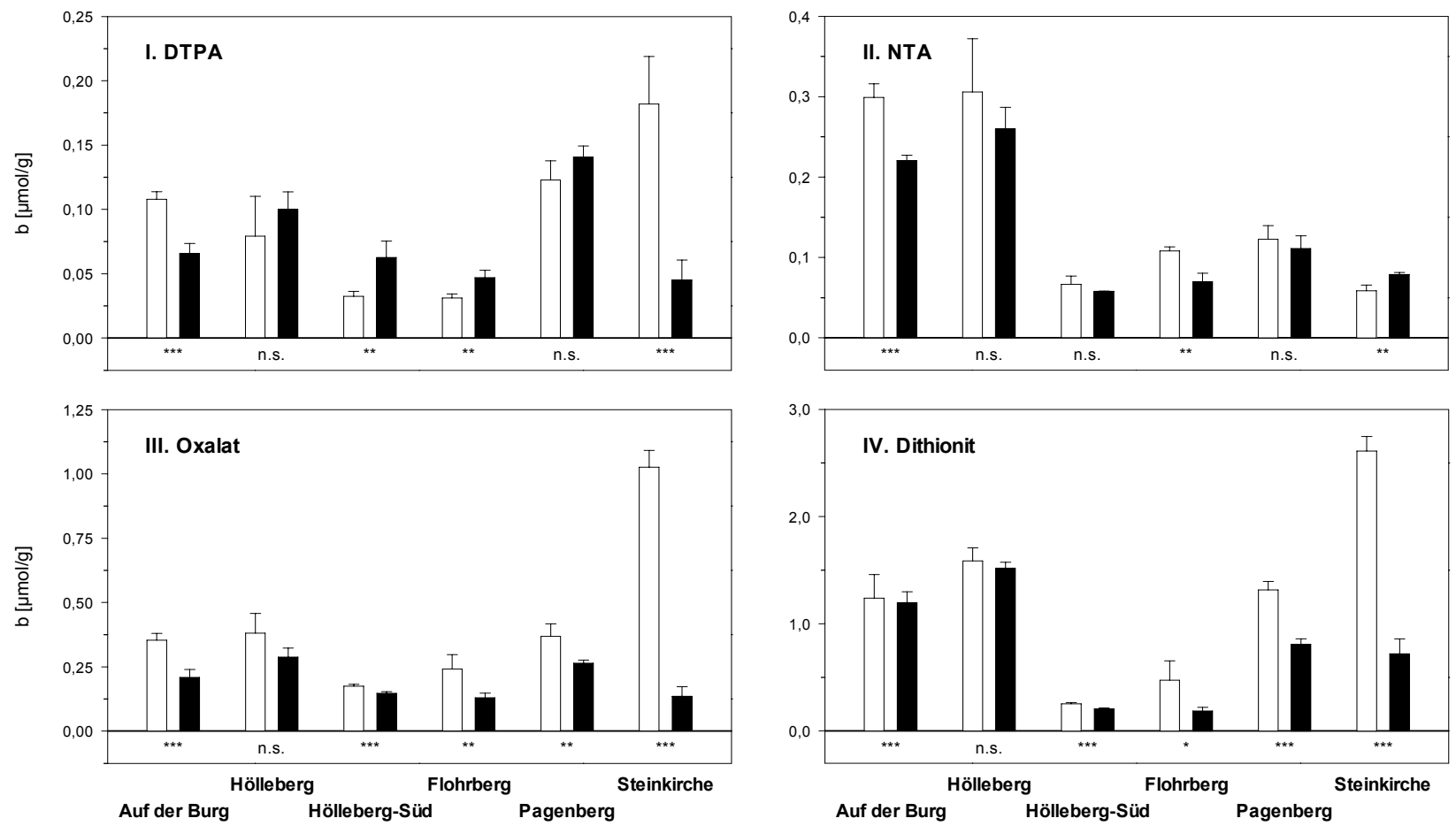

Abbildung 50: Löslichkeiten verschiedener Zn-Fraktionen feldfrischer Feinerdehomogenate $\left[\mathrm{mol}^{\circ} \mathrm{g}_{\mathrm{TG}}^{-1}\right] . \mathrm{MW} \pm \mathrm{SD}$ $(n=4)$; Sternsignaturen kennzeichnen die Ergebnisse der paarweisen Vergleiche CC vs. CF mittels Student-t-Tests (n.s. $\alpha>0,05, * \alpha \leq 0,050, * * \alpha \leq 0,010$, *** $\alpha \leq 0,001$ ).

Die Analysen der Lösungen von jeweils drei der vier Extraktionsmittel lassen für die verbleibenden KalkHalbtrockenrasen niedrigere Zn-Verfügbarkeiten im Gentiano-Koelerietum danthonietosum vermuten. Für die Standorte Hölleberg, Hölleberg-Süd, Flohrberg und Pagenberg liegen die DTPA-extrahierbaren Zn-Gehalte, für den Standort Steinkirche diejenigen der NTA-Extraktion in den CF-Beständen über denen der CC-Bestände. Bei maximal dreißigprozentigen Abweichungen zwischen den Mittelwerten erreichen die Ergebnisse für den Standort Hölleberg in keinem Fall das Signifikanzniveau. Besonders hohe Abweichungen der DTPA-, Oxalat- und Dithionit-Fraktionen zwischen den Vergleichsbeständen finden sich für den Standort Steinkirche. Im Schnitt liegen hier die feinerdebezogenen Zn-Konzentrationen der CCBestände fünffach über denen der CF-Einheiten.

Tabelle 19: CC/CF-Verhältnisse verschiedener Zn-Fraktionen feldfrischer Feinerdehomogenate. $M W \pm S D$ bzw. Mediane (Pool) ( $n=4)$; Sternsignaturen kennzeichnen die Ergebnisse der paarweisen Vergleiche CC vs. CF mittels Student-t-Tests bzw. U-Tests nach Mann-Whitney (n.s. $\alpha>0,05, * \alpha \leq 0,050$, ** $\alpha \leq 0,010$, *** $\alpha \leq 0,001$ ).

\begin{tabular}{|c|c|c|c|c|c|c|c|}
\hline $\begin{array}{l}\text { Extraktions- } \\
\text { mittel }\end{array}$ & $\begin{array}{l}\text { Auf der Burg } \\
\text { CC : CF }\end{array}$ & $\begin{array}{l}\text { Hölleberg } \\
\text { CC : CF }\end{array}$ & $\begin{array}{l}\text { Hölleberg-Süd } \\
\qquad \text { CC : CF }\end{array}$ & $\begin{array}{l}\text { Flohrberg } \\
\text { CC : CF }\end{array}$ & $\begin{array}{l}\text { Pagenberg } \\
\text { CC : CF }\end{array}$ & $\begin{array}{l}\text { Steinkirche } \\
\text { CC : CF }\end{array}$ & $\begin{array}{c}\text { Pool } \\
C C: C F\end{array}$ \\
\hline DTPA & $1: 0,6^{* * *}$ & $1: 1,3^{\text {n.s. }}$ & $1: 1,9^{* *}$ & $1: 1,5^{* *}$ & $1: 1,1^{\text {n.s. }}$ & $1: 0,2^{* * *}$ & $1: 1,2$ n.s. \\
\hline NTA & $1: 0,7^{* * *}$ & $1: 0,9^{\text {n.s. }}$ & $1: 0,9^{\text {n.s. }}$ & $1: 0,6^{* *}$ & $1: 0,9^{\text {n.s. }}$ & $1: 1,3^{* *}$ & $1: 0,9^{*}$ \\
\hline Oxalat & $1: 0,6^{* * *}$ & $1: 0,8^{\text {n.s. }}$ & $1: 0,8^{* * *}$ & $1: 0,5^{* *}$ & $1: 0,7^{* *}$ & $1: 0,1^{* * *}$ & $1: 0,7^{* *}$ \\
\hline Dithionit & $1: 1,0^{* * *}$ & $1: 1,0$ n.s. & $1: 0,8^{* * *}$ & $1: 0,4^{*}$ & $1: 0,6^{* * *}$ & $1: 0,3^{* * *}$ & $1: 0,7^{* *}$ \\
\hline
\end{tabular}




\section{Kupfer-Fraktionen}

Die Feinerdefraktionierungen zeichnen ein vollkommen indifferentes Bild hinsichtlich der Cu-Verfügbarkeiten in den beiden Subassoziationen des Gentiano-Koelerietum (Abbildung 51). In nur wenigen Fällen können hier Unterschiede zwischen den beiden Vegetationstypen statistisch abgesichert werden. Die Untersuchungen des Standorts Pagenberg lassen etwas höhere Cu-Konzentrationen in Böden der CCBestände erkennen. DTPA extrahiert in mindestens drei Fällen mehr $\mathrm{Cu}$ aus Böden des Gentiano-Koelerietum danthonietosum, Oxalat in der Regel vermehrt solches aus Böden der typischen Subassoziation. Insgesamt gibt es aber keine Hinweise auf systematische Unterschiede der pflanzlichen Cu-Verfügbarkeiten zwischen den beiden Vegetationseinheiten der hier untersuchten Kalk-Halbtrockenrasen.

Tabelle 20: CC/CF-Verhältnisse verschiedener Cu-Fraktionen feldfrischer Feinerdehomogenate. $M W \pm S D$ bzw. Mediane (Pool) ( $n=4)$; Sternsignaturen kennzeichnen die Ergebnisse der paarweisen Vergleiche CC vs. CF mittels Student-t-Tests bzw. U-Tests nach Mann-Whitney (n.s. $\alpha>0,05, * \alpha \leq 0,050$, ** $\alpha \leq 0,010$, *** $\alpha \leq 0,001$ ).

\begin{tabular}{|c|c|c|c|c|c|c|c|}
\hline $\begin{array}{l}\text { Extraktions- } \\
\text { mittel }\end{array}$ & $\begin{array}{l}\text { Auf der Burg } \\
\text { CC : CF }\end{array}$ & $\begin{array}{l}\text { Hölleberg } \\
\text { CC : CF }\end{array}$ & $\begin{array}{l}\text { Hölleberg-Süd } \\
\text { CC : CF }\end{array}$ & $\begin{array}{l}\text { Flohrberg } \\
\text { CC : CF }\end{array}$ & $\begin{array}{l}\text { Pagenberg } \\
\text { CC : CF }\end{array}$ & $\begin{array}{l}\text { Steinkirche } \\
\text { CC : CF }\end{array}$ & $\begin{array}{c}\text { Pool } \\
\text { CC : CF }\end{array}$ \\
\hline DTPA & $1: 1,0^{\text {n.s. }}$ & $1: 1,0^{\text {n.s. }}$ & $1: 2,0^{\text {n.s. }}$ & $1: 2,1$ ** & $1: 1,0^{\text {n.s. }}$ & $1: 1,8^{*}$ & $1: 1,4^{\text {n.s. }}$ \\
\hline NTA & $1: 1,1^{\text {n.s. }}$ & $1: 0,9^{\text {n.s. }}$ & $1: 1,0^{\text {n.s. }}$ & $1: 0,6^{* *}$ & $1: 0,9^{\text {n.s. }}$ & $1: 6,9^{* * *}$ & $1: 1,0^{\text {n.s. }}$ \\
\hline Oxalat & $1: 0,8^{*}$ & $1: 0,9^{\text {n.s. }}$ & $1: 0,9^{\text {n.s. }}$ & $1: 0,5^{* * *}$ & $1: 0,8^{\text {n.s. }}$ & $1: 1,4^{\text {n.s. }}$ & $1: 0,8^{*}$ \\
\hline Dithionit & $1: 1,5^{\text {n.s. }}$ & $1: 1,7^{\text {n.s. }}$ & $1: 0,8^{*}$ & $1: 0,5^{*}$ & $1: 0,5^{\text {n.s. }}$ & $1: 0,3^{*}$ & $1: 0,6{ }^{\text {n.s. }}$ \\
\hline
\end{tabular}
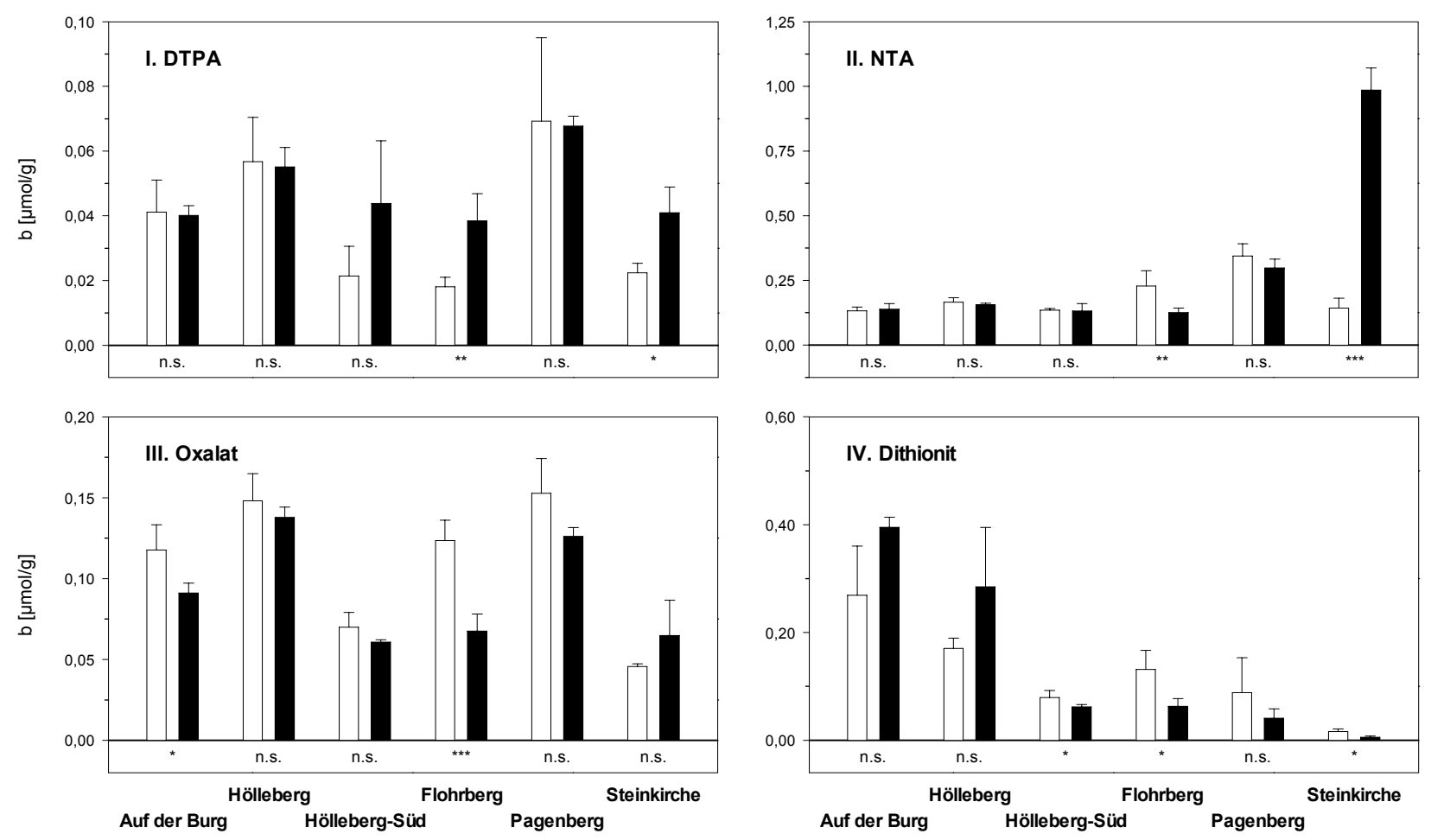

Abbildung 51: Löslichkeiten verschiedener Cu-Fraktionen feldfrischer Feinerdehomogenate $\left[\mathrm{mol} \cdot \mathrm{g}_{\mathrm{TG}}{ }^{-1}\right] . \mathrm{MW} \pm S D$ $(n=4)$; Sternsignaturen kennzeichnen die Ergebnisse der paarweisen Vergleiche CC vs. CF mittels Student-t-Tests (n.s. $\alpha>0,05, * \alpha \leq 0,050, * * \alpha \leq 0,010, * * * \alpha \leq 0,001$ ). 


\section{Redoxdynamik von Eisen und Mangan in Bodenmonolithen}

Untersuchungen zur Fe- und Mn-Dynamik zielten darauf ab, Art, Umfang und Geschwindigkeit oxidoreduktiver Umsetzungen in verschiedenen Böden und ihre potenzielle Bedeutung für die pflanzliche Mineralstoffernährung aufzuzeigen. Die Untersuchungen zur Redox-Dynamik wurden exemplarisch für die beiden Bestände des Standorts Hölleberg durchgeführt. Abiotische und mikrobielle Reduktion führen unter anaeroben oder mikroaerophilen Milieubedingungen zu einer Erhöhung der Fe- und Mn-Konzentrationen (Nealson 1983; Fischer 1988; Nealson \& Saffarini 1994).

\section{Eisendynamik}

Die Abbildung 52.A zeigt die Effekte der aufeinanderfolgenden reduktiven, d. h. wassergesättigten (d0d40), re-oxidativen, d. h. entwässerten (d40-d41/d42/d44), und re-reduktiven, d. h. wiederaufgesättigten (d41/d42/d44-d49) Inkubation von Bodenmonolithen der CC- und CF-Bestände auf die Gesamtkonzentrationen des Fe in der Bodenlösung. Die graphischen Darstellungen I. und II. in Abbildung 52.B stellen die jeweiligen prozentualen Anteile von Fe(II) und Fe(III) während der reduktiven Phase dar.

Kennzeichnend für die prozentuale Verteilung der zwei- und dreiwertigen Fe-Fraktionen sind die nahezu identischen Kurvenverläufe in den Böden der beiden Subassoziationen des Gentiano-Koelerietum. Die reduktive Lösung von Fe(III) beginnt spätestens mit dem vierten Inkubationstag. Hohe Variationen zu Beginn der Untersuchungen sind nicht zuletzt auf die noch sehr niedrigen Gesamt-Fe-Konzentrationen und die daraus resultierenden Ungenauigkeiten der kolorimetrischen Fe-Analytik zurückzuführen. In den Bodenmonolithen des CC-Bestands liegen am 10. Versuchstag (d9), in Bodenmonolithen des CFBestands am 11. Tag (d10) ausgeglichene Fe(II)- und Fe(III)-Konzentrationen vor. Zwischen d15 und d20 erreichen die Kurven die Scheitelpunkte der Einstellung maximaler Fe(II)- und minimaler Fe(III)-Anteile. Dies ist bei der CC-Variante etwas früher als bei der CF-Variante der Fall. Wie entsprechende Untersuchungen gezeigt haben, kann die Oxidation von $\mathrm{Fe}^{2+}$ auch bei der Verwendung von Mikrolysimetern nicht vollständig unterbunden werden. Es ist daher zu vermuten, dass gegen Ende der reduktiven Inkubation an $\mathrm{d} 40$ bei weiter steigenden Fe-Konzentrationen fast ausschließlich $\mathrm{Fe}^{2+}$ vorlag.

Die Untersuchungsergebnisse lassen einen exponentiellen Anstieg der reduktiven Fe-Lösung mit fortdauernder Wassersättigung erkennen. Die Fe-Messungen der ersten beiden Versuchstage bestätigen die Untersuchungen aus Abschnitt 3.2.2 (S. 58 f.), nach denen die Fe(II+III)-Konzentrationen in den wässrigen Bodenextrakten des CF-Bestands über denen des CC-Bestands liegen. Im weiteren Verlauf ist aber eine verstärkte reduktive Fe-Mobilisierung in den Böden der typischen Subassoziation des GentianoKoelerietum zu erkennen. So beträgt am neunten Tag die Fe-Gesamtkonzentration der CF-Variante etwas das Sechsfache des Initialwertes, während im selben Zeitraum die Fe-Konzentration in den CC-Monolithen um das Siebzehnfache ansteigt (Abbildung 52.A). Aufgrund sehr hoher Variabilitäten können die in der Graphik dargestellten Unterschiede zwischen den Böden der beiden Vegetationsbestände nur in Ausnahmefällen statistisch abgesichert werden.

Der Entwässerung der Bodenmonolithen folgte eine sofortige und fast vollständige Oxidation des zweiwertigen Eisens. Diese umgehende Immobilisierung von $\mathrm{Fe}^{2+}$ stimmt mit den Ausführungen zur Fe-Oxidationskinetik in Systemen hoher pH-Werte in Abschnitt 4.2.4 (S. 117) überein. Wie die weiteren Kurvenverläufe zwischen dem 42. Versuchstag (d41) und dem Versuchende zeigen, geht die Wiederaufsättigung der Bodenmonolithen nach einer langen reduktiven und einer kurzen oxidativen Phase mit einem sehr schnellen Anstieg der Fe-Lösung einher. Welche Bedeutung hierbei einerseits einer schnelleren Ein- 

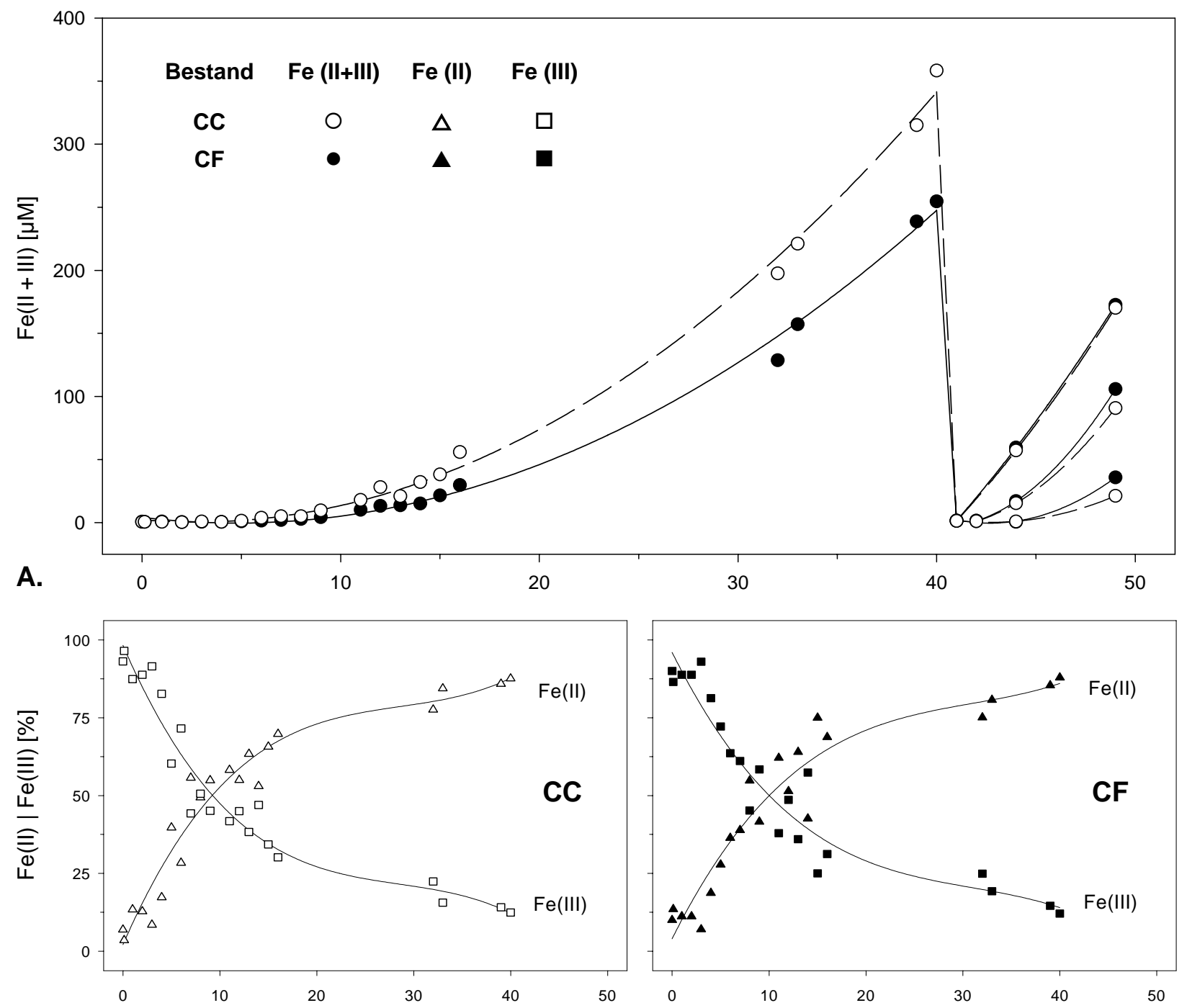

B.

Inkubationszeit [d]

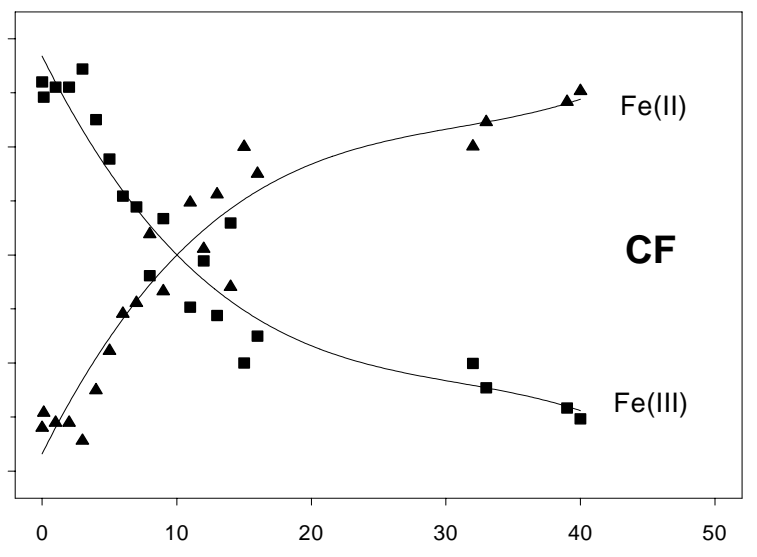

Inkubationszeit [d]

Abbildung 52: Dynamik der Fe-Lösung in Bodenmonolithen von CC-Beständen und CF-Beständen des Standorts Hölleberg unter reduktiven, re-oxidativen und re-reduktiven Inkubationsbedingungen. Der Aufsättigung der Bodenmonolithen an Tag 0 (d0) und der Entwässerung an Tag 40 (d40) folgte die Wiederaufsättigung mit $\mathrm{H}_{2} \mathrm{O}$ demin. nach weiteren 1, 2 und 4 Tagen (d41, d42, d44). A. Fe(II + III)-Konzentrationen $[\mu M]$; B. Prozentualer Anteil von $\mathrm{Fe}(\mathrm{III})$ und Fe(II) in Bodenlösungen von CC- und CF-Monolithen. $M W\left(n_{d 1+2}=32, n_{d 3-40}=16, n_{d 41-49}=8\right)$.

stellung sehr niedriger Redoxpotenziale im Bodensystem, d. h. der Beteiligung auch anderer nicht analysierter Redoxsysteme, und andererseits der Genese amorpher, labiler und leicht reduzierbarer Fe(III)Spezies nach vorübergehender Oxidation von $\mathrm{Fe}^{2+}$ zukommt, kann abschließend nicht geklärt werden. Mit zunehmender Dauer der oxidativen Inkubation wird allerdings nach Wiederaufsättigung der Eintritt der Bodenmonolithe in eine erneute exponentielle Phase der reduktiven Fe-Mobilisierung deutlich verzögert.

\section{Mangandynamik}

Anders als bei den Untersuchungen zur Fe-Dynamik, konnte keine Differenzierung zwischen Mn-Fraktionen unterschiedlichen Redox-Zustands, also v.a. Mn IV und MnII, vorgenommen werden. Abbildung 53 zeigt die absolute und relative Entwicklung der Mn-Konzentrationen in den Bodenmonolithen der beiden Vergleichsbestände während der reduktiven Inkubationsphase. 


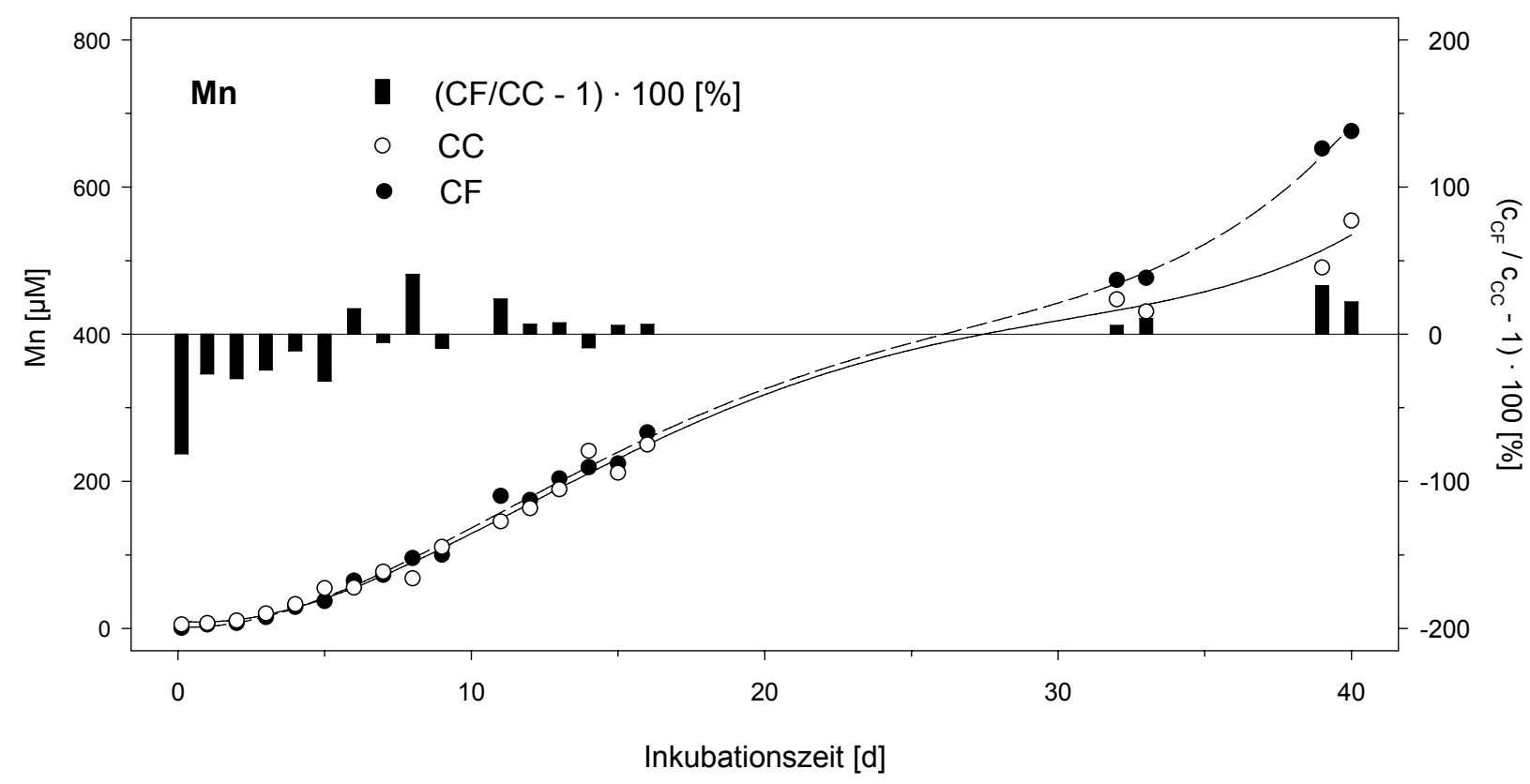

Abbildung 53: Dynamik der Mn-Lösung in Bodenmonolithen des Standorts Hölleberg während einer 40tägigen reduktiven Inkubation. Das Liniendiagramm zeigt die Entwicklung der absoluten Mn-Konzentrationen [ $\mu M]$ in Mikrolysimeterlösungen von CC- $(\bigcirc)$ und CF- $(\bullet)$ Monolithen, das Balkendiagramm die relativen CF-Konzentrationen entsprechend (CF :CC - 1) $100[\%] . M W\left(n_{d 1+2}=32, n_{d 3-40}=16\right)$.

Früher noch als für Fe lässt sich nach der Aufsättigung der Bodenmonolithen eine reduktive Mobilisierung von Mn erkennen. Bereits in den ersten 48 Stunden der Inkubation steigt die Mn-Konzentration in der Bodenlösung der CC-Monolithen um etwa $100 \%$, in den CF-Monolithen sogar um mehr als $600 \%$ an. Die Kurvenverläufe beider Varianten lassen mit dem 20. Tag der Wassersättigung einen langsameren Anstieg der Mn-Konzentrationen in der Bodenlösung erkennen. Im gleichen Zeitraum steigt die FeReduktion drastisch an. Ein unmittelbarer Bezug zur Fe-Lösung findet sich hingegen für den Wiederanstieg der reduktiven Mn-Mobilisierung gegen Ende der Untersuchungen nicht.

Während zu Versuchsbeginn die Fe-Konzentrationen wässriger CF-Bodenextrakte diejenigen der CCVariante übersteigen und sich dieses Verhältnis im weiteren Inkubationsverlauf umkehrt, zeigen die Untersuchungen für Mn eine entgegengesetzte Entwicklung. Das Balkendiagramm der Abbildung 53 belegt initial um etwa $80 \%$ niedrigere Mn-Konzentrationen der CF-Bestände. Erst im weiteren Verlauf wird durch die stärkere Mn-Mobilisierung in den CF-Monolithen dieses Verhältnis umgekehrt, so dass gegen Ende der reduktiven Inkubation deren Mn-Konzentrationen 20\% bis 30\% über denen des Bodenmaterials des Gentiano-Koelerietum typicum liegen.

Mit fast $700 \mu \mathrm{M}$ erreicht die Bodenlösung der CF-Monolithen nach sechs Wochen reduktiver Inkubation eine Mn-Konzentration, die um mehr als das Sechshundertfache über dem Ausgangswert liegt. Im gleichen Zeitabschnitt ist bei einem Zielwert von etwa $550 \mu \mathrm{M}$ Mn die Konzentration in den CC-Monolithen nur um das Hundertfache angestiegen. Im Vergleich dazu betrugen die maximalen Fe-Konzentrationen $255 \mu \mathrm{M}$ für die CF-Variante und $358 \mu \mathrm{M}$ für die CC-Variante. Bezogen auf die jeweiligen Initialwerte ergeben sich über die Reduktion von Fe(III) Mobilisierungsfaktoren von etwa 350 und 600. 


\section{Mobilisierung/lmmobilisierung von Eisen durch Chelatlösungen}

In einem ergänzenden Versuch zur Fe-Verfügbarkeit in Böden der beiden Subassoziationen des GentianoKoelerietum wurde exemplarisch für den Standort Auf der Burg der Effekt einer Schüttelung von lufttrockenen Feinerdehomogenaten in zwei verschiedenen Chelatlösungen definierter Fe-Konzentrationen untersucht. Dabei konnte je nach Fe-Substrat und Boden eine zusätzliche Mobilisierung von bodenbürtigem Fe(III) oder eine Fe-Immobilisierung von Fe der vorgegebenen Fe-Komplexe durch die Feinerde nachgewiesen werden (Abbildung 54).

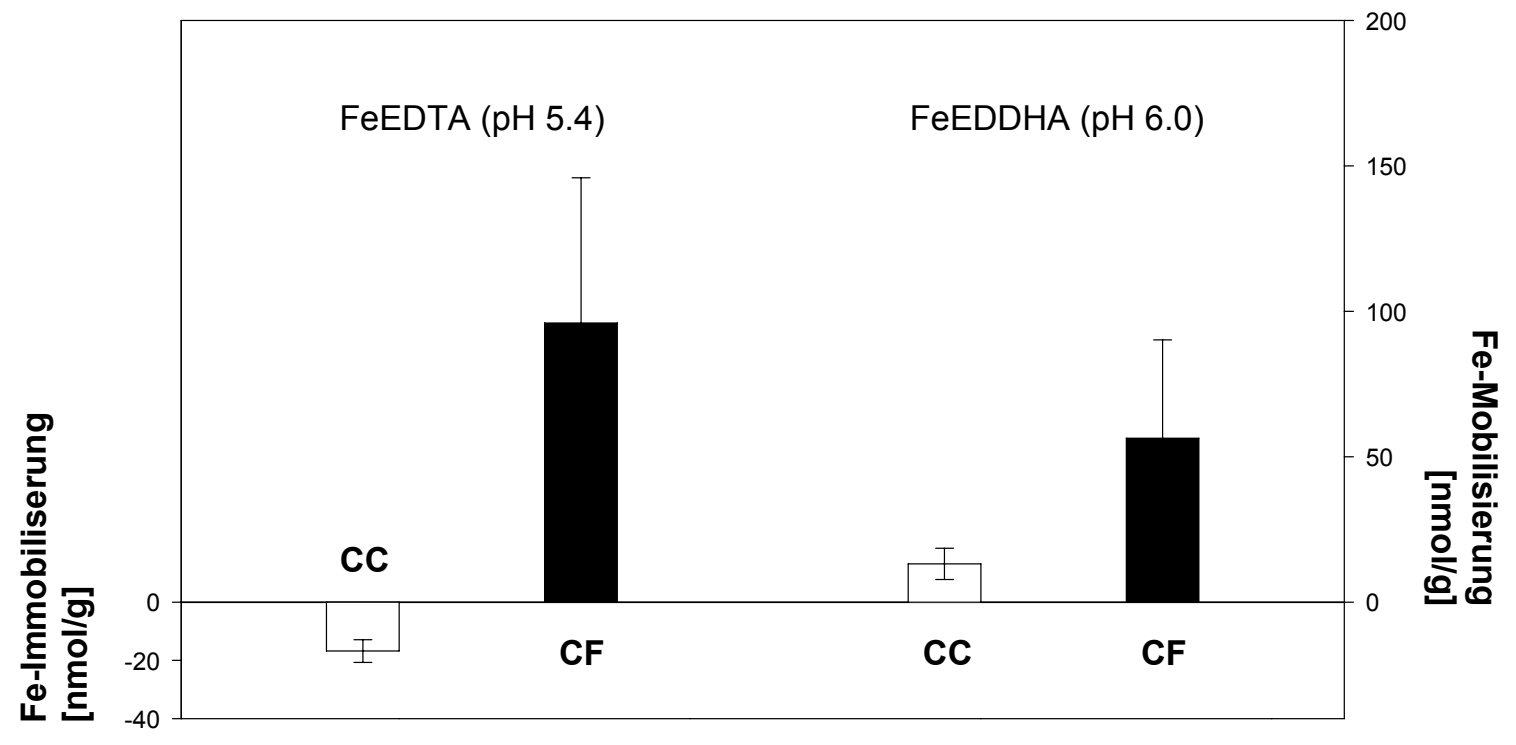

Abbildung 54: Fe-Mobilisierung/Immobilisierung [nmol $\cdot g^{-1}{ }_{F E-T G}$ ] durch $24 \mathrm{~h}$ Schüttelung von 2,5 $\mathrm{g}$ CC/CF-Trockenhomogenaten des Standorts Auf der Burg mit 12,5 ml $20 \mu$ M FeEDTA- und FeEDDHA-Lösungen. MW $\pm S D(n=8)$.

Ausgehend von 100 nmol Fe-Chelat $\cdot \mathrm{g}^{-1}$ FE-TG Feinerdehomogenat, wurden durch FeEDDHA aus der Feinerde des Gentiano-Koelerietum danthinietosum weitere $50 \%$ Fe extrahiert. Eine Erhöhung der Fe-Löslichkeiten ist auch für das Bodenmaterial der typischen Subassoziation nachzuweisen. Allerdings ist hier der Umfang der Fe-Mobilisierung deutlich niedriger. Demgegenüber zeigen die Trockenhomogenate der beiden Vergleichsbestände bei der Schüttelung in FeEDTA-Lösungen ein gänzlich voneinander abweichendes Verhalten. Während aus Bodenmaterial des CF-Bestands weitere $100 \mathrm{nmol} \mathrm{Fe} \cdot \mathrm{g}^{-1}$ FE-TG mobilisiert wurden, zog die Schüttelung von Trockenhomogenat des Bestands Auf der Burg-CC offensichtlich die Spaltung des löslichen Fe(EDTA)-Komplexes und eine Immobilisierung von ca. $20 \%$ der diesbezüglichen Fe-Fraktion nach sich.

\subsubsection{Phosphorverfügbarkeiten}

Verschiedene Autoren betrachten suboptimale P-Verfügbarkeiten als einen maßgeblichen Faktor für den Ausschluss calcifuger/acidophiler Arten von $\mathrm{CaCO}_{3}$-reichen Standorten (Grime 1965b; Tyler 1994, 1995, 1996a). Zur Überprüfung dieser Hypothese wurden für lufttrockene Feinerdehomogenate der beiden Subassoziationen des Gentiano-Koelerietum der Referenzstandorte Auf der Burg und Hölleberg sequentielle Fraktionierungen der potenziell pflanzenverfügbaren P-Fraktionen durchgeführt. Im Anschluss werden die Ergebnisse der wasserlöslichen Fraktion dieser stufenweisen Extraktion mit den GBL-Analysen für die CC- und CF-Bestände der verbleibenden Versuchsstandorte im Unteren Diemeltal und am Südharzrand verglichen. 


\section{Sequentielle Phosphatfraktionierung lufttrockener Feinerdehomogenate}

Anders als bei den Schwermetallfraktionierungen wurde das Bodenmaterial für die Untersuchung der pflanzlichen P-Verfügbarkeiten sequentiell, d.h. aufeinanderfolgend, mit ausgewählten Lösungen extrahiert. Entsprechend der Reihenfolge ihres Einsatzes und ihrer Austausch- und Lösungsreaktionen werden durch die verschiedenen Extraktionsmittel zunehmend stabilere P-Fraktionen erfasst. Die Balkendiagramme der Abbildung 55 führen von unten nach oben die $\mathrm{H}_{2} \mathrm{O}^{-}, \mathrm{HCO}_{3}^{-}-, \mathrm{OH}^{-}$- und $\mathrm{HCl}$-extrahierbaren P-Fraktionen auf.

Die in der Summe aus dem Bodenmaterial der CC-Bestände extrahierten P-Mengen übersteigen diejenigen des Bodenmaterials der CF-Einheiten. Diese Unterschiede gehen im Wesentlichen auf die säurelösliche Fraktion und damit auf deutlich voneinander abweichende Apatitgehalte zurück. Bei Gesamtkonzentrationen von 4,9 $\mu \mathrm{mol} \cdot \mathrm{g}^{-1} \mathrm{P}$ bzw. 4,6 $\mu \mathrm{mol} \cdot \mathrm{g}^{-1} \mathrm{P}$ für die CC-Einheiten der Standorte Auf der Burg und Hölleberg betragen die Anteile der HCl-Fraktionen 57\% und 51\% (Tabelle 21). Demgegenüber liegen die $\mathrm{P}\left(\mathrm{HCl}\right.$ )-Fraktionen der CF-Bestände bei lediglich etwa $13 \%$ von insgesamt $2,8 \mu \mathrm{mol} \cdot \mathrm{g}{ }^{1} \mathrm{P}$ (Auf der Burg) bzw. etwa $26 \%$ von $2,9 \mu \mathrm{mol} \cdot \mathrm{g}^{-1} \mathrm{P}$ (Hölleberg). Diese Relationen zeigen eine gute Übereinstimmung mit den $\mathrm{CaCO}_{3}$-Gehalten der Feinerdehomogenate (vgl. Tabelle 5, S. 46).

Lässt man die säurelösliche P-Fraktion unberücksichtigt, so geben die Feinerdeanalysen des Standorts Auf der Burg Hinweise auf eine etwas bessere P-Verfügbarkeit im Gentiano-Koelerietum danthonietosum. Im Gegensatz dazu verweisen die Untersuchungen des Standorts Hölleberg auf ein besseres PAngebot in der typischen Subassoziation. Bei annähernd gleichen P(Resin)-Gehalten von ca. $0,5 \mu \mathrm{mol} \cdot \mathrm{g}^{-1}$ und $0,4 \mu \mathrm{mol} \cdot \mathrm{g}^{-1}$ für die jeweiligen CC- und CF-Einheiten liegt aber an beiden Standorten die Konzentration des sehr labil gebundenen und daher besonders leicht verfügbaren Phosphors im Gentiano-Koelerietum typicum um mehr als $20 \%$ über demjenigen der Subassoziation von Danthonia decumbens.

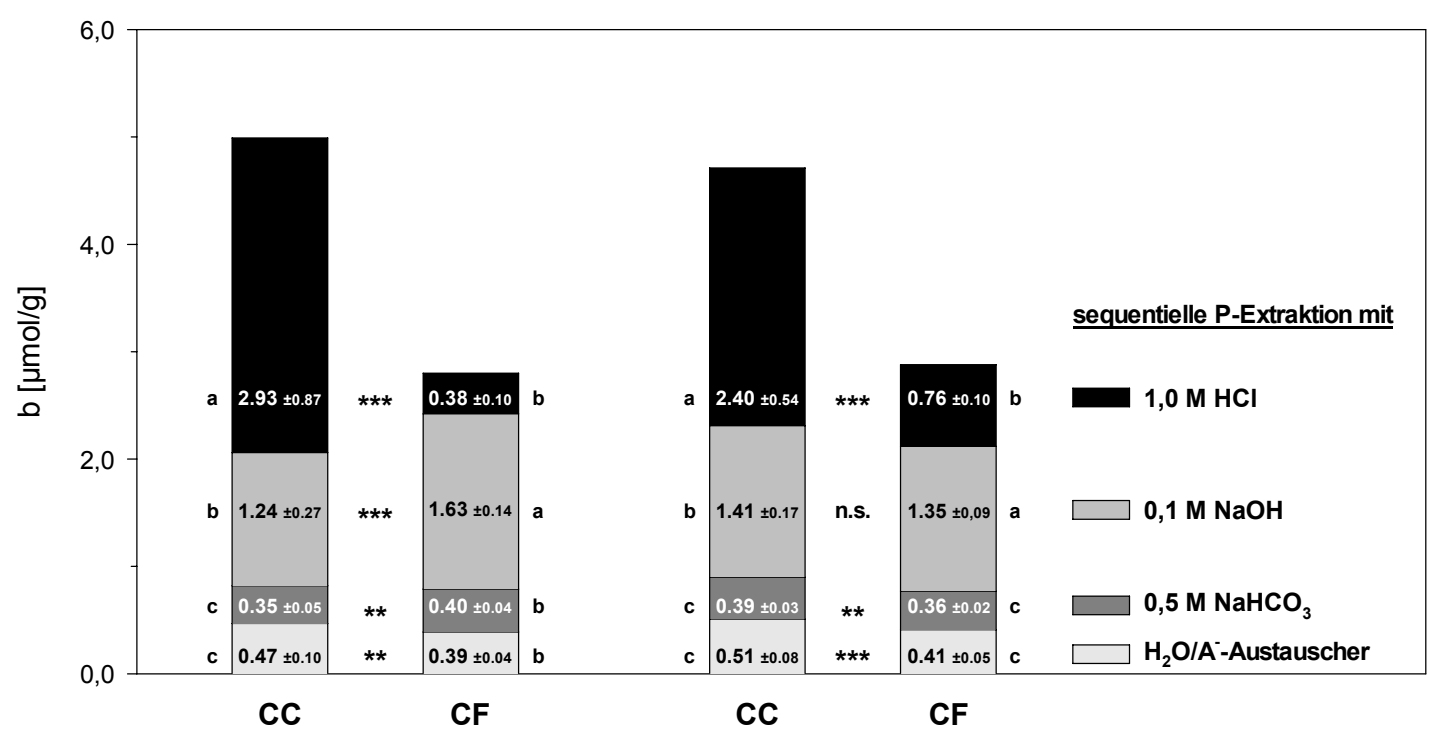

Auf der Burg Hölleberg

Abbildung 55: Löslichkeiten verschiedener P-Fraktionen $\left[\mu \mathrm{mol} \cdot \mathrm{g}_{\mathrm{TG}}{ }^{-1}\right.$ ] im Rahmen der sequentiellen P-Fraktionierung gemahlener, luftrockener Feinerdehomogenate von CC- und CF-Beständen der Standorte Auf der Burg und Hölleberg. $M W \pm S D(n=16)$; Sternsignaturen kennzeichnen die Ergebnisse der Student-t-Tests CC vs. CF (n.s. $\alpha>0,05, * \alpha \leq 0,050$, ** $\alpha \leq 0,010$, *** $\alpha \leq 0,001$ ), voneinander abweichende Buchstaben signifikante Unterschiede zwischen den verschiedenen P-Fraktionen entsprechend Varianzanalysen mit anschließenden multiplen Mittelwertsvergleichen nach Scheffé $(\alpha \leq 0,050)$. 
Tabelle 21: P-Gesamtlöslichkeiten [ $\mu \mathrm{mol} \cdot \mathrm{g}_{\mathrm{TG}}{ }^{-1}$ ] und P-Fraktionsanteile [\%] im Rahmen der sequentiellen Extraktion gemahlener, lufttrockener Feinerdehomogenate. Median \pm MAD $(n=16)$. Voneinander abweichende Buchstaben kennzeichnen signifikante Unterschiede zwischen den Versuchsbeständen entsprechend Rangvarianzanalysen nach Kruskal-Wallis mit anschließenden paarweisen Vergleichen nach Schaich-Hamerle $(\alpha \leq 0,050)$.

\begin{tabular}{|c|c|c|c|c|c|c|}
\hline \multicolumn{2}{|c|}{ Standort/Bestand } & $\begin{array}{c}\Sigma P \\
{\left[\mu \mathrm{mol} \cdot \mathrm{g}^{-1} \mathrm{TG}\right]}\end{array}$ & $\begin{array}{c}P\left(\mathrm{H}_{2} \mathrm{O}\right) \\
{[\%]}\end{array}$ & $\begin{array}{c}\mathrm{P}\left(\mathrm{NaHCO}_{3}\right) \\
{[\%]}\end{array}$ & $\begin{array}{c}\mathrm{P}(\mathrm{NaOH}) \\
{[\%]}\end{array}$ & $\begin{array}{c}\mathbf{P}(\mathrm{HCl}) \\
{[\%]}\end{array}$ \\
\hline \multirow[t]{2}{*}{ Auf der Burg } & $\mathrm{cc}$ & $4,9 \pm 0,3 \quad a$ & $9,9 \pm 1,4$ & $7,2 \pm 1,0 \quad b$ & $25,5 \pm 4,9$ & $57,2 \pm 6,6$ \\
\hline & $\mathrm{CF}$ & $2,8 \pm 0,2$ & $14,4 \pm 0,9$ a & $14,3 \pm 0,6 \quad a$ & $58,5 \pm 1,7 \quad a$ & $12,9 \pm 1,1$ \\
\hline \multirow[t]{2}{*}{ Hölleberg } & $\mathrm{cc}$ & $4,6 \pm 0,3 \quad a$ & $11,2 \pm 1,3$ & $8,7 \pm 1,1$ & $29,2 \pm 3,1 \quad b$ & $50,9 \pm 4,3$ \\
\hline & $\mathrm{CF}$ & $2,9 \pm 0,1$ & $14,6 \pm 1,2$ a & $12,5 \pm 0,6 \quad a$ & $46,6 \pm 1,3 \quad a$ & $26,4 \pm 2,3$ \\
\hline
\end{tabular}

Für die unterschiedlichen Gesamtkonzentrationen der ersten drei Feinerdeextrakte sind die $\mathrm{HCO}_{3}{ }^{-}$- und v. a. die $\mathrm{OH}^{-}$-Fraktionen verantwortlich. Letztere bestreiten in den CF-Beständen etwa 50-60\% des durch die sequentiellen Extraktionen insgesamt nachgewiesenen Phosphors. Die Löslichkeiten sowohl von $\mathrm{P}\left(\mathrm{NaHCO}_{3}\right)$ als auch von $\mathrm{P}(\mathrm{NaOH})$ der CF-Bestände übersteigen nur am Standort Auf der Burg diejenigen der CC-Bestände. Die anorganischen und organischen P-Fraktionen in den $\mathrm{HCO}_{3}^{-}$- und $\mathrm{OH}^{-}$-Extrakten weichen in allen Fällen signifikant voneinander ab (Tabelle 22). In den $\mathrm{NaHCO}_{3}$-Extrakten beider Versuchsflächen des Standorts Hölleberg sowie des CC-Bestands am Standort Auf der Burg liegt $\mathrm{P}_{\mathrm{i}}$ im Durchschnitt etwa $40 \%$ über $\mathrm{P}_{0}$. Abweichend hiervon bestreitet organisch gebundenes $\mathrm{P}$ in der Feinerde des Bestands Auf der Burg-CF etwa zwei Drittel der $\mathrm{HCO}_{3}^{-}$-extrahierbaren Fraktion. In allen $\mathrm{OH}^{-}$-Extrakten liegen die $\mathrm{P}_{\mathrm{o}}$-Anteile deutlich über denen des $\mathrm{P}_{\mathrm{i}}$. In den CC-Beständen der beiden Referenzstandorte entsprechen sie etwa $75 \%$, in den CF-Beständen 65-70 \%.

Tabelle 22: Prozentuale Verteilung von $\mathrm{P}_{i}$ und $\mathrm{P}_{o}$ in $\mathrm{NaHCO}_{3}$ - und $\mathrm{NaOH}$-Extrakten der sequentiellen P-Fraktionierung gemahlener, lufttrockener Feinerdehomogenate. Median \pm MAD $(n=16)$. Voneinander abweichende Buchstaben kennzeichnen signifikante Unterschiede zwischen den Versuchsbeständen entsprechend Rangvarianzanalysen nach Kruskal-Wallis mit anschließenden paarweisen Vergleichen nach Schaich-Hamerle $(\alpha \leq 0,050)$.

\begin{tabular}{|c|c|c|c|c|c|c|}
\hline \multirow{2}{*}{\multicolumn{2}{|c|}{ Standort/Bestand }} & \multirow{2}{*}{\multicolumn{2}{|c|}{$\begin{array}{l}\mathrm{P}\left(\mathrm{NaHCO}_{3}\right) \\
\mathrm{P}_{\mathrm{i}}: \mathrm{P}_{\circ}[\%]\end{array}$}} & \multicolumn{3}{|c|}{$\mathrm{P}(\mathrm{NaOH})$} \\
\hline & & & & $P_{i}: P_{0} \quad[$ & & \\
\hline \multirow[t]{2}{*}{ Auf der Burg } & $\mathrm{CC}$ & $58,6: 41,4$ & $\pm 10 \quad a$ & $24,2: 75,8$ & $\pm 1,2$ & c \\
\hline & $\mathrm{CF}$ & $32,1: 67,9$ & $\pm 2,7 \quad b$ & $34,9: 65,1$ & $\pm 1,0$ & a \\
\hline \multirow[t]{2}{*}{ Hölleberg } & $\mathrm{cc}$ & $58,7: 41,3$ & $\pm 3,3$ a & $25,5: 74,5$ & $\pm 1,5$ & bc \\
\hline & $\mathrm{CF}$ & $57,0: 43,0$ & $\pm 5,0 \quad$ a & $30,6: 69,4$ & $\pm 1,5$ & ab \\
\hline
\end{tabular}

\section{Phosphatanalytik wässriger Bodenextrakte}

Während für die Standorte Auf der Burg und Hölleberg verschiedene P-Fraktionen des Bodens analysiert wurden, beschränkten sich die Untersuchungen der P-Verfügbarkeiten für die verbleibenden Kalk-Halbtrockenrasen auf das wasserlösliche P der GBL. Bei der Ionenchromatographie wässriger Bodenextrakte der Daueruntersuchungsflächen traten wiederholt Probleme hinsichtlich der Trennung der benachbarten P- und $\mathrm{HCO}_{3}^{-}$- bzw. $\mathrm{Cl}^{-}$-Peaks auf. Aus diesem Grund werden in Abbildung 56 die Fraktionen des $\mathrm{P}\left(\operatorname{Resin} / \mathrm{H}_{2} \mathrm{O}\right)$ für die Standorte Auf der Burg und Hölleberg, wie sie bereits im Balkendiagramm der Abbildung 55 aufgeführt wurden, den P(GBL)-Fraktionen der Vergleichsstandorte gegenübergestellt. 


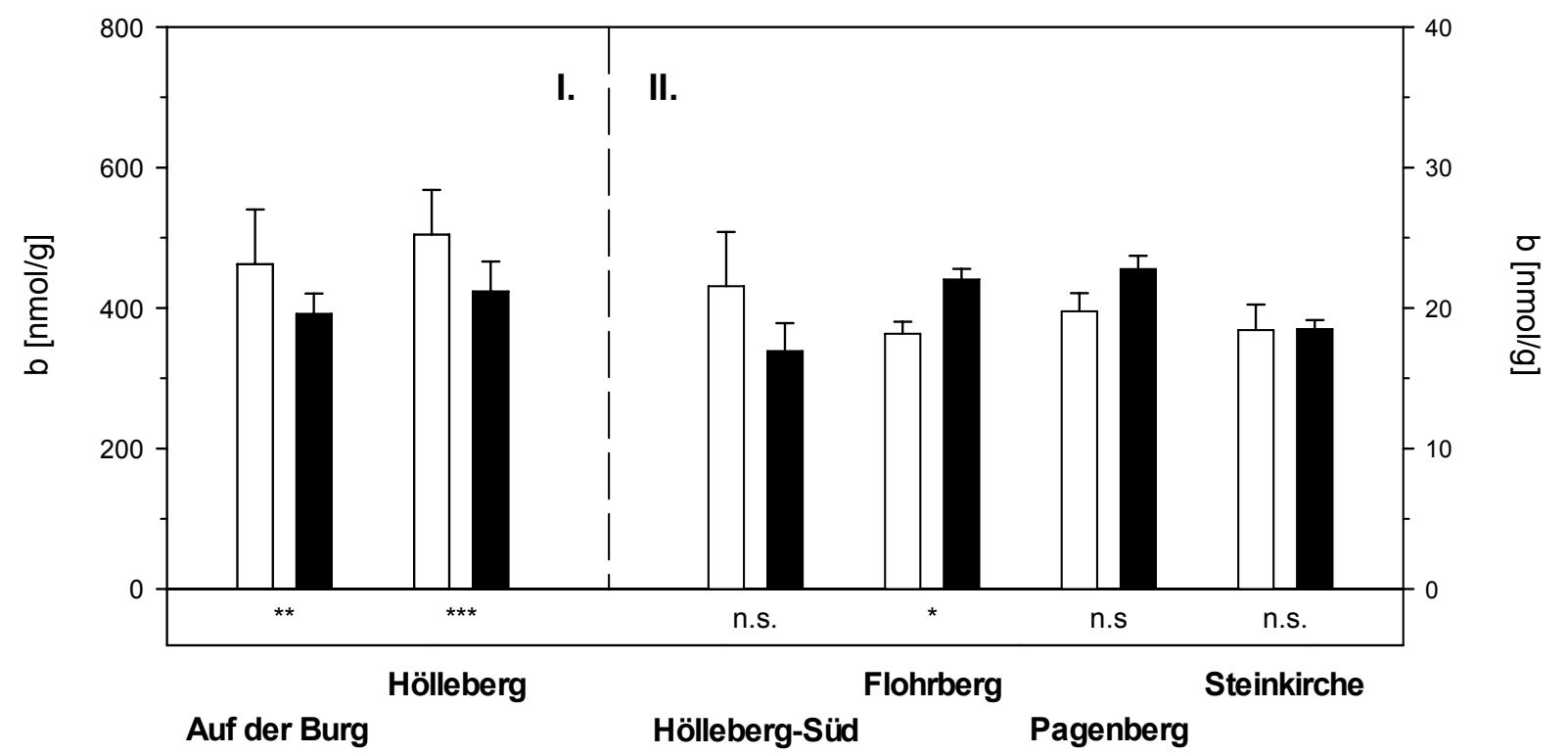

Abbildung 56: P-Löslichkeit von CC- und CF-Feinerdehomogenaten [nmol $\left.\cdot \mathrm{g}_{\mathrm{TG}}{ }^{-1}\right]$ im Rahmen verschiedener wässriger Extraktionsverfahren. I. $\mathrm{H}_{2} \mathrm{O} /$ Anionenaustauscher-Extrakte luftgetrockneter und gemahlener Feinerdehomogenate; II. GBL feldfrischer Feinerdehomogenate. Median \pm MAD (I. $n=16$; II. $n=4)$; Sternsignaturen kennzeichnen die Ergebnisse der paarweisen Vergleiche CC vs. CF mittels U-Tests nach Mann-Whitney (n.s. $\alpha>0,05$, $* \alpha \leq 0,050, * * \alpha \leq 0,010, * * * \alpha \leq 0,001)$.

Die Untersuchungen der pflanzlichen P-Verfügbarkeiten in den Subassoziationen des Gentiano-Koelerietum ergeben für die sechs Standorte ein uneinheitliches Bild. Den signifikant oder tendenziell höheren PLöslichkeiten in den CC-Beständen der Kalk-Halbtrockenrasen Auf der Burg, Hölleberg und HöllebergSüd stehen Ergebnisse gegenüber, die für die Standorte Flohrberg und Pagenberg eine bessere P-Verfügbarkeit in der Subassoziation von $D$. decumbens vermuten lassen. In den beiden Vegetationsbeständen an der Steinkirche schließlich unterscheiden sich die P-Konzentrationen in den wässrigen Feinerdeextrakten der Vergleichsbestände nicht voneinander. Vergleicht man die Ergebnisse der P-Analysen mit denen anderer Bodenuntersuchungen, so fällt auf, dass sowohl zwischen den verschiedenen Standorten als auch zwischen den Vergleichsbeständen eines Standorts nur sehr geringe Unterschiede vorliegen. In keinem Fall differieren die feinerdebezogenen P-Löslichkeiten der CC- und CF-Bestände um mehr als 25\%.

\subsubsection{Zusammenfassung der bodenkundlichen Untersuchungen}

Im Hinblick auf die Bewertung der relativen Bedeutung der verschiedenen Standortfaktoren für die Vegetationsdifferenzierung des Gentiano-Koelerietum werden in Tabelle 24 noch einmal diejenigen bodenchemischen Untersuchungen zusammengefasst, die für alle Versuchsbestände durchgeführt wurden. Neben den GBL-Analysen sowie den nicht-sequentiellen Schwermetallfraktionierungen handelt es sich hierbei um die aktuellen und potenziellen Aciditäten sowie die $\mathrm{CaCO}_{3}$ - und $\mathrm{C} / \mathrm{N}-$ Gehalte der Feinerde.

Signifikanzindizes nicht-parametrischer Vergleiche nach Mann-Whitney ergänzen die Medianwerte für die Vergleichsbestände jedes Untersuchungsstandorts. In den beiden letzten Tabellenspalten werden die Unterschiede zwischen dem Gentiano-Koelerietum typicum und Gentiano-Koelerietum danthonietosum aller sechs Untersuchungsstandorte in Form sog. Ordinationsindizes sowie deren Orientierung dargestellt. Bei den Ordinationsindizes handelt es sich um den Betrag der Summe der in Tabelle 23 definierten Klassenwerte für die jeweiligen chemoedaphischen Faktoren. 
Tabelle 23: Signaturen und Definitionen der Klassenkennwerte für die Berechnung sog. Ordinationsindizes.

\begin{tabular}{lll}
\hline Signatur & Klassenkennwert & CC/CF-Verhältnis \\
\hline$=\mid \approx$ & 0 & Mediane differieren um $<10 \%$ \\
$>\mid<$ & $-1 \mid 1$ & Mediane differieren zwischen $10 \%-100 \%$ \\
$>>\mid<<$ & $-2 \mid 2$ & Mediane differieren um $\geq 100 \%$ \\
\hline
\end{tabular}

Den Standortfaktoren werden Klassenkennwerte zwischen -2 und +2 zugeordnet. Die Ordinationsindizes können demnach bei gänzlich indifferenten Verhältnissen zwischen den CC- und CF-Bestände in den sechs Kalk-Halbtrockenrasen einen minimalen Wert von 0, bei einer starken und in allen Fällen gleich gerichteten Orientierung einen Betragswert von 12 annehmen. Die auf diesen Werten basierende tabellarische Reihenfolge gibt einen Hinweis darauf, in welchem Umfang die CC/CF-Relationen für den betreffenden Faktor gleich gerichtet sind und wie stark dieser zwischen den Vegetationsbeständen differiert. Auf diese Weise wird die potenzielle Bedeutung der einzelnen Faktoren für die Vegetationsdifferenzierung der hier untersuchten Kalk-Halbtrockenrasen aufgezeigt. Die gestrichelte Linie trennt Standortfaktoren, die einen signifikanten Unterschied in der Verteilung der CC- und CF-Beständen aller Standorte aufweisen, von solchen, deren Mediane eine eher zufällige Verteilung der Verhältnisse zwischen den Vegetationsbeständen vermuten lassen. Nicht unterschieden wurde bei diesem Auswertungsansatz zwischen Einflüssen, die auf Ebene der Einzelstandorte signifikante Unterschiede zwischen den Beständen aufweisen und solchen, deren Mediane nur tendenziell voneinander abweichen.

Die Standortfaktoren lassen sich verschiedenen Gruppen zuordnen. Acht von ihnen weisen mit Ordinationsindizes $\geq 6$ eine mindestens halbmaximale Übereinstimmung der Standorte hinsichtlich der oben ausgeführten Kriterien auf. Mit Ausnahme derer für den Standort Hölleberg finden sich für alle Untersuchungsstandorte gleich gerichtete und um mindestens $10 \%$ voneinander abweichende Verhältnisse des $\mathrm{pH}\left(\mathrm{H}_{2} \mathrm{O}\right)$ zwischen den CC- und CF-Medianen. In $85 \%$ der Fälle konnten für diese Faktoren Signifikanzen auf Ebene des Einzelstandorts belegt werden. Von den verbleibenden, nur tendenziellen Abweichungen zwischen den Vegetationsbeständen entfallen fast alle auf die beiden Standorte des Höllebergs. Neben den potenziellen und aktuellen Aciditäten als Schlüsselfaktoren des Bodenchemismus und dem $\mathrm{CaCO}_{3}$-Gehalt der Feinerde besitzen auch drei der insgesamt sechs untersuchten Fe-Fraktionen eine hohe Übereinstimmung hinsichtlich ihrer Quantitäten in den beiden Subassoziationen.

Zwei weitere Fe-Fraktionen sind Teil einer Gruppe von sechs Faktoren, die Ordinationsindizes von 5 und 4 besitzen. Auch hier entsprechen die absoluten Verhältnisse zwischen den CC- und CF-Beständen in der Regel einander. Ergebnisse, die von diesem Bild abweichen - zwei indifferente Fe(NTA)-Varianten (CC: $\mathrm{CF}=1,0-1,1)$ und eine Fe (DTPA)-Variante mit CC : $\mathrm{CF}=1,1-10$ - unterscheiden sich nicht signifikant. Entsprechendes gilt auch für Untersuchungen des wasserlöslichen Ca (3). In den meisten Fällen lagen die feinerdebezogenen Ca-Konzentrationen der CC-Bestände deutlich über denen der CF-Bestände. Für den Standort Hölleberg-Süd, lässt sich das hier inverse Verhältnis zwischen den Vergleichsbeständen statistisch nicht belegen.

Mit Ordinationsindizes zwischen 3 und 1 finden sich unmittelbar über der gestrichelten Linie Faktoren, deren Untersuchungen auf grundsätzliche, dabei aber nur geringe Unterschiede zwischen den CC- und CF-Beständen hinweisen. Auf Ebene der einzelnen Standorte erreichen die Unterschiede zwischen den Vergleichsbeständen in vielen Fällen nicht das vorgegebene Signifikanzniveau. Die letzte Gruppe bilden schließlich Faktoren, die keine grundsätzlichen Unterschiede zwischen den beiden Subassoziationen Gentiano-Koelerietum erkennen lasen. 


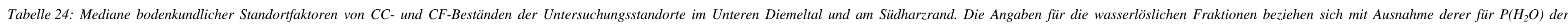

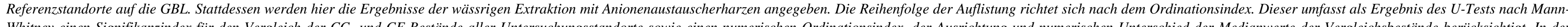

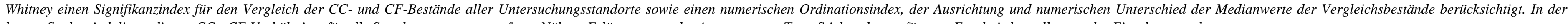
letzten Spalte sind die medianen CC : CF-Verhältnisse für alle Standorte zusammengefasst. Nähere Erläuterungen der Auswertung s. Text; Stichprobenumfänge s. Ergebnisdarstellungen der Einzeluntersuchungen

\begin{tabular}{|c|c|c|c|c|c|c|c|c|c|c|c|c|c|c|c|c|c|c|c|c|c|c|c|c|c|c|c|}
\hline \multirow[b]{3}{*}{$\mathrm{CaCO}_{3}$} & \multirow[b]{3}{*}[\%\mathrm{m}/\mathrm{m}]{} & \multicolumn{4}{|c|}{ Auf der Burg } & \multicolumn{4}{|c|}{ Hölleberg } & \multicolumn{4}{|c|}{ Hölleberg-Süd } & \multicolumn{4}{|c|}{ Flohrberg } & \multicolumn{4}{|c|}{ Pagenberg } & \multicolumn{4}{|c|}{ Steinkirche } & \multirow[t]{2}{*}{ Index } & \multirow[t]{2}{*}{$\mathrm{CC} / \mathrm{CF}$} \\
\hline & & $\mathrm{CC}$ & & CF & & $\mathrm{cc}$ & & CF & & CC & & CF & & $\mathrm{CC}$ & & CF & & $\mathrm{CC}$ & & CF & & CC & & $\mathrm{CF}$ & & & \\
\hline & & 31,2 & $\gg$ & 0,5 & $* * *$ & 14,6 & $\gg$ & 1,4 & $* * *$ & 4,0 & $\gg$ & 0,1 & * & 1,8 & $>$ & 0,3 & * & 3,7 & $\gg$ & 0,3 & * & 80,8 & $>$ & 10,8 & * & 10 * & $>$ \\
\hline $\mathrm{H}^{+}(1 \mathrm{M} \mathrm{KCl})$ & $-\log a[M]$ & 7,1 & $\ll$ & 4,8 & $* * *$ & 7,0 & $<$ & 6,2 & $* * *$ & 7,0 & $<$ & 6,5 & * & 6,9 & $\ll$ & 4,3 & * & 6,9 & $\ll$ & 4,5 & * & 7,4 & $\ll$ & 6,6 & * & 10 * & $<$ \\
\hline $\mathrm{NO}_{3}^{-}\left(\mathrm{H}_{2} \mathrm{O}\right)$ & {$[\mathrm{nmol} / \mathrm{g}]$} & 31,5 & $\gg$ & 1,4 & $* * *$ & 7,7 & $>$ & 3,4 & * & 7,4 & $>$ & 0,9 & n.s. & 264 & $\gg$ & 4,3 & * & 20,6 & $\gg$ & 0,2 & * & 427 & $>$ & 44 & * & 9 * & $>$ \\
\hline Fe (Ferrozine) & {$[\mathrm{nmol} / \mathrm{g}]$} & 8,5 & $<$ & 67,2 & $* * *$ & 4,9 & $<$ & 12,7 & $* * *$ & 2,4 & $<$ & 6,1 & * & 7,5 & $\ll$ & 78,7 & * & 17,1 & $<$ & 60,4 & * & 1,9 & $<$ & 9,7 & * & $7^{*}$ & $<$ \\
\hline $\mathrm{Fe}\left(\mathrm{H}_{2} \mathrm{O}\right)$ & [nmol/g] & 1,0 & $<$ & 8,0 & $* * *$ & 1,2 & $<$ & 1,9 & $* * *$ & 1,9 & $<$ & 9,1 & n.s. & 11,8 & $\ll$ & 185,3 & * & 21,1 & $<$ & 110,1 & * & 2,7 & $<$ & 4,9 & * & $7^{*}$ & $<$ \\
\hline $\mathrm{H}^{+}\left(\mathrm{H}_{2} \mathrm{O}\right)$ & $-\log a[M]$ & 8,0 & $<$ & 7,4 & $* * *$ & 7,9 & $\cong$ & 7,9 & n.s. & 7,8 & $<$ & 7,4 & * & 7,7 & $\ll$ & 5,8 & * & 7,8 & $\ll$ & 6,0 & * & 7,8 & $<$ & 7,7 & n.s. & $7^{*}$ & $<$ \\
\hline $\mathrm{Zn}$ (Oxalat) & [nmol/g] & 365 & $>$ & 196 & * & 351 & $>$ & 273 & n.s. & 175 & $>$ & 147 & * & 260 & $>$ & 134 & * & 366 & $>$ & 268 & * & 1043 & $>$ & 126 & * & 6 * & $>$ \\
\hline Fe (Oxalat) & {$[\mu \mathrm{mol} / \mathrm{g}]$} & 18,9 & $<$ & 33,7 & * & 22,9 & $<$ & 28,3 & n.s. & 18,6 & $<$ & 21,3 & n.s. & 24,6 & $<$ & 28,6 & * & 26,1 & $<$ & 34,8 & * & 12,0 & $<$ & 21,7 & * & 6 * & $<$ \\
\hline Zn (Dithionit) & {$[\mu \mathrm{mol} / \mathrm{g}]$} & 1,28 & $>$ & 1,15 & n.s. & 1,58 & $\cong$ & 1,51 & n.s. & 0,26 & $>$ & 0,20 & * & 0,51 & $>$ & 0,18 & * & 1,34 & $>$ & 0,83 & * & 2,68 & $>$ & 0,73 & * & 5 * & $>$ \\
\hline $\mathrm{Cl}\left(\mathrm{H}_{2} \mathrm{O}\right)$ & [nmol/g] & 261 & $>$ & 177 & $* * *$ & 227 & $>$ & 206 & $* *$ & 291 & $>$ & 220 & n.s. & 202 & $>$ & 117 & n.s. & 189 & $>$ & 161 & n.s. & 140 & $\cong$ & 130 & n.s. & 5 * & $>$ \\
\hline Fe (DTPA) & [umol/g] & 0,41 & $<$ & 0,98 & * & 0,42 & $>$ & 0,36 & n.s. & 0,12 & $<$ & 0,21 & * & 0,17 & $<$ & 1,23 & * & 0,19 & $<<$ & 2,06 & * & 0,11 & $<$ & 0,16 & * & 5 * & $<$ \\
\hline $\mathrm{Fe}$ (NTA) & {$[\mu \mathrm{mol} / \mathrm{g}]$} & 7,28 & $<$ & 10,21 & n.s. & 6,60 & $\cong$ & 7,01 & n.s. & 3,12 & $\cong$ & 3,15 & n.s. & 3,86 & $<$ & 7,06 & * & 4,47 & $<$ & 15,11 & * & 3,49 & $<$ & 5,04 & * & 4 * & $<$ \\
\hline Cu (DTPA) & [nmol/g] & 42 & $\cong$ & 40 & n.s. & 51 & $\cong$ & 55 & n.s. & 20 & $<$ & 39 & n.s. & 18 & $<$ & 39 & * & 60 & $<$ & 68 & n.s. & 22 & $<$ & 41 & * & 4 * & $<$ \\
\hline $\mathrm{C}_{\text {org }} / \mathrm{N}$ & {$[\mathrm{m} / \mathrm{m}]$} & 11,4 & $\cong$ & 12,1 & $* * *$ & 11,0 & $\cong$ & 11,9 & $* * *$ & 11,7 & $<$ & 13,0 & n.s. & 11,6 & $<$ & 13,3 & n.s. & 12,8 & $\cong$ & 12,7 & n.s. & 0,0 & $\ll$ & 7,1 & * & 4 * & $<$ \\
\hline $\mathrm{Ca}\left(\mathrm{H}_{2} \mathrm{O}\right)$ & {$[\mu \mathrm{mol} / \mathrm{g}]$} & 4,17 & $>$ & 1,33 & $* * *$ & 2,57 & $\cong$ & 2,37 & n.s. & 3,74 & $<$ & 4,30 & n.s. & 3,89 & $>$ & 0,49 & * & 1,71 & $>$ & 0,34 & * & 2,76 & $>$ & 1,81 & * & 3 * & $>$ \\
\hline Zn (NTA) & [nmol/g] & 305 & $>$ & 220 & * & 271 & $\cong$ & 248 & n.s. & 66 & $>$ & 58 & n.s. & 110 & $>$ & 71 & * & 125 & $>$ & 105 & n.s. & 61 & $<$ & 78 & * & 3 * & $>$ \\
\hline Cu (Oxalat) & [nmol/g] & 123 & $>$ & 94 & n.s. & 141 & $\cong$ & 138 & n.s. & 69 & $>$ & 60 & n.s. & 124 & $>$ & 68 & * & 145 & $>$ & 127 & * & 46 & $<$ & 69 & n.s. & 3 * & $>$ \\
\hline $\mathrm{K}\left(\mathrm{H}_{2} \mathrm{O}\right)$ & [nmol/g] & 70 & $>$ & 21 & $* * *$ & 60 & $>$ & 30 & $* * *$ & 41 & $<$ & 64 & n.s. & 117 & $\cong$ & 116 & n.s. & 87 & $>$ & 73 & n.s. & 114 & $>$ & 27 & n.s. & 3 * & $>$ \\
\hline Fe (Dithionit) & {$[\mu \mathrm{mol} / \mathrm{g}]$} & 198 & $<$ & 368 & * & 324 & $<$ & 385 & n.s. & 75 & $\cong$ & 75 & n.s. & 78 & $<$ & 87 & n.s. & 156 & $>$ & 123 & * & 100 & $<$ & 136 & * & 3 * & $<$ \\
\hline $\mathrm{Cu}$ (NTA) & [nmol/g] & 136 & $\cong$ & 131 & n.s. & 170 & $\cong$ & 156 & n.s. & 133 & $\cong$ & 121 & n.s. & 236 & $>$ & 130 & * & 333 & $>$ & 289 & n.s. & 140 & $<$ & 977 & * & 1 * & $>$ \\
\hline $\mathbf{N}$ & {$[\% \mathrm{~m} / \mathrm{m}]$} & 0,52 & $>$ & 0,43 & $* * *$ & 0,59 & $>$ & 0,48 & $* * *$ & 0,36 & $\cong$ & 0,36 & n.s. & 0,35 & $>$ & 0,22 & n.s. & 0,31 & $\cong$ & 0,35 & n.s. & 0,34 & $>$ & 0,23 & n.s. & $4^{\text {n.s. }}$ & $>$ \\
\hline $\mathrm{Mn}\left(\mathrm{H}_{2} \mathrm{O}\right)$ & {$[\mathrm{nmol} / \mathrm{g}]$} & 0,15 & $<$ & 0,69 & $* * *$ & 1,42 & $\cong$ & 1,33 & n.s. & 0,0 & $=$ & 0,0 & n.s. & 0,2 & $\ll$ & 8,3 & n.s. & 0,5 & $\ll$ & 8,0 & * & 1,0 & $>$ & 0,5 & * & $4^{\text {n.s. }}$ & $<$ \\
\hline Cu (Dithionit) & {$[\mathrm{nmol} / \mathrm{g}]$} & 255 & $<$ & 392 & n.s. & 170 & $<$ & 223 & * & 77 & $>$ & 62 & * & 126 & $>$ & 66 & * & 85 & $>$ & 35 & n.s. & 17 & $>$ & 5 & n.s. & $2^{\text {n.s. }}$ & $>$ \\
\hline $\mathrm{Na}\left(\mathrm{H}_{2} \mathrm{O}\right)$ & [nmol/g] & 186 & $\cong$ & 176 & n.s. & 89 & $<$ & 127 & $* *$ & 195 & $\cong$ & 202 & n.s. & 201 & $>$ & 160 & n.s. & 132 & $>$ & 83 & n.s. & 203 & $>$ & 162 & n.s. & $2^{\text {n.s. }}$ & $>$ \\
\hline $\mathrm{Mg}\left(\mathrm{H}_{2} \mathrm{O}\right)$ & {$[\mu \mathrm{mol} / \mathrm{g}]$} & 0,11 & $>$ & 0,05 & $* * *$ & 0,13 & $<$ & 0,15 & $* *$ & 0,14 & $<$ & 0,21 & n.s. & 0,16 & $>$ & 0,06 & $*$ & 1,39 & $>$ & 0,16 & * & 1,94 & $>$ & 1,27 & * & $2^{\text {n.s. }}$ & $>$ \\
\hline $\mathrm{NH}_{4}^{+}\left(\mathrm{H}_{2} \mathrm{O}\right)$ & [nmol/g] & 0 & $\cong$ & 0 & $* * *$ & 100 & $\cong$ & 95 & n.s. & 45 & $>$ & 18 & n.s. & 50 & $\cong$ & 53 & n.s. & 0 & $=$ & 0 & n.s. & 40 & $>$ & 0 & n.s. & $2^{\text {n.s. }}$ & $>$ \\
\hline Mn (DTPA) & [nmol/g] & 273 & $<$ & 643 & * & 333 & $<$ & 441 & * & 60 & $>$ & 42 & n.s. & 71 & $<$ & 158 & n.s. & 39 & $<$ & 231 & * & 84 & $>$ & 51 & * & $2^{\text {n.s. }}$ & $<$ \\
\hline $\mathrm{NO}_{2}^{-}\left(\mathrm{H}_{2} \mathrm{O}\right)$ & {$[\mathrm{nmol} / \mathrm{g}]$} & 8,7 & $>$ & 7,3 & ** & 3,4 & $>$ & 0,9 & n.s. & 0,1 & $\cong$ & 0,0 & n.s. & 0,0 & $<$ & 0,3 & n.s. & 0,0 & $=$ & 0,0 & n.s. & 0,0 & $<<$ & 0,9 & n.s. & $2^{\text {n.s. }}$ & $<$ \\
\hline $\mathrm{Zn}$ (DTPA) & [nmol/g] & 108 & $>$ & 64 & * & 65 & $<$ & 97 & n.s. & 33 & $<$ & 63 & * & 31 & $<$ & 48 & $*$ & 118 & $<$ & 140 & n.s. & 173 & $>$ & 42 & * & $2^{\text {n.s. }}$ & $<$ \\
\hline $\mathrm{C}_{\text {org }}$ & {$[\% \mathrm{~m} / \mathrm{m}]$} & 5,9 & $>$ & 5,3 & $* * *$ & 6,6 & $>$ & 5,7 & $* * *$ & 4,2 & $\cong$ & 4,5 & n.s. & 4,2 & $>$ & 2,9 & n.s. & 4,0 & $\cong$ & 4,4 & n.s. & 0,0 & $<<$ & 2,1 & n.s. & $1^{\text {n.s. }}$ & $>$ \\
\hline $\mathrm{P}\left(\mathrm{H}_{2} \mathrm{O}\right)$ & [nmol/g] & 462 & $>$ & 392 & * & 505 & $>$ & 423 & ${ }^{* * *}$ & 22 & $>$ & 17 & n.s. & 18 & $<$ & 22 & * & 20 & $<$ & 23 & n.s. & 18 & $\cong$ & 19 & n.s. & $1^{\text {n.s. }}$ & $>$ \\
\hline Mn (Dithionit) & {$[\mu \mathrm{mol} / \mathrm{g}]$} & 15,4 & $<$ & 19,2 & n.s. & 13,1 & $<$ & 26,7 & * & 12,7 & $>$ & 10,8 & n.s. & 9,2 & $>$ & 6,9 & * & 8,2 & $\cong$ & 8,2 & n.s. & 32,8 & $>$ & 20,9 & n.s. & $1^{\text {n.s. }}$ & $>$ \\
\hline Mn (Oxalat) & {$[\mu \mathrm{mol} / \mathrm{g}]$} & 9,9 & $<$ & 12,7 & n.s. & 14,8 & $<$ & 19,2 & * & 10,5 & $\cong$ & 10,0 & n.s. & 8,2 & $>$ & 5,4 & * & 6,1 & $<$ & 7,8 & * & 36,3 & $>$ & 4,5 & * & $1^{\text {n.s. }}$ & $<$ \\
\hline $\mathrm{SO}_{4}{ }^{2-}\left(\mathrm{H}_{2} \mathrm{O}\right)$ & [nmol/g] & 157 & $\cong$ & 167 & n.s. & 167 & $\cong$ & 166 & n.s. & 183 & $>$ & 158 & n.s. & 91 & $<$ & 130 & n.s. & 138 & $<$ & 154 & n.s. & 175 & $>$ & 146 & n.s. & $0^{\text {n.s. }}$ & - \\
\hline$M n$ (NTA) & {$[\mu \mathrm{mol} / \mathrm{g}]$} & 7,4 & $<$ & 12,8 & * & 15,1 & $<$ & 23,8 & n.s. & 9,3 & $>$ & 7,5 & * & 6,1 & $>$ & 2,5 & * & 6,3 & $>$ & 4,3 & * & 6,5 & $<$ & 7,9 & n.s. & $0^{\text {n.s. }}$ & - \\
\hline
\end{tabular}




\subsection{Keimungs- und Kulturexperimente}

Die vergleichenden Untersuchungen von zwei typischen Vertretern der Kalk-Magerrasen, der Klassenkennart der Brometalia erecti Potentilla neumanniana und der Assoziationskennart des Gentiano-Koelerietum Koeleria pyramidata, sowie der beiden Differentialarten des Gentiano-Koelerietum danthonietosum Potentilla erecta und Danthonia decumbens, von denen für die Versuche jeweils eine Population bzw. Unterart aus einem Kalk-Halbtrockenrasen und eine von einem sauren, basenarmen Standort herangezogen wurden, zielten darauf ab, die Bedeutung standörtlicher und autökologischer Eigenschaften für die Vegetationsdifferenzierung der Enzian-Schillergrasrasen aufzuzeigen. Hierfür wurde das Keimungs- und Wachstumsverhalten der betreffenden Arten, Unterarten und Populationen in Bodenmonolithen der CCund CF-Bestände des Standort Auf der Burg untersucht.

Das Saatgut von Koeleria pyramidata, Potentilla neumanniana und einer der beiden Danthonia-Populationen wurde in den Daueruntersuchungsflächen des Gentiano-Koelerietum am Hölleberg gesammelt. Saatgut von Potentilla erecta konnte in einem dem CF-Referenzbestand hangabwärts benachbarten und etwas tiefgründigeren Bereich, das Vergleichsmaterial saurer, basenarmer Standorte für P. erecta in einem Sand-Trockenrasen und für D. decumbens in einem Borstgrasrasen geerntet werden. Tabelle A 10 (S. 307) fasst die Bodenanalysen der Standorte der Saatguternten, Tabelle 24 die der Vegetationsbestände zusammen, in deren Bodenmaterial die Keimungs- und Kulturexperimente durchgeführt wurden. Die chemoedaphischen Unterschiede der Standorte der Saatguternten folgen im Wesentlichen deren aktuellen und potenziellen Aciditäten und beziehen sich insbesondere auf die Ca-und Fe-Konzentrationen der Bodenlösungen. Die Bodenreaktion am Standort Hölleberg nimmt von pH 7,9 in den Daueruntersuchungsflächen auf pH 6,7 im Boden der Saatguternte von P. erecta ab. Der Boden des Borstgrasrasens weist $\mathrm{pH} 4,8$, derjenige des Sand-Trockenrasen $\mathrm{pH} 4,2$ auf. Während die Ca-Konzentrationen in dieser Reihenfolge von $2,4 \mathrm{mmol} \cdot \mathrm{g}^{-1}$ auf $0,16 \mathrm{mmol} \cdot \mathrm{g}^{-1}$ abnehmen, steigen die Fe-Löslichkeiten von $1,9 \mathrm{nmol} \cdot \mathrm{g}^{-1}$ auf $80 \mathrm{nmol} \cdot \mathrm{g}^{-1}$ an. Die Feinerdeextraktionen mit Ferrozine ${ }^{\circledR}$ und DTPA bestätigen, dass das Auftreten von P. erecta im Gentiano-Koelerietum mit einem deutlichen Anstieg der Fe-Verfügbarkeiten einhergeht.

Tabelle 25: Mediane Keimraten [\%], Sprossmassen [g], S(pross)/W(urzel)-Verhältnisse [g/g] und Chlorophyllkonzentrationen $[\mathrm{mg} / \mathrm{g}]$ von Pflanzenpopulationen basischer, kalkreicher und saurer, basenarmer Standorte (vgl. Tabelle A 10, S. 307) in CC- bzw. CF-Bodenmonolithen des Standorts Auf der Burg (vgl. Tabelle 24, S. 101). Die Keimraten beziehen sich auf einen Zeitraum von einem Monat (K. pyramidata, D. d. ssp. decipiens, P. neumanniana) bzw. drei Monaten (D. d. ssp. decumbens, P. erecta), Sprossmassen und korrespondierende S(pross)/W(urzel)Verhältnisse auf eine zehnmonatige Kultivierung. Sternsignaturen kennzeichnen die Ergebnisse der paarweisen Vergleiche CC vs. CF mittels U-Tests nach Mann-Whitney (n.s. $a>0,05, * a \leq 0,050 ; n=10$ ).

\begin{tabular}{|c|c|c|c|c|c|c|c|c|c|c|c|c|c|}
\hline \multirow[t]{2}{*}{ Art/Unterart } & \multirow[t]{2}{*}{ Herkunft } & \multicolumn{3}{|c|}{ Keimrate [\%] } & \multicolumn{3}{|c|}{ Spross [g] } & \multicolumn{3}{|c|}{$\mathrm{S} / \mathrm{W}[\mathrm{g} / \mathrm{g}]$} & \multicolumn{3}{|c|}{ Chl. $a+b[\mathrm{mg} / \mathrm{g}]$} \\
\hline & & CC & CF & & CC & CF & & CC & CF & & CC & CF & \\
\hline K. pyramidata & Hölleberg & 58 & 64 & n.s. & 0,57 & 0,54 & n.s. & 1,1 & 2,9 & n.s. & 1,9 & 2,4 & * \\
\hline P. neumanniana & Hölleberg & 48 & 38 & * & 0,41 & 0,35 & * & 1,1 & 1,0 & n.s. & 2,3 & 3,5 & n.s. \\
\hline D. d. ssp. decipiens & Hölleberg & 50 & 38 & n.s. & 0,80 & 1,29 & n.s. & 1,1 & 1,9 & * & 1,6 & 1,5 & n.s. \\
\hline D. d. ssp. decumbens & Viehhaus & 20 & 16 & n.s. & 0,91 & 1,15 & * & 0,8 & 2,1 & *** & 1,4 & 1,5 & n.s. \\
\hline P. erecta & Hölleberg & 4 & 10 & n.s. & 0,37 & 0,46 & n.s. & 0,8 & 1,1 & n.s. & 2,3 & 2,8 & n.s. \\
\hline P. erecta & Glaner Braut & 6 & 10 & n.s. & 0,35 & 0,38 & n.s. & 1,1 & 1,2 & n.s. & 2,0 & 3,0 & * \\
\hline
\end{tabular}


Während mittels karyologischer und blattmorphologischer Untersuchungen belegt wurde, dass D. decumbens auf dem Hölleberg durch die Unterart D. decumbens ssp. decipiens, in dem Borstgrasrasen durch D. decumbens ssp. decumbens vertreten ist (Abbildung A 6, S. 315), können die beiden Populationen von $P$. erecta taxonomisch nicht unterschieden werden.

Wie in Tabelle 25 angegeben, zeigte das Saatgut der meisten Arten, Unterarten und Populationen vom Hölleberg in den Bodenmonolithen sowohl der CC- als auch der CF-Bestände überdurchschnittlich hohe Keimungsraten. Eine diesbezügliche Ausnahme stellt Potentilla erecta dar, deren Population aus dem Unteren Diemeltal mit maximal 10 \% kein besseres Keimungsvermögen aufwies als die des sauren Sandbodens. P. neumanniana keimte übereinstimmend mit seiner höheren Präsenz im Gentiano-Koelerietum typicum in den CC-Monolithen besonders gut.

Da trotz der Korrekturen um das Wurzelmaterial in den Kontrollmonolithen ohne Einsaat die Genauigkeit der Wurzelmassenbestimmung begrenzt ist, werden in Tabelle 25 nicht die Gesamt-, sondern Sprossbiomassen aufgeführt. In den meisten Fällen tendenziell, für P. neumanniana und $D$. decumbens ssp. decumbens auch signifikant, folgt das Sprosswachstum der Pflanzen den Bodeneigenschaften ihrer Herkunftsorte: Koeleria pyramidata und P. neumanniana wachsen in dem kalk- und skelettreicheren Bodenmaterial der CC-Monolithe, die Pflanzen der verbleibenden Arten bzw. Unterarten in den basenärmeren CFMonolithen besser. In der Regel übersteigt das Spross/Wurzel-Verhältnis von Versuchspflanzen, die in Bodenmaterial des Gentiano-Koelerietum danthonietosum kultiviert wurden, das der Vergleichsvarianten. Dies lässt vorbehaltlich der methodischen Probleme exakter Wurzelmassenbestimmungen eine Stimulation des Wurzelwachstums in den CC-Monolithen vermuten.

Im Versuchsverlauf wurden vorübergehend sehr hohe Wassergehalte in den Bodenmonolithen erreicht. Trotz der daraus resultierenden recht hohen Fe-Konzentrationen der Bodenlösungen - wie regelmäßige Analysen von Mikrolysimeterlösungen ergaben, lagen diese im Versuchszeitraum in den CC-Monolithen median bei 6,6 $\mu \mathrm{M}$, in den CF-Monolithen median bei $40 \mu \mathrm{M}$ - zeigten verschiedene Pflanzen Chlorosen. Dies gilt, wie die Messungen der Chlorophyll a- und Chlorophyll b-Konzentrationen belegen, insbesondere für Danthonia decumbens, in deren vier Versuchsvarianten mit den Faktoren Unterart und Bodenherkunft gleichzeitig von allen Kulturansätzen die höchsten Wachstumsraten auftraten. Während die Chlorophyllbildung von D. decumbens ssp. decipiens und D. decumbens ssp. decumbens in etwa gleichem Maß durch die Verhältnisse in den CC- und CF-Monolithen beeinträchtigt wurde, geben die Untersuchungen der anderen Arten Hinweise auf eine stärkere Störung der Chlorophyllbiosynthese in dem skelettreichen Bodenmaterial des Gentiano-Koelerietum typicum. Als mögliche Ursachen können hier indirekte Beeinträchtigungen der Fe-Ernährung durch unterschiedliche Ca- und daraus abzuleitende $\mathrm{HCO}_{3}{ }^{-}$-Konzentrationen in den CC- und CF-Monolithen in Betracht gezogen werden. Die Ergebnisse dieser Kulturversuche sind aber unter dem Gesichtspunkt der im Vergleich zu den natürlichen Standorten deutlich höheren Bodenwassergehalte und der geringeren Bodenvolumina für das Pflanzenwachstum zu interpretieren. Es kann daher nicht ausgeschlossen werden, dass sich z. B. die pflanzliche N-Versorgung aufgrund des Pflanzenwachstums während der Kultur und trotz der hier zunächst höheren feinerdebezogenen $\mathrm{N}_{\min }$-Gehalte der verschiedenen wässrigen Extrakte gerade in den skelettreichen Bodenmonolithen des Gentiano-Koelerietum typicum zu einem limitierenden Faktor entwickelte. 
Der Calcicolen/Calcifugen-Komplex 


\subsection{Allgemeines}

Kaum ein Phänomen in der Botanik wurde so früh und so eingehend hinterfragt, wie die Präferenz mancher Pflanzenarten für Kalk- und Carbonatböden, anderer für kalkarme Sand- und Silikatböden (Larcher 1994). Die Behandlung der sog. Calcicolen/Calcifugen-Problematik nahm ihren Ausgang in zwei Arbeiten, die Ende des 18. und Anfang des 19. Jahrhunderts in Göttingen veröffentlicht wurden. Von einer abweichenden Vegetationsdifferenzierung trockener Kalkböden und feuchter Tonböden berichtet im Jahr 1789 erstmals H. F. Link. Diese Beobachtung findet ein Vierteljahrhundert später Bestätigung in der "Flora Carpatorum Principalium" von Wahlenberg (1814). Beginnend mit den ersten Untersuchungen von Unger (1836) zum "Einfluss des Bodens auf die Vertheilung der Gewaechse" über Schiefer- und Kalkgestein, wurde die Calcicolen/Calcifugen-Komplex in der Folge unter verschiedensten aut- und synökologischen Gesichtspunkten behandelt. Bereits in der zusammenfassenden Arbeit "Reaktion des Bodens und Pflanzenwachstum" von Mevius (1927) werden 759 Veröffentlichungen zur erweiterten Thematik zitiert. Umfangreiche Übersichten zum Forschungsstand legten auch Ellenberg (1958) und Kinzel (1982) vor. Den letzten zusammenfassenden Rückblick v. a. auf ökophysiologische Arbeiten zum Thema gab Lee (1999). Seine Forderung, bisher ungenutzte elektrophysiologische (z. B. patch clamp), chemoanalytische (z. B. NMR-Spektroskopie) und molekularbiologische Techniken zur Klärung weiterhin offener Fragen im Themenkomplex einzusetzen, gründet auch auf der Beobachtung eines allgemein nachlassenden Interesses an diesem Forschungsgebiet und dem daraus resultierenden Stagnieren des diesbezüglichen Wissensstands in den vergangenen Jahren und Jahrzehnten.

Die Definition der beiden Begriffe 'calcicol' und 'calcifug' basiert in ihrem Kern allein auf der standörtlichen Verbreitung der Arten (Hope Simpson 1938): "Calcicoles are regarded as species affecting the more important types of calcareous soils and rare or absent from acid soils, and calcifuges as the reverse". Die Termini calcifug und calcicol finden sich zwar bereits in der älteren Literatur (Salisbury 1920 ${ }_{\mathrm{K}}$; Chodat $\left.1913_{\mathrm{K}}\right)^{1}$, doch erkannte Hope Simpson als erster das Missverhältnis zwischen der Verbreitung der Arten unter den in der Vegetation einwirkenden Faktoren, u. a. der interspezifischen Konkurrenz, sowie den häufig davon abweichenden physiologischen Präferenzen. Aus diesem später von Ellenberg (1953) eingehender behandelten Sachverhalt differierender ökologischer und physiologischer Optima ergab sich die Notwendigkeit, zwischen rein deskriptiven und kausalen Definitionen zu unterscheiden.

Der grundlegenden Differenzierung calcicoler und calcifuger Pflanzen entspricht im Prinzip die standörtliche Klassifizierung in Gruppen (absolut) kalksteter bzw. kieselsteter, (relativ) kalkholder bzw. kieselholder und schließlich indifferenter Arten, wie sie bereits von Unger (1836) vorgenommen wurde. Je nach Fragestellung und verfügbarem Datenmaterial wurden in der Folge für die Zuordnung von Pflanzenarten zu calcifugen oder calcicolen Verbreitungsgruppen unterschiedliche Abgrenzungen vorgenommen. Da eine uneingeschränkte Bindung von Pflanzenarten an einen Bodentyp die Ausnahme ist, legt Etherington (1981) der Definition Calcifuger einen mathematischen Verbreitungsindex zugrunde. Für Untersuchungsflächen in Nordwestengland bezeichnet er Arten als calcifug, wenn sie zu mehr als $40 \%$

\footnotetext{
1 Im Weiteren wird an verschiedenen Stellen auf Literatur verwiesen, die in zwei der genannten Übersichtsarbeiten zitiert, im Rahmen der vorliegenden Bearbeitung aber nicht noch einmal gesichtet wurde. Diese Zitate sind durch entsprechende Indizes gekennzeichnet: $M=$ Mevius (1927); $K=$ Kinzel (1982).
} 
auf Böden mit pH<5,5 auftreten. Ewald (2003) fasst in seiner Kausalanalyse der abweichenden Biodiversitäten saurer, kalkarmer und basischer/kalkreicher Böden in Zentraleuropa Arten als calcifug zusammen, die nach Ellenberg et al. (1992) Zeigerwerte für die Bodenreaktion von R 1 bis R 6 aufweisen. Arten mit Zeigerwerten zwischen R 7 und R 9 werden hingegen als calcicol betrachtet. ${ }^{1}$ Demnach unterliegen hier alle Pflanzen, mit Ausnahme solcher, die eine vollkommen indifferente Verbreitung besitzen, der Zuordnung entweder zu der einen oder anderen Verbreitungsgruppe. Dies gilt auch für Taxa, die innerhalb des für das Pflanzenwachstum relevanten pH-Spektrums (ca. pH 2,5-9) vorwiegend auf intermediären, leicht sauren Böden (ca. pH 5,5-6,5) auftreten. In ähnlicher Weise unterteilt Lawesson (2003) Pflanzen mit einer unimodalen Verbreitung entlang des pH-Gradienten in nur zwei Gruppen. Acidophytisch sind nach seiner Definition all diejenigen, die ihren Verbreitungsschwerpunkt auf Böden mit $\mathrm{pH}<5,5$ finden, calciphytisch solche, die vorwiegend in Böden mit $\mathrm{pH} \leq 5,5$ wachsen. Tatsächlich sind unter den 3364 Arten der Schweizer Flora von Landolt (1977) lediglich 3,9 \% auf sehr basenreiche und 1,3 \% auf sehr saure Böden beschränkt (Wohlgemuth \& Gigon 2003). Ähnliche Verhältnisse dürften auch in Deutschland gelten. Allerdings können Pflanzen je nach geographischer Lage und klimatischen Faktoren unterschiedliche Böden besiedeln (Webb 1947; Lötschert 1959; Perring 1960; Holzner 1978; Gaston et al. 1998). So ergeben sich häufig Abweichungen von einer calcifugen Standortpräferenz an Standorten sehr hoher Niederschlagsneigung (Etherington 1981). Hintergrund geographisch abweichender Standorte können u.a. Veränderungen interkorrelierter, ökophysiologisch relevanter Standortfaktoren sowie die damit einhergehenden Verschiebungen im Artengefüge und der interspezifischen Konkurrenz sein.

Die Begriffe 'basiphil' (basenliebend) und 'acidophil' (säureliebend) tragen der Tatsache Rechnung, dass alkalische Böden nicht notwendigerweise Kalkböden sind und dass die Förderung bzw. Hemmung entsprechender Arten häufig weniger im Zusammenhang mit der Calciumkonzentration als vielmehr mit der Bodenreaktion gesehen werden muss. In gleicher Weise, wie sich die beiden Begriffe calcicol und calcifug in ihrer weiten Fassung nicht nur auf den Verbreitungsschwerpunkt, sondern auch auf die Ökophysiologie der Arten beziehen, finden auch die Bezeichnungen basiphil und acidophil entweder einen rein standörtlichen oder einen ergänzenden physiologischen Bezug. Weitere Begriffe dieses Themenkomplexes sind 'basiphob' bzw. 'basifug' (basenmeidend) und 'acidophob' bzw. 'acidofug' (säuremeidend). Diese Ausführungen zur Terminologie deuten bereits an, wie schwer eine eindeutige Klassifizierung von Pflanzen in verbreitungs- und v. a. in kausalökologischer Hinsicht ist. Abiotische und biotische, physikalische und chemische Faktoren bedingen einander und bilden ein gemeinsames Wirkungsgefüge. Besonders deutlich wird dies bei der Betrachtung der Schlüsselfaktoren $\mathrm{pH}$ und $\mathrm{E}_{\mathrm{h}}$, die miteinander korreliert sind und gleichzeitig eine Vielzahl weiterer Bodenfaktoren beeinflussen. Letztlich ist das Lösungsverhalten des $\mathrm{CaCO}_{3}$ im geologischen Ausgangsmaterial zusammen mit den klimatischen Rahmenbedingungen für die neutrale bis basische Reaktion von Kalkböden verantwortlich.

Im Hinblick darauf, dass die Standortpräferenz einer Pflanzenart je nach geographischer Lage variieren und durch viele, für die meisten Arten noch nicht näher definierte Einzelfaktoren bestimmt werden kann, zeigen die Begriffe calcicol und basiphil sowie calcifug und acidophil nur begrenzt die tatsächlichen Eigenschaften der Arten auf. Deshalb wird in der vorliegenden Arbeit zumeist von acidophilen/calcifugen und basiphilen/calcicolen Arten gesprochen und dabei der in der Regel unbestimmte ökophysiologische

\footnotetext{
1 In Tabelle $A 1$ (s. 300) des Anhangs sind - soweit verfügbar - die L(icht)-, T(emperatur)-, K(ontinentalitäts)-, F(euchte)-, $R$ (eaktions)- und N(ährstoff)-Zeigerwerte nach Ellenberg et al. (1992) aller Taxa aufgelistet, die im Weiteren behandelt werden. Bei Bedarf geben sie dem Leser eine Vorstellung der Standorteigenschaften der jeweiligen Pflanzen.
} 
Aspekt inhaltlich mit einbezogen. Diese Klassifizierungen sollen hier aber solchen Arten vorbehalten bleiben, die nach Übereinstimmung der meisten Autoren einen eindeutigen Verbreitungsschwerpunkt außerhalb intermediärer Bodenreaktionen (ca. pH 5,5-6,5) aufweisen.

Unterschiede zwischen sauren Mineralböden und alkalischen Kalkböden werden wesentlich durch das Verwitterungsverhalten des Ausgangsgesteins bestimmt. Stark vereinfachend lassen sich die betreffenden physikalischen und chemischen Bodeneigenschaften im Hinblick auf das Pflanzenwachstum und die pflanzliche Mineralstoffernährung wie in Tabelle 26 zusammenfassen. Tatsächlich gibt es saure und basische Böden, die von dem hier dargestellten Bild abweichen. Leicht verwitternde Silikatböden können tiefgründig und recht nährstoffreich sein, während über schlecht löslichem Granit oder Gneis flachgründige, nährstoffarme Böden entstehen. Nicht angeführt sind auch Solontschaks und Solonetzs, Salzböden bzw. Böden mit hoher Na-Sättigung, deren alkalische Bodenreaktion auf NaCl- bzw. $\mathrm{Na}_{2} \mathrm{CO}_{3}$-reiches Ausgangsgestein oder den Eintrag v. a. von $\mathrm{NaCl}$ durch trockene oder nasse Depositionen zurückgeht. Im Gegensatz zu Kalkböden sind diese nicht durch hohe $\mathrm{Ca}^{2+}$-Konzentrationen gekennzeichnet.

Bis hinein in das zweite Jahrzehnt des 20. Jahrhunderts vertraten Forscher, wie zunächst Thurmann (1849 ) und de Candolle (1855 $)$, die Ansicht, dass nicht chemo- sondern physikoedaphische Faktoren für die Vegetationsdifferenzierung von Silikat- und Kalkböden verantwortlich zeichnen. In der Regel sind Kalkböden trockener, besser durchlüftet und damit wärmer als saure Mineralböden. Kennzeichnend für saure, aber auch extrem basische Böden ist, dass der Aufbau einer kolloidalen Krümelstruktur verhindert und damit die Verdichtung des Bodens gefördert wird (Ellenberg 1958, Kuntze et al. 1994). Bei hohen $\mathrm{H}^{+}$-Aktivitäten erfolgt ein Austausch bivalenter Kationen, insbesondere $\mathrm{Ca}^{2+}$, die bei intermediären $\mathrm{pH}$ Werten durch Quervernetzungen zwischen den negativen Seitengruppen von Tonmineralien koagulierend wirken. Ein hoher $\mathrm{pH}$ und hohe Konzentrationen an Alkaliionen sind dafür verantwortlich, dass beispielsweise in Solonetzen $\mathrm{Na}^{+}$nicht durch $\mathrm{H}^{+}$von den Austauschern der Tonmineralien verdrängt werden und hier tonreiche Böden aufgrund der ausgedehnten Hydrathülle des $\mathrm{Na}^{+}$zur Quellung und Verdichtung neigen. Regenwürmer finden bei mittleren $\mathrm{pH}$-Werten und $\mathrm{CaCO}_{3}$-Gehalten optimale Bedingungen vor. Die Ausbildung stabiler Ton-Humus-Komplexe in ihrem Darm geht mit einer Strukturierung des Bodens einher.

Kraus (1911) belegte im Rahmen seiner Arbeiten zur kleinräumigen Vegetationsdifferenzierung auf Muschelkalk in Franken, dass Kalkpflanzen, wie Pulsatilla vernalis, unter bestimmten Umständen auch auf kalkfreien Böden anzutreffen sind. Nach seiner Einschätzung konnte damit $\mathrm{CaCO}_{3}$ keine zentrale Rolle für die Vegetationsdifferenzierung spielen. Kalk sollte vielmehr über das Verwitterungsverhalten und zusammen mit geographischen Faktoren, wie der Exposition und Inklination sowie des Klimas, die physikalischen Eigenschaften von Kalkböden und darüber den Aufbau einer Vegetation mit vielen xeround thermophilen Arten bestimmen.

Bereits im 19. Jahrhundert ging indes die Mehrzahl der Wissenschaftler davon aus, dass chemische Faktoren für die Vegetationsdifferenzierung von Silikat- und Kalkböden verantwortlich zeichnen (Kinzel 1982). Die physikalischen Bodeneigenschaften beeinflussen zugleich verschiedene chemoedaphische Faktoren. Bodenart und Bodengefüge sowie die oben genannten geographischen Faktoren sind Determinanten insbesondere des Wasserhaushalts und der Durchlüftung der Böden. Neben einer grundsätzlichen Beeinflussung der Bodenbildungsprozesse und der Verlagerung der Lösungskomponenten sind Umsetzungen redoxlabiler Elemente, wie N, Fe und Mn, und somit Aspekte der pflanzlichen Mineralstoffernährung und -intoxikation in diesem Zusammenhang von besonderer Bedeutung. Obwohl Liebig, Sachs und 
Tabelle 26: Charakteristika saurer Mineralböden und alkalischer Kalkböden (nach Angaben von Kinzel 1982, Scheffer \& Schachtschabel 1992 und Marschner 1995).

\begin{tabular}{lcc}
\hline Standortfaktoren & saure Mineralböden & Kalkböden \\
\hline Physikalische Parameter & niedrig & hoch \\
- Bodendurchlüftung & hoch & niedrig \\
- Bodenfeuchte & niedrig & hoch \\
- Bodentemperatur & & \\
Chemische Parameter & niedrig $(\mathrm{pH}<4)$ & hoch $(\mathrm{pH} 7,5-8,5)$ \\
- Boden-pH & $\mathrm{Al}, \mathrm{Fe}, \mathrm{Mn}$ & $\mathrm{Ca}, \mathrm{HCO}_{3}^{-},(\mathrm{B})$ \\
- potenzielle Mineralstofftoxizitäten & $\mathrm{Ca}, \mathrm{Mg}, \mathrm{P},(\mathrm{Cu}, \mathrm{K}, \mathrm{Mo}, \mathrm{S}, \mathrm{Zn})$ & $\mathrm{Fe}, \mathrm{P}_{1} \mathrm{Mn}_{\mathrm{Zn}}$ \\
- potenzielle Mineralstoffdefizienzen & $\mathrm{NH}{ }^{+}$ & $\mathrm{NO}_{3}^{-}$ \\
\hline
\end{tabular}

andere bereits die Grundlagen der pflanzlichen Mineralstoffernährung und die essentielle Bedeutung einer ganzen Reihe chemischer Elemente für die Pflanzenernährung aufgedeckt hatten, reduzierten einige Forscher anfangs die hier behandelte Vegetationsdifferenzierung darauf, dass für Kalkpflanzen $\mathrm{CaCO}_{3}$ in hohen Konzentrationen erforderlich sei, Silikatpflanzen hingegen Calcium nicht oder nur in sehr geringen Konzentrationen, andererseits Silicium in erheblichem Umfang bedürfen (Unger 1836; von Mohl 1845 ${ }_{\mathrm{M}}$ ). Vergleichende Analysen von Bodenmaterial und Pflanzenaschen sowie die Untersuchung der Wirkung von $\mathrm{CaCO}_{3}, \mathrm{CaSO}_{4}$ und $\mathrm{Ca}\left(\mathrm{NO}_{3}\right)_{2}$ auf Torfmoose widerlegten bald diese vereinfachende Annahme und deuteten darauf hin, dass letztlich das Carbonat die ausschlaggebende Rolle spielt (Johnson \& Sendtner 1854 ${ }_{\mathrm{M}}$; Öhlmann 1898 ; Paul 1906 ). Steele (1955) prägte später für Arten, deren Wachstum tatsächlich an hohe $\mathrm{Ca}^{2+}$-Konzentrationen gebunden ist, den Begriff 'exacting calcicoles'.

Mit der Einführung des pH-Konzepts durch Sørensen $\left(1909_{\mathrm{K}}\right)$ und der Entwicklung praktikabler Methoden zur Messung der Wasserstoffionenaktivität wurde die Bedeutung der Bodenreaktion sowie mit dieser korrelierter bodenchemischer Eigenschaften erkannt. Neben anderen erbrachten Olsen $\left(1923_{\mathrm{K}}, 1925_{\mathrm{K}}\right)$, Tansley \& Adamson (1925) und Hope Simpson (1938) den Beweis, dass in erster Linie chemische Faktoren, und hier als übergeordneter Schlüsselfaktor die Bodenreaktion, für die Etablierung oder Eliminierung von basiphilen/calcicolen bzw. acidophilen/calcifugen Arten und die Ausbildung entsprechender Pflanzengesellschaften verantwortlich sind. Für den Ausschluss basiphiler/calcicoler Arten von Standorten saurer Böden müssen in der Regel toxische Al-, Fe- und Mn-Konzentrationen bei suboptimaler Versorgung mit Ca und Mg sowie P als limitierend betrachtet werden (Mengel 1991; Scheffer \& Schachtschabel 1992; Marschner 1995). Böden hoher pH-Werte sind demgegenüber in aller Regel durch geringe Fe-, Mn- und Zn-Löslichkeiten gekennzeichnet. Schon früh war eine unzureichende Fe-Versorgung für die Ausbildung von Chlorosen nicht adaptierter Pflanzenarten auf Kalkstandorten verantwortlich gemacht worden (Gris $1843_{\mathrm{M}}, 1845_{\mathrm{M}}$ ). In Kalkböden spielen außerdem verminderte P-Löslichkeiten und hohe $\mathrm{Ca}^{2+}$ - und $\mathrm{HCO}_{3}{ }^{-}$-Konzentrationen eine Rolle. Sowohl in sehr sauren als auch in flachgründigen, trockenen Kalkböden kann das Pflanzenwachstum N-limitiert sein. Während im erstgenannten Fall die mikrobielle Nitrifikation gehemmt ist und damit in erster Linie $\mathrm{NH}_{4}{ }^{+}$vorliegt, führt diese in Kalkböden weiter zur Bildung von $\mathrm{NO}_{3}{ }^{-}$. Allerdings beeinträchtigt in vielen Kalkböden Bodentrocknis die Mineralisation des organischen Materials. 
Auch aufgrund methodisch-apparativer Neuerungen entwickelte sich die Calcicolen/Calcifugen-Thematik in den 50er und 60er Jahren des vergangenen Jahrhunderts zu einem der wichtigsten ökologischen Forschungsfelder. In Großbritannien wurde sie auf fast allen systemaren Ebenen behandelt. Insbesondere in der 1961 gegründeten Arbeitsgruppe Grassland Ecology, der späteren Abteilung Comparative Plant Ecology an der Universität Sheffield, wurden Fragestellungen nach dem Muster und den Ursachen der Verbreitung der betreffenden Ökophysiotypen intensiv verfolgt. ${ }^{1}$ Vegetationskundlich-bodenkundliche Arbeiten bezogen sich hier auf die Untersuchung von kleinräumigen geologischen, topographischen und edaphischen Transekten (z. B. Webb 1947; Balme 1953, Grime 1963a; Grubb et al. 1969; Jarvis 1974; Etherington 1981) sowie großräumigen, klimatischen Gradienten (z. B. Perring 1960). Frühe autökologische Untersuchungen konzentrierten sich auf Experimente zur Keimung, Konkurrenz und Mineralstoffernährung von Arten (Rorison 1960a, 1960b; Grime 1963b; Jefferies \& Willis 1964a, 1964b; Hutchinson 1967a, 1967c; Marrs \& Bannister 1978a), Vikarianten (Grime 1965b) und Ökotypen bzw. Populationen (Rorison 1960a, 1960b; Snaydon 1962; Grime 1965b; Hutchinson 1967b; Marrs \& Bannister 1978b). Schließlich wurden in der Calcicolen/Calcifugen-Forschung verstärkt auch autökologisch-ökophysiologische Fragestellungen, etwa zum Kohlenstoffhaushalt (Woolhouse 1966; Lee \& Woolhouse 1969a, 1969b, 1971) sowie zur pflanzlichen Stickstoff- (Gigon \& Rorison 1972; Havill et al. 1974) und Eisenernährung (Hutchinson 1968; Grime \& Hodgson 1969) behandelt.

In den 70er und v. a. im Laufe der 80er und 90er Jahre des vergangenen Jahrhunderts nahm das Interesse an den Ursachen der Vegetationsdifferenzierung saurer, kalkarmer und basischer/kalkreicher Böden mehr und mehr ab. Trotz ihrer intensiven Behandlung in der Vergangenheit sind aber auch heute noch viele der diesbezüglichen Fragen ungeklärt. Die vorliegende Arbeit behandelt die nach wie vor kontrovers diskutierte Frage, welche Standortfaktoren für den regelhaften Ausschluss acidophiler, calcifuger Arten von Standorten kalkreicher, basischer Böden ausschlaggebend sind. Vergleichende Untersuchungen, die über die Erfassung der übergeordneten edaphischen Faktoren, wie Bodentyp, $\mathrm{CaCO}_{3}$-Gehalt und $\mathrm{pH}$, älterer vegetationskundlicher Arbeiten hinausgehen, beziehen sich hier auf zwei Subassoziationen der EnzianSchillergrasrasen (Gentiano-Koelerietum). Bei einem gemeinsamen basiphilen/calcicolen Artenbestand treten nur im Gentiano-Koelerietum danthonietosum gleichzeitig Acidophile/Calcifuge auf. Im Vordergrund der bodenchemischen Untersuchungen steht dabei die Frage, inwieweit suboptimale Eisen-, Mangan- oder Phosphorverfügbarkeiten sowie abweichende N-Angebote für den Ausschluss von acidophilen/ calcifugen Arten aus Kalk-Halbtrockenrasen verantwortlich zeichnen.

Ungeachtet dessen, dass methodisch-apparative Entwicklungen ganz neue Perspektiven für die Untersuchung des Calcicolen/Calcifugen-Komplexes eröffnen, befassen sich heute nur noch sehr wenige Arbeitsgruppen mit dieser Thematik. Gleichzeitig wurden aber in den vergangenen Jahren viele grundlegende Fragen der pflanzlichen Mineralstoffernährung geklärt, die in der vorliegenden Arbeit gezielt in Beziehung zu älteren Untersuchungen der Calcicolen/Calcifugen-Problematik gestellt werden sollen und der Bewertung der eigenen Untersuchungen dienen können.

\subsection{Bodenkundliche Aspekte des Calcicolen/Calcifugen-Komplexes}

Nachdem hier bereits ein zusammenfassender Überblick der verschiedenen physikochemischen Aspekte des Calcicolen/Calcifugen-Komplexes gegeben wurde, sollen nachfolgend die dem abweichenden Che-

\footnotetext{
1 Vgl. http.//www.shef.ac.uk/uni/academic/N-Q/nuocpe/ucpe/ (University of Sheffield, Department of Animal and Plant Sciences, Unit of Comparative Ecology, Stand Mai 2005).
} 
mismus basenarmer, saurer und kalkreicher, basischer Standorte primär zugrunde liegenden Faktoren im Detail behandelt werden. Im Vordergrund stehen hier die Protonenaktivitäten und das Redoxpotenzial der Böden. In diesem Zusammenhang werden außerdem die verschiedenen Puffersysteme und die grundlegenden Reaktionen vorgestellt, die für die Entwicklung basenreicher, alkalischer hin zu basenarmen, sauren Böden eine ausschlaggebende Rolle spielen. Das Calciumcarbonatsystem ist in Kalkböden nicht nur für die Einstellung von pH-Werten im neutralen oder leicht alkalischen Bereich verantwortlich, sondern es beeinflusst durch seine Dissoziationsspezies mehr oder minder spezifisch auch die pflanzliche Mineralstoffernährung. Aufgrund seiner besonderen Bedeutung für das Pflanzenwachstum in Kalkböden soll in diesem Kapitel außerdem auf den recht komplexen Lösungschemismus des Eisens eingegangen werden. Ausführungen zur Verfügbarkeit weiterer Mineralstoffe finden sich in Abschnitten, die sich diesbezüglich mit wichtigen ökophysiologischen Aspekten der Pflanzenernährung in sauren und basischen Böden befassen sowie in der Diskussion der eigenen Untersuchungen.

\subsubsection{Bedeutung von $\mathrm{pH}$ und $\mathrm{E}_{\mathrm{h}}$ für den Bodenchemismus}

Der pH-Wert und das Redoxpotenzial $\mathrm{E}_{\mathrm{h}}$ sind Schlüsselfaktoren der Bodenlösungschemie (Lindsay 1979; Wolt 1994). Sie werden v. a. durch die geologisch-topographischen und klimatischen Standortbedingungen bestimmt. Je nach Material der Bodenbildung - seien es das unterliegende Gestein, laterale Stoffeinträge oder auch Einträge aus der lokalen Vegetation - sowie Alter und Klima sind Böden durch spezifische pH-Werte und Pufferungseigenschaften gekennzeichnet. Das Redoxpotenzial ist im Wesentlichen eine Funktion der Konzentration organischen Materials sowie der Diffusionswiderstände im Boden.

Beide Schlüsselfaktoren stehen in enger Beziehung zueinander. Dies lässt sich beispielhaft anhand der reduktiven Dissoziation von $\mathrm{H}_{2} \mathrm{O}$ hin zu molekularem $\mathrm{H}_{2}$ einerseits und anhand der oxidativen Spaltung zu $\mathrm{O}_{2}$ andererseits verdeutlichen (Lindsay 1979):

\begin{tabular}{lll}
$\mathrm{H}_{2} \mathrm{O}+e^{-}$ & $\leftrightarrows$ & $0,5 \mathrm{H}_{2}(g)+\mathrm{OH}^{-}$ \\
$H^{+}+\mathrm{OH}^{-}$ & $\leftrightarrows$ & $\mathrm{H}_{2} \mathrm{O}$ \\
\hline $\mathrm{H}^{+}+e^{-}$ & $\leftrightarrows$ & $0,5 \mathrm{H}_{2}(g)$
\end{tabular}

Ein wesentlicher Nachteil der (voltametrischen) Angabe von Redoxgleichgewichten als Spannungsunterschied $\mathrm{E}_{\mathrm{h}}$ des betreffenden Redoxsystems zu einer Normalwasserstoff-Elektrode (umspült von $\mathrm{H}_{2}$ in $\left[\mathrm{H}^{+}\right]=1 \mathrm{M}$ bei 0,1 bar) beruht darauf, dass elektrochemische Potenziale in dieser Form nicht in chemische Gleichgewichtsberechnungen einbezogen und somit Redoxreaktionen nicht unmittelbar durch chemische Gleichgewichtskonstanten $\mathrm{K}^{\circ}$ charakterisiert werden können (Truesdell 1969). Wie der pH-Wert kann aber auch die Elektronenaktivität als negativer dekadischer Logarithmus pe und damit als fiktive Stoffmengenkonzentration dargestellt werden. Redoxpotenzial $\mathrm{E}_{\mathrm{h}}$ und pe besitzen die folgende Beziehung (Scheffer \& Schachtschabel 1992):

$$
\begin{array}{ll}
\text { pe } & =\frac{E_{h}}{2,3 R \cdot T} ; \quad \text { pe }=\frac{E_{h}}{0,059} \text { bei } 25^{\circ} \mathrm{C} \\
\text { pe } & \text { negativer dekadischer Logarithmus der Elektronenaktivität, [M] } \\
E_{h} & \text { Redoxpotenzial, }[\mathrm{V}] \\
R & \text { Gaskonstante, } \mathrm{R}=8,314510 \mathrm{~J} \cdot \mathrm{mol}^{-1} \cdot \mathrm{K}^{-1} \\
T & \text { Temperatur, }[\mathrm{K}]
\end{array}
$$


Im Gegensatz zum pH ist pe eine relative Größe. Sie orientiert sich, wie das Redoxpotenzial $\mathrm{E}_{\mathrm{h}}$, an der in Gleichung 11 dargestellten Reaktion von $\mathrm{H}_{2}$ unter den genannten Standardbedingungen. Definitionsgemäß gilt:

$$
\begin{aligned}
& K^{\circ}=\frac{\left[H_{2}(g)\right]^{0,5}}{\left[H^{+}\right] \cdot\left[e^{-}\right]}=1 \\
& \log K^{\circ}=0,5 \cdot \log H_{2}(g)-\log H^{+}-\log e^{-}=0 \\
& p e+p H=-0,5 \cdot \log H_{2}(g)
\end{aligned}
$$

Der maximale $\mathrm{H}_{2}$-Partialdruck in wässrigen Systemen beträgt 1 bar und damit $p e+p H=0 .{ }^{1}$ Bei Erhöhung der Protonenaktivität oder der relativen Elektronenaktivität wird $\mathrm{H}_{2} \mathrm{O}$ protolytisch oder elektrolytisch gespalten und damit bei $p e+p H<0$ das Stabilitätsfeld von $\mathrm{H}_{2} \mathrm{O}$ verlassen (vgl. Gleichung 11). Analog lässt sich die oxidative Spaltung von $\mathrm{H}_{2} \mathrm{O}$ formulieren:

$$
\begin{aligned}
& H^{+}+e^{-}+0,25 \mathrm{O}_{2}(g) \leftrightarrows 0,5 \mathrm{H}_{2} \mathrm{O} \\
& K^{\circ}=\frac{\left[\mathrm{H}_{2} \mathrm{O}\right]^{0,5}}{\left[H^{+}\right] \cdot\left[e^{-}\right] \cdot\left[\mathrm{O}_{2}(g)\right]^{0,25}}=6,03 \cdot 10^{20} \\
& \log K^{\circ}=0,5 \cdot \log \mathrm{H}_{2} \mathrm{O}-\log H^{+}-\log e^{-}-0,25 \cdot \log \mathrm{O}_{2}(g)=20,78
\end{aligned}
$$

In verdünnten Lösungen gilt $\left[\mathrm{H}_{2} \mathrm{O}\right] \cong 1$ und damit:

$$
p e+p H=20,78+0,25 \cdot \log O_{2}(g)
$$

Legt man einen maximalen $\mathrm{O}_{2}$-Partialdrucks von $\mathrm{p} \cong 1$ bar zugrunde, so verlässt das System bei $p e+p H>20,78$ das Stabilitätsfeld von Wasser, d. h. bei pH 0, wenn $p e>20,78$ oder $\mathrm{E}_{\mathrm{h}}>1,22 \mathrm{~V}$ ist (vgl. Abbildung 59, S. 117). Das Redox pe $+p H$ ist ein integrativer Parameter zur Kennzeichnung des Redoxstatus wässriger Systeme und für die Berechnung von Gleichgewichtsreaktionen. Bei Atmosphärendruck liegt das Stabilitätsfeld des Wassers zwischen $p e+p H=0$ und $p e+p H=20,78$ (Gleichungen 13 und 15). Das Redox der meisten Böden bewegt sich zwischen $p e+p H=3$ und $p e+p H=14$ (Baas Becking et al. 1960). Alle Redoxreaktionen, darunter die in Abschnitt 4.2.4 (S. 115 ff.) dargestellten Gleichgewichtsreaktionen der Fe-Mineralien, finden innerhalb dieses Bereichs statt.

\subsubsection{Reaktionen der Bodenpufferung und Bodenversauerung}

Tabelle 27 gibt einen Überblick der im Nachfolgenden beschriebenen Reaktionen und pH-Bereiche der Bodenpufferung (Ulrich 1987; Scheffer \& Schachtschabel 1992; Kuntze et al. 1994). Primäre Silikate puffern den Boden im gesamten pH-Bereich. Übersteigt die Freisetzung von Metallkationen aus dem Kristallgitter diejenige der Lösung von $\mathrm{SiO}_{4}{ }^{2-}$, wird unter Bildung von Tonmineralien die Kationenaustauschkapazität und damit die chemische Elastizität des Bodens erhöht. Mit Ausnahme organischer Verbindungen, wie Huminstoffen, Phenolen oder niedermolekularen organischen Säuren mit ihren Carboxyl-, Hydroxyl- und Aminogruppen, sowie Tonmineralien und Oxiden mit oberflächigen (Al, Fe)OH - bzw. (Al, Fe) $\mathrm{OH}_{2}$-Gruppen, die aufgrund ihrer Heterogenität den Boden-pH ebenfalls in einem sehr weiten Bereich von pH 3 bis pH 8 abpuffern können, regulieren andere Systeme die Bodenreaktion sehr viel enger.

\footnotetext{
1 Der Parameter pe $+p H$ wird im weiteren Text als 'Redox' bezeichnet und so dem Redoxpotenzial $E_{h}$ gegenübergestellt.
} 
Tabelle 27: pH-Pufferbereiche und Pufferreaktionen von Böden (Kuntze et al. 1994; Scheffer \& Schachtschabel 1992; Ulrich 1987).

\begin{tabular}{|c|c|c|c|}
\hline Pufferbereich & pH & Pufferung durch & Reaktion \\
\hline Silikat- & indifferent & Primäre Silikate & $-\mathrm{Si}-\mathrm{O}-\mathrm{M}-\mathrm{O}-\mathrm{Si}-+2 \mathrm{H}^{+} \leftrightarrows(\mathrm{SiOH})_{2}+\mathrm{M}^{2+}$ \\
\hline Carbonat- & $8,6-6,2$ & $\mathrm{CaCO}_{3}$ & $\mathrm{CaCO}_{3}+\mathrm{H}^{+} \leftrightarrows \mathrm{Ca}^{2+}+\mathrm{HCO}_{3}^{-}$ \\
\hline \multirow[t]{4}{*}{ Kationenaustauscher- } & $5,0-4,2$ & Tonminerale (I) & $-\mathrm{Si}-\mathrm{O}-\mathrm{Al}-\mathrm{O}-\mathrm{Si}-+3 \mathrm{H}^{+} \leftrightarrows \mathrm{Al}^{3+}+(\mathrm{SiOH})_{2}$ \\
\hline & & Mn-Oxide & z. B. $\mathrm{MnO}_{4}{ }^{2-}+4[\mathrm{H}]+4 \mathrm{H}^{+} \leftrightarrows \mathrm{Mn}^{2+}+4 \mathrm{H}_{2} \mathrm{O}$ \\
\hline & & Tonminerale (II) & $-\mathrm{Si}-\mathrm{O}-\mathrm{Al}-\mathrm{O}-\mathrm{Si}-+3 \mathrm{H}^{+} \leftrightarrows \mathrm{Al}^{3+}{ }_{(\mathrm{CEC})}+(\mathrm{SiOH})_{2}$ \\
\hline & & Zwischenschicht-Al & {$\left[\mathrm{Al}(\mathrm{OH})^{2+}\right]_{\mathrm{n}}+\mathrm{n} \mathrm{H}_{2} \mathrm{SO}_{4} \leftrightarrows \mathrm{n} \mathrm{AlOHSO}{ }_{4}+2 \mathrm{n} \mathrm{H}^{+}$} \\
\hline \multirow[t]{3}{*}{ Aluminium- } & $\mathrm{pH}<4,2$ & Zwischenschicht-Al & {$\left[\mathrm{Al}(\mathrm{OH})_{\mathrm{x}}^{(3-\mathrm{x})+}\right]_{\mathrm{n}}+\mathrm{xH}^{+} \leftrightarrows \mathrm{Al}^{3+}+\mathrm{x} \mathrm{H}_{2} \mathrm{O}$} \\
\hline & & Al-Hydroxosulfate & $\mathrm{AlOHSO}_{4}+3 \mathrm{H}^{+} \leftrightarrows \mathrm{Al}^{3+}+\mathrm{H}_{2} \mathrm{O}+\mathrm{H}_{2} \mathrm{SO}_{4}$ \\
\hline & & CEC-AI & $\mathrm{Al}_{\mathrm{CEC}}+3 \mathrm{H}^{+} \leftrightarrows \mathrm{CEC}-\mathrm{H}+\mathrm{Al}^{3+}$ \\
\hline Aluminium/Eisen- & $\mathrm{pH}<3,8$ & Fe-Oxide ('soil Fe') & $\mathrm{Fe}(\mathrm{OH})_{3}+3 \mathrm{H}^{+}\left(+\right.$org. C) $\leftrightarrows \mathrm{Fe}^{3+}-($ org. $\mathrm{C})+3 \mathrm{H}_{2} \mathrm{O}$ \\
\hline Eisen- & $\mathrm{pH}<3,2$ & Ferrihydrit & $\mathrm{Fe}(\mathrm{OH})_{3}+3 \mathrm{H}^{+} \leftrightarrows \mathrm{Fe}^{3+}+3 \mathrm{H}_{2} \mathrm{O}$ \\
\hline
\end{tabular}

Ausschlaggebend sind hierfür die $\mathrm{pK}_{\mathrm{s}}$-Werte der betreffenden Säure/Base-Paare. Ulrich (1987) hat für besonders häufig vertretene $\mathrm{pH}$-Intervalle Pufferbereiche nach den darin primär wirksamen Komponenten benannt.

$\mathrm{CaCO}_{3}$ besitzt, insbesondere wenn es fein verteilt vorliegt, zwischen $\mathrm{pH}$ 8,6-6,2 ein sehr effektives Pufferungsvermögen. Bache (1984) führt für Kalkböden eine Pufferkapazität $d \mathrm{~A}_{\text {cidBase}} / d \mathrm{pH} \cong 1000 \mathrm{eq} \cdot \mathrm{m}^{-3}$ und damit zehn- bzw. hundertfach höhere Werte als für Sand- und Torfböden an. Die Lösung von Kalk führt nicht nur zur Auswaschung von Hydrogencarbonaten des Calciums, sondern auch von Kationen, die im Austausch mit $\mathrm{Ca}^{2+}$ freigesetzt werden. Von pH 6,2-5,0 spielt die Verwitterung von Silikaten eine zentrale Rolle. Zwischen pH5,0-4,2 werden vermehrt Reaktionen wirksam, an denen der Kationenaustauscherkomplex der Tonminerale beteiligt ist. Durch Säureeintrag wird im oberen Kationenaustauscherbereich mineralisches Aluminium gelöst, in seiner freien Form als $\mathrm{Al}^{3+}$ zunächst aber umgehend wieder hydroxyliert. Polymere Al-Hydroxo-Kationen blockieren permanente Ladungen der Zwischenschichten von Tonmineralen und reduzieren darüber die Kationenaustauschkapazität. Bei weiterer Versauerung belegen $\mathrm{Al}^{3+}$-Ionen vermehrt die Kationenaustauscher und reduzieren damit die Basensättigung. Gleichzeitig werden $\mathrm{Mn}^{2+}$-Ionen verschiedenster Mn-Oxide gelöst und im Gleichgewicht mit der Bodenlösung an Kationenaustauschern gebunden oder aber ausgewaschen.

Unterhalb pH 4,2 wird Aluminium aus den Zwischenschichten der Tonminerale gelöst, von Kationenaustauschern verdrängt oder aus Al-Hydroxosulfaten freigesetzt. Letztere sind das Produkt der Sulfoxierung von Al-Hydroxopolymeren nach Eintrag großer Mengen $\mathrm{H}_{2} \mathrm{SO}_{4}$ im Kationenaustauscherbereich. Charakteristisch für den Al-Pufferbereich sind hohe Konzentrationen an freiem $\mathrm{Al}^{3+}$. Bei fortschreitender Versauerung wird im Aluminium/Eisen-Pufferbereich $\mathrm{Fe}^{3+}$ unter Beteiligung organischer Komplexoren aus Fe-Hydroxiden freigesetzt. Schließlich liegt kein reaktives $\mathrm{Al}$ mehr vor, so dass bei $\mathrm{pH}>3,2$ - und dies auch in Abwesenheit organischer Verbindungen - die Pufferung vollständig durch Fe-Hydroxide erfolgt.

Die Reaktionsgeschwindigkeit der Puffersysteme hängt wesentlich vom Löslichkeitsverhalten ihrer Reaktanden ab. Normalerweise erfolgt keine Versauerung des Bodens, solange vergleichsweise gut lösliches $\mathrm{CaCO}_{3}$ in der Feinerde vorhanden ist. Intensive Versauerungsschübe können aber zu einer temporären Überlastung des Pufferungsvermögens anderer Systeme führen. Sofern noch Tonmineralien im Boden 
vorhanden sind, deren langsame Verwitterung zunächst nicht mit der Geschwindigkeit des Protoneneintrags bzw. der Protonenfreisetzung hat Schritt halten können, kann ein Boden beispielsweise aus dem Eisenpufferbereich in den Aluminiumpufferbereich und aus diesem in den Austauscherbereich zurückkehren. Veränderungen des $\mathrm{pH}$ müssen also langfristig nicht unidirektional verlaufen.

\subsubsection{Reaktionen des Calciumcarbonat-Systems}

Bereits in Tabelle 26 (S. 109) wurden verschiedene Eigenschaften saurer Mineral- und basischer Kalkböden beschrieben, die auf die Pufferreaktionen der Tabelle 27 zurückzuführen sind. In Kalkböden werden durch die Lösung von $\mathrm{CaCO}_{3}$ große Mengen $\mathrm{Ca}^{2+}$ und $\mathrm{HCO}_{3}{ }^{-}$freigesetzt (16). Eine besondere Rolle spielen in Böden mit nur geringen Diffussionsraten die Anreicherung von Atmungs- $\mathrm{CO}_{2}$ und die damit einhergehenden Verschiebungen des Carbonat/Kohlensäuresystems (17):

$$
\begin{array}{llll}
\mathrm{CaCO}_{3}+\mathrm{H}^{+} & \leftrightarrows & \mathrm{Ca}^{2+}+\mathrm{HCO}_{3}^{-} & \\
\mathrm{CaCO}_{3}+2 \mathrm{H}^{+} & \leftrightarrows & \mathrm{Ca}^{2+}+\mathrm{CO}_{2} \uparrow+\mathrm{H}_{2} \mathrm{O} & \\
\mathrm{CO}_{2}+\mathrm{H}_{2} \mathrm{O} & \leftrightarrows & \mathrm{H}_{2} \mathrm{CO}_{3} & \\
\mathrm{H}_{2} \mathrm{CO}_{3} & \leftrightarrows & \mathrm{HCO}_{3}^{-}+\mathrm{H}^{+} & p K_{\mathrm{S}}=6,46 \\
\mathrm{HCO}_{3}^{-} & \leftrightarrows & \mathrm{CO}_{3}^{2-}+\mathrm{H}^{+} & p K_{\mathrm{S}}=10,4 \\
\hline \mathrm{CaCO}_{3}+\mathrm{H}_{2} \mathrm{CO}_{3} & \leftrightarrows & \mathrm{Ca}^{2+}+2 \mathrm{HCO}_{3}^{-} \leftrightarrows \mathrm{Ca}^{2+}+2 \mathrm{CO}_{2} \uparrow+\mathrm{H}_{2} \mathrm{O}
\end{array}
$$

Abbildung 57 zeigt die Beziehung von $\mathrm{pH}$ und $\mathrm{HCO}_{3}{ }^{-}$-Konzentration zum $\mathrm{CO}_{2}$-Partialdruck in einem calcitgesättigten, wässrigen System (Loeppert 1988). Eine idealisierte Funktion, die in der entsprechenden Darstellung pH vs. $\log \mathrm{p}\left(\mathrm{CO}_{2}\right)$ linear verläuft, geben Scheffer \& Schachtschabel (1992):

$\mathrm{pH}=-0,67 \cdot \log \mathrm{p}\left(\mathrm{CO}_{2}\right)+7,23$

Minimale $\mathrm{CO}_{2}$-Partialdrücke von 0,032 kPa in der Bodenlösung beziehen sich auf die Gleichgewichtseinstellung mit atmosphärischer Luft. Entsprechend Gleichung 18 berechnet sich daraus ein Boden-pH von 8,2. Infolge der langsameren Diffusion liegen die $\mathrm{CO}_{2}$-Partialdrücke in Böden zumeist zwischen 0,2 kPa und 0,7 $\mathrm{kPa}(\mathrm{pH} 7,7-7,3)$. In verdichteten Böden mit hohen Wassergehalten und daraus resultierenden hohen Diffusionswiderständen können sie aber auch Werte $>10 \mathrm{kPa}(\mathrm{pH} 6,6)$ erreichen (Loeppert 1986). Dies gilt insbesondere für die Rhizosphäre, in der durch die mikrobiellen und pflanzlichen Atmungsaktivitäten vermehrt $\mathrm{CO}_{2}$ bzw. $\mathrm{HCO}_{3}{ }^{-}$freigesetzt wird.

Die Entwicklung des terrestrischen Lebens geht mit der Verlagerung von Alkalinität - v. a. von Bicarbonaten - in aquatische Systeme einher (Ulrich 1987). Bei massivem Säureeintrag kann als Folge der Kalkverwitterung Säureneutralisationskapazität auch gasförmig als $\mathrm{CO}_{2}$ verloren gehen (Gleichungen 16). Bei fortdauerndem Säureeintrag erfolgt, wie oben dargestellt, eine Reduktion der Kapazität und Basensättigung der Kationenaustauscher. Säurestress und potenzielle Defizienzen, etwa von Ca und Mg, kompetitiv verstärkt durch $\mathrm{H}^{+}, \mathrm{Al}^{3+}, \mathrm{Mn}^{2+}$ oder $\mathrm{Fe}^{3+}$, bilden daher einen gemeinsamen Faktorenkomplex des Pflanzenwachstums.

Diese Ausführungen zeigen, dass die in Tabelle 26 (S. 109) dargelegten chemoedaphischen Standortcharakteristika saurer/silikatischer oder organischer und basischer/kalkreicher Böden weitgehend als Folge der Verwitterung des Ausgangsgesteins und der damit einhergehenden Pufferreaktionen zu betrachten sind. Einen Überblick über das reale Löslichkeitsverhalten von 60 bodenbürtigen Elementen in Abhängigkeit vom $\mathrm{CaCO}_{3}$-Gehalt und pH geben Tyler \& Olsson (2001). 


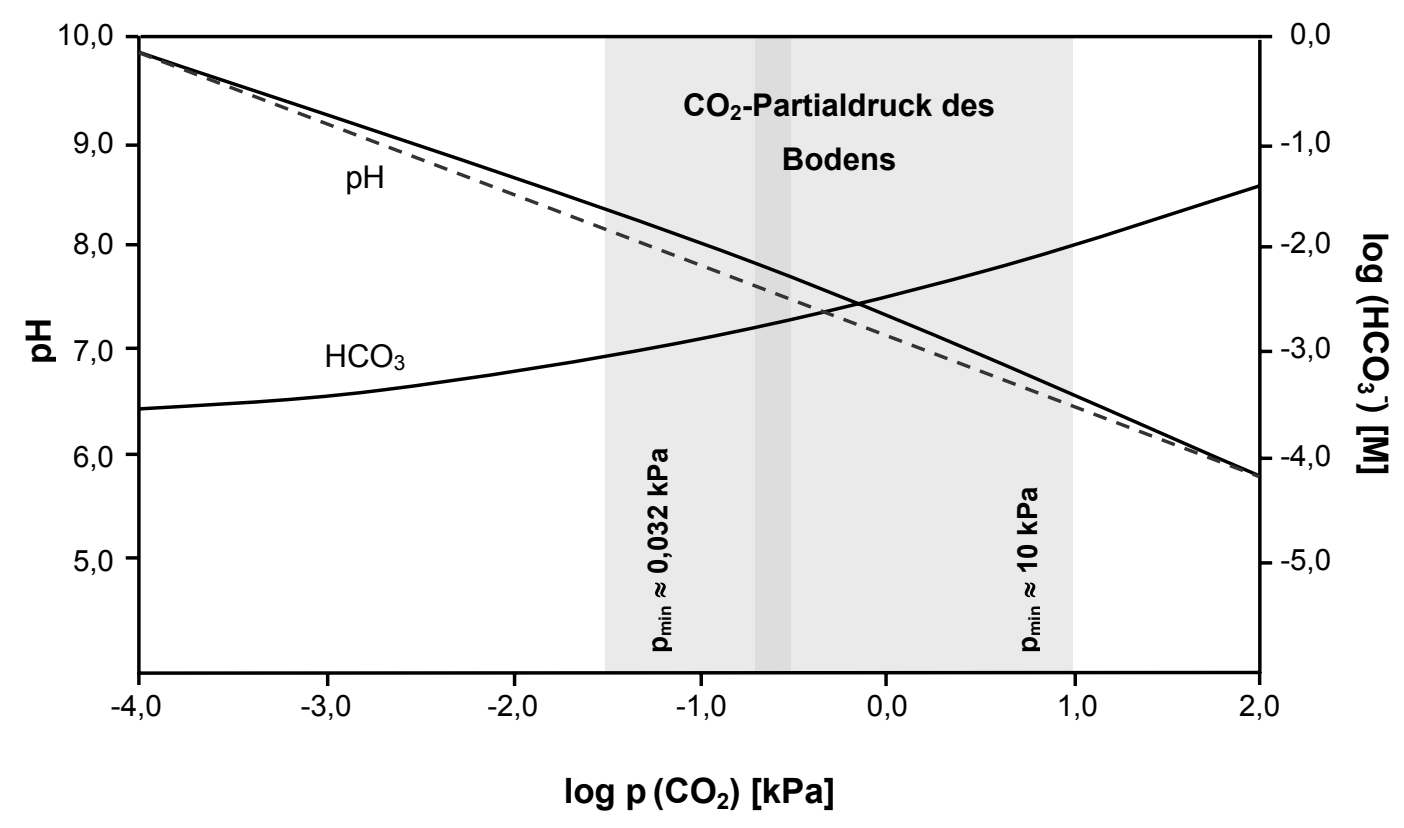

Abbildung 57: Einfluss des $\mathrm{CO}_{2}$-Partialdrucks auf den $\mathrm{pH}$ und die $\mathrm{HCO}_{3}^{-}$-Konzentration im Lösungsgleichgewicht mit Calcit. Die gestrichelte Linie kennzeichnet die idealisierte Beziehung $\mathrm{pH}=-0,67 \cdot \log p\left(\mathrm{CO}_{2}\right)+7,23$ (verändert nach Loeppert 1988 und Scheffer \& Schachtschabel 1992).

\subsubsection{Parameter der pflanzlichen Eisenverfügbarkeit}

Eisen ist in Böden das dritthäufigste Element (Gotoh \& Patrick 1974). Bei guter Bodendurchlüftung und entsprechenden Sauerstoffpartialdrücken bilden Eisenoxid-, Eisenhydroxid- und Eisenoxyhydroxidverbindungen (Eisen(hydr)oxide) die thermodynamisch stabilsten Fe-Formen und bestimmen über ihre Löslichkeitsprodukte die Eisenkonzentration in der Bodenlösung (Schwertmann 1991). Goethit ( $\alpha$-FeOOH) und Hämatit $\left(\alpha-\mathrm{Fe}_{2} \mathrm{O}_{3}\right)$ sind die dominierenden mineralischen Fe-Fraktionen. Bezogen auf das Hämatit variiert der Massengehalt des Fe in temperaten Böden zwischen $2 \%$ und $6 \%$ und steigt in tropischen Ferralsolen auf Werte bis zu $60 \%$ an (Bould 1963).

Trotz hoher Gesamtkonzentrationen im Boden kann unzureichende Eisenversorgung der wachstumslimitierende Faktor insbesondere für Pflanzen trockener, basischer Böden sein (Marschner 1995). Etwa 40 \% der terrestrischen Oberfläche sind potenzielle Eisenmangelstandorte (Vose 1982). Wie die weiteren Ausführungen zeigen werden, ist die Eisenverfügbarkeit in erster Linie eine Funktion des $\mathrm{pH}$ und $\mathrm{E}_{\mathrm{h}}$.

\section{Lösung von Eisen(hydr)oxiden durch $\mathrm{H}^{+}$}

Protonierungen führen zur Fe-Lösung aus dem Kristallgitter von Eisen(hydr)oxidverbindungen (Schwertmann 1991). Aufgrund der hohen Kristallisationsenergie und vielfältiger Störeffekte sind Eisen(hydr)oxide häufig sehr klein ( $\varnothing$ 5-100 nm) und besitzen eine entsprechend große spezifische Oberfläche. Die Eisenaktivitäten in der Lösung werden durch die Komponente mit der höchsten Löslichkeit bestimmt. Diese wiederum ist insbesondere eine Funktion der spezifischen Oberfläche. Mit Ausnahme gut durchlüfteter, stark verwitterter Böden, in denen nur selten Redoxreaktionen ablaufen und damit v. a. hochgeordnete, kristalline Eisen(hydr)oxide geringer Löslichkeit vorliegen, bestimmt in den meisten Böden sog. 'soil iron' $\left(\mathrm{Fe}(\mathrm{OH})_{3}\right)$ die Fe-Aktivität. Im Vergleich zu Goethit $(\alpha-\mathrm{Fe}(\mathrm{OOH})$ besitzt es eine mehr als fünfhundertfach höhere Löslichkeit (Lindsay 1979):

$$
\begin{array}{ll}
\mathrm{Fe}(\mathrm{OH})_{3}(\mathrm{soil})+3 \mathrm{H}^{+} \leftrightarrows \mathrm{Fe}^{3+}+3 \mathrm{H}_{2} \mathrm{O} & \log \mathrm{K}^{\circ}=2,70 \\
\alpha-\mathrm{Fe}(\mathrm{OOH})+3 \mathrm{H}^{+} \leftrightarrows \mathrm{Fe}^{3+}+2 \mathrm{H}_{2} \mathrm{O} & \log K^{\circ}=-0,02
\end{array}
$$




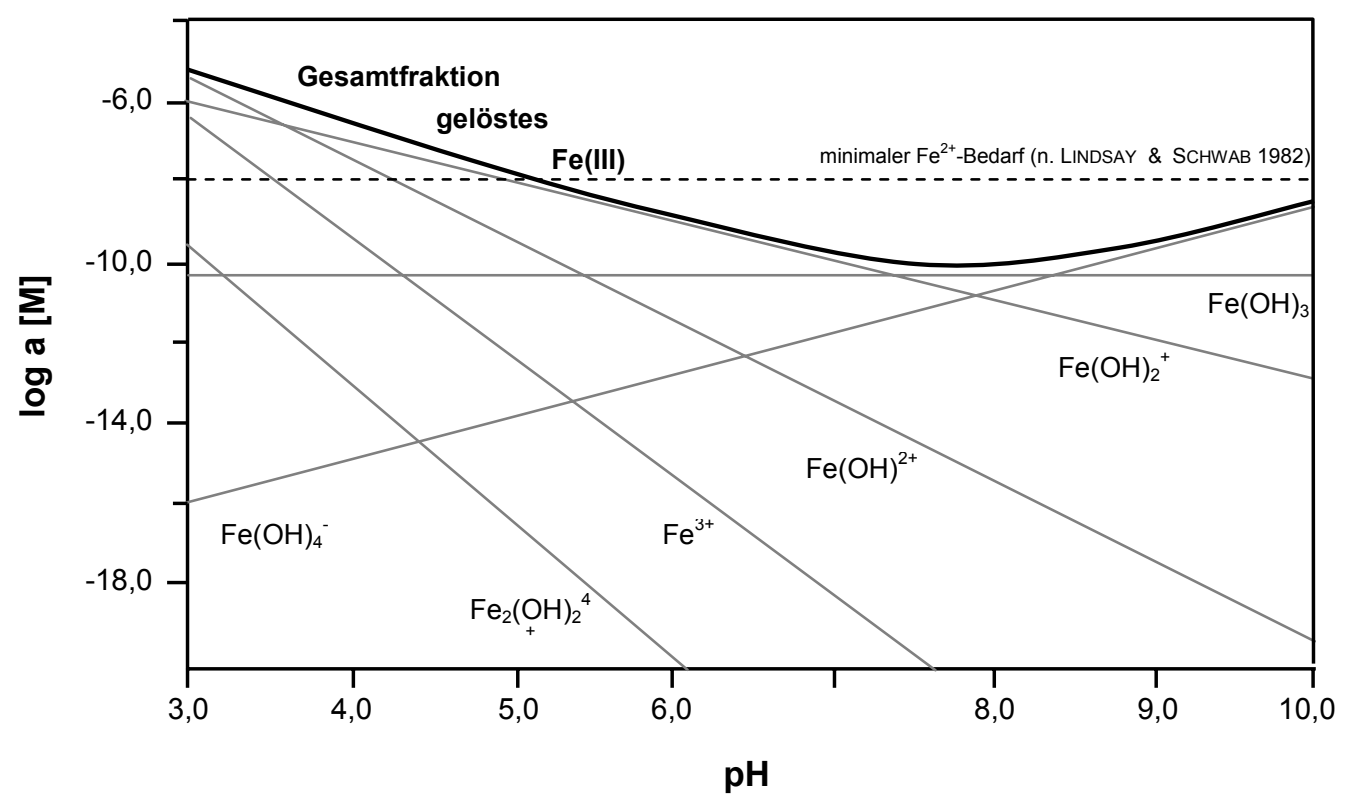

Abbildung 58: Einfluss des pH auf die Aktivitäten anorganischer Fe(III)-Spezies im Gleichgewicht mit `soil iron’ (Lindsay 1979).

Soil iron ist eine empirische, strukturell nicht näher definierte $\mathrm{Fe}(\mathrm{OH})_{3}$-Fraktion, die einen höheren Ordnungsgrad und durch die daraus resultierende Stabilisierung eine geringere Löslichkeit als frisch ausgefälltes, amorphes $\mathrm{Fe}(\mathrm{OH})_{3}$ (Ferrihydrit, $\log \mathrm{K}^{\circ}=3,54$ ) besitzt. In der Regel steigt mit Abnahme des $\mathrm{pH}$ um eine Einheit die Löslichkeit der Eisen(hydr)oxidverbindungen um das Tausendfache (Lindsay 1979). Im Bereich physiologisch verträglicher $\mathrm{pH}-$ Werte ist die Aktivität freier $\mathrm{Fe}^{3+}$-Ionen so niedrig, dass sie von nur geringer Bedeutung für die Deckung des pflanzlichen Eisenbedarfs sein kann. So liegt im Gleichgewicht mit soil iron die $\mathrm{Fe}^{3+}$-Aktivität bei $\mathrm{pH} 8,0$ unter $10^{-21} \mathrm{M}$ (Lindsay 1979). Im Allgemeinen sind Hydrolysespezies des $\mathrm{Fe}(\mathrm{OH})_{3}$ die einzigen anorganischen Fe-Formen in der Bodenlösung, die bei Redoxpotenzialen gut durchlüfteter Böden nennenswert zur pflanzlichen Mineralstoffversorgung beitragen.

Abbildung 58 zeigt die Aktivitäten der Dissoziationsprodukte in Abhängigkeit vom pH-Wert. Die Löslichkeit von anorganischem Fe(III) ist bei pH 7,4-8,5 und damit im Reaktionsbereich der Kalkböden minimal (Abbildung 57). Bei pH 8,0 befindet sich die Gesamtkonzentration des gelösten Eisens im chemischen Gleichgewicht mit soil iron in einer Größenordnung von etwa $10^{-10,2} \mathrm{M}$ (Lindsay 1979). Mit abnehmendem $\mathrm{pH}$ wird die Konzentration von Fe(III) durch Protonierung von $\mathrm{Fe}(\mathrm{OH})_{3} \mathrm{zu} \mathrm{Fe}(\mathrm{OH})_{2}{ }^{+}, \mathrm{Fe}(\mathrm{OH})^{2+}$ und schließlich $\mathrm{Fe}^{3+}$ erhöht. Bei $\mathrm{pH}>8,5$ kommt es zu verstärkter Wirksamkeit des löslicheren $\mathrm{Fe}(\mathrm{OH})_{4}{ }^{-}$. Polymeres $\mathrm{Fe}_{2}(\mathrm{OH})_{2}{ }^{4+}$ trägt nur in geringem Umfang zur Fe-Lösung bei.

\section{Reduktive Lösung von Eisen(hydr)oxiden}

Die Protonenaktivitäten beeinflussen nicht nur die Lösung der dreiwertigen Fe-Spezies. Bei stark erhöhter Löslichkeit von $\mathrm{Fe}^{2+}$ gegenüber $\mathrm{Fe}^{3+}$ und $\mathrm{Fe}(\mathrm{III})$-Verbindungen können insbesondere in sauren Böden mit schlechter Durchlüftung toxische Fe-Konzentrationen auftreten (Ponnamperuma 1972; Satawathananont et al. 1991). Dies ist daher v. a. in überfluteten und verdichteten Böden der Fall, in denen durch den aeroben mikrobiellen Abbau organischer Substanz und eine verringerte Nachdiffusion von Sauerstoff aus der Atmosphäre das Redoxpotenzial absinkt. Die Beziehung zwischen Redoxpotenzial, pH-Wert und der reduktiven Lösung von Fe-(Hydr)oxiden machen beispielhaft folgende Reaktionsgleichungen deutlich (Lindsay 1979): 


$$
\begin{array}{ll}
\mathrm{Fe}(\mathrm{OH})_{3}(\mathrm{soil})+3 \mathrm{H}^{+}+e^{-} \leftrightarrows \mathrm{Fe}^{2+}+3 \mathrm{H}_{2} \mathrm{O} & \log \mathrm{K}^{\circ}=15,74 \\
\mathrm{Fe}_{3}(\mathrm{OH})_{8}+8 \mathrm{H}^{+}+2 e^{-} \leftrightarrows 3 \mathrm{Fe}^{2+}+8 \mathrm{H}_{2} \mathrm{O} & \log \mathrm{K}^{\circ}=43,75
\end{array}
$$

Abbildung 59.I zeigt das Stabilitätsfeld von 1,0 mM Fe${ }^{2+}$ in Abhängigkeit von $\mathrm{E}_{\mathrm{h}}$ und $\mathrm{pH}$ (Ponnamperuma et al. 1967). Im Bereich zwischen etwa pH 2,3 und pH 6,7 kontrolliert soil iron die Fe-Löslichkeit. Hier ist zur Aufrechterhaltung einer vorgegebenen $\mathrm{Fe}^{2+}$-Aktivität bei Anstieg des $\mathrm{pH}$ um eine Einheit eine Erniedrigung des Redoxpotenzials um 0,177 V erforderlich. Oberhalb pH 6,7 unterliegt das System der Gleichgewichtseinstellung mit $\mathrm{Fe}_{3}(\mathrm{OH})_{8}$ (= Hydromagnetit, ferrosic iron). Diese Mischfraktion aus $\mathrm{Fe}(\mathrm{II})-$ und Fe(III)-Oxiden besitzt als metastabiles Präzipitat eine vergleichsweise hohe Löslichkeit und ist wahrscheinlich das Produkt zeitlich und räumlich fluktuierender Redoxverhältnisse (Lindsay \& Schwab 1982; Schwab \& Lindsay 1983; Schwertmann 1991).

Unterhalb pH 2,3 liegt Fe(III) weitgehend gelöst vor, so dass hier die $\mathrm{Fe}^{2+}$-Aktivität allein eine Funktion des Redoxpotenzials ist. Neben der abiotischen Reduktion tragen v. a. auch mikrobielle Fe-Umsetzungen im Rahmen der anaeroben Atmung mit Fe(III) als terminalem Elektronenakzeptor zu einer Erhöhung der $\mathrm{Fe}^{2+}$-Konzentration in der Bodenlösung bei. Außer obligat und fakultativ anaeroben Bakterien v.a. der Gattungen Bacillus, Enterobacter, Pseudomonas, Clostridium und Desulfovibrio, reduzieren auch einige Pilze der Gattungen Actinomucor, Alternaria und Fusarium Fe(III) (Fischer 1988). Die mikrobielle FeMobilisierung erfolgt in erster Linie durch Kontaktreduktion an den Oberflächen von Eisen(hydr)oxiden und nicht durch die Übertragung von Elektronen auf freie $\mathrm{Fe}^{3+}$-Ionen (Munch \& Ottow 1982; Pfanneberg \& Fischer 1984). Mittlerweile existieren eine Reihe von Hinweisen darauf, dass Fe-reduzierende Bakterien den terminalen Elektronentransfer auf Fe(III) mittels Quinonen oder Cytochromen katalysieren, die sie in das Medium abgeben (Seeliger et al. 1998; Newman \& Kolter 2000). Durch die Vergesellschaftung in oberflächigen Biofilmen wird der Abbau dieser Redoxsysteme begrenzt (Straub et al. 2001). Die FeLösung aus dem mineralischen Komplex erfolgt durch Protonierung der Fe(II)-O- oder Fe-OH-
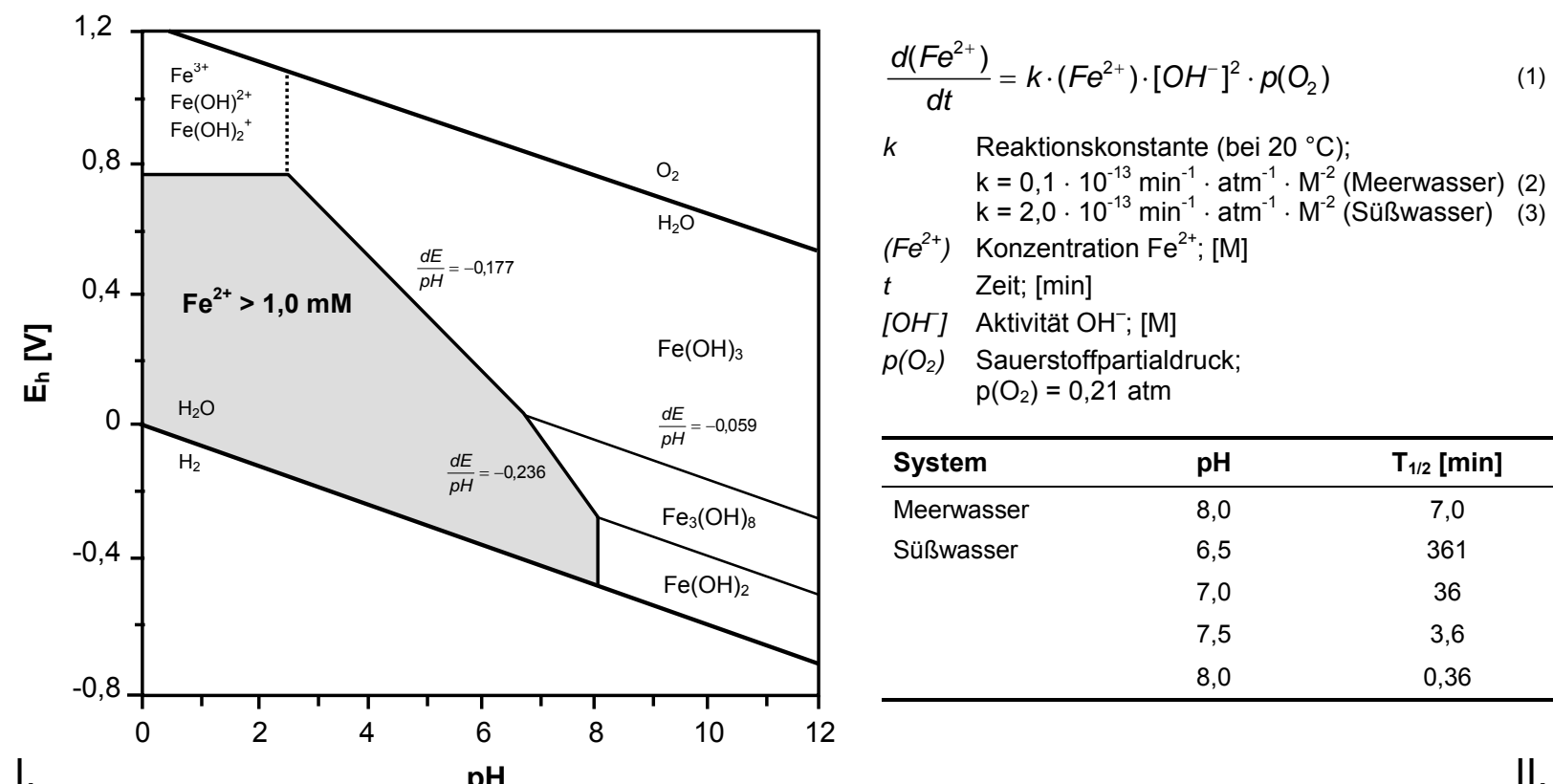
$\mathrm{p}\left(\mathrm{O}_{2}\right)=0,21 \mathrm{~atm}$

\begin{tabular}{lcc}
\hline System & $\mathbf{p H}$ & $\mathbf{T}_{\mathbf{1 / 2}}[\mathbf{m i n}]$ \\
\hline Meerwasser & 8,0 & 7,0 \\
Süßwasser & 6,5 & 361 \\
& 7,0 & 36 \\
& 7,5 & 3,6 \\
& 8,0 & 0,36 \\
\hline
\end{tabular}

II.

Abbildung 59: I. Stabilitätsfelder von Fe-Hydroxiden überfluteter Böden bei $a\left(\mathrm{Fe}^{2+}\right)=1,0 \mathrm{mM}$ in Abhängigkeit von $E_{h}$ und $p H$ bei $25{ }^{\circ} \mathrm{C}$ (verändert n. Ponnamperuma et al. 1967). II. Abhängigkeit der Fe ${ }^{2+}$-Oxidationskinetiken von Hydroxidkonzentration, Sauerstoffpartialdruck und Lösungstyp (Stumm \& Lee 1961(1); Liang \& Kester 1977(2); Davison \& Seed 1983(3)). 
Gruppen. Dabei soll die Reduktion verschiedener Fe(III)-Oxide nur begrenzt von deren Löslichkeitsprodukt und Redoxpotenzial abhängig sein: Während die Löslichkeitsprodukte von Ferrihydrit und hochgeordneten Hämatit- und Goethit-Kristallen zwischen $10^{-38}$ und $10^{-43}$ liegen, unterscheiden sich die Reduktionsraten von Corynebacterium für diese Fe(III)-Oxide um nur eine Zehnerpotenz (Fischer \& Pfanneberg 1984).

Erst in neuerer Zeit wurde die Bedeutung von Huminstoffen und v. a. Huminsäuren für einen alternativen Weg der mikrobiellen Fe(III)-Reduktion erkannt. Untersuchungen von Lovley et al. (1996) belegten zunächst für Geobacter metallireducens und Shewanella alga, dass Huminsäuren als Redoxsysteme dienen können. In einem ersten Schritt werden Huminsäuren mikrobiell reduziert und die Elektronen anschließend auf Ferrihydrit übertragen. Mittlerweile konnten eine ganze Reihe weiterer Bakterien identifiziert werden, die Huminstoffe als terminale Elektronenakzeptoren verwenden und damit indirekt zur reduktiven Fe-Mobilisierung beitragen (Benz et al. 1998). Am Ende solcher Redoxkaskaden stehen schließlich freie $\mathrm{Fe}^{2+}$-Ionen für die pflanzliche Fe-Ernährung zur Verfügung (Benz et al. 1988; Adani et al. 1998; Lovley et al. 1998).

Nicht nur die Richtung der Fe-Redoxreaktionen, sondern auch die Geschwindigkeit, in der sie ablaufen, ist eine Funktion des pH-Werts (Abbildung 59.II). Überdies wird die Kinetik der Oxidation von Fe(II) durch den $\mathrm{O}_{2}$-Partialdruck und damit das Redoxpotenzial sowie durch die variable Größe der Reaktionskonstante $k$ beeinflusst (Stumm \& Lee 1961). Als Funktion zweiter Ordnung des pH-Werts verzehnfacht sich die Geschwindigkeit der oxidativen Immobilisierung bei einem $\mathrm{pH}$-Anstieg um eine halbe Einheit. Demnach beträgt die Halbwertszeit $\mathrm{T}_{1 / 2}$ der Fe(II)-Oxidation bei atmosphärischem Sauerstoffpartialdruck im Süßwasser bei pH 7,0 etwa 36 min, bei pH 7,5 3,6 min. Die Reaktionskonstante $k$ wird erheblich durch die Anionenaktivität beeinflusst. In Meerwasser besitzt die Reaktionskonstante einen zwanzigfach niedrigeren Wert als in Süßwassersystemen, so dass $\mathrm{Fe}^{2+}$ nicht nach 0,36 min sondern erst nach 7 min zur Hälfte immobilisiert vorliegt (Liang \& Kester 1977; Davison \& Seed 1983).

\section{Lösung von Eisen durch organische Komplexoren}

Nach Untersuchungen von Lindsay \& Schwab (1982) an Glycine max wird die Eisenversorgung durch Lösungskonzentrationen von etwa $10^{-8} \mathrm{M} \mathrm{Fe}^{2+}$ gedeckt. $\mathrm{Fe}^{2+}$-Konzentrationen dieser Größenordnung werden in gut durchlüfteten Böden mit hohen $\mathrm{pH}$-Werten in der Regel nicht erreicht. Suffiziente $\mathrm{Fe}^{2+}$-Konzentrationen für die Pflanzenernährung sind erst bei einem Redox $p e+p H<8$ zu erwarten (Lindsay 1991). ${ }^{1}$

Kulturversuche in Nährlösungen mit synthetischen Fe-Chelaten haben gezeigt, dass eine ausreichende Mineralstoffversorgung bei Fe(III)-Konzentrationen von 1-20 $\mu \mathrm{M}$ vorliegt (Römheld \& Marschner 1986b; Fühner 1997). In der Regel ist im Boden bei $\mathrm{pH}<4$ ausreichend anorganisches Fe(III) gelöst, um den pflanzlichen Fe-Bedarf zu decken (Abbildung 58). Häufig tragen organische Verbindungen zur

\footnotetext{
1 Die Darstellung log a $\left(\mathrm{Fe}^{2+}\right)$ vs. $p e+p H$ greift die Beziehung von $\mathrm{pH}$ und $\mathrm{E}_{h}$ aus Abbildung 59.I auf und erlaubt eine lineare, zweidimensionale Darstellung der Löslichkeit verschiedener Fe-Mineralien (Lindsay \& Sadiq 1983; vgl. auch Abschnitt 14.24.2.1). Ausgehend von $\mathrm{pH} 8,0$ für typische Kalkböden ist suffiziente $\mathrm{Fe}^{2+}$-Verfügbarkeit von $\mathrm{a}\left(\mathrm{Fe}^{2+}\right) \cong 10^{-8} \mathrm{M}$ bei Vorlage von 'soil$\mathrm{Fe}(\mathrm{OH})_{3}$ ' bei $\mathrm{E}_{h} \geq 0,10 \mathrm{~V}$ (pe $+\mathrm{pH}=9,5$ ) gegeben. Für metastabiles Hydromagnetit ('ferrosic iron', $\left.\mathrm{Fe}_{3}(\mathrm{OH})_{8}\right)$ wird eine entsprechende $\mathrm{Fe}^{2+}$-Aktivität bereits bei $\mathrm{pe}+\mathrm{pH}=12$, d. $h$. bei $\mathrm{pH} 8,0$ mit Unterschreiten eines Redoxpotenzials von 0,24 $\mathrm{V}$ erreicht (Schwab \& Lindsay 1983). Das Redox der meisten gut durchlüfteten Böden liegt zwischen 12-16 (Lindsay 1991).
} 


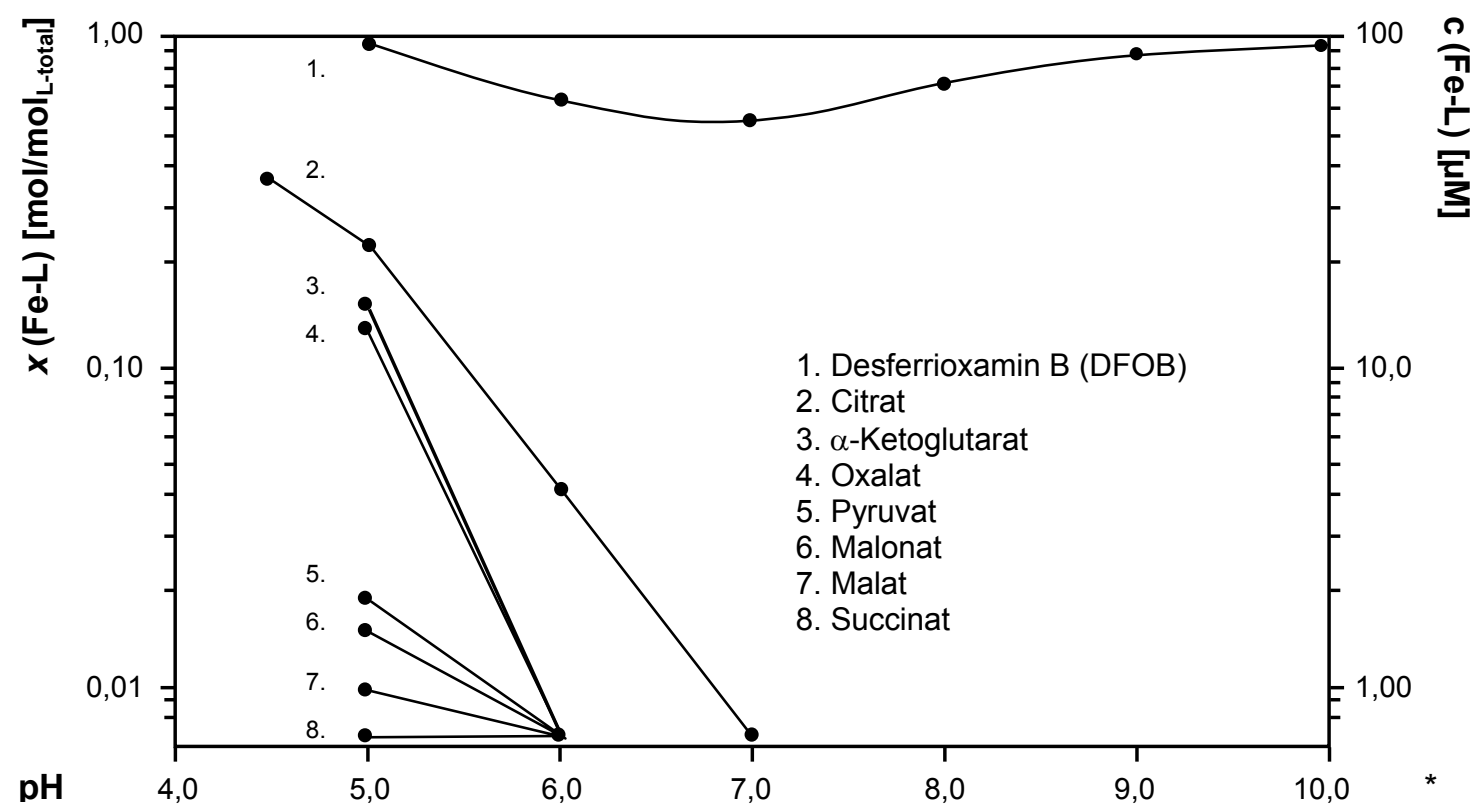

Abbildung 60: pH-Abhängigkeit der Stabilität von Fe(III)-Komplexen verschiedener organischer Säuren und des Siderophors Desferrioxamin B (DFOB) in Nährlösungen mit $100 \mu$ M Komplexbildner und Ferrihydrit im Überschuss (verändert $n$. Cline et al. 1982).

Lösung von $\mathrm{Fe}(\mathrm{II})$ und $\mathrm{Fe}(\mathrm{III})$ bei. Diese können nicht nur ähnlich der Wirkung eines Säureangriffs Bodenmineralien verwittern (Schwertmann 1991), sondern sind als Komplexbildner in vielen Böden auch an der Aufrechterhaltung ausreichender Konzentrationen gelöster Eisenverbindungen beteiligt. Bei den Fe(III)-Liganden der Bodenlösung handelt es sich v. a. um Produkte des mikrobiellen Abbaus oder Umbaus organischen Materials, darunter organische Säuren, Humine, Humin- und Fulvinsäuren (Uren 1984; Lindsay 1991). Wie Abbildung 60 zeigt, verlieren die meisten niedermolekularen organischen Säuren bereits zwischen $\mathrm{pH}$ 5,0-6,0 ihr gesamtes Komplexbildungsvermögen für $\mathrm{Fe}^{3+}$. Bei pH 6,0 besitzt nur Fe(III)-Citrat begrenzte Stabilität. Während hier noch 4 \% des in einer Konzentration von $100 \mu \mathrm{M}$ eingesetzten Citrats Fe aus dem im Überschuss vorliegenden Ferrihydrit binden, sind bei pH6,8 etwa 99\% des Liganden dissoziiert. Im Gegensatz zu den organischen Säuren behält Desferrioxamin B, ein Hydroxamatsiderophor des ectomykorrhizierenden Basidiomyceten Boletus edulis, im Bereich von pH 5-10 mindestens 50 \% seiner Komplexbildungskapazität für Fe (Abbildung 60).

Neben ihrer Funktion als Elektronenakzeptoren und -donatoren im Rahmen der mikrobiellen Fe(III)Reduktion besitzen die Humine der Bodenlösung eine wesentliche Bedeutung auch als Fe-Adsorbentien und Fe-Komplexoren. Eisen ist das dominierende Element in der Asche von Huminsäuren (Kallianou 2000). Huminstoffe tragen offensichtlich durch die Bindung kolloidaler Fe-Oxide erheblich zur Fraktion des gelösten Eisens bei (Dolfing et al. 1999) und können darüber, wie Kulturversuche an Cucumis sativus in Nährlösungen mit pH 7,3 gezeigt haben, auch bei hohen pH-Werten den Fe-Bedarf der Pflanzen decken (Mohamed et al. 1998). Dies wird von Cesco et al. (2002) nicht nur für Cucumis sondern auch für Hordeum vulgare bestätigt. Modellierungen lassen vermuten, dass das Fe der Huminkomplexe insbesondere für sog. Strategie II-Pflanzen (vgl. Abschnitt 4.3.3, S. 123 ff.) besser verfügbar ist als das von Fe(Hydr)oxiden, wie Goethit oder sogar Ferrihydrit (Gerke 2000). Mehrwertige Kationen besitzen angesichts der hohen Kationenaustauschkapazität des Donnan Free Space (DFS) eine sehr begrenzte Mobilität im Wurzelapoplasten. Positiv geladene Fe-Komplexe können daher allenfalls eine untergeordnete Rolle für die Eisenernährung der Pflanzen spielen (Sattelmacher 2001). 


\subsection{Autökologische Aspekte des Calcicolen/Calcifugen-Komplexes}

Die Etablierung einer Pflanzenart an einem Standort setzt die Aufrechterhaltung aller essentieller Lebensfunktionen unter den gegebenen biotischen und abiotischen Umweltbedingungen voraus. Im Hinblick auf die physikochemischen Bodeneigenschaften bedeutet dies, dass die Pflanzen Anpassungen besitzen müssen, die ihnen u.a. eine ausreichende Versorgung mit Wasser und Nährstoffen sowie eine ausreichende Toleranz gegenüber potenziell schädigenden Einflüssen vermitteln.

Grundlage der in dieser Arbeit behandelten Frage nach den vegetationsdifferenzierenden Faktoren an Standorten saurer, kalkarmer und basischer/kalkreicher Böden ist die Annahme, dass manche acidophile/ calcifuge Arten in bestimmten Kalk-Halbtrockenrasen die für ihre physiologische Konstitution erforderlichen Wachstumsvoraussetzungen vorfinden. Die Kenntnis autökologischer Anpassungen erlaubt eine gezielte Suche nach Faktoren, die für den Ausschluss bestimmter Artengruppen verantwortlich sind. Obwohl bodenkundliche Aspekte im Vordergrund der vorliegenden Arbeit stehen, wird daher im Folgenden eine Zusammenfassung der Grundlagen und der Bedeutung pflanzlicher Mineralstofftoleranzen und -effizienzen für das Wachstum an sauren, basenarmen und alkalischen, basenreichen Standorten gegeben.

Hintergrund der spezifischen Adaptationen acidophiler/calcifuger und basiphiler/calcicoler Konstitutionstypen sind in erster Linie die bereits in anderen Kapiteln dargestellten chemoedaphischen Faktoren, die sich aus der Bodengenese der betreffenden Standorte ableiten und mit sub- und supraoptimalen Mineralstoffkonzentrationen in der Bodenlösung einhergehen.

\subsubsection{Grundlagen der pflanzlichen Mineralstofftoleranzen und -effizienzen}

Viele Mineralstoffdefizienzen sind nicht die unmittelbare Folge niedriger Nährstoffkonzentrationen, sondern sekundärer Effekte von Ionenimbalancen, die sich auf andere, besonders hoch konzentrierte und dadurch toxisch wirkende Komponenten der Bodenlösung zurückführen lassen. So sind beispielsweise die Mn- und Ca-Konzentrationen oder Al- und Mg-Konzentrationen und die darauf potenziell zurückzuführenden Mineralstofftoxizitäten und Mineralstoffdefizienzen durch Antagonismen des membranären Transports miteinander verbunden (Marschner 1995). In anderen Fällen stellen Mineralstoffstörungen nicht das Resultat absolut oder relativ unzureichender Mineralstoffverfügbarkeiten, sondern sehr viel komplexerer Reaktionsmechanismen dar. Dazu gehören beispielsweise Beeinträchtigungen der Fe-Ernährung durch hohe $\mathrm{HCO}_{3}{ }^{-}$-Konzentrationen. Diese sollen angesichts ihrer besonderen Bedeutung für die Calcicolen/Calcifugen-Problematik in einem eigenen Kapitel behandelt werden.

\section{Mechanismen der pflanzlichen Mineralstoffeffizienz}

Ernst (1983) unterscheidet verschiedene Ebenen der pflanzlichen Mineralstoffeffizienz. Danach umfasst die Mobilisierungseffizienz physiologische und morphologische Reaktionen, die durch pflanzeninduzierte Modifikationen der Rhizosphäre eine ausreichende Nährstoffverfügbarkeit gewährleisten. Die Absorptionseffizienz kann durch morphologische Anpassungen sowohl auf Ebene des ganzen Organs, beispielsweise ein verstärktes Wurzelwachstum, als auch im zellulären und subzellulären Bereich erhöht werden. Zudem sind in diesem Zusammenhang adaptive Veränderungen rhizodermaler Enzymsysteme zu nennen. Die Retranslokationseffizienz kann als Teilkomponente der allgemeinen endogenen Verwertungseffizienz untergeordnet werden. Diese wird zum einen durch Leistungen des Kurz- und Langstreckentransports innerhalb und zwischen Wurzel und Sproß, zum anderen durch den Bedarf des entsprechenden Nährstoffs in den Zellen bestimmt. 


\section{Mechanismen der pflanzlichen Mineralstofftoleranz}

Die pflanzliche Mineralstofftoleranz kann grundsätzlich auf zwei verschiedene Mechanismen zurückgeführt werden: externe Toleranz und interne Toleranz. Sie entsprechen den Begriffen 'avoidance' und 'tolerance' im Stresskonzept nach Levitt (1980). Im Fall der externen Toleranz erfolgt ein Ausschluss toxischer Elemente oder Verbindungen aus dem Symplasten, etwa durch die Immobilisierung in der Zellwand, durch die Exsudation chelatisierender Liganden oder durch den Aufbau von pH und/oder Redox-Barrieren (Taylor 1987). Häufig werden potenziell schädigende Kationen im Wurzelapoplasten angereichert und damit ein effektiver Schutz gegen die Akkumulation toxischer Konzentrationen im Spross geschafft. Im Gegensatz dazu verhindern bei der internen Toleranz cytoplasmatische oder vakuoläre Kompartimentierungen und/oder die Ausstattung mit detoxifizierenden oder resistenten Enzymen Schädigungen der Pflanzen (Larcher 1994; Marschner 1995). Von besonderer Bedeutung sind überdies Adaptationen, die trotz weit reichender Ionenimbalancen im Medium eine reguläre Mineralstoffernährung erlauben. Diese betreffen u. a. die Regulation und die Selektivität der Aufnahmesysteme.

\subsubsection{Aspekte pflanzlicher Aluminiumintoxikationen und Aluminiumtoleranzen}

Aufgrund ihrer grundlegenden Bedeutung im Calcicolen/Calcifugen-Komplexes soll hier vor der Behandlung der in Vegetationsgesellschaften alkalischer, v. a. kalkreicher Böden erforderlichen ökophysiologischen Anpassungen kurz auch auf die Wirkung hoher Aluminiumkonzentrationen bodensaurer Standorte und die daraus resultierenden Anforderungen an den acidophilen Physiotypus eingegangen werden.

Die Versauerung von Böden auf Werte unter $\mathrm{pH} \cong 5,0$ geht mit der Freisetzung des Aluminium aus Tonmineralien einher (vgl. Tabelle 27, S. 113). Im Gegensatz zu oktahedralem $\mathrm{Al}\left(\mathrm{H}_{2} \mathrm{O}\right)_{6}{ }^{3+}\left(" \mathrm{Al}^{3+} "\right)$ und $\mathrm{Al}_{13^{-}}$ Polymeren besitzen $\mathrm{Al}(\mathrm{OH})_{4}{ }^{-}$und $\mathrm{Al}$-Chelate eine nur geringe Phytotoxizität (Kinraide 1991; Kochian 1995). Maximale Al-Konzentrationen werden bei $\mathrm{pH} 3,5$ erreicht. Unterhalb dieses Werts tauschen Protonen in der Regel keine weiteren $\mathrm{Al}^{3+}$-Ionen aus (Wieland \& Stumm 1992). Nicht nur in landwirtschaftlichen Nutzböden, von denen weltweit 30 \% pH-Werte unter 5,5 aufweisen (von Uexkull \& Mutert 1995), sondern auch in der natürlichen Vegetation saurer Standorte muss Al-Toxizität als ein zentraler Ausschlussfaktor nicht adaptierter Pflanzen angesehen werden (Runge \& Rode 1991). So verweisen beispielsweise Untersuchungen des Wurzellängenwachstum verschiedener Ökotypen von Anthoxantum odoratum (Davies \& Snaydon 1973) sowie an zehn Arten acidophiler/calcifuger, indifferenter und basiphiler/calcicoler Verbreitung (Rode 1988) auf einen Bezug zwischen der Al-Toleranz und der Standortpräferenz.

Aluminiumtoxizität geht v. a. auf Schädigungen des Apikalmeristems der Wurzeln zurück (s. Marschner 1995; s. Kochian 1995). Sowohl im Apoplasten als auch im Symplasten kann $\mathrm{Al}^{3+}$ mit verschiedenen Liganden sehr stabile Komplexe bilden (Godbold et al. 1988; Runge \& Rode 1991). Beispielsweise bindet $\mathrm{Al}^{3+}$ um einen Faktor 560 fester an bestimmte membranäre Phospholipide als $\mathrm{Ca}^{2+}$ (Akeson et al. 1989). Schnelle Abnahmen des Wurzelwachstums, bei Weizen innerhalb nur einer Stunde, lassen eine umgehende Hemmung der Zellextension vermuten (Ryan et al. 1993). Für eine primär apoplasmatische Wirkung sprechen Untersuchungen, nach denen Citrat innerhalb von 30 min diesen Al-Effekt aufhebt (Ownby \& Popham 1989). Zugleich sind auch eine Vielzahl symplastischer Störungen bekannt. So ist möglicherweise die Bindung von $\mathrm{Al}$ an Calmodulin für die Hemmung membranärer $\mathrm{H}^{+}$-ATPasen und damit für die verminderte Zellwandplastizität und die Beeinträchtigung des Streckungswachstums verant- 
wortlich (Haug 1984). In gleichem Kontext ist die Hemmung der Phospholipase C und damit die Störung des Phosphoinositol-Signalweges mit $\mathrm{Ca}^{2+}$ als second messenger zu sehen (Jones \& Kochian 1995).

Antagonismen können im Fall hoher Al-Konzentrationen insbesondere zu Ca-Mangel (z. B. Foy et al. 1969) und Mg-Mangel (z. B. Tan et al. 1993) führen. Hohe Al-Konzentrationen sollen außerdem membranäre $\mathrm{Ca}^{2+}$-Kanäle (Jones et al. 1998) sowie $\mathrm{K}^{+}$-Kanäle (Gassmann \& Schroeder 2001) blockieren und die $\mathrm{NO}_{3}{ }^{-}$-Aufnahme bei einer gleichzeitig vermehrten $\mathrm{H}^{+}$-Abgabe hemmen (Calba \& Jaillard 1997). Aluminium beeinträchtigt demnach die pflanzliche Mineralstoffernährung zugleich durch die unmittelbare Hemmung des Wurzelwachstum und durch indirekte Störungen des membranären Nährstofftransports.

Während vergleichsweise wenig über die Mechanismen der symplasmatischen Al-Toleranz bekannt ist (Aniol 1994), sind mittlerweile verschiedene Al-Ausschlussmechanismen belegt, die auf dem vielseitigen Komplexbildungsvermögen von $\mathrm{Al}^{3+}$ basieren. Johnson \& Bennett (1991) führen erhöhte Al-Toleranz auf eine vermehrte Mucilage-Sekretion an der Wurzelspitze zurück. Malat und Citrat binden hochaffin Al und können auf diese Weise die phytotoxische Wirkung von Al aufheben (Bartlett \& Riego 1972; Delhaize et al. 1993). Für Al-tolerante Mutanten von Arabidopsis thaliana (alr-108, alr-128, alr-131) konnten eine vermehrte Exsudation von Citrat und/oder Malat sowie eine verminderte Al-Akkumulation in der Wurzelspitze belegen werden (Larsen et al. 1998). Ebenfalls molekularbiologisch bestätigt wurde mittlerweile ein Modell von Foy et al. (1965), dass auf der $\mathrm{Al}^{3+}$-Immobilisierung durch die Erhöhung des pH im Wurzelraum basiert. Für die Al-insensitive A. thaliana-Mutante alr-104 konnte eine spezifische Induktion der apikalen Rhizosphärenalkalisierung durch $\mathrm{Al}$ nachgewiesen werden (Degenhardt et al. 1998). Untersuchungen in gepufferten Nährlösungen zeigten, dass die rhizodermale Erhöhung des $\mathrm{pH}$ um nur 0,15 Einheiten im Zusammenhang mit einer erhöhten Al-Toleranz steht. Außerdem werden seit langem unterschiedliches Bindungsvermögen der Zellwand und besondere Selektivitäten des Plasmalemmas für Al als Grundlagen erhöhter Al-Toleranzen diskutiert.

\subsubsection{Aspekte variierender Eisenkonzentrationen}

Eisen ist mit $37 \%(\mathrm{~m} / \mathrm{m})$ das häufigste Element der Erde. Zum Aufbau der Erdkruste trägt es etwa $5 \%(\mathrm{~m} / \mathrm{m})$ bei und ist damit nach Sauerstoff, Silicium und Aluminium die viertwichtigste Komponente der Lithosphäre (Mason \& Moore 1985). Auf den Bodenchemismus des Eisens wurde bereits in Abschnitt 4.2.4 eingegangen.

\section{Eisentoxizität und Eisentoleranz}

Fe-Toxizität ist in der Regel auf überflutete, vernässte und/oder verdichtete Böden beschränkt und damit Gegenstand der Behandlung von Toleranzmechanismen, die die Besiedlung anaerober Standorte erlauben. Im Vordergrund stehen hier Adaptationen, die eine oxidative Ausfällung von $\mathrm{Fe}^{2+}$ in der Rhizosphäre gewährleisten und darüber die Verlagerung hoher Fe-Konzentrationen in die Pflanze verhindern (s. z. B. Laan et al. 1989; Blom \& Voesenek 1995). Unter aeroben Bedingungen treten Fe-Toxizitäten praktisch nur in sog. acid sulfate soils auf, in denen nach der Oxidation von Fe-Sulfiden extrem niedrige pH-Werte und damit sehr hohe $\mathrm{Fe}^{3+}$-Konzentrationen vorliegen (van Breemen 1988; Satawathananont et al. 1991; McBride 1994). Neben kompetitiven Effekten entwickeln hohe Fe-Konzentrationen im Pflanzengewebe toxische Wirkung durch ihre Beteiligung an Reaktionen, die zur Genese besonders reaktiver Sauerstoffspezies und Hydroxylradikale führen. Im Zusammenhang mit der Calcicolen/Calcifugen-Problematik spielt Fe-Toxizität eine untergeordnete Rolle. 


\section{Eisendefizienz und Eiseneffizienz}

Die essentielle Bedeutung von Fe für die pflanzliche Mineralstoffernährung geht v. a. auf seine Fähigkeit zum schnellen Valenzwechsel im Rahmen enzymkatalysierter Redoxreaktionen zurück (Smith 1984; Marschner 1995). Mittlerweile ist die Beteiligung von Fe an 40 Enzymen mit Häm- oder ProtohämCofaktoren und weiteren 99 Enzymen mit Nichthäm-Cofaktoren nachgewiesen (Imsande 1998). Als Zentralatom des Porphyrins, z. B. in Cytochromen, aber auch in schwefelhaltigen Nichthämproteinen ist es Bestandteil von membranären Elektronentransportketten v. a. der Chloroplasten und Mitochondrien. Darüber hinaus dient es der Katalyse oxidoreduktiver Reaktionen im Cytoplasma (Smith 1984). Verschiedene eisenhaltige Enzyme sind an der Biosynthese des Porphyrins und damit des Chlorophylls beteiligt, so dass sich akuter Eisenmangel in charakteristischen Chlorosen der Blätter äußert. Zudem haben FeDefizienzen eine irreguläre Entwicklung der Chloroplasten zur Folge (s. Marschner 1995). Welcher Art die Prozesse sind, die bei suboptimaler Fe-Versorgung primär zu einer Hemmung des Pflanzenwachstums führen, ist umstritten (Mengel 1994).

\section{Bedeutung der Eiseneffizienz für die Vegetationsdifferenzierung}

Die Ausführungen zum Lösungsverhalten des Eisens in Abschnitt 4.2.4 haben gezeigt, dass die begrenzte Fe-Verfügbarkeit in gut durchlüfteten Böden mit pH-Werten im neutralen bis alkalischen Bereich ein möglicher Ausschlussfaktor für Arten unzureichender Fe-Effizienz ist. Basiphile Arten müssen daher Anpassungen aufweisen, die ihnen auch unter diesen Bedingungen eine suffiziente Fe-Versorgung erlauben. Niedrige pH-Werte gehen in der Regel mit hohen Fe-Konzentrationen der Bodenlösung einher und machen entsprechende Adaptationen säuresteter Arten überflüssig. Die unterschiedliche Fe-Effizienz basiphiler/calcicoler und acidophiler/calcifuger Arten wird in vielen Arbeiten als Ursache für die Vegetationsdifferenzierung saurer, kalkarmer und basischer/kalkreicher Standorte angeführt (z. B. Snaydon 1962; Grime \& Hodgson 1969; Gries \& Runge 1995; Tyler \& Falkengren-Grerup 1998). Wie Untersuchungen von Grime \& Hutchinson (1967) gezeigt haben, treten Chlorosen nicht nur bei Kulturpflanzen, sondern temporär auch in der natürlichen Vegetation kalkreicher Standorte auf. Symptome unzureichender Fe-Versorgung wurden hier v. a. im Frühjahr beobachtet. Der Rückgang von Fe-Chlorosen im Sommer ist nach Ansicht der Autoren auf die mit der zunehmenden Bodentrockenheit fortschreitende Entwicklung von P-Defizienzen zurückzuführen, die das Wachstum der Pflanzen begrenzen und darüber einen Ausgleich des Fe-Defizits erlauben. Besonders starke Chlorosen zeigten acidophile Arten, wie Calluna vulgaris. Eine ausgesprochene Chloroseanfälligkeit in Bodenmaterial kalkreicher Standorte wurde auch bei Potentilla erecta beobachtet (Grime \& Hodgson 1969).

\section{Strategien der pflanzlichen Eiseneffizienz}

Eisen liegt in den meisten Böden primär in Form verschiedener (Hydr)Oxide vor. In Abhängigkeit vom Versorgungsstatus können Pflanzen diese Fraktionen durch Protonierung, Austauschchelatisierung und/oder Reduktion mobilisieren. Dicotyle Arten und Monocotyledoneae mit Ausnahme der Poales besitzen hierfür ein als Strategie I bezeichnetes Muster adaptiver Reaktionen, mit Hilfe dessen die Fe-Effizienz erhöht werden kann. Während die Strategie II der Süßgräser v. a. auf der vermehrten Abgabe nichtproteinogener, $\mathrm{Fe}^{3+}$-chelatisierender Aminosäuren, sog. Phytosiderophore, in die Rhizosphäre und dem Transport des Fe(III)-Komplexes in die Wurzelzellen basiert (Takagi et al. 1984; Römheld 1991), nehmen Strategie I-Arten primär freies $\mathrm{Fe}^{2+}$ auf (Römheld \& Marschner 1986b). In Böden mit einem hohen Redox $p e+\mathrm{pH}$ muss daher $\mathrm{Fe}(\mathrm{III})$ von diesen vor seinem membranären Transport in den Symplasten nicht nur gelöst, sondern auch reduziert werden. 
Insgesamt sind die Eisenmangelreaktionen der Strategie I vielfältiger, aber auch besser untersucht als die der Poaceae. Die Differenzierung von Transferzellen (Kramer et al. 1980; Landsberg 1989; Schmidt \& Bartels 1996) und Veränderungen der Wurzelstruktur, wie z. B. die Ausbildung von cluster roots (White \& Robson 1989) und die Hemmung des Längenwachstums bei gleichzeitig verstärkter Wurzelhaarbildung (Römheld \& Marschner 1981) stellen morphologische Anpassungen der Strategie I-Arten an suboptimale Fe-Versorgung dar.

Eisenmangel induziert bei manchen Strategie I-Arten die Exsudation von phenolischen Verbindungen (Brown \& Ambler 1973; Olsen et al. 1981) und Flavinen (Welkie \& Miller 1989; Brown 1978; Welkie 1996), die die Lösung und/oder Reduktion dreiwertiger Fe-Verbindungen fördern. Verschiedene Untersuchungen verweisen darauf, dass calcicole und calcifuge Arten eine konstitutiv unterschiedliche Zusammensetzung der organischen Säuren ihrer Wurzelexsudate aufweisen. Demnach geben Calcicole/Basiphile vermehrt Tricarbonsäuren (v.a. Citrat) mit Fe-komplexierendem Potenzial, und Dicarbonsäuren (v. a. Oxalat) mit einem hohen P-Bindungsvermögen, in die Rhizosphäre ab (Ström et al. 1994; Tyler \& Ström 1995; Ström 1997). Demgegenüber weisen Rhizodepositionen von Calcifugen/Acidophilen hohe Acetat-Gehalte auf. Inwieweit bei Eisenmangel die Exsudation organischer Säuren erhöht wird und ob diese daher als eine typische Reaktion der Strategie I betrachtet werden darf, ist noch nicht abschließend geklärt. Gleichgewichtsberechnungen haben aber für Pinus radiata gezeigt, dass bei pH 4 bis pH 8 in $1 \mathrm{~mm}$ Entfernung von der Wurzeloberfläche aufgrund der hier zu erwartenden Carboxylatkonzentrationen die lösliche Fe(III)-Fraktion um Faktoren von $10^{3}$ bis $10^{5}$ erhöht sein kann (Inskeep \& Comfort 1986; Parker \& Chaney 1995). Bei diesen Berechnungen wurde bereits berücksichtigt, dass in situ ein schneller mikrobieller Abbau der energiereichen, organischen Verbindungen erfolgt. Eine räumlich und zeitlich konzentrierte Abgabe von Wurzelexsudaten, wie die der 'cluster roots' oder Proteoidwurzeln ${ }^{1}$, steigert erheblich die Mobilisierungseffizienz für Fe, aber auch für andere Pflanzennährstoffe, darunter insbesondere P (Dinkelaker et al. 1995, 1997; Watt \& Evans 1999a, 1999b; Skene 2003). Kerley et al. (2000) haben gezeigt, dass Lupinus-Arten in heterogenen Böden cluster roots bevorzugt dort ausbilden, wo günstige Voraussetzungen für eine effektive Mineralstoffaufnahme, etwa die von Eisen aus sauren Bereichen eines ansonsten basischen, kalkreichen Substrats, vorliegen. Auch Kalkulationen von Jones \& Darrah (1994) lassen vermuten, dass Citratkonzentrationen zwischen 0,1-50 $\mu \mathrm{M}$, wie sie in der Rhizosphäre auftreten, u. U. die Deckung des pflanzlichen Fe-Bedarfs gewährleisten können. Aufgrund der begrenzten Stabilität von Fe(III)-Citrat bei $\mathrm{pH}>6$ ist aber in neutralen und basischen Böden eine simultane Absenkung des $\mathrm{pH}$, etwa durch die Induktion oder Stimulation membranärer $\mathrm{H}^{+}$-ATPasen (z. B. Landsberg 1981; Alcantara et al. 1991), für eine ausreichende Fe-Mobilisierung (Jones et al. 1996) erforderlich. Wie Marschner et al. (1987) belegen, kann der pH in der Rhizosphäre Fe-defizienter Pflanzen den Wert des wurzelfreien Bodenraums um bis zu zwei Einheiten unterschreiten (Marschner et al. 1987).

Die Acidifizierung der Rhizosphäre bei Fe-Mangel fördert nicht nur die Fe-Mobilisierung (Landsberg 1981; Marschner et al. 1987; Wei et al. 1997), sondern auch die nachfolgende Reduktion von Fe(III). Kennzeichnend für Strategie I-Arten ist die Stimulation oder vermehrte Expression rhizodermaler Fe(III)Reduktasen bei unzureichender Fe-Versorgung. Die Kinetik dieser Enzyme ist eine Funktion des lokalen pH und des transmembranären Potenzials (Alcantara et al. 1991; Susin et al. 1996). Blockaden der mem-

\footnotetext{
Die Begriffe "proteoid roots" und "cluster roots" beschreiben homologe Wurzelbildungen und sind daher synonym. Heute verwenden allerdings die meisten Autoren den von Purnell (1960) geprägten Begriff 'proteoid roots' exklusiv für Wurzelbildungen von Mitgliedern der Proteaceae und Lupinus albus. Hingegen werden entsprechende Wurzelbildungen anderer Arten in der Regel als 'cluster roots' bezeichnet.
} 
branären $\mathrm{H}^{+}$ATPasen durch Vanadat führen aber auch in Lösungen mit optimalen pH-Werten zu einer vollständigen Hemmung der Fe-Reduktion - ein Hinweis darauf, dass die enzymatische Fe(III)-Reduktion und der transmembranäre $\mathrm{H}^{+}$-Tansport nicht allein über die Absenkung des apoplasmatischen $\mathrm{pH}$ Werts miteinander gekoppelt sind (Toulon et al. 1992).

Als Voraussetzung für die Fe(III)-Reduktion trägt der transmembranäre Elektronentransport zu einer Erhöhung der löslichen Fe-Fraktion bei, dient insbesondere aber auch der Bereitstellung von $\mathrm{Fe}^{2+}$ für das Aufnahmesystem der Wurzelzellen (Yi \& Guerinot 1996). Wie die Mobilisierungseffizienz wird auch die Absorptionseffizienz von Strategie I-Arten bei einer unzureichenden Fe-Versorgung erhöht. Verantwortlich hierfür sind Modifikationen des membranären Transportsystems (Römheld \& Marschner 1983; Fox et al. 1996).

Welche Bedeutung die vermehrte Synthese und Akkumulation organischer Säuren, und hier v. a. die von Citrat, in den Wurzeln für die Fe-Effizienz hat (Landsberg 1986), ist in vielen Punkten noch ungeklärt. Einer positiven Wirkung auf die Rhizosphärenacidifizierung (de Vos et al. 1986) stehen mögliche Beeinträchtigungen des Wurzelwachstums gegenüber (vgl. Abschnitt 4.3.5, S. 135). Da der Transport von Fe(III) im Xylem als Citratkomplex erfolgt, könnten hohe Citratkonzentrationen die interne Fe-Translokation begünstigen (Tiffin 1966a, 1966b; Maas et al. 1988).

\section{Bedeutung mikrobieller Symbiosen für die pflanzliche Eisen-Ernährung}

Pflanzen verändern auf vielfältige Weise die Milieuverhältnisse ihres Wurzelraums und beeinflussen so die Verfügbarkeit verschiedener Nährstoffe. In Abhängigkeit von den Außenfaktoren werden bis zu 30 \% (Helal \& Sauerbeck 1989; Marschner 1991; Hodge et al. 1996), nach Ansicht von Harris \& Paul (1987) in Extremfällen sogar 50 \% des assimilierten Kohlenstoffs über die Wurzeln in die Rhizosphäre abgegeben. Dabei handelt es sich um abgestoßene Zellen insbesondere der Calyptra, um Mucilage, einem viskosen Gemisch u. a. aus Polysacchariden und Polygalacturonsäure, und schließlich um niedermolekulare Wurzelexsudate, darunter Zucker, organische Säuren, Aminosäuren und Phenole. Während die zuletzt genannten Solute als Liganden oder Reduktionsmittel die pflanzliche Fe-Verfügbarkeit auch unmittelbar beeinflussen können, zeigen tote Zellen und hochpolymere Verbindungen erst als Folge ihres mikrobiellen Abbaus eine Wirkung auf die Fe-Löslichkeit.

Die Abgabe organischer Verbindungen in die Rhizosphäre ist die treibende Kraft für die Ausbildung mutualistischer Beziehungen zwischen Pflanzen und Mikroorganismen. Foster et al. (1983) haben in einem Gramm Rhizosphärenboden insgesamt $10^{28}$ Bakterien, Actinomyceten, Pilze, Protozoen und Algen nachweisen können. Während die meisten Mikrobionten von der Deckung ihres Kohlenstoff- und Energiebedarf profitieren, erfahren die Phytobionten u. a. eine Verbesserung der Versorgung mit bestimmten Mineralstoffen, darunter insbesondere auch Fe (Hemming 1986). Masalha et al. (2000) belegten anhand des Wachstums und der Ausbildung von Chlorosen der Strategie I-Art Helianthus annuus und der Strategie II-Art Zea mays in sterilen und nicht sterilen Bodenkulturen, dass die Mikroflora selbst in Böden mit beschränktem Chlorosepotenzials für eine suffiziente Fe-Ernährung der Pflanzen unerlässlich ist. Ihre Bedeutung liegt primär in der Mobilisierung schwerlöslicher Fe-Verbindung durch die Abgabe spezifischer Fe(III)-Chelatoren, daneben aber auch in der reduktiven Umsetzung bodenbürtiger Fe(III)-Verbindungen (Cline et al. 1982; Reid et al. 1984; Marschner et al. 1987). Pseudomonas-Arten schützen die pflanzlichen Symbiosepartner mit Hilfe dieser Siderophore auch vor der Ausbreitung von Pathogenen (Klöpper et al. 1980). 
Offenbar korrelieren die Siderophorenkonzentrationen und die Gehalte an organischem Material. In der Rhizosphäre finden sich fünfzigmal mehr Hydroxamatsiderophore als in wurzelfernen Bodenbereichen (Powell et al. 1982). Für Wiesenböden konnte ein Zunahme solcher Komplexbildner im Verlauf der Vegetationsperiode nachgewiesen werden (Bossier \& Verstraete 1986). Aufgrund der geringeren Diffusionsraten und der daraus resultierenden Beeinträchtigung der Fe-Versorgung werden in trockene Böden besonders viele Hydroxamatsiderophore abgegeben (Bossier et al. 1988).

Mikrobielle Siderophore erhöhen die Fe-Konzentrationen der Bodenlösung und erlauben auf diese Weise einen vermehrten Massenfluss sowie - in Kombination mit der Aufnahme in die Wurzeln - eine vermehrte Diffusion von Fe entlang seines Konzentrationsgradienten hin zur Rhizodermis. Das Ausmaß, in dem Siderophore zur pflanzlichen Fe-Ernährung beitragen, hängt in erster Linie von dem $\mathrm{pH}$ und pe des Bodens, der Art der Fe-Chelatisierung, aber auch von der Fe-Effizienz der betrachteten Pflanzenart ab. Szaniszlo et al. (1985) unterscheiden verschiedene Mechanismen der Verwertung mikrobiell gebildeter Fe-Komplexe (zitiert in Bossier et al. 1988). Im einfachsten Fall erfolgt zunächst eine abiotische Spaltung des Fe-Chelats. In der Folge bedingt die Aufnahme von freiem Fe aus der Rhizosphäre in die Wurzel eine Verlagerung im Gleichgewichtssystem des Siderophorenkomplexes und führt so zur Dissoziation von Fe. "Eiseneffiziente Arten" können das Fe dieser Komplexe auch direkt verfügbar machen (Cline et al. 1984). Insbesondere Strategie I-Arten, aber auch manche Strategie II-Arten, wie z. B. Zea mays, spalten die Siderophore mit Hilfe rhizodermaler Fe(III)-Reduktasen (Walter et al. 1993). Über den Umfang der Verwertung mikrobieller Fe(III)-Chelate entscheiden nicht zuletzt das Redoxpotenzial (Shenker et al. 1992, 1995) sowie die Affinität des betreffenden Siderophors für $\mathrm{Fe}^{2+}$ (Shenker et al. 1996).

Strategie II-Arten nutzen das Eisen mikrobieller Siderophore in der Regel durch Austauschchelatisierung (Yehuda et al. 1996). Von zentraler Bedeutung für diese Reaktion sind neben den Konzentrationsverhältnissen zwischen den konkurrierenden mikrobiellen und pflanzlichen Siderophoren deren apparente Gleichgewichtskonstanten $\mathrm{K}_{\text {app. }}$ für den Fe-Komplex und damit die Stabilität der Chelatbindung (Chen et al. 1994):

$K_{\text {app. }}=\frac{\left(F e L_{\text {total }}\right)}{\left(F e^{3+}\right) \cdot\left(L_{\text {total }}\right)}$

$K_{\text {app. }} \quad$ apparente Gleichgewichtskonstante, $\left[\mathrm{l} \cdot \mathrm{mol}^{-1}\right]$

(Fe) Fe-Konzentrationen, [M]

(Ltotal) Konzentration aller Dissoziationsspezies des Liganden, [M]

In den meisten Fällen ist die Verwertbarkeit mikrobieller Siderophore durch die Pflanzen weit geringer als die von Phytosiderophoren oder synthetischen Fe-Chelaten (Römheld \& Marschner 1983; Jurkevitch et al. 1986, 1988; Bar-Ness et al. 1991). Allerdings gibt es auch Siderophore, die von vielen Pflanzen sehr effizient genutzt werden können. Dazu gehört beispielsweise das Rhizoferrin (=Raphorin) des Pilzes Rhizopus arrhizus, das gleichermaßen für Strategie I-Arten (Shenker et al. 1992, 1995) und Strategie IIArten, darunter Gerste und Mais (Yehuda et al. 1996, 2000), verwertbar ist. Duijff et al. (1994) konnten nachweisen, dass das Pseudobactin des Pseudomonas putida-Stamms WCS358 sogar eine bessere FeErnährung von Hordeum vulgare erlaubt als das Fe-Chelat des synthetischen Komplexbildners EDDHA. Im Vergleich zu Phytosiderophoren besitzen mikrobielle Siderophore eine höhere Degradationsresistenz. Der mikrobielle Abbau von Phytosiderophoren in der Rhizosphäre kann unter bestimmten Umständen für die unzureichende Fe-Versorgung von Strategie II-Arten verantwortlich sein (von Wiren et al. 1995). 
Eine besonders enge Form pflanzlich-mikrobieller Symbiosen sind die verschiedenen Formen der Mykorrhiza. Hinweise auf die Bedeutung (vesikulär-) arbuskulärer Mykorrhizae (VAM) für die Fe-Ernährung geben u. a. Inokulationsversuche von Cress et al. (1986) mit dem semiariden Gras Hilaria jamesii und vier Glomus-Arten, Untersuchungen von Bavaresco \& Fogher (1996) zur Ausbildung von Kalkchlorosen der Weinrebe in Abhängigkeit von der Infektion mit Glomus mosseae sowie Experimente von Al-Karaki \& Al-Raddad (1997) zur Mineralstoffernährung verschiedener Kulturvarietäten des Weizens in Abhängigkeit von der aktuellen Wasser- und P-Versorgung. Caris et al. (1998) konnten durch die räumliche Trennung eines mit ${ }^{32} \mathrm{P}$ und ${ }^{59} \mathrm{Fe}$ markierten, ausschließlich für Pilzhyphen zugänglichen kalkreichen Bodensegments nachweisen, dass (V)AM zur P-Versorgung sowohl von Arachis hypogaea als auch Sorghum bicolor beitragen. Erhöhte Spross-Fe-Konzentrationen als Folge der Inokulation mit G. mosseae wurden nur für Sorghum nachgewiesen. Diese Untersuchungen geben erste Hinweise auf einen direkt durch die Hyphen vermittelten Fe-Transport in die Pflanzenwurzeln. Insbesondere im Hinblick auf die unterschiedliche Fe-Effizienzstrategien von Arachis (Strategie I) und Sorghum (Strategie II), die der letztgenannten Art wohl eine bessere Verwertung von mikrobiellen Siderophoren erlaubt, muss diese Interpretation aber durch weitere Experimente untermauert werden.

Die ericoide Mykorrhiza von Hymesnoscyphus ericae mit Calluna vulgaris kann erheblich zur Fe-Ernährung des Makrobionten beitragen (Leake et al. 1990). Auch hier ist noch nicht geklärt, ob Pilzhyphen nur die Fe-Löslichkeit durch Abgabe von Hydroxamatsiderophoren in der Rhizosphäre erhöhen oder aber unmittelbar am Transport in die Wurzeln beteiligt sind. Untersuchungen zum Einfluss variierender FeKonzentrationen (0-1,25 $\left.\mathrm{mM} \mathrm{Fe}^{2+}\right)$ auf das Wachstum und die Fe-Gehalte von Vaccinium macrocarpon sowie Untersuchungen zur Kinetik der Fe-Aufnahme von C. vulgaris bei $120 \mu \mathrm{M}$ Fe(III) stützen die verbreitete Annahme, dass die Mykorrhiza eine "puffernde" Wirkung auf den pflanzlichen Mineralstoffhaushalt hat (Shaw et al. 1990). Hashem (1995) bestätigte in Untersuchungen mit Konzentrationen bis zu $500 \mu \mathrm{M}$ eine ausgesprochene Fe-Toleranz des Mikrobionten H. ericae sowie mit diesem infizierter Individuen von $V$. macrocarpon. Wie auch im Fall anderer Metallionen, wird also durch die Mykorrhizierung einerseits bei niedrigen Konzentrationen die Fe-Aufnahme gefördert, andererseits bei hohen Konzentrationen eine Intoxikation verhindert. Neuere molekulargenetische Untersuchungen verweisen darauf, dass in Abhängigkeit vom Standort eine genotypische Differenzierung endotropher Mykobionten, wie H. ericae, und Ascomyceten (bei C. vulgaris und anderen Ericaceae) vorliegt (Perotto \& Bonfante 1998; Sharples et al. 2000). Im Zentrum dieser Untersuchungen stehen schwermetallkontaminierte Böden.

Insbesondere die Ausführungen zur Bedeutung der Mykorrhiza für die pflanzliche Fe-Effizienz und FeToleranz zeigen, dass bei engen symbiontischen Bindungen nicht allein die pflanzliche Ökophysiologie, sondern auch die ökotypische Konstitution des Mikrobionten von Bedeutung für die Besiedlung eines Standorts sein kann. Die Etablierung von Ericaceen an einem Standort gründet nicht zuletzt auf der Nmobilisierenden Wirkung saurer Exoproteasen verschiedener Ascomyceten. Mittlerweile wurden zehn Arten identifiziert, die am Aufbau entsprechender Mykorrhizae beteiligt sind (F. Buscot, mündl. Mitteilung). In den vergangenen Jahren wurde diesem Aspekt auch im Zusammenhang mit kausalen Untersuchungen der Differenzierung und Biodiversität unterschiedlicher Standorte verstärkte Aufmerksamkeit geschenkt (Streitwolf-Engel et al. 1997; van der Heijden et al. 1998a, 1998b). Abschnitt 15.45.4.5 (S. 233 ff.) geht im Detail auf diese Punkte ein. 


\subsubsection{Aspekte variierender Mangankonzentrationen}

Mit 0,1 \% (m/m) liegt Mn in der Erdkruste und daher in den meisten Böden in deutlich geringeren Mengen als Fe und $\mathrm{Al}$ vor. Diese niedrigeren Gesamtkonzentrationen bilden den Hintergrund des Auftretens von Mn-Mangelsymptomen und des Ausbleibens von Mn-Intoxikationen an Standorten stark verwitterter Böden. Wie Fe wird Mn nicht nur durch organische Komplexbildner und niedrige pH-Werte, sondern auch durch biotische und abiotische Redoxreaktionen gelöst. Anders als Eisen, das nur in metallischer, diund trivalenter Form auftritt, kann Mangan auch vierwertig, d.h. im Boden als Mn(II), Mn(III) und Mn(IV), vorliegen. Dadurch erhält der Chemismus des Mn eine besondere Komplexität (Lindsay 1979). Insgesamt entspricht aber das Lösungsverhalten von Mn dem des Fe und bedarf daher hier keiner weiteren Erörterung. Als Beispiel für den Bezug zwischen der Mn-Konzentration und dem pH-Wert der Bodenlösung sei auf Analysen von Sanders (1983) verwiesen, nach denen die Gesamtkonzentrationen an gelöstem Mn zwischen pH 5,2 und pH 7,3 von $182 \mu \mathrm{M}$ auf 0,8 $\mu \mathrm{M}$ abnehmen. Angesichts der stark variierenden Mn-Anteile im Ausgangsgestein und der potenziell niedrigeren Mn-Gehalte ist die Korrelation zwischen der Bodenreaktion und Lösungskonzentration aber weit weniger ausgeprägt als beim Fe.

\section{Mangantoxizität und Mangantoleranz}

Mn-Toxizitäten können durch die Freisetzung austauschbarer Mn-Fraktionen bereits bei moderaten Bodenreaktionen $(\mathrm{pH}<5)$ auftreten (vgl. Tabelle 27, S. 113). Braune Flecken auf den Blättern gehen ähnlich dem bronzing bei Fe-Intoxikation auf die lokale Anreicherung von Polyphenolen zurück (Wissemeier \& Horst 1991).

Intercostalchlorosen bei hohen Mn-Konzentrationen verweisen auf eine sekundäre Fe-Defizienz, gewellte Blattränder auf Ca-Mangel (Foy et al. 1981). Während für den Mn-induzierten Fe- und Mg-Mangel kompetitive Reaktionen verantwortlich gemacht werden (Le Bot et al. 1990), gibt es Hinweise, dass CaDefizienzen auf einen stimulierten Auxinabbau im Spross zurückzuführen sind (Horst 1988). Der akropetale Ca-Transport wird durch den basipetalen IAA-Transport gesteuert. Möglicherweise ist eine abweichende Degradation von Auxin Hintergrund unterschiedlicher Mn-Toleranzen (Horst 1988). Wie Pfropfungsexperimente an Glycine max zeigten, bestimmt der Spross das Ausmaß der Mn-Resistenz (Heenan et al. 1981). Als weiterer Toleranzmechanismus wird eine Komplexierung von Mn durch Polyphenole diskutiert (Horst 1988). Zumindest bei Kulturarten, wie Reis und Weizen, sind Al- und Mn-Toleranz nicht notwendigerweise miteinander korreliert (Foy et al. 1973; Nelson 1983). Insgesamt ist die Bedeutung hoher Mn-Konzentrationen für den Ausschluss nicht adaptierter Arten in der natürlichen Vegetation von Standorten mit sauren Böden nur unzureichend untersucht. Angesichts seiner viel früheren Lösung im $\mathrm{H}^{+}$-Gradienten muss aber davon ausgegangen werden, dass an trockenen Standorten Intoxikationen durch hohe Mn-Konzentrationen im Zusammenhang mit der Calcicolen/Calcifugen-Thematik ein größeres Gewicht haben als solche durch hohe Fe-Konzentrationen.

\section{Mangandefizienz und Manganeffizienz}

Ein Cluster aus vier $\mathrm{Mn}^{2+}$-Ionen bildet das Zentrum des wasserspaltenden Komplexes des Photosystem II (Stryer 1988). Der einzige weitere Fall, in dem Mn als Enzymkomponente nachgewiesen wurde, ist ein entsprechendes Isoenzym der Superoxid-Dismutase (SOD). Das Mn-Isoenzym ist wie die CuZnSOD und anders als die plastidäre Fe-SOD v. a. in den Mitochondrien und darüber hinaus in den Peroxisomen lokalisiert (Sandmann \& Böger 1983). Außerdem dient Mangan als Co-Faktor (Aktivator) vieler enzy- 
matischer Reaktionen, etwa der Decarboxylierungen mittels Isocitrat-Dehydrogenase und Malat-Dehydrogenase im TCC. Während Mn sehr häufig durch Mg substituiert werden kann, ist es für die PEP-Carboxykinase von C4-Arten des Oxaloacetat-Typs essentiell (s. Marschner 1995).

Mn-Mangel tritt gelegentlich in stark verwitterten Böden und in Böden kalkreicher Ausgangsgesteine auf. Mit Trockenmassegehalten von 10-20 mg/kg Mn und 50-150 mg/kg Fe unterscheiden sich die CDC (critical deficiency contents) dieser beiden Übergangsmetalle im Schnitt um einen Faktor 6-7. Über spezifische Mechanismen der pflanzlichen Mn-Effizienz ist sehr wenig bekannt. Als benachbarte Elemente des Periodensystems besitzen Mn (Ordnungszahl 25) und Fe (Ordnungszahl 26) eine vergleichbare Größe und Elektronenkonfiguration. Ähnliche Lösungs- und Komplexbildungseigenschaften sind dafür verantwortlich, dass die pflanzliche Mn- und Fe-Ernährung eng miteinander verbunden sind. Mn-Toxizitäten können bei Flachs durch FeEDDHA amelioriert werden (Moraghan \& Freeman 1978). Die Induktion von Strategie I-Reaktionen durch Fe-Mangel führt zur Erhöhung der Mn-Gehalte im Pflanzengewebe (Brown \& Jones 1977).

\subsubsection{Aspekte variierender Calcium- und Hydrogencarbonatkonzentrationen}

In den Abschnitten 4.2.2 und 4.2.3 (S. 112 ff.) wurden verschiedene Reaktionen der Kalklösung und die Bedeutung von Calciumcarbonat für die Bodenpufferung dargestellt. Neben Sekundäreffekten, die auf den Boden-pH zurückgehen, beeinflussen die Hydrolysespezies des $\mathrm{CaCO}_{3}$ die pflanzliche Mineralstoffernährung auch direkt. Der Nährstoff Calcium kann insbesondere in stark verwitterten und sauren Böden in unzureichenden Konzentrationen vorliegen. Auf der anderen Seite resultieren nicht nur in Calcit-, sondern auch in Dolomit- oder Gipsböden aus sehr hohen $\mathrm{Ca}^{2+}$-Konzentrationen potenziell toxische Effekte. Hydrogencarbonat, zu mehr als $50 \%$ anionische Komponente der Kalklösung bei pH-Werten zwischen 6,5-10,5, beeinträchtigt v.a. die pflanzliche Eisenernährung und führt bei vielen nicht adaptierten Arten zur Ausbildung sog. Kalkchlorosen. In den beiden nachfolgenden Unterkapiteln soll auf diese Punkte näher eingegangen werden.

\section{Bedeutung von Calcium für die pflanzliche Mineralstoffernährung}

Calcium nimmt eine Sonderstellung unter den pflanzlichen Makronährstoffen ein. Aufgrund seiner Größe, geringen Ladungsdichte und Elektronenkonfiguration kann Calcium eine Vielzahl ionarer und kovalenter Verbindungen eingehen (Hepler \& Wayne 1985; McLaughlin \& Wimmer 1999). Im Vergleich zum häufig kompetitiven $\mathrm{Mg}^{2+}$ zeigt $\mathrm{Ca}^{2+}$ eine geringe Affinität gegenüber $\mathrm{H}_{2} \mathrm{O}$ und $\mathrm{N}$. Die Bindung an unpolare O-Gruppen von Polysacchariden und Lipiden sowie multiple, komplexe Bindungen mit cytosolischen Liganden führen zu einer starken Einschränkung der Mobilität von $\mathrm{Ca}^{2+}$ in der Pflanze. Daher wird Calcium im Gegensatz zu den meisten anderen Nährstoffen fast ausschließlich apoplasmatisch transportiert (Kirkby \& Pilbeam 1984). Zugleich ist die $\mathrm{Ca}^{2+}$-Aufnahme in die Pflanze bei hohen externen Konzentrationen in erster Linie ein passiver Prozess. Sie erfolgt v. a. im Bereich der Wurzelspitzen, in deren Endodermis die Ausbildung des suberinisierten Caspari-Streifens noch nicht abgeschlossen ist (Russell \& Clarkson 1976). Da der Langstreckentransport von $\mathrm{Ca}^{2+}$ auf das Xylem beschränkt ist, sind Defizienzen primär durch das Phloem versorgter Gewebe, wie z. B. von Früchten, weniger auf eine limitierte Aufnahme durch die Wurzeln als vielmehr auf eine unzureichende interne Translokation zurückzuführen (Kirkby \& Pilbeam 1984). 
Calcium besitzt aufgrund seiner spezifischen Verknüpfung von Carboxyl- und Phosphatgruppen der Membranlipide sowie von Membranproteinen eine essentielle Bedeutung für die Membranstabilität (Epstein 1972; Legge et al. 1982). Überdies ist es an der Zellwandsynthese beteiligt. Calcium spielt nicht nur für die Zellintegrität, sondern auch bei der zellulären Signaltransduktion physikalischer, chemischer und elektrischer Reize eine zentrale Rolle. Seine Funktion als second messenger setzt die Aufrechterhaltung eines ausreichenden elektrochemischen Gradienten zwischen dem Symplasten und Apoplasten durch ein besonders leistungsfähiges membranäres $\mathrm{Ca}^{2+}$-Transportsystem voraus. Während sich die apoplasmatischen und vakuolären $\mathrm{Ca}^{2+}$-Konzentrationen im millimolaren Bereich bewegen, liegen die Konzentrationen im Cytoplasma bei $10^{-8} \mathrm{M}$ bis $10^{-5} \mathrm{M}$ (Bush 1995). An der intrazellulären Antwort auf einen reizvermittelten $\mathrm{Ca}^{2+}$-Influx sind als regulative Komponenten Calmodulin und calmodulinbindende Proteine beteiligt (Bush 1995; Snedden \& Fromm 1998).

Die genannten strukturellen und regulativen Aufgaben lassen $\mathrm{Ca}^{2+}$ Einfluss auf fast alle lebenswichtige Funktionen der Pflanzen nehmen. So äußert sich suboptimale $\mathrm{Ca}^{2+}$-Versorgung in Beeinträchtigungen der Abwehr- und Reparaturmechanismen (Bangerth 1979; Kirkby \& Pilbeam 1984; Dixon et al. 1994), verminderter Kälteresistenz (Minorsky 1985) sowie vorzeitiger Seneszenz (Poovaiah 1988). Niedrige $\mathrm{Ca}^{2+}$ Verfügbarkeiten in sauren Böden gehen häufig mit hohen Konzentrationen kompetitiv wirkender Al-, H-, Fe- und Mn-Ionen einher (Stienen \& Bauch 1988). Auf die besondere Bedeutung von Aluminium für den pflanzlichen Calciumhaushalt wurde bereits in Abschnitt 4.3.5 hingewiesen. Untersuchungen an verschiedenen Farnen (Koedam et al. 1992) und Lotus-Arten (Blamey et al. 1990) geben Hinweise darauf, dass die Kationenaustauschkapazität des Wurzelapoplasten vieler Acidophiler besonders gering ist. Unter der Voraussetzung, dass die strukturellen Anforderungen an die Zellwand nicht durch $\mathrm{Al}^{3+}$-austauschbares $\mathrm{Ca}^{2+}$ erfüllt werden, könnten niedrige CEC die Retention von $\mathrm{Ca}^{2+}$ vermindern und damit dessen effektiveren und schnelleren Transport in den Spross erlauben (McLaughlin \& Wimmer 1999).

Toxische Wirkungen erzielt Calcium durch die Ausfällung von Phosphaten, durch Kompetitionen der $\mathrm{Mg}^{2+}$-Aufnahme sowie durch die Beeinträchtigung verschiedener Enzymaktivitäten (Kirkby \& Pilbeam 1984). Hohe cytosolische $\mathrm{Ca}^{2+}$-Konzentrationen induzieren die Schließung der Stomata und belasten darüber den pflanzlichen Kohlenstoff- und Energiehaushalt (McAinsh et al. 1996). So besitzt möglicherweise bei der calcicolen Leontodon hispidus die $\mathrm{Ca}^{2+}$-Abgabe durch Trichome eine zentrale Bedeutung für die Regulation der stomatären Leitfähigkeiten (Lionel et al. 2001).

Detoxifizierend, gleichzeitig aber auch für den pflanzlichen Carbohydrathaushalts belastend wirkt die Komplexierung von Calcium durch organische Säuren (Kinzel 1982; McLaughlin \& Wimmer 1999). Die vakuoläre Ausfällung von Ca-Oxalat ist charakteristisch für den calciophoben Physiotypus vieler Caryophyllaceae, Chenopodiaceae, Amaranthaceae, Violaceae sowie mancher Lamiaceae. Im Gegensatz dazu ist v.a. bei Arten der Crassulaceae, Brassicaceae, Resedaceae und Papaveraceae ein calciotropher Physiotypus verbreitet. Hier werden toxische Effekte des $\mathrm{Ca}^{2+}$ durch die Bildung löslicher, osmotisch wirksamer Komplexe v. a. mit Malat, aber auch Citrat oder Isocitrat verhindert. Tendenziell sind unter den Calciotrophen mehr calcicole Arten, unter den Calciophoben mehr calcifuge Arten vertreten (Kinzel 1982). Möglicherweise trägt zu dieser Verteilung bei, dass beim calciophoben Typus neben der umfangreichen Synthese von Oxalat zusätzliche Investitionen für die Aufrechterhaltung eines ausreichenden osmotischen Potenzials im Cytoplasma und damit für die Regulation des pflanzlichen Wasserhaushalts anstehen. Angesichts der vermehrten Synthese organischer Säuren von Pflanzen auf kalkreichen Böden (s. S. 134) erstaunt es übrigens, dass die Aktivität der PEP-Carboxylase durch Calcium gehemmt werden soll (Gavalas \& Manetas 1980). 
Le Gales et al. (1980) verweisen auf hohe Gehalte calciumbindender Proteine im Cytoplasma mancher calcicoler Arten. Bis heute liegen allerdings keine Ergebnisse weiter führender Untersuchungen vor, die eine grundsätzliche Bewertung dieses Phänomens für das Wachstum von Pflanzen auf kalkreichen Standorte erlauben würden. Neben der Komplexierung durch organische Säuren (und Proteine) zeigen verschiedener Pflanzenarten kalkreicher Standorte ein besonders umfangreiches Bindungs- und Immobilisierungsvermögen der Zellwände, begrenzte Membranpermeabilitäten sowie Trichomeinlagerungen oder, wie bei vielen Saxifragaceae und Tamarix-Arten, eine vermehrte Abgabe von $\mathrm{Ca}^{2+}$ mit Hilfe spezialisierter Drüsen (s. Rorison \& Robinson 1984).

Lange war eine unmittelbare Bedeutung von Calcium für die autökologische und daraus resultierende vegetationskundliche Differenzierung saurer, kalkarmer und basischer/kalkreicher Standorte umstritten (Paul 1906; Mevius 1921). Steele (1955) versetzte einen NPK-gedüngten sauren (pH 4,8), $\mathrm{Ca}^{2+}$ - und $\mathrm{Mg}^{2+}$-armen Boden alternativ mit neutral und basisch wirkenden Ca- und Mg-Salzen und ordnete darin kultivierte Arten je nach Wachstumsantwort verschiedenen Gruppen zu. Solche, wie z. B. Plantago media, deren Wachstum allein durch $\mathrm{CaCO}_{3}$ stimuliert wird und die gleichzeitig des hohen $\mathrm{pH}$-Werts und der hohen $\mathrm{Ca}^{2+}$-Konzentrationen bedürfen, bezeichnete Steele als exacting calcicoles. Bei der Gruppe der sog. less exacting calcicoles handelt es sich demgegenüber um Arten, die auch durch $\mathrm{CaSO}_{4}$ positiv beeinflusst werden und für die demnach eine neutrale oder basische Bodenreaktion von untergeordneter Bedeutung ist. Hierzu zählt beispielsweise Pimpinella saxifraga. Nährlösungsuntersuchungen konnten für eine Reihe von Arten (Bradshaw et al. 1958; Jefferies \& Willis 1964a, 1964b; Clarkson 1965) und Ökotypen (Snaydon \& Bradshaw 1961, 1969; Snaydon 1962) eine Beziehung zwischen dem $\mathrm{Ca}^{2+}$-Bedarf bzw. der $\mathrm{Ca}^{2+}$-Toleranz und der natürlichen Verbreitung nachweisen. In diesen Fällen erscheinen die Termini calcicol und calcifug in ihrer engeren Fassung gerechtfertigt.

\section{Bedeutung von Hydrogencarbonat für die pflanzliche Mineralstoffernährung}

Kalkchlorosen besitzen sowohl unter bodenchemischen als auch unter physiologischen Gesichtspunkten eine außerordentlich komplexe Ätiologie. Wengleich diese Mineralstoffstörung aufgrund ihrer agrarökonomischen Bedeutung seit den 40er Jahren des 20. Jahrhunderts in einer kaum zu überschauenden Anzahl von Untersuchungen behandelt wurde, sind auch heute noch viele der diesbezüglichen Fragen ungeklärt.

Das Auftreten von Kalkchlorosen korreliert hfg. weniger mit niedrigen Fe-Konzentrationen der Bodenlösung oder des Blattgewebes als vielmehr mit hohen $\mathrm{HCO}_{3}^{-}$-Konzentrationen des Substrats (Jacobson 1945; Place et al. 1969; Boos et al. 1982). Dennoch kann diese Mangelerscheinung vielfach durch Wurzel- oder Sprossapplikation von Fe-Chelaten behandelt werden. Frühe Beobachtungen von Molz (1907; zitiert in Mengel \& Geurtzen 1986), nach denen insbesondere auf verdichteten, kalkreichen Böden bei kühler und feuchter Witterung Schlechtwetterchlorosen auftreten, stimmen mit Störungen der exogenen und/oder endogenen Fe-Verwertung durch hohe $\mathrm{HCO}_{3}{ }^{-}$-Konzentrationen überein. Unter diesen Bedingungen werden die Diffusionsraten in der Rhizosphäre erniedrigt und zugleich die Löslichkeit des Atmungs- $\mathrm{CO}_{2}$ erhöht. Bodenlösungen, die durch die Zentrifugation feldfrischer Feinerde von Rendzinen gewonnen wurden, zeigten zwischen $70 \%$ und $80 \%$ Wasserkapazität einen Anstieg der $\mathrm{HCO}_{3}{ }^{-}$-Konzentrationen von $100 \mu \mathrm{M}$ auf $850 \mu \mathrm{M}$ (Misra \& Tyler 1999). Wie Abbildung 57 (S. 114) verdeutlicht, gehen steigende $\mathrm{CO}_{2}$-Konzentrationen mit einer vermehrten $\mathrm{HCO}_{3}^{-}$-Bildung und einer Erniedrigung des $\mathrm{pH}$ Werts in kalkreichen Böden einher. Der Erhöhung des $\mathrm{CO}_{2}$-Partialdrucks von 0,032 kPa auf $10 \mathrm{kPa}$ im Boden folgt in calcitgesättigten Systemen ein Absinken des pH von 8,3 auf 6,6. Unter Bedingungen, die die Ausbildung von Kalkchlorosen fördern, liegen somit Voraussetzungen für eine vermehrte protolyti- 
sche und reduktive Fe-Lösung und damit solche für eine Erhöhung der Fe-Konzentrationen im Wurzelraum vor. Chlorosen von Pflanzen, die auf kalkreichen Böden wachsen, können also auch auf physiologische Störungen des pflanzlichen Fe-Haushalts zurückzuführen sein. Verschiedene Untersuchungen belegen, dass $\mathrm{HCO}_{3}{ }^{-}$in eisenhaltigen Nährlösungen nicht selten zu einer schnelleren und stärkeren Störung der Chlorophyllbiosynthese führt als die Kultivierung in eisenfreien Nährlösungen, denen kein $\mathrm{HCO}_{3}{ }^{-}$ zugesetzt wird (z. B. Mengel \& Mallisiovas 1981).

Nach wie vor sind die Ursachen des sog. Chloroseparadoxons - das Auftreten von Chlorophylldefekten trotz "normaler" oder sogar erhöhter Fe-Gehalte im Substrat und Pflanzengewebe - Gegenstand einer kontrovers geführten Debatte. Ein Erklärungsansatz basiert auf der Erhöhung des pH-Werts im Pflanzengewebe durch $\mathrm{HCO}_{3}{ }^{-}$. Plänker (1991) beobachtete bei Inkubation abgeschnittener (!) Blätter von Helianthus annuus in Lösungen mit $10 \mathrm{mM}$ Hydrogencarbonat ein Absinken der $\mathrm{H}^{+}$-Aktivitäten im Apoplasten von pH 6,2 auf pH 7,0. Diese pH-Erhöhung soll über die Hemmung bestimmter symplasmatischer Reaktionen mit sehr engen pH-Optima (Kolesch et al. 1984) oder - plausibler - durch die apoplasmatische Immobilisierung von Fe (Mengel \& Geurtzen 1986; Mengel 1994) die reguläre Chlorophyllsynthese verhindern und darüber Chlorosen und Wachstumsretardationen nach sich ziehen. Die Aufnahme von Fe in die Zelle wird nach dieser Immobilisierungshypothese von Mengel durch Nitraternährung und die daraus resultierende zusätzliche apoplasmatische Alkalisierung (als Folge des $\mathrm{NO}_{3}{ }^{-} / \mathrm{OH}^{-}$oder $\mathrm{NO}_{3}{ }^{-} / \mathrm{HCO}_{3}{ }^{-}$-Antiports bzw. $\mathrm{NO}_{3}{ }^{-} / \mathrm{H}^{+}$-Symports) zusätzlich beeinträchtigt (Kosegarten et al. 1999). Eine zentrale Bedeutung soll dabei - in Analogie zu Reaktionen in den Wurzeln - die Hemmung plasmalemmagebundener Fe(III)-Reduktasen durch hohe pH-Werte haben. Für eine Fe-Immobilisierung im Rahmen der Ausbildung von Kalkchlorosen spricht die Beobachtung, dass Behandlungen, die, wie die Stickstoffernährung mit $\mathrm{NH}_{4}{ }^{+}$oder die Applikation verdünnter Säuren, mit einer Erniedrigung des apoplasmatischen pH-Werts einhergehen, zu einem Ergrünen chlorotischer Blätter führen. Einen entsprechenden Effekt zeigen auch Stimulantien membranärer $\mathrm{H}^{+}$-ATPasen, wie Fusicoccin und Indolessigsäure. Negative Korrelationen zwischen pH-Wert im Blatt und dem Chlorophyllgehalt konnten neben Mengel et al. (1994) auch Englisch (1993; zitiert in Mengel 1994) sowie Tagliavini et al. (1995) nachweisen.

Dennoch ist dieses Modell, dem zufolge die Ursache des Chloroseparadoxons in einer pH-vermittelten Ausfällung von Fe im Blattapoplasten begründet liegt, umstritten (Römheld 2000). Untersuchungen von Nikolic \& Römheld (1999) an Mesophyllgewebe von Helianthus annuus und Vicia faba lassen zwar vermuten, dass die Reduktion von Fe(III) eine Voraussetzung für die Fe-Aufnahme in die Blattzellen ist, doch konnte weder für die enzymatische Fe-Reduktion noch für den Fe-Transport in die Zellen eine Abhängigkeit vom pH festgestellt werden. Zudem wurde bei Kultivierung der Pflanzen in Nährlösungen mit $10 \mathrm{mM} \mathrm{NaHCO} 3$ kein Anstieg der pH-Werte im Xylem und Blattapoplasten gefunden. Die verminderte Aufnahme und Reduktion von Eisen aus Fe-Citrat-Komplexen bei pH Werten oberhalb 6,0 bzw. 6,5 führen die Autoren auf die Ausbildung von relativ immobilen Fe-Citrat-Polymeren sowie - bei einem weiteren Anstieg des pH - auf die Spaltung der Citratkomplexe und Ausfällung von Fe-Hydroxiden bzw. Fe-Phosphaten zurück. Allerdings sehen sie in apoplasmatischen pH-Werten dieser Höhe eine Ausnahme und damit für eine regelhafte Fe-Immobilisierung dieser Art keine Grundlage. Zudem konnten in weiter führenden Untersuchungen keine Korrelationen zwischen dem $\mathrm{pH}$ und dem Fe-Gehalt des Apoplasten chlorotischer und nicht chlorotischer Blätter von Weinstöcken eines kalkreichen Luvisols mit Bodenlösungskonzentrationen von 5-10 $\mathrm{mM} \mathrm{HCO}_{3}{ }^{-}$gefunden werden (Nikolic \& Römheld 2002).

Verschiedene Untersuchungen stützen einen alternativen Erklärungsansatz des Chloroseparadoxons (s. Römheld 2000). Dieser basiert auf einer unzureichenden Fe-Aufnahme durch die Wurzeln, einer Hem- 
mung der internen Fe-Translokation und einer temporären Fe-Unterversorgung des Sprosses. Phasen geringer Fe-Verlagerung in den Spross können in älteren Pflanzen ohne Folgen bleiben, offenbar jedoch nicht in sehr jungen Individuen. Besonders deutliche Inkonsistenzen zwischen Sprosseisengehalt und Wachstumshemmung zeigen sich, wenn in der frühen Entwicklung die reguläre Ausbildung des Photosyntheseapparats durch "absoluten" Fe-Mangel verhindert wird. Das im weiteren in den Spross transportierte Fe vermag die Störungen der Blattentwicklung nicht restituieren. Folge der Wachstumshemmung ist eine Akkumulation von physiologisch inaktivem Fe, die ggf. sogar zum Überschreiten des Löslichkeitsprodukts und damit zu einer Ausfällung von Eisen(hydr)oxiden und Eisenphosphaten bei unveränderten pH-Werten im Assimilationsgewebe führt (Häussling et al. 1985). In Übereinstimmung mit dieser Hypothese stehen Untersuchungen an verschiedenen Obstgehölzen, deren chlorotischen Blätter zwar keine niedrigeren massebezogenen Fe-Konzentrationen, wohl aber bei verminderten absoluten und auf die Blattflächen bezogenen Blattgewichten geringere Fe-Gehalte der einzelnen Blätter aufweisen (Plänker 1991; Morales et al. 1998; Bavaresco et al. 1999). Eine Rolle spielt hierbei möglicherweise Abscisinsäure, die einerseits das Blattwachstum hemmt, andererseits aber zu einer Erhöhung des $\mathrm{pH}$-Werts und damit zu einer Fe-Immobilisierung im Xylem beiträgt (Wilkinson et al. 1998; Nikolic \& Römheld 2002).

Wie offen, umstritten und komplex die Frage nach der Wirkungsweise von Hydrogencarbonat und den Ursachen des Chloroseparadoxons ist, zeigen auch Untersuchungen der Arbeitsgruppe von J. Abadía in Zaragoza (Spanien), die an verschiedenen Pflanzenarten und auf verschiedenen systemaren Ebenen durchgeführt wurden.

Isolate der Plasmamembran verweisen auf einen Anstieg der proteinbezogenen Fe(III)-Reduktaseaktivität in Blättern Fe-defizienter Individuen von Beta vulgaris um 50-100 \% (Gonzalez-Vallejo et al. 1999). Der optimale pH-Wert für die enzymatische Fe-Citrat-Reduktion liegt nach dieser Studie zwischen $\mathrm{pH} 6,5-$ 7,0. Ergebnisse, denen zufolge diese Reaktion erst bei Unterschreiten von pH 5,8 oder Überschreiten von pH 7,5 um $30 \%$ gehemmt wird, werden dahingehend interpretiert, dass die reale Variabilität des apoplasmatischen pH-Werts für die Fe(III)-Reduktaseaktivität Fe-defizienter Blätter nicht relevant ist.

Untersuchungen an Blattzellen-Protoplasten belegen demgegenüber eine erhebliche Hemmung der flächenbezogenen Fe(III)-Reduktaseaktivität Fe-defizienter Pflanzen (Gonzalez-Vallejo et al. 2000). Das pH-Optimum des Reduktasesystems der Protoplasten liegt zwischen pH5,5-6,0. Bei einer Erhöhung über pH 6,0 wird die enzymatische Fe-Reduktion gehemmt und damit (ganz im Sinne des oben dargestellten hypothetischen Modells von Mengel) die Voraussetzungen für eine Akkumulation physiologisch inaktiven Eisens in chlorotischen Blättern geschaffen.

Nicht eindeutig geklärt ist die Frage, in welcher Weise der pH-Wert des Xylems und des Blattapoplasten durch Fe-Mangel beeinträchtigt wird. Direkte pH-Messungen von Zentrifugationsextrakten des Xylems und des Blattapoplasten sowie indirekte pH-Bestimmungen des Blattapoplasten mit Hilfe von Fluoreszenzmessungen nach Inkubation mit 5-Carboxyfluorescein belegen für Beta vulgaris ein leichtes Absinken des $\mathrm{pH}$ bei Kultivierung in eisenfreien, carbonatgepufferten Nährlösungen (Lopez-Millan et al. 2000a). Im Gegensatz dazu verweisen $\mathrm{pH}$-Werte von 5,5-5,9 in grünen und pH 6,5-6,6 in stark chlorotischen Blättern von Birnenbäumen kalkreicher Standorte auf einen gegenteiligen Effekt (Lopez-Millan et al. 2001a). Es muss davon ausgegangen werden, dass diese konträren pH-Entwicklungen auf unterschiedliche Hydrogencarbonatkonzentrationen in den Substraten zurückzuführen sind. Durch Zusatz von $1 \mathrm{mM}$ $\mathrm{NaOH}$ und $1 \mathrm{~g} / \mathrm{C} \mathrm{CaCO}_{3}(=10 \mathrm{mM})$ werden in Nährlösungen $(\mathrm{pH} 7,7)$ nicht annähernd $\mathrm{HCO}_{3}{ }^{-}$-Konzentrationen erreicht, wie sie im Wurzelraum kalkreicher Böden auftreten können. 
Inkonsistent erscheinen die Interpretationen des Einflusses verschiedener Fe-Citrat-Spezies auf die membranären Reduktaseaktivitäten der Blätter in den Nährlösungsuntersuchungen von Beta vulgaris und den Festsubstratkulturen von Pyrus communis (Lopez-Millan et al. 2000a, 2001a). Obwohl in beiden Studien Fe-Defizienz zu einem signifikanten Anstieg des Gehalts organischer Säuren führte, sollen deren Konzentrationen für die uneinheitlichen Gleichgewichtsverhältnisse zwischen $[\mathrm{FeCitOH}]^{-}$bzw. $\left[\mathrm{FeCit}_{2}\right]^{3-}$ in $\mathrm{Fe}-$ suffizienten und Fe-defizienten Pflanzen der beiden Untersuchungen verantwortlich sein. Kalkulationen mit dem Spezifizierungsprogramm MintaqA2 (U.S. Environmental Protection Agency, Washington, DC) ergeben für die chlorotischen Blätter der in carbonatreichen Böden kultivierten Birnenbäume eine Verlagerung hin zu erhöhten $[\mathrm{FeCitOH}]^{-}$-Konzentrationen. Hingegen sollen in Fe-defizienten, hydroponisch kultivierten Pflanzen von Beta vulgaris die $\left[\mathrm{FeCit}_{2}\right]^{3-}$-Konzentrationen ansteigen. Angesichts dessen, dass die relative Verteilung dieser Fe-Citrat-Komplexe den pH-Werten in den Xylem- und Apoplasten-Extrakten der beiden Studien folgt, erscheint die Negierung eines Einflusses der Protonenaktivitäten auf die chemische Spezifizierung fraglich. In Kenntnis der Untersuchungsergebnisse von Gonzalez-Vallejo et al. (1999), nach denen bei einer Erhöhung des Citrat: Fe-Verhältnisses von 100 auf 500 der reduktive Umsatz von Fe-Citraten durch Membranvesikel um $80 \%$ erniedrigt wird, sind Interpretationen widersprüchlich, die dieses Phänomen bei Beta vulgaris auf eine erhöhte Repulsion des in proportional höheren Konzentrationen vorliegenden $\left[\mathrm{FeCit}_{2}\right]^{3-}$ von der negativ geladenen Plasmamembran zurückführen (Lopez-Millan et al. 2000b), während der gleiche Mechanismus als Hinweis auf eine mögliche Strategie zur Verbesserung der zellulären Fe-Aufnahme von Pyrus communis unter Defizienzbedingungen gewertet wird (Lopez-Millan et al. 2001a).

Untersuchungen von Larbi et al. (2001) an Mesophyllgewebe von Beta vulgaris belegen schließlich, dass $\mathrm{Fe}(\mathrm{III})$ auf verschiedene Weise reduziert und damit für die Aufnahme in die Blattzellen bereitgestellt werden kann. Neben einer durch Licht stimulierten enzymatischen Fe(III)-Reduktion kann die Abgabe zellulärer Verbindungen, wie z. B. organischer Säuren, zur Bereitstellung von $\mathrm{Fe}^{2+}$ beitragen. Außerdem unterliegt Fe(III)-Citrat auch einer direkten photoreduktiven Umsetzung, wie bereits Brown et al. (1979) nachgewiesen haben. Aus diesen Gründen wird die Erfordernis einer membrangebundenen Reduktase für die Fe-Aufnahme in die Blattzellen heute von vielen Seiten in Frage gestellt (W. Schmidt, mündl. Mitteilung).

Hydrogencarbonat kann den pflanzlichen Fe-Haushalt also auf verschiedene Weise stören. $\mathrm{HCO}_{3}{ }^{-}$puffert die Bodenlösung im neutralen bis leicht alkalischen Bereich. Entsprechende pH-Werte gehen nicht nur mit potenziell niedrigen Fe-Löslichkeiten einher, sondern bewegen sich auch außerhalb des pH-Optimums der rhizodermalen Fe(III)-Reduktase (Susin et al. 1996). Offensichtlich wird die Fe(III)-Reduktion aber nicht nur durch die Protonenaktivität sondern auch durch die Pufferkapazität und auf diese Weise durch die $\mathrm{HCO}_{3}{ }^{-}$-Konzentrationen beeinflusst (Toulon et al. 1992). Untersuchungen von Romera et al. (1997) weisen darauf hin, dass $\mathrm{HCO}_{3}{ }^{-}$die Aufnahme solcher Metallionen beeinträchtigt, die für eine reguläre Fe-Stressantwort und die Induktion entsprechender Fe-Reduktasekapazitäten erforderlich sind.

Der im Zusammenhang mit der Wirkung hoher $\mathrm{HCO}_{3}{ }^{-}$-Konzentrationen auf die pflanzliche Fe-Ernährung unbestritten wichtigste Aspekt ist die vermehrte Synthese von organischen Säuren in den Wurzeln und ihre Translokation in den Spross. Dieses Phänomen kann sowohl bei Strategie I- als auch bei Strategie IIArten beobachtet werden. Erhöhte Citrat- und Malat-Konzentrationen gehen auf eine Stimulation der PEP-Carboxylase (und Malat-Dehydrogenase) durch erhöhte $\mathrm{HCO}_{3}{ }^{-}$-Konzentrationen (Lee \& Woolhouse 1969b) und durch suboptimale Fe-Versorgung zurück (Landsberg 1986). Untersuchungen von Lopez- 
Millan et al. (2001b) belegen, dass die Aktivität der PEP-Carboxylase in Wurzeln Fe-defizienter Pflanzen von Beta vulgaris durch Fe-Applikation innerhalb von $24 \mathrm{~h}$ um $19 \%$ und nach $96 \mathrm{~h}$ annähernd auf die Basisaktivität verringert wird. Bei verschiedenen Varietäten von Glycine max geht verminderte Chloroseresistenz mit einer erhöhten $\mathrm{HCO}_{3}{ }^{-}$-Dunkelfixierung einher (Bedri et al. 1960).

Die vermehrte Synthese organischer Säuren führt zu Störungen des Wurzelwachstums. Dieser Effekt ist bei der calcifugen Avenella flexuosa stärker ausgeprägt als bei dem calcicolen Arrhenaterum elatius (Lee \& Woolhouse 1969a). Hutchinson (1967a) hat in Untersuchungen an 30 Wildarten einen Zusammenhang zwischen der Ausbildung von Chlorosen auf carbonatreichen Böden und Störungen des Extensionswachstums der Lateralwurzeln gefunden. Eine entsprechende Beziehung zwischen hohen $\mathrm{HCO}_{3}{ }^{-}{ }^{-}$Konzentrationen, Störungen des Wurzelwachstums und Fe-Effizienz belegten u. a. auch Untersuchungen von White \& Robson (1990) an der sensitiven Lupinus angustifolius und der insensitiven Pisum sativum. Alhendawi et al. (1997) führen den vermehrten Efflux von $\mathrm{NO}_{3}{ }^{-}$und $\mathrm{K}^{+}$bei steigenden $\mathrm{HCO}_{3}{ }^{-}$-Konzentrationen auf Beeinträchtigungen der Membranintegrität und Störungen der Fe-Aufnahme auf die damit einhergehenden Wurzelschädigungen zurück. Bereits Untersuchungen von Doney et al. (1960) zeigten, dass $\mathrm{HCO}_{3}{ }^{-}$ auch die interne Fe-Translokation hemmt.

Die Hypothese, dass eine temporär unzureichende Fe-Nachlieferung während der Individualentwicklung die Ursache hoher Fe-Konzentrationen in chlorotischen Blättern ist, lässt die Frage offen, aus welchem Grund bei Erreichen adäquater Konzentrationen der Gesamteisenfraktion im Spross keine nachträgliche Chlorophyllbiosynthese erfolgt. Diskutiert wird in diesem Zusammenhang der Einfluss erhöhter CitratKonzentrationen in chlorotischen Blättern. Nikolic \& Römheld (1999) wiesen in Untersuchungen mit ${ }^{59} \mathrm{Fe}$ an Helianthus annuus nach, dass bei Konzentrationsverhältnissen von Citrat : Fe(III) zwischen 100 und 1000, die Fe-Aufnahme in den Blattsymplasten um mehr als zwei Drittel reduziert wird. Weite Citrat : Fe(III)-Verhältnisse, wie sie in vitro eingestellt wurden, entsprechen den relativen Konzentrationen Fe-defizienter Pflanzen im Xylem und Blattapoplasten. Hohe Citrat-Konzentrationen verringern insbesondere auch die photoreduktive Bereitstellung von $\mathrm{Fe}^{2+}$ für den Transport in die Blattzellen (Bienfait \& Scheffers 1992).

Fasst man diese Ausführungen zusammen, so sind die vielfach auch mit hohen Fe-Konzentrationen der Blätter einhergehenden Chlorosen von Pflanzen an kalkreichen Standorten v.a. auf folgende Punkte zurückzuführen:

- Verminderte Fe-Löslichkeit im Substrat durch hohe pH-Werte

- Hemmung der rhizodermalen Fe-Reduktase sowie der Fe-Aufnahme in die Wurzeln durch hohe pHWerte und Pufferkapazitäten des Substrats

- Hemmung des Wurzelwachstums und der Fe-Translokation in den Spross u. a. infolge erhöhter Konzentrationen organischer Säuren

- Fe-Akkumulation im Xylem und im Blattapoplasten infolge unzureichender enzymatischer oder photoreduktiver Bereitstellung von $\mathrm{Fe}^{2+}$ für die transmembranäre Aufnahme bei weiten Citrat : FeVerhältnissen

- Apoplasmatische Immobilisierung (und Akkumulation) von Fe-Hydroxiden und Fe-Phosphaten als Folge einer $\mathrm{HCO}_{3}{ }^{-}$-spezifischen und $\mathrm{NO}_{3}{ }^{-}$-verstärkten Alkalisierung des Blattapoplasten. 


\subsubsection{Aspekte variierender Phosphorkonzentrationen}

Phosphor ist als zentrale Komponente der Nukleinsäuren, der Adenylate und der membranären Phospholipide für alle Lebewesen von genetischer, energetischer und struktureller Bedeutung. Suboptimale PVersorgung äußert sich u. a. in der Reduktion der Blattgröße (Fredeen et al. 1989) und Blattzahl (Lynch 1995) sowie in der Abnahme der Wurzelleitfähigkeiten (Radin 1990). Phosphordefiziente Pflanzen sind häufig durch erhöhte Chlorophyll-Gehalte gekennzeichnet (Hecht-Buchholz 1967; Rao \& Terry 1989).

Unter den pflanzlichen Nährstoffen zeichnet sich Phosphor dadurch aus, dass seine Verfügbarkeit sowohl in sauren, kalkarmen als auch in basischen, kalkreichen Böden vergleichsweise gering ist. Im Gegensatz zu anderen Anionen der pflanzlichen Mineralstoffernährung, wie $\mathrm{SO}_{4}{ }^{2-}$ oder $\mathrm{NO}_{3}{ }^{-}$, bilden die Dissoziationsspezies der Phosphorsäure schwerlösliche Verbindungen mit Metallkationen, im sauren Bereich v.a. Minerale der Variscitgruppe ( $\left.\mathrm{Al}[\mathrm{PO} 4] \cdot 2 \mathrm{H}_{2} \mathrm{O}\right)$ und Strengitgruppe $\left(\mathrm{Fe}[\mathrm{PO} 4] \cdot 2 \mathrm{H}_{2} \mathrm{O}\right.$ ), im basischen insbesondere Fluor-, Chlor- und Hydroxylapatite $\left(\mathrm{Ca}_{5}\left[\left(\mathrm{~F}, \mathrm{Cl}, \mathrm{OH}, 1 / 2 \mathrm{CO}_{3}\right) \mid\left(\mathrm{PO}_{4}\right)_{3}\right]\right)$, die im Gleichgewicht mit löslichem $\mathrm{Ca}_{2}\left(\mathrm{HPO}_{4}\right)_{2}$ und $\mathrm{Ca}\left(\mathrm{H}_{2} \mathrm{PO}_{4}\right)$ stehen (Scheffer \& Schachtschabel 1992). In sehr sauren Böden kann die P-Verfügbarkeit durch Auswaschungen vermindert sein, bei sehr hohen $\mathrm{Fe}^{2+}$-Konzentrationen in Böden niedriger Redoxpotenziale durch die Präzipitation von Vivianit $\left(\mathrm{Fe}_{3}\left[\mathrm{PO}_{4}\right]_{2} \cdot 8 \mathrm{H}_{2} \mathrm{O}\right)$. Mit dem pH nimmt zudem die P-Löslichkeit durch die Adsorption an Sesquioxide und Tonminerale sowie an die organische Substanz ab. Eine weiter reichende Immobilisierung erfolgt durch Okklusion in Fe-Oxiden. Der Anteil der organischen P-Fraktion im Boden beträgt 20-70 \% (Welp et al. 1983; Ron Vaz et al. 1993) und kann in der Rhizosphäre auf bis zu 80-90 \% ansteigen (Helal \& Dressler 1989). Neben Inositolphosphaten (darunter v. a. Phytat) finden sich hier Nukleinsäuren, Phopholipide und verschiedenartige Ester (Scheffer \& Schachtschabel 1992).

Phosphate besitzen eine sehr geringe Mobilität im Boden. Anders als beispielsweise Calcium gelangt Phosphor in erster Linie diffusiv und nicht durch transpirationsvermittelten Massenfluss zur Wurzel. Als Folge niedriger Diffusionskoeffizienten $\left(10^{-12}-10^{-15} \mathrm{~m}^{2} \cdot \mathrm{s}^{-1}\right)$ bilden sich rasch rhizosphärische Verarmungszonen aus (Schachtman et al. 1998). Geringe Wassergehalte beeinträchtigen zusätzlich die Verlagerung des P im Boden. Zudem wird unter diesen Bedingungen das Wurzelwachstum und damit die Erschließung neuer Bodenräume gehemmt. Mehr noch als das Auftreten von Mangelerscheinungen anderer Nährelemente begünstigen Trockenperioden daher das von P-Defizienzen.

Die Effizienz der pflanzlichen P-Mobilisierung und P-Aufnahme wird unter Bedingungen unzureichender P-Versorgung v. a. durch eine Vergrößerung der resorbierenden Oberfläche erhöht. Der Wurzelraum kann dabei durch Anpassungen der Wurzelgeometrie und Wurzelmorphologie (Lynch 1995), häufig einhergehend mit einer Verringerung des Spross/Wurzel-Verhältnisses (Fredeen et al. 1989), vergrößert werden. Die Proteoidwurzeln mancher Taxa - neben den namengebenden Proteaceae weisen Mitglieder aus zehn weiteren Familien solche cluster-Bildungen verkürzter Seitenwurzeln auf - sind in den meisten Fällen spezifische Anpassungen an P-Mangelstandorte (Dinkelaker et al. 1995, 1997; Watt \& Evans 1999a, 1999b). Wie bei diesen cluster roots, zielt die umfangreiche Abgabe von niedermolekularen organischen Säuren (v. a. Citrat und Oxalat) auch bei Arten ohne spezielle Wurzelmorphologie v. a. auf die Aufnahme von P ab (Jones \& Darrah 1994; Tyler \& Ström 1995; Ström 1997).

Eine gleichartige Mobilisierungsstrategie für schwerlösliche P-Verbindungen verfolgen Mykorrhizapilze, mit denen mehr als 90 \% der Landpflanzen assoziiert sind. Mykorrhizierung kann die pflanzliche P-Aufnahme um das drei- bis fünffache erhöhen (Smith \& Read 1997). Die Mykorrhiza wird offensichtlich durch Regulative von Seiten beider Symbionten kontrolliert. Obwohl der Mykobiont auch bei hohen P- 
Substratkonzentrationen auskeimen kann, nimmt die Mykorrhizierung (wahrscheinlich als Folge unzureichender C-Versorgung durch den Phytobionten) bei guter P-Versorgung ab (Tawaraya et al. 1996). Auf der anderen Seite kontrolliert der Pilz das Ausmaß der P-Translokation in die Pflanzenwurzeln und damit seine eigene energetische Versorgung durch die Pflanze (MacFall et al. 1992).

$\mathrm{P}_{\mathrm{o}}$ wird durch wurzelbürtige und bakterielle saure Phosphatasen, bei Pilzen zusätzlich durch alkalische Phosphatasen hydrolysiert. Enge Korrelationen zwischen der P-Verarmung des Bodens sowie der Aktivität saurer Phosphatasen geben Hinweise auf deren Bedeutung für die P-Ernährung von Picea abies. Der Anteil organischer P-Verbindungen an der Versorgung der Pflanzen kann bei 50-100 \% liegen (Häussling \& Marschner 1989; Helal \& Dressler 1989). Maximale $\mathrm{P}_{\mathrm{i}}$-Konzentrationen treten in der Bodenlösung bei pH5,5-6,5 auf (Tisdale et al. 1993). Zugleich ist das bei diesen $\mathrm{pH}$-Werten vorliegende monovalente $\mathrm{H}_{2} \mathrm{PO}_{4}{ }^{-}$die primäre Transportform des Phosphors für die Aufnahme in die Wurzelzellen. Die höchsten Aufnahmeraten finden sich in vitro bei pH 5-6 (Ullrich et al. 1984; Furihata et al. 1992). Da Phosphat im Symport mit $\mathrm{H}^{+}$(Schachtman et al. 1998) oder im Antiport mit $\mathrm{OH}^{-}$(Lin 1979) aufgenommen wird, ist der membranäre P-Transport mit dem $\mathrm{pH}$ des Substrats negativ korreliert.

Unterschreitet die membranäre Aufnahme den transpirationsvermittelten Massenfluss, so kann es in der Rhizosphäre kalkreicher Böden zu einer Anreicherung von Ca, in der saurer und/oder anaerober Böden zu einer solchen von Al, Fe oder Mn kommen. Folgen sind die Bildung schwerlöslicher [Ca, Al, Fe, Mn]Phosphate oder die P-Immobilisierung durch Adsorption in Wurzelplaques sowie, daraus resultierend, sekundäre P-Defizienzen (Barber \& Gunn 1974; Jones \& Fox 1978; Ding \& Musgrave 1995; Lidon et al. 1999).

Die Aktivität von sehr vielen Enzymen wird durch die symplasmatischen Phosphatkonzentrationen kontrolliert. Dies gilt beispielsweise für die Phosphofruktokinase der Glykolyse, deren Aktivität allosterisch durch Orthophosphat stimuliert wird (Theodorou \& Plaxton 1993). Die Freisetzung von Orthophosphat aus ATP und das damit einhergehende Absinken der Energieladung des Adenylatsystems (AEC, adenylate energy charge) erhöht hier, wie in anderen Fällen, autoregulativ den katabolen Substratfluss. Bedeutung hat Phosphor nicht nur im Rahmen aller energetisch relevanten Reaktionen, sondern als Bestandteil des Inositol-1,4,5-trisphosphats auch bei der Transduktion extrazellulärer Signale. Inositoltrisphosphat koppelt die Rezeptoraktivierung an die Freisetzung des second messengers $\mathrm{Ca}^{2+}$ (Lehle 1990; Darnell et al. 1994). Diese Ausführungen machen verständlich, warum die cytoplasmatische $\mathrm{P}_{\mathrm{i}}$-Konzentration sehr eng reguliert wird. Sie beträgt beispielsweise 4,2 $\mathrm{mM}$ bei Pisum sativum und 6,0 $\mathrm{mM}$ bei Zea mays (Lee et al. 1990). Die vakuolären Konzentrationen sind sehr viel variabler und liegen bei 0-25 mM (Lee et al. 1990, Lee \& Ratcliffe 1993). Grundlage der cytoplasmatischen Homöostasis sind neben den beschriebenen adaptiven Mechanismen der P-Mobilisierung durch die Wurzeln Regulative der membranären Transportsysteme, die P-Speicherung in Phytat und Polyphosphaten sowie eine effektive P-Translokation durch das Phloem (Jeschke et al. 1997).

In verschiedenen Arbeiten wird das Fehlen acidophiler Arten an Standorten kalkreicher Böden auf eine suboptimale P-Versorgung der Pflanzen zurückgeführt (Marrs \& Bannister 1978a; Tyler 1996a). Ein gleichgearteter Ausschluss Acidophiler von Kalkböden und Basiphiler von sauren Böden durch niedrige P-Löslichkeiten erscheint aber nur schlüssig, wenn Adaptationen an verminderte P-Verfügbarkeiten substratspezifisch sind. Diesbezügliche Arbeiten werden in Abschnitt 5.3.11 (S. 202) zusammen mit den Untersuchungen zur P-Verfügbarkeit in den beiden hier behandelten Subassoziationen des GentianoKoelerietum diskutiert. 


\subsubsection{Interaktion und Regulation autökologischer Adaptationen}

Die Ausführungen zur Nährstoffverfügbarkeit in sauren, kalkarmen bzw. basischen, kalkreichen Böden sowie die Betrachtungen der Mineralstofftoleranzen und -effizienzen acidophiler/calcifuger bzw. basiphiler/calcicoler Arten zeigen, dass viele edaphische und autökologische Faktoren intra- und interkorreliert sind und diese daher in Arbeiten zur Calcicolen/Calcifugen-Problematik möglichst integrativ behandelt werden sollten.

Ein Punkt, auf den Kinzel (1982) in diesem Zusammenhang eingeht, sind Interferenzen zwischen Eisen, Phosphor und Hydrogencarbonat. An der Induktion von Fe-Mangelchlorosen durch $\mathrm{HCO}_{3}{ }^{-}$soll auch $\mathrm{P}$ beteiligt sein. Anders als im Fall landwirtschaftlich intensiv genutzter Böden dürfte indes die externe oder interne Fe-Immobilisierung in Form von Fe-Phosphaten oder Fe-Komplexen P-haltiger-Verbindungen, wie Phosphoproteiden, Phospholipiden oder Zuckerphosphaten, an ungedüngten kalkreichen Standorten für die Ausbildung von Eisenmangelchlorosen allenfalls eine untergeordnete Rolle spielen.

Verschiedene autökologische Anpassungen an basische/kalkreiche Standorte, wie etwa die vermehrte Exsudation niedermolekularer organischer Säuren, erlauben zugleich die Mobilisierung von Fe und P. Entsprechendes gilt beispielsweise auch für die hochaffine Bindung von Fe an bestimmte Zellwandkomponenten und die damit potenziell einhergehende Spaltung der betreffenden Verbindungen, wie sie für Arachis hypogaea beschrieben wird (Ae et al. 1996; Ae \& Otani 1997).

Im Rahmen methodologischer Überlegungen zur Bearbeitung von Fragen der Vegetationsdifferenzierung und auf Grundlage von bodenkundlichen Untersuchungen an zwei vikariierenden Lathyrus-Arten (Grime 1965b) sowie älteren hydroponischen Untersuchungen an Avenella flexuosa (Olsen 1958) wurde erstmals ein Bezug zwischen der Ausbildung von Chlorosen calcifuger/acidophiler Arten auf Kalkböden und ihrer besonderen Toleranz gegenüber hohen Konzentrationen anderer Metallkationen in sauren, kalkarmen Böden postuliert (Grime 1965a).

Grime \& Hodgson (1969) führten Korrelationen zwischen der Fe-Chloroseanfälligkeit und der Al-Toleranz acidophiler/calcifuger Arten auf eine hypothetische Komponente der Wurzeln zurück, die durch Komplexierung die Aufnahme beider Metalle unterbindet. Diese Annahme stimmt mit der Beobachtung überein, dass die Applikation von $\mathrm{Al}^{3+}$, beispielsweise über Austauschreaktionen, das Ausmaß von Chlorosen bei suboptimaler Fe-Verfügbarkeit verringert. Angesichts dessen, dass die meisten Carboxylate Fe nur bei vergleichsweise niedrigen $\mathrm{pH}$-Werten binden und gleichzeitig Fe-Citrat ein gut zu verwertendes Substrat der pflanzlichen Mineralstoffernährung sowie die Transportform des Fe im Xylem ist (Tiffin 1966a, 1966b), erscheint aber eine diesbezügliche Wirkung niedermolekularer organischer Säuren, wie sie von den Autoren vermutet wird, fraglich.

Im Hinblick auf die detoxifizierenden Wirkung organischer Säuren bei hohen $\mathrm{Al}^{3+}$-Konzentrationen in Böden niedriger pH-Werte und die Bedeutung solcher Carboxylate für die Mineralstoffeffizienz bei eingeschränkten Fe- und P-Verfügbarkeiten in basischen, kalkreichen Böden entwickelte Lee (1999) ein Modell, das auf der Annahme einer abweichenden Regulation membranärer Anionenkanäle basiert. Danach wird bei Calcicolen/Basiphilen die Öffnung dieser Kanäle durch $\mathrm{Al}^{3+}$ blockiert und damit die Abgabe von detoxifizierendem Malat und Citrat unterbunden. Die daraus resultierende $\mathrm{Al}^{3+}$-Aufnahme soll im Cytoplasma zu geringeren Konzentration an Oxalacetat, dem Substrat der PEP-Carboxylase-vermittelten Malat-Synthese, führen und damit die $\mathrm{Al}^{3+}$-Detoxifizierung im Symplasten und Apoplasten zusätzlich beeinträchtigen. Andererseits verhindert nach diesem Entwurf die vermehrte Bindung von $\mathrm{Ca}^{2+}$ am Plasmalemma bei acidophilen/calcifugen Arten die Exsudation von organischen Säuren und damit deren 
mineralstoffmobilisierende Wirkung bei suboptimaler Fe- und P-Versorgung in Kalkböden. Erhöhte zelluläre $\mathrm{HCO}_{3}{ }^{-}$-Konzentrationen und Reaktionen im Rahmen des $\mathrm{pH}$-stat-Mechanismus sollen hier eine weitere Anreicherung organischer Säuren und darüber die Desintegration cytoplasmatischer und vakuolärer Kompartimente verursachen. Viele Punkte dieses Modells sind bis heute rein hypothetisch und warten auf ihre experimentelle Überprüfung.

Gleiches gilt für einen sehr ähnlichen Erklärungsansatz, den Tyler (2003) im Zusammenhang mit der Ursachenanalyse der außergewöhnlichen Artenvielfalt basischer/kalkreicher Standorte in Mitteleuropa entwickelt hat. Danach induziert $\mathrm{Ca}^{2+}$ bei basiphilen/calcicolen und $\mathrm{Al}^{3+}$ bei acidophilen/calcifugen Arten nahezu identische Stressreaktionen, die aber, wie die vermehrte Synthese und Exsudation organischer Säuren, sowohl an Standorten mit sauren, basenarmen als auch alkalischen, kalkreichen Böden ameliorierend wirken. Ausgangspunkt dieses Modells ist eine Hypothese von Ewald (2003), nach der sich infolge der Ausweitung bodensaurer Standorte im Holozän Arten mit bis dahin basiphilem/calcicolem Physiotypus an die hier vorherrschenden Bedingungen anpassen mussten. Die besonders große Biodiversität der verbleibenden Kalkstandorte soll auf die längere Entwicklungsgeschichte solcher Arten zurückzuführen sein, die nach dem Rückzug der pleistozänen Gletscher zunächst sehr große Areale besiedelten. Tyler (2003) geht davon aus, dass die Zeit für die Evolution ganz neuer Reaktionskaskaden und eine derartige Differenzierung acidophiler/calcifuger Arten zu kurz, für eine Modifikation der regulativen Zentren der Stressantworten aber durchaus lang genug war.

Eigenschaften von Pflanzen, die im Zusammenhang mit der Mineralstoffernährung eine fundamentale Bedeutung für die Vegetationsdifferenzierung haben, finden ihren Bezug in erster Linie in Kenngrößen des allgemeinen Wachstumsverhaltens, darunter der RGR (relative growth rate, relative Wachstumsrate) und der diesbezüglichen Plastizität der Arten. Oligotrophe Arten sind langsamwüchsig und zeichnen sich bezogen auf ihre potenziellen RGR ( $\mathrm{RGR}_{\max }$ ) durch hohe Mineralstoffeffizienzen aus. Korrelationen zwischen der Fe-Effizienz und $\mathrm{RGR}_{\max }$ haben beispielsweise Nährlösungsuntersuchungen an verschiedenen Arten der Gattung Plantago belegen können (Schmidt \& Fühner 1998). Grundsätzlich niedrige Biomasseproduktivitäten und ein daraus resultierender geringer Nährstoffbedarf kann dafür verantwortlich gemacht werden, dass z. B. das besonders kleine, acidophile/calcifuge Nardus stricta in Kalkböden keine Chlorosen ausbildet (Grime \& Hodgson 1969). Oligotrophie, wie sie angesichts absolut oder - als Folge von Ionenantagonismen - relativ verminderter Verfügbarkeiten v. a. von Stickstoff, Phosphor, Magnesium und Kalium sowohl bei Acidophilen/Calcifugen als auch bei Basiphilen/Calcicolen verbreitet ist, dürften im Zusammenwirken mit Konkurrenzmechanismen ein grundlegender, aber nicht der ausschlaggebende Faktor für die natürliche Vegetationsdifferenzierung von sauren, basenarmen und alkalischen, kalkreichen Böden sein. Auf diese Punkte wird in Abschnitt 5.4 (S. 224 ff.) näher eingegangen. 

Die Etablierung acidophiler/calcifuger $\mathbf{5}$

Pflanzenarten im Gentiano-Koelerietum 


\subsection{Vegetationskundliche Aspekte des Auftretens acidophiler/calcifuger Arten in Kalk-Halbtrockenrasen}

Anders als beispielsweise in Großbritannien wurden die Rasengesellschaften über kalkreichem Ausgangsgestein, in denen acidophile/calcifuge und basiphile/calcicole Arten miteinander vergesellschaftet sind, in Deutschland mehr unter pflanzensoziologisch-synökologischen als unter ökophysiologisch-autökologischen Gesichtspunkten untersucht. Dem Auftreten von Acidophilen/Calcifugen ist hier durch Ausweisung entsprechender Gesellschaften innerhalb der Klasse Festuco-Brometea (Kalkmagerrasen i.w. S.) Rechnung getragen.

\subsubsection{Synsystematik der Festuco-Brometea}

Kalkmagerrasen sind der wichtigste Lebensraum basiphiler/calcicoler Pflanzenarten. Ellenberg (1996) fasst die Festuco-Brometea (Kalkmagerrasen i. w. S.) mit vier weiteren Klassen, darunter den Borstgrastriften und Zwergstrauchheiden (Nardo-Callunetea), zu einer Gruppe anthropo-zoogener Heiden und Rasen zusammen. Abbildung 61 zeigt die Synsystematik dieser Klasse in Anlehnung an Oberdorfer \& Korneck (1976), Pott (1992) und Ellenberg (1996).

Gesellschaften der Festuco-Brometea sind typisch für warme, trockene, offene und vorwiegend basenreiche Standorte. Allerdings ist angesichts des Koelerio-Phleion phleoides als Verband bodensaurer Trockenrasen und der bodensauren Pechnelken-Wiesenhafer-Gesellschaft (Viscario-Avenetum pratensis) im Mesobromion erecti die deutsche Bezeichnung Kalkmagerrasen nur bedingt zutreffend. Der Verbreitungsschwerpunkt der artenreichen Rasengesellschaften liegt im südlichen und südöstlichen Mitteleuropa. Die heutigen Gesellschaften sind Produkte der nacheiszeitlichen Vermischung von Arten der kontinentalen Steppenvegetation, submediterraner Gras- und Zwergstrauchformationen und von alpigenen Restbeständen. Die pflanzensoziologische Gliederung des Taxons in die Ordnungen der Festucetalia valesiacae und Brometalia erecti gründet auf der Verteilung mehr kontinental-subkontinentaler bzw. submediterraner oder subatlantischer Geoelemente. Beide Ordnungen werden jeweils in einen xerothermen (Festucion valesiacae, Cirsio-Brachypodion) und einen mesophilen Verband (Xerobromion, Mesobromion erecti) unterteilt. Eine umstrittene Stellung hat nach wie vor der von Oberdorfer \& Korneck (1976) den Brometalia erecti zugeordnete und bereits oben erwähnte Verband Koelerio-Phleion phleoides.

Ursprünglich auf enge Bereiche beschränkt, führten anthropogene Einflüsse, wie Brand, Rodung, Mahd und Beweidung, zu einer sekundären Ausbreitung der Kalkmagerrasen. In Deutschland gehören das Gentiano-Koelerietum (Enzian-Schillergrasrasen) und das Mesobrometum (Halbtrockenwiese) zu den häufigsten Gesellschaften der Festuco-Brometea. Sie sind dem Verband Mesobromion erecti zuzuordnen. Es handelt sich bei ihnen um menschlich bedingte Halbkulturformationen, die als Folge extensiver Beweidung bzw. einschüriger Mahd an die Stelle von Waldgesellschaften der Querco-Fagetea traten. Die Assoziationen des Mesobromion umfassen vorwiegend Arten submediterranen und submediterran-subatlantischen Ursprungs und bilden je nach Gesellschaft eine mehr oder weniger mesophile, gras-, orchideenund enzianreiche Vegetation.

Tiefgreifende Verschiebungen der charakteristischen Artenkombinationen vom in der Regel gemähten Mesobrometum hin zum vorwiegend beweideten Gentiano-Koelerietum ergeben sich v. a. durch die Verdrängung nur eingeschränkt weidefester Arten (z. B. Bromus erectus) und die Begünstigung von Pflanzen, 


\section{Festuco-Brometea}

basiphile Halbtrocken-,Trocken- und Steppenrasen der planaren

bis hochmontanen Stufe $=$ Kalk-Magerrasen i. w. S.

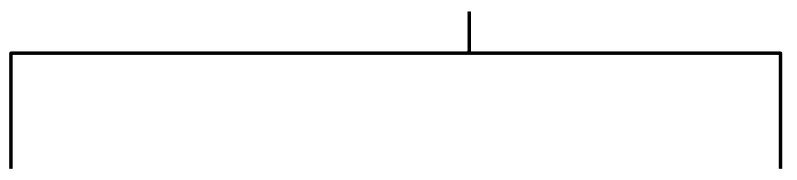

Festucetalia valesiacae

kontinentale Steppen-, Trocken- und Halbtrockenrasen

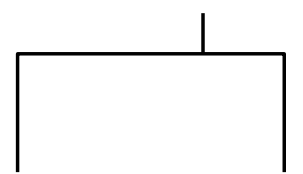

Festucion

valesiacae

kontinentale

Trockenrasen

\section{Cirsio-} Brachypodion

kontinentalsubkontinentale Halbtrockenrasen

\section{Brometalia erecti}

submediterrane-subozeanische

Trocken- und Halbtrockenrasen

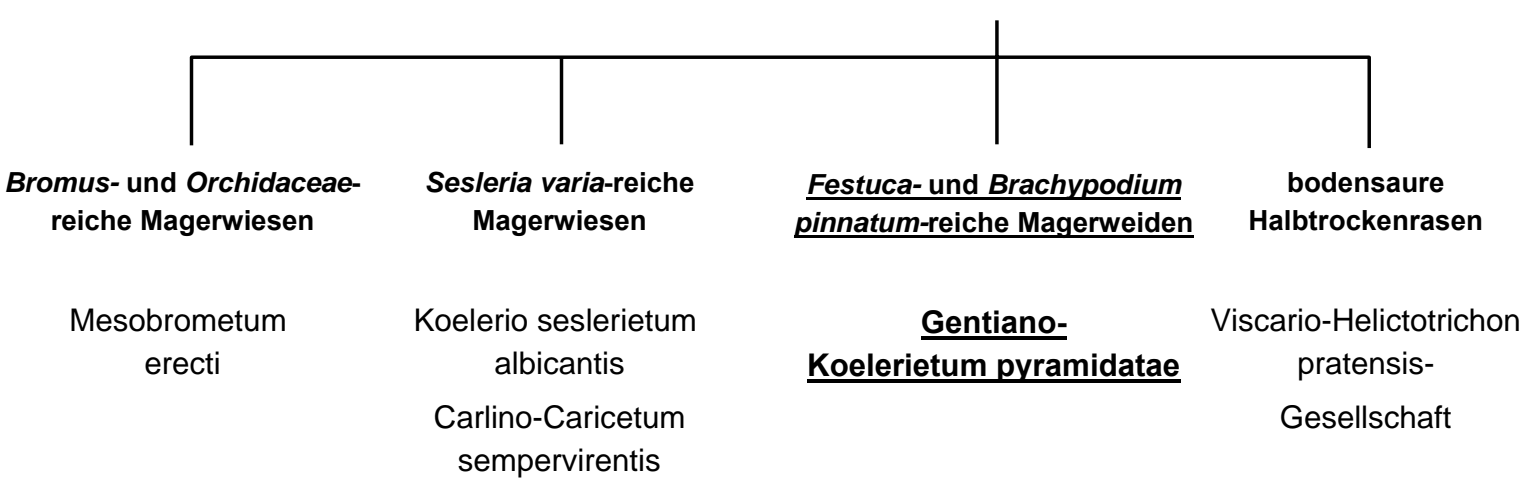

Abbildung 61: Synsystematische Stellung des Gentiano-Koelerietum innerhalb der Klasse Festuco-Brometea in Anlehnung an Oberdorfer \& Korneck (1976), Pott (1992) und Ellenberg (1996). Assoziationen und Gesellschaften i. w. S. sind nur für den Verband Mesobromion erecti angegeben.

die aufgrund ihrer Morphologie (z. B. Cirsium acaule) oder spezifischer Inhaltsstoffe (Gentianella germanica) vom Vieh gemieden werden. Demgegenüber kann Bromus erectus in brachliegenden oder kaum genutzten Halbtrockenrasen zur Dominanz gelangen (Dierschke 1984). Unter diesen Bedingungen zeigt sich die Art wachstumsstärker als das konkurrierende Brachypodium pinnatum, das seinerseits hfg. im Gentiano-Koelerietum dominiert. Corcket et al. (2003b) verweisen darauf, dass B. erectus an besonders trockenen Standorten, B. pinnatum dort, wo Beschattung den Wasserhaushalt entspannt, bevorzugt auftritt. Der Konkurrenzdruck auf B. pinnatum kann in offenen Vegetationsbereichen durch herbivore Insekten, in den französischen Alpen insbesondere durch Grashüpfer, verstärkt werden (Corcket et al. 2003a). Andererseits wird B. pinnatum im Vergleich zu B. erectus deutlich weniger durch Vieh beweidet (Delescaille 1999; Barbaro et al. 2000). Nach Gibson et al. (1987) ist bei Co-Herbivorie in der Regel die Wirkung von Vertebraten für die Vegetationsentwicklung ausschlaggebend - eine Einschätzung, die mit dem bevorzugten Auftreten von B. erectus im Mesobrometum und B. pinnatum im Gentiano-Koelerietum übereinstimmt. 
Die in der Regel geringen N-Verfügbarkeiten in den Gesellschaften des Mesobromion können auf die niedrigen N-Mineralisationsraten infolge der Austrocknung des Oberbodens einerseits und den kontinuierlichen Mineralstoffentzug durch die landwirtschaftliche Nutzung andererseits zurückgeführt werden. So liegt etwa die N-Nettomineralisation in Magerrasen mit 20-30 kg $\cdot \mathrm{ha}^{-1} \cdot \mathrm{a}^{-1}$ im Schnitt um zwei Drittel unter der gedüngter Wiesen (Gigon 1968).

Die Assoziationen des Mesobromion werden entsprechend der Art und Intensität ihrer Nutzung geprägt und pflanzensoziologisch gegliedert. Hingegen folgt die Differenzierung der Subassoziationen den jeweiligen Bodeneigenschaften des Standorts. Halbtrockenrasen vergleichsweise trockener oder feuchter bzw. basenreicher/alkalischer oder basenarmer/saurer Böden leiten zu verwandten Syntaxa über. Der allmähliche Vegetationswechsel entlang von Gradienten wichtiger Standortfaktoren und das gleichzeitige Fehlen eindeutiger synökologischer Grenzen bilden den Hintergrund für die nicht selten widersprüchliche Einordnung vergleichbarer Vegetationsbestände in das pflanzensoziologische System. In vielen Fällen werden geringfügige floristische Abweichungen, die aus ganz spezifischen Kombinationen der Standortfaktoren resultieren, zum Anlass genommen, bestehende Pflanzengesellschaften mehr und mehr zu fragmentieren - mit der Folge, dass bereits auf Ebene der Subassoziationen die Übersichtlichkeit und der Nutzen des Systems verloren zu gehen droht. Defizite und Unstimmigkeiten der pflanzensoziologischen Klassifikation und die Möglichkeiten der Anwendung numerischer Verfahren für die Neuordnung der Klasse Festuco-Brometea werden im Detail von Jandt (1999) behandelt.

\subsubsection{Synsystematik des Gentiano-Koelerietum}

Tabelle 28 fasst Arbeiten zusammen, die das Auftreten von acidophilen/calcifugen Pflanzenarten in Vegetationsbeständen des Gentiano-Koelerietum und vergleichbaren Gesellschaften beschreiben. Soweit im Rahmen der betreffenden Untersuchungen erfasst, sind die geologischen und edaphischen Standorteigenschaften aufgeführt, die potenziell für diese Vegetationsdifferenzierung verantwortlich zeichnen.

Das Gentiano-Koelerietum wurde 1928 erstmals von Tüxen als Mesobrometum gentianetosum ciliatae aus der Umgebung Göttingens beschrieben. Knapp nahm 1942 nach Durchsicht von umfangreichem Aufnahmematerial eine syntaxonomische Einstufung als Assoziation vor, die er als Koelerio-Gentianetum bezeichnete. Nachdem bereits Tüxen 1955 die Gesellschaft unter dem Namen Gentianeto-Koelerietum boreoatlanticum in sein "System der nordwestdeutschen Pflanzengesellschaften" aufgenommen hatte, veröffentlichte schließlich Bornkamm (1960) die Assoziation gültig als Gentiano-Koelerietum boreoatlanticum. Die Gesellschaft wird heute als Gentiano-Koelerietum pyramidatae (KNAPP 1942) ex BORNKAMM 1960 geführt (Dierschke 1994). In ihrem Kern repräsentiert sie die Halbtrockenrasen auf flachgründigen Kalkböden. Neben dem Gentiano-Koelerietum typicum umfasst die Gesellschaft weitere feuchtigkeits- und substratbedingte Subassoziationen (Pott 1992). Dabei grenzen Untergesellschaften frischer Standorte an Taxa der Molinio-Arrhenateretea, Subassoziationen saurer Böden an solche der Nardo-Callunetea (Bornkamm 1958; Jandt 1999).

Tüxen (1928) ordnete seinem Mesobrometum gentianetosum eine Degenerationsphase von Calluna vulgaris zu, die auf mehr oder weniger feinerdereichen, entkalkten Standorten über Muschelkalk säureliebende/kalkmeidende Arten aufweist. Im Rahmen seiner Bearbeitung der Halbtrockenrasen im oberen Leinegebiet beschreibt Bornkamm (1960) neben einer typischen Subassoziation trockener und einer Prunella vulgaris-Subassoziation feuchterer Standorte eine Subassoziation von Danthonia decumbens. Außer D. decumbens und C. vulgaris weist diese mit Potentilla erecta eine weitere Charakterart der 
Nardo-Callunetea auf. Differentialarten des Gentiano-Koelerietum danthonietosum decumbentis, die ihren Verbreitungsschwerpunkt in Gesellschaften der Zwergstrauch-Heiden und Borstgras-Triften besitzen, sind weiterhin Anthoxantum odoratum sowie die Moose Polytrichum juniperinum und Atrichum undulatum. Dominierendes Moos in der Subassoziation von D. decumbens ist Hypnum cupressiforme var. lacunosum, in allen anderen Subassoziationen das basiphile/calcicole Ctenidium molluscum. Für die Etablierung dieser acidophilen/calcifugen Arten in Kalk-Halbtrockenrasen werden tiefgründigere Böden mit Lössauflage und einer zumeist sauren Reaktion des Oberbodens verantwortlich gemacht (Bornkamm 1960). Sowohl floristisch als auch standörtlich mit dem Gentiano-Koelerietum danthonietosum vergleichbar ist das Mesobrometum collinum agrostidetosum tenuis von Korneck (1960), das er später selber als recht isolierte Agrostis tenuis-Subassoziation des Gentiano-Koelerietum auffasste (Oberdorfer \& Korneck 1976; Abbildung 61). Dieser Klassifizierung als Gentiano-Koelerietum agrostietosum folgen auch Bergmeier (1987) und Geringhoff \& Daniels (1994). Außer Agrostis tenuis differenzieren diese Gesellschaft mit Polygala vulgaris ssp. oxyptera, Viola canina und Galium pumilum weitere Arten, die von Ellenberg et al. (1992) als Säurezeiger betrachtet werden. Bultmann (1993) ordnet in einem stark fragmentierten System den Differentialartengruppen von zwei Danthonia-Subvarianten in der Parnassia palustris-Variante und der typischen Variante ihres Gentiano-Koelerietum trisetetosum auch Luzula campestris zu. Von den bereits genannten Bodeneigenschaften soll erhöhte Gründigkeit als Folge einer fortgeschrittenen Verwitterung oder verminderter Lössabträge v. a. in Plateaulagen dafür verantwortlich sein, dass acidophile/calcifuge Arten und mesophile Arten, wie Trisetum flavescens, in diesen Vegetationseinheiten miteinander vergesellschaftet sind.

Betrachtet man die floristischen und standörtlichen Eigenschaften der in Tabelle 28 aufgeführten Halbtrockenrasen-Gesellschaften, so finden sich Hinweise auf nur geringe Unterschiede zwischen den betreffenden Vegetationseinheiten. Wie sehr letzten Endes die jeweiligen Klassifikationen subjektiven Bewertungen unterliegen, machen pflanzensoziologische Bearbeitungen an der Steinkirche in Scharzfeld deutlich. Während Bornkamm (1960) hier ein Euphorbio-Brachypodietum ausweist, ordnet Jandt (1999) dieselben Rasen dem Gentiano-Koelerietum zu. Jandt klassifiziert Rasen, in denen acidophile/calcifuge und mesophile Arten vertreten sind, anhand einer numerisch ermittelten Anthoxantum odoratum-Gruppe, die wiederum weitestgehend der gemeinsamen Differentialartengruppe des Gentiano-Koelerietum danthonietosum und Euphorbio-Brachypodietum danthonietosum von Bornkamm entspricht. Dieser begründet im übrigen die Abtrennung seines Euphorbio-Brachypodietum vom Gentiano-Koelerietum durch das Fehlen von Bromus erectus, die Dominanz von Brachypodium pinnatum und die hohe Stetigkeit von Euphorbia cyparissias. Andererseits basiert aber heute die Trennung von mehr südlich vorzufindendem Mesobrometum und mehr nördlichem Gentiano-Koelerietum gerade auf der Ablösung von B. erectus durch B. pinnatum, die, wie oben beschrieben, unter pflanzengeographischen Aspekten und unter dem vegetationsgeschichtlichen Gesichtspunkt unterschiedlicher Bewirtschaftungsweise zu bewerten ist. 


\begin{tabular}{|c|c|c|c|c|c|}
\hline Autoren & Nomenklatur & $\begin{array}{l}\text { Untersuchungs- } \\
\text { Gebiet }\end{array}$ & $\begin{array}{l}\text { Geologie/ } \\
\text { Ausgangsgestein }\end{array}$ & $\begin{array}{l}\text { Boden/Boden- } \\
\text { Charakteristika }\end{array}$ & $\mathrm{pH}$ \\
\hline Tüxen 1928 & $\begin{array}{l}\text { Mesobrometum gentianetosum ciliatae, } \\
\text { Calluna vulgaris-Degenerationsphase }\end{array}$ & $\begin{array}{l}\text { Göttingen, } \\
\text { Plessewald }\end{array}$ & Muschelkalk & \pm feinerdehaltig, entkalkt & - \\
\hline Knapp 1948 & $\begin{array}{l}\text { Mesobrometum, } \\
\text { Haupt-Subass. von Sieglingia decumbens* }\end{array}$ & Übersicht & $\begin{array}{l}\text { kalkreiche, basische } \\
\text { Silikatgesteine }\end{array}$ & \pm feinerdereich, hfg.flachgründig & - \\
\hline $\begin{array}{l}\text { Lohmeyer } \\
1953\end{array}$ & $\begin{array}{l}\text { Mesobrometum erecti subatlanticum, } \\
\text { Subass. von S. decumbens }\end{array}$ & $\begin{array}{l}\text { Weser-Bergland, } \\
\text { Höxter }\end{array}$ & $\begin{array}{l}\text { Keuper, } \\
\text { Keupermergel }\end{array}$ & $\begin{array}{l}\text { sandiger Lehm, oberflächig entkalkt, } \\
\text { Lössauflage }\end{array}$ & - \\
\hline \multirow[t]{2}{*}{$\begin{array}{l}\text { Bornkamm } \\
1960\end{array}$} & $\begin{array}{l}\text { Euphorbio-Brachypodietum, } \\
\text { Subass. von S. decumbens, typ. Variante } \\
\text { Subass. von S. decumbens, Parnassia-V. }\end{array}$ & $\begin{array}{l}\text { LK Göttingen, Friedland } \\
\text { LK Osterode, Scharzfeld }\end{array}$ & $\begin{array}{l}\text { mittlerer Keuper } \\
\text { Zechstein }\end{array}$ & & $\begin{array}{l}5,0-5,5 \\
5,0-7,0\end{array}$ \\
\hline & $\begin{array}{l}\text { Gentiano-Koelerietum boreoatlanticum, } \\
\text { Subass. von S. decumbens }\end{array}$ & $\begin{array}{l}\text { Göttingen, } \\
\text { Göttinger Wald }\end{array}$ & $\begin{array}{l}\text { Mittlerer Muschelkalk } \\
\text { Oberer Muschelkalk }\end{array}$ & tiefgründig, frisch, Lössauflage & $5,0-5,5$ \\
\hline $\begin{array}{l}\text { Korneck } \\
1960\end{array}$ & $\begin{array}{l}\text { Mesobrometum collinum } \\
\text { agrostidetosum tenuis }\end{array}$ & $\begin{array}{l}\text { Südhessen, } \\
\text { Übersicht }\end{array}$ & & $\begin{array}{l}\text { basenarme schieferige } \\
\text { Verwitterungsböden }\end{array}$ & - \\
\hline $\begin{array}{l}\text { Bornkamm } \\
\text { \& Eber } 1967\end{array}$ & $\begin{array}{l}\text { Euphorbio-Brachypodietum, } \\
\text { Subass. von S. decumbens, typ. Variante } \\
\text { Subass. von S. decumbens, Trifolium-V. }\end{array}$ & $\begin{array}{l}\text { LK Göttingen, } \\
\text { Groß-Schneen } \\
\text { Groß-Schneen }\end{array}$ & Keuper & & $\begin{array}{l}4,6 \\
5,2\end{array}$ \\
\hline Ruthsatz 1970 & $\begin{array}{l}\text { Gentiano-Koelerietum, } \\
\text { Subass. von S. decumbens }\end{array}$ & $\begin{array}{l}\text { Göttingen, } \\
\text { Göttinger Wald }\end{array}$ & Muschelkalk & $\begin{array}{l}\text { entkalkte, tiefgründige Böden } \\
\text { (Parabraunerde?) }\end{array}$ & - \\
\hline $\begin{array}{l}\text { von der Heide } \\
1984\end{array}$ & $\begin{array}{l}\text { Gentiano-Koelerietum boreoatlanticum, } \\
\text { Prunella-Var., Subvar. v. D. decumbens }\end{array}$ & $\begin{array}{l}\text { LK Werra-Meißner, } \\
\text { Witzenhausen }\end{array}$ & Zechstein & tiefgründige Braunerde-Rendzina & $5,0-5,6$ \\
\hline $\begin{array}{l}\text { Hofmeister } \\
1984\end{array}$ & Gentiano-Koelerietum danthonietosum & $\begin{array}{l}\text { Mittelleine-Innerste- } \\
\text { Bergland }\end{array}$ & Trias, Kreide, Jura & $\begin{array}{l}\text { lößbedeckt, relativ tiefgründig, } \\
\text { oberflächlich versauert }\end{array}$ & $4,8-5,8$ \\
\hline
\end{tabular}

* S(ieglingia) decumbens (L.) BERNH. synonym D(anthonia) decumbens (L.) DC 
Tabelle 28 (Fortsetzung): Übersicht pflanzensoziologischer Bearbeitungen zum Auftreten von acidophilen/calcifugen Pflanzenarten in Kalk-Halbtrockenrasen.

\begin{tabular}{|c|c|c|c|c|c|}
\hline Autoren & Nomenklatur & $\begin{array}{l}\text { Untersuchungs- } \\
\text { Gebiet }\end{array}$ & $\begin{array}{l}\text { Geologie/ } \\
\text { Ausgangsgestein }\end{array}$ & $\begin{array}{l}\text { Boden/Boden- } \\
\text { Charakteristika }\end{array}$ & pH \\
\hline $\begin{array}{l}\text { Lauterbach } \\
1984\end{array}$ & $\begin{array}{l}\text { Halbtrockenrasen mit } C \text {. vulgaris } \\
\text { und } D \text {. decumbens }\end{array}$ & $\begin{array}{l}\text { LK Kassel, } \\
\text { Unteres Diemeltal }\end{array}$ & Unterer Muschelkalk & Lössauflage & - \\
\hline $\begin{array}{l}\text { Rohde } \\
1984\end{array}$ & $\begin{array}{l}\text { Gentiano-Koelerietum prunelletosum, } \\
\text { Variante von } D \text {. decumbens }\end{array}$ & $\begin{array}{l}\text { LK Northeim, } \\
\text { Weper }\end{array}$ & Unterer Muschelkalk & Braunerde-Terra fusca, Lösseintrag & $5,4-5,7$ \\
\hline $\begin{array}{l}\text { Brinkoch \& } \\
\text { Jork } 1985\end{array}$ & Gentiano-Koelerietum danthonietosum & $\begin{array}{l}\text { LK Hildesheim, Dunsen } \\
\text { LK Northeim, Ahrendshs. }\end{array}$ & $\begin{array}{l}\text { Oberer Muschelkalk } \\
\text { Unterer Muschelkalk }\end{array}$ & Rendzina-Braunerde & $6,2-7,1$ \\
\hline $\begin{array}{l}\text { Bergmeier } \\
1987\end{array}$ & Gentiano-Koelerietum agrostietosum & $\begin{array}{l}\text { Lahn-Dill-Kreis, } \\
\text { Niederlemp }\end{array}$ & $\begin{array}{l}\text { Unteres Karbon } \\
\text { Diabas, Tonschiefer }\end{array}$ & Braunerde & - \\
\hline $\begin{array}{l}\text { Geringhoff \& } \\
\text { Daniels } 1994\end{array}$ & Gentiano-Koelerietum agrostietosum & $\begin{array}{l}\text { Sauerland, } \\
\text { Briloner Hochfläche }\end{array}$ & $\begin{array}{l}\text { Oberes, Unteres } \\
\text { Devon, Massenkalke }\end{array}$ & $\begin{array}{l}\text { Lehmdecke aus pleistozänem Löss } \\
\text { und cenomanem Mergel }\end{array}$ & $6,6-7,4$ \\
\hline Bultmann 1993 & $\begin{array}{l}\text { Gentiano-Koelerietum trisetetosum, } \\
\text { Typische-Var., D. decumbens-Subvar. } \\
\text { Parnassia-Var., D. decumbens-Subvar. }\end{array}$ & $\begin{array}{l}\text { LK Kassel, } \\
\text { Unteres Diemeltal }\end{array}$ & $\begin{array}{l}\text { Unterer und Mittlerer } \\
\text { Muschelkalk, Röt }\end{array}$ & $\begin{array}{l}\text { Renzina, Braunerde-Terra fusca } \\
\text { Kalk-Braunerde, Para-Rendzina }\end{array}$ & $\begin{array}{l}5,8-7,5 \\
6,5-7,7\end{array}$ \\
\hline Ihl 1994 & $\begin{array}{l}\text { Gentiano-Koelerietum, } \\
\text { D. decumbens-Variante }\end{array}$ & $\begin{array}{l}\text { Göttingen, } \\
\text { Gartetal }\end{array}$ & Mittlerer Buntsandstein & $\begin{array}{l}\text { Braunerde-Ranker, } \\
\text { flachgründige Braunerden }\end{array}$ & $5,3-7,0$ \\
\hline Becker 1996 & $\begin{array}{l}\text { Gentiano-Koelerietum, } \\
\text { Agrostis tenuis-Variante }\end{array}$ & $\begin{array}{l}\text { LK Nordhausen, } \\
\text { Rüdigsdorf }\end{array}$ & Zechstein (G) & Mull-Rendzina & $4,8-5,2$ \\
\hline Bartram 1997 & $\begin{array}{l}\text { Gentiano-Koelerietum trisetetosum, } \\
\text { Variante von } D \text {. decumbens }\end{array}$ & $\begin{array}{l}\text { Nördliches Sollingvorland, } \\
\text { Ith-Hils-Bergland }\end{array}$ & $\begin{array}{l}\text { Oberer Muschelkalk } \\
\text { Oberer Jura }\end{array}$ & flachgründige Braunerden & $6,4-7,4$ \\
\hline Jandt 1999 & $\begin{array}{l}\text { Gentiano-Koelerietum, } \\
\text { Variante von } D \text {. decumbens }\end{array}$ & $\begin{array}{l}\text { Südharzrand, Kyffhäuser, } \\
\text { Übersicht }\end{array}$ & $\begin{array}{l}\text { Zechstein } \\
\text { (G2, zm1, zm2, G1), }\end{array}$ & $\begin{array}{l}\text { Rendzina (?), } \\
\text { Braunerde-Rendzina (?) }\end{array}$ & $5,0-7,9$ \\
\hline
\end{tabular}




\subsubsection{Synökologie der Subassoziationen des Gentiano-Koelerietum im Unteren Diemeltal und am Südharzrand}

Die Clusteranalyse der Vegetationsaufnahmen verdeutlicht die floristischen Unterschiede der beiden Vegetationsbestände des Standort Steinkirche, aber auch des Bestands Pagenberg-CF zu den Kalk-Halbtrockenrasen im Unteren Diemeltal (Abbildung 13, S. 43). Tabelle 29 führt getrennt nach Untersuchungsräumen und Vegetationseinheiten die bereits in Abschnitt 3.1 (S. 42) für die einzelnen Versuchstandorte dargestellten Zeigerwerte nach Ellenberg (1996) auf. Die mittleren Kontinentalitätszahlen lassen mit Werten von 3,8 für die Untersuchungsflächen am Südharzrand und 3,7 für die Kalkmagerrasen im Unteren Diemeltal nur geringe Unterschiede in der Verteilung (sub)ozeanischer und (sub)kontinentaler Florenelemente erkennen. Zwar stehen diese Werte ebenso in Übereinstimmung mit der thermischen und hygrothermischen Kontinentalität wie die mittleren Feuchtezahlen mit den mittleren jährlichen Niederschlagsmengen (vgl. Abschnitt 2.1.1, S. 14 f.), doch übersteigen die Abweichungen zwischen den CCund CF-Vergleichsbeständen z. T. erheblich die Unterschiede zwischen den Untersuchungsräumen. In gleicher Weise geben auch die meisten anderen Zeigerwerte keine Hinweise auf grundsätzliche Unterschiede in der Verteilung ökologischer Physiotypen zwischen den Versuchstandorten im Unteren Diemeltal und am Südharzrand. Vielmehr betonen sie Unterschiede zwischen den Subassoziationen des Gentiano-Koelerietum.

Die Ursachen für die isolierte Stellung der Vegetationsaufnahmen vom Standort Steinkirche und des Bestands Pagenberg-CF in der Clusteranalyse liegen möglicherweise auch in den abweichenden Artenzahlen begründet. Eine höhere Alpha-Diversität, wie diese von mehreren der in Tabelle 28 aufgeführten Autoren für das Gentiano-Koelerietum danthonietosum beschrieben wird, lässt sich nur für die Untersuchungsflächen am Südharzrand belegen. Im Unteren Diemeltal unterscheiden sich die beiden Subassoziationen in dieser Hinsicht nicht voneinander. Mit verantwortlich für die floristischen Unterschiede sind wohl edaphische Faktoren, die auf unterschiedliche Ausgangsmaterialien der Bodenbildung - hier Muschelkalk aus der Trias, dort dolomitisches Material aus dem Zechstein - zurückgehen. Auf die weit reichende Übereinstimmung der pflanzensoziologisch (Tabelle 4) und clusteranalytisch-numerisch (Abbildung 13) erfassten Differentialartengruppen wurde bereits in Abschnitt 3.1 (S. 42 ff.) eingegangen.

Tabelle 29: Artenzahlen und mittlere Zeigerwerte nach Ellenberg et al. (1992) in Abhängigkeit vom Bestandstyp und Untersuchungsraum (vgl. Tabelle 5, S. 46). Abbildung A 1 (S. 312) zeigt ergänzend die Zeigerwertspektren der betreffenden CC- und CF-Bestände.

\begin{tabular}{lcccccccc}
\hline & \multicolumn{2}{c}{ Unteres Diemeltal } & \multicolumn{2}{c}{ Südharzrand } & \multicolumn{2}{c}{ Pool } \\
& MW & CC & CF & MW & CC & CF & CC & CF \\
\hline Anzahl Arten & 38 & 38 & $>37$ & 42 & $35<50$ & $36<43$ \\
Licht-Zahl & 7,3 & 7,3 & $>7,2$ & 7,3 & $7,3=7,3$ & $7,3>7,2$ \\
Temperatur-Zahl & 5,3 & $5,3>5,2$ & 5,3 & $5,5>5,1$ & $5,4>5,1$ \\
Kontinent.-Zahl & 3,7 & $3,7<3,8$ & 3,8 & $3,7<3,9$ & $3,7<3,8$ \\
Feuchte-Zahl & 3,9 & $3,9<4,0$ & 4,0 & $3,8<4,2$ & $3,8<4,1$ \\
Reaktions-Zahl & 6,2 & $6,5>6,0$ & 6,6 & $6,8>6,5$ & $6,6>6,2$ \\
Stickstoff-Zahl & 2,7 & $2,5<2,8$ & 2,6 & $2,5<2,7$ & $2,5<2,8$ \\
\hline
\end{tabular}


Sowohl die pflanzensoziologischen als auch die numerischen und standortökologischen Auswertungen des Aufnahmenmaterials lassen eine Zuordnung aller untersuchten CC-Bestände in eine typische Subassoziation des Gentiano-Koelerietum und der CF-Bestände in eine Subassoziation von D. decumbens gerechtfertigt und für die Diskussion der weiter führenden Untersuchungen sinnvoll erscheinen. Die Verhältnisse der mittleren Reaktionszahlen der CC- und CF-Beständen geben Hinweise darauf, dass niedrigere pH-Werte bzw. geringere Kalkgehalte der Böden des Gentiano-Koelerietum danthonietosum die Etablierung säureliebender/kalkmeidender Arten erlauben, während höhere Feuchte- und Reaktionszahlen derselben Standorte auf Bodenbedingungen hinweisen, die das Wachstum mesophiler Arten in KalkHalbtrockenrasen fördern.

Die mittleren Zeigerwerte eines Vegetationsbestands dienen einer ersten integrativen Beschreibung des Standorts. Bei ihrer Interpretation ist zu berücksichtigen, dass die zugrundeliegenden artspezifischen Zeigerwerte auf der Verbreitung der Arten unter dem komplexen Gefüge aller Wirkungsfaktoren am natürlichen Standort und der daraus resultierenden interspezifische Konkurrenz, basieren (Ellenberg et al. 1992). Nur selten gehen die Zeigerwerte auf Messungen der betreffenden Parameter zurück. Mit ihrer ordinalen Skalierung besitzen sie v.a. heuristischen und orientierenden Wert. Die Herstellung einer Beziehung zwischen der durch die ökologischen Zeigewerte dargestellten Standortpräferenz und der (öko)physiologischen Konstitution einer Art birgt die Gefahr einer Redundanz und ist auch daher mit Vorbehalt zu betrachten.

\subsubsection{Autökologie ausgewählter Arten des Gentiano-Koelerietum danthonietosum}

Häufig lassen sich in der Literatur voneinander abweichende Beschreibungen des natürlichen Wuchsorts oder der ökophysiologischen Konstitution ein- und derselben Art finden. Auf die Bedeutung geographisch-klimatischer und edaphischer Interaktionen wurde bereits in Abschnitt 4.1 (S. 106 ff.) eingegangen. Beispielsweise zeigen Calluna vulgaris und Danthonia decumbens im trockenen Südosten Englands eine acidophile/calcifuge Verbreitung, während sie in Gebieten mit extremen Niederschlagsneigungen auch auf basenreichen Böden auftreten (Perring 1960). Vermutlich aus diesem Grund wächst $C$. vulgaris auch auf den Faröer-Inseln verbreitet an basenreichen Standorten (Lawesson et al. 2003).

Divergierende Standortbeschreibungen von Arten haben hfg. einen systemaren Hintergrund. Während bei der Beschreibung von Vikarianten auf Artebene deren unterschiedlichen Eigenschaften besonders betont werden, können bei geringen morphologischen Unterschieden und einer weiten Verbreitung Gruppen vergleichsweise eigenständiger Genotypen und ihre physiologischen Unterschiede unerkannt bleiben. Schwierig ist daher insbesondere auch der Nachweis von Ökotypen, Sippen einer Art, die eine ererbte Anpassung an bestimmte klimatische oder edaphische Verhältnisse zeigen (Turesson 1922,1925). Die genotypische Heterogenität innerhalb eines Artkonstrukts kann so weit reichen, dass trotz einer geringen Plastizität auf Individualebene die Art insgesamt als standörtlich indifferent betrachtet wird. Folglich kann die Ausweisung indifferenter Taxa darauf zurückzuführen sein, dass (1) auf Individualebene eine besonders weit reichende physiologische Plastizität oder (2) im Konstrukt eine große genotypische Heterogenität vorliegt.

Unter diesen Gesichtspunkten vermindert die zusammenfassende ökologische Betrachtung aller floristischen Elemente in Form mittlerer Zeigerwerte die Gefahr, Abweichungen einzelner Arten von ihrer üblichen Verbreitung als Grundlage für eine insgesamt unzutreffenden Bewertung der standörtlichen und vegetationskundlichen Gegebenheiten zu nehmen. 


\section{Calluna vulgaris}

Von den Differentialarten des Gentiano-Koelerietum danthonietosum zeigt Calluna vulgaris die stärkste acidophile Bindung. Neben ihrer Einstufung als Starksäurezeigerin (R 1), ist für sie eine ozeanisch-subozeanischer Verbreitung (K3) auf den stickstoffärmsten Böden (N1) lichter Standorte (L 8) kennzeichnend (Ellenberg et al. 1992). Mevius (1931) und Hope Simpson (1938) betrachten sie übereinstimmend als chemoedaphisch determinierte Calcifuge. Gimingham (1960) beschreibt sie als oligotrophe, calcifuge Art, die in Großbritannien auf Sand, Kies, verwitterten Böden verschiedener Ausgangsgesteine und v. a. auf organischen Substraten wächst. Für die Rekonstruktion von Calluna-Heiden in Bereichen, die zuvor intensiv landwirtschaftlich genutzt wurden, wird Bodenversauerung als Voraussetzung angesehen. Optimales Wachstum konnte hier im Bereich zwischen pH 3-4 beobachtet werden (Davy et al. 1998; Dunsford et al. 1998). An anderer Stelle wird C. vulgaris als acidophil-basitolerante Art beschrieben, deren pH-Optimum zwar bei niedrigen pH-Werten liegt, die aber auch bei neutraler bis basischer Bodenreaktion wachsen kann (Ellenberg 1958). Grime (1963b) bestätigt, dass ein niedriger Boden-pH und ein hoher Rohhumus-Gehalt nicht notwendig sind und hinter die Bedeutung der Konkurrenz durch anspruchsvollere Arten zurücktritt. Im Rahmen von Untersuchungen zum Wachstum von drei calcicolen und fünf acidophilen Ericaceen in gesiebtem Bodenmaterial der oberen $10 \mathrm{~cm}$ eines sauren Gleys (pH 4,1), einer sauren Braunerde (pH 5,7) und eines Kalkbodens (pH 6,9) erreichte C. vulgaris zwar im carbonatreichen Boden durchschnittlich nur 76 \% der Biomasse der beiden anderen Varianten (Marrs \& Bannister 1978b), doch wird auch von Calluna-Wachstum in Böden sehr hoher pH-Werte, etwa an trockenen Hängen nördlich von Lübeck bei pH 8,5 (Raabe 1960; zitiert in Ellenberg 1996), berichtet.

Aufschluss über die physiologische Konstitution der Art geben detaillierte Untersuchungen zum Einfluss variierender $\mathrm{Ca}^{2+}$-Konzentrationen $(0,2-12 \mathrm{mM})$ und Protonenaktivitäten (pH3-7) auf das Pflanzenwachstum und die Aufnahme essentieller Mineralstoffe (Grothus 1986). Demnach liegen für Calluna vulgaris in $1: 5$ verdünnten SHIVE-Nährlösungen, die mit entsprechenden Mikronährstoffen supplementiert und auf pH 3,8 eingestellt wurden, bei 0,4 mM optimale und bereits bei 1,0 mM supraoptimale $\mathrm{Ca}^{2+}$ Konzentrationen vor. Im Gegensatz dazu zeigten Calcicole, wie Geum urbanum oder Origanum vulgare, über den gesamten Konzentrationsbereich einen Anstieg der Biomasse. C. vulgaris wies, ähnlich anderen calcifugen Arten, wie Galium harcynicum oder Avenella flexuosa, unter entsprechenden Kulturbedingungen nur geringe Unterschiede des Trockengewichtszuwachs zwischen pH3,5-5,0 auf (Kiehne 1986). Signifikant höhere Spross- und Wurzelgewichte sind für pH 3,0 belegt. Die deutliche Hemmung des Wachstums folgte in diesen Untersuchungen der Erhöhung des Nährlösungs-pH auf 7,0. Alle zehn untersuchten calcicolen und calcifugen Arten entwickelten zwischen pH 7,0-8,0 Chlorosen - bei Applikation von $50 \mu \mathrm{M} \mathrm{FeCl}_{3}$ ein Hinweis darauf, dass eine weit reichende Ausfällung von Fe-Hydroxiden erfolgte. Kennzeichnend ist in diesem Zusammenhang, dass in Übereinstimmung mit den Ausführungen zum Chloroseparadoxon in Abschnitt 4.3.5 (S. 132) trotz ausgeprägter Chlorophylldefekte die Fe-Konzentrationen im Blattgewebe vielfach stark erhöht waren. Dies gilt insbesondere für die calcifugen Arten, deren Wachstumsretardationen bei hohen $\mathrm{pH}$-Werten offensichtlich mit einer Aufkonzentrierung verschiedener Mineralstoffe im Spross einhergingen. Eine entsprechende negative Korrelation zwischen Trockengewichtszuwachs und Fe-Konzentration findet sich aber auch für die untersuchten calcicolen Arten, deren Wachstum in den meisten Fällen trotz Ausbildung von Chlorosen nur wenig beeinträchtigt wurde.

Während Grime (1963b) keine Hinweise auf die Existenz einer ökotypischen Differenzierung von Calluna-Populationen saurer und basischer Standorte finden konnte, lassen transplant-Experimente von Marrs \& Bannister (1978b) die Existenz edaphischer Ökotypen unterschiedlicher Schwermetalltoleranzen 
vermuten. Allerdings sind die von diesen Autoren vorgestellten Untersuchungen vor dem Hintergrund zu bewerten, dass das Untersuchungsmaterial hier im Verhältnis 1:1 mit einem Torf-Sand-Gemisch versetzt und damit die ursprünglichen Bodeneigenschaften erheblich verändert wurden.

\section{Danthonia decumbens}

Mevius (1931) beschreibt Danthonia decumbens als kalkmeidend. Ellenberg et al. (1992) werten die Art als Säurezeigerin (R3). Neben einer Vielzahl weiterer Arbeiten, die die acidophile/calcifuge Standortpräferenz betonen, werden aber auch abweichende Verbreitungsmuster beschrieben. Etwa $40 \%$ der Danthonia-Populationen treten in Südengland an Standorten mit pH > 5,5 auf (Etherington 1981). Havill et al. (1974) haben im Rahmen ihrer Untersuchungen zur Nitratreduktase (NR)-Aktivität von Arten saurer und kalkreicher Böden D. decumbens in unmittelbarer Nachbarschaft sowohl bei pH 3,9 als auch pH 6,9 vorgefunden. Bruelheide (1991) konnte in seinen Untersuchungen des Gentiano-Koelerietum keine abweichenden pH-Werte in der Rhizosphäre von D. decumbens nachweisen. Jefferies \& Willis (1964a, 1964b) betrachten die Art hinsichtlich ihres Verhaltens gegenüber der Bodenreaktion und dem Kalkgehalt als indifferent und verweisen auf weite Amplituden der standörtlichen Protonenaktivitäten (pH3,2-7,3) und der Ca-Gehalte (1,1-293 mg $\cdot \mathrm{kg}^{-1}$ bezogen auf Ammoniumacetat-Extrakte). In Sandkultur toleriert $D$. decumbens Ca-Konzentrationen, wie sie in Kalkböden auftreten. Zugleich wurden von diesen Autoren keine Unterschiede zwischen Populationen kalkfreier und kalkreicher Standorte gefunden (Jefferies \& Willis 1964a). Hinweise darauf, dass andere Faktoren als die Bodenreaktion und der Kalkgehalt für das Verbreitungsmuster der Art verantwortlich zeichnen, gibt auch Grime (1963b). D. decumbens konnte er bei pH6,5-7,1 nur auf Mullrendzinen, nicht aber auf jüngeren, vergleichsweise trockenen Rendzinen vorfinden. Als Gründe für das Auftreten acidophiler Arten über kalkreichen Ausgangsgesteinen nennt er neben einer erhöhten Gründigkeit und oberflächigen Verwitterung der Böden höhere Tongehalte und verminderte Diffusionsraten. Es handelt sich hierbei um Standorteigenschaften, die zugleich eine bessere FeLöslichkeit nach sich ziehen. Hinweise von Jefferies \& Willis (1964a) auf eine ausgesprochene Chloroseanfälligkeit von D. decumbens werden von Hutchinson (1967a) bestätigt. Letzterer konnte eine Beeinträchtigung der Chlorophyllbiosynthese und des Wurzelwachstums der Art bei Kultivierung in Bodenmaterial sowohl einer flachgründigen Protorendzina als auch einer kalkreichen Braunerde (brown calcareous soil) nachweisen.

Ein Aspekt, der in all diesen Arbeiten unberücksichtigt bleibt, ist die mittlerweile fundierte Differenzierung der Art in zwei vikariierende Subspezies (Wisskirchen \& Häupler 1998). Die beiden Unterarten $D$. decumbens ssp. decumbens und $D$. decumbens ssp. decipiens lassen sich morphologisch kaum unterscheiden (Hegi 1998). Die Beobachtung, dass D. decumbens durchaus nicht nur auf sauren, kalkarmen Böden, sondern auch auf kalkreichen und trockenen Böden und hier v. a. in Gesellschaften der FestucoBrometea auftritt, veranlasste Schwarz \& Bässler (1964) zu genaueren Untersuchungen und zur Abtrennung der Unterart D. decumbens ssp. decipiens. Die Differenzierung der beiden Subspezies geht auf Vegetationsanalysen im Thüringer Muschelkalkgebiet zurück. Hier konnten die Autoren mit vier Aufnahmen das Auftreten von Danthonia decumbens auf einem leicht geneigten Hang südlicher Exposition bei Bodenreaktionen von pH 7,4-7,8 und an weniger feuchten bis recht trockenen Stellen zusammen mit calcicolen und indifferenten Arten belegen. In weiter führenden Untersuchungen wurden für Individuen saurer, kalkarmer und basischer/kalkreicher Standorte die in Tabelle 30 dargestellten Eigenschaften hinsichtlich ihrer geographischen und standörtlichen Verbreitung sowie ihrer Morphologie und Cytologie gefunden. 
Tabelle 30: Standörtliche, morphologische und cytologische Charakteristika der Subspezies von Danthonia decumbens (L.) LAMK. et DC. Synthese nach Arbeiten von Schwarz \& Bässler (1964), Löve \& Löve (1975) und Wisskirchen \& Häupler (1998).

\begin{tabular}{|c|c|c|}
\hline & D. decumbens ssp. decumbens & $\begin{array}{l}\text { D. decumbens ssp. decipiens } \\
\text { O. SCHWARZ \& BÄSSLER ex BÄSSLER }\end{array}$ \\
\hline \multicolumn{3}{|l|}{ Verbreitung/Standort } \\
\hline geographisch & $\begin{array}{l}\text { in fast ganz Europa, im Süden nur im } \\
\text { Gebirge, Nordafrika; eingebürgert in Kanada, } \\
\text { Neufundland bis Neuschottland, } \\
\text { Nordinsel Neuseelands }\end{array}$ & $\begin{array}{l}\text { noch unzureichend untersucht; } \\
\text { wahrscheinlich v. a. mediterran (Balkan!), } \\
\text { aber auch im alpinen Zentraleuropa, } \\
\text { Kaukasus, Kleinasien, Großbritannien, Irland }\end{array}$ \\
\hline phytosoziologisch & $\begin{array}{l}\text { in Nardo-Callunetea, Mesobromion- und } \\
\text { Molinion-Gesellschaften saurer Böden }\end{array}$ & $\begin{array}{l}\text { v. a. im Mesobrometum und } \\
\text { Gentiano-Koelerietum }\end{array}$ \\
\hline edaphisch & $\begin{array}{l}\text { nährstoffarm, basenarm, entkalkt, sauer, } \\
\text { modrig-torfig, humusreich }\end{array}$ & kalkreich \\
\hline Bestandswuchs & horstbildend & lockerrasig \\
\hline Wuchshöhe & $10-30(40) \mathrm{cm}$ & $30-50 \mathrm{~cm}$ \\
\hline Halmphänologie & gedrungen, kräftig & schlank, zierlich \\
\hline Zwischennerven & $2-4$ & $4-6$ \\
\hline Gelenkzellen & $5-7$ & $7-9$ \\
\hline Ploidie & hexaploid & tetraploid \\
\hline Chromosomen (2 n) & 36 & 24 \\
\hline
\end{tabular}

Besonders zuverlässige Unterscheidungsmerkmale der beiden Unterarten sind ihre Chromosomenzahlen und die Anzahl der Gelenkzellen ihrer Blätter. Bei der intraspezifischen Differenzierung von D. decumbens handelt es sich um den seltenen Fall, dass eine Änderung des Ploidiegrads bei Blütenpflanzen mit weit reichenden ökologischen und soziologischen Veränderungen einhergeht. Hexaploidie der einen und Tetraploidie der anderen Unterart sind Grundlage einer außerordentlich wirksamen Kreuzungsschranke. Die pentaploide $f_{1}$-Generation kann keine normale Meiose durchlaufen und sollte daher hochgradig steril sein (Schwarz \& Bässler 1964). Hieraus ergeben sich bisher ungenutzte Möglichkeiten für gezielte ökologische, ökophysiologische, aber auch biochemische und molekulargenetische Untersuchungen innerhalb des Calcicolen/Calcifugen-Komplexes.

Trotz der deutlichen cytologischen und ökologischen Trennung der beiden Gruppen konnten sich übrigens Löve \& Löve (1975) nicht mit ihrer Forderung durchsetzen, der basiphilen/calcicolen Vikariante eigenen Artrang zuzuordnen. Wahrscheinlich handelt es sich bei der tetraploiden Danthonia decumbens ssp. decipiens um den ursprünglichen, bei der hexaploiden D. decumbens ssp. decumbens um den abgeleiteten Typus. Diese Interpretation soll auch durch das synökologische Verhalten der beiden Unterarten gestützt werden: D. decumbens ssp. decumbens folgt in Übereinstimmung mit ihrer Verbreitung der Tischler-Regel, nach der die Zahl polyploider Sippen in Europa von Süden nach Norden zunimmt. Zunehmende Ploidie geht nach dieser Theorie mit einem ausgeprägten Pionierverhalten und vegetationsgeschichtlich daher mit einer effizienteren postglazialen Invasion eisfrei werdender Gebiete einher. Auch heute noch zeigt diese Unterart angeblich die Tendenz, offene Bodenstellen besonders schnell zu besiedeln, während die Subspezies D. decumbens decipiens in stabilen Komplexen eingefasst sein soll.

\section{Potentilla erecta}

Wie von Tüxen (1928) und Bornkamm (1960) wird Potentilla erecta auch in britischen Arbeiten zur Calcicolen/Calcifugen-Thematik zumeist als Acidophile/Calcifuge beschrieben (Grubb et al. 1969). Nach 
Grime \& Hodgson (1969) soll sie ihren Verbreitungsschwerpunkt in Böden mit pH 4-6 besitzen und sich durch eine ausgesprochene Chloroseanfälligkeit bei der Kultivierung auf Rendzinen mit moderatem Chlorose-Potenzial auszeichnen. Auf der anderen Seite sind die Zuordnungen der Zeigerwerte nach Ellenberg et al. (1992) in guter Übereinstimmung mit den Standortbeschreibungen von Hegi (1923) und Hess et al. (1970). Demnach verhält sich P. erecta nicht nur gegenüber der Bodenfeuchte und der Temperatur, sondern auch gegenüber der Bodenreaktion und dem Kalkgehalt indifferent (Tx - F x - R x). Grundsätzlich wird aber ihre Verbreitung auf nährstoffarmen Böden betont (N2).

Neben den Kalk-Halbtrockenrasen wurden im Rahmen der vorliegenden Arbeit auch andere Standorte von Potentilla erecta bodenkundlich untersucht. Populationen eines niedrigwüchsigen Rasens auf trockenem Sandboden sowie solche von einem bodenfeuchten, dichtwüchsigen Wegrand eines offenbar gekalkten Walds über Buntsandstein bestätigen die weite Amplitude, die P. erecta hinsichtlich der Bodenfeuchte und Bodenreaktion toleriert. Bei $\mathrm{CaCO}_{3}$-Gehalten von 0,1-5,1\% (m/m) wurden hier Protonenaktivitäten von pH 4,1-7,7 gemessen. Die Analysen der Böden ergaben außerdem, dass die wasserlöslichen und DTPA-extrahierbaren Fe-Gehalte des Sandbodens mit Werten von $85 \mathrm{nmol} \cdot \mathrm{g}^{-1}$ und 3,6 $\mu \mathrm{mol} \cdot \mathrm{g}^{-1}$ diejenigen des Waldbodens um mehr als das Fünffache übersteigen. Während die kristalline Fraktion des Dithionit-extrahierbaren Fe an den beiden Standorten keine Abweichung zeigte, lagen die Gehalte des organisch gebundenen Fe im Boden des Waldrands mit $24 \mu \mathrm{mol} \cdot \mathrm{g}^{-1}$ mehr als zehnfach über denen des Sandbodens.

Hegi (1923) führt zwölf verschiedene Formen bzw. Varietäten von P. erecta auf. Hiermit ist sie die am meisten euryözische und häufigste Art der Gattung Potentilla in Mitteleuropa. Ökotypische Differenzierungen sind daher nicht unwahrscheinlich. Allerdings konnten beispielsweise für Populationen von flachgründigen Hang- und tiefgründigen Plateaulagen über einem kalkreichen Ausgangsgestein durch die wechselseitige Kultur in Bodenmaterial, dass auf $10 \mathrm{~mm}$ gesiebt wurde, keinerlei Hinweise auf entsprechende Standortanpassungen gefunden werden (Grime 1963b). Unterschiedliche Häufigkeiten und Größen der Individuen in den Populationen waren offensichtlich allein auf edaphische Faktoren zurückzuführen. Bis heute liegen keine experimentell fundierten Hinweise auf intraspezifische Adaptationen für die Besiedlung von Kalkböden vor. Im Hinblick auf die Induktion der Nitratreduktase bei der Spross- und Wurzelapplikation von $\mathrm{NO}_{3}{ }^{-}$verhält sich P. erecta nicht anders als calcicole Arten (Havill et al. 1974).

\section{Zusammenfassung}

Unter dem Gesichtspunkt der weit reichenden Plastizitäten und/oder intraspezifischen Differenzierungen der Trennarten des Gentiano-Koelerietum danthonietosum ist auch die erste von zwei floristischen Auffälligkeiten der eigenen vegetationskundlichen Untersuchungen zu bewerten. Am Standort Steinkirche erreicht Danthonia decumbens nicht nur im Gentiano-Koelerietum danthonietosum einen hohen Deckungsgrad, sondern mit 5-25 \% auch im Gentiano-Koelerietum typicum. Vergleichende mikroskopische Untersuchungen der Chromosomen und Gelenkzellen von Individuen der Population des Standorts Hölleberg und solcher eines Borstgrasrasen zeigen, dass eine ökotypische Differenzierung der Art auch im Hinblick auf die hier behandelte Frage nach den Ursachen der Vegetationsdifferenzierung des GentianoKoelerietum relevant sein kann (vgl. Abbildung A 6, S. 315).

Bemerkenswert ist die hohe Abundanz von Potentilla erecta in den beiden CF-Beständen am Südharzrand. Demgegenüber lässt sich die Art in den Untersuchungsflächen des Unteren Diemeltal nur am Hangfuß des Höllebergs und damit möglicherweise im Übergangsbereich zwischen dem Unteren Muschelkalk und Röt finden. 


\subsection{Allgemeine standortökologische Aspekte des Auftretens acidophiler/calcifuger Arten in Kalk-Halbtrockenrasen}

Die Untersuchungen des Auftretens acidophiler/calcifuger Arten in Rasengesellschaften über kalkreichen Ausgangsgesteinen besitzen in Großbritannien seit jeher einen ausgeprägt kausalökologischen Bezug. Untersucht wurde hier auch die Genese von Boden/Vegetations-Komplexen mit spezifischen räumlichen Mustern des gemeinsamen Wachstums basiphiler/calcicoler und acidophiler/calcifuger Spezies.

\subsubsection{Geologisch-geographische, edaphische und zeitliche Muster der Etablierung acidophiler/calcifuger Arten in Kalk-Halbtrockenrasen}

Abbildung 62 illustriert Untersuchungen von Balme (1953) zur Vegetationszonierung hangorientierter Transekte über karbonischem Kalkgestein in Derbyshire (Nordwestengland). Unter dem kühl-humiden Klima wird hier die Bodenbildung wesentlich durch die Topographie des Standorts bestimmt. Ausgehend von stark geneigten Bereichen mit flachgründigen, nicht konsolidierten Rendzinen und typischen KalkHalbtrockenrasen am Hangfuß entwickeln sich mit abnehmender Hangneigung und als Folge zunehmender Verwitterung oberflächig versauerte Rendzinen, Braunerden und schließlich tiefgrüdige podsolierende Braunerden, die charakteristische Rasen- oder Heidegesellschaften der Nardo-Callunetea aufweisen.

Die Vegetation des Abschnitts II in Abbildung 62, in der v.a. in lokal tiefgründigeren Bereichen erste acidophile/calcifuge Arten auftreten, ist mit dem Gentiano-Koelerietum danthonietosum vergleichbar. Die in der vegetationskundlichen Literatur angeführten Beobachtungen, nach denen bestimmte Bodenbedingungen für das gemeinsame Auftreten von säureliebenden/kalkmeidenden und basenliebenden/kalksteten Arten verantwortlich sind, werden hier bestätigt. Als Gründe für das Auftreten Acidophiler/Calcifuger in Kalk-Halbtrockenrasen sind demnach eine erhöhte Bodengründigkeit und eine Abnahme des pH-Werts bzw. des Kalkgehalts im Oberboden anzusehen.

Die Bodenentwicklung und die Vegetationsdifferenzierung der betreffenden Standorte ist eine Funktion verschiedener Faktoren. Im Laufe der Bodenentwicklung wurde die Mächtigkeit des Solums durch Lössaufträge erhöht und damit der pH des Oberbodens erniedrigt (Etherington 1981). Mulden, Löcher oder Risse erlauben eine Anreicherung von Feinerdematerial, geringe Inklination vermindert die Erosionsgefahr und erlaubt eine Stabilisierung des Bodens. Kühl-humides Klima beschleunigt den Verwitterungsprozess und damit die Bodenversauerung. Mit abnehmender Temperatur wird vermehrt $\mathrm{CO}_{2}$ und damit zusätzliches $\mathrm{CaCO}_{3}$ gelöst. Weiterhin beeinflusst die Exposition des Standorts zusammen mit der Hauptwindrichtung die Niederschlagswirkung und Evapotranspiration und darüber Umfang und Geschwindigkeit der Verwitterungsprozesse (Balme 1953). Klimatische und topographische Faktoren können also auch durch ihren Einfluss auf den Boden vegetationsdifferenzierend wirken (Perring 1960). Beispielsweise entwickeln sich im extrem humiden Klima Nordwestirlands bei $1400 \mathrm{~mm}$ Niederschlag direkt über karbonischem Kalkgestein saure Moorböden und auf diesen Calluna-Heiden (Webb 1947). Demgegenüber ist in Abwesenheit von Lössschichten trotz der deutlich höheren Löslichkeit des Ausgangsmaterials die Heidebildung über Kreidegestein in dem trockeneren Klima Süd- und Ostenglands die Ausnahme. Eine komplette Abfolge der räumlichen und zeitlichen Entwicklung des Vegetations-Boden-Komplexes, einer sog. Catena, wie sie in Abbildung 62 beispielhaft für den Übergang von halbtrockenen Magerrasen hin zu sauren Heide- oder Rasengesellschaften dargestellt ist, kann in der Regel nur dort beobachtet werden, wo weder zu trockene noch zu feuchte Klimabedingungen vorherrschen (Balme 1953). 


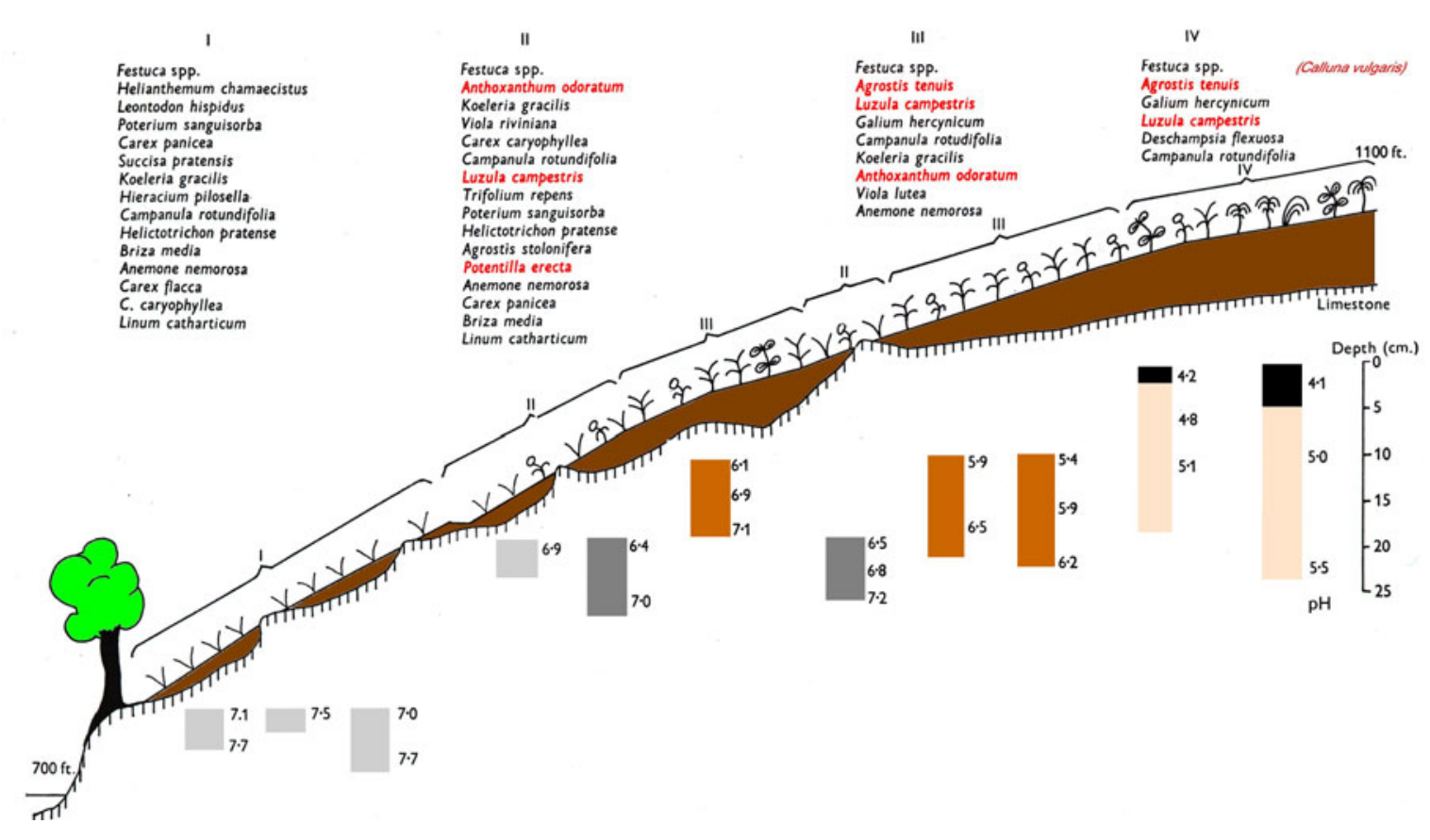

Abbildung 62: Vegetationszonierung entlang eines hangparallelen Transektes in Abhängigkeit von der Bodenbildung über karbonischem Kalkstein (kalkreiche Rendzina $\rightarrow$ oberflächig versauerte Rendzina $\rightarrow$ Braunerde $\rightarrow$ podsolierende Braunerden). Aufgeführt sind Arten mit einer Präsenz $>50 \%$, rot markierte differenzieren die Subassoziation von D. decumbens innerhalb des Gentiano-Koelerietum (verändert nach Balme 1953).

Angesichts des in Plateau- und wenig geneigten Hanglagen verbreiteten Auftretens von Löss, ist davon auszugehen, dass auch in den Untersuchungsflächen in Derbyshire die Ausbildung unterschiedlicher Bodentypen nicht allein eine Folge der fortschreitenden Verwitterung des carbonatreichen Ausgangsgesteins ist (Pigott 1962, Grime 1963a).

Die beiden Schlüsselfaktoren Bodengründigkeit und Bodenreaktion beeinflussen eine Reihe weiterer Bodenparameter, die ihrerseits auf die Pflanzen einwirken. Tiefere Bodengründigkeit führt zu einer besseren Wasserversorgung und reduziert die Gefahr von Schädigungen der Pflanzen durch sommerliche Bodentrocknis (Ratcliffe 1961; Grime 1963a). Letztere kann in sehr flachgründigen Böden zugleich die N-Mineralisation und damit die N-Verfügbarkeit, aber auch die von P, Fe und anderen Elementen beeinträchtigen (Scheffer \& Schachtschabel 1992). Mit zunehmender Bodentiefe und/oder abnehmenden Skelettgehalten wird zudem die Nährstoffverfügbarkeit pro Einheit investierten Wurzelmaterials erhöht. Wie bereits Untersuchungen von Lohmeyer (1953) andeuteten, ist eine höhere Bodengründigkeit aber nicht die Voraussetzung für die Etablierung säurezeigender/kalkmeidender Arten in Halbtrockenrasen.

Nicht in allen Fällen ist eine mit fortschreitender Bodenverwitterung einhergehende Invasion acidophiler/calcifuger Arten in bestehende Kalkmagerrasen Ursache für das gemeinsame Auftreten mit Basiphilen/Calcicolen. Etherington (1981) führte an Standorten in Süd- und Südwestengland sowie Wales standortökologische Untersuchungen von speziellen Heideformationen über verschiedenen $\mathrm{CaCO}_{3}$-reichen Ausgangsgesteinen durch. Er unterscheidet zwei Arten sog. Kalkheiden ('calcareous heath'):

- 'Limestone heath' auf flachgründigen $(<10 \mathrm{~cm})$, steilen $\left(>20^{\circ}\right)$ v. a. karbonischen (oder devonischen) Kalkhängen mit weitgehend abgetragenen periglazialen Lössauflagen und einer Bodenreaktion von pH 6-7 im Oberboden

- 'Chalk heath' in Plateau- und flachen Hanglagen über Kreideformationen mit pH 5-6 im Oberboden. 
Ganz offensichtlich sind die Verwitterungseigenschaften der kalkreichen Ausgangsgesteine zusammen mit Lössaufträgen und der Nutzungsgeschichte für die Vegetationsdifferenzierung dieser Standorte verantwortlich. Etherington erklärt das vegetationskundliche Muster von limestone heath damit, dass der Lösungsrückstand des karbonischen (oder devonischen) Ausgangsgesteins eine vergleichsweise hohe Bodenstabilität bedingt, die nach Brandrodung der ursprünglichen Agrosto-Ulicetum-Gesellschaft einen nur begrenzten Abtrag des verwitterten, lössreichen Bodens von den steilen Hängen erlaubt. Während sich hier Acidophile/Calcifuge der alten Pflanzengesellschaft reliktisch erhalten haben, dringen in stärker durch das Ausgangsgestein beeinflusste offene Bereiche Basiphile/Calcicole vor. Beweidung mit daraus resultierenden Tritteffekten fördert demnach die Etablierung kalksteter Arten. Zu den acidophilen/calcifugen Arten, die sich nach Brandrohdung durch Wiederaustreiben von Rhizomen oder Stolonen verjüngen, gehören u. a. Calluna vulgaris und Potentilla erecta. In Plateaulage verhindern tiefgründige Lössschichten das Wachstum von basiphilen/calcicolen Arten. Hier findet man heute anstelle der Gesellschaften der Nardo-Callunetea zumeist landwirtschaftlich genutzte Flächen. Typische Kalk-HalbtrockenrasenGesellschaften ('semi arid calcareous grasslands'), die keine Acidophile/Calcifuge aufweisen, sind über karbonischem und devonischem Kalkgestein auf Gebiete ohne periglaziale Lössaufträge beschränkt.

Im Gegensatz zum Hanggefüge harter, schlecht löslicher Kalkgesteine ist jenes von gut löslichen und weichen Kreideformationen so instabil, dass immer wieder das $\mathrm{CaCO}_{3}$-reiche Ausgangsgestein zu Tage tritt. Die daraus resultierenden Bodeneigenschaften verhindern das Wachstum acidophiler/calcifuger Arten. Der Oberboden dieser 'chalk grasslands' weist wie derjenige von 'limestone grasslands' über Kalkgestein pH-Werte zwischen 7,7-8,2 auf. Typische Kalkmagerrasen können sich über Kreide also auch in Lössgebieten entwickeln. Etherington (1981) lässt allerdings die Frage offen, warum auf nur schwach geneigten Hängen und in Plateaulagen über Kreidegestein Basiphile/Calcicole nicht vollständig verdrängt werden und hier die oben beschriebenen 'chalk heaths' vorzufinden sind. Möglicherweise bleibt in flachgründigeren Bereichen der Einfluss des $\mathrm{CaCO}_{3}$-reichen Ausgangsgesteins erhalten.

Es können viele weitere Faktoren angeführt werden, die die Bodengenese und damit das Vegetationsmuster über kalkreichen Ausgangsgesteinen beeinflussen, darunter nicht zuletzt auch biotische, wie z. B. die Aktivität von Regenwürmern, die kalkreiches Material vertikal verlagern, oder die Wirkung der Streu von Pflanzen wie Calluna vulgaris, die durch hohe Phenolgehalte und ein erhebliches Ansäuerungspotenzial die Bodenverwitterung beschleunigen (Grubb \& Suter 1971, Jarvis 1974; Jarvis \& Duncan 1976).

\subsubsection{Topographische und physikoedaphische Faktoren der Etablierung acidophiler/calcifuger Arten in Kalk-Halbtrockenrasen}

Die standörtliche Differenzierung, wie sie in der Literatur für die verschiedenen Halbtrockenrasen über Kalkgesteinen beschrieben wird, entspricht in vielen Punkten den Ergebnissen der eigenen Untersuchungen (Tabelle 5, S. 46). CC-Bestände finden sich mit Ausnahme des Standorts Flohrberg auf stärker geneigten Hängen. Außer auf dem Pagenberg sind sie flachgründiger und in allen Fällen weist ihr Oberboden erheblich höhere $\mathrm{CaCO}_{3}$-Gehalte als die jeweiligen Vergleichsbestände auf. ${ }^{1}$ Hinweise auf

\footnotetext{
1 Die in Tabelle 5 (S. 41 ) angegebenen Carbonatgehalte wurden unter der Annahme berechnet, dass sie quantitativ auf $\mathrm{CaCO}_{3}$ zurückgehen. Daraus können bei den Böden dolomitischen Ausgangsgesteins am Südharzrand Werte resultieren, die um etwa $10 \%$ über den tatsächlichen Gehalten liegen. Die rechnerischen Carbonatanteile beider Bestände des Standorts Steinkirche sind außergewöhnlich hoch. Mit $\mathrm{CO}_{3}{ }^{2-}$-Gehalten von etwa 6,5\% $(\mathrm{m} / \mathrm{m})$ für den CF- und $50 \%$ für den CC-Bestand stimmen diese zwar gut mit den von Jandt (1999) für dieselben Rasen ermittelten Werte von 4,7\% bzw. 51 \% überein, doch überschreiten die daraus abzuleitenden $C_{i}$ die von $C_{t}$ der C/N-Analytik. Interferenzen der Analyse durch Sulfid, wie sie Steubing \& Fangmeier (1992) in
} 
bevorzugte Hangexpositionen, wie sie auch für das Untere Diemeltal und den Südharzrand beschrieben werden (Bultmann 1993; Jandt 1999), existieren für die eigenen Untersuchungsflächen aber nicht.

Die Korngrößenverteilungen in Abbildung 15 lassen keine grundsätzlichen Unterschiede zwischen den Bodenarten der CC- und CF-Bestände erkennen. Schluffanteile der Feinerde von über $70 \%$, wie sie mit Ausnahme des Bestands Steinkirche-CC in den Böden aller anderen Kalk-Halbtrockenrasen gefunden wurden, verweisen auf Lösseinträge. Hinweise von Etherington (1981), aber auch Geringhoff (1992) und anderen Autoren der in Tabelle 28 aufgeführten Arbeiten, nach denen das Auftreten von Acidophilen/Calcifugen auf höhere Löss- und Tonanteile im Boden zurückzuführen ist, bestätigen die eigenen Untersuchungen aber nicht. Der Boden des Gentiano-Koelerietum typicum am Standort Steinkirche weist als Verwitterungsmaterial des dolomitischen Ausgangsgesteins einen deutlich erhöhten Feinsandanteil auf (Möbus 1966). Bei Gründigkeiten von mehr als $40 \mathrm{~cm}$ findet sich hier im Oberboden beider Vergleichsbestände kein Skelettmaterial. Demgegenüber enthalten die oberen $10 \mathrm{~cm}$ der Böden der anderen Untersuchungsflächen z. T. erhebliche Anteile des Ausgangsgesteins. Soweit in den CF-Beständen Skelettmaterial vorgefunden wurde, lassen Geröll und kleine Mengen Kies mit ihren abgerundeten Ecken und Kanten auf eine fortgeschrittene Bodenverwitterung schließen. Wie die Untersuchungen der Standorte Auf der Burg und Hölleberg belegen, unterschreiten die Skelettanteile der CF-Bestände erheblich die der CCBestände (Abbildung 18, S. 50). In letzteren bilden scharfkantige Steine und Grus die Skelettfraktion des Oberbodens. In den CC- und CF-Beständen der Referenzstandorte korrelieren zudem die Skelettgehalte und Bodengründigkeiten.

Trotz der allenfalls geringfügig voneinander abweichenden Schluff- und Tongehalte ihrer Feinerde lassen sich für die Referenzstandorte Auf der Burg und Hölleberg deutliche Hinweise auf unterschiedliche Durchlüftungs- und Dränungseigenschaften der beiden Subassoziationen finden. Höhere volumenbezogene Wassergehalte, höhere Feinerde-Lagerungsdichten und niedrigere hydraulische Leitfähigkeiten verweisen auf geringere Diffusionsraten und eine schlechtere Durchlüftung der Böden des Gentiano-Koelerietum danthonietosum (Abbildung 18, S. 50; Abbildung 20, S. 55). Diese Eigenschaften beeinflussen v. a. die Redoxreaktionen im Boden.

Insbesondere die Differenzialartengruppe der typischen Subassoziation umfasst Arten, die als heliophil und xerophil gelten. So finden sich in D1 der pflanzensoziologischen Tabelle bzw. im Artencluster der Gemeinschaftsanalyse nach Sørensen (1948) mit dem Moos Hypnum cupressiforme var. lacunosum und dem Wundklee Anthyllis vulneraria Arten, die durch hohe Lichtzahlen (L 8) und niedrige Feuchtezahlen (F 2 bzw. F 3) nach Ellenberg et al. (1992) gekennzeichnet sind (Tabelle 4, S. 43; Abbildung 14, S. 45). Nach Untersuchungen von Bornkamm (1958) besitzt v. a. A. vulneraria einen sehr stabilen Wasserhaushalt. Von den zehn Arten des Gentiano-Koelerietum, die im Rahmen seiner Studie behandelt wurden, darunter die Klassenkennarten der Festuco-Brometea Brachypodium pinnatum und Pimpinella saxifraga, sowie die Brometalia-Kennarten Bromus erectus, Scabiosa columbaria und Helictotrichon pratense, weist A. vulneraria die niedrigsten maximalen Transpirationsraten auf. Neben der recht engen Regulation der Transpiration ist das umfangreiche und tief reichende Wurzelsystem dafür verantwortlich, dass die Art nur geringe Tagesschwankungen des Wassersättigungsdefizits und ungeachtet ihres vergleichsweise niedrigen subletalen Wassersättigungsdefizits um 60 \% sehr selten Trocknisschädigungen erfährt.

Betracht ziehen, sind als Fehlerquelle auszuschließen. Unzureichend erscheint auch ein Rückschluss auf temperaturbedingte Volumenexpansion im Reaktionsgefäß infolge exothermer Lösung großer Mengen von Carbonat durch den Zusatz von $\mathrm{HCl}$. Die Gründe dieser Inkonsistenzen müssen daher, wie bei Jandt (1999), offen bleiben. 
In der Differentialartengruppe D 2 der pflanzensoziologischen Tabelle und im entsprechenden Cluster der numerischen Analyse sind außer Acidophilen/Calcifugen, wie Calluna vulgaris und Pleurozium schreberi, auch mesophile Arten, wie Trifolium repens oder Achillea millefolium, vertreten. Neben C. vulgaris verhalten sich mit Danthonia decumbens oder Agrostis tenuis weitere Arten, die von vielen Autoren als acidophil/calcifug betrachtet werden (z. B. Mevius 1931; Ellenberg et al. 1992), im Hinblick auf die Bodenfeuchte ihrer Standorte indifferent. Andererseits verweist das Auftreten von Vertretern dieser Konstitutionsgruppe auf sehr carbonatreichen, basischen Standorten zusammen mit typischen Feuchtezeigern, wie z. B. Parnassia palustris im Bestand Steinkirche-CF, auf einen Bezug zum Wasserhaushalt der Böden. In aller Regel wachsen acidophile/calcifuge Arten nicht auf carbonatreichen/basischen Böden, wenn diese sehr trocken sind. Hohe Niederschlagsneigungen und geringe Evapotranspirationen kennzeichnen die Standorte von Calluna vulgaris über kalkreichen Ausgangsgesteinen, wie beispielsweise im schottischen Hochland (McVean \& Ratcliffe 1962) und im Nordwesten Irlands (Webb 1947).

Der Wasserhaushalt der Böden ist für den Keimungserfolg der Art von ausschlaggebender Bedeutung. Hingegen soll ihre Keimrate bei ausreichender Bodenfeuchte weitgehend unabhängig von den bodenchemischen Eigenschaften des Standorts sein. Auch die Überlebensrate wird durch den Wasserhaushalt des Bodens beeinflusst (Bannister 1964a). Für die Austrocknungsempfindlichkeit der Art zeichnet die besonders kleine Radikula der Sämlinge verantwortlich (Ellenberg 1996). Insgesamt ist aber die Etablierung eine Funktion sowohl des Wasserhaushalts als auch der bodenchemischen Eigenschaften. In situ soll sie in Mineralböden größer als in organischen Substraten sein (Watt 1955). Hinweise darauf, dass der Wasserhaushalt des Standorts für adulte Pflanzen eine eher mittelbare Bedeutung hat, gibt die weite Amplitude der Bodenfeuchten, die von C. vulgaris toleriert wird. Hintergrund ist hier nicht eine besonders schnelle und enge stomatäre Regulation oder eine besonders geringe kutikuläre Transpiration, sondern eine ausgeprägte Toleranz gegenüber hohen Wassersättigungsdefiziten (Bannister 1964b). Dennoch sind Populationen trockener Standorte ökotypisch dahingehend differenziert, dass ihre Stomata bereits bei geringeren Sättigungsdefiziten schließen als die von Pflanzen bodenfeuchter oder bodennasser Herkunft (Bannister 1964c). Besonders hohe Wassersättigungsdefizite acidophiler/calcifuger Arten, darunter C. vulgaris, Potentilla erecta, Galium saxatile, Vaccinium myrtillus und Nardus stricta, während extremer Trockenperioden haben auch Buckland et al. (1997) für Rasengesellschaften über karbonischem Kalkgestein in Nordengland nachgewiesen.

Untersuchungen zum Fe-Mobilisierungsvermögen wässriger Spross- und Blattextrakte von Calluna sollen die Präferenz der Art für trockene Standorte bestätigen (Fisher \& Yam 1984). Das besonders hohe FeLösungsvermögen der Extrakte von Pflanzen nasser Standorte führen die Autoren auf eine stressstimulierte Synthese von Polyphenolen zurück. Dementsprechend handelt es sich hierbei um eine Reaktion, die gerade nicht im Kontext mit einer regulativen Erhöhung der Fe-Mobilisierungseffizienz gesehen werden darf. Das Vermögen der Art, über Auswaschungen des Sprossmaterials und der Streu die Bodenacidität und damit die Konzentration Fe-mobilisierender Verbindungen zu erhöhen, ist aber durchaus im Zusammenhang mit dem Auftreten von C. vulgaris auf basischen, kalkreichen Böden zu sehen (Gimingham 1960; Grubb et al. 1969; Jarvis \& Duncan 1976). Dieser Aspekt soll in Abschnitt 5.37 (S. 182 ff.) zusammen mit den pH-Werten der im Rahmen der vorliegenden Arbeit untersuchten Vegetationsbestände diskutiert werden. Höhere Wasserverfügbarkeiten und geringerer Trockenstress allein können das Phänomen des Eindringens von Calcifugen/Acidophilen in Kalkmagerrasen nicht erklären (Grime 1963b).

Abweichend von der Vegetationstabelle ordnet die Clusteranalyse Arten mit Präferenzen für feuchtere und/oder nährstoffreichere Böden, darunter Holcus lanatus und Prunella vulgaris sowie die Moose 
Rhytidiadelphus squarrosus und Calliergonella cuspidata, einer eigenen Gruppe zu (Abbildung 14, S. 45). Die Ursachen für diese Vergesellschaftung können nicht eindeutig benannt werden, lassen sich aber in einer spezifischen Kombination bodenchemischer Eigenschaften, möglicherweise hohen pHWerten bei guter Wasserverfügbarkeit, vermuten.

\subsection{Chemoedaphische und autökologische Aspekte des Auftretens acidophiler/calcifuger Arten in Kalk-Halbtrockenrasen}

Die für die Vegetation relevanten Bodeneigenschaften sind das Produkt eines komplexen Wirkungsgefüges physikalischer, chemischer und biologischer Faktoren. Es kann davon ausgegangen werden, dass v. a. chemoedaphische Faktoren und die darauf abgestimmten autökologischen Eigenschaften der Pflanzen für die Differenzierung des Gentiano-Koelerietum verantwortlich sind. Darauf deuten auch die verbreiteten Wurzelstratifikationen basiphiler/calcicoler und acidophiler/calcifuger Arten hin. In Mischbeständen vergleichsweise flachgründiger Standorte über kalkreichen Ausgangsgesteinen durchwurzeln Acidophile/ Calcifuge häufig v.a. den kalkarmen, versauerten Oberboden, Basiphile/Calcicole den basenreichen Unterboden. Dieses Phänomen wurde bereits Anfang des 20. Jahrhunderts beschrieben (Tansley \& Rankin 1911), in der Folge von verschiedenen Autoren betont (Balme 1953; Jarvis 1974), von anderen als nicht notwendig erachtet (Grime \& Hodgson 1969; Etherington 1981) und schließlich für manche Untersuchungsstandorte widerlegt (Grubb et al. 1969). Wurzelstratifikationen sind demnach verbreitet, aber für die Vertreter der verschiedenen Konstitutionstypen nicht obligatorisch. Grime (1963b) verweist darauf, dass einige besonders tief wurzelnde Calcicole, wie Sanguisorba minor oder Koeleria macrantha gerade im Übergangsbereich zwischen flachgründigen Böden in Hanglage und tiefgründigen Böden in Plateaulage ein besonders vitales Wachstum zeigen. Es wird angenommen, dass die Pflanzen hier ihren Mineralstoffbedarf je nach Verfügbarkeit der betreffenden Nährstoffe sowohl aus alkalischen, basenreichen als auch aus sauren, basenarmen Bodenschichten decken. Die Analysenergebnisse der vorliegenden Arbeit bilden mit wenigen Ausnahmen nur die durchschnittlichen Verhältnisse in den oberen zehn Zentimetern der Böden ab, d. h. es wurden in der Regel keine weiteren horizontalen Differenzierungen vorgenommen.

\subsubsection{Operationale und konzeptionelle Definition von Bodenlösungen}

Im Mittelpunkt der Untersuchungen standen mineralstoffökologische Aspekte. Für die Ernährung und mögliche Intoxikationen der Pflanzen ist letztlich die Bodenlösung ausschlaggebend. Deren in experimentellen Untersuchungen ermittelte Zusammensetzung hängt nicht nur von den Bodeneigenschaften, sondern, wie nachfolgend dargestellt, v. a. auch von der Art ihrer Herstellung ab.

Unter dem Begriff der Bodenlösung i.w. S. werden sowohl das Bodenwasser bei aktueller Feuchte des Bodenmaterials in situ (Bodenlösung i. e. S., aktuelle Bodenlösung) als auch Extrakte des Bodens gefasst, deren Gewinnung mit einer Supplementierung und Vermischung des Bodenwassers einhergehen. Die Zusammensetzung der Bodenlösungen kann v. a. durch folgende Faktoren beeinflusst werden:

- Probennahme und Probenaufbereitung - Aufrechterhaltung oder Aufhebung der natürlichen

Bodenstruktur,Verwendung feldfrischer oder getrockneter Bodenproben

- Art und Dauer der Lagerung des Probenmaterial

- Art und Umfang der Supplementierung der Bodenlösung

- Extraktionsdauer

- Verfahren zur Trennung der Bodenlösung und der Bodenmatrix. 


\section{Probennahme, Probenaufbereitung und Probenlagerung}

Die Zusammensetzung von Bodenlösungen i. e. S. und Bodenextrakten wird bereits durch die Probennahme, die Probenaufbereitung sowie die Art und Dauer der Lagerung des Bodenmaterials beeinflusst. Ein ausschlaggebender Faktor ist die Struktur des Untersuchungsmaterials. Bodenmonolithe erlauben die Lösungsgewinnung aus mehr oder weniger definierten Bodenporen. Die Homogenisation von Bodenproben hingegen geht mit der Aufhebung des Bodengefüges und der "Öffnung" des Meso- und Mikroporensystems einher. Massenflüsse, die für die Verlagerung vieler Nährstoffe zur Wurzel ausschlaggebend sind, erfolgen in erster Linie durch die Makroporen und weiten Mesoporen (vgl. Tabelle 31, S. 163). Bodenlösungen und Bodenextrakte, die aus Bodenhomogenaten gewonnen werden, umfassen demnach also auch Fraktionen, die in situ einem nur langsamen Austausch entlang von Diffusionsgradienten unterliegen und daher für die Pflanzen eine untergeordnete Rolle spielen.

In vielen Fällen können Bodenproben nicht unmittelbar nach ihrer Entnahme am Standort weiterbehandelt werden. Die Art der Vorbehandlung und Lagerung des Probenmaterials kann die Ergebnisse der Bodenuntersuchungen entscheidend beeinflussen. Bei einem Boden/Lösungs-Verhältnis von 1:2 und einer eintägigen Gleichgewichtseinstellung führte die Trocknung und das Sieben einer Parabraunerde zu Konzentrationsanstiegen von $\mathrm{NH}_{4}{ }^{+}$(Faktor 60), K (Faktor 11), Mn (Faktor 5), $\mathrm{K}$ und Ca (Faktor 3), Mg, $\mathrm{Al}$ und Fe (Faktor 2) (Ludwig et al. 1999). Vierfach höhere DOC-Konzentrationen sind nach Ansicht der Autoren auf die Zersetzung von Bodenorganismen und die Desorption organischer Komponenten vom Tonmineraliensystem infolge des Trocknungsprozesses zurückzuführen. Mit der Lagerungsdauer nimmt die mikrobiologische Aktivität von getrocknetem Bodenmaterial nach dessen Wiederanfeuchtung zu (Edmeades et al. 1985; Campbell et al. 1989; Song \& McComb 1996).

Ähnliche Artefakte resultieren aus dem Einfrieren von feldfrischem Bodenmaterial (Walworth 1992). Auch die Lagerung von Bodenproben im Kühlschrank führt zu Konzentrationsänderungen von Verbindungen, die einer schnellen biologischen Umsetzung unterliegen, darunter solchen pflanzlicher Nährelemente. Innerhalb eines Tags können beispielsweise bei $5{ }^{\circ} \mathrm{C}$ die Nitratkonzentrationen in der Lösung feldfrischer Böden deutlich ansteigen (Edmeades et al. 1985).

\section{Verfahren zur Gewinnung von in situ-Bodenlösungen}

\section{Lysimetrie}

Die Lysimetrie umfasst in erster Linie Verfahren, die der Gewinnung von Lösungen sowohl des Inter- als auch des Intraaggregatporensystems bei aktuellen Bodenwassergehalten im Gelände dienen (Wolt 1994). Als Lysimeter werden aber nicht nur Bodenwassersammler bezeichnet, die wie Ebermayer-Lysimeter unterhalb großer ungestörter Bodenbereiche oder wie Tensionslysimeter punktuell im Freiland installiert werden, sondern auch solche, die wie Einfülllysimeter unter Aufhebung der natürlichen Bodenstruktur im Labor zum Einsatz kommen. Litaor (1988) gibt einen Überblick über die verschiedenen Typen sowie die Vor- und Nachteile dieser soil solution sampler.

Die weiteste Verbreitung bei der Untersuchung mineralstoffökologischer Fragestellungen besitzen Tensionslysimeter, bei deren Verwendung mit Hilfe einer porösen Saugkerze und einer Unterdruckeinheit ein Wasserpotenzialgefälle zum Bodenporensystem aufgebaut wird. Um eine weitgehend ungestörte und natürliche Bodenstruktur zu gewährleisten und Kontaminationen durch das Lysimetermaterial zu minimieren, müssen die Saugkerzen frühzeitig installiert werden. Gleichzeitig können aber gerichtete Wasserund Stoffflüsse mittel- bis langfristig die strukturellen und chemischen Bodenbedingungen im Bereich der 
Tensionslysimeter verändern (Schmidt 1992). Selektive Sorptionsreaktionen des Lysimetermaterials sind dafür verantwortlich, dass insbesondere die Phosphat- und Nitratgehalte der Bodenlösung beeinträchtigt werden (Hansen \& Harris 1975; Schlinkert 1992). Für die Gewinnung von Lysimeterlösungen sind häufig lange Probennahmezeiträume erforderlich. Diese erhöhen die Gefahr, dass bei entsprechenden Witterungsbedingungen v. a. die nicht repräsentative Lösung dränender Bodenporen gewonnen wird und Lagerungseffekte die Lösungszusammensetzung beeinflussen (Ludwig et al. 1999). Die auch als Folge fluktuierender Bodenfeuchten unzureichende Möglichkeit, die Bedingungen zum Zeitpunkt der Lösungsgewinnung exakt zu benennen, ist ein wesentlicher Nachteil bei der Verwendung von Tensionslysimetern. In grobstrukturierten, skelettreichen Böden ist zudem deren funktionsgerechte Installation häufig nicht möglich. Unterdrucksysteme, die im Gelände zum Einsatz kommen, bauen in der Regel nur vergleichsweise geringe Saugspannungen $(<-100 \mathrm{kPa})$ auf (Campbell et al. 1989). Tensionslysimeter sind aus diesen Gründen für die Dokumentation jahreszeitlicher Entwicklungen ungeeignet. Sie wurden daher für die Untersuchung der z. T. sehr skelettreichen und temporär sehr trockenen Böden der vorliegenden Arbeit untersuchten Kalk-Halbtrockenrasen nicht eingesetzt.

\section{Verdrängungs- und Zentrifugationsverfahren}

Verdrängungsmethoden erlauben die Gewinnung der Bodenlösung feldfrischer Feinerdehomogenate. Beim miscible column displacement erfolgt der Austausch der Bodenlösung in hohen Glaszylindern durch hydrophile Lösungen, beispielsweise $\mathrm{CaSO}_{4}$-Lösungen mit Kaliumthiocyanat. Häufig wird die Verdrängungsfront durch $\mathrm{FeCl}_{2} \cdot \mathrm{HCl}$, das unter Oxidation mit Thiocyanat einen intensiv roten Farbkomplex bildet, nachgewiesen (Adams et al. 1980). Nachteile dieses Verfahrens sind, dass es große Probenmengen erfordert und bei gleichzeitig recht hohem Versuchsaufwand einen nur geringen Probendurchsatz erlaubt.

Beim sog. immisciple displacement erfolgt die Gewinnung der aktuellen Bodenlösung unter Einsatz von apolaren, organischen Lösungsmitteln, wie Tetrachlorkohlenstoff (Mubarak \& Olsen 1976), 1,1,2-Trichlor-1,2,2-trifluorethan (Dahlgren 1993) oder Perfluorkohlenwasserstoffen (Gollany et al. 1997). Von Nachteil sind hier nicht nur die hohen Kosten und die aufwändige Entsorgung des behandelten Bodenmaterials, sondern auch die Lösung organischer Verbindungen.

Prinzipiell erlauben Verdrängungsmethoden unter Atmosphärendruck eine effektive Bodenlösungsgewinnung erst bei Bodenwassergehalten nahe der Wasserkapazität $\left(\Psi_{\mathrm{w}} \cong 33 \mathrm{kPa}\right)$. Verschiedene Systeme umfassen daher apparative Einrichtungen zum Aufbau von Unter- oder Überdrücken. Bei der highpressure immiscible displacement-Methode nach Whelan \& Barrow (1980) wird mittels Zentrifugation ein Druck von mehr als $1 \mathrm{MPa}$ aufgebaut und die aktuelle Bodenlösung durch einen Überschuss organischer Lösungen hoher Dichte nach oben verlagert, wo sie abpipettiert werden kann. Dahlgren (1993) beschreibt ein solches Verfahren mit Beschleunigungen von 20000 . g, die unter den gegebenen Versuchsbedingungen einem Druck von mehr als 8,4 MPa entsprachen.

Bei geringen Bodenfeuchten und den daraus resultierenden sehr niedrigen Wasserpotenzialen sind für die Gewinnung der aktuellen Bodenlösung in der Regel Hochgeschwindigkeitszentrifugationen erforderlich. Die bei dieser Methodik einzusetzenden Zentrifugenröhrchen weisen in ihrem unteren Bereich eine poröse Platte und ein Reservoir für die Bodenlösung auf (Mubarak \& Olsen 1976; Adams et al. 1980). Wie bei allen Verfahren, die auf dem Aufbau sehr hoher Drücke oder Unterdrücke basieren, ergeben sich hier nicht nur Probleme durch die Verschiebung der Lösungsgleichgewichte, sondern auch durch die Zerstörung tierischer, pflanzlicher und mikrobieller Zellen und Gewebe. Diese führen zu Kontaminationen und zu Verfälschungen der realen Zusammensetzung der Bodenlösung (Ludwig et al. 1999). 


\section{Bodenextrakte}

Grundsätzlich zielen die bis hierher beschriebenen Verfahren auf die Gewinnung von Lösungen ab, die denen der Böden in situ weitestgehend entsprechen. Häufig verhindert aber bereits der große apparative Aufwand ihren Einsatz bei dem für die Bearbeitung ökologischer Fragestellungen in der Regel notwendigen großen Probenumfang. Zudem sinkt in Trockenperioden das Wasserpotenzial vieler Böden soweit ab, dass selbst durch Hochgeschwindigkeitszentrifugationen keine ausreichenden Volumina der aktuellen Bodenlösung gewonnen werden können (Campbell et al. 1989; Karathanasis 1991). Ein weiterer Nachteil ist, dass in der Regel bei der Anwendung dieser Methoden die natürliche Bodenstruktur zerstört wird. Da mögliche saisonale Variabilitäten der Nährstoffverfügbarkeiten und der Einfluss des Bodengefüges auf die Zusammensetzung der Bodenlösungen berücksichtigt werden sollten, kamen im Rahmen der vorliegenden Arbeit Methoden zur Anwendung, die eine $\mathrm{H}_{2} \mathrm{O}$-Supplementierung gestörter bzw. ungestörter Bodenproben erfordern.

\section{Wasserextrakte}

Grundsätzlich wird bei Bodenlösungen, die nach Aufsättigung des Probenmaterials mit $\mathrm{H}_{2} \mathrm{O}$ gewonnen werden, zwischen sog. Sättigungsextrakten und Wasserextrakten i. e. S. unterschieden. Von Sättigungsextrakten spricht man, wenn, wie z. B. bei der Herstellung der Gleichgewichtsbodenlösung nach Meiwes et al. (1984), das Lösungs/Boden-Verhältnis eng $(<0,8)$ und die Zeitdauer der Bodenextraktion vergleichsweise lang (24 h) ist. Im Gegensatz dazu sollen Wasserextrakte i. e. S. nicht das chemische Gleichgewicht sondern die Zusammensetzung der Bodenlösung zum Zeitpunkt der Probennahme widerspiegeln. Hierfür werden die Konzentrationen der Analysenlösung auf die initiale Bodenfeuchte und das Volumen des zugesetzten Wasser bezogen.

Ein zentrales Problem aller Aufsättigungsverfahren ist, dass Reaktionen, die die Zusammensetzung der Bodenextrakte bestimmen, in unterschiedlichem Umfang und in nicht kalkulierbarer Weise durch die Verdünnung der aktuellen Bodenlösung beeinflusst werden können. Hierzu gehören beispielsweise die Lösung von Salzen und der Austausch oder die Sorption von Ionen an der Bodenmatrix. Bereits Burgess (1922) hat für wässrige Bodenextrakte sandiger Lehmböden (nach Aufsättigung des Bodens mit Wasser im Verhältnis 1:5) im Vergleich zu Überdrucklösungen aus Böden mit aktuellem Wassergehalt durchweg höhere trockengewichtsbezogene Mineralstoffkonzentrationen nachgewiesen. Die Nitratkonzentrationen sind hier am wenigsten (Faktor 1,4-1,8), diejenigen des Phosphats am stärksten (Faktor 20-71) vom Extraktionsverfahren abhängig. Böden mit relativ hoher Pufferkapazität sollen aber bei kurzen Einwirkungszeiten des zugesetzten Wassers die Gewinnung von Bodenlösungen erlauben, die die Verhältnisse der in situ-Bodenlösung verlässlich widerspiegeln (Hoagland et al. 1920). Dieser Umstand wurde der Konzeption der DBL in den eigenen Untersuchungen zugrunde gelegt. Um unterschiedliche Verdünnungseffekte soweit wie möglich auszuschließen, wurde sowohl für die beiden Sättigungsextrakte (GBL, PBL) als auch für die Druck-Wasserextrakte (DBL) die Einstellung einheitlicher Feinerdetrockengewicht/ Lösung-Verhältnisse von $1: 2$ angestrebt.

\section{Charakterisierung von Bodengefüge und Bodenporen}

Das Gefüge und die Textur des Bodens sind nicht nur für die pflanzliche Wasseraufnahme, sondern aufgrund der lokal variierenden Stoffzusammensetzung verschiedener Bereiche der Bodenfestphase und der mit dieser entlang von elektrochemischen Potenzialdifferenzen im Austausch stehenden Bodenlösung auch für die pflanzliche Mineralstoffernährung von zentraler Bedeutung. Unter Annahme einer ausrei- 
chenden Gefügestabilität lassen sich den Bodenporen mit Hilfe der nachfolgenden Gleichung für den Wassertransport idealer Kapillaren sog. Äquivalenzdurchmesser zuordnen (Kuntze et al. 1994):

$$
d=\frac{4 \gamma_{\mathrm{H}_{2} \mathrm{O}} \cdot \cos \alpha}{h \cdot \rho_{\mathrm{H}_{2} \mathrm{O}} \cdot g}=\frac{0,297 \mathrm{~cm}}{h}
$$

d Kapillardurchmesser [m]

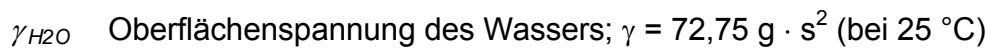

$\alpha \quad$ Benetzungswinkel; unter Annahme von $\alpha=90^{\circ} \rightarrow \cos \alpha=1$

$h \quad$ Aufstiegshöhe des Wassers, Saugspannung [m WS]

$\rho_{\mathrm{H} 2 \mathrm{O}}$ Wasserdichte; $\rho_{\mathrm{H} 2 \mathrm{O}}=1,0 \mathrm{~g} \cdot \mathrm{cm}^{-3}$

$g \quad$ Erdbeschleunigung; $\mathrm{g}=9,81 \mathrm{~m} \cdot \mathrm{s}^{-2}$

In Anlehnung an wichtige bodenkundliche Parameter des Wasserhaushalts, wie nutzbare Feldkapazität (nFK), permanenter Welkepunkt (PWP) oder Dränungseigenschaften, können die Bodenporen klassifiziert werden. Die Einteilungen der Porenklassen variieren je nach Autor. Während beispielsweise die Tabelle 31 den Vorschlägen von F. Sekera und M. de Boodt folgend bereits Bodenporen mit Äquivalenzdurchmessern von mehr als $10 \mu \mathrm{m}$ den Grobporen zuordnet (Scheffer \& Schachtschabel 1992; Kuntze et al. 1994), definiert Luxmoore (1981) diese bis zu einer Größe von $10 \mathrm{~mm}$ (ab $1 \mathrm{~mm}$ in Klasseneinheit mit den macropores) als mesopores.

Tabelle 31: Charakteristika und Funktionen der Bodenporenklassen nach F. Sekera und M. de Boodt (Scheffer \& Schachtschabel 1992; Kuntze et al. 1994; Luxmoore 1981)

\begin{tabular}{lcccl}
\hline Porenklasse & $\begin{array}{c}\text { Äquivalenz- } \varnothing \\
{[\mu \mathrm{m}]}\end{array}$ & \multicolumn{2}{c}{ Saugspannung } & \multicolumn{2}{l}{$\begin{array}{l}\text { Charakteristika } \\
\text { physikalisch/biotisch }\end{array}$} \\
\hline Feinporen & $<0,2$ & $>1500$ & $>4,2$ & $\begin{array}{l}\text { Evapotranspiration, Lösungsverteilung } \\
\text { entlang matrikaler Druckgradienten, PWP }\end{array}$ \\
Mittelporen & $0,2-10$ & $1500-30$ & $4,2-2,5$ & $\begin{array}{l}\text { Evapotranspiration, Lösungsverteilung } \\
\text { entlang matrikaler Druckgradienten, nFK }\end{array}$ \\
Grobporen, eng & $10-50$ & $30-6$ & $2,5-1,8$ & $\begin{array}{l}\text { langsame Dränung, nFK } \\
\text { Grobporen, weit }\end{array}$ \\
\hline
\end{tabular}

PWP = permanenter Welkepunkt, nFK = nutzbare Feldkapazität

\subsubsection{Gleichgewichts-, Perkolations- und Druckbodenlösungen}

Alle Bodenextraktionsverfahren besitzen spezifische Vor- und Nachteile und sind daher unter Berücksichtigung der jeweiligen Fragestellung auszuwählen. Campbell et al. (1989) und Ludwig et al. (1999) empfehlen, in bodenkundliche und mineralstoffökologische Analysen möglichst verschiedene Lösungstypen einzubeziehen. Da die im Rahmen der vorliegenden Arbeit durchgeführten Untersuchungen z. T. grob strukturierte, zumindest temporär sehr trockene Böden und deren jahreszeitlichen Variabilitäten betreffen, musste hier auf die Gewinnung von in situ-Lösungen verzichtet werden. Mit Hilfe der bereits in Abschnitt 2.2.4 (S. 20) beschriebenen Extraktionsverfahren werden dem Einfluss des Bodengefüges auf die Zusammensetzung der Bodenlösungen (GBL vs. PBL) sowie den Unterschieden zwischen Gleichgewichtslösungen und Wasserextrakten i. e. S. (PBL vs. DBL) Rechnung getragen. 


\section{Lagerungseffekte}

Im Hinblick auf potenzielle Lagerungseffekte erfolgte eine sofortige und kontinuierliche Kühlung aller Bodenproben sowie eine umgehende Herstellung der verschiedenen Bodenlösungen. Mit den GBL- und DBL-Extraktionen der jeweils acht Proben eines jeden Referenzbestands wurde spätestens $24 \mathrm{~h}$ nach der Probennahme begonnen. Aufgrund der begrenzten Anzahl verfügbarer Perkolationsapparaturen konnten die PBL von jeweils nur vier Bodenmonolithen pro CC- und CF-Bestand gleichzeitig hergestellt werden. Die verbleibenden Bodenkerne wurden umittelbar im Anschluss perkoliert. Statistiken der Untersuchungsergebnisse dieser Quadrantengruppen geben nur für die Proben des Gentiano-Koelerietum danthonietosum Hinweise darauf, dass die längere Lagerung einen signifikanten Einfluss auf die Zusammensetzung der Bodenlösungen hatte (vgl. Tabelle A 5, S. 303). Vergleiche mit den Ergebnissen der GBLund DBL-Analysen lassen darauf schließen, dass diese Unterschiede zudem in den meisten Fällen nicht allein auf die Lagerung, sondern auch auf räumliche Variabilitäten innerhalb der Untersuchungsflächen zurückzuführen waren. Die höheren Fe-Konzentrationen in den PBL des jeweils zweiten Probenquartetts dürften indes die Folge der reduktiven Mobilisierung von Fe(III) in den luftdicht verschlossenen Bodenmonolithen gewesen sein. Die Fe-Konzentrationen der PBL des Bestands Hölleberg-CF korrelieren mit einer Zunahme der Protonenaktivitäten und einer Abnahme der $\mathrm{NO}_{2}{ }^{-}$-Konzentrationen. Anders als am Standort Auf der Burg ist hier für die Fe-Konzentrationen ein verstärkender Positionseffekt auszuschließen. Der Anstieg der $\mathrm{Ca}^{2+}$ - und $\mathrm{Mg}^{2+}$-Konzentrationen in der PBL ist möglicherweise auf die Lösung von $\mathrm{CaCO}_{3}$ und $\mathrm{MgCO}_{3}$ durch die mit der mikrobiellen Atmung fortschreitenden $\mathrm{CO}_{2}$-Freisetzung zurückzuführen. In den PBL des Gentiano-Koelerietum danthonietosum des Standorts Auf der Burg korrelieren die erhöhten Leitfähigkeiten mit den $\mathrm{Ca}^{2+}$ und $\mathrm{Mg}^{2+}$-Konzentrationen.

Die Untersuchungen geben keine Hinweise darauf, dass durch die Lagerung der Proben im Kühlschrank die $\mathrm{NO}_{3}{ }^{-}$-Konzentrationen in der Bodenlösungen ansteigen. Anders lautende Ergebnisse von Edmeades et al. (1985) sind u. U. auf hohe Sauerstoffkonzentrationen und ausreichende Wassergehalte des feldfrischen, hier aber nach Aufhebung des natürlichen Gefüges gelagerten Bodenmaterials zurückzuführen. Zudem lassen die Analysenergebnisse der vorliegenden Arbeit keine signifikanten Veränderungen der $\mathrm{NH}_{4}{ }^{+}$-Gehalte in den PBL der beiden Perkolationsdurchgänge erkennen.

\section{Energetische und bodenchemische Aspekte der Extraktion von GBL, PBL und DBL}

Legt man den Berechnungen der Kapillarität eine Saugspannung von $80 \mathrm{kPa}$ (8,16 mWS) zugrunde, so werden durch die PBL Bodenporen mit einem minimalen Äquivalenzdurchmesser von $364 \mu \mathrm{m}$ und damit nach der Klassifizierung in Tabelle 31 nur weite Grob- oder Makroporen erfasst. Bei der Gewinnung der DBL entwässern Drücke von bis zu 1 MPa auch enge Grobporen mit Äquivalenzlumina > 29,1 $\mu \mathrm{m}$. Probleme bei der Verwendung von Bodenmonolithen ergeben sich durch das Auftreten von Randeffekten, d. h. durch erhöhte Flussraten der Aufsättigungslösungen im Bereich der Zylinderwandungen. Dieser Effekt kommt um so deutlicher zum Tragen, je kleiner der Durchmesser der Bodenkerne ist. Entsprechendes gilt für Störungen, die aus der Unterbindung des vertikalen Lösungsflusses resultieren. Aus diesen Gründen fordert Bergstrom (1990) für Untersuchungen zum Sickerverhalten von Pestiziden minimale Lysimeterdurchmesser von $25 \mathrm{~cm}$. Auch bei der Herstellung der eigenen Perkolations- und Druckextrakte muss davon ausgegangen werden, dass höhere Flussraten in den skelettreichen Bodenmonolithen der CCBestände nicht allein auf ein umfangreicheres System besonders weitlumiger Poren, sondern auch auf partielle Störungen der Bodenstruktur zurückgingen. 
Während mit den PBL und DBL Lösungen des Interaggregatporensystems untersucht werden können, erlaubt die Aufhebung des Bodengefüges durch Horizontalschüttelung der Feinerdehomogenate die Gleichgewichtseinstellung auch mit Bodenoberflächen, die im Inneren der Bodenaggregaten lokalisiert und damit den Intergranularporen zuzuordnen sind. GBL betreffen somit sowohl Lösungen des Makro-, als auch des Mittel- oder Mesoporensystems. Deren Lösungen können von den Pflanzenwurzeln entweder direkt durch das Vordringen der Wurzelhaare in Poren mit einem Durchmesser von mehr als $10 \mu \mathrm{m}$ oder indirekt durch den Aufbau hoher Saugspannungen bis in den Bereich des PWP von 1,5 MPa und der daraus resultierenden kapillaren Nachleitung aus Poren mit Äquivalenzlumina von mehr als 0,2 $\mu \mathrm{m}$ gewonnen werden (Scheffer \& Schachtschabel 1992; Wolt 1994). Die GBL repräsentieren zugleich Lösungen der Fein- oder Mikroporen, die nicht mehr der nutzbaren Feldkapazität zuzurechnen sind und die lediglich entlang matrikaler Wasserpotenzialgradienten und auf Grundlage von Diffusionsprozessen mit dem übrigen Boden im Austausch stehen.

\section{Bezugsgrößen der GBL,-- PBL- und DBL-Analysen}

Ein Problem der vergleichenden Darstellung von Untersuchungen an Sättigungsextrakten und Wasserextrakten i. e. S. ist die Auswahl geeigneter Bezugsgrößen. Da konzeptionell die GBL und PBL das chemische Gleichgewicht zwischen der Matrix der o.g. Bodenporen und ihrer Lösung abbilden, können bei einer entsprechenden Pufferung die Konzentrationen der Bodenextrakte selber angegeben werden. Demgegenüber wird davon ausgegangen, dass die DBL der aktuellen Bodenlösung in verdünnter Form entspricht, und daher die Analysenergebnisse auf den aktuellen Bodenwassergehalt zu beziehen sind. Um den Vergleich der verschiedenen Bodenlösungstypen und ihrer Extraktionsverfahren zu vereinfachen, wurde in der vorliegenden Arbeit mit dem Bezug auf die Feinerdetrockengewichte ein sinnvoller Kompromiss gewählt. Die Grundaussagen der Ergebnisse, d. h. die Relationen der Analyte zwischen den verschiedenen Vegetationsbeständen, bleiben bestehen, da in allen Fällen ein Verhältnis von etwa 1:2 zwischen Feinerdetrockengewicht und Gesamtlösungsvolumen eingestellt wurde. Überdies bestehen angesichts des Einflusses der Extraktionszeit lediglich graduelle Unterschiede zwischen Wasserextrakten i. e. S. (DBL) und den Gleichgewichtsbodenlösungen (GBL, PBL). Diese können daher nur in erster Näherung ihren theoretischen Definitionen als reine Verdünnungslösungen (Einwirkungszeit der Aufsättigungslösung $\mathrm{dt}=0$ ) und Lösungen, die im chemischen Gleichgewicht mit der Bodenfestphase stehen (Einwirkungszeit der Aufsättigungslösung $\mathrm{dt}=\infty$ ), gerecht werden.

Eine Ausnahme hinsichtlich ihrer Bezugsgröße stellen die Messungen der Protonenaktivitäten dar. ${ }^{1}$ Als negative dekadische Logarithmen werden die pH-Werte nur geringfügig durch Änderungen des Boden/ Lösungs-Verhältnisses beeinflusst. Zudem sind gerade sie in der Regel gut gepuffert und unterliegen daher nur geringen Verdünnungseffekten.

\footnotetext{
1 Auf die Berechnung der Aktivitäten $a_{i}$ der mineralischen Lösungskomponenten wurde verzichtet. Unterschiede zwischen den Konzentrationen und Aktivitäten der betreffenden lonen können bei den hier durchgeführten Untersuchungen vernachlässigt werden. Prinzipiell lässt sich die Aktivität $a_{i}$ eines lons i durch Multiplikation seiner Konzentration $c_{i}$ mit einem spezifischen Aktivitätskoeffizienten $y_{i}$ berechnen (Lindsay 1979; Wolt 1994). Letzterer ist $u$. a. eine Funktion der Valenz $z_{i}$ und der lonenstärke I der Lösung. Die erweiterte Debeye-Hückel-Gleichung berücksichtigt zudem die effektive Größe $d_{i}$ des hydratisierten lons und erlaubt darüber exaktere Kalkulationen für Lösungen hoher lonenstärke. Mit zunehmender lonenstärke I und Valenz $z_{i}$ sowie Größe der hydratisierten lonen nimmt $y_{i}$ ab. Das chemische Spezifizierungsprogramm GEOCHEM-PC, das für die Bestimmung der $\mathrm{HCO}_{3}{ }^{-}-$ Konzentrationen in den Bodenlösungen verwendet wurde, legt seinen Kalkulationen einheitliche $d_{i}$ für alle lonen zugrunde.
} 


\section{Bewertung der GBL, PBL und DBL}

Die drei wässrigen Extraktionsverfahren sind im Hinblick auf ihre relative Extraktionseffizienz (Tabelle 10, S. 76 und Abbildung 44, S. 76), ihre räumliche und zeitliche Auflösungseffizienz (Tabelle A 2 und Tabelle A 3, S. 302) sowie ihre potenzielle ökologische Differenzierungseffizienz (Tabelle 11, S. 77) zu bewerten.

\section{Relative Extraktionseffizienzen}

Die relativen Effizienzen der Extraktionsverfahren für die verschiedenen Analyte sind aus den jeweiligen Konzentrationsverhältnissen der GBL, PBL und DBL abzuleiten. Hierzu wurden die Untersuchungsergebnisse für die benachbart und zeitgleich gewonnenen Bodenproben der einzelnen Quadranten miteinander verglichen. Zugleich können auf diese Weise Rückschlüsse auf die Reaktionen während der Bodenextraktion (PBL vs. DBL) und die Eigenschaften der durch die verschiedenen Extraktionsverfahren erfassten Bodenkompartimente (GBL vs. PBL) gezogen werden.

Die Gleichgewichtsreaktionen zwischen der Bodenfestphase und Lösung folgen dem Massenwirkungsgesetz (Scheffer \& Schachtschabel 1992; Kuntze et al. 1994). Für den Austausch der Ionen A und B an den Bindungsstellen der Austauscher E (exchanger) kann es unter Bezug auf ihre Konzentrationen $c$ bzw. (bei $c>10^{-3} \mathrm{M}$ ) Aktivitäten $a$ idealisiert wie folgt formuliert werden:

$E-A x+y B \leftrightarrows E-B y+x A$

$K=\frac{\left[E-B_{y}\right] \cdot[A]^{x}}{\left[E-A_{x}\right] \cdot[B]^{y}}$

K Gleichgewichtskonstante

E Austauscher (exchanger) des Bodens

$x$, y stöchiometrische Koeffizienten

Die Aktivitäten der adsorbierten Kationen lassen sich nicht berechnen. Stattdessen werden zumeist deren auf die Feinerdetrockenmasse bezogenen Äquivalenzkonzentrationen $c_{c}\left[\mathrm{~mol}_{\mathrm{c}} / \mathrm{kg}\right]$ verwendet. Das Ausmaß der Adsorption eines Kations ist in erster Linie eine Funktion seiner Valenz und seiner Größe. In der Regel nimmt innerhalb einer Periode von Elementen die Eintauschstärke der Kationen mit der Wertigkeit zu. Entsprechendes gilt für die Elemente einer jeden Gruppe innerhalb des Periodensystems. Je größer der Ionendurchmesser ist, desto kleiner ist die Hydratationshülle und desto stärker ist die Bindung der betreffenden Ionen an den Kationenaustaschern des Bodens. Kompliziert wird der Gleichgewichtschemismus durch viele weitere Faktoren, darunter die unterschiedlichen Ionenselektivitäten der Austauscher. Diese variieren je nach Gesamtkonzentration des betreffenden Kations in der Lösung und an den Austauschern. So werden mit steigender Verdünnung der Bodenlösung polyvalente Kationen gegenüber einwertigen bevorzugt adsorbiert. Da unter diesen Voraussetzungen die Austauschprozesse im Boden thermodynamisch nicht exakt zu behandeln sind, bezeichnet man $K$ in Bodenaustauschersystemen nicht als Gleichgewichskonstante, sondern als Selektivitätskoeffizient.

Wenn die Ionenselektivitäten innerhalb des Porensystems voneinander abweichen, führen Extraktionen unter Aufrechterhaltung und Aufhebung des Bodengefüges zur Einstellung unterschiedlicher Gleichgewichtskonzentrationen in den Bodenlösungen. Diese orientieren sich ggf. an intermediären apparenten $K$ Werten. Die Konzentrationen der GBL können theoretisch trotz einer Vergrößerung des Bodenoberflächen/Lösungs-Verhältnisses diejenigen der PBL unterschreiten, wenn die fixierten Spezies des untersuchten Analyts, beispielsweise die konjugierten Kationen-Austauscher-Komplexe der Tonminerale oder der 
organischen Substanz, im Mikro- und Mesoporensystem eine höhere Stabilität besitzen und damit das Gesamtsystem eine niedrigere Gleichgewichtskonstante aufweist als das der Makroporen.

Das Massenwirkungsgesetz und der Gleichgewichtsterm $K$ erlauben keine Aussagen zur Geschwindigkeit, mit der die betreffenden Reaktionen ablaufen. Wie die Untersuchungen zur Abhängigkeit der Elektrolytkonzentrationen von der Perkolationsdauer zeigen (vgl. Abbildung 19, S. 53), erfahren insbesondere monovalente Ionen entsprechend ihrer geringeren Sorptionsstärke eine rasche Gleichgewichtseinstellung zwischen der Bodenfestphase und der Bodenlösung. Im Gegensatz dazu dauert die Equilibrierung bivalenter Anionen und Kationen deutlich länger. Aus diesem Grund liegen die feinerdebezogenen $\mathrm{Ca}^{2+}$ - und $\mathrm{Mg}^{2+}$-Konzentrationen für die beiden Gleichgewichtslösungen und die elektrischen Leitfähigkeiten um mehr als 100 \% über denen der DBL. Die Unterschiede der einwertigen Ionen zwischen den beiden Monolithenlösungen $\left(\mathrm{Cl}^{-}\right)$oder auch zwischen den beiden Gleichgewichtslösungen und der DBL $\left(\mathrm{K}^{+}, \mathrm{Na}^{+}\right)$ sind vergleichsweise gering. Bei einigen Mineralstoffen, darunter $\mathrm{SO}_{4}{ }^{2-}, \mathrm{NO}_{3}{ }^{-}, \mathrm{NO}_{2}{ }^{-}$und $\mathrm{Fe}$, führt aber die Erfassung der Meso- und Mikroporen zu besonders hohen Konzentrationen der GBL.

Von besonderem Interesse für die abweichenden N- und Fe-Gehalte in den drei Lösungstypen sind Reaktionen, die nicht primär im Zusammenhang mit den Austauschgleichgewichten sondern mit anderen Reaktionen der Lösung bzw. Eliminierung oder Immobilisierung im Zusammenhang stehen. Im Anschluss an die schnelle Gleichgewichtseinstellung von $\mathrm{NO}_{3}{ }^{-}$und $\mathrm{NO}_{2}{ }^{-}$, die nicht zuletzt auf die in der Regel niedrigen Anionenaustauscherkapazitäten im Boden zurückzuführen ist, wird im weiteren Extraktionsverlauf der Einfluss mikrobieller Umsetzungen deutlich. Die $\mathrm{NO}_{3}{ }^{-}$- und $\mathrm{NO}_{2}{ }^{-}$-Konzentrationen sinken mit zunehmender Perkolationszeit deutlich ab. Entsprechend liegen die N-Gehalte in den DBL über denen der PBL. Das Ausmaß der mikrobiellen Nitrifikation und Denitrifikation während der eintägigen Schüttelung der feldfrischen Feinerdehomogenate kann anhand der hier durchgeführten Untersuchungen nicht exakt ermittelt werden. Es ist aber davon auszugehen, dass auch im Verlauf der GBL-Herstellung erhebliche Mengen $\mathrm{N}$ verloren gehen. Da dennoch die GBL-bezogenen Konzentrationen signifikant über denen der DBL liegen, ist von hohen $\mathrm{NO}_{3}{ }^{-}$- und $\mathrm{NO}_{2}{ }^{-}$-Gehalten im Mikro- und Mesoporensystem auszugehen. Insbesondere in den englumigen Poren mit ihren niedrigen Matrixpotenzialen können sich anaerobe Bedingungen einstellen (Lindsay 1991). Es erstaunt daher, dass hier nicht nur die oxidierten N-Fraktionen besonders stark vertreten sind, sondern auch, dass die $\mathrm{NH}_{4}{ }^{+}$-Konzentration der PBL diejenigen der GBL übersteigen. Obwohl in Vorversuchen zur Ermittlung der für die verschiedenen Lösungskomponenten erforderlichen Equilibrierungszeiten eine Abnahme der $\mathrm{NH}_{4}{ }^{+}$-Konzentrationen nach etwa $12 \mathrm{~h}$ beobachtet wurde, übersteigen die $\mathrm{NH}_{4}{ }^{+}$-Gehalte beider Gleichgewichtsbodenlösungen signifikant diejenigen der DBL, bezogen auf Feinerdetrockengewichte im Median um Faktoren von 2,8 (GBL) bzw. 3,4 (PBL).

Die Verteilung der N-Fraktionen in den verschiedenen wässrigen Bodenlösungen stimmt also nicht mit der Annahme überein, nach der bei potenziell niedrigen $\mathrm{E}_{\mathrm{h}}$-Werten im Mikro- und Mesoporensystem ungünstigere Voraussetzungen für die Nitrifikation und günstigere für die Denitrifikation vorliegen $\left(\mathrm{NH}_{4}{ }_{\mathrm{GBL}}<\mathrm{NH}_{4}{ }_{\mathrm{PBL}}, \mathrm{NO}_{3}{ }^{-} \mathrm{GBL}, \mathrm{NO}_{2}{ }^{-} \mathrm{GBL}^{-}>\mathrm{NO}_{3}{ }_{\mathrm{PBL}}^{-}, \mathrm{NO}_{2}^{-}{ }_{\mathrm{PBL}}\right)$ und andererseits $\mathrm{NH}_{4}{ }^{+}$sehr schnell das chemische Gleichgewicht zwischen der Bodenlösung und der Bodenfestphase erreicht $\left(\mathrm{NH}_{4}{ }^{+}{ }_{\mathrm{PBL}}>\mathrm{NH}_{4}{ }^{+}{ }_{\mathrm{DBL}}\right)$. Es sollte in diesem Zusammenhang allerdings berücksichtigt werden, dass die $\mathrm{NH}_{4}{ }^{+}$-Konzentrationen nur in Lösungen der ersten drei Probennahmen analysiert wurden. Ein Vergleich der betreffenden Werte in Tabelle 10 (S. 76) mit denen der anderen Analyte ist daher nur eingeschränkt möglich. Zudem lagen für Konzentrationen aller N-Fraktionen sehr hohe Variabilitäten vor. Insbesondere in Bezug auf die hier analysierten redoxlabilen Elemente ist darauf zu verweisen, dass bei der PBL-Herstellung die Bodenlösung zyklisch bodenfreie Bereiche mit hohen $\mathrm{E}_{\mathrm{h}}$-Werten passiert. Aus diesem Grund können bei diesem 
Verfahren sehr viel stärker als bei der Schüttelung homogenisierter Bodenproben Oxidationsreaktionen, wie z. B. Ammonifikation bzw. Nitrifikation, und Reduktionsreaktionen, wie z. B. Denitrifikation, räumlich getrennt, aber zeitgleich ablaufen.

Wie die Ausführungen in Abschnitt 4.2.4 (S. 117 f.) gezeigt haben, bestimmen v. a. reduktive Lösungsund oxidative Fällungsreaktionen die Fe-Konzentrationen in der Bodenlösung. Die feinerdebezogenen FeGehalte der GBL, PBL und DBL finden sich in Übereinstimmung mit der abweichenden Erfassung reduktiver Mikrohabitate sowie dem Umfang der Einstellung oxidativer Bedingungen. Mediane Fe-Verhältnisse von 1,4 (GBL) : 0,6 (PBL) : 1,0 (DBL) können also dahingehend interpretiert werden, dass die eintägige zyklische Perkolation von Bodenmonolithen mit einer nur geringen Fe-Extraktion aus Bodenbereichen niedriger Redoxpotenziale (PBL < GBL) und einer recht umfangreichen oxidativen Fe-Immobilisierung (PBL < DBL) einhergeht. Die Aufhebung des natürlichen Bodengefüges und die Schüttelung der homogenisierten Feinerde für die GBL-Herstellung erlaubt im Gegensatz zu den beiden anderen Extraktionsverfahren die Erfassung des Intraaggregatraums mit hohen Fe-Löslichkeiten. Offenbar kompensieren die Fe-Fraktionen dieser Bodenbereiche bei weitem das Ausmaß der oxidativen Fe-Immobilisierung im Extraktionsverlauf (GBL > DBL). Es kann nicht ausgeschlossen werden, dass auch lösliche Fe(III)-Komplexe im Mikro- und Mesoporensystem zu den hohen Fe-Konzentrationen der GBL beitragen. Die Untersuchungen der effektiven Kationenaustauschkapazitäten geben keine Hinweise darauf, dass es sich bei dem durch die GBL erfassten Fe zu nennenswerten Anteilen um solches austauschbarer Fraktionen handelt (vgl. Abschnitt 3.2.3, S. 80 ff.).

Mangan ist der einzige Mineralstoff, dessen Konzentrationen in den DBL über denen beider anderen Lösungstypen lagen. Die Untersuchungen lassen demnach auch für Mn eine oxidative Immobilisierung bei der Herstellung der Gleichgewichtsbodenlösungen vermuten. In vielen Fällen bewegten sich indes die Mn-Konzentrationen im Bereich der analytischen Nachweisgrenze. Die mit etwa $10 \%$ vergleichweise geringen Unterschiede zwischen den GBL bzw. PBL und den DBL sollen daher trotz ihrer Signifikanz nicht weiter diskutiert werden.

Die Zusammensetzung wässriger Bodenextrakte wird einerseits durch die Vorbehandlung des Probenmaterials und die Zeitdauer der Lösungsgewinnung, andererseits durch das Boden/Lösungs-Verhältnis sowie die Bodenart und den Bodentyp beeinflusst. Diese Multikausalität ist dafür verantwortlich, dass die eigenen GBL- und PBL-Analysen für einige Analyte, wie $\mathrm{Fe}, \mathrm{Mg}^{2+}$ und $\mathrm{NH}_{4}^{+}$, gut mit den Ergebnissen ähnlicher Untersuchungen von Ludwig et al. (1999) übereinstimmen, für andere Mineralstoffe, wie $\mathrm{K}^{+}$ und $\mathrm{Ca}^{2+}$, aber recht große Abweichungen zeigen. In der genannten Arbeit wird zudem von methodenbezogenen Inkonsistenzen der Analysen des Ober- und Unterbodenmaterials der hier behandelten Parabraunerde (spodic dystric cambisol) berichtet. Auf inverse Konzentrationsverhältnisse in unterschiedlichen Bodentiefen verwiesen hier die Gleichgewichtslösungen der feldfrischen Feinerdehomogenate und Bodenmonolithe beispielsweise für $\mathrm{Na}^{+}, \mathrm{SO}_{4}{ }^{2-}$ und $\mathrm{NO}_{3}{ }^{-}$. Im Gegensatz dazu zeichnen die eigenen Untersuchungen ein recht einheitliches Bild. Für ein gegebenes Extraktionsverfahren weichen die absoluten, auf die Feinerde bezogenen Gehalte der einzelnen Analyte zwischen den Vegetationsbeständen zwar z. T. deutlich voneinander ab, doch sind die Verhältnisse der Analytgehalte der drei Lösungstypen für alle Untersuchungsbestände in der Regel gleich. Dies belegt auch Abbildung 44 (S. 76), die logarithmisch die Relationen zwischen den verschiedenen Mineralstoffen für die GBL, PBL und DBL darstellt. Bei den kationischen Analyten sind grundlegende Abweichungen der Konzentrationsverhältnisse nur für die Fe- und $\mathrm{NH}_{4}{ }^{+}$, bei den Anionen nur für $\mathrm{NO}_{3}{ }^{-}$und $\mathrm{NO}_{2}{ }^{-}$zu erkennen. Die GBL erfasst tendenziell mehr Eisen und Nitrat, die PBL mehr Ammonium und Nitrit. Unterschiede, wie sie die verschiedenen wässrigen Boden- 
extraktionsverfahren für die diversen Kompartimente des Bodensystems und die chemischen Gleichgewichtszustände aufzeigen, sind daher mit Ausnahme der genannten Nährionen für die Bewertung der bodenkundlichen Eigenschaften des Gentiano-Koelerietum von untergeordneter Bedeutung.

\section{Räumliche und zeitliche Auflösungseffizienzen}

Die Koeffizienten der räumlichen und zeitlichen Varianzen $C V_{\text {lok }}$ und $C V_{\text {temp }}$ der Analyte stellen eine Bewertungsgrundlage für die Auflösungseffizienzen der verschiedenen Bodenlösungstypen dar (Tabelle A 2/Tabelle A 3, S. 300). Je größer die Variationskoeffizienten der Konzentrationen einer Lösungskomponente innerhalb der Untersuchungsflächen sind, desto größer sollte das Auflösungsvermögen des betreffenden Extraktionsverfahrens sein. Für die diesbezüglichen Auswertungen wurden die Analysenergebnisse aller Beprobungen eines Standorts berücksichtigt. Den mittleren $\mathrm{CV}_{\text {lok }}$ und $\mathrm{CV}_{\text {temp }}$ der GBL liegen jeweils sieben, denen der PBL und DBL nur sechs Probennahmen zugrunde. Die verschiedenen Extraktionsverfahren können daher hinsichtlich ihres zeitlichen und räumlichen Differenzierungsvermögens nur eingeschränkt miteinander verglichen werden. Entsprechendes gilt für die Vergleiche zwischen den räumlichen und zeitlichen Variabilitäten, wie sie in Tabelle A 4 ( S. 303) dargestellt sind. Da die Probennahmen der einzelnen Untersuchsstandorte innerhalb weniger Stunden abgeschlossen wurden, kann die räumliche Variabilität der verschiedenen Standortfaktoren in den Untersuchungsbeständen anhand von $\mathrm{CV}_{\text {lok }}$ recht genau benannt werden. Demgegenüber sind die zeitlich bedingten Abweichungen nur unzureichend von der räumlichen Variabilität im Bestand zu trennen. Die Auswertung der zeitlichen Veränderungen erfolgte unter Zusammenfassung von je zwei benachbarten Quadranten der beiden Beprobungsreihen A und B (vgl. Abbildung 6, S. 19). Demnach beziehen sich die mittleren $\mathrm{CV}_{\text {temp }}$ auf acht Flächeneinheiten von je 12,5 $\mathrm{m}^{2}$, also einem Achtel der Fläche, die der Erfassung der $\mathrm{CV}_{\text {lok }}$ zugrunde gelegt wurde. In der Literatur wird darauf verwiesen, dass bereits in Untersuchungsflächen von einem Quadratmeter die Hälfte der Gesamtvariabilität einer homogenen Untersuchungsfläche auftreten kann (Beckett \& Webster 1971). Es ist hier daher eher von einer mittleren zeit-räumlichen als von einer rein zeitlichen Variabilität zu sprechen. Die Tatsache, dass in fast allen Fällen die $\mathrm{CV}_{\text {temp }}$ einer kleinen Probennahmefläche die $\mathrm{CV}_{\text {lok }}$ eines deutlich größeren Raumsegments überschreiten (Tabelle A 4, S. 303), belegt ebenso wie die signifikanten Unterschiede der Analysenergebnisse zwischen den verschiedenen Probennahmen, dass zumindest in diesen Fällen die räumlichen Abweichungen nicht die zeitlichen Veränderungen überdecken.

Die mittleren Variationskoeffizienten der Untersuchungen aller Standorte, Bestände und Lösungstypen zeigen für $\mathrm{SO}_{4}^{-}$, EC, $\mathrm{Mg}^{2+}, \mathrm{Cl}^{-}$und $\mathrm{Ca}^{2+}$ mit Werten zwischen $20 \%$ und $40 \%$ sowohl vergleichsweise niedrige lokale als auch temporäre Variabilitäten. Demgegenüber sind alle in den Bodenlösungen erfassten N-Spezies durch hohe CV-Werte gekennzeichnet. Sehr hohe zeitliche und räumliche Fluktuationen von $\mathrm{NO}_{3}{ }^{-}$belegen auch Messungen des TON (total oxidized nitrogen) von Campbell et al. (1989). Ebenfalls erhebliche räumliche und zeitliche Abweichungen weisen die löslichen Fe-Gehalte auf. Die Vergleiche der $\mathrm{CV}_{\text {lok }}$ und $\mathrm{CV}_{\text {temp }}$ deuten darauf hin, dass nur für $\mathrm{NO}_{3}{ }^{-}$und $\mathrm{K}^{+}$der zeitbedingte hinter den raumbedingten Einfluss zurücktritt. Besonders kleinräumige Unterschiede der $\mathrm{NO}_{3}{ }^{-}$-Gehalte und N-Mineralisierung haben Starr et al. (1992, 1995) gefunden. Je kleiner hier die Durchmesser der Probennehmer und die Konzentrationen des Mineralstoffs waren, desto größer war die Schiefe der zumeist normallogarithmischen Verteilung und die Varianzen der Messwerte. Während die zeitlich und räumlich bedingten Abweichungen der Eisenlöslichkeit nahezu ausgeglichen sind, werden die Protonen- und Mangankonzentrationen primär durch zeitvariable Faktoren beeinflusst. 
Hantschel et al. (1986, 1988) belegen besonders hohe $\mathrm{CV}_{\text {lok }}$ für Perkolationsbodenlösungen und werten diese dahingehend, dass PBL v. a. für die Aufdeckung kleinräumiger Unterschiede, GBL für die Kennzeichnung des mittleren Bodenzustands geeignet sind. Die eigenen Untersuchungen geben demgegenüber keine Hinweise darauf, dass die Homogenisation des Bodenmaterials zu einer verminderten Erfassung räumlicher oder auch zeitlicher Unterschiede führt: In ausgeglichener Anzahl über- und unterschreiten die Varianzen von GBL und PBL einander. Die DBL zeigt etwas häufiger niedrigere $\mathrm{CV}_{\text {lok }}$ und $\mathrm{CV}_{\text {temp }}$ als die GBL und PBL. Insgesamt lassen die Untersuchungen der vorliegenden Arbeit aber keine grundsätzlichen Unterschiede der verschiedenen Extraktionsverfahren hinsichtlich ihrer Auflösungseffizienz für die räumlichen und zeitlichen Entwicklungen der Analyte in den Untersuchungsflächen erkennen.

\section{Potenzielle ökologische Differenzierungseffizienzen}

Die ökologische Differenzierungseffizienz der verschiedenen Extraktionsverfahren bezieht sich auf ihr Vermögen, bodenkundliche Unterschiede der hier untersuchten Vegetationseinheiten abzubilden. Da die GBL, PBL und DBL lediglich konzeptionell definiert sind und ihre Aussagekraft für die pflanzliche Mineralstoffernährung zunächst nicht benannt werden kann, sollte besser von einer potenziellen Differenzierungseffizienz gesprochen werden.

Die Bodenlösungen und Bodenextrakte erfassen je nach Methodik unterschiedliche Bodenfraktionen. Dies bestätigen Arbeiten, nach denen Perkolationsgleichgewichtsbodenlösungen im Vergleich zu anderen wässrigen Bodenextrakten und in situ-Bodenlösungen besonders enge Ca/Al-Verhältnisse aufweisen (Meiwes et al. 1984; Ludwig et al. 1999). Wie Hantschel et al. $(1986,1988)$ gezeigt haben, handelt es sich bei der Perkolation von Bodenmonolithen um eine besonders empfindliche Methode zur Diagnose der pflanzlichen Al-Intoxikation in Waldböden. Niedrigere pH-Werte und höhere Konzentrationen sauer wirkender Kationen in PBL sowie höhere Konzentrationen basisch wirkender Kationen in GBL werden auf eine unterschiedliche Austauscherbelegung der Aggregatoberflächen und des gesamten Bodenmaterials zurückgeführt. Arbeiten im Rahmen der Waldschadensforschung ergaben, dass GBL im Vergleich zu PBL ein stärkeres Pufferungsvermögen der Böden anzeigen (Kaupenjohann \& Hantschel 1987; Schaller \& Fischer 1985). In den eigenen Untersuchungen fallen die Ergebnisse der $\mathrm{Ca}^{2+}$-Analysen der drei Bodenlösungstypen für den Standort Hölleberg auf. Die GBL lassen auf nur tendenziell höhere $\mathrm{Ca}^{2+}-$ Löslichkeiten der besonders kalkreichen Feinerde der typischen Subassoziation im Vergleich zu der des kalkärmeren Bodenmaterials der Subassoziation von Danthonia decumbens im Gentiano-Koelerietum schließen. Im Gegensatz dazu stimmen die Werte der PBL und DBL mit den Kalkgehalten des jeweiligen Bodens überein. Dies könnte darauf zurückzuführen sein, dass infolge einer bevorzugten Wasserleitung die Entbasung im weitlumigen Makroporensystem bereits weiter vorangeschritten ist.

Die Zusammensetzungen der verschiedenen Bodenextrakte des Gentiano-Koelerietum danthonietosum und Gentiano-Koelerietum typicum, geben keine Hinweise darauf, dass sich die Vegetationseinheiten grundsätzlich in den durch die Extraktionsverfahren definierten Fraktionen eines Elements unterscheiden (Tabelle 11, S. 77). In den meisten Fällen stimmen die Relationen der Analyte zwischen den Vergleichsbeständen eines Standorts für alle Extrakte überein. Gleichzeitig lassen die Untersuchungen nicht erkennen, dass ein bestimmtes Extraktionsverfahren grundsätzlich besonders geeignet ist, diesbezügliche Unterschiede zwischen den Standorten aufzuzeigen. So wiesen die Extrakte von Bodenmaterial des Standorts Auf der Burg in allen drei Fällen signifikant höhere Ca-Konzentrationen im CC-Bestand auf. Die oben dargestellten Ergebnisse für den Standort Hölleberg, nach denen GBL diese Unterschiede weniger stark differenzieren als Extrakte von Bodenmonolithen, werden hier also nicht bestätigt. 


\section{Zusammenfassung}

Die Untersuchungen der GBL, PBL und DBL zeigen, dass sich in diesen die Konzentrationen und Konzentrationsverhältnisse verschiedener Bodenlösungskomponenten unterscheiden. Daraus resultieren für die betreffenden Extraktionsverfahren stoffspezifische Abweichungen der relativen Extraktionseffizienzen, aber auch der zeitlichen und räumlichen Auflösungseffizienzen sowie der potenziellen ökologischen Differenzierungseffizienzen. Verantwortlich hierfür sind u. a. Unterschiede der Analyte hinsichtlich ihrer Verteilung im Bodenporensystem, der Geschwindigkeit ihrer Gleichgewichtseinstellung zwischen der Bodenfestphase und der Bodenlösung sowie der Art und des Umfangs ihrer biotischen oder abiotischen Reaktionen im Rahmen der verschiedenen Extraktionen.

Für mineralstoffökologische Untersuchungen eignen sich v. a. Lösungen, die der nutzbaren Feldkapazität und damit den Meso- und Makroporen des Bodens zuzuordnen sind (Kuntze et al. 1994). Zeitweilig verhindern sehr niedrige Wasserpotenziale in Halbtrockenrasen die Gewinnung von in situ-Bodenlösungen und damit ein repräsentatives Bild der pflanzlichen Nährstoffverfügbarkeiten unter Erfassung der zeitlichen Fluktuationen im Jahresverlauf. Für die Charakterisierung der Bodenmatrix und der Bodenlösung erscheinen daher Untersuchungen ihrer potenziell stabilsten Zustände, also derjenigen im chemischen Gleichgewicht, besonders wertvoll. Die verschiedenen Mineralstoffe bedürfen hierfür unterschiedlicher Equilibrierungszeiten. Anionen und monovalente Kationen erfahren eine schnelle, Kationen höherer Valenzen eine vergleichsweise langsame Gleichgewichtseinstellung. PBL, die durch die zyklische Perkolation feldfrischer Bodenmonolithen gewonnen werden, dürften unter diesen Gesichtspunkten für kausalökologische Untersuchung der standörtlichen Vegetationsdifferenzierung besonders geeignet sein. Die GBL, PBL und DBL lassen gleichzeitig aber darauf schließen, dass die Gleichgewichtssysteme des Bodens durch die Extraktionsverfahren in unterschiedlicher Weise beeinflusst und damit Analyte in unterschiedlichem Ausmaß mobilisiert bzw. immobilisiert oder eliminiert werden. Höhere Konzentrationen in der Druckbodenlösung (DBL) belegen, dass die redoxlabilen N-, Fe- und Mn-Spezies im Verlauf der Perkolation von Bodenmonolithen (PBL) zu großen Teilen aus der Lösung entfernt werden. Eine zuverlässige Kennzeichnung des Bodens im Hinblick auf die Verfügbarkeit dieser Nährelemente erfordert demnach eine besonders schnelle Bodenextraktion, durch die der Umfang der betreffenden Reaktionen minimiert wird. Folglich sind PBL für die Untersuchung diesbezüglicher Fragestellungen nur bedingt geeignet.

Wie diese Ausführungen zeigen, sind chemische Untersuchungen wässriger Bodenlösungen oder Bodenextrakte immer durch Unschärfen in der Bestimmung des einen oder des anderen Analyts gekennzeichnet. Es gibt kein für alle Nährstoffe in gleicher Weise geeignetes Bodenextraktionsverfahren. Die Untersuchungen der GBL, PBL und DBL belegen aber, dass in der Regel alle drei Methoden ganz ähnliche Unterschiede in den Mineralstoffverhältnissen zwischen den Vegetationseinheiten eines Standorts aufzeigen und damit für die Behandlung der Frage nach den mineralstoffökologischen Ursachen des unterschiedlichen Arteninventars von Kalk-Halbtrockenrasen prinzipiell geeignet sind. Auch geben die Untersuchungen Hinweise darauf, dass sich die Extraktionsverfahren nicht grundsätzlich in ihrem Vermögen unterscheiden, zeitliche oder räumliche Abweichungen in den Vegetationsbeständen abzubilden.

Unter diesen Gesichtspunkten erscheint für Untersuchungen zur standörtlichen Vegetationsdifferenzierung diejenige Methodik besonders geeignet, die bei einem möglichst geringen apparativen und zeitlichen Aufwand die Behandlung einer maximalen Anzahl von Untersuchungsflächen und Bodenproben erlaubt. Daher wurden für die Vergleichsstandorte der vorliegenden Arbeit nur Gleichgewichtsbodenlösungen 
feldfrischer Feinerdehomogenate (GBL) hergestellt und analysiert. Unzulänglichkeiten dieser wässrigen Extrakte hinsichtlich möglicher Immobilisierungs- oder Eliminierungsreaktionen von Pflanzennährstoffen, die nach bisheriger Kenntnis von zentraler Bedeutung für die Vegetationsdifferenzierung sein können, trug die Anwendung konzeptionell abweichender Extraktionsverfahren Rechnung. Nährstoffspezifische Extraktionsmittel sowie Untersuchungen zum Redoxverhalten im Boden zielten hier insbesondere auf eine differenzierte Betrachtung der Bedeutung von Fe und Mn für die Etablierung acidophiler/calcifuger Arten in Kalk-Halbtrockenrasen ab. C/N-Analysen lufttrockener Feinerdehomogenate ergänzten die Analysen der verschiedenen N-Fraktionen in den GBL. Schließlich erfuhren die P-Fraktionen in den Böden der beiden Daueruntersuchungsstandorte Auf der Burg und Hölleberg durch die Anwendung sequentieller Untersuchungensverfahren besondere Aufmerksamkeit.

\subsubsection{Bodenfaktoren in Abhängigkeit von den jahreszeitlichen Witterungsbedingungen}

Die Analysen der verschiedenen wässrigen Bodenextrakte geben für die meisten Lösungskomponenten keine Hinweise auf eine jahreszeitliche Abhängigkeit der Mineralstoffkonzentrationen. In Fällen, in denen zeitliche Fluktuationen nicht durch hohe räumliche Variabilitäten überzeichnet werden, finden signifikante Unterschiede zwischen verschiedenen Untersuchungsterminen für eine Lösungsvariante in aller Regel keine Bestätigung durch die Ergebnisse anderer Extraktionsverfahren bzw. anderer Vegetationsbestände. Bei nur sieben (GBL) bzw. sechs (PBL, DBL) Beprobungen im Jahresverlauf muss also davon ausgegangen werden, dass mögliche saisonale Entwicklungen durch die temporäre Wirkung jahreszeitlich unabhängiger Faktoren überzeichnet werden.

Andere Autoren belegen Korrelationen zwischen den Mineralstoffkonzentrationen in der Bodenlösung und den aktuellen Bodenwassergehalten oder Witterungsbedingungen (z. B. Edmeades et al. 1985; Litaor 1988b). Besonders ausgeprägte Bezüge zwischen der Niederschlagsneigung und den Bodenlösungskonzentrationen sind, wie bereits weiter oben ausgeführt, insbesondere bei der Lösungsgewinnung mit Hilfe von Tensions- und Ebermayer-Lysimetern zu erwarten (Zabowski \& Ugolini 1990). Diese erfassen primär das Wasser schnell leitender Makroporen, deren Verweilen im Boden bei hoher Niederschlagsneigung vielfach unterhalb der Residenzzeit liegt, die für die Einstellung der dynamischen Gleichgewichte erforderlich ist. Im Rahmen ökologischer Untersuchungen können hieraus v. a. bei längerer Dauer der Lösungsgewinnung Ergebnisse resultieren, die ein unzutreffendes Bild der pflanzlichen Mineralstoffverfügbarkeiten zeichnen. Campbell et al. (1989) führen Sommermaxima, wie sie mittels immiscible displacement in der Lösung der oberen $20 \mathrm{~cm}$ verschiedener Böden nachgewiesen wurden, u. a. auch auf die vertikale Verlagerungen von Soluten durch erhöhte Evapotranspirationraten zurück.

Für die hier untersuchten Bodenextrakte sind Beziehungen zwischen dem Bodenwassergehalt $\Theta$ und den Lösungskonzentrationen $c$ auszuschließen. Ergebnisse statistischer Analysen, nach denen mit Ausnahme der PBL-Variante Hölleberg-CF und der DBL-Variante Hölleberg-CC keine negativen Korrelationen zwischen dem Summenparameter der elektrischen Leitfähigkeit EC und damit der Ionenstärke I sowie dem Bodenwassergehalt $\Theta_{\mathrm{m}}$ vorliegen (vgl.Abbildung A 2, S. 313), sind dahingehend zu werten, dass im Fall der GBL und PBL bei standardisierten Feinerde/Lösungs-Verhältnissen eintägige Equilibrierungen mögliche Abweichungen der aktuellen Bodenlösung vom chemischen Gleichgewicht ausgleichen. Zugleich sollten auch beim DBL-Verfahren Verdünnungseffekte in niederschlagsreichen Perioden nur dann nachzuweisen sein, wenn eine Equilibrierung zwischen den festen, flüssigen und gasförmigen Kom- 
partimenten des Bodens weder im Vorfeld der Probennahmen noch bei der Lösungsgewinnung selber erfolgt. Im Fall einer abgeschlossenen Gleichgewichtseinstellung in situ und einer reinen Verdünnung der aktuellen Bodenlösung im Rahmen der DBL-Gewinnung ist demnach vielmehr eine positive Korrelation zwischen den Leitfähigkeiten bzw. Ionenstärken und den ursprünglichen Bodenwassergehalten zu erwarten. Tatsächlich bestätigen aber nur zusammenfassende Rangkorrelationsanalysen nach Spearman der GBL aller Untersuchungsflächen ein solches Verhältnis zwischen den feinerdebezogenen Wassergehalten $\Theta_{\mathrm{m}}$ der Bodenproben und den Leitfähigkeiten EC der wässrigen Bodenextrakte. Dieser Effekt wird wahrscheinlich durch $\mathrm{CaCO}_{3}$-Lösung verursacht: Der Anstieg der Wassergehalte im Boden geht mit einer Beeinträchtigung der Diffusionsraten und auf diese Weise mit einer Stimulation der $\mathrm{CO}_{2}$-vermittelten $\mathrm{Ca}^{2+}$-Freisetzung einher.

Korrelieren im Jahresverlauf niedrige volumetrische Bodenwassergehalte mit erhöhten EC-Werten, wie dies für die beiden oben genannten PBL- und DBL-Varianten des Standorts Hölleberg der Fall ist, so ist der Einfluss der aktuellen Bodenfeuchte während der Bodenprobennahme weniger unter dem Gesichtspunkt möglicher Verdünnungen als vielmehr in sekundären biotischen und/oder abiotischen Effekten zu suchen. Ebenfalls keine engen Korrelationen zwischen Lösungskonzentrationen und Parametern der Bodenfeuchte fanden Karathanasis (1991) in Zentrifugationsbodenlösungen und Federer \& Sticher (1994) in Lysimeterlösungen, die mit Hilfe von Polyethylen-Saugkerzen bei Unterdrücken zwischen -100 mbar und -300 mbar gewonnen wurden. Abweichend von den eigenen Untersuchungsergebnissen konnten aber in der letztgenannten Arbeit für einen calcic fluvisol deutliche jahreszeitliche Schwankungen verschiedener Lösungskomponenten nachgewiesen werden. Winterminima und Sommermaxima von $\mathrm{Ca}^{2+}, \mathrm{Mg}^{2+}, \mathrm{Na}^{+}, \mathrm{CO}_{3}{ }^{2-}$, DOC sowie verschiedenen Schwermetallen werden auf die Temperaturabhängigkeit der Bodenaktivität zurückgeführt. Die Metabolisierung von organischem Material führt zu einer Erhöhung des DOC sowie der $\mathrm{CO}_{2}$-Konzentrationen. Aus der dadurch bedingten Lösung von Calcit resultiert nicht nur eine Erhöhung der $\mathrm{Ca}^{2+}$-Konzentrationen sondern u. U. auch die Desorption verschiedener Schwermetallionen.

Die eigenen Untersuchungen lassen lediglich tendenzielle Veränderungen der Bodenlösungszusammensetzung erkennen. Diese dürften auf unterschiedliche biologische Aktivitäten und die daraus resultierenden Abweichungen der Atmungsraten im Jahresverlauf zurückzuführen sein. Insbesondere für den Standort Auf der Burg zeichnet sich ein Bild, dass auf eine geringfügige Sommerdepression des $\mathrm{pH}$ hinweist. Ebenfalls in Übereinstimmung mit der Wirkung erhöhter $\mathrm{CO}_{2}$-Konzentrationen finden sich Sommermaxima der $\mathrm{Ca}^{2+}$-Konzentrationen v. a. in den Böden des Standorts Hölleberg. Betrachtet man die Jahresverläufe aller Analyte, darunter etwa diejenigen des in ihrer Löslichkeit pH-abhängigen Fe und Mn, so folgen diese allerdings keineswegs einem Erklärungsmuster, dass auf eine Temperatur- und Feuchtigkeitsbeeinflussung der physikochemischen und biologischen Reaktionen im Boden zu reduzieren ist. Gegen eine vereinfachende Erklärung der jahreszeitlichen $\mathrm{pH}$-Schwankungen auf Grundlage einer temperaturund feuchtigkeitskontrollierten $\mathrm{CO}_{2}$-Freisetzung und $\mathrm{CO}_{2}$-Diffusion spricht übrigens die Beobachtung, dass die pH-Amplitude unbewachsener Böden höher ist als die bewachsener (Smith \& Robertson 1939). Desgleichen lässt sich die Interpretation, nach der die Endprodukte des anaeroben Stoffwechsels der Bodenorganismen eine Anreicherung von organischen Säuren und dadurch ein Absenken des pH-Wertes verursachen, nicht halten. Wie bereits von Ellenberg (1958) betont, existiert keine eindeutige Korrelation zwischen dem Wassergehalt und dem pH-Wert des Bodens. 


\subsubsection{Bodenaciditäten}

Kaum ein anderer Faktor nimmt auf so viele Bodeneigenschaften Einfluss wie der pH-Wert. Ihrerseits eine Funktion v. a. des Ausgangsgesteins und des Klimas, stehen die Protonenaktivitäten im Zentrum des Bodenchemismus und bestimmen darüber chemo- und physikoedaphische Parameter, die unmittelbaren Einfluss auf die Vegetationsdifferenzierung eines Standorts ausüben (vgl. Abschnitt 4.1, S. 110 ff.). Wie eine Reihe von Nährlösungsexperimenten gezeigt haben, sind die Protonenaktivitäten selber nur in sehr wenigen Fällen für die Standortpräferenz einer Pflanze von Bedeutung (s. Kinzel 1982; s. Marschner 1995).

Fasst man die in Abschnitt 3.2.2 (S. 55 ff.) dargestellten Bodenaciditäten zusammen, so finden sich diese in der Regel, aber nicht immer, in Übereinstimmung mit den Standortbeschreibungen des Gentiano-Koelerietum danthonietosum in der pflanzensoziologischen Literatur (z. B. Lohmeyer 1953; Bornkamm 1960; Hofmeister 1984) und den experimentellen Befunden geobotanischer Untersuchungen, wie sie v. a. in Großbritannien für Mischbestände acidophiler/calcifuger und basiphiler/calcicoler Arten durchgeführt wurden (z. B. Balme 1953; Grime 1963b; Etherington 1981). Demnach treten Acidophile/Calcifuge in Kalk-Halbtrockenrasen v. a. dort auf, wo ein mit oberflächiger Bodenverwitterung oder verstärktem Löss-

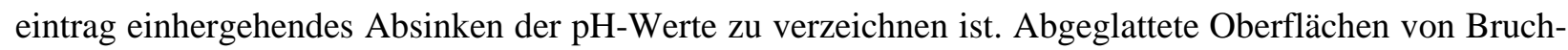
stücken des Ausgangsgesteins und tiefere Bodengründigkeiten lassen ebenso wie die niedrigeren $\mathrm{CaCO}_{3}$ Gehalte $(0,3 \% \mathrm{~m} / \mathrm{m})$ und $\mathrm{Ca}^{2+}$-Gehalte (ca. 0,4 $\mu \mathrm{mol} \cdot \mathrm{g}_{\mathrm{TG}}{ }^{-1}$ ) der Feinerde auf eine fortgeschrittene bzw. andersartige Bodengenese im Gentiano-Koelerietum danthonietosum schließen.

Andererseits unterschreiten die $\mathrm{pH}\left(\mathrm{H}_{2} \mathrm{O}\right)$-Werte im $\mathrm{A}_{\mathrm{h}}$-Horizont der CF-Bestände nicht prinzipiell diejenigen der typischen Subassoziation. Mit pH 7,7-7,9 sind die aktuellen Aciditäten von Feinerdehomogenaten der oberen $10 \mathrm{~cm}$ des Bodens in den CC- und CF-Vergleichsbeständen der Standorte Hölleberg und Steinkirche nahezu identisch. Aber auch im Gentiano-Koelerietum danthonietosum der Standorte Auf der Burg und Hölleberg-Süd liegen mit $\mathrm{pH}\left(\mathrm{H}_{2} \mathrm{O}\right) \approx 7,4$ Bodenreaktionen vor, die den $\mathrm{pH}$ der CC-Bestände bei einer offensichtlichen Carbonatpufferung nur um etwa eine halbe pH-Einheit unterschreiten. Sehr ähnliche Bodenreaktionen in den Vergleichsbeständen verleihen den im weiteren diskutierten Mineralstoffuntersuchungen besondere Aussagekraft. Mit den Standorten Flohrberg im Unteren Diemeltal und Pagenberg am Südharzrand wurden hier lediglich zwei Kalk-Halbtrockenrasen berücksichtigt, die im Hinblick auf die Bodenreaktionen den klassischen Vorstellungen der Differenzierung des Gentiano-Koelerietum typicum und Gentiano-Koelerietum danthonietosum entsprechen.

Dass die Bodenreaktionen der beiden Subassoziationen trotz vergleichbarer $\mathrm{pH}\left(\mathrm{H}_{2} \mathrm{O}\right)$-Werte voneinander abweichen, belegen die $\mathrm{pH}(\mathrm{KCl})$ von Mischfraktionen des Feinerdematerials der oberen $10 \mathrm{~cm}$ sowie die aktuellen und potentiellen Aciditäten in Bodentiefen von 0-5 cm bzw. 5-10 cm. An allen Standorten überschreiten die $\mathrm{pH}(\mathrm{KCl})$-Werte der typischen Subassoziation signifikant diejenigen der Subassoziation von Danthonia decumbens. Auch in Böden von CF-Einheiten, die nahezu identische $\mathrm{pH}\left(\mathrm{H}_{2} \mathrm{O}\right)$-Werte wie die CC-Vergleichsbestände aufweisen, werden deutlich mehr Protonen ausgetauscht. Dies wird durch die Basensättigungen der Standorte Auf der Burg und Hölleberg bestätigt. Sowohl die $\mathrm{pH}\left(\mathrm{H}_{2} \mathrm{O}\right)$-als auch die der $\mathrm{pH}(\mathrm{KCl})$-Messungen lassen darauf schließen, dass das Auftreten acidophiler/calcifuger Arten an den Standorten Auf der Burg und Hölleberg mit einer erhöhten Acidität in der obersten Bodenschicht einhergeht. In den oberen $5 \mathrm{~cm}$ des Bodens herrschen demnach Milieubedingungen vor, die nur noch begrenzt den Einfluss des Ausgangsgesteins widerspiegeln. 
Die Bodenarten geben keine Hinweise darauf, dass an den hier untersuchten Standorten unterschiedliche Lössanteile für die floristische Differenzierung der beiden Subassoziationen des Gentiano-Koelerietum verantwortlich sind. Mit Ausnahme der niedrigeren Anteile im Gentiano-Koelerietum typicum an der Steinkirche liegen in den Böden aller anderen Vegetationsbestände vergleichbare Schluffgehalte vor. Die bodenchemische Horizontierung geht hier also primär auf eine abweichende Bodenverwitterung zurück.

Der Boden-pH unterliegt nicht nur abiotischen, sondern auch biotischen Einflüssen. Neben mikrobiellen Stoffwechselreaktionen und pH-Effekten infolge von Anionen- bzw. Kationendefiziten der pflanzlichen Mineralstoffaufnahme können auch pflanzliche Sekundärstoffe zu pH-Veränderungen führen. Beispielsweise tragen Auswaschungen aus den Blättern und der Streu von Calluna vulgaris erheblich zur Ansäuerung des Bodens bei (Grubb \& Suter 1971; Jarvis 1974). Untersuchungen von Grubb et al. (1969) belegen negative Korrelationen zwischen der Pflanzengröße und dem Boden-pH sowie einen radialen Anstieg der pH-Werte vom Zentrum zur Peripherie der Pflanzen. Beide Ergebnisse lassen darauf schließen, dass niedrige $\mathrm{pH}$-Werte hier nicht die Ursache, sondern die Folge der Besiedlung durch C. vulgaris sind. Diese Untersuchungen erlauben allerdings keine Rückschlüsse darauf, ob kleinräumig versauerte Bereiche die Voraussetzung für die erstmalige Besiedlung eines Kalk-Halbtrockenrasens durch C. vulgaris sind. Im Gegensatz zu großflächigen bodenchemischen Veränderungen, etwa durch den Bestandsabfall, beschränken sich die dafür aber häufig um so intensiveren wurzelbürtigen Beeinflussungen im Wesentlichen auf die Rhizosphäre.

\section{Keimung und Keimlingsentwicklung}

Insbesondere die frühen Entwicklungsstadien eines Individuums unterliegen der physikochemischen Einwirkung des Oberbodens. Dessen Eigenschaften können daher zentrale Bedeutung für die Etablierung einer Art haben. Aus diesem Grund wurden die bodenkundlichen Untersuchungen der vorliegenden Arbeit durch solche zur Keimung und Keimlingsentwicklung ausgewählter Basiphiler/Calcicoler und Acidophiler/Calcifuger in Bodenmonolithen der CC- und CF-Bestände Auf der Burg ergänzt. Die Kulturversuche bezogen sich auf Populationen von Koeleria pyramidata und Potentilla neumanniana sowie Danthonia decumbens und Potentilla erecta aus dem Gentiano-Koelerietum vom Hölleberg. Im Hinblick auf mögliche ökotypische Differenzierungen wurden außerdem jeweils eine $D$. decumbens- und eine P. erecta-Population von Standorten mit saurer Bodenreaktion untersucht (Tabelle 25, S. 103). Durch anatomische und chromosomale Untersuchungen konnte für die $D$. decumbens-Population des Kalk-Halbtrockenrasens eine Zuordnung zur Unterart $D$. decumbens ssp. decipiens, für die des Borstgrasrasens zur Unterart $D$. decumbens ssp. decumbens erfolgen.

Die Versuchsergebnisse geben zwar keine Hinweise auf abweichende Präferenzen der beiden Unterarten von Danthonia decumbens, doch keimte $D$. decumbens ssp. decipiens in Bodenmaterial sowohl des Gentiano-Koelerietum typicum als auch des Gentiano-Koelerietum danthonietosum mehr als doppelt so gut wie D. decumbens ssp. decumbens. Angesichts der vergleichsweise hohen Basizität beider Versuchsböden deutet dieses Ergebnis darauf hin, dass unterschiedliches Keimungsverhalten durchaus für die Standortbindungen der beiden Unterarten von $D$. decumbens verantwortlich sein kann. Im Gegensatz dazu lassen die Keimungsexperimente keine autökologischen Unterschiede der Populationen von P. erecta erkennen. Es sei aber darauf verwiesen, dass $P$. erecta überhaupt nur in den feuchtesten und tiefgründigsten Bereichen der Kalk-Halbtrockenrasen auftrat. Wie Tabelle A 10 (S. 307) zeigt, musste für die Saatguternte von P. erecta am Hölleberg ein Bereich außerhalb des Vegetationsbestands der Saatguternte für die anderen Versuchsarten ausgewählt werden. Insgesamt verweisen Keimungsexperimente darauf, 
dass die auf das kalkreiche Ausgangsgestein zurückgehenden Bodenbedingungen die Entwicklung von D. decumbens ssp. decumbens und beider P. erecta-Populationen nicht nur in den Monolithen der CC-, sondern auch in denen der CF-Bestände hemmen. Wenngleich für $P$. neumanniana in Übereinstimmung mit seiner höheren Präsenz im Gentiano-Koelerietum typicum eine etwas bessere Keimung in den CCMonolithen belegt wurde, lassen die experimentellen Untersuchungen insgesamt nicht erkennen, dass eine chemoedaphische Beeinflussung des Keimungsverhalten für die floristische Differenzierung des Gentiano-Koelerietum verantworlich ist.

Während die Untersuchungen im Rahmen der vorliegenden Arbeit diesbezüglich allenfalls geringe Unterschiede acidophiler/calcifuger und basiphiler/calcicoler Konstitutionstypen erkennen lassen, konnte Rorison (1960a) für Scabiosa columbaria (R 8) und Asperula cynanchica (R 8) sowie für Holcus mollis (R 2) und Galium saxatile (=G. harcynicum, R 2) ein den Standortpräferenzen entsprechendes Keimungsverhalten in alkalischen und sauren Festsubstraten belegen. Dabei ist zu berücksichtigen, dass für die eigenen Kulturversuche Bodenproben gleicher Ausgangsgesteine verwendet wurden, die, anders als die von Rorison verwendeten Kreide- und Sandböden, nur geringe chemische und physikalische Unterschiede aufweisen. Auch Fockenbrock (1992) gewann im Rahmen ihrer Bearbeitung von insgesamt 27 calcifugen, intermediären, calcicolen und indifferenten Arten ${ }^{1}$ Hinweise auf einen Bezug zwischen der Standortpräferenz und dem Keimungsverhalten. Während Samen von C. vulgaris in Quarzsand zu fast 50 \% aufliefen, wurde die Keimung in $\mathrm{CaCO}_{3}$-reichem Bodenmaterial $(\mathrm{pH} 7,4)$ vollständig unterbunden. Hingegen zeigte das Saatgut der Danthonia decumbens-Population eines trockenen Sandmagerrasens über Buntsandstein in beiden Substraten Keimungsraten um 75 \%.

In der Literatur finden sich aber auch eine Reihe von Beispielen, die zeigen, dass hinsichtlich der Bodenreaktion kein allgemeingültiges Muster des Keimungsverhaltens acidophiler/calcifuger und basiphiler/calcicoler Arten existiert. In Abhängigkeit von den experimentellen Rahmenbedingungen kann zudem die pH-Abhängigkeit der Keimung ein- und derselben Art sehr stark variieren. So führt Gimingham (1960) neben Versuchen, die auf ein indifferentes Keimungsverhalten der acidophilen Calluna vulgaris zwischen pH 3,2-6,6 in Sand-Nährlösungskulturen schließen lassen, Untersuchungen an, die bei pH 4,0 in einem Agarmedium maximale und in Gartenerde bei pH6,8 sehr niedrige Keimungsraten belegen. In anderen Sandkulturen zeigte die Art bei pH 6,0 bessere Keimung als bei pH 3,2. Dunsford \& Davy (1989) und Davy et al. (1998) konnten nachweisen, dass die Behandlung nährstoffreicher, zuvor landwirtschaftlich genutzter Böden mit pyritreichem Torf unter Ansäuerung des Bodens auf pH 2,0-4,0 die Rekonstruktion von Calluna-Heiden unterstützt. Hierbei ist der Ausschluss konkurrierender, schnellwüchsiger Arten von besonderer Bedeutung. Andererseits zeigten diese Arbeiten, dass C. vulgaris wohl bei sehr niedrigen pH-Werten, nicht aber auf reinem Torf keimen kann. Whittaker \& Gimmingham (1962) kommen zu dem Schluss, dass der Keimungserfolg und die Etablierung von $C$. vulgaris weniger vom pH-Wert als vielmehr von dem Wassergehalt desSubstrats abhängt. Angesichts der geringen Samengröße und der Ausbildung nur sehr kleiner Keimlingswurzeln ist die Wasserversorgung der Jungpflanzen an vielen Standorten gefährdet.

\footnotetext{
1 R 9: Reseda luteola; R 8: Echinops sphaerocephalus; $\boldsymbol{R}$ 7: Brachypodium pinnatum, Bromus ramosus, Festuca arundinacea, Hordelymus europaeus, Silene dioica; $\boldsymbol{R}$ 6: Brachypodium sylvaticum, Festuca gigantea; $\boldsymbol{R}$ 5: Milium effusum, Poa nemoralis; R 4: Agrostis capillaris; $R$ 3: Arnica montana, Danthonia decumbens, Digitalis purpurea, Festuca ovina agg., Festuca filiformis, Luzula luzuloides; R 2: Anthoxanthum aristatum, Avenella flexuosa, Galium harcynicum, Nardus stricta, Rumex acetosella, Teucrium scorodonia; $\boldsymbol{R} 1$ : Calluna vulgaris, Juncus squarrosus; $\boldsymbol{R}$ X: Deschampsia cespitosa
} 
Grundsätzlich besitzen Böden hoher Acidität ein stärkeres Intoxikationspotenzial als solche neutraler und moderat alkalischer Bodenreaktion. Darauf verweisen u. a. Untersuchungen von Rorison (1967) zum Keimungsverhalten und Keimlingswachstum in neun Böden variierender $\mathrm{pH}$-Werte und damit korellierter Faktoren. Während insbesondere die Entwicklung der basiphilen/calcicolen Scabiosa columbaria (R 8) und Erigeron acer (= E. acris, R 8), aber auch der acidophilen Digitalis purpurea (R3) in sauren Böden (pH 3,5-4,1) beeinträchtigt wird, erfuhr mit Ausnahme von Avenella flexuosa (R 2) keine der sieben hier untersuchten Arten in Böden neutraler oder basischer Bodenreaktion (pH 7,0-7,4) nennenswerte Störungen ihrer frühen Entwicklung. Zu entsprechenden Ergebnissen kamen auch Mustart \& Cowling (1993) in Transplantationsexperimenten mit jeweils zwei im südafrikanischen Fynbos vikariierenden Arten der Proteaceae Leucadendron und Protea. Chemoedaphische Faktoren carbonatreicher Standorte wirken demnach offenbar erst über die Schädigung späterer Entwicklungsstadien vegetationsdifferenzierend.

\section{Wurzelstratifikation}

Die Erkenntnis, dass weniger die Protonenaktivitäten selber als vielmehr pH-abhängige bodenchemische Faktoren im Vordergrund ökophysiologischer Anpassungen und daraus resultierender vegetationskundlicher Differenzierungen stehen, gründet in erster Linie auf hydroponischen Untersuchungen. So belegten beispielsweise Kulturversuche mit Hilfe synthetischer Nährlösungen und wässriger Bodenextrakte, dass die Schädigung der basiphilen/calcicolen Scabiosa columbaria in sauren Festsubstraten primär auf die toxische Wirkung hoher Al-Konzentrationen und nicht auf abweichende $\mathrm{H}^{+}$-Aktivitäten der Böden zurückzuführen ist (Rorison 1960b). In anderen Fällen besitzt aber offensichtlich die Protonenaktivität selber einen relevanten Einfluss auf das Pflanzenwachstum. Lehmann (1993) konnte bei variierenden pHWerten zwar keine Unterschiede der Keimraten, wohl aber systematische Unterschiede im Wachstum der Keimwurzel von je zwei calcicolen, calcifugen und indifferenten Arten $^{1}$ in Nährlösung nachweisen.

In Übereinstimmung mit einer diesbezüglich ausgeprägten Sensitivität des Wurzelsystems steht die Beobachtung, dass an Standorten basisch verwitternder Ausgangsgesteine acidophile/calcifuge Arten bevorzugt in den oberen Bodenschichten wurzeln (z. B. Tansley \& Rankin 1911; Balme 1953; Jarvis 1974). Hintergrund dieser Horizontierung ist die oben dargestellte oberflächige Entbasung des Bodens oder der Auftrag von basenärmeren Bodenmaterialien. Beschrieben wurde dieses Phänomen u.a. von Meusel (1939) für eine Festuca glauca-Calluna vulgaris-Gesellschaft. Über Gipsgestein wurzelt C. vulgaris ausschließlich im Oberboden, während die calcicole Sesleria varia mit ihren Wurzeln bis in den Bereich des Ausgangsgesteins vordringt.

Marschner (1995) gibt eine zusammenfassende Darstellung der internen und externen Wirkungsmechanismen, die die phänotypische Plastizität des Wurzelwachstums bedingen und damit zu einer Stratifizierung des Wurzelsystems führen können. Verschiedene Untersuchungen haben gezeigt, dass die Wurzelmorphogenese in der Regel sekundär durch den pH beeinflusst wird. Die Bodenreaktion wirkt hierbei in erster Linie über die Ausbildung von Mineralstofftoxizitäten und Mineralstoffdefizienzen. Die intoxikative Hemmung des Wurzelwachstums erfolgt bei niedrigen $\mathrm{pH}$-Werten z. B. durch verschiedene Aluminiumspezies (s. Marschner 1995; s. Kochian 1995), bei hohen pH-Werten durch Hydrogencarbonat (Lee \& Woolhouse 1969a; Alhendawi et al. 1997) oder das bei bestimmten Düngungsmaßnahmen auftretende $\mathrm{NH}_{3}$ (Bennett \& Adams 1970; Creamer \& Fox 1980). In einigen Fällen wurde aber auch eine unmittel-

\footnotetext{
1 R 8: Legousia speculum-veneris, Consolida regalis; $\boldsymbol{R} 2$ : Scleranthus annuus, Spergula arvensis; $\boldsymbol{R} X$ : Centaurea cyanis,
} Aphanes arvensis. 
bare Wirkung der $\mathrm{H}^{+}$- bzw- $\mathrm{OH}^{-}$-Aktivitäten belegt, wie etwa im Fall der reversiblen Hemmung des Wurzelwachstum von Lupinus angustifolius durch hohe $\mathrm{pH}$-Werte (Tang et al. 1992). Schließlich wachsen die Wurzeln - soweit keine supraoptimalen Konzentrationsverhältnisse erreicht werden - v. a. dort, wo für die betreffende Art verbesserte Nährstoffverfügbarkeiten vorliegen. Dieses Phänomen bezieht sich insbesondere auf die Stickstoffversorgung (Gliemeroth 1953; Drew \& Saker 1975), aber auch, wie split rootExperimente zeigten, auf Phosphor (Drew \& Saker 1978) und Eisen (Lee \& Woolhouse 1969a; Schmidt et al. 1996). Gleichzeitig belegen Untersuchungen von Sydes \& Grime (1984), dass das Wurzelwachstum von Anthoxanthum odoratum, Festuca ovina, F. rubra und Sanguisorba minor in Kultursystemen, deren Wassergehalte vertikal geschichtet wurden, dem saisonalen Wachstumsverlauf der Arten entspricht: Während A. odoratum seinen Entwicklungshöhepunkt im feuchten Frühsommer erreicht und auch bei geringen Wasserverfügbarkeiten vorwiegend im Oberboden wurzelt, dringt das Wurzelsystem von S. minor - eine Art, die erst im deutlich trockeneren August maximale Wachstumsraten zeigt - bei gezielter Anspannung des Wasserhaushalts in sehr viel tiefere Bodenbereiche vor. Solche unterschiedlichen Eigenschaften werden von den Autoren als Voraussetzung für die Koexistenz dieser Arten auf flachgründigen Kalkstandorten betrachtet.

Auch wenn in vielen Fällen eine bevorzugte Durchwurzelung basenarmer, versauerter Bodenhorizonte durch Acidophile/Calcifuge (und basenreicher Bodenschichten hoher pH-Werte durch Basiphile/Calcicole) beobachtet wurde, sind oberflächige Entbasung und Wurzelstratifikation nicht unbedingt die Voraussetzung für das Auftreten acidophiler/calcifuger Konstitutionstypen über basenreichen Ausgangsgesteinen (Grime 1963b; Grubb et al. 1969). Messungen für Danthonia decumbens und Antennaria dioica geben keine Hinweise darauf, dass ihr Wurzelraum in einem Gentiano-Koelerietum agrostietosum niedrigere pH-Werte aufweist als der benachbarter Bodenbereiche ohne acidophile/calcifuge Arten (Bruelheide 1991). Ebenso wenig konnten hier auf Bestandsebene höhere Aciditäten gemessen werden als in Böden der typischen Subassoziation. Dieses Ergebnis wurde von Geringhoff \& Daniels (1994) bestätigt.

\subsubsection{Ionenaktivitäten}

Die elektrischen Leitfähigkeiten und die damit korrelierten Ionenstärken I der Bodenlösung werden bei den hier untersuchten kalkreichen Böden in erster Linie durch die $\mathrm{Ca}^{2+}$-Konzentrationen bestimmt. Die Koeffizienten der Korrelationsanalysen bestätigen einen entsprechend engen Bezug dieser Parameter für alle drei Extraktionsverfahren. ${ }^{1}$ Mit Ausnahme vergleichsweise variabler Analyte, wie $\mathrm{Mn}^{2+}, \mathrm{Na}^{+}, \mathrm{NH}_{4}{ }^{+}$, $\mathrm{NO}_{2}{ }^{-}$, aber auch $\mathrm{SO}_{4}{ }^{2-}$, folgen die meisten Lösungskomponenten den Leitfähigkeiten der wässrigen Bodenextrakte.

Die analytischen Anionendefizite und deren enger Bezug zu den $\mathrm{Ca}^{2+}$-Konzentrationen geben einen Hinweis darauf, dass (unter den gegebenen $\mathrm{pH}$-Bedingungen) $\mathrm{HCO}_{3}{ }^{-}$als Produkt der Kalklösung für den Ladungsausgleich in den Bodenextrakten verantwortlich zeichnet. Legt man der Regression von EC und I, wie sie für die Berechnung der Ionenstärken auf Grundlage elektrischer Leitfähigkeiten verwendet wird (Robbins et al. 1980; Edmeades et al. 1985; Parker et al. 1987), neben den Konzentrationen der analysierten Anionen und Kationen entsprechende Mengen $\mathrm{HCO}_{3}^{-}$für den Ausgleich des Anionendefizits zugrunde, finden sich die daraus resultierenden Ergebnisse in guter Übereinstimmung mit diesbezüglichen Literaturangaben. In den vorliegend dargestellten Untersuchungen besitzt die lineare Regressions-

\footnotetext{
1 Ergebnisse der Rangkorrelationsanalysen nach Spearman für die feinerdebezogenen Konzentrationen der verschiedenen Analy-
} te sind in Tabelle A 11, Tabelle A 12 und Tabelle A 13 aufgeführt. Nachfolgende Angaben beziehen sich auf diese Tabellen. 
funktion I=0,014 EC + 0,338 ( $r=0,856)$ einen Regressionskoeffizienten, der zwischen dem von Griffin \& Jurinak (1973) für Sättigungsextrakte sowie Flusswasser $\left(b_{1}=0,013\right)$ und dem von Alva et al. (1991) für aktuelle Bodenlösungen $\left(b_{1}=0,015\right)$ kalkulierten liegt. Wie im zweitgenannten Fall, wurde auch hier auf die Berücksichtigung interionarer Anziehungskräfte verzichtet und damit die Regressionsfunktion nicht für die Aktivitäten, sondern für Konzentrationen der Ionen in den Lösungen berechnet. Gillman \& Bell (1978) gehen davon aus, dass bei $\mathrm{I}<12 \mathrm{mM}$ solche Interaktionen nur einen geringfügigen Effekt auf die Ionenstärke haben. Korrekturen, wie sie etwa auf Grundlage der Debye-Hückel- oder Davies-Gleichungen erfolgen, können aber nach Einschätzung anderer Autoren bereits bei I > $1 \mathrm{mM}$ wirksam werden und zu einer Abnahme der betreffenden Regressionskoeffizienten für die Beziehung zwischen I und EC führen. Ionenpaarbindungen wurden von Griffin \& Jurinak (1973) bei der Auswertung ihrer Untersuchungen berücksichtigt und sind möglicherweise für die Unterschiede der hier angeführten Regressionskoeffizienten verantwortlich (Lindsay 1979; Wolt 1994).

\subsubsection{Hydrogencarbonat}

Eine exakte Analyse der Carbonatfraktionen in der Bodenlösung ist außerordentlich schwierig. Die $\mathrm{HCO}_{3}{ }^{-}$-Konzentration ist, wie bereits in Abschnitt 4.2.3 (S. 114 f.) ausgeführt wurde, eine Funktion des $\mathrm{pH}$-Werts und des $\mathrm{CO}_{2}$-Partialdrucks. Zudem wird die Konzentration an Gesamtcarbonat $\mathrm{C}_{\mathrm{T}}$ (=DIC) im Gleichgewichtssystem u. a. auch durch die Temperatur beeinflusst. $\mathrm{C}_{\mathrm{T}}$ umfasst nicht nur die Kohlensäure und deren Dissoziationsspezies, sondern auch gelöstes $\mathrm{CO}_{2}$. Das Gesamtcarbonat lässt sich für Modelllösungen wie folgt berechnen (Wolt 1994):

$$
\begin{array}{ll}
C_{T}=K_{H} \cdot R \cdot T \cdot\left[\mathrm{CO}_{2 g}\right] \cdot\left(1+\frac{K_{1}}{\left[H^{+}\right]}+\frac{K_{1} \cdot K_{2}}{\left[H^{+}\right]^{2}}\right)=K_{H} \cdot P\left(\mathrm{CO}_{2}\right) \cdot\left(1+\frac{K_{1}}{\left[H^{+}\right]}+\frac{K_{1} \cdot K_{2}}{\left[H^{+}\right]^{2}}\right) \\
C_{T} \quad \text { Gesamtkonzentration Carbonat }\left(\mathrm{H}_{2} \mathrm{CO}_{3}{ }^{*}+\mathrm{HCO}_{3}{ }^{-}+\mathrm{CO}_{3}{ }^{2-}\right) ;[\mathrm{M}] \\
K_{H} \quad \text { Henry-Konstante; temperaturabhängige Löslichkeitskonstante für } \mathrm{CO}_{2 \mathrm{~g}} ;\left[\mathrm{M} \cdot \mathrm{Pa}^{-1}\right] \\
R & \text { Allgemeine Gaskonstante; } \mathrm{R}=8,143 \mathrm{~J} \cdot \mathrm{mol}^{-1} \cdot \mathrm{K} \\
T & \text { Temperatur; }[\mathrm{K}] \\
K_{1} & \text { Gleichgewichtskonstante für die Dissoziation } \mathrm{H}_{2} \mathrm{CO}_{3} \leftrightarrows \mathrm{HCO}_{3}^{-}+\mathrm{H}^{+} \\
K_{2} & \text { Gleichgewichtskonstante für die Dissoziation } \mathrm{HCO}_{3}^{-} \leftrightarrows \mathrm{CO}_{3}{ }^{2-}+\mathrm{H}^{+} \\
\mathrm{CO}_{2 g} & \text { Konzentration des gasförmigen } \mathrm{CO}_{2} ;[\mathrm{M}] \\
P & \text { Partialdruck; }[\mathrm{Pa}] .
\end{array}
$$

Sowohl der $\mathrm{CO}_{2}$-Partialdruck als auch die $\mathrm{CO}_{2}$-Löslichkeitskonstante sind temperaturabhängig. Die Henry-Konstante sinkt, der Partialdruck steigt mit Zunahme der Temperatur (Holleman et al. 1985). Auch $\mathrm{K}_{1}$ und $\mathrm{K}_{2}$ werden durch Temperatur- und Druckänderungen beeinflusst: Temperatur- und Druckanstieg gehen hier mit einem leichten Abfall der Dissoziationskonstanten einher. $\mathrm{P}\left(\mathrm{CO}_{2}\right)$ ist abhängig von der Menge an $\mathrm{CO}_{2}$, die im System freigesetzt wird, und der Geschwindigkeit, mit der es entweichen kann. Insbesondere in der Rhizosphäre treten infolge der Wurzelatmung und der mikrobiellen Umsetzungen erhöhte $\mathrm{CO}_{2}$-Konzentrationen auf. In $\mathrm{CaCO}_{3}$-reichen Böden wird $\mathrm{C}_{\mathrm{T}}$ zudem durch die $\mathrm{CO}_{2}$-vermittelte Auflösung von Kalk erhöht:

$$
\mathrm{CaCO}_{3}+\mathrm{CO}_{2}+\mathrm{H}_{2} \mathrm{O} \leftrightarrows 2 \mathrm{HCO}_{3}^{-}+\mathrm{Ca}^{2+}
$$

Temperaturänderungen gehen mit der Überlagerung von zwei gegenläufigen Effekten einher: Einerseits steigt mit der Abnahme der Temperatur die $\mathrm{CO}_{2}$-Löslichkeit, andererseits stimulieren hohe Temperaturen die biologische Aktivität und damit die Freisetzung von $\mathrm{CO}_{2}$. In der Regel ist der letztgenannte Faktor 
von größerer Relevanz, so dass maximale $\mathrm{CO}_{2}$-Partialdrücke zumeist im Sommer auftreten (Castelle \& Galloway 1990; Terhune \& Harden 1991; Federer \& Sticher 1994). Die Bodentemperatur wiederum findet einen Bezug zur Bodentextur. Feinstrukturierte Böden sind in aller Regel feuchter und kühler. Andererseits kann Bodentrocknis in skelettreichen Böden die Mineralisationsraten und damit die Freisetzung von $\mathrm{CO}_{2}$ einschränken.

Hohe Tongehalte sowie die Verdichtung und/oder Wassersättigung des Bodens beeinträchtigen die Diffusionsraten und lassen die $\mathrm{CO}_{2}$-Partialdrücke auf Werte von mehr als $10 \mathrm{kPa}$ ansteigen (Loeppert 1986). Die Erhöhung des $\mathrm{CO}_{2}$-Partialdruck von $40 \mathrm{~Pa}$ auf $500 \mathrm{~Pa}$ führt in Modellsystemen zu einem Absinken der Protonenaktivitäten von $\mathrm{pH}$ 7,5 auf $\mathrm{pH}$ 6,8 und zu einem Anstieg der $\mathrm{HCO}_{3}{ }^{-}$-Konzentrationen von 2,53,0 mM auf $7 \mathrm{mM}$ (Kinzel 1982). Modellrechnungen für fiktive Bodenlösungen verweisen auf einen Anstieg von $\mathrm{pH}$ 7,0 auf pH 8,0, wenn durch Entgasung $\mathrm{P}\left(\mathrm{CO}_{2}\right)$ von $304 \mathrm{~Pa}$ auf $30 \mathrm{~Pa}$ absinkt (Wolt 1994).

Druck- und Temperaturveränderungen während der Lösungsextraktion haben theoretisch keinen Einfluss auf die Ergebnisse der Bodenanalytik, wenn die initialen Bedingungen wiederhergestellt werden. Allerdings bedeutet bereits die Trennung von Bodenlösung, Bodenfestphase und Bodenluft eine Irreversibilität aller Reaktionen, die zwischen diesen Fraktionen als Folge temporär veränderter Rahmenbedingungen stattfinden. Besonders weit reichen Effekte, die auf die Ausgasung von $\mathrm{CO}_{2}$ während oder nach der Lösungsextraktion zurückzuführen sind (Takkar et al. 1987). Diese bedingen nicht nur eine Abnahme von $\mathrm{C}_{\mathrm{T}}$ und der betreffenden Carbonatspezies, sondern, wie Gleichung 26 belegt, auch Änderungen des $\mathrm{pH}-$ Werts. Praktische und theoretische Ansätze von Suarez (1986, 1987), auf die hier nicht näher eingegangen werden soll, zielen darauf ab, derartige Versuchsartefakte zu umgehen. Veränderungen des $\mathrm{CO}_{3}{ }^{2-}-$ und $\mathrm{pH}$-Haushalts, die aus dem Entweichen von $\mathrm{CO}_{2}$ resultieren, wirken in sauren, schwach gepufferten Bodenlösungen stärker als in Lösungen kalkreicher Böden mit ihren hohen Alkalinitäten.

Zusammenfassend lassen sich Konzentrationsunterschiede des Gesamtcarbonats und seiner Teilfraktionen auf folgende Faktoren des Bodens zurückführen:

- $\mathrm{CaCO}_{3}$-Gehalt

- Textur und Wassergehalt

- Temperatur

- Atmungsaktivität

- $\mathrm{pH}-$ Wert.

Experimentell kann $\mathrm{HCO}_{3}{ }^{-}$nicht nur durch Rücktitration der Analysenlösung (mit 0,1 $\mathrm{M} \mathrm{HCl}$ auf $\mathrm{pH}$ 4,3; Deutsches Institut für Normung 1979), sondern entsprechend der in Abschnitt 2.2 .5 (S. 25 f.) dargestellten Methodik auch ionenchromatographisch analysiert werden. Eine diesbezügliche Auswertung der Chromatogramme war in der vorliegenden Arbeit wegen der sehr hohen $\mathrm{HCO}_{3}{ }^{-}$-Konzentrationen, die eine starke Verdünnung der Analysenlösungen erforderlich gemacht hätten, nicht möglich. Zudem sind wegen der extremen Druckverhältnisse Ergebnisse von HPIC-Analysen kritisch zu betrachten. Das Titrationsverfahren ist in solchen Fällen unzulässig, in denen die Probe starke Basen oder andere Säure verbrauchende Stoffe, wie etwa Phosphate oder Polyphosphate enthält. Auch aufgrund dieser Unzulänglichkeiten der praktischen Methoden wurden hier für die Bewertung der $\mathrm{HCO}_{3}{ }^{-}$-Konzentrationen in den Vegetationsbeständen der verschiedenen Kalk-Halbtrockenrasen Auswertungsansätze gewählt, die auf anderen Messgrößen basieren. 
Neben den analytischen Anionendefiziten der Tabelle 9 geben Gleichgewichtsberechnungen für das Carbonatsystem Hinweise auf die $\mathrm{HCO}_{3}{ }^{-}$-Konzentrationen in den Bodenlösungen der Vegetationsbestände. Die Datengrundlage für diese Kalkulationen mit Hilfe des chemischen Spezifizierungsprogramms GEOCHEM-PC (Parker et al. 1995; Parker \& Chaney 1995) bildeten Ergebnisse der Mineralstoffanalysen und $\mathrm{pH}-$ Messungen sowie die $\mathrm{C}_{\mathrm{T}}$-Konzentrationen der Bodenextrakte. Letztere wurden im Rahmen der DOC-Analysen für den jeweils dritten Probennahmetermin mittels Infrarotspektrometrie bestimmt. Die $\mathrm{HCO}_{3}^{-}$-Konzentrationen in Tabelle 32 beziehen sich auf ein offenes System, in dem ein freier Austausch von $\mathrm{CO}_{2}$ zwischen der Lösungs- und Gasphase erfolgen kann. Bezugstemperatur aller GEOCHEM-PC-Berechnungen ist $25^{\circ} \mathrm{C}$. Weitere Informationen zur bodenkundlichen Carbonatanalytik sowie zur diesbezüglichen Anwendung von GEOCHEM-PC und anderer Spezifizierungsprogramme finden sich in Suarez (1995).

Tabelle 32: Ergebnisse der GEOCHEM-PC-Berechnungen der $\mathrm{HCO}_{3}^{-}-$Konzentrationen [ $\left.\mu \mathrm{M}\right]$ auf Grundlage von Kationen/Anionen-Analysen sowie Messungen des $p H$ und $C_{T}$ von GBL, PBL und DBL für ein offenes System bei $25^{\circ} \mathrm{C}$ (Suarez 1995; Parker \& Chaney 1995). $M W \pm S D(n=8)$.

\begin{tabular}{lccc}
\hline Standort & GBL & PBL & DBL \\
\hline Auf der Burg CC & $704 \pm 452$ & $1414 \pm 569$ & $642 \pm 90$ \\
Auf der Burg CF & $563 \pm 248$ & $494 \pm 113$ & $269 \pm 86$ \\
Hölleberg CC & $386 \pm 74$ & $279 \pm 68$ & $139 \pm 50$ \\
Hölleberg CF & $447 \pm 115$ & $248 \pm 37$ & $115 \pm 28$ \\
\hline
\end{tabular}

Die $\mathrm{HCO}_{3}{ }^{-}$-Konzentrationen, wie sie anhand der in Tabelle 9 (S. 73) aufgeführten Anionendefizite berechnet wurden, und solche, die aus den oben beschriebenen GEOCHEM-PC-Kalkulationen resultieren, zeigen deutliche Abweichungen voneinander. Demnach liegen die Hydrogencarbonatkonzentrationen in der vereinfachenden Annahme eines 100 \%igen Ausgleichs des Anionendefizits durch $\mathrm{HCO}_{3}{ }^{-}$für die GBL und PBL zwischen 1-4 mM, nach den GEOCHEM-PC-Berechnungen hingegen zwischen 0,251,4 mM. Vergleichbare methodisch begründete Differenzen ergeben sich auch für die Auswertungen der DBL. Hintergrund abweichender Ergebnisse der GEOCHEM-PC-Spezifizierungen sind offensichtlich Inkonsistenzen zwischen den vorgegebenen $\mathrm{H}^{+}$-Aktivitäten und $\mathrm{C}_{\mathrm{T}}$-Werten. GEOCHEM-PC erlaubt eine ergänzende Angabe des $\mathrm{CO}_{2}$-Partialdrucks, so dass entsprechend Gleichung 26 auch die dritte Variable des Carbonatsystems in die Berechnungen mit einbezogen werden kann. $\mathrm{P}\left(\mathrm{CO}_{2}\right)$ dient in diesem Fall allein der Kontrolle der Untersuchungen. Wird den Kalkulationen ein atmosphärischer $\mathrm{CO}_{2}$-Partialdruck von 3,5 Pa zugrunde gelegt, müssen bei den in Tabelle 32 angegebenen $\mathrm{HCO}_{3}{ }^{-}$-Konzentrationen theoretisch etwa $80 \%$ des $\mathrm{C}_{\mathrm{T}}$ als $\mathrm{CO}_{2}$ aus der Lösung entweichen, damit die vorgegebenen Gleichgewichtsverhältnisse erreicht werden. Demnach waren die Bodenlösungen zum Zeitpunkt der $\mathrm{pH}$ - und $\mathrm{C}_{\mathrm{T}}-\mathrm{Messungen}$ hinsichtlich ihres Kohlenstoffgehalts übersättigt. Dennoch liegen die $\mathrm{HCO}_{3}^{-}$-Konzentrationen der GEOCHEM-PC-Kalkulationen in Bereichen, wie sie auch von Misra \& Tyler (2000) titrimetrisch für Kalkböden variierender Wassersättigungen bestimmt wurden. Die Erhöhung der Wasserkapazitäten der Feinerde von Rendzinen auf Werte über 70 \% ging hier mit einem sprunghaften Anstieg der $\mathrm{HCO}_{3}{ }^{-}$-Konzentrationen von $100 \mu \mathrm{M}$ auf $850 \mu \mathrm{M}$ einher.

Im Hinblick auf die Bedeutung von $\mathrm{HCO}_{3}^{-}$für die Differenzierung verschiedener Subassoziationen des Gentiano-Koelerietum sind weniger die absoluten $\mathrm{HCO}_{3}^{-}$-Konzentrationen als vielmehr deren Verhältnisse zwischen den betreffenden Vegetationseinheiten von Interesse. Während alle Auswertungsansätze für den Standort Auf der Burg auf höhere $\mathrm{HCO}_{3}^{-}$-Konzentrationen im Gentiano-Koelerietum typicum 
schließen lassen, liegen diesbezüglich am Standort Hölleberg nur tendenzielle Abweichungen zwischen den beiden Subassoziationen vor. Die Einträge in Tabelle 9 und Tabelle 32 verweisen für die GBL auf gleiche bzw. etwas höhere, für die PBL und DBL auf 10-30 \% niedrigere $\mathrm{HCO}_{3}^{-}$-Konzentrationen im Gentiano-Koelerietum danthonietosum.

Die hier aufgeführten Werte für die GBL, PBL und DBL dürfen nur als Annäherungen an die tatsächlichen $\mathrm{HCO}_{3}{ }^{-}$-Konzentrationen in situ betrachtet werden. Verminderte Diffusionsraten führen zu hohen $\mathrm{CO}_{2}$-Partialdrücken im Boden sowie erhöhten $\mathrm{HCO}_{3}{ }^{-}$- (und $\mathrm{C}_{\mathrm{T}}{ }^{-}$) Konzentrationen in der realen Bodenlösung. Dieser Effekt ist v. a. für die skelettarmen, feinstrukturierten Böden der CF-Bestände mit ihren etwas höheren Lagerungsdichten und den daraus abzuleitenden geringeren Porenanteilen der Feinerde von Bedeutung (vgl. Tabelle 6, S. 51). Theoretisch können daher die $\mathrm{HCO}_{3}{ }^{-}$Konzentrationen kalkärmerer Böden diejenigen kalkreicherer Böden übersteigen, so wie dies die GBL für die CF-Vegetationsbestände des Standorts Hölleberg andeuten. Dies gilt v. a. für Böden, in deren Feinerde verwittertes Kalkgestein sehr feiner Körnung vorliegt. Da der biotische $\mathrm{CO}_{2}$ - bzw. $\mathrm{HCO}_{3}{ }^{-}$-Eintrag in vielen Böden beträchtlich ist, wird $\mathrm{CaCO}_{3}$ v. a. im Wurzelraum gelöst. Nach Kalkulationen von Chapman (1979) bestreitet die rhizosphärische Atmung beispielsweise in einer Calluna-Heide etwa 70 \% der gesamten Bodenatmung.

Sowohl direkte als auch indirekte Hydrogencarbonatanalysen sind angesichts der oben dargestellten Unzulänglichkeiten mit Fehlern behaftet. Wenngleich eine abschließende Bewertung der hier behandelten Böden somit nur unter Vorbehalt erfolgen kann, geben die Untersuchungsergebnisse zusammen mit den theoretischen Überlegungen Hinweise darauf, dass in der Rhizosphäre des Gentiano-Koelerietum danthonietosum nicht grundsätzlich niedrigere $\mathrm{HCO}_{3}{ }^{-}$-Konzentrationen vorliegen als in der des GentianoKoelerietum typicum.

Gleichgewichtsberechnungen, wie sie in Abschnitt 4.2.3 (S. 114 f.) vorgestellt wurden, lassen in kalkreichen Böden $\mathrm{HCO}_{3}{ }^{-}$-Konzentrationen bis zu 10-20 mM erwarten (Woolhouse 1966; Loeppert 1988). An diesen Werten orientiert sich in den meisten Nährlösungsuntersuchungen der Zusatz von Hydrogencarbonatsalzen (Cinelli 1995; Alhendawi et al. 1997; Romera et al. 1997). Nach wie vor bleiben leider auch heute noch bei vielen experimentellen Ansätze die Gleichgewichtsreaktionen unberücksichtigt, die in offenen Systemen zu einer umgehenden Drift der pH-Werte oder - bei Fixierung der Protonenaktivitäten - zu Veränderungen der $\mathrm{HCO}_{3}{ }^{-}$-Konzentrationen führen. Entsprechend kritisch müssen diese Untersuchungen betrachtet werden.

\subsubsection{Calcium}

Wie bereits die Ausführungen zum Gleichgewichtssystem anorganischer Kohlenstoffverbindungen gezeigt haben, stehen die $\mathrm{HCO}_{3}^{-}-$und $\mathrm{Ca}^{2+}$-Konzentrationen sowie die $\mathrm{pH}$-Werte und Kalkgehalte des Bodens in einer engen Beziehung zueinander. Anders als $\mathrm{HCO}_{3}{ }^{-}$wurden die letztgenannten und die nachfolgend diskutierten Standortfaktoren für alle Untersuchungsbestände und Probennahmetermine direkt analysiert. Daher kann ihre Bedeutung für die Vegetationsdifferenzierung des Gentiano-Koelerietum umfassender bewertet werden als die des Hydrogencarbonats.

Die Reihenfolge, in der die Standortfaktoren in Tabelle 24 (S. 101 f.) aufgelistet sind, gibt Hinweise auf ihre Bedeutung für die Etablierung von acidophilen/calcifugen Arten in der Pflanzengesellschaft. Neben den potenziellen Aciditäten differieren die Kalkgehalte der Feinerde in den beiden Subassoziationen besonders deutlich. An allen Untersuchungsstandorten liegen die Werte dieser beiden Faktoren für das Gentiano-Koelerietum typicum signifikant über denen des Gentiano-Koelerietum danthonietosum. 
Die aktuellen Aciditäten und die feinerdebezogenen Calciumkonzentrationen finden sich tendenziell in Übereinstimmung mit den Carbonatgehalten des Oberbodens. Allerdings weichen die aktuellen Aciditäten und v. a. die feinerdebezogenen $\mathrm{Ca}^{2+}$-Konzentrationen zwischen den Vergleichsbeständen weit weniger voneinander ab als die potentiellen Aciditäten und die Kalkgehalte. An den Untersuchungsstandorten Hölleberg und Hölleberg-Süd existieren für diese beiden Faktoren keine signifikanten Unterschiede zwischen den beiden Subassoziationen. Hier wie dort belegen die Analysen hohe $\mathrm{Ca}^{2+}$-Gehalte im GentianoKoelerietum danthonietosum. Die wässrigen Extrakte verweisen sogar auf tendenziell höhere Calciumlöslichkeiten im Boden des CF-Bestands am Standort Hölleberg-Süd. Insbesondere hier, aber auch anderenorts, korrelieren die Carbonatgehalte und Calciumlöslichkeiten der Feinerde kaum miteinander.

Die Untersuchungen der Kationenaustauscherbelegungen für die beiden Referenzstandorte bestätigen, dass das Auftreten acidophiler/calcifuger Arten im Gentiano-Koelerietum mit nur geringen Abnahmen der Calciumkonzentrationen einhergeht. Bei einer fast vollständigen Basensättigung und einer mehr als 90 \%igen $\mathrm{Ca}^{2+}$-Belegung der Kationenaustauscher aller untersuchten Böden, weichen die austauschbaren Calciumgehalte zwischen den Vergleichsbeständen lediglich um 22 \% (Auf der Burg) und 12 \% (Hölleberg) zugunsten der CC-Bestände voneinander ab.

Experimentelle Untersuchungen, wie sie in der Literatur beschrieben werden, vermitteln ein uneinheitliches Bild des Calciumbedarfs bzw. der Calciumtoleranz basiphiler/calcicoler und acidophiler/calcifuger Arten. Neben solchen, die auf einen Bezug zwischen der natürlichen Verbreitung der Arten und ihrem Wachstum bei abgestuften $\mathrm{Ca}^{2+}$-Konzentrationen aber einheitlichen $\mathrm{pH}-$ Werten hindeuten, finden sich Veröffentlichungen, die eine unmittelbare Bedeutung von Calcium für die Differenzierung der genannten Konstitutionstypen ausschließen.

Die Erhöhung des austauschbaren $\mathrm{Ca}^{2+}$ eines flachgründigen Podsols (pH 4,1) von 18,5 $\mu \mathrm{mol} / \mathrm{g}$ auf $164 \mu \mathrm{mol} / \mathrm{g}$ durch Zusatz von $\mathrm{CaSO}_{4}$ sowie die Erhöhung der $\mathrm{Ca}^{2+}$-Konzentrationen in Nährlösungen (pH 4,2) von $25 \mu \mathrm{M}$ auf 2,5 mM führten bei vier Agrostis-Arten zu einer gleich gerichteten, in ihrem Ausmaß aber unterschiedlichen Wachstumsförderung (Clarkson 1965). Auch die stark acidophile A. setacea zeigte keine Wachstumshemmung bei einem Anstieg der austauschbaren Calciumgehalte in Sandkulturen auf Werte, die die Maximalkonzentrationen in den hier untersuchten Kalk-Halbtrockenrasen um fast das Doppelte übersteigen. Diese Untersuchungen belegen für alle vier Arten eine kontinuierliche Biomassezunahme durch die schrittweise Erhöhung der $\mathrm{Ca}^{2+}$-Konzentration auf 2,5 mM. Wird der Projektion weiter steigender $\mathrm{Ca}^{2+}$-Konzentrationen eine Optimumkurve der Biomasseentwicklung zugrunde gelegt, so ist davon auszugehen, dass auch Konzentrationen von mehr als 4,0 $\mathrm{mM} \mathrm{Ca}^{2+}$, wie sie in Gleichgewichtsbodenlösungen der Varianten Auf der Burg CC und Hölleberg-Süd CF gemessen wurden, zu keiner Wachstumshemmung der genannten Agrostis-Arten führen. Ein wesentlicher Unterschied zwischen A. setacea und den verbleibenden Arten liegt allerdings darin, dass letztere durch Erhöhung der $\mathrm{Ca}^{2+}$ Konzentrationen sowohl im Festsubstrat als auch in Hydroponik sehr viel stärker in ihrem Wachstum gefördert werden. Dies gilt insbesondere für die von den Autoren als calcicol eingestufte A. stolonifera, aber auch für die acidophilen/calcifugen A. canina und A.tenuis. Die Untersuchungen lassen daher vermuten, dass an den natürlichen Standorten weniger ein Ausschluss Acidophiler/Calcifuger durch $\mathrm{Ca}^{2+}$ Intoxikation erfolgt als vielmehr eine Auskonkurrierung durch Vikarianten, die durch hohe $\mathrm{Ca}^{2+}$-Konzentrationen besonders stark gefördert werden. Mit dieser Interpretation stimmen auch Gewebeanalysen überein, nach denen bei den untersuchten Agrostis-Arten eine positive Korrelation zwischen den $\mathrm{Ca}^{2+}$ Konzentrationen und der Biomasse vorliegt. Clarkson (1965) geht zudem von einem Bezug zwischen der potenziellen Wachstumsrate und der Sättigungskonzentration des $\mathrm{Ca}^{2+}$-Aufnahmesystems aus. 
Untersuchungen von Grothus (1986) bestätigen, dass acidophile/calcifuge und basiphile/calcicole Arten einen unterschiedlichen Calciumhaushalt besitzen. Variationen der hydroponischen $\mathrm{CaSO}_{4}$-Konzentrationen zwischen 0-12 mM (pH3,2) führten bei Calluna vulgaris oberhalb 2,2 $\mathrm{mM}$ zu einer signifikanten Abnahme der Trockengewichte. Unter den jeweils fünf Arten mit Präferenzen für kalkreiche, neutrale bis basische Böden einerseits und saure, basenarme Böden andererseits ${ }^{1}$ fanden sich aber mit Carex remota eine basiphile/calcicole oder indifferente Art, deren Wurzelwachstum bereits bei weniger als $1 \mathrm{mM} \mathrm{Ca}{ }^{2+}$ signifikant, und mit Digitalis purpurea und Juncus squarrosus zwei acidophile/calcifuge Arten, deren Biomasseproduktion auch durch $12 \mathrm{mM} \mathrm{Ca}{ }^{2+}$ nicht gehemmt wurde. Insgesamt lassen diese Untersuchungen auf einen Zusammenhang zwischen den potenziellen Wachstumsraten und dem Calciumbedarf der Arten schließen. Korrelationen des spezifischen Mineralstoffbedarfs und des Wachstums sind aber nicht nur für Calcium belegt. Bereits 1888 hat Sachs auf die Bedeutung der Wachstumsgeschwindigkeit für den pflanzlichen Eisenbedarf hingewiesen (Bergmann 1988).

Anders als die eigenen Untersuchungen und die genannten Arbeiten von Clarkson (1965) und Grothus (1986) verweisen Kulturexperimente von Jefferies \& Willis (1964b) an drei Monocotylen sowie einer Dicotylen auf einen Bezug zwischen dem Ca-Bedarf bzw. der Ca-Toleranz und den Standortpräferenzen. Untersuchungen zum Einfluss variierender $\mathrm{CaCl}_{2}$ - und $\mathrm{Ca}\left(\mathrm{NO}_{3}\right)_{2}$-Konzentrationen in Sandkulturen bestätigen nicht die von Grothus (1986) ermittelte Calciumtoleranz von Juncus squarrosus. Unter den gegebenen Kulturbedingungen wurde für die Art eine Wachstumshemmung bereits bei $\mathrm{Ca}^{2+}$-Konzentrationen oberhalb 0,25 mM gefunden. Diese vermeintlichen Inkonsistenzen dürften in abweichenden pH-Werten, im Einsatz verschiedener $\mathrm{Ca}^{2+}$-Salze oder in physikochemischen Unterschieden der jeweiligen Versuchsanordnungen begründet liegen. Eine Vielzahl von Untersuchungen weisen auf Antagonismen zwischen Calcium einerseits und Magnesium, Kalium, Aluminium, Eisen und Mangan andererseits hin (s. Kinzel 1982; s. Marschner 1995). In Nährlösungsuntersuchungen zur Calciumeffizienz und Calciumtoleranz werden häufig sehr viel engere $\mathrm{c}\left(\mathrm{Ca}^{2+}\right) / \mathrm{c}\left(\sum \mathrm{Kat}^{+}\right)$-Verhältnisse eingestellt als sie an den natürlichen Standorten vorzufinden sind. Auf kompetitive Reaktionen zwischen $\mathrm{H}^{+}$und $\mathrm{Ca}^{2+}$ haben schon Marschner \& Mengel (1966) verwiesen. Kulturexperimente bei niedrigen $\mathrm{pH}$-Werten führen zu einer Überschätzung der Calciumtoleranzen unter Bedingungen, wie sie in kalkreichen Böden auftreten. Während in den Sandkulturen von Jefferies \& Willis (1964b) pH5,0 $\pm 0,5$ vorlag, überstiegen die Protonenaktivitäten in den Nährlösungskulturen (pH 3,2) von Grothus (1986) diesen Wert um das Zweihundertfache. Bei der Bewertung von Nährlösungsexperimenten sind überdies abweichende physikalische Bedingungen in der Rhizosphäre und die daraus resultierenden Abweichungen in den Diffusions- und Massenflussraten zwischen wurzelnahen und wurzelfernen Bereichen zu berücksichtigen. So kann auch eine rhizosphärische $\mathrm{Ca}^{2+}$ Anreicherung, wie sie in Sandkultur, nicht aber in Nährlösungskulturen zu erwarten ist, als eine Ursache für die geringere Calciumtoleranz von J. squarrosus in den Untersuchungen von Jefferies \& Willis betrachtet werden.

Danthonia decumbens, eine Art, die von vielen Autoren als Acidophile betrachtet wird, zeigte in den Untersuchungen von Jefferies \& Willis (1964b) ein ausgeglichenes Wachstum über einen sehr weiten $\mathrm{Ca}^{2+}$-Konzentrationsbereich. Bemüht werden für die Erklärung ihres Wachstums auf kalkreichen Standorten neben einer besonderen Toleranz adulter Pflanzen gegenüber variierenden $\mathrm{Ca}^{2+}$-Konzentrationen auch die Keimung in niederschlagsreichen Wintermonaten, oberflächige Entbasung und Wurzelstratifika-

\footnotetext{
$1 \quad \boldsymbol{R}$ 8: Origanum vulgare; $\boldsymbol{R}$ 6: Brachypodium sylvaticum; $\boldsymbol{R}$ 3: Digitalis purpurea; $\boldsymbol{R} 2$ : Avenella flexuosa, Galium harcynicum; $\boldsymbol{R} 1$ :
} Calluna vulgaris, Juncus squarrosus; $\boldsymbol{R}$ X: Carex remota, Geum urbanum, Mycelis muralis 
tionen. Die Übereinstimmung von Calciumbedarf bzw. Calciumtoleranz und der natürlichen Verbreitung der Arten wird in dieser Arbeit auf unterschiedliche Selektivitäten der Aufnahmesysteme zurückgeführt. Ein hohes Ausschlussvermögen calcicoler Arten gegenüber $\mathrm{Ca}^{2+}$ soll gleichzeitig einen hohen $\mathrm{Ca}^{2+}-$ Bedarf zur Folge haben. Verschiedene Arbeiten führen erhöhte Calciumtoleranzen auf eine spezifische Zusammensetzung der Lipidfraktionen des Plasmalemma und der intrazellulären Membransysteme zurück, die das Ausmaß der passiven Calciumaufnahme bei calcicolen Arten reduzieren soll (s. Kinzel 1982). Allerdings finden diese Interpretationen keine Bestätigung in den Untersuchungsergebnissen von Clarkson (1965), nach denen die Calciumgehalte des Sprossmaterials von A. stolonifera durch die Erhöhung der externen $\mathrm{Ca}^{2+}$-Konzentrationen sehr viel schneller ansteigen als die der calcifugen $A$. setacea. Vielmehr wäre in diesem Fall nicht ein Ausschlussmechanismus der Wurzel sondern eine besonders effiziente Immobilisierung oder Sequestrierung von Calcium im Sprossgewebe calcicoler Arten zu fordern.

Eine entsprechende ökophysiologische Reaktion auf hohe Calciumkonzentrationen diskutieren Ernst \& Nelissen (1998) für die calcicole Schoenus nigricans. Allerdings besitzt diese Art nicht nur eine hohe $\mathrm{Ca}^{2+}$-Toleranz sondern auch einen vergleichsweise geringen $\mathrm{Ca}^{2+}$-Bedarf. Bereits bei $\mathrm{c}\left(\mathrm{Ca}^{2+}\right) / \mathrm{c}\left(\sum \mathrm{Kat}^{+}\right)$Verhältnissen von 0,15 in wässrigen Bodenlösungen und einem korrespondierenden Calciumgehalt der Bodentrockenmasse von 0,25 \% liegen für sie ausreichende Calciumverfügbarkeiten vor. Die ausgesprochene Toleranz geht hier, wie Gewebeanalysen belegen, u. a. auf eine effiziente $\mathrm{Ca}^{2+}$ Retention in den Wurzeln zurück. Hohe Konzentrationen gelöster Calciumverbindungen und entsprechend enge $\mathrm{K}^{+} / \mathrm{Ca}^{2+}$ Verhältnisse im Spross verweisen zugleich aber auch auf einen calciotrophen Physiotypus sensu Horak \& Kinzel (1971).

Untersuchungen, die in den vergangenen Jahren die vielfältige und komplexe Bedeutung des Calciums für den pflanzlichen Organismus belegt haben, verdeutlichen, dass Ca-Effizienzen und -Toleranzen unter Berücksichtigung verschiedenster anatomisch-morphologischer und physiologischer Gesichtspunkte bewertet werden müssen (vgl. 4.3.5, S. 129 ff.). Es wird immer deutlicher, dass sich die internen $\mathrm{Ca}^{2+}$ Konzentrationen acidophiler/calcifuger und basiphiler/calcicoler Arten nicht prinzipiell unterscheiden. Welche Bedeutung einzelne Reaktionen für die betreffenden Standortpräferenzen spielen, ist in den meisten Fällen auch heute noch offen (Lee 1999).

Wenngleich eine ganze Reihe von in vivo-Untersuchungen auf einen Bezug zwischen der ökophysiologischen Konstitution einerseits und der Standortpräferenz andererseits und damit auf die Bedeutung der $\mathrm{Ca}^{2+}$-Konzentrationen für die Vegetationsdifferenzierung calciumarmer und calciumreicher Standorte hinweisen (Jefferies \& Willis 1964b; Clarkson et al. 1965), lässt sich keine Kausalität zwischen den leicht verfügbaren Calciumfraktionen und der Artenzusammensetzung der beiden hier untersuchten Subassoziationen des Gentiano-Koelerietum erkennen. Geringe Unterschiede der gelösten und austauschbaren Calciumgehalte verweisen darauf, dass $\mathrm{Ca}^{2+}$ allenfalls eine sekundäre Rolle für die diesbezügliche Vegetationsdifferenzierung spielt. Hiermit stimmen Ausführungen überein, nach denen viele acidophile Arten eine recht große Toleranz gegenüber variierenden Calciumkonzentrationen im Substrat besitzen. Steele (1955) hat darauf verwiesen, dass sich viele Acidophile/Calcifuge zwar nicht indifferent gegenüber hohen externen Calciumkonzentrationen (und hohen $\mathrm{pH}$-Werten) verhalten, sie aber unter diesen Bedingungen bei geringen Wachstumsraten überleben können. 


\subsubsection{Magnesium}

Neben den in der Regel niedrigeren $\mathrm{Ca}^{2+}$-Konzentrationen und $\mathrm{CaCO}_{3}$-Gehalten sowie den abweichenden Aciditäten in verschiedenen Bodentiefen geben auch die $\mathrm{Ca}^{2+} / \mathrm{Mg}^{2+}-$ Verhältnisse der GBL und die Austauscherlösungen Hinweise auf eine fortgeschrittene Bodengenese der Standorte des Gentiano-Koelerietum danthonietosum. Karathanasis (1991) betrachtet das Ca/Mg-Verhältnis als einen geeigneten Indikator des Verwitterungsgrads von Böden gleicher Ausgangsgesteine. Je enger dieses Verhältnis ist, desto weiter soll die Bodenentwicklung vorangeschritten sein. Zumindest die $\mathrm{Ca} / \mathrm{Mg}$-Verhältnisse der Untersuchungsstandorte des Unteren Diemeltal bestätigen eine stärkere Verwitterung der Böden des GentianoKoelerietum danthonietosum (Tabelle 33).

Tabelle 33: Mittlere Ca/Mg-Verhältnisse der GBL feldfrischer Feinerdehomogenate der CC- und CF-Beständen des Gentiano-Koelerietum. $M W \pm S D$ ( $n=4$ bzw. $n=56$ für Auf der Burg und Hölleberg). Signaturen kennzeichnen die Ergebnisse der paarweisen Vergleiche CC vs. CF mittels Student-t-Tests (n.s. $\alpha>0,05, * \alpha \leq 0,050, * * \alpha \leq 0,010$, $* * * \alpha \leq 0,001)$.

\begin{tabular}{lccc}
\hline Standort & G.-K. typicum (CC) & G.-K. danthonietosum (CF) & CC vs. CF \\
\hline Auf der Burg & $38 \pm 12$ & $22 \pm 8,8$ & $* \star *$ \\
Hölleberg & $27 \pm 14$ & $20 \pm 10$ & $* \star *$ \\
Hölleberg-Süd & $26 \pm 1,7$ & $20 \pm 2,3$ & n.s. \\
Flohrberg & $25 \pm 2,4$ & $8,9 \pm 2,9$ & $* *$ \\
Pagenberg & $1,2 \pm 0,0$ & $2,2 \pm 0,2$ & $* * *$ \\
Steinkirche & $1,5 \pm 0,1$ & $1,4 \pm 0,1$ & $* *$ \\
\hline
\end{tabular}

Tabelle 24 (S. 101 f.) lässt erkennen, dass mit Ausnahme der beiden Untersuchungsstandorte auf dem Hölleberg die GBL-bezogenen Magnesiumlöslichkeiten des Gentiano-Koelerietum typicum diejenigen des Gentiano-Koelerietum danthonietosum übersteigen. Somit bestätigen die eigenen Untersuchungen nicht die Vermutungen von Rayner \& Jones (1911), nach denen das Auftreten von Calluna vulgaris mit besonders hohen $\mathrm{Mg}^{2+}$-Konzentrationen einhergeht. Möglicherweise sind die tendenziell höheren Magnesiumgehalte der beiden CF-Bestände auf dem Hölleberg darauf zurückzuführen, dass sich diese Flächen im Übergangsbereich zwischen dem Unteren Muschelkalk und dem magnesiumreicheren Oberen Buntsandstein befinden. Die $\mathrm{Mg}^{2+}$-Löslichkeiten in der Feinerde der beiden Bestände an der Steinkirche und diejenigen des Bestands Pagenberg-CC verweisen auf den Einfluss des dolomitischen Ausgangsgesteins dieser Standorte. Sie liegen hier etwa zehnfach über dem Durchschnitt. Die Bodenanalysen lassen eine fortgeschrittene Auswaschung der Gesamtfraktion basisch wirkender Kationen für die Untersuchungsstandorte am Südharzrand erkennen. Allerdings folgen die $\mathrm{Ca}^{2+} / \mathrm{Mg}^{2+}-$ Verhältnisse zwischen den CC- und CF-Beständen hier nicht dem Bild, dass für die Standorte des Unteren Diemeltal gezeichnet wurde. Die Analysenergebnisse für den Standort Steinkirche belegen nur sehr geringe Unterschiede zwischen den beiden Subassoziationen. Die Analysen lassen für den Pagenberg sogar auf ein weiteres $\mathrm{Ca} / \mathrm{Mg}$-Verhältnis in der Feinerde des CF-Bestands schließen.

Die $\mathrm{BaCl}_{2}$-Extraktionen deuten eine bessere $\mathrm{Mg}^{2+}$-Verfügbarkeit in den CF-Beständen der beiden Referenzstandorte an. Signifikant höhere Werte für die austauchbare $\mathrm{Mg}^{2+}$-Fraktion in der Feinerde des Bestands Auf der Burg-CF finden sich indes nicht in Übereinstimmung mit den Ergebnissen der GBLAnalysen. Insgesamt zeichnen die Untersuchungen kein schlüssiges Bild hinsichtlich der $\mathrm{Mg}^{2+}$-Konzentrationen im Gentiano-Koelerietum typicum und Gentiano-Koelerietum danthonietosum. 
Danthonia decumbens besitzt nach Untersuchungen von Jefferies \& Willis (1964b) zwar eine weite Toleranz variierenden $\mathrm{Ca}^{2+}$-Konzentrationen des Substrats, doch darf offenbar das $\mathrm{Ca}^{2+} / \mathrm{Mg}^{2+}$-Verhältnis nicht zu weit sein. Es ist daher denkbar, dass hohe $\mathrm{Mg}^{2+}$-Konzentrationen, so wie sie an der Steinkirche in den Böden beider Subassoziationen des Gentiano-Koelerietum vorliegen, für das Auftreten von D. decumbens auch im CC-Bestand förderlich sind. Ausschlaggebend dürften diese hohen Konzentrationen angesichts des Fehlens der Art in der typischen Subassoziation auf dem Pagenberg, in dessen Boden ähnliche absolute und relative $\mathrm{Ca}^{2+}$ - und $\mathrm{Mg}^{2+}$-Verhältnisse wie im CF-Bestand vorliegen, allerdings nicht sein.

\subsubsection{Kalium}

Neben der Bedeutung anderer Makronährstoffe (Ca, N, P) wurde in älteren Arbeiten auch die von Kalium für die Vegetationsdifferenzierung basenarmer, saurer und kalkreicher, alkalischer Böden diskutiert. So sollten nach Hewitt (1948) und Jones (1950) unzureichende $\mathrm{K}^{+}$-Verfügbarkeiten die Ausbildung von FeMangelchlorosen begünstigen (Rorison 1960a, 1960b).

Wie nicht anders zu erwarten und von Kinzel (1982) im Detail ausgeführt, kann v.a. in Kalkböden die $\mathrm{K}^{+}$-Aufnahme klassischen Mineralstoffkompetitionen unterliegen. In diesem Zusammenhang weisen einige Untersuchungen auf art- und verbreitungsspezifische Grenzkonzentrationen hin, bei denen $\mathrm{Ca}^{2+}$ auf der einen Seite als essentieller Faktor der Membran- und Zellwandintegrität sowie membranärer Transportsysteme zu einer Stimulation, auf der anderen Seite antagonistisch zu einer Hemmung der $\mathrm{K}^{+}$-Aufnahme führt. Diese Grenze ist nicht nur eine Funktion der $\mathrm{Ca}^{2+}$ - und $\mathrm{K}^{+}$-Konzentrationen sondern auch des $\mathrm{pH}$ Werts (s. Kinzel 1982). Wenngleich für manche Arten, wie Tussilago farfara, eine ihrer natürlichen Verbreitung entsprechende Anpassung der $\mathrm{K}^{+}$-Aufnahme auf Variationen der $\mathrm{Ca}^{2+}$-Konzentrationen nachgewiesen wurde (Olsen 1942), finden sich weder in neueren Arbeiten anderer Autoren (Mahdi et al. 1989; Lee 1999) noch in den Ergebnissen der eigenen Untersuchungen Indizien einer Bedeutung des Kaliums für das Auftreten acidophiler/calcifuger und basiphiler/calcicoler Arten im Gentiano-Koelerietum. Die im Rahmen der vorliegenden Arbeit behandelten Kalk-Halbtrockenrasen weisen nicht grundsätzlich geringere $\mathrm{K}^{+}$-Verfügbarkeiten in der typischen Subassoziation des Gentiano-Koelerietum auf. Ebenso wenig lassen sich einheitliche Konzentrationsverhältnisse zwischen $\mathrm{Ca}^{2+}$ und $\mathrm{K}^{+}$erkennen (Tabelle 24, S. $101 \mathrm{f}$.). Es fällt sogar auf, dass gerade an Standorten mit besonders hohen $\mathrm{Ca}^{2+}$-Konzentrationen im GentianoKoelerietum typicum (Auf der Burg, Hölleberg, Steinkirche) die $\mathrm{Ca}^{2+} / \mathrm{K}^{+}$-Verhältnisse enger sind als in den CF-Beständen (Tabelle 34). Demnach ist davon auszugehen, dass hier das Auftreten von Vertretern der beiden Verbreitungsgruppen nicht durch das $\mathrm{K}^{+}$-Angebot entscheidend beeinflusst wird.

Tabelle 34: Mittlere Ca/K-Verhältnisse der GBL feldfrischer Feinerdehomogenate der CC- und CF-Bestände des Gentiano-Koelerietum. $M W \pm S D$ ( $n=4$ bzw. $n=56$ für Auf der Burg und Hölleberg). Signaturen kennzeichnen die Ergebnisse der paarweisen Vergleiche CC vs. CF mittels Student-t-Tests (n.s. $\alpha>0,05, * \alpha \leq 0,050$, ** $\alpha \leq 0,010$, $* * * \alpha \leq 0,001)$.

\begin{tabular}{lccc}
\hline Standort & G.-K. typicum (CC) & G.-K. danthonietosum (CF) & CC vs. CF \\
\hline Auf der Burg & $67 \pm 34$ & $91 \pm 89$ & n.s. \\
Hölleberg & $52 \pm 31$ & $110 \pm 89$ & $* * *$ \\
Hölleberg-Süd & $85 \pm 9,1$ & $65 \pm 16$ & n.s. \\
Flohrberg & $34 \pm 16$ & $9,0 \pm 7,2$ & n.s. \\
Pagenberg & $26 \pm 14$ & $5,6 \pm 4,7$ & n.s. \\
Steinkirche & $34 \pm 4,7$ & $71 \pm 24$ & \\
\hline
\end{tabular}




\subsubsection{Eisen}

Wie bereits in den Abschnitten 4.2.4 (S. 115 ff.) und 4.3.3 (S. 123 ff.) dargestellt, ist die pflanzliche FeVerfügbarkeit eine Funktion verschiedener abiotischer und biotischer Faktoren. Sowohl für die Fe-Löslichkeit als auch für die Fe-Verwertung ist in terrestrischen Lebensräumen zumeist der pH-Wert, hfg. in Kombination mit dem Carbonatgehalt der Böden ausschlaggebend. Chlorosen von Pflanzen kalkreicher Standorte sind in vielen Fällen die Folge einer mangelhaften Fe-Ernährung. Das Fe-Angebot kann hier das Auftreten nicht adaptierter Pflanzen limitieren.

\section{Bedeutung von Fe für die Individualentwicklung}

Durch Kulturversuche in gesiebtem Bodenmaterial einer Rendzina (pH6,7) und einer sauren Braunerde (pH 3,4) konnte Kühne (1987) für insgesamt sechs Dicotyle und Monocotyle ${ }^{1}$ ihren natürlichen Standortpräferenzen entsprechende Keimungs- und Überlebensraten nachweisen. Nährlösungsexperimente zeigten, dass Fe-Konzentrationen in einem Bereich von 0-200 $\mu \mathrm{M}$ keinen Einfluss auf die Keimung der betreffenden Arten nehmen. Hingegen wird die weitere Entwicklung verschiedener acidophiler/calcifuger Pflanzen durch verminderte Fe-Verfügbarkeiten in basischen, kalkreichen Böden beeinträchtigt. Eine Reihe von Autoren belegen abweichende Chloroseanfälligkeiten edaphisch vikariierender Arten, wie etwa Tansley (1917) für Galium saxatile (=G. harcynicum: acidophil/calcifug) und G. sylvestre (=G. pumilum: basiphil/calcicol) oder Grime (1965b) für Lathyrus montanus (=L. linifolius; acidophil/calcifug) und L. pratensis (basiphil/calcicol). Hinweise auf eine vegetationsdifferenzierende Wirkung unterschiedlicher Fe-Effizienzen geben auch Ökotypen einer Art. Snaydon (1962) wies in Kulturversuchen mit Trifolium repens nach, dass Populationen saurer Böden in kalkreichen Substraten stärkere Chlorosen ausbilden als solche von Standorten kreidehaltiger Ausgangsgesteine. Eine Düngung mit FeEDTA wirkte hier ameliorierend und bestätigte die unzureichende Fe-Versorgung der Pflanzen. Ökotypisch variierende Fe-Effizienzen acidophiler/calcifuger und basiphiler/calcicoler Populationen treten auch bei Festuca ovina (Snaydon \& Bradshaw 1961) und Teucrium scorodonia (Hutchinson 1967a, 1968) auf.

Nicht immer aber ist das Wachstum an (vermeintlich) adversativen Standorten die Folge einer ökotypischen Differenzierung der Arten. Untersuchungen an zwei benachbarten Populationen von Potentilla erecta - die eine von einer tiefgründigen, stellenweise podsolierten Braunerde ( $\mathrm{pH} 3,8-5,4)$ in Plateaulage, die andere von einer hangorientierten, flachgründigen und kalkreichen Rendzina (pH6,0-7,4) gaben keine Hinweise auf geno- und physiotypische Unterschiede (Grime 1963b). Kulturexperimente verwiesen viel mehr darauf, dass die unterschiedliche Biomasseproduktion der beiden Populationen und der unterschiedliche Habitus ihrer Individuen in situ allein auf die abweichenden Bodeneigenschaften der beiden Standorte zurückgingen.

Die eigenen Kulturversuche haben gezeigt, dass der Boden des Gentiano-Koelerietum typicum am Standort Auf der Burg ein größeres Chlorosepotenzial besitzt als derjenige der Subassoziation von Danthonia decumbens (Tabelle 25, S. 103). Die Messungen der Chlorophyllkonzentrationen geben diesbezüglich keine Hinweise auf autökologische Unterschiede zwischen Koeleria pyramidata, Potentilla neumanniana und den beiden Populationen von Potentilla erecta. Kennzeichnend für beide Unterarten von D. decumbens ist eine sehr geringe Chlorophyllbiosynthese sowohl bei der Kultivierung in CC- als auch in CF-Monolithen. Eine besondere Chloroseanfälligkeit von D. decumbens betonen auch Jefferies \&

\footnotetext{
1 R 9: Reseda lutea; $\mathbf{R}$ 8: Origanum vulgare; $\mathbf{R}$ 7: Hordelymus europaeus; $\mathbf{R}$ 6: Brachypodium sylvaticum; $\mathbf{R} 2$ : Avenella flexuosa;
} $R$ 1: Juncus squarrosus 
Willis (1964a) und Hutchinson (1967a). Damit übereinstimmend wies Fockenbrock (1992) für die Danthonia-Population eines flachgründigen Sandtrockenrasens über Buntsandstein die Ausbildung von Chlorosen und eine weit reichende Wachstumshemmung in Kalkboden nach. Geringe Wachstumsraten und ein niedriger Fe-Bedarf in Nährlösungskulturen, wie auch die Beobachtung, dass $\mathrm{CaCO}_{3}$ die $\mathrm{Fe}-$ Mangelerscheinungen verstärkt, lassen vermuten, dass nicht allein verminderte Fe-Löslichkeiten für diese Beeinträchtigungen verantwortlich sind. Für die Bewertung der eigenen Untersuchungen ist darauf zu verweisen, dass die Substrate hier zeitweilig nahezu wassergesättigt waren. Die daraus resultierenden Redoxpotenziale und Fe-Konzentrationen schließen einen absoluten Fe-Mangel als Ursache für die Wachstumsstörungen aus und sind dahingehend zu interpretieren, dass in diesen Fällen andere Faktoren, wie etwa hohe $\mathrm{HCO}_{3}{ }^{-}$-Konzentrationen, die Chlorophyllsynthese beeinträchtigten. Ungeachtet dessen können aber in situ die standortspezifischen Fe-Löslichkeiten für das Wachstum verschiedener Arten in Kalk-Halbtrockenrasen und damit für deren Vegetationsdifferenzierung ausschlaggebend sein.

\section{Fe-Konzentrationen und $\mathrm{pH}$ wässriger Bodenextrakte}

In Abschnitt 4.2.4 (S. 115 ff.) wurde die Abhängigkeit der Eisenlösung von der Bodenreaktion dargestellt. Auf einen engen Bezug dieser Faktoren lässt auch Tabelle 24 (S. 101 f.) schließen, nach der die GBLbezogenen Fe-Gehalte der Feinerde und die aktuelle Acidität in gleichem Umfang für die Differenzierung der Subassoziationen im Gentiano-Koelerietum verantwortlich zeichnen. Rangkorrelationsanalysen bestätigen eine negative Beziehung zwischen den Fe-Konzentrationen aller drei wässriger Bodenextrakte und dem pH (Tabelle A 11-Tabelle A 13, S. 308-310).

Die Analysen der GBL, PBL und DBL zeigen aber, dass auch pH-unabhängige Variablen die Fe-Verfügbarkeit in den beiden Subassoziationen beeinflussen. In Abbildung 63 sind die Fe-Konzentrationen für die Lösungen aller wässrigen Extraktionsverfahren und Versuchsstandorte logarithmisch gegen den pH aufgetragen. Die nicht-lineare Regression verweist auf einen Löslichkeitsverlauf, der bei einer pH-Verschiebung um etwa eine Einheit derjenigen anorganischer Fe-Verbindungen entspricht (vgl. Abbildung 58, S. 116). Demnach liegen hier in wässriger Lösung minimale Fe-Konzentrationen bei etwa pH 9,0 vor. Abbildung 63 belegt nicht nur, dass bezogen auf die oberen $10 \mathrm{~cm}$ der Böden die mittlere aktuelle Acidität der CF-Bestände diejenige der CC-Bestände überschreitet, sondern auch, dass im Fall gleicher pHWerte höhere Fe-Konzentrationen in der Bodenlösung des Gentiano-Koelerietum danthonietosum auftreten. Zwischen pH 7,4-8,5 ist in den wässrigen Bodenextrakten des Gentiano-Koelerietum typicum mit 0,58 $\mu \mathrm{M}$ etwa $50 \%$ weniger Fe gelöst als in solchen der Subassoziation von Danthonia decumbens. Die medianen Protonenaktivitäten sind hier hingegen mit pH 7,94 bzw. pH 7,91 nahezu gleich.

Diese Ergebnisse geben zusammen mit denen der Fe-Fraktionierungen fundierte Hinweise darauf, dass das Auftreten von acidophilen/calcifugen Arten auf kalkreichen Böden mit einer verbesserten Fe-Löslichkeit einhergeht, und dass die aktuelle Bodenacidität hier eine untergeordnete Rolle für die Vegetationsdifferenzierung spielt. Bei der Bewertung aller Mineralstoffanalysen der vorliegenden Arbeit muss allerdings berücksichtigt werden, dass sich diese auf Mischproben der oberen $10 \mathrm{~cm}$ des Bodens beziehen. Es ist nicht auszuschließen, dass hohe Carbonatgehalte im unteren $\mathrm{A}_{\mathrm{h}}$ den $\mathrm{pH}$ der Bodenextrakte puffern und damit oberflächige Versauerungen überdecken. Darauf lassen die pH-Werte von Bodenproben aus Tiefen von 0-5 cm und 5-10 cm schließen, wie sie in Tabelle 8 (S. 57) für die Standorte Auf der Burg und Hölleberg aufgeführt sind. Sollten indes die Fe-Konzentrationen allein den $\mathrm{pH}$-Veränderungen im Bodenprofil folgen, so müsste bei der Extraktion von Mischproben die Immobilisierung der Fe-Spezies im Vergleich zur pH-Erhöhung sehr viel langesamer ablaufen. 


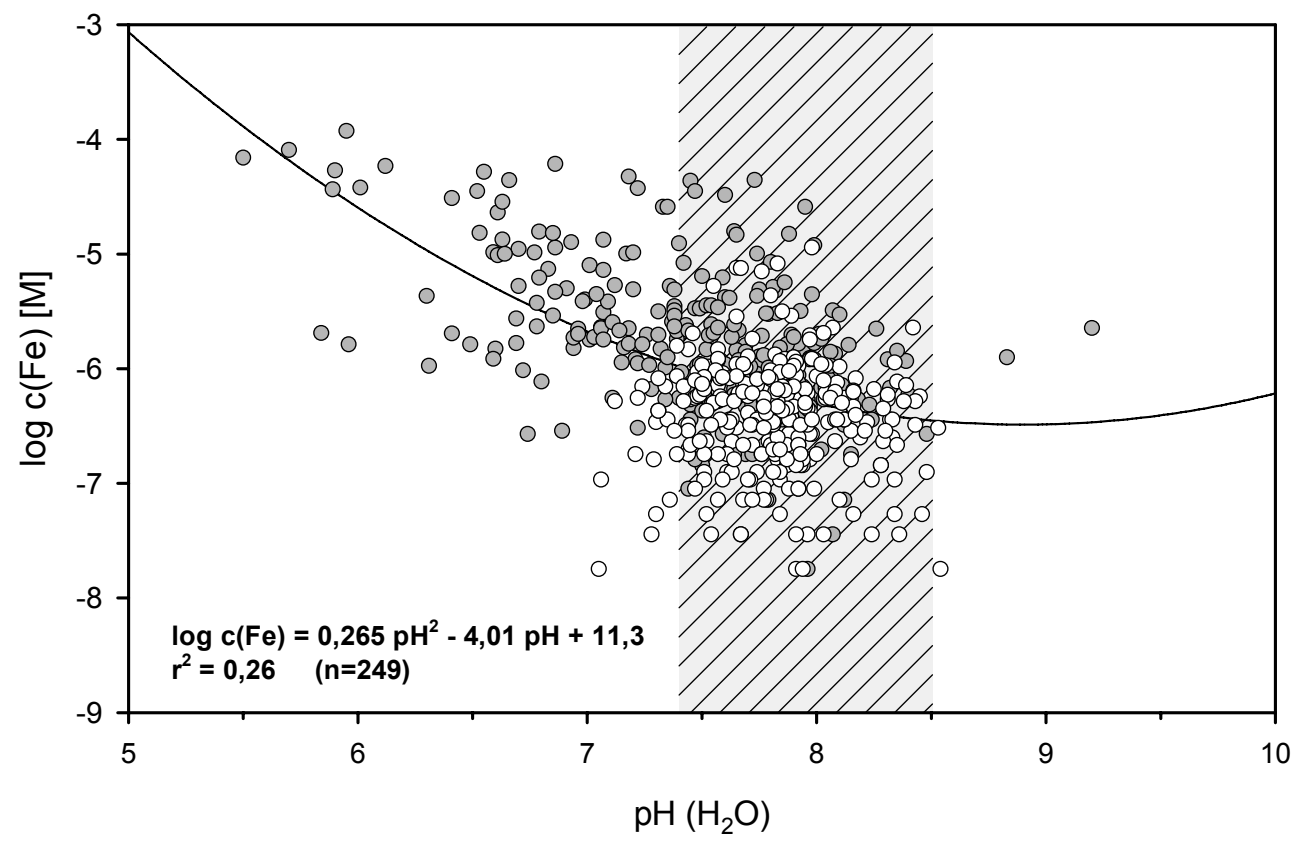

Abbildung 63: Nichtlineare Regression der Beziehung $\log c(\mathrm{Fe})[\mathrm{M}]$ vs. $\mathrm{pH}\left(\mathrm{H}_{2} \mathrm{O}\right)$ aller Untersuchungsbestände und Lösungstypen. Offene Symbole verweisen auf Analysen wässriger Bodenextrakte des Gentiano-Koelerietum typicum, geschlossene auf solche des Gentiano-Koelerietum danthonietosum. Die Schraffur kennzeichnet den pHBereich minimaler Löslichkeiten anorganischer Fe-Spezies).

\section{Organisch gebundenes Fe wässriger Bodenlösungen}

Organische Komplexbildner scheinen besonders geeignet, den gelösten Fe-Pool bei hohen pH-Werten zu stabilisieren (Loeppert \& Hallmark 1985; Lindsay 1991; Bar-Ness \& Chen 1991a, 1991b; Pandeya et al. 1998). Messungen des DOC ergaben jeweils um etwa $25 \%$ höhere Konzentrationen gelöster organischer Kohlenstoffverbindungen in den GBL des Gentiano-Koelerietum danthonietosum - und dies, obwohl die Gehalte des organischen Materials hier in der Feinerde signifikant (Hölleberg) oder doch zumindest tendenziell (Auf der Burg) unter denen der typischen Subassoziation lagen (Tabelle 12, S. 79). Dies lässt darauf schließen, dass sich die Zusammensetzung der organischen Fraktion in den Böden der Vegetationsbestände unterscheidet. Die mikrobielle Aktivität ist in Kalkmagerrasen v.a. eine Funktion der Bodenfeuchte (Ellenberg 1996). Hohe Mineralisierungsraten können auf der einen Seite zu einer Erniedrigung von $\mathrm{C}_{\mathrm{o}}$ im Boden, damit andererseits aber zu einer Erhöhung der Konzentration Fe-komplexierender Verbindungen führen. Korrelationen des DOC und der Bodenfeuchte sowie der Fe-Konzentration werden von Falkengren-Grerup \& Tyler (1993) auch für die Bodenlösung in Buchenwäldern beschrieben.

\section{Untersuchungen divalenter Eisenfraktionen}

Wenngleich in verschiedenen Veröffentlichungen davon berichtet wird, dass auch in terrestrischen, kalkreichen Böden kleinräumig Bedingungen vorherrschen können, die eine reduktive Lösung von $\mathrm{Fe}(\mathrm{III})$ fördern (Loeppert \& Hallmark 1985; Loeppert 1988), wurde dieser Aspekt offenbar in noch keiner anderen Arbeit gezielt untersucht. Die meisten Extraktionsverfahren erfassen zudem vergleichsweise selektiv Fe(III), so dass gelöste und gebundene Fe(II)-Fraktionen zumeist nicht in die Bewertung der pflanzlichen Fe-Verfügbarkeit mit einfließen. Unter diesen Gesichtspunkten dienten Extraktionen feldfrischer Feinerdehomogenate mit Ferrozine ${ }^{\circledR}$ sowie Versuche zur Redoxdynamik einer Abschätzung der Bedeutung von Fe(II) für das Auftreten von acidophilen/calcifugen Arten in Kalk-Halbtrockenrasen. 


\section{Ferrozine ${ }^{\circledR}$-Extraktion von $\mathrm{Fe}$ (II)}

Eindeutiger noch als die Fe-Konzentrationen und die pH-Werte in den rein wässrigen Bodenlösungen differenzieren Fe-Konzentrationen in Ferrozine ${ }^{\circledR}$-Extrakten die beiden hier untersuchten Subassoziationen des Gentiano-Koelerietum. Das Auftreten von acidophilen/calcifugen Arten korreliert mit einer vermehrten $\mathrm{Fe}^{2+}$-Komplexierung aus feldfrischen Feinerdehomogenaten. Median liegen die so ermittelten Fe(II)Konzentrationen in Böden der CF-Bestände mehr als vierfach über denen der typischen Subassoziation.

Als Substrat kataboler Stoffwechselreaktionen und als Komplexbildner besitzen organische Verbindungen eine besondere Bedeutung für die Eisenlösung im Boden. Mit dem Gehalt an leicht abbaubarer organischer Substanz steigt in der Regel die Sauerstoffzehrung. Verminderte Diffusionsraten in sehr feuchten und/oder verdichteten Böden führen zu einem mikroaerophilen oder anaeroben Milieu, dieses zu einer v. a. mikrobiellen Fe-Lösung im Rahmen des chemoorganotrophen, aber auch chemolithotrophen Stoffwechsels mit Fe(III) als terminalem Elektronenakzeptor (Fischer 1988; Lindsay 1991). Darüber hinaus kann Fe(III) in stark reduzierenden Salzmarschsedimenten beispielsweise durch Schwefelverbindungen (Canfield 1989; Luther et al. 1992), in anderen Böden auf Grundlage einer Redoxkaskade mit Huminen als katalytischer Komponente (Adani et al. 1998; Lovley et al. 1998; Benz et al. 1998; vgl. Abschnitt 4.2.4, S. 118) abiotisch reduziert werden.

Wie die Ergebnisse der Ferrozine ${ }^{\circledR}$-Extraktionen und die der C/N- und GV-Analysen zeigen, stehen die so ermittelten $\mathrm{Fe}(\mathrm{II})$-Konzentrationen in keiner unmittelbaren Beziehung zu den Gesamtgehalten an organischem Feinerdematerial. Die insbesondere auch durch die Bodenfeuchte beeinflussten Mineralisierungsraten und die damit einhergehende Sauerstoffzehrung spielen eine zentrale Rolle für die reduktive FeLösung und dürften das inverse Verhältnis zwischen dem Gehalt des organischen Festmaterials und dem Ferrozine ${ }^{\circledR}$-extrahierbaren Fe(II) in den Böden der beiden Subassoziationen des Gentiano-Koelerietum erklären. Bereits im letzten Kapitel wurde auf einen entsprechenden Bezug zwischen den Fe-Konzentrationen und dem Gehalt gelöster Kohlenstoffverbindungen in rein wässrigen Bodenextrakten hingewiesen.

Einer exakten Quantifizierung der $\mathrm{Fe}^{2+}$-Konzentrationen in der Bodenlösung mittels Ferrozine ${ }^{\circledR}$ sind durch die parallele Erfassung weiterer, nicht näher definierter Fe(II)-Fraktionen Grenzen gesetzt. Die Reaktionskinetiken der Komplexierung bodenbürtigen Eisens lassen aber darauf schließen, dass Ferrozine ${ }^{\circledR}$ bei initial sehr hohen Komplexierungsraten zunächst freie $\mathrm{Fe}^{2+}$-Ionen und labil gebundenes $\mathrm{Fe}(\mathrm{II})$ extrahiert (Abbildung 46, S. 85). Im weiteren werden stabilere Fraktionen gelöst. Dafür spricht auch die Tatsache, dass trotz der recht hohen Bildungskonstante des Fe(Ferrozine) ${ }_{3}$-Komplexes von $\log \mathrm{K}=17,0$, wie sie Kalkulationen des chemischen Spezifizierungsprogramms GEOCHEM-PC zugrunde gelegt wird (Parker et al. 1987; Parker \& Chaney 1995), die konstitutive Bindungsrate mit der Chelatorkonzentration stark ansteigt. Würde ausschließlich freies $\mathrm{Fe}^{2+}$ durch den Chelatbildner erfasst, so sollte die Komplexbildung weitestgehend abgeschlossen sein, wenn die Ferrozine ${ }^{\circledR}$-Gehalte im Bodensuspendat diejenigen des initial gebundenen $\mathrm{Fe}^{2+}$ um mehr als das Dreifache übersteigen. Tatsächlich liegen bereits in Testansätzen mit nur $125 \mu \mathrm{M}$ Ferrozine ${ }^{\circledR}$-Gehalte vor, die diejenigen des in der ersten Stunde extrahierten $\mathrm{Fe}^{2+}$ um mehr als das Hundertfache übertreffen. Verdoppelungen der Ferrozine ${ }^{\circledR}$-Konzentrationen auf bis zu 2 mM führen indes zu einer Vervielfachung der Komplexierungsraten.

Auch wenn die betreffenden Fraktionen qualitativ nicht näher untersucht werden konnten, ist angesichts der Glühverluste und Kohlenstoffgehalte eine bevorzugte Bindung des im weiteren Extraktionsverlauf chelatisierten Fe(II) in oder an der organischen Festphase unwahrscheinlich. Vielmehr darf vermutet werden, dass es sich hierbei in erster Linie um Eisen mineralischen Ursprungs handelt, dass aus seiner zwei- 
wertigen Bindung gelöst und komplexiert wird. Wenn durch Komplexierung $\mathrm{Fe}^{2+}$ kontinuierlich dem chemischen Gleichgewicht entzogen wird und die Reduktion von Fe(III) den vorgegebenen Aktivitätsverhältnissen des Massenwirkungsgesetzes folgt, kann durch Ferrozine ${ }^{\circledR}$ zwar auch Fe(III) nachgewiesen werden, doch dürfte diese Reaktion unter den gegebenen Versuchsbedingungen in Kalkböden irrelevant sein. Neutraler bis basischer Boden-pH und ein intensiver Sauerstoffeintrag durch Horizontalschüttelung vermitteln bei dem hier beschriebenen Extraktionsverfahren ein hohes Redox pe $+\mathrm{pH}$, das sowohl Verschiebungen des Gleichgewichtssystems hin zu den betreffenden Fe(III)-Spezies als auch verminderte Reduktionskinetiken bedingt (vgl. Abbildung 59, S. 117).

Welche Bedeutung mineralisches Fe(II) prinzipiell für die pflanzliche Mineralstoffernährung haben kann, verdeutlichen dessen Anteile in der Erdkruste. Mit ca. 3,3\% (m/m) übersteigt der $\mathrm{Fe}^{2+}$-Anteil hier den $\mathrm{Fe}^{3+}$-Anteil $(2,8 \% \mathrm{~m} / \mathrm{m})$ um fast ein Fünftel. Unter den Mineralien magmatischen oder metamorphen Ursprungs besitzen v. a. phyllosilikatische Biotite, bändersilikatische Augite und Hornblenden sowie inselsilikatische Olivine hohe Fe(II)-Gehalte in ihrem Kristallgitter (Ronov \& Yaroshevsky 1969). Von den Verwitterungsneubildungen spielen neben den Tonmineralien und verschiedenen Fe(II/III)(Hydr)oxiden insbesondere Siderit $\left(\mathrm{FeCO}_{3}\right)$, disulfidisches Pyrit bzw. Markasit $\left(\mathrm{FeS}_{2}\right)$ und monosulfidisches Pyrrhotin (FeS) sowie Vivianit $\left[\mathrm{Fe}_{3}\left(\mathrm{PO}_{4}\right)_{2} \cdot 8 \mathrm{H}_{2} \mathrm{O}\right]$ eine Rolle für die $\mathrm{Fe}(\mathrm{II})$-Löslichkeit. Naturgemäß treten diese Fe-Verbindungen allerdings vorwiegend in anaeroben und redoxomorphen Böden auf (Scheffer \& Schachtschabel 1992).

\section{Redox-Dynamik von Fe (und Mn) in wassergesättigten Bodenmonolithen}

Bezogen auf die Fe(III)-(Hydr)oxide nimmt die Relevanz der potenziellen Lösungsmechanismen in der Reihenfolge Fe(III)-Reduktion > Fe(III)-Komplexierung > Fe(III)-Protonierung ab (Schwertmann 1991). Schon früh hat Grime (1959) auf die Bedeutung der reduktiven Mobilisierung für die pflanzliche Eisenernährung hingewiesen. Für das Auftreten verschiedener calcifuger Arten, darunter Potentilla erecta, Danthonia decumbens, Calluna vulgaris, Agrostis tenuis und Holcus mollis, sollen an basenreichen Standorten v. a. schlechte Durchlüftung und geringe Diffusionsraten der Böden verantwortlich sein (Grime 1963b). Die Versuchsergebnisse zur Fe- und Mn-Dynamik in überstauten Bodenmonolithen des Standorts Hölleberg, nach denen die Fe-Konzentrationen in Material des Gentiano-Koelerietum typicum mit andauernder Wassersättigung stärker ansteigen als in solchem des Gentiano-Koelerietum danthonietosum (Abbildung 52, S. 94), können, wie die nachfolgenden Ausführungen zeigen, dieser Annahme nicht widersprechen. Bei der Bewertung der eigenen Untersuchungen ist zu berücksichtigen, dass in den Böden der Kalk-Halbtrockenrasen mit ihren vergleichsweise geringen Lagerungsdichten und hohen hydraulischen Leitfähigkeiten die für eine umfassende Fe-Reduktion erforderliche Zeitdauer vollständiger Wassersättigung in situ zu keiner Zeit erwartet werden darf. Tatsächlich folgte die höhere Fe-Mobilisierung in den CC-Monolithen v. a. den Gesamtgehalten an organischem Material. Mit 200-400 $\mu \mathrm{M}$ bewegten sich die Fe-Konzentrationen in den Mikrolysimeterlösungen nach fünfwöchiger Wassersättigung in einer Größenordnung, wie sie unter natürlichen Bedingungen in nur sehr wenigen hydromorphen Böden, wie etwa nach der oxidativen Lösung von Pyrit in der Porenlösung schwefelreicher Salzwiesensedimente (Luther \& Church 1988), erreicht wird.

Die abweichenden Gehalte an organischen Kohlenstoffverbindungen bilden zusammen mit weiteren quantitativen und qualitativen Unterschieden der Redoxsysteme die Erklärungsgrundlage für die divergente Entwicklung der Fe-Konzentrationen in den CC- und CF-Monolithen während der verschiedenen Inkubationsphasen. Übereinstimmend mit den höheren $\mathrm{C}_{0}$-Konzentrationen wurde nach der ersten Über- 
stauung in den CC-Monolithen mehr Eisen mobilisiert als in den CF-Monolithen. In der zweiten Reduktionsphase kehrte sich dieses Verhältnis um. Entsprechend ihrer abnehmenden Normalpotenziale $\mathrm{E}^{\circ}$ werden aufeinanderfolgend $\mathrm{N}(+\mathrm{V}), \mathrm{Mn}(+\mathrm{IV}), \mathrm{Fe}(+\mathrm{III}), \mathrm{S}(+\mathrm{VI})$ und schließlich $\mathrm{C}(+\mathrm{IV})$ reduziert (Brümmer 1974; Madigan et al. 2001). Dies spiegeln auch die Ergebnisse der eigenen Untersuchungen wider. Während nach etwa 20 Tagen die Mn-Mobilisierung abnimmt, steigen im selben Zeitraum die Fe-Konzentrationen stark an (Abbildung 52, S. 94; Abbildung 53, S. 95). Im Boden liegen viele verschiedene (Hydr)Oxide des Eisens und Mangans vor, die sich hinsichtlich ihres Kristallisationsgrads, ihrer Stöchiometrie sowie ihrer Zusammensetzung unterscheiden und darüber ein sehr unterschiedliches Redoxverhalten besitzen können. Zudem nehmen bodenspezifische Sorptions- und Fällungsreaktionen Einfluss auf die Aktivität der Reaktanden (Brümmer 1974; Lindsay 1979). Der Wiederanstieg der Mn-Konzentrationen nach dem 30. Versuchstag ist in diesem Zusammenhang zu sehen und verweist auf die Komplexität der Redoxvorgänge im Boden. Möglicherwerweise werden mit dem fortschreitenden Absinken des Redoxpotenzials Manganverbindungen mit niedrigerem $\mathrm{E}^{\circ}$ reduziert und gelöst.

Reduktive Umsetzungen beschränken sich offenbar zunächst auf das gelöste Fe(III). In den ersten vier Tagen des Inkubationsversuchs kommt es zu keiner nennenswerten Lösung von gebundenem Eisen. Andererseits erfolgt eine sofortige Immobilisierung des $\mathrm{Fe}^{2+}$ nach der Entwässerung der Bodenmonolithen am 40. Versuchstag. Je länger die Lagerung unter oxidativen Bedingungen andauert, desto stärker wird im Anschluss an die erneute Überstauung der Monolithen der Wiedereintritt in die exponentielle Phase der Fe-Mobilisierung verzögert. Dies kann als ein Indiz für die Ausbildung höher geordneter und damit redoxstabilerer Fe-Oxide gewertet, zugleich aber auch mit einem langsamen und zunächst nur begrenzten Absinken des Redoxpotenzials im Boden erklärt werden. Art und Umfang der Eisen(hydr)oxidbildung sind Funktionen verschiedener Faktoren, wie des $\mathrm{pH}$, der Geschwindigkeit und des Ausmaßes der Fluktuationen des Redoxpotenzials sowie der Konzentration an organischen Verbindungen. Grundsätzlich führen Bodenbedingungen, die eine rasche Fe-Oxidation fördern, zur Ausbildung wenig geordneter, amorpher Fe-Oxide mit vergleichsweise geringer Stabilität und erhöhter Löslichkeit (Ferrihydrit, hydrosic iron = Hydromagnetit, Lepidocrocit). Hochgeordnete Kristallstrukturen, wie z. B. die des Goethit, erfordern hingegen eine langsame Oxidation von $\mathrm{Fe}^{2+}$ und in der Folge ein anhaltend hohes Redox $p e+p H$ (Loeppert 1988; Schwertmann 1988a). Dieser Aspekt spielt in den hier beschriebenen Untersuchungen wohl keine Rolle. Grundsätzlich ist nicht zu erwarten, dass innerhalb nur weniger Tage in nennenswertem Umfang solche Fe-(Hydr)oxide gebildet werden.

Bei einer langsameren Entwässerung geht die nachfolgende Wiederaufsättigung der CF-Monolithe mit einem schnelleren Anstieg der Fe-Konzentrationen einher. Vieles deutet darauf hin, dass in beiden Varianten nach der Entwässerung zwar eine vollständige oxidative Immobilisierung des zweiwertigen Eisens, zugleich aber eine nur teilweise Oxidation der Redoxsysteme mit höheren Normalpotenzialen erfolgte. Werden aufgrund entsprechender Bodentextur und/oder Lagerungsdichte sowie der daraus resultierenden höheren Restwassergehalte bzw. verminderten Diffusionsgeschwindigkeiten in den CF-Monolithen beispielsweise Mn- oder N-Spezies nicht oder nur teilweise reoxidiert, können die Redoxpotenziale nach Wiederaufsättigung schneller in Bereiche absinken, die eine Rücklösung von Fe(III) erlauben.

\section{Zusammenfassung der Fe(II)-Untersuchungen}

Die Versuche zur Fe-Dynamik in den Bodenmonolithen des Standorts Hölleberg geben keine Hinweise auf eine besonders schnelle und weit reichende Fe-Reduktion in Böden von Kalk-Halbtrockenrasen, die von acidophilen/calcicolen Arten besiedelt werden. Eine Voraussetzung für die Lösungsgewinnung mit 
Tensionslysimetern, wie sie hier durchgeführt wurde, sind vergleichsweise hohe Wasserpotenziale. Anders als in den vorliegend behandelten Untersuchungen wird die für eine umfassende Fe-Reduktion erforderliche Zeitdauer vollständiger Wassersättigung in Böden des Gentiano-Koelerietum niemals erreicht. Außerdem können die Analysenergebnisse nur bedingt auf die Verhältnisse in anderen Vegetationsbeständen übertragen werden. Von allen hier untersuchten Kalk-Halbtrockenrasen besitzen die beiden Subassoziationen des Gentiano-Koelerietum auf dem Hölleberg die ähnlichsten Bodeneigenschaften. Die Redoxdynamik überfluteter Bodenmonolithen dieses Standorts sollte demnach nicht die Grundlage weiterer Schlussfolgerungen sein.

Ein weiterer methodischer Nachteil der hier dargestellten Untersuchungen ist, dass durch sie die spezifischen und ernährungsphysiologisch relevanten Reaktionen in den durchwurzelten Bodenbereichen und in der Rhizosphäre nur unzureichend aufgezeigt werden. So extrahieren Mikrolysimeter bei einem (initialen) Unterdruck von -80 kPa nur die Lösung sehr weitlumiger Mesoporen und Grobporen. Wie begleitende Untersuchungen gezeigt haben, birgt die Verwendung von Tensionslysimetern außerdem die Gefahr einer oxidativen Fe-Immobilisierung während der recht langen Zeiträume, die bei niedrigen Bodenwassergehalten für die Gewinnung ausreichender Lösungsvolumina erforderlich sind. Im Gegensatz dazu erlaubt das neue Ferrozine ${ }^{\circledR}$-Extraktionsverfahren Versuchsanordnungen, mit Hilfe derer die Redoxdynamik auch im Bereich standorttypischer Wassergehalte des Bodenmaterials untersucht werden kann. Dieses Verfahren hat allerdings den Nachteil, dass anders als bei den hier dargestellten Inkubationsversuchen Analysen derselben Bodenprobe zu verschiedenen Versuchszeitpunkten nicht möglich und somit für die Untersuchung zeitabhängiger Faktoren deutlich mehr Versuchsansätze erforderlich sind.

Bodenart und Bodengefüge sind für die Lösung des zweiwertiges Eisens ausschlaggebend. Die Bedeutung der Kristallinität, Teilchengröße und reaktiven Oberfläche von Eisen(hydr)oxiden wird u.a. von Schwertmann (1991) betont. Auch Tonmineralen können wegen ihrer großen spezifischen Oberfläche und ihres Eisengehalts eine Rolle für die pflanzliche Fe-Ernährung spielen (Stucki 1988). Insgesamt ist die Frage nach der relativen Verfügbarkeit und dem Freisetzungsmechanismus des Eisens aus Tonmineralien in Kalkböden allerdings noch weitestgehend unbeantwortet. Da aber mit einer Zunahme des Tongehalts in den Böden der Anteil an Makro- und Mesoporen zugunsten englumiger Mikroporen abnimmt, sind bereits durch die bevorzugte Ausbildung reduktiver Mikrohabitate erhöhte Fe-Konzentrationen in der Bodenlösung zu erwarten. Zudem wird davon ausgegangen, dass Tonminerale wenig kristalline und damit recht gut lösliche Fe-Fraktionen stabilisieren (Loeppert 1988). Obwohl diesbezüglich durch Fingerproben keine grundsätzlichen Unterschiede nachgewiesen werden konnten, weicht die Bodentextur der beiden hier untersuchten Subassoziationen des Gentiano-Koelerietum deutlich voneinander ab. Der geringere Porenanteil sowie die höheren Roh- und effektiven Lagerungsdichten der Feinerde geben zusammen mit den standörtlichen Wassergehalten Hinweise darauf, dass in den CF-Beständen insgesamt günstigere Bedingungen für die reduktive Lösung von Fe(III) vorliegen. Stärker noch als durch das umgehend komplexierte $\mathrm{Fe}^{2+}$ kommen die Unterschiede zwischen den beiden Subassoziationen durch die im späteren Extraktionsverlauf ermittelten Fe(II)-Extraktionsraten zur Geltung. Diese lassen letztlich doch auf höhere Tongehalte im Gentiano-Koelerietum danthonietosum schließen.

Insgesamt ist die Extraktion feldfrischer Feinerdehomogenate mit Ferrozine ${ }^{\circledR}$ ein geeignetes Verfahren, um Anhaltspunkte für die Konzentration löslicher Fe(II)-Fraktionen im Boden zu gewinnen. In Kombination mit entsprechenden Kulturversuchen dürften u. a. Anpassungen der Extraktionszeiten Hinweise auf die Bedeutung der so definierten Fe-Fraktionen für die pflanzliche Mineralstoffernährung geben und eine weitere Optimierung dieses Extraktionsverfahrens erlauben. 


\section{Nicht-sequentielle Extraktion von Eisen, Mangan, Zink und Kupfer}

Die rein wässrigen Extrakte sowie die Ferrozine ${ }^{\circledR}$-Lösungen neutraler und basischer Böden enthalten vergleichsweise geringe Eisenkonzentrationen. Gelöste zwei- und dreiwertige Fraktionen bestreiten lediglich Bruchteile des bodenbürtigen Eisens, sind zugleich labiler und variabler als solche, die an der Festphase sorbiert oder in dieser gebunden sind. Daher erfordern $\mathrm{H}_{2} \mathrm{O}$ - und Ferrozine ${ }^{\circledR}$-Extraktionen eine umgehende und besonders sorgfältige Analytik mit vergleichsweise vielen Versuchswiederholungen. Häufiger noch als die Fe-Konzentrationen liegen diejenigen anderer essentieller Schwermetalle der pflanzlichen Mineralstoffernährung, wie $\mathrm{Mn}, \mathrm{Zn}$ und $\mathrm{Cu}$, in wässrigen Bodenlösungen unterhalb der Nachweisgrenze üblicher Analysenmethoden. Deshalb werden für Standarduntersuchungen in der Regel Extraktionsmittel verwendet, die zugleich stabilere Bindungsformen erfassen.

Bodenmonolithe sowie feldfrische und luftgetrocknete Feinerdehomogenate der Referenzstandorte wurden nicht nur mit $\mathrm{H}_{2} \mathrm{O}$ - und Ferrozine ${ }^{\circledR}$, sondern auch mit Acetat-, DTPA-, NTA-, Oxalat- und DithionitLösungen extrahiet . Die betreffenden Versuchsergebnisse gaben Veranlassung, die Untersuchungen der verschiedenen Schwermetallfraktionen für die verbleibenden Standorte standardisiert an feldfrischen Feinerdehomogenaten vorzunehmen (vgl. Abschnitt 3.2.5, S. 86). Im Zusammenhang mit den DTPAExtraktionen wird im Folgenden auch auf die effektiven und potenziellen Kationenaustauscherkapazitäten der Böden eingegangen.

Im Rahmen der vorliegend diskutierten Arbeiten wurde Feinerdematerial mit jeweils nur einem Lösungsmittel, d. h. nicht-sequentiell, behandelt. Wenn hier von "Fraktionierung" gesprochen wird, so ist zu berücksichtigen, dass die jeweiligen Extraktionsverfahren eine nur begrenzte Selektivität besitzen (Borggaard 1988; Goodman 1988). Die Fülle verschiedener Bindungsformen im Boden verhindert die spezifische und quantitative Lösung exakt definierter Elementspezies. Beispielsweise erfasst nicht nur Dithionit, sondern in begrenztem Umfang auch Ammoniumoxalat silikatisches Fe (Jarvis \& Duncan 1976). Entsprechend ist hier der Begriff "Fraktion" in erster Linie auf das Extraktionsmittel zu beziehen.

\section{DTPA- und $\mathrm{BaCl}_{2}$-Extraktion}

Nach Ansicht verschiedener Autoren soll DTPA vorwiegend austauschbare und labil gebundene Schwermetallfraktionen erfassen. Da sehr enge Korrelationen zwischen den DTPA-extrahierbaren Gehalten der Böden v. a. an Zn und Fe, aber auch $\mathrm{Mn}$ und $\mathrm{Cu}$ einerseits, und der pflanzlichen Mineralstoffaufnahme sowie den landwirtschaftlichen Erträgen andererseits existieren, werden diese Fraktionen als "pflanzenverfügbar" betrachtet (Lindsay \& Norvell 1978). Austauschbare Schwermetallfraktionen können zudem durch $\mathrm{BaCl}_{2}$-Lösungen extrahiert werden. Das vorliegende Kapitel behandelt deshalb ergänzend die elementspezifischen Untersuchungen der Kationenaustauscherkapazitäten.

Anders als Ionen mit hoher Eintauschstärke, die für die Bestimmung der Kapazitäten und der Belegung der Kationenaustauscher eingesetzt werden, extrahiert DTPA Fe, Mn, Zn und Cu nicht unmittelbar durch Austauschreaktionen zwischen der Festphase des Bodens und der Extraktionslösung, sondern durch Chelatisierung bereits gelöster Ionen (Lindsay \& Norvell 1978; Kuntze et al. 1994). Die Komplexierung erniedrigt deren Aktivitäten und führt bis zum Erreichen des chemischen Gleichgewichts zu einer anhaltenden Desorption der betreffenden Schwermetalle.

Neben den effektiven Kationenaustauscherkapazitäten (Abschnitt 3.2.4, S. 80 ff.) wurden in begrenztem Umfang auch die potenziellen Kationenaustauscherkapazitäten untersucht. Bei der Bestimmung von $\mathrm{CEC}_{\mathrm{pot}}$ dienen Puffer der Einstellung von pH-Werten, die eine weitgehende Dissoziation potenzieller 
Kationenaustauscher bewirken. Zu letzteren gehören funktionelle Gruppen der organischen Bodenfraktion sowie diejenigen verschiedener Metall(hydr)oxide. Für die Untersuchung der $\mathrm{CEC}_{\text {pot }}$ werden zunächst alle Träger negativer Ladungen mit $\mathrm{Ba}^{2+}$-Ionen belegt und diese nach Rücktausch analysiert (Steubing \& Fangmeier 1992). CEC $_{\text {pot }}$ kennzeichnet demnach nicht nur die Kationenaustauscher des aktuellen Boden-pH sondern auch all diejenigen $\mathrm{pH}$-variabler Ladungsträger.

Offensichtlich spielen $\mathrm{Ba}^{2+}$-austauschbare Fe-Fraktionen in den betrachteten Böden eine untergeordnete

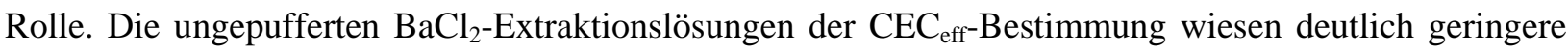
Fe-Konzentrationen auf als die GBL. Dies ist möglicherweise darauf zurückzuführen, dass für die Untersuchung der $\mathrm{CEC}_{\text {eff }}$ luftgetrocknetes, für die rein wässriger Bodenextrakte hingegen feldfrisches Feinerdehomogenat eingesetzt wurde. Offenbar geht die Trocknung des Untersuchungsmaterials mit einer oxidativen Immobilisierung des gelösten Fe(II) einher.

In den hier nicht im Detail dargestellten Untersuchungen der $\mathrm{CEC}_{\text {pot }}$ kommen $\mathrm{BaCl}_{2}$-Lösungen zum Einsatz, die mit Triethanolamin (TEA) auf pH 8,2 gepuffert werden (Steubing \& Fangmeier 1992). TEA wird in anderen Bereichen aufgrund seines Komplexierungsvermögen für die Titration von Schwermetallionen verwendet (Römpp 1992). Die vergleichenden $\mathrm{CEC}_{\text {pot }}{ }^{-}$und $\mathrm{CEC}_{\mathrm{eff}}$-Untersuchungen zeigen, dass der Zusatz von 0,13 M TEA die Fe-Extraktion der $\mathrm{BaCl}_{2}$-Lösungen um mehr als das Dreißigfache erhöht. Abweichungen des pH-Werts der beiden Austauscherlösungen spielen in diesem Zusammenhang keine Rolle. Durch TEA wird die Protonenaktivität der untersuchten Böden sogar geringfügig erniedrigt. Im betreffenden Reaktionsbereich dürfte dies demnach allenfalls zu einer Absenkung und nicht zu einem Anstieg der Fe-Löslichkeit führen.

Mit 0,10 M ist TEA in vergleichbaren Konzentrationen auch in den DTPA-Lösungen für die Bestimmung "pflanzenverfügbarer" Schwermetalle enthalten. DTPA/TEA- und $\mathrm{BaCl}_{2} / \mathrm{TEA}$-Extrakte verweisen auf ähnliche Fe-Relationen zwischen den CC- und CF-Vergleichsbeständen der Referenzstandorte Auf der Burg und Hölleberg. Durch $\mathrm{BaCl}_{2} / \mathrm{TEA}$ werden in $2 \mathrm{~h}$ durchschnittlich fast $20 \%$ des in $4 \mathrm{~h}$ durch DTPA/TEA-extrahierten Fe erfasst. Diese Ergebnisse lassen darauf schließen, dass beide Verfahren gleiche Fe-Fraktionen betreffen und demnach Austauscherlösungen, die im Rahmen der $\mathrm{CEC}_{\text {pot }}$-Analysen anfallen, gleichzeitig für die Bestimmung des "pflanzenverfügbaren" Fe geeignet sind. Neben DTPA ist offensichtlich also auch TEA an der Extraktion "pflanzenverfügbarer" Schwermetalle beteiligt. Dass es sich hierbei primär um eine austauschbare Fraktion handelt, muss im Hinblick auf die Untersuchungsergebnisse der effektiven und potenziellen Kationenaustauscherkapazitäten in Frage gestellt werden.

Lindsay \& Norvell (1978) zufolge sind für eine suffiziente Mineralstoffernährung von Zea mays DTPAextrahierbare Konzentrationen von mehr als $80 \mathrm{nmol} \mathrm{Fe}, 19 \mathrm{nmol} \mathrm{Mn}, 12 \mathrm{nmol} \mathrm{Zn}$ und $3 \mathrm{nmol} \mathrm{Cu}$ pro Gramm Bodentrockenmasse erforderlich. Römheld (1987) wies in einem leichten Tonboden (63\% $\mathrm{CaCO}_{3}$, $\mathrm{pH} 7$,9) Fe-Gehalte von $27 \mathrm{nmol} \cdot \mathrm{g}^{-1}$, in einem Lehmboden $\left(7,7 \% \mathrm{CaCO}_{3}, \mathrm{pH} 7,3\right) 140 \mathrm{nmol} \cdot \mathrm{g}^{-1}$ nach. In anderen Veröffentlichungen werden für Böden mit pH 7,0-8,3 und $\mathrm{CaCO}_{3}$-Konzentrationen bis 25 \% Fe(DTPA)-Konzentrationen von 20-80 nmol $\cdot \mathrm{g}^{-1}$ genannt (Lindsay \& Norvell 1978; Römheld \& Marschner 1986b). Die Werte der eigenen Untersuchungen liegen für den betreffenden pH-Bereich z. T. erheblich darüber. Mehr noch gilt dies für $\mathrm{Mn}, \mathrm{Zn}$ und $\mathrm{Cu}$. Hintergrund dieser Untersuchungsergebnisse ist u.a. die Verlängerung der Extraktionszeit von $2 \mathrm{~h}$ auf $4 \mathrm{~h}$, die im Hinblick auf die vergleichende Extraktion von Bodenmonolithen der beiden Referenzstandorte Auf der Burg und Hölleberg notwendig war. Ein Vergleich der eigenen Untersuchungsergebnisse mit denen anderer Autoren ist daher nur bedingt möglich. 
Auch wenn die absoluten Werte der DTPA-Extraktionen, wie sie hier durchgeführt wurden, nicht auf suboptimale Fe-Verfügbarkeiten hinweisen, lassen die Untersuchungen auf einen systematischen Unterschied zwischen den beiden Subsassoziationen und somit auf eine potenzielle Relevanz der Fe-Konzentrationen für die Differenzierung des Gentiano-Koelerietum schließen. An fünf der sechs Standorte liegen die DTPA-extrahierbaren Fe-Gehalte in der Feinerde der CF-Bestände mehr als $100 \%$ über denen der CC-Bestände. Hingegen geben die Ergebnisse der DTPA-Extraktionen keine Hinweise auf eine vegetationsdifferenzierende Wirkung der anderen Schwermetalle.

\section{NTA-Extraktion}

Der Nachweis organisch gebundener Fe- und Al-Fraktionen erfolgt zumeist mit Hilfe von Pyrophosphatlösungen. Ein wesentlicher Nachteil dieses Verfahrens ist die Suspension von Bodenmaterial, das aufwendig durch Flockungshilfsmittel, Ultrafiltrations- und/oder Ultrazentrifugationsschritte aus den Analysenlösungen entfernt werden muss (s. Borggaard 1988; Loveland \& Digby 1984). Im Rahmen der vorliegenden Arbeit wurde für die Extraktion von organisch gebundenem Fe NTA verwendet (Yuan et al. 1993). Bei sehr weit reichenden Korrelationen der Versuchsergebnisse besitzt NTA gegenüber Pyrophosphat den Vorteil, dass die Extraktionslösungen keine Trübungen aufweisen. NTA komplexiert nicht nur Fe, sondern auch $\mathrm{Mn}, \mathrm{Zn}$ und $\mathrm{Cu}$ und wurde daher zugleich für die Untersuchung dieser Elemente verwendet. Trotz der genannten Vorteile hat sich die NTA-Extraktion bisher nicht als Standardmethodik durchsetzen können. Auch hier ist daher ein Vergleich der eigenen Untersuchungsergebnisse mit denen anderer Autoren nur begrenzt möglich.

Insgesamt bewegen sich die Fe(NTA)-Gehalte in der Feinerdetrockenmasse der hier untersuchten Rendzinen mit $<15 \mu \mathrm{mol} \cdot \mathrm{g}^{-1}$ im unteren Bereich derjenigen verschiedener kanadischer Haplorthoden und Hapludalfen (Yuan et al. 1993). Die Konzentrationen des NTA-extrahierbaren Fe liegen in den CFBeständen des Gentiano-Koelerietum median um etwa $40 \%$ über denjenigen der typischen Subassoziation. Im Gegensatz dazu lassen die Untersuchungen von $\mathrm{Mn}, \mathrm{Zn}$ und $\mathrm{Cu}$ keine systematischen Unterschiede zwischen den Vegetationsbeständen erkennen. Insgesamt ist für keines der genannten Elemente ein unmittelbarer Bezug zu den Gehalten an organischem Material in der Feinerdefraktion nachzuweisen.

Anders als Goodman (1988) gehen die meisten Autoren davon aus, dass organische Komplexe eine zentrale Rolle für die Fe-Löslichkeit im Boden spielen (Lobartini \& Orioli 1988; Bar-Ness \& Chen 1991a, 1991b; Lobartini et al. 1998). Wie in Abschnitt 4.2 .4 (S. 118 ff.) ausgeführt, können zwar nur wenige organische Verbindungen Eisen auch bei hohen pH-Werten in Lösung halten, doch ist die NTAextrahierbare Fraktion insbesondere auch im Hinblick auf biologische Reaktionen, wie die Abgabe von Siderophoren bzw. Phytosiderophoren oder die Acidifizierung der Rhizosphäre, als potenziell pflanzenverfügbar zu betrachten. Die NTA-Extraktionen lassen demnach darauf schließen, dass die Böden des Gentiano-Koelerietum danthonietosum bessere Voraussetzungen für eine Mobilisierung von Fe aus der organischen Festphase bieten.

\section{Oxalat-Extraktion}

Auch Oxalatextrakte von feldfrischen Feinerdehomogenaten belegen eine bessere Fe-Verfügbarkeit in den Kalk-Halbtrockenrasen mit acidophilen/calcifugen Arten. Wie bei keinem anderen Extraktionsmittel werden diese Ergebnisse durch Untersuchungen von Bodenmonolithen und lufttrockenen Feinerdehomogenaten bestätigt. Besonders deutlich treten die Unterschiede zwischen den Vergleichsbeständen durch die Perkolation von Bodenproben ungestörter Lagerung zu Tage. Während für die feldfrischen und luft- 
getrockneten Feinerdehomogenate der beiden Referenzstandorte durchschnittlich etwa $60 \%$ mehr Oxalatextrahierbares Fe im Gentiano-Koelerietum danthonietosum nachgewiesen wurde, weichen die betreffenden Werte der Bodenmonolithen um das Neunfache voneinander ab (vgl. Tabelle A 6, S. 304).

Ammoniumoxalatlösungen extrahieren in erster Linie amorphe Fe-(Hydr)oxide (Schwertmann 1973; Borggaard 1988), die als primäre Fällungsprodukte des gelösten Fe eine nur begrenzte Lebensdauer besitzen. Während diese metastabilen Präzipitate unter geeigneten Bedingungen zur Ausbildung hochgeordneter, schlecht löslicher Fe-Minerale - im temparaten Klima v. a. zu Goethit ( $\alpha$-FeOOH), in den Tropen v. a. zu Hämatit $\left(\alpha-\mathrm{Fe}_{2} \mathrm{O}_{3}\right)$ - führen (Schwertmann 1991), werden sie bei Fluktuationen des Redox $p e+p H$ vergleichsweise schnell rückgelöst. Angesichts der in Abschnitt 4.3 .4 (S. 123 ff.) ausgeführten Mobilisierungsstrategien sind daher große Teile des oxalatlöslichen Fe als geeignete Substrate der pflanzlichen Mineralstoffernährung zu betrachten.

Geht man davon aus, dass gerade Perkolate von Bodenmonolithen die Verhältnisse der durchwurzelten Meso- und Makroporen widerspiegeln, in denen bezüglich des Intervalls, aber auch der Amplitude intensive Schwankungen der lösungsrelevanten Faktoren auftreten, dürfte Fe(Oxalat) eine besonders wichtige Rolle für die pflanzliche Fe-Versorgung spielen. Besonders hier ist eine Anreicherung labiler amorpher Fe-(Hydr)oxide zu erwarten. Diese geht auf den diffusiven und evapotranspirationsbedingten Eintrag von gelöstem Fe aus Bodenräumen mit geringeren Porendurchmessern und zumeist niedrigeren Wasser- und Redoxpotenzialen zurück. Die rasche Oxidation von gelöstem Fe sowie die Abwesenheit von hochgeordneten Mineralen, die eine weitergehende Nukleation erlauben, sollte in den mittel- und weitlumigen Poren primär zur Ausfällung von Ferrihydrit führen (Schwertmann 1988a).

Möglicherweise ist die Anreicherung amorpher Fe-(Hydr)Oxide in unmittelbar von den Wurzeln erschlossenen Bodenbereichen ein Grund dafür, dass Loeppert \& Hallmark (1985) sehr enge Korrelationen zwischen den Konzentrationen oxalatlöslichen Eisens auf der einen und dem Chlorosegrad sowie dem FeGehalt von Sorghum bicolor auf der anderen Seite hat nachweisen konnten. Extrakte von Kalkböden mit Ammoniumoxalat kennzeichnen hier die pflanzlichen Fe-Verfügbarkeiten viel besser als solche mit Dithionit, DTPA und EDDHA. Vorbehalte von Hesse (1971), denen zufolge saure Extraktionsmittel durch Lösung von $\mathrm{CaCO}_{3}$ unrealistisch hohe Fe-Konzentrationen freisetzen, spielen bei den hier untersuchten Böden keine Rolle. Trotz durchschnittlich zehnfach höherer Kalkgehalte weisen die Feinerdehomogenate der CC-Bestände signifikant niedrigere Fe(Oxalat)-Konzentrationen als die der Vergleichsstandorte auf (Tabelle 5).

Während offenbar aus dem Kalkgestein nur wenig Fe gelöst wird, geben Regressions- und Korrelationsanalysen der Carbonat- und der oxalatextrahierbaren Zn-Gehalte der Feinerde aller Vegetationsbestände Hinweise darauf, dass die median mehr als doppelt so hohen Zn(Oxalat)-Konzentrationen in den Böden der CC-Bestände aus einer besonders umfangreichen Carbonatlösung resultieren. ${ }^{1}$ Sollte es sich bei der

\footnotetext{
1 Dass die vermehrte Zink- und Kupferextraktion aus Feinerdehomogenaten der CC-Bestände auf die Verwendung von Messingzylindern für die Probennahme (etwa infolge eines besonders starken Materialabriebs bei erhöhten Skelettgehalten) zurückzuführen ist, kann anhand der vergleichenden Extraktion von feldfrischen bzw. lufttrockenen Feinerdehomogenaten einerseits und feldfrischen Bodenmonolithen andererseits ausgeschlossen werden (vgl. Tabelle A 6, S. 304 f.). Da während der Perkolation relativ mehr Lösung mit den Randbereichen der Probe in Kontakt tritt, würden derartige Versuchsartefakte inbesondere bei der Extraktion von Bodenmonolithen zu Tage treten. Tatsächlich weichen zwischen den Vergleichsbeständen der Referenzstandorte aber gerade für $\mathrm{Zn}_{\text {Oxalat }}$ und $\mathrm{Cu}_{\text {oxalat }}$ die Ergebnisse der Feinerdeextraktionen von denen der Monolithenextraktion ab. Perkolate verweisen anders als Schüttelungslösungen auf höhere Zn- und Cu-Gehalte in den Böden des Gentiano-Koelerietum danthonietosum.
} 
oxalatlöslichen Fraktion in erster Linie um kalkgebundenes Zink handeln, so wäre dieses allerdings für die pflanzliche Mineralstoffernährung von geringer Bedeutung. Die Ergebnisse der Oxalatextraktion von feldfrischem Feinerdematerial stehen demnach nicht im Widerspruch zu der verbreiteten Annahme, dass hohe Kalkgehalte (und pH-Werte) als Ursache unzureichender pflanzlicher Zn-Versorgung v. a. vieler Getreidearten und -sorten zu betrachten sind (Marschner et al. 1987; Cakmak et al. 1996; Cakmak et al. 2001). Entsprechend sind auch die durchschnittlich um 20 \% höheren $\mathrm{Cu}($ Oxalat)-Gehalte in der Feinerde der CC-Bestände zu werten.

\section{Dithionit-Extraktion}

Wie Oxalat verursacht auch Dithionit Störungen bei der Perkolation von Bodenmonolithen (s. Abschnitt 3.2.5, S. 85). Die hydraulische Leitfähigkeit wird hier offenbar durch die Reduktion von strukturrelevantem Fe(III) beeinträchtigt. Bereits McNeal et al. (1968) haben auf die Dispersion von Bodenmaterial als Folge der Auflösung von tongebundenen Eisenoxiden durch Dithionit verwiesen (Schwertmann 1988b). Darüber hinaus wirkt $\mathrm{Na}^{+}$, das in den Extraktionslösungen zu 0,9 M enthalten ist, durch den Austausch von $\mathrm{Ca}^{2+}$ peptisierend (Scheffer \& Schachtschabel 1992). Die daraus resultierenden Beeinträchtigungen des Aggregatgefüges machen sich insbesondere in Bodenmonolithen des Gentiano-Koelerietum danthonietosum bemerkbar und sind für die besonders niedrigen Fe-Konzentrationen in den CF-Perkolaten verantwortlich. Eine zuverlässige Extraktion von Bodenproben natürlicher Lagerung mit Dithionitlösungen ist daher nicht möglich.

Anders als bei der Fe-Extraktion mit DTPA verursacht die Lufttrocknung von Feinerdehomogenaten bei der Fe-Extraktion mit Dithionit nicht eine höhere, sondern eine geringere Lösung von bodenbürtigem Fe (und Zn). Hierfür ist vermutlich weniger eine spezifische Stabilisierung der betreffenden Fe-Fraktionen verantwortlich als die Tatsache, dass redoxlabile Komponenten des Bodens durch den Trocknungsprozess aufoxidieren und damit die für die Fe-Lösung erforderlichen Dithionitkonzentrationen erhöhen. Entsprechend wird die Reduktionskapazität von Dithionitlösungen durch Luftsauerstoff rasch herabgesetzt. Es muss davon ausgegangen werden, dass die generell niedrigeren Fe-Konzentrationen in den Extraktionslösungen der Vergleichsstandorte in einem diesbezüglichen Zusammenhang stehen.

Wie vergleichende XRD-Untersuchungen gezeigt haben, handelt es sich bei dem mit Dithionit extrahierbaren Eisen in erster Linie um solches kristalliner Fe-Oxide (Kämpf 1981). Dieses stellt somit von allen hier untersuchten Fe-Fraktionen die stabilste und am wenigsten pflanzenverfügbare Form dar. Während ihre Bedeutung für die pflanzliche Mineralstoffernährung hinter die anderer Bindungsformen zurücktritt, erlauben gerade hochgeordnete, kristalline Fe-Oxide Aussagen zur Bodengenese (Schwertmann 1988a). Die irreversible Auflösung primärer Minerale, darunter v. a. die von Fe(II)-Silikaten, führt grundsätzlich im Laufe der Pedogenese zu einer Anreicherung der bodenspezifisch stabilsten Fe-Oxide. Deshalb können aus dem Verhältnis Fe(Dithionit) : Fe(gesamt) Rückschlüsse auf das Stadium, aus der die verschiedenen kristallinen Fe-Oxide kennzeichnenden Bodenfärbung solche auf die Richtung der Bodenentwicklung gezogen werden.

Dithionit reduziert und löst neben kristallinen natürlich auch amorphe Fe-Oxide. Einen besseren Hinweis auf die Gehalte hochgeordneter Fe-Oxide im Boden geben demnach die Differenzen der Feinerdegehalte an dithionit- und oxalatextrahierbarem Eisen. Geht man davon aus, dass für die jeweiligen Vergleichsbestände des Gentiano-Koelerietum das Ausgangsgestein der Bodenbildung identisch ist, lassen die median fast 20 \% höheren Gehalte an hochgeordneten Fe-Oxiden in den CF-Beständen auf eine weiter vorangeschrittene Bodenverwitterung in dieser Subassoziation schließen. Ausnahmen stellen die Standorte Hölle- 
berg-Süd (CC : $\mathrm{CF}=1,0)$ und Pagenberg (CC : $\mathrm{CF}=1,5)$ dar. Allerdings ist der Carbonatgehalt wohl als besserer Indikator für das Entwicklungsstadium der jeweiligen Böden zu betrachten. Die Lösung von Kalkgestein geht mit einer Aufkonzentrierung verschiedener Bodenkomponenten, darunter v. a. auch derjenigen von Tonmineralien einher. Die Anreicherung kristalliner Fe-Oxide ist auch in diesem Zusammenhang zu sehen.

Wenngleich die Ergebnisse der Dithionitextraktion tendenziell mit denen der anderen Fraktionen übereinstimmen, besitzen die diesbezüglichen Fe-Konzentrationen nur geringe Aussagekraft für die Vegetationsdifferenzierung des Gentiano-Koelerietum. Entsprechendes gilt für $\mathrm{Mn}, \mathrm{Cu}$ und $\mathrm{Zn}$. Während das durch Dithionit extrahierbare $\mathrm{Mn}$ und $\mathrm{Cu}$ in den Vegetationsbeständen vollkommen indifferent verteilt ist, zeigen die Untersuchungen, dass aus der Feinderde der typischen Subassoziation vergleichsweise mehr Zn freigesetzt werden kann. Es ist indes davon auszugehen, dass angesichts der sehr festen, aber nicht exakt definierten Bindung (Adsorption an Fe- und Mn-Oxide?) dieser Aspekt für die Etablierung acidophiler/calcifuger Arten in Kalk-Halbtrockenrasen allenfalls eine untergeordnete Rolle spielt.

\section{Zusammenfassung}

Die langsame und irreversible Überführung des lithogenen Eisens in die Pedo- und Biosphäre erfolgt in erster Linie durch die Hydrolyse und oxidoreduktive Lösung primärer Minerale (Schwertmann 1988a). Mit Ausnahme dieses nur zu geringen Anteilen durch Oxalat und Dithionit extrahierbaren Eisens (Jarvis \& Duncan 1976) wurden im Rahmen der vorliegenden Arbeit alle anderen relevanten Bodenfraktionen untersucht. Die Reihenfolge, in der die betreffenden Fe-Formen in Tabelle 35 aufgeführt sind, orientiert sich im Wesentlichen an ihren methoden- und bindungsspezifisch zunehmenden Konzentrationen und ihren daraus abzuleitenden Lösungsstabilitäten.

Die im Bodenwasser gelösten Fe-Fraktionen spielen trotz ihrer sehr geringen Konzentrationen eine zentrale Rolle für den Eisenhaushalt des Bodens und die pflanzliche Eisenversorgung. Sie stehen im Zentrum der Umwandlung fast aller Bindungsformen (Schwertmann 1988a). Festphasentransformationen von Ferrihydrit in Hämatit oder von Magnetit und Ilmenit in Maghemit und/oder Hämatit sind Ausnahmen von dieser Regel (Schwertmann 1988a). Prinzipiell wird in der Bodengenese primärmineralisches Eisen nach und nach in die unter den gegebenen Milieubedingungen thermodynamisch stabilste Form überführt. In terrestrischen Böden sind dies in der Regel hochgeordnete, kristalline Fe-(Hydr)oxide, wie z. B. Goethit. Wie das zumeist silikatisch gebundene Eisen der primären Minerale ist diese große, durch Dithionit extrahierbare Fraktion aufgrund ihrer geringen Löslichkeit für die pflanzliche Mineralstoffernährung vergleichsweise unbedeutend. Alle anderen Fe-Spezies werden von den Pflanzen besser verwertet.

Die Konzentrationsunterschiede zwischen den beiden Subassoziationen des Gentiano-Koelerietum nehmen mit der Pflanzenverfügbarkeit der Fe-Fraktionen zu. Unter diesem Gesichtspunkt und im Hinblick darauf, dass fast alle Bindungsformen in einem direkten Gleichgewicht mit der Lösungsphase stehen, kennzeichnen neben den in situ-Bodenlösungen wässrige Bodenextrakte die potenzielle Fe-Versorgung der Pflanzen am Standort wohl am besten. Von Nachteil ist dieses Verfahren aber überall dort, wo aufgrund carbonatgepufferter pH-Werte die Fe-Löslichkeit in Konzentrationsbereiche absinkt, die eine zuverlässige Analytik erschweren. So konnte der Nachweis, dass bei gleichem $\mathrm{pH}$ die Fe-Konzentrationen in der Bodenlösung des Gentiano-Koelerietum danthonietosum diejenigen der typischen Subassoziation signifikant übersteigen, nur mit vergleichsweise großem Aufwand erfolgen. 
Tabelle 35: Extraktionsmittel und bindungschemische Eigenschaften sowie mediane Verhältnisse und absolute Konzentrationswerte $\left[\mu \mathrm{mol} \cdot \mathrm{g}^{-1}\right]$ verschiedener Fe-Fraktionen in feldfrischen Feinerdehomogenaten des GentianoKoelerietum typicum (CC) und Gentiano-Koelerietum danthonietosum (CF).

\begin{tabular}{llcc}
\hline \multicolumn{2}{l}{ Extraktionsmittel/Bindungsform } & $\mathrm{Fe}(\mathrm{CC}): \mathrm{Fe}(\mathrm{CF})$ & $\mathrm{Fe}\left[\boldsymbol{\mu m o l} \cdot \mathbf{g}^{-1}\right]$ \\
\hline $\mathbf{H}_{2} \mathbf{O}$ & $\mathrm{Fe}(\mathrm{II} / \mathrm{III})$-Hydrolysespezies, gelöste org. Komplexe & $1: 5,0^{*}$ & 0,004 \\
Ferrozine $^{\circledR}$ & $\mathrm{Fe}^{2+}, \mathrm{Fe}(\mathrm{II})$ & $1: 4,3^{* *}$ & 0,01 \\
DTPA & austauschbares (?) und labil gebundenes Fe(III) & $1: 2,2^{*}$ & 0,3 \\
NTA & organisch gebundenes Fe(III) & $1: 1,4^{* *}$ & 6 \\
Oxalat & amorphe Fe-(Hydr)oxide & $1: 1,3^{* *}$ & 24 \\
Dithionit & kristalline Fe-(Hydr)oxide & $1: 1,1^{*}$ & 130 \\
\hline
\end{tabular}

Eine quantitative Erfassung der im Boden gelösten Fe-Fraktionen wird durch die rasche Immobilisierung von $\mathrm{Fe}^{2+}$ während der Herstellung von rein wässrigen Bodenextrakten erschwert. Mit der Entwicklung des Ferrozine ${ }^{\circledR}$-Extraktionsverfahrens für feldfrische Feinerdehomogenate wurde ein erster Schritt zur Lösung dieses Problems getan. Um freies und gebundenes $\mathrm{Fe}^{2+}$ besser differenzieren zu können, ist eine weitere Optimierung dieser Methodik v. a. in Bezug auf die Extraktionszeit und Chelatorkonzentration sowie auf die Bodenvorbehandlung und das Boden/Lösungs-Verhältnis wünschenswert. Wie die GBL besitzt aber bereits die hier gewonnene Ferrozine ${ }^{\circledR}$-Fraktion besondere Aussagekraft für die pflanzliche Fe-Ernährung. Von allen Extrakten lassen diejenigen mit $\mathrm{H}_{2} \mathrm{O}$ und Ferrozine ${ }^{\circledR}$ die unterschiedlichen Fe-Verfügbarkeiten in den beiden hier behandelten Vegetationseinheiten des Gentiano-Koelerietum am deutlichsten erkennen.

DTPA und NTA bilden mit vielen Schwermetallionen stabile Chelate. Welche Reaktionen der Lösung vermeintlich unterschiedlicher Bodenfraktionen durch diese beiden Extraktionsmittel zugrunde liegen, ist weitestgehend ungeklärt. Vergleiche mit den Analysenergebnissen ungepufferter und TEA-gepufferter $\mathrm{Ba}^{2+}$-Extrakte lassen aber eine nennenswerte Desorption des DTPA-extrahierbaren Fe vom Austauscherkomplex des Bodens fraglich erscheinen. Wie die elementspezifischen $\mathrm{CEC}_{\mathrm{eff}}$-Analysen gezeigt haben, spielt austauschbares Eisen in carbonatreichen Böden keine nennenswerte Rolle. Insgesamt stimmen die Ergebnisse der DTPA- und NTA-Extraktionen in Bezug auf die Fe-Relationen zwischen den Vergleichsbeständen der einzelnen Standorte recht gut überein. Die Durchführung beider Extraktionsverfahren führt daher offenbar zu keinem weiteren Erkenntnisgewinn. Werden im Rahmen vergleichender ökologischer Untersuchungen potenzielle Kationenaustauschkapazitäten ermittelt, so können die hier anfallenden Austauscherlösungen aufgrund ihrer hohen Konzentrationen an schwermetallchelatisierendem TEA die DTPA-Extrakte des "pflanzenverfügbaren" Eisens ersetzen .

Synthetische Chelatbildner kamen auch in einem hier nicht im Detail diskutierten Zusatzversuch zum Einsatz. Durch Schüttelung von Feinerdehomogenaten mit Lösungen definierter FeEDTA- und FeEDDHA-Konzentrationen kann gleichzeitig das Lösungs- und Immobilisierungspotenzial verschiedener Böden bestimmt werden. Auch die Ergebnisse dieser an Feinerdehomogenaten des Standorts Auf der Burg durchgeführten Untersuchungen bestätigen, dass in Vegetationsbeständen mit acidophilen/calcifugen Arten eine bessere Fe-Verfügbarkeit vorliegt.

Amorphe Fe-Oxide besitzen eine vergleichsweise hohe Wasserlöslichkeit und können überdies durch mikrobiell und pflanzlich induzierte Reaktionen v. a. in der Rhizosphäre mobilisiert werden. Hierauf basiert die weit reichende Korrelation zwischen den oxalatextrahierbaren Fe-Konzentrationen und dem Pflanzenwachstum in kalkreichen Böden, wie sie von Loeppert \& Hallmark (1985) nachgewiesen wurde. Wenngleich Oxalatextraktionen feldfrischer Feinerdehomogenate eine geringere Differenzierungseffizi- 
enz für die hier untersuchten Vegetationsbestände besitzen, erscheint dieses Extraktionsmittel neben $\mathrm{H}_{2} \mathrm{O}$ und Ferrozine ${ }^{\circledR}$ für die Untersuchung des pflanzenverfügbaren Fe-Angebots im Boden besonders geeignet. Dies gilt v. a. auch, wenn es für die Perkolationen von Bodenmonolithen eingesetzt wird.

Alle hier beschriebenen Extraktionsverfahren zeigen, dass die Etablierung acidophiler/calcifuger Arten in Kalk-Halbtrockenrasen mit einer verbesserten Eisenverfügbarkeit einhergeht. Hingegen weisen die Ergebnisse der Mn-, Zn- und Cu-Analysen keine einheitlichen Muster bezüglich der Konzentrationsverhältnisse in den Böden der verschiedenen Subassoziationen auf. Daher ist eine vegetationsdifferenzierende Bedeutung dieser Nährelemente für das Gentiano-Koelerietum unwahrscheinlich.

\subsubsection{Phosphor}

Verschiedene Autoren bringen die Vegetationsdifferenzierung kalkreicher Standorte mit einer unzureichenden Phosphorversorgung nicht adaptierter Arten, Unterarten und Ökotypen in Verbindung (James 1962; Snaydon \& Bradshaw 1962; Grime 1963a, 1963b; Marrs \& Bannister 1978a; Ström et al. 1994; Tyler 1994, 1995, 1996a, 1996b; Tyler \& Ström 1995; Shen et al. 1996, Bonis et al. 1997). Bezugnehmend auf diese Hypothese sollen im Nachfolgenden neben bodenkundlichen v. a. auch ökophysiologische Aspekte der P-Ernährung diskutiert werden. Angesichts der geringen P-Löslichkeiten sowohl in basenarmen, sauren als auch basenreichen, alkalischen Böden sowie ähnlicher Mobilisierungsstrategien bei suboptimalem P- und Fe-Angebot in Kalk-Halbtrockenrasen werden die pflanzlichen Mineralstoffeffizienzen für diese beiden Nährelemente in Beziehung zueinander gestellt.

\section{Pflanzliche P-Defizienzen und P-Verfügbarkeiten in basischen/kalkreichen Böden}

Bereits Balme (1953) führte im Rahmen ihrer Untersuchungen entlang der Catena einer flachgründigen, kalkreichen Rendzina über verschiedene Braunerden hin zu einem basenarmen, sauren Podsol P-Analysen des Boden- und Sprossmaterials sowie P-Düngungsversuche in Festsubstratkulturen durch. Während die P-Konzentrationen in Essigsäureextrakten mit dem $\mathrm{pH}$ des Bodens abnahmen, stiegen die P-Gehalte im Pflanzengewebe mit der Bodenacidität an. Offenbar ist die Fraktion des säurelöslichen Phosphats für die pflanzliche P-Ernährung von untergeordneter Bedeutung. Die Kulturversuche belegten suboptimale PVerfügbarkeiten in allen Böden, v. a. aber in einer kalkreichen Rendzina. Dabei stimulierte der Einsatz von Wirtschaftsdünger nicht nur das Wachstum eines als acidophil/calcifug gefassten Taxons von Viola lutea, sondern auch das verschiedener - allerdings nicht benannter - basiphiler/calcicoler Arten. Angesichts ihrer unzureichenden Darstellung und Konzeption geben die Untersuchungen von Balme leider nur vage Hinweise auf die Bedeutung von Phosphor für die hier betrachtete Vegetationsdifferenzierung.

Entsprechendes gilt für Arbeiten anderer Autoren. Grime (1963b) interpretiert nicht näher definierte phänologische Symptome acidophiler/calcifuger Arten auf kalkreichen Böden als Ausdruck einer unzureichenden, offenbar aber weder bodenkundlich noch auf Ebene des Pflanzengewebes untersuchten P-Versorgung. Im selben Jahr veröffentlichte Ergebnisse von Topfversuchen zum Einfluss der Düngung des Bodenmaterials einer flachgründigen Rendzina mit $\mathrm{MgSO}_{4}, \mathrm{H}_{3} \mathrm{PO}_{4}, \mathrm{~K}_{2} \mathrm{SO}_{4}$ sowie $\mathrm{FeSO}_{4}$, FeEDTA und FeEEHPA auf das Wachstum der basiphilen/calcicolen (!) Sanguisorba minor (R 8, N2) belegten allein für P einen wachstumsstimulierenden Effekt (Grime 1963a).

Besonders eingehend wurde in den vergangenen Jahren die Bedeutung der pflanzlichen P-Ernährung für die Besiedlung basenarmer, saurer und basenreicher, alkalischer Böden in der Arbeitsgruppe von G. Tyler in Lund (Schweden) untersucht. Das Screening von 12 Acidophilen/Calcifugen, die in unbehandeltem so- 
wie P-gedüngtem Bodenmaterial der Rendzina eines ordovizischen Kalksteins $\left(\mathrm{pH}_{\mathrm{KCl}} 7,4\right)$ und in dem der Parabraunerde $\left(\mathrm{pH}_{\mathrm{KCl}} 4,8\right)$ ihres Herkunftsstandorts kultiviert wurden, verwies auf eine unzureichende PVerfügbarkeit in dem carbonatreichen Substrat (Tyler 1996a). Leider wurden in diese Versuche keine basiphilen/calcicolen Arten einbezogen, so dass Wachstumsstimulationen und erhöhte P-Konzentrationen im Pflanzengewebe durch P-Düngung nicht als besonderes Kennzeichen kalkmeidender Arten betrachtet werden dürfen. Wie oben belegt, können Basiphile/Calcicole in gleicher Weise auf eine Verbesserung des P-Angebots reagieren.

Die Ergebnisse weiter führender Kulturversuche an Veronica officinalis (R3, N3) und Carex pilulifera (R 3, N 4) in 50 Böden mit pH-Werten zwischen pH3,4-8,6 und austauschbaren Ca-Gehalten zwischen 1,1-330 $\mu \mathrm{mol} \cdot \mathrm{g}^{-1}$ TG verdichten zwar die Hinweise darauf, dass niedrige P-Verfügbarkeiten zumindest in kalkreichen Böden moderater Alkalinität wachstumslimitierend wirken (Tyler 1996b), doch gewinnen mit steigenden pH-Werten Faktoren an Gewicht, die zur Ausbildung von Chlorosen führen. Gerade Pdefiziente Pflanzen sind durch hohe Chlorophyllkonzentrationen gekennzeichnet (Hecht-Buchholz 1967; Rao \& Terry 1989). Offensichtlich führen bereits vergleichsweise geringe Erhöhungen der Bodenreaktion dazu, dass an diesen Standorten primär Fe-Defizienzen das Pflanzenwachstum beeinträchtigen. In carbonatreichen Böden wird bei verschiedenen acidophilen/calcifugen Arten Fe-Mangel erst durch P-Düngung und die daraus resultierende Wachstumsförderung induziert (Tyler 1996a). Bei anderen, wie beispielsweise Galium saxatile (=G. harcynicum; R 2, N3) treten in demselben Bodenmaterial indes auch ohne PSupplementierung Eisenmangelchlorosen auf. Inwieweit Basiphile/Calcicole als Folge einer P-Düngung in kalkreichen Substraten ebenfalls Fe-Defizienz erleiden oder ihren Fe-Bedarf trotz erhöhter Wachstumsraten an diesen Standorten decken können, wurde hier nicht untersucht.

Auch wenn die Ergebnisse weiterer Kulturversuche von Tyler (1994) P-Limitierungen in basenreichen Substraten andeuten, sind in situ die für eine unzureichende Fe-Versorgung typischen Intercostalchlorosen zumindest im Frühjahr das am weitesten verbreitete Mangelsymptom acidophiler/calcifuger und mesophiler Pflanzenarten in Kalkböden (Grime \& Hodgson 1969). Das Ausbleiben eines Fe-Düngungseffekts bei sieben von acht Acidophilen/Calcicolen wird von Tyler zwar dahingehend gedeutet, dass Fe im Gegensatz zu P das Pflanzenwachstum in dem hier untersuchten Kalkboden nicht limitiert, doch bedarf die Interpretation dieser Versuchsergebnisse einer genaueren Betrachtung. Zum einen wurden für die Untersuchungen adulte Pflanzen verwendet, die unmittelbar von ihren natürlichen basenarmen Standorten in den carbonatreichen Versuchsboden überführt wurden. Eine Nutzung interner Fe-Speicherpools während der etwa zweimonatigen Kultivierung kann daher als Ursache für das unveränderte Wachstum der Arten nicht ausgeschlossen werden. Zudem erfolgte die Eisendüngung mit Fe(III)-Citrat. Wie in Abbildung 60 (S. 119) dargestellt, verliert der Fe-Komplex seine Stabilität bereits bei einer Abnahme der Protonenaktivitäten von pH 6 auf pH 7. Ungeachtet dessen, dass die Kulturgefäße jeden zweiten Tag mit $10 \mu \mathrm{M}$ Fe(III)-Citrat-Lösung bewässert wurden, stiegen die Fe-Konzentrationen der Bodenlösung bei pH 8,1 im Schnitt nur um $30 \%$ an. Hingegen übertraf die P-Konzentration der Bodenlösung trotz nur einmaliger $\mathrm{CaHPO}_{4}$-Applikation zu Versuchsbeginn auch noch nach 60 Tagen die der Kontrollvariante um einen Faktor 20. Die Effekte dieser Fe- und P-Supplementierungen sollten daher nur mit Vorsicht in Zusammenhang mit dem Fehlen von Acidophilen/Calcifugen an kalkreichen Standorten gebracht werden.

Arbeiten von Jefferies \& Willis (1964a) zur Ca-Toleranz und Mineralstoffernährung der calcifugen/acidophilen Juncus squarrosus (R1, N1) und Nardus stricta (R 2, N2), der calcicolen Origanum vulgaris (R 8, N3) sowie der von diesen Autoren im Hinblick auf die Bodenreaktion als indifferent eingeordneten Danthonia decumbens (R3, N 2; vgl. aber Abschnitt 5.1.4, S. 151) geben keine Hinweise auf Unterschiede der 
Tabelle 36: Fraktionen und Bindungsformen der sequentiellen P-Extraktion lufttrockener Feinerdehomogenate (Schlichting et al. 2002).

\begin{tabular}{ll}
\hline Fraktion & Bindungsform \\
\hline $\mathbf{P}(\mathrm{GBL})$ & Gelöstes, leicht desorbierbares und nicht okkludiertes P reaktiver Oberflächen \\
$\mathbf{P}($ Resin) & Gelöstes, leicht desorbierbares und nicht okkludiertes P reaktiver Oberflächen \\
$\mathbf{P}_{\mathbf{i}}\left(\mathrm{HCO}_{3}{ }^{-}\right)$ & Gelöstes, leicht desorbierbares und nicht okkludiertes P reaktiver Oberflächen \\
$\mathbf{P}_{\mathrm{o}}\left(\mathrm{HCO}_{3}{ }^{-}\right)$ & Assoziiertes $\mathrm{P}$ organischer Fe-Komplexe \\
$\mathbf{P}_{\mathbf{i}}\left(\mathrm{OH}^{-}\right)$ & P wenig kristalliner Fe- und Al-(Hydr)oxide \\
$\mathbf{P}\left(\mathrm{OH}^{-}\right)$ & Assoziiertes P organischer Al-Komplexe und von Huminstoffen \\
$\mathbf{P}(\mathrm{HCl})$ & Ca-P (Apatite) \\
\hline
\end{tabular}

standörtlichen P-Verfügbarkeiten und des pflanzlichen P-Bedarfs der durch sie repräsentierten Konstitutionstypen. Abweichend von der oben formulierten Annahme einer suboptimalen P-Versorgung acidophiler/calcifuger Arten in Kalkböden, lagen die P-Konzentrationen von Bodenperkolaten mit 2 M Ammoniumacetatlösungen (pH 7,0) für die Bestände der Basiphilen/Calcicolen tendenziell sogar über denen der Vergleichsgruppe. Gleichzeitig zeigten die Bodenextrakte der 17 sauren, kalkfreien bzw. alkalischen, kalkreichen Standorte von $D$. decumbens keine systematisch differierenden P-Konzentrationen. Die eigenen Untersuchungen bestätigen diese Ergebnisse. Mit Hilfe des in Anlehnung an Hedley et al. (1982) durchgeführten sequentiellen Extraktionsverfahrens wurden für lufttrockene Feinerdehomogenate der Standorte Auf der Burg und Hölleberg verschiedene P-Fraktionen analysiert. Wie Tabelle 36 zeigt, sind diese mehr durch die Art ihrer Extraktion als durch exakt definierte chemische Eigenschaften gekennzeichnet.

Für die Phosphorversorgung der Pflanzen ist die Konzentration des wasserlöslichen P besonders wichtig. Wie bereits Untersuchungen von Sutton \& Gunary (1969) gezeigt haben, erklärt P(Resin) etwa 70 \% der Variation der pflanzlichen P-Aufnahme. Durch den Einsatz von Anionenaustauschermaterial gibt diese Fraktion bei geeigneten Versuchsanordnungen gleichzeitig Hinweise auf die Gleichgewichtskonzentrationen in der Bodenlösung, die Geschwindigkeit der zugrunde liegenden Lösungs- und Immobilisierungsreaktionen sowie das Nachlieferungspotenzial des Bodens (Saggar et al. 1990; Schoenau \& Huang 1991). Wässrige Extraktionen zeigten für beide Referenzstandorte, dass die feinerdebezogenen P-Löslichkeiten in den CC-Beständen diejenigen des Gentiano-Koelerietum danthonietosum nicht unter-, sondern überschreiten. Tendenziell bestätigten die GBL des Standorts Hölleberg-Süd die höheren P-Konzentrationen in der Bodenlösung des Gentiano-Koelerietum typicum. Auch Untersuchungen von Welp et al. (1983) haben darauf verwiesen, dass die gelösten P-Konzentrationen kalkreicher Standorte und v. a. solcher, deren Gehalte an organischer Substanz bei mehr als 1\% liegen, häufig mit den $\mathrm{pH}$-Werten zunehmen. Die P-Löslichkeit wird hier offenbar stärker durch $\mathrm{OH}^{-}$-vermittelte Desorptionsreaktionen als durch die Bildung schwerlöslicher Phosphate bestimmt. Erst mit steigenden $\mathrm{pH}$-Werten und abnehmenden Gehalten an organischer Substanz gewinnen Präzipitations- und Kristallisationsreaktionen an Bedeutung. Insgesamt geben die GBL aller in der vorliegenden Arbeit untersuchten Kalk-Halbtrockenrasen aber keine Hinweise darauf, dass sich die P-Löslichkeiten in den CC- und CF-Beständen systematisch unterscheiden. .

Diese Einschätzung wird durch die indifferenten Ergebnisse der $\mathrm{P}(\mathrm{NaOH})$ - und $\mathrm{P}\left(\mathrm{HCO}_{3}{ }^{-}\right)$-Extraktionen bestätigt. Während die Untersuchungen des Standorts Auf der Burg bessere P-Verfügbarkeiten im Gentiano-Koelerietum danthonietosum andeuten, verweisen diese für den Standort Hölleberg auf eine bessere P-Versorgung im Gentiano-Koelerietum typicum. Mit dem Carbonatgehalt nimmt der Anteil des anorga- 
nisch gebundenen $\mathrm{P}$ in den $\mathrm{HCO}_{3}{ }^{-}$-Extrakten $\mathrm{zu}$ - ein Ergebnis, das möglicherweise auf die Lösung von fein suspendierten Calciumphosphaten im Rahmen der differentiellen Analyse von $\mathrm{P}_{\mathrm{i}}$ und $\mathrm{P}$ zurückzuführen ist (vgl. Abschnitt 2.2.9, S. 34 ff.). NaOH-Lösungen mit einer Konzentration von 0,1 M extrahieren sehr viel mehr organisches Material. Die höheren Anteile von $\mathrm{P}_{\mathrm{o}}$ an der Gesamtfraktion des $\mathrm{OH}^{-}-$ extrahierbaren $\mathrm{P}$ in den CC-Beständen gehen offenbar auf die Anreicherung organischer Verbindungen im Boden zurück.

Die Lösung von Calciumphosphaten spielt bei der Subfraktionierung des $\mathrm{P}(\mathrm{NaOH})$ eine untergeordnete Rolle. Angesichts der uneinheitlichen Ergebnisse für die beiden Referenzstandorte und der unzureichenden Separierung verschiedener P-Bindungsformen (s. Tiessen \& Moir 1993), soll auf eine weiter gehehende Diskussion der $\mathrm{CO}_{3}^{-}$- und $\mathrm{OH}^{-}$-extrahierbarer P-Fraktionen für die Vegetationsdifferenzierung verzichtet werden. Gleiches gilt auch für die säurelösliche und mit dem Carbonatgehalt der Böden korrelierte P-Fraktion. Ähnlich dem residualen P, das durch einen abschließenden Gesamtaufschluss des sequentiell extrahierten Bodenmaterials bestimmt werden kann, ist das vorwiegend in Form von Apatiten gebundene $\mathrm{P}(\mathrm{HCl})$ für die pflanzliche Mineralstoffernährung ohne nennenswerte Bedeutung (Tiessen \& Moir 1993). Daher können aus den höheren P-Gesamtgehalten der Böden im Gentiano-Koelerietum typicum keine besseren P-Verfügbarkeiten der betreffenden Standorte abgeleitet werden.

Die Konzentrationen der Extraktionslösungen und die diesbezüglichen Gehalte der Feinerde geben keine Hinweise darauf, dass das Auftreten von acidophilen/calcifugen und basiphilen/calcicolen Arten mit den P-Konzentrationen des Substrats in Verbindung steht. Bezieht man die P-Analysen der Feinerde auf die Gesamtvolumina (vgl. Tabelle 7, S. 52), so lassen die Untersuchungen aufgrund der höheren Skelettgehalte vieler CC-Bestände auf ein etwas besseres P-Angebot im Gentiano-Koelerietum danthonietosum schließen. Beispielsweise liegen in den CF-Beständen der Referenzstandorte die Volumenkonzentrationen der Böden für $\mathrm{P}(\mathrm{Resin})$ und $\mathrm{P}\left(\mathrm{HCO}_{3}{ }^{-}\right)$im Mittel etwa $34 \%$ bzw. $75 \%$ über denen des GentianoKoelerietum typicum.

Prinzipiell erscheinen Volumenbezüge für die Bewertung der pflanzlichen P-Ernährung besonders geeignet. Wegen seiner vergleichsweise geringen Mobilität im Boden (Schachtman et al. 1998) sowie des Vorrangs der diffusiven Nachleitung über den transpirationsvermittelten Massenfluss (Jungk \& Claassen 1997; Claassen \& Steingrobe 1999) bilden sich für P sehr schnell rhizosphärische Verarmungszonen aus. Hierzu trägt bei, dass der P-Gehalt im Vergleich zu dem anderer Mineralstoffe im Boden gering ist. So liegen die mittleren Gesamtkonzentrationen im Boden beispielsweise für Fe bei 2,6 \% (m/m), für P hingegen bei nur 0,05 \% (m/m) (Scheffer \& Schachtschabel 1992).

Aufgrund der geringen Löslichkeiten und potenziellen Nachlieferungskapazitäten des Bodenphosphats sowie des vergleichsweise hohen Pflanzenbedarfs sind mehr noch als bei anderen Pflanzennährstoffen anatomisch-morphologische Anpassungen des Wurzelsystems und die Erschließung neuer Bodenbereiche für die P-Effizienz von zentraler Bedeutung (s. Smith et al. 2003). Dies gilt v. a. dort, wo physikoedaphische Parameter, wie eine feinstrukturierte Bodentextur und geringe Wassergehalte, die Diffusionsgeschwindigkeiten beeinträchtigen. Insgesamt erfordern demnach geringe volumenbezogene P-Konzentrationen besonders hohe Aufwendungen für die Deckung des Pflanzenbedarfs. Andererseits haben split rootExperimente in Nährlösungen und lokalisierte P-Applikationen in Festsubstraten z. B. für Hordeum vulgare (Drew \& Saker 1978), Phaseolus vulgaris (Snapp et al. 1995), Arabidopsis thaliana (Zhang \& Forde 1998) und Oryzum sativum (He et al. 2003) zeigen können, dass die Ökonomie dieser Investitionen durch ein bevorzugtes Wurzelwachstum ("Kompensationswachstum") in Bereichen höherer P-Verfügbarkeiten 
verbessert wird. Wie an der Regulation rhizodermaler Fe(III)-Reduktasen (Schmidt et al. 1996), ist auch hier ein internes Defizienzsignal an der Stressantwort beteiligt.

Das Ausmaß, in dem die Pflanzenverfügbarkeiten gegebener P-Fraktionen durch unterschiedliche Bodenvolumenkonzentrationen $(\mathrm{CC}<\mathrm{CF})$ sowie Wassergehalte $(\mathrm{CC}<\mathrm{CF})$ und Lagerungsdichten $(\mathrm{CC}<\mathrm{CF})$ der Feinerde beeinflusst werden, lässt sich nicht exakt benennen. Insgesamt ist aber davon auszugehen, dass die vergleichsweise geringen Unterschiede der P-Konzentrationen in den hier untersuchten Böden selber nicht für die syntaxonomische Differenzierung des Gentiano-Koelerietum verantwortlich sind. Allein auf Grundlage von Bodenanalysen kann indes nicht ausgeschlossen werden, dass die P-Ernährung eine Rolle für das standortspezifische Auftreten acidophiler/calcifuger und basiphiler/calcicoler Arten spielt.

\section{Ökophysiologische Aspekte der P-Ernährung in basischen/kalkreichen Böden}

Im Hinblick auf die geringen P-Löslichkeiten sowohl in alkalischen, kalkreichen als auch in sauren, basenarmen Böden (vgl. Abschnitt 4.3.6, S. 136 ff.) müssen neben edaphischen v.a. auch ökophysiologische Aspekte diskutiert werden, die potenziell für die pflanzliche P-Versorgung und die Vegetationsdifferenzierung von Bedeutung sind. Eine P-abhängige Besiedlung von sauren Böden einerseits und Kalkböden andererseits ist nur schlüssig, wenn die Präferenzen der Arten mit Adaptationen einhergehen, die sie zu einer spezifischen Verwertung der unterschiedlichen P-Fraktionen unter den gegebenen Milieubedingungen befähigen. So verweisen Bhadoria et al. (2002), allerdings ohne Angabe konkreter Beispiele, darauf, dass standorttypische, mit der natürlichen Verbreitung der Pflanzenarten korrelierte P-Effizienzen existieren.

Bereits in Abschnitt 4.3.6 (S. 136 ff.) wurden allgemeine Grundlagen der P-Effizienz vorgestellt. Im Nachfolgenden soll insbesondere auf Arbeiten eingegangen werden, die gezielt Aspekte der P-Ernährung acidophiler/calcifuger und basiphiler/calcicoler Arten behandeln. Anders als beispielsweise für Aluminium, Eisen oder Calcium war allerdings die Aufnahme und der Ausschluss, die Translokation und Restriktion, aber auch die Mobilisierung und Immobilisierung sowie die Speicherung und Verwertung von Phosphaten bisher im Zusammenhang mit der Calcicolen/Calcifugen-Thematik Gegenstand nur sehr weniger Untersuchungen.

\section{P-Aufnahme}

Eine Reihe molekularbiologischer und physiologischer Arbeiten haben gezeigt, dass unter P-Mangelstress vermehrt membranäre P-Transporter exprimiert und damit die Kapazität der P-Aufnahme erhöht wird (s. Smith et al. 2003). Andererseits sollen sich die P-Aufnahmesysteme der Wurzeln verschiedener Arten hinsichtlich ihrer Substrataffinitäten nicht oder nur geringfügig unterscheiden (Hendriks et al. 1981; Buhse 1992). Ein Faktor, der die P-Ernährung im alkalischen Milieu erschweren kann, ist die Kompetition der $\mathrm{HPO}_{4}^{2-}$ - bzw. $\mathrm{H}_{2} \mathrm{PO}_{4}^{-}$-Aufnahme durch $\mathrm{OH}^{-}$(s. Schachtman et al. 1998). Vermutlich v. a. deshalb ist bei gleichen Konzentrationen der Bodenlösung in einem kalkreichen Luvisol der P-Bedarf deutlich höher als in einem sauren Oxisol (Bhadoria et al. 2002). Inwieweit insbesondere bei acidophilen/calcifugen Arten die P-Aufnahme durch diesen Effekt beeinflusst wird, ist bisher ebenso wenig geklärt, wie die schon früh diskutierte Beeinträchtigung der pflanzlichen P-Ernährung acidofuger/calcicoler Arten durch hohe (interne) Al- (und Fe-) Konzentrationen in sauren Böden (Wright 1943; Rorison 1960b). 
Hinweise darauf, dass die $\mathrm{OH}^{-}$-Aktivitäten im Zusammenhang mit der P-Ernährung keine Rolle für den Ausschluss acidophiler/calcifuger Arten von basenreichen Standorten spielen, geben Untersuchungen von Nassery \& Harley (1969). Dekapitierte Wurzeln der acidophilen Avenella flexuosa (R 2) zeigten sowohl in calciumfreien Testlösungen als auch in solchen mit moderaten $\mathrm{Ca}^{2+}$-Konzentrationen (1 mM) zwischen pH 3-7 durchschnittlich vierfach, bei pH 7 sogar fünffach höhere P-Aufnahmeraten als die basiphile Scabiosa columbaria (R 8). Bei pH 3 betrug das P-Aufnahmeverhältnis zwischen den beiden Arten lediglich 3,8. Gleichzeitig wurde nachgewiesen, dass sehr hohe $\mathrm{Ca}^{2+}$-Konzentrationen $(10 \mathrm{mM})$ die P-Aufnahme von S. columbaria aus Lösungen mit $10 \mu \mathrm{M} \mathrm{KH}_{2} \mathrm{PO}_{4}$ und $\mathrm{pH} 4,5$ deutlich stärker stimulieren als die von Urtica dioica (R 7), Rumex acetosa (R x) und A. flexuosa. Indes wird von den Autoren selber eine Relevanz dieses Phänomens für die natürliche Verbreitung der Arten in Frage gestellt und stattdessen auf die Stimulation der P-Aufnahme auch durch andere Kationen, wie $\mathrm{Mg}^{2+}, \mathrm{K}^{+}$und $\mathrm{Na}^{+}$, verwiesen.

\section{P-Mobilisierung}

Während der P-Transport in die Wurzeln und innerhalb der Pflanze bisher unter ökologischen Gesichtspunkten nur wenig Beachtung gefunden hat und dementsprechend dessen Bedeutung für die P-Effizienz und die daraus resultierende Vegetationsdifferenzierung weitestgehend offen ist, besitzen verschiedene PMobilisierungsstrategien zweifelsohne eine Bedeutung für die pflanzlichen Standortpräferenzen. Das prominenteste Beispiel hierfür ist die Ausbildung von cluster roots. Kumulierte und durch die fortschreitende Degeneration der Apikalmeristeme in ihrem Längenwachstum gehemmte Lateralwurzeln, die bei Arten mancher Familien einen dichten Wurzelhaarbesatz und besonders viele rhizodermale Transferzellen aufweisen, bilden den Rahmen für die hohe Mobilisierungseffizienz der Abgabe von Protonen, organischen Säuren, Phenolen und verschiedenen Exoenzymen (s. Lamont 2003).

Während die Ausbildung von cluster roots bei vielen Arten, wie z. B. Myrica cerifera (Louis et al. 1990) und Lupinus albus (Keerthisinghe et al. 1998), in unmittelbarem Zusammenhang mit der P-Verfügbarkeit steht, werden derartige Adaptationen bei Ficus benjamini (Dinkelaker et al. 1995) sowie verschiedenen Arten der Gattungen Alnus und Casuarina durch Fe-Defizienz induziert (Hurd \& Schwintzer 1996; Zaid et al. 2003). Casuarina glauca bildet nur in alkalischen, nicht aber in sauren Böden cluster roots (Arahou \& Diem 1997). Lupinus consentinii ist die einzige Art, von der bekannt ist, dass die Morphogenese ihres Proteoidwurzelsystems sowohl durch den P- als auch durch den Fe-Ernährungsstatus reguliert wird (Watt \& Evans 1999b).

Wie diese Ausführungen zeigen, dürfen cluster roots nicht als morphologisch-physiologische Anpassungen betrachtet werden, die allein auf die Mobilisierung und Aufnahme von P abzielen. Vielmehr handelt es sich hierbei um Wurzeladaptationen, die allgemein die Mineralstoffeffizienz von Arten nährstoffarmer Standorte erhöhen, offensichtlich aber, wie ihre unterschiedlichen Induktionen zeigen, in den meisten Fällen primär auf die Mobilisierung und Aufnahme eines bestimmten Nährstoffs abzielen. In Australien besitzen Arten mit cluster roots ihren Verbreitungsschwerpunkt beispielsweise an Standorten stark verwitterter und damit basenarmer, saurer Böden (Lambers et al. 1998). Inwieweit sich deren Wurzelsysteme von solchen der Pflanzenarten basenreicher, alkalischer Böden anatomisch-morphologisch und v. a. physiologisch unterscheiden, wurde bisher noch nicht untersucht.

Die P-Löslichkeit ist u. a. eine Funktion der pedogenen Fe-Fraktionen. An überfluteten Standorten wird sie durch die Ausfällung von Vivianit, in initialen Stadien der Fe-Reduktion oder Fe-Oxidation wechselfeuchter Böden durch die Adsorption an Hydromagnetit (hydrosic iron) bestimmt (Zhang et al. 2003). In terrestrischen Böden liegt, wie die im Rahmen der vorliegenden Arbeiten untersuchten $\mathrm{P}_{0}\left(\mathrm{HCO}_{3}{ }^{-}\right)$- und 
$\mathrm{P}_{\mathrm{i}}\left(\mathrm{OH}^{-}\right)$-Fraktionen zeigen, ein erheblicher Anteil des $\mathrm{P}$ in gebundener oder okkludierter Form zusammen mit Fe vor. Nennenswerte Fe-Phosphat-Gehalte kalkreicher Standorte wurden auch von Welp et al. (1983) nachgewiesen. Dennoch korrelieren, wie Analysen von 110 Böden verschiedener Rasengesellschaften in Südostschweden gezeigt haben, der Anteil der primären P-Fraktionen v. a. mit der Bodenreaktion (und den Kalkgehalten): log Fe-P [\%] folgt einer invers linearen, log Ca-P [\%] einer kurvilinearen Beziehung zu pH(KCl) (Tyler 2002).

Grundsätzlich geht die Lösung von anorganisch gebundenem P mit der Mobilisierung des komplexierenden Kations einher. Aspekte der Fe- und P-Ernährung können aufgrund der oben dargestellten Parallelen hinsichtlich Art und Regulation der Mangelstressreaktionen und potenzieller Kolimitierungen gerade in alkalischen, kalkreichen Böden nicht eindeutig voneinander getrennt werden. Gestützt wird diese Annahme durch Bilanzierungen von Bhadoria et al. (2002), nach denen Wurzelexsudate Fe/Al-gebundenes P sehr viel stärker als Ca-P mobilisieren.

Nicht nur Arten mit cluster roots, sondern auch solche ohne proteoide Wurzelbildungen exsudieren bei sub-, aber auch supraoptimalen Mineralstoffkonzentrationen vermehrt niedermolekulare organische Säuren (Hoffland et al. 1989; Gerke et al. 1995). Sowohl bei P- als auch Fe-Mangel wird v. a. Citrat in die Rhizosphäre abgegeben (Jones et al. 1996; Watt \& Evans 1999a; Penaloza et al. 2002). Von allen niedermolekularen Carboxylaten besitzt Citrat das beste Fe-Komplexierungsvermögen (Cline et al. 1982; Tyler \& Ström 1995). Die Fe-Mobilisierungseffizienz wird dadurch erhöht, dass die zeitlich wie auch räumlich kontrollierte und konzentrierte Abgabe von Citrat mit einer $\mathrm{H}^{+}$-ATPase-vermittelten Acidifizierung der Rhizosphäre einhergeht (Neumann et al. 1999; Kania et al. 2003). Zu welchen Anteilen Zitronensäure Fe(Hydr)oxide extrahiert und ob eine unter ernährungsphysiologischen Gesichtspunkten vorteilhafte überproportionale Fe-Komplexierung aus Fe-Phosphaten erfolgt, wurde bislang allerdings noch nicht untersucht.

Nach einer Hypothese der Arbeitsgruppe von G. Tyler soll eine besonders intensive Oxalat-Exsudation die Grundlage der (vermeintlich) höheren P-Effizienzen basiphiler/calcicoler Pflanzen sein und diesen im Gegensatz zu Acidophilen/Calcifugen die Besiedlung kalkreicher Böden erlauben. Um diese Annahme zu überprüfen, wurde einerseits das P- und Fe-Mobilisierungsvermögen von Oxalsäure und Zitronensäure sowie ihrer konjugierten Basen aus verschiedenen Böden, andererseits das diesbezügliche Exsudationsvermögen von Vertretern der acidophilen/calcifugen und der basiphilen/calcicolen Konstitutionsgruppe untersucht.

Ström et al. (1994, 2001) haben gezeigt, dass Oxalat ungeachtet seiner vergleichsweise begrenzten Austauschstärke für organisch adsorbiertes Phosphat sowie der relativ geringen Stabilität seiner Fe-Komplexe ein besseres Mobilisierungsvermögen für P besitzt als Citrat und im Gegensatz zu diesem die P-Aufnahme von Mais aus Kalkböden erhöht (Ström et al. 2002). Der Beitrag von Oxalat zur pflanzlichen PEffizienz wird auf die rhizosphärische Austauschkomplexierung von Ca-Phosphaten zurückgeführt. Als Ursache für die geringere P-Mobilisierung durch Citrat diskutieren die Autoren dessen besonders rasche mikrobielle Degradation (Ström et al. 2001). Die hohe Abbauresistenz von Oxalat in Bodensuspendaten wird mit der umgehenden Ausfällung von Calciumoxalat begründet. Eine kritische Untersuchung und Bewertung der hier dargestellten Reaktionen und Interpretationen, die im Hinblick auf die hohen freien $\mathrm{Ca}^{2+}$-Konzentrationen und die im Vergleich zu den $\mathrm{CaCO}_{3}$-Anteilen geringen Ca-P-Gehalte der Böden angebracht erscheint, steht allerdings noch aus. 
Die ursprünglich angegebene im Vergleich zu Zitronensäure zwanzigfach höhere $\mathrm{PO}_{4}{ }^{3-}$-Extraktion durch Oxalsäure (Ström et al. 1994) konnte in einer Versuchswiederholung mit dem gleichen ordovizischen Kalkboden nicht bestätigt werden (Ström 1997). ${ }^{1}$ Die Säurelösung von Kalk führt nach Darstellungen der neueren Arbeit bereits bei pH 6,3-6,5 zu einer nennenswerten Erhöhung der freien $\mathrm{Ca}^{2+}$-Konzentrationen und diese durch Verschiebung der Gleichgewichtsverhältnisse zu einem verminderten Ca-P-Angriff oder einer Repräzipitation des durch Austauschkomplexierung von Ca-P bzw. Fe-P freigesetzen $\mathrm{PO}_{4}{ }^{3-}$. Daher extrahieren Lösungen von Na-Oxalat und $\mathrm{Na}-\mathrm{Citrat}(\mathrm{pH} \approx 10)$ deutlich mehr $\mathrm{P}$ als die ihrer komplementären Säuren. Mit Ausnahme einer fünffach stärkeren P-Extraktion aus einem von zwei untersuchten kalkreichen Böden, die aber zumindest teilweise auf eine deutlich höhere Oxalatkonzentration der Extraktionslösungen zurückzuführen war, finden sich im Bereich um pH10 keine Hinweise auf Unterschiede des P-Mobilisierungsvermögens von Oxalat und Citrat. Untersuchungen an Bodenmaterial, dass durch Chloroformbegasung sterilisiert und 15 min mit ${ }^{14} \mathrm{C}$-markierten und auf $\mathrm{pH}$ 7,5 eingestellten (gepufferten?) $10 \mathrm{mM}$ Oxalat- und Citratlösungen geschüttelt wurde, ließen eine signifikante Steigerung der PExtraktion durch beide Carboxylate erkennen (Ström et al. 2002). Inwieweit allerdings die im Vergleich zur Citratextraktion um etwa $80 \%$ höhere P-Mobilisierung durch Oxalat signifikant ist, kann der betreffenden Veröffentlichung nicht entnommen werden.

Trotz ihres schnelleren mikrobiellen Abbaus extrahiert Zitronensäure bei pH 6-7 durchschnittlich um einen Faktor 25 mehr Fe aus Kalkböden als Oxalsäure (Ström et al. 1994, Ström 1997). Voraussetzung für das unterschiedliche Fe-Lösungsvermögen der Carboxylate ist in basenreichen Böden eine begleitende Absenkung des pH. Während bei einer Erhöhung der Protonenaktivitäten in kalkreichen Böden das bessere Fe-Bindungsvermögen von Citrat zum Tragen kommt (vgl. Abbildung 60, S. 119), zeigen NaSalze beider Säuren unter Alkalisierung auf $\mathrm{pH} \approx 10$ ein vergleichbares und recht hohes Fe-Lösungsvermögen. Dieses steht offenbar primär mit der Hydroxylierung von $\mathrm{Fe}(\mathrm{OH})_{3}$ und einer verminderten $\mathrm{Ca}^{2+}$-Lösung im Zusammenhang.

Untersuchungen sowohl an sehr jungen Keimlingen (Tyler \& Ström 1995) als auch an adulten Pflanzen (Ström et al. 1994, Ström 1997) haben gezeigt, dass Basiphile/Calcicole konstitutiv mehr bi- und trivalente organische Säuren in die Rhizosphäre abgeben als Acidophile/Calcifuge (Tabelle 37). Ström (1997) selber geht davon aus, dass die für die Fe- und P-Mobilisierung irrelevanten Monocarbonsäuren im Boden in erster Linie nicht pflanzlichen, sondern mikrobiellen Ursprungs sind und sie insgesamt keine ernährungsphysiologische Bedeutung besitzen. Im Widerspruch zu der Hypothese eines primären Ausschlusses acidophiler/calcifuger Arten von Kalkböden durch unzureichende Abgabe von Oxalat und daraus resultierenden P-Defizienzen, exsudieren acidophile/basiphile Arten im Vergleich zu basiphilen/calcicolen proportional deutlich mehr Oxalat als Citrat. Inwieweit die in allen Fällen relativ höheren Oxalatkonzentrationen der Wurzelausscheidungen auf einen schnelleren mikrobiellen Citratabbau in den Versuchssystemen zurückzuführen sind, kann hier aber nicht geklärt werden.

Tabelle 38 fasst die Exsudation der beiden Carboxylate in Abhängigkeit vom Kulturmedium und Konstitutionstypus zusammen (Ström et al. 1994; Ström 1997). Da sich die betreffenden Untersuchungen über Variationen der Kulturbedingungen hinaus auch im Hinblick auf die Auswahl und Anzahl der Pflanzenarten unterschieden, können die Versuchsergebnisse nur bedingt miteinander verglichen werden. Die Unter-

\footnotetext{
1 Variationen des Versuchsprozedere bezogen sich auf die Extraktionsdauer und die Extraktionsmittelkonzentrationen: Ström et al. (1994): Extraktionszeit $30 \mathrm{~min}, c$ (Oxalsäure) $=10 \mathrm{mM}, c$ (Zitronensäure) $=10 \mathrm{mM}$

Ström (1997): Extraktionszeit $60 \mathrm{~min}, c($ Oxalsäure $)=15 \mathrm{mM}, c($ Zitronensäure $)=10 \mathrm{mM}$
} 
Tabelle 37: Exsudation organischer Säuren durch acidophile/calcifuge (CF) und basiphile/calcicole (CC) Arten in Abhängigkeit von der Kultivierung der Versuchspflanzen und der Gewinnung der Analysenlösung.

\begin{tabular}{|c|c|c|c|c|c|c|}
\hline & \multicolumn{2}{|c|}{ Ström et al. (1994) } & \multicolumn{2}{|c|}{ Tyler \& Ström (1995) } & \multicolumn{2}{|c|}{ Ström (1997) } \\
\hline & CF & CC & $\mathrm{CF}$ & CC & $\mathrm{CF}$ & CC \\
\hline Arten & 9 & 9 & 10 & 10 & 2 & 2 \\
\hline Kultursubstrat & Silikatboden & Kalkboden & \multicolumn{2}{|c|}{ Filterpapier } & \multicolumn{2}{|c|}{ Braunerde } \\
\hline pH & 4,5 & 8,0 & \multicolumn{2}{|c|}{$\sim 7$} & \multicolumn{2}{|c|}{$4,9-5,3$} \\
\hline Pflanzenalter & \multicolumn{2}{|c|}{$8-12 w$} & \multicolumn{2}{|c|}{$10-19 d$} & \multicolumn{2}{|c|}{$20 w$} \\
\hline Analysenlsg. & \multicolumn{2}{|c|}{$\mathrm{H}_{2} \mathrm{O}$} & \multicolumn{2}{|c|}{$\mathrm{H}_{2} \mathrm{O}$} & \multicolumn{2}{|c|}{ Bodenzentrifugat } \\
\hline Inkubationszeit & \multicolumn{2}{|c|}{$24 \mathrm{~h}$} & \multicolumn{2}{|c|}{$5 \mathrm{~min}$} & \multicolumn{2}{|c|}{-} \\
\hline$\Sigma$ org. Säuren & \multicolumn{2}{|c|}{$\begin{array}{c}2,2 \quad 2,5 \\
\mu \mathrm{mol} / \mathrm{g}_{\text {Wurzel }}\end{array}$} & \multicolumn{2}{|c|}{$\begin{array}{l}0,9 \quad 2,9 \\
\mu \mathrm{mol} / \mathrm{g}_{\text {samen }}\end{array}$} & \multicolumn{2}{|c|}{$\begin{array}{cr}18,0 & 36,7 \\
\mu \mathrm{mol} / \text { /Bodenlsg. }^{2}\end{array}$} \\
\hline Monocarbonsr. & 75,6 & 31,5 & 43,5 & 11,2 & 75,5 & 44,0 \\
\hline Dicarbonsr. & 21,3 & 49,6 & 45,5 & 62,8 & 18,3 & 42,6 \\
\hline \multirow[t]{2}{*}{ Tricarbonsr. } & 3,1 & 19,0 & 11,0 & 26,0 & 6,2 & 13,4 \\
\hline & \multicolumn{2}{|c|}{$\%\left(n / n_{t}\right)$} & \multicolumn{2}{|c|}{$\%\left(n / n_{t}\right)$} & \multicolumn{2}{|c|}{$\%\left(n / n_{t}\right)$} \\
\hline Oxalat/Citrat & 43,9 & 4,7 & 3,8 & 2,2 & 4,0 & 1,8 \\
\hline
\end{tabular}

suchungsergebnisse zeigen, dass mit dem pH-Wert des Kulturmediums der Citratanteil in den Exsudaten acidophiler/calcifuger und basiphiler/calcicoler Pflanzen ansteigt. Hingegen erfährt Oxalat ein relatives Exsudationsminimum bei intermediären $\mathrm{pH}$-Werten. Sowohl in den sauren Silikatboden als auch in die Rendzina wird mit wenigen Ausnahmen mehr Oxalat abgegeben als in die Braunerde. Hierbei wird davon ausgegangen, dass sich acidophile/calcifuge und basiphile/calcicole Arten im Gradienten der Bodenacidität hinsichtlich der Carboxylatabgabe gleich verhalten. Aussagen darüber, ob die vermehrte Oxalatabgabe in den sauren Silikatboden im Zusammenhang mit Adaptationen an die Mineralstoffverhältnisse steht, können nicht getroffen werden. Obwohl Oxalsäure 700 \% mehr P aus einem Silikatboden extrahiert als Zitronensäure (Ström 1997), erscheint es angesichts des gleichzeitig besonders guten Komplexbildungsvermögens für Calcium und der wahrscheinlich aus der Ausbildung von schwerlöslichem Ca-Oxalat resultierenden Einschränkung der Ca-Verfügbarkeit fraglich, ob eine stimulierte Oxalatexsudation als Stressantwort auf die potenziellen Mineralstoffdefizienzen und/ oder Mineralstofftoxizitäten in Böden niedriger $\mathrm{pH}$-Werte geeignet ist. Im Gegensatz dazu ist die vermehrte Abgabe von Citrat und Malat durch Triticum aestivum und Arabidopsis thaliana ein ausreichend fundierter Bestandteil der Al-Toleranz von Pflanzen bodensaurer Standorte (Delhaize et al. 1993; Larsen et al. 1998; Ryan et al. 2001).

Die Arbeiten von L. Ström gehören zu den wenigen, die kausalanalytisch auf die Bedeutung der PVerfügbarkeiten und P-Effizienzen für die Standortdifferenzierung durch acidophile/calcifuge und basiphile/calcicole Pflanzen eingehen. Oxalat verbessert potenziell v.a. die pflanzliche P-Versorgung bei $\mathrm{pH} \geq 7,5$, während Citrat v. a. zwischen $\mathrm{pH}$ 6-7 und damit unter der Voraussetzung einer gleichzeitigen Acidifizierung der Rhizosphäre die Fe-Effizienz erhöht. Die Abgabe niedermolekularer Carboxylate wird durch die Aktivität membranärer $\mathrm{H}^{+}$-ATPasen unterstützt und geht daher mit einer $\mathrm{pH}$-Absenkung einher. Im Rahmen bestimmter Mineralstoffstressantworten kann der $\mathrm{pH}$-Wert weiter erniedrigt werden (s. Marschner 1995). Während bei einer solchen Ansäuerung die Komplexierung von Fe durch Citrat und damit dessen Mobilisierung unterstützt wird, führt sie zu einer verminderten P-Lösung durch Oxalat. Eine sehr starke Alkalisierung des Mediums würde v. a. die $\mathrm{PO}_{4}{ }^{3-}$-Mobilisierung durch Oxalat erhöhen. Ein ausreichender $\mathrm{pH}$-Anstieg ist aber selbst bei ausschließlicher $\mathrm{NO}_{3}{ }^{-}$-Ernährung nicht zu erwarten. 
Tabelle 38: Anteil [\% $n / n$ ] von Oxalat und Citrat an der Exsudation organischer Säuren acidophiler/calcifuger (CF) und basiphiler/calcicoler (CC) Arten in Abhängigkeit vom Kultursubstrat (Bodentyp/Bodenreaktion). Daten für "Silikatboden" (Sauerbraunerde, dystric cambisol, pH4,5) und "Kalkboden" (Rendzina, rendzic leptosol, pH 8,0) aus Ström et al. (1994), Daten für Braunerde (eutric cambisol, pH4,9-5,3) aus Ström (1997). Pfeilstärken kennzeichnen die Unterschiede der Exsudation in den betreffenden Versuchsansätzen. Vgl. auch Tabelle 37).

\begin{tabular}{|c|c|c|c|c|c|c|}
\hline \multirow[t]{2}{*}{ Gruppe/Art } & \multicolumn{3}{|c|}{ Oxalat } & \multicolumn{3}{|c|}{ Citrat } \\
\hline & $\begin{array}{l}\text { Silikatb. } \\
\text { "sauer" }\end{array}$ & $\begin{array}{c}\text { Braunerde } \\
------\rightarrow\end{array}$ & $\begin{array}{c}\text { Kalkb. } \\
\text { "basisch" }\end{array}$ & $\begin{array}{l}\text { Silikatb. } \\
\text { "sauer" }\end{array}$ & $\begin{array}{c}\text { Braunerde } \\
------\rightarrow\end{array}$ & $\begin{array}{c}\text { Kalkb. } \\
\text { "basisch" }\end{array}$ \\
\hline \multicolumn{7}{|l|}{ CF } \\
\hline alle Arten & 17,1 & 12,8 & & 1,8 & $\Rightarrow \quad 4,3$ & \\
\hline Avenella flexuosa & 4,5 & $\longrightarrow$ & & 1,0 & 5,8 & \\
\hline Lychnis viscaria & 27,3 & $\longleftarrow \quad 16,6$ & & 2,2 & $\longrightarrow$ & \\
\hline \multicolumn{7}{|l|}{ CC } \\
\hline alle Arten & & 19,7 & 42,0 & & 11,4 & $\rightarrow \quad 13,7$ \\
\hline Sanguisorba minor & & $24,2 \longrightarrow$ & 25,8 & & $11,7 \quad \longrightarrow$ & 25,9 \\
\hline
\end{tabular}

Basiphile/Calcicole exsudieren konstitutiv mehr organische Säuren mit einem höheren Anteil an di- und trivalenten Carboxylaten. Letztlich kann davon ausgegangen werden, dass Citrat und Oxalat an Standorten neutraler und moderat alkalischer Bodenreaktionen sowohl die pflanzliche Fe- als auch P-Ernährung verbessern. Auch wenn durchschnittlich eine mehr als vierfach höhere Oxalatkonzentration in allen hier untersuchten Systemen nachgewiesen wurde, erscheint eine besondere Bedeutung dieses Carboxylats und - davon abgeleitet - der pflanzlichen P-Verfügbarkeiten für die Standortdifferenzierung basenarmer, saurer und basenreicher, alkalischer Böden auch deshalb fraglich, weil das Oxalat/Citrat-Verhältnis der Wurzelexsudate von acidophilen/calcifugen jenes von basiphilen/calcicolen Pflanzenarten deutlich übersteigt.

Anders als für Citrat wurde eine adaptive Erhöhung der Exsudation von Oxalat unter P-Mangelbedingungen bisher noch nicht ausreichend belegt. Als Folge dessen, dass eine längerfristige Kultivierung unter adversativen Bodenbedingungen an der einseitigen Intoleranz von Vertretern der einen oder anderen Konstitutionsgruppe scheitert, konnten die Untersuchungen von Ström nicht klären, ob sich acidophile/ calcifuge und basiphile/calcicole Arten hinsichtlich der Entwicklung der Oxalat- und Citratexsudation im pH-Gradienten und damit korrelierter chemoedaphischer Eigenschaften unterscheiden. Es sollte daher in Nährlösungen untersucht werden, ob mit steigenden pH-Werten bzw. unter Bedingungen suboptimaler Pund Fe-Versorgungen nicht nur die Citrat- sondern auch die Oxalatabgabe stimuliert wird und ob sich acidophile/calcifuge und basiphile/calcicole Arten in dieser Hinsicht voneinander unterscheiden. Weitere diesbezüglich noch unzureichend untersuchte Aspekte sind das Acidifizierungsvermögen von Vertretern der verschiedenen Verbreitungsgruppen sowie der Reaktionsmechanismus und die Substratspezifität der P- und Fe-Mobilisierung in verschiedenen Medien. So ist wenig darüber bekannt, in welchem Umfang

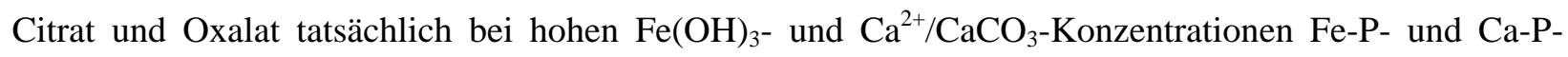
Verbindungen in der Rhizosphäre mobilisieren.

Nach wie vor messen die meisten Veröffentlichungen gerade Citrat eine besondere Bedeutung für die Lösung von Al- und Fe-, aber auch Ca-Phosphaten bei (Dinkelaker et al. 1989; Jones 1998; Neumann \& Römheld 2001). Zitronensäure besitzt aufgrund seines schnellen mikrobiellen Abbaus eine sehr kurze Lebensdauer. Ihre Halbwertzeit in organischen Böden liegt in einer Größenordnung von nur 1-12 h (Jones 1998). Citrat kann aber gleichzeitig durch die Erniedrigung des Redox im Rahmen dieser Abbauprozesse 
insbesondere zur Fe-Lösung beitragen. Hingegen wird Oxalsäure durch Ca-Komplexierung stabilisiert (Ström et al. 2001). Über eine Anreicherung von Calciumoxalat ist indes ebenso wenig bekannt, wie über dessen Schicksal im Boden. Möglicherweise limitiert die sehr große Calciumaffinität die Mobilisierungseffizienz von Oxalat in der Rhizosphäre. Gleichzeitig ist aber auch nicht auszuschließen, dass unter bestimmten Voraussetzungen eine sprunghafte Lösung und Metabolisierung von Oxalat erfolgt, die gerade darüber mit positiven Effekten für die pflanzliche P- und Fe-Ernährung einhergeht. Beide Szenarien sind so lange rein spekulativer Natur, wie über die Reaktionen und den Verbleib von Oxalat in der Rhizosphäre keine konkreten Aussagen zu treffen sind. Da aber in kalkreichen Böden, wie bereits an anderer Stelle ausgeführt, potenziell eine (Co-)Limitierung des Pflanzenwachstums durch suboptimale Fe- und P-Versorgung vorliegt, besitzt Citrat durch sein höheres Fe-Mobilisierungsvermögen den Vorteil, dass es über die Spaltung von Eisenphosphaten gleichzeitig und damit besonders ökonomisch die pflanzliche Verfügbarkeit beider Mineralstoffe erhöht. Fest steht auch, dass die Hypothese einer primären PLimitierung nicht adaptierter Arten in kalkreichen Böden, die auf einer Wachstumsförderung acidophiler/ calcifuger Arten durch P-Düngung kalkreicher Böden (Tyler 1994, 1996a, 1996b), einer besonders umfangreichen P-Mobilisierung aus kalkreichen Böden durch Oxalat (Ström 1997; Ström et al. 1994, 2002) sowie einer überproportional starken Oxalatexsudation durch basiphile/calcicole Arten (Ström et al. 1994, 2001; Tyler 1995; Ström 1997) basiert, bei genauerer Betrachtung durch die betreffenden Untersuchungen nicht ausreichend gestützt wird. Wenngleich eine Bedeutung der P-Ernährung nicht ausgeschlossen werden kann, deuten auch in diesen Veröffentlichungen viele Punkte darauf hin, dass die FeVerfügbarkeit eine zentrale Rolle für den Ausschluss nicht adaptierter Arten von Kalkböden spielt.

Der von Rorison (1968) im Zusammenhang mit der Mobilisierung von Bodenphosphaten formulierte Hinweis, dass Vertreter der beiden Artengruppen entsprechend ihrer Standortpräferenzen besser in solchen Böden wachsen, in denen $\mathrm{P}$ entweder primär in Ca- oder in Fe- und Al-Bindung vorliegt, muss indes als unzulässiger Versuch gewertet werden, durch Redundanz eine Kausalität der pflanzlichen P-Ernährung für die Vegetationsdifferenzierung der betreffenden Standorte festzuschreiben. Tatsächlich geben weder die hier zitierten Publikationen (Rorison 1960a; Rorison 1967) noch die oben vorgestellten Arbeiten zum Thema ausreichende Belege dafür, dass sich Acidophile/Calcifuge und Basiphile/Calcicole im Hinblick auf die Verwertung verschiedener P-Verbindungen unterscheiden. Es ist davon auszugehen werden, dass Strategien, wie die Abgabe di- und trivalenter organischer Säuren zu einer Lösung sowohl der primären P-Formen saurer, kalkarmer Böden (Fe/Al-P) als auch solcher basischer kalkreicher Standorte (Ca-P) beitragen. Die meisten anderen Mobilisierungsreaktionen für Bodenphosphate, wie z. B. die Abgabe spezifischer Exoenzyme, wurden im Rahmen des Calcicolen/Calcifugen-Komplexes leider noch nicht untersucht. Auf die besondere Bedeutung von Wurzelsymbiosen für die pflanzliche Mineralstoffernährung und hier insbesondere für die P-Versorgung, soll an anderer Stelle eingegangen werden.

\section{P-Speicherung und P-Bedarf}

Wachstumsexperimente von Grime (1965b) belegen eine ausgesprochene Fe-Chloroseanfälligkeit der acidophilen/calcifugen Lathyrus montanus (=L. linifolius; R 2, N2) in Böden kalkreichen Ausgangsmaterials (pH 6,5-7,8) und eine suboptimale P-Versorgung der moderat basiphilen/calcicolen L. pratensis (R 7, N6) bei $\mathrm{pH}>7,0$. Trotz ihrer signifikanten Wachstumsförderung führt P-Düngung bei L. pratensis nicht zu einer Ausbildung von Eisenmangelsymptomen. Diese Untersuchungsergebnisse stützen die Annahme, dass unzureichende Fe-Effizienzen für den Ausschluss acidophiler/calcifuger Arten von kalkreichen Standorten verantwortlich sind. Hingegen kann das Wachstum basiphiler/calcicoler Arten in sehr kalkreichen Böden mit hohen pH-Werten durch eine suboptimale P-Ernährung beeinträchtigt werden. 
Ergebnisse ergänzender Kulturversuche, nach denen das Wachstum der acidophilen/calcifugen und im Vergleich zu den beiden Lathyrus-Arten sehr kleinsamigen Digitalis purpurea (R3, N6) in Kalkböden unmittelbar nach der Keimung gehemmt wird, werden von Grime (1965b) auf die geringen P-Gehalte ihrer Samen zurückgeführt. Daraus resultierend sollen Keimpflanzen von D. purpurea im Gegensatz zu solchen der ebenfalls säureliebenden L. montanus keine Fe-Mangelsymptome ausbilden. Diese Interpretation ist indes nur dann schlüssig, wenn sich die Konzentrationsverhältnisse des in den Samen gespeicherten $\mathrm{P}$ und Fe zwischen den beiden Arten unterscheiden (P/Fe: D. purpurea $<$ L. montanus) oder aber bei gleichen $\mathrm{P} / \mathrm{Fe}$-Relationen der Mineralstoffbedarf artspezifisch voneinander abweicht, demnach L. montanus also ein schlechteres internes und/oder externes Fe-Mobilisierungs- und/oder Verwertungsvermögen besitzt. Ein Erklärungsansatz, der sich allein auf den absoluten P-Gehalt der Diasporen bezieht, setzt voraus, dass in frühen Stadien der Individualentwicklung die P-Ernährung im Wesentlichen durch interne Speicherressourcen, der Fe-Bedarf hingegen primär durch das Substrat gedeckt werden muss.

Als Makronährstoff beeinflusst P dass Pflanzenwachstum sehr viel schneller und in einem sehr viel weiteren Konzentrationsbereich als Fe. Suboptimale Fe-Versorgung äußert sich zunächst nur in Chlorosen und wirkt erst mit Verzögerung wachstumslimitierend. Leider hat Grime (1965b) in seinen Arbeiten nicht die P- und Fe-Konzentrationen der Samen untersucht, so dass über die Ursachen des unterschiedlichen Wachstumsverhaltens von L. pratensis sowie L. montanum und D. purpurea in kalkreichen Böden keine abschließenden Aussagen getroffen werden können. Indes scheint die Annahme, dass in den Diasporen bezogen auf den Bedarf grundsätzlich weniger Fe als $\mathrm{P}$ gespeichert wird, ebenso fraglich, wie die einer bevorzugten Deckung der Fe-Ernährung während des Keimlingstadiums aus dem Substrat.

Während Grime (1965b) davon ausgeht, dass die Fe-Reserven der Samen im Gegensatz zu denen des P eine untergeordnete Rolle für die Keimlingsentwicklung spielen, verweisen Arbeiten von Tyler \& Zohlen (1998) darauf, dass die Fe-Speicherung in den Diasporen von zentraler Bedeutung für die frühe Ontogenese und die Standortbindung der Pflanzen ist. Durch vergleichende Untersuchungen von insgesamt 35 Arten abweichenden Standortpräferenzen wurde nachgewiesen, dass Basiphile/Calcicole an ihren natürlichen Standorten relativ mehr Fe in den Samen akkumulieren als Acidophile/Calcifuge. Bezogen auf die Konzentrationen in den Blättern wird P in den Samen zwar noch stärker angereichert als Fe, doch unterscheiden sich die beiden Artengruppen diesbezüglich nicht voneinander.

Auch Ergebnisse der Untersuchungen an dekapitierten Wurzeln (Nassery 1969) und intakten Pflanzen (Nassery 1971) von Avenella flexuosa (R2), Rumex acetosa (Rx), Urtica dioica (R7) und Scabiosa columbaria (R8) geben keine Hinweise darauf, dass sich die verschiedenen Konstitutionstypen hinsichtlich der Anreicherung von Speicherphosphaten unterscheiden. Differierende $\mathrm{P}_{\mathrm{i}}$-Anteile, darunter v. a. Polyphosphate, in den Wurzeln sind die Folge abweichender Wachstumsraten. Das in die Pflanze aufgenommene $\mathrm{P}$ wird bei hohem Bedarf offenbar umgehend und vollständig in organische Bindungsformen überführt.

Bradshaw et al. (1960) haben in Sand-Nährlösungversuchen nachgewiesen, dass sich Arten auch gleicher pH-Präferenzen hinsichtlich ihrer P-Ansprüche unterscheiden können. Insbesondere bei Adulten, die vermutlich in geringerem Umfang als Keimpflanzen auf interne Speicherressourcen zurückgreifen können und daher auf die Deckung ihres Mineralstoffbedarfs aus dem Boden angewiesen sind, spielen die potenziellen RGR eine zentrale Rolle für die Ausbildung von Ernährungsstörungen. Auch Rorison (1968) und Nassery (1970) betonen in ihren Arbeiten zur hydroponischen P-Ernährung acidophiler/calcifuger

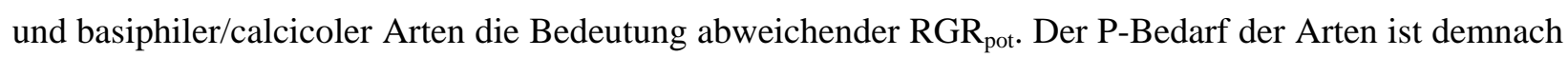
nicht primär eine Funktion der natürlichen Standortpräferenz, sondern der potenziellen Wachstumsrate. 


\section{Zusammenfassung}

Bodenchemische Untersuchungen geben keine eindeutigen Hinweise darauf, dass die Konzentrationen gelöster oder labil gebundener P-Fraktionen für das Fehlen acidophiler/calcifuger Arten in Kalk-Halbtrockenrasen verantwortlich zeichnen. Zudem lassen die Ergebnisse ökophysiologischer Arbeiten nicht darauf schließen, dass bei verminderten P-Löslichkeiten sowohl in sauren als auch basischen Böden die Vegetationsdifferenzierungen an den betreffenden Standorten auf unterschiedliche P-Effizienzen acidophiler/calcifuger und basiphiler/calcicoler Arten zurückzuführen sind. Nicht nur Basiphile/Calcicole, sondern auch Acidophile/Calcifuge können anatomisch-morphologische und physiologische Anpassungen aufweisen, die ihnen eine effiziente Verwertung schwerlöslicher Bodenphosphate erlauben. Konstitutiv höhere Exsudationsraten di- und trivalenter organischer Säuren bei basiphilen/calcicolen Arten wurden bisher nur unzureichend unter dem Gesichtspunkt ihrer gleichzeitigen Wirkung sowohl auf die P- als auch die Fe-Ernährung betrachtet. Die Hypothese einer vermehrten Abgabe des Phosphate bei sehr hohem Boden-pH besonders effektiv extrahierenden Oxalats durch Basiphile/Calcicole und einer im Umkehrschluss daraus resultierenden Verdrängung Acidophiler/Calcifuger von lässt sich bei genauerer Betrachtung des Datenmaterials nicht stützen.

Oligotrophie ist ein gemeinsames Kennzeichen der meisten Arten mit Verbreitungsschwerpunkten auf Standorten grenzwertiger Bodenreaktionen. Wie die Verfügbarkeit anderer (Makro-)Nährstoffe auch, kann die P-Versorgung in Kombination mit der Intensität der daraus abzuleitender Konkurrenzeffekte eine Rolle für die Vegetationsdifferenzierung spielen, nicht aber unbedingt für das alternative Auftreten acidophiler/calcifuger und basiphiler/calcicoler Arten auf sauren, basenarmen und basischen, kalkreichen Böden. In Düngungsexperimenten wurde v. a. eine Limitierung mesotropher und eutropher Arten durch P nachgewiesen. Hingegen finden sich bis heute keine eindeutigen Belege für eine ausschließliche PLimitierung von acidophilen/calcifugen Arten in Kalkböden und Basiphilen/Calcicolen in sauren Böden.

Die Bedeutung der pflanzlichen P-Ernährung für die vegetationskundliche Differenzierung saurer, basenarmer und alkalischer, basenreicher Standorte allgemein und die des Gentiano-Koelerietum im Speziellen ist bis heute nicht abschließend geklärt. Mehr noch als in Bezug auf die Fe-Ernährung stehen detaillierte Untersuchungen standortspezifischer P-Effizienzen acidophiler/calcifuger und basiphiler/calcicoler Pflanzen aus. Es ist in diesem Zusammenhang noch einmal darauf hinzuweisen, dass Reaktionen, die auf die Mobilisierung schwerlöslicher P-Verbindungen abzielen, gleichzeitig auch der Fe-Lösung dienen können. Aspekte der P- und Fe-Effizienz lassen sich daher gerade für basische, carbonatreiche Böden nur schwer voneinander trennen. Um dennoch experimentell fundierte Hinweise auf die Bedeutung der P-Verfügbarkeiten für die Differenzierung der acidophilen/calcifugen und basiphilen/calcicolen Verbreitungsgruppen und das Auftreten säureliebender Arten in Kalk-Halbtrockenrasen zu gewinnen, ist es notwendig, neben möglichen Adaptationen, wie der quantitativen und qualitativen Zusammensetzung von Wurzelexsudaten bei unterschiedlichen P-Verfügbarkeiten, zu untersuchen, ob sich die genannten Konstitutionstypen auch im Hinblick auf die Nutzung spezifischer P-Fraktionen unterscheiden, wie sie in sauren, kalkarmen $(\rightarrow \mathrm{Al} / \mathrm{Fe}-\mathrm{P}$ ) und basischen, kalkreichen $(\rightarrow \mathrm{CaP}$ ) Böden bevorzugt auftreten. Zudem blieben - anders als bei der Behandlung der Fe-Ernährung - bodenspezifische Faktoren, die sekundär die pflanzliche Mineralstoffernährung beeinträchtigen können, bisher in Untersuchungen zur P-Aufnahme und -Verwertung nahezu unberücksichtigt. So gibt es bis heute nur vorläufige Anhaltspunkte, dass $\mathrm{OH}^{-}$im alkalischen, Fe und $\mathrm{Al}$ im sauren Medium mit der P-Ernährung interferieren. 


\subsubsection{Stickstoff}

Neben Phosphor kann von den Makronährstoffen v. a. Stickstoff die Vegetationsdifferenzierung sowohl kalkreicher als auch saurer Böden beeeinflussen. Grundsätzlich unterscheiden sich weniger die NGesamtkonzentrationen dieser Standorte voneinander als deren Konzentrationsverhältnisses zwischen den verschiedenen mineralischen N-Formen. Die N-Verfügbarkeit kann nicht nur in basenarmen, sauren, sondern auch in flachgründigen Kalkböden limitiert sein. Stickstoff liegt in ersteren primär als $\mathrm{NH}_{4}{ }^{+}$, in letzteren als $\mathrm{NO}_{3}{ }^{-}$vor.

\section{Bodenkundliche Aspekte der N-Ernährung}

Der Kreislauf des Stickstoffs auf der Erde ist stärker als der aller anderen mineralischen Pflanzennährstoffe durch Austauschreaktionen zwischen der Atmosphäre und der Pedosphäre gekennzeichnet. Auf der einen Seite steht die abiotische und mikrobielle Fixierung von $\mathrm{N}_{2}$ und der daraus resultierende Eintrag von $\mathrm{NO}_{\mathrm{x}}$ - bzw. $\mathrm{NH}_{\mathrm{x}}$ in den Boden und die Pflanze, auf der anderen Seite der Verlust von Stickstoff durch die Denitrifikation von $\mathrm{NO}_{3}{ }^{-}$in sauerstoffarmen Bereichen edaphischer oder aquatischer Lebensräume mit hohen Gehalten an leicht abbaubarer organischer Substanz. Während die Freisetzung von $\mathrm{N}$ aus der Lithosphäre in der Regel eine untergeordnete Rolle für den N-Haushalt der Böden spielt, gewinnen diffuse N-Einträge anthropogenen Ursprungs seit vielen Jahrzehnten v.a. für oligotrophe Standorte an Bedeutung. Vorrangig für die pflanzliche N-Verfügbarkeit sind an den meisten Standorten aber interne Umsätze des bodenbürtigen und biogenen N-Pools, die gleichzeitig im Zentrum des globalen N-Kreislaufs stehen (Blackburn 1983; Tamm 1991; Bobbink et al. 1998).

Primär ist die Mineralisierung des organischen Materials und die daraus resultierende Bereitstellung pflanzenverfügbarer N-Fraktionen eine Funktion des Wassergehaltes, des C/N-Verhältnisses sowie der Acidität des Bodens (s. Runge 1983). An sehr trockenen und sauren $(\mathrm{pH}<5)$ oder basischen $(\mathrm{pH}>8)$ Standorten wird die mikrobielle Freisetzung von $\mathrm{NH}_{4}{ }^{+}$aus der organischen Substanz gehemmt. Neben dem $\mathrm{pH}$ beeinträchtigen in basenarmen Böden vielfach auch Hemmstoffe der Pflanzenstreu, wie z. B. allelopathische Polyphenole in Calluna-Heiden, die zugrundeliegenden Stoffwechselreaktionen. Bei einer vergleichbaren Stabilität der organischen Substanz gegenüber mikrobieller Degradation nimmt die Ammonifikation mit zunehmenden $\mathrm{C} / \mathrm{N}-$ Verhältnissen ab.

In sehr feuchten und wassergesättigten Substraten, in denen die Sauerstoffzehrung dessen diffusive Nachleitung überschreitet, wird die Nitrifikation von $\mathrm{NH}_{4}{ }^{+}$durch $\mathrm{O}_{2}$-Mangel behindert. Chemolithoautotrophe Nitrifikanten der Gattungen Nitrosomonas, Nitrosolobus, Nitrospira und Nitrobacter, die in den meisten Böden für die $\mathrm{NH}_{4}{ }^{+}$-Oxidation verantwortlich zeichnen, besitzen überdies ein ausgesprochenes pH-Optimum im neutralen Bereich. Bei $\mathrm{pH}<5,0$ nimmt ihre Aktivität drastisch ab (Gigon \& Rorison 1972; Runge 1983). Hingegen erfahren heterotrophe Nitrifikanten, die durch eine sehr viel größere $\mathrm{pH}-$ Toleranz gekennzeichnet sind, in verschiedenen sauren Böden eine Beeinträchtigung ihres Wachstums durch unzureichende Nährstoffverfügbarkeiten und die bereits oben genannten standorttypischen Hemmstoffe (Kinzel 1982), Letztere dürften mitverantwortlich dafür sein, dass nährstoffarme Heiden zu den wenigen Pflanzengesellschaften gehören, in deren Böden praktisch nur $\mathrm{NH}_{4}{ }^{+}$und kein $\mathrm{NO}_{3}{ }^{-}$nachgeliefert wird (Kriebitzsch 1978). Außerdem wird die Nitrifikation durch niedrige Temperaturen gehemmt (Stark \& Hart 1997). Besonders geringe Mineralisierungs- und Nitrifikationsraten weisen auch trockene Kalkböden auf. Hier wie dort verschärfen häufig Beweidung oder Mahd und die damit einhergehenden Nährstoffausträge den N-Mangel (Runge 1983). 
Aufgrund der vergleichsweise niedrigen Anionenaustauscherkapazitäten der meisten Böden werden $\mathrm{NO}_{3}{ }^{-}$ und $\mathrm{NO}_{2}^{-}$im Gegensatz zu $\mathrm{NH}_{4}{ }^{+}$in nur geringem Umfang an die Festphase adsorbiert und daher sehr schnell ausgewaschen. Nach allgemeiner Auffassung spielt $\mathrm{NO}_{2}^{-}$für die pflanzliche Mineralstoffernährung eine untergeordnete Rolle. Als Intermediat der Nitrifikation wird es in der Regel umgehend aufoxidiert. In anderen Böden könnte $\mathrm{NO}_{2}{ }^{-}$durch die Ausbildung besonders stabiler organischer Verbindungen der pflanzlichen Mineralstoffernährung entzogen werden. Nach einem Modell von Davidson et al. (2003) katalyiert $\mathrm{Fe}(\mathrm{II})$ hierbei die Reduktion von $\mathrm{NO}_{3}{ }^{-} \mathrm{zu} \mathrm{NO}_{2}{ }^{-}$. Das so anfallende $\mathrm{Fe}(\mathrm{III})$ wird durch organische Elektronendonatoren erneut reduziert. Dieser Kreislauf soll in Böden mit hohen Gehalten an organischer Substanz eine fortwährende und sehr schnelle Nitration und Nitrosation von Aromaten und die Bildung von zunächst gelösten organischen Stickstoffverbindungen (DON, dissolved organic nitrogen) bewirken, die aufgrund ihrer besonderen Stabilität, ihrer Adsorption an die Bodenfestphase oder durch Auswaschung nicht für die pflanzliche N-Ernährung zur Verfügung stehen. Indes ist dieses Modell der abiotischen Immobilisierung von $\mathrm{NO}_{3}^{-}$bzw. $\mathrm{NO}_{2}^{-}$unter Beteiligung von Oxidoreduktionszyklen des $\mathrm{Fe}$ (ferrous wheel hypothesis') in vielen Punkten noch ungeklärt.

\section{N-Verfügbarkeiten in den Subassoziationen des Gentiano-Koelerietum}

Die N-Analysen zeichnen ein Bild, das sich nicht mit der Artenzusammensetzung der hier untersuchten Subassoziationen des Gentiano-Koelerietum in Übereinstimmung bringen lässt. Obwohl in ihnen deutlich weniger Mesophile vertreten sind, übersteigen die feinerdebezogenen Konzentrationen des $\mathrm{N}_{\min }$, d.h. die Summe der Einzelkonzentrationen des $\mathrm{NH}_{4}{ }^{+}, \mathrm{NO}_{2}{ }^{-}$und $\mathrm{NO}_{3}{ }^{-}$der wässrigen Bodenextrakten, in den CCBeständen diejenigen der CF-Bestände median um mehr als das Fünffache (Tabelle 24, S. 101).

Alle N-Fraktionen der wässrigen Bodenextrakte sind durch sehr hohe räumliche und zeitliche Variabilitäten gekennzeichnet (Tabelle A 2/Tabelle A 3, S. 302). Dies gilt mit Werten von 0-2,2 $\mu \mathrm{mol} \cdot \mathrm{g}^{-1}$ insbesondere für die $\mathrm{NH}_{4}{ }^{+}$-Gehalte. Vor diesem Hintergrund konnte in den meisten Fällen kein Unterschied zwischen den Vergleichsbeständen eines Standorts nachgewiesen werden. Die Aussagekraft der hier vorgestellten $\mathrm{NH}_{4}{ }^{+}$-Untersuchungen wird außerdem dadurch begrenzt, dass die für die pflanzliche Mineralstoffernährung wichtige $\mathrm{NH}_{4}{ }^{+}$-Belegung der Kationenaustauscher unberücksichtigt bleiben musste. Abweichend von der Annahme höherer $\mathrm{NH}_{4}{ }^{+}$-Verfügbarkeiten in Kalk-Halbtrockenrasen mit acidophilen/calcifugen Arten lassen aber die CEC $_{\text {eff }}$ der Referenzstandorte nicht darauf schließen, dass die Bindungskapazitäten für $\mathrm{NH}_{4}{ }^{+}$im Gentiano-Koelerietum danthonietosum über denen der typischen Subassoziation liegen (Abschnitt 3.2.4, S. 80 f.).

Während in der Regel kein Bezug zwischen $\mathrm{NH}_{4}{ }^{+}$und den beiden anderen mineralischen Stickstofffraktionen zu erkennen ist, zeigen die Ergebnisse aller drei wässrigen Extraktionsverfahren positive Korrelationen zwischen den $\mathrm{NO}_{2}^{-}-$und $\mathrm{NO}_{3}{ }^{-}$-Konzentrationen. Diese Beziehung stimmt mit der Reaktionskaskade der mikrobiellen Nitrifikation überein(vgl. Tabelle A 11 ff., S. 308 ff.). Gegenläufige Entwicklungen der $\mathrm{N}_{\text {min }}$ - bzw. $\mathrm{NO}_{3}{ }^{-}$-Gehalte auf der einen und der $\mathrm{C} / \mathrm{N}-$ Verhältnisse auf der anderen Seite, die mittels Rangkorrelationsanalysen nach Spearman überprüft wurden $(\alpha<0,01)$, entsprechen den obigen Ausführungen zur N-Mineralisierung. Außerdem korrespondieren die $\mathrm{N}_{\mathrm{t}}$ der CC- und CF-Bestände in den meisten Fällen mit denen des $\mathrm{N}_{\text {min. }}$. Von den gelösten $\mathrm{N}$-Fraktionen weist nur $\mathrm{NO}_{3}{ }^{-}$signifikante Unterschiede zwischen den beiden Subassoziationen des Gentiano-Koelerietum auf. An allen Standorten geht das Auftreten von acidophilen/calcifugen und mesophilen Arten mit erheblich niedrigeren $\mathrm{NO}_{3}{ }^{-}$-Konzentrationen einher (Tabelle 24, S. 101 f.). Im Median erreichen die GBL hier nur 6,2 \% der $\mathrm{NO}_{3}^{-}-\mathrm{Kon}-$ zentrationen in den CC-Beständen. 
Die Analysen der beiden Gleichgewichtsbodenlösungen (GBL, PBL) belegen eine gegenläufige Entwicklung der $\mathrm{NO}_{3}{ }^{-}$- und Fe-Löslichkeiten (Tabelle A 11 f., S. 308 f.). Nicht nur diesbezüglich, sondern auch im Hinblick auf die saisonale Entwicklung der $\mathrm{NO}_{3}{ }^{-}$-Konzentrationen zeichnen die Untersuchungen der DBL ein abweichendes Bild. Anders als die GBL deuten die Druckbodenlösungen keine Sommerdepression der $\mathrm{NO}_{3}{ }^{-}$-Konzentrationen an. Hintergrund der abnehmenden $\mathrm{NO}_{3}{ }^{-}$-Gehalte in den Sommermonaten könnte die Hemmung der N-Mineralisierung und der Nitrifikation durch Bodentrockenheit in beiden Subassoziationen der Referenzstandorte sein. Aus welchen Gründen die Entwicklung der $\mathrm{NO}_{3}^{-}{ }^{-} \mathrm{Kon}^{-}$ zentrationen in den DBL von denen der beiden anderen Bodenextrakte abweicht, kann hier nicht geklärt werden. Anders als beim $\mathrm{NO}_{3}{ }^{-}$verweisen alle wässrigen Bodenextraktionsverfahren auf gleiche Entwicklungen der $\mathrm{NO}_{2}{ }^{-}$-Konzentrationen im Jahresverlauf. Erhöhte $\mathrm{NO}_{2}{ }^{-}$-Gehalte in den Wintermonaten finden sich in Übereinstimmung mit Untersuchungen von Tyler et al. (1959) und Justice \& Smith (1962), denen zufolge niedrige Temperaturen zumindest bei ungünstigen $\mathrm{pH}-$ Werten die Nitritoxidation stärker beeinträchtigen als die Ammoniumoxidation.

\section{Alternative Verfahren zur Untersuchung edaphischer N-Verfügbarkeiten}

Aussagekräftiger als Statusanalysen, wie sie im Rahmen der vorliegenden Arbeit für die N-Gesamtfraktion der Feinerdehomogenate sowie für $\mathrm{NH}_{4}{ }^{+}, \mathrm{NO}_{2}{ }^{-}$und $\mathrm{NO}_{3}{ }^{-}$in wässrigen Bodenextrakten durchgeführt wurden, sind aufgrund der wechelseitigen Überführung organischer und anorganischer Bindungsformen Versuchsanordnungen, die gezielt die N-Mineralisierung und somit die Nachlieferung pflanzenverfügbarer N-Fraktionen berücksichtigen (Runge 1974a, 1974b, 1978). Vielfach werden hierfür Bodenproben unter definierten Laborbedingungen oder auch in situ inkubiert (s. Runge 1983). Die labortechnische Inkubationsmethode nach Hesselmann (1917) zielt auf die Bestimmung der potenziellen, die von Gerlach (1973) methodisch eingehend untersuchte Beutelmethode auf die der tatsächlichen Mineralisierungsraten im Freiland ab. In der landwirtschaftlichen Praxis wird dem pflanzlichen N-Entzug durch regelmäßige Untersuchungen der austauschbaren N-Fraktionen Rechnung getragen (Haynes \& Goh 1978). Die Untersuchungsergebnisse für die beiden Referenzstandorte Auf der Burg und Hölleberg lassen vermuten, dass der N-Entzug durch die Vegetation für die abweichenden $\mathrm{NO}_{3}{ }^{-}$-Konzentrationen in den CC- und CFBeständen der Enzian-Schillergrasrasen eine untergeordnete Rolle spielt. Obwohl das Gentiano-Koelerietum danthonietosum eine dichtere, höherwüchsige Vegetation und eine größere Biomasseproduktion aufweist, sinken die $\mathrm{NO}_{3}{ }^{-}$-Konzentrationen in der typischen Subassoziation zum Sommer viel stärker ab.

\section{$\mathrm{N}$-Limitierung in Kalk-Halbtrockenrasen}

Da die austauschbaren N-Fraktionen nicht und die saisonalen Entwicklungen der $\mathrm{N}_{\min }$-Gehalte nur für die Referenzstandorte analysiert wurden, bildet die vorliegende Arbeit lediglich einen Ausschnitt der N-Verfügbarkeiten in den hier untersuchten Vegetationsbeständen ab. Die Ergebnisse der Bodenanalysen machen aber deutlich, dass bei einer isolierten Betrachtung der N-Konzentrationen der Ausschluss acidophiler/calcifuger Arten bestenfalls auf supraoptimale $\mathrm{NO}_{3}{ }^{-}$-Konzentrationen in den CC-Beständen zurückgeführt werden kann. Das gemeinsame Auftreten mit mesophilen Arten lässt indes andere Ursachen oder doch einen sehr viel komplexeren Wirkungsmechanismus vermuten. Gerade von mesotrophen Arten ist bekannt, dass ihr Wachstum in Kalk-Halbtrockenrasen häufig durch unzureichende N-Versorgung und nicht etwa, wie im vorherigen Kapitel diskutiert, durch unzureichende P-Verfügbarkeiten behindert wird. So haben beispielsweise Untersuchungen von Jeffrey \& Pigott (1973) in Nordengland gezeigt, dass die Düngung von flachgründigen Böden über 'sugar limestone', einem metamorph modifizierten Kalkgestein, mit $5 \mathrm{~g} \cdot \mathrm{m}^{-2} \mathrm{P}\left(\right.$ als $\mathrm{CaH}_{2} \mathrm{PO}_{4}$ ) nur bei ausreichender Bodenfeuchte das Wachstum von Festuca 
ovina, F. rubra und Agrostis stolonifera fördert. Hingegen profitieren diese Arten auch in trockenen Böden von einer Düngung mit $10 \mathrm{~g} \cdot \mathrm{m}^{-2} \mathrm{~N}$ (als $\mathrm{NH}_{4} \mathrm{NO}_{3}$ ). Wie Unkovich et al. (1998) nachgewiesen haben, kann Bodentrocknis temporär die N-Mineralisierung und damit das Pflanzenwachstum in Gesellschaften der Festuco-Brometea beeinträchtigen.

Hinweise darauf, dass die Biomasseproduktion in Kalk-Halbtrockenrasen primär durch unzureichende Nund nicht durch die P-Versorgung begrenzt wird, geben auch Düngungsversuche von Battmer (1999). Durch Supplementierung von $10 \mathrm{~g} \cdot \mathrm{m}^{-2} \mathrm{P}$ wurde von den hier untersuchten Arten nur das Wachstum des symbiontisch stickstofffixierenden Lotus corniculatus stimuliert. ${ }^{1}$ Ergebnisse fünfjähriger in situ-Untersuchungen sowie begleitender Gewächshausexperimente zum Einfluss erhöhter atmosphärischer $\mathrm{CO}_{2}-$ und bodenbürtiger P-Konzentrationen bestätigen, dass in Kalk-Halbtrockenrasen v.a. Leguminosen Plimitiert sind (Niklaus et al. 1998). Die Produktivität des Ökosystems insgesamt wird hingegen durch unzureichende N-Verfügbarkeiten bestimmt. Bei einer Wachstumsförderung der $\mathrm{CO}_{2}$-Behandlung um durchschnittlich $15 \%$ zeigten ausschließlich Fabaceae, die weniger als $2 \%$ der gesamten oberirdischen Biomasse bestritten, unveränderte $\mathrm{C} / \mathrm{N}$ - und erweiterte N/P-Verhältnisse in ihrem Sprossgewebe.

\section{Ökophysiologische Aspekte der N-Ernährung}

Wenngleich der exakte Umfang der N-Mineralisierung in den Böden nicht bestimmt werden konnte, verweisen die im Rahmen der vorliegenden Arbeit durchgeführten Untersuchungen und verschiedene ökophysiologische Aspekte darauf, dass acidophile/calcifuge und mesophile Arten nicht primär und direkt als Folge einer mangelhaften N-Versorgung von der Besiedlung des Gentiano-Koelerietum typicum ausgeschlossen werden.

Da in der Regel sowohl Acidophile/Calcifuge als auch Basiphile/Calcicole oligotroph sind (vgl. Abschnitt 5.3.12, S. 224 ff.), kommt N - in gleicher Weise wie $\mathrm{P}$ - als ausschlaggebender Faktor einer diesbezüglichen Vegetationsdifferenzierung nur dann in Betracht, wenn sich die genannten Konstitutionstypen im Hinblick auf die Verwertung der verschiedenen N-Formen unter den jeweils vorherrschenden Standortbedingungen unterscheiden. Verschiedene Arbeiten verweisen auf standorttypische Präferenzen acidophiler/calcifuger Arten für $\mathrm{NH}_{4}{ }^{+}$(Gigon \& Rorison 1972; Krajina et al. 1973; Wiltshire 1973; Havill et al. 1974; Ingestad 1976). Hingegen sollen die meisten anderen Arten und v. a. solche, die bevorzugt auf Standorten mit hohen $\mathrm{pH}$-Werten auftreten, primär $\mathrm{NO}_{3}{ }^{-}$verwerten (s. Haynes 1986). Diesem Bild entsprechen auch die Untersuchungen von Falkengren-Grerup (1995) an insgesamt 23 Pflanzenarten mit verschiedenen Verbreitungsschwerpunkten.

Von den Faktoren, die im Hinblick auf die N-Ernährung für die Besiedlung saurer, basenarmer und basischer/kalkreicher Standorte eine besondere Rolle spielen, sollen hier drei eingehend diskutiert werden: (1) Ionenantagonismen und Mineralstoffkompetitionen bei einseitigem $\mathrm{NH}_{4}{ }^{+}$- bzw. $\mathrm{NO}_{3}{ }^{-}$-Angebot, (2) die Aktivität der Nitratreduktase (NR) an Standorten mit geringen $\mathrm{NH}_{4}{ }^{+}$-Konzentrationen und (3) der Einfluss von $\mathrm{NO}_{3}{ }^{-}$auf die Regulation des Wasserhaushalts. Weitere grundlegende Aspekte der N-Ernährung und hier v. a. Bezüge zum C- und pH-Haushalt der Pflanzen werden von Stitt et al. (2002) behandelt.

\footnotetext{
1 Die P-Düngung erfolgte mit $\mathrm{NaH}_{2} \mathrm{PO}_{4}$. Neben Lotus corniculatus wurden Brachypodium pinnatum, Scabiosia columbaria und Cirsium acaule untersucht. Die Applikation von $500 \mathrm{mg} \cdot \mathrm{m}^{-2} \mathrm{Fe}$ (als FeEDDHA) führte in dieser Arbeit zu keiner Erhöhung der DTPA-extrahierbaren Fe-Fraktion des Bodens und möglicherweise deshalb zu keinen Effekten auf das Pflanzenwachstum und die Fe-Konzentrationen in der Biomasse und Nekromasse der hier untersuchten vier Kalkmagerrasen über Oberem Buntsandstein, Unterem und Oberem Muschelkalk sowie Mittlerem Keuper.
} 


\section{lonenantagonismen und Mineralstoffkompetitionen}

Unter optimalen Ernährungsbedingungen bestreitet Stickstoff bezogen auf die Teilchenmengen etwa zwei Drittel der in mineralischer Form aufzunehmenden Nährelemente (Epstein 1965). Imbalancen der Anionen- und Kationenaufnahme und daraus resultierende Beeinträchtigungen der Aufnahme anderer Nährelemente sowie des syn- und apoplasmatischen pH spiegeln daher sehr häufig die Art der N-Ernährung wider.

Wie oben ausgeführt, liegt in sauren Böden v. a. $\mathrm{NH}_{4}{ }^{+}$, in trockenen, basischen und neutralen Böden überwiegend $\mathrm{NO}_{3}{ }^{-}$vor (Jackson 1967). Von besonderer Bedeutung für die einseitige Verteilung der NFormen im Boden sind Ionenantagonismen und Nährstoffkompetitionen. Hierbei müssen die $\mathrm{H}^{+}-\mathrm{bzw}$. $\mathrm{OH}^{-}$-Aktivitäten und damit der $\mathrm{pH}$ des Substrats als übergeordnete Faktoren betrachtet werden (Haynes \& Goh 1978). Während $\mathrm{NH}_{4}{ }^{+}$die Aufnahme von $\mathrm{Ca}^{2+}, \mathrm{Mg}^{2+}$ und $\mathrm{K}^{+}$beeinträchtigt (Reisenauer 1978), fördert es die von $\mathrm{H}_{\mathrm{x}} \mathrm{PO}_{4}{ }^{\mathrm{x}-3}$ - und $\mathrm{SO}_{4}{ }^{2-}$ (Blair et al. 1970). Auf der anderen Seite wird durch $\mathrm{NO}_{3}{ }^{-}$die Kationenaufnahme stimuliert, die Anionenaufnahme gehemmt (Haynes \& Goh 1978). Verschiedene Arbeiten verweisen diesbezüglich auf besondere Sensitivitäten bzw. Adaptationen von acidophilen/calcifugen und basiphilen/calcicolen Arten (Bogner 1968; Raven et al. 1992).

In diesem Zusammenhang wurden von Gigon \& Rorison (1972) Nährlösungsuntersuchungen zum Einfluss der N-Form $\left(\mathrm{NH}_{4}{ }^{+}, \mathrm{NO}_{3}{ }^{-}\right)$und des $\mathrm{pH}$-Werts ( $\left.\mathrm{pH} 4,8, \mathrm{pH} 5,8, \mathrm{pH} 7,2\right)$ auf das Wachstum und die Mineralstoffaufnahme der calcifugen Nardus stricta und Avenella flexuosa, der indifferenten Rumex acetosa sowie der calcicolen Scabiosa columbaria und Sesleria varia durchgeführt. In den meisten Fällen zeigten junge Keimpflanzen eine optimale Entwicklung unter Bedingungen, wie sie an ihren natürlichen Standorten vorherrschen. Abweichende Präferenzen für $\mathrm{NH}_{4}{ }^{+}$bzw. $\mathrm{NO}_{3}{ }^{-}$traten insbesondere bei niedrigen bzw. hohen pH-Werten auf: Acidophile/Calcifuge konnten $\mathrm{NH}_{4}{ }^{+}$auch bei niedrigen $\mathrm{pH}-$ Werten, basiphile/calcicole Arten $\mathrm{NO}_{3}{ }^{-}$auch bei hohen $\mathrm{pH}$-Werten mit hoher Effizienz aufnehmen und verwerten. Die Kulturversuche zeigten zudem, dass eine $\mathrm{NH}_{4}{ }^{+}$-Ernährung die $\mathrm{K}^{+}$-Aufnahme der indifferenten und calcicolen Arten um etwa $50 \%$ hemmt - ein Effekt, der bei der calcifugen Avenella flexuosa nicht nachgewisen wurde. Dem widersprechen Nährlösungsuntersuchungen von Falkengren-Grerup (1995), deren Ergebnisse keine Hinweise auf Kompetitionen der $\mathrm{Ca}^{2+}-\mathrm{Mg}^{2+}$ - und $\mathrm{K}^{+}$-Aufnahme durch $\mathrm{NH}_{4}{ }^{+}$ geben. Anders als in Ausführungen von Haynes \& Goh (1978) dargestellt, soll $\mathrm{NO}_{3}{ }^{-}$die Aufnahme von Phosphaten nicht beeinträchtigen (Gigon \& Rorison 1972; Troelstra et al. 1995a). Wie die eigenen Untersuchungen auch, verweisen Arbeiten von Mahdi et al. (1989) zur Koexistenz von acht acidophilen/calcifugen, indifferenten und basiphilen/calcicolen Arten ${ }^{1}$ in Kalk-Halbtrockenrasen einer Braunerde über karbonischem Kalkstein darauf, dass vielmehr die P-, N- und K-Konzentrationen in den Böden selber eine Rolle für die Standortpräferenzen der Arten spielen.

Woolhouse \& Hardwick (1966) gehen davon aus, dass eine vermehrte Dunkelfixierung von $\mathrm{CO}_{2}$ über die Synthese organischer Säuren das Anionendefizit bei ausschließlicher oder vorwiegender $\mathrm{NH}_{4}{ }^{+}$-Ernährung ausgleicht. Carboxylierungs- und Decarboxylierungsreaktionen sind aber v. a. auch für die Regulation des cytoplasmatischen $\mathrm{pH}$ von Bedeutung. So bilden die PEP-Carboxylase/Anhydrase, die bei $\mathrm{pH}>7$ vermehrt Oxalacetat für die nachfolgende Reduktion zu Malat bereitstellt, und das Malatenzym mit einer bei $\mathrm{pH}<7$ besonders hohen Decarboxylierungsrate von Malat zu Pyruvat, die Grundlage des von Davies $(1973,1986)$ entworfenen und von Sakano (1998) überarbeiteten biochemischen pH-stat-Modells. In die-

\footnotetext{
1 Potentilla erecta, Plantago lanceolata, Carex flacca, Ranunculus bulbosus, Trifolium pratense, Sanguisorba minor, Lotus corniculatus, Carex caryophyllea
} 
sem autoregulativen Wechselspiel der reduktiven Carboxylierung und oxidativen Decarboxylierung und der daraus resultierenden Synthese organischer Säuren mit unterschiedlichem Dissoziationsverhalten erfolgt die cytoplasmatische Feinjustierung auf pH 7,5. Demnach würde die mit einer relativen zellulären Alkalisierung einhergehende Reduktion von $\mathrm{NO}_{3}{ }^{-}$und nicht die zelluläre $\mathrm{NH}_{4}{ }^{+}$-Aufnahme erhöhte Carboxylierungsraten erfordern. Neben dem biochemischen $\mathrm{pH}$-stat tragen indes membranäre $\mathrm{H}^{+}$-ATPasen (biophysikalischer $\mathrm{pH}$-stat) und pufferwirksame Verbindungen, wie $\mathrm{P}_{\mathrm{i}}$ und Aminosäuren, zur Stabilisierung des intrazellulären pH bei (Mimura et al. 2000).

All diese Reaktionen werden sowohl bei $\mathrm{NH}_{4}{ }^{+}$- als auch $\mathrm{NO}_{3}{ }^{-}$-Ernährung und den jeweils damit einhergehenden pH-Effekten wirksam. ${ }^{1}$ Eine Alkalisierung des cytoplasmatischen $\mathrm{pH}$ droht v. a. bei einer bevorzugten Translokation von $\mathrm{NO}_{3}{ }^{-}$in den Spross und dessen dortiger Reduktion. Anders als in der Wurzel ist hier lediglich ein begrenzter Anionen-/Kationen- bzw. $\mathrm{OH}^{-} / \mathrm{H}_{3} \mathrm{O}^{+}$-Austausch zwischen dem Sym- und Apoplasten möglich. Aufgrund der Stoffflüsse zwischen der Boden- und Apoplastenlösung wird das transmembranäre Potenzial rhizodermaler und cortikaler Zellen durch die Aufnahme von $\mathrm{NH}_{4}{ }^{+}$oder $\mathrm{NO}_{3}{ }^{-}$ weit weniger beansprucht als das von Zellen aller anderen Gewebe. Entsprechend müssen ionen- und pHrelevante Einflüsse im Spross viel stärker auf biochemischer Ebene abgepuffert werden. Überschüssiges $\mathrm{OH}^{-}$kann beispielsweise durch Oxalatausfällung oder durch die Verlagerung von organischen Säuren in die Wurzeln, deren Decarboxylierung und die Abgabe von $\mathrm{HCO}_{3}{ }^{-}$in die Rhizosphäre nachhaltig entsorgt werden (Runge 1983).

$\mathrm{NO}_{3}{ }^{-}$-Ernährung geht mit einer Alkalisierung (Pierre et al. 1970; Pierre \& Banwart 1973), $\mathrm{NH}_{4}{ }^{+}$-Ernährung mit einer Acidifizierung (Smiley 1974) des Apoplasten und diese Veränderungen mit den bereits an anderer Stelle ausgeführten spezifischen Störungen des pflanzlichen Mineralstoffhaushalts einher. Grundsätzlich ist daher davon auszugehen, dass gerade auch auf dieser Ebene die ökophysiologische Differenzierung von Arten der acidophilen/calcifugen und basiphilen/calcicolen Verbreitungsgruppen stattfindet. Bereits früh wurde das Auftreten von Kalkchlorosen mit der Stickstoffernährung in Zusammenhang gebracht (Cain 1952; Cain 1954; Colgrove \& Roberts 1956; Ingestad 1973). Die aus der $\mathrm{NO}_{3}{ }^{-}$-Aufnahme resultierende lokale Alkalisierung beeinträchtigt u. a. die Fe-Löslichkeiten im Wurzel- bzw. Sprossapoplasten, dessen membranäre Reduktion und damit letztlich die zelluläre Aufnahme von Fe nicht adaptierter Pflanzenarten (Kosegarten et al. 1999). Voraussetzung dafür, dass hohe $\mathrm{NO}_{3}{ }^{-}$-Konzentrationen und nicht etwa spezifische Adaptationen des Fe-Haushalts die Besiedlung des Gentiano-Koelerietum typicum durch Acidophile/Calcifuge und Mesophile verhindern, ist allerdings, dass ein hohes $\mathrm{NO}_{3}^{-}$-Angebot gerade bei diesen Arten zu einer besonders umfangreichen $\mathrm{NO}_{3}{ }^{-}$-Aufnahme in die Pflanze führen. Leider wurden in diesem Komplex noch keine Untersuchungen durchgeführt.

\section{Die Bedeutung der Nitratreduktase}

Potenzielle Ursachen für den Ausschluss acidophiler/calcifuger Arten von Standorten, in denen ausschließlich oder doch ganz überwiegend Nitrat vorliegt, sind ein unzureichendes $\mathrm{NO}_{3}{ }^{-}$-Aufnahme- und/ oder Reduktionsvermögen. Apparente Enzymkinetiken geben keine Hinweise darauf, dass sich Arten mit unterschiedlichen Standortansprüchen hinsichtlich der Substrataffinität $\left(\mathrm{K}_{\mathrm{m}}\right)$ des $\mathrm{NO}_{3}{ }^{-}$-Aufnahmesystems

\footnotetext{
1 Britto \& Kronzucker (2002) führen unter Berücksichtigung aller Reaktionen, die die N-Ernährung betreffen, darunter die zelluläre $\mathrm{N}$-Aufnahme, die $\mathrm{NO}_{3}{ }^{-}$-Reduktion sowie die $\mathrm{NH}_{4}{ }^{+}$-Assimilation inklusive der für die Reaktionen der Glutaminsynthetase und Glutamatsynthase (GS-GOGAT) erforderlichen Synthese von 2-Oxoglutarat, aus, dass die organischen Inkorporation von $\mathrm{NO}_{3}^{-}$ und $\mathrm{NH}_{4}{ }^{+}$zu einer gleich starken cytoplasmatischen Nettoacidifizierung führt. Der pH-stat ist gerade auch im Hinblick auf die $\mathrm{N}$ Ernährung sehr viel komplexer als i.d. R. dargestellt.
} 
unterscheiden. Dessen Kapazität $\left(\mathrm{V}_{\max }\right)$ ist vielmehr eine Funktion der potenziellen Wachstumsraten (Van de Dijk 1981; Van de Dijk et al. 1982; Bijlsma et al. 2000). Gerade in dieser Hinsicht unterscheiden sich aber acidophile/calcifuge und basiphile/calcicole Arten nicht voneinander.

Rorison (1986) hat das Fehlen cytoplasmatischer Nitratreduktasen (NR) mit dem Ausschluss Acidophiler/Calcifuger von kalkreichen Standorten in Zusammenhang gebracht. Ohne NR kann bei $\mathrm{NO}_{3}^{-}$-Ernährung kein $\mathrm{NH}_{4}{ }^{+}$für die Synthese organischer $\mathrm{N}$-Verbindungen bereitgestellt werden. Indes haben Untersuchungen von Gigon \& Rorison (1972) gezeigt, dass auch die acidophilen/calcifugen Nardus stricta und Avenella flexuosa in Nährlösungen wachsen, die nur $\mathrm{NO}_{3}{ }^{-}$enthalten. Havill et al. (1974) wiesen mit Hilfe von in situ- und Laborexperimenten für diese und andere acidophile/calcifuge Arten recht hohe konstitutive und induzierbare Nitratreduktaseaktivitäten (NRA) nach. Potentilla erecta verhält sich im Hinblick auf den Umfang und die Lokalisation der Nitratreduktion sogar wie eine basiphile/calcicole Art. Nach $\mathrm{NO}_{3}{ }^{-}$-Zusatz wurde bei ihr innerhalb von $72 \mathrm{~h}$ die NRA um fast das Achtfache erhöht. Von den im Gentiano-Koelerietum danthonietosum auftretenden acidophilen/calcifugen Arten wurden zudem für Danthonia decumbens und Calluna vulgaris nennenswerte NRA nachgewiesen.

Auch Kulturexperimente von Troelstra et al. (1995a) relativieren Hinweise auf eine ausgesprochene Präferenz von acidophilen/calcifugen Pflanzen für $\mathrm{NH}_{4}{ }^{+}$und von basiphilen/calcicolen für $\mathrm{NO}_{3}{ }^{-}$. Alle hier untersuchten Arten ${ }^{1}$ saurer Heiden zeigten bei $\mathrm{pH}$ 4,0 und einem alternativen Angebot von 2,0 mM N als $\mathrm{NH}_{4}{ }^{+}$oder $\mathrm{NO}_{3}{ }^{-}$nur geringfügig abweichende Wachstumsraten. Ausgerechnet Nardus stricta als besonders acidophile/calcifuge Art erfuhr eine Intoxikation durch hohe hydroponische $\mathrm{NH}_{4}{ }^{+}$-Konzentrationen. In vivo-Messungen haben belegen können, dass $\mathrm{NO}_{3}{ }^{-}$nicht nur bei Calluna vulgaris, sondern auch bei Erica tetralix und der nah verwandten Empetrum nigrum hohe NRA induziert. Allerdings beschränkt sich die NR-Expression bei den Ericaceae und Empetraceae auf die Wurzeln, so dass hier unter Transfer entsprechend großer Mengen an Kohlenstoffverbindungen in die Wurzeln der N-Transport in den Spross ganz überwiegend in Form von Aminosäuren, Amiden und Ureiden erfolgt. In der Regel geht die Nitraternährung mit einer deutlichen Abnahme des Spross/Wurzel-Verhältnisses einher, ein Effekt, der sich grundsätzlich positiv auf die Mineralstoffaufnahme auswirken kann. Als zentrale Regulative wirken hier offenbar in Kombination mit den organischen N-Fraktionen (Bijlsma \& Lambers 2000) die sprossbürtigen $\mathrm{NO}_{3}{ }^{-}-$Konzentrationen (Scheible et al. 1997a, 1997b; Stitt \& Scheible 1998). Diskutiert werden in diesem Zusammenhang hormonelle Steuerungen der Carbohydratpartitionierung, an denen insbesondere Auxin und Cytokinin beteiligt sein sollen (Britto \& Kronzucker 2002). Dass die Begrenzung der Nitratreduktion auf die Wurzeln die Etablierung der genannten Pflanzengruppen in Kalk-Halbtrockenrasen beeinträchtigt, ist nicht gänzlich auszuschließen. Während möglicherweise bei einer unzureichenden basipetalen Translokation von Photosyntheseassimilaten das aktuell verfügbare $\mathrm{NO}_{3}{ }^{-}$nicht optimal genutzt wird, würde aus einer besonders umfangreicher Verlagerung von Carbohydraten in die Wurzeln u. U. ein vermindertes oberirdisches Konkurrenzvermögen resultieren.

Weiter führende Untersuchungen von Troelstra et al. (1995b), in denen Calluna vulgaris, Erica tetralix, Molinia caerulea sowie Avenella flexuosa in Nährlösungen mit abgestuften $\mathrm{NO}_{3}^{-}$- und $\mathrm{NH}_{4}{ }^{+}$-Anteilen kultiviert wurden, lassen zwar für die drei erstgenannten Arten eine bevorzugte $\mathrm{NH}_{4}{ }^{+}$-Aufnahme, zugleich aber auch eine Förderung des Wachstums durch den gleichzeitigen Zusatz geringer $\mathrm{NO}_{3}{ }^{-}$-Mengen erkennen. Grundsätzlich dürften im Hinblick auf die Anionen/Kationen-Ernährung diese Ergebnisse insbeson-

1 Nardus stricta $(R 2, N 2)$, Avenella flexuosa (R2, N3), Calluna vulgaris (R1,N1), Empetrum nigrum $(R x, N 2)$, Erica tetralix (R 1 , $N 2)$, Molinia caerulea $(R x, N 3)$, Potentilla erecta $(R x, N 2)$ 
dere auch eine Funktion des pH-Werts sein. Infolge der physikochemischen Belastungen bei einem unausgeglichenen Anionen-Kationen-Aufnahmeverhältnis ist die Verwertung nur einer Stickstoffform auch für solche Pflanzen nachteilig, deren Standorte in großem Überschuss entweder $\mathrm{NH}_{4}{ }^{+}$oder $\mathrm{NO}_{3}{ }^{-}$ bereitstellen. Ebenso wie in sauren Böden temporär recht hohe $\mathrm{NO}_{3}^{-}$-Konzentrationen auftreten (Runge 1974a, 1974b; Davy \& Taylor 1974; Taylor et al. 1982), liegen in kalkreichen Böden phasenweise nennenswerte $\mathrm{NH}_{4}{ }^{+}$-Konzentrationen vor (vgl. Abbildung 33, S. 66; Mahdi et al. 1989).

Bleiben die ggf. erforderlichen Investitionen für Schutz- oder Detoxifikationsreaktionen unberücksichtigt, so ist eine $\mathrm{NH}_{4}{ }^{+}$-Ernährung angesichts der zusätzlichen Kosten für die $\mathrm{NO}_{3}{ }^{-}$-Reduktion und deren Kompartimentierung energetisch günstiger (Raven 1985; Lewis et al. 1986). Darauf lassen u. a. Modellberechnungen von Bijlsma et al. (2000) schließen. Unter Vernachlässigung möglicher pH-Effekte veranschlagen sie für den transmembranären Transport von $1 \mathrm{Mol} \mathrm{NO}_{3}{ }^{-} 2 \mathrm{Mol} \mathrm{ATP}$, für $1 \mathrm{Mol} \mathrm{NH}_{4}{ }^{+}$hingegen nur $1 \mathrm{Mol}$ ATP. Die Autoren vermuten aber, dass die Investitionskosten pro Einheit aufgenommenem und assimiliertem $\mathrm{N}$ insgesamt eine artspezifische Funktion des $\mathrm{NH}_{4}{ }^{+} / \mathrm{NO}_{3}{ }^{-}$-Konzentrationsverhältnisses im Substrat ist und dieses die natürliche Vegetationsdifferenzierung beeinflussen kann. In Kurzzeitversuchen über 2$24 \mathrm{~h}$ wurde für Arten mit unterschiedlichen Standortpräferenzen ${ }^{1}$ grundsätzlich eine bevorzugte Aufnahme von $\mathrm{NH}_{4}{ }^{+}$bei alleinigem, aber auch gleichzeitigem Angebot von $\mathrm{NH}_{4}{ }^{+}$und $\mathrm{NO}_{3}{ }^{-}$nachgewiesen (Falkengren-Grerup \& Lakkenborg-Kristensen 1994). Unabhängig vom Verbreitungsschwerpunkt zeigten aber alle Arten ein schlechteres Wachstum bei ausschließlicher $\mathrm{NH}_{4}{ }^{+}$-Ernährung. Mit Ausnahme der Nährlösungsexperimente von Bogner (1968), die auf eine geringfügige (Avenella flexuosa) bzw. deutliche (Calluna vulgaris) Wachstumshemmung durch $\mathrm{NO}_{3}{ }^{-}$verweisen, geben die Arbeiten anderer Autoren, auch für diese Arten, keine Hinweise auf negative Nitrateffekte (s. Bijlsma et al. 2000).

Eigene Untersuchungen an Individuen von Koeleria pyramidata, Potentilla neumanniana und Danthonia decumbens, die nach ihrer Anzucht in Bodenmonolithen hydroponisch kultiviert wurden, verdeutlichen, dass die Form der Stickstoffernährung die Entwicklung basiphiler/calcicoler und acidophiler/calcifuger Arten in unterschiedlicher Weise beeinflusst (Abbildung A 3, S. 313). Die basiphilen/calcicolen K. pyramidata und $P$. neumanniana besitzen eine deutliche Präferenz für $\mathrm{NO}_{3}^{-}$. Die Versuchsergebnisse geben Hinweise darauf, dass $P$. neumanniana selbst bei einer Mischernährung mit $\mathrm{NO}_{3}{ }^{-}$durch $\mathrm{NH}_{4}{ }^{+}$geschädigt wird. Hingegen besitzt $D$. decumbens bei getrennter und gemeinsamer Applikation von $\mathrm{NO}_{3}{ }^{-}$und $\mathrm{NH}_{4}{ }^{+}$ (c = 6,0 mM N) ein annähernd gleiches Wachstumsvermögen. Kultivierungen in eisenfreien Nährlösungen verweisen auf Wechselwirkungen zwischen der mineralischen Stickstoffform, der rhizosphärischen pH-Entwicklung und der Fe-Ernährung. Während ausgehend von einem initialen pH 6,0 die Protonenaktivität in $\mathrm{NH}_{4}{ }^{+}$-haltigen Nährlösungen auf etwa pH 2,9 erhöht wurde, sank sie in $\mathrm{NO}_{3}{ }^{-}$-Lösungen auf etwa pH 7,3 ab. In allen Fällen ging die eisenfreie Anzucht in $\mathrm{NO}_{3}{ }^{-}$-Lösungen mit der Ausbildung von Chlorosen einher (Abbildung A 4, S. 314). Trotz ihrer vergleichsweise geringen Wachstumsraten in Nährlösungskultur war dieser Effekt bei Danthonia decumbens besonders ausgeprägt. Demgegenüber beeinträchtigte die $\mathrm{NH}_{4}{ }^{+}$-Ernährung in Abwesenheit von FeEDTA nur die Chlorophyllbiosynthese von $K$. pyramidata und $P$. neumanniana. Unter den gegebenen Versuchsbedingungen wurden offenbar in allen Fällen apoplasmatische Fe-Fraktionen mobilisiert. Aufgrund der nur ungenügend definierten Anzucht und der für eine statistische Auswertung unzureichenden Anzahl an Versuchswiederholungen bedürfen die Ergebnisse der hier dargestellten Untersuchungsen sicherlich einer Überprüfung. Grundsätzlich stimmen

\footnotetext{
1 Avenella flexuosa $(R 2, N 3)$, Carex sylvatica $(R 6, N 5)$, Carex pilulifera $(R 3, N 3)$, Aegopodium podagraria $(R 7, N 8), M i l i u m$ effusum (R5, N5), Bromus benekenii (R 7,N5), Poa nemoralis (R5,N4)
} 
sie aber mit der Hypothese einer vegetationsdifferenzierenden Wirkung abweichender N- und Fe-Interaktionen bei Ökophysiotypen mit Präferenzen für alkalische, basenreiche und saure, basenarme Böden überein. Ergänzende Versuche zum Fe-Bedarf von Koeleria pyramidata und Danthonia decumbens in $\mathrm{NO}_{3}{ }^{-}$-haltiger Nährlösung fügen sich in dieses Bild einer unzureichenden Fe-Versorgung acidophiler/ calcifuger Arten an Standorten mit geringen Fe-Löslichkeiten (Abbildung A 5, 314). Gries (1991) bestätigt für diese beiden sowie verschiedene andere Arten dem Fe-Angebot ihrer Herkunftsstandorte entsprechende Fe-Effizienzen.

\section{Die Bedeutung von $\mathrm{NO}_{3}{ }^{-}$für den pflanzlichen Wasserhaushalt}

Die $\mathrm{NO}_{3}{ }^{-}$-Konzentrationen des Substrats können mittelbar und unmittelbar den pflanzlichen Wasserhaushalt beeinflussen. $\mathrm{NO}_{3}{ }^{-}$ist für viele Arten eines der wichtigsten Regulative des zellulären Wasserpotenzials. Wie von einem solchen Osmotikum nicht anders zu erwarten, korrelieren die auf das Trockengewicht bezogenen $\mathrm{NO}_{3}{ }^{-}-$Konzentrationen in der Pflanze mit dem Wassergehalt (Cárdenas-Navarro et al. 1999b). Die Kontrolle der Wurzelleitfähigkeit durch $\mathrm{NO}_{3}^{-}$(Carvajal et al. 1996; Hoarau et al. 1996), Modifikationen der SLA (specific leaf area) und der daraus abzuleitenden Transpirationsraten (Le Bot et al. 1998) sowie die Reduktion von $\mathrm{NO}_{3}{ }^{-}$und die Assimilation von $\mathrm{NH}_{4}{ }^{+}$bilden neben einer rückgekoppelten Kontrolle der $\mathrm{NO}_{3}{ }^{-}$-Aufnahme (Lainé et al. 1995; Cárdenas-Navarro et al. 1999a) die Grundlagen eines diesbezüglichen Homöostasemodells. Es ist daher denkbar, dass sich der Wasserhaushalt verschiedener Pflanzenarten infolge der abweichenden Regulation ihrer endogenen $\mathrm{NO}_{3}{ }^{-}$-Konzentrationen unterscheidet. Nach Angaben von Bijlsma et al. (2000) verwenden v. a. langsamwüchsige Arten mit hohen $\mathrm{NO}_{3}{ }^{-}$-Aufnahme- und geringen NR-Raten $\mathrm{NO}_{3}{ }^{-}$als Osmotikum. Niedrige Wassergehalte im Boden des Gentiano-Koelerietum typicum könnten demnach bei fehlenden Adaptationen des N-Haushalts eine zusätzliche Belastung der betreffenden Pflanzen bedeuten. Da für die vegetationsdifferenzierenden Arten des Gentiano-Koelerietum keine Informationen über ihre Mineralstoffkonzentrationen und Wasserpotenziale im Pflanzengewebe vorliegen, ist eine Wirkungsschema von der N-Ernährung über den Wasserhaushalt bis hin zum Ausschluss acidophiler/calcifuger Arten von Standorten der typischen Assoziation bisher aber rein spekulativ.

\section{Zusammenfassung}

Anhand der hier diskutierten bodenkundlichen und ökophysiologischen Aspekte ist die Bedeutung der Stickstoffernährung für den Ausschluss acidophiler/calcifuger Arten aus dem Gentiano-Koelerietum typicum nicht abschließend zu klären. Die Untersuchungen der vorliegenden Arbeit geben keine Hinweise darauf, dass entsprechend der verbreiteten Annahme einer spezifischen $\mathrm{NH}_{4}{ }^{+}$-Präferenz acidophiler/calcifuger Arten höhere $\mathrm{NH}_{4}{ }^{+}$-Konzentrationen in der Subassoziation von Danthonia decumbens vorliegen. Hingegen wurde in Bodenextrakten der CC-Bestände fast zwanzigfach mehr $\mathrm{NO}_{3}{ }^{-}$nachgewiesen. Aufgrund fehlender Korrelationen zwischen der Standortpräferenz und der Enzymkinetik der $\mathrm{NO}_{3}{ }^{-}$-Aufnahme und angesichts dessen, dass sehr viele Acidophile/Calcifuge, darunter verschiedene Arten, die das Gentiano-Koelerietum danthonietosum differenzieren, hohe NRA besitzen und diese Arten allenfalls ein geringfügig besseres Wachstum bei $\mathrm{NH}_{4}{ }^{+}$-Ernährung zeigen, kann davon ausgegangen werden, dass ihr Ausschluss nicht unmittelbar durch suboptimale N-Versorgung verursacht wird. Dies gilt um so mehr, da in den betreffenden Kalk-Halbtrockenrasen eine Vergesellschaftung von Vertretern der acidophilen/calcifugen Konstitutionsgruppe mit mesophilen Arten zu verzeichnen ist. 
Dass unzureichendes oder fehlendes Vermögen acidophiler/calcifuger Arten, $\mathrm{NO}_{3}{ }^{-}$als Osmotikum zu nutzen, bei sehr niedrigen Wasserpotenzialen in den CC-Beständen den Wasserhaushalt acidophiler/calcifuger Arten zusätzlich belastet, ist lediglich als ein hypothetischer Erklärungsansatz zu betrachten, der aber noch einmal aufzeigt, wie vielseitig der Einfluss der Stickstoffversorgung auf die Vegetationsdifferenzierung des Gentiano-Koelerietum sein kann. Betroffen von einem solchen Effekt wären vorwiegend Arten, deren NRA auf die Wurzeln beschränkt ist und die gleichzeitig nicht in der Lage sind, $\mathrm{N}$ etwa in Form methylierter quartärer Ammoniumverbindungen als kompatible osmotische Solute des Cytoplasmas zu nutzen. Neuere Untersuchungen zeigen aber, dass entgegen bisheriger Annahmen bei einigen Arten auch $\mathrm{NH}_{4}{ }^{+}$in hohen Konzentrationen vakuolär gespeichert wird und hier zu einer Justierung des zellulären Wasserpotenzials beiträgt (Britto \& Kronzucker 2002).

Während es fraglich erscheint, dass das N-Angebot durch Beeinträchtigungen des Wasserhaushalts für den Ausschluss von acidophilen/calcifugen Arten aus Kalk-Halbtrockenrasen verantwortlich zeichnet, dürfte als gesichert gelten, dass hohe $\mathrm{NO}_{3}^{-}$-Konzentrationen sekundäre Störungen der pflanzlichen Mineralstoffernährung bei Arten verursachen, die nicht an die spezifischen Bedingungen besonders kalkreicher und trockener Böden angepasst sind. Prinzipiell wird die Anionenaufnahme durch hohe $\mathrm{OH}^{-}-$und $\mathrm{HCO}_{3}^{-}$Aktivitäten beeinträchtigt. Denkbar ist, dass $\mathrm{NO}_{3}{ }^{-}$als Mineralstoff, der bei entsprechendem Angebot von allen Pflanzennährstoffen in der größten Quantität aufgenommen wird, diesbezügliche Effekte verstärkt. Von zentraler Bedeutung könnte unter den gegebenen Standortbedingungen beispielsweise eine zusätzliche Belastung der Fe-Ernährung durch die mit der zellulären $\mathrm{NO}_{3}{ }^{-}$-Aufnahme einhergehende lokale Alkalisierung des Wurzel- und Sprossapoplasten sein.

\subsection{Integrative Betrachtung biotischer und abiotischer Faktoren}

Die standörtliche Vegetationsdifferenzierung ist die Folge der wechselseitigen Beziehung einer kaum zu überschauenden Anzahl biotischer und abiotischer Faktoren. Während im Rahmen der vorliegenden Arbeit v. a. bodenkundliche Aspekte intensiv untersucht wurden, mussten andere wichtige Faktoren des Pflanzenwachstums versuchstechnisch unberücksichtigt bleiben. Daher können diese hier nur unter Bezugnahme auf die Arbeiten anderer Autoren und unter theoretischen Gesichtspunkten behandelt werden.

Von besonderer Bedeutung für die Vegetationsentwicklung eines Standorts sind die direkte Konkurrenz um Raum (interference competition) und die indirekte Konkurrenz um Nährstoff- und Wasserressourcen sowie Licht (exploitation competition). Die Konkurrenz betrifft sowohl vegetative Aspekte, wie etwa die Biomasseproduktion, als auch generative, d. h. insbesondere solche des Reproduktionserfolgs (Begon et al. 1996). Sie ist damit ein Motor der Evolution und der Ausgestaltung verschiedenartiger Lebensräume. In Übereinstimmung mit den standortökologischen Konzepten physiologischer und ökologischer Optima von Ellenberg (1953) bzw. fundamentaler und realisierter Nischen von Hutchinson (1965) sind unmittelbare letale Schädigungen durch abiotische Standortfaktoren die Ausnahme. Bereits Tansley (1917) hat in Kulturexperimenten nachgewiesen, dass die physiologischen Unterschiede des acidophilen/calcifugen Galium harcynicum und des basiphilen/calcicolen G. pumilum erst unter Konkurrenzbedingungen zur Vikarianz führen. Prinzipiell vermögen beide Arten sowohl auf sauren, kalkarmen als auch basischen, kalkreichen Standorten zu wachsen. Die Bedeutung autökologischer Unterschiede wird in vollem Umfang also erst in natürlichen oder naturnahen Systemen und bei der gemeinsamen Kultivierung verschiedener Arten deutlich. Dabei kann sich die Entwicklungsgeschichte des Standorts in der aktuellen Vegetationsdifferenzierung widerspiegeln. 
Im Folgenden werden unter Berücksichtigung der interspezifischen Beziehungen zwischen den Pflanzen noch einmal ausgewählte Gesichtspunkte der Nährstoff- und Wasserversorgung, anthropo-zoogene Einflüsse sowie mikrobielle Symbiosen und palaeogeographische Entwicklungen im Hinblick auf ihre Bedeutung für die standörtliche Vegetationsdifferenzierung der Kalk-Halbtrockenrasen behandelt. Hierbei sollen v. a. auch die Wechselwirkungen zwischen diesen Ebenen aufgezeigt werden. Die Überschriften des vorliegenden Kapitels können somit nur auf die inhaltlichen Schwerpunkte der betreffenden Absätze verweisen.

\subsubsection{Nährstoff- und Wasserverfügbarkeiten}

Der Ansicht mancher Autoren widersprechend, finden sich weder theoretisch noch experimentell fundierte Hinweise darauf, dass überdurchschnittliche $\mathrm{P}$ - und $\mathrm{NH}_{4}{ }^{+}$-Verfügbarkeiten für das Auftreten von acidophilen/calcifugen Arten in Kalk-Halbtrockenrasen verantwortlich sind. Demgegenüber kann ein unzureichendes N- und P-Angebot in vielen Fällen als ausschlaggebend für das Fehlen eutropher und mesotropher Arten in Vegetationsgesellschaften sowohl trockener, basenreicher als auch basenarmer, saurer Böden betrachtet werden.

Obwohl aufgrund methodischer Unterschiede in vielen Fällen ein direkter Vergleich mit Literaturangaben nicht möglich ist, lassen die eigenen Untersuchungen auf recht niedrige $\mathrm{N}$ - und P-Verfügbarkeiten in beiden Subassoziationen des Gentiano-Koelerietum schließen. Mit $\mathrm{NH}_{4}{ }^{+}$-Konzentrationen zwischen 10$50 \mu \mathrm{M}$ und mittleren $\mathrm{NO}_{3}{ }^{-}$-Konzentrationen von etwa $100 \mu \mathrm{M}$ (Novoa \& Loomis 1981) liegen die NGehalte der Bodenlösung landwirtschaftlicher Nutzflächen durchschnittlich mehr als zweitausendfach über denen in den GBL der hier untersuchten Kalk-Halbtrockenrasen. Für die Vergleichsstandorte der eigenen Untersuchungen wurden mediane P-Konzentrationen in den GBL von 8,5-11,5 nM nachgewiesen. Diese unterschreiten die für eine optimale Pflanzenproduktion erforderliche P-Lösung sogar um einen Faktor von etwa $10^{-4}$ (Scheffer \& Schachtschabel 1992).

Die Arbeiten von Mahdi et al. (1989) bestätigen vergleichsweise geringe N- und P-Verfügbarkeiten für einen Halbtrockenrasen über Kalkgestein in Mittelengland. Nach zweistündiger KCl-Extraktion der lufttrockenen Feinerde lagen hier die $\mathrm{NH}_{4}{ }^{+}$-Gehalte des lössreichen Standorts bei $0,84 \mu \mathrm{mol} / \mathrm{g}$, die $\mathrm{NO}_{3}{ }^{-}$Gehalte bei $0,21 \mu \mathrm{mol} / \mathrm{g}$ und somit die unter Erfassung der austauschbaren Fraktionen ermittelten Gesamtwerte jeweils um etwa das Dreißigfache über den medianen Feinerdekonzentrationen, wie sie hier anhand der GBL für das Gentiano-Koelerietum bestimmt wurden.

Obwohl die feinerdebezogenen GBL-Konzentrationen mit ca. $20 \mathrm{nmol} / \mathrm{g} \mathrm{P}$ nur etwa ein Drittel der von Mahdi et al. nach einstündiger $\mathrm{NH}_{4} \mathrm{NO}_{3}$-Extraktion nachgewiesenen Werte erreichen, ist nicht davon auszugehen, dass die Versuchsstandorte der vorliegenden Arbeit im Vergleich zu denen anderer KalkHalbtrockenrasen außergewöhnlich geringe P-Verfügbarkeiten aufweisen. Beispielsweise geben Grime \& Curtis (1976) für feldfrische Bodenhomogenate ähnlicher Pflanzengesellschaften die austauschbare, labil gebundene P-Fraktion mit 0,12 $\mu \mathrm{mol} / \mathrm{g}$ an. Auch wenn der Veröffentlichung nicht zu entnehmen ist, ob sich dieser Wert auf das Frisch- oder Trockengewicht der Feinerde bezieht, liegt er mit Sicherheit deutlich unter den etwa 0,4 $\mu \mathrm{mol} / \mathrm{g} \mathrm{P}$, die mit dem gleichen Extraktionsmittel $\left(0,5 \mathrm{M} \mathrm{NaHCO}_{3}, \mathrm{pH} 8,5\right)$ im Rahmen der sequentiellen Fraktionierung von lufttrockenen Feinerdehomogenaten der Referenzstandorte Auf der Burg und Hölleberg ermittelt wurden.

In den Abschnitten 5.3.11 (S. 202 ff.) und 5.3.12 (S. 215 ff.) wurden bereits die Gründe für das konstitutiv sehr niedrige N- und P-Angebot saurer, basenarmer und alkalischer, basenreicher Böden erläutert. In 
den vergangenen Jahrzehnten haben anthropogene N-Depositionen dazu geführt, dass die Produktivität und Artenzusammensetzung einer Reihe ursprünglich oligotropher Ökosysteme, wie bestimmter Heidegesellschaften (Aerts \& Berendse 1988), Hochmoore (Aerts et al. 1992) oder Nadelwälder (Aber et al. 1989) bzw. die durch diese Eutrophierung entstandenen Vegetationsformen heute nicht mehr von der Nsondern von der P-Verfügbarkeit bestimmt werden. An anderen Standorten liegen Kolimitierungen beider Makronährstoffe vor, so etwa in Rasengesellschaften über Kreidegestein im zentralenglischen Peak District (Morecroft et al. 1994) oder in den Küstendünen Südwestenglands (Willis et al. 1963). Während Kooijman et al. (1998) an der holländischen Nordseeküste für eisen- und kalkarme Dünengesellschaften Hinweise auf eine Begrenzung des Pflanzenwachstums allein durch suboptimale N-Verfügbarkeiten gefunden haben, lassen eisen- und kalkreichere Standorte Limitierungen sowohl durch $\mathrm{N}$ als auch P vermuten. Mikrobiologische Untersuchungen bestätigen, dass N-Düngung den P-Mangel in Heide- und Rasengesellschaften saurer und basischer Böden lediglich verstärkt, d. h. bereits im Vorfeld beide Mineralstoffe in unzureichenden Mengen vorgelegen haben (Johnson et al. 1998). Eine Kolimitierung können bei niedrigen Bodenfeuchten auch Sämlinge von Arrhenaterum elatius erfahren. Nur der gleichzeitige Zusatz von N und P und die damit einhergehende Stimulation des Wachstums der Keimwurzeln verhindert bei dieser Art das Auftreten von Trockenschäden in Kalk-Halbtrockenrasen (Grime \& Curtis 1976).

Auch die Wasserverfügbarkeit selber kann in Halbtrockenrasen vegetationsdifferenzierend wirken. Das schnellere Wachstum meso- und eutropher Arten erfordert entsprechend hohe stomatäre $\mathrm{CO}_{2}$-Aufnahmeraten. Um diese ohne eine Gefährdung des Wasserhaushalts zu decken, müssen hohe Bodenwassergehalte oder hohe Wassereffizienzen vorliegen. Hinweise darauf, dass feuchte Witterungsbedingungen im Jahresverlauf oder die Entspannung des Wasserhaushalts durch die Erhöhung der atmosphärischen $\mathrm{CO}_{2^{-}}$ Konzentration eine Dominanz von mesophilen Arten und die Zurückdrängung von oligophilen, insbesondere annuellen Arten in Kalk-Halbtrockenrasen bewirken, geben Untersuchungen von Niklaus et al. (1998) und Sternberg et al. (1999). Nach Untersuchungen von Sykes \& van der Maarel (1991) limitieren auch im Alvar auf Öland nicht primär die Nährstoffkonzentrationen, sondern die Wasserverfügbarkeiten das Auftreten vieler Arten in Kalk-Halbtrockenrasen. Die Düngung mit Stickstoff zeigte hier nur bei gleichzeitiger Bewässerung einen Einfluss auf die Vegetationszusammensetzung. Auf die Bedeutung der Wassergehalte des Bodens im Zusammenspiel mit Aspekten der Mineralstoffernährung, inbesondere ihren Einflüssen auf die Mineralisierung organischer Stickstoffverbindungen sowie auf die reduktive Lösung essentieller Nährelemente wie Fe, wurde bereits an anderen Stellen im Detail eingegangen (vgl. Abschnitt 5.3.12, S. 215 f.; vgl. Abschnitt 4.2.4, S. 115 ff.). Es kann nicht ausgeschlossen werden, dass das gemeinsame Auftreten mesophiler und acidophiler/calcifuger Arten im Gentiano-Koelerietum dantonietosum auch auf die höheren Wassergehalte der betreffenden Standorte zurückzuführen ist.

\subsubsection{Interaktionen abiotischer Faktoren}

In beiden Subassoziationen des Gentiano-Koelerietum unterschreiten die P- und N-Verfügbarkeiten die für eine maximale Biomasseproduktion schnellwüchsiger Arten erforderlichen Konzentrationen. Welcher Art die Limitierung dieser Pflanzen im Gentiano-Koelerietum ist, kann anhand der hier durchgeführten Untersuchungen nicht abschließend beurteilt werden.

Der Wuchsort oligo-, meso- oder eutropher Arten ist indes nicht allein abhängig von der Nährstoff- und Wasserverfügbarkeit, sondern v. a. auch von den geographischen Rahmenbedingungen, wie der Lage, Exposition, Inklination und des damit verbundenen Klimas, sowie der Nutzungsform und der im Rahmen der Biogeographie behandelten Vegetationsgeschichte des Standorts. Häufig wirken diese Faktoren wie- 
derum über die pflanzliche Mineralstoffernährung, sei es hinsichtlich der Beeinflussung der Bodengenese durch das Ausgangsgestein und das für die Verwitterungsgeschwindigkeit ausschlaggebende Klima oder durch die indirekte Beeinflussung des Nährstoffmobilisierungs- und aufnahmevermögens der Pflanzen. So haben beispielsweise Cui \& Caldwell (1997) für Artemisia tridentata und Agropyron desertorum gezeigt, dass die N- und P-Ausbeute durch Beschattung deutlich vermindert wird. Geringe Photosyntheseraten führen zu einer unzureichenden Carbohydratverlagerung in die Wurzeln und Rhizosphäre, diese zu einer mangelhaften Wurzelentwicklung und Erschließung des Bodenraums sowie zu Störungen der rhizodermalen Mobilisierungs- und Aufnahmesysteme. Untersuchungen von Peace \& Grubb (1982) bestätigen für Impatiens parviflora derartige Zusammenhänge. Weiter führende Arbeiten an zehn Straucharten $^{1}$ und Fagus sylvatica, in denen die Abhängigkeit des Pflanzenwachstums sowohl von der Strahlungsintensität als auch von dem Nährstoffangebot des Substrats untersucht wurde, geben Hinweise darauf, dass diesbezügliche Unterschiede für die sekundäre Sukzession von Kalk-Halbtrockenrasen eine zentrale Rolle spielen (Grubb et al. 1996). Die Ausbreitung des Wacholders bei der Nutzungsaufgabe solcher Standorte und dem daraus resultierenden Ausbleiben von Sprossschädigungen findet möglicherweise ihre Ursache darin, dass Juniperus communis unter nährstoffarmen Bedingungen besonders von hohen Strahlungsintensitäten profitiert. Schließlich können durch unzureichende Photosynthese und eine unzureichende Verlagerung energiereicher Kohlenstoffverbindungen in die Wurzeln mikrobielle Symbiosen gestört werden, die für die Mineralstoffernährung vieler Pflanzen und damit potenziell für die Vegetationsdifferenzierung des Standorts von zentraler Bedeutung sind.

Unter dem Gesichtspunkt der vielfältigen Interaktionen zwischen den verschiedenen Standortfaktoren sind zugleich die z. T. deutlich voneinander abweichenden Versuchsergebnisse zu bewerten, wie sie hier für die Böden von Vegetationsbeständen auch dergleichen Subassoziationen innerhalb des GentianoKoelerietum gewonnen wurden. Tabelle 24 (S. 101 f.) zeigt, dass mit Ausnahme des pH(KCl) kein anderer Faktor die beiden Gesellschaften über die Vergleichsbestände des Einzelstandorts hinaus differenziert. So liegen die Fe-Konzentrationen der GBL für die CF-Bestände zwar grundsätzlich über denen der jeweiligen CC-Bestände, doch überschreiten diese beispielsweise im Gentiano-Koelerietum typicum auf dem Pagenberg die des Gentiano-Koelerietum danthonietosum auf dem Hölleberg um mehr als das Zehnfache.

Multivariate Verfahren mögen selbst unter diesen Voraussetzungen Hinweise auf die relative Bedeutung der einzelnen Standortfaktoren geben. Indes ist die Aussagekraft auch solcher Auswertungsansätze immer vor dem Hintergrund der begrenzten Anzahl potenzieller Einflussgrößen zu sehen, die in praktischen Arbeiten berücksichtigt werden können. Zu der Fülle einflussnehmender Faktoren und ihren Interaktionen kommt die Vielzahl möglicher Untersuchungsverfahren. So werden die Ergebnisse mineralstoffökologischer Analysen bereits durch die Struktur und Lagerung des Bodenmaterials beeinflusst (vgl. Abschnitt 5.3.1, S. 159 ff.). Von besonderem Interesse ist die Auswahl des Extraktionsmittels und der somit für das pflanzliche Wachstum als ausschlaggebend betrachteten Fraktion eines Mineralstoffs. Aufgrund abweichender physiologischer Eigenschaften kann aber ein- und dieselbe Mineralstoffform für verschiedene Pflanzen eine unterschiedliche Bedeutung besitzen. Hinzu kommt, dass Fluktuationen in Zeit und Raum eine wichtige Rolle für die Koexistenz oder den gegenseitigen Ausschluss von Arten eines Lebensraums spielen (Begon et al. 1996). Schließlich setzen multivariate Verfahren lineare oder durch Transformation

\footnotetext{
1 Cornus sanguinea, Crataegus monogyna, Euonymus europaeus, Juniperus communis, Ligustrum vulgare, Prunus spinosa,
} Rhamnus catharticus, Rosa canina, Viburnum lantana, Viburnum opulus, 
linearisierbare Beziehungen voraus. In der Realität ist in vielen Fällen aber die pflanzliche Mineralstoffernährung durch Optimumfunktionen gekennzeichnet, die durch diese Auswertungsansätze nicht hinreichend abgebildet werden können.

\subsubsection{Interspezifische Konkurrenz}

Unter Annahme der klassischen Nischentheorie von Gause (1934), nach der zwei oder mehr konkurrierende Arten nicht an identischen Standorten existieren können und demnach ihr gemeinsames Wachstum in einem Vegetationsbestand auf räumliche und/oder zeitliche Hetereogenitäten zurückzuführen ist (Grubb 1979), haben Mahdi et al. (1989) versucht, die differenzierenden Faktoren für die Verteilung von acht Arten ${ }^{1}$ in einem Halbtrockenrasen aufzuklären. Von den untersuchten Bodenfaktoren ${ }^{2}$ konnten durch einfaktorielle Varianzanalysen nur für den rhizosphärischen $\mathrm{pH}$-Wert und die Bodengründigkeit eine signifikante Beziehung zum kleinräumigen Vegetationsmuster nachgewiesen werden. Die N-, P- und KKonzentrationen der Mikrohabitate zeigten keinen Bezug zum Auftreten der Arten. Auch der pH-Wert wies lediglich für die Rhizosphäre von Potentilla erecta und Carex caryophyllea einerseits sowie C. flacca andererseits signifikante Unterschiede auf.

Die zusammenfassende Auswertung aller Untersuchungsergebnisse mit Hilfe einer kanonischen Varianzanalyse deutet darauf hin, dass für das Vegetationsmuster des hier untersuchten Halbtrockenrasens die Phänologie der Arten eine größere Rolle spielt als die Bodenverhältnisse des Standorts. Während in der vorliegenden Arbeit zwei Subassoziationen, d.h. ganze Vegetationsbestände miteinander verglichen wurden, in denen - bezogen auf die Bodeneigenschaften - Pflanzen mit z. T. sehr unterschiedlichen Verbreitungsschwerpunkten vergesellschaftet sind, führten Mahdi et al. (1989) gezielt Untersuchungen für Arten durch, die mit Ausnahme von Potentilla erecta praktisch in allen Halbtrockenrasen auftreten und offenbar recht ähnliche Standortansprüche stellen. Aufgrund der abweichenden Versuchsansätze ist die Vergleichbarkeit der Ergebnisse dieser beiden Studien begrenzt. Indes können neben methodischen Unzulänglichkeiten der horizontalen und vertikalen Differenzierung des Wurzelraums einzelner Individuen oder Ramets sowie der nicht exakten Lokalisierung der Bodenbereiche, aus denen tatsächlich eine Mineralstoffaufnahme erfolgt, auch die unzureichende Anzahl und Auswahl edaphischer Faktoren für das Ergebnis der geringen bodenkundlichen Nischenseparierung der einzelnen Arten in dem mittelenglischen KalkHalbtrockenrasen verantwortlich zeichnen. Mit welchen grundlegenden Problemen die Trennung des Wurzelraums koexistierender Arten verbunden ist, verdeutlichten Untersuchungen von Skalova et al. (1999) und Pechackova et al. (2004), nach denen die Distanz, in der benachbarte Individuen oder Ramets gemeinsam wurzeln, um bis zu einer Größenordnung über derjenigen liegt, die oberirdisch eine gegenseitige Beeinträchtigung der Strahlungsperzeption erwarten lässt. Wichtige Faktoren wie die Fe-Verfügbarkeiten, die aufgrund ihrer Lösungschemie in kalkreichen Böden vegetationsdifferenzierend wirken können, blieben in der Arbeit von Mahdi et al. (1989) unberücksichtigt.

Im Wechselspiel insbesondere mit Faktoren wie dem Nährstoffangebot und der Wasserverfügbarkeit nehmen aber zweifelsohne die phänotypischen Eigenschaften und das Wachstumspotenzial der Pflanzen Einfluss auf die Vegetationsdifferenzierung. Dies gilt insbesondere auch für Kalk-Halbtrockenrasen (AlMufti et al. 1977; Grime 1979; Sydes 1984). Wie bereits mehrfach ausgeführt, finden N sowie P und

\footnotetext{
1 Carex caryophyllea, Carex flacca, Lotus corniculatus, Plantago lanceolata, Potentilla erecta, Ranunculus bulbosus, Sanguisorba minor, Trifolium pratense

2 Bodengründigkeit, $\mathrm{NH}_{4}^{+}$und $\mathrm{NO}_{3}^{-}$(in $2 \mathrm{M} \mathrm{KCl}$ ), $\mathrm{P}$ und $\mathrm{K}$ (in $0,5 \mathrm{M} \mathrm{NH}_{4} \mathrm{NO}_{3}{ }^{-}$)
} 
damit diejenigen Makronährstoffe, die besonders häufig die Produktivität eines Standorts bestimmen, eine Entsprechung darin, dass ihre Verfügbarkeit in der Regel sowohl an sehr sauren als auch an trockenen, basenreichen Standorten vergleichsweise gering ist. Angesichts der verbreiteten Oligotrophie in beiden Konstitutionsgruppen, der acidophilen/calcifugen und der basiphilen/calcicolen, liegt an nährstoffreichen Standorten mit intermediären pH-Werten ein Ausweichen dieser Arten vor wachstumsstärkeren Konkurrenten nahe (s. z. B. Hacket 1965). Nur wenige Arten zeigen eine bimodale Verteilung entlang der Bodenreaktion. Da keine ausreichenden Belege für ein abweichendes Verwertungsvermögen unterschiedlicher $\mathrm{N}$ - und P-Formen durch acidophile/calcifuge und basiphile/calcicole Arten vorliegen, müssen andere Faktoren eine größere Bedeutung für die unterschiedliche Artenzusammensetzung dieser Standorte besitzen. Vergleichsweise direkt beeinträchtigen geringe $\mathrm{N}$ - und P-Verfügbarkeiten in der Regel nur das Wachstum von Arten mit hohen Nährstoffansprüchen. Suboptimale Wachstumsbedingungen führen generell zu einem Vitalitätsverlust der Pflanzen (Larcher 1994). Entsprechende Grenzen werden von eutrophen Arten bereits bei recht hohen, von oligotrophen Arten erst bei deutlich niedrigeren Nährstoffkonzentrationen erreicht. Das Auftreten oligotropher Arten wird häufig also v.a. durch die aus dem Ressourcenangebot resultierenden Konkurrenzverhältnisse sowie durch physiologische Nebeneffekte der betreffenden Nährstofffraktionen beeinflusst.

Von den Pflanzen der mitteleuropäischen Flora, die Ellenberg et al. (1992) mit Nährstoffzahlen von N 1 und N 2 auflisten, zeigen die meisten entweder ein ausgesprochen acidophiles oder basiphiles Verbreitungsmuster. Bei den verbleibenden Oligotrophen, für die hinsichtlich der Bodenreaktion kein ökologisches Optimum (sensu Ellenberg 1953) beschrieben wird, handelt es sich in der Regel um Unterarten formenreicher Aggregate (z. B. Thymus pulegoides ssp. pulegoides, Festuca ovina ssp. cinerea). Bei den wenigen oligotrophen Taxa mit indifferenter Verbreitung entlang des Boden-pH könnte es sich um Zusammenfassungen von Genotypen mit nur graduell abweichenden Standortansprüchen handeln, die sich phänotypisch ungenügend oder allenfalls mit viel Aufwand unterscheiden lassen. Wie das Beispiel Danthonia decumbens zeigt, gibt manchmal erst das Auftreten von Populationen an konträren Standorten Anlass für tiefer gehende systematische Bearbeitungen (vgl. 5.1.4, S. 151).

Dass das Wachstum von Oligotrophen weit weniger durch geringe Makronährstoffverfügbarkeiten begrenzt wird als das mesotropher und eutropher Arten, belegen z. B. Untersuchungen von Glimskär \& Ericsson (1999). Während das Wurzelsystem von Danthonia decumbens zum Erreichen halbmaximaler Wachstumsraten $\left(\mathrm{RGR}_{50}=0,052 \mathrm{~d}^{-1}\right)$ täglich mit 5,0 l einer $50 \mu \mathrm{M}$ N-Lösung besprüht werden muss, liegt der Stickstoffbedarf von Dactylis glomerata und Agrostis capillaris etwa proportional zu ihren höheren Wachstumsleistungen bei dem Zweieinhalbfachen. Grundsätzlich wird bei N-Mangel die Biomassepartition zugunsten der Wurzeln verschoben (van der Werf \& Nagel 1996). Diesbezüglich zeigen Arten mit abweichenden potenziellen Wachstumsraten (RGR $\mathrm{Rax}_{\text {ax }}$ ) keine Unterschiede (Glimskär \& Ericsson 1999). Solche mit hohen $\mathrm{RGR}_{\max }$ sind bei saturierendem N-Angebot im Vergleich zu Oligotrophen durch höhere spezifische Blattoberflächen (SLA, specific leaf area) und Nährstoffverwertungseffizienzen (NUE, nutrient use efficiency) gekennzeichnet. Zudem bestreiten die unterirdischen Organe von meso- und eutrophen Arten in der Regel einen höheren Anteil an der Gesamtbiomasse (RWR, root weight ratio). Der stärkere Lichtgenuss großwüchsiger Arten geht mit einer besonders umfangreichen Carbohydrattranslokation in die Wurzeln einher und kann z. B. Dactylis glomerata und Holcus lanatus durch die Ausbildung eines weitläufigen Wurzelsystems und die vermehrte Abgabe von Wurzelexsudaten gegenüber den in Halbtrockenrasen verbreiteten Brachypodium pinnatum, Briza media und Carex flacca Konkurrenzvorteile auch hinsichtlich der Nährstoffaufnahme vermitteln (Peace \& Grubb 1982; van der Werf et al. 1993). 
Im Kurzzeitversuch bleiben die Unterschiede der RGR, SLA, NUE und RWR von Vertretern der verschiedenen Trophiestufen auch bei niedrigen N-Verfügbarkeiten bestehen. Langfristig aber werden an nährstoffarmen und trockenen Standorten meso- und eutrophe Arten durch solche mit niedrigen potenziellen Wachstumsraten auskonkurriert. Nach Ansicht von van der Werf et al. (1993) spielt dabei die Effizienz der Mineralstoffaufnahme und -metabolisierung, hier speziell bezogen auf den Stickstoff, eine untergeordnete Rolle. Wichtiger soll sein, dass die Gewebe von Arten, die an nährstoffarme Standorte angepasst sind, eine längere Lebensdauer besitzen, so dass aus dem langsameren Biomasseumsatz insgesamt eine höhere Ökonomie in Bezug auf die Nutzung der verfügbaren Ressourcen resultiert (Berendse et al. 1987). Zu dem besonders effizienten Umgang oligotropher und damit zumeist acidophiler/calcifuger oder basiphiler/calcicoler Arten mit geringen Nährstoffverfügbarkeiten trägt bei, dass sie infolge der bei ihnen verbreiteten Sklerophyllie und Abwehrstoffe weit weniger von Herbivorie betroffen sind (Grubb 1986; Coley 1987; Niemann et al. 1992; Poorter \& Bergkotte 1992). Ein hoher Gewebeverlust kann aber aufgrund der damit einhergehenden Investitionskosten und des langsamen Regenerationsvermögens bei diesen Funktionstypen besonders folgenreich sein (Fraser \& Grime 1999). Abweichend von der verbreiteten Annahme einer top down-Kontrolle in hochproduktiven, nährstoffreichen Ökosystemen und einer bottom up-Kontrolle in nährstoffarmen Ökosystemen sollen nach der Fretwell-Oksanen-Theorie Herbivore nur in Pflanzengesellschaften mit geringer Biomasseproduktion das Pflanzenwachstum limitieren. Vergleichsuntersuchungen bestätigen, dass der Einsatz von Pestiziden die Produktivität eines Kalk-Halbtrockenrasens erhöht, während der Biomasseaufbau in einem Brennnesselbestand unverändert bleibt. Gleichzeitig wurde gezeigt, dass Urtica dioica bei der Transplantation an den nährstoffarmen Standort eine besonders starke Schädigung durch phytophage Insekten erfährt (Fraser 1998).

Dass hohe N-Verfügbarkeiten nicht nur auf dem Weg der interspezifischen Konkurrenz um Licht und andere Ressourcen zu einer Verdrängung oligotropher Arten beitragen, verdeutlichen Arbeiten an Calluna vulgaris. In Heidegesellschaften führen N-Düngungen zu einer verminderten Frosttoleranz, deren Wirkung durch die Induktion eines verfrühten Blattaustrieb verstärkt wird (Power et al. 1998b). Wie der schnellere Wasserverlust dekaptierter Sprosse zeigt, sind zudem Trocknisschäden durch supraoptimale NVerfügbarkeiten nicht auszuschließen und möglicherweise an der Ausbildung von Vegetationslücken im Bestand beteiligt. Lee \& Caporn (1998) bestätigen für Rasengesellschaften saurer und basischer/kalkreicher Böden einen mittelfristigen Effekt durch die Wechselwirkung klimatischer und ernährungsphysiologischer Faktoren. Einer Wachstumsförderung von C. vulgaris in den ersten vier Jahren durch N-Applikationen von bis zu $20 \mathrm{~g} \cdot \mathrm{m}^{-2} \cdot \mathrm{a}^{-1}$ folgten in den nächsten Jahre weit reichende Frostschädigungen und ein vermehrter Schädlingsbefall. Viele Arten synthetisieren nur bei geringen Nährstoffverfügbarkeiten und einhergehend mit geringen Wachstumsraten in ausreichendem Maß sekundäre Metabolite, die ihnen an ihren typischen Standorten einen effektiven Fraßschutz vermitteln (Coley et al. 1985). Zugleich wird die Entwicklung und Reproduktion phytophager Insekten durch hohe N-Konzentrationen der Wirtspflanzen begünstigt (s. Waring \& Cobb 1992). Der stetige Rückgang von Heideflächen ist demnach also die Folge des Zusammenwirkens einer ganzen Reihe von Faktoren, die durch N-Immisionen beeinflusst werden (Lee 1998): Zunehmende N-Konzentrationen des Pflanzengewebes fördern die Larvalentwicklung und Herbivorie des Heidekäfers Lochmea suturalis (Heil \& Diemont 1983; Brunsting \& Heil 1985; van der Eerden et al. 1991), vermindern die Toleranz gegenüber Frost und Trockenheit (Dueck et al. 1990; Lee \& Caporn 1998; Power et al. 1998b) und führen über die veränderten Konkurrenzverhältnisse in den Bestandslücken schließlich zu einer fortschreitenden Verdrängung von C. vulgaris durch Grasarten mit höherem Wachstums- und/oder Beschattungspotenzial (Aerts et al. 1990). Wie die eigenen Untersu- 
chungen gezeigt haben, weisen die Böden des Gentiano-Koelerietum in der Subassoziation von Danthonia decumbens im Jahresdurchschnitt besonders niedrige $\mathrm{N}_{\min }$-Konzentrationen auf. Es kann nicht gänzlich ausgeschlossen werden, dass ein solches Beziehungsgefüge für das Verteilungsmuster zumindest von C. vulgaris auch in Kalk-Halbtockenrasen eine Rolle spielt.

Für den Ausschluss von Arten mit hohem Nährstoffbedarf diskutiert Hodge (2004) eine weitere Hypothese. Untersuchungen von Gross et al. (1993) haben gezeigt, dass Holcus lanatus in heterogenen Böden gezielt nährstoffreiche spots erschließt. Aus den außergewöhnlich schnellen Auf- und Abbauraten der Wurzeln gerade in diesen Bodenbereichen soll bei der mesotrophen Art nachhaltig ein negativer Wachstumseffekt resultieren. Das ausgesprochen oligotrophe Nardus stricta zeigt hier kein selektives Wurzelwachstum und somit keine diesbezüglichen Beeinträchtigungen. Ob dieser Wirkungsmechanismus ausreichend fundiert ist, muss indes bezweifelt werden. Es erscheint fraglich, dass sich eine Strategie zur Mineralstoffakquisition hat evolutiv durchsetzen können, die in der Endbilanz mit einer verminderten Nährstoffeffizienz einhergeht. Denkbar erscheint dies nur bei sehr spezifischen Bodenverhältnissen hinsichtlich der Dichte und Größe dieser spots sowie der in diesen vorliegenden Nährstoffkonzentrationen.

\subsubsection{Anthropo-zoogene Einflüsse}

Die Vegetationsgeschichte und hier insbesondere die Art und Weise der Bewirtschaftung ist neben dem Nährstoff- und Wassermangel eine weitere Gemeinsamkeit vieler Pflanzengesellschaften saurer, basenarmer und alkalischer, basenreicher Böden. Die meisten Magerrasen, d.h. Grünlandbestände mit einem Trockenmasseertrag von weniger als 3,5 $\mathrm{t} \cdot \mathrm{ha}^{-1} \cdot \mathrm{a}^{-1}$ (Nitsche \& Bultmann 1995), und Heidegesellschaften befinden sich im Bereich ehemals bewaldeter Gemeinschaftsflächen (Allmenden), die anfänglich eine Bewirtschaftung durch die bis in das 19. Jahrhundert hinein praktizierte Waldweide erfahren haben. Häufig wurden solche Wälder auch durch Brand gerohdet. Die Schweine-, Rinder-, Schaf- und Ziegenhaltung diente hier nicht nur der Fleisch- und Milchproduktion, sondern auch dem gezielten Transfer von Pflanzennährstoffen in die ackerbaulich genutzen Flächen nahe den Siedlungen. Bei der Dreifelderwirtschaft beispielsweise wurde das Vieh über Nacht auf dem brachliegenden Feld eingepfercht, wo es durch die Abgabe von Faeces und Urin zur Erhöhung der Bodenfruchtbarkeit beitrug. Anderenorts wurde den Allmenden mit dem Rechen oder der Sense geerntetes Material für die Einstreu der Lagerflächen des Viehs und die spätere Ausbringung auf die Felder entzogen. Aus den ursprünglichen Waldgesellschaften entwickelten sich auf diese Weise nutzungsbedingte und gleichzeitig durch den Basengehalt des Ausgangsgesteins der Bodenbildung beeinflusste Ersatzgesellschaften, deren Vegetation zunehmend durch den Nährstoffentzug, durch gezielten Verbiss oder selektive Meidung bestimmter Pflanzenarten sowie durch Trittbelastung, die nicht selten mit der Erosion von Bodenmaterial und einer Abnahme der Bodengründigkeiten einherging, geprägt wurden (Pott 1992; Beinlich 1997; Schläpfer et al. 1998). In Pflanzengesellschaften, die auch heute noch auf diese Weise bewirtschaftet werden, treten v.a. lichtliebende Hemikryptophyten, aber auch Geo- und Chamaephyten auf (vgl. Abbildung A 1, S. 312).

Während in Deutschland Mitte des 19. Jahrhunderts ca. 30 Millionen Schafe gehalten wurden (s. Beinlich 1997), waren es 2002 nur noch ca. 2,7 Millionen (BMVEL 2003). Unter Berücksichtigung der territorialen Veränderungen entspricht dies einer Abnahme der durchschnittlichen Bestandsdichte von mehr als 55 Tiere $/ \mathrm{km}^{2}$ auf 7,6 Tiere $/ \mathrm{km}^{2}$ und unter Annahme einer vergleichbaren Beweidungsintensität dem Verlust von mehr als 85 \% derart bewirtschafteter Flächen. Insbesondere diese Entwicklung zeichnet für den Rückgang von Magerrasen und Heidegesellschaften verantwortlich. Gesellschaften der anthropo-zoogenen Heiden und Rasen sensu Ellenberg (1996) können heute in der Regel nur noch durch finanziell geför- 
derte Pflegemaßnahmen erhalten werden. Die Nährstoffausträge durch Mahd und Beweidung stellen besonders auch angesichts der weiterhin steigenden N-Depositionen und der damit gerade in Kalkböden einhergehenden N-Retentionen notwendige Maßnahmen zum Schutz von Kalk-Halbtrockenrasen (Phoenix et al. 2003), aber auch Heide- und Graslandgesellschaften sandiger Böden (Power et al. 1998a) dar.

Dass die Präsenz und Abundanz der Arten in Kalk-Halbtrockenrasen eine Funktion ihres Konkurrenzvermögens unter den gegebenen Rahmenbedingungen ist, haben beispielsweise Mitchley \& Grubb (1986) gezeigt. Bei großwüchsigen Arten wird durch Mahd und - soweit keine physikalischen oder chemischen Schutzmechanismen wirken - Beweidung tendenziell ein viel größerer Anteil der Biomasse entfernt. Kleinwüchsige Arten erfahren daher bei niedrigen Nährstoff- und Wassergehalten durch diese Bewirtschaftungsweisen einen relativen Konkurrenzvorteil. Das aktuelle Arteninventar eines Magerrasens hängt v. a. auch von dem Zeitraum der jeweiligen Nutzung ab. So vermuten Schläpfer et al. (1998), dass die vergleichsweise große Übereinstimmung der Arten von beweideten und gemähten Kalk-Halbtrockenrasen im Schweizer Jura darauf zurückzuführen ist, dass in letzteren erst vor vergleichsweise kurzer Zeit die Beweidung aufgegeben wurde. Während hier 90 \% der Arten in beiden Nutzungsformen auftreten, verweisen Untersuchungen von Baker (1937) an 900 Jahre alten Weiden in der Nähe von Oxford und solchen, die seit ebenfalls sehr langer Zeit als Heuwiesen bewirtschaftet werden, auf einen gemeinsamen Artenpool von lediglich 32 \%. Unterschiede der beweideten Rasengesellschaften sind u. a. auf die Art und Intensität ihrer Bewirtschaftung zurückzuführen. Während Schafe die Vegetation bis unmittelbar an die Bodenoberfläche abgrasen, wird von Kühen, einhergehend mit einer besonders hohen Trittbelastung, in der Regel nur Pflanzenmaterial mit einer Höhe von mehr als $5 \mathrm{~cm}$ erfasst (Schläpfer et al. 1998). Ziegen sind für die Restaurierung verbuschter Magerrasen besonders geeignet, da sie auch verholzte, dornige und stachelige Pflanzen verbeißen (Nitsche \& Bultmann 1995).

Ein bedeutender Aspekt für die abweichende Vegetationsdifferenzierung von Weiden und Mähden ist zudem der Transfer von Diasporen. Die traditionelle Wanderschäferei und die damit einhergehende Zoochorie erscheint besonders geeignet, die Folgen der zunehmenden Fragmentierung und Isolierung dieser Lebensräume zu reduzieren und deren große Biodiversität aufrecht zu erhalten (Fischer et al. 1996; Beinlich 1997). Die Kalk-Halbtrockenrasen im Unteren Diemeltal werden im Jahr ein- bis dreimal mit Schafen beweidet und bei drohender Verbuschung v.a. durch Prunus spinosa und Verfilzung durch Dominanzbildung von Brachypodium pinnatum - das übrigens mehr durch P- als durch N-Einträge, in erster Linie aber durch unzureichende Beweidung gefördert wird (Morecroft et al. 1994; Wilson et al. 1995; Bobbink et al. 1998) - maschinell aufgelichtet (Albrecht 1998). Diesbezüglich existieren keine Unterschiede zwischen den Subassoziationen des Gentiano-Koelerietum. Hinsichtlich des gemeinsamen Auftretens acidophiler/calcifuger und basiphiler/calcicoler Taxa im Gentiano-Koelerietum sind die bis hierher dargestellten Punkte aber insofern von Bedeutung, als erst sie die für beide oligotrophe Konstitutionsgruppen notwendigen Voraussetzungen schaffen, der Konkurrenz durch Pflanzen mit stärkerem Wachstumspotenzial auszuweichen.

Offensichtlich steht insbesondere das Auftreten von Calluna vulgaris in Kalk-Halbtrockenrasen im Zusammenhang mit deren anthropo-zoogener Nutzung. Nach Angaben des lokalen Schäfers wurden die Calluna-Sträucher der Standorte Hölleberg und Auf der Burg bis vor wenigen Jahrzehnten beschnitten und das Material als Einstreu verwendet. Für die Verjüngung der Art ist eine regelmäßige Beweidung oder ein regelmäßiges Schneiteln der Bestände erforderlich (s. Ellenberg 1996). Damit keine fortschreitende Bodenversauerung und Eliminierung basiphiler/calcicoler Arten erfolgt, muss die Anreicherung der Streu von C. vulgaris verhindert werden (Grubb et al. 1969; Grubb \& Suter 1971). Während die Aufgabe 
der Schafhaltung in Weidegesellschaften über Podsolen und sauren Braunerden keinen Einfluss auf die Abundanz von Potentilla erecta hat, führt sie kurz- bis mittelfristig zu einem Auswachsen bisher unterdrückter Calluna-Sträucher und zu einer Zurückdrängung langsamwüchsiger Gräser wie Danthonia decumbens (Hill et al. 1992). Es ist aber aus den oben genannten Gründen davon auszugehen, dass Brache langfristig zu einer Degeneration der Calluna-Bestände führt.

Ursprüngliche Bewirtschaftungsformen, insbesondere die Wanderschäferei, können theoretisch das Auftreten Acidophiler/Calcifuger an basenreichen Standorten begünstigen, indem sie den Diasporenaustausch zwischen entfernt gelegenen Standorten erlauben und somit die Wahrscheinlichkeit einer Aussaat der betreffenden Arten erhöhen. Indes muss ihre Etablierung an diesen Standorten andere Ursachen haben.

\subsubsection{Mikrobielle Symbiosen}

Die Konkurrenz zwischen verschiedenen Pflanzenarten wird durch eine Vielzahl äußerer Faktoren mediiert. Während ausgehend von der Bedeutung abiotischer Ressourcen für die Sukzession und standörtliche Vegetationsdifferenzierung v. a. oberirdische Wechselwirkungen auf höheren trophischen Ebenen, etwa die selektive Schädigung durch Phytophage bzw. Herbivore (z. B. Odum 1969; Grime 1977; Bryant et al. 1983; Reader 1992; Fraser \& Grime 1999; Corcket et al. 2003a; Corcket et al. 2003b) oder Pathogene (Bruehl 1987; Burdon 1987) sowie multitrophe Interaktionen zwischen diesen funktionellen Gruppen (Clay et al. 1993), seit einigen Jahrzehnten eingehend untersucht werden, erfahren solche innerhalb der Bodengemeinschaft erst in den letzten Jahren vermehrte Aufmerksamkeit (Grace \& Tilman 1990; Tilman \& Pacala 1993; Bever et al. 1997; Westover et al. 1997; Wilson \& Hartnett 1997, 1998; van der Heijden et al. 1998a, 1998b; Hartnett \& Wilson 1999, 2002; Westover \& Bever 2001; O'Connor et al. 2002; Johnson et al. 2003)

Im Hinblick auf die komplementären Stoffwechselreaktionen photoautotropher und chemoheterotropher Organismen sowie den darauf basierenden ökosystemaren Stoffkreislauf liegt es auf der Hand, dass selbst Pflanzen, die keine ausgeprägten bodenbürtigen Symbiosen eingehen, nur in Ausnahmefällen autark existieren können. Eine besonders wichtige Rolle für die Vegetationsdifferenzierung spielen artspezifische Wechselwirkungen zwischen Pflanzen einerseits sowie Prokaryoten und Pilzen andererseits.

Für das Verständnis der engen Beziehungen zwischen der Mikroflora des Bodens und den Pflanzen ist deren gemeinsame Entwicklungsgeschichte von grundlegender Bedeutung. Die Umweltbedingungen im Palaeozoikum und hier v. a. die hohen Strahlungsintensitäten und $\mathrm{CO}_{2}$-Konzentrationen der Atmosphäre gingen wahrscheinlich mit besonders umfangreichen Rhizodepositionen der ersten terrestrischen Pflanzen einher. Es wird daher vermutet, dass letztere bereits sehr früh mit Mikroorganismen assoziiert waren und in der Folge beide Gruppen eine intensive Koevolution erfahren haben. Neben freilebenden Arten entwickelten sich auch solche, die die Interzellularen der Pflanzenwurzeln und die Wurzelzellen selber besiedelten (Saikkonen et al. 1998). Kennzeichnend für die entwicklungsgeschichtlich und ökologisch engen Beziehungen zwischen Pflanzen und Mikroorganismen ist u. a. die Synthese von Hormonanaloga und gemeinsamen Signalstoffen durch die Symbionten (Tein et al. 1979; Neitko \& Frankenberg 1989; Murphy et al. 1997).

Die Bedeutung der Rhizoflora für die Pflanzen ist außerordentlich vielfältig. Manche Mikroorganismen beispielsweise beeinflussen das Pflanzenwachstum als Pathogene (Bruehl 1987; Burdon 1987; Augspurger 1990), andere wirken diesen antagonistisch entgegen (Thomashow \& Weller 1990; Handman et al. 1991). Die wichtigste Rolle spielt die Mikroflora des Bodens aber sicherlich im Zusammenhang mit 
der pflanzlichen Mineralstoffernährung und hier insbesondere mit der Stickstoffversorgung. Während freilebende Diazotrophe (z.B. Azotobacter, Azomonas, Azospirillum, Beijerinckia) mit den meisten Pflanzen in vergleichsweise lockerer Beziehung stehen, bilden Vertreter der gramnegativen Gattungen Rhizobium, Bradyrhizobium, Sinorhizobium, Mesorhizobium und Azorhizobium mit den Fabaceae, Ascomyceten der Gattung Frankia mit verschiedenen Nicht-Leguminosen (z. B. Alnus, Hippophaë) stickstofffixierende Endosymbiosen aus, die sich in charakteristischen Wurzelknöllchen äußern (Madigan et al. 2001). Wie bereits weiter oben ausgeführt, weichen die limitierenden Faktoren der Fabaceae in KalkHalbtrockenrasen häufig von denen der Arten anderer Familien ab.

Die wohl am weitesten verbreiteten und wichtigsten pflanzlich-mikrobiellen Symbiosen sind indes die verschiedenen Formen der Mykorrhiza (Brundrett 1991, 2002). In den meisten Fällen mutualistisch vermitteln hier die Mykobionten den Pflanzen mit Hilfe ihres fein verzweigten Hyphengeflechts, der damit besonders effektiven Erschließung des Bodenraums sowie durch die Wirkung ihres Exoenzymsystems, das viele Hydrolasen (Proteinasen, Cellulasen, Phosphatasen etc.) umfasst, v. a. eine verbesserte Mineralstoffversorgung. Es wird davon ausgegangen, dass Assoziationen, die der heutigen vesikulär-arbuskulären Mykorrhiza (VAM) entsprechen, bereits bei den frühesten moosähnlichen Landpflanzen zu Beginn des Devons (vor ca. 400 Millionen Jahren) und damit noch vor den ersten echten Wurzeln auftraten. Letztere sollen nach Ansicht einiger Palöobotaniker erst darüber entstanden sein, dass Rhizombildungen zwecks Intensivierung der endophytischen Symbiosen evolutiv eine Ausweitung und Differenzierung erfahren haben (s. Brundrett 2002).

Nach Untersuchungen von Trappe (1987) sind $82 \%$ aller Angiospermen mykorrhiziert. In Kalk-Halbtrockenrasen weisen ca. 70 \% der höheren Pflanzen entsprechende Assoziationen auf (Peat \& Fitter 1993). Die führende Rolle unter den Mykobionten spielt mit den Glomales eine Gruppe, deren Vertreter, wenngleich auch heute systematisch und taxonomisch noch nicht hinreichend bearbeitet, von manchen Biologen als die "wichtigsten" Lebewesen überhaupt angesehen werden (Brundrett 2002). Zweifelsohne kommt ihnen als Symbionten der (V)AM in vielen Ökosystemen eine besondere Bedeutung für die Vernetzung der verschiedenen trophischen Ebenen zu.

Während für die obligat symbiontischen Glomales lange Zeit angenommen wurde, dass sie bei nur geringer Wirtsspezifität v. a. an die Bodenverhältnisse adaptiert sind, weist die geringe Kompatibilität vieler Ascomyceten und Basidiomyceten bei der ektotrophen Mykorrhiza (ECM) auf eine enge Koevolution mit den Wirtspflanzen hin (Molina et al. 1992; Smith \& Read 1997). Dies gilt auch für die ekto(endo)trophe Mykorrhiza der Ericaceae und ganz besonders für die arbutoide und monotrope Mykorrhiza (Kretzer et al. 2000; Bruns \& Read 2000). Die Mykobionten autotropher Orchideen zeigen sowohl eine ausgesprochene Wirts- als auch Habitatspezifität (Currah et al. 1997). Die engsten Symbiosen bilden mykoheterotrophe Orchideen (z. B. Corallorhiza, Gastrodia, Galeola), deren parasitische Existenz von der ECM-Assoziation mit Vertretern einer einzigen Pilzgattung abhängen kann (Leake 1994; Taylor \& Bruns 1999). Grundsätzlich ist davon auszugehen, dass mit fortschreitender Evolution die Spezifität sowohl der Symbiosepartner als auch deren Standortbindung zunahm (Brundrett 2002). Einige angiosperme Pflanzenfamilien sind als Folge sekundärer Entwicklungen nicht mykorrhiziert (NM), darunter die Brassicaceae, Caryophyllaceae, Juncaceae und Cyperaceae. Manche (V)AM-Gruppen, wie z. B. die Poaceae, leiten sich wiederum von solchen NM-Pflanzen ab und belegen, dass diese Form der Mykorrhiza polyphyletisch ist.

Die Ausbildung der Symbiose wird nicht zuletzt durch den Chemotropismus des Pilzpartners beeinflusst. Sekundäre pflanzliche Metabolite können in geringsten Konzentrationen als Lockstoffe wirken und so die 
Kompatibilität der Symbionten (mit)bestimmen. Dies wurde z. B. für das Flavonol Rutin in den Wurzelexsudaten von Eukalyptus nachgewiesen, auf das nur bestimmte Pisolithus-Stämme und einige andere Pilzarten reagieren (Lagrange et al. 2002). An der Ausbildung der ECM können außerdem bestimmte Bakterien, sog. MHB (mycorrhiza helper bacteria), beteiligt sein, durch die möglicherweise Inhaltsstoffe der Pflanzenexsudate modifiziert oder deren Abgabe stimuliert werden (s. Garbaye 1994).

Nährstoff- und hier insbesondere P-reiche Standorte sind durch einen hohen Anteil an NM-Pflanzen gekennzeichnet (Allison \& Goldberg 2002). Bei der (V)AM ist offenbar die interne P-Konzentration für die Zusammensetzung der Wurzelexsudate und die Ausbildung der Symbiose von Bedeutung (Suriyapperuma \& Koske 1995). So können hohe P-Verfügbarkeiten z. B. bei Plantago lanceolata die Mykorrhizierung unterdrücken (Fransson et al. 2003). Es ist davon auszugehen, dass die hier wirksamen Mechanismen auch für die Ernährung der Pflanzen mit anderen Mineralstoffen eine Rolle spielen und grundsätzlich das Wechselspiel aus Investition und Profit bestimmen (Olsson \& Tyler 2004). Wie wichtig die Mykorrhiza potenziell ist, mit welchen Investitionen sie aber auch einhergeht, verdeutlichen gerade die ältesten mykorrhizafreien Pflanzenfamilien. Die cluster roots der Proteaceae und Restionaceae weisen morphologische und physiologische Anpassungen auf, die den Pflanzen eine eigenständige Mineralstoffernährung selbst unter extremen Bodenverhältnissen erlauben. Da dem Mykobionten bis zu $50 \%$ der photosynthetischen Nettoprimärproduktion zufließen (Harris \& Paul 1987), kann die Möglichkeit, durch solche Adaptationen auf die Ausbildung einer Mykorrhiza zu verzichten, unter bestimmten Umständen einen ausschlaggebenden Selektionsvorteil bedeuten. Andererseits postuliert Grime (1979), dass (V)AM nicht nur in konkurrenzintensiven Lebensräumen, sondern auch bei stresstoleranten Pflanzen verbreitet sind, weil dort die verbesserte symbiontische Mineralstoffversorgung die Kosten der Bereitstellung von Photosyntheseassimilaten für den Mykobionten überkompensiert. Hierzu passen die Ergebnisse von Untersuchungen an Arenaria serpyllifolia und Cerastium fontanum, zwei NM-Arten nährstoffreicher und störungsintensiver Standorte (Bonis et al. 1997). In Böden mit intermediären pH-Werten und vergleichsweise guter P-Versorgung verstärken die Mykorrhizae anderer Pflanzen offenbar den Konkurrenzdruck und führen so zu einer Verdrängung von A. serpyllifolia und C. fontanum. In Kalkböden hingegen erfolgt in der Regel ein unmittelbarer Ausschluss der beiden Caryophyllaceae durch unzureichende P-Versorgung. Hier spielt die interspezifische Konkurrenz eine untergeordnete Rolle.

Wie die bisherigen Ausführungen gezeigt haben, existieren alle denkbaren Konstellationen hinsichtlich der Notwendigkeit oder des Effekts der Interaktionen sowie der Kompatibilität und der standort- bzw. milieutypischen Toleranz der Symbiosepartner. Mykorrhizae können je nach Pflanzenart und Mikroorganimus fakultativ oder obligatorisch, mutualistisch oder parasitär sein. Bei einigen Pflanzenfamilien fehlen sie ganz. Die Phytobionten/Mykobionten-Bindung ist in manchen Fällen spezifisch, in anderen unspezifisch. Schließlich können nicht nur die Pflanzen, sondern auch die mit ihnen assoziierten Pilze eine stenbis euryöke Verbreitung besitzen. Es liegt daher auf der Hand, dass die pflanzlichen Standortpräferenzen und damit die Vegetationsdifferenzierung potenziell auch durch den Pilzsymbionten der Mykorrhizae oder die Mikrobinonten anderer Symbiosen beeinflusst werden.

Auf theoretischer Ebene haben Bever et al. (1997) dargelegt, dass selbst Vergesellschaftungen von jeweils nur zwei Phyto- und Mikrobionten als Folge abweichender Kombinationen positiver und negativer feedback-Effekte sehr unterschiedliche Entwicklungen erfahren können. Während negatives feedback die Koexistenz verschiedener Pflanzenarten fördert, schränken positive Rückwirkungen die Biodiversität auf lokaler Ebene ein, stabilisieren zugleich aber die Unterschiede zwischen den Pflanzengesellschaften. Ungleich komplexer ist der mikrobielle Einfluss in den vielgliedrigen natürlichen Biomen mit ihren 
räumlichen und zeitlichen Fluktuationen, zumal hier die Artenzusammensetzung gleichzeitig auch eine Funktion der interspezifischen Konkurrenz zwischen den Pflanzen selber ist.

Die Vielfalt pflanzlich-mikrobieller Wechselwirkungen und die methodisch gerade in Bodenmaterial schwierige Separierung, Identifizierung und Quantifizierung verschiedener Individuen, Arten und Stämme zeichnet dafür verantwortlich, dass erst mit der Entwicklung bestimmter molekularbiologischer Verfahren, wie z. B. dem des T-RFLP (terminal restriction fragment length polymorphism; Liu et al. 1997), die synökologische Forschung auf diesem Gebiet voranschreitet. Mittlerweile versuchen eine ganze Reihe von Arbeitsgruppen, durch den Einsatz solcher Techniken auch experimentell fundierte Hinweise auf die Bedeutung pflanzlich-mikrobieller Symbiosen für die Vegetationsentwicklung und Biodiversität in situ zu gewinnen. Im Mittelpunkt der meisten dieser Untersuchungen stehen bisher Mykorrhizae und hier v. a. die (V)AM.

Während bis vor wenigen Jahren noch davon ausgegangen wurde, dass weltweit nur etwa 150 verschiedene Glomales und Endogonales existieren (Walker \& Trappe 1993), die die in 90 \% aller Pflanzenfamilien vertretenen (V)AM bilden sollten (Clapp et al. 2002), wurde mittlerweile durch den Nachweis einer Vielzahl neuer Stämme und Arten (Helgason et al. 1998; Helgason et al. 1999; Daniell et al. 2001; Husband et al. 2002; Vandenkoornhuyse et al. 2002a) sowie einer deutlich höheren Wirtspezifität (Bidartondo et al. 2002; Vandenkoornhuyse et al. 2002b; Vandenkoornhuyse et al. 2003) gezeigt, dass tatsächlich auch die Mykobionten der (V)AM an der standorttypischen Vegetationsdifferenzierung beteiligt sein können. Hinweise darauf, dass gerade in Kalk-Halbtrockenrasen die Artenzusammensetzung maßgeblich durch die (V)AM beeinflusst wird, geben beispielsweise Untersuchungen von van der Heijden et al. (1998a, 1998b), denen zufolge hier die Diversitäten der Pflanzenarten und der (V)AM-Pilze miteinander korrelieren. In manchen Fällen wird zwar nicht die Anzahl, wohl aber die Zusammensetzung der Pflanzenarten an einem Standort durch die (V)AM beeinflusst (Smilauer \& Smilauerova 2000). Dass die Eigenschaften der Mykobionten vegetationsdifferenzierend wirken, zeigten Arbeiten von StreitwolfEngel et al. (1997; 2001) an Prunella vulgaris: Isolate gemeinsam auftretender (V)AM-Pilze beeinflussen auch bei gleichen abiotischen Bodenbedingungen und gleichem Infektionsgrad die pflanzliche Populationsstruktur in unterschiedlicher Weise.

Zobel \& Moora (1995) haben Hinweise darauf gefunden, dass die Phytodiversität in europäischen KalkHalbtrockenrasen aufgrund der bevorzugten Förderung dominierender Arten durch die Mykorrhizierung abnimmt. Bestätigt wird dieses Ergebnis für Pflanzengesellschaften der nordamerikanischen Prärie (Wilson \& Hartnett 1997; Hartnett \& Wilson 1999). Grime et al. (1987) hingegen vermuten, dass Mykorrhizapilze durch die Ausbildung eines intra- und interspezifischen Hyphengeflechts eine gleichmäßigere Verteilung der Systemressourcen erlauben, auf diese Weise zu einer Relativierung der Konkurrenz zwischen den Pflanzen beitragen und so die Etablierung von Begleitarten fördern. Hartnett \& Wilson (2002) fassen Untersuchungen zusammen, die belegen, dass entsprechende Interkonnektionen v. a. für die Translokation von P eine wichtige Rolle spielen.

Aufgrund ihrer begrenzten Kompatibilität und ihrer ökophysiologischen Eigenschaften ist der Einfluss der Mykorrhizapilze auf die Zusammensetzung und Sukzession von Pflanzengesellschaften immer eine Funktion der abiotischen Rahmenbedingungen (Francis \& Read 1995; Johnson et al. 1997). Einige (V)AM- und ECM-Pilze werden durch niedrige $\mathrm{pH}-$ Werte und die damit einhergehenden hohen Al-Konzentrationen in der Bodenlösung geschädigt (Vosatka et al. 1999; van Aarle et al. 2003). Auf der anderen Seite ist die ekto(endo)trophe Mykorrhiza der Ericaeae eine Voraussetzung für die Ausbildung von Hei- 
degesellschaften an Standorten sehr niedriger pH-Werte und der daraus resultierenden geringen Makronährstoffverfügbarkeiten. Die ericoide Mykorrhiza unterstützt aber nicht nur die Mobilisierung von Stickstoff aus der organischen Bodenfraktion, sondern schützt die Phytobionten auch vor bestimmten in hohen Konzentrationen auftretenden und daher potenziell toxisch wirkenden Komponenten der Bodenlösung (z. B. Shaw et al. 1990).

Wie enzymkinetische Untersuchungen an Calluna vulgaris gezeigt haben, fördert die Infektion mit Hymenoscyphus ericae - wahrscheinlich in erster Linie durch die Induktion entsprechender carrier - die Transportkapazität der Wurzelhaarzellen für verschiedene Aminosäuren (Sokolovski et al. 2002). Die sehr niedrigen apparenten $\mathrm{K}_{\mathrm{m}}$-Werte des Transportsystems und die den eigenen Bedarf deutlich übersteigenden Aufnahmeraten des Pilzes lassen darauf schließen, dass ein Großteil des Stickstoffs den Pflanzen direkt durch das Hyphengeflecht zufließt.

Mykorrhizae spielen insbesondere für die P-Ernährung vieler Pflanzenarten eine ausschlaggebende Rolle. Folgt man zugleich der in Abschnitt 5.3.11 (S. 202 ff.) behandelten Hypothese, nach der die Eliminierung acidophiler/calcifuger Arten von trockenen Kalkstandorten primär auf eine unzureichende P-Versorgung zurückgeht, muss daraus die Schlussfolgerung gezogen werden, dass hier der Pilzpartner oder doch zumindest die Funktion der Symbiose beeinträchtigt wird (Lee 1999). Die Mykorrhiza ist indes in KalkHalbtrockenrasen auch für die Ernährung der Pflanzen mit anderen Elementen von Bedeutung. Bereits in Abschnitt 4.3.3 (S. 125 ff.) wurde im Detail auf die Bedeutung mikrobieller Symbiosen für die pflanzliche Fe-Ernährung eingegangen. Neben der Assoziation freilebender Bakterien und Pilze, die als Folge der Veratmung leicht abbaubarer Rhizodepositionen und der damit verbundenen Ausbildung anaerober Bodenbereiche oder aber durch die Abgabe von Siderophoren bzw. anderen Komplexbildnern die FeLöslichkeit in der Rhizosphäre erhöhen, ist die Mykorrhizierung in anderen Fällen die Grundlage für die suffiziente Fe-Ernährung der Pflanzen. So kann beispielsweise Hymenoscyphus ericae die Fe-Versorgung von Calluna vulgaris deutlich verbessern (Leake et al. 1990). Eine Voraussetzung für die Erhöhung der Absorptionsrate und der Fe-Konzentrationen im Spross ist in diesem Fall allerdings ein nicht zu hoher pH-Wert. Nährlösungskulturen mit 0-25 $\mathrm{mM} \mathrm{CaCl}_{2}$ bzw. $\mathrm{CaCO}_{3}$ haben gezeigt, dass bei einer Erhöhung der $\mathrm{CaCO}_{3}$-Konzentration von 1,25 mM (pH 4,2) auf 2,5 mM (pH 7,0) die Verhältnisse umgekehrt und die pflanzliche Fe-Ernährung durch eine Inokulation mit $H$. ericae negativ beeinflusst wird. Demgegenüber stimuliert die Mykorrhizierung auch noch bei $25 \mathrm{mM} \mathrm{CaCl}_{2}(\mathrm{pH} 3,6)$ die Fe-Aufnahme.

Bereits Büsgen (1914) hat auf die Schädigung der Mykorrhiza von Calluna vulgaris in Kalkböden hingewiesen. Gleichzeitig setzt aber das Wachstum vieler Ericaceae die Ausbildung einer funktionsfähigen Mykorrhiza voraus. Das Auftreten von C. vulgaris sowie anderen acidophilen/calcifugen Arten im Gentiano-Koelerietum danthonietosum könnte demnach auch mit der Existenz kompatibler alkalotoleranter Mikrobiontenstämme zusammenhängen. Wie die Ausführungen dieses Kapitels zeigen, sind nicht nur die ökomorphologischen und ökophysiologischen Unterschiede der Pflanzen sondern potenziell auch die autökologischen Eigenschaften ihrer Symbionten für die Vegetationsdifferenzierung eines Standorts verantwortlich. Allerdings ist die Erforschung der zugrundeliegenden Wirtsbindungen, Milieupräferenzen und symbiontischen Leistungen der Mikrobionten erst seit wenigen Jahren Gegenstand standortökologischer Arbeiten. Bisher haben sich von diesen leider noch keine gezielt mit Aspekten des Auftretens acidophiler/calcifuger und basiphiler/calcicoler Pflanzenarten befasst. In welchem Ausmaß artspezifische Symbiosen die Vegetationsdifferenzierung saurer, basenarmer und alkalischer, basenreicher Standorte beeinflussen, ist daher bis heute vollkommen offen. 


\subsubsection{Palaeogeographie acidophiler/calcifuger und basiphiler/calcicoler Arten}

Im Rahmen der Biodiversitätsforschung wurde in den vergangenen Jahren die Frage aufgeworfen, warum trotz des kleineren Areals alkalischer, basenreicher Böden in Mitteleuropa die Alpha- und Gamma-Diversitäten, d. h. die lokale Dichte und der regionale Pool (Whittaker 1977), der basiphilen/calcicolen Arten deutlich höher ist als die der Acidophilen/Calcifugen (Ewald 2003). Wenngleich die von manchen Autoren in diesem Zusammenhang vorgenommene Klassifizierung der Pflanzen in nur drei Gruppen - acidophil, indifferent, basiphil - nicht befriedigend ist, trifft dieses Verteilungsmuster in vielen Vergesellschaftungen auch bei einer diesbezüglich strikteren Trennung der Arten zu (Lawesson 2003).

Nach Annahme von Ewald (2003) lässt sich der fehlende Bezug zwischen der Biodiversität der Konstitutionstypen und der Größe ihres potenziellen Verbreitungsraums auf Entwicklungen im Zuge der pleistozänen Eiszeit zurückführen. Danach entsprach bis ins Tertiär der Anteil acidophiler/calcifuger Arten der größeren Ausdehnung basenarmer, saurer Standorte. Die nachfolgende Vergletscherung führte zu einer Verdrängung der Pflanzen in einige, zumeist basenreiche Rückzugsgebiete. Im Postglazial wurde der Lebensraum Basiphiler/Calcicoler durch Solifluktion, Kryoturbation, Denudation und Lösseinträge nach und nach vergrößert und damit die Grundlage für die zunehmende Diversifizierung dieser Arten geschaffen. Erst die vermehrten Basenausträge im temperat-humiden Holozän führten - seit der industriellen Revolution verstärkt durch anthropogene Immissionen v.a. von Schwefel- und Stickoxiden - zu einer weitflächigen Wiederversauerung der Böden. Der für eine umfassendere Adaptation und Fortentwicklung recht kurze Zeitraum (<10.000 Jahre) soll dafür verantwortlich zeichnen, dass heute die Anzahl Acidophiler/Calcifuger nicht mit dem Areal basenarmer, saurer Böden übereinstimmt.

Die Hypothese einer temporären Einengung und Ausweitung des Areals der betreffenden Böden als Ursache für die heutige Diversität der beiden Gruppen wird von verschiedenen Autoren in Frage gestellt (Chytrý et al. 2003; Palmer et al. 2003; Peet et al. 2003; Wohlgemuth \& Gigon 2003). Positive Korrelationen zwischen der Artenanzahl und dem Boden-pH bzw. den Reaktionszahlen nach Ellenberg et al. (1992) finden sich nicht für alle Vegetationsformen. Nach Untersuchungen von Chytrý et al. (2003) bezieht sich dieses Verteilungsmuster im Wesentlichen auf Laubwälder und - mit allerdings nur geringem Erklärungsanteil der Bodenacidität - auf Graslandgesellschaften trockener Standorte. Bestätigt wird dieses Bild für die erstgenannte Gruppe u. a. durch Untersuchungen von Ray Benayas (1995), Brunet et al. (1997), Brosofske et al. (2001), Dumortier et al. (2002) und Lawesson (2003), für letztere durch Silvertown (1980) und Tilman \& Olff (1991). Im Nordosten Oklahomas/USA weisen Waldgesellschaften positive, hochwüchsige Graslandgesellschaften der Prärie hingegen negative Korrelationen zwischen der Biodiversität und dem Boden-pH auf (Palmer et al. 2003).

Auf regionaler und lokaler Ebene zeigen auch Schilf- und Großseggenbestände sehr feuchter und überfluteter Standorte eine negative Korrelation zwischen der Phytodiversität und den Zeigerwerten der Bodenreaktion (Chytrý et al. 2003). Es liegt auf der Hand, dass hier die potenziellen Limitierungen trockener, kalkreicher Böden, wie mangelndes Wasser- und Fe-Angebot, entfallen und gerade wegen der hohen Basensättigungen die Voraussetzungen für eine Dominanzbildung eutropher Arten, wie Schilf und bestimmte Großseggen, vorliegen.

Vegetationsanalysen temperater Wälder im Südosten der USA, deren Böden von der pleistozänen Eiszeit unbeeinflusst blieben, haben ebenfalls gezeigt, dass die palaeogeographische Kontraktion des Lebensraums und die damit einhergehende ökologische Drift keine Voraussetzung für die besonders hohe Anzahl calcicoler/basiphiler Arten ist (Peet et al. 2003). Trotz der seit frühester Zeit basenarmen Böden 
finden sich auch in diesen Gesellschaften vergleichsweise wenige acidophile/calcifuge Arten. Anders als von Pärtel (2002) und Ewald (2003) angenommen, spielt demnach die Arealgröße der jeweiligen Bodenverhältnisse für die regionale und lokale Diversität der beiden Konstitutionsgruppen allenfalls eine untergeordnete Rolle. Es ist vielmehr davon auszugehen, dass nicht die Bodenreaktion selber, sondern Faktoren, die mit dieser in Beziehung stehen, für die abweichenden Phytodiversitäten saurer und alkalischer Böden verantwortlich zeichnen. Die vergleichsweise schnelle Verwitterung basenreicher Sedimentgesteine führt zu einer besonderen Vielfalt an Mikrohabitaten, die sich hinsichtlich ihrer Topographie, ihres Mikroklimas, ihrer Bodentextur sowie der damit verbundenen physikalischen und chemischen Eigenschaften unterscheiden. Standorte basenarmer Ausgangsgesteine, deren Böden sich in der Regel auf silikatische Magmatite und Metamorphite zurückführen lassen oder einen organogenen Ursprung haben, sind in der Regel sehr viel homogener (Wohlgemuth \& Gigon 2003). Es darf daher angenommen werden, dass die Biodiversität von Standorten gleicher Bodenreaktion eher durch das Ausmaß ihrer Heterogenität als durch ihre Arealgröße beeinflusst wird.

Tyler (2003) macht neben den erdgeschichtlichen Klima- und Bodenentwicklungen auch anthropogene Faktoren für die Anzahl und das Verteilungsmuster acidophiler/calcifuger und basiphiler/calcicoler Taxa verantwortlich. Beispielsweise sollen sich in Teilen Skandinaviens mit Beginn der Landwirtschaft im Neolithikum v. a. solche Arten ausgebreitet haben, die moderat saure oder basische Standorte bevorzugen und sich in diesem Umfeld diversifizieren konnten. Auf der anderen Seite wirken anthropogene Einflüsse dieser Entwicklung entgegen. Chytrý et al. (2003) vermuten, dass in der Tschechischen Republik das inverse Verhältnis zwischen der Artenzahl in synanthropen, einjährigen Unkrautfluren und den mittleren Zeigerwerten der Bodenreaktion u. a. auf den Einsatz von Herbiziden in der modernen Landwirtschaft zurückzuführen ist. Die meisten basenreichen Standorte in Mitteleuropa befinden sich auf geringer Meereshöhe. Sie werden wegen ihrer klimatischen Begünstigung viel intensiver bewirtschaftet als die basenarmen Böden der höheren Lagen.

Erst der fortschreitende Basenaustrag im Holozän soll zur Evolution solcher Taxa geführt haben, die die chemischen und physikalischen Eigenschaften saurer Böden tolerieren. Aufgrund der im Wesentlichen unidirektionalen Bodensukzession muss davon ausgegangen werden, dass das Vermögen unter dem an kalkreichen Standorten vorherrschenden Nährstoffmangel zu wachsen, entwicklungsgeschichtlich älter ist als die Toleranz gegenüber den in sauren, basenarmen Böden einwirkenden Toxizitätsfaktoren. Wenn auch in sehr unterschiedlichem Ausmaß, werden beispielsweise durch unzureichendes Fe-Angebot bei allen diesbezüglich untersuchten Dikotylen und allen nicht-gramineen Monocotylen rhizodermale Fe(III)Reduktasen, bei allen Poaceae die Abgabe von Phytosiderophoren induziert. Gleichzeitig können die meisten Pflanzen, an deren Standorten fast ausschließlich $\mathrm{NH}_{4}{ }^{+}$verfügbar ist, auch $\mathrm{NO}_{3}{ }^{-}$verwerten.

Bereits an anderer Stelle wurde im Detail auf die postglaziale Differenzierung von Danthonia decumbens eingegangen (Abschnitt 5.1.4, S. $151 \mathrm{f}$.). Die Tatsache, dass es sich bei der tetraploiden D. decumbens ssp. decipiens um die ursprüngliche und auch heute noch an alkalischen, basenreichen Standorten auftretende, bei der hexaploiden $D$. decumbens ssp. decumbens um die abgeleitete acidophile/calcifuge Unterart handelt, lässt sich mit den klimatischen und edaphischen Entwicklungen im Quartär sowie den darüber erforderlichen autökologischen Entwicklung in Übereinstimmung bringen.

Das rasche Auftreten acidophiler/calcifuger Arten im Postglazial, vergleichbare Stressantworten der beiden Verbreitungsgruppen auf die divergierenden Belastungen an ihren angestammten Standorten sowie die in manchen Fällen nur geringen anatomisch-morphologischen Unterschiede vikariierender Taxa sind der Hintergrund von zwei sehr ähnlichen Erklärungsmodellen für die ökophysiologische Entwicklung der 
beiden Konstitutionsgruppen. Tyler (2003) zieht in Betracht, dass die unterschiedlichen Mineralstoffeffizienzen bzw. -toleranzen acidophiler/calcifuger und basiphiler/calcicoler Arten lediglich auf Modifikationen der Rezeptoren bestehender und nicht auf die Entwicklung komplett neuer Stressreaktionen zurückzuführen sind. So soll bei Acidophilen/Calcifugen die Bindung von $\mathrm{Al}^{3+}$, bei Basiphilen/Calcicolen die Bindung von $\mathrm{Ca}^{2+}$ die Abgabe organischer Säuren induzieren und diese der standortspezifischen Detoxifizierung von Al bzw. der Mobilisierung von Fe und P dienen. Bereits früher hatte Lee (1999) eine vergleichbare Hypothese formuliert, nach der die Anionenkanäle für die Exsudation der organischen Säuren bei der einen Gruppe durch $\mathrm{Ca}^{2+}$, bei der anderen durch $\mathrm{Al}^{3+}$ blockiert werden. Leider wurden beide Hypothesen bis heute noch nicht überprüft.

Trotz ihrer Stringenz können die hier vorgestellten Überlegungen selbstverständlich nur bedingt die reale Evolution und die Vegetationsentwicklung alkalischer, basenreicher und saurer, basenarmer Standorte abbilden. So ist davon auszugehen, dass die pflanzliche Acidotoleranz polyphyletisch ist und sich diese auch in Mitteleuropa nicht bei allen Taxa erst nach der pleistozänen Eiszeit entwickelt hat. Zudem ist ein sprunghafter und monokausaler Übergang von einem acidofugen zu einem acidotoleranten Physiotypus auszuschließen.

\subsection{Synthese und Ausblick}

Wie die bisherigen Ausführungen gezeigt haben, wurden im Calcicolen/Calcifugen-Komplex bis heute v. a. bodenphysikalische und bodenchemische sowie damit verbundene ökophysiologische Aspekte behandelt. Natürlich nimmt eine viel größere Anzahl miteinander interagierender Faktoren Einfluss auf die standörtliche Vegetationsdifferenzierung. Ausgehend von kleinräumigen aperiodischen und periodischen Fluktuationen, wie sie im Zusammenhang mit den eigenen bodenkundlichen Untersuchungen diskutiert wurden, über die Geschichte regionaltypischer Nutzungsformen bis hin zu palaeogeographischen und globalen anthropogenen Einflüssen sind im Rahmen kausaler Ökosystemanalysen die biotischen und abiotischen Standortfaktoren v.a. auch im Hinblick auf ihre räumliche und zeitliche Vernetzung zu betrachten. Grundsätzlich lassen sich ökologische Phänomene nicht auf eine begrenzte Anzahl von Parametern, Objekten, Arten und Wechselwirkungen zurückführen (Nentwig et al. 2004). Es ist daher illusorisch, Ökosysteme ausschließlich über Analysen ihrer Einzelkomponenten begreifen zu wollen. Nach Ansicht von Mayr (2002) stehen rein typologische und deterministische Ansätze einem Verständnis der Ökologie entgegen. Aus dieser Sicht widerspricht die eingangs formulierte Frage nach dem wichtigsten Faktor der standörtlichen Vegetationsdifferenzierung grundlegenden ökologischen Prinzipien.

Folgt man dem hierarchischen Ansatz kausaler Ökosystemanalysen von Gigon (1987), liegen der biologischen Ausgestaltung eines Standorts letztlich v. a. systemunabhängige Faktoren, wie das Ausgangsgestein der Bodenbildung und das Klima, zugrunde. Diesen kausalen Faktoren werden korrelative Faktoren untergeordnet. Dazu zählen beispielsweise chemische Schlüsselfaktoren, wie der pH, die Ionenaktivität und das Redoxpotenzial, die einander und viele andere Bodeneigenschaften beeinflussen. Häufig sind es letztere, die über die Etablierung bestimmter Pflanzen an einem Standort entscheiden. Gleichzeitig unterliegen sie selber der Einflussnahme durch die belebte Umwelt, d.h. biotische und abiotische Faktoren sind auf dieser Ebene interkorreliert.

Eine Trennung kausaler und korrelativer Faktoren allein anhand dieser Definition ist indes nicht möglich. Beispielsweise wurde seit dem Archaeozoikum die Zusammensetzung der Atmosphäre im wesentlichen durch die Entwicklung des Lebens auf der Erde und hier v. a. durch das Auftreten der bakteriellen und 
pflanzlichen Photosynthese bestimmt (Cloud 1968). Auch heute noch nehmen Ökosysteme, wie z. B. tropische Regenwälder, maßgeblichen Einfluss auf das globale Klima. Solche systemabhängigen kausalen Faktoren sollen sich nach Gigon (1987) von korrelativen Faktoren dadurch unterscheiden, dass sie nicht zu einer Stabilisierung der Ökosysteme beitragen, sondern deren Sukzession fördern. Wenngleich eine strikte Trennung kausaler und korrelativer Faktoren auch unter Einbeziehung dieses Kriteriums nicht möglich erscheint, kann der Ansatz einer hierarchischen Gliederung der Standorteinflüsse helfen, Ergebnisse ökologischer Untersuchungen, wie in der vorliegenden Arbeit beispielsweise solche der Ursachen der Vegetationsdifferenzierung von Kalk-Halbtrockenrasen, zu ordnen und zu bewerten.

\section{Geologische, geographische und anthropogene Faktoren von Kalk-Halbtrockenrasen}

Ellenberg (1996) fasst die Gesellschaften der Festuco-Brometea (Kalkmagerrasen i.w. S.) und NardoCallunetea (Borstgrastriften und Zwergstrauchheiden) in eine gemeinsame Gruppe anthropo-zoogener Heiden und Rasen zusammen. Die meisten Syntaxa der Festuco-Brometea finden sich in Mitteleuropa auf offenen, warmen und trockenen Standorten über basenreichen Ausgangsgesteinen. In ihnen sind v. a. Vertreter der kontinentalen Steppenvegetation, submediterraner Gras- und Zwergstrauchformationen sowie alpigene Restbestände der pleistozänen Eiszeit vergesellschaftet. Wie die zumeist flachgründigen und kalkreichen Böden des Gentiano-Koelerietum weisen auch die sauren, basenarmen Böden der NardoCallunetea in der Regel niedrige N- und P-Verfügbarkeiten auf. Die Nährstoffarmut dieser Standorte geht insbesondere auf die geologischen, topographischen und klimatischen Rahmenbedingungen zurück. Für eine anderweitige landwirtschaftliche Nutzung ungeeignet, erfuhren viele von ihnen durch eine extensive Beweidung oder Mahd einen zusätzlichen Austrag und damit eine weitere Verarmung an Nährstoffen. Geologische, geographische und anthropogene Faktoren führten hier also zu Verhältnissen, die insbesondere für die Etablierung oligotropher Arten geeignet sind. Die diesbezüglichen Gemeinsamkeiten von Gesellschaften der Festuco-Brometea und Nardo-Callunetea lassen darauf schließen, dass für ihr abweichendes Arteninventar in erster Linie Faktoren verantwortlich sind, die sich auf die unterschiedlichen Basengehalte der Böden beziehen.

\section{Bodenkundliche Aspekte der Differenzierung des Gentiano-Koelerietum danthonietosum}

Bodensaure Standorte können nicht nur auf die Pedogenese basenarmer Ausgangsgesteine, sondern auch auf die Entwicklung ursprünglich basenreicher Böden zurückgehen. Die Sukzession des Gentiano-Koelerietum an Standorten, die aufgrund ihrer geographisch-topographischen und regionalklimatischen Voraussetzungen den Basenaustrag sowie die Anreicherung des Verwitterungsmaterials begünstigen, ist durch das Auftreten acidophiler/calcifuger Arten gekennzeichnet. Pflanzensoziologisch leitet die Subassoziation von Danthonia decumbens zu Gesellschaften der Borstgrastriften und Zwergstrauchheiden über. Die in der vegetationskundlichen Literatur beschriebenen, in den betreffenden Arbeiten zumeist aber nicht näher untersuchten Standortunterschiede zwischen dem Gentiano-Koelerietum typicum und dem Gentiano-Koelerietum danthonietosum werden durch die eigene Arbeit bestätigt. In der Regel treten demnach typische Arten der Nardo-Callunetea, aber auch der Molinio-Arrhenateretea in Kalk-Halbtrockenrasen ebener Lage oder an Hängen mit allenfalls geringer Inklination auf, wo durch eine vergleichsweise langsame Entwässerung, die damit einhergehenden höheren Wassergehalte und Verwitterungsintensitäten unter Abnahme des Skelettanteils und Stabilisierung des Solums erhöhte Bodengründigkeiten, geringere Carbonatkonzentrationen sowie zumindest oberflächig niedrigere $\mathrm{pH}-$ Werte vorliegen. Gleichzeitig geben die Untersuchungen Hinweise auf höhere Feinerde-Lagerungsdichten sowie niedrigere hydraulische Leitfähigkeiten und damit auf geringere Diffusionsraten und eine schlechtere Durchlüftung dieser Böden. 
Die Untersuchungen der vorliegenden Arbeit sind, wenngleich experimentell-analytisch, vorwiegend deskriptiver Natur und erlauben daher isoliert betrachtet noch keine Aussagen über die Ursachen des Wachstums von Acidophilen/Calcifugen in Kalk-Halbtrockenrasen. Korrelationen zwischen der Ausprägung der Standortfaktoren und dem Auftreten bestimmter Pflanzen können aber unter Einbeziehung autökologischer Aspekte der Kausalanalyse der Vegetationsdifferenzierung dienen. Im Hinblick auf eine umfassende Charakterisierung der Standorte berücksichtigten die eigenen bodenkundlichen Analysen auch solche Mineralstoffe, von denen nach bisheriger Kenntnis kein wesentlicher Einfluss auf die unterschiedlichen Standortpräferenzen acidophiler/calcifuger und basiphiler/calcicoler Taxa ausgeht.

Die potenziellen Bodenaciditäten der Kalk-Halbtrockenrasen folgen den $\mathrm{CaCO}_{3}$-Gehalten ihrer Feinerde. Letztere liegen an allen Standorten des Gentiano-Koelerietum typicum über denen der Subassoziation von Danthonia decumbens. Nicht in jedem Fall spiegeln die $\mathrm{Ca}^{2+}$-Konzentrationen der wässrigen Bodenextrakte die Kalkanteile der Feinerde wider. Inwieweit das Fehlen acidophiler/calcifuger Taxa in der typischen Subassoziation in Zusammenhang mit Schädigungen der Pflanzen durch sehr hohe $\mathrm{Ca}^{2+}$-Konzentrationen steht, kann anhand dieser Untersuchungen nicht beurteilt werden. Allerdings haben autökologische Arbeiten schon früh Hinweise darauf gegeben, dass die $\mathrm{Ca}^{2+}$-Lösung nicht unmittelbar für den Ausschluss acidophiler/calcifuger Arten verantwortlich ist. Mit Ausnahme derjenigen eines Untersuchungsstandorts unterschreiten auch die aktuellen Bodenaciditäten der CC- diejenigen der CF-Bestände. Mit Hilfe von Nährlösungsexperimenten konnte gezeigt werden, dass die $\mathrm{H}^{+}$-Aktivitäten selber eine untergeordnete Rolle für die Standortpräferenz von Vertretern der beiden Konstitutions- und Verbreitungsgruppen spielen. Als Schlüsselfaktor beeinflusst der pH aber maßgeblich die Lösung und Umsetzung sowie die pflanzliche Aufnahme fast aller Mineralstoffe. Schädigungen nicht adaptierter Pflanzen sind in sauren Böden in der Regel auf $\mathrm{Al}^{3+}$-Intoxikationen zurückzuführen.

Unabhängig von der Bezugsgröße (Lösungsvolumen, Trockenmasse der Feinerde, Bodenvolumen) geben die Ergebnisse der Bodenanalysen keine Hinweise auf ein unterschiedliches $\mathrm{K}^{+}$- und $\mathrm{Mg}^{2+}$-Angebot in den beiden Subassoziationen des Gentiano-Koelerietum. Wie die sehr ausgeglichenen Bodenlösungskonzentrationen aller Kalk-Halbtrockenrasen zeigen, gilt entsprechendes auch für $\mathrm{SO}_{4}{ }^{2-}$. $\mathrm{Zwar}$ wurde die Mobilisierung und Aufnahme von Kalium, Magnesium und Schwefel im Zusammenhang mit dem charakteristischen Arteninventar saurer, basenarmer und alkalischer, basenreicher Standorte bisher nur am Rande untersucht, doch darf angesichts der indifferenten Verteilung dieser Nährelemente davon ausgegangen werden, dass sie im Calcicolen/Calcifugen-Komplex keine unmittelbare Rolle spielen. Während diese Makronährstoffe für die hier behandelte Vegetationsdifferenzierung der Kalk-Halbtrockenrasen nicht zur Diskussion stehen, betrachten verschiedene Autoren suboptimale N- und P-Versorgung als Ursache für den Ausschluss acidophiler/calcifuger Pflanzen von trockenen, basenreichen Standorten.

Die Art und der Umfang des N-Angebots hängt v. a. von den mikrobiellen Umsetzungen im Boden ab. In trockenen Böden wird die Mineralisierung, in Böden mit sehr niedrigen pH-Werten zudem die Nitrifikation gehemmt. Soweit keine umfangreichen anthropogenen Einträge erfolgen, resultieren daraus gleichermaßen geringe, in ihrer Zusammensetzung aber abweichende $\mathrm{N}_{\min }$-Verfügbarkeiten an den betreffenden Standorten. Nährlösungsexperimente, die die primär bodenkundlichen Untersuchungen der vorliegenden Arbeit ergänzten, lassen unterschiedliche Effekte von $\mathrm{NO}_{3}{ }^{-}$und $\mathrm{NH}_{4}{ }^{+}$auf das Wachstum basiphiler/calcicoler und acidophiler/calcifuger Arten erkennen. Während Koeleria pyramidata offenbar eine deutliche Präferenz für $\mathrm{NO}_{3}{ }^{-}$besitzt und Potentilla neumanniana durch $\mathrm{NH}_{4}{ }^{+}$sogar geschädigt wird, hat die NForm keinen Einfluss auf die Entwicklung von Danthonia decumbens. Prinzipiell können fast alle Pflanzen $\mathrm{NO}_{3}{ }^{-}$nutzen. Die bodenkundlichen Untersuchungen haben gezeigt, dass die $\mathrm{N}_{\text {min }}$-Konzentrationen im 
Gentiano-Koelerietum typicum deutlich über denen des Gentiano-Koelerietum danthonietosum liegen. Dies gilt nicht nur für $\mathrm{NO}_{3}{ }^{-}$, sondern - bei allerdings sehr hohen zeitlichen und räumlichen Fluktuationen - auch für $\mathrm{NH}_{4}{ }^{+}$. Eine unzureichende N-Versorgung ist daher als Ursache für das Fehlen acidophiler/calcifuger Arten in den hier untersuchten Kalk-Halbtrockenrasen auszuschließen.

Indes kann die Form der Stickstoffernährung die pflanzliche Versorgung mit anderen Nährelementen entscheidend beeinflussen. Bekanntlich führt die Substitution von $\mathrm{NH}_{4}{ }^{+}$durch $\mathrm{NO}_{3}{ }^{-}$zu einem deutlichen Anstieg des Eisenbedarfs und zur Ausbildung charakteristischer Eisenmangelchlorosen. Dieser Effekt ist offenbar bei acidophilen/calcifugen stärker ausgeprägt als bei basiphilen/calcicolen Pflanzen. So deuten Nährlösungsexperimente an, dass die Fe-Versorgung von Danthonia decumbens durch $\mathrm{NO}_{3}{ }^{-}$-Ernährung besonders stark beeinträchtigt wird. Koeleria pyramidata erfährt in nitrathaltigen Nährlösungen bei 2,5 $\mu \mathrm{M}$ FeEDTA eine ausreichende Fe-Versorgung. Hingegen wird der Fe-Bedarf von Danthonia decumbens trotz geringerer Wachstumsraten auch bei der fünffachen Fe-Konzentration noch nicht gedeckt. Eisenmangel induziert verschiedene Reaktionen zur Steigerung der Fe-Mobilisierung, -Aufnahme und -Verwertung. Neben möglichen konstitutiven Unterschieden des Fe-Haushalts zeichnet wahrscheinlich der Umfang dieser Fe-Stressantworten für die abweichenden Grenzkonzentrationen suffizienter Fe-Ernährung acidophiler/calcifuger und basiphiler/calcicoler Taxa verantwortlich.

Nicht nur die N-, sondern auch die P-Ernährung steht in einer engen Beziehung zur pflanzlichen Fe-Versorgung. $\mathrm{NO}_{3}{ }^{-}$und $\mathrm{NH}_{4}{ }^{+}$beeinflussen v. a. über die mit den Membrantransportprozessen einhergehenden Verschiebungen des pH-Werts in der Rhizosphäre sowie im Wurzel- und Sprossapoplasten die Fe-Löslichkeit und das Fe-Verwertungsvermögen. Phosphor- und Eisenhaushalt sind hingegen über Reaktionen miteinander verbunden, die die Mobilisierung beider Elemente betreffen. Beispielsweise hat in alkalischen, kalkreichen Böden die Ausbildung von cluster roots bzw. Proteoidwurzeln und deren konzentrierte Exsudation organischer Säuren eine Verbesserung sowohl der pflanzlichen Fe- als auch P-Versorgung zur Folge. Die Fe-Löslichkeit findet um $\mathrm{pH} 8$ und somit im Pufferbereich des $\mathrm{HCO}_{3}{ }^{-} / \mathrm{CO}_{3}{ }^{2}$-Systems ihr absolutes Minimum. Gleichzeitig wird in Kalkböden die pflanzliche P-Verfügbarkeit durch die Ausfällung von Calciumphosphaten beeinträchtigt. Während aber die Fe-Konzentrationen der Bodenlösung mit zunehmender Acidität ansteigt und somit in sehr sauren Böden eher eine Fe-Intoxikation als Fe-Mangel droht, wird durch die Ausbildung schwer löslicher Al- und Fe-Phosphate die pflanzliche P-Ernährung auch bei niedrigen $\mathrm{pH}$-Werten behindert. Inwieweit sich acidophile/calcifuge und basiphile/calcicole Arten in ihrem Vermögen zur Verwertung der betreffenden anorganischen P-Fraktionen unterscheiden, wurde bisher nur am Rande untersucht. Experimentelle Arbeiten zur Überprüfung einer Hypothese, nach der das Pflanzenwachstum an Standorten mit neutraler oder alkalischer Bodenreaktion auf eine vermehrte Oxalat-Exsudation und eine daraus resultierende Steigerung der P-Mobilisierung zurückgeht, haben noch keine eindeutigen Ergebnisse erbracht. Unter bindungschemischen Gesichtspunkten erscheint indes auch die Plausibilität dieser Annahme fraglich. Denkbar ist ein verbreitungsspezifisches Verwertungsvermögen organischer P-Fraktionen. Hinweise auf ein abweichendes Muster der Abgabe saurer und alkalischer Phosphatasen durch Acidophile/Calcifuge und Basiphile/Calcicole liegen allerdings bisher nicht vor.

Da überdies die Analysen der vorliegenden Arbeit keine grundlegenden Unterschiede des P-Angebots in den Böden des Gentiano-Koelerietum typicum und Gentiano-Koelerietum danthonietosum erkennen lassen, weist Vieles darauf hin, dass die pflanzliche P-Versorgung nicht für die unterschiedliche Vegetationsdifferenzierung ausgesprochen saurer, kalkarmer und alkalischer, kalkreicher Standorte sowie die auffällige Vergesellschaftung basiphiler/calcicoler und acidophiler/calcifuger Arten in Kalk-Halbtrockenrasen verantwortlich zeichnet. 
Grundsätzlich sind die in beiden Subassoziationen sehr niedrigen N- und P-Konzentrationen solange als nur meso- und eutrophe Pflanzen ausschließende Faktoren zu betrachten, wie für Vertreter der beiden hier behandelten Verbreitungsgruppen keine gesicherten Erkenntnisse über ein abweichendes Verwertungsvermögen dieser Nährelemente unter den in Kalkböden vorherrschenden Milieubedingungen vorliegen. Nicht nur im Hinblick auf ihre in der Regel geringeren Trockenheitsresistenzen, sondern auch aufgrund der besonderen Bedeutung für die Mineralisierung organischer N-Verbindungen und die Verlagerung von $\mathrm{P}$ in die Rhizosphäre muss die Verbreitung schnellwüchsiger Pflanzen im Zusammenhang mit dem Bodenwassergehalt gesehen werden. Das vermehrte Auftreten mesophiler Arten im Gentiano-Koelerietum danthonietosum dürfte nicht zuletzt auf die relativ hohe Bodenfeuchte der betreffenden Standorte zurückzuführen sein.

Anders als im Fall von $\mathrm{P}$ und $\mathrm{NO}_{3}{ }^{-}$ist ein unterschiedliches Mobilisierungs- und Verwertungsvermögen acidophiler/calcifuger und basiphiler Taxa für Fe hinreichend belegt. Der in der Regel höhere Fe-Bedarf von Pflanzen mit Verbreitungsschwerpunkten auf sauren, basenarmen Böden hoher Fe-Löslichkeit findet sich in Übereinstimmung mit der Zusammensetzung von Bodenextrakten der beiden Subassoziationen des Gentiano-Koelerietum. Diesbezügliche Unterschiede lassen sich durch das schnelle Abpressen aufgesättigter Bodenmonolithe ungestörter Lagerung mit Hilfe von $\mathrm{N}_{2}$ (DBL) besonders gut abbilden. Aber auch Gleichgewichtsbodenlösungen feldfrischer Feinerdehomogenate (GBL), die weniger selektiv die Verhältnisse der für die Durchwurzelung und Mineralstoffernährung ausschlaggebenden Meso- und Makroporen aufzeigen und bei deren Herstellung offenbar eine weit reichende oxidative Ausfällung von $\mathrm{Fe}^{2+}$ erfolgen kann, belegen im Schnitt fünffach höhere Fe-Löslichkeiten der Böden des Gentiano-Koelerietum danthonietosum. Besonders wichtig für die Bewertung dieser Untersuchungsergebnisse ist, dass entsprechende Verhältnisse zwischen den beiden Subassoziationen auch bei gleichen $\mathrm{pH}$-Werten des Bodens vorliegen.

Als Folge der höheren Feinerde-Lagerungsdichten sowie der damit einhergehenden Beeinträchtigung der hydraulischen Leitfähigkeiten treten in den Böden des Gentiano-Koelerietum danthonietosum Wassergehalte und damit Diffusionsgeschwindigkeiten auf, die v. a. in Bereichen mit leicht abbaubarer organischer Substanz die reduktive Freisetzung von Fe(III) begünstigen. Der Einsatz von Ferrozine ${ }^{\circledR}$ als Extraktionsmittel erlaubt den selektiven Nachweis zweiwertiger Fe-Fraktionen.

Oxidoreduktive Zyklen verhindern die nachhaltige Stabilisierung von Fe-(Hydr)oxiden. Böden der CFBestände weisen daher signifikant höhere Gehalte des vergleichsweise labil gebundenen DTPA-, NTAund Oxalat-extrahierbaren Fe auf. Diese Fe(III)-Fraktionen dürften aufgrund ihrer Bindungseigenschaften von den Pflanzen recht gut verwertet werden. Während angesichts der geringeren Fe-Effizienz von Taxa acidophiler/calcifuger Konstitution die Fe-Löslichkeiten wohl im Zusammenhang mit deren Auftreten im Gentiano-Koelerietum danthonietosum stehen, geben die für dieselben Extraktionslösungen analysierten und in den beiden hier behandelten Subassoziationen des Gentiano-Koelerietum indifferent verteilten $\mathrm{Cu}-$, Mn- und Zn-Fraktionen keine Hinweise auf eine Bedeutung dieser Nährstoffe für die Vegetationsdifferenzierung der Kalk-Halbtrockenrasen.

\section{Palaeogeographische Aspekte der Evolution basiphiler/calcicoler und acidophiler/calcifuger Taxa}

Die floristische Prägung vieler Pflanzengesellschaften kann auf bestimmte palaeogeographische Entwicklungen zurückgeführt werden. Manche Autoren glauben, dass die Vergletscherung weiter Teile Europas im Pleistozän zu einer postglazialen Ausweitung des Areals alkalischer, kalkreicher Böden und diese zu einer frühzeitigen Diversifizierung basiphiler/calcicoler Pflanzen führte. Auch heute noch besitzen basen- 
reiche Standorte eine besonders große Phytodiversität auf. Erst die fortschreitende Bodenversauerung im Holozän soll mit einem vermehrten Auftreten acidophiler/calcifuger Physiotypen einhergegangen sein.

Anthropo-zoogene Faktoren, darunter v. a. solche, die sich aus spezifischen landwirtschaftlichen Nutzungsformen ergeben, bilden den Hintergrund für die Entwicklung der meisten Kalk-Halbtrockenrasen in Mitteleuropa. Die Etablierung von Acidophilen/Calcifugen in manchen dieser Vegetationsbestände hat zur Ausweisung des Gentiano-Koelerietum danthonietosum geführt. Bemerkenswerterweise gibt es auf der anderen Seite keine Beispiele für ein regelhaftes Auftreten basiphiler/calcicoler Arten an Standorten sehr saurer, basenarmer Böden. Angesichts der oben beschriebenen Entwicklungen ist nicht auszuschließen, dass den meisten basiphilen/calcicolen Pflanzen Toleranzmechanismen für die hier vorherrschenden Milieubedingungen fehlen, phylogenetisch die in Kalkböden erforderlichen Reaktionen der Mineralstoffeffizienz aber zur Grundausstattung aller Pflanzen gehören. In alkalischen, basenreichen Böden steht die Mobilisierung, Aufnahme und Verwertung essentieller Nährstoffe im Vordergrund. Hingegen sehen sich Pflanzen bei $\mathrm{pH}>$ 4,2 einem drastischen Anstieg der Al-Konzentrationen ausgesetzt, eines Elements, das für den Stoffwechsel der meisten Pflanzen nicht erforderlich ist, aber schwerwiegende Intoxikationen verursachen kann. Dieses Bild stimmt mit der Annahme überein, dass bei $\mathrm{pH}>5$ v. a. Konkurrenzmechanismen die Vegetationsdifferenzierung bestimmen (Jeffrey \& Pigott 1973a). In der Regel liegt hier eine negative Korrelation zwischen der Alpha-Diversität und der Nährstoffverfügbarkeit vor. Hingegen sind für die Artenzusammensetzung in Böden mit $\mathrm{pH}<5$ Intoxikationen nicht adaptierter Pflanzen verantwortlich.

\section{Artspezifische Ursachen des Auftretens von Acidophilen/Calcifugen im Gentiano-Koelerietum}

Im Rahmen kausalökologischer Untersuchungen muss vielfach von vereinfachenden Grundannahmen ausgegangen werden. Dazu gehört beispielsweise, dass die Eigenschaften aller Populationen und Individuen eines Taxons und somit die Determinanten ihres Wachstums einander entsprechen. In realen Ökosystemen ist dies nicht der Fall. Entsprechendes gilt um so mehr für verschiedene Spezies, auch wenn diese einer gemeinsamen Verbreitungsgruppe angehören. Multifaktorielle Analysen zum Auftreten von 110 Arten nicht gedüngter Wiesenstandorte in Südschweden haben gezeigt, dass offenbar ganz unterschiedliche Bodenfaktoren für die Etablierung der Pflanzen eine Rolle spielen (Tyler 2000). Das Wachstum der meisten Arten korreliert mit der Bodenreaktion, häufig aber in Kombination mit der Bewirtschaftungsweise und/oder der Exposition des Standorts.

Das Auftreten acidophiler/calcifuger Moose im Gentiano-Koelerietum danthonietosum dürfte aufgrund ihrer nur wenige Millimeter des Bodens erfassenden Rhizoide v. a. auf Versauerungen der obersten Substratschicht zurückzuführen sein. Anders als bei den tiefer wurzelnden Cormophyten sollten sich für Arten, wie Pleurozium schreberi, die Standorteigenschaften in den betreffenden Kalk-Halbtrockenrasen nicht wesentlich von denen etwa in Gesellschaften der Nardo-Callunetea unterscheiden.

Die zusammenfassende Betrachtung autökologischer und bodenkundlicher Arbeiten lässt darauf schließen, dass die Etablierung von Potentilla erecta an ein hohes Fe-Angebot gebunden ist. Im Heidegebiet der Glaner Braut, das als Teil der Wildeshausener Geest im Landkreis Oldenburg fluviatile Talsande der Weichsel-Kaltzeit (120.000-8.000 v. Chr.) aufweist, kommt die Art bei pH4,1 auch in sehr trockenen Bereichen vor. An basenreichen, alkalischen Standorten tritt P. erecta, wie Untersuchungen eines aufgekalkten Bodens über Buntsandstein im Bramwald westlich von Göttingen gezeigt haben, dort auf, wo die Bodenfeuchte und hohe Gehalte an organischem Material eine vermehrte reduktive Freisetzung und die Bildung löslicher Fe-Komplexe erlauben. Kennzeichnend für viele der basenreichen Standorte von $P$. erecta, so etwa die an der Steinkirche bei Scharzfeld im Südharz und im Bereich der tiefgründigen und 
feuchten Hangfüße der beiden Standorte Hölleberg und Auf der Burg im Unteren Diemeltal, ist das gemeinsame Auftreten mit Parnassia palustris, einer nässezeigenden, basiphilen/calcicolen Art.

Während bis heute keine autökologischen Unterschiede der Potentilla erecta-Populationen von Standorten abweichender Bodenreaktion bekannt sind, lässt die Vikarianz der beiden Unterarten von Danthonia decumbens auf eine ökophysiologische Differenzierung der Art schließen. An der Steinkirche tritt $D$. decumbens ssp. decipiens in hoher Dichte nicht nur im Gentiano-Koelerietum danthonietosum, sondern trotz der sehr hohen Carbonatgehalte, geringen Bodenaciditäten und begrenzten Fe-Löslichkeiten auch in der typischen Subassoziation auf. Dolomit ist in beiden Fällen das Ausgangsgestein der Pedogenese und zeichnet für die sehr hohen Mg-Gehalte der Bodenlösungen verantwortlich. Die Bodenanalysen weisen auf deutlich höhere Konzentrationen der meisten Mn- und Zn-Fraktionen sowie niedrigere Konzentrationen der labil gebundenen Cu-Fraktionen im Gentiano-Koelerietum typicum hin. Dies gilt nicht nur für die Kalk-Halbtrockenrasen an der Steinkirche, sondern auch auf für die aller anderen hier untersuchten Standorte. Inwieweit das Wachstum von $D$. decumbens ssp. decipiens in einem hinsichtlich der sonstigen Artenzusammensetzung typischen Gentiano-Koelerietum auf solche Mineralstoffrelationen zurückzuführen ist, muss angesichts der noch mangelhaften Kenntnis ihrer Autökologie offen bleiben.

\section{Mikrobielle Symbiosen}

Wenngleich die hydroponische Grenzkonzentration einer suffizienten Fe-Ernährung von D. decumbens ssp. decipiens die von Koeleria pyramidata deutlich übertrifft, belegt das Wachstum dieser Unterart an einigen sehr basenreichen und trockenen Standorten, dass sie unter bestimmten Umständen ihren FeBedarf auch aus Böden mit sehr niedrigen Fe-Löslichkeiten decken kann. Grundsätzlich sind bei der Bewertung von in vivo-Untersuchungen immer die komplexen Interaktionen der pflanzlichen Mineralstoffernährung in situ zu berücksichtigen. Einer der größten Nachteile von Nährlösungsuntersuchungen besteht darin, dass durch sie die Bedeutung mikrobieller Symbiosen nicht abgebildet werden kann. Dabei spielen diese für die Mineralstoffernährung der meisten Pflanzen am natürlichen Standort eine ausschlaggebende Rolle. Neben Reaktionen der pflanzlichen Mineralstoffeffizienz, deren Wirksamkeit ebenfalls in Nährlösungen, etwa infolge hoher Diffusionsgeschwindigkeiten, nur unzureichend zur Geltung kommt, können spezifische mikrobielle Symbiosen Einfluss auf die Vegetationsdifferenzierung nehmen. So ist es denkbar, dass unterschiedliche Infektionskompatibilitäten die Standortpräferenzen der beiden Unterarten von $D$. decumbens mitbestimmen.

Im Zusammenhang mit Untersuchungen zur Biodiversität und Vegetationsdifferenzierung wird seit einigen Jahren v. a. der (V)AM große Aufmerksamkeit geschenkt. Das Wachstum der meisten Ericaceae ist an die Ausbildung einer ecto-endotrophen Mycorrhiza gebunden. Das Auftreten von Calluna vulgaris in Kalk-Halbtrockenrasen könnte daher im Zusammenhang mit entsprechenden mikrobiellen Symbiosen stehen. In Annahme des Fehlens einer ökotypischen Differenzierung des Makrobionten ist nicht auszuschließen, dass alkalotolerante Stämme kompatibler Mykobionten die potenziell unzureichenden Mineralstoffeffizienzen und/oder -toleranzen von C. vulgaris in alkalischen, basenreichen Böden ausgleichen und damit die Grundlage für die Etablierung der Art im Gentiano-Koelerietum danthonietosum bilden. Erst mit fortschreitendem Wachstum und der damit einhergehenden Streuanreicherung können die bodenchemischen Eigenschaften des Standorts durch C. vulgaris selber beeinflusst und darüber die Standortvoraussetzungen zu eigenen Gunsten verbessert werden. Prinzipiell ist aber die Feststellung von Gimingham (1960) "It is unlikely that the calcifuge behaviour of Calluna is determined by any single factor ..." zu betonen und auf jede andere Art zu übertragen. 


\section{Quintessenzen und offene Fragen}

Unabhängig davon, ob mikrobielle Symbiosen am Auftreten acidophiler/calcifuger Pflanzen im GentianoKoelerietum beteiligt sind, können vergleichende bodenkundliche Untersuchungen Hinweise auf wichtige vegetationsdifferenzierende Faktoren eines Standorts geben. Welche der zahllosen abiotischen und biotischen Faktoren für die Standortpräferenzen eines Taxons von Bedeutung sind, lässt sich dabei um so besser eingrenzen, je größer die Kenntnis der jeweiligen pflanzlichen Autökologie ist.

Die eigenen Untersuchungen belegen, dass sich die Böden der beiden Subassoziationen des GentianoKoelerietum nicht nur in Bezug auf den Kalkgehalt, die Acidität und den Wasserhaushalt, sondern v.a. auch im Hinblick auf die Löslichkeit ihrer Fe-Fraktionen unterscheiden. Die Ergebnisse der am Rande der vorliegenden Arbeit durchgeführten Kulturversuche und die Untersuchungen anderer Autoren, verweisen zugleich darauf, dass acidophile/calcifuge Taxa in der Regel eine geringere Fe-Effizienz und einen höheren Fe-Bedarf besitzen als basiphile/calcicole. Das Auftreten von Pflanzen in Kalk-Halbtrockenrasen, deren Verbreitungsschwerpunkt eigentlich an Standorten saurer, kalk- bzw. basenarmer Böden liegt, ist daher v. a. im Zusammenhang mit vergleichsweise hohen Fe-Verfügbarkeiten zu sehen. Für keinen anderen Faktor lässt sich eine so Übereinstimmung zwischen den physiko-chemischen Bodeneigenschaften des Standorts und den ökophysiologischen Eigenschaften der hier wachsenden Pflanzen belegen.

Ungeachtet dessen, dass sich die hydroponischen Fe-Effizienzen vieler Pflanzen mit den Fe-Löslichkeiten in den Böden der angestammten Standorte decken, gibt es auch offene Fragen hinsichtlich einer diesbezüglichen Ursächlichkeit der Vegetationsdifferenzierung. Beispielsweise muss davon ausgegangen werden, dass als Folge verminderter Diffusionsraten eine besonders starke Anreicherung von $\mathrm{HCO}_{3}{ }^{-}$in der Rhizosphäre des Gentiano-Koelerietum danthonietosum erfolgt. Hydrogencarbonat ist für die Ausbildung sog. Schlechtwetterchlorosen an kalkreichen Standorten verantwortlich. Während diese Bedingungen also auf der einen Seite die Fe-Löslichkeit erhöhen, erschweren sie gleichzeitig die pflanzliche Fe-Aufnahme und Fe-Verwertung. Viele Aspekte der Kalkchlorose sind bis heute nicht geklärt. Möglicherweise existieren grundlegende Unterschiede zwischen Pflanzen, die bevorzugt in trockenen Kalkböden bzw. in verdichteten, feuchten Kalkböden wachsen. Inwieweit sich auch in dieser Hinsicht die typischen Pflanzen des Gentiano-Koelerietum von den acidophilen/calcifugen Taxa im Gentiano-Koelerietum danthonietosum unterscheiden, muss noch untersucht werden.

Die im Rahmen der vorliegenden Arbeit durchgeführten Nährlösungsversuche an $D$. decumbens ssp. decipiens sowie die vergleichenden Keimungsuntersuchungen und Festsubstratkulturen beider Subspezies sollten nur am Anfang einer sehr viel eingehenderen Bearbeitung dieser Art stehen. Aufgrund ihrer engen Verwandtschaft und außergewöhnlichen morphologischen Ähnlichkeit bieten die vikariierenden $D$. decumbens ssp. decipiens und $D$. decumbens ssp. decumbens hervorragende Möglichkeiten, neue Erkenntnisse über die spezifischen Mineralstoffeffizienzen und Mineralstofftoleranzen sowie deren Regulation bei acidophilen/calcifugen und basiphilen/calcicolen Pflanzen zu gewinnen.

Die Calcicolen/Calcifugen-Thematik wurde in den beiden vergangenen Jahrzehnten nur noch von sehr wenigen Arbeitsgruppen verfolgt. Viele Fragen, die mit den in dieser Zeit entwickelten Methoden untersucht werden könnten, wurden bisher noch nicht behandelt. So bieten neue molekularbiologische Techniken die Möglichkeit, einer gezielteren Analyse von mikrobiellen Symbiosen. Insbesondere das Fehlen der regulären Mykorrhizierung, aber auch sonstiger Wurzelassoziationen zeichnet dafür verantwortlich, dass viele Kulturversuche und hier v. a. solche in Nährlösungen nur bedingt Aussagen über die Ursachen der pflanzenspezifischen Standortpräferenzen zulassen. Es ist daher notwendig, diese Aspekte künftig auch im Calcicolen/Calcifugen-Komplex stärker zu berücksichtigen. Auf der anderen Seite verwundert es 
angesichts der in vielen Fällen herausragenden Bedeutung der Mykorrhiza für die Mineralstoffernährung und die Wasserversorgung sowie die Immobilisierung und den Abbau phytotoxischer Elemente bzw. Verbindungen, dass Taxa, die grundsätzlich keine Mykorrhiza ausbilden, nicht viel häufiger für grundlegende Untersuchungen des diesbezüglichen Leistungsvermögens der Pflanzen selber herangezogen werden.

Der Lösung ökologischer Fragestellungen sind vielfach nicht nur durch die außergewöhnliche Komplexität ökologischer Systeme, sondern auch heute noch durch das Fehlen geeigneter Untersuchungsverfahren Grenzen gesetzt. Besonders wichtig erscheint in diesem Zusammenhang die Entwicklung von Methoden, mit Hilfe derer die räumlichen und zeitlichen Heterogenitäten im Boden und v. a. in der Rhizosphäre besser abgebildet werden können. Ein Nachteil vieler Verfahren besteht zudem darin, dass sie selber die zu untersuchenden Faktoren beeinflussen. Beispielsweise droht bei wässrigen Bodenextraktionen eine oxidative Immobilisierung von $\mathrm{Fe}^{2+}$, das aufgrund der hohen Wurzelexsudatkonzentrationen v. a. in der Rhizosphäre gebildet werden kann. Die $\mathrm{HCO}_{3}{ }^{-}$-Gehalte der Bodenlösung werden durch die Gleichgewichtsreaktionen des Kohlensäuresystems bestimmt. Veränderungen des $\mathrm{CO}_{2}$-Partialdrucks, wie sie bei der Bodenextraktion praktisch unausweichlich sind, gehen demnach mit Veränderungen der $\mathrm{HCO}_{3}^{-}$Lösung einher. Eine besondere Herausforderung ist demnach die Entwicklung von Methoden, die derartige Versuchsartefakte berücksichtigen und wo möglich ausschließen. Dies bezieht sich auf räumlich vergleichsweise unspezifische Ansätze, wie beispielsweise die Untersuchung der Redoxdynamik im gesamten Bodenraum (Glinski et al. 1996; Uhlig et al. 2002), mehr noch aber auf solche, die sich speziell auf die Rhizosphäre beziehen (Schöttelndreier \& Falkengren-Grerup 1999).

Im Rahmen der vorliegenden Arbeit wurde durch die Extraktion von Monolithen intakter Bodentextur versucht, die Bodenlösung der Makro- und Mesoporen zu gewinnen und damit diejenigen Nährstofffraktionen nachzuweisen, die der Aufnahme durch die Wurzeln unmittelbar zur Verfügung stehen. Gleichzeitig dienten Schüttelungen feldfrischer Feinerdehomogenate mit verschiedenen Extraktionsmitteln der Charakterisierung des Fe- und P-Angebots. Indes wurde die Pflanzenverfügbarkeit dieser speziellen Fraktionen bisher nur unzureichend überprüft. Ihre Bedeutung für die pflanzliche Mineralstoffernährung und die Vegetationsdifferenzierung kann daher in vielen Fällen nur auf theoretischer Grundlage abgeschätzt werden. Mit Hilfe von Nährlösungs- und Festsubstratkulturen sollte daher die Relevanz dieser und anderer Nährstofffraktionen für die pflanzliche Mineralstoffernährung näher untersucht werden.

Untersuchungsansätze, die gezielt die komplexen zeitlichen und räumlichen Interaktionen zwischen verschiedenen abiotischen und biotischen Faktoren in situ berücksichtigen, eröffnen kausalökologischen Ökosystemanalysen besondere Perspektiven. Im Zusammenhang mit den eigenen bodenkundlichen Untersuchungen wurde eine Vielzahl aut- und synökologischer sowie palaeogeographischer und anthropogener Aspekte im Hinblick auf ihre Bedeutung für die Vegetationsdifferenzierung des GentianoKoelerietum und den Calcicolen/Calcifugen-Komplex behandelt. Die verstärkte Zusammenarbeit von Vertretern verschiedener Disziplinen würde eine noch detailliertere und effizientere Behandlung dieser und anderer biologischer Fragestellungen erlauben und damit eine allgemeingültige Quintessenz aufgreifen, die Jones et al. (2004) aus seinen Untersuchungen zum Einfluss der Wurzelexsudation auf das pflanzliche Mineralstoffmobilisierung- und detoxifizierungsvermögen zieht:

Working in isolation can still advance the field, however, the biggest advances will be made when scientific fields are integrated. 
Die vorliegende Arbeit behandelt die Frage nach den ausschlaggebenden Faktoren für die Vegetationsdifferenzierung von Standorten alkalischer, kalkreicher und saurer, kalkarmer Böden. Hierfür wurden vergleichende Untersuchungen zweier Subassoziationen des in Mitteleuropa einstmals weit verbreiteten, anthropo-zoogen geprägten Gentiano-Koelerietum durchgeführt. In der typischen Subassoziation dieser Kalk-Halbtrockenrasen sind v. a. basiphile/calcicole Pflanzen miteinander vergesellschaftet. Neben Vertretern dieser Gruppe wachsen im Gentiano-Koelerietum danthonietosum mit der namengebenden Danthonia decumbens sowie Calluna vulgaris und Potentilla erecta Differentialarten, denen acidophile/ calcifuge Eigenschaften zugeschrieben werden. Darüber hinaus sind hier mesophile Arten am Aufbau der Vegetation beteiligt.

Den experimentellen Untersuchungen dienten vier Standorte im Unteren Diemeltal und zwei Standorte am Südharzrand. Im erstgenannten Untersuchungsgebiet sind Calcite aus dem Oberen Muschelkalk, in letzterem Dolomite aus dem Zechstein das Ausgangsmaterial der Bodenbildung. An jedem dieser Standorte finden sich unmittelbar benachbart und damit unter gleichen geologisch-geographischen Rahmenbedingungen Bestände der beiden Subassoziationen des Gentiano-Koelerietum. Mit Hilfe pflanzensoziologischer Untersuchungen nach Braun-Blanquet sowie numerischer Verfahren nach Sørensen und Digby \& Kempton wurde die floristische Differenzierung der Vergleichsbestände insbesondere im Hinblick auf die Verteilung basiphiler/calcicoler und acidophiler/calcifuger Taxa analysiert. Für die bodenkundliche Charakterisierung der Standorte kamen neben etablierten verschiedene neu entwickelte Extraktionsmethoden zum Einsatz, deren räumliche bzw. chemische Selektivität eine gezieltere Betrachtung solcher Fraktionen erlaubt, die für die Mineralstoffernährung und die potenzielle Intoxikation der Pflanzen von besonderem Interesse sind. An zwei der Kalk-Halbtrockenrasen des Unteren Diemeltals wurde durch regelmäßige Untersuchungen wässriger Extrakte von Feinerdehomogenaten und Monolithen intakter Bodenstruktur die Entwicklung des Bodenchemismus im Jahresverlauf untersucht. Bodenmaterial dieser Referenzstandorte diente außerdem verschiedenen Versuchsansätzen, die Hinweise auf die Redox- und Bindungseigenschaften der Böden beider Subassoziationen geben sollten. Angesichts ihrer umstrittenen Bedeutung als primär das Wachstum in alkalischen, basenreichen Böden limitierende Faktoren standen hierbei die pflanzlichen Fe- und P-Verfügbarkeiten im Mittelpunkt der Untersuchungen. Keimungs- und Wachstumsexperimente an ausgewählten Acidophilen/Calcifugen und Basiphilen/Calcicolen ergänzten die standortökologischen Analysen. In die Diskussion der experimentellen Untersuchungen wurden weitere autökologische und synökologische sowie palaeogeographische und evolutionsbiologische Aspekte einbezogen. Schließlich wurde eingehend die mögliche Bedeutung mikrobieller Symbiosen für die Vegetationsdifferenzierung behandelt.

Bodenkundliche Untersuchungen aller Versuchsbestände bestätigten einige der in der vegetationskundlichen Literatur beschriebenen, in der Regel aber experimentell nicht überprüften Unterschiede der beiden Subassoziationen. Mit einer Ausnahme finden sich an allen Standorten mehr oder weniger flachgründige Rendzinen. Tiefere Bodengründigkeiten, niedrigere Kalkgehalte der Feinerde sowie die Struktur und der Anteil des Skettmaterials im $\mathrm{A}_{\mathrm{h}}$-Horizont lassen darauf schließen, dass auch aufgrund einen geringeren Inklination die Bodenentwicklung der Standorte des Gentiano-Koelerietum danthonietosum weiter vorangeschritten ist. Die aktuellen Aziditäten in Feinerdehomogenaten der oberen $10 \mathrm{~cm}$ der Böden liegen in allen Beständen des Gentiano-Koelerietum typicum zwischen $\mathrm{pH}$ 7,5 und pH 8,0. Messungen für die Subassoziation von Danthonia decumbens bestätigten, dass in vielen Fällen das Auftreten acidophiler/ 
calcifuger Arten mit einer Basenverarmung der Böden einhergeht. Allerdings wird auch hier der $\mathrm{pH}$ in nur zwei Fällen nicht mehr primär durch Carbonate, sondern durch Silikate gepuffert. Die Feinerde des Gentiano-Koelerietum typicum der beiden Referenzstandorte besitzt mit einem durchschnittlichen Wert von 17,5 mmol $_{\mathrm{c}} / 100 \mathrm{~g}$ um etwa $13 \%$ höhere effektive Kationenaustauscherkapazitäten als die der Vergleichsbestände. In beiden Fällen erreicht die Basensättigung der Böden fast 100 \%. Auch die Korngrößenverteilung des Feinerdematerials beider Subassoziationen weist keine nennenswerten Unterschiede auf. In allen Versuchsbeständen bestimmen hohe bis sehr hohe Schluffgehalte die Bodenart. Besonders umfangreiche Lösseinträge, die von verschiedenen Autoren für die Etablierung acidophiler/calcifuger Arten in Kalk-Halbtrockenrasen verantwortlich gemacht werden, konnten für das Gentiano-Koelerietum danthonietosum nicht nachgewiesen werden. Untersuchungen der Referenzbestände ließen bei allgemein sehr niedrigen effektiven Lagerungsdichten $\left(<1,4 \mathrm{~kg} \cdot \mathrm{l}^{-1}\right)$ geringere Porenvolumina und im Jahresschnitt mehr als $15 \%$ (V/V) höhere Wassergehalte in der Feinerde dieser Subassoziation erkennen. Das abweichende Bodengefüge der Gesellschaften bestätigen auch die hydraulischen Leitfähigkeiten der Bodenmonolithe.

In den Böden beider Subassoziationen, insbesondere aber in denen des Gentiano-Koelerietum typicum wurden sehr enge $C_{0} / \mathrm{N}$-Verhältnisse $(11,8$ vs. 12,7$)$ vorgefunden. Die Feinerde der typischen Subassoziation ist auf der einen Seite durch höhere organische Kohlenstoffgehalte (TOC) und höhere Stickstoffgehalte (TON), auf der anderen Seite durch niedrigere organische Kohlenstoffkonzentrationen in ihren wässrigen Bodenextrakten (DOC) gekennzeichnet. Es ist davon auszugehen, dass diese Relationen durch die Beeinträchtigung der mikrobiellen Mineralisierung infolge einer temporär besonders ausgeprägten Bodentrockenheit, möglicherweise außerdem durch höhere feinerdebezogene Biomasseeinträge im Gentiano-Koelerietum typicum verursacht werden.

Die meisten chemoedaphischen Untersuchungen gehen mit der Zerstörung des natürlichen Bodengefüges einher. Theoretisch enthalten Gleichgewichtsbodenlösungen (GBL), die durch die eintägige Schüttelung aufgesättigter feldfrischer Feinerdehomogenate gewonnen werden, auch Mineralstofffraktionen, die für die Ernährung der Pflanzen in situ nicht oder nur bedingt zur Verfügung stehen. Aus diesem Grund wurden zwei Verfahren entwickelt, die eine gezielte Extraktion des von den Pflanzen durchwurzelten Makroporensystems erlauben sollten. Für die Herstellung sogenannter Perkolationsgleichgewichtsbodenlösungen (PBL) erfolgte unter Einstellung definierter Feinerde/Lösungs-Verhältnisse eine eintägige zyklische Perkolation feldfrischer Bodenmonolithe. Druckbodenlösungen (DBL) wurden nach Zusatz entsprechender $\mathrm{H}_{2} \mathrm{O}$-Volumina durch das sofortige Anlegen eines Überdrucks von bis zu $1 \mathrm{MPa}$ gewonnen. Die Verwendung von $\mathrm{N}_{2}$ für den Druckaufbau diente hier der Minimierung oxidativer Umsetzungen. Theoretisch können durch das DBL-Verfahren Extrakte gewonnen werden, die unter Berücksichtigung der Aufsättigungsvolumina und der ursprünglichen Wassergehalte der Proben die Zusammensetzung der in situLösungen in den Grobporen widerspiegeln. Konzeptionell lassen sich also durch vergleichende Untersuchungen dieser Extrakte Unterschiede zwischen verschiedenen Bodenbereichen (GBL vs. PBL) sowie solche der aktuellen und der potenziellen, gleichgewichtsbezogenen Zusammensetzung der Bodenlösung im Makroporensystem (DBL vs. PBL) analysieren. In einigen Fällen wurden die hier formulierten Annahmen bestätigt. Während mit Hilfe des Drucklösungsverfahrens die oxidative Fe-Immobilisierung während der Bodenextraktion minimiert und darüber die bessere Fe-Verfügbarkeit im Gentiano-Koelerietum danthonietosum verdeutlicht wurde, zeigten die $\mathrm{Ca}^{2+}$-Konzentrationen der GBL und PBL, dass v. a. durch die zyklische Perkolation von Monolithen mit intaktem Aggregatgefüge die fortgeschrittene Entbasung des Bodenmaterials dieser Subassoziation abgebildet werden kann. 
Die Analysen wässriger Bodenextrakte der Referenzbestände gaben für die meisten Mineralstoffe keine Hinweise auf eine jahreszeitliche Abhängigkeit ihrer Lösungskonzentrationen. Keines der hier erörterten Extraktionsverfahren ist für die Aufdeckung der zeitlichen und räumlichen Variabilitäten aller Analyte prädestiniert. In der Regel stimmen die Konzentrationsverhältnisse der einzelnen Mineralstoffe zwischen den Vergleichsbeständen des Gentiano-Koelerietum typicum und Gentiano-Koelerietum danthonietosum eines Standorts unabhängig vom Extraktionsverfahren überein, so dass der ungleich höhere Versuchsaufwand für die Herstellung von Bodenmonolithenlösungen nur in Ausnahmefällen gerechtfertigt erscheint.

Von den in den GBL analysierten Pflanzennährstoffen Ca, Mg, K, Fe, $\mathrm{Mn}, \mathrm{NH}_{4}{ }^{+}$sowie $\mathrm{NO}_{3}{ }^{-}, \mathrm{NO}_{2}^{-}$und $\mathrm{SO}_{4}{ }^{2-}$ weisen lediglich Nitrat und Eisen für alle Kalk-Halbtrockenrasen gleichgerichtete Lösungsverhältnisse zwischen den Vergleichsbeständen auf. Es darf daher davon ausgegangen werden, dass die anderen Analyte allenfalls eine untergeordnete oder indirekte Rolle für die Differenzierung der beiden Subassoziationen spielen. Bei großen Abweichungen der absoluten Gehalte von Standort zu Standort übertreffen die $\mathrm{NO}_{3}{ }^{-}$-Konzentrationen in der Feinerde des Gentiano-Koelerietum typicum diejenigen der Subassoziation von Danthonia decumbens im Mittel um einen Faktor 25. Die Fe-Löslichkeiten liegen im Gentiano-Koelerietum danthonietosum mehr als das Fünffache über denen in der typischen Subassoziation. Bei gegebenen pH-Werten ist das Auftreten acidophiler/calcifuger Arten an eine bessere Fe-Verfügbarkeit gebunden. So wiesen Bodenextrakte des Gentiano-Koelerietum typicum im Bereich der minimalen Löslichkeit anorganischer Fe-Fraktionen zwischen $\mathrm{pH}$ 7,4 und pH 8,5 mit 0,58 $\mu \mathrm{M}$ etwa 50 \% geringere Fe-Konzentrationen auf als solche des Gentiano-Koelerietum danthonietosum. Möglicherweise spielen in diesem Zusammenhang höhere DOC in den Bodenlösungen der Subassoziation von D. decumbens eine Rolle. Werden die abweichenden Skelettanteile der Böden berücksichtigt und somit die Fe-Konzentrationen der Extrakte auf das Gesamtvolumen der Böden bezogen, wird dieses Verhältnis zwischen den beiden Subassoziationen noch verdeutlicht.

Nicht sequentielle Fe-Fraktionierungen feldfrischer Feinerdehomogenate mit DTPA-, NTA-, Ammoniumoxalat- und Dithionit-Lösungen bestätigten diese Ergebnisse. Die Cu-, Mn- und Zn-Konzentrationen der Extrakte ließen hingegen keine systematischen Unterschiede zwischen den Vergleichsbeständen erkennen. Je besser die Löslichkeit und damit die Pflanzenverfügbarkeit der betreffenden Fe-Fraktionen ist, desto stärker differenzieren sie die beiden Subassoziationen des Gentiano-Koelerietum. Untersuchungen, in denen Feinerdehomogenate eines Referenzstandorts mit EDTA- und EDDHA-Lösungen definierter Fe-Konzentrationen versetzt wurden, verwiesen auf ein hohes Fe-Immobilisierungsvermögen des Substrats der typischen Subassoziation.

Als besonders geeignet für den Nachweis von Fe(II) erwies sich das im Rahmen der vorliegenden Arbeit entwickelte Verfahren zur Extraktion feldfrischer Feinerdehomogenate mit dem $\mathrm{Fe}^{2+}$-spezifischen Komplexbildner Ferrozine ${ }^{\circledR}$. Mehr als vierfach höhere Fe(II)-Konzentrationen lassen auf eine umfangreichere Fe(III)-Reduktion und eine vermehrte Lösung von mineralischem Fe(II) in Bodenmaterial des GentianoKoelerietum danthonietosum schließen. Die höheren Lagerungsdichten und Wassergehalte sowie die geringeren TOC- und die höheren DOC-Konzentrationen der betreffenden Böden finden sich hiermit in Übereinstimmung. Auch Inkubationsversuche an aufgesättigten Bodenmonolithen bestätigten letztlich das Bild einer höheren oxidoreduktiven Aktivität in den Böden der Subassoziation von Danthonia decumbens. Unter Wassersättigung wurde aufgrund der höheren TOC-Konzentrationen im Bodenmaterial des Gentiano-Koelerietum typicum zwar vergleichsweise mehr Fe gelöst, doch schritt die Entwässerung dieser Bodenproben sehr viel schneller voran, so dass hier eine umgehende oxidative Fe-Immobilisierung erfolgte. Dieses Entwässerungsverhalten dürfte zu entsprechenden Fe-Verfügbarkeiten in situ führen. 
Sequentielle P-Extraktionen lufttrockener Feinerdehomogenate der Referenzbestände mit Hilfe eines Anionenaustauscherharzes sowie $\mathrm{NaHCO}_{3}-\mathrm{NaOH}$ - und $\mathrm{HCl}$-Lösungen gaben keine Hinweise darauf, dass der Ausschluss acidophiler/calcifuger Arten von basischen, kalkreichen Standorten auf eine unzureichende P-Versorgung zurückzuführen ist. Die höheren HCl-extrahierbaren P-Konzentrationen im Gentiano-Koelerietum typicum korrelieren mit den Kalkgehalten der Böden und beziehen sich auf Apatite, die für die pflanzliche P-Ernährung eine geringe Bedeutung haben. Indifferente Verhältnisse der pflanzlichen P-Verfügbarkeiten zwischen den Vergleichsbeständen, wie sie die anderen, besser löslichen P-Fraktionen erkennen lassen, wurden durch die GBL der Vergleichsstandorte bestätigt.

Aussaaten von Koeleria pyramidata und Potentilla neumanniana als typische Vertreter der Kalk-Halbtrockenrasen sowie von Danthonia decumbens und Potentilla erecta als Differentialarten des GentianoKoelerietum danthonietosum in Bodenmonolithen beider Subassoziationen gaben keine eindeutigen Hinweise darauf, dass deren abweichenden chemoedaphischen Eigenschaften den Keimungserfolg dieser Arten beeinflussen. In dieser Hinsicht weisen auch Populationen von D. decumbens und P. erecta alkalischer, kalkreicher und saurer, basenarmer Standorte keine signifikanten Unterschiede auf. Das Taxon D. decumbens umfasst mit der tetraploiden $D$. decumbens ssp. decipiens und der hexaploiden D. decumbens ssp. decumbens zwei standörtlich vikariierende Unterarten. Bisher wurde dies in keiner anderen Arbeit zur Calcicolen/Calcifugen-Thematik berücksichtigt. Da die erstgenannte Unterart ihren Verbreitungsschwerpunkt an basischen, kalkreichen Standorten findet, ist die Art also nicht grundsätzlich als acidophil/calcifug zu betrachten. Als einziges Taxon der Kulturversuche zeigte D. decumbens ssp. decumbens ein signifikant schlechteres Wachstum in den Bodenmonolithen des Gentiano-Koelerietum typicum. In der Tendenz galt dies aber auch für D. decumbens ssp. decipiens. Obwohl die Fe-Konzentrationen infolge hoher Wassergehalte zeitweilig recht hohe Werte erreichten, bildeten Pflanzen beider Unterarten in Bodenmaterial des Gentiano-Koelerietum typicum und des Gentiano-Koelerietum danthonietosum starke Chlorosen aus.

Nährlösungsuntersuchungen zeigten, dass $\mathrm{NO}_{3}{ }^{-}$die Fe-Ernährung von $D$. decumbens ssp. decipiens erheblich beeinträchtigt. Während Koeleria pyramidata in nitrathaltigen Nährlösungen bereits bei 2,5 $\mu \mathrm{M}$ FeEDTA eine suffiziente Fe-Versorgung erfährt, wird der Bedarf von D. decumbens ssp. decipiens trotz insgesamt deutlich niedrigerer Wachstumsraten auch bei einem fünffachen Fe-Angebot noch nicht gedeckt. Diesbezüglich offene Fragen im Calcicolen/Calcifugen-Komplex, etwa die nach der Bedeutung von Hydrogencarbonat und $\mathrm{NO}_{3}{ }^{-}$sowie die nach der Bedeutung mikrobieller Symbiosen für die FeErnährung und die Vegetationsdifferenzierung werden in der vorliegenden Arbeit eingehend diskutiert.

Unter Berücksichtigung der in der Regel abweichenden Fe-Effizienzen von Vertretern der acidophilen/ calcifugen und basiphilen/calcicolen Verbreitungs- und Konstitutionsgruppen stimmen die Ergebnisse der bodenkundlichen Analysen mit der Hypothese einer unzureichenden Fe-Versorgung acidophiler/calcifuger Taxa an Standorten besonders alkalischer, kalkreicher und trockener Böden überein. Hingegen konnten keine Hinweise auf eine Beziehung zwischen dem Auftreten acidophiler/calcifuger Pflanzen in KalkHalbtrockenrasen und der P-Löslichkeit gefunden werden. Da zudem standortspezifische P- und N-Effizienzen der in gleicher Weise oligotrophen Acidophilen/Calcifugen und Basiphilen/Calcicolen nicht ausreichend belegt sind, muss davon ausgegangen werden, dass die Versorgung der Pflanzen mit diesen Makronährstoffen für die Vegetationsdifferenzierung des Gentiano-Koelerietum danthonietosum allenfalls eine untergeordnete, indirekte Rolle spielt. 

Literatur 
AARSEN W.I. (1983): Ecological combining ability and competitive combining ability in plants: towards a general evolutionary theory of coexistence in systems of competition. Am. Nat. 122: 707-731.

Aber J.D., NADelhoffer K.J., STeudler P., Melillo J.M. (1989): Nitrogen saturation in northern forest ecosystems. Bioscience 39: 378-386.

Adams F., Burmester C., Hue N.V., Long F.L. (1980): A comparison of column-displacement and centrifuge methods for obtaining soil solutions. Soil Sci. Soc. Am. J. 44: 733-735.

AdANi F., GeneVini P., Zaccheo P., Zocchi G. (1998): The effect of commercial humic acid on tomato plant growth and mineral nutrition. J. Plant Nutr. 21: 571-575.

AE N., OTANI T. (1997): The role of cell wall components from groundnut roots in solubilizing sparingly soluble phosphorus in low fertility soils. Plant Soil 196: 265-270.

Ae N., OtAni T., Makino T., TAZAWA J. (1996): Role of cell wall of groundnut roots in solubilizing sparingly soluble phosphorus in soil. Plant Soil 186: 197-204.

AERTS R., BERENDSE F. (1988): The effects of increased nutrient availability on vegetation dynamics in wet heathlands. Vegetatio 76: 63-69.

Aerts R., Berendse F., DeCaluWe H., Schmitz M. (1990): Competition in heathland along an experimental gradient of nutrient availability. Oikos 57: 310-318.

Aerts R., WALlen B., MALmer N. (1992): Growth limiting nutrients in Sphagnum-dominated bogs subjected to low and high atmospheric nitrogen supply. J. Ecol. 80: 131-140.

AG BODEN (1994): Bodenkundliche Kartieranleitung. 4. verb., erw. Auflage. Schweizerbart'sche Verlagsbuchhandlung, Stuttgart: $392 \mathrm{~S}$.

AKeson M., Munns D., BuRAu R.G. (1989): Adsorption of $\mathrm{Al}^{3+}$ to phosphatidylcholin vesicles. Biochim. Biophys. Acta 986: 33-40.

AL-KARAKI G.-N., AL-RADDAD A. (1997): Effects of arbuscular mycorrhizal fungi and drought stress on growth and nutrient uptake of two wheat genotypes differing in drought resistance. Mycorrhiza 7: 83-88.

AL-Mufti M.M., WALl C.L., FuRneSS S.B., GRIME J.P., BAND S.R. (1977): A quantitative analysis of shoot phenology and dominance in herbaceous vegetation. J. Ecol. 65: 759-791.

ALBRECHT E. (1998): Exkursion in das NSG "Stahlberg und Hölleberg" bei Deisel. Jahrbuch Naturschutz in Hessen 3: 242-245.

AlCANTARA E., DE LA GuARDiA M.D., Romera F.J. (1991): Plasmalemma redox activity and $\mathrm{H}^{+}$-extrusion in roots of Fe-deficient cucumber plants. Plant Physiol. 96: 1034-1037.

AlhendaWi R.A., Römheld V., KiRKBy E.A., MARSCHNeR H. (1997): Influence of increasing bicarbonate concentrations on plant growth, organic acid accumulation in roots and iron uptake by barley, sorghum, and maize. J. Plant Nutr. 20: 1731-1753.

ALLISON V.J., GoldBeRg D.E. (2002): Species-level versus community-level patterns of mycorrhizal dependence on phosphorus: an example of Simpson's paradox. Funct. Ecol. 16: 346-352.

Alva A.K., Sumner M.E., Miller W.P. (1991): Relationship between ionic strength and electrical conductivity of soil solutions. Soil Sci. 152: 239-242.

AMER F., BOULdin D.R., BLACK C.A., DUKE F.R. (1955): Characterisation of soil phosphorus by anion exchange resin absorption and ${ }^{32} \mathrm{P}$ equilibration. Plant Soil 6: 391-408. 
ANIOL A. (1994): Induction of aluminum tolerance in wheat seedlings by low doses of aluminum in the nutrient solution. Plant Physiol. 123: 223-227.

Arahou M., Diem H.G. (1997): Iron deficiency induces cluster (proteoid) root formation in Casuarina glauca. Plant Soil 196: 71-79.

AUGSPURGER C.K. (1990): Spatial patterns of damping-off disease during seedling recruitment in tropical forests. In: Burdon J.J., Leather S.R. (Eds.): Pests, Pathogens and Plant Communities. Blackwell Scientific Publications, Oxford: 131-144.

BAAS BeCking L.G.N., KAPLAN I.R., MooRe D. (1960): Limits of the natural environment in terms of pH and oxidation reduction potentials. J. Geol. 68: 243-284.

BACHE B.W. (1984): The role of calcium in buffering soils. Plant Cell Environ. 7: 391-395.

BACKhaus K., ERIChSON B., PLINKe W., Weiber R. (1994): Multivariate Analysemethoden. 7. Auflage. Springer, Berlin: $594 \mathrm{~S}$.

BAKER H. (1937): Alluvial meadows: a comparative study of grazed and mown meadows. J. Ecol. 25: 408-420.

BALME O.E. (1953): Edaphic and vegetational zoning on the Carboniferous limestone of the Derbyshire Dales. J. Ecol. 41: 331-344.

BANGERTH F. (1979): Calcium-related physiological disorders of plants. Annu. Rev. Phytopathol. 17: 97-122.

BANNISTER P. (1964a): The water relations of certain heath plants with reference to their ecological amplitude. I. Introduction: Germination and establishment. J. Ecol. 52: 423-432.

BANNISTER P. (1964b): The water relations of certain heath plants with reference to their ecological amplitude. II. Field studies. J. Ecol. 52: 481-497.

BANNISTER P. (1964c): The water relations of certain heath plants with reference to their ecological amplitude. III. Experimental studies: General conclusions. J. Ecol. 52: 499-509.

BAR-Ness E., CHEN Y. (1991a): Manure and peat based iron-organo complexes. I. Characterization and enrichment. Plant Soil 130: 35-43.

BAR-Ness E., CHEN Y. (1991b): Manure and peat based iron-organo complexes. II. Transport in soils. Plant Soil 130: 45-50.

Bar-Ness E., Chen Y., HAdaR Y., MARschner H., Römheld V. (1991): Siderophores of Pseudomonas putida as an iron source for dicot and monocot plants. Plant Soil 130: 231-241.

Barbaro L., Corcket E., Dutoit T., Peltier J.-P. (2000): Résponses functionelles des communautés de pelouses calcicoles aux facteurs agro-écologiques dans les Préalpes francaises. Can. J. Bot. 78: 1010-1020.

BARBER D.A., GUNN K.B. (1974): The effect of mechanical forces on the exudation of organic substances by the roots of cereal plants grown under sterile conditions. New Phyt. 73: 39-45.

BARROW N.J. (1983): On the reversibility of phosphorus sorption of soils. J. Soil Sci. 34: 751-758.

BARTLETT R.J., RIEgo D.C. (1972): Effect of chelation on the toxicity of aluminium. Plant Soil 37: 419-423.

BATTMER C. (1999): Der Einfluß von Phosphor und Eisen auf das Pflanzenwachstum auf Kalkmagerrasenstandorten. Diplomarbeit, Universität Göttingen, $109 \mathrm{~S}$.

BAVARESCO L., FOGHER C. (1996): Lime-chlorosis occurence and leaf mineral composition of grapevine treated by microorganisms. J. Plant Nutr. 19: 87-98. 
BAVARESCo L., GiACHino E., Colla R. (1999): Iron chlorosis paradox in grapevine.

J. Plant Nutr. 22: 1589-1597.

BeCKett P.H.T., WebSTER R. (1971): Soil variability: A review. Soils Fertilizers 34: 1-15.

BedRI A.A., WALLACE A., RHOAdS W.A. (1960): Assimilation of bicarbonate by roots of different plant species. Soil Sci. 89: 257-263.

Begon M., HARPer J.L., TownSend C.R. (1996): Ecology. Third Edition. Blackwell, Oxford: 1068 S.

BEINLICH B. (1997): Die Bedeutung der Hüteschäferei für Erhalt und Pflege der Kalkmagerrasen. J. Agric. Sci. 2: 45-52.

BenNetT A.C., AdAms F. (1970): Calcium deficiency and ammonia toxicity as separate causal factors of $\left(\mathrm{NH}_{4}\right)_{2} \mathrm{HPO}_{4}$ injury to seedlings. Soil Sci. Soc. Am. Proc. 34: 255-259.

Benz M., SChNIK B., BRUNe A. (1998): Humic acid reduction by Propionibacterium freudenreichii and other fermenting bacteria. Appl. Environ. Microbiol. 64: 4507-4512.

BERENDSE F., OUdHOF H., Bol J. (1987): A comparative study on nutrient cycling in wet heathland ecosystems. I. Litter production and nutrient losses from the plant. Oecologia 74: 174-184.

BERGMANN W. (1988): Ernährungsstörungen bei Kulturpflanzen. 2. Auflage. Fischer, Stuttgart: 762 S.

BERGMEIER E. (1987): Magerrasen und Therophytenfluren im NSG "Wacholderheiden bei Niederlemp" (Lahn-Dill-Kreis, Hessen). Tuexenia 7: 267-293.

BERGSTROM L. (1990): Use of lysimeters to estimate leaching of pesticides in agricultural soils. Environ. Pollut. 67: 325-347.

BEVER J.D., Westover K.M., ANTONOVICS J. (1997): Incorporating the soil community into plant population dynamics: the utility of the feedback approach. J. Ecol. 85: 561-573.

Bhadoria P.S., Steingrobe B., ClaAssen N., Liebersbach H. (2002): Phosphorus efficiency of wheat and sugar beet seedlings grown in soils with mainly calcium, or iron and aluminum phosphate. Plant Soil 246: 41-52.

Bidartondo M.I., Redecker D., Hijri I., Wiemken A., Bruns T.D., Dominguez L., Sersic A., Leake J.R., READ D.J. (2002): Epiparasitic plants specialized on arbuscular mycorrhizal fungi. Nature 419: 389-392.

Bienfalt H.F., Scheffers M.R. (1992): Some properties of ferric citrate relevant to the iron nutrition of plants. Plant Soil 143: 141-144.

BIJLSMA R.J., LAMBERS H. (2000): A dynamic whole-plant model of integrated metabolism of nitrogen and carbon. 2. Balanced growth driven by $\mathrm{C}$ fluxes and regulated by signals from $\mathrm{C}$ and $\mathrm{N}$ substrate. Plant Soil 220: 71-87.

BIJLSMA R.J., LAMBERS H., KooIJMAN S.A.L.M. (2000): A dynamic whole-plant model of integrated metabolism of nitrogen and carbon. 1. Comparative ecological implications of ammonium-nitrate interactions. Plant Soil 220: 49-69.

BLACKBURN T.E. (1983): The microbial nitrogen cycle. In: Krumbein W.E. (Ed.): Microbial Geochemistry. Blackwell Scientific Publications, Oxford: 63-89.

BLAIR G.J., MiLleR M.H., MitCHeLL W.A. (1970): Nitrogen and ammonium as sources of nitrogen for corn and their influence on the intake of other ions. Agron. J. 62: 530-532.

Blamey F.P.C., Edmeades D.C., WHeELeR D.M. (1990): Role of root cation-exchange capacity in differential aluminum tolerance of different Lotus species. J. Plant Nutr. 13: 729-744. 
BLOM C.W.P.M., VoESENEK L.A.C.J. (1995): Flooding: The survival strategies of plants. Trend Ecol. Evol. 7: 290-295.

Bmvel (2003): Tierschutzbericht 2003 - Bericht über den Stand des Tierschutzes. Deutscher Bundestag Drucksache 15/723: $148 \mathrm{~S}$.

Bobbink R., HoRnUng M., Roelofs J.G.M. (1998): The effects of air-borne nitrogen pollutants on species diversity in natural and semi-natural European vegetation. J. Ecol. 86: 717-738.

BOGNER W. (1968): Experimentelle Prüfung von Waldbodenpflanzen auf ihre Ansprüche an die Form der Stickstoff-Ernährung. Mitt. Verein Forstl. Standortskunde Forstpflanzenzüchtung 18: 3-45.

Bonis A., GRubb P.J., Coomes D.A. (1997): Requirements of gap-demanding species in chalk grassland: reduction of root competition versus nutrient-enrichment by animals. J. Ecol. 85: 625-633.

Boos A., Kolesch H., HöFNER W. (1982): Chlorosis-Ursachen bei Reben am natürlichen Standort. Z. Pflanzenernähr. Bodenkd. 145: 246-260.

BoRgGAARD O.K. (1988): Phase identification by selective dissolution techniques. In: Stucki J.W., Goodman B.A., Schwertmann U. (Eds.): Iron in Soils and Clay Minerals. Reidel, Dordrecht: 83-98.

BORNKAMM R. (1958): Standortsbedingungen und Wasserhaushalt von Trespen-Halbtrockenrasen (Mesobromion) im oberen Leinegebiet. Flora 146: 23-67.

BoRnKAMm R. (1960): Die Trespen-Halbtrockenrasen im oberen Leinegebiet. Mitt. Florist.-Soziol. Arbeitsgem. N.F. 8: 181-208.

BORTZ J. (1999): Statistik für Sozialwissenschaftler. 5. Auflage. Springer, Berlin: 836 S.

BoRTZ J., LIENERT G.A., BoeHNKE K. (1990): Verteilungsfreie Methoden in der Biostatistik. Springer, Berlin: $939 \mathrm{~S}$.

Bossier P., Hofte M., Verstraete W. (1988): Ecological significance of siderophores in soil. Adv. Microbial Ecol. 10: 385-414.

Bossier P., Verstraete W. (1986): A direct bioassay for the detection of hydroxamate siderophores in soil. Soil Biol. Biochem. 18: 487-492.

BouLD C. (1963): Mineral nutrition of plants in soils. In: Steward F.C. (Ed.): Plant Physiology. Academic Press, New York: 16-91.

Bowman R.A., Cole C.V. (1978): Transformation of organic phosphorus substances in soils as evaluated by $\mathrm{NaHCO}_{3}$ extraction. Soil Sci. 1978: 49-54.

BradshaW A.D., ChadWick M.J., JoWett D., Lodge R.W., Snaydon R.W. (1960): Experimental investigations into the mineral nutrition of several grass species. Part III. Phosphate level. J. Ecol. 48: 631-637.

BradshaW A.D., Lodge R.W., JoWett D., CHADWick M.J. (1958): Experimental investigations into the mineral nutrition of several grass species. Part I: Calcium level. J. Ecol. 46: 749-757.

Braun-Blanquet J. (1964): Pflanzensoziologie. 3. Auflage. Springer, Wien: 865 S.

Braune W., Lehmann A., Taubert H. (1999): Pflanzenanatomisches Praktikum I. 8., durchges. u. erw. Auflage. Spektrum Akademischer Verlag, Heidelberg: $368 \mathrm{~S}$.

BRITTO D.T., KRONZUCKER H.J. (2002): $\mathrm{NH}_{4}{ }^{+}$toxicity in higher plants: a critical review. J. Plant Phys. 159: 567-584.

BRosofsKe K.D., CHEN J., CROW T.R. (2001): Understory vegetation and site factors: implication for a managed Wisconsin landscape. Forest Ecol. Managem. 146: 75-87.

BRown J.C. (1978): Mechanisms of iron uptake by plants. Plant Cell Environ. 1: 249-257. 
BRown J.C., AmBLER J.E. (1973): "Reductants" released by roots of Fe-deficient soybeans. Agron. J. 65: 311-314.

Brown J.C., Foy C.D., BennetT J.H., Christiansen M.N. (1979): Two light sources differentially affected ferric iron reduction and growth of cotton. Plant Physiol. 63: 692-695.

BRoWN J.C., Jones D.L. (1977): Manganese and iron toxicities dependent on soybean variety. Commun. Soil Sci. Plant Anal. 8: 1-15.

BROWN V.K., GANGE A. (1989): Herbivory by soil dwelling insects depresses plant species richness. Funct. Ecol. 3: 667-671.

BRUEHL G.W. (1987): Soilborne Plant Pathogens. Macmillan Publishing, New York: 368 S.

BRUELHEIDE H. (1991): Kalkmagerrasen im östlichen und westlichen Meißner-Vorland. Tuexenia 11: 205-233.

BRÜMmER G. (1974): Redoxpotentiale und Redoxprozesse von Mangan, Eisen- und Schwefelverbindungen in hydromorphen Böden und Sedimenten. Geoderma 12: 207-222.

BRUNDRETT M.C. (1991): Mycorrhizas in natural ecosystems. Adv. Ecol. Res. 21: 171-313.

BRUNDRETT M.C. (2002): Coevolution of roots and mycorrhizas of land plants. New Phyt. 154: 275-304.

Brunet J., FALKengRen-Grerup U., RüHLING A., TYLeR G. (1997): Regional differences in floristic change in South Swedish oak forests as related to soil chemistry and land use. J. Veg. Sci. 8: 329-336.

BRUNS T.D., READ D.J. (2000): In vitro germination of nonphotosynthetic myco-heterotrophic plants stimulated by fungi isolated from the adult plants. New Phyt. 148: 335-342.

BRUNSTING A.M.H., HeIL G.W. (1985): The role of nutrients in the interactions between a herbivorous beetle and some competing plant species in heathlands. Oikos 44: 23-26.

BRYANT J.P., ChaPIN III F.S., KLEIN D.R. (1983): Carbon/nutrient balance of boreal plants in relation to vertebrate herbivory. Oikos 40: 357-368.

BuckLAND S.M., GRIME J.P., Hodgson J.G., Thompson K. (1997): A comparison of plant responses to the extreme drought of 1995 in northern England. J. Ecol. 85: 875-882.

BüHL A., ZöFEL P. (2000): SPSS Version 9 - Einführung in die moderne Datenanalyse unter Windows. 6. , überarb. und erw. Auflage. Addison-Wesley, München: $686 \mathrm{~S}$.

BUHSE J. (1992): Wirkung der Wurzelraumtemperatur auf das Phosphataneignungsvermögen von Pflanzen und die Phosphatverfügbarkeit im Boden. Dissertation, Universität Göttingen, 146 S.

BULTMANN M. (1993): Flora und Vegetation der Kalkmagerrasen an der unteren Diemel. Philippia 6: 331-380.

BuRdon J.J. (1987): Diseases and Plant Population Biology. Cambridge University Press, Cambridge (Mass.): $208 \mathrm{~S}$.

BURGESS P.S. (1922): The soil solution, extracted by Lipman's direct-pressure method, compared with 1:5 water extracts. Soil Sci. 14: 191-216.

Büsgen M. (1914): Kieselpflanzen auf Kalkboden. Bot. Jahrb. v. Engler Bd. 50, 526-538.

BusH D.S. (1995): Calcium regulation in plant cells and its role in signaling. Annu. Rev. Plant Physiol. Plant Mol. Biol. 46: 95-122.

CAIN J.C. (1952): A comparison of ammonium and nitrate nitrogen for blueberries. Proc. Am. Soc. Hortic. Sci. 64: 61-70.

CAIN J.C. (1954): Blueberry chlorosis in relation to leaf $\mathrm{pH}$ and mineral composition. Proc. Am. Soc. Hortic. Sci. 64: 61-70. 
CAKMAK I., OztÜRK L., KARANLIK S., MARschneR H., EkIz H. (1996): Zinc-efficient wild grasses enhance release of phytosiderophores under zinc deficiency. J. Plant Nutr. 19: 551-563.

CaKmak O., Oztürk L., Karanlik S., OzKan H., CaKmaK I. (2001): Tolerance of 65 durum wheat genotypes to zinc deficiency in a calcareous soil. J. Plant Nutr. 24: 1831-1847.

CALba H., JaillaRD B. (1997): Effect of aluminium on ion uptake and $\mathrm{H}^{+}$release by maize. New Phyt. 137: 607-616.

Campbell A.S., Schwertmann U. (1984): Iron oxide mineralogy of placic horizons. J. Soil Sci. 35: 569-582.

Campbell D.J., KinnibuRgh D.G., Beckett P.H.T. (1989): The soil solution chemistry of some Oxfordshire soils: temporal and spatial variability. J. Soil Sci. 40: 321-339.

CANFIELD D.E. (1989): Reactive iron in marine sediments. Geochim. Cosmochim. Acta 53: 619-632.

CÁrdenas-Navarro R., Adamowicz S., Gojon A., Robin P. (1999a): Modelling nitrate influx in young tomato (Lycopercum esculentum MILL.) plants. J. Exp. Bot. 50: 625-635.

CÁrdenas-NAVARro R., Adamowicz S., Robin P. (1999b): Nitrate accumulation in plants: a role for water. J. Exp. Bot. 50: 613-624.

Caris C., Hoerdt W., HAWkins H.J., RömHeld V., George E. (1998): Studies of iron transport by arbuscular mycorrhizal hyphae from soil to peanut and sorghum plants. Mycorrhiza 8: 35-39.

Carvajal M., Cooke D.E., ClaRkson D.T. (1996): Responses of wheat plants to nutrient deprivation may involve the regulation of water channel functions. Planta 199: 372-381.

Castelle A.J., Galloway J.N. (1990): Carbon dioxide dynamics in acid forest soils in Shenandoah National Park, Virginia. Soil Sci. Soc. Am. J. 54: 252-257.

Cesco S., Nikolic M., Roemheld V., VARanini Z., Pinton R. (2002): Uptake of ${ }^{59} \mathrm{Fe}$ from soluble ${ }^{59} \mathrm{Fe}-$ humate complexes by cucumber and barley plants. Plant Soil 241: 121-128.

ChAPMAN S.B. (1979): Some interrelationships between soil and root respiration in lowland Calluna heathland in southern England. J. Ecol. 67: 1-20.

Chen Y., JURKeVITCH E., BAR-Ness E., HADAR Y. (1994): Stability constants of pseudobactin complexes with transition metals. Soil Sci. Soc. Am. J. 58: 390-396.

Chodat R. (1913): Sur le Digitalis purpurea, plante calcifuge. Bull. de la Soc. Bot. de Genève 5: $288 \mathrm{ff}$.

CHYTRÝ M., TICHÝ L., RoLECEK J. (2003): Local and regional patterns of species richness in central European vegetation types along the pH/calcium gradient. Folia Geob. 38: 429-442.

CINELLI F. (1995): Physiological responses of clonal quince rootstocks to iron-deficiency induced by addition of bicarbonate to nutrient solution. J. Plant Nutr. 18: 77-89.

ClaAssen N., SteingRobe B. (1999): Mechanistic simulation models of nutrient uptake. In: Rengel Z. (Ed.): Mineral Nutrition of Crops, Fundamental Mechanisms and Implications. Haworth Press, New York: 327-367.

CLAPP J.P., RodRIGUEZ A., Dodd J.C. (2002): Glomales rRNA gene diversity - all that glisten's is not necessarily glomalean. Mycorrhiza 12: 269-270.

CLARKson D.T. (1965): Calcium uptake by calcicole and calcifuge species in the genus Agrostis L. J. Ecol. 53: 427-435.

CLAY K., MARKS S., Cheplick G.P. (1993): Effects of insect herbivory and fungal endophyte infection on competitive interactions among grasses. Ecol. 74: 1767-1777. 
Cline G.R., Powell P.E., Szaniszlo P.J., Reid C.P.P. (1982): Comparison of the abilities of hydroxamic synthetic and other natural organic acids to chelate iron and other ions in nutrient solution. Soil Sci. Soc. Am. J. 46: 1158-1164.

Cline G.R., Reid C.P.P., Powell P.E., Szaniszlo P.J. (1984): Effect of a hydroxamate siderophore on iron absorption by sunflower and sorghum. Plant Physiol. 76: 36-39.

CLoud P.E.JR. (1968): Atmospheric and hydrospheric evolution on the primitive earth. Science 160: 729-736.

CoLEY P.D. (1987): Interspecific variation in anti-herbivorie properties: The role of habitat quality and rate of disturbance. New Phyt. 106: 251-263.

Coley P.D., BRYANT J.P., ChaPIN III F.S. (1985): Resource availability and plant antiherbivore defense. Science 230: 895-899.

Colgrove M.S., RobertS A.N. (1956): Growth of the acalea as influenced by ammonium and nitrate nitrogen. Proc. Am. Soc. Hortic. Sci. 68: 522-536.

ColWELL J.D. (1963): The estimation of the phosphorus fertilizer requirement of wheat in southern New South Wales by soil analysis. Aust. J. Exp. Agric. Anim. Husb. 3: 190-197.

Corcket E., Callaway R.M., Michalet R. (2003a): Insect herbivory and grass competition in a calcareous grassland: results from a plant removal experiment. Acta Oecologica 24: 139-146.

Corcket E., Liancourt P., Callaway R.M., Michalet R. (2003b): The relative importance of competition for two dominant grass species as affected by environmental manipulations in the field. Ecoscience 10: 186-194.

CREAmeR F.L., Fox R.H. (1980): The toxicity of banded urea or diammonium phosphate to corn as influenced by temperature, moisture and pH. Soil Sci. Soc. Am. J. 44: 296-300.

CRESS W.A., Johnson G.V., BARTON L.L. (1986): The role of endomycorrhizal fungi in iron uptake by Hilaria jamesii. J. Plant Nutr. 9: 547-556.

CUI M., CALDWELL M.M. (1997): Shading reduces exploitation of soil nitrate and phosphate by Agropyron desertorum and Artemisia tridentata from soils with patchy and uniform nutrient distributions. Oecologia 109: 177-183.

CURRAH R.S., ZeLmER C.D., HAMBleton S., RichARDSon K.A. (1997): Fungi from orchid mycorrhizas. In: Arditti J., Pridgeon A.M. (Eds.): Orchid Biology: Reviews and Perspectives, VII. Kluwer Academic Publisher, Dordrecht: 117-170.

DAHLGREN R.A. (1993): Comparison of soil solution extraction procedures: effect on solute chemistry. Commun. Soil Sci. Plant Anal. 24: 1783-1794.

Daniell T.J., Husband R., FitTer A.H., Young J.P.W. (2001): Molecular diversity of arbuscular mycorrhizal fungi colonizing arable crops. FEMS Microbiol. Ecol. 36: 203-209.

DaRnell J., Lodish H., BaLtimoRe D. (1994): Molekulare Zellbiologie. De Gruyter, Berlin: 1277 S.

DAVIDSon E.A., Chorover J., DaIL D.B. (2003): A mechanism of abiotic immobilization of nitrate in forest ecosystems: the ferrous wheel hypothesis. Global Change Biol. 9: 228-236.

DAVIES D.D. (1973): Control of and by pH. Symp. Soc. Exp. Biol. 27: 513-529.

DaVIES D.D. (1986): The fine control of cytosolic pH. Physiol. Plant. 67: 702-706.

DAVISON W., SEed G. (1983): The kinetics of the oxidation of ferrous iron in synthetic and natural waters. Geochim. Cosmochim. Acta 47: 67-79. 
Davy A.J., DunSford S.J., Free A.J. (1998): Acidifying peat as an aid to the reconstruction of lowland health on arable soil: Lysimeter experiments. J. Appl. Ecol. 35: 649-659.

DAVY A.J., TAYLOR K. (1974): Seasonal patterns of nitrogen availability in the Chiltern hills. J. Ecol. 62: 793-807.

De CANDolle A. (1855): Géographique botanique raisonnee ou exposition des traits principaux et des loits concernant la distribution géographique des plantes de l'époque actuelle. Masson, Paris: $80 \mathrm{~S}$.

De Ruiter P.C., Neutel A., Moore J.C. (1995): Energetics, patterns of of interaction strength and stability in real ecosystems. Science 269: 1257-1260.

De Vos C.R., Lubberding H.J., Bienfait H.F. (1986): Rhizosphere acidification as a response to iron deficiency in bean plants. Plant Physiol. 81: 842-846.

Degenhardt J., LARSEN P.B., Howell S.H., Kochian L.V. (1998): Aluminum resistance in the Arabidopsis mutant alr-104 is caused by an aluminum-induced increase in rhizosphere $\mathrm{pH}$. Plant Phys. 117: 19-27.

DelescailLe L.M. (1999): La gestion conservatoire des pelouses sèches par le pâturache ovin. Aspects théoriques et practiques. Parcs et Réserves 54: 2-9.

Delhaize E., Ryan P.R., Randall P.J. (1993): Aluminum tolerance in wheat (Triticum aestivum L.). II: Aluminum-stimulated excretion of malic acid from root apices. Plant Physiol. 103: 81-85.

Deutscher Wetterdienst (1964): Klima-Atlas von Niedersachsen. Selbstverlag, Offenbach: 38 S.

DEUTSCHER WETTERDIENST (1999): Monatlicher Witterungsbericht, Jahresbericht 1998. Jahrgang 46, Nr. 13. Selbstverlag, Offenbach: $12 \mathrm{~S}$.

DEUTSCHES INSTITUT FÜR NORMUNG (1979): Deutsche Einheitsverfahren zur Wasser-, Abwasser- und Schlammuntersuchung; Summarische Wirkungs- und Stoffkenngrößen (Gruppe H): DIN 38409-7 1979-05 Bestimmung der Säure- und Basekapazität ( $p$ - und m-Wert), Berechnung der Konzentration an Hydrogencarbonat. Beuth, Berlin.

DIERSCHKE H. (1984): Experimentelle Untersuchungen zur Bestandesdynamik von Kalkmagerrrasen (Mesobromion) in Südniedersachsen. Münstersche Geogr. Arb. 20: 9-24.

DieRsCHKE H. (1994): Pflanzensoziologie. Ulmer, Stuttgart: 683 S.

Digby P.G.N., KemPton R.A. (1987): Multivariate Analysis of Ecological Communities. Chapman \& Hall, London: 206 S.

DiNg N., Musgrave M.E. (1995): Relationship between mineral coating on roots and yield performance of wheat under waterlogging stress. J. Exp. Bot. 46: 939-945.

Dinkelaker B., Hengeler C., MARschner H. (1995): Distribution and function of proteoid roots and other root clusters. Bot. Acta 108: 183-200.

Dinkelaker B., Hengeler C., Neumann G., Eltrop L., Marschner H. (1997): Root exudates and mobilization of nutrients. In: Rennenberg H., Eschrich W., Ziegler H. (Eds.): Trees - Contributions to modern Tree Physiology. Backhuys, Leiden: 441-452.

DinKelaKer B., RömHeLd V., MARSChNeR H. (1989): Citric acid excretion and precipitation of calcium citrate in the rhizosphere of white lupin (Lupinus albus L.). Plant Cell Environ. 12: 285-292.

Dixon R.A., HARRISON M.J., LAMB C.J. (1994): Early events in the activation of plant defense responses. Annu. Rev. Phytopathol. 32: 479-501.

Dobson A. (1994): Pathogens and the structure of plant communities. Tree 9: 393-398. 
Dolfing J., Chardon W.J., Japenga J. (1999): Association between colloidal iron, aluminum, phosphorus, and humic acids. Soil Sci. 164: 171-179.

Doney R.C., Smith R.L., Wiebe H.H. (1960): Effects of various levels of bicarbonate, phosphorus and $\mathrm{pH}$ on the translocation of foliar-applied iron in plants. Soil Sci. 89: 269-275.

DREW M.C., SAKER L.R. (1975): Nutrient supply and the growth of seminal root system in barley. II. Localized compensatory increases in laterla root growth and rates of nitrate uptake when nitrate supply is restricted to only part of the root system. J. Exp. Bot. 26: 79-90.

DREW M.C., SAKER L.R. (1978): Nutrient supply and the growth of the seminal root system in barley. III. Compensatory increase in growth of lateral roots, and in rates of phosphate uptake, in response to localized supply of phosphate. J. Exp. Bot. 29: 435-451.

Dueck T.A., Dorel F.G., TeRHORSt R., VAN DER EeRden L.J. (1990): Effects of ammonia, ammoniumsulfate and sulfur-dioxide on the frost sensitivity of Scots pine (Pinus sylvestris L.). Water Air Soil Pollution 54: 35-49.

DuIJfF B.J., DE KogeL W.J., BAKKeR P.A.H.M., SchiPPERS B. (1994): Influence of pseudobactin 358 on the iron nutrition of barley. Soil Biol. Biochem. 26: 1681-1688.

Dumortier M., Butaye J., Jacquemyn H., van Camp N., Lust N., Hermy M. (2002): Predicting vascular plant species richness of fragmented forests in agricultural landscapes in central Belgium. Forest Ecol. Managem. 158: 85-102.

DUNSFORD S.J., FREE A.J., DAVY A.J. (1998): Acidifying peat as an aid to the reconstruction of lowland heath on arable soil: A field experiment. J. Appl. Ecol. 35: 660-672.

DURKA W., ACKERMANN W. (1993): SORT - Ein Computerprogramm zur Bearbeitung floristischer und faunistischer Artenlisten. Nat. Landsch. 68: 16-21.

DURKA W., ACKERMANN W. (1994): SORT, ein Computerprogramm zur Bearbeitung und Analyse floristischer und faunistischer Artenlisten und Tabellen im wissenschaftlichen und gutachterlichen Bereich. In: Pfaff-Schley H., Schimmelpfeng L. (Eds.): EDV-Einsatz in Umweltschutz und Landschaftsplanung: Datengrundlagen, Landschaftsplanung, Abfallentsorgung, Integration. Springer, Berlin: 107-122 210 S.

Edmeades D.C., Wheeler D.M., Clinton O.E. (1985): The chemical composition and ionic strength of soil solutions from new Zealand topsoils. Aust. J. Soil Res. 23: 151-165.

ElLenBeRg H. (1953): Physiologisches und ökologisches Verhalten derselben Pflanzenarten. Ber. Dtsch. Bot. Ges. 65: 351-362.

ElLeNBeRg H. (1958): Bodenreaktion (einschließlich Kalkfrage). In: Ruhland W. (Ed.): Handbuch der Pflanzenphysiologie. Springer, Berlin: 638-708.

ElLeNBerg H. (1996): Vegetation Mitteleuropas mit den Alpen. 5., stark veränd. und verb. Auflage. Ulmer, Stuttgart: $1095 \mathrm{~S}$.

Ellenberg H., Weber, H. E., Düll, R., WiRth, V., Werner, W., Paulissen, D. (1992): Zeigerwerte von Pflanzen in Mitteleuropa. Scr. Geobot. 18 (2. Auflage): $258 \mathrm{~S}$.

ENGLISCH G. (1993): Der Einfluß unterschiedlicher Stickstoff-Ernährungsformen auf den pH-Wert im Apoplasten von Blattmesophyllzellen sowie auf die Ausbildung einer Eisenmangelchlorose bei Glycine max L. und Zea mays L. Diplomarbeit, Universität Gießen.

EPSTEIN E. (1965): Mineral metabolism. In: Bonner J., Varner J.E. (Eds.): Plant Biochemistry. Academic Press, London: 438-466.

EpSTEIN E. (1972): Mineral Nutrition of Plants: Principles and Perspectives. Wiley, New York: 412 S. 
ERNST W.H.O. (1983): Ökologische Anpassungsstrategien an Bodenfraktionen. Ber. Dtsch. bot. Ges. 96: 49-71.

ERnSt W.H.O., Nelissen H.J.M. (1998): The calcium demand of the calcicole sedge Schoenus nigricans. J. Plant Phys. 152: 173-179.

ETHERINGTON J.R. (1981): Limestone heaths in South-West Britain: their soils and the maintenance of their calcicole-calcifuge mixtures. J. Ecol. 69: 277-294.

EWALD J. (2003): The calcareous riddle: Why are there so many calciphilous species in the central European flora? Folia Geobot. 38: 357-366.

FALKENGREN-GRERUP U. (1995): Interspecies Differences in the Preference of Ammonium and Nitrate in Vascular Plants. Oecologia 102: 305-311.

FALKENGREN-GRERUP U., LAKKENBORG-KRISTENSEN H. (1994): Importance of Ammonium and Nitrate to the Performance of Herb-Layer Species from Deciduous Forests in Southern Sweden. Environ. Exp. Bot. 34: 31-38.

FALKENGREN-GRERUP U., QUIST M.E., TYLER G. (1995): Relative importance of exchangeable and soil solution cation concentrations to the distribution of vascular plants. Environ. Exp. Bot. 35: 9-15.

FALKENGREN-GRERUP U., TYLER G. (1993): The importance of soil acidity, moisture, exchangeable cation pools and organic matter solubility to the cationic composition of beech forest (Fagus sylvatica L.) soil solution. Z. Pflanzenernähr. Bodenkd. 156: 365-370.

Federer P., Sticher H. (1994): Zusammensetzung und Speziierung der Bodenlösung eines mit Schwermetallen belasteten kalkreichen Bodens. Z. Pflanzenernähr. Bodenkd. 157: 131-138.

Fischer S.F., Poschlod P., Beinlich B. (1996): Experimental studies on the dispersal of plants and animals on sheep in calcareous grasslands. J. Appl. Ecol. 33: 1206-1222.

FISCHER W.R. (1988): Microbiological reactions of iron in soils. In: Stucki J.W., Goodman B.A., Schwertmann U. (Eds.): Iron in Soils and Clay Minerals. Reidel, Dordrecht: 715-748.

Fischer W.R., PfanNeberg T. (1984): An improved method for testing the rate of iron(III) oxide reduction by bacteria. Zbl. Mikrobiol. 139: 163-166.

FISHER G.C., YAM O.L. (1984): Iron mobilization by heathland plant extracts. Geoderma 32: 339-345.

FocKENBROCK D. (1992): Keimung und Wachstum calcicoler und calcifuger Pflanzen auf carbonatreichem Boden unter besonderer Berücksichtigung der Eisen-Versorgung.

Diplomarbeit, Universität Göttingen, $61 \mathrm{~S}$.

Foster R.C., RoviRA A.D., Cock T.W. (1983): Ultrastructure of the Root Soil Interface. The American Phytopathological society, St. Paul (MN): 157 S.

Fox T.C., Shaff J.E., Grusak M.A., Norvell W.E., Chen Y., Chaney R.L., Kochian L.V. (1996): Direct measurement of ${ }^{59} \mathrm{Fe}$-labeled $\mathrm{Fe}^{2+}$ influx in roots of pea using a chelator buffer system to control free $\mathrm{Fe}^{2+}$ in solution. Plant Phys. 111: 93-100.

Foy C.D., BuRNS G.R., BRown J.C., FLeming A.L. (1965): Differential aluminum tolerance of two wheat varieties associated with plant induced $\mathrm{pH}$ changes around their roots.

Soil Sci. Soc. Am. Proc. 29: 64-67.

Foy C.D., Fleming A.L., ARmiger W.H. (1969): Aluminium tolerance of soybean varieties in relation to calcium nutrition. Agron. J. 61: 505-511.

Foy C.D., FLeming A.L., SchWARTZ J.W. (1973): Opposite aluminium and manganese tolerance of two wheat varieties. Agron. J. 65: 123-126. 
FoY C.D., WeBB H.W., Jones J.E. (1981): Adaptation of cotton genotypes to an acid, manganese toxic soil. Agron. J. 73: 107-111.

FRANCIS R., READ D.J. (1995): Mutualism and antagonism in the mycorrhizal symbiosis, with special reference to impacts on plant community structure. Can. J. Bot. 73: 1301-1309.

Fransson A.M., van AARLE I.M., Olsson P.A., TYLer G. (2003): Plantago lanceolata L. and Rumex acetosella L. differ in their utilisation of soil phosphorus. Plant Soil 248: 285-295.

FRASER L.H. (1998): Top-down vs bottom-up control influenced by productivity in a North Derbyshire, UK, dale. Oikos 81: 99-108.

FRASER L.H., GRIME J.P. (1999): Interacting effects of herbivory and fertility on a synthesized plant community. J. Ecol. 87: 514-525.

FREDEEN A.L., RAO I.M., TERRY N. (1989): Influence of phosphorus nutrition on growth and carbon partitioning in Glycine max. Plant Physiol. 89: 225-230.

FüHNER C. (1997): Adaptive Reaktionen verschiedener Arten der Gattung Plantago auf sub- und supraoptimales Fe-Angebot. Diplomarbeit, Universität Oldenburg, $126 \mathrm{~S}$.

FURIHATA T., SUZUKI M., SAKURAI H. (1992): Kinetic characterization of two phosphate uptake systems with different affinities in suspension-cultured Catharanthus roseus protoplasts.

Plant Cell Physiol. 33: 1151-1157.

GARBAYE J. (1994): Helper bacteria: a new dimension to the mycorrhizal symbiosis. New Phyt. 128: 197-210.

GASSMANN W., Schroeder J.I. (2001): Inward rectifying $\mathrm{K}^{+}$channels in root hairs of wheat. A mechanims for aluminum-sensitive low affinity $\mathrm{K}^{+}$uptake. Plant Physiol. 105: 1399-1408.

GASTON K.J., BLACKBURN T.M., SPICER J.I. (1998): Rapoport's rule: time for an epitaph. Trends Ecol. Evol. 13: 198-206.

GAUSE G.F. (1934): The Struggle for Existence. Williams \& Wilkins, Baltimore: 163 S.

Gavalas N.A., MANetas Y. (1980): Calcium inhibition of phosphoenolpyruvate carboxylase: Possible physiological consequences for 4-carbon-photosynthesis. Z. Pflanzenphysiol. 100: 179-184.

GEIGER S.C., LOEPPERT R.H. (1994): Influence of air drying and soil gas-phase carbon dioxide on DTPAextractable iron in calcareous soils. Commun. Soil Sci. Plant Anal. 25: 341-349.

GERINGHOFF H. (1992): Vegetationskundliche Untersuchungen der Kalkkuppen der Briloner Hochebene, Sauerland. Diplomarbeit, Universität Münster, $139 \mathrm{~S}$.

GeRINGhoff H., Daniels F.J.A. (1994): Das Gentiano-Koelerietum agrostietosum Korneck 1960 der Briloner Hochfläche. Nat. Heim. 54: 103-110.

GERKE J. (2000): Mathematical modelling of iron uptake by graminaceous species as affected by iron forms in soil and phytosiderophore efflux. J. Plant Nutr. 23: 1579-1587.

Gerke J., MeYer U., RömeR W. (1995): Phosphate, Fe and Mn uptake of N2 fixing red clover and ryegrass from an oxisol as affected by $P$ and model humic substances application. 1. Plant parameters and soil solution composition. Z. Pflanzenernähr. Bodenkd. 158: 261-268.

GERLACH A. (1973): Methodische Untersuchungen zur Bestimmung der Stickstoffnettomineralisation. Scr. Geobot., 5: 115 S.

Gibson C.W.D., BRoWn V.K., JEPSEN M. (1987): Relationships between the effects of insect herbivory and sheep grazing on seasonal chenges in an early successional plant community.

Oecologia 71: 245-253. 
GIGON A. (1968): Stickstoff- und Wasserversorgung von Trespen-Halbtrockenrasen (Mesobromion) im Jura bei Basel. Ber. Geobot. Inst. ETH, Stftg. Rübel, Zürich 38: 28-85.

GIGON A. (1987): A hierarchic approach in causal ecosystem analysis. The calcifuge-calcicole problem in alpine grasslands. In: Schulze E.D., Zwölfer H. (Eds.): Potentials and limitations of ecosystem analysis. Springer, Berlin, Heidelberg: 228-244.

GIGON A., RoRISON I.H. (1972): The ecology of some ecologically distinct plant species to nitrate- and to ammonium-nitrogen. J. Ecol. 60: 93-102.

GiLLmAN G.P., BeLL L.C. (1978): Soil solution studies on weathered soils from tropical north Queensland. Aust. J. Soil Res. 16: 67-77.

Gimingham C.H. (1960): Biological Fora of the British Isles: Calluna vulgaris (L.) HULL. J. Ecol. 48: 455-483.

GLÄSSER R. (1994): Das Klima des Harzes. Dr. Kovac, Hamburg: 341 S.

GLAVAC V. (1996): Vegetationsökologie. Fischer, Stuttgart: 358 S.

GLIEMEROTH G. (1953): Barbeitung und Düngung des Unterbodens in ihrer Wirkung auf Wurzelentwicklung, Stoffaufnahme und Pflanzenwachstum. Z. Acker- Pflanzenbau 96: 1-44.

GLIMSKÄR A., ERICsSON T. (1999): Relative nitrogen limitation at steady-state nutrition as a determinant of plasticity in five grassland plant species. Ann. Bot. 84: 413-420.

Glinski J., StAHR K., StePNiEWSKA, BRzezinSKA M. (1996): Changes of redox and pH conditions in a flooded soil amended with glucose and manganese oxide or iron oxide under laboratory conditions. Z. Pflanzenernähr. Bodenkd. 159: 297-304.

GodBold D.L., FRITZ E., HütTERmANN A. (1988): Aluminium toxicity and forest decline. Proc. Natl. Acad. Sci. USA 85: 3888-3892.

Gollany H.T., Bloom P.R., Schumacher T.E. (1997): Rhizosphere soil-water collection by immiscible displacement-centrifugation technique. Plant Soil 188: 59-64.

Gonzalez-Vallejo E.B., Gonzalez-Reyes J.A., Abadia A., Lopez-Millan A.F., Yunta F., Lucena J.J., ABADIA J. (1999): Reduction of ferric chelates by leaf plasma membrane preparations from Fedeficient and Fe-sufficient sugar beet. Aust. J. Plant Physiol. 26: 601-611.

Gonzalez-Vallejo E.B., Morales F., Cistue L., Abadia A., Abadia J. (2000): Iron deficiency decreases the $\mathrm{Fe}(\mathrm{III})$-chelate reducing activity of leaf protoplasts. Plant Physiol. 122: 337-344.

GoodmAN B.A. (1988): The characterization of iron complexes with soil organic matter. In: Stucki J.W., Goodman B.A., Schwertmann U. (Eds.): Iron in Soils and Clay Minerals. Reidel, Dordrecht: 677-687.

Gотон S., PATRICK W.H. (1974): Transformation of iron in a waterlogged soil as influenced by redox potential and pH. Soil Sci. Soc. Am. Proc. 38: 66-71.

Grace J.B., Tilman D. (1990): Perspectives on Plant Competition. Academic Press, San Diego: 483 S.

GRIES D. (1991): Die ökologische Bedeutung der Eisen-Anaeignungsfähigkeit von Poaceen. Dissertation, Universität Göttingen, 85 S.

GRIES D., RUNGE M. (1995): Responses of calcicole and calcifuge Poaceae species to iron limiting conditions. Bot. Acta 108: 482-489.

GRIFFIN R.A., JURINAK J.J. (1973): Estimation of activity coefficients from the electric conductivity of natural aquatic systems and soil extracts. Soil Sci. 116: 26-30.

GRIME J.P. (1959): An investigation of the ecology of a group of Derbyshire plants with particular reference to their nutritional requirements. Ph.D thesis, University of Sheffield. 
GRIME J.P. (1963a): An ecological investigation at a junction between two plant communities in Coombsdale on the Derbyshire limestone. J. Ecol. 51: 391-402.

GRIME J.P. (1963b): Factors determining the occurence of calcifuge species on shallow soils over calcareous substrata. J. Ecol. 51: 375-390.

GRIME J.P. (1965a): Comparative experiments as a key to the ecology of flowering plants. Ecol. 46: 513-515.

GRIME J.P. (1965b): The ecological significance of lime-chlorosis. An experiment with two species of Lathyrus. New Phyt. 64: 477-487.

GRIME J.P. (1977): Evidence for the existence of three primary strategies in plants and its relevance to ecological and evolutionary theory. American Naturalist 111: 1169-1194.

GRIME J.P. (1979): Plant Strategies and Vegetation Processes. Wiley, Chichester: 222. S.

GRIME J.P., CURTIS A.V. (1976): The interaction of drought and mineral nutrient stress in calcareous grassland. J. Ecol. 64: 975-988.

GRIME J.P., HodGson J.G. (1969): An investigation of the ecological significance of lime-chlorosis by means of large-scale comparative experiments. In: Rorison R.H. (Ed.): Ecological Aspects of the Mineral Nutrition of Plants. Blackwell, Oxford: 67-99.

GRIME J.P., HUTCHINSON T.C. (1967): The incidence of lime-chlorosis in the natural vegetation of England. J. Ecol. 55: 557-566.

Grime J.P., MACKeY J.M., HiLlier S.H., ReAD D.J. (1987): Floristic diversity in a model system using experimental microcosms. Nature 328: 420-422.

GRIS L. (1843): De l'action des composés ferrugineux sur la végétation. C. R. Acad. Sci..

GRIS L. (1845): De l'action des sels ferrugineux solubles appliqués à la végétation et specielement au traitement de la chlorose et de la débilité des plants. C. R. Acad. Sci. 21: 1836.

Gross K.L., Peters A., Pregitzer K.S. (1993): Fine root growth and demographic responses in nutrient patches in four old-field plant species. Oecologia 95: 61-64.

GrossmanN J. (1988): Physikalische und chemische Prozesse bei der Probenahme von Sickerwasser mittels Saugsonden. Dissertation, TU München, $120 \mathrm{~S}$.

GROTHUS R. (1986): Wachstum und Nährstoffaufnahme calcicoler und calcifuger Arten in Abhängigkeit vom Calcium-Gehalt des Substrats. Diplomarbeit, Universität Göttingen, $108 \mathrm{~S}$.

GRUBB P.J. (1979): The maintenance of species-richness in plant communities; the importance of the regeneration niche. Biol. Rev. 52: 107-145.

GRUBB P.J. (1986): Sclerophylls, pachyphylls and pyenophylls: The nature and significance of hard leaf surfaces. In: Juniper B., Southwood R. (Eds.): Insects and Plant Surfaces.

Edward Arnold, London: 5-30.

GRUBb P.J., GReEN H.E., MERRIFIELD R.C.J. (1969): The ecology of chalk heath: its relevance to the calcicole-calcifuge and soil acidification problems. J. Ecol. 57: 175-212.

Grubb P.J., Lee W.G., KollmanN J., WiLson J.B. (1996): Interaction of irradiance and soil nutrient supply on growth of seedlings of ten European tall-shrub species and Fagus sylvatica. J. Ecol. 84: 827-840.

GRUBb P.J., SUTER M.B. (1971): The mechanism of soil acidification by Calluna and Ulex and the significance for conservation. In: Duffey E., Watt A.S. (Eds.): The Scientific Management of Plant and Animal Communities for Conservation. Blackwell, Oxford: 115-133. 
HACKET C. (1965): Ecological aspects of the nutrition of Deschampsia flexuosa (L.). TRIN. II. The effects of $\mathrm{Al}, \mathrm{Ca}, \mathrm{Fe}, \mathrm{K}, \mathrm{Mn}, \mathrm{P}$ and $\mathrm{pH}$ on the growth of seedlings and established plants. J. Ecol. 53: 315-333.

HANDMAN H., WeLleR D.M., Thomashow L.S. (1991): Relative importance of fluoreccent siderophores and other factors in biological control of Gaeumannomyces graminis var. tritici by Pseudomonas fluorescens. Appl. Environ. Microbiol. 57: 3270-3277.

HANSEN E.A., HARRIS A.R. (1975): Validity of soil-water samples collected with porous ceramic cups. Soil Sci. Soc. Am. J. 39: 528-536.

HANTSCHEL R., KAUPENJOHANN M., HORN R., GRADL J., ZeCH W. (1988): Ecologically important differences between equilibrium and percolation soil extracts, Bavaria. Geoderma 43: 213-227.

HANTSCHEl R., KAUPENJOHANn M., HORn R., ZeCH W. (1986): Kationenkonzentrationen in der Gleichgewichts- und Perkolationsbodenlösung (GBL und PBL) - ein Methodenvergleich. Z. Pflanzenernähr. Bodenkd. 149: 136-139.

HARRIS K.K., PAUL E.A. (1987): Carbon requirement of vesicular-arbuscular mycorrhizae. In: Safir G.R. (Ed.): Carbon Requirements of Vesicular-Arbuscular Plants. CRC Press, Boca Raton: 93-105.

HARTNETT D.C., WILSON G.W.T. (1999): Mycorrhizal influence plant community structure and diversity in tallgras prairie. Ecol. 80: 1187-1195.

HARTNETT D.C., WILSON G.W.T. (2002): The role of mycorrhizas in plant community structure and dynamics: lessons from grasslands. Plant Soil 244: 319-331.

HASHEM A.R. (1995): The role of mycorrhizal infection in the tolerance of Vaccinium macrocarpon to iron. Mycorrhiza 5: 451-454.

HAUG A. (1984): Molecular aspects of aluminium toxicity. Crit. Rev. Plant Sci. 1,I.4: 345-373.

HÄUSSLING M., MARSCHNER H. (1989): Organic and inorganic soil phosphates and acid phosphatase activity in the rhizosphere of 80-year-old Norway spruce (Picea abies (L.) Karst.) trees. Biol. Fert. Soils 8: 128-133.

HÄUSSLING M., RöMHeLd V., MARSCHNER H. (1985): Beziehungen zwischen Chlorosegrad, Eisengehalten und Blattwachstum von Weinreben auf verschiedenen Standorten. Vitis 24: 158-168.

HAVILL D.C., LeE J.A., SteWART G.R. (1974): Nitrate utilization by species from acidic and calcareous soils. New Phyt. 73: 1221-1231.

HAYNES R.J. (1986): Uptake and assimilation of mineral nitrogen by plants. In: Haynes R.J. (Ed.): Mineral Nitrogen in the Plant-Soil System. Academic Press, Orlando: 303-378.

HAYNES R.J., GoH K.J. (1978): Ammonium and nitrate nutrition of plants. Biol. Rev. 53: 465-510.

HE Y., LIAO H., YAN X. (2003): Localized supply of phosphorus induces root morphological and architectural changes of rice in split and stratified soil cultures. Plant Soil 248: 247-256.

HeCHT-BuchHolz C. (1967): Über die Dunkelfärbung des Blattgrüns bei Phosphormangel. Z. Pflanzenernähr. Bodenkd. 118: 12-22.

Hedley M.J., Stewart J.W.B., Chauhan B.S. (1982): Changes in inorganic and organic soil phosphorus fractions induced by cultivation practices and by laboratory incubations.

Soil Sci. Soc. Am. J. 46: 970-976.

Heenan D.P., Campbell L.C., Carter O.G. (1981): Inheritance of tolerance to high manganese supply in soybean. Crop Science 21: 625-627.

HEGI G. (1923): Illustrierte Flora von Mitteleuropa. Band 4, Teil 2: Dicotyledones.

G.F. Lehmann, München: 497-1112 S. 
HegI G. (1998): Illustrierte Flora von Mitteleuropa. Band I, Teil 3: Poaceae. Conert H.J. (Hrsg.). 3., vollst. neubearb. Auflage. Parey, Berlin: $898 \mathrm{~S}$.

HEIL G.W., DIEMONT W.H. (1983): Raised nutrient levels change heathland into grassland. Vegetatio 53: 113-120.

Helal H.M., DRessler A. (1989): Mobilization and turnover of soil phosphorus in the rhizosphere. Z. Pflanzenernähr. Bodenkd. 152: 175-180.

Helal H.M., SAUeRBeck D. (1989): Carbon turnover in the rhizophere.

Z. Pflanzenernähr. Bodenkd. 152: 211-216.

Helgason T., Daniell T.J., Husband R., Fitter A.H., Young J.P.W. (1998): Ploughing up the wood-wide web. Nature 394: 431.

HeLgason T., FitTeR A.H., Young J.P.W. (1999): Molecular diversity of arbuscular mycorrhizal fungi colonising Hyacinthoides non-scripta (bluebell) in a semi-natural woodland. Mol. Ecol. 8: 659-666.

Hemming B.C. (1986): Microbial-iron interactions in the plant rhizosphere - an overview. J. Plant Nutr. 9: 505-521.

HendRiks L., ClaAssen N., Jungk A. (1981): Phosphatverarmung des wurzelnahen Bodens und Phosphataufnahme von Mais und Raps. Z. Pflanzenernähr. Bodenkd. 144: 486-499.

HePLER P.K., WAYNE R.O. (1985): Calcium and plant development. Annu. Rev. Plant Physiol. 36: 397-439.

HerRmann A. (1956): Unterlagen zur Exkursion B 10 anlässlich der 108. Hauptversammlung der Deutschen Geologischen Gesellschaft. Deutsche Geologische Gesellschaft, Hannover.

Hess H.E., Landolt E., HiRzel R. (1970): Flora der Schweiz. Band 2: Nymphaeaceae bis Primulaceae. Birkhäuser, Basel: $956 \mathrm{~S}$.

Hesse P. (1971): A Textbook of Soil Chemical Analysis. John Murray, London: 520 S.

HesselmanN H. (1917): Studien über die Nitratbildung in natürlichen Böden und ihre Bedeutung in pflanzenökologischer Hinsicht. Medd Statens Skogsförsöksanst 13/14: 297-422.

HEWITT E.J. (1948): The resolution of the factors in soil acidity. The comparative effects of manganese and aluminium toxicities on some farm and market garden crops. Rep. agric. hort. Res. Sta. Bristol 58.

HILDEBRAND E.E. (1991): Die Untersuchung ungestört gelagerter Waldbodenproben - Methoden und Informationsgewinn. Kernforschungszentrum Karlsruhe (Eigenverlag), Karlsruhe: $201 \mathrm{~S}$.

HILDEBRAND E.E. (1994): The heterogeneous distribution of mobile ions in the rhizosphere of acid forest soils: Facts, causes and consequences. J. Environ. Sci. Health 29: 1973-1992.

Hill M.O., Evans D.F., BelL S.A. (1992): Long-term effects of excluding sheep from hill pastures in North Wales. J. Ecol. 1992: 1-13.

HoAgland D.R., MARTIN J.C., STeWART G.R. (1920): Relation of the soil solution to the soil extract. J. Agric. Res. 20: 381-395.

hoarau J., Barthes L., Bousser A., Deléens E., Prioul J.L. (1996): Effect of nitrate on water transfer across roots of nitrogen pre-starved maize seedlings. Planta 200: 405-415.

Hodge A. (2004): The plastic plant: root responses to heterogeneous supplies of nutrients. New Phyt. 162: 9-24.

Hodge A., GRAYSTon S.J., ORD B.G. (1996): A novel method for characterisation and quantification of root exudates. Plant Soil 184: 97-104. 
Hoffland E., Findenegg G.R., Nelemans J.A. (1989): Solubilization of rock phosphate by rape. II. Local exudation of organic acids as a response to P-starvation. Plant Soil 113: 161-165.

HOFMEISTER H. (1984): Das Gentiano Koelerietum Knapp 1942 im Mittelleine-Innerste Bergland. Braunschw. Naturkdl. Schr. 2: 45-56.

Holleman A.F., Wiberg E., Wiberg N. (1985): Lehrbuch der Anorganischen Chemie. 91.-100., verb. u. stark erw. Auflage, De Gruyter, Berlin: 1451 S.

HOLMGREN G.G.S. (1967): A rapid citrate-dithionite extractable iron procedure. Soil Sci. Soc. Am. J. 31: 210-211.

HOLZNER W. (1978): Weed species and weed communities. Vegetatio 38: 13-20.

HOPE SIMPSON J.F. (1938): A chalk flora on the Lower Greensand: Its use in interpreting the calcicole habit. J. Ecol. 26: 218-235.

HoraK O., Kinzel H. (1971): Typen des Mineralstoffwechsels bei den höheren Pflanzen. Österr. Bot. Z. 119: 475-495.

HoRST W.J. (1988): The physiology of manganese toxicity. In: Graham R.D., Hannam R.J., Uren N.C. (Eds.): Manganese in Soils and Plants. Kluwer Academic, Dordrecht: 175-188.

HövermanN J. (1963): Die naturräumlichen Einheiten auf Blatt 99 Göttingen. Geographische Landesaufnahme $1: 200$ 000. Bundesanstalt für Landeskunde und Raumforschung, Bad Godesberg: 39 S.

HURD T.M., SCHWINTZER T.R. (1996): Cluster roots of Alnus incana ssp. rugosa in the field and of four Alnus species in water culture with phosphorus and iron deficiency. Can. J. Bot. 74: 1684-1686.

Husband R., Herre A.E., TuRner S.L., Gallery R., Young J.P.W. (2002): Molecular diversity of arbuscular mycorrhizal fungi and patterns of host association over time and space in a tropical forest. Mol. Ecol. 11: 2669-2678.

HUTCHINSON G.E. (1965): The Ecological Theater and The Evolutionnary Play. Yale University Press, New Haven: 139 S.

HUtchinson T.C. (1967a): Ecotypic differentiation in Teucrium scorodonia with respect to susceptibility to lime-induced chlorosis and to shade factors. New Phyt. 66: 439.

HUTCHINSON T.C. (1967b): Lime chlorosis as a factor in seedling establishment on calcareous soils. I. A comparative study of species from acid and calcareous soils in their susceptibility to limechlorosis. New Phyt. 66: 697-705.

HUTCHINSON T.C. (1967c): The occurence of coralloid root systems in plants showing lime-chlorosis. Nature 214: 943.

HUtCHINSON T.C. (1968): A physiological study of Teucrium scorodonia ecotypes which differ in their susceptibility to lime-induced chlorosis. Plant Soil 28: 81-105.

IMSANDE J. (1998): Iron, sulfur, and chlorophyll deficiencies: A need for an integrative approach in plant physiology. Physiol. Plant. 103: 139-144.

INGESTAD T. (1973): Mineral nutrient requirements of Vaccinium vitis idaea and V. myrtillus. Physiol. Plant. 29: 239-246.

INGESTAD T. (1976): Nitrogen and cation nutrition of three ecologically different plant species. Physiol. Plant. 38: 29-34.

INSKEEP W.P., COMFORT S.D. (1986): Thermodynamic predictions for the effects of root exudates on metal speciation in the rhizosphere. J. Plant Nutr. 9: 567-586. 
Jackson W.A. (1967): Physiological effects of soil acidity. In: Pearson R.W., Adams F. (Eds.): Soil Acidity and Liming. American Society of Agronomy, Madison: 43-124.

JACOBSON L. (1945): Iron in the leaves and chloroplasts of some plants in relation to their chlorophyll content. Plant Physiol. 20: 233-245.

JAMES D.B. (1962): Factors affecting the growth of Molinia caerulea on a calcareous soil. J. Ecol. 50: 521-527.

JANDT U. (1999): Kalkmagerrasen am Südharzrand und im Kyffhäuser - Gliederung im überregionalen Kontext, Verbreitung, Standortsverhältnisse und Flora. Dissertationes Botanicae Bd. 322, 246 S.

JARVIS M.C. (1974): Soil factors affecting the distribution of plant communities on the cliffs of Craig Breidden, Montgomeryshire. J. Ecol. 62: 721-733.

JaRVIS M.C., DunCaN H.J. (1976): Profile distribution of sesquioxides under bracken, heather and other vegetation. Plant Soil 44: 129-140.

JefFeries R.L., WiLlis A.J. (1964a): Studies on the calcicole-calcifuge habit. I. Methods of analysis of soil and plant tissues and some results of investigations on four species. J. Ecol. 52: 121-138.

JefFeries R.L., WiLLIS A.J. (1964b): Studies on the calcicole-calcifuge habit. II. The influence of calcium on the growth and establishment of four species in soil and sand cultures. J. Ecol. 52: 691-707.

JefFREY D.W., PigotT C.D. (1973): The response of grasslands on sugar-limestone in Tessdale to application of phosphorus and nitrogen. J. Ecol. 61: 85-92.

Jeschke W., KiRk E., Peuke A., Pate J., Hartung W. (1997): Effects of P-efficiency on assimilation and transport of nitrate and phosphate in intact plants of castor bean (Ricinus communis L.).

J. Exp. Bot. 48: 75-91.

JofFE J.S. (1933): Lysimeter studies. 2. The movement and translocation of soil constituents in the soil profile. Soil Sci. 35: 239-257.

Johnson D., Leake J.R., Lee J.A., CAmpbell C.D. (1998): Changes in soil microbial biomass and microbial activities in response to 7 years simulated pollutant nitrogen deposition on a heathland and two grasslands. Environ. Pollut. 103: 239-250.

Johnson D., VANDenkoornhuYse P.J., Leake J.R., Gilbert L., Booth R.E., GRIME J.P., Young J.P.W., READ D.J. (2003): Plant communities affect arbuscular mycorrhizal fungal diversity and community composition in grassland microcosms. New Phyt. 161: 503-515.

Johnson H.S., SENDTNER O. (1854): Chemische Untersuchungen verschiedener Pflanzenaschen, Bodenarten und Gewässer und ihre Beziehung zu gewissen Vegetationsverhältnissen in Bayern. Flora 38: 645-652.

Johnson N.C., Graham J.H., SMITH F.A. (1997): Functioning of mycorrhizal associations along the mutualism-parasitism continuum. New Phyt. 135: 575-585.

JOHNSON P.A., BENNETT R.J. (1991): Aluminium tolerance of root cap cells. J. Plant Physiol. 137: 760-762.

JONES D.L. (1998): Organic acids in the rhizosphere - A critical review. Plant Soil 205: 25-44.

JONES D.L., DARRAH P.R. (1994): Role of root derived organic acids in the mobilization of nutrients from the rhizosphere. Plant Soil 166: 247-257.

Jones D.L., DARRAH P.R., KochiAn L.V. (1996): Critical evaluation of organic acid mediated iron dissolution in the rhizosphere and its potential role in root iron uptake. Plant Soil 180: 57-66.

JONES D.L., KochIAN L.V. (1995): Aluminium inhibition of the inositol 1,4,5-triphosphat transduction pathway in wheat roots: a role in aluminum toxicity? Plant Cell 7: 1913-1922. 
JoNES D.L., KochIAN L.V., GILROY S. (1998): Aluminum induces a decrease in cytosolic calcium concentration in BY-2 tobacco cell cultures. Plant Physiol. 116: 81-89.

JONES E.W. (1950): Experiments on iron metabolism in plants. IV. The inter-relationship of iron and potassium in the potato as affected by the presence of calcium carbonate. Rep. agric. hort. Res. Sta. Bristol, 71.

Jones H.E., Hodge A., KuzYAKov Y. (2004): Plant and mycorrhizal regulation of rhizodeposition. New Phyt. 163: 459-480.

JONES J.P., Fox R.L. (1978): Phosphorus nutrition of plants influenced by manganese and aluminum uptake from an Oxisol. Soil Sci. 126: 230-236.

JoRdAN H. (1976a): Geologische Karte von Niedersachsen 1 : 25000: Blatt Osterode Nr. 4227. 2., völlig neu bearb. Auflage. Niedersächsisches Landesamt für Bodenforschung, Hannover.

JoRDAN H. (1976b): Geologische Karte von Niedersachsen 1 : 25000: Erläuterungen zu Blatt Osterode Nr. 4227. Niedersächsisches Landesamt für Bodenforschung, Hannover: $148 \mathrm{~S}$.

JungK A., ClaAssen N. (1997): Ion diffusion in the soil-root system. Adv. Agron. 61: 53-110.

JURKeVItCH E., HADAR Y., CHEN Y. (1986): The remedy of lime-induced chlorosis in peanuts by Pseudomonas sp. siderophores. J. Plant Nutr. 9: 535-545.

JURKEVITCH E., HADAR Y., Chen Y. (1988): Involvement of bacterial siderophores in the remedy of lime-induced chlorosis. Soil Sci. Soc. Am. J. 52: 1032-1037.

JUSTICE J.K., SMITH R.L. (1962): Nitrification of ammonium sulfate in a calcareous soil as influenced by combination of moisture, temperature and levels of added nitrogen.

Soil Sci. Soc. Am. Proc. 26: 246-250.

KALLIANOU C.S. (2000): Chemical and physical characteristics of humic substances extracted from Greek soils varying in classification order and natural drainage. Commun. Soil Sci. Plant Anal. 31: 3063-3076.

KÄMPF N. (1981): Die Eisenoxidmineralogie einer Klimasequenz von Boden aus Eruptiva in Rio Grande do Sul, Brasilien. Dissertation, TU München, $271 \mathrm{~S}$.

Kania A., Langlade N., Martinoia E., Neumann G. (2003): Phosphorus deficiency-induced modifications in citrate catabolism and in cytosolic $\mathrm{pH}$ as related to citrate exudation in cluster roots of white lupin. Plant Soil 248: 117-127.

KARATHANASIS A.D. (1991): Seasonal variation in solution composition and mineral stability of two Kentucky Alfisols. Soil Sci. Soc. Am. J. 55: 881-890.

KAUPENJOHANN M., HANTSCHEL R. (1987): Die kurzfristige pH-Pufferung gestörter und ungestörter Waldbodenproben. Z. Pflanzenernähr. Bodenkd. 150: 156-160.

Keerthisinghe G., Hocking P.J., Ryan P.R., Delhaize E. (1998): Effect of phosphorus supply on the formation on the formation and function of proteoid roots of white lupin (Lupinus albus $L$.). Plant Cell Environ. 21: 467-478.

KeRLey S.J., LeACH J.E., Swain J.L., HuYghe C. (2000): Investigations into the exploitation of heterogeneous soils by Lupinus albus $L$. and $L$. pilosus Murr. and the effect upon plant growth. Plant Soil 222: 241-253.

KIEHNE U. (1986): Wachstum und Nährstoffaufnahme calcicoler und calcifuger Arten in Abhängigkeit vom pH-Wert des Substrats. Diplomarbeit, Universität Göttingen, 79 S.

KINRAIDE T.B. (1991): Identity of the rhizotoxic aluminium species. Plant Soil 134: 167-178.

KINZEL H. (1982): Pflanzenökologie und Mineralstoffwechsel. Ulmer, Stuttgart: 534 S. 
KIRKBy E.A., PILbeam D.J. (1984): Calcium as a plant nutrient. Plant Cell Environ. 7: 397-405.

KLAUSING O. (1988): Die Naturräume Hessens mit einer Karte der naturräumlichen Gliederung $1: 200$ 000. Schriftenr. Hess. Landesanst. Umwelt 67: 43 S.

KLÖPPER J.W., LEONG L., TEINTZE M., SCHROTH M.N. (1980): Enhanced plant growth by siderophores produced by PGPR. Nature 286: 885-886.

KNAPP R. (1942): Zur Systematik der Wälder, Zwergstrauchheiden und Trockenrasen des eurosibirischen Vegetationskreises. Arb. Zentralst. Veget. kartierung d. Reiches, Beilage zum 12. Rundbrief: $81 \mathrm{~S}$.

KochiAN L.V. (1995): Cellular mechanisms of aluminum toxicity and resistance in plants. Annu. Rev. Plant Physiol. Plant Mol. Biol. 46: 237-260.

Koedam N., Büscher P., van Speybroeck D. (1992): Acidiphily in Pteridophytes: Accessment of the role of root cation-exchange properties. J. Plant Nutr. 15: 2605-2619.

KOLESCH H., OKTAY M., HöFNeR W. (1984): Effects of iron chlorosis-inducing factors on the pH of the cytoplasm of sunflower (Helianthus annuus). Plant Soil 82: 215-221.

Kooijman A.M., Dopheide J.C.R., Sevink J., TAKKen I., Verstraten J.M. (1998): Nutrient limitations and their implications on the effects of atmospheric deposition in coastal dunes; lime poor and lime rich sites in the Netherlands. J. Ecol. 86: 511-526.

Koperski M., SaUer M., Braun W., Gradstein S.R. (2000): Referenzliste der Moose Deutschlands. Landwirtschaftsverlag, Münster: 519 S.

KoRNECK D. (1960): Das Mesobrometum collinum agrostietosum tenuis (subass. nov.). Hess. Florist. Briefe 9: 13-16.

Kosegarten H.U., Hoffmann B., Mengel K. (1999): Apoplastic $\mathrm{pH}$ and $\mathrm{Fe}^{3+}$ reduction in intact sunflower leaves. Plant Physiol. 121: 1069-1079.

KostKA J.E., LUTHER G.W. (1994): Partitioning and speciation of solid phase iron in saltmarsh sediments. Geochim. Cosmochim. Acta 58: 1701-1710.

KRAJina V.J., Madoc-Jones S., MelloR G. (1973): Ammonium and nitrate in the nitrogen economy of some conifers growing in Douglas-fir communities of the Pacific northwest of America.

Soil Biol. Biochem. 5: 143-147.

KRAMER D., RömHeld V., LANDSBeRg C.E., MARSCHNeR H. (1980): Induction of transfer-cell formation by iron deficiency in the root epidermis of Helianthus annuus. Planta 147: 335-339.

KRAUS G. (1911): Boden und Klima auf kleinstem Raum. Fischer, Jena: 184 S.

Kretzer A.M., Bidartondo M.I., Grubisha L.C., Spatafora J.W., Szaro T.M., Bruns T.D. (2000): Regional specialisation of Sarcodes sanguinea (Ericaceae) on a single fungal symbiont from the Rhizopogon ellenae (Rhizopoganaceae) species complex. Am. J. Bot. 87: 1778-1782.

KRIEBITZSCH W.U. (1978): Stickstoffnachlieferung in sauren Waldböden Nordwestdeutschlands. Scr. Geobot. 14: 66 S.

KüHNE B. (1987): Die Wirkung von Fe(II) und Fe(III) lonen auf die Keimung von calcicolen und calcifugen Pflanzenarten. Diplomarbeit, Universität Göttingen, $120 \mathrm{~S}$.

Kuntze H., Roeschmann G., Schwerdtfeger G. (1994): Bodenkunde. 5., neubearb. und erw. Auflage. Ulmer, Stuttgart: $424 \mathrm{~S}$.

LAAN P., Smolders A.J.P., Blom C.W.P.M., ARMStRong W. (1989): The relative roles of internal aeration, radial oxygen losses, iron exclusion and nutrient balances in flood tolerance of Rumex species.

Acta Bot. Neerl. 38: 131-145. 
LAGRANGe H., JAY-AlLgmAND C., LePeyRie F. (2002): Rutin, the phenoglycoside from eucalyptus root exudates, stimulates Pisolithus hyphal growth at picomolar concentrations. New Phyt. 149: 349-355.

LAINÉ P., OURRY A., BoucAUD J. (1995): Shoot control of nitrate uptake rates by roots of Brassica napus L.: Effects of localized nitrate supply. Planta 196: 77-83.

Lambers H., ChapIN III F.S., Pons T.L. (1998): Plant Physiological Ecology. Springer, New York: 540 S.

LAMONT B.B. (2003): Structure, ecology and physiology of root clusters: A review. Plant Soil 248: 1-19.

LANDOLT E. (1977): Ökologische Zeigerwerte zur Schweizer Flora. Veröffentlichungen des Geobotanischen Instituts der ETH, Stiftung Rübel, 64: 208 S.

LANDSBERG C.E. (1981): Organic acid synthesis and release of hydrogen ions in response to iron deficiency stress of mono- and dicotolydeneous plant species. J. Plant Nutr. 3: 579-581.

LANDSBERG C.E. (1986): Function of rhizodermal transfer cells in the iron stress response of Capsicum annuum L. Plant Physiol. 82: 511-517.

LANDSBERG C.E. (1989): Proton efflux and transfer cell formation as response to Fe deficiency of soybean in nutrient solution culture. Plant Soil 114: 53-61.

Larbi A., Morales F., Lopez-Millan A.F., Gogorcena Y., Abadia A., Moog P.R., Abadia J. (2001): Technical advance: Reduction of Fe(III)-chelates by mesophyll leaf disks of sugar beet. Multicomponent origin and effects of Fe deficiency. Plant Cell Physiol. 42: 94-105.

LARCHER W. (1994): Ökophysiologie der Pflanzen. 5. Auflage. Ulmer, Stuttgart: 394 S.

LaRsen P.B., Degenhardt J., Tal C.-Y., Stenzler L.M., Howell R.K., Kochian L.V. (1998): Aluminumresistant Arabidopsis mutants that exhibit altered patterns of aluminum accumulation and organic acid release from roots. Plant Phys. 117: 9-18.

LAWESSON J.E. (2003): pH optima for Danish forest species compared with Ellenberg reaction values. Folia Geobot. 38: 403-418.

LAWESSON J.E., FosAa A.M., Olsen E. (2003): Calibration of Ellenberg indicator values to the Faroe Islands. Appl. Vet. Sci. 6: 53-62.

Le Bot J., AdAmowicz S., Robin P. (1998): Modelling plant nutrition of horticultural crops: a review. Sci. Hortic. 74: 47-82.

Le Bot J., KIRKBY E.A., VAN Beusichem M.L. (1990): Manganese toxicity in tomato plants: effects on cation uptake and distribution. J. Plant Nutr. 13: 513-525.

Le Gales Y., Lamant A., Heller R. (1980): Fixation du calcium par des fractions macromoleculaires solubles isolées a partir de végétaux supérieurs. Physiol. Vég. 18: 431-444.

LEAKE J.R. (1994): The biology of myco-heterotrophic ('saprophytic') plants. New Phyt. 127: 171-216.

LeAKe J.R., ShaW G., READ D.J. (1990): The biology of mycorrhiza in the Ericaceae XVI. Mycorrhiza and iron uptake in Calluna vulgaris (L.) Hull in the presence of two calcium salts. New Phyt. 114: 651-657.

LEE J.A. (1998): Unintentional experiments with terrestrial ecosystems: ecological effects of sulphur and nitrogen pollutants. J. Ecol. 86: 1-12.

LeE J.A. (1999): The calcicole-calcifuge problem revisited. Adv. Bot. Res. 30: 1-30.

LEE J.A., CAPORN S.J.M. (1998): Ecological effects of atmospheric reactive nitrogen deposition on seminatural terrestrial ecosystems. New Phyt. 139: 127-134.

LeE J.A., Woolhouse H.W. (1969a): A comparative study of bicarbonate inhibition of root growth in calcicole and calcifuge grasses. New Phyt. 68: 1-11. 
LeE J.A., Woolhouse H.W. (1969b): Root growth and dark fixation of carbon dioxide in calcicoles and calcifuges. New Phyt. 68: 247-255.

LeE R.B., RATCLIFFe R.G. (1993): Subcellular distribution of inorganic phosphate, and levels of nucleoside triphosphate, in mature maize roots at low external phosphate concentrations: Measurement with ${ }^{31}$ P-NMR. J. Exp. Bot. 44: 587-598.

LeE R.B., RATCLIFfe R.G., SOUthon T.E. (1990): 31P NMR measurements of the cytoplasmic and vacuolar $\mathrm{Pi}$ content of mature maize roots: relationships with phosphorus status and phosphate fluxes. J. Exp. Bot. 41: 1063-1078.

Legge L.R., Thompson J.E., BAKER J.E., LIEBERMAN M. (1982): The effect of calcium on the fluidity of phase properties of microsomal membranes isolated from postclimacteric golden delicious apples. Plant Cell Physiol. 23: 161-169.

Leggett G.E., ARgYLE D.P. (1983): The DTPA-extractable iron, manganese, copper, and zinc from neutral and calcareous soils dried under different conditions. Soil Sci. Soc. Am. J. 47: 518-522.

LeHLE L. (1990): Phosphatidyl inositol metabolism and its role in signal transducing in growing plants. Plant Mol. Biol. 15: 647-658.

LEHMANN A. (1993): Samenkeimung und Keimwurzelentwicklung bei Ackerunkräutern in Abhängigkeit von pH-Wert und Ca-Gehalt des Substrats. Diplomarbeit, Universität Göttingen, 64 S.

LEPPER J. (1976a): Geologische Karte von Nordrhein-Westfalen 1 : 25 000: Blatt 4322 Karlshafen. Geologisches Landesamt Nordrhein-Westfalen, Krefeld.

LEPPER J. (1976b): Geologische Karte von Nordrhein-Westfalen 1 : 25 000: Erläuterungen zu Blatt 4322 Karlshafen. Geologisches Landesamt Nordrhein-Westfalen, Krefeld:190 S.

LEVITT J. (1980): Responses of Plants to Environmental Stressses - Vol. 2: Water, Salt, Radiation, and other Stresses. 2. Ed. Academic Press, New York: 607 S.

Lewis G.N., Randall M. (1961): Thermodynamics. 2nd Ed. McGraw-Hill, New York: 108 S.

LEWIS O.A.M., SOARES M.I.M., LIPS S.U. (1986): A photosynthetic and ${ }^{15} \mathrm{~N}$ investigation of the differential growth response of barley to nitrate, ammonium and nitrate + ammonium nutrition. In: Lambers $\mathrm{H}$., et al. (Eds.): Fundamental, Ecological and Agricultural Aspects of Nitrogen Nutrition in Higher Plants. Martinius Nijhoff Publishers, Dordrecht: 295-300.

LIANG Y.J., KESTER D.R. (1977): Kinetics of ferrous oxidation in aqueous media. EOS, Trans. Amer. Geophys. Union 58: 1168.

LIDON F.C., BARREIRO M.G., RAMALHO J.C., LAURIANO J.A. (1999): Effects of aluminum toxicity on nutrient accumulation in maize shoots: implications on photosynthesis. J. Plant Nutr. 22: 379-416.

LIN W. (1979): Potassium and phosphate uptake in corn roots. Further evidence for an electrogenic $\mathrm{H}^{+} / \mathrm{K}^{+}$ exchanger and an $\mathrm{OH}^{-} / \mathrm{P}_{\mathrm{i}}$ antiporter. Plant Physiol. 952-955.

LINDSAY W.L. (1979): Chemical Equilibria in Soils. Wiley, New York: 449 S.

LINDSAY W.L. (1988): Solubility and redox equilibria of iron compounds in soils. In: Stucki J.W., Goodman B.A., Schwertmann U. (Eds.): Iron in Soils and Clay Minerals. Reidel, Dordrecht: 37-62.

LINDSAY W.L. (1991): Iron oxide solubilization by organic matter and its effect on iron availibility. Plant Soil 130: 27-34.

LINDSAY W.L., NoRVELL W.A. (1978): Development of a DTPA soil test for zinc, iron, manganese, and copper. Soil Sci. Soc. Am. J. 42: 421-428.

LINDSAY W.L., SADIQ M. (1983): Use of pe $+\mathrm{pH}$ to predict and interpret metal solubility relationships in soils. Sci. Total Environ. 28: 169-178. 
LINDSAY W.L., SchWAB A.P. (1982): The chemistry of iron in soils and its availibility to plants. J. Plant Nutr. 5: 821-840.

LiNK H.F. (1789): Florae Goettingensis - Specimen Sistens Vegetabilia Saxo Calcareo Propria. Dissertation, Universität Göttingen, $43 \mathrm{~S}$.

Lionel D., De Silva R., MANSfield T.A., McAinsh M.R. (2001): Changes in stomatal behaviour in the calcicole Leontodon hispidus due to the disruption by ozone of the regulation of apoplastic $\mathrm{Ca}^{2+}$ by trichomes. Planta 214: 158-162.

LITAOR M.I. (1988a): Review of soil solution samplers. Water Resour. Res. 24: 727-733.

LITAOR M.I. (1988b): Soil solution chemistry in an alpine watershed, Front Range, Colorado, U.S.A. Arctic Alpine Res. 20: 485-491.

LIU W.-T., MARSH T.L., CHENG H., FoRNEY L.J. (1997): Characterization of microbial diversity by determining terminal restriction fragment length polymorphism of genes encoding $16 S$ rDNA. Appl. Environm. Microbiol. 63: 4516-4522.

LOBARTINI J.C., ORIOLI G.A. (1988): Absorption of iron Fe-humate in nutrient solutions by plants. Plant Soil 106: 153-157.

LOBARTINI J.C., TAN K.H., PAPE C. (1998): Dissolution of aluminum and iron phosphate by humic acids. Commun. Soil Sci. Plant Anal. 29: 535-544.

LOEPPERT R.H. (1986): Chemistry and interaction of Fe with soil carbonate. J. Plant Nutr. 9: 195-214.

LOEPPERT R.H. (1988): Chemistry of iron in calcareous systems. In: Stucki J.W., Goodman B.A., Schwertmann U. (Eds.): Iron in Soils and Clay Minerals. Reidel, Dordrecht: 689-713.

LOEPPERT R.H., HALLMARK C.T. (1985): Indigenous soil properties influencing the availability of iron in calcareous soil. Soil Sci. Soc. Am. J. 49: 597-603.

LOHMEYER W. (1953): Beitrag zur Kenntnis der Pflanzengesellschaften in der Umgebung von Höxter an der Weser. Mitt. Florist.-Soziol. Arbeitsgem. N. F. 4: 59-76.

Lopez-Millan A.F., Morales F., Abadia A., Abadia J. (2000a): Effects of iron deficiency on the composition of the leaf apoplastic fluid and xylem sap in sugar beet. Implications for iron and carbon transport. Plant Physiol. 124: 873-884.

Lopez-Millan A.F., Morales F., Andaluz S., Gogorcena Y., Abadia A., De-Las-Rivas J., Abadia J. (2000b): Responses of sugar beet roots to iron deficiency. Changes in carbon assimilation and oxygen use. Plant Physiol. 124: 885-897.

Lopez-Millan A.F., Morales F., Abadia A., Abadia J. (2001a): Iron deficiency-associated changes in the composition of the leaf apoplastic fluid from field-grown pear (Pyrus communis L.) trees. J. Exp. Bot. 52: 1489-1498.

Lopez-Millan A.F., Morales F., Gogorcena Y., Abadia A., Abadia J. (2001b): Iron resupply-mediated deactivation of Fe-deficiency stress responses in roots of sugar beet.

Aust. J. Plant Physiol. 28: 171-180.

LöTSCHERT W. (1959): Kalkpflanzen auf saurem Untergrund. Flora 147: 417-428.

LOUIS I., RACETTE S., TORREY J.G. (1990): Occurence of cluster roots on Myrica cerifera L. (Myricaceae) in water culture in relation to phosphorus nutrition. New Phyt. 115: 311-317.

LöVE A., LöVE D. (1975): Nomenclatural adjustments in some European monocotyledons. Folia Geobot. Phytotaxon. 10: 271-276.

LoVELAND P.J. (1988): The assay for iron in soils and clay minerals. In: Stucki J.W., Goodman B.A., Schwertmann U. (Eds.): Iron in Soils and Clay Minerals. Reidel, Dordrecht: 99-140. 
Loveland P.J., DigBY P.G. (1984): The extraction of Fe and Al by $0.1 \mathrm{M}$ pyrophosphate solutions: a comparion of some techniques. J. Soil Sci. 35: 243-250.

Lovley D.R., Coates J.D., Blunt-HaRris E.L., Phillips E.J.P., WoodWARd J.C. (1996): Humic substances as electron acceptors for microbial respiration. Nature 382: 445-448.

Lovley D.R., Fraga J.L., Blunt-Harris E.L., Hayes L.A., Phillips E.-J.P., Coates J.D. (1998): Humic substances as a mediator for microbially catalyzed metal reduction.

Acta Hydrochim. Hydrobiol. 26: 152-157.

Ludwig B., Meiwes K.J., Khanna P., Gehlen R., Fortmann H., Hildebrand E.E. (1999): Comparison of different laboratory methods with lysimetry for soil solution composition - experimental and model results. J. Plant Nutr. Soil Sci. 162: 343-351.

LUTHER G.W., ChURCH T.M. (1988): Seasonal cycling of sulfur and iron porewaters of a Delaware salt marsh. Mar. Chem. 23: 295-309.

Luther G.W., KostKa J.E., Church T.M., Sulzberger B., Stumm W. (1992): Seasonal iron cycling in the salt-marsh sedimentary environment: the importance of ligand complexes with $\mathrm{Fe}(\mathrm{II})$ and $\mathrm{Fe}(\mathrm{III})$ in the dissolution of $\mathrm{Fe}$ (III) minerals and pyrite, respectively. Mar. Chem. 40: 81-103.

LUXMOORE R.J. (1981): Micro-, meso-, and macroporosity of soil. Soil Sci. Soc. Am. J. 45: 671-671.

LYNCH J. (1995): Root architecture and plant productivity. Plant Physiol. 109: 713-717.

MAAS F.M., VAN DE Wetering D.A.M., VAN Beusichem M., Bienfait H.F. (1988): Characterization of phloem iron and its possible role in the regulation of Fe efficiency reactions. Plant Phys. 87: 167-171.

MACFALL J.S., SLACK S.A., WEHRLI S. (1992): Phosphorus distribution in red pine roots and the ectomycorrhizal fungus Hebeloma arenosa. Plant Physiol. 100: 713-717.

MAdigan M.T., MARTinko J.M., PACK P. (2001): Mikrobiologie. Spektrum Akademischer Verlag, Heidelberg: $1175 \mathrm{~S}$.

MAHDI A., LAW R., WILLIS A.J. (1989): Large niche overlaps among coexisting plant species in a limestone grassland community. J. Ecol. 77: 386-400.

MARRS R.H., BANNISTER P. (1978a): Response of several members of the Ericaceae to soils of contrasting pH and base-status. J. Ecol. 66: 829-834.

MARRS R.H., BANNISTER P. (1978b): The adaptation of Calluna vulgaris (L.) Hull to contrasting soil types. New Phyt. 81: 753-761.

MARSCHNER H. (1991): Root-induced changes in the availability of micronutrients in the rhizosphere. In: Waisel Y., Eshel A., Kafkafi U. (Eds.): Plant-Roots: The Hidden Half. Marcel Dekker, Inc., New York: 503-528.

MARSCHNER H. (1995): Mineral Nutrition of Higher Plants. Second edition. Academic Press, London: 889 S.

Marschner H., Mengel K. (1966): Der Einfluß von Ca- und H-lonen bei unterschiedlichen Stoffwechselbedingungen auf die Menbranpermeabilität junger Gerstenwurzeln.

Z. Pflanzenernähr. Düng. Bodenk. 112: 39-49.

MARSCHNER H., RöMHELD V., CAKMAK I. (1987): Root-induced changes of nutrient availability in the rhizosphere. J. Plant Nutr. 10: 1175-1184.

Masalha J., Kosegarten H., Elmaci O., Mengel K. (2000): The central role of microbial activity for iron acquisition in maize and sunflower. Biol. Fertil. Soils 30: 433-439.

MASON B., MooRE C.B. (1985): Grundzüge der Geochemie. Enke, Stuttgart: 340 S. 
MAYR E. (2002): Die Autonomie der Biologie. Naturwissen. Rundschau 55: 23-29.

McAinsh M.R., Clayton H., Mansfield T.A., Hetherington A.M. (1996): Changes in stomatal behavior and guard cell cytosolic free calcium in response to oxidative stress. Plant Physiol. 111: 1031-1042.

MCBRIDE M.B. (1994): Environmental Chemistry of Soils. Oxford University Press, Oxford: 406 S.

McLAUghLin S.B., WimmeR R. (1999): Tansley Review No. 104: Calcium physiology and terrestrial ecosystem processes. New Phyt. 142: 373-417.

McNeal B.L., LaYfield D.A., NoRVell W.A., RHOAdes J.D. (1968): Factors influencing hydraulic conductivity of soils in the presence of mixed salt solutions. Soil Sci. Soc. Am. Proc. 32: 187-190.

McVean D.N., Ratcliffe D. (1962): Plant Communities of the Scottish Highlands. Nature Conversation Monographs No. 1. HMSO, London.

Meiwes K.-J., KöniG, N., Khanna, P. K., Prenzel, J., UlRich, B. (1984): Chemische Untersuchungsverfahren für Mineralboden, Auflagehumus und Wurzeln zur Charakterisierung und Bewertung der Versauerung in Waldböden. Ber. Forschungszentrum Waldökosysteme/Waldsterben 7: $142 \mathrm{~S}$.

Mengel K. (1991): Ernährung und Stoffwechsel der Pflanze. 7. überarb. Auflage. Fischer, Jena: 446 S.

MENGEL K. (1994): Iron availability in plant tissues - iron chlorosis on calcareous soils. Plant Soil 165: 275-283.

Mengel K., GeURTZen G. (1986): Iron chlorosis on calcareous soils. Alkaline nutritional conditions as the cause for the chlorosis. J. Plant Nutr. 9: 161-173.

Mengel K., Mallisiovas N. (1981): Bicarbonate as inducing factor of iron chlorosis in vine (Vitis vinifera). Vitis 20: 235-243.

Mengel K., Plänker R., Hoffmann B. (1994): Relationship between leaf apoplast pH and Fe chlorosis of sunflowers (Helianthus annuus L.). J. Plant Nutr. 17: 1053-1064.

Menzies N.W., Bell L.C., EdwARDs D.G. (1991): A simple positive pressure apparatus for the ultrafiltration of soil solution. Commun. Soil Sci. Plant Anal. 22: 137-145.

MeUSEL H. (1939): Die Vegetationsverhältnisse der Gipsberge im Kyffhäuser und im südlichen Harzvorland. Hercynia 2: 372 S.

Mevius W. (1921): Beiträge zur Physiologie "kalkfeindlicher Gewächse". Jb. wiss. Bot. 60: 147-183.

Mevius W. (1927): Reaktion des Bodens und Pflanzenwachstum. Naturwissenschaft und Landwirtschaft Heft 11: $153 \mathrm{~S}$.

Mevius W. (1931): Die Bestimmung des Fruchtbarkeitszustandes des Bodens auf Grund des natürlichen Pflanzenbestandes. In: Blanck E. (Ed.): Handbuch der Bodenlehre, 8. Band: Der Kulturboden und die Bestimmung seines Fruchtbarkeitszustandes. Springer, Berlin: 49-106.

Mimura T., Shindo C., Kato M., Yokota E., Sakano K., Ashihara H., Shimmen T. (2000): Regulation of cytoplasmic $\mathrm{pH}$ under extreme acid conditions in suspension cultured cells of Catranthus roseus: a possible role of inorganic phosphate. Plant Cell Physiol. 41: 424-431.

MiNORSKY P.V. (1985): A heuristic hypothesis of chilling injury in plants: A role of calcium as the primary physiological transducer of injury. Plant Cell Environ. 8: 75-94.

MISRA A., TYLER G. (1999): Influence of soil moisture on soil solution chemistry and concentrations of minerals in the calcicoles Phleum phleoides and Veronica spicata grown on a limestone soil. Ann. Bot. 84: 401-410. 
Mitchley J., GRUBb P.J. (1986): Control of Relative Abundance of Perennials in Chalk Grassland in Southern England. I. Constancy of Rank Order and Results of Pot-Experiments and FieldExperiments on the Role of Interference. J. Ecol. 74: 1139-1166.

Möвus G. (1966): Abriß der Geologie des Harzes. B. G. Teubner Verlagsgesellschaft, Leipzig: 219 S.

Mohamed A.A., Agnolon F., Cesco S., Varanini Z., Pinton R. (1998): Incidence of lime-induced chlorosis: plant response mechanisms and role of water soluble humic substances. Agrochimica 42: 255-262.

Molina R., MASSicotTe H., TRAPPE J.M. (1992): Specificity phenomena in mycorrhizal symbiosis: community-ecological consequences and practical implications. In: Allen M.F. (Ed.): Mycorrhzial Functioning. Chapman \& Hall, London: 357-423.

MoLz E. (1907): Untersuchungen über die Chlorose von Reben. Dissertation, Universität Jena.

MORAGHAN J.T., FREEMAN T.J. (1978): Influence of FeEDDHA on growth and manganese accumulation in flax. Soil Sci. Soc. Am. J. 42: 445-460.

Morales F., Grasa R., Abadia A., Abadia J. (1998): Iron chlorosis paradox in fruit trees. J. Plant Nutr. 21: 815-825.

MORAN R. (1982): Formulae for determination of chlorophyllous pigments extracted with N, NDimethylformamide. Plant Physiol. 69: 1376-1381.

MORAN R., PORATH D. (1980): Chlorophyll determination in intact tissues using N, N-Dimethylformamide. Plant Physiol. 65: 478-479.

MoReCROFt M.D., SeLLeRs E.K., LeE J.A. (1994): An experimental investigation into the effects of atmospheric nitrogen deposition on two semi-natural grasslands. J. Ecol. 82: 475-483.

MubaRAK A., Olsen R.A. (1976): Immiscible displacement of the soil solution by centrifugation. Soil Sci. Soc. Am. J. 40: 329-331.

MunCH J.C., OtTow J.C.G. (1982): Einfluss von Zellkontakt und Eisen(III)-oxidform auf die bakterielle Eisenreduktion. Z. Pflanzenernähr. Bodenkd. 145: 66-77.

MURPHY J., RILEY J.P. (1962): A modified single solution method for the determination of phosphate in natural waters. Anal. Chim. Acta 27: 31-36.

MURPHY P.J., LANGRIDGE P., SMITH S.E. (1997): Cloning plant genes differentially expressed during colonization of roots of Hordeum vulgare by the vesicular-arbuscular mycorrhizal fungus Glomus intraradices. New Phyt. 135: 291-301.

MustaRT P.J., Cowling R.M. (1993): The Role of Regeneration Stages in the Distribution of Edaphically Restricted Fynbos Proteaceae. Ecol. 74: 1490-1499.

NASSERY H. (1969): Polyphosphate formation in the roots of Deschampsia flexuosa and Urtica dioica. New Phyt. 68: 21-23.

NASSERY H. (1970): Phosphate absorption by plants from habitats of different phosphate status. II. Absorption and incorporation of phosphate by intact plants. New Phyt. 69: 197-203.

NASSERY H. (1971): Phosphate absorption by plants from habitats of different phosphate status. III. Phosphate fractions in the roots of different plants. New Phyt. 70: 949-951.

NASSERY H., HARLEY J.L. (1969): Phosphate absorption by plants from habitats of different phosphate status. I. Absorption and incorporation of phosphate by excised roots. New Phyt. 68: 13-20.

Nealson H., SAfFarini D. (1994): Iron and manganese in anaerobic respiration: environmental significance, physiology, and regulation. Annu. Rev. Microbiol. 48: 311-343. 
NeALson K.H. (1983): The microbial manganese cycle. In: Krumbein W.E. (Ed.): Microbial Geochemistry. Blackwell, Oxford: 191-221.

NeITKo K.F., FRANKEnBerg W.T.JR. (1989): Biosynthesis of cytokinins in soil. Soil Sci. Soc. Am. J. 53: 735-740.

NeLson L.E. (1983): Tolerance of 20 rice cultivars to excess Al and Mn. Agr. J. 21: 434-436.

Nentwig W., Bacher S., Beierkuhnlein C., BRANDL R., GrabherR G. (2004): Ökologie. Spektrum Akademischer Verlag, Heidelberg: 466 S.

NeumANn G., RömHeLd V. (2001): The release of root exudates as affected by the plant's physiological status. In: Pinton R., Varanini Z., Nannipieri P. (Eds.): Rhizosphere: Biogeochemistry and Organic Substances at the Soil-Plant Interface. Marcel Dekker, New York: 41-93.

Neumann G., Massonneau A., Martinoia E., Römheld V. (1999): Physiological adaptations to phosphorus deficiency during proteoid root development in white lupin. Planta 208: 373-382.

NeWman D.K., KolteR R. (2000): A role for excreted quinones in extracellular electron transfer. Nature 405: 94-97.

Niemann G.J., PuReveen J.B.M., EiJkel G.B., PoORTeR H., Boon J. (1992): Differences in relative growth rate in 11 grasses correlate with differences in chemical composition as determined by pyrolysis mass spectrometry. Oecologia 89: 657-573.

NikLAus P.A., Leadley P.W., Stöcklin J., KöRNeR C. (1998): Nutrient relations in calcareous grassland under elevated $\mathrm{CO}_{2}$. Oecologia 116: 67-75.

Nikolic M., RömHeLd V. (1999): Mechanism of Fe uptake by the leaf symplast: Is Fe inactivation in leaf a cause of Fe deficiency chlorosis? Plant Soil 215: 229-237.

NIKolıc M., RöMHELD V. (2002): Does high bicarbonate supply to roots change availability of iron in the leaf apoplast? Plant Soil 241: 67-74.

NitsChe S., BultmanN, M. (1995): Magerrasen und Heiden im Raum Kassel. Naturschutz in Hessen, Sonderheft 1: $108 \mathrm{~S}$.

NovoA R., Loomis R.S. (1981): Nitrogen and plant production. Plant Soil 58: 177-204.

O'CoNNOR P.J., Smith P.J., SMITH F.A. (2002): Arbuscular mycorrhizas influence plant diversity and community structure in a semiarid herbland. New Phyt. 154: 209-218.

Oberdorfer E., Korneck D. (1976): Klasse: Festuco-Brometea. In: Oberdorfer E. (Ed.): Süddeutsche Pflanzengesellschaften. Fischer, Stuttgart: 86-180.

ODum E.P. (1969): The strategy of ecosystem development. Science 164: 262-270.

ÖHLMANN V. (1898): Vegetative Fortpflanzung der Sphagnen. Dissertation, Freiburg (Schweiz).

OLSEN C. (1923): Studies on the H-conc. of the soil and its significance to the vegetation, especially to the natural distribution of plants. C. R. Lab. Carlsberg 15 (1).

OLSEN C. (1925): Studies on the growth of some Danish agricultural plants in soils with different H-conc. C. R. Lab. Carlsberg 16 (2).

OLSEN C. (1942): Water culture experiments with higher green plants in nutrient solutions having different concentrations of calcium. Compt. Rend. Trav. Lab. Carlsberg, Sér. chim. 24: 69-97.

OLSEN C. (1958): Iron uptake in different plant species as a function of the $\mathrm{pH}$ value of the nutrient solution. Physiol. Plant. 11: 889-905.

Olsen R.A., Bennett J.H., Blume D., Brown J.C. (1981): Chemical aspects of the Fe stress response mechanisms in tomatoes. J. Plant Nutr. 3: 905-921. 
Olsen S.R., Cole C.V., Watanabe F.S., Dean L.A. (1954): Estimation of available phosphorus in soils by extraction with sodium bicarbonate. U.S. Department of Agriculture Circular, 939.

OLSSON P.A., TYLER G. (2004): Occurence of non-mycorrhizal plant species in south Swedish rocky habitats is related to exchangeable soil phosphate. J. Ecol. 92: 808-815.

OWNBY J.D., PoPHAM H.R. (1989): Citrate reverses the inhibition of wheat root growth caused by aluminium. J. Plant Physiol. 135: 588-591.

Palmer M.W., ARevalo J.R., Cobo M.D., EarLs P.G. (2003): Species richness and soil reaction in a northeastern Oklahoma landscape. Folia Geobot. 38: 381-389.

PANDEYA S.B., Singh A.K., DhaR P. (1998): Influence of fulvic acid on transport of iron in soils and uptake by paddy seedlings. Plant Soil 198: 117-125.

PARKER D.R., ChANEY R.L. (1995): GEOCHEM-PC - A chemical speciation program for IBM and compatible personal computers. In: Loeppert R.H., Schwab A.P., Goldberg S. (Eds.): Chemical Equilibrium and Reaction Models. Soil Science Society of America Inc., Madison: 253-269.

Parker D.R., Chaney R.L., Norvell W.E. (1995): Chemical equilibrium models: applications to plant nutrition research. In: Loeppert R.H., Schwab A.P., Goldberg S. (Eds.): Chemical equilibrium and reaction models. Soil Science Society of America Inc., Madison: 163-200.

PARKER D.R., ZelaZnY L.W., KINRAIDE T.B. (1987): Improvements to the program GEOCHEM. Soil Sci. Soc. Am. J. 51: 488-491.

PÄRTEL M. (2002): Local plant diversity patterns and evolutionary history at the regional scale. Ecol. 83: 2361-2366.

PAUL H. (1906): Zur Kalkempfindlichkeitsfrage der Torfmoose. Ber. Dtsch. Bot. Ges. 24: 148-154.

PEACE W.J.H., GRUBB P.J. (1982): Interaction of light and mineral nutrient supply in the growth of Impatiens parviflora. New Phyt. 90: 127-150.

PeAt H.J., FitTeR A.H. (1993): The distribution of arbuscular mycorrhizas in the British Flora. New Phyt. 125: 845-854.

Pechackova S., Albrechtova M., Hadincova V., Krahulec F., Herben T. (2004): Horizontal and vertical distribution of root absorption zones of four common grass species in a mountain grassland. New Phyt. 161: 303-312.

Peet R.K., FridLey J.D., GramLing J.M. (2003): Variation in species richness and species pool size across a pH gradient in forests of the southern blue ridge mountains. Folia Geobot. 38: 391-401.

Penaloza E., Corcuera L., Martinez J. (2002): Spatial and temporal variation in citrate and malate exudation and tissue concentration as affected by $\mathrm{P}$ stress in roots of white lupin.

Plant Soil 241: 209-221.

Perotto S., Bonfante P. (1998): Genetic and functional diversity of ericoid mycorrhizal fungi. Symbiosis 25: 19-27.

Perring F. (1960): Climatic gradients of chalk grasslands. J. Ecol. 48: 415-442.

Pfanneberg T., Fischer W.R. (1984): An aerobic Corynebacterium from soil and its capability to reduce various iron oxides. Zbl. Mikrobiol. 139: 167-172.

Phoenix G.K., Booth R.E., Leake J.R., Read D.J., Grime J.P., Lee J.A. (2003): Effects of enhanced nitrogen deposition and phosphorus limitation on nitrogen budgets of semi-natural grasslands. Global Change Biol. 9: 1309-1321.

PierRe W.H., BANWART W.L. (1973): Excess-base and excess-base/nitrogen ratio of various crop species and parts of plants. Agron. J. 65: 91-96. 
PierRe W.H., Meisinger J., BiRChett J.R. (1970): Cation-anion balance in crops as a factor in determining the effect of nitrogen fertilizers. Agron. J. 62: 106-112.

PIGotT C.D. (1962): Soil formation and development on the Carboniferous limestone of Derbyshire. I. Parent materials. J. Ecol. 50: 145-156.

PlaCe G.A., DunN J.E., HARDY G.W. (1969): Statistical technique for predicting chlorosis of rice growing in calcareous soil. Soil Sci. 107: 31-38.

PLÄNKeR R. (1991): Bedeutung des Apoplasten-pH-Werts für die Eisenchlorose. Untersuchungen an Helianthus annuus. Dissertation, Universität Gießen.

Ponnamperuma F.N. (1972): The chemistry of submerged soils. Adv. Agron. 24: 29-96.

Ponnamperuma F.N., Tianco E.M., LoY T. (1967): Redox equilibria in flooded soils: I. The iron hydroxide systems. Soil Sci. 103: 374-382.

POORTER H., BeRgKotTe M. (1992): Chemical composition of 24 wild species differing in relative growth rate. Plant Cell Environ. 15: 221-229.

PoovalAH B.W. (1988): Calcium and senescence. In: Nooden L.D., Leopold A.C. (Eds.): Senescence and Aging in Plants. Academic Press, San Diego: $526 \mathrm{~S}$.

Pотт R. (1992): Die Pflanzengesellschaften Deutschlands. Ulmer, Stuttgart: 426 S.

Powell P.E., Szaniszlo P.J., Cline J.R., Reid C.P.P. (1982): Hydroxamate siderophores in the iron nutrition of plants. J. Plant Nutr. 5: 653-673.

PoWer S.A., ASHMORE M.R., Cousins D.A. (1998a): Impacts and fate of experimentally enhanced nitrogen deposition on a British lowland heath. Environ. Pollut. 102: 27-34.

Power S.A., Ashmore M.R., Cousins D.A., ShepPARd L.J. (1998b): Effects of nitrogen addition on the stress sensitivity of Calluna vulgaris. New Phyt. 138: 663-673.

PuRNelL H.M. (1960): Studies of the family Proteaceae: I. Anataomy and morphology of the roots of some Victorian species. Austr. J. Bot. 8: 38-50.

RAABE E.-W. (1960): Über die Vegetationstypen am Dummersdorfer Ufer, dem linken Ufer der Untertrave. Ber. Ver. "Natur u. Heimat" u. Naturhist. Mus. Lübeck 2: 5-78.

RADIN J.W. (1990): Responses of transpiration and hydraulic conductance to root temperature in nitrogen- and phosphorus-deficient cotton seedlings. Plant Physiol. 92: 855-857.

RAO I.M., TERRY N. (1989): Leaf phosphate status, photosynthesis, and carbon partitioning in sugar beet. I. Changes in growth, gas exchange, and Calvin cycle enzymes. Plant Physiol. 90: 814-819.

RATCLIFFE D. (1961): Adaptation to habitat in a group of annual plants. J. Ecol. 49: 187-203.

RAVEN J.A. (1985): Regulation of $\mathrm{pH}$ and generation of osmolarity in vascular plants: a cost-benefit analysis in relation to efficiency of use of energy, nitrogen and water. New Phyt. 101: 25-77.

RAVEN J.A., WollenWEBer B., HANDLEY L.L. (1992): A comparison of ammonium and nitrate as nitrogen source for photolithotrophs. New Phyt. 121: 19-32.

RAY BENAYAS J.M. (1995): Patterns of diversity in the strata of boreal montane forests in British Columbia. J. Veg. Sci. 6: 95-98.

RAYNER M.L., JONES W.N. (1911): Preliminary observation on the ecology of Calluna vulgaris on the Wiltshire and Berkshire Downs, with soil analyses by J. W. Taylor. New Phyt. 10: 227-240.

READER R.J. (1992): Herbivory as confounding factor in an experiment measuring competition among plants. Ecol. 73: 373-376. 
Reid R.K., Reid C.P.P., Powell P.E., Szaniszlo P.J. (1984): Comparison of siderophore concentrations in aqueous extracts of rhizosphere ans adjacent bulk soils. Pedobiol. 26: 263-266.

REISENAUER H.M. (1978): Absorption and utilization of ammonium nitrogen by plants. In: Nielsen D.R., MacDonald J.G. (Eds.): Nitrogen in the Environment. Academic Press, New York: 157-189.

RICHTER G. (1941): Zur vergleichenden Stratigraphie des Zechsteins in Mitteldeutschland. Z. Kali 35: 193-197.

RICHTER G. (1942): Zur vergleichenden Stratigraphie des Zechsteins in Mitteldeutschland. Z. Kali 36: 4-12.

RICKLEFS R.W. (1977): Environmental heterogeneityand plant species diversity: a hypothesis. Am. Nat. 111: 376-381.

RoBbins C.W., WAGENET R.J., JURINAK J.J. (1980): A combined salt transport-chemical equilibrium model for calcareous and gypsiferous soils. Soil Sci. Soc. Am. J. 44: 1191-1194.

ROMERA F.J., ALCANTARA E., DE LA GUARDIA M.D. (1997): Influence of bicarbonate and metal ions on the development of root $\mathrm{Fe}(\mathrm{III})$ reducing capacity by Fe-deficient cucumber (Cucumis sativus) plants. Physiol. Plant. 101: 143-148.

RöMHELD V. (1987): Existence of two different strategies for the acquisition of iron in higher plants. In: Winkelmann G., van der Helm D., Neilands J.B. (Eds.): Iron Transport in Microbes, Plants and Animals. VCH, Weinheim: 353-373.

RöMHELD V. (1991): The role of phytosiderophores in acquisition of iron and other micronutrients in graminaceous species: An ecological approach. Plant Soil 130: 127-134.

RömHeLD V. (2000): The chlorosis paradox: Fe inactivation as a secondary event in chlorotic leaves of grapevine. J. Plant Nutr. 23: 1629-1643.

RöMHELD V., MARSCHNER H. (1981): Rhythmic iron stress reactions in sunflower at suboptimal iron supply. Physiol. Plant. 53: 354-360.

RöMHELD V., MARSCHNER H. (1983): Mechanisms of iron uptake by peanut plants: 1. Fe reduction, chelate splitting and release of phenolics. Plant Physiol. 71: 649-954.

RöMHELD V., MARSCHNER H. (1986a): Evidence for a specific uptake system for iron phytosiderophores in roots of grasses. Plant Physiol. 80: 175-180.

RÖMHELD V., MARSCHNER H. (1986b): Mobilization of iron in the rhizosphere of different plant species. In: Tinker B., Läuchli A. (Eds.): Advances in Plant Nutrition, Vol. 2. Praeger Scientific, New York: 155-204.

RömPP H. (1992): Römpp-Chemie-Lexikon. 9. erw. und bearb. Auflage. Thieme, Stuttgart.

Ron VAZ M.D., EdWARdS A.C., ShAND C.A., CRESSER M.S. (1993): Phosphorus fractions in soil solution: influence of soil acidity and fertilizer addition. Plant Soil 148: 175-183.

Ronov A.B., YAROSHEVSKY A.A. (1969): Chemical composition of the earth's crust. In: Hart P.J. (Ed.): The Earth's Crust and Upper Mantle: Structure, Dynamic Processes, and their Relation to DeepSeated Geological Phenomena. American Geophysical Union, Washington: 37-57.

RoRISON I.H. (1960a): Some experimental aspects of the calcicole-calcifuge problem. I. The effects of competition and mineral nutrition upon seedling growth in the field. J. Ecol. 48: 585-599.

RoRIson I.H. (1960b): The calcicole-calcifuge problem. II. The effects of mineral nutrition on seedling growth in solution culture. J. Ecol. 48: 679-688.

RoRISON I.H. (1967): A seedling bioassay on some soils in the Sheffield area. J. Ecol. 55: 725-741. 
RoRISON I.H. (1968): The response to phosphorus of some ecologically distinct plant species: I. Growth rates and phosphorus absorption. New Phyt. 67: 913-923.

RORISON I.H. (1986): The response of plants to acid soils. Experientia 42: 357-362.

RoRISON I.H., RoBINSON D. (1984): Calcium as an environmental variable. Plant Cell Environ. 7: 381-390.

RUNGE M. (1974a): Die Stickstoff-Mineralisation im Boden eines Sauerhumus-Buchenwaldes. I. Mineralstickstoff-Gehalt und Nettomineralisation. Oecol. Plant. 9: 201-218.

Runge M. (1974b): Die Stickstoff-Mineralisation im Boden eines Sauerhumus-Buchenwaldes. II. Die Nitratproduktion. Oecol. Plant. 9: 219-230.

RUNGE M. (1978): Die Stickstoff-Mineralisation im Boden einer montanen Goldhafer-Wiese (Trisetetum flavescentis). Oecol. Plant. 13: 147-162.

RUNGE M. (1983): Physiology and ecology of nitrogen nutrition. In: Lange O.L., Nobel P.S., Osmond C.B., Ziegler H. (Eds.): Encyclopedia of Plant Physiology. New Series, Volume 12 C: Physiological Plant Ecology III. Springer, Berlin: 163-200.

RUNGE M., RoDE M.W. (1991): Effects of soil acidity on plant associations. In: Ulrich B., Sumner M.E. (Eds.): Soil Acidity. Springer, Berlin: 183-202.

Russell R.S., CLARKSON D.T. (1976): Ion transport in root systems. In: Sunderland N. (Ed.): Perspectives in Experimental Botany, Vol. 2: Botany. Pergamon Press, Oxford: 401-411.

RyAn P.R., Delhaize E., Jones D.L. (2001): Function and mechanism of organic anion exudation from plant roots. Annu. Rev. Plant Physiol. Plant Mol. Biol. 52: 527-560.

RYAN P.R., DI TOMASO J.M., KochIAN L.V. (1993): Aluminium toxicity in roots: an investigation of spatial sensitivity and the role of the root cap. J. Exp. Bot. 44: 437-446.

SACHS L. (1992): Angewandte Statistik. 7. Auflage. Springer, Berlin: 846 S.

Saggar S., Hedley M.J., White R.E. (1990): A simplified resin membrane technique for extracting phosphorus from soils. Fertil. Res. 24: 173-180.

Saikkonen K., Faeth S.H., Helander M., Sullivan T.J. (1998): Fungal endophytes: a continuum of interactions with host plants. Annu. Rev. Ecol. Syst. 29: 319-343.

SAKANO K. (1998): Revision of biochemical pH-stat: involvement of alternative pathway metabolism. Plant Cell Physiol. 39: 467-477.

SALISBURY E.J. (1920): The significance of the calcicolous habit. J. Ecol. 8: $202 \mathrm{ff}$.

SANDERS J.R. (1983): The effect of $\mathrm{pH}$ on the total and free ionic concentrations of manganese, zinc and cobalt in soil solutions. J. Soil Sci. 34: 315-323.

SANDMANN G., BögeR P. (1983): The enzymatological function of heavy metals and their role in electron transfer processes of plants. In: Läuchli A., Bieleski R.L. (Eds.): Encyclopedia of Plant Physiology, New Series. Springer, Berlin: 563-596.

Satawathananont S., Patrick W.H., Moore P.A. (1991): Effect of controlled redox conditions on metal solubility in acid sulfate soils. Plant Soil 133: 281-290.

SATtelmaCheR B. (2001): Tansley review no. 22 - The apoplast and its significance for plant mineral nutrition. New Phyt. 149: 167-192.

Schachtman D.P., Reid R.J., Ayling S.M. (1998): Phosphorus uptake by plants: From soil to cell. Plant Physiol. 116: 447-453.

SCHALLER G., FISCHER W.R. (1985): Kurzfristige pH-Pufferung von Böden. Z. Pflanzenernähr. Bodenkd. 148: 471-480. 
SCHEFfer F., SchaChtSchabel P. (1992): Lehrbuch der Bodenkunde. 13., durchges. Auflage. Enke, Stuttgart: $491 \mathrm{~S}$.

Scheible W.R., GonzalezFontes A., Lauerer M., MullerRober B., Caboche M., Stitt M. (1997a): Nitrate acts as a signal to induce organic acid metabolism and repress starch metabolism in tobacco. Plant Cell 9: 783-798.

Scheible W.R., LaUerer M., Schulze E.D., Caboche M., Stitt M. (1997b): Accumulation of nitrate in the shoot acts as a signal to regulate shoot-root allocation in tobacco. Plant Journal 11: 671-691.

SCHLÄPfER M., ZoLLER H., KöRNER C. (1998): Influences of mowing and grazing on plant species composition in calcareous grassland. Bot. Helv. 108: 57-67.

Schlichting A., Leinweber P., Meissner R., Altermann M. (2002): Sequentially extracted phosphorus fractions in peat-derived soils. J. Plant Nutr. Soil Sci. 165: 290-298.

Schlichting E., Blume H.-P., Stahr K. (1995): Bodenkundliches Praktikum. 2. Auflage. Blackwell, Berlin: 295 S.

SCHLINKERT A. (1992): Jahreszeitliche Dynamik der Inhaltsstoffe von Bodenlösungen aus A-Horizonten unterschiedlicher Böden in Abhängigkeit von Bewirtschaftungsweise und Standorteigenschaften. Bonner Bodenkdl. Abh. 7: $271 \mathrm{~S}$.

SCHMIDT J.P. (1992): Kritische Anmerkungen zur Ermittlung von Stoffflüssen mittels Saugkerzen. Teil I: Theoretische Aspekte der Bodenlösungsgewinnung. Mitt. Dtsch. Bodenkdl. Ges. 67: 143-146.

SCHMIDT W., BARTELS M. (1996): Formation of root epidermal transfer cells in Plantago. Plant Phys. 110: 217-225.

SCHMidt W., BoomgaARden B., AhRens V. (1996): Reduction of root iron in Plantago lanceolata during recovery from Fe deficiency. Physiol. Plant. 98: 587-593.

SCHMIDT W., FÜHNER C. (1998): Sensitivity to and requirement for iron in Plantago species. New Phyt. 138: 639-651.

SCHOENAU J.J., HUANG W.Z. (1991): Anion exchange membrane, water, and sodium bicarbonate extractions as soil tests for phosphorus. Commun. Soil Sci. Plant Anal. 22: 465-492.

ScHolz P. (2000): Katalog der Flechten und flechtenbewohnenden Pilze. Schriftenr. Vegetationskd. 31, 298 S.

SCHÖTTELNDREIER M., FALKENGREN-GRERUP U. (1999): Plant induced alterations in the rhizosphere and the utilisation of heterogeneity. Plant Soil 209: 297-309.

SCHRIEL W. (1939): Erläuterungen zur Geologischen Karte von Preußen und benachbarten deutschen Ländern. Blatt 4328 - Bad Lauterberg, 76 S.

SCHWAB A.P., LINDSAY W.L. (1983): Effect of redox on the solubility and availibility of iron. Soil Sci. Soc. Am. J. 47: 201-205.

SCHWARZ O., BÄSSLER M. (1964): Danthonia (Sieglingia) decumbens, ein bemerkenswerter Fall chromosomaler und ökologischer Divergenz. Oesterr. Botan. Z. 111: 193-207.

SCHWERTMANN U. (1964): Differenzierung der Eisenoxide des Bodens durch photochemische Extraktion mit saurer Ammoniumoxalat-Lösung. Z. Pflanzenernähr. Düng. Bodenk. 105: 194-202.

SchWERTMANN U. (1973): Use of oxalate for Fe extraction from soils. Can. J. Soil Sci. 53: 244-246.

SCHWERTMANN U. (1988a): Occurrence and formation of iron oxides in various pedoenvironments. In: Stucki J.W., Goodman B.A., Schwertmann U. (Eds.): Iron in Soils and Clay Minerals.

D. Reidel Publishing Co, Dordrecht: 267-308. 
SCHWERTMANN U. (1988b): Some properties of soil and synthetic iron oxides. In: Stucki J.W., Goodman B.A., Schwertmann U. (Eds.): Iron in Soils and Clay Minerals. D. Reidel Publishing Co, Dordrecht: 203-250.

SCHWERTMANN U. (1991): Solubility and dissolution of iron oxides. Plant Soil 130: 1-25.

Seeliger S., CoRd-Ruwisch R., Schink B. (1998): A periplasmatic and extracellular c-type cytochrome of Geobacter sulfurreducens acts as ferric iron reductase and as an electron carrier to other acceptors or to partner bacteria. J. Bacteriol. 180: 3686-3691.

Sharples J.M., Chambers S.M., Meharg A.A., CaiRney J.-W.G. (2000): Genetic diversity of rootassociated fungal endophytes from Calluna vulgaris at contrasting field sites. New Phyt. 148: 153-162.

Shaw G., LeAKE J.R., BAKer A.J.M., ReAD D.J. (1990): The biology of mycorrhiza in the Ericaceae. $X V I I$. The role of mycorrhizal infection in the regulation of iron uptake by ericaceous plants. New Phyt. 115: 251-258.

SHEN Y., StRöm L., JönSSON J.A., TYLER G. (1996): Low-molecular organic acids in the rhizosphere soil solution of beech forest (Fagus sylvatica L.) Cambisols determined by ion chromatography using supported liquid membrane enrichment technique. Soil Biol. Biochem. 28: 1163-1169.

Shenker M., GhiRlando R., Oliver I., Helmann M., Hadar Y., Chen Y. (1995): Chemical structure and biological activity of rhizoferrin - a siderophore produced by Rhizopus arrhizus. Soil Sci. Soc. Am. J. 59: 837-843.

Shenker M., HADAR Y., Chen Y. (1996): Stability constants of the fungal siderophore rhizoferrin with various microelements and calcium. Soil Sci. Soc. Am. J. 60: 1140-1144.

Shenker M., Oliver I., Helmann M., Hadar Y., Chen Y. (1992): Utilization by tomatoes of iron mediated by a siderophore produced by Rhizopus arrhizus. J. Plant Nutr. 15: 2173-2182.

SIBBESEN E. (1977): A simple ion-exchange resin procedure for extracting plant-available elements from soil. Plant Soil 46: 665-669.

SILVERTOWN J.W. (1980): The dynamics of a grassland ecosystem: botanical equilibrium in the Park grass experiment. J. Appl. Ecol. 17: 491-504.

Skalova H., Krahulec F., During V., Pechackova S., Herben T. (1999): Grassland canopy composition and spatial heterogeneity in the light quality. Plant Ecol. 143: 129-139.

SKENE K.R. (2003): The evolution of physiology and development in the cluster root: Teaching an old dog new tricks? Plant Soil 248: 21-30.

SmilaUer P., SmilaUerova M. (2000): Effect of AM symbiosis exclusion on grassland community composition. Folia Geobot. Phytotaxon. 35: 13-25.

SMILEY R.W. (1974): Rhizosphere pH as influenced by plant, soil and nitrogen fertilizers. Soil Sci. Soc. Am. Proc. 38: 795-799.

SMith A.M., Robertson J.M. (1939): The influence of the plant upon seasonal changes in soil acidity. J. Agricult. Sci. 21: 822-851.

SMITH B.N. (1984): Iron in higher plants: Storage and metabolic role. J. Plant Nutr. 7: 759-766.

Smith F.W., Mudge S.R., RAE A.L., Glassop D. (2003): Phosphate transport in plants. Plant Soil 248: 71-83.

Smith S.E., ReAd D.J. (1997): Mycorrhizal Symbiosis. Academic Press, San Diego: 605 S.

SNAPP S., KOIDE R., LYNCH J.P. (1995): Exploitation of localized phosphorus-patches by common bean roots. Plant Soil 177: 211-218. 
SNAYDON R.W. (1962): The growth and ability of contrasting natural populations of Trifolium repens on calcareous and acidic soils. J. Ecol. 50: 439-447.

SNAYDON R.W., BRADSHAW A.D. (1961): Differential response to calcium within the species Festuca ovina L. New Phyt. 60: 219-234.

SNAYDON R.W., BRADSHAW A.D. (1962): Differences between natural populations of Trifolium repens L. in response to mineral nutrients. I. Phosphate. J. Exp. Bot. 13: 422-434.

SNAYDON R.W., BRADSHAW A.D. (1969): Differences between natural populations of Trifolium repens L. in response to mineral nutrients. II. Calcium, magnesium and potassium. J. Appl. Ecol. 6: 185-202.

SNedden W.A., Fromm J. (1998): Calmodulin, calmodulin-related proteinsand plant responses to the environment. Trends Plant Sci. 3: 299-304.

Sokolovski S.G., MehaRg A.A., MAATHUIS F.J.M. (2002): Calluna vulgaris root cells show increased capacity for amino acid uptake when colonized with the mycorrhizal fungus Hymenoscyphus ericae. New Phyt. 155: 525-530.

SoNG Q., McСомв A.J. (1996): Drying-induced stimulation of ammonium release and nitrification in reflooded lake sediment. Mar. Freshwater Res. 47: 531-536.

Sørensen S.P.L. (1909): Enzymstudien II. Über die Messung und die Bedeutung der H-Konzentration bei enzymatischen Prozessen. Bioch. Zeitschr. 21: $131 \mathrm{ff}$.

SøRENSEN T.A. (1948): A method of establishing groups of equal amplitude in plant sociology based on similarity of species content, and its application to analyses of the vegetation on Dannish commons. Biol. Skr. Dansk. Vidensk. Selsk. 5: 1-34.

STARK J.M., HART S.C. (1997): High rates of nitrification and nitrate turnover in undisturbed coniferous forests. Nature 385: 61-64.

StARR J.L., PARkin T.B., Meisinger J.J. (1992): Sample size consideration in the determination of soil nitrate. Soil Sci. Soc. Am. J. 56: 1824-1830.

StARR J.L., PARkin T.B., MeISInger J.J. (1995): Influence of sample size on chemical and physical soil measurements. Soil Sci. Soc. Am. J. 59: 713-719.

SteELE B. (1955): Soil pH and base status as factors in the distribution of calcicoles. J. Ecol. 43: 120-132.

Sternberg M., BRown V.K., MAsters G.J., ClaRke I.P. (1999): Plant community dynamics in a calcareous grassland under climate change manipulations. Plant Ecol. 143: 29-37.

Steubing L. (1965): Pflanzenökologisches Praktikum. Parey, Berlin: 262 S.

Steubing L., Fangmeier A. (1992): Pflanzenökologisches Praktikum. Ulmer, Stuttgart: 205 S.

StIENEN H., BAUCH J. (1988): Element content in tissues of spruce seedlings from hydroponic cultures simulating acidification and deacidification. Plant Soil 106: 231-238.

Stitt M., Muller C., Matt P., Gibon Y., Carillo P., Morcuende R., Scheible W.R., Krapp A. (2002): Steps towards an integrated view of nitrogen metabolism. J. Exp. Bot. 53: 959-970.

STITT M., SCHEIBLE W.R. (1998): Understanding allocation to shoot and root growth will require molecular information about which compounds act as signals for the plant nutrient status, and how meristem activity and cellular growth are regulated: Opinion. Plant Soil 201: 259-263.

StRaub K.L., Benz M., Schink B. (2001): Iron metabolism in anoxic environments at near neutral pH. FEMS Microbiol. Ecol. 34: 181-186. 
Streitwolf-Engel R., Boller T., Wiemken A., Sanders I.R. (1997): Clonal growth traits of two Prunella species are determined by co-occurring arbuscular mycorrhizal fungi from a calcareous grassland. J. Ecol. 85: 181-191.

Streitwolf-Engel R., van der HeiJden M.G.A., Wiemken A., Sanders I.R. (2001): The ecological significance of arbuscular mycorrhizal fungal effects on clonal reproduction in plants. Ecol. 82: 2846-2859.

STRÖM L. (1997): Root exudation of organic acids: Importance to nutrient availability and the calcifuge and calcicole behaviour of plants. Oikos 80: 459-466.

STRÖM L., OLSSON T., TYLER G. (1994): Differences between calcifuge and acidifuge plants in root exudation of low-molecular organic acids. Plant Soil 167: 239-245.

StRöm L., OWen A.G., GodBold D.L., Jones D.L. (2001): Organic acid behaviour in a calcareous soil: Implications for rhizosphere nutrient cycling. Soil Biol. Biochem. 33: 2125-2133.

STRÖM L., OWen A.G., Godbold D.L., Jones D.L. (2002): Organic acid mediated P mobilization in the rhizosphere and uptake by maize roots. Soil Biol. Biochem. 34: 703-710.

STRYER L. (1988): Biochemistry. 3. Edition. Freeman, New York: 1089 S.

STUCKI J.W. (1988): Structural iron in smectites. In: Stucki J.W., Goodman B.A., Schwertmann U. (Eds.): Iron in Soils and Clay Minerals. D. Reidel Publishing Co, Dordrecht: 625-675.

Stumm W., Lee G.F. (1961): Oxygenation of ferrous iron. Ind. Eng. Chem. 53: 143-146.

SUAREZ D.L. (1986): A soil water extractor that minimizes $\mathrm{CO}_{2}$ degassing and $\mathrm{pH}$ errors. Water Resour. Res. 22: 876-880.

SUAREZ D.L. (1987): Prediction of pH errors in soil-water extractors due to degassing. Soil Sci. Soc. Am. J. 51: 64-68.

SUAREZ D.L. (1995): Carbonate chemistry in computer programs and application to soil chemistry. In: Loeppert R.H., Schwab A.P., Goldberg S. (Eds.): Chemical equilibrium and reaction models. Soil Science Society of America Inc., Madison: 53-73.

SURIYAPPERUMA S.P., KoSKE R.E. (1995): Attraction of germ tubes and germination of spores of the arbuscular mycorrhizal fungus Gigaspora gigantea in the presence of roots of maize exposed to different concentrations of phosphorus. Mycologia 87: 772-778.

Susin S., Abadia A., Gonzales-Reyes J.A., LuCEnA J.J., Abadia J. (1996): The pH requirement for in vivo activity of the iron deficiency-induced "turbo" ferric chelate reductase. Plant Phys. 110: 111-123.

SutTon C.D., GunARY D. (1969): Phosphate equilibria in soils. In: Rorison I.H. (Ed.): Ecological Aspects of the Mineral Nutrition of Plants. Blackwell, Oxford: 127-134.

SYDES C.L. (1984): A comparative study of leaf demography in limestone grassland. J. Ecol. 72: 331-345.

SYDES C.L., GRIME J.P. (1984): A comparative study of root development using a simulated rock crevice. J. Ecol. 72: 937-946.

SYKES,M.T., VAN DER MAAREL,E. (1991): Spatial and temporal patterns in species turnover in the limestone grassland of Öland, Sweden. Abstracts 34th IAVS Symposium on Mechanisms in Vegetation Dynamics. Eger, Hungary: $36 \mathrm{~S}$.

Szaniszlo,P.J., TAI,S.C., CRowley,D.E., ReID,C.P.P. (1985): Mechanisms of iron acquisition from hydroxamate siderophores by two monocot plant species. Abstract: Advanced Nato Research Workshop, London.

TAGLIAVINI M., ScudellaRI D., MARANGoni B., Toselli M. (1995): Acid-spray regreening of kiwifruit leaves affected by lime-induced iron chlorosis. In: Abadia J. (Ed.): Kluwer, Dordrecht: 191-195. 
TAKAgI S., Nomoto K., TAKEmOTO T. (1984): Physiological aspects of mugeneic acid, a possible phytosiderophore of graminaceous plants. J. Plant Nutr. 7: 469-477.

TAKKAR P.N., ULRICH B., MeiWES K.-J. (1987): Method for estimation of $\mathrm{CO}_{2}$ (aq) plus $\mathrm{H}_{2} \mathrm{CO}_{3}{ }^{\circ}, \mathrm{HCO}_{3}{ }^{-}$and $\mathrm{pH}$ in soil solution collected under field conditions. Z. Pflanzenernähr. Bodenkd. 150: 319-326.

TAMm C.O. (1991): Nitrogen in Terrestrial Ecosystems. Ecological Studies, Vol. 81. Springer, Berlin: $115 \mathrm{~S}$.

TAN K., KeltJens W.G., Findenegg G.R. (1993): Evaluating the contribution of magnesium deficiency in the aluminium toxicity syndrome in twelve sorghum genotypes. Plant Soil 149: 255-261.

TANg C., LongneCKer N.E., Thomson C.J., Greenway H., Robson A.D. (1992): Lupin (Lupinus angustifolius L.) and pea (Pisum sativum L.) roots differ in their sensitivity to $\mathrm{pH}$ above 6.0. J. Plant Physiol. 140: 715-719.

TANSLEY A.G. (1917): On competition between Galium saxatile L. (G. hercynicum Weig.) and G. sylvestre Poll. (G. asperum Schreb.) on different types of soil. J. Ecol. 5: 173-179.

TANSLey A.G., Adamson R.S. (1925): Studies of the vegetation of the English chalk. J. Ecol. 13: 177-223.

TANSLEY A.G., RANKIN W.M. (1911): The plant-formation of calcareous soils. B. The sub-formation of the chalk. In: Tansley A.G. (Ed.): Types of British Vegetation. Cambridge University Press, Cambridge: 161-186.

Tawaraya K., Saito M., Morioka M., Wagatsuma T. (1996): Effect of concentration of phosphate on spore germination and hyphal growth of the arbuscular mycorrhizal fungus, Gigaspora margarita. Soil Sci. Plant Nutr. 42: 667-671.

TAYLOR A.A., De-FeliCE J., HAVILL D.C. (1982): Seasonal variation in nitrogen availability and utilization in an acidic and calcareous soil. New Phyt. 92: 141-152.

TAYLOR D.L., BRUNS T.D. (1999): Population, habitat, and genetic correlates of mycorrhizal specialization in the 'cheating' orchids Corallorhiza maculatum and C. merteniana. Mol. Ecol. 8: 1719-1732.

TAYLOR G.J. (1987): Exclusion of metals from the symplasm: a possible mechanism of metal tolerance in plants. J. Plant Nutr. 10: 1213-1222.

TeIN T.M., Gaskins M.H., Hubbell D.H. (1979): Plant growth substances produced by Azospirillum brasilense and their effect on the growth of pearl millet (Pennisetum americanum). Appl. Environ. Microb. 37: 1016-1024.

TERHUNE C.L., HARDEN J.W. (1991): Seasonal variation of carbon dioxide concentrations in stony, coarsetextured desert soils of Southern Nevada, USA. Soil Sci. 151: 417-429.

TheOdorou M.E., PLAXTON W.C. (1993): Metabolic adaptations of plant respiration to nutritional phosphate deprivation. Plant Physiol. 101: 339-344.

ThomAshow L.S., WeLLeR D.M. (1990): Role of antibiotics and siderophores of take-all disease in wheat. Plant Soil 129: 93-99.

Thurmann J. (1849): Essai phytostatique appliqué à la chaine du Jura. Jeut et Reinert, Bern.

Tiessen H., MoIR J.O. (1993): Characterization of available P by sequential extraction. In: Carter M.R. (Ed.): Soil Sampling and Methods of Analysis. Lewis Publishers, Boca Raton: 75-86.

TIFFIN L.O. (1966a): Iron translocation. I. Plant culture, exudate sampling, iron citrate analysis. Plant Physiol. 41: 510-514.

TIFFIN L.O. (1966b): Iron translocation. II. Citrate/iron ratios in plant stem exudates.

Plant Physiol. 41: 515-518. 
TILMAN D., OLfF H. (1991): An experimental study of the effects of $\mathrm{pH}$ and nitrogen on grassland vegetation. Acta Oecol. 12: 427-441.

Tilman D., PACALA S. (1993): The maintenance of species richness in plant communities. In: Ricklefs R.E., Schluter D. (Eds.): Species Diversity in Ecological Communities: Historical and Geographical Perspectives. University of Chicago Press, Chicago: 13-25.

Tisdale S.L., Nelson W.L., Beaton J.D., Havlin J.L. (1993): Soil Fertility and Fertilizers. 5. Edition. MacMillan, New York: $634 \mathrm{~S}$.

Toulon V., Sentenac H., Thibaud J.-B., Davidian J.C., Moulineau C., Grignon C. (1992): Role of apoplast acidification by the $\mathrm{H}^{+}$-pump. Planta 186: 212-218.

TRAPPE J.M. (1987): Phylogenetic and ecologic aspects of mycotrophy in the angiosperms from an evolutionary standpoint. In: Safir G.R. (Ed.): Ecophysiology of VA Mycorrhizal Plants. CRC Press, Boca Raton: 5-25.

TROELSTRA S.R., WAGenaAR R., SMANT W. (1995a): Nitrogen utilization by plant species from acid heathland soils: I. Comparison between nitrate and ammonium nutrition at constant low pH. J. Exp. Bot. 46: 1103-1112.

TROELSTRA S.R., WAGENAAR R., SMANT W. (1995b): Nitrogen utilization by plant species from acid heathland soils: II. Growth and shoot/root partitioning of $\mathrm{NO}_{3}{ }^{-}$-assimilation at constant low pH and varying $\mathrm{NO}_{3}{ }^{-} / \mathrm{NH}_{4}{ }^{+}$-ratio. J. Exp. Bot. 46: 1113-1121.

TRUESDELL A. (1969): The advantage of using pe rather than $E h$ in redox equilibrium calculations. J. Geol. Ed. 17: 17-20.

TURESSON G. (1922): The genotypical response of the plant species to the habitat. Hereditas 3: 211-350.

TURESSON G. (1925): The plant species in relation to habitat and climate. Hereditas 6: 147-236.

TüXEN R. (1928): Bericht über die pflanzensoziologische Exkursion der flor.-soz. Arbeitsgemeinschaft nach dem Pleßwalde bei Göttingen am 14.08.1927.

Mitt. Florist.-Soziol. Arbeitsgem. Nieders. 1: 25-51.

TüXEN R. (1955): Das System der nordwestdeutschen Pflanzengesellschaften. Mitt. Florist.-Soziol. Arbeitsgem. N. F. 5: 155-176.

TYLER G. (1994): A new approach to understanding the calcifuge habit of plants. Ann. Bot. 73: 327-330.

TYLER G. (1995): Soil chemical limits of existence and the ability of plants to modify their soil environment. Memoranda Soc. Fauna Flora Fennica 71: 3-6.

TYLER G. (1996a): Mineral nutrient limitations of calcifuge plants in phosphate sufficient limestone soil. Ann. Bot. 77: 649-656.

TYLER G. (1996b): Soil chemical limitations to growth and development of Veronica officinalis L. and Carex pilulifera L. Plant Soil 184: 281-289.

TYLER G. (2000): Integrated analysis of conditions accounting for intersite distribution of grassland plants. Nordic J. Bot. 20: 485-500.

TYLER G. (2002): Phosphorus fractions in grassland soils. Chemosphere 48: 343-349.

TYLER G. (2003): Some ecophysiological and historical approaches to species richness and calcicole/calcifuge behaviour - Contribution to a debate. Folia Geobot. 38: 419-428.

TYLER G., FALKENGREN-GRERUP U. (1998): Soil chemistry and plant performance - Ecological considerations. Prog. Bot. 59: 634-658. 
TYLER G., OLsSON T. (2001): Concentrations of 60 elements in the soil solution as related to the soil acidity. Eur. J. Soil Sci. 52: 151-165.

TYLER G., STRÖM L. (1995): Differing organic acid exudation pattern explains calcifuge and acidifuge behaviour of plants. Ann. Bot. 75: 75-78.

TYLeR G., Zohlen A. (1998): Plant seeds as mineral nutrient resource for seedlings: A comparison of plants from calcareous and silicate soils. Ann. Bot. 81: 455-459.

TYLeR K.B., BRoAdBent F.E., HiLl G.N. (1959): Low temperature effects on nitrification in four California soils. Soil Sci. 87: 123-129.

Uhlig C., Wriedt G., BaUmgartl T., HoRn R. (2002): Measurement of redox potential inside a suction probe. J. Plant Nutr. Soil Sci. 165: 35-38.

UlLRICH C.I., Novacky A., van Bel A. (1984): Phosphate uptake in Lemna gibba G1: energetics and kinetics. Planta 161: 46-52.

ULRICH B. (1987): Stability, elasticity, and resilience of terrestrial ecosystems with respect to matter balance. In: Schulze E.D., Zwölfer H. (Eds.): Potentials and Limitations of Ecosystem Analysis. Springer, Berlin: 11-49.

UNGER F. (1836): Ueber den Einfluss des Bodens auf die Vertheilung der Gewaechse, nachgewiesen in der Vegetation des nordoestlichen Tirols. Rohrmann \& Schweigert, Wien: $367 \mathrm{~S}$.

UnKovich M., Jamieson N., Monaghan R., BaRRAClough D. (1998): Nitrogen mineralisation and plant nitrogen acquisition in a nitrogen-limited calcareous grassland. Environ. Exp. Bot. 40: 209-219.

UREN N.C. (1984): Forms, reactions and availability of iron in soils. J. Plant Nutr. 7: 165-176.

VAN AARLE I.M., SöDERSTRÖM B., OLSSON P.A. (2003): Growth and interactions of arbuscular mycorrhizal fungi in soils from limestone and acid rock habitats. Soil Biol. Biochem. 35: 1557-1564.

VAN BREemen N. (1988): Redox processes of iron and sulfur involved in the formation of acid sulfate soils. In: Stucki J.W., Goodman B.A., Schwertmann U. (Eds.): Iron in Soils and Clay Minerals.

D. Reidel Publishing Co, Dordrecht: 825-841.

VAN DE DIJK S.J. (1981): Differences in nitrate uptake of species from habitats rich or poor in nitrogen when grown at low nitrate concentrations, using a new growth technique. Plant Soil 62: 278.

VAN de DiJk S.J., Lanting L., Lambers H., Posthumus F., Stulen l., Hofstra R. (1982): Kinetics of nitrate uptake by different species from nutrient-rich and nutrient poor habitats as affected by the nutrient supply. Physiol. Plant. 55: 103-110.

VAN der Eerden L.J., Dueck T.A., Berdowski J.J.M., GreVen H., VANDobben H.F. (1991): Influence of $\mathrm{NH}_{3}$ and $\left(\mathrm{NH}_{4}\right)_{2} \mathrm{SO}_{4}$ on heathland vegetation. Acta Bot. Neerl. 40: 281-296.

VAN der HeiJden M., Boller T., Wiemken A., SANDers I.R. (1998a): Different arbuscular mycorrhizal fungal species are potential determinants of plant community structure. Ecol. 79: 2082-2091.

Van der HeiJden M., Klironomos J.N., Ursic M., Moutoglis P., Streitwolf-Engel R., Boller T., WIEMKEN A., SANDERS I.R. (1998b): Mycorrhizal fungal diversity determines plant biodiversity, ecosystem variability and productivity. Nature 396: 69-72.

VAN DER WeRF A., NAGel O.W. (1996): Carbon allocation to shoots and roots in relation to nitrogen supply is mediated by cytokinins and sucrose: opinion. Plant Soil 185: 21-32.

Van der Werf A., van Nuenen M., Visser A.J., Lambers H. (1993): Contribution of physiological and morphological plant traits to a species' competitive ability at high and low nitrogen supply.

Oecologia 94: 434-440. 
Vandenkoornhuyse P., Baldauf S.L., Leyval C., Straczek J., Young J.P.W. (2002a): Extensive fungal diversity in plant roots. Science 295: 2051.

Vandenkoornhuyse P., Husband R., Daniell T.J., Watson I.J., Duck J.M., Fitter A., Young J.P.W. (2002b): Arbuscular mycorrhizal community composition associated with two plant species in a grassland ecosystem. Mol. Ecol. 11: 1555-1564.

VANDenkoornhuyse P., Ridgway K.P., Watson I.J., FitTer A.H., Young J.P.W. (2003): Co-existing grass species have distinctive arbuscular mycorrhizal communities. Mol. Ecol. 12: 3085-3095.

VARIAN-TECHTRON (1989): Analytical Methods: Flame Atomic Absorption Spectrometry. Mulgrave, Victoria: $146 \mathrm{~S}$.

Voelker B.M., SUlzberger B. (1996): Effects of fulvic acid on Fe(II) oxidation by hydrogen peroxide. Environ. Sci. Technol. 30: 1106-1114.

Von LiNStow O. (1928): Erläuterungen zur Geologischen Karte von Preußen und benachbarten deutschen Ländern. Blatt 2517 Trendelburg, 36 S.

Von LINSTOW O. (1929): Geologische Karte von Preußen und benachbarten deutschen Ländern: Blatt 2517 - Trendelburg. Preußische Geologische Landesanstalt, Berlin.

Von MoHL H. (1845): Über den Einfluß des Bodens auf die Verteilung der Alpenpflanzen. Vermischte Schriften botanischen Inhalts. Fues, Tübingen: $442 \mathrm{~S}$.

Von UeXkUlL H.R., MUtert E. (1995): Global extent, development and economical impact of acid soils. Plant Soil 171: 1-15.

Von WiRen N., RömHeld V., ShIOIRI T., MARSChNeR H. (1995): Competition between microorganisms and roots of barley and sorghum for iron accumulated in the root apoplasm. New Phyt. 130: 511-521.

Vosatka M., BatkhuUgyin E., Albrechtova J. (1999): Response of three arbuscular mycorrhizal fungi to stimulated acid rain and aluminium stress. Biol. Plant. 42: 289-296.

VoSE P.B. (1982): Iron nutrition in plants: a world overview. J. Plant Nutr. 5: 233-249.

WAHLENBERG G. (1814): Flora Carpatorum principalium. Vandenhoeck \& Ruprecht, Göttingen: 408 S.

WALKER C., TRAPPE J.M. (1993): Names and epithets in the Glomales and Endogonales. Mycol. Res. 97: 339-344.

WALter,A., Pinton,R., Römheld,V., MARSChNeR,H. (1993): Reduction of naturally occuring iron chelates by intact plant roots and isolated plasma membrane vesicles of cucumber. Abstract: 7 th International Symposium on Iron Nutritition and Interactions in plants, Zaragoza.

WALWORTH J.L. (1992): Soil drying and rewetting, or freezing and thawing, affects soil solution composition. Soil Sci. Soc. Am. J. 56: 433-437.

WARING G.L., Совв N.S. (1992): The impact of plant stress on herbivore population dynamics. In: Bernays E. (Ed.): Insect-Plant-Interactions, Vol. I. CRC Press, Ann Arbor: 167-226.

WATT A.S. (1955): Bracken versus heather, a study in plant sociology. J. Ecol. 36: 283-304.

WATT M., EVANS J.R. (1999a): Linking development and determinacy with organic acid efflux from proteoid roots of white lupin grown with low phosphorus and ambient or elevated atmospheric $\mathrm{CO}_{2}$ concentration. Plant Physiol. 120: 705-716.

Watt M., Evans J.R. (1999b): Proteoid roots. Physiology and development. Plant Physiol. 121: 317-323.

WEBB D.A. (1947): The vegetation of Carrowkeel, a limestone hill in north-west Ireland.

J. Ecol. 35: 105-129. 
WeI L.C., LoepPeRT R.H., Ocumpaugh W.R. (1997): Fe-deficiency stress response in Fe-deficiency resistant and susceptible subterranean clover: Importance of induced $\mathrm{H}^{+}$release.

J. Exp. Bot. 48: 239-246.

WEIß J. (1991): Ionenchromatographie. 2. erw. Auflage. VCH, Weinheim: $475 \mathrm{~S}$.

WeLKIE G.W. (1996): Iron-deficiency stress responses of a chlorosis-susceptible and a chlorosis-resistant cultivar of muskmelon as related to root riboflavin excretion. J. Plant Nutr. 19: 1157-1169.

WELKIE G.W., MiLLER G.W. (1989): Sugar beet responses to iron nutrition and stress.

J. Plant Nutr. 12: 1041-1054.

WeLP G., HeRms U., BRüMmer G. (1983): Einfluss von Bodenreaktion, Redoxbedingungen und organischer Substanz auf die Phosphatgehalte der Bodenlösung.

Z. Pflanzenernähr. Bodenkd. 146: 38-52.

Westover K.M., BeVer J.D. (2001): Mechanisms of plant species coexistence: Roles of rhizosphere bacteria and root fungal pathogens. Ecol. 82: 3285-3294.

Westover K.M., KenNedy A.C., Kelley S.E. (1997): Patterns of rhizosphere microbial community structure associated with co-occurring plant species. J. Ecol. 85: 863-873.

WHELAN B.R., BARROW N.J. (1980): A study of a method for displacing soil solution by centrifuging with an immiscible liquid. J. Environ. Qual. 9: 315-318.

White P.F., Robson A.D. (1989): Rhizosphere acidification and $\mathrm{Fe}^{3+}$ reduction in lupins and peas: Iron deficiency in lupins is not due to a poor ability to reduce $\mathrm{Fe}^{3+}$. Plant Soil 119: 163-175.

WHITE P.F., RoBson A.D. (1990): Response of lupins (Lupinus angustifolius L.) and peas (Pisum sativum L.) to Fe deficiency induced by low concentrations of $\mathrm{Fe}$ in solution or by addition of $\mathrm{HCO}_{3}$. Plant Soil 125: 39-47.

WhitTAKER E., Gimmingham C.H. (1962): The effect of fire on regeneration of Calluna vulgaris (L.) Hull. from seed. J. Ecol. 50: 815-822.

WHITTAKER R.H. (1977): Evolution of species diversity in land communities. Evol. Biol. 10: 1-67.

Wieland E., Stumm W. (1992): Dissolution kinetics of kaolinite in acidic aqueous solutions at $25^{\circ} \mathrm{C}$. Geochim. Cosmochim. Acta 56: 3339-3355.

Wilkinson S., CoRlett J.E., Oger L., Davies W.J. (1998): Effects of xylem pH on transpiration from wildtype and flca tomato leaves. Plant Physiol. 117: 703-709.

Williams J.D.H., Syers J.K., HARRIS R.F., ARMStRong D.E. (1971): Fractionation of inorganic phosphate in calcareous lake sediments. Soil Sci. Soc. Am. J. 35: 250-255.

Willis A.J., Folkes B.F., Hope-Simpson J.F., Yemm E.M. (1963): Braunton Burrows: the effects on the vegetation of the addition of mineral nutrients to the dune soils. J. Ecol. 51: 353-374.

WiLson E.J., WelLS T.C.E., SpARKs T.H. (1995): Are calcareous grasslands in the UK under threat from nitrogen deposition? An experimental determination of a critical load. J. Ecol. 83: 823-832.

WILSON G.W.T., HARTNETT D.C. (1997): Effects of mycorrhizae on plant growth and dynamics in experimental tallgras prairie microcosms. Am. J. Bot. 84: 478-482.

WILSON G.W.T., HARTNETT D.C. (1998): Interspecific variation in plant responses to mycorrhizal colonization in tallgrass prairie. Am. J. Bot. 85: 1732-1738.

WILTSHIRE G.H. (1973): Responses of grasses to nitrogen source. J. Appl. Ecol. 10: 429-435.

WISSEMEIER A.H., HORST W.J. (1991): Simplified methods for screening cowpea cultivars for manganese leaf tissue tolerance. Crop Science 31: 435-439. 
WISSKIRCHEN R., HÄUPLER H. (1998): Standardliste der Farn- und Blütenpflanzen Deutschlands. Ulmer, Stuttgart: $765 \mathrm{~S}$.

WoHLgemuth T., Gigon A. (2003): Calcicole plant diversity in Switzerland may reflect a variety of habitat templets. Folia Geobot. 38: 443-452.

WoLT J.D. (1994): Soil Solution Chemistry. Wiley, New York: 345 S.

WOolhouse H.W. (1966): Comparative physiological studies on Deschampsia flexuosa, Holcus mollis, Arrhenaterum elatius and Koeleria gracilis in relation to growth in calcareous soils. I. Growth and root respiration. New Phyt. 65: 22-31.

WOOLHOUSE H.W., HARDWICK K. (1966): The growth of tomato seedlings in relation to the form of nitrogen supply. New Phyt. 65: 518-525.

WRIGHT K.E. (1943): Internal precipitation of phosphorus in relation to aluminum toxicity. Plant Physiol. 18: 708-712.

Yehuda Z., Shenker M., Hadar Y., Chen Y. (2000): Remedy of chlorosis induced by iron deficiency in plants with the fungal siderophore rhizoferrin. J. Plant Nutr. 23: 1991-2006.

Yehuda Z., Shenker M., Römheld V., MARschner H., Hadar Y., Chen Y. (1996): The role of ligand exchange in the uptake of iron from microbial siderophores by gramineous plants. Plant Physiol. 112: 1273-1280.

YI Y., GUERINOT M.L. (1996): Genetic evidence that induction of root Fe(III) chelate reductase activity is necessary for iron uptake under iron. Plant J. 10: 835-844.

YUAN G., LAVKuLICH L.M., WANG C. (1993): A method for estimating organic bound iron and aluminum contents in soils. Commun. Soil Sci. Plant Anal. 24: 1333-1343.

ZABOWSKI D., UGoLINI F.C. (1990): Lysimeter and centrifuge soil solutions: Seasonal differences between methods. Soil Sci. Soc. Am. J. 54: 1130-1135.

Zaid E.H., ARahou M., Diem H.G., El MoRAbet R. (2003): Is Fe deficiency rather than P deficiency the cause of cluster root formation in Casuarina species? Plant Soil 248: 229-235.

ZeIEN H., BRÜMmER G.W. (1989): Chemische Extraktionen zur Bestimmung von Schwermetallbindungsformen in Böden. Mitt. Dtsch. Bodenkdl. Ges. 59: 505-510.

ZHANG H., FORDE B.G. (1998): An Arabidopsis MADS box gene that controls nutrient induced changes in root architecture. Science 297: 407-409.

ZHANG Y., LIN X., WERNER W. (2003): The effect of soil flooding on the transformation of Fe oxides and the adsorption/desorption behavior of phosphate. J. Plant Nutr. Soil Sci. 166: 68-75.

ZoBel M., MOORA M. (1995): Interspecific competition and arbuscular mycorrhiza: importance of two calcareous grassland species. Folia Geobot. Phytotaxon. 30: 223-230. 

Anhang 8 



\section{Tabellen des Anhangs}

Tabelle A 1: Ökologische Zeigerwerte nach Ellenberg et al. (1992) der in den vegetationskundlichen Untersuchungen und im Text behandelten Taxa

Tabelle A 2: Mittlere räumliche Variationskoeffizienten der $\mathrm{H}^{+}$-Aktivitäten und der Mineralstoffkonzentrationen verschiedener Bodenextrakte der CC- und CF-Einheiten der Standorte Auf der Burg und Hölleberg

Tabelle A 3: Mittlere zeit(-räum)liche Variationskoeffizienten der $\mathrm{H}^{+}$-Aktivitäten und der Mineralstoffkonzentrationen verschiedener Bodenextrakte der CC- und CFEinheiten der Standorte Auf der Burg und Hölleberg

Tabelle A 4: Prozentuales Verhältnis zeit-räumlicher und räumlicher Variabilitäten der $\mathrm{H}^{+}$-Aktivitäten und der Mineralstoffkonzentrationen verschiedener Bodenextrakte der CC- und CF-Einheiten der Standorte Auf der Burg und Hölleberg

Tabelle A 5: Lagerungseffekte von PBL und Positionseffekte von GBL und DBL in CC- und CF-Beständen der Standorte Auf der Burg und Hölleberg

Tabelle A 6: Schwermetallfraktionen der Feinerde von CC- und CF-Beständen der Standorte Auf der Burg und Hölleberg entsprechend der Extraktion von Bodenmaterial unterschiedlicher Struktur und Lagerung mit $\mathrm{NH}_{4}$-Acetat, DTPA, NTA, Oxalat und Dithionit

Tabelle A 7: Verhältnisse der Feinerdefraktionen verschiedener Schwermetalle auf Grundlage der Extraktion von Bodenmaterial unterschiedlicher Struktur und Lagerung mit $\mathrm{NH}_{4}$-Acetat, DTPA, NTA, Oxalat und Dithionit

Tabelle A 8: Varianzanalyse nicht-sequentieller Schwermetallfraktionierungen von Bodenmaterial der Standorte Auf der Burg und Hölleberg

Tabelle A 9: Varianzanalyse nicht-sequentieller Schwermetallfraktionierungen feldfrischer Feinerdehomogenate aller Untersuchungsstandorte.

Tabelle A 10: Geographische Lage und Medianwerte bodenchemischer Parameter der Standorte der Saatguternten für die Keimungs- und Kulturexperimente

Tabelle A 11: Ergebnisse der Rangkorrelationsanalysen nach Spearman für verschiedene Analyte der GBL

Tabelle A 12: Ergebnisse der Rangkorrelationsanalysen nach Spearman für verschiedene Analyte der PBL

Tabelle A 13: Ergebnisse der Rangkorrelationsanalysen nach Spearman für verschiedene Analyte der DBL 
Tabelle A 1: Zeigerwerte der in den vegetationskundlichen Untersuchungen und im Text behandelten Taxa. In ordinaler Skalierung von 1 bis 9 nehmen L(ichtintensität), T(emperatur, K(ontinalität), F(euchte), R(eaktion; Substrat$\mathrm{pH}$ ) und $\mathrm{N}$ (ährstoffgehalt) der betreffenden Standorte zu. $x$ verweist auf eine indifferente Verbreitung, $\sim$ und $=$ auf Wechselfeuchte bzw. temporäre Überschwemmung (Ellenberg et al. 1992).

\begin{tabular}{|c|c|c|c|c|c|c|c|c|c|c|c|c|c|}
\hline Taxon & $\mathbf{L}$ & $\mathbf{T}$ & $\mathbf{K}$ & $\mathbf{F}$ & R $N$ & $\mathbf{N}$ & Taxon & $\mathbf{L}$ & $\mathbf{T}$ & $\mathbf{K}$ & $\mathbf{F}$ & $\mathbf{R}$ & $\mathbf{N}$ \\
\hline Acer pseudoplatanus & 4 & $x$ & 4 & 6 & $\times 7$ & 7 & Convolvulus arvensis & 7 & 6 & $x$ & 4 & 7 & $x$ \\
\hline Achillea millefolium & 8 & $x$ & $x$ & 4 & $\times 5$ & 5 & Cornus sanguinea & 7 & 5 & 4 & 5 & 7 & $x$ \\
\hline Acinos arvensis & 9 & 6 & 3 & 2 & 51 & 1 & Crataegus monogyna agg. & 7 & 5 & 3 & 4 & 8 & 4 \\
\hline Aegopodium podagraria & 5 & 5 & 3 & 6 & 78 & 8 & Dactylis glomerata & 7 & $x$ & 3 & 5 & $\mathrm{x}$ & 6 \\
\hline Agrimonia eupatoria & 7 & 6 & 4 & 4 & 84 & 4 & Danthonia (=Sieglingia) decumbens & 8 & $x$ & 2 & $x$ & 3 & 2 \\
\hline Agrostis canina & 9 & 5 & 5 & 9 & 32 & 2 & Deschampsia cespitosa & 6 & $x$ & $\mathrm{x}$ & & $\mathrm{x}$ & 3 \\
\hline Agrostis capillaris & 7 & $x$ & 3 & $\mathrm{x}$ & 44 & 4 & Digitalis purpurea & 7 & 5 & 2 & 5 & 3 & 6 \\
\hline Agrostis stolonifera ssp. stolonifera & 8 & $x$ & 5 & $7 \sim$ & $\times 5$ & 5 & Echinops sphaerocephalus & 8 & 7 & 6 & 4 & 8 & 7 \\
\hline Agrostis tenuis (=A. capillaris) & 7 & $x$ & 3 & $\mathrm{x}$ & 44 & 4 & Empetrum nigrum & 7 & $x$ & 3 & 6 & $x$ & 2 \\
\hline Antennaria dioica & 8 & $x$ & $x$ & 4 & 32 & 2 & Epipactis atrorubens & 6 & $x$ & 3 & 3 & 8 & 2 \\
\hline Anthoxanthum aristatum (=A. puëlii) & 7 & 6 & 2 & $\mathrm{x}$ & 23 & 3 & Erica herbacea (=E. carnea) & 7 & $\mathrm{x}$ & 3 & 3 & $\mathrm{x}$ & 2 \\
\hline Anthoxanthum odoratum & $x$ & $x$ & $x$ & $\mathrm{x}$ & $5 \times$ & $x$ & Erica tetralix & 8 & 5 & 1 & 8 & 1 & 2 \\
\hline Anthyllis vulneraria & 8 & 6 & 3 & 3 & 72 & 2 & Erigeron acer (=E. acris) & 9 & 5 & 7 & 4 & 8 & 2 \\
\hline Aphanes arvensis & 6 & 6 & 2 & 6 & $\times 5$ & 5 & Euonymus europaea & 6 & 5 & 3 & 5 & 8 & 5 \\
\hline Arabidopsis thaliana & 6 & 6 & 3 & 4 & 44 & 4 & Euphorbia cyparissias & 8 & $x$ & 4 & 3 & $\mathrm{x}$ & 3 \\
\hline Arabis hirsuta ssp. hirsuta & 7 & 5 & 3 & $4 \sim$ & $8 \times$ & $x$ & Euphrasia rostkoviana & 6 & $x$ & 3 & $x$ & $x$ & 4 \\
\hline Arenaria serpyllifolia agg. & 8 & $x$ & $x$ & 4 & $7 \times$ & $\mathrm{x}$ & Euphrasia stricta agg. (=E. ericetorum) & 8 & $x$ & 4 & 4 & $\mathrm{x}$ & 2 \\
\hline Arnica montana & 9 & 4 & 4 & 5 & 32 & 2 & Fagus sylvatica & (3) & 5 & 2 & 5 & $\mathrm{x}$ & $x$ \\
\hline Arrhenaterum elatius & 8 & 5 & 3 & $x$ & 77 & 7 & Festuca arundinacea ssp. arundinacea & 8 & 5 & $x$ & & 7 & 5 \\
\hline Asperula cynanchica & 7 & $x$ & 5 & 3 & 83 & 3 & Festuca gigantea & 4 & 5 & 3 & 7 & 6 & 6 \\
\hline Avenella (=Deschampsia) flexuosa & 6 & $x$ & 2 & $\mathrm{x}$ & 23 & 3 & Festuca ovina ssp. ovina & 7 & $x$ & 3 & $x$ & 3 & 1 \\
\hline Betula pendula & (7) & $x$ & $x$ & $x$ & $x \quad x$ & $x$ & Festuca rubra ssp. rubra & $x$ & $x$ & 5 & 6 & 6 & $x$ \\
\hline Brachypodium pinnatum & 6 & 5 & 5 & 4 & 74 & 4 & Fragaria vesca & 7 & $x$ & 5 & 5 & $\mathrm{x}$ & 6 \\
\hline Brachypodium sylvaticum & 3 & 5 & 3 & 5 & 66 & 6 & Fragaria viridis & 8 & 6 & 5 & 3 & 8 & 3 \\
\hline Briza media & 8 & $x$ & 3 & $x>$ & $\times 2$ & 2 & Galium album ssp. album & 7 & $x$ & 5 & $\mathrm{x}$ & 7 & 6 \\
\hline Bromus erectus & 8 & 5 & 2 & $3 \varepsilon$ & 83 & 3 & Galium harcynicum (=G. saxatile) & 7 & 5 & 2 & 5 & 2 & 3 \\
\hline Bromus ramosus ssp. benekenii & 5 & 5 & 4 & 57 & 75 & 5 & Galium pumilum (=G. sylvestre) & 7 & 5 & 2 & & 4 & 2 \\
\hline Bromus ramosus ssp. ramosus & 6 & 6 & 2 & 5 & 76 & 6 & Galium verum agg. (=Cruciata glabra) & 7 & 6 & $x$ & & 7 & 3 \\
\hline Calluna vulgaris & 8 & $x$ & 3 & $\mathrm{x}$ & 11 & 1 & Genista tinctoria & 8 & 6 & 3 & & 6 & 1 \\
\hline Campanula rapunculoides & 6 & 6 & 4 & 47 & 74 & 4 & Gentianella ciliata & 7 & $x$ & 4 & 3 & 8 & 2 \\
\hline Campanula rotundifolia & 7 & 5 & $x$ & $x>$ & $\times 2$ & 2 & Gentianella germanica & 7 & 5 & & 4 & 8 & 3 \\
\hline Carex caryophyllea (=C. verna) & 8 & $x$ & 3 & $4>$ & $\times 2$ & 2 & Geum urbanum & 4 & 5 & 5 & 5 & $\mathrm{x}$ & 7 \\
\hline Carex flacca (=C. glauca) & 7 & $x$ & 3 & $6 \sim$ & 84 & 4 & Helianthemum nummularium ssp. $n$. & 7 & 6 & 4 & 3 & 7 & 2 \\
\hline Carex montana & 5 & $x$ & 4 & 4 & 63 & 3 & Helictotrichon (=Avenula) pratense & 7 & 6 & 4 & & $x$ & 2 \\
\hline Carex panicea & 8 & $x$ & 3 & $8 \sim$ & $x 4$ & 4 & Hieracium pilosella & 7 & $x$ & 3 & 4 & $x$ & 2 \\
\hline Carex pilulifera & 5 & $x$ & 2 & $5 \sim$ & 33 & 3 & Holcus lanatus & 7 & 6 & 3 & 6 & $\mathrm{x}$ & 5 \\
\hline Carex remota & 3 & 5 & 3 & $8>$ & $x \quad x$ & $\mathrm{x}$ & Hordelymus europaeus & 4 & 5 & 4 & 5 & 7 & 6 \\
\hline Carex sylvatica & 2 & 5 & 3 & 5 & 65 & 5 & Hypericum perforatum & 7 & 6 & 5 & 4 & 6 & 4 \\
\hline Carlina vulgaris & 7 & 5 & 3 & 47 & 73 & 3 & Impatiens parviflora & 4 & 6 & 5 & 5 & $x$ & 6 \\
\hline Carpinus betulus & (4) & 6 & 4 & $x>$ & $x \quad x$ & $x$ & Juncus squarrosus & 8 & 5 & 2 & $7 \sim$ & 1 & 1 \\
\hline Centaurea cyanus & 7 & 6 & 6 & $5>$ & $x \quad x$ & $x$ & Juniperus communis ssp. communis & 9 & $x$ & $x$ & 4 & $x$ & 2 \\
\hline Centaurea jacea & 7 & $x$ & 5 & $x>$ & $x \quad x$ & $x$ & Knautia arvensis & 7 & 6 & 3 & 4 & $x$ & 4 \\
\hline Centaurea scabiosa & 7 & $x$ & 3 & $3 \varepsilon$ & 84 & 4 & Koeleria macrantha (=K. gracilis) & 7 & 6 & 7 & 3 & 8 & 2 \\
\hline Cerastium fontanum ssp. fontanum & 6 & 3 & 4 & 5 & 55 & 5 & Koeleria pyramidata agg. & 7 & 6 & 4 & 4 & 7 & 2 \\
\hline Cerastium holosteoides & 6 & $x$ & $x$ & $5>$ & $\times 5$ & 5 & Lathyrus montanus (=L. linifolius) & $\mathrm{x}$ & 5 & 2 & 5 & 3 & 2 \\
\hline Cerastium pumilum agg. & 8 & 7 & 4 & $2 \varepsilon$ & 82 & 2 & Lathyrus pratensis & 7 & 5 & $x$ & 6 & 7 & 6 \\
\hline Cirsium acaule & 9 & 5 & 4 & $3 \varepsilon$ & 82 & 2 & Legousia speculum-veneris & 7 & 7 & 4 & 4 & 8 & 3 \\
\hline Consolida regalis ssp. regalis & 6 & 7 & 6 & $4 \varepsilon$ & 85 & 5 & Leontodon hispidus & 8 & $x$ & 3 & 5 & 7 & 6 \\
\hline
\end{tabular}


Tabelle A 1 (Fortsetzung): Zeigerwerte nach Ellenberg et. al. (1992)

\begin{tabular}{|c|c|c|c|c|c|c|c|c|c|c|c|c|}
\hline Taxon & $\mathbf{L}$ & $\mathbf{T}$ & $\mathbf{K}$ & $\mathbf{F}$ & R $\mathrm{I}$ & $\mathbf{N}$ & Taxon & $\mathbf{L} \mathbf{T}$ & $\mathbf{K}$ & $\mathbf{F}$ & $\mathbf{R}$ & $\mathbf{N}$ \\
\hline Leucanthemum vulgare agg. & 7 & $x$ & 3 & 4 & $x 3$ & 3 & Silene dioica (=Melandrium rubrum) & $x \quad x$ & 4 & 6 & 7 & 8 \\
\hline Ligustrum vulgare & 7 & 6 & 3 & 4 & 83 & 3 & Solidago virgaurea ssp. virgaurea & $5 \times$ & $x$ & $5 \sim$ & $x$ & 4 \\
\hline Linum catharticum & 7 & $x$ & 3 & $\mathrm{x}$ & 72 & 2 & Spergula arvensis & 65 & 3 & 5 & 3 & 6 \\
\hline Lotus corniculatus & 7 & $x$ & 3 & 4 & 73 & 3 & Taraxacum officinale agg. & $7 x$ & $x$ & 5 & $x$ & 8 \\
\hline Luzula campestris ssp. campestris & 7 & $x$ & 3 & 4 & 33 & 3 & Teucrium scorodonia & 65 & 2 & 4 & 2 & 3 \\
\hline Luzula luzuloides (=L. albida) & 4 & $x$ & 4 & 5 & 34 & 4 & Thymus pulegioides ssp. pulegioides & $8 x$ & 4 & 4 & $x$ & 1 \\
\hline Lychnis viscaria (=Viscaria alba) & 7 & 6 & 4 & 3 & 42 & 2 & Trifolium campestre & 86 & 3 & 4 & 6 & 3 \\
\hline Medicago lupulina & 7 & 5 & $x$ & 4 & $8 \times$ & $x$ & Trifolium medium ssp. medium & 76 & 4 & 4 & 6 & 3 \\
\hline Milium effusum & 4 & $x$ & 3 & 5 & 55 & 5 & Trifolium montanum & $8 x$ & 4 & & 8 & 2 \\
\hline Molinia caerulea ssp. caerulea & 7 & $x$ & 3 & 8 & $\times 2$ & 2 & Trifolium pratense & $7 x$ & 3 & 5 & $x$ & $x$ \\
\hline Mycelis muralis & 4 & 6 & 2 & 5 & $\times 6$ & 6 & Trifolium repens & $8 x$ & $x$ & 5 & 6 & 6 \\
\hline Nardus stricta & 8 & $x$ & 3 & $x \sim$ & 22 & 2 & Trisetum flavescens & $7 \times$ & 5 & $\mathrm{x}$ & $\mathrm{x}$ & 5 \\
\hline Ononis spinosa ( $=0$. campestris) & 8 & 6 & 5 & $4 \sim$ & 73 & 3 & Tussilago farfara & $8 x$ & 3 & 6 & 8 & $x$ \\
\hline Orchis mascula & 6 & $x$ & 3 & 4 & $8 \times$ & $x$ & Urtica dioica & $x$ & $x$ & & 7 & 9 \\
\hline Origanum vulgare & 7 & $x$ & 3 & 3 & 83 & 3 & Vaccinium macrocarpon & 75 & 3 & 8 & 1 & 3 \\
\hline Parnassia palustris & 8 & $x$ & $x$ & $8 \sim$ & 72 & 2 & Veronica officinalis & $6 \times$ & 3 & 4 & 3 & 4 \\
\hline Pimpinella saxifraga ssp. saxifraga & 7 & $x$ & 5 & 3 & $\times 2$ & 2 & Viburnum lantana & 75 & 2 & 4 & 8 & 4 \\
\hline Pinus sylvestris & $(7)$ & $x$ & 7 & $x$ & $x \quad x$ & $x$ & Viburnum opulus & 65 & 3 & $x$ & 7 & 6 \\
\hline Plantago lanceolata & 6 & $x$ & 3 & $x$ & $x \quad x$ & $x$ & Vicia cracca & 75 & $x$ & 6 & $x$ & $\mathrm{x}$ \\
\hline Plantago media & 7 & $x$ & 7 & 4 & 73 & 3 & Viola canina & $7 \times$ & 3 & 5 & 3 & 2 \\
\hline Poa angustifolia ( $P$. pratensis agg.) & 7 & 6 & $x$ & $\mathrm{x}$ & $x 3$ & 3 & Viola hirta & 65 & 5 & 3 & 8 & 3 \\
\hline Poa nemoralis & 5 & $x$ & 5 & 5 & 54 & 4 & Viola riviniana & $5 \times$ & 3 & 4 & 4 & $x$ \\
\hline Polygala comosa & 8 & 6 & 6 & 3 & 82 & 2 & & & & & & \\
\hline Polygala vulgaris & 7 & $x$ & 3 & 4 & 32 & 2 & Moose & $\mathbf{L}$ & $\mathbf{T}$ & $\mathbf{K}$ & $\mathbf{F}$ & $\mathbf{R}$ \\
\hline Potentilla erecta (=Tormentilla erecta) & 6 & $x$ & 3 & $x>$ & $\times 2$ & 2 & Atrichum undulatum var. undulatum & 6 & $x$ & 5 & 6 & 4 \\
\hline Potentilla neumanniana ( $P$. verna agg.) & 8 & 6 & 4 & 3 & 72 & 2 & Brachythecium rutabulum var. rutabulum & 5 & $x$ & 5 & 4 & $x$ \\
\hline Primula veris (=P. officinalis) & 7 & $x$ & 3 & $4 \varepsilon$ & 83 & 3 & Calliergonella cuspidata & 8 & 3 & 5 & 7 & 7 \\
\hline Prunella vulgaris & 7 & $x$ & 3 & 5 & $7 \times$ & $x$ & Campylium calcareum & 4 & 5 & 5 & 4 & 8 \\
\hline Prunus avium & $(4)$ & 5 & 4 & 5 & 75 & 5 & Campylium chrysophyllum & 9 & 2 & 6 & 2 & 8 \\
\hline Prunus spinosa & 7 & 5 & 5 & $x>$ & $x \quad x$ & $x$ & Ctenidium molluscum var. molluscum & 5 & 4 & 5 & 4 & 8 \\
\hline Pyrus communis agg. & $(6)$ & 6 & 5 & 5 & $8 \times$ & $x$ & Dicranum polysetum & 6 & 3 & 6 & 4 & 5 \\
\hline Ranunculus bulbosus & 8 & 6 & 3 & 3 & 73 & 3 & Dicranum scoparium & 5 & $x$ & 5 & 4 & 4 \\
\hline Ranunculus polyanthemos ssp. $p$. & 6 & 6 & 5 & $4 \sim>$ & $\times 2$ & 2 & Ditrichum flexicaule & 6 & $\mathrm{x}$ & 6 & 5 & 9 \\
\hline Reseda lutea & 7 & 6 & 3 & $3 \varepsilon$ & 85 & 5 & Eurhynchium hians var. hians (=E. swartzii) & i) 7 & 4 & 5 & 5 & 7 \\
\hline Reseda luteola & 8 & 7 & 3 & 4 & 96 & 6 & Fissidens taxifolius & 5 & 4 & 5 & 6 & 7 \\
\hline Rhamnus catharticus & 7 & 5 & 5 & 4 & 84 & 4 & Frullania tamarisci & 7 & 3 & 4 & 4 & 5 \\
\hline Rhinanthus minor & 7 & 5 & 3 & 42 & $x 3$ & 3 & Hylocomium splendens var. spendens & 6 & 3 & 6 & 4 & 5 \\
\hline Rosa canina agg. & 8 & 5 & 3 & $4>$ & $x \quad x$ & $x$ & Hypnum cupressiforme var. lacunosum & 9 & 4 & 5 & 2 & 6 \\
\hline Rosa rubiginosa (=R. eglanteria) & 7 & 6 & 2 & 3 & 83 & 3 & Lophocolea bidentata (=L. cuspidata) & 7 & 3 & 5 & 6 & 5 \\
\hline Rumex acetosa & 8 & $x$ & $x$ & $x>$ & $x \quad 6$ & 6 & Plagiomnium affine & 5 & 4 & 5 & 5 & 5 \\
\hline Rumex acetosella ssp. acetosella & 8 & 5 & 3 & 3 & 22 & 2 & Plagiomnium undulatum & 4 & 3 & 5 & 6 & 6 \\
\hline Sanguisorba minor & 7 & 6 & 5 & 3 & 82 & 2 & Pleurozium schreberi & 6 & 3 & 6 & 4 & 2 \\
\hline Scabiosa columbaria ssp. columbaria & 8 & 5 & 2 & 3 & 83 & 3 & Polytrichum juniperinum & 8 & 2 & ? & 4 & 3 \\
\hline Schoenus nigricans & 9 & 6 & 3 & $9=$ & 92 & 2 & Rhytidiadelphus squarrosus & 7 & 3 & 6 & 6 & 5 \\
\hline Scleranthus annuus & 6 & 5 & 4 & 5 & 25 & 5 & Scleropodium purum & 6 & 4 & 5 & 4 & 5 \\
\hline Sedum sexangulare (=S. mite) & 7 & 5 & 4 & 2 & 61 & 1 & Thuidium abietinum var. abietinum & 8 & $x$ & 6 & 2 & 7 \\
\hline Senecio jacobaea & 8 & 5 & 3 & 4 & 75 & 5 & Thuidium delicatulum & 7 & 4 & 5 & 4 & 7 \\
\hline Sesleria varia (=S. albicans) & 7 & 3 & 2 & 4 & 93 & 3 & Weissia condensa & 9 & 6 & 5 & 1 & 9 \\
\hline
\end{tabular}


Tabelle A 2: Mittlere räumliche Variationskoeffizienten $\mathrm{CV}_{\mathrm{lok}}[\%]$ der $\mathrm{H}^{+}$-Aktivitäten und der Mineralstoffkonzentrationen verschiedener Bodenextrakte der CC- und CF-Einheiten der Standorte Auf der Burg und Hölleberg. Die mittleren $C V_{\text {lok }}$ berechnen sich auf Grundlage der Variationskoeffizienten der acht Parallelen der jeweils sieben (GBL) bzw. sechs (PBL, DBL) Probennahmen jeder Untersuchungsfläche. Rangwerte kennzeichnen die Abfolge der Gesamtmittelwerte der CV (MW) für die untersuchten Faktoren.

\begin{tabular}{|c|c|c|c|c|c|c|c|c|c|c|c|c|c|c|c|c|c|}
\hline \multirow[t]{3}{*}{ Faktor } & \multicolumn{6}{|c|}{ Auf der Burg } & \multicolumn{6}{|c|}{ Hölleberg } & \multicolumn{5}{|c|}{ Pool } \\
\hline & & $\mathrm{CC}$ & & & $\mathrm{CF}$ & & & $\mathrm{CC}$ & & & CF & & & & & & \\
\hline & GBL & PBL & DBL & GBL & PBL & DBL & GBL & PBL & DBL & GBL & PBL & DBL & GBL & PBL & DBL & MW & Rang \\
\hline $\mathrm{H}^{+}$ & 31 & 31 & 33 & 64 & 56 & 60 & 30 & 28 & 30 & 25 & 29 & 35 & 41 & 38 & 41 & 40 & (8) \\
\hline $\mathrm{Fe}^{\mathrm{x+}}$ & 90 & 120 & 127 & 120 & 89 & 79 & 60 & 61 & 62 & 51 & 79 & 47 & 90 & 90 & 90 & 90 & $(12)$ \\
\hline$M n^{x+}$ & 47 & 38 & 25 & 59 & 45 & 20 & 39 & 40 & 27 & 22 & 31 & 22 & 48 & 41 & 24 & 38 & (6) \\
\hline $\mathrm{Ca}^{2+}$ & 13 & 19 & 19 & 62 & 51 & 56 & 14 & 16 & 17 & 20 & 15 & 25 & 30 & 29 & 31 & 30 & (4) \\
\hline $\mathrm{Mg}^{2+}$ & 17 & 19 & 18 & 48 & 43 & 31 & 23 & 15 & 14 & 21 & 23 & 22 & 29 & 26 & 21 & 25 & (2) \\
\hline $\mathrm{K}^{+}$ & 46 & 68 & 42 & 64 & 77 & 69 & 57 & 63 & 70 & 51 & 49 & 43 & 56 & 69 & 61 & 62 & (9) \\
\hline $\mathrm{Na}^{+}$ & 77 & 66 & 51 & 30 & 22 & 31 & 17 & 15 & 49 & 14 & 25 & 57 & 41 & 34 & 43 & 40 & (7) \\
\hline $\mathrm{NH}_{4}^{+}$ & - & 147 & 46 & 103 & 51 & 35 & 34 & 66 & 115 & 41 & 36 & 111 & 68 & 88 & 65 & 74 & (10) \\
\hline $\mathrm{SO}_{4}{ }^{2-}$ & 20 & 30 & 22 & 18 & 24 & 36 & 17 & 29 & 20 & 22 & 32 & 41 & 18 & 28 & 26 & 24 & (1) \\
\hline $\mathrm{NO}_{3}^{-}$ & 131 & 102 & 108 & 161 & 64 & 91 & 135 & 107 & 108 & 97 & 74 & 68 & 143 & 91 & 103 & 112 & (13) \\
\hline $\mathrm{NO}_{2}^{-}$ & 78 & 129 & 71 & 70 & 64 & 98 & 73 & 114 & 85 & 54 & 92 & 62 & 74 & 102 & 85 & 87 & (11) \\
\hline $\mathrm{Cl}^{-}$ & 28 & 35 & 26 & 37 & 37 & 37 & 24 & 35 & 23 & 25 & 40 & 36 & 30 & 36 & 29 & 31 & (5) \\
\hline EC & 15 & 18 & 17 & 51 & 49 & 43 & 18 & 17 & 18 & 15 & 13 & 22 & 28 & 28 & 26 & 27 & (3) \\
\hline
\end{tabular}

Tabelle A 3: Mittlere zeit(-räum)liche Variationskoeffizienten $C V_{\text {temp }}$ [\%] der $H^{+}$-Aktivitäten und der Mineralstoffkonzentrationen verschiedener Bodenextrakte der CC- und CF-Einheiten der Standorte Auf der Burg und Hölleberg. Die mittleren $C V_{\text {temp }}$ berechnen sich auf Grundlage der Variationskoeffizienten der sieben (GBL) bzw. sechs (PBL, $D B L)$ Probennahmen aus acht Quadrantenpaaren $(Q 1+2, Q 3+4$ usw.) jeder Untersuchungsfläche. Rangwerte kennzeichnen die Abfolge der Gesamtmittelwerte der CV (MW) für die untersuchten Faktoren.

\begin{tabular}{|c|c|c|c|c|c|c|c|c|c|c|c|c|c|c|c|c|c|}
\hline \multirow[t]{3}{*}{ Faktor } & \multicolumn{6}{|c|}{ Auf der Burg } & \multicolumn{6}{|c|}{ Hölleberg } & \multicolumn{5}{|c|}{ Pool } \\
\hline & & CC & & & CF & & & CC & & & CF & & & & & & \\
\hline & GBL & PBL & DBL & GBL & PBL & DBL & GBL & PBL & DBL & GBL & PBL & DBL & GBL & PBL & DBL & MW & Rang \\
\hline $\mathrm{H}^{+}$ & 61 & 60 & 69 & 105 & 138 & 80 & 34 & 38 & 30 & 36 & 39 & 37 & 67 & 79 & 60 & 68 & (8) \\
\hline $\mathrm{Fe}^{\mathrm{x+}}$ & 111 & 99 & 114 & 108 & 108 & 83 & 63 & 84 & 75 & 62 & 85 & 45 & 94 & 97 & 91 & 94 & (10) \\
\hline $\mathrm{Mn}^{\mathrm{x}+}$ & 108 & 91 & 63 & 81 & 101 & 61 & 68 & 84 & 80 & 59 & 80 & 70 & 86 & 92 & 68 & 82 & (9) \\
\hline $\mathrm{Ca}^{2+}$ & 17 & 21 & 27 & 66 & 47 & 52 & 36 & 44 & 48 & 34 & 46 & 47 & 40 & 38 & 42 & 40 & (5) \\
\hline $\mathrm{Mg}^{2+}$ & 21 & 23 & 58 & 60 & 41 & 30 & 38 & 22 & 56 & 32 & 28 & 55 & 40 & 29 & 48 & 39 & (4) \\
\hline $\mathrm{K}^{+}$ & 42 & 57 & 36 & 84 & 59 & 72 & 49 & 54 & 54 & 53 & 65 & 56 & 58 & 57 & 54 & 56 & (7) \\
\hline $\mathrm{Na}^{+}$ & 79 & 72 & 69 & 46 & 33 & 38 & 56 & 36 & 44 & 41 & 32 & 43 & 60 & 47 & 50 & 53 & (6) \\
\hline $\mathrm{NH}_{4}{ }^{+}$ & n.d. & 145 & 98 & 166 & 53 & 38 & 122 & 70 & 108 & 103 & 101 & 125 & 144 & 89 & 81 & 105 & (12) \\
\hline $\mathrm{SO}_{4}{ }^{2-}$ & 21 & 35 & 27 & 21 & 24 & 32 & 25 & 34 & 33 & 22 & 35 & 35 & 22 & 31 & 31 & 28 & (1) \\
\hline $\mathrm{NO}_{3}{ }^{-}$ & 109 & 95 & 89 & 116 & 66 & 96 & 138 & 106 & 87 & 111 & 96 & 71 & 121 & 89 & 91 & 100 & (11) \\
\hline $\mathrm{NO}_{2}^{-}$ & 129 & 113 & 77 & 83 & 118 & 105 & 135 & 103 & 93 & 132 & 141 & 85 & 116 & 111 & 92 & 106 & (13) \\
\hline $\mathrm{Cl}^{-}$ & 29 & 43 & 33 & 40 & 40 & 39 & 24 & 44 & 30 & 27 & 54 & 40 & 31 & 42 & 34 & 36 & (3) \\
\hline EC & 19 & 19 & 24 & 64 & 47 & 37 & 21 & 23 & 25 & 21 & 19 & 25 & 35 & 29 & 29 & 31 & (2) \\
\hline
\end{tabular}


Tabelle A 4: Prozentuales Verhältnis zeit-räumlicher und räumlicher Variabilitäten der $H^{+}$-Aktivitäten und der Mineralstoffkonzentrationen verschiedener Bodenextrakte der CC- und CF-Einheiten der Standorte Auf der Burg und Hölleberg. Berechnungsgrundlage für die angegebenen Prozentwerte ist $\left(C V_{\text {temp }}-C V_{\text {lok }}\right): C V_{\text {temp }} \cdot 100 \%$ (vgl. Tabelle A 2 und Tabelle A3). Rangwerte kennzeichnen die Abfolge der Gesamtmittelwerte der CV (MW) für die untersuchten Faktoren.

\begin{tabular}{|c|c|c|c|c|c|c|c|c|c|c|c|c|c|c|c|c|c|}
\hline \multirow[t]{3}{*}{ Faktor } & \multicolumn{6}{|c|}{ Auf der Burg } & \multicolumn{6}{|c|}{ Hölleberg } & \multicolumn{5}{|c|}{ Pool } \\
\hline & & $\mathrm{CC}$ & & & CF & & & $\mathrm{CC}$ & & & CF & & & & & & \\
\hline & GBL & PBL & DBL & GBL & PBL & DBL & GBL & PBL & DBL & GBL & PBL & DBL & GBL & PBL & DBL & MW & Rang \\
\hline $\mathrm{H}^{+}$ & +97 & +94 & +109 & +66 & +146 & +34 & +14 & +38 & +2 & +44 & +33 & +6 & +55 & +78 & +38 & 57 & (8) \\
\hline $\mathrm{Fe}^{\mathrm{x+}}$ & +23 & -18 & -11 & -10 & +22 & +5 & +4 & +37 & +21 & +21 & +8 & -3 & +10 & +12 & +3 & 8 & (3) \\
\hline $\mathrm{Mn}^{\mathrm{x+}}$ & +130 & +137 & +152 & +38 & +124 & +200 & +75 & +109 & +201 & +173 & +160 & +219 & +104 & +133 & +193 & 143 & (13) \\
\hline $\mathrm{Ca}^{2+}$ & +30 & +9 & +44 & +6 & -7 & -7 & +151 & +178 & +185 & +68 & +202 & +87 & +64 & +96 & +77 & 79 & (12) \\
\hline $\mathrm{Mg}^{2+}$ & +29 & +20 & +218 & +24 & -4 & -4 & +63 & +42 & +314 & +52 & +22 & +147 & +42 & +20 & +169 & 77 & (10) \\
\hline $\mathrm{K}^{+}$ & -10 & -16 & -14 & +30 & -23 & +4 & -14 & -14 & -23 & +3 & +33 & +30 & +2 & -5 & -1 & -1 & (2) \\
\hline $\mathrm{Na}^{+}$ & +3 & +10 & +37 & +53 & +51 & +24 & +226 & +144 & -10 & +196 & +28 & -24 & +119 & +58 & +7 & 61 & (9) \\
\hline $\mathrm{NH}_{4}^{+}$ & & -2 & +111 & +61 & +4 & +7 & +261 & +7 & -6 & +151 & +182 & +13 & +157 & +48 & +31 & 79 & (11) \\
\hline $\mathrm{SO}_{4}{ }^{2-}$ & +1 & +15 & +19 & +19 & +2 & -12 & +49 & +16 & +68 & -2 & +10 & -13 & +17 & +11 & +16 & 14 & (4) \\
\hline $\mathrm{NO}_{3}^{-}$ & -17 & -6 & -18 & -28 & +3 & +5 & +2 & -1 & -19 & +15 & +29 & +3 & -7 & +6 & -7 & -3 & (1) \\
\hline $\mathrm{NO}_{2}^{-}$ & +65 & -13 & +9 & +18 & +86 & +7 & +85 & -10 & +9 & +144 & +53 & +38 & +78 & +29 & +16 & 41 & (7) \\
\hline $\mathrm{Cl}^{-}$ & +5 & +22 & +28 & +9 & +8 & +5 & -3 & +25 & +35 & +10 & +36 & +13 & +5 & +23 & +20 & 16 & (5) \\
\hline EC & +27 & +4 & +37 & +27 & -4 & -15 & +18 & +35 & +45 & +39 & +46 & +14 & +28 & +20 & +21 & 23 & (6) \\
\hline
\end{tabular}

Tabelle A 5: Lagerungseffekte von PBL (个Konzentrationszunahme, $\downarrow$ Konzentrationsabnahme) und Positionseffekte* von GBL und DBL in CC- und CF-Beständen der Standorte Auf der Burg und Hölleberg. Positionseffekte werden dadurch bestätigt, dass signifikante Ergebnisse eines Bodenlösungstyps mit entsprechenden Tendenzen der anderen Bodenlösungen koinzidieren. Die Ergebnisse beziehen sich auf den nichtparametrischen Vergleich (U-Test nach Mann-Whitney) der jeweils vier Kleinquadranten einer Untersuchungsfläche, deren PBL gleichzeitig extrahiert wurden ( $\alpha=0,05 n=24, n=12$ für Fe-Analytik der DBL des Standorts Hölleberg CF) .

\begin{tabular}{|c|c|c|c|c|c|c|c|c|c|c|c|c|}
\hline \multirow[t]{3}{*}{ Faktor } & \multicolumn{6}{|c|}{ Auf der Burg } & \multicolumn{6}{|c|}{ Hölleberg } \\
\hline & \multicolumn{3}{|c|}{$\mathrm{cc}$} & \multicolumn{3}{|c|}{$\mathrm{CF}$} & \multicolumn{3}{|c|}{$\mathrm{CC}$} & \multicolumn{3}{|c|}{ CF } \\
\hline & GBL & PBL & DBL & GBL & PBL & DBL & $\mathrm{GBL}$ & PBL & DBL & GBL & PBL & DBL \\
\hline $\mathrm{H}^{+}$ & & & & & & & & & & & $\downarrow$ & \\
\hline $\mathrm{Fe}^{\mathrm{x+}}$ & & & & & $\uparrow^{(*)}$ & & & & & & $\uparrow$ & \\
\hline \multicolumn{13}{|l|}{$\mathbf{M n}^{\mathrm{x+}}$} \\
\hline $\mathrm{Ca}^{2+}$ & & & & & $\uparrow^{(*)}$ & & & & & & & \\
\hline $\mathbf{M g}^{2+}$ & & & & & $\uparrow^{(*)}$ & & & & & $*$ & & \\
\hline $\mathrm{K}^{+}$ & $*$ & & & & & & & & & & & \\
\hline \multicolumn{13}{|l|}{$\mathrm{Na}^{+}$} \\
\hline \multicolumn{13}{|l|}{$\mathrm{NH}_{4}^{+}$} \\
\hline $\mathrm{SO}_{4}{ }^{2-}$ & & & & & & & & & & & & $*$ \\
\hline \multicolumn{13}{|l|}{$\mathrm{NO}_{3}^{-}$} \\
\hline $\mathrm{NO}_{2}^{-}$ & & & & & & & & & & & $\downarrow$ & \\
\hline \multicolumn{13}{|l|}{$\mathrm{Cl}^{-}$} \\
\hline EC & & & & & $\uparrow^{(*)}$ & & & & & & & \\
\hline
\end{tabular}


Tabelle A 6: Schwermetallfraktionen der Feinerde $\left[\mathrm{mol} \cdot \mathrm{g}_{\mathrm{TG}}{ }^{-1}\right]$ von CC- und CF-Beständen der Standorte Auf der Burg und Hölleberg entsprechend der Extraktion von Bodenmaterial unterschiedlicher Struktur und Lagerung mit $\mathrm{NH}_{4}$-Acetat, DTPA, NTA, Oxalat und Dithionit. $\mathrm{MW} \pm \mathrm{CV}[\%](n=4)$.

\section{Eisen}

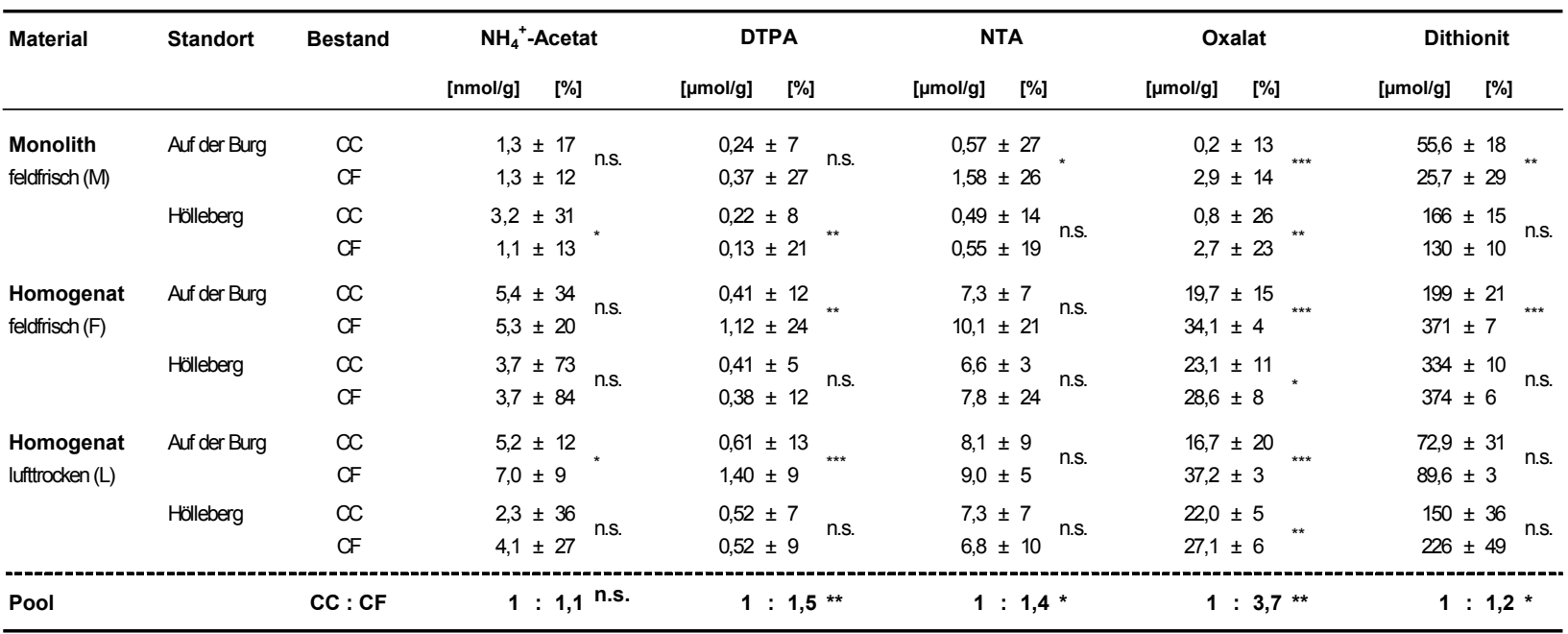

\section{Mangan}

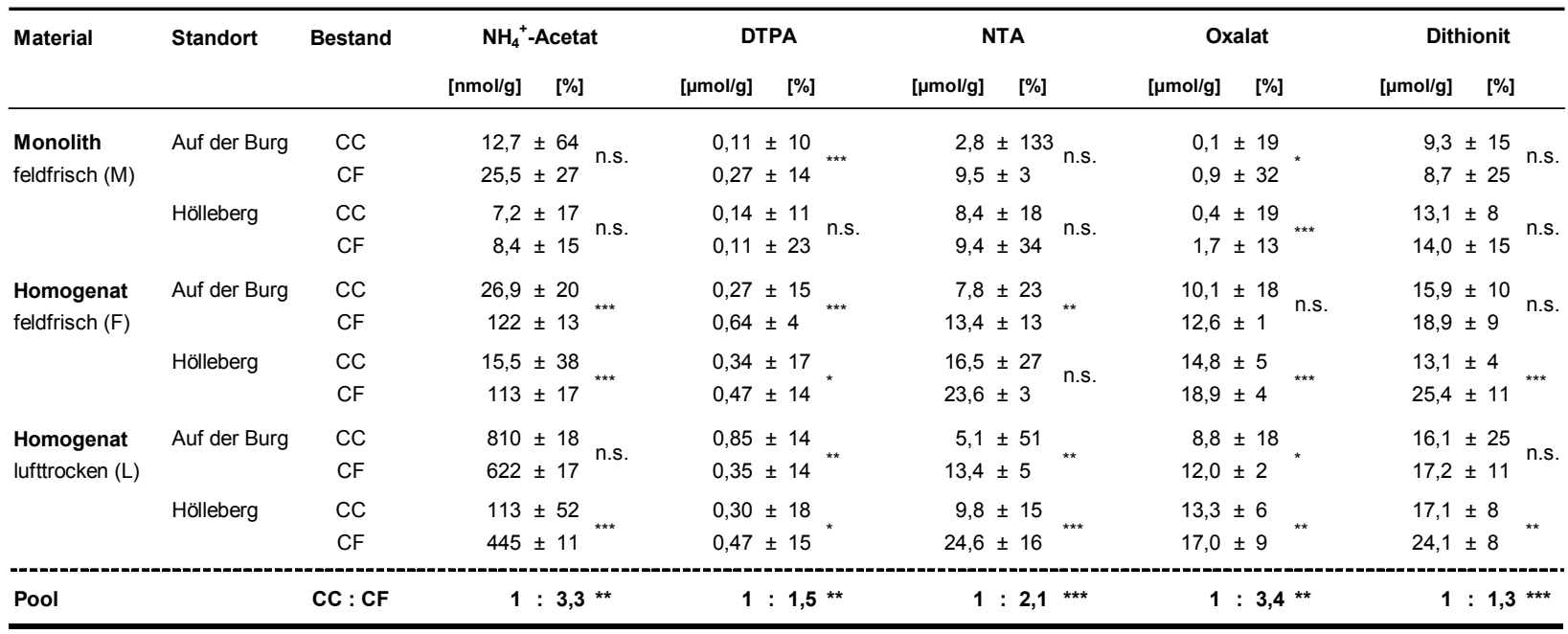

Zink

\begin{tabular}{|c|c|c|c|c|c|c|c|c|c|c|c|c|c|c|c|c|c|}
\hline \multirow[t]{2}{*}{ Material } & \multirow[t]{2}{*}{ Standort } & \multirow[t]{2}{*}{ Bestand } & \multicolumn{3}{|c|}{$\mathrm{NH}_{4}{ }^{+}$-Acetat } & \multicolumn{3}{|c|}{ DTPA } & \multicolumn{3}{|c|}{ NTA } & \multicolumn{3}{|c|}{ Oxalat } & \multicolumn{3}{|c|}{ Dithionit } \\
\hline & & & {$[\mathrm{nmol} / \mathrm{g}]$} & [\%] & & [nmol/g] & [\%] & & {$[\mathrm{nmol} / \mathrm{g}]$} & [\%] & & [nmol/g] & [\%] & & {$[\mathrm{nmol} / \mathrm{g}]$} & {$[\%]$} & \\
\hline \multirow[t]{2}{*}{$\begin{array}{l}\text { Monolith } \\
\text { feldfrisch (M) }\end{array}$} & Auf der Burg & $\begin{array}{l}\mathrm{CC} \\
\mathrm{CF}\end{array}$ & $\begin{array}{r}5,6 \\
49,0\end{array}$ & $\begin{array}{l} \pm 24 \\
\pm 46\end{array}$ & & $\begin{array}{r}90,7 \\
295\end{array}$ & $\begin{array}{l} \pm 8 \\
\pm 22\end{array}$ & ** & $\begin{array}{l}228 \\
374\end{array}$ & $\begin{array}{l} \pm 21 \\
\pm 18\end{array}$ & & $\begin{array}{r}3,3 \\
71,0\end{array}$ & $\begin{array}{l} \pm 19 \\
\pm 54\end{array}$ & n.s. & $\begin{array}{l}315 \\
258\end{array}$ & $\begin{array}{l} \pm 9 \\
\pm 29\end{array}$ & n.s. \\
\hline & Hölleberg & $\begin{array}{l}\mathrm{CC} \\
\mathrm{CF}\end{array}$ & $\begin{array}{r}4,9 \\
15,0\end{array}$ & $\begin{array}{l} \pm 12 \\
\pm 43\end{array}$ & & $\begin{array}{r}69,9 \\
217\end{array}$ & $\begin{array}{l} \pm 19 \\
\pm 16\end{array}$ & 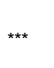 & $\begin{array}{l}177 \\
411\end{array}$ & $\begin{array}{l} \pm 14 \\
\pm 21\end{array}$ & & $\begin{array}{l}12,1 \\
80,7\end{array}$ & $\begin{array}{l} \pm 18 \\
\pm 44\end{array}$ & & $\begin{array}{l}416 \\
545\end{array}$ & $\begin{array}{l} \pm 14 \\
\pm 11\end{array}$ & \\
\hline \multirow[t]{2}{*}{$\begin{array}{l}\text { Homogenat } \\
\text { feldfrisch }(F)\end{array}$} & Auf der Burg & $\begin{array}{l}\mathrm{CC} \\
\mathrm{CF}\end{array}$ & $\begin{array}{l}20,9 \\
36,6\end{array}$ & $\begin{array}{l} \pm 3 \\
\pm 9\end{array}$ & $* * *$ & $\begin{array}{r}108 \\
65,5\end{array}$ & $\begin{array}{l} \pm 6 \\
\pm 12\end{array}$ & $* * *$ & $\begin{array}{l}299 \\
220\end{array}$ & $\begin{array}{l} \pm 6 \\
\pm 3\end{array}$ & 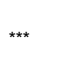 & $\begin{array}{l}353 \\
209\end{array}$ & $\begin{array}{l} \pm 8 \\
\pm 14\end{array}$ & & $\begin{array}{l}1239 \\
1197\end{array}$ & $\begin{array}{l} \pm 18 \\
\pm 8\end{array}$ & $* * *$ \\
\hline & Hölleberg & $\begin{array}{l}\mathrm{CC} \\
\mathrm{CF}\end{array}$ & $\begin{array}{l}18,9 \\
25,6\end{array}$ & $\begin{array}{l} \pm 20 \\
\pm 15\end{array}$ & n.s. & $\begin{array}{l}79,0 \\
99,8\end{array}$ & $\begin{array}{l} \pm 39 \\
\pm 14\end{array}$ & n.s. & $\begin{array}{l}305 \\
260\end{array}$ & $\begin{array}{l} \pm 22 \\
\pm 10\end{array}$ & n.s. & $\begin{array}{l}381 \\
287\end{array}$ & $\begin{array}{l} \pm 20 \\
\pm 12\end{array}$ & n.s. & $\begin{array}{l}1588 \\
1520\end{array}$ & $\begin{array}{l} \pm 8 \\
\pm 4\end{array}$ & n.s. \\
\hline \multirow[t]{2}{*}{$\begin{array}{l}\text { Homogenat } \\
\text { lufttrocken }(\mathrm{L})\end{array}$} & Auf der Burg & $\begin{array}{l}\mathrm{CC} \\
\mathrm{CF}\end{array}$ & $\begin{array}{l}24,3 \\
39,7\end{array}$ & $\begin{array}{l} \pm 5 \\
\pm 15\end{array}$ & & $\begin{array}{l}94,5 \\
75,3\end{array}$ & $\begin{array}{l} \pm 5 \\
\pm 17\end{array}$ & n.s. & $\begin{array}{l}261 \\
201\end{array}$ & $\begin{array}{l} \pm 13 \\
\pm 16\end{array}$ & n.s. & $\begin{array}{l}339 \\
209\end{array}$ & $\begin{array}{l} \pm 10 \\
\pm 12\end{array}$ & & $\begin{array}{l}662 \\
566\end{array}$ & $\begin{array}{l} \pm 6 \\
\pm 7\end{array}$ & * \\
\hline & Hölleberg & $\begin{array}{l}\mathrm{CC} \\
\mathrm{CF}\end{array}$ & $\begin{array}{l}16,7 \\
22,4\end{array}$ & $\begin{array}{l} \pm 22 \\
\pm 17\end{array}$ & n.s. & $\begin{array}{l}110 \\
106\end{array}$ & $\begin{array}{l} \pm 31 \\
\pm 17\end{array}$ & n.s. & $\begin{array}{l}282 \\
249\end{array}$ & $\begin{array}{l} \pm 23 \\
\pm 16\end{array}$ & n.s. & $\begin{array}{l}360 \\
280\end{array}$ & $\begin{array}{l} \pm 18 \\
\pm 12\end{array}$ & n.s. & $\begin{array}{l}903 \\
932\end{array}$ & $\begin{array}{l} \pm 9 \\
\pm 17\end{array}$ & n.s. \\
\hline Pool & & $\mathrm{CC}: \mathrm{CF}$ & 1 & $: 3,0$ & & 1 & $: 1,7$ & $* * *$ & 1 & $: 1,2$ & n.s. & 1 & $: 5,2$ & $* * *$ & 1 & $: 1,0$ & n.s. \\
\hline
\end{tabular}


Tabelle A 6 (Fortsetzung): Schwermetallfraktionen der Feinerde [mol $\left.\cdot \mathrm{g}_{\mathrm{TG}}{ }^{-1}\right]$ von CC- und CF-Beständen der Untersuchungsstandorte Auf der Burg und Hölleberg entsprechend der Extraktion von Bodenmaterial unterschiedlicher Struktur und Lagerung mit $\mathrm{NH}_{4}$-Acetat, DTPA, NTA, Oxalat und Dithionit. $\mathrm{MW} \pm \mathrm{CV}$ [\%] (n=4).

\section{Kupfer}

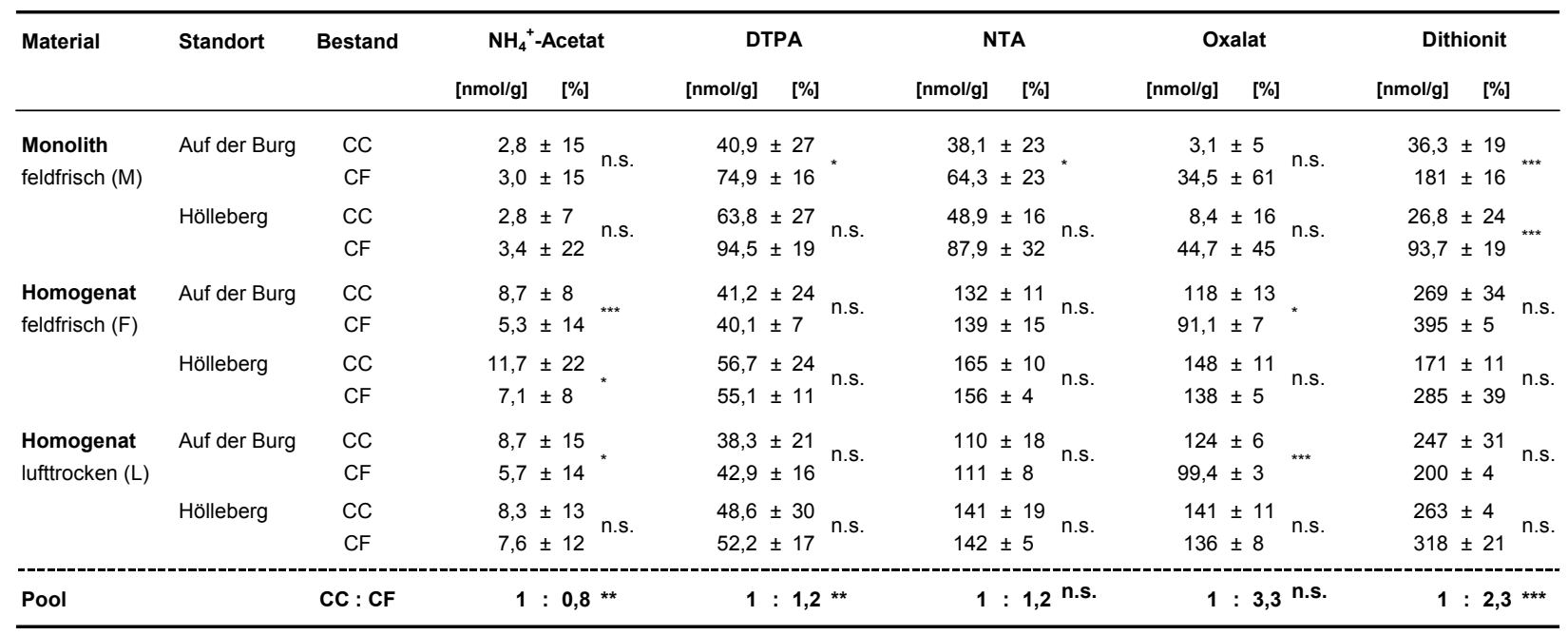

Tabelle A 7: Verhältnisse der Feinerdefraktionen verschiedener Schwermetalle auf Grundlage der Extraktion von Bodenmaterial unterschiedlicher Struktur und Lagerung mit $\mathrm{NH}_{4}$-Acetat, DTPA, NTA, Oxalat und Dithionit. $M=$ feldfrische Bodenmonolithe, $F=$ feldfrische Feinerdehomogenate, $L=$ luftrockene Feinerdehomogenate. MW $(n=4)$.

\begin{tabular}{|c|c|c|c|c|c|c|c|c|c|c|c|c|c|c|c|c|}
\hline \multirow[t]{2}{*}{ Element } & \multirow{2}{*}{$\begin{array}{l}\text { Extraktions- } \\
\text { mittel }\end{array}$} & \multicolumn{3}{|c|}{ Auf der Burg CC } & \multicolumn{3}{|c|}{ Auf der Burg CF } & \multicolumn{3}{|c|}{ Hölleberg CC } & \multicolumn{3}{|c|}{ Hölleberg CF } & \multicolumn{3}{|c|}{ Pool } \\
\hline & & $\mathbf{M}$ & $\mathbf{F}$ & L & $\mathbf{M}$ & $\mathbf{F}$ & L & $\mathbf{M}$ & $\mathbf{F}$ & L & $\mathbf{M}$ & $\mathbf{F}$ & $\mathbf{L}$ & $\mathbf{M}$ & $\mathbf{F}$ & L \\
\hline \multirow[t]{5}{*}{$\mathrm{Fe}$} & Acetat & $1^{a}$ & $: 4,3^{a}$ & $: 4,1^{\text {a }}$ & $1^{b}$ & $4,0^{a b}$ & $: 5,3^{a}$ & $1^{\text {a }}$ & $: 1,2^{a}$ & $: 0,7^{\mathrm{a}}$ & $1^{a}$ & $: 3,3^{a}$ & $: 3,6^{a}$ & $1^{b}$ & $: 3,2^{a}$ & $: 3,4^{\mathrm{a}}$ \\
\hline & DTPA & $1^{b}$ & $: 1,7^{a b}$ & $: 2,6^{a}$ & $1^{b}$ & $3,0^{a b}$ & $: 3,8^{a}$ & $1^{b}$ & : $1,9^{a b}$ & $: 2,4^{a}$ & $1^{b}$ & $: 3,0^{a b}$ & $: 4,0^{a}$ & $1^{c}$ & $: 2,4^{\mathrm{b}}$ & $: 3,2^{a}$ \\
\hline & NTA & $1^{b}$ & $: 13^{a b}$ & $: 14^{\mathrm{a}}$ & $1^{\mathrm{b}}$ & $6,4^{a}$ & $: 5,7^{a b}$ & $1^{b}$ & : $13^{a b}$ & $: 15^{a}$ & $1^{b}$ & $: 14^{\mathrm{a}}$ & $: 12^{a b}$ & $1^{b}$ & $: 12^{a}$ & $: 12^{a}$ \\
\hline & Oxalat & $1^{b}$ & $: 85^{a}$ & $: 72^{a b}$ & $1^{\mathrm{b}}$ & $: 12^{a b}$ & $: 13^{\mathrm{a}}$ & $1^{b}$ & $: 27^{a}$ & $: 26^{a b}$ & $1^{b}$ & $: 11^{\mathrm{a}}$ & $: 10^{a b}$ & $1^{b}$ & $: 34^{a}$ & $: 30^{\mathrm{a}}$ \\
\hline & Dithionit & $1^{b}$ & $: 3,6^{a}$ & $: 1,3^{a b}$ & $1^{b}$ & $14^{\mathrm{a}}$ & : $3,5^{a b}$ & $1^{\mathrm{a}}$ & $: 2,0^{a}$ & $: 0,9^{a}$ & $1^{b}$ & $: 2,9^{a}$ & $: 1,7^{a b}$ & $1^{b}$ & $: 5,7^{a}$ & $: 1,9^{b}$ \\
\hline \multirow[t]{5}{*}{ Mn } & Acetat & $1^{b}$ & $: 2,1^{\mathrm{ab}}$ & $: 64^{a}$ & $1^{b}$ & $4,8^{a b}$ & $: 24^{a}$ & $1^{b}$ & : $2,1^{a b}$ & $: 16^{\mathrm{a}}$ & $1^{b}$ & $: 13^{a b}$ & $: 53^{a}$ & $1^{b}$ & $: 5,6^{a}$ & $: 39^{b}$ \\
\hline & DTPA & $1^{b}$ & $: 2,5^{a b}$ & $: 7,6^{a}$ & $1^{b}$ & $2,4^{a}$ & $: 1,3^{a b}$ & $1^{b}$ & $: 2,5^{a}$ & $: 2,2^{a b}$ & $1^{b}$ & $: 4,1^{a b}$ & $: 4,2^{\mathrm{a}}$ & $1^{c}$ & $: 2,9^{\mathrm{b}}$ & $: 3,8^{a}$ \\
\hline & NTA & $1^{a}$ & $: 2,8^{a}$ & $: 1,8^{a}$ & $1^{b}$ & $1,4^{a b}$ & $: 1,4^{\mathrm{a}}$ & $1^{b}$ & $: 2,0^{a}$ & $: 1,2^{a b}$ & $1^{b}$ & $: 2,5^{a b}$ & $: 2,6^{a}$ & $1^{b}$ & $: 2,2^{a}$ & $: 1,7^{\mathrm{a}}$ \\
\hline & Oxalat & $1^{b}$ & $: 122^{a}$ & $: 106^{a b}$ & $1^{\mathrm{b}}$ & $: 14^{a}$ & $: 13^{a b}$ & $1^{b}$ & $: 37^{a}$ & $: \quad 33^{a b}$ & $1^{b}$ & $: 11^{\mathrm{a}}$ & $: 10^{\mathrm{ab}}$ & $1^{c}$ & $: 46^{\mathrm{b}}$ & $: 41^{\mathrm{a}}$ \\
\hline & Dithionit & $1^{b}$ & $: 1,7^{\mathrm{a}}$ & $: 1,7^{a b}$ & $1^{b}$ & $2,2^{a}$ & $: 2,0^{a b}$ & $1^{a}$ & $: 1,0^{a}$ & $: 1,3^{\mathrm{a}}$ & $1^{b}$ & $: \quad 1,8^{a}$ & $: 1,7^{a b}$ & $1^{b}$ & $: 1,7^{\mathrm{a}}$ & $: 1,7^{\mathrm{a}}$ \\
\hline \multirow[t]{5}{*}{$\mathrm{Zn}$} & Acetat & $1^{b}$ & $: \quad 3,7^{a b}$ & $: 4,3^{a}$ & $1^{a}$ & $0,7^{\mathrm{a}}$ & $: 0,8^{a}$ & $1^{b}$ & $3,8^{a}$ & $: 3,4^{a b}$ & $1^{a}$ & $: 1,7^{\mathrm{a}}$ & $: 1,5^{a}$ & $1^{\mathrm{a}}$ & $: 2,5^{a}$ & $: 2,5^{a}$ \\
\hline & DTPA & $1^{a}$ & $: 1,2^{a}$ & $: 1,0^{a}$ & $1^{\mathrm{a}}$ & $0,2^{b}$ & $: 0,3^{a b}$ & $1^{a}$ & $: 1,1^{a}$ & $: 1,6^{a}$ & $1^{a}$ & $: 0,5^{\mathrm{b}}$ & $: 0,5^{a b}$ & $1^{a}$ & $: 0,8^{\mathrm{b}}$ & $: 0,8^{\mathrm{b}}$ \\
\hline & NTA & $1^{a}$ & $: 1,3^{a}$ & $: 1,1^{a}$ & $1^{\mathrm{a}}$ & $0,6^{a b}$ & $: 0,5^{\mathrm{b}}$ & $1^{b}$ & $: 1,7^{a}$ & $: 1,6^{a b}$ & $1^{a}$ & $: 0,6^{a}$ & $: 0,6^{a}$ & $1^{a}$ & $: 1,1^{a}$ & $: 1,0^{a}$ \\
\hline & Oxalat & $1^{b}$ & $: 108^{a}$ & $: 104^{a b}$ & $1^{\mathrm{b}}$ & $2,9^{a}$ & $: 2,9^{a b}$ & $1^{b}$ & $: 31^{a}$ & $: \quad 30^{a b}$ & $1^{b}$ & $: 3,6^{\mathrm{a}}$ & $: 3,5^{a b}$ & $1^{b}$ & $: 36^{a}$ & $: 35^{\mathrm{a}}$ \\
\hline & Dithionit & $1^{b}$ & $: 3,9^{\text {a }}$ & $: 2,1^{a b}$ & $1^{b}$ & $: 4,6^{a}$ & $: 2,2^{a b}$ & $1^{b}$ & $: 3,8^{a}$ & $: 2,2^{a b}$ & $1^{b}$ & $: 2,8^{a}$ & $: 1,7^{a b}$ & $1^{c}$ & $: 3,8^{a}$ & $: 2,0^{b}$ \\
\hline \multirow[t]{5}{*}{$\mathrm{Cu}$} & Acetat & $1^{a}$ & $: 3,1^{a}$ & $: 3,1^{a}$ & $1^{b}$ & $1,8^{a b}$ & $: 1,9^{a}$ & $1^{b}$ & $4,2^{a}$ & : $3,0^{a b}$ & $1^{b}$ & $: \quad 2,1^{a b}$ & $: 2,3^{a}$ & $1^{b}$ & $: 2,8^{a}$ & $: 2,5^{\mathrm{a}}$ \\
\hline & DTPA & $1^{a}$ & $: 1,0^{a}$ & $: 0,9^{\mathrm{a}}$ & $1^{\mathrm{a}}$ & $0,5^{b}$ & $: 0,6^{a b}$ & $1^{\mathrm{a}}$ & $: 0,9^{a}$ & $: 0,8^{a}$ & $1^{a}$ & $: 0,6^{\mathrm{a}}$ & $: 0,6^{\mathrm{a}}$ & $1^{a}$ & $: 0,8^{\mathrm{b}}$ & $: 0,7^{\mathrm{b}}$ \\
\hline & NTA & $1^{b}$ & $: 3,5^{\mathrm{a}}$ & $: 2,9^{a b}$ & $1^{\mathrm{b}}$ & $2,2^{a}$ & $: 1,7^{a b}$ & $1^{b}$ & $: 3,4^{a}$ & $2,9^{a b}$ & $1^{b}$ & $: 1,8^{a}$ & $: 1,6^{a b}$ & $1^{c}$ & $: 2,7^{a}$ & $: 2,3^{b}$ \\
\hline & Oxalat & $1^{b}$ & $: \quad 38^{a b}$ & $: 40^{\mathrm{a}}$ & $1^{b}$ & $2,6^{a b}$ & $: 2,9^{\mathrm{a}}$ & $1^{b}$ & $: 18^{a}$ & $: \quad 17^{\mathrm{ab}}$ & $1^{a}$ & $: 3,1^{\mathrm{a}}$ & $: 3,1^{a}$ & $1^{b}$ & $: 15^{a}$ & $: 16^{\mathrm{a}}$ \\
\hline & Dithionit & $1^{a}$ & $: 7,4^{a}$ & $: 6,8^{a}$ & $1^{b}$ & $: 2,2^{a}$ & $: 1,1^{a b}$ & $1^{b}$ & : $6,4^{a b}$ & : $9,8^{\mathrm{a}}$ & $1^{b}$ & $: \quad 3,0^{a b}$ & $: 3,4^{a}$ & $1^{b}$ & $: 4,8^{a}$ & $: 5,3^{a}$ \\
\hline
\end{tabular}


Tabelle A 8: Varianzanalyse nicht-sequentieller Schwermetallfraktionierungen von Bodenmaterial der Standorte Aufder Burg und Hölleberg. Faktor I = Standort (Auf der Burg/Hölleberg), Faktor II = Bestand (CC/CF), Faktor III = Lagerung. Signifikanzgruppen $(A, B, C)$ der Faktorenstufen von III (M feldfrische Bodenmonolithe, F feldfrische Bodenhomogenate, L luftrockene Bodenhomogenate). Multiple Vergleiche entsprechend Post-HocTests nach Scheffé (Datenmaterial vgl. Tabelle A6). Die Auswertung bezieht sich auf ein 'pseudo-gesättigtes' Modell, d. h. die CC- und die CF-Bestände beider Standorte wurden als eine Einheit betrachtet.

\begin{tabular}{|c|c|c|c|c|c|c|c|c|c|c|c|}
\hline \multirow[t]{2}{*}{ Element } & \multirow{2}{*}{$\begin{array}{l}\text { Extraktions- } \\
\text { mittel }\end{array}$} & \multirow{2}{*}{ Standort } & \multirow{2}{*}{$\begin{array}{l}\text { Bestand } \\
\text { II }\end{array}$} & \multicolumn{4}{|c|}{ Lagerung } & \multicolumn{4}{|c|}{ Interaktionen } \\
\hline & & & & III & $A$ & B & C & $|x| \mid$ & I x III & II x III & | $x$ || $x$ ||| \\
\hline \multirow[t]{5}{*}{$\mathrm{Fe}$} & Acetat & n.s. & n.s. & $* *$ & M & LF & & n.s. & * & n.s. & n.s. \\
\hline & DTPA & $* *$ & $* *$ & $* *$ & M & $\mathrm{F}$ & $\mathrm{L}$ & ** & ** & ** & ** \\
\hline & NTA & $* *$ & * & $* *$ & M & $\mathrm{FL}$ & & * & n.s. & n.s. & n.s. \\
\hline & Oxalat & n.s. & $* *$ & $* *$ & M & $\mathrm{FL}$ & & ** & n.s. & $* *$ & ** \\
\hline & Dithionit & $* *$ & * & ** & M L & $\mathrm{F}$ & & n.s. & n.s. & ** & n.s. \\
\hline \multirow[t]{5}{*}{ Mn } & Acetat & $* *$ & $* *$ & $* *$ & M F & L & & * & $* *$ & n.s. & $* *$ \\
\hline & DTPA & $* *$ & $* *$ & $* *$ & M & $\mathrm{F}$ & $\mathrm{L}$ & $* *$ & $* *$ & $* *$ & $* *$ \\
\hline & NTA & $* * *$ & $* * *$ & $* * *$ & M & LF & & n.s. & ** & $* *$ & * \\
\hline & Oxalat & ** & $* *$ & ** & M & $\mathrm{F}$ & $L$ & n.s. & $* *$ & * & n.s. \\
\hline & Dithionit & $* * *$ & $* * *$ & $* * *$ & $M$ & LF & & $* * *$ & n.s. & $* * *$ & n.s. \\
\hline \multirow[t]{5}{*}{$\mathrm{Zn}$} & Acetat & $* *$ & $* *$ & * & M F L & & & $* *$ & n.s. & $* *$ & n.s. \\
\hline & DTPA & n.s. & $* * *$ & $* * *$ & F L & $M$ & & n.s. & $* *$ & * & * \\
\hline & NTA & n.s. & n.s. & n.s. & M F L & & & n.s. & n.s. & $* *$ & n.s. \\
\hline & Oxalat & * & $* * *$ & $* *$ & M & LF & & n.s. & n.s. & $* *$ & n.s. \\
\hline & Dithionit & $* *$ & n.s. & $* *$ & M & L & $\mathrm{F}$ & n.s. & n.s. & n.s. & n.s. \\
\hline \multirow[t]{5}{*}{$\mathrm{Cu}$} & Acetat & * & $* *$ & $* *$ & M & LF & & n.s. & n.s. & $* *$ & n.s. \\
\hline & DTPA & $* * *$ & $* *$ & $* * *$ & LF & $M$ & & n.s. & n.s. & $* *$ & n.s. \\
\hline & NTA & $* * *$ & n.s. & $* * *$ & M & L & $\mathrm{F}$ & n.s. & n.s. & * & n.s. \\
\hline & Oxalat & $* *$ & n.s. & $* *$ & M & $\mathrm{F} \mathrm{L}$ & & n.s. & n.s. & $* *$ & n.s. \\
\hline & Dithionit & n.s. & $* * *$ & $* *$ & $M$ & LF & & n.s. & $* * *$ & n.s. & n.s. \\
\hline
\end{tabular}

Tabelle A 9: Varianzanalyse nicht-sequentieller Schwermetallfraktionierungen feldfrischer Feinerdehomogenate aller Untersuchungsstandorte. Faktor I = Standort, Faktor II = Bestand (CC/CF). Multiple Vergleiche entsprechend Post-Hoc-Tests nach Scheffé (vgl. Abbildung 48 bis Abbildung 51).

\begin{tabular}{|c|c|c|c|c|c|c|c|c|c|}
\hline \multirow[t]{2}{*}{ Element } & \multirow{2}{*}{$\begin{array}{l}\text { Extraktions- } \\
\text { mittel }\end{array}$} & \multicolumn{4}{|c|}{ Standort } & \multicolumn{4}{|c|}{ Bestand } \\
\hline & & $I$ & A & B & C & D & $E$ & II & $|x| \mid$ \\
\hline \multirow{6}{*}{$\mathrm{Fe}$} & $\mathrm{H}_{2} \mathrm{O}$ (GBL) & $\star \star *$ & $H S B X$ & $\mathrm{P}$ & $\mathrm{F}$ & & & $* *$ & ** \\
\hline & Ferrozine & $* *$ & $X S H$ & B P F & & & & $* *$ & ** \\
\hline & DTPA & $* *$ & $\mathrm{~S} \times \mathrm{H}$ & H F & F B & $P$ & & $* *$ & ** \\
\hline & NTA & $* *$ & $B S F$ & $\mathrm{~F} \mathrm{H}$ & $\mathrm{H} \mathrm{B}$ & $B P$ & & $* *$ & $* *$ \\
\hline & Oxalat & $* *$ & $s x$ & $\mathrm{H} \mathrm{F} \mathrm{B}$ & F B P & & & $* *$ & $* *$ \\
\hline & Dithionit & $* *$ & $x \mathrm{~F}$ & F S & $S P$ & B & $\mathrm{H}$ & $* *$ & ** \\
\hline \multirow[t]{5}{*}{ Mn } & $\mathrm{H}_{2} \mathrm{O}$ (GBL) & $* *$ & $X B S H$ & $\mathrm{SHF}$ & $\mathrm{P}$ & & & $* *$ & ** \\
\hline & DTPA & $* *$ & $X F S P$ & $\mathrm{H} \mathrm{B}$ & & & & n.s. & n.s. \\
\hline & NTA & $* *$ & $F P \times B S$ & $\mathrm{SH}$ & & & & $* *$ & ** \\
\hline & Oxalat & $* *$ & F P & $x B$ & $\mathrm{H}$ & s & & $* *$ & ** \\
\hline & Dithionit & $* *$ & $\mathrm{FP} \times \mathrm{BH}$ & $\mathrm{BHS}$ & & & & n.s. & n.s. \\
\hline \multirow[t]{4}{*}{$\mathrm{Zn}$} & DTPA & $* *$ & $\mathrm{FX}$ & $\mathrm{BHS}$ & $S P$ & & & $* *$ & n.s. \\
\hline & NTA & $* *$ & $X S F$ & F P & $\mathrm{B} \mathrm{H}$ & & & $* *$ & $* *$ \\
\hline & Oxalat & $* *$ & $X \mathrm{~F}$ & B P H & $s$ & & & $* *$ & ** \\
\hline & Dithionit & $* *$ & $x F$ & P B & $\mathrm{HS}$ & & & ** & $* *$ \\
\hline \multirow[t]{4}{*}{$\mathrm{Cu}$} & DTPA & $* *$ & $F S \times B$ & $\mathrm{~B} \mathrm{H}$ & $\mathrm{H} \mathrm{P}$ & & & $* *$ & n.s. \\
\hline & NTA & $* *$ & $X \mathrm{BHF}$ & $P$ & $s$ & & & $* *$ & $* *$ \\
\hline & Oxalat & $* *$ & $s x$ & $\mathrm{~F} \mathrm{~B}$ & $\mathrm{PH}$ & & & $* *$ & ** \\
\hline & Dithionit & $* *$ & $S P X F$ & $\mathrm{H}$ & $\mathrm{B}$ & & & n.s. & * \\
\hline
\end{tabular}

$B=$ Auf der Burg, H=Hölleberg, $X=$ Hölleberg-Süd, F=Flohrberg, $P=$ =Pagenberg, $S=$ Steinkirche 
Tabelle A 10: Geographische Lage (vgl. auch Abbildung 1) und Medianwerte bodenchemischer Parameter der Standorte der Saatguternten für die Keimungs- und Kulturexperimente in Bodenmonolithen der CC- und CFBestände des Standorts Auf der Burg. ( $n \geq 4)$

\begin{tabular}{|c|c|c|c|c|c|}
\hline Standort & $\begin{array}{r}\text { Name } \\
\text { Gemeinde } \\
\text { Ortsteil } \\
\text { Rechtswert } \\
\text { Hochwert } \\
\text { Arten }\end{array}$ & $\begin{array}{c}\text { Hölleberg } \\
\text { Trendelburg } \\
\text { Langenthal } \\
3528052 \\
5719893 \\
\text { D. d. ssp. decipiens } \\
\text { K. pyramidata } \\
\text { P. neumanniana }\end{array}$ & $\begin{array}{c}\text { Hölleberg } \\
\text { Trendelburg } \\
\text { Langenthal } \\
3528052 \\
5719893 \\
\text { P. erecta }\end{array}$ & $\begin{array}{c}\text { Viehhaus } \\
\text { Hessisch-Lichtenau } \\
\text { Hausen } \\
3558988 \\
5675730 \\
\text { D.d. ssp. decumbens }\end{array}$ & $\begin{array}{c}\text { Glaner Braut } \\
\text { Dötlingen } \\
\text { Glane } \\
3457409 \\
5866571 \\
\text { P. erecta }\end{array}$ \\
\hline $\mathrm{CaCO}_{3}$ & {$[\% \mathrm{~m} / \mathrm{m}]$} & 1,4 & 0,4 & 0,4 & 0,0 \\
\hline$C_{\text {org }}$ & {$[\% \mathrm{~m} / \mathrm{m}]$} & 5,7 & 4,1 & 4,9 & 4,2 \\
\hline $\mathbf{N}$ & {$[\% \mathrm{~m} / \mathrm{m}]$} & 0,48 & 0,33 & 0,26 & 0,29 \\
\hline $\mathrm{C}_{\text {org }} / \mathrm{N}$ & {$[\mathrm{m} / \mathrm{m}]$} & 11,9 & 12,3 & 19,9 & 14,3 \\
\hline $\mathrm{pH}\left(\mathrm{H}_{2} \mathrm{O}\right)$ & $-\log [\mathrm{M}]$ & 7,9 & 6,7 & 4,8 & 4,1 \\
\hline $\mathrm{pH}(1 \mathrm{M} \mathrm{KCl})$ & $-\log [\mathrm{M}]$ & 6,5 & 6,0 & 3,9 & 3,1 \\
\hline $\mathrm{Fe}\left(\mathrm{H}_{2} \mathrm{O}\right)$ & [nmol/g] & 1,9 & 10,9 & 28,5 & 80,6 \\
\hline $\mathrm{Mn}\left(\mathrm{H}_{2} \mathrm{O}\right)$ & [nmol/g] & 1,33 & 0,44 & 4,95 & 2,02 \\
\hline $\mathrm{Ca}\left(\mathrm{H}_{2} \mathrm{O}\right)$ & [nmol/g] & 2371 & 506 & 220 & 155 \\
\hline $\mathrm{Mg}\left(\mathrm{H}_{2} \mathrm{O}\right)$ & [nmol/g] & 153 & 222 & 85 & 47 \\
\hline $\mathrm{K}\left(\mathrm{H}_{2} \mathrm{O}\right)$ & [nmol/g] & 30 & 48 & 49 & 63 \\
\hline $\mathrm{Na}\left(\mathrm{H}_{2} \mathrm{O}\right)$ & [nmol/g] & 127 & 101 & 183 & 102 \\
\hline $\mathrm{NH}_{4}{ }^{+}\left(\mathrm{H}_{2} \mathrm{O}\right)$ & [nmol/g] & 95 & 0 & 0 & 14 \\
\hline$P\left(\mathrm{H}_{2} \mathrm{O}\right)$ & [nmol/g] & n.d. & 18 & 19 & 39 \\
\hline $\mathrm{SO}_{4}{ }^{2-}\left(\mathrm{H}_{2} \mathrm{O}\right)$ & [nmol/g] & 166 & 190 & 217 & 57 \\
\hline $\mathrm{NO}_{3}^{-}\left(\mathrm{H}_{2} \mathrm{O}\right)$ & {$[\mathrm{nmol} / \mathrm{g}]$} & 3,4 & 1,8 & 3,2 & 2,7 \\
\hline $\mathrm{NO}_{2}^{-}\left(\mathrm{H}_{2} \mathrm{O}\right)$ & [nmol/g] & 0,9 & 0,0 & 0,0 & 0,0 \\
\hline $\mathrm{Cl}\left(\mathrm{H}_{2} \mathrm{O}\right)$ & {$[\mathrm{nmol} / \mathrm{g}]$} & 206 & 141 & 115 & 69 \\
\hline Fe (Ferrozine) & [nmol/g] & 13 & 30 & 98 & 127 \\
\hline Fe (DTPA) & {$[\mu \mathrm{mol} / \mathrm{g}]$} & 0,36 & 4,40 & 38,5 & 2,07 \\
\hline Fe (NTA) & {$[\mu \mathrm{mol} / \mathrm{g}]$} & 7,01 & 0,46 & 1,64 & 3,56 \\
\hline Fe (Oxalat) & {$[\mu \mathrm{mol} / \mathrm{g}]$} & 28,3 & 21,1 & 182,9 & 18,4 \\
\hline Fe (Dithionit) & {$[\mu \mathrm{mol} / \mathrm{g}]$} & 385 & 11 & 297 & 35 \\
\hline Mn (NTA) & {$[\mu \mathrm{mol} / \mathrm{g}]$} & 23,8 & 8,2 & 1,9 & 0,1 \\
\hline Mn (DTPA) & [nmol/g] & 441 & 53 & 43 & 57 \\
\hline Mn (Oxalat) & {$[\mu \mathrm{mol} / \mathrm{g}]$} & 19,2 & 10,6 & 7,3 & 0,1 \\
\hline Mn (Dithionit) & {$[\mu \mathrm{mol} / \mathrm{g}]$} & 26,7 & 11,5 & 12,0 & 0,2 \\
\hline Cu (NTA) & [nmol/g] & 156 & 155 & 337 & 87 \\
\hline Cu (DTPA) & [nmol/g] & 55 & 23 & 10 & 9 \\
\hline Cu (Oxalat) & [nmol/g] & 138 & 62 & 73 & 30 \\
\hline Cu (Dithionit) & [nmol/g] & 223 & 21 & 66 & 1 \\
\hline Zn (NTA) & {$[\mathrm{nmol} / \mathrm{g}]$} & 248 & 78 & 87 & 39 \\
\hline Zn (DTPA) & [nmol/g] & 97 & 52 & 48 & 35 \\
\hline Zn (Oxalat) & [nmol/g] & 273 & 167 & 279 & 76 \\
\hline Zn (Dithionit) & {$[\mathrm{nmol} / \mathrm{g}]$} & 1511 & 160 & 413 & 100 \\
\hline
\end{tabular}


Tabelle A 11: Ergebnisse der Rangkorrelationsanalysen nach Spearman für verschiedene Analyte der GBL.

\begin{tabular}{|c|c|c|c|c|c|c|c|c|c|c|c|c|c|c|c|}
\hline & & $\Theta_{\mathrm{FE}-\mathrm{m}}$ & EC & $\mathrm{pH}$ & $\mathrm{Fe}^{\mathrm{x+}}$ & $\mathrm{Mn}^{\mathrm{x+}}$ & $\mathrm{Ca}^{2+}$ & $\mathrm{Mg}^{2+}$ & $\mathrm{K}^{+}$ & $\mathrm{Na}^{+}$ & $\mathrm{NH}_{4}{ }^{+}$ & $\mathrm{SO}_{4}{ }^{2-}$ & $\mathrm{NO}_{3}^{-}$ & $\mathrm{NO}_{2}^{-}$ & $\mathrm{Cl}^{-}$ \\
\hline$\Theta_{\mathrm{FE}-\mathrm{m}}$ & $\begin{array}{l}\text { Korrelationskoeffizient } \\
\text { Sig. 2-seitig } \\
\text { N }\end{array}$ & & & & & & & & & & & & & & \\
\hline EC & $\begin{array}{l}\text { Korrelationskoeffizient } \\
\text { Sig. 2-seitig } \\
\text { N }\end{array}$ & $\begin{array}{l}0,340^{\star *} \\
0,000 \\
216\end{array}$ & & & & & & & & & & & & & \\
\hline $\mathrm{pH}$ & $\begin{array}{l}\text { Korrelationskoeffizient } \\
\text { Sig. 2-seitig } \\
\text { N }\end{array}$ & $\begin{array}{l}0,416^{\star \star} \\
0,000 \\
216\end{array}$ & $\begin{array}{l}0,476^{\star \star} \\
0,000 \\
216\end{array}$ & & & & & & & & & & & & \\
\hline $\mathrm{Fe}^{\mathrm{x+}}$ & $\begin{array}{l}\text { Korrelationskoeffizient } \\
\text { Sig. 2-seitig } \\
\text { N }\end{array}$ & $\begin{array}{l}-0,182^{* *} \\
0,007 \\
218\end{array}$ & $\begin{array}{l}-0,608^{\star \star} \\
0,000 \\
217\end{array}$ & $\begin{array}{l}-0,331^{* *} \\
0,000 \\
217\end{array}$ & & & & & & & & & & & \\
\hline $\mathrm{Mn}^{\mathrm{x}+}$ & $\begin{array}{l}\text { Korrelationskoeffizient } \\
\text { Sig. 2-seitig } \\
\text { N }\end{array}$ & $\begin{array}{l}-0,155^{\star} \\
0,021 \\
220\end{array}$ & $\begin{array}{l}-0,184^{\star \star} \\
0,006 \\
217\end{array}$ & $\begin{array}{l}-0,125 \\
0,066 \\
217\end{array}$ & $\begin{array}{l}0,186^{* *} \\
0,006 \\
219\end{array}$ & & & & & & & & & & \\
\hline $\mathrm{Ca}^{2+}$ & $\begin{array}{l}\text { Korrelationskoeffizient } \\
\text { Sig. 2-seitig } \\
\text { N }\end{array}$ & $\begin{array}{l}0,224^{* *} \\
0,001 \\
215\end{array}$ & $\begin{array}{l}0,718^{\star *} \\
0,000 \\
215\end{array}$ & $\begin{array}{l}0,542^{* *} \\
0,000 \\
214\end{array}$ & $\begin{array}{l}-0,659^{\star *} \\
0,000 \\
216\end{array}$ & $\begin{array}{l}-0,242^{* *} \\
0,000 \\
216\end{array}$ & & & & & & & & & \\
\hline $\mathrm{Mg}^{2+}$ & $\begin{array}{l}\text { Korrelationskoeffizient } \\
\text { Sig. 2-seitig } \\
\mathrm{N}\end{array}$ & $\begin{array}{l}0,384^{\star *} \\
0,000 \\
216\end{array}$ & $\begin{array}{l}0,701^{* *} \\
0,000 \\
216\end{array}$ & $\begin{array}{l}0,340^{* *} \\
0,000 \\
215\end{array}$ & $\begin{array}{l}-0,399^{* *} \\
0,000 \\
217\end{array}$ & $\begin{array}{l}-0,081 \\
0,238 \\
217\end{array}$ & $\begin{array}{l}0,251^{* \star} \\
0,000 \\
216\end{array}$ & & & & & & & & \\
\hline $\mathrm{K}^{+}$ & $\begin{array}{l}\text { Korrelationskoeffizient } \\
\text { Sig. 2-seitig } \\
\text { N }\end{array}$ & $\begin{array}{l}-0,001 \\
0,993 \\
211\end{array}$ & $\begin{array}{l}0,414^{\star *} \\
0,000 \\
211\end{array}$ & $\begin{array}{l}0,188^{* *} \\
0,006 \\
210\end{array}$ & $\begin{array}{l}-0,467^{\star *} \\
0,000 \\
212\end{array}$ & $\begin{array}{l}-0,136^{*} \\
0,048 \\
212\end{array}$ & $\begin{array}{l}0,367^{* *} \\
0,000 \\
211\end{array}$ & $\begin{array}{l}0,317^{\star *} \\
0,000 \\
212\end{array}$ & & & & & & & \\
\hline $\mathrm{Na}^{+}$ & $\begin{array}{l}\text { Korrelationskoeffizient } \\
\text { Sig. 2-seitig } \\
\text { N }\end{array}$ & $\begin{array}{l}0,179^{* *} \\
0,008 \\
216\end{array}$ & $\begin{array}{l}0,073 \\
0,289 \\
215\end{array}$ & $\begin{array}{l}-0,037 \\
0,588 \\
215\end{array}$ & $\begin{array}{l}-0,097 \\
0,153 \\
217\end{array}$ & $\begin{array}{l}-0,136^{*} \\
0,046 \\
217\end{array}$ & $\begin{array}{l}-0,190^{* *} \\
0,005 \\
214\end{array}$ & $\begin{array}{l}0,329^{\star *} \\
0,000 \\
215\end{array}$ & $\begin{array}{l}0,100 \\
0,147 \\
210\end{array}$ & & & & & & \\
\hline $\mathrm{NH}_{4}{ }^{+}$ & $\begin{array}{l}\text { Korrelationskoeffizient } \\
\text { Sig. 2-seitig } \\
\mathrm{N}\end{array}$ & $\begin{array}{l}0,013 \\
0,902 \\
96\end{array}$ & $\begin{array}{l}0,021 \\
0,839 \\
95\end{array}$ & $\begin{array}{l}-0,088 \\
0,399 \\
95\end{array}$ & $\begin{array}{l}-0,066 \\
0,521 \\
96\end{array}$ & $\begin{array}{l}-0,431^{* *} \\
0,000 \\
96\end{array}$ & $\begin{array}{l}-0,240^{*} \\
0,021 \\
93\end{array}$ & $\begin{array}{l}0,483^{* *} \\
0,000 \\
94\end{array}$ & $\begin{array}{l}0,153 \\
0,145 \\
92\end{array}$ & $\begin{array}{l}0,146 \\
0,156 \\
96\end{array}$ & & & & & \\
\hline $\mathrm{SO}_{4}{ }^{2-}$ & $\begin{array}{l}\text { Korrelationskoeffizient } \\
\text { Sig. 2-seitig } \\
\text { N }\end{array}$ & $\begin{array}{l}-0,004 \\
0,957 \\
218\end{array}$ & $\begin{array}{l}-0,019 \\
0,781 \\
216\end{array}$ & $\begin{array}{l}0,034 \\
0,622 \\
216\end{array}$ & $\begin{array}{l}0,093 \\
0,173 \\
218\end{array}$ & $\begin{array}{l}0,096 \\
0,157 \\
219\end{array}$ & $\begin{array}{l}0,114 \\
0,097 \\
215\end{array}$ & $\begin{array}{l}-0,155^{*} \\
0,023 \\
216\end{array}$ & $\begin{array}{l}-0,037 \\
0,592 \\
211\end{array}$ & $\begin{array}{l}-0,236^{\star \star} \\
0,000 \\
216\end{array}$ & $\begin{array}{l}-0,058 \\
0,575 \\
96\end{array}$ & & & & \\
\hline $\mathrm{NO}_{3}{ }^{-}$ & $\begin{array}{l}\text { Korrelationskoeffizient } \\
\text { Sig. 2-seitig } \\
\text { N }\end{array}$ & $\begin{array}{l}0,260^{* *} \\
0,000 \\
218\end{array}$ & $\begin{array}{l}0,340^{* *} \\
0,000 \\
216\end{array}$ & $\begin{array}{l}0,403^{* *} \\
0,000 \\
216\end{array}$ & $\begin{array}{l}-0,274^{* *} \\
0,000 \\
218\end{array}$ & $\begin{array}{l}-0,004 \\
0,948 \\
219\end{array}$ & $\begin{array}{l}0,289 * * \\
0,000 \\
215\end{array}$ & $\begin{array}{l}0,243^{* *} \\
0,000 \\
216\end{array}$ & $\begin{array}{l}0,392^{* *} \\
0,000 \\
211\end{array}$ & $\begin{array}{l}0,118 \\
0,082 \\
216\end{array}$ & $\begin{array}{l}-0,203^{*} \\
0,047 \\
96\end{array}$ & $\begin{array}{l}-0,033 \\
0,625 \\
218\end{array}$ & & & \\
\hline $\mathrm{NO}_{2}{ }^{-}$ & $\begin{array}{l}\text { Korrelationskoeffizient } \\
\text { Sig. 2-seitig } \\
\text { N }\end{array}$ & $\begin{array}{l}0,137^{*} \\
0,043 \\
219\end{array}$ & $\begin{array}{l}0,095 \\
0,163 \\
217\end{array}$ & $\begin{array}{l}-0,029 \\
0,675 \\
217\end{array}$ & $\begin{array}{l}-0,066 \\
0,328 \\
219\end{array}$ & $\begin{array}{l}-0,056 \\
0,411 \\
220\end{array}$ & $\begin{array}{l}-0,194^{\star *} \\
0,004 \\
216\end{array}$ & $\begin{array}{l}0,269^{* *} \\
0,000 \\
217\end{array}$ & $\begin{array}{l}0,271^{* *} \\
0,000 \\
212\end{array}$ & $\begin{array}{l}0,521^{\star *} \\
0,000 \\
217\end{array}$ & $\begin{array}{l}-0,128 \\
0,213 \\
96\end{array}$ & $\begin{array}{l}-0,194^{\star *} \\
0,004 \\
219\end{array}$ & $\begin{array}{l}0,417^{* *} \\
0,000 \\
219\end{array}$ & & \\
\hline $\mathrm{Cl}^{-}$ & $\begin{array}{l}\text { Korrelationskoeffizient } \\
\text { Sig. 2-seitig } \\
\text { N }\end{array}$ & $\begin{array}{l}0,090 \\
0,190 \\
214\end{array}$ & $\begin{array}{l}0,346^{\star *} \\
0,000 \\
212\end{array}$ & $\begin{array}{l}0,183^{* *} \\
0,007 \\
213\end{array}$ & $\begin{array}{l}-0,258^{* *} \\
0,000 \\
214\end{array}$ & $\begin{array}{l}-0,109 \\
0,110 \\
215\end{array}$ & $\begin{array}{l}0,269^{* *} \\
0,000 \\
211\end{array}$ & $\begin{array}{l}0,234^{* *} \\
0,001 \\
212\end{array}$ & $\begin{array}{l}0,489^{* *} \\
0,000 \\
207\end{array}$ & $\begin{array}{l}0,140^{*} \\
0,041 \\
212\end{array}$ & $\begin{array}{l}-0,201 \\
0,056 \\
91\end{array}$ & $\begin{array}{l}0,154^{*} \\
0,025 \\
214\end{array}$ & $\begin{array}{l}0,311^{* *} \\
0,000 \\
214\end{array}$ & $\begin{array}{l}0,204^{* *} \\
0,003 \\
215\end{array}$ & \\
\hline
\end{tabular}


Tabelle A 12: Ergebnisse der Rangkorrelationsanalysen nach Spearman für verschiedene Analyte der PBL.

\begin{tabular}{|c|c|c|c|c|c|c|c|c|c|c|c|c|c|c|c|}
\hline & & $\Theta_{\mathrm{FE}-\mathrm{m}}$ & $\mathrm{EC}$ & $\mathrm{pH}$ & $\mathrm{Fe}^{\mathrm{x+}}$ & $\mathrm{Mn}^{\mathrm{x+}}$ & $\mathrm{Ca}^{2+}$ & $\mathrm{Mg}^{2+}$ & $\mathrm{K}^{+}$ & $\mathrm{Na}^{+}$ & $\mathrm{NH}_{4}{ }^{+}$ & $\mathrm{SO}_{4}{ }^{2-}$ & $\mathrm{NO}_{3}{ }^{-}$ & $\mathrm{NO}_{2}^{-}$ & $\mathrm{Cl}^{-}$ \\
\hline$\Theta_{\mathrm{FE}-\mathrm{m}}$ & $\begin{array}{l}\text { Korrelationskoeffizient } \\
\text { Sig. 2-seitig } \\
\text { N }\end{array}$ & & & & & & & & & & & & & & \\
\hline EC & $\begin{array}{l}\text { Korrelationskoeffizient } \\
\text { Sig. 2-seitig } \\
\mathrm{N}\end{array}$ & $\begin{array}{l}0,086 \\
0,253 \\
178\end{array}$ & & & & & & & & & & & & & \\
\hline $\mathrm{pH}$ & $\begin{array}{l}\text { Korrelationskoeffizient } \\
\text { Sig. 2-seitig } \\
\mathrm{N}\end{array}$ & $\begin{array}{l}0,178^{*} \\
0,016 \\
181\end{array}$ & $\begin{array}{l}0,398^{* *} \\
0,000 \\
177\end{array}$ & & & & & & & & & & & & \\
\hline $\mathrm{Fe}^{\mathrm{xt}}$ & $\begin{array}{l}\text { Korrelationskoeffizient } \\
\text { Sig. 2-seitig } \\
\text { N }\end{array}$ & $\begin{array}{l}-0,297^{* *} \\
0,000 \\
190\end{array}$ & $\begin{array}{l}-0,622^{* *} \\
0,000 \\
179\end{array}$ & $\begin{array}{l}-0,592^{* *} \\
0,000 \\
182\end{array}$ & & & & & & & & & & & \\
\hline $\mathrm{Mn}^{\mathrm{x+}}$ & $\begin{array}{l}\text { Korrelationskoeffizient } \\
\text { Sig. 2-seitig } \\
\mathrm{N}\end{array}$ & $\begin{array}{l}-0,099 \\
0,18 \\
187\end{array}$ & $\begin{array}{l}0,216^{* *} \\
0,004 \\
179\end{array}$ & $\begin{array}{l}-0,208^{* *} \\
0,005 \\
182\end{array}$ & $\begin{array}{l}0,186^{*} \\
0,011 \\
188\end{array}$ & & & & & & & & & & \\
\hline $\mathrm{Ca}^{2+}$ & $\begin{array}{l}\text { Korrelationskoeffizient } \\
\text { Sig. 2-seitig } \\
\text { N }\end{array}$ & $\begin{array}{l}-0,034 \\
0,645 \\
187\end{array}$ & $\begin{array}{l}0,807^{\star *} \\
0,000 \\
176\end{array}$ & $\begin{array}{l}0,366^{\star *} \\
0,000 \\
179\end{array}$ & $\begin{array}{l}-0,478^{\star *} \\
0,000 \\
188\end{array}$ & $\begin{array}{l}0,251^{* *} \\
0,001 \\
185\end{array}$ & & & & & & & & & \\
\hline $\mathrm{Mg}^{2+}$ & $\begin{array}{l}\text { Korrelationskoeffizient } \\
\text { Sig. 2-seitig } \\
\mathrm{N}\end{array}$ & $\begin{array}{l}0,157^{*} \\
0,031 \\
188\end{array}$ & $\begin{array}{l}0,604^{* *} \\
0,000 \\
177\end{array}$ & $\begin{array}{l}0,022 \\
0,772 \\
180\end{array}$ & $\begin{array}{l}-0,263^{* *} \\
0,000 \\
189\end{array}$ & $\begin{array}{l}0,496^{* *} \\
0,000 \\
186\end{array}$ & $\begin{array}{l}0,421^{* *} \\
0,000 \\
188\end{array}$ & & & & & & & & \\
\hline $\mathrm{K}^{+}$ & $\begin{array}{l}\text { Korrelationskoeffizient } \\
\text { Sig. 2-seitig } \\
N\end{array}$ & $\begin{array}{l}-0,005 \\
0,942 \\
185\end{array}$ & $\begin{array}{l}0,644^{\star *} \\
0,000 \\
175\end{array}$ & $\begin{array}{l}0,263^{\star *} \\
0,000 \\
178\end{array}$ & $\begin{array}{l}-0,391^{* *} \\
0,000 \\
186\end{array}$ & $\begin{array}{l}0,206^{* *} \\
0,005 \\
183\end{array}$ & $\begin{array}{l}0,487^{* *} \\
0,000 \\
184\end{array}$ & $\begin{array}{l}0,522^{* *} \\
0,000 \\
185\end{array}$ & & & & & & & \\
\hline $\mathrm{Na}^{+}$ & $\begin{array}{l}\text { Korrelationskoeffizient } \\
\text { Sig. 2-seitig } \\
N\end{array}$ & $\begin{array}{l}0,192^{* *} \\
0,008 \\
190\end{array}$ & $\begin{array}{l}0,181^{*} \\
0,015 \\
179\end{array}$ & $\begin{array}{l}0,132 \\
0,075 \\
182\end{array}$ & $\begin{array}{l}-0,187^{* *} \\
0,010 \\
191\end{array}$ & $\begin{array}{l}0,01 \\
0,888 \\
188\end{array}$ & $\begin{array}{l}-0,019 \\
0,795 \\
188\end{array}$ & $\begin{array}{l}0,221^{* *} \\
0,002 \\
189\end{array}$ & $\begin{array}{l}0,267^{* *} \\
0,000 \\
186\end{array}$ & & & & & & \\
\hline $\mathrm{NH}_{4}^{+}$ & $\begin{array}{l}\text { Korrelationskoeffizient } \\
\text { Sig. 2-seitig } \\
\mathrm{N}\end{array}$ & $\begin{array}{l}-0,278^{* *} \\
0,006 \\
96\end{array}$ & $\begin{array}{l}-0,218^{*} \\
0,039 \\
90\end{array}$ & $\begin{array}{l}-0,146 \\
0,166 \\
92\end{array}$ & $\begin{array}{l}0,275^{\star *} \\
0,007 \\
96\end{array}$ & $\begin{array}{l}-0,232^{*} \\
0,024 \\
95\end{array}$ & $\begin{array}{l}-0,260^{*} \\
0,012 \\
94\end{array}$ & $\begin{array}{l}-0,242^{*} \\
0,018 \\
95\end{array}$ & $\begin{array}{l}-0,083 \\
0,42 \\
96\end{array}$ & $\begin{array}{l}-0,051 \\
0,622 \\
96\end{array}$ & & & & & \\
\hline $\mathrm{SO}_{4}{ }^{2-}$ & $\begin{array}{l}\text { Korrelationskoeffizient } \\
\text { Sig. 2-seitig } \\
\mathrm{N}\end{array}$ & $\begin{array}{l}0,033 \\
0,651 \\
187\end{array}$ & $\begin{array}{l}0,363^{\star *} \\
0,000 \\
178\end{array}$ & $\begin{array}{l}0,108 \\
0,148 \\
180\end{array}$ & $\begin{array}{l}-0,166^{*} \\
0,023 \\
188\end{array}$ & $\begin{array}{l}-0,019 \\
0,795 \\
186\end{array}$ & $\begin{array}{l}0,473^{* *} \\
0,000 \\
185\end{array}$ & $\begin{array}{l}0,163^{*} \\
0,026 \\
186\end{array}$ & $\begin{array}{l}0,257^{* *} \\
0,000 \\
183\end{array}$ & $\begin{array}{l}0,074 \\
0,314 \\
188\end{array}$ & $\begin{array}{l}0,106 \\
0,306 \\
96\end{array}$ & & & & \\
\hline $\mathrm{NO}_{3}{ }^{-}$ & $\begin{array}{l}\text { Korrelationskoeffizient } \\
\text { Sig. 2-seitig } \\
\mathrm{N}\end{array}$ & $\begin{array}{l}-0,037 \\
0,618 \\
180\end{array}$ & $\begin{array}{l}0,284^{* *} \\
0,000 \\
170\end{array}$ & $\begin{array}{l}0,146 \\
0,057 \\
172\end{array}$ & $\begin{array}{l}-0,210^{* *} \\
0,005 \\
181\end{array}$ & $\begin{array}{l}0,13 \\
0,085 \\
178\end{array}$ & $\begin{array}{l}0,058 \\
0,439 \\
178\end{array}$ & $\begin{array}{l}0,324^{* *} \\
0,000 \\
179\end{array}$ & $\begin{array}{l}0,388^{* *} \\
0,000 \\
177\end{array}$ & $\begin{array}{l}0,509^{* *} \\
0,000 \\
181\end{array}$ & $\begin{array}{l}0,154 \\
0,147 \\
90\end{array}$ & $\begin{array}{l}-0,024 \\
0,747 \\
180\end{array}$ & & & \\
\hline $\mathrm{NO}_{2}^{-}$ & $\begin{array}{l}\text { Korrelationskoeffizient } \\
\text { Sig. 2-seitig } \\
\text { N }\end{array}$ & $\begin{array}{l}-0,118 \\
0,107 \\
189\end{array}$ & $\begin{array}{l}0,086 \\
0,251 \\
179\end{array}$ & $\begin{array}{l}-0,024 \\
0,744 \\
181\end{array}$ & $\begin{array}{l}-0,03 \\
0,681 \\
190\end{array}$ & $\begin{array}{l}0,376^{* *} \\
0,000 \\
187\end{array}$ & $\begin{array}{l}-0,076 \\
0,299 \\
187\end{array}$ & $\begin{array}{l}0,352^{* *} \\
0,000 \\
188\end{array}$ & $\begin{array}{l}0,323^{* *} \\
0,000 \\
185\end{array}$ & $\begin{array}{l}0,270^{* *} \\
0,000 \\
190\end{array}$ & $\begin{array}{l}-0,038 \\
0,716 \\
96\end{array}$ & $\begin{array}{l}-0,216^{* *} \\
0,003 \\
188\end{array}$ & $\begin{array}{l}0,638^{* *} \\
0,000 \\
181\end{array}$ & & \\
\hline $\mathrm{Cl}^{-}$ & $\begin{array}{l}\text { Korrelationskoeffizient } \\
\text { Sig. 2-seitig } \\
\text { N }\end{array}$ & $\begin{array}{l}0,087 \\
0,242 \\
183\end{array}$ & $\begin{array}{l}0,519^{* *} \\
0,000 \\
175\end{array}$ & $\begin{array}{l}0,286^{\star *} \\
0,000 \\
178\end{array}$ & $\begin{array}{l}-0,423^{* *} \\
0,000 \\
184\end{array}$ & $\begin{array}{l}-0,015 \\
0,844 \\
182\end{array}$ & $\begin{array}{l}0,423^{* *} \\
0,000 \\
181\end{array}$ & $\begin{array}{l}0,390^{* *} \\
0,000 \\
182\end{array}$ & $\begin{array}{l}0,513^{* *} \\
0,000 \\
179\end{array}$ & $\begin{array}{l}0,250^{* *} \\
0,001 \\
184\end{array}$ & $\begin{array}{l}0,077 \\
0,465 \\
93\end{array}$ & $\begin{array}{l}0,521^{\star *} \\
0,000 \\
184\end{array}$ & $\begin{array}{l}0,410^{* *} \\
0,000 \\
177\end{array}$ & $\begin{array}{l}0,163^{*} \\
0,027 \\
184\end{array}$ & \\
\hline
\end{tabular}

Korrelationskoeffizient $\quad 0,086$

Korrelationskoeffizient $-0,099 \quad 0,216^{\star \star} \quad-0,208^{\star *} \quad 0,186^{*}$

Korrelationskoeffizient $\begin{array}{lllll}-0,034 & 0,807^{* *} & 0,366^{* *} & -0,478^{* *} & 0,251\end{array}$

$\mathrm{N}$ S. 2-seitig $\quad 0,645 \quad 0,000 \quad 0,000 \quad 0,000 \quad 0,001$

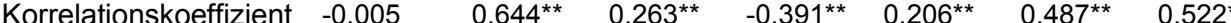

$0,221^{* *} \quad 0,267^{* *}$

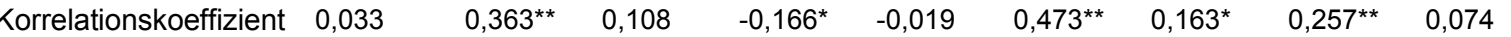

$\mathrm{N}$. 2-seitig $\quad 0,651 \quad 0,000 \quad 0,148 \quad 0,023 \quad 0,795 \quad 0,000 \quad 0,026 \quad 0,000-0,314$

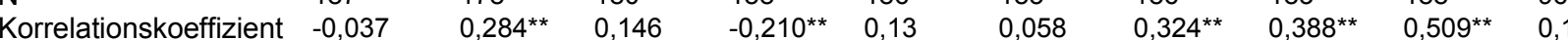

(18

$170 \quad 172$

$81 \quad 178$

$0,087 \quad 0,519^{* *} \quad 0,286^{* *}$

$175 \quad 178$

$184 \quad 182$ 
Tabelle A 13: Ergebnisse der Rangkorrelationsanalysen nach Spearman für verschiedene Analyte der DBL.

\begin{tabular}{|c|c|c|c|c|c|c|c|c|c|c|c|c|c|c|c|}
\hline & & $\Theta_{\mathrm{FE}-\mathrm{m}}$ & EC & $\mathrm{pH}$ & $\mathrm{Fe}^{\mathrm{x+}}$ & $\mathrm{Mn}^{\mathrm{x+}}$ & $\mathrm{Ca}^{2+}$ & $\mathrm{Mg}^{2+}$ & $\mathrm{K}^{+}$ & $\mathrm{Na}^{+}$ & $\mathrm{NH}_{4}^{+}$ & $\mathrm{SO}_{4}{ }^{2-}$ & $\mathrm{NO}_{3}^{-}$ & $\mathrm{NO}_{2}^{-}$ & $\mathrm{Cl}^{-}$ \\
\hline$\Theta_{\mathrm{FE}-\mathrm{m}}$ & $\begin{array}{l}\text { Korrelationskoeffizient } \\
\text { Sig. 2-seitig } \\
\mathrm{N}\end{array}$ & & & & & & & & & & & & & & \\
\hline EC & $\begin{array}{l}\text { Korrelationskoeffizient } \\
\text { Sig. 2-seitig } \\
\mathrm{N}\end{array}$ & $\begin{array}{l}0,051 \\
0,488 \\
188\end{array}$ & & & & & & & & & & & & & \\
\hline $\mathrm{pH}$ & $\begin{array}{l}\text { Korrelationskoeffizient } \\
\text { Sig. 2-seitig } \\
\text { N }\end{array}$ & $\begin{array}{l}0,400^{* *} \\
0,000 \\
190\end{array}$ & $\begin{array}{l}0,383^{* \star} \\
0,000 \\
189\end{array}$ & & & & & & & & & & & & \\
\hline $\mathrm{Fe}^{\mathrm{x+}}$ & $\begin{array}{l}\text { Korrelationskoeffizient } \\
\text { Sig. 2-seitig } \\
N\end{array}$ & $\begin{array}{l}-0,168^{*} \\
0,030 \\
167\end{array}$ & $\begin{array}{l}-0,628^{\star *} \\
0,000 \\
165\end{array}$ & $\begin{array}{l}-0,335^{\star *} \\
0,000 \\
167\end{array}$ & & & & & & & & & & & \\
\hline $\mathrm{Mn}^{\mathrm{x}+}$ & $\begin{array}{l}\text { Korrelationskoeffizient } \\
\text { Sig. 2-seitig } \\
\text { N }\end{array}$ & $\begin{array}{l}-0,399^{* *} \\
0,000 \\
189\end{array}$ & $\begin{array}{l}0,154^{\star} \\
0,035 \\
188\end{array}$ & $\begin{array}{l}-0,380^{* *} \\
0,000 \\
190\end{array}$ & $\begin{array}{l}-0,100 \\
0,201 \\
166\end{array}$ & & & & & & & & & & \\
\hline $\mathrm{Ca}^{2+}$ & $\begin{array}{l}\text { Korrelationskoeffizient } \\
\text { Sig. 2-seitig } \\
N\end{array}$ & $\begin{array}{l}-0,006 \\
0,940 \\
190\end{array}$ & $\begin{array}{l}0,810^{\star *} \\
0,000 \\
189\end{array}$ & $\begin{array}{l}0,317^{\star *} \\
0,000 \\
191\end{array}$ & $\begin{array}{l}-0,571^{\star *} \\
0,000 \\
167\end{array}$ & $\begin{array}{l}0,316^{* *} \\
0,000 \\
190\end{array}$ & & & & & & & & & \\
\hline $\mathbf{M g}^{2+}$ & $\begin{array}{l}\text { Korrelationskoeffizient } \\
\text { Sig. 2-seitig } \\
N\end{array}$ & $\begin{array}{l}0,228^{* *} \\
0,002 \\
189\end{array}$ & $\begin{array}{l}0,499^{* *} \\
0,000 \\
188\end{array}$ & $\begin{array}{l}0,207^{* *} \\
0,004 \\
190\end{array}$ & $\begin{array}{l}-0,345^{* *} \\
0,000 \\
167\end{array}$ & $\begin{array}{l}-0,121 \\
0,097 \\
189\end{array}$ & $\begin{array}{l}0,126 \\
0,084 \\
190\end{array}$ & & & & & & & & \\
\hline $\mathrm{K}^{+}$ & $\begin{array}{l}\text { Korrelationskoeffizient } \\
\text { Sig. 2-seitig } \\
\text { N }\end{array}$ & $\begin{array}{l}-0,138 \\
0,060 \\
186\end{array}$ & $\begin{array}{l}0,542^{\star *} \\
0,000 \\
185\end{array}$ & $\begin{array}{l}0,064 \\
0,384 \\
187\end{array}$ & $\begin{array}{l}-0,457^{* *} \\
0,000 \\
165\end{array}$ & $\begin{array}{l}0,131 \\
0,075 \\
186\end{array}$ & $\begin{array}{l}0,375^{* *} \\
0,000 \\
187\end{array}$ & $\begin{array}{l}0,409^{* *} \\
0,000 \\
187\end{array}$ & & & & & & & \\
\hline $\mathrm{Na}^{+}$ & $\begin{array}{l}\text { Korrelationskoeffizient } \\
\text { Sig. 2-seitig } \\
N\end{array}$ & $\begin{array}{l}-0,010 \\
0,888 \\
189\end{array}$ & $\begin{array}{l}0,132 \\
0,070 \\
188\end{array}$ & $\begin{array}{l}0,083 \\
0,256 \\
190\end{array}$ & $\begin{array}{l}-0,189^{*} \\
0,015 \\
166\end{array}$ & $\begin{array}{l}0,163^{*} \\
0,025 \\
189\end{array}$ & $\begin{array}{l}0,150^{*} \\
0,039 \\
190\end{array}$ & $\begin{array}{l}-0,046 \\
0,530 \\
189\end{array}$ & $\begin{array}{l}0,254^{* *} \\
0,000 \\
186\end{array}$ & & & & & & \\
\hline $\mathrm{NH}_{4}{ }^{+}$ & $\begin{array}{l}\text { Korrelationskoeffizient } \\
\text { Sig. 2-seitig } \\
N\end{array}$ & $\begin{array}{l}0,067 \\
0,518 \\
96\end{array}$ & $\begin{array}{l}0,373^{* *} \\
0,000 \\
96\end{array}$ & $\begin{array}{l}0,438^{* *} \\
0,000 \\
96\end{array}$ & $\begin{array}{l}-0,354^{* *} \\
0,001 \\
88\end{array}$ & $\begin{array}{l}-0,214^{*} \\
0,038 \\
95\end{array}$ & $\begin{array}{l}0,371^{* *} \\
0,000 \\
96\end{array}$ & $\begin{array}{l}0,100 \\
0,333 \\
96\end{array}$ & $\begin{array}{l}0,355^{\star *} \\
0,000 \\
95\end{array}$ & $\begin{array}{l}0,094 \\
0,365 \\
95\end{array}$ & & & & & \\
\hline $\mathrm{SO}_{4}{ }^{2-}$ & $\begin{array}{l}\text { Korrelationskoeffizient } \\
\text { Sig. 2-seitig } \\
N\end{array}$ & $\begin{array}{l}0,013 \\
0,854 \\
190\end{array}$ & $\begin{array}{l}0,746^{* *} \\
0,000 \\
189\end{array}$ & $\begin{array}{l}0,247^{* *} \\
0,001 \\
191\end{array}$ & $\begin{array}{l}-0,455^{* *} \\
0,000 \\
167\end{array}$ & $\begin{array}{l}0,115 \\
0,115 \\
190\end{array}$ & $\begin{array}{l}0,654^{* *} \\
0,000 \\
191\end{array}$ & $\begin{array}{l}0,298^{* *} \\
0,000 \\
190\end{array}$ & $\begin{array}{l}0,424^{\star *} \\
0,000 \\
187\end{array}$ & $\begin{array}{l}0,310^{\star *} \\
0,000 \\
190\end{array}$ & $\begin{array}{l}0,316^{* *} \\
0,002 \\
96\end{array}$ & & & & \\
\hline $\mathrm{NO}_{3}{ }^{-}$ & $\begin{array}{l}\text { Korrelationskoeffizient } \\
\text { Sig. 2-seitig } \\
\mathrm{N}\end{array}$ & $\begin{array}{l}0,079 \\
0,283 \\
187\end{array}$ & $\begin{array}{l}0,369^{\star *} \\
0,000 \\
185\end{array}$ & $\begin{array}{l}0,271^{* *} \\
0,000 \\
187\end{array}$ & $\begin{array}{l}-0,278^{\star *} \\
0,000 \\
164\end{array}$ & $\begin{array}{l}0,013 \\
0,859 \\
186\end{array}$ & $\begin{array}{l}0,294^{* *} \\
0,000 \\
187\end{array}$ & $\begin{array}{l}0,247^{* *} \\
0,001 \\
186\end{array}$ & $\begin{array}{l}0,261^{* *} \\
0,000 \\
183\end{array}$ & $\begin{array}{l}0,258^{* *} \\
0,000 \\
186\end{array}$ & $\begin{array}{l}0,327^{* *} \\
0,001 \\
96\end{array}$ & $\begin{array}{l}0,334^{* *} \\
0,000 \\
187\end{array}$ & & & \\
\hline $\mathrm{NO}_{2}^{-}$ & $\begin{array}{l}\text { Korrelationskoeffizient } \\
\text { Sig. 2-seitig } \\
\mathrm{N}\end{array}$ & $\begin{array}{l}0,044 \\
0,542 \\
190\end{array}$ & $\begin{array}{l}0,154^{*} \\
0,035 \\
189\end{array}$ & $\begin{array}{l}0,056 \\
0,443 \\
191\end{array}$ & $\begin{array}{l}-0,155^{*} \\
0,045 \\
167\end{array}$ & $\begin{array}{l}0,057 \\
0,435 \\
190\end{array}$ & $\begin{array}{l}-0,073 \\
0,315 \\
191\end{array}$ & $\begin{array}{l}0,581^{* *} \\
0,000 \\
190\end{array}$ & $\begin{array}{l}0,207^{* *} \\
0,004 \\
187\end{array}$ & $\begin{array}{l}0,154^{*} \\
0,034 \\
190\end{array}$ & $\begin{array}{l}0,159 \\
0,121 \\
96\end{array}$ & $\begin{array}{l}0,024 \\
0,741 \\
191\end{array}$ & $\begin{array}{l}0,421^{* *} \\
0,000 \\
187\end{array}$ & & \\
\hline $\mathrm{Cl}^{-}$ & $\begin{array}{l}\text { Korrelationskoeffizient } \\
\text { Sig. 2-seitig } \\
\text { N }\end{array}$ & $\begin{array}{l}-0,053 \\
0,468 \\
188\end{array}$ & $\begin{array}{l}0,690^{* *} \\
0,000 \\
187\end{array}$ & $\begin{array}{l}0,147^{*} \\
0,044 \\
189\end{array}$ & $\begin{array}{l}-0,482^{* *} \\
0,000 \\
165\end{array}$ & $\begin{array}{l}0,124 \\
0,091 \\
188\end{array}$ & $\begin{array}{l}0,492^{* *} \\
0,000 \\
189\end{array}$ & $\begin{array}{l}0,562^{* *} \\
0,000 \\
188\end{array}$ & $\begin{array}{l}0,676^{\star *} \\
0,000 \\
185\end{array}$ & $\begin{array}{l}0,260^{\star *} \\
0,000 \\
188\end{array}$ & $\begin{array}{l}0,395^{* *} \\
0,000 \\
96\end{array}$ & $\begin{array}{l}0,722^{* *} \\
0,000 \\
189\end{array}$ & $\begin{array}{l}0,381^{* *} \\
0,000 \\
185\end{array}$ & $\begin{array}{l}0,310^{* *} \\
0,000 \\
189\end{array}$ & \\
\hline
\end{tabular}




\section{Abbildungen des Anhangs}

Abbildung A 1: Zeigerwertspektren der CC- und CF-Bestände aller Untersuchungsstandorte nach Ellenberg et al. (1992)

Abbildung A 2: Feinerdebezogene elektrische Leitfähigkeiten in Abhängigkeit vom Bodenwassergehalt der Feinerde

Abbildung A 3: Relative lineare Wachstumsraten von Koeleria pyramidata, Danthonia decumbens ssp. decipiens und Potentilla neumanniana in Abhängigkeit von der N- und Fe-Ernährung

Abbildung A 4: Chlorophyllkonzentrationen in Blattmaterial von Koeleria pyramidata, Danthonia decumbens ssp. decipiens und Potentilla neumanniana in Abhängigkeit von der hydroponischen $\mathrm{N}$ - und Fe-Ernährung

Abbildung A 5: Frischgewichte [g] von Koeleria pyramidata und Danthonia decumbens ssp. decipiens nach Kultivierung in Nährlösungen abgestufter FeEDTA-Konzentration

Abbildung A 6: Karyologische und blattanatomische Charakteristika von Danthonia decumbens ssp. decumbens und $D$. decumbens ssp. decipiens

Abbildung A 7: Erläuterung der Graphikelemente in den Abbildungen der bodenkundlichen Analysen der Referenzstandorte 

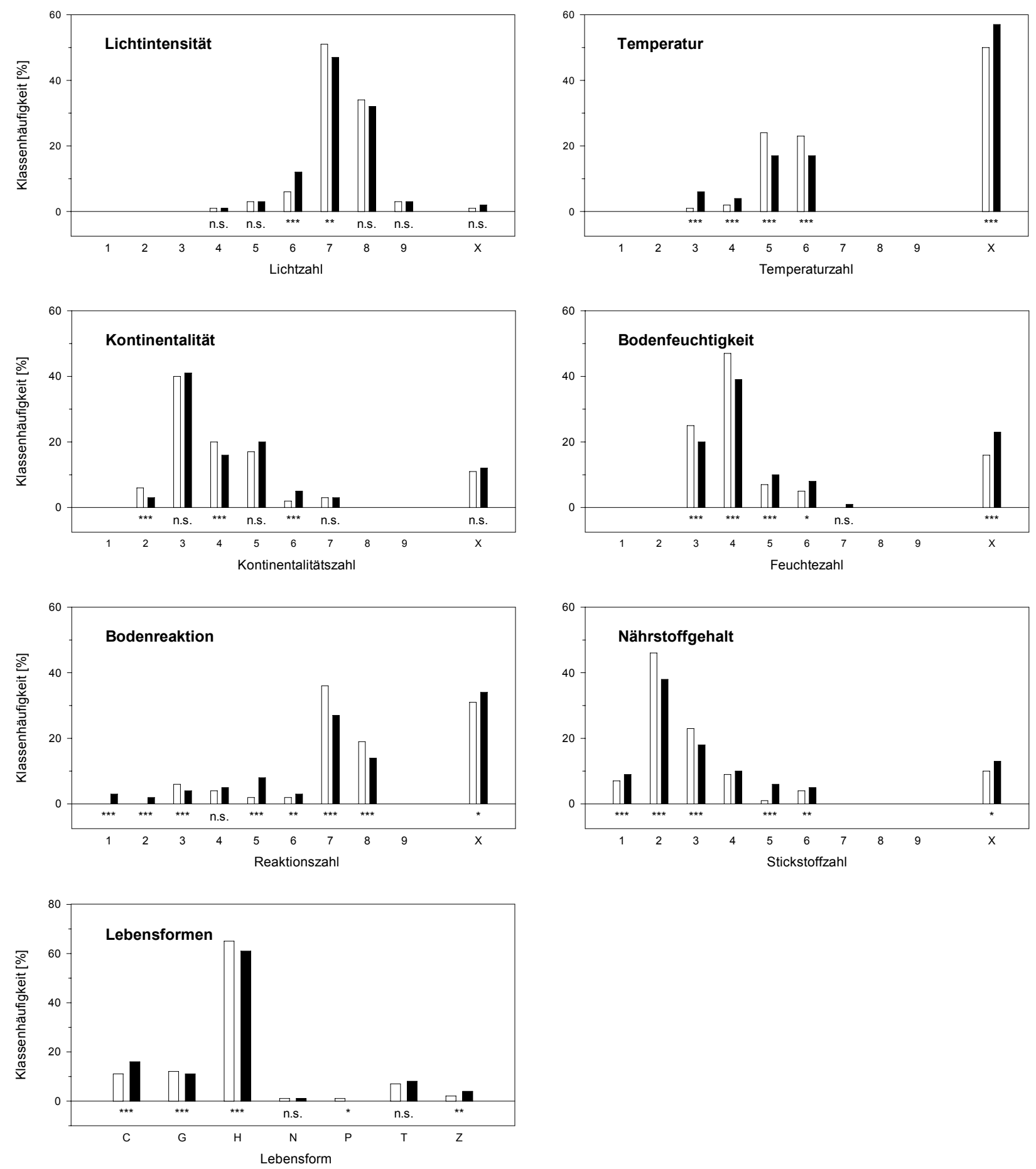

Abbildung A 1: Zeigerwertspektren der CC- und CF-Bestände aller Untersuchungsstandorte nach Ellenberg et al. (1992). In ordinaler Skalierung von 1 bis 9 nehmen L(ichtintensität), T(emperatur, K(ontinalität), F(euchte), R(eaktion; Substrat-pH) und N(ährstoffgehalt) der betreffenden Standorte zu. x verweist auf eine indifferente Verbreitung; $C=$ krautige Chamaephyten, $G=$ Geophyten, H=Hemikryptophyten, Nanophanerophyt (Sträucher oder Kleinbäume, 0,5-5 $m$ hoch), $P=$ Phaneropyten, $T=$ Therophyten, $Z=$ holzige Chamaephyten 

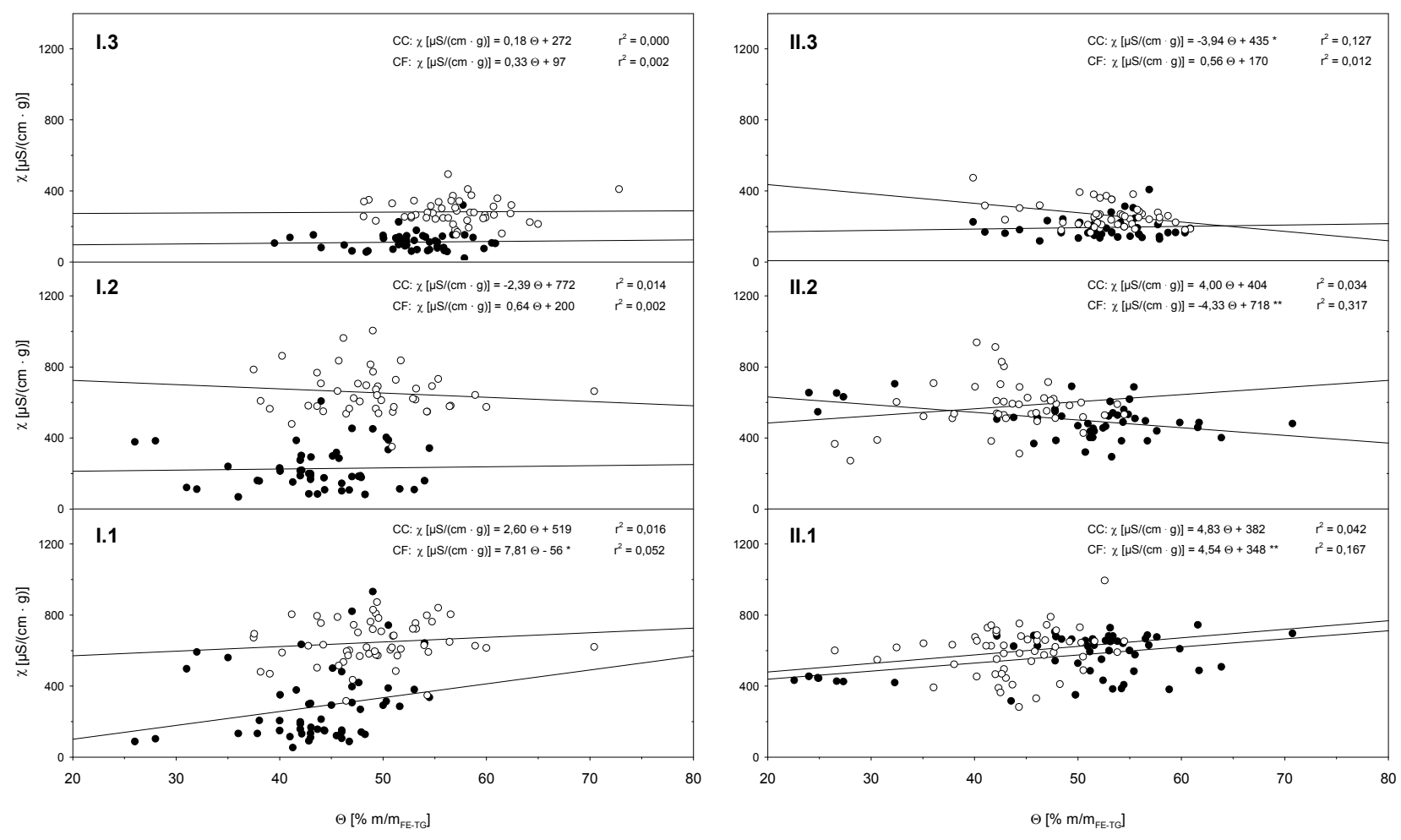

Abbildung A 2: Feinerdebezogene elektrische Leitfähigkeiten EC $\left[\mu \mathrm{S} \cdot \mathrm{cm}^{-1} \cdot \mathrm{g}^{-1} T G\right]$ in Abhängigkeit vom Bodenwassergehalt der Feinerde $\Theta_{m}[\% \mathrm{~m} / \mathrm{m}$ TG]. Sternsignaturen kennzeichnen Signifikanzen der linearen Regressionsfunktionen von EC und $\Theta_{m}$ entsprechend den Korrelationsanalysen nach Pearson.

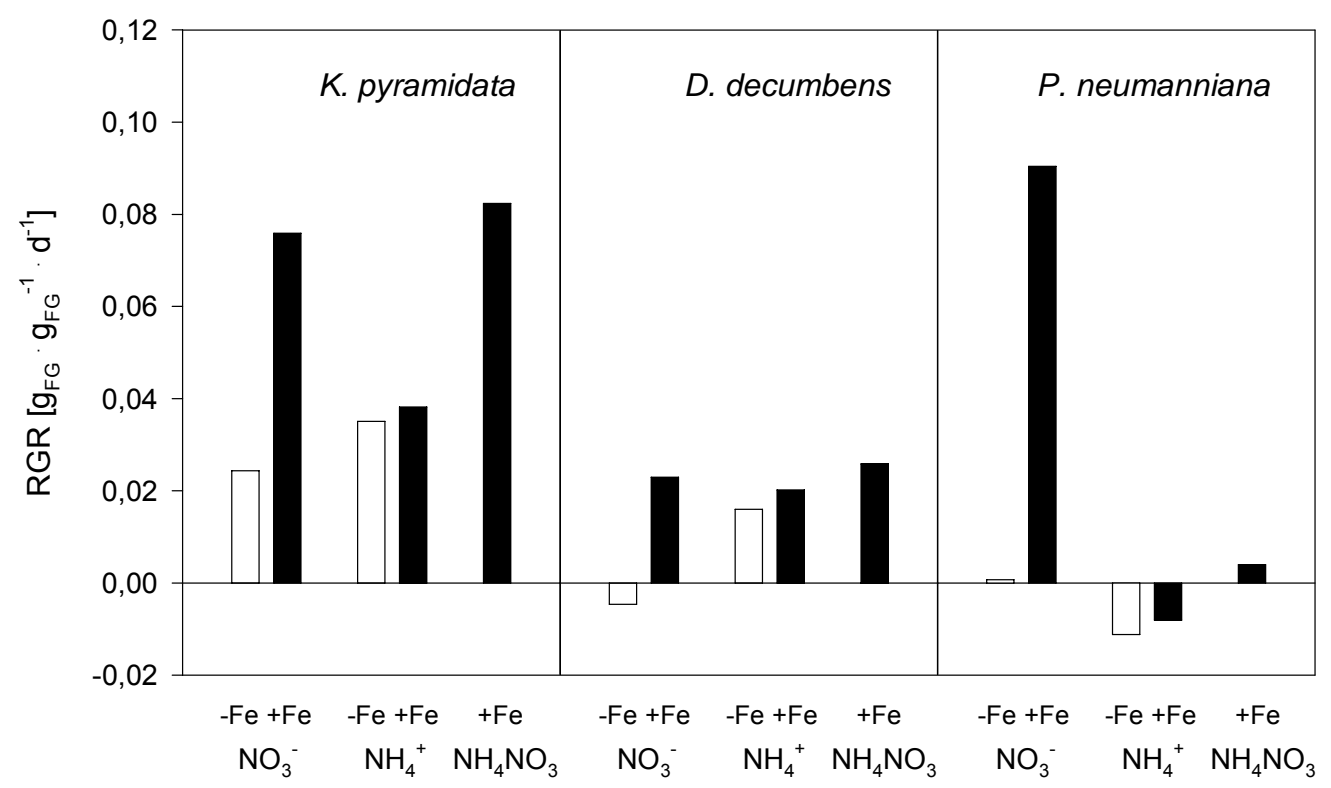

Abbildung A 3: Relative lineare Wachstumsraten $\left[g_{F G} \cdot g_{F G}{ }^{-1} \cdot d^{-1}\right]$ von Koeleria pyramidata, Danthonia decumbens ssp. decipiens und Potentilla neumanniana in Abhängigkeit von der hydroponischen $N$-Ernährung (6,0 mM N als

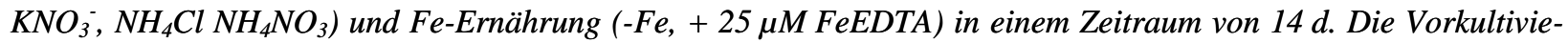
rung der Pflanzen $(n=2)$ erfolgte in Bodenmonolithen (vgl. Tabelle 25, S. 103). Nach sorgfältiger Entfernung des anhaftenden Bodenmaterials wurden die Pflanzen $7 \mathrm{w}$ vor Versuchsbeginn in Nährlösungskultur überführt (Nährlösungszusammensetzung und Kulturbedingungen s. Abbildung A 5). Einheitliche $\mathrm{K}^{+}$- und $\mathrm{Cl}^{-}$-Konzentrationen der $\mathrm{N}$ Varianten wurden durch Supplementierung von $\mathrm{NaCl}$ und $\mathrm{KCl}$ eingestellt. 


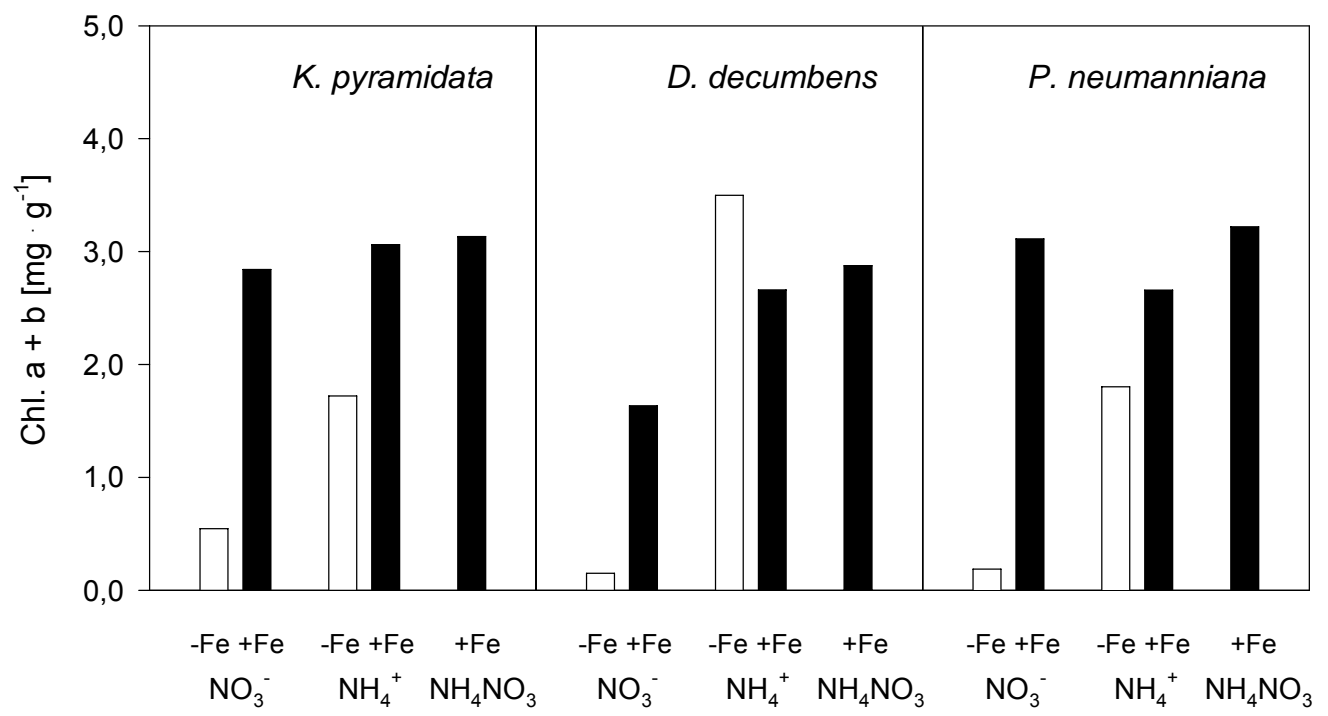

Abbildung A 4: Chlorophyllkonzentrationen $\left[\mathrm{mg} \cdot \mathrm{g}^{-1}\right.$ ] in Blattmaterial von Koeleria pyramidata, Danthonia decumbens ssp. decipiens und Potentilla neumanniana in Abhängigkeit von der hydroponischen N- und Fe-Ernährung (vgl. Abbildung A 3/Abbildung A 5, Chlorophyllbestimmung nach Moran \& Porath 1980; Moran 1982).

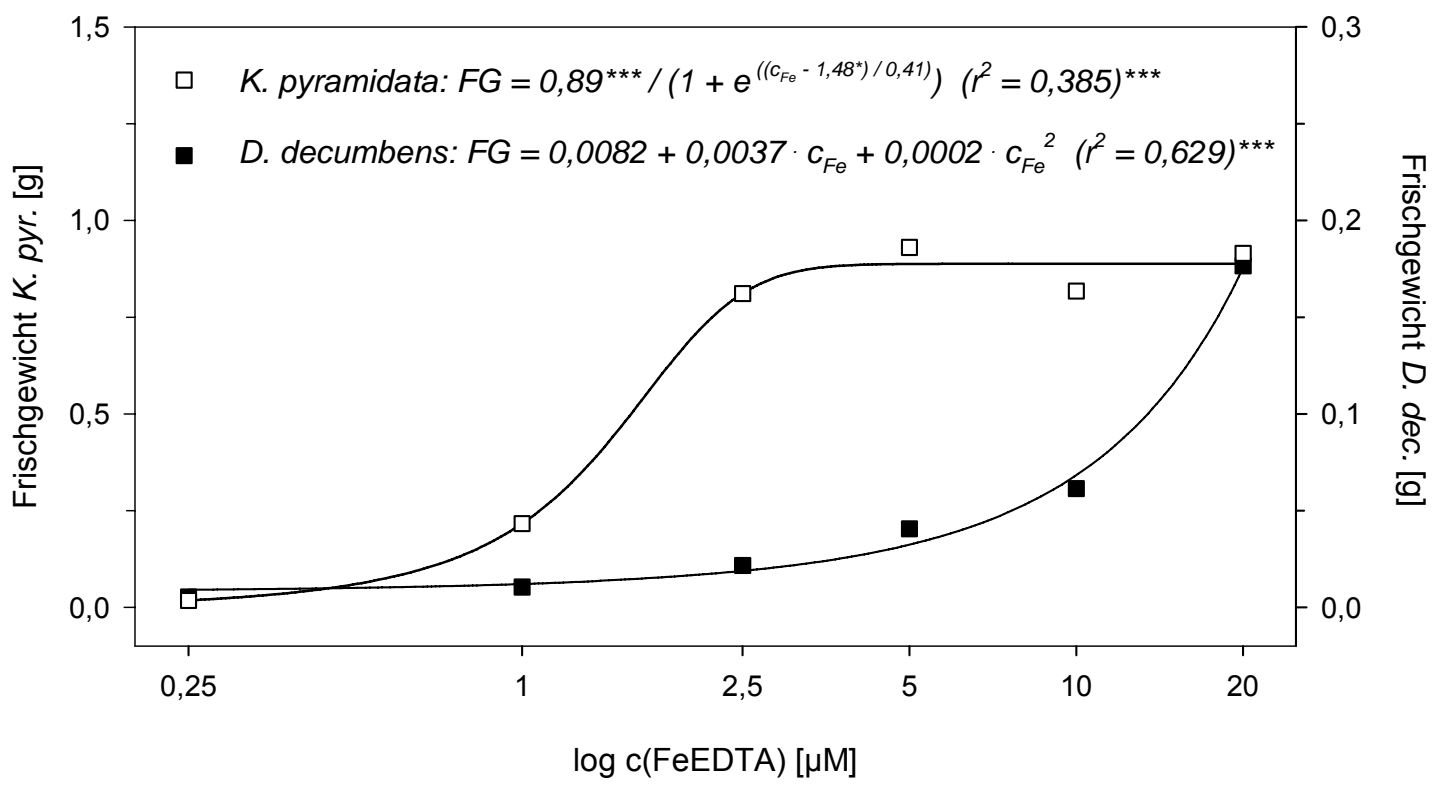

Abbildung A 5: Frischgewichte [g] von Koeleria pyramidata und Danthonia decumbens ssp. decipiens nach Kultivierung über $4 \mathrm{w}$ (K. pyramidata) bzw. $8 \mathrm{w}$ (D. decumbens) in Nährlösungen abgestufter FeEDTA-Konzentration. Sternsignaturen kennzeichnen Signifikanzen $(\alpha=0,001)$ der nicht-linearen Regressionsfunktionen (K. pyramidata $n=8$; D. decumbens $n=6$ ).

Versuchsdurchführung:

Aussaat von Saatgut des Standorts Hölleberg in Quarzsand.

Überführung der Keimpflanzen nach 4 w (K. pyramidata) bzw. 8 w (D. decumbens) in Nährlösung mit:

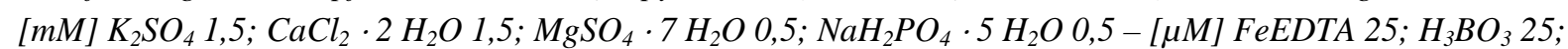

$\mathrm{MnSO}_{4} \cdot \mathrm{H}_{2} \mathrm{O} ; \mathrm{ZnSO}_{4} \cdot 7 \mathrm{H}_{2} \mathrm{O}$ 0,5; $\mathrm{CuSO}_{4} \cdot 5 \mathrm{H}_{2} \mathrm{O}$ 0,3; $\left(\mathrm{NH}_{4}\right)_{6} \mathrm{MO}_{7} \mathrm{O}_{24} \cdot 4 \mathrm{H}_{2} \mathrm{O}$ 0,05; $\mathrm{pH} 6,0$.

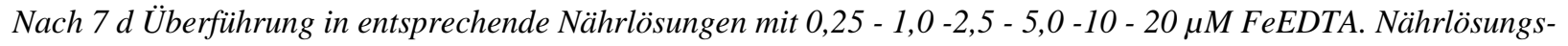
wechsel im Abstand von 7 d unter Justierung des $\mathrm{pH}$ 6,0 mit $\mathrm{NaOH} \mathrm{bzw.} \mathrm{NaCl.}$

Photo-/Temperaturperiodik: $16 \mathrm{~h} / 8 \mathrm{~h}, 23 / 17^{\circ} \mathrm{C}, \mathrm{PAR}: \mathrm{ca} .300 \mu \mathrm{mol} \cdot \mathrm{m}^{-2} \cdot \mathrm{s}^{-1}$.

Relative Luftfeuchte: ca. $75 \%$. 


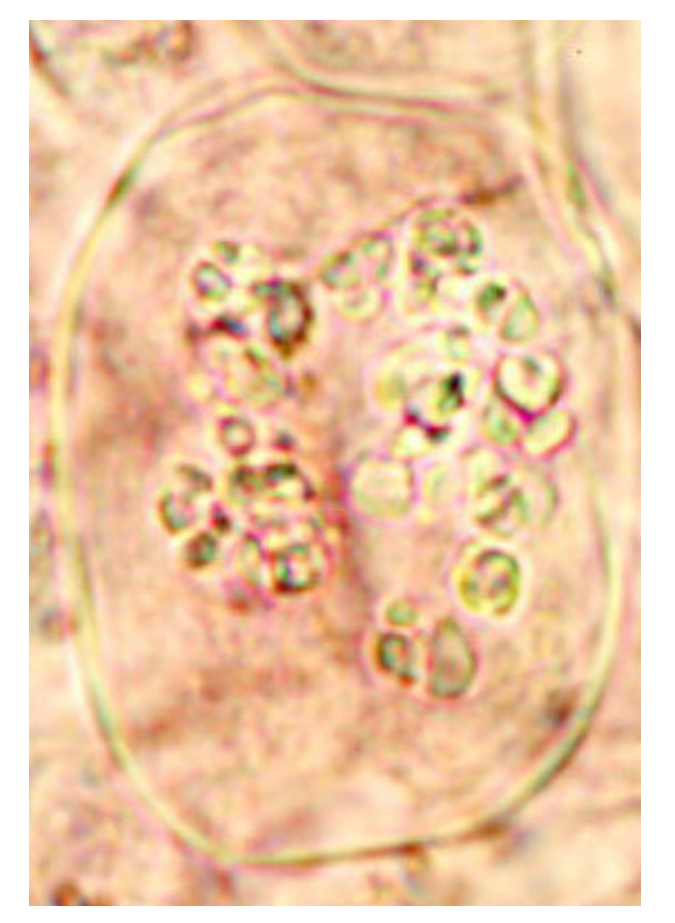

A. D. decumbens ssp. decumbens

I.

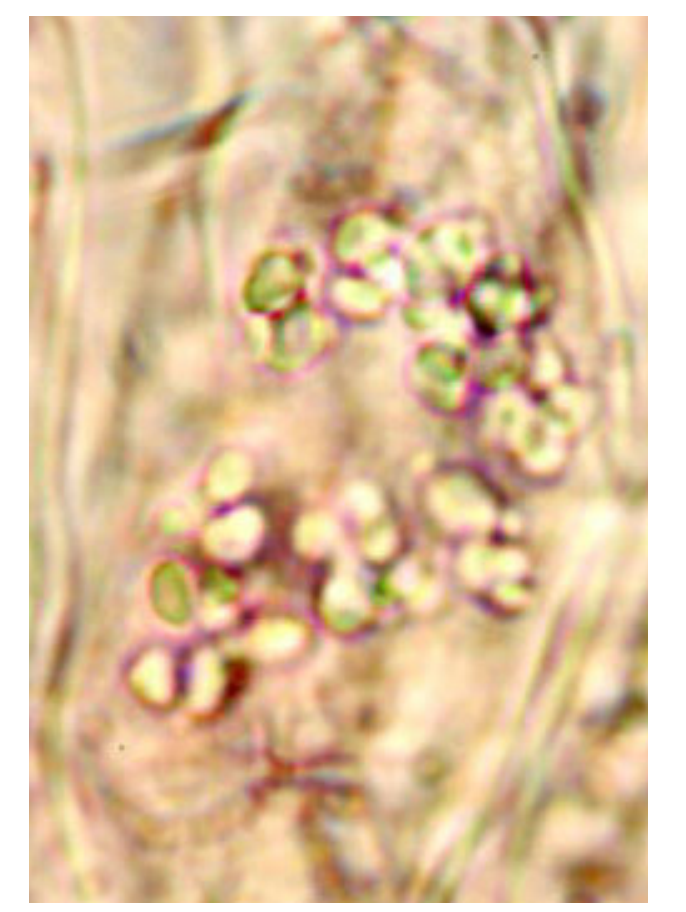

B. D. decumbens ssp. decipiens

a.

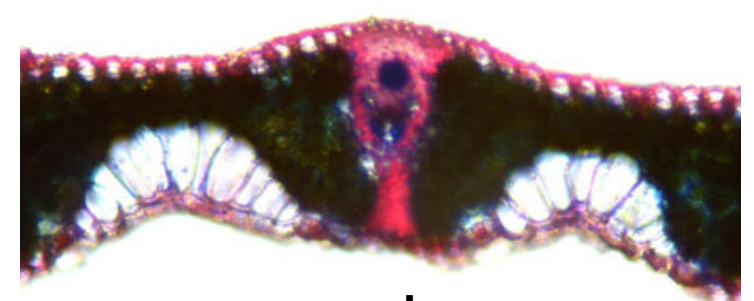

b.

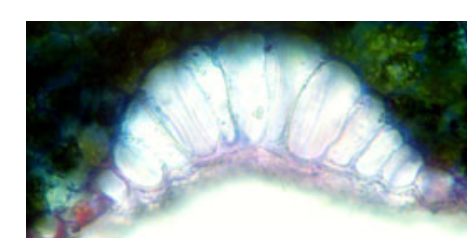

II.
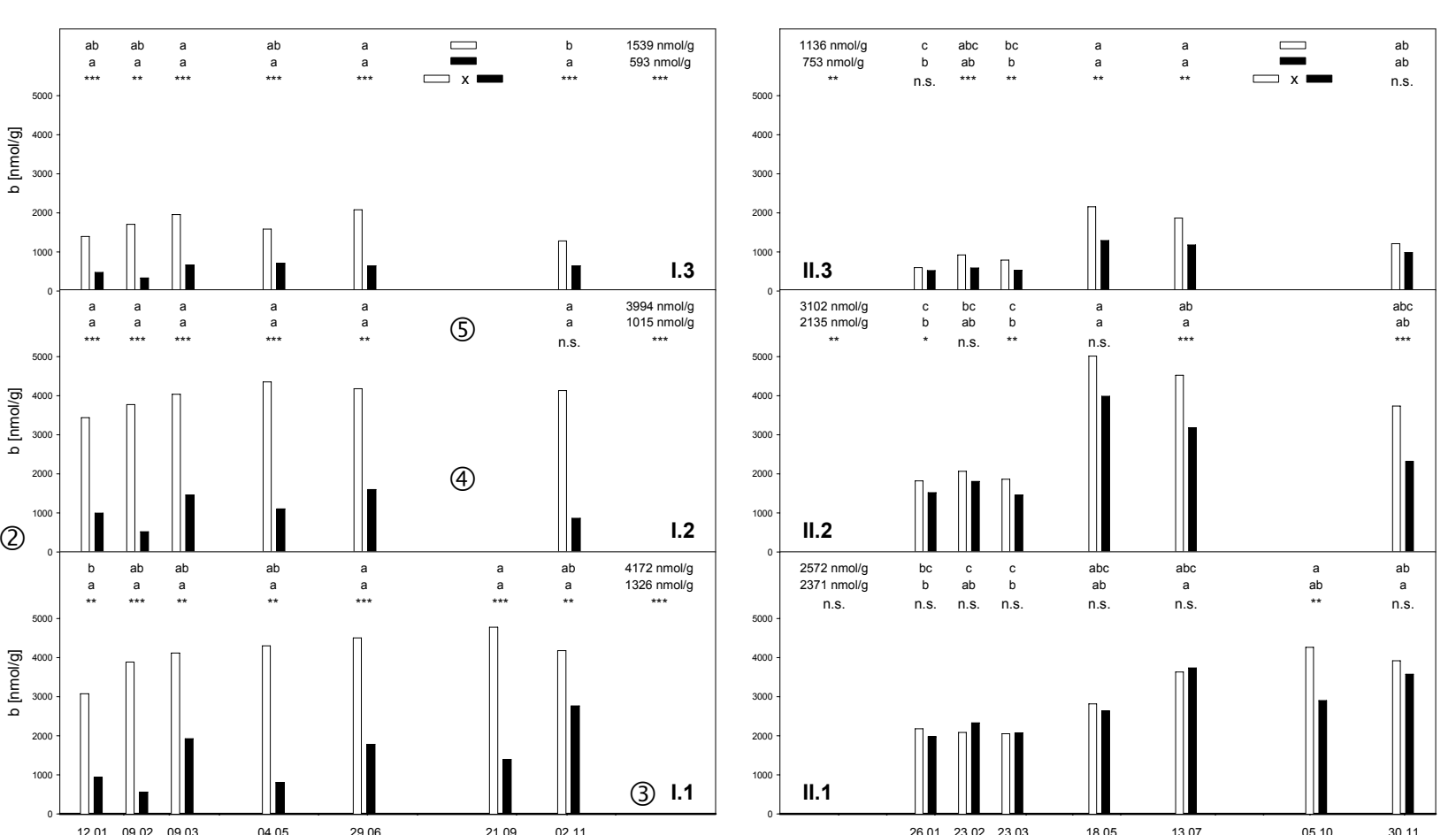

Abbildung A 7: Erläuterung der Graphikelemente in den Abbildungen der bodenkundlichen Analysen der Referenzstandorte.

(1) Abszisse mit Terminangabe der Probennahmen.

(2) Index für Standort und Lösungstyp der Messungen, soweit nicht anders angegeben: $I=G B L, 2=P B L, 3=D B L$.

(3) Ordinate mit Formelzeichen und [Einheiten]

(4) Balkendiagramm der Mediane (soweit nicht anders angegeben $n=8)$ qeschlossene Balken $=$ CF-Bestand.

(5) Zeilen 1 und 2: Kleinbuchstaben als Signifikanzindizes des Schaich-Hamerle-Einzelvergleichstests für die Medianvariationen im Jahresverlauf $(\alpha \leq 0,05)$ sowie numerische Angabe der Jahresmediane in CC- bzw. CF-Beständen;
Zeile 3: Sternsignaturen des U-Tests nach Mann-Whitney für den Vergleich der Untersuchungsergebnisse der CCund CF-Vegetationsbestände. n.s. $\alpha>0,05, * \alpha \leq 0,05, * * \alpha \leq 0,01, * * * \alpha \leq 0,001$

Abbildung A 6: Karyologische und blattanatomische Charakteristika von Danthonia decumbens ssp. decumbens (A.) und $D$. decumbens ssp. decipiens (B.).

I. Chromosomen apikalmeristematischer Wurzelzellen. Quetschpräparat junger Wurzeln nach vierstündiger Inkubation in $2 \mu \mathrm{M}$ Hydroxychinolin, Fixierung und Lagerung in $3: 1$ Ethanol/Eisessig, zehnminütiger Hydrolyse in $1 \mathrm{~N} \mathrm{HCl} \mathrm{bei} 60^{\circ} \mathrm{C}$ und Anfärbung mit Orcein-Essigsäure.

II. Blattquerschnitt mit Gelenkzellen. Handquerschnitt in $\mathrm{H}_{2} \mathrm{O}$ nach Simultananfärbung mit Safranin und Astrablau (vgl. Braune et al. 1999); a. Überblick mit Zentralnerv, b. Ausschnitt mit Gelenkzellen. 